HELIO YOCHIHIRO FUCHIGAMI

\title{
Flexible flow line com tempos de setup: métodos heurísticos
}

Tese apresentada à Escola de Engenharia de São Carlos - Universidade de São Paulo como parte dos requisitos para obtenção do título de Doutor em Engenharia de Produção.

Área de concentração: Processos e Gestão de Operações

Linha de Pesquisa: Pesquisa Operacional Aplicada aos Sistemas de Produção

Orientador: Prof. Tit. João Vitor Moccellin 
Candidato(a): Bacharel HÉLIO YOCHIHIRO FUCHIGAMI.

Tese defendida e julgada em 03/05/2010 perante a Comissão Julgadora:

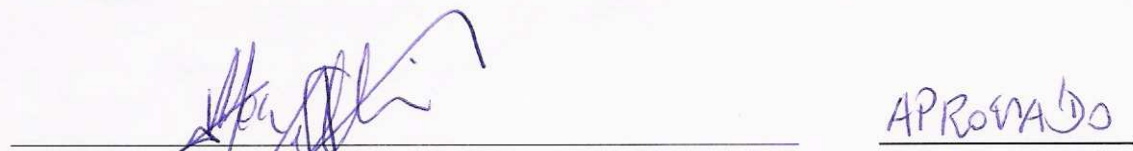

Prof. Titular JOÂO XYKடிR MOCCELLIN - (Orientador)

(Escola de Engenharia de São Carlos/USP)

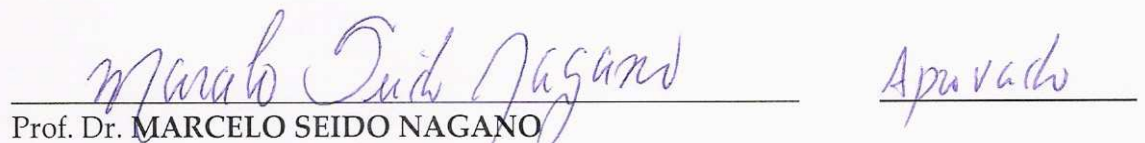

(Escola de Engenharia de São Carlos/USP)

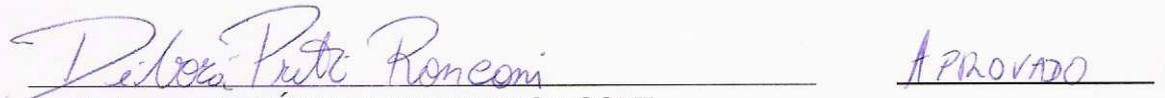

Prof $f^{a}$. Associada DÉBORA PRETTI RONCONI

(Escola Politécnica/USP)

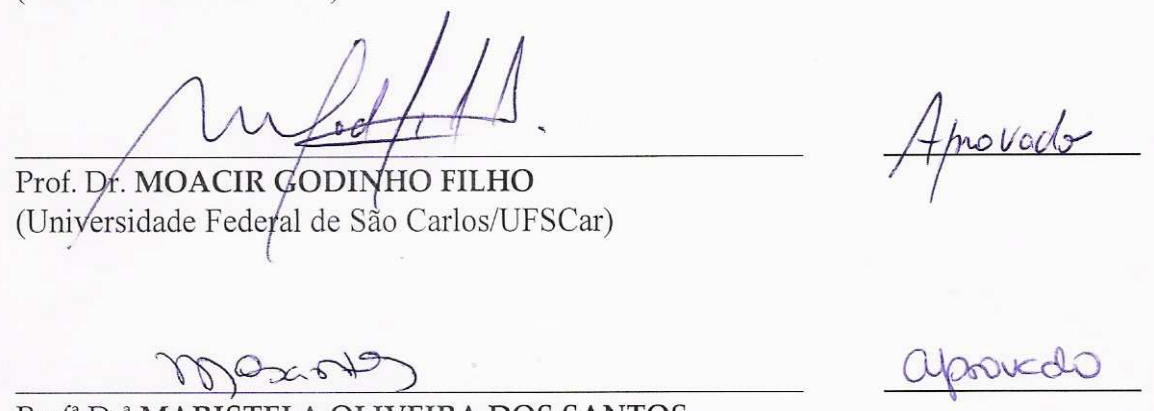

Prof $^{\mathrm{a}} \mathrm{Dr}^{\mathrm{a}}$ MARISTELA OLIVEIRA DOS SANTOS

(Instituto de Ciências Matemáticas e de Computação/USP)

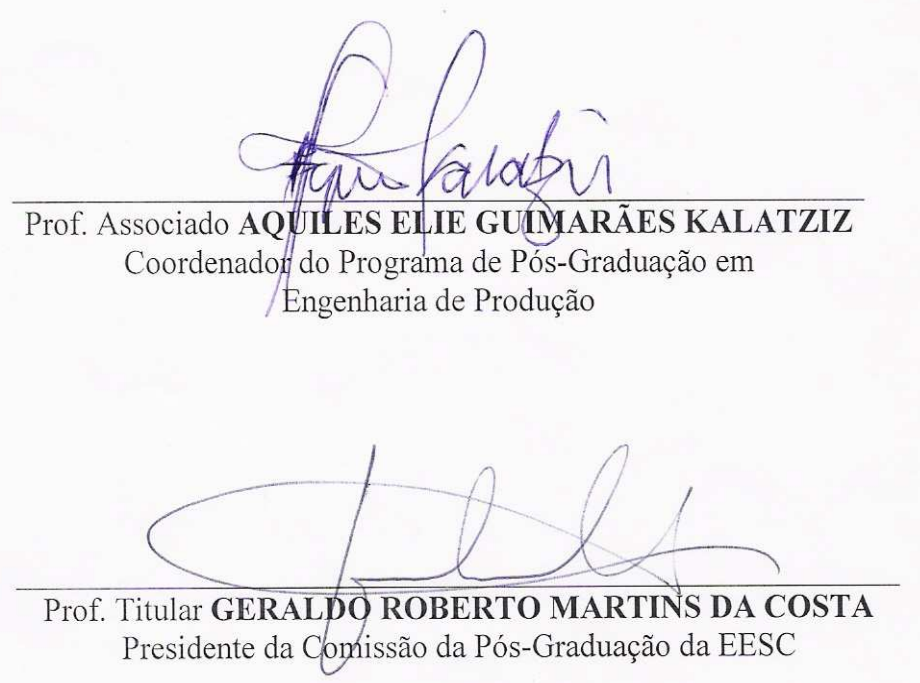


À minha amada família,

Yochio, Lourdes e Rafael,

e ao meu mestre da vida,

DaisakuIkeda. 


\section{Agradecimentos}

\section{"Aqueles que passam por nós, não vão sós, não nos deixam sós. Deixam um pouco de si, levam um pouco de nós." Antoine de Saint-Exupéry}

Estes cinco anos em que fiz esta pesquisa foram uma árdua jornada de desafio, construção e amadurecimento. Nenhum empreendimento é realizado de forma fácil e sem esforço.

Daisaku Ikeda discorreu que os grandes empreendimentos são construidos em meio a muitas dificuldades: "Ser herói não significa acertar constantemente. É muito mais que isso. O verdadeiro espírito de um herói encontra-se na intensa convicção de enfrentar e vencer as dificuldades em vez de desistir de tudo. $\mathcal{N a}$ vida de todos nós poderão surgir situações inesperadas. Poderão manifestar obstáculos ou problemas que jamais havíamos imaginado. É justamente nesses momentos que revelamos o que verdadeiramente carregamos no coração."

$\mathcal{N}$ este período, aprendi que uma tese ou qualquer outro trabalho é a extensão da vida do autor. Então, para que algo de valor seja produzido, a pessoa deve primeiro criar algo de valor em si. Pessoa e obra são consistentes com o resultado. Por este motivo, agradeço sincera e profundamente a todas as pessoas que muito me encorajaram e me ajudaram a produzir algo de valor em minha vida.

Primeiramente, agradeço ao meu grande exemplo, o professor Moccellin. Para mim, é uma imensa honra e orgulho tê-lo como orientador por mais de sete anos (desde o mestrado). NNão esqueço seus eternos ensinamentos, seus preciosos conselhos e sua inestimável confiança. Muito obrigado!

Agradeço também aos valientes amigos de Valência, na Espanha, que gentilmente me receberam e com quem tenho aprendido muito: Rubén, Thijs, Gerardo, Eva e Michele. ¡Muchas gracias! O professor Rubén tem me ensinado e ajudado substancialmente.

Manifesto aqui a minha gratidão a todos professores, funcionários e amigos do Departamento de Engenharia de Produção da EESC/USP, em particular, ao professor N Nagano e aos colegas Fábio Branco, Mariana Almeida, Mariana Sarmanho, Lie, Ana Elisa, Naja e Ava, e aos companheiros de trabalho da UFG/Campus Catalão. Não deixo de agradecer também ao imprescindível apoio da CAPES (Coordenação de Aperfeiçoamento de Pessoal de SNivel Superior) e ao programa Santander/Banespa pela oportunidade de fazer o estágio na Espanha.

Meus respeitosos agradecimentos pela contribuição da banca do exame de qualificação e pela participação dos membros da banca examinadora da defesa.

Meu muito obrigado a quem me encoraja em todos os aspectos da vida, meu mestre Daisaku Ikeda, e aos meus amigos do 6udismo, em particular as queridas Adriana, Ilda e Pat Melinn.

Por fim, agradeço em especial àqueles que sempre me apoiaram incondicionalmente, que apostaram em mim mais do que ninguém e que seguramente são os que mais compartilham da minha alegria: minha amada família.

Mais uma etapa foi vencida! Sei que ainda é só o começo... 


\section{O poeta e o acadêmico}

O poeta diz muito

Em poucas palavras,

Até nas entrelinhas

- com o coração, emoção.

O acadêmico diz pouco

Em muitas palavras,

Até nos rodapés

- com experimentação.

O tamanho de um poema

$\mathcal{N a ̃ o ~ e ́ ~ m e d i d o ~ e m ~ v e r s o s , ~ l i n h a s ~}$

Nem a extensão de uma tese

É mensurada em capítulos

É algo oculto, profundo

Verdadeira fusão:

Autor, obra, Ceitor.

O poeta vê beleza

Leveza, com amor.

O acadêmico prova,

Comprova, com labor.

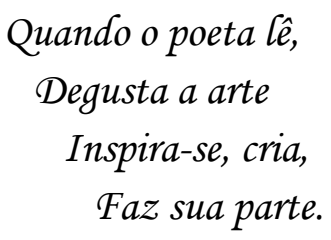

Quando o acadêmico lê,

Discute cada parte

$\mathcal{E}$ assim contribui

Com o estado da arte.

Poeta e acadêmico

Amam a vida

Trabalham com arte,

Apaixonadamente. 


\section{RESUMO}

FUCHIGAMI, H.Y. Flexible flow line com tempos de setup: métodos heurísticos. 2010. 170f. Tese (Doutorado) - Escola de Engenharia de São Carlos, Universidade de São Paulo, São Carlos, 2010.

Este trabalho aborda o problema de programação da produção em um flexible flow line com tempos de setup. De acordo com a literatura, este ambiente pode ser considerado como um caso especial do Flow Shop com múltiplas máquinas, onde as tarefas podem saltar estágios. Neste estudo, foram analisados dois problemas: o primeiro, com tempos de setup independentes da sequência, e o segundo, com setup dependente da sequência de tarefas. Além disso, o setup das máquinas para as tarefas pode ser antecipado ou não. No primeiro caso, as máquinas de um estágio podem ser preparadas para o processamento de uma tarefa antes do seu término no estágio anterior. Se o setup não pode ser antecipado, a tarefa deve esperar o seu término no estágio de produção anterior. Este ambiente produtivo pode ser encontrado em um vasto número de indústrias tais como química, eletrônica, automotiva e têxtil. A medida de desempenho dos problemas é a duração total da programação (makespan). Este é um critério apropriado para sistemas de produção com grandes cargas de trabalho e em que a utilização dos recursos produtivos em longo prazo deve ser otimizada. O exame da literatura mostrou que há poucos estudos abordando a programação em flexible flow line. Considerando este aspecto, este trabalho apresenta heurísticas construtivas originais para a obtenção de programações apropriadas ao problema mencionado. Uma extensiva experimentação computacional foi executada para avaliar o desempenho relativo das heurísticas. Os resultados experimentais foram analisados e discutidos.

Palavras-chave: Programação da produção. Flexible flow line. Tempos de setup. Heurísticas. 


\section{ABSTRACT}

FUCHIGAMI, H.Y. Flexible flow line with setup times: heuristic methods. 2010. 340p. Thesis (Ph.D.) - Escola de Engenharia de São Carlos, Universidade de São Paulo, São Carlos, 2010 .

This work addresses the job scheduling on a flexible flow line with separate setup times. According to the literature, this scheduling problem can be considered as a special case of the Flow Shop with Multiple Machines, where the jobs may skip stages. Two modeled problems have been studied. In the first scheduling problem the setup times are sequence independent, and in the second one these times are sequence dependent. Moreover, the machine setup task can be either anticipatory or non-anticipatory. In the first case, a k-stage machine may be prepared for a job processing before its completion on the k-1 production stage. Otherwise, the setup task must wait for the job completion on the former production stage. This production environment can be found in a number of industries such as chemicals, electronics, automotive, and textiles. The performance measure of the production schedules is the makespan, that is, the total time to complete the schedule. This is an appropriate performance criterion for production systems with large workloads, and where the utilization of productive resources in the long term should be optimized. The literature examination has shown that there is a small number of studies dealing with flexible flow line scheduling. Having this in mind, this work introduces original constructive heuristics in order to obtain suitable schedules for the aforementioned scheduling problem. An extensive computational experience has been carried out in order to evaluate the relative performance of the heuristics. Experimental results are discussed.

Keywords: Production scheduling. Flexible flow line. Setup times. Heuristics. 


\section{LISTA DE ILUSTRAÇÕES}

FIGURA 1.1 - Exemplo de Gráfico de Gantt 29

FIGURA 1.2 - Relação entre as classes de problemas 32

FIGURA 3.1 - Relação entre problemas de fluxo unidirecional 64

FIGURA 3.2 - Esquema ilustrativo de um flexible flow line 66

FIGURA 3.3 - Esquema do cenário do problema exemplo 71

FIGURA 3.4 - Ilustração de uma programação factível 73

FIGURA 3.5 - Ilustração do makespan definido por estágio intermediário 75

FIGURA 4.1 - Programação dos estágios 1 e 2 definida pela regra LPT1 83

FIGURA 4.2 - Programação definida pela regra LPT2 85

FIGURA 4.3 - Programação definida pela regra LPT3 87

FIGURA 4.4 - Programação definida pela regra LPT1_ERD ................................................ 90

FIGURA 5.1 - Programação da primeira tarefa pela heurística Hi4 105

FIGURA 5.2 - Programação da segunda e da terceira tarefas pela heurística Hi4 106

FIGURA 5.3 - Programação pela heurística Hi4 107

FIGURA 6.1 - Comparação de desempenho das regras de prioridade para setup independente (em \% de sucesso) 130

FIGURA 6.2 - Desempenho das regras para setup independente por porte do problema (em \% de sucesso)

FIGURA 6.3 - Desempenho das regras para setup independente por flexibilidade e porte do problema (em \% de sucesso) 133

FIGURA 6.4 - Desempenho das regras para setup independente por intervalo de setup e porte do problema (em \% de sucesso) 
FIGURA 6.5 - Desempenho das regras para setup independente por probabilidade de antecipação do setup e porte do problema (em \% de sucesso)

FIGURA 6.6 - Desempenho das regras para setup independente por probabilidade de salto e porte do problema (em \% de sucesso)

FIGURA 6.7 - Comparação do desvio relativo médio (em \%) das regras para setup independente

FIGURA 6.8 - Desvio relativo médio (em \%) das regras para setup independente por porte do problema

FIGURA 6.9 - Comparação do desvio-padrão das regras para setup independente

FIGURA 6.10 - Desvio-padrão das regras para setup independente por porte do problema . 140

FIGURA 6.11 - Comparação de desempenho das heurísticas para setup independente (em \% de sucesso)

FIGURA 6.12 - Desempenho das heurísticas para setup independente por porte do problema (em \% de sucesso)

FIGURA 6.13 - Desempenho das heurísticas para setup independente por flexibilidade e porte do problema (em \% de sucesso) 146

FIGURA 6.14 - Desempenho das heurísticas para setup independente por intervalo de setup e porte do problema (em \% de sucesso)

FIGURA 6.15 - Desempenho das heurísticas para setup independente por probabilidade de antecipação do setup e porte do problema (em \% de sucesso)

FIGURA 6.16 - Desempenho das heurísticas para setup independente por probabilidade de salto e porte do problema (em \% de sucesso) 148

FIGURA 6.17 - Comparação do desvio relativo médio (em \%) das heurísticas para setup independente 150 
FIGURA 6.18 - Desvio relativo médio (em \%) das heurísticas para setup independente por porte do problema

FIGURA 6.19 - Comparação do desvio-padrão das heurísticas para setup independente 152

FIGURA 6.20 - Desvio-padrão das heurísticas para setup independente por porte do problema

FIGURA 6.21 - Comparação do tempo médio de computação das heurísticas para setup independente (em ms)

FIGURA 6.22 - Comparação de desempenho das regras de prioridade para setup dependente (em \% de sucesso) 156

FIGURA 6.23 - Desempenho das regras de prioridade para setup dependente (em \% de sucesso) 158

FIGURA 6.24 - Desempenho das regras para setup dependente por flexibilidade e porte do problema (em \% de sucesso) 160

FIGURA 6.25 - Desempenho das regras para setup dependente por intervalo de setup e porte do problema (em \% de sucesso) 161

FIGURA 6.26 - Desempenho das regras para setup dependente por probabilidade de antecipação do setup e porte do problema (em \% de sucesso) 162

FIGURA 6.27 - Desempenho das regras para setup dependente por probabilidade de salto e porte do problema (em \% de sucesso) 163

FIGURA 6.28 - Comparação do desvio relativo médio (em \%) das regras para setup dependente 165

FIGURA 6.29 - Desvio relativo médio (em \%) das regras para setup dependente por porte do problema 166

FIGURA 6.30 - Comparação do desvio-padrão das regras para setup dependente 167

FIGURA 6.31 - Desvio-padrão das regras para setup dependente por porte do problema ..... 168 
FIGURA 6.32 - Comparação de desempenho das heurísticas para setup dependente (em \% de sucesso) 170

FIGURA 6.33 - Desempenho dos algoritmos heurísticos por porte do problema (em \% de sucesso)

FIGURA 6.34 - Desempenho das heurísticas para setup dependente por flexibilidade e porte do problema (em \% de sucesso) 174

FIGURA 6.35 - Desempenho das heurísticas para setup dependente por intervalo de setup e porte do problema para flexibilidade baixa (em \% de sucesso)

FIGURA 6.36 - Desempenho das heurísticas para setup dependente por intervalo de setup e porte do problema para flexibilidade média (em \% de sucesso) 178

FIGURA 6.37 - Desempenho das heurísticas para setup dependente por intervalo de setup e porte do problema para flexibilidade alta (em \% de sucesso) 178

FIGURA 6.38 - Desempenho das heurísticas para setup dependente por probabilidade de antecipação do setup e porte do problema para flexibilidade baixa (em \% de sucesso) 179

FIGURA 6.39 - Desempenho das heurísticas para setup dependente por probabilidade de antecipação do setup e porte do problema para flexibilidade média (em \% de sucesso) 180

FIGURA 6.40 - Desempenho das heurísticas para setup dependente por probabilidade de antecipação do setup e porte do problema para flexibilidade alta (em \% de sucesso) 180

FIGURA 6.41 - Desempenho das heurísticas para setup dependente por probabilidade de salto e porte do problema para flexibilidade baixa (em \% de sucesso) 181

FIGURA 6.42 - Desempenho das heurísticas para setup dependente por probabilidade de salto e porte do problema para flexibilidade média (em \% de sucesso) 182 
FIGURA 6.43 - Desempenho das heurísticas para setup dependente por probabilidade de salto e porte do problema para flexibilidade alta (em \% de sucesso) 182

FIGURA 6.44 - Comparação do desvio relativo médio (em \%) dos algoritmos heurísticos .. 184

FIGURA 6.45 - Desvio relativo médio (em \%) dos algoritmos heurísticos por flexibilidade e porte do problema 184

FIGURA 6.46 - Comparação do desvio-padrão dos algoritmos heurísticos 185

FIGURA 6.47 - Desvio-padrão dos algoritmos heurísticos por flexibilidade e porte do problema 186

FIGURA 6.48 - Comparação do tempo médio de computação das heurísticas para setup dependente (em ms) 187

FIGURA C.1 - Exemplo de arquivo de dados do problema com setup independente 216

FIGURA C.2 - Exemplo de arquivo de dados do problema com setup dependente 217 


\section{LISTA DE TABELAS}

TABELA 2.1 - Relação dos trabalhos citados (em ordem cronológica) 59

TABELA 3.1 - Trabalhos com múltiplas máquinas nos estágios e tempos de setup separados 63

TABEla 3.2 - Dados do Problema I (a) 71

TABela 3.3 - Dados do Problema I (b) 71

TABela 3.4 - Dados do Problema I (c) 71

TABela 3.5 - Dados do Problema II (a) 72

TABela 3.6 - Dados do Problema II (b) 72

Tabela 3.7 - Dados do Problema II (c) 72

TABELA 4.1 - Valores para ordenação pela regra LPT1 83

TABELA 4.2 - Dados do problema exemplo 2 (a) 84

TABELA 4.3 - Dados do problema exemplo 2 (b) 84

TABELA 4.4 - Dados do problema exemplo 2 (c) 84

TABELA 4.5 - Valores para ordenação pela regra LPT2 84

TABELA 4.6 - Valores para ordenação pela regra LPT3 86

TABELA 4.7 - Valores para ordenação do primeiro estágio pela regra LPT1_ERD 88

TABELA 4.8 - Resumo das regras de prioridade para setup independente 92

TABELA 4.9 - Resumo das regras de prioridade para setup dependente 96

TABELA 5.1 - Valores de ordenação para programação pela heurística Hi4 105

TABELA 5.2 - Resumo dos algoritmos heurísticos para setup independente 111

TABELA 5.3 - Resumo dos algoritmos heurísticos para setup dependente 122

TABELA 6.1 - Parâmetros e valores da experimentação computacional do problema com setup independente 
TABELA 6.2 - Parâmetros e valores da experimentação computacional do problema com setup dependente 124

TABELA 6.3 - Regras de prioridade para setup independente 129

TABELA 6.4 - Melhores regras para setup independente por porte do problema e suas porcentagens de sucesso 132

TABELA 6.5 - Valores da AMV para os parâmetros das regras com setup independente .... 136 TABELA 6.6 - Algoritmos heurísticos e melhores regras de prioridade para setup independente 141

TABELA 6.7 - Melhores heurísticas para setup independente por porte do problema e suas porcentagens de sucesso 145

TABELA 6.8 - Valores da AMV para os parâmetros das heurísticas com setup independente 149

TABELA 6.9 - Regras de prioridade para setup dependente 155

TABELA 6.10 - Melhores regras para setup dependente por porte do problema e suas porcentagens de sucesso 159

TABELA 6.11 - Valores da AMV para os parâmetros das regras de prioridade com setup dependente 165

TABELA 6.12 - Algoritmos heurísticos e melhores regras de prioridade para setup dependente 169

TABELA 6.13 - Colocação das heurísticas por desempenho (em \% de sucesso) para os níveis de flexibilidade 171

TABELA 6.14 - Valores da AMV para os parâmetros das heurísticas com setup dependente

TABELA 6.15 - Melhores heurísticas para setup dependente por flexibilidade e porte do problema e suas porcentagens de sucesso 176 
TABELA D. 1 - Resultados das regras para setup independente por porte do problema (em \% de sucesso)

TABELA D.2 - Resultados das regras para setup independente por flexibilidade e porte do problema (em \% de sucesso)

TABELA D.3 - Resultados das regras para setup independente por intervalo de setup e porte do problema (em \% de sucesso) 220

TABELA D.4 - Resultados das regras para setup independente por probabilidade de antecipação do setup e porte do problema (em \% de sucesso) 220

TABELA D.5 - Resultados das regras para setup independente por probabilidade de salto e porte do problema (em \% de sucesso) 221

TABELA D.6 - Desvio relativo médio (em \%) das regras para setup independente por porte do problema 221

TABELA D.7 - Desvio-padrão do desvio relativo das regras para setup independente por porte do problema 221

TABELA D.8 - Resultado das regras para setup independente por parâmetro (em \% de sucesso) 222

TABELA D.9 - Desvio relativo médio (em \%) das regras para setup independente 225

TABELA D.10 - Desvio-padrão do relativo das regras para setup independente 229

TABELA D.11 - Resultados das heurísticas para setup independente por porte do problema (em $\%$ de sucesso) 232

TABELA D.12 - Resultados das heurísticas para setup independente por flexibilidade e porte do problema (em \% de sucesso) 233

TABELA D.13 - Resultados das heurísticas para setup independente por intervalo de setup e porte do problema (em \% de sucesso) 233 
TABELA D.14 - Resultados das heurísticas para setup independente por probabilidade de antecipação do setup e porte do problema (em \% de sucesso) 234

TABELA D.15 - Resultados das heurísticas para setup independente por probabilidade de salto e porte do problema (em \% de sucesso) 234

TABELA D.16 - Desvio relativo médio (em \%) das heurísticas para setup independente por porte do problema 235

TABELA D.17 - Desvio-padrão do desvio relativo das heurísticas para setup independente por porte do problema 235

TABELA D.18 - Resultado das heurísticas para setup independente por parâmetro (em \% de sucesso) 235

TABELA D.19 - Desvio relativo médio (em \%) das heurísticas para setup independente .... 239

TABELA D.20 - Desvio-padrão do relativo das heurísticas para setup independente 242

TABELA D.21 - Resultados das regras para setup dependente por porte do problema (em \% de sucesso) 246

TABELA D.22 - Resultados das regras para setup dependente por flexibilidade e porte do problema (em \% de sucesso) 247

TABELA D.23 - Resultados das regras para setup dependente por intervalo de setup e porte do problema (em \% de sucesso) 248

TABELA D.24 - Resultados das regras para setup dependente por probabilidade de antecipação do setup e porte do problema (em \% de sucesso) 249

TABELA D.25 - Resultados das regras para setup dependente por probabilidade de salto e porte do problema (em \% de sucesso) 250

TABELA D.26 - Desvio relativo médio (em \%) das regras para setup dependente por porte do problema 250 
TABELA D.27 - Desvio-padrão do desvio relativo das regras para setup dependente por porte do problema

TABELA D.28 - Resultado das regras para setup dependente por parâmetro (em \% de sucesso)

TABELA D.29 - Desvio relativo médio (em \%) das regras para setup dependente 257

TABELA D.30 - Desvio-padrão do relativo das regras para setup dependente 263

TABELA D.31 - Resultados das heurísticas para setup dependente por porte do problema (em

$\%$ de sucesso) 269

TABELA D.32 - Resultados das heurísticas para setup dependente por flexibilidade e porte do problema (em \% de sucesso) 269

TABELA D.33 - Resultados das heurísticas para setup dependente por intervalo de setup e porte do problema para flexibilidade baixa (em \% de sucesso) 270

TABELA D.34 - Resultados das heurísticas para setup dependente por intervalo de setup e porte do problema para flexibilidade média (em \% de sucesso) 271

TABELA D.35 - Resultados das heurísticas para setup dependente por intervalo de setup e porte do problema para flexibilidade alta (em \% de sucesso) 272

TABELA D.36 - Resultados das heurísticas para setup dependente por probabilidade de antecipação do setup e porte do problema para flexibilidade baixa (em \% de sucesso)

TABELA D.37 - Resultados das heurísticas para setup dependente por probabilidade de antecipação do setup e porte do problema para flexibilidade média (em \% de sucesso) 274

TABELA D.38 - Resultados das heurísticas para setup dependente por probabilidade de antecipação do setup e porte do problema para flexibilidade alta (em \% de sucesso) ... 
TABELA D.39 - Resultados das heurísticas para setup dependente por probabilidade de salto e porte do problema para flexibilidade baixa (em \% de sucesso) 276

TABELA D.40 - Resultados das heurísticas para setup dependente por probabilidade de salto e porte do problema para flexibilidade média (em \% de sucesso)

TABELA D.41 - Resultados das heurísticas para setup dependente por probabilidade de salto e porte do problema para flexibilidade alta (em \% de sucesso) 278

TABELA D.42 - Desvio relativo médio (em \%) das heurísticas para setup dependente por flexibilidade e porte do problema 279

TABELA D.43 - Desvio-padrão do desvio relativo das heurísticas para setup dependente por flexibilidade e porte do problema 280

TABELA D.44 - Resultado das heurísticas para setup dependente por parâmetro (em \% de su-

cesso) 281

TABELA D.45 - Desvio relativo médio (em \%) das heurísticas para setup dependente 283

TABELA D.46 - Desvio-padrão do relativo das heurísticas para setup dependente 293 


\section{LISTA DE ABREVIATURAS E SIGLAS}

\begin{tabular}{|c|c|}
\hline AMV & Amplitude Média de Variação (da porcentagem de sucesso) \\
\hline CDS & Algoritmo de Campbell, Dudek e Smith \\
\hline$E C T$ & Earlist Completion Time \\
\hline$E D D$ & Earliest Due Date \\
\hline$E R D$ & Earliest Release Date \\
\hline FIFO & First In First Out \\
\hline FITSP & Farthest Insertion Traveling Salesman Problem \\
\hline GRASP & Greedy Randomized Search Procedure \\
\hline$L I F O$ & Last In First Out \\
\hline$L P T$ & Longest Processing Lime \\
\hline$M I$ & Multiple Insertion \\
\hline $\mathrm{ms}$ & milissegundos \\
\hline MST & Minimum Slack Time \\
\hline $\mathrm{NEH}$ & Algoritmo de Nawaz, Enscore Jr. e Ham \\
\hline NITSP & Nearest Insertion Traveling Salesman Problem \\
\hline NJSM & Next Job Same Machine \\
\hline N\&M & Algoritmo de Nagano e Moccellin \\
\hline PCP & Planejamento e Controle da Produção \\
\hline$R A N D$ & Randomized (aleatória) \\
\hline SMED & Single Minute Exchange of Die \\
\hline SPST & Shortest Processing + Setup Time \\
\hline$S P T$ & Shortest Processing Time \\
\hline
\end{tabular}


Troca Rápida de Ferramenta

TSP

Traveling Salesman Problem (Problema do Caixeiro Viajante)

WSPT Weighted Shortest Processing Time

WLPT Weighted Longest Processing Lime 


\section{LISTA DE SímBOLOS}

a probabilidade do setup ser antecipado

$A_{i j k} \quad$ variável binária que define se o setup da tarefa $i$ para a tarefa $j$ no estágio $k$ é antecipado (1) ou não antecipado (0)

$A_{j k} \quad$ variável binária que define se o setup da tarefa $j$ no estágio $k$ é antecipado (1) ou não antecipado (0)

$C_{j} \quad$ data de término da tarefa $j$ (no último estágio)

$C_{j k} \quad$ data de término da tarefa $j$ no estágio $k$

$C_{\max }$ tempo total da programação (makespan)

$C_{\max }^{*} \quad$ makespan ótimo

$d_{j} \quad$ prazo de entrega (due date) da tarefa $j$

$E_{j} \quad$ adiantamento (earliness) da tarefa $j$

$E_{\max } \quad$ adiantamento (earliness) máximo das tarefas

$f \quad$ nível de flexibilidade

$F_{j} \quad$ tempo de fluxo da tarefa $j$ (flow time)

$F_{\max }$ tempo máximo de fluxo das tarefas

$\bar{F} \quad$ tempo médio de fluxo (mean flow time) das tarefas

$g \quad$ número de estágios de produção

$g_{j} \quad$ último estágio visitado pela tarefa $j$

$G \quad$ conjunto dos estágios de produção, $G=\{1, \ldots, g\}$

$G_{j} \quad$ conjunto dos estágios visitados pela tarefa $j$

$I_{m} \quad$ tempo ocioso (idle time) da máquina $m$

$J \quad$ conjunto das tarefas a serem programadas, $J=\{1, \ldots, n\}$

[j] tarefa que ocupa a $j$-ésima posição em uma sequência

$l \quad$ probabilidade das tarefas saltarem estágios 
$L_{j} \quad$ lateness da tarefa $\mathrm{j}$

$L_{\max } \quad$ lateness máximo das tarefas

$m \quad$ número de máquinas do problema

$m_{k} \quad$ número de máquinas do estágio $k$

$M_{k} \quad$ conjunto das máquinas do estágio $k$

$n \quad$ número de tarefas a serem programadas

$O(x) \quad$ ordem de grandeza da variável $x$

$p_{j} \quad$ tempo de processamento da tarefa $j$

$p_{j k} \quad$ tempo de processamento da tarefa $j$ no estágio $k$

$r_{j} \quad$ data de liberação (inicial) da tarefa $j$

$r_{j k} \quad$ data de liberação da tarefa $j$ no estágio $k$

$R_{h} \quad$ desvio relativo do método $h$

$s_{i j} \quad$ restrição que indica presença de setup dependente

$s_{i k} \quad$ tempo de setup (independente da sequência) para a tarefa $j$ no estágio $k$

$s_{i j k} \quad$ tempo de setup (dependente da sequência) da tarefa $i$ para a tarefa $j$ no estágio $k$

$S_{h} \quad$ desvio-padrão do desvio relativo do método $h$

$T_{j} \quad$ atraso da tarefa $j$ (tardiness)

$T_{\max } \quad$ atraso (tardiness) máximo das tarefas

$u_{m} \quad$ índice da última tarefa alocada à máquina $m$

$\sum U_{k} \quad$ número de tarefas com atraso (tardy jobs)

$v_{k} \quad\left(\right.$ ou $\left.\left|V_{k}\right|\right)$ número de tarefas que visitam o estágio $k$

$V_{k} \quad$ conjunto das tarefas que visitam o estágio $k$

$w_{j} \quad$ peso (ou prioridade) da tarefa $j$

$W_{j} \quad$ tempo de espera da tarefa $j$ 


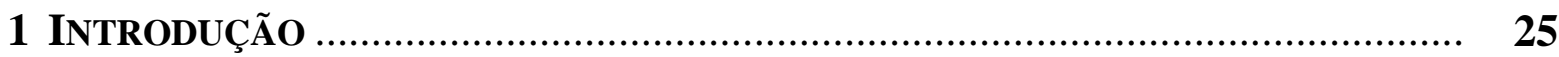

1.1 Sistemas de produção ............................................................................ 25

1.2 Programação da produção ........................................................................ 27

1.3 Problemas de programação de operações em máquinas ................................ 30

1.4 Métodos de solução ................................................................................... 33

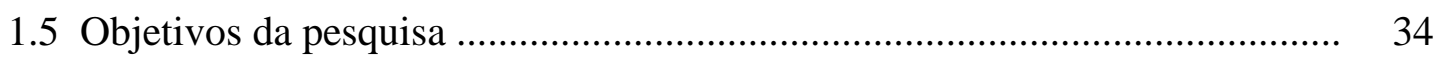

1.6 Estrutura dos capítulos ................................................................... 35

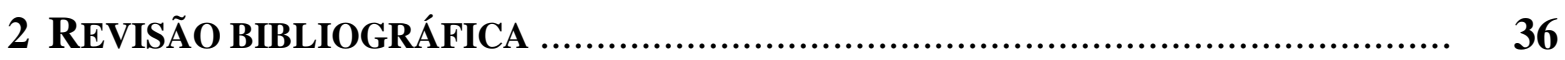

2.1 Notação dos problemas de programação da produção .................................. 36

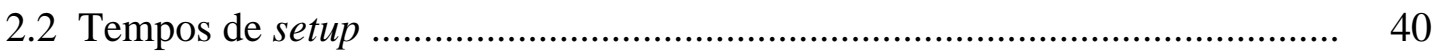

2.3 Máquina única com tempos de setup ..................................................... 42

2.4 Máquinas paralelas com tempos de setup ................................................... 45

2.5 Máquinas em série com fluxo unidirecional ............................................. 48

2.6 Sistemas multiestágio híbridos ............................................................... 52

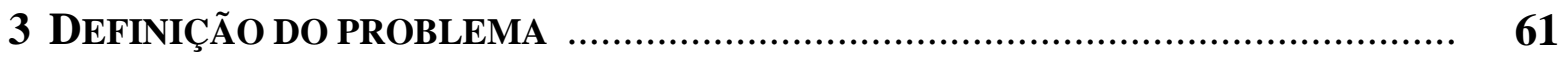

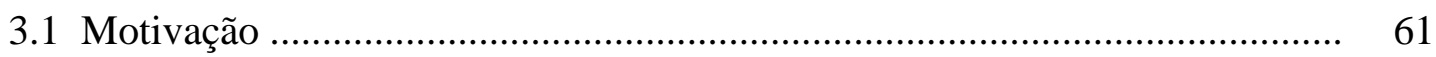

3.2 Características do ambiente de produção .................................................... 62

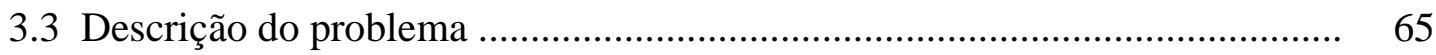

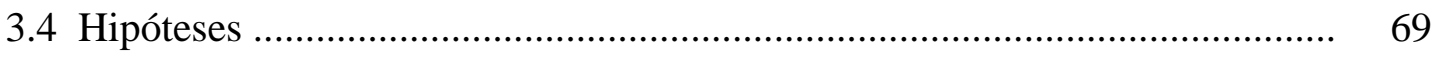

3.5 Problemas exemplo ................................................................... $\quad 70$ 
4.1 Classificação dos métodos heurísticos ............................................................ $\quad 76$

4.2 Importância das regras de prioridade ……………………………………...... 77

4.3 Regras propostas para setup independente ……………………………….. 78

4.4 Regras propostas para setup dependente ...................................................... 93

5 HEURÍSTICAS PROPOSTAS …............................................................... 97

5.1 Importância dos métodos heurísticos ……………………………………..... 97

5.2 Heurísticas propostas para setup independente …………………………..... 98

5.3 Heurísticas propostas para setup dependente ................................................ 111

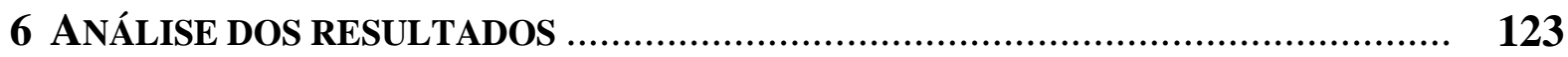

6.1 Experimentação computacional .................................................................... 123

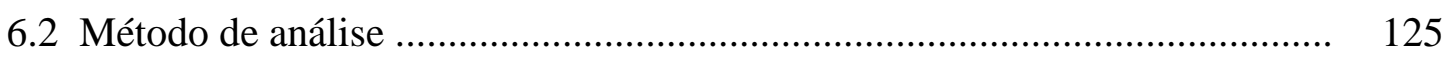

6.2.1 Proposição da medida estatística AMV …………………………….... 127

6.3 Resultados do problema com setup independente ……………………….... 128

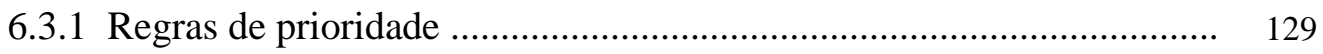

6.3.2 Heurísticas .................................................................................. 140

6.4 Resultados do problema com setup dependente …………………………..... 155

6.4.1 Regras de prioridade ..................................................................... 155

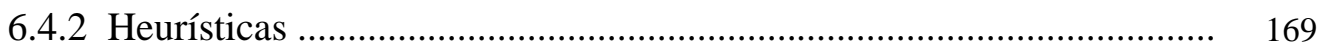

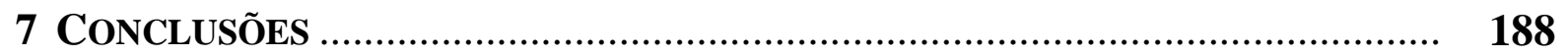

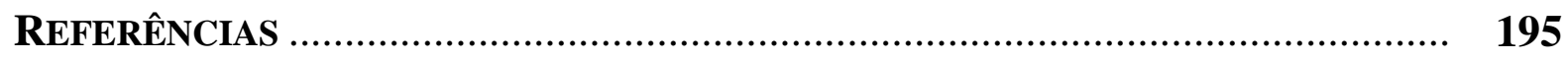

APÊNDICE A - Trabalhos Publicados _..................................................... 211 
APÊNDiCE B - ESTUdos EM PROGRAMAÇÃo de OPERAÇÕes EM MÁQuinas ...... 213

APÊNDICE C - Formato dos ARquivos de Dados ................................... 216

APÊNDiCE D - Resultados dos Problemas-TESTE DA EXPERIMENTAÇÃO (CD) $\mathbf{2 1 8}$

APÊNDICE E - Código-Fonte dos Programas COMPUTACIONAIS ............. (CD) 299 



\title{
1 INTRODUÇÃO
}

\author{
"Vma jornada de mil milhas \\ começa com o primeiro passo." \\ Lao-tzu, filósofo chinês
}

\subsection{Sistemas de produção}

Há mais de cinquenta anos a metodologia de estudo da Pesquisa Operacional vem sendo empregada e muitas das aplicações atuais ainda utilizam as técnicas propostas nos primórdios da área. Isto porque tal metodologia apresenta ferramentas concretas em que, a partir da construção de um modelo que representa bem um problema real, um software é usado e assim a melhor solução possível para tal modelo é obtida.

A Pesquisa Operacional procura substituir a tomada de decisões intuitiva para problemas grandes e complexos por uma abordagem que identifique a melhor alternativa por meio de algum critério de análise (GAITHER; FRAZIER, 2004, p.12). Desta forma, ela oferece métodos de solução para problemas das diversas áreas do conhecimento em que haja a necessidade de tomada de decisão, como é o caso dos sistemas produtivos.

Segundo Harding (1981, p.24), um sistema de produção “é um conjunto de partes inter-relacionadas, as quais quando ligadas atuam de acordo com padrões estabelecidos sobre inputs (entradas) no sentido de produzir outputs (saídas)". Pode-se classificar os sistemas de produção de várias formas. Erdmann (2000, p.19) define como determinísticos os sistemas exatamente previsíveis em suas operações e probabilísticos aqueles com previsões das ativi- 
dades em termos de probabilidade. Johnson e Montgomery (1974, p.3-4) classificaram os sistemas de produção em três tipos, segundo o fluxo de materiais:

- Contínuo: fabricação em larga escala de produtos padronizados e com pouca diversificação, como no caso da produção de aço;

- Intermitente: caracterizado pela flexibilidade, ou seja, a capacidade de produzir uma grande variedade de produtos; as linhas de produção devem se ajustar a cada caso, representando maior dificuldade de operação e controle. Exemplos claros são as indústrias têxteis e automobilísticas.

- Projeto: produção de itens complexos ou de grande porte, geralmente únicos, tais como a construção de navios e edifícios.

O mercado consumidor competitivo tem forçado as empresas a oferecerem seus produtos e serviços com alta qualidade, baixo preço e reduzidos prazos de entrega. Além disso, os clientes frequentemente solicitam mudanças nas especificações dos produtos e dos pedidos, exigindo maior flexibilidade por parte das organizações.

Esta situação contrasta com muitos sistemas produtivos, em que existem linhas de produção dimensionadas para fabricar grandes lotes de produtos a baixo custo. Entretanto, há o inconveniente de que as mudanças exigem ajustes nas linhas, o que requer tempo e investimento.

Neste contexto, as empresas devem oferecer um amplo catálogo de produtos inovadores e diferenciados e possuir um sistema de produção flexível que permita ao mesmo tempo a rapidez na entrega e custos baixos para assegurar a completa satisfação do cliente. É evidente 
que com estas premissas, faz-se necessário um uso racional e eficiente dos recursos produti$\operatorname{vos}($ RUIZ, 2003, p.2).

\subsection{Programação da produção}

$\mathrm{Na}$ indústria, independentemente do tipo de sistema de produção, é necessário tomar uma série de decisões que dependem do horizonte de tempo considerado. As funções dos sistemas de produção são desenvolvidas pelo Planejamento e Controle da Produção (PCP). De acordo com Tubino (2006, p.24), as atividades do PCP são exercidas nos três níveis hierárquicos de uma empresa. No nível estratégico, em que são definidas as políticas estratégicas de longo prazo da companhia, o PCP participa da formulação do Planejamento Estratégico da Produção, gerando um Plano de Produção. No nível tático, em que são preparados os planos de médio prazo para a produção, o PCP desenvolve o Planejamento Mestre da Produção, obtendo o Plano Mestre de Produção. E no nível operacional, em que são preparados os programas de curto prazo de produção e realizado o seu acompanhamento, o PCP é responsável por administrar estoques, elaborar sequenciamento e emitir e liberar ordens de compras, fabricação e montagem, constituindo a programação da produção.

A programação da produção ou "scheduling" pode ser definida como a alocação de recursos escassos para a execução de tarefas em uma base de tempo (BAKER, 1974, p.2). Os recursos podem ser máquinas em uma fábrica, pistas em um aeroporto, trabalhadores em construções, unidades de processamento em ambiente computacional. As tarefas podem ser os pedidos de produção, as decolagens e aterrissagens de aviões, os estágios em um projeto de construção, as execuções de programas de computador, entre outros (PINEDO, 1995, p.1). 
Neste texto, serão adotadas algumas definições clássicas. Uma operação é uma atividade elementar a ser executada. O tempo requerido pela operação é chamado tempo de processamento. Uma tarefa é um conjunto de operações inter-relacionadas por restrições de precedência derivadas de limitações tecnológicas. As restrições de precedência definem a rota das operações, ou seja, a ordem em que são processadas. Uma máquina é um equipamento, dispositivo ou instalação capaz de executar uma operação (HAX; CANDEA, 1984, p.258-9).

A atividade de "scheduling" envolve a alocação (associação das tarefas nas máquinas), o sequenciamento (ordenação das tarefas em cada máquina) e a posterior programação (obtenção dos tempos de início e término de cada operação). Segundo Pinedo (1995, p.1), "scheduling" é um processo de tomada de decisão presente tanto em sistemas de produção como em ambientes de processamento de informações, além das empresas de transporte e distribuição e outros tipos de serviços industriais.

Ruiz (2003, p.5) observou que a programação da produção supõe que o planejamento da produção já tenha sido realizado. Portanto, conhecem-se os produtos a fabricar e suas correspondentes quantidades, assim como a configuração, disposição e quantidade de recursos disponíveis. Um sequenciamento adequado da produção é vital para o funcionamento da empresa, garantindo os resultados almejados. Como afirmou Pinedo (1995, p.1), os objetivos do sequenciamento podem ser diversos como, por exemplo, a minimização da data de término da última tarefa ou do número de pedidos que se finalizam após a data de entrega prometida ao cliente.

De acordo com Slack et al. (1999, p.245), a programação é uma das mais complexas atividades no gerenciamento da produção. Os programadores precisam lidar com diversos tipos diferentes de recursos simultaneamente. Além disso, as máquinas terão capacidades variáveis e o pessoal terá diferentes habilidades. Ainda mais importante, o número de programações possíveis cresce rapidamente à medida que o número de tarefas e operações aumenta. Ou seja, para um conjunto de $n$ tarefas a serem processadas em uma máquina, há $n !$ ( $n$ fatorial) 
sequências possíveis. Considerando mais de uma máquina, o número de programações possíveis passa para $(n !)^{m}$. Isto é válido quando as tarefas têm a mesma data de liberação para serem executadas.

Assim, a primeira característica que torna os problemas de programação difíceis de serem resolvidos é sua natureza combinatorial, o que significa que o número de soluções possíveis cresce exponencialmente em várias dimensões, de acordo com a quantidade de tarefas, operações ou máquinas.

Uma ferramenta comumente usada na programação é o Gráfico de Gantt, inventado em 1917 por Henry Laurence Gantt (1861-1919), que representa graficamente por barras o tempo de processamento das operações. Os momentos de início e fim de atividades podem ser indicados no gráfico e algumas vezes o progresso real do trabalho também é indicado. As vantagens dos gráficos de Gantt é que eles proporcionam uma representação visual simples do que deve ocorrer em cada operação (SLACK et al., 1999, p.244-245).

A Figura 1.1 mostra um exemplo de Gráfico de Gantt com a execução das operações de quatro tarefas em um sistema com três máquinas consecutivas.

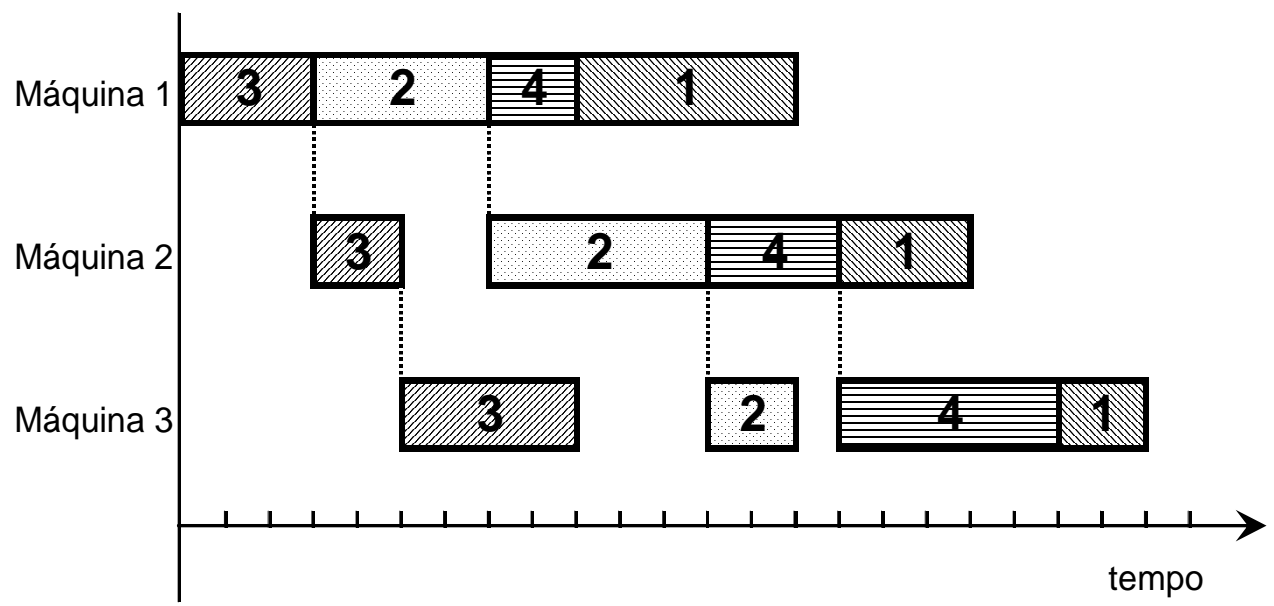

FIGURA 1.1 - Exemplo de Gráfico de Gantt 


\subsection{Problemas de programação de operações em máquinas}

Um problema de programação da produção é determinado pelo número de tarefas e operações a serem processadas, pelo número e tipo de máquinas disponíveis, pelo padrão de fluxo das operações nas máquinas e pelo critério de otimização com que se avalia uma solução (CONWAY et al., 1967, p.6). Normalmente, nos problemas de programação assume-se que o número de tarefas e de máquinas seja finito e determinado.

Os problemas tornam-se mais complexos com a presença de restrições, por exemplo, relacionando uma tarefa a outra, recursos a tarefas, um recurso ao outro e um recurso ou tarefa a eventos externos ao sistema. Pode haver também uma restrição de precedência entre tarefas ou pode não ser possível usar dois recursos simultaneamente durante certo período de tempo. Ou então um recurso pode não estar disponível durante um intervalo de tempo específico devido a manutenção. Como estes complexos inter-relacionamentos podem tornar muito difícil a busca da solução exata ou mesmo aproximada de um grande problema, é natural resolver primeiro versões mais simples. Então, a sensibilidade da solução pode ser testada quanto a sua complexidade e soluções aproximadas podem ser encontradas para problemas difíceis (MORTON; PENTICO, 1993, p.6).

Para classificar os principais modelos de programação, é necessário caracterizar a configuração dos recursos e o comportamento das tarefas (BAKER, 1974, p.6). Segundo MacCarthy e Liu (1993), as restrições tecnológicas são determinadas principalmente pelo padrão do fluxo das tarefas nas máquinas, levando à seguinte classificação dos problemas:

口 Job shop: cada tarefa tem seu fluxo individual ou rota específica nas máquinas; 
- Flow shop: todas as tarefas possuem o mesmo fluxo de processamento nas máquinas;

- Open shop: não há fluxo padrão estabelecido para as tarefas;

- Flow shop permutacional: flow shop em que a ordem de processamento das tarefas em cada máquina é estritamente a mesma;

- Máquina única: existe apenas uma única máquina disponível para o processamento das tarefas;

- Máquinas paralelas: em um único estágio de produção, há duas ou mais máquinas disponíveis que podem executar qualquer tarefa, sendo que cada tarefa só pode ser processada em uma única máquina.

Moccellin e Nagano (2003a) adaptaram esta classificação, acrescentando as seguintes classes:

- Job shop com máquinas múltiplas: job shop em que existem duas ou mais máquinas paralelas em cada estágio, sendo que cada tarefa é processada por somente uma máquina em cada um dos estágios; e

- Flow shop com máquinas múltiplas: as tarefas são processadas em múltiplos estágios na mesma ordem e em cada um deles há máquinas paralelas, podendo variar a quantidade por estágio. As tarefas são processadas por apenas uma máquina em cada estágio.

O diagrama da Figura 1.2 esquematiza o relacionamento entre os diferentes problemas de programação. 


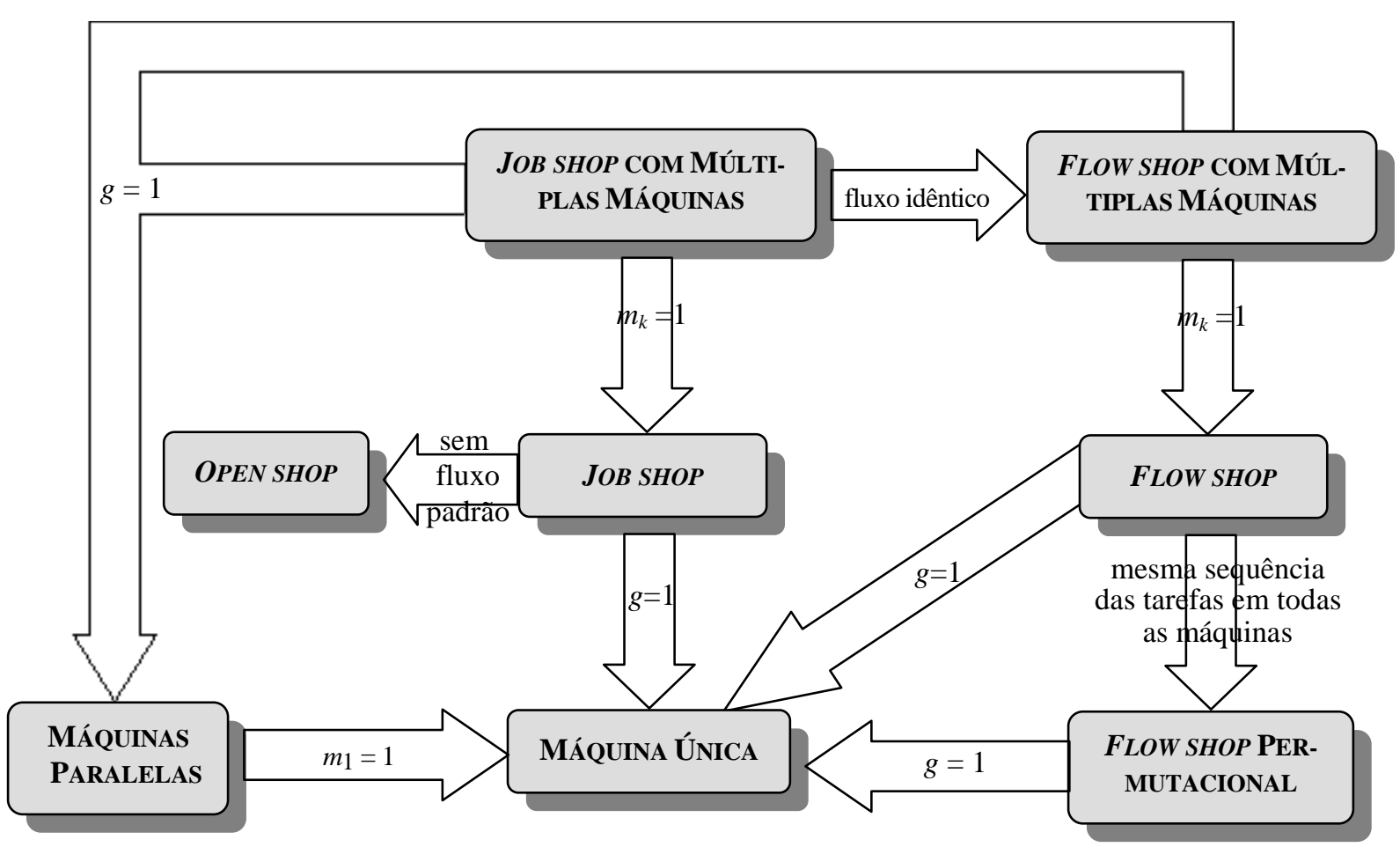

$g$ : número de estágios de produção

$m_{k}$ : número de máquinas do estágio $k(\operatorname{com} k=1,2, \ldots, g)$

FIGURA 1.2 - Relação entre as classes de problemas (adaptado por MOCCELLIN; NAGANO, 2003)

O problema tratado neste trabalho é o flexible flow line, uma generalização do flow shop com múltiplas máquinas (ou flow shop híbrido), removendo a restrição de que as tarefas precisam passar por todos os estágios de produção. Portanto, o ambiente estudado é multiestágio com fluxo unidirecional onde as tarefas podem saltar estágios. Em cada estágio pode haver uma ou mais máquinas paralelas idênticas. Os tempos de preparação ou tempos de setup são considerados separados dos tempos de processamento das tarefas e a medida de desempenho é o makespan (duração total da programação). Uma descrição detalhada deste sistema de produção será apresentada no capítulo 3. 


\subsection{Métodos de solução}

A teoria de scheduling inclui uma variedade de técnicas úteis para resolver problemas de programação da produção. Além disso, esse campo de pesquisa tem o foco no desenvolvimento, aplicação e avaliação de procedimentos combinatórios, técnicas de simulação, problemas de rede e métodos de solução heurística. A seleção de uma técnica apropriada depende da complexidade do problema, da natureza do modelo, do critério de otimização, entre outros fatores. Em muitos casos, é mais adequado utilizar várias técnicas alternativas. Por esta razão, a teoria de scheduling compreende tanto o estudo de métodos como o de modelos (BAKER, 1974, p.6).

Nas últimas décadas, um considerável esforço de pesquisa tem sido dedicado à solução dos problemas de programação de operações em máquinas. Alguns métodos de solução exata (ou de solução ótima) têm sido empregados tais como as técnicas de Programação Matemática, por exemplo os modelos de Programação Linear Inteira de Selen e Hott (1986) e Wilson (1989), o método de enumeração branch-and-bound de Ignall e Schrage (1965) e Potts (1980a). Entretanto, tais técnicas não são eficientes computacionalmente em problemas de grande e médio porte. Por este motivo, muitos métodos heurísticos têm sido propostos para a solução de problemas de programação da produção.

Um método heurístico é um processo de solução de problema apoiado em critérios racionais ou computacionais para escolher um caminho entre vários possíveis, sem a preocupação de percorrer todas as possibilidades ou atingir a melhor solução. Esta busca por um determinado objetivo visa encontrar uma solução viável, pelo menos próxima da ótima, cujo tempo de computação seja aceitável.

Os métodos heurísticos podem ser classificados de diversas formas, sendo em geral divididos em métodos construtivos (em que a solução é obtida por meio de um procedimento 
iterativo sobre soluções parciais) e métodos melhorativos (onde procedimentos iterativos são aplicados a uma solução inicial visando melhorá-la quanto à medida de desempenho adotada).

As meta-heurísticas têm gerado a publicação de aplicações bem sucedidas. Tais procedimentos consistem de uma busca entre as soluções possíveis utilizando alguma estratégia de exploração racional. Alguns exemplos de meta-heurísticas são: Algoritmo Genético (REEVES, 1995; RUIZ; MAROTO; ALCARAZ, 2005 e 2006), Busca Tabu (WIDMER; HERTZ, 1989; MOCCELLIN, 1995; LOGENDRAN; deSZOEKE; BARNARD, 2006; YIP; CHENG; LOW, 2006), Simulated Annealing (OSMAN; POTTS, 1989; LOW, 2005; JENABI et al., 2007), Greedy Randomized Search Procedure (GRASP) (PRABHAHARAN; KHAN; RAKESH, 2006), Algoritmo Memético (MOSCATO, 1999; MENDES et al., 2002), Colônia de Formigas (Ant Colony) (GAJPAL; RAJENDRAN; ZIEGLER, 2006; LIAO; JUAN, 2007), Algoritmo Imunológico (ZANDIEH; GHOMI; HUSSEINI, 2006) e Busca Local Iterativa (NADERI; RUIZ; ZANDIEH, in press).

\subsection{Objetivos da pesquisa}

Os principais objetivos desta pesquisa são:

1) Investigar o problema de programação da produção flexible flow line com tempos de setup separados dos tempos de processamento das tarefas para identificar as características que mais influenciam no valor do makespan;

2) Definir e implementar regras de prioridade a serem aplicadas separadamente como métodos de solução heurística nos dois problemas específicos tratados: ambientes com setup independente e dependente da sequência de tarefas; e 
3) Desenvolver e implementar algoritmos heurísticos construtivos eficazes e eficientes.

\subsection{Estrutura dos capítulos}

Este texto foi estruturado da seguinte forma. O primeiro capítulo apresenta a contextualização dos sistemas de produção e a sua relação com a área de Pesquisa Operacional, além de introduzir conceitos de programação da produção e alguns métodos de solução. A notação dos problemas de programação da produção, a conceituação de tempos de setup e a revisão bibliográfica dos ambientes relacionados ao problema em estudo constam no segundo capítulo. O terceiro capítulo especifica a motivação, as características detalhadas do ambiente de produção estudado e as hipóteses do problema, e apresenta exemplos ilustrativos numéricos. A definição das regras de prioridade tanto para problemas com setup dependente como independente, sua importância prática e os algoritmos para implementação são apresentados no capítulo quatro. Heurísticas construtivas mais complexas e os procedimentos em que foram baseadas são detalhados no quinto capítulo. O sexto capítulo apresenta a metodologia da experimentação computacional e a análise dos resultados. E, por fim, as conclusões da pesquisa e sugestões para trabalhos futuros são descritos no sétimo capítulo. 


\title{
2 REVISÃO BIBLIOGRÁFICA
}

\author{
"Nunca ande pelo caminho traçado, pois ele \\ conduz somente aonde outros já foram." \\ Alexander Graham Bell
}

\subsection{Notação dos problemas de programação da produção}

Pinedo (1995, p.339) definiu um problema como uma "descrição genérica" do ambiente de produção, por exemplo, um problema $P m \| C_{\max }$. Já uma instância ou problema-teste indica um problema com seu respectivo conjunto de dados numéricos. Por exemplo, o conjunto " 2 máquinas, 5 tarefas com tempos de processamento $2,3,5,5,8$ e minimização do makespan" é uma instância do problema $P m \| C_{\max }$.

$\mathrm{Na}$ literatura, os problemas de programação da produção são representados pela conhecida notação de três campos: $\alpha|\beta| \gamma$. As definições básicas desta notação podem ser encontradas em Pinedo (1995, p.8-14). Vignier, Billaut e Proust (1999) adaptaram a notação proposta por Rinnooy $\operatorname{Kan}^{1}$ (1976) particularmente para flow shop híbridos e Kurz (2001, p.21-22) fez algumas adequações para o ambiente flexible flow line. Allahverdi, Gupta e Aldowaisan (1999) também propuseram algumas representações adicionais e Lin e Cheng (2005) utilizaram uma notação para setups antecipados e não antecipados.

\footnotetext{
${ }^{1}$ RINNOOY KAN, A.H.G. (1976). Machine scheduling problems: classification, complexity and computations. Nijhoff: The Hague, 1976.
} 
O primeiro campo $\alpha$ representa o ambiente do sistema e é composto por quatro parâmetros: $\alpha=\alpha_{1} \alpha_{2},\left(\left(\alpha_{3} \alpha_{4}^{(k)}\right)_{k=1}^{\alpha_{2}}\right)$. O primeiro indica a disposição das máquinas, com $\alpha_{1} \in\{1, P, Q, R, J, O, F, H F, F F S\}$, onde

1: $\quad$ máquina única (também se representa $\alpha_{1}=\varnothing$ )

$P: \quad$ máquinas paralelas idênticas

$Q: \quad$ máquinas paralelas uniformes

$R: \quad$ máquinas paralelas não relacionadas

J: $\quad$ job shop

O: $\quad$ open shop

F: $\quad$ flow shop

HF: flow shop híbrido

FFS: flexible flow shop ou flexible flow line.

O segundo parâmetro, $\alpha_{2}$, informa o número de estágios quando superior a 1 . O par $\alpha_{3} \alpha_{4}$ é repetido de acordo com o número de estágios, com $\alpha_{3} \in\{1, P, Q, R\}$ e $\alpha_{4} \in\left\{1, M^{(k)}, M^{(k)}(t)\right\}$, onde

1: $\quad$ uma máquina em cada estágio (também se representa $\alpha_{3} \alpha_{4}=\varnothing$ )

$M^{(k)}$ : número de máquinas do estágio $k$ $M^{(k)}(t)$ : número de máquinas do estágio $k$ variável no tempo.

Pode-se ainda utilizar a notação $\left(\alpha_{3} \alpha_{4}\right)^{k}$ para indicar os $k$ estágios consecutivos de uma configuração com $\alpha_{4}$ máquinas paralelas do tipo $\alpha_{3}$. 
Assim, por exemplo, para um flexible flow line com 5 estágios compostos por 3 máquinas idênticas nos dois primeiros e 2 máquinas idênticas nos seguintes, a notação do campo $\alpha$ será $\quad F F S 5,\left(P 3^{(1)}, P 3^{(2)}, P 2^{(3)}, P 2^{(4)}, P 2^{(5)}\right), \quad F F S 5,\left(\left(P 3^{(k)}\right)_{k=1}^{2},\left(P 2^{(k)}\right)_{k=3}^{5}\right) \quad$ ou então FFS5, $\left((P 3)^{2},(P 2)^{3}\right)$. Se os detalhes forem irrelevantes, pode-se representar $\alpha$ por

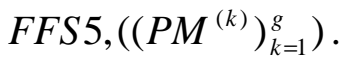

O campo $\beta$ descreve as propriedades dos recursos e tarefas, podendo ter vários componentes. Alguns dos componentes mais comuns são:

$r_{j}: \quad$ presença de datas de liberação (release dates ou ready times)

$d_{j}: \quad$ presença de prazos de entrega (due dates)

$s_{i j}$ : $\quad$ presença de tempos de setup dependentes da sequência

as: $\quad$ tempos de setup antecipados

ns: $\quad$ tempos de setup não antecipados

prmp: as operações podem ser interrompidas (preemption)

prmu: a solução deve ser uma programação permutacional

brkdwn: as máquinas podem não estar continuamente disponíveis (breakdown)

split: $\quad$ as operações podem ser subdivididas (splitting)

block: bloqueio (blocking); indica que existe uma capacidade finita de armazenamento temporário (buffer) entre duas máquinas. Se o armazenamento atingir a capacidade total, a máquina que o antecede ficará bloqueada.

$M_{j}$ : $\quad$ elegibilidade de máquina; conjunto de máquinas que podem processar a operação $j$

$n w t: \quad$ as tarefas não podem esperar entre duas máquinas sucessivas (no-wait) recrc: as tarefas podem visitar uma máquina mais de uma vez (recirculation) 
prec: presença de restrições de precedência geral; outros tipos de restrições de precedência são:

chain: cada tarefa pode ter somente uma antecessora e uma sucessora in tree: cada tarefa pode ter somente uma sucessora out tree: cada tarefa pode ter somente uma antecessora.

O terceiro campo $\gamma$ indica a medida de desempenho do problema. As medidas mais usuais, denominadas medidas de desempenho regulares, são:

$C_{\text {max }}$ : duração total da programação (makespan)

$\bar{F}: \quad$ tempo médio de fluxo (flow time) das tarefas

$L_{\text {max }}: \quad$ maior diferença da pontualidade (lateness) das tarefas

$T_{\max }: \quad$ maior atraso (tardiness) das tarefas

$E_{\text {max }}:$ maior adiantamento (earliness) das tarefas

$\sum C_{j}$ : soma das datas de término das tarefas

$\sum U_{j}:$ número de tarefas em atraso (tardy jobs)

$\sum I_{m}: \quad$ total de tempo ocioso das máquinas (idle time)

$\sum w_{j} C_{j}$ : soma ponderada (com peso $w_{j}$ ) das datas de término das tarefas

$\sum w_{j} T_{j}$ : soma ponderada do atraso (tardiness) das tarefas.

Essa notação pode acomodar quaisquer elementos desejados, evolui constantemente e pode haver variação dependendo do autor. Os dois problemas considerados neste trabalho, que serão descritos na seção 3.3 , são denotados por $F F S g,\left(\left(P M^{(k)}\right)_{k=1}^{g}\right)\left|s_{j k}, a s, n s\right| C_{\max }$ e 
$F F S g,\left(\left(P M^{(k)}\right)_{k=1}^{g}\right)\left|s_{i j k}, a s, n s\right| C_{\max }$, respectivamente com setup independente e dependente da sequência de execução das tarefas.

A seção 2.2 apresenta uma revisão bibliográfica de tempos de setup. Foram examinados na literatura os trabalhos cujas características do layout e das tarefas estejam relacionadas ao ambiente estudado. Assim, a seção 2.3 reporta o problema de máquina única com tempos de setup, pois no flexible flow line estudado um estágio pode ter apenas uma máquina. Em seguida, foi analisado o problema de máquinas paralelas com tempos de setup, que constitui uma parte do problema principal abordado (um estágio do problema). Sistemas de máquinas em série, tanto os denominados flow shop como os flow line, com tempos de setup, foram discutidos na sequência. De forma semelhante a estes últimos problemas, neste trabalho cada tarefa deve ser processada em exatamente uma máquina em cada estágio. Para reportar a evolução do ambiente de produção em estudo, foram examinados amplamente os sistemas compostos, como flow shop híbrido e flexible flow line, tanto no caso em que o tempo de setup é incluído no tempo de processamento das tarefas (operações) como no caso em que o setup é tratado separadamente.

\subsection{Tempos de setup}

Muitas pesquisas em programação da produção desconsideram os tempos de preparação das máquinas ou então os incluem nos tempos de processamento das tarefas. Isto simplifica a análise das aplicações, porém afeta a qualidade da solução quando tais tempos têm uma variabilidade relevante em função da ordenação das tarefas nas máquinas. 
O tempo de setup ou tempo de preparação da máquina inclui o trabalho de preparar a máquina, o processo ou a oficina para a fabricação de produtos (OSTWALD, 1992 apud ALLAHVERDI; GUPTA; ALDOWAISAN, 1999). Isto inclui o tempo para obtenção das ferramentas, posicionamento dos materiais a serem usados no trabalho, processos de limpeza, preparação e ajuste das ferramentas e inspeção de materiais (ALLAHVERDI; GUPTA; ALDOWAISAN, 1999).

Existem dois tipos de problemas que requerem que o tempo de setup seja explícito ou separado do tempo de processamento das tarefas: tempos de setup dependentes da sequência, cujo setup depende tanto da tarefa a ser processada quanto daquela que foi processada imediatamente antes, e tempos de setup independentes da sequência, em que o setup depende somente da tarefa a ser processada (MOCCELLIN; NAGANO, 2007).

Pinedo (1995, p.48) mostrou que mesmo para problemas de máquina única, a presença de tempos de setup dependentes da sequência torna o problema fortemente NP-hard. Como afirmou Baker (1974, p.95), esta abordagem é necessária em indústrias químicas, por exemplo, onde o processo de limpeza entre diferentes componentes é diferenciado para assegurar os baixos níveis toleráveis de impureza. Situações semelhantes podem ser encontradas na produção de diferentes cores de tinta, concentrações de detergente e misturas de combustível.

Liaee e Emmons (1997) apresentaram uma classificação por critério de desempenho dos problemas de processamento de famílias de tarefas com tempos de setup. Allahverdi, Gupta e Aldowaisan (1999) fizeram uma revisão da literatura de problemas de programação da produção envolvendo tempos de setup. Os problemas foram classificados em batch e nonbatch, e setup dependente e independente da sequência. Zhu e Wilhelm (2006) publicaram uma revisão da literatura de diversas configurações de ambientes com tempos e custos de $s e$ tup dependentes da sequência de execução das tarefas. E Allahverdi et al. (2008) atualizaram 
a revisão da literatura de problemas com tempos e custos de setup, classificando mais de 300 trabalhos publicados após o levantamento de Allahverdi, Gupta e Aldowaisan (1999).

Conforme afirmaram Reddy e Narendran (2003), como o setup é uma atividade que não agrega valor, muitas pesquisas nas últimas décadas têm se voltado para técnicas de sequenciamento que minimizem o tempo total de setup. Burbidge (1975), Robinson (1990) e Shingo (1996) descrevem as várias vantagens em reduzir o setup no processo produtivo. Allahverdi e Soroush (2008) discorreram sobre a importância de reduzir tanto o tempo como o custo de setup.

A produção em grandes lotes é empregada para reduzir os efeitos prejudiciais dos longos tempos de setup. Shingo (1996, p.254) propõe a utilização da "troca rápida de ferramenta" (TRF ou SMED, Single Minute Exchange of Die) para não haver a necessidade de produzir em grandes lotes. Segundo ele, os setups rápidos fizeram com que o cálculo de lotes econômicos ficasse sem sentido, porque não existe mais a necessidade de equilibrar os méritos da produção com lotes grandes às desvantagens do aumento de estoque.

Shingo (2000) definiu o conceito de "troca de ferramentas em um tempo inferior a dez minutos" como a melhoria do setup envolvendo três estágios: separação do setup interno do externo, conversão do setup interno em externo e racionalização dos setups para que atinjam menos de 10 minutos.

\subsection{Máquina única com tempos de setup}

A programação de tarefas em uma máquina tem sido extensivamente estudada. Nos casos gerais em que os tempos de setup não são explícitos, o makespan é simplesmente a soma dos tempos de processamento, não importando a ordem das tarefas. O problema com tem- 
pos de setup dependentes da sequência para minimização do makespan $\left(1\left|s_{i j}\right| C_{\max }\right)$ é conhecido como Problema do Caixeiro Viajante (Traveling Salesman Problem - TSP).

Este problema foi proposto por Hassler Whitney, em 1934, durante um seminário na Universidade de Princeton. O nome do problema deve-se ao fato de representar a viagem de um caixeiro que deseja percorrer o caminho mais curto desde a sua moradia, passando por todas as cidades que deve visitar e retornando ao ponto de origem. Conhecendo as distâncias entre cada par de cidades da viagem, pode-se utilizar um método de otimização para encontrar o caminho desejado (FLOOD, 1956). Mais detalhes sobre este problema podem ser encontrados em Lawler et al. (1985) e Reinelt (1994).

O problema de máquina única com setup dependente da sequência é relevante na presente pesquisa pela possibilidade de haver um estágio com apenas uma máquina, constituindo um estágio gargalo do sistema, ou no mínimo um estágio crítico (dominante).

A pesquisa em programação da produção com tempos de setup dependentes da sequência iniciou com os modelos desenvolvidos para máquina única, destacando o trabalho de Gavett (1965). Três heurísticas construtivas foram desenvolvidas a partir do Problema do Caixeiro Viajante com o objetivo de minimizar o makespan.

O ambiente com máquina única e datas de liberação diferentes de zero também tem sido estudado por vários pesquisadores. Este caso específico é importante em sistemas multiestágio porque as datas de liberação das tarefas nos estágios posteriores ao primeiro dependem das suas datas de término no estágio anterior. Segurar as tarefas liberadas a serem processadas em um estágio até que todas estejam prontas para execução apenas aumentará o makespan, reduzirá a utilização e diminuirá a efetividade da linha multiestágio (KURZ, 2001, p.24). 
O problema com datas de liberação (release time) e de entrega (delivery time) foi abordado por vários autores, entre eles: Potts (1980b), Hall e Shmoys (1992), Vakhania (2004), Hall, Liu e Potts (2007), Mazdeh, Sarhadi e Hindi (2008) e Su e Chen (2008).

Bianco et al. (1988) investigaram o problema com diferentes datas de liberação e tempos de processamento dependentes da sequência, porém sem tempos de setup. Utilizando-se tempos de processamento modificados, formados pela soma dos tempos originais e dos tempos de setup dependentes da sequência, o problema $1\left|s_{i j}\right| C_{\max }$ pode ser transformado no problema considerado por Bianco et al. (1988).

O problema de máquina única com diferentes datas de liberação e tempos de setup dependentes da sequência para minimização do makespan $\left(1\left|s_{i j}, r_{j}\right| C_{\max }\right)$ foi abordado por Chudzik e Janiak (1997), com um algoritmo genético, e por Yuan et al. (2006), considerando setup entre famílias de tarefas.

Rosenkrantz, Yu e Ravi (2001) desenvolveram algoritmos de tempo linear para minimização do makespan no caso em que as tarefas possuíam datas de liberação diferentes e um número fixo de intervalos de tempos de processamento, mesmo quando as tarefas satisfaziam restrições de precedência.

Liu e Cheng (2002) estudaram o problema de programação com diferentes datas de liberação, tempos de entrega, penalidades de interrupção e tempos de setup independentes da sequência de tarefas. O objetivo era minimizar o tempo em que todas as tarefas estivessem liberadas. O problema de minimização do tempo total de fluxo com diferentes datas de liberação, penalidades de interrupção e tempos de setup independentes das tarefas foi tratado por Liu e Cheng (2004).

Recentemente, o problema de máquina única com tempos de setup dependentes da sequência de tarefas foi tratado por vários pesquisadores. Gupta e Sivakumar (2005) analisa- 
ram o problema com prazos de entrega e múltiplos objetivos. Choobineh, Mohebbi e Khoo (2006) também estudaram o problema com múltiplos objetivos e propuseram métodos de busca tabu. A minimização da soma ponderada das datas de término e do atraso total foi analisada por Eren e Guner (2006). Gupta e Smith (2006) propuseram algoritmos para minimizar o atraso total. Luo e Chu (2006) e Luo e Chu (2007) propuseram métodos branch-and-bound para a minimização do atraso das tarefas. Liao e Juan (2007) propuseram um algoritmo colônia de formigas para minimizar o atraso ponderado.

Lu e Yuan (2007) demonstraram que o problema de minimização do atraso máximo com setup entre famílias de tarefas é NP-hard. Schaller (2007) analisaram o problema de minimização do atraso total com setup entre famílias de tarefas, apresentando um algoritmo branch-and-bound para problemas de pequeno porte e heurísticas para os de grande porte.

Kuo e Yang (2007) trataram do problema em que o tempo de setup era proporcional ao tempo das tarefas já programadas (past-sequence-dependent). Eles consideraram várias medidas de desempenho, incluindo makespan e tempo total de fluxo.

O problema de programação em máquina única com manutenção periódica e setup dependente da sequência foi analisado por Chen (2008). Foi desenvolvida uma heurística para minimizar o makespan utilizando o método de Stinson. A qualidade da solução foi comparada com a solução ótima derivada de um algoritmo branch-and-bound.

\subsection{Máquinas paralelas com tempos de setup}

A outra classe de problemas relevante nesta pesquisa é a das máquinas paralelas idênticas com tempos de setup e minimização do makespan. O caso em que as datas de liberação 
são consideradas iguais a zero $\left(P\left|s_{i j}\right| C_{\max }\right)$ representa o subproblema de programação no primeiro estágio do flexible flow line em estudo. Já o problema em que há diferentes datas de liberação para as tarefas $\left(P\left|s_{i j}, r_{j}\right| C_{\max }\right)$ é o caso dos estágios subsequentes ao primeiro. Por haver propriedades relacionadas nos diversos trabalhos reportados na literatura, esta seção trata de distintos ambientes deste problema com tempos de setup.

Cheng e Sin (1990) publicaram uma revisão do estado da arte para aquele momento dos principais resultados de pesquisas com máquinas paralelas. Mokotoff (2001) apresentou uma revisão com ênfase em métodos que fornecem o makespan ótimo para máquinas paralelas idênticas.

Lancia (2000) enfocou o problema de alocação de tarefas com datas de liberação diferentes em duas máquinas paralelas não relacionadas. $\mathrm{O}$ objetivo foi a minimização do makespan. Um procedimento baseado no método branch-and-bound foi descrito para a solução deste problema. Radhakrishnan and Ventura (2000) estudaram o problema de minimização da soma dos desvios absolutos da data de término em relação ao prazo de entrega das tarefas. Foi proposta uma técnica simulated annealing.

Park, Kim e Lee (2000) propuseram uma heurística para minimizar o atraso total ponderado utilizando índices de prioridade e uma rede neural. Zhu e Heady (2000) abordaram o ambiente de máquinas não relacionadas. Foi apresentada uma formulação de programação inteira mista para minimizar o adiantamento e o atraso das tarefas.

Kurz e Askin (2001b) consideraram o problema de minimização do makespan com diferentes datas de liberação das tarefas (ready times). Várias heurísticas, incluindo algoritmos genéticos e o problema do caixeiro viajante, foram desenvolvidas e comparadas. Foi proposta também uma heurística de inserção (algoritmo Multiple Insertion).

O ambiente de máquinas paralelas não relacionadas foi analisado por Weng, Lu e Ren (2001). O critério utilizado para otimização foi a minimização da média ponderada das datas 
de término. O estudo é proveniente de um problema industrial real. Sete heurísticas foram propostas e testadas com simulação.

Kravchenko e Werner (2001) consideraram o problema de minimização do tempo médio de fluxo, para o caso de tempos de setup unitários e tempos de processamento arbitrários. Hurink e Knust (2001) estudaram o problema com restrições de precedência e tempos de $s e$ tup dependentes da sequência com o critério de minimização do makespan. As restrições representam uma ordenação linear que define qual a próxima tarefa a ser realizada. Gendreau, Laporte e Guimarães (2001) propuseram limitantes inferiores (lower bounds) como também um algoritmo de divisão e fusão (divide and merge). Eles compararam sua heurística com algoritmos baseados em busca tabu, atingindo maior rapidez para soluções com qualidade similar.

Kim et al. (2002) sugeriram uma técnica baseada no método Simulated Annealing para minimizar o atraso total em processamento de lotes de tarefas. Os tempos de setup não dependiam da máquina mas unicamente da sequência de processamento das tarefas.

Mendes et al. (2002) compararam uma heurística baseada na busca tabu e um algoritmo memético. As definições e o procedimento do algoritmo memético podem ser encontrados em Moscato (1999).

Hiraishi, Levner e Vlach (2002) estudaram o problema de maximização do número ponderado de tarefas que terminam seu processamento exatamente no seu prazo de entrega (due dates). Kim, Na e Chen (2003) apresentaram uma heurística para minimizar o atraso total ponderado. Fowler, Horng e Cochran (2003) utilizaram algoritmos genéticos para problemas em que as tarefas possuíam diferentes datas de liberação e prazos de entrega. Três funções-objetivo foram consideradas: minimização do makespan, da soma ponderada das datas de término e do atraso ponderado. 
Kim e Shin (2003) propuseram um algoritmo baseado na busca tabu para a minimização do atraso máximo em ambos os casos com máquinas paralelas idênticas e não idênticas. As tarefas possuíam datas de liberação diferentes e prazos de entrega.

O problema de programação da produção de placas de circuito impresso em um ambiente de máquinas paralelas com tempos de setup foi considerado por Van Hop e Nagarur (2004). Eles propuseram um algoritmo genético para a minimização do makespan.

Bilge et al. (2004) enfocaram o problema com máquinas paralelas uniformes. As tarefas possuíam diferentes datas de liberação e prazos de entrega. Um método de busca tabu foi empregado. Eles investigaram vários parâmetros da busca tabu e encontraram seus melhores valores.

\subsection{Máquinas em série com fluxo unidirecional}

A outra classe de problemas relevante no presente estudo é a das máquinas em série com fluxo unidirecional, ou seja, ambientes constituídos por uma sequência de máquinas em que as tarefas possuem o mesmo fluxo de processamento. Este grupo inclui os flow shops e flow shops permutacionais, em que as tarefas necessariamente passam por todas as máquinas, e também os flow lines, onde as tarefas podem saltar máquinas.

Desde o trabalho pioneiro de Johnson (1954), que aborda o flow shop permutacional com duas máquinas, muitas pesquisas foram conduzidas na busca de métodos exatos e heurísticos. A Regra de Johnson fornece a solução ótima para o problema de minimização do makespan em um flow shop com duas máquinas $\left(F 2 \| C_{m a x}\right)$. Ignall e Schrage (1965) aplicaram o 
método de enumeração exata branch-and-bound ao problema com três máquinas $\left(F 3 \mid\right.$ prmu $\left.\mid C_{\max }\right)$.

Garey, Johnson e Sethi (1976) demonstraram que o problema com três ou mais máquinas é NP-completo. Devido a esta complexidade, os pesquisadores têm enfocado principalmente o desenvolvimento de heurísticas e meta-heurísticas. Entre as heurísticas mais conhecidas estão o método CDS, de Campbell, Dudek e Smith (1970), e o NEH, de Nawaz, Enscore Jr. e Ham (1983). Algumas meta-heurísticas pioneiras e relevantes são: Simulated Annealing de Osman e Potts (1989), Busca Tabu de Widmer e Hertz (1989) e Algoritmo Genético de Reeves (1995).

Uma revisão de programação em flow shop com tempos de setup foi apresentada por Cheng, Gupta e Wang (2000). Framinan, Gupta e Leisten (2004) propuseram uma classificação dos problemas de programação em flow shop permutacional. Ruiz e Maroto (2005) publicaram uma revisão e avaliação de heurísticas e meta-heurísticas para o problema de programação em flow shop permutacional com minimização do makespan. Reza Hejazi e Saghafian (2005) fizeram uma revisão de métodos de solução exata, heurísticas construtivas e metaheurísticas para o problema de minimização do makespan em flow shop. Gupta e Stafford Jr. (2006) relataram a evolução do ambiente flow shop durante os últimos 50 anos.

A seguir serão relatados alguns trabalhos relevantes com ambientes flow shop. Moccellin (1995) propôs uma nova heurística de Busca Tabu com desempenho superior ao método de Widmer e Hertz (1989).

O problema de programação em flow shop permutacional com duas máquinas, minimização do makespan e agrupamento de tarefas foi estudado por Yang e Chern (2000). Foram considerados também tempos de setup e de transporte entre as máquinas. 
O método heurístico construtivo para minimização do makespan denominado N\&M foi introduzido por Nagano e Moccellin (2002). Para problemas com até 10 máquinas e 100 tarefas, o método N\&M supera a bem conhecida heurística NEH.

Rajendran e Ziegler (2003) enfocaram o problema com tempos de setup dependentes e minimização da soma ponderada do tempo de fluxo e do atraso das tarefas. Reddy e Narendran (2003) propuseram heurísticas para programar famílias de tarefas em células de manufatura, com o objetivo de aumentar a utilização das máquinas e reduzir o tempo de atraso e o número de tarefas em atraso. Os tempos de setup eram dependentes da sequência de processamento das famílias em cada célula.

O problema de minimização do makespan em flow shop com duas máquinas, tempos de setup independentes da sequência e tempos de remoção foi estudado por Pranzo (2004).

Ruiz, Maroto e Alcaraz (2005) propuseram um algoritmo genético avançado e uma versão híbrida para a minimização do makespan em um flow shop com tempos de setup dependentes da sequência. Dois novos algoritmos genéticos robustos foram apresentados por Ruiz, Maroto e Alcaraz (2006) também com o objetivo de minimizar o makespan.

Um novo algoritmo colônia de formigas (ant colony) foi desenvolvido por Gajpal, Rajendran e Ziegler (2006) para minimização do makespan em flow shop com tempos de setup dependentes da sequência. Uma heurística baseada em busca tabu para minimização do makespan em que os tempos de setup e de remoção são independentes da sequência foi apresentado por Yip, Cheng e Low (2006).

É importante ressaltar que alguns autores não fazem distinção entre flow shop e flow line. O recente trabalho de Alfieri e Nicosia (2007) é um exemplo desta situação, pois eles apresentam o ambiente como flow line, porém as tarefas não saltam máquinas. As pesquisas descritas a seguir referem-se ao problema de programação em flow line, também denominado na literatura como "flow shop faltando operações" (flow shop with missing operations). 
Leisten e Kolbe (1998) analisaram a situação de tarefas saltarem máquinas em problemas reais e propuseram um sequenciamento que chamaram de "parcialmente permutacional".

Rajendran e Holthaus (1999) apresentaram um estudo comparativo do desempenho de regras de prioridade em vários ambientes de produção, incluindo flow line, e com várias funções-objetivo, entre elas o makespan, tempo médio de fluxo e atraso médio. Novas regras de prioridade foram propostas por Jayamohan e Rajendran (2000). Programações permutacionais e não permutacionais usando heurísticas para minimização do tempo total de fluxo foram apresentadas por Rajendran e Ziegler (2001). Também foram comparadas algumas regras de prioridade, inclusive utilizando o makespan como uma medida de desempenho secundária.

A relevância de programações não permutacionais e seus efeitos no aumento da medida de desempenho foram analisados por Pugazhendhi et al. (2003). Foi proposto um procedimento heurístico para derivar programações não permutacionais de sequências permutacionais. A minimização do makespan foi considerada como objetivo principal e a do tempo total de fluxo como secundário.

Pugazhendhi et al. (2004a) focaram no desenvolvimento de soluções não permutacionais. A minimização do tempo total de fluxo ponderado foi considerada em primeira instância, seguida pelo estudo da minimização do makespan. Este foi o único trabalho encontrado com flow line e tempos de setup dependentes da sequência. O mesmo ambiente foi considerado por Pugazhendhi et al. (2004b), porém com objetivo principal de minimizar o tempo total de fluxo, seguido do tempo de fluxo ponderado. Algumas regras de prioridade foram comparadas. 


\subsection{Sistemas multiestágio híbridos}

Os ambientes mais complexos com a presença de várias máquinas em paralelo são denominados "sistemas híbridos", como é o caso do flow shop híbrido, também referenciado na literatura como flow shop com múltiplas máquinas, flow shop com múltiplos processadores e flexible flow shop. Além destes, há os flexible flow lines que se distinguem dos demais pela possibilidade das tarefas saltarem estágios.

Muitos trabalhos publicados já abordaram o problema de programação em flow shop híbrido, desde que foi introduzido por Salvador (1973). Linn e Zhang (1999) propuseram uma classificação das pesquisas em três categorias: problemas com dois estágios, três estágios e $g$ estágios $(g>3)$. Definições de variações flexíveis deste ambiente podem ser encontradas em Vairaktarakis (2004).

Vignier, Billaut e Proust (1999) apresentaram para aquele momento o estado da arte de sistemas flow shop híbridos. Kis e Pesch (2005) atualizaram o estado da arte com trabalhos posteriores a 1999, enfocando métodos de solução exata para minimização do makespan e tempo médio de fluxo. Wang (2005) fez uma revisão da literatura, classificando em métodos de solução ótima, heurística e de inteligência artificial. Quadt e Khun (2007a) publicaram uma taxonomia para flow shop híbridos, porém denominando-o de flexible flow line.

Como observou Quadt e Kuhn (2007a), o sistema flexible flow line pode ser encontrado em um vasto número de indústrias. Numerosos exemplos podem ser encontrados na literatura, incluindo a indústria química (SALVADOR, 1973), eletrônica (WITTROCK, 1988), de empacotamento (ADLER et al., 1993), farmacêutica (GUINET; SOLOMON, 1996), automotiva (AGNETIS et al., 1997), fabricação de embalagens de vidro (LEON; RAMAMOORTHY, 1997), indústria madeireira, têxtil e de herbicidas (RIANE, 1998), alimentícia e de cosméticos (MOURSLI; POCHET, 2000) e de semicondutores (QUADT; KUHN, 2005). 
Em geral as pesquisas se restringiram a situações ou configurações específicas de máquinas nos estágios, ou com os tempos de setup incluídos nos tempos de processamento das tarefas. A fim de verificar a evolução dos ambientes de produção multiestágio complexos, esta seção reporta as principais publicações de sistemas flow shop híbridos desde os problemas mais simples até os mais recentes com setup separado, salientando quando se tratar de flexible flow line.

Lee e Vairaktarakis (1994) demonstraram que o problema de minimização do makespan em flow shop híbridos é NP-hard, mesmo sem a presença de setups explícitos.

A maioria dos algoritmos que fornecem solução ótima de problemas sem setup separado baseia-se no método branch-and-bound, como é o caso de Brah e Hunsucker (1991), Rajendran e Chaudhuri (1992a), Rajendran e Chaudhuri (1992b), Portmann et al. (1998), Carlier e Néron (2000), Moursli e Pochet (2000), Néron, Baptiste e Gupta (2001) e Azizoglu, Cakmak e Kondakci (2001). Devido à complexidade do problema, os métodos de solução ótima têm maior interesse teórico do que prático, uma vez que somente apresentam viabilidade computacional em problemas de pequeno porte.

O ambiente com dois estágios, sendo uma máquina no primeiro e várias máquinas paralelas idênticas no segundo, com o critério de minimização do makespan, foi estudado por Gupta e Tunc (1994), Li (1997) e Huang e Li (1998). O mesmo problema com máquinas paralelas não relacionadas no segundo estágio foi analisado por Riane, Artiba e Elmaghraby (2002).

O problema de três estágios, minimização do makespan e a seguinte configuração específica foi estudado por Riane, Artiba e Elmaghraby (1998): uma máquina no primeiro e no terceiro estágios e duas máquinas no segundo.

Alguns trabalhos utilizaram a técnica de decomposição por estágio, reduzindo a complexidade do problema: Kochhar e Morris (1987), Wittrock (1988), Ding e Kittichartphayak 
(1994), Lee e Vairaktarakis (1994), Guinet e Solomon (1996), Brah e Loo (1999), Koulamas e Kyparisis (2000), Soewandi e Elmaghraby (2001) e Riane, Artiba e Iassinovski (2001). Por outro lado, outras pesquisas abordaram o método de decomposição por tarefa, onde a cada iteração uma tarefa é selecionada e alocada a uma máquina em cada estágio de produção, como no caso de Sawik (1993), Sawik (1995), Gupta et al. (2002).

Adler et al. (1993) desenvolveram uma programação para fábricas de embalagens de papel, considerando os tempos de setup dependentes da sequência. Agnetis et al. (1997) analisram o problema de programação em uma indústria automotiva.

Leon e Ramamoorthy (1997) consideraram a vizinhança dos dados do problema, ao invés da vizinhança da solução. A ideia era que uma pequena variação nos dados de entrada ainda resultaria em boas soluções para o problema, assemelhando-se ao conceito de Análise de Sensibilidade.

O problema de minimização do atraso máximo foi estudado por Botta-Genoulaz (2000), com restrições de precedência em árvore e tempos de setup independentes da sequência, de remoção e de transporte. Os estágios eram compostos por máquinas paralelas idênticas. Liu e Chang (2000) apresentaram métodos baseados em relaxação lagrangeana para ambientes onde o tempo e o custo de setup eram relevantes.

Häyrinen et al. (2000) propuseram heurísticas para programação de flexible flow line em indústrias eletrônicas. As tarefas eram agrupadas em famílias e os tempos de setup eram dependentes da sequência e da máquina.

O problema com máquinas paralelas uniformes nos estágios foi abordado por Sethanan (2001) com o objetivo de minimizar o makespan. Um modelo matemático e duas heurísticas foram desenvolvidos, sendo uma delas baseada na busca tabu. Kurz e Askin (2001a) melhoraram o limitante inferior de Leon e Ramamoorthy (1997) para o ambiente flexible flow line e minimização do makespan. 
Moccellin e Nagano (2003a) estudaram o problema com duas máquinas paralelas genéricas em cada estágio e a minimização do makespan. Moccellin e Nagano (2003b) investigaram o flow shop híbrido com estágio gargalo.

Lin e Liao (2003) enfocaram um problema real com tempos de setup dependentes da sequência no primeiro estágio, máquinas dedicadas no segundo e dois prazos de entrega. $\mathrm{O}$ objetivo era minimizar o atraso máximo ponderado na programação de um dia de produção. Chang, Hsieh e Wang (2003) examinaram uma fábrica de filme polipropileno, propondo um algoritmo genético com taxas de mutação variáveis cuja solução foi melhor do que a prática adotada pela empresa.

Oğuz et al. (2003) estudaram o problema de multiprocessamento de tarefas, que permite o processamento simultâneo das operações. Foram apresentados algoritmos construtivos para a minimização do makespan em ambientes com dois estágios. Para o mesmo problema, Oğuz et al. (2004) mostraram que, sem restrições de precedência, a minimização do makespan é alcançada em tempo polinomial, enquanto que a sua consideração torna o problema $N P$ hard.

Kurz e Askin (2003) compararam regras de sequenciamento para minimização do makespan em flexible flow line com tempos de setup não antecipados e dependentes da sequência de tarefas. Kurz e Askin (2004) estudaram o mesmo problema e apresentaram várias heurísticas de inserção e algoritmos genéticos random keys. Foi proposto também um limitante superior para avaliar as heurísticas.

Várias medidas de desempenho foram analisadas por Allaoui e Artiba (2004), entre elas a minimização do makespan e do atraso máximo, considerando tempos de transporte. Şerifoğlu e Ulusoy (2004) revolveram o problema de minimização do makespan em que uma operação pode ser processada simultaneamente em várias máquinas de um estágio. Foi empregado um algoritmo genético para o sequenciamento do primeiro estágio. 
O problema de programação em indústria de móveis foi estudado por Wilson, King e Hodgson (2004). Havia várias máquinas paralelas idênticas em cada estágio. As heurísticas desenvolvidas baseiam-se em um algoritmo genético e demonstraram eficiência na minimização do tempo de setup (independente da sequência) e do makespan.

Fuchigami e Moccellin (2005b) propuseram quatro métodos heurísticos construtivos para programação em flow shop híbridos com tempos de setup assimétricos e dependentes da sequência. O objetivo era minimizar o makespan. Fuchigami e Moccellin (2005a) estudaram a influência da relação entre os tempos de processamento e de setup. Um método de solução foi sugerido dependendo da relação entre tais tempos.

Low (2005) enfocou a minimização do tempo total de fluxo em problemas em que os estágios possuíam várias máquinas paralelas não relacionadas, tempos de setup independentes da sequência e tempos de remoção.

Andrés et al. (2005) aplicaram procedimentos heurísticos para o problema de agrupamento de tarefas em indústrias de telha e obtiveram resultados positivos. O principal objetivo era identificar um conjunto de famílias com características comuns. Tang e Zhang (2005) propuseram uma heurística combinada com método de redes neurais artificiais para o problema com tempos de setup dependentes da sequência.

Heurísticas construtivas para minimização do makespan foram apresentadas por Logendran, Carson e Hanson (2005). As tarefas foram agrupadas em famílias e foram considerados tempos de setup dependentes das máquinas e independentes das famílias de tarefas. Logendran, deSzoeke e Barnard (2006) estudaram o mesmo problema e apresentaram três diferentes algoritmos baseados na busca tabu.

Ruiz e Maroto (2006) propuseram algoritmos genéticos para problemas com máquinas paralelas não relacionadas em cada estágio, tempos de setup dependentes e elegibilidade de 
máquina. Foram realizados experimentos com dados simulados e reais de indústrias de cerâmica.

Um algoritmo imunológico (immune algorithm) foi apresentado por Zandieh, Ghomi e Husseini (2006). Este método simula o processo de defesa do sistema imunológico do organismo: a função-objetivo é representada por "antígenos" (invasores do organismo) e as soluções viáveis são os "anticorpos". O anticorpo que melhor "atacar" o antígeno por meio de uma função de avaliação (fitness) é escolhido como solução do problema de programação da produção. Os resultados apresentaram desempenho superior ao algoritmo genético random key de Kurz e Askin (2004), principalmente para problemas de médio e grande porte.

Fuchigami (2005) propôs quatro heurísticas construtivas para minimização do makespan em flow shop híbrido com tempos de setup assimétricos e dependentes da sequência. $\mathrm{O}$ foco da pesquisa foi o estudo da influência da relação entre as ordens de grandeza dos tempos de processamento e de setup em cada método de solução.

O estudo da influência da programação do primeiro estágio para problemas com tempos de setup independentes da sequência foi realizado por Fuchigami e Moccellin (2006). A pesquisa comprovou a grande relevância do primeiro estágio para a minimização do makespan. Fuchigami, Moccellin e Ruiz (2007) compararam o desempenho de regras de prioridade em sistemas flexible flow line com tempos de setup independentes da sequência. $\mathrm{O}$ estudo identificou as regras mais eficientes para a minimização do makespan. A mesma análise foi feita também para o ambiente flow shop híbrido por Fuchigami e Moccellin (2007), acrescentando duas regras de prioridade aleatórias na comparação.

Jenabi et al. (2007) consideraram o sistema flexible flow line com máquinas paralelas não relacionadas. O objetivo era minimizar a soma do custo de setup e de armazenamento sem ruptura (stock-out). Duas heurísticas construtivas foram propostas para fornecer a solução inicial a um algoritmo genético híbrido e um simulated annealing. 
O problema de dimensionamento de lote em um flexible flow line com custos de setup foi considerado por Quadt e Kuhn (2007b). O objetivo era minimizar os custos de setup e o tempo médio de fluxo.

Jungwattanakit et al. (2008) propuseram algoritmos heurísticos para o problema flexible flow line com setup dependente da sequência e da máquina. Cada estágio possuía máquinas paralelas não relacionadas. O objetivo era minimizar uma combinação convexa do makespan e do número de tarefas atrasadas.

Ruiz, Şerifoğlu e Urlings (2008) abordaram um problema real de minimização do makespan em um flexible flow line com máquinas paralelas não relacionadas e tempos de setup dependentes da sequência. Várias outras restrições foram consideradas: presença de tempos de setup antecipado e não antecipado, diferentes datas de liberação das máquinas, elegibilidade de máquina e restrições de precedência das tarefas. Foi apresentada uma formulação de programação inteira mista e foram propostos seis métodos heurísticos.

Como pode ser observado, embora o ambiente flow shop híbrido tenha sido extensivamente estudado há muitos anos, existem poucas publicações com os sistemas flexible flow line. Além disso, não foi encontrado nenhum trabalho abordando o mesmo problema proposto nesta pesquisa. Os problemas mais similares foram tratados por Kurz e Askin (2003) e Kurz e Askin (2004), porém os tempos de setup não eram antecipados e somente dependentes da sequência.

Mais recentemente, Naderi, Ruiz e Zandieh (in press) propuseram dois algoritmos para programação em flexible flow line com setup dependente da sequência e minimização do makespan: uma regra de prioridade dinâmica e o uma meta-heurística de busca local iterativa.

A Tabela 2.1 apresenta a relação dos trabalhos citados neste capítulo, separados por ambiente e em ordem cronológica. 
TABELA 2.1 - Relação dos trabalhos citados (em ordem cronológica)

\begin{tabular}{|c|c|c|}
\hline \multirow[t]{12}{*}{ MÁQUINA ÚNICA } & GAVETT (1965) & GUPTA; SMITH (2006) \\
\hline & POTTS (1980b) & LUO; CHU (2006) \\
\hline & BIANCO et al. (1988) & YUAN et al. (2006) \\
\hline & HALL; SHMOYS (1992) & HALL; LIU; POTTS (2007) \\
\hline & CHUDZIK; JANIAK (1997) & KUO; YANG (2007) \\
\hline & $\begin{array}{l}\text { ROSENKRANTZ; YU; RAVI } \\
(2001)\end{array}$ & LUO; CHU (2007) \\
\hline & LIU; CHENG (2002) & LIAO; JUAN (2007) \\
\hline & LIU; CHENG (2004) & LU; YUAN (2007) \\
\hline & VAKHANIA (2004) & SCHALLER (2007) \\
\hline & GUPTA; SIVAKUMAR (2005) & CHEN (2008) \\
\hline & $\begin{array}{l}\text { CHOOBINEH; MOHEBBI; KHOO } \\
(2006)\end{array}$ & $\begin{array}{l}\text { MAZDEH; SARHADI; HINDI } \\
(2008)\end{array}$ \\
\hline & EREN; GUNER (2006) & SU; CHEN (2008) \\
\hline \multirow[t]{10}{*}{ MÁQUINAS PARALELAS } & CHENG; SIN (1990) & WENG; LU; REN (2001) \\
\hline & $\begin{array}{l}\text { GENDREAU; LAPORTE; GUIMA- } \\
\text { RÃES (2001) }\end{array}$ & $\begin{array}{l}\text { HIRAISHI; LEVNER; VLACH } \\
\text { (2002) }\end{array}$ \\
\hline & HURINK; KNUST (2001) & KIM et al. (2002) \\
\hline & KRAVCHENKO; WERNER (2001) & MENDES et al. (2002) \\
\hline & KURZ; ASKIN (2001b) & $\begin{array}{l}\text { FOWLER; HORNG; COCHRAN } \\
(2003)\end{array}$ \\
\hline & LANCIA (2000) & KIM; SHIN (2003) \\
\hline & PARK； KIM； LEE (2000) & KIM; NA; CHEN (2003) \\
\hline & $\begin{array}{l}\text { RADHAKRISHNAN; VENTURA } \\
(2000)\end{array}$ & BILGE et al. (2004) \\
\hline & ZHU; HEADY (2000) & \multirow{2}{*}{ VAN HOP; NAGARUR (2004) } \\
\hline & MOKOTOFF (2001) & \\
\hline \multirow[t]{14}{*}{ MÁQUINAS EM SÉRIE } & JOHNSON (1954) & NAGANO; MOCCELLIN (2002) \\
\hline & IGNAL; SHRAGE (1965) & RAJENDRAN; ZIEGLER (2003) \\
\hline & $\begin{array}{l}\text { GAREY; JOHNSON; SETHI } \\
(1976)\end{array}$ & REDDY; NARENDRAN (2003) \\
\hline & $\begin{array}{l}\text { CAMPBELL; DUDEK; SMITH } \\
(1970)\end{array}$ & PUGAZHENDHI et al. (2003) \\
\hline & $\begin{array}{l}\text { NAWAZ; ENSCORE JR.; HAM } \\
(1983)\end{array}$ & $\begin{array}{l}\text { FRAMINAN; GUPTA; LEISTEN } \\
(2004)\end{array}$ \\
\hline & OSMAN; POTTS (1989) & PRANZO (2004) \\
\hline & WIDMER; HERTZ (1989) & PUGAZHENDHI et al. (2004a) \\
\hline & REEVES (1995) & PUGAZHENDHI et al. (2004b) \\
\hline & MOCCELLIN (1995) & RUIZ; MAROTO (2005) \\
\hline & LEISTEN; KOLBE (1998) & $\begin{array}{l}\text { RUIZ; MAROTO; ALCARAZ } \\
(2005)\end{array}$ \\
\hline & RAJENDRAN; HOLTHAUS (1999) & $\begin{array}{l}\text { GAJPAL; RAJENDRAN; ZIEGLER } \\
(2006)\end{array}$ \\
\hline & CHENG; GUPTA; WANG (2000) & $\begin{array}{l}\text { RUIZ; MAROTO; ALCARAZ } \\
(2006)\end{array}$ \\
\hline & $\begin{array}{l}\text { JAYAMOHAN; RAJENDRAN } \\
(2000)\end{array}$ & YIP; CHENG; LOW (2006) \\
\hline & $\begin{array}{l}\text { YANG; CHERN (2000) } \\
\text { RAJENDRAN; ZIEGLER (2001) }\end{array}$ & ALFIERI; NICOSIA (2007) \\
\hline \multirow[t]{6}{*}{ SISTEMAS HÍBRIDOS } & SALVADOR (1973) & $\begin{array}{l}\text { SOEWANDI; ELMAGHRABY } \\
(2001)\end{array}$ \\
\hline & KOCHHAR; MORIS (1987) & GUPTA et al. (2002) \\
\hline & RIANE (1988) & $\begin{array}{l}\text { RIANE; ARTIBA; ELMAGHRABY } \\
(2002)\end{array}$ \\
\hline & WITTROCK (1988) & KURZ; ASKIN (2003) \\
\hline & BRAH; HUNSUCKER (1991) & LIN; LIAO (2003) \\
\hline & $\begin{array}{l}\text { RAJENDRAN; CHAUDHURI } \\
(1992 \mathrm{a})\end{array}$ & MOCCELLIN; NAGANO (2003a) \\
\hline
\end{tabular}




\begin{tabular}{|c|c|c|}
\hline \multirow[t]{28}{*}{$\begin{array}{l}\text { SISTEMAS HÍBRIDOS } \\
\text { (continuação) }\end{array}$} & $\begin{array}{l}\text { RAJENDRAN; CHAUDHURI } \\
(1992 \mathrm{~b})\end{array}$ & MOCCELLIN; NAGANO (2003b) \\
\hline & ADLER et al. (1993) & OĞUZ et al. (2003) \\
\hline & SAWIK (1993) & ALLAOUI; ARTIBA (2004) \\
\hline & $\begin{array}{l}\text { DING; KITTICHARTPHAYAK } \\
\text { (1994) }\end{array}$ & KURZ; ASKIN (2004) \\
\hline & GUPTA; TUNC (1994) & OĞUZ et al. (2004) \\
\hline & LEE; VAIRAKTARRAKIS (1994) & ŞERIFOĞLU; ULUSOY (2004) \\
\hline & SAWIK (1995) & VAIRAKTARAKIS (2004) \\
\hline & GUINET; SOLOMON (1996) & $\begin{array}{l}\text { WILSON; KING; HODGSON } \\
\text { (2004) }\end{array}$ \\
\hline & AGNETIS et al. (1997) & ANDRÉS et al. (2005) \\
\hline & LEON; RAMAMOORTHY (1997) & FUCHIGAMI (2005) \\
\hline & LI (1997) & $\begin{array}{l}\text { FUCHIGAMI; MOCCELLIN } \\
(2005 \mathrm{~b})\end{array}$ \\
\hline & HUANG; LI (1998) & $\begin{array}{l}\text { FUCHIGAMI; MOCCELLIN } \\
(2005 \mathrm{a})\end{array}$ \\
\hline & PORTMANN et al. (1998) & KIS; PESCH (2005) \\
\hline & $\begin{array}{l}\text { RIANE; ARTIBA; ELMAGHRABY } \\
(1998)\end{array}$ & $\begin{array}{l}\text { LOGENDRAN; CARSON; HANSON } \\
(2005)\end{array}$ \\
\hline & BRAH; LOO (1999) & LOW (2005) \\
\hline & LINN; ZHANG (1999) & QUADT; KHUN (2005) \\
\hline & $\begin{array}{l}\text { VIGNIER; BILLAUT; PROUST } \\
(1999)\end{array}$ & TANG; ZHANG (2005) \\
\hline & BOTTA-GENOULAZ (2000) & WANG (2005) \\
\hline & CARLIER; NÉRON (2000) & $\begin{array}{l}\text { ZANDIEH; GHOMI; HUSSEINI } \\
(2006)\end{array}$ \\
\hline & HÄYRINEN et al. (2000) & $\begin{array}{l}\text { FUCHIGAMI; MOCCELLIN; RUIZ } \\
\text { (2007) }\end{array}$ \\
\hline & KOULAMAS; KYPARISIS (2000) & FUCHIGAMI; MOCCELLIN (2007) \\
\hline & LIU; CHANG (2000) & JENABI et al. (2007) \\
\hline & MOURSLI; POCHET (2000) & QUADT; KHUN (2007a) \\
\hline & $\begin{array}{l}\text { AZIZOGLU; CAKMAK; KONDAKCI } \\
(2001)\end{array}$ & QUADT; KHUN (2007b) \\
\hline & KURZ; ASKIN (2001a) & JUNGWATTANAKIT et al. (2008) \\
\hline & $\begin{array}{l}\text { NÉRON; BAPTISTE; GUPTA } \\
(2001)\end{array}$ & $\begin{array}{l}\text { RUIZ; ŞERIFOĞLU; URLINGS } \\
(2008)\end{array}$ \\
\hline & $\begin{array}{l}\text { RIANE; ARTIBA; IASSINOVSKI } \\
(2001)\end{array}$ & $\begin{array}{l}\text { NADERI; RUIZ; ZANDIEH (in } \\
\text { press) }\end{array}$ \\
\hline & SETHANAN (2001) & \\
\hline
\end{tabular}




\section{DEFINIÇÃO DO PROBLEMA}

"Uma mente que se abre para uma nova ideia, jamais retornará ao seu tamanho original."

Albert Einsten

\subsection{Motivação}

Conforme apresentado anteriormente (seção 1.2), é importante salientar que a competitividade do mercado consumidor exige que os sistemas produtivos sejam mais flexíveis, com custo de produção reduzido e com rápida resposta à flutuação da demanda. Assim, as companhias precisam atualizar suas técnicas de produção e aumentar o grau de automação do sistema.

Neste sentido, o gerenciamento da produção é uma atividade de grande importância para a eficiência dos processos produtivos. Como salientou Sethanan (2001), o desenvolvimento da programação da produção é uma tarefa muito importante na indústria. Muitos pesquisadores enfocaram o sequenciamento e o controle do tempo da programação de múltiplas tarefas em um ou mais estágios de produção. O desafio encontrado por muitas indústrias é a alocação de tarefas a processadores paralelos (máquinas ou trabalhadores).

Companhias aéreas, por exemplo, podem associar um dos vários tipos de aeronaves a uma rota específica. Na indústria de semicondutores, é comum encontrar máquinas modernas funcionando juntamente com outras mais velhas e menos eficientes. Mesmo as máquinas menos modernas podem ser mantidas na linha de produção pelo alto custo de substituição dos 
equipamentos. Tais máquinas podem desempenhar as mesmas operações que as novas, mas geralmente requerem maior tempo de processamento para o mesmo tipo de operações. Outros exemplos incluem as indústrias têxteis que atribuem tarefas a teares e indústrias de papel que associam os produtos às diferentes máquinas (SETHANAN, 2001).

Desta forma, os sistemas denominados flexible flow line estão se tornando cada vez mais comuns na indústria, principalmente devido à grande carga de trabalho exigida pelas tarefas.

\subsection{Características do ambiente de produção}

Como há uma considerável divergência na definição dos ambientes de produção, é importante ressaltar as definições consideradas dos sistemas com fluxo unidirecional. A Tabela 3.1 relaciona alguns trabalhos com sistemas que possuem múltiplas máquinas em paralelo, as denominações dadas ao ambiente e algumas características. Todos os problemas tratados consideram os tempos de setup das máquinas separados dos tempos de processamento das tarefas.

Pode-se destacar também o problema analisado por Lee, Sikora e Shaw (1997), com tempos de setup dependentes da sequência, tamanho de lote variável e a minimização do makespan. O ambiente de produção foi denominado "flexible flow-line”, porém em cada estágio existe somente uma máquina.

Se, num flow shop as tarefas puderem saltar máquinas, este ambiente é denominado flow line, com uma máquina em cada estágio (PUGAZHENDHI et al., 2004a). 
TABELA 3.1 - Trabalhos com múltiplas máquinas nos estágios e tempos de setup separados

\begin{tabular}{|l|l|l|l|}
\hline TRABALHO & $\begin{array}{l}\text { DENOMINAÇÃO } \\
\text { DO AMBIENTE }\end{array}$ & $\begin{array}{l}\text { TIPO DE MÁQUINAS } \\
\text { NOS ESTÁGIOS }\end{array}$ & $\begin{array}{l}\text { TAREFAS SALTAM } \\
\text { ESTÁGIOS }\end{array}$ \\
\hline \hline KURZ (2001) & Flexible flow line & Idênticas & Sim \\
\hline SETHANAN (2001) & Flexible flowshop & Uniformes & Não \\
\hline KURZ; ASKIN (2003) & Flexible flow line & Idênticas & Sim \\
\hline LIN; LIAO (2003) & Hybrid flow shop & Não relacionadas & Não \\
\hline $\begin{array}{l}\text { ALLAOUI; ARTIBA } \\
\text { (2004) }\end{array}$ & Hybrid flow shop & $\begin{array}{l}\text { Idênticas, uniformes } \\
\text { ou não relacionadas }\end{array}$ & Não \\
\hline KURZ; ASKIN (2004) & Flexible flow line & Idênticas & Sim \\
\hline ANDRÉS et al. (2005) & Hybrid flowshop & $\begin{array}{l}\text { Idênticas, uniformes } \\
\text { e não relacionadas }\end{array}$ & Não \\
\hline $\begin{array}{l}\text { LOGENDRAN; CARSON; } \\
\text { HANSON (2005) }\end{array}$ & Flexible flow shop & Idênticas & Não \\
\hline $\begin{array}{l}\text { LOGENDRAN; deSZOE- } \\
\text { KE; BARNARD (2006) }\end{array}$ & Flexible flow shop & Idênticas & Não \\
\hline RUIZ; MAROTO (2006) & Hybrid flow shop & Não relacionadas & Não \\
\hline $\begin{array}{l}\text { ZADIEH; GHOMI; HUS- } \\
\text { SEINI (2006) }\end{array}$ & Hybrid flow shop & Idênticas & Não \\
\hline JENABI et al. (2007) & Flexible flow line & Não relacionadas & Sim \\
\hline $\begin{array}{l}\text { JUNGWATTANAKIT et al. } \\
\text { (2008) }\end{array}$ & Flexible flow shop & Não relacionadas & Não \\
\hline $\begin{array}{l}\text { RUIZ; ŞERIFOĞLU; UR- } \\
\text { LINGS (2008) }\end{array}$ & $\begin{array}{l}\text { Hybrid flexible } \\
\text { flowshop }\end{array}$ & $\begin{array}{l}\text { Nyão relacionadas } \\
\text { flowshop flexible }\end{array}$ & Sim \\
\hline $\begin{array}{l}\text { NADERI; RUIZ; ZAN- } \\
\text { DIEH (in press) }\end{array}$ & Sim \\
\hline
\end{tabular}

Por sua vez, o flow shop híbrido representa o flow shop com a presença de múltiplas máquinas em paralelo em um ou mais estágios, sendo que cada tarefa deve ser processada em exatamente uma máquina em todos os estágios (KURZ; ASKIN, 2004). Alguns autores denominam o flow shop híbrido como "flexible flow shop" (LOGENDRAN; CARSON; HANSON, 2005; LOGENDRAN; deSZOEKE; BARNARD, 2006; SETHANAN, 2001) ou então como "flow shop com múltiplas máquinas" ou "flow shop com múltiplos processadores" (KIS e PESCH, 2005; LOW, 2005). 
Como afirmou Low (2005), é mais realista que em cada estágio, certo número de máquinas idênticas disponíveis possa operar de forma paralela. Este tipo de ambiente de produção é relativamente comum e pode ser encontrado em indústrias petroquímicas, eletrônicas e de semi-condutores. A presença de múltiplas máquinas nos estágios torna o problema mais complexo, pois a sequência de processamento das tarefas em cada estágio pode não ser a mesma. Em essência, tal problema consiste de dois subproblemas: associar as operações às máquinas (problema de alocação) e sequenciar as operações nas máquinas (problema de sequenciamento).

Um flexible flow line (ou flexible flow shop) é um flow line com máquinas em paralelo, onde pelo menos uma tarefa necessariamente não será processada em pelo menos um estágio, ou seja, as tarefas podem saltar estágios. Isto ocorre em indústrias em que algumas tarefas não requerem uma operação como a manufatura de placas de circuito impresso e a indústria automotiva (KURZ; ASKIN, 2004). A Figura 3.1 apresenta as relações entre os sistemas de fluxo unidirecional.

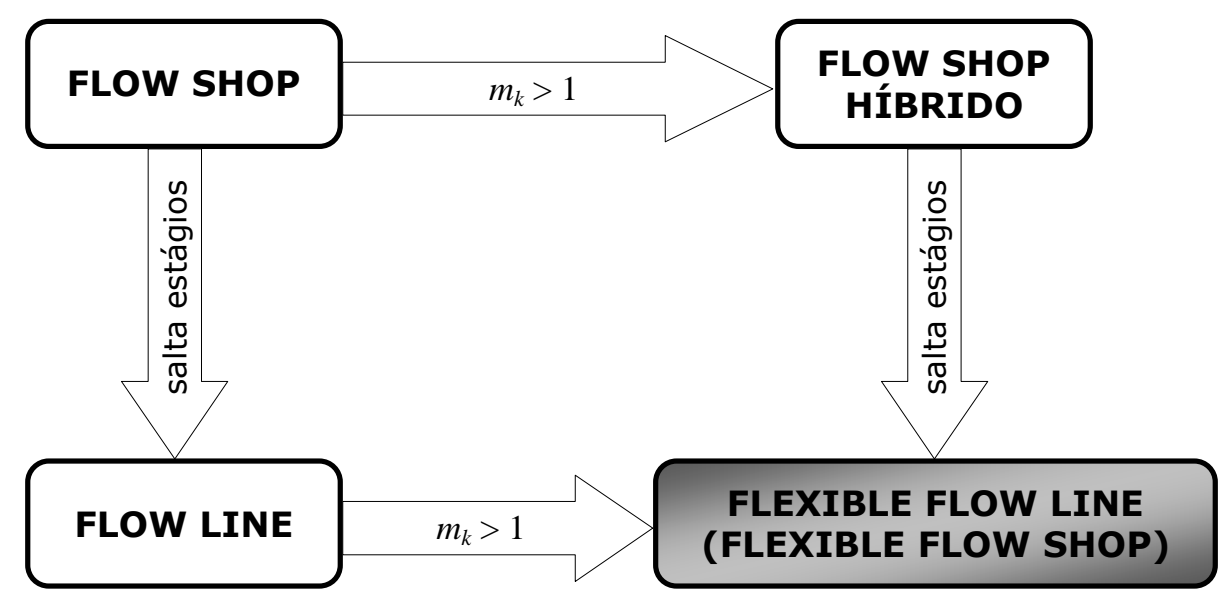

$m_{k}$ : número de máquinas do estágio $k(\operatorname{com} k=1,2, \ldots, g)$

FIGURA 3.1 - Relação entre problemas de fluxo unidirecional 
O problema de programação em sistemas flexible flow line é NP-hard para todos os critérios de otimização tradicionais, mesmo quando o setup não é considerado explicitamente (GAREY; JOHNSON; SETHI, 1976; KIS; PESCH, 2005; QUADT; KUHN, 2007a).

\subsection{Descrição do problema}

O problema consiste em programar um conjunto de $n$ tarefas, definido como $J=\{1, \ldots$, $n\}$, que será processado em uma série de $g$ estágios, indicada por $G=\{1, \ldots, g\}$. Em cada estágio $k, k \in G$, existe um conjunto de $m_{k}$ máquinas paralelas idênticas, onde $m_{k} \geq 1$, que estão disponíveis e podem processar qualquer tarefa. Todas as tarefas têm o mesmo fluxo, passando pelos estágios na mesma ordem e sendo processadas por apenas uma máquina em cada estágio. As tarefas podem saltar estágios, ou seja, podem não ser processadas em alguns dos estágios. O conjunto de tarefas que visitam o estágio $k$, com $k \in G$, é indicado por $V_{k}$, com $V_{k} \subseteq J$, e o conjunto de estágios visitados pela tarefa $j, \operatorname{com} j \in J$, é representado por $G_{j}$, com $G_{j} \subseteq G$. O número de tarefas que visitam o estágio $k$ é denotado por $v_{k}$. O tempo de processamento da tarefa $j, j \in J$, no estágio $k, k \in G$, é indicado por $p_{j k}$. Sem perda de generalidade, o tempo de processamento das tarefas que não visitam um estágio foi considerado igual a zero, ou seja, $p_{j k}=0$ se $j \notin V_{k}$.

A Figura 3.2 ilustra um sistema flexible flow line com $g$ estágios de produção e $m_{k}$ máquinas no estágio $k$. Tipicamente, estoques intermediários (buffers) são representados entre os estágios para armazenamento temporário das tarefas. 


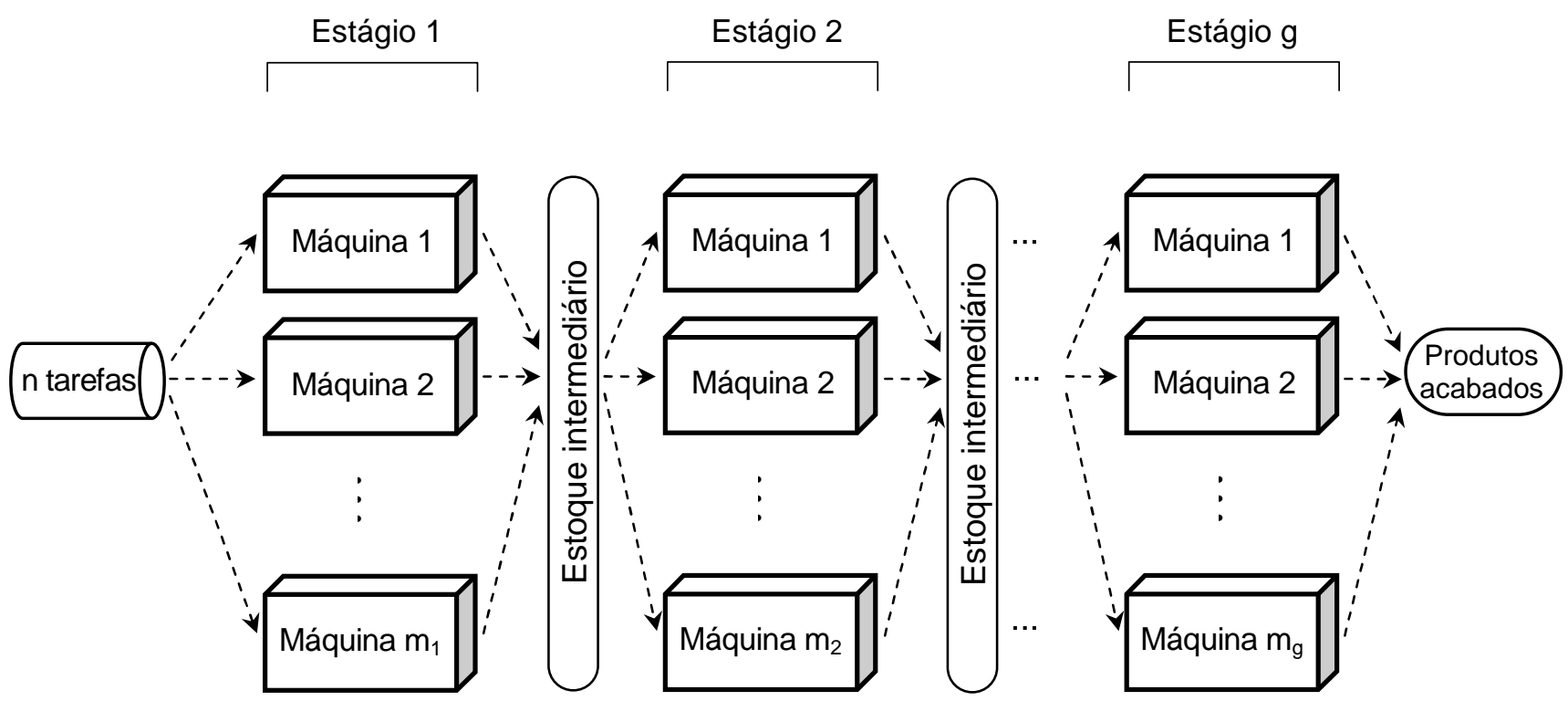

FIGURA 3.2 - Esquema ilustrativo de um flexible flow line

Com relação aos tempos de setup das máquinas do estágio $k$, foram estudados dois ambientes. O Problema I considera o tempo de setup independente da sequência de execução das tarefas, representado por $s_{j k}$, onde $j$ é a tarefa para a qual se realizará a operação de setup no estágio $k$. O Problema II é mais complexo, pois o setup é dependente da sequência, ou seja, o tempo de setup depende tanto da tarefa que será processada, como também da imediatamente anterior na mesma máquina. Nas máquinas do estágio $k$, o tempo de setup da tarefa $j$ tendo executado a tarefa $i$ é denotado por $s_{i j k}$. Os tempos de setup dependentes da sequência são assimétricos, ou seja, $s_{i j k} \neq s_{j i k}$.

Da mesma forma que os tempos de processamento, em ambos os problemas os tempos de setup das tarefas que não visitam um estágio são considerados iguais a zero, ou seja, $s_{j k}=0$ se $j \notin V_{k}$ no Problema I e $s_{i j k}=0$ se $i$ ou $j$ não pertencem a $V_{k}$ no Problema II.

O tempo de setup da primeira tarefa programada em cada máquina também foi considerado. Assim, no Problema II, foi utilizada uma tarefa fictícia 0 como ponto nominal para 
cada máquina. Como exemplificou Kurz (2001, p.17), um “ponto nominal” poderia representar uma prensa sem as telas carregadas e sem paletes instalados. A tarefa fictícia 0 não requer tempo de processamento. O setup da tarefa 0 para cada tarefa $\left(s_{0 j k}\right)$ indica o tempo necessário para a preparação a partir do ponto nominal. No PROBLEMA I, como o setup independe da tarefa anterior, não há a necessidade de considerar uma tarefa fictícia, e o ponto nominal marca o início do setup $\left(s_{j k}\right)$ da primeira tarefa em cada máquina.

Além disso, o setup pode ser antecipado ou não. O setup antecipado é aquele que pode ser realizado antes do término da operação no estágio anterior. A variável binária $A_{i j k}$, com $i, j \in J$ e $k \in G$, define se o setupda tarefa i para a tarefa j no estágio k é antecipado $\left(A_{i j k}=1\right)$ ou não antecipado $\left(A_{i j k}=0\right)$.

Conforme observado por Aldowaisan (2001), uma importante implicação dos tempos de setup antecipados é que a operação de setup na máquina ou estágio subsequente pode ser iniciada enquanto a tarefa ainda está sendo executada. Como exemplificado por Allahverdi (2000), se há tempo ocioso na segunda máquina, o que geralmente acontece, então o setup nesta máquina pode ser realizado antes do término do processamento da tarefa na primeira máquina. Isto significa que quando o setup pode ser antecipado, uma medida de desempenho regular, como no caso do makespan, pode ser melhorada considerando os tempos de setup separados dos tempos de processamento.

Entretanto, há casos que requerem que a peça ou o produto que será processado esteja presente na máquina para que o setup seja concluído, como por exemplo operações de posicionamento e ajuste. Assim, para que o problema tratado seja mais realista foram considerados ambos os casos de setup antecipado e não antecipado.

Neste trabalho, a medida de desempenho utilizada foi o makespan, ou seja, a duração total da programação, denotada por $C_{\max }$. Segundo Morton e Pentico (1993, p.302), o makespan é um critério útil para ambientes com grande carga de trabalho quando a utilização dos 
recursos produtivos em longo prazo deve ser maximizada. Além disso, é uma função-objetivo suficientemente simples para fornecer resultados analíticos em ambientes com múltiplas máquinas e para tornar métodos branch-and-bound praticáveis em problemas de médio porte. Por este motivo, esta medida de desempenho é tradicional em muitos sistemas flexible flow line na literatura.

Pinedo (1995, p.13) também afirma que baixos valores do makespan indicam uma eficiente utilização dos recursos. Kurz e Askin (2003) confirmam que, além da sua aplicabilidade aos ambientes de produção multitarefa, o makespan também pode ser considerado para maximização da utilização da capacidade produtiva.

A data de término e o tempo de setup da máquina são influenciados pelo mix e pela sequência de produção. Processar grandes lotes pode aumentar a utilização da máquina e reduzir o tempo total de setup, por outro lado, aumenta também o tempo de fluxo (Pinedo, 1995).

Os problemas considerados neste estudo são complexos por três principais motivos:

1) Ainda que o ambiente flexible flow line tenha sido abordado por alguns pesquisadores anteriormente, poucos consideraram os tempos de setup separados dos tempos de processamento das tarefas. Além disso, até o momento não foi encontrado nenhum trabalho na literatura com as mesmas características do ambiente em questão.

2) Foram consideradas ambas as opções de tempos de setup dependente e independente da sequência de execução das tarefas. Em outras palavras, dois ambientes distintos, porém relacionados, são tratados neste trabalho.

3) O sistema com máquinas paralelas nos estágios torna a análise mais realista, pois na prática os processos de produção podem ter diferentes números de máquinas em 
cada estágio. Isto não ocorria em alguns trabalhos publicados, como por exemplo em Ruiz e Maroto (2006) e Ruiz, Şerifoğlu e Urlings (2008), onde o número de máquinas em todos os estágios é sempre o mesmo.

\subsection{Hipóteses}

As hipóteses consideradas nos problemas tratados são as seguintes:

1) Presume-se que as decisões acerca de plano de produção e de layout da fábrica tenham sido tomadas no planejamento a longo e médio prazo.

2) A produção é "fazer-para-estoque" (make-to-stock), assim, não há prazos de entrega (due dates) associados aos produtos.

3) Em cada um dos vários estágios de produção, existem uma ou mais máquinas consideradas idênticas.

4) Todas as máquinas estão disponíveis no início do processo de programação (data zero).

5) Não há parada de máquina e todas estão continuamente disponíveis.

6) Uma tarefa é uma ordem de serviço, representando um produto individual, e consiste de múltiplas operações, uma para cada estágio de produção.

7) Cada operação é processada em no máximo uma máquina em cada estágio.

8) Os tempos de processamento das tarefas em cada estágio que visita são fixos e conhecidos previamente.

9) As tarefas têm a mesma data de liberação, a partir da qual podem ser programadas e executadas. Esta data de liberação pode ser considerada igual a zero, sem perda de generalidade. 
10) A execução de uma tarefa em uma máquina só pode começar após o término da sua operação no estágio anterior e desde que a máquina já esteja preparada.

11) As tarefas não necessariamente são programadas na mesma ordem em todos os estágios.

12) As tarefas podem esperar entre dois estágios de produção e o armazenamento intermediário (buffer) é ilimitado.

13) Como o fluxo das tarefas é linear e unidirecional, não há tempos de transporte das tarefas entre os estágios.

14) Como as máquinas de um estágio são idênticas, o tempo de setup de uma tarefa é o mesmo em todas as máquinas do estágio.

15) As operações de cada tarefa não podem ser subdivididas em sub-operações simultâneas (no splitting).

16) Uma vez iniciadas, as operações de cada tarefa devem terminar sem interrupção (no preemption).

\subsection{Problemas exemplo}

A seguir serão apresentados exemplos ilustrativos do problema de programação da produção estudado. No primeiro exemplo, existem três estágios, sendo duas máquinas no primeiro, uma no segundo e três no terceiro, conforme pode ser visto no esquema da Figura 3.3. Cada estágio é visitado pelas tarefas listadas na mesma Figura 3.3. 


\section{Estágio 1}

Tarefas:

$1,2,4,6,9$
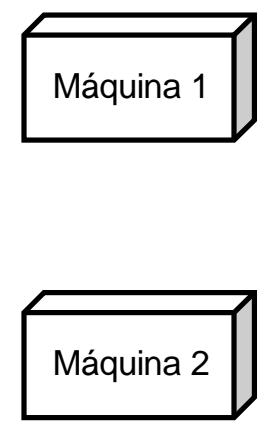

\section{Estágio 2}

Tarefas:

2, 3, 4, 8

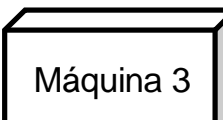

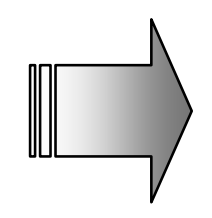

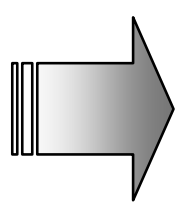

Máquina 4

Tarefas:

$1,2,3,5,6,7,9$
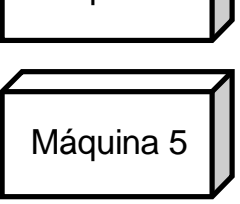

Máquina 6

FIGURA 3.3 - Esquema do cenário do problema exemplo

Para ilustrar o Problema I, as Tabelas 3.2 a 3.4 apresentam os dados do exemplo, considerando-o com tempos de setup independentes da sequência de tarefas para efeito de comparação. Da mesma forma, somente os dados das tarefas que visitam os estágios são mostrados e os tempos de setup antecipados estão representados entre parênteses.

TABEla 3.2 - Dados do PRoblema I (a)

\begin{tabular}{|c|c|c|c|c|c|}
\hline \multicolumn{7}{|c|}{ ESTÁGIO 1 } \\
\hline Tarefa & $\mathbf{1}$ & $\mathbf{2}$ & $\mathbf{4}$ & $\mathbf{6}$ & $\mathbf{9}$ \\
\hline $\boldsymbol{p}_{\boldsymbol{j} 1}$ & 5 & 13 & 3 & 3 & 8 \\
\hline $\boldsymbol{s}_{\boldsymbol{j} 1}$ & 3 & 2 & 2 & 3 & 1 \\
\hline
\end{tabular}

TABela 3.3 - Dados do Problema I (b)

\begin{tabular}{|c|c|c|c|c|}
\hline \multicolumn{5}{|c|}{ ESTÁGIO 2 } \\
\hline Tarefa & $\mathbf{2}$ & $\mathbf{3}$ & $\mathbf{4}$ & $\mathbf{8}$ \\
\hline $\boldsymbol{p}_{j 2}$ & 4 & 4 & 5 & 2 \\
\hline $\boldsymbol{s}_{j 2}$ & 2 & $(3)$ & $(1)$ & 2 \\
\hline
\end{tabular}

TABela 3.4 - Dados do Problema I (c)

\begin{tabular}{|c|c|c|c|c|c|c|c|}
\hline \multicolumn{10}{|c|}{ ESTÁGIO 3 } \\
\hline Tarefa & $\mathbf{1}$ & $\mathbf{2}$ & $\mathbf{3}$ & $\mathbf{5}$ & $\mathbf{6}$ & $\mathbf{7}$ & $\mathbf{9}$ \\
\hline $\boldsymbol{p}_{\boldsymbol{j}}$ & 11 & 5 & 5 & 4 & 4 & 3 & 8 \\
\hline $\boldsymbol{s}_{\boldsymbol{j}}$ & $(2)$ & $(3)$ & 3 & 5 & $(2)$ & 4 & $(6)$ \\
\hline
\end{tabular}


As Tabelas 3.5 a 3.7 apresentam os dados do exemplo ilustrativo do Problema II (setup dependente) com os tempos de processamento e de setup de cada tarefa em cada estágio. Somente os dados das tarefas que visitam os estágios são mostrados. Os tempos de setup antecipados, ou seja, aqueles que podem ser realizados antes do término da tarefa no estágio anterior, estão representados entre parênteses.

TABELA 3.5 - Dados do PROBlema II (a)

\begin{tabular}{|c|c|c|c|c|c|c|}
\hline \multicolumn{7}{|c|}{ ESTÁGIO 1} \\
\hline Tarefa & 0 & 1 & 2 & 4 & 6 & 9 \\
\hline$p_{j 1}$ & 0 & 5 & 13 & 3 & 3 & 8 \\
\hline \multirow{7}{*}{$s_{i j 1}$} & para & 1 & 2 & 4 & 6 & 9 \\
\hline & 0 & 4 & 3 & 2 & 3 & 5 \\
\hline & 1 & - & 5 & 7 & 2 & 1 \\
\hline & 2 & 8 & - & 1 & 4 & 2 \\
\hline & 4 & 3 & 1 & - & 7 & 4 \\
\hline & 6 & 4 & 2 & 3 & - & 3 \\
\hline & 9 & 2 & 5 & 1 & 8 & - \\
\hline
\end{tabular}

TABElA 3.6 - Dados do Problema II (b)

\begin{tabular}{|c|c|c|c|c|c|}
\hline \multicolumn{6}{|c|}{ ESTÁGIO 2} \\
\hline Tarefa & 0 & 2 & 3 & 4 & 8 \\
\hline$p_{i 2}$ & 0 & 4 & 4 & 5 & 2 \\
\hline \multirow{6}{*}{$s_{i j 2}$} & para & 2 & 3 & 4 & 8 \\
\hline & 0 & (3) & 5 & 6 & (2) \\
\hline & 2 & - & (4) & 5 & (1) \\
\hline & 3 & 1 & - & 1 & (7) \\
\hline & 4 & 2 & 6 & - & (4) \\
\hline & 8 & (3) & (3) & 5 & - \\
\hline
\end{tabular}

TABElA 3.7 - Dados do Problema II (c)

\begin{tabular}{|c|c|c|c|c|c|c|c|c|}
\hline \multicolumn{9}{|c|}{ ESTÁGIO 3} \\
\hline Tarefa & 0 & 1 & 2 & 3 & 5 & 6 & 7 & 9 \\
\hline$p_{j 3}$ & 0 & 11 & 5 & 5 & 4 & 3 & 8 & 4 \\
\hline \multirow{9}{*}{$s_{i j 3}$} & para & 1 & 2 & 3 & 6 & 7 & 9 & 10 \\
\hline & 0 & (9) & 3 & 5 & (2) & 4 & 3 & (5) \\
\hline & 1 & - & 4 & 4 & (1) & (7) & (5) & (8) \\
\hline & 2 & (2) & - & 6 & (7) & (5) & 2 & 2 \\
\hline & 3 & 5 & (3) & - & 2 & (6) & 2 & 1 \\
\hline & 6 & 2 & (9) & 4 & - & 1 & (6) & 2 \\
\hline & 7 & (8) & (5) & 3 & (3) & - & 2 & (9) \\
\hline & 9 & 1 & (4) & (6) & 2 & 5 & - & (3) \\
\hline & 10 & (2) & 5 & (3) & (8) & (7) & 1 & - \\
\hline
\end{tabular}

A Figura 3.4 mostra o gráfico de Gantt para uma programação factível (viável) para o PROBLEMA II, em que o valor do makespan é 32 unidades de tempo. 
Neste ambiente, do segundo estágio em diante, assim como no primeiro, o setup de algumas tarefas pode ser iniciado na data zero da programação. Por exemplo, a tarefa 8 salta o primeiro estágio e, portanto, já está liberada no segundo estágio desde o início da programação.

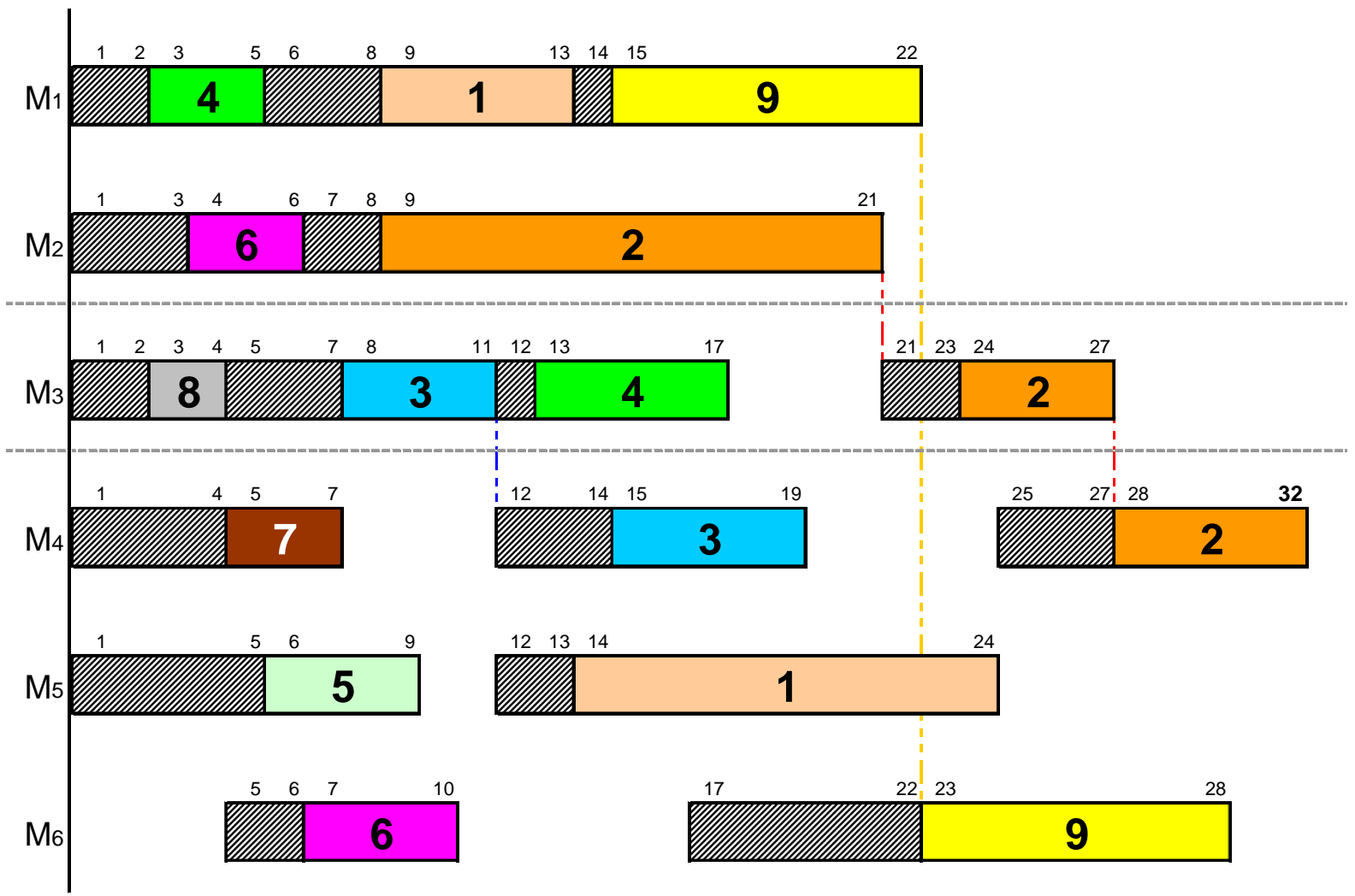

FIGURA 3.4 - Ilustração de uma programação factível

Em alguns casos, pode-se constatar visualmente a diferença entre tempos de setup antecipados e não antecipados. Por exemplo, no estágio 2, o setup da tarefa 4 para a 2 é não antecipado e no estágio 3, o setup da tarefa 6 para a 9 é antecipado. Por outro lado, apenas pelo gráfico, não é possível identificar o tipo do setup da tarefa 3 para a 4 no estágio 2.

A característica de antecipação do setup não influencia a programação do primeiro estágio. Isto porque o setup de todas as tarefas deve ser realizado a partir da data zero e todas já estão liberadas no início da programação, consequentemente nenhum setup do primeiro está- 
gio pode ser antecipado. Além disso, o conceito de antecipação tem como referência a data de término da tarefa no estágio anterior, o que não se aplica ao primeiro estágio.

Isto acontece não apenas no primeiro estágio do sistema, como também com a data de término de uma tarefa no primeiro estágio em que visita. Deve-se enfatizar que o "primeiro estágio visitado por uma tarefa" não é necessariamente o "primeiro estágio do sistema" (ela pode saltar o primeiro estágio).

Portanto, a antecipação ou não do setup não afeta nem o primeiro estágio do sistema nem a data de término das tarefas no primeiro estágio visitado.

É interessante notar também que uma tarefa pode ter setup antecipado em um estágio e não antecipado em outro, uma vez que as operações são diferentes. É o caso da tarefa 2 nos estágios 2 (setup não antecipado) e 3 (setup antecipado).

Existe uma tendência de se considerar que o setup não antecipado sempre posterga a programação, como, por exemplo, na máquina 3, o setup entre as tarefas 4 e 2. Entretanto, é interessante notar pelo gráfico que nem sempre isto acontece, devido à folga existente pela liberação da tarefa seguinte, como é o caso do setup entre as tarefas 7 e 3 na máquina 4, e a data mais cedo de início da tarefa 2 nesta mesma máquina. Como já foi dito, quando a liberação da máquina é posterior à liberação da tarefa (data de término no estágio anterior), não é possível identificar no gráfico de Gantt se o setup é antecipado ou não.

Uma das consequências da possibilidade das tarefas saltarem estágios é que o makespan pode ser determinado por qualquer estágio e não apenas pelo último estágio. Considerando os dados do ProBlema I e a programação ilustrada na Figura 3.5, tem-se a situação em que a maior data de término ocorre no segundo estágio. Neste caso, o makespan é 31 unidades de tempo. 


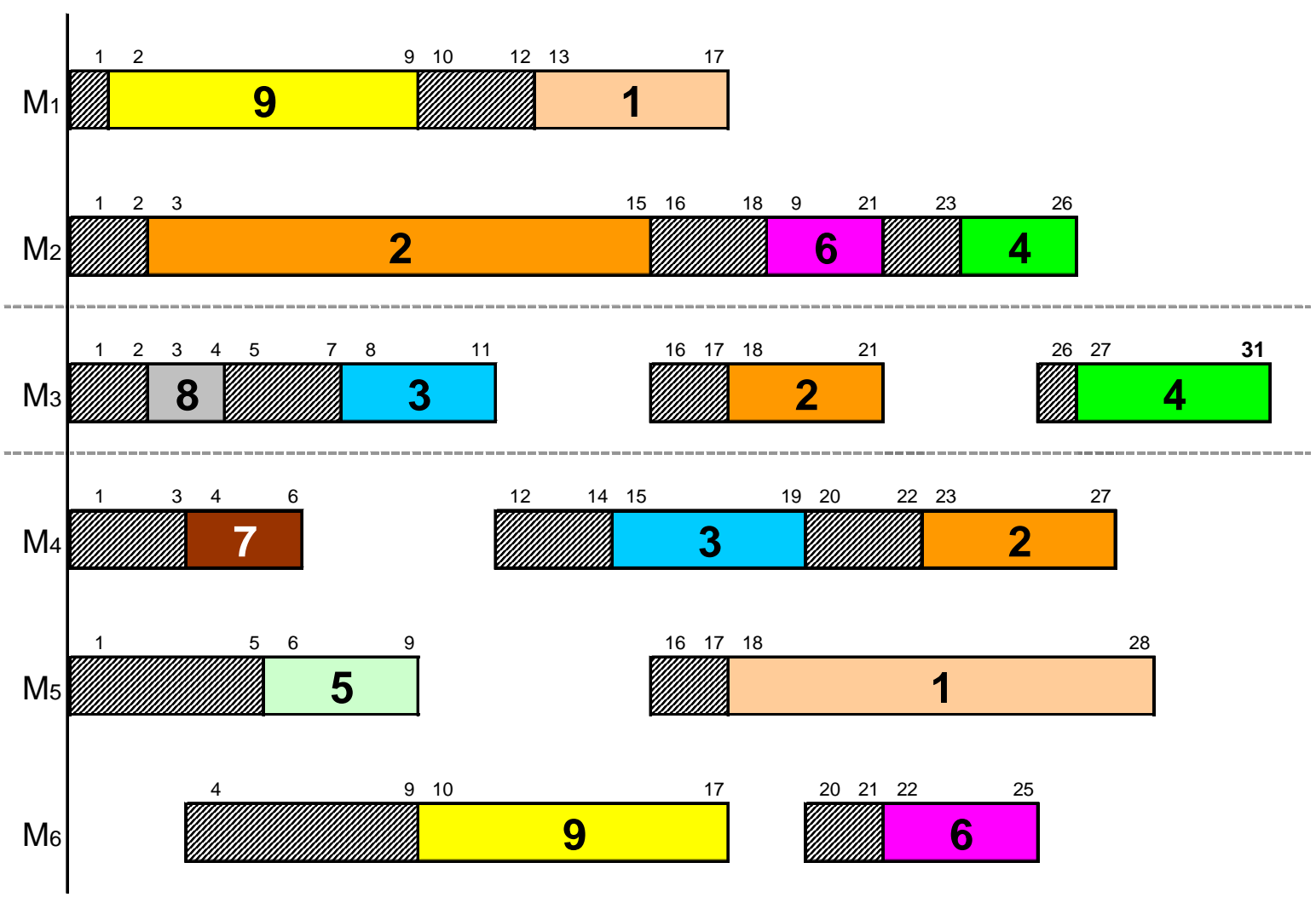

FIGURA 3.5 - Ilustração do makespan definido por estágio intermediário 


\title{
4 REGRAS DE PRIORIDADE PROPOSTAS
}

\author{
"A melhor maneira de ter uma \\ Goa ideia é ter muitas ideias." \\ Linus Pauling
}

\subsection{Classificação dos métodos heurísticos}

Os métodos de solução heurística foram classificados por Quadt e Kuhn (2007a) em métodos holísticos e de decomposição.

Os métodos holísticos consideram o problema todo de forma integrada. Um exemplo simples desta abordagem é a utilização de regras de prioridade para selecionar a próxima tarefa a ser programada em uma máquina. A maioria dos métodos holísticos são procedimentos de busca local ou meta-heurísticas.

Os métodos de decomposição subdividem o problema em etapas sucessivas. Esta decomposição permite simplificar o problema original, mas requer uma estratégia para tratar as interdependências entre as diferentes etapas. Estes métodos podem ainda ser classificados em decomposição por estágio, por tarefa ou por subproblema.

Neste trabalho, foram propostos métodos de solução heurística de ambos os tipos descritos acima, organizados em regras de prioridade, tratados neste capítulo, e algoritmos heurísticos construtivos, apresentados no capítulo 5. 


\subsection{Importância das regras de prioridade}

Como já mencionado na seção 1.3, para realizar a programação da produção, é preciso antes efetuar as atividades de sequenciamento e alocação. Segundo Ruiz (2003, p.5), um sequenciamento adequado da produção é vital para o funcionamento da empresa, garantindo os resultados almejados.

Dentre as heurísticas existentes para a solução de problemas de programação da produção, as mais simples são as regras de sequenciamento. Aqui as regras de sequenciamento e de prioridade (também chamadas regras de despacho) serão consideradas indistintamente e atendem a classificação de Quadt e Kuhn (2007a) como métodos holísticos.

Assim, é importante salientar que os métodos de solução denominados neste trabalho como "regras de prioridade" são também métodos heurísticos construtivos, pois incluem em sua definição a política de alocação adotada nos estágios. A designação de "regra de prioridade" serve para enfatizar o estabelecimento de uma ordenação inicial e diferenciar das heurísticas mais complexas.

Segundo Tubino (2006, p.155), as regras de sequenciamento são heurísticas usadas para selecionar em uma fila de lotes aquele que terá prioridade de processamento, com base nas informações dos próprios lotes ou do estado do sistema produtivo.

As regras mais empregadas na prática são: $\boldsymbol{S P T}$ (Shortest Processing Time), LPT (Longest Processing Time), EDD (Earliest Due Date), MST (Minimum Slack Time), FIFO (First In First Out) e LIFO (Last In First Out). As regras também podem ser utilizadas com pesos, como WSPT e WLPT, onde "W" simboliza weighted, ou seja, "ponderada". 
A necessidade de definir a sequência de tarefas é mais evidente em sistemas de produção empurrados ${ }^{3}$, em que se utilizam critérios pré-determinados para emitir ordens de compra, fabricação e montagem dos itens. Já nos sistemas puxados ${ }^{4}$, normalmente são implementados kanbans para gerenciar a produção.

As regras de prioridade são procedimentos de grande importância prática por serem tecnicamente simples, fáceis de compreender e por requererem pouco esforço computacional para aplicá-las. Geralmente a utilização de regras de prioridade é suficiente para a programação em diversos ambientes de produção. Além disso, tais regras são fáceis de codificar em linguagens de programação modernas e seus cálculos são bastante rápidos.

Por todas estas razões, a pesquisa com regras de prioridade em ambientes complexos de programação da produção, como no caso deste estudo, é um tópico importante e exige cuidadosa atenção.

Neste capítulo, foram propostas regras de prioridade para ambos os problemas tratados neste trabalho - com setup independente (ProBlemA I) e dependente (ProblemA II).

\subsection{Regras propostas para setup independente}

Para obter a solução do problema de programação com setup independente da sequência, foram inicialmente definidas doze regras de sequenciamento para as tarefas nos diversos estágios de produção. Tais propostas baseiam-se nas bem conhecidas regras $S P T$ e $L P T$, e em adaptações de heurísticas apresentadas por Gupta e Tunc (1994) e Li (1997).

\footnotetext{
${ }^{3}$ Sistema de produção empurrado: cada centro de trabalho empurra o trabalho, sem levar em consideração se o centro de trabalho seguinte pode realizá-lo, podendo acarretar tempo ocioso, estoque e filas (SLACK et al., 1999, p.247).

${ }^{4}$ Sistema de produção puxado: o ritmo e as especificações do que é feito são estabelecidos pelo centro de trabalho consumidor, que puxa o trabalho do centro antecedente (fornecedor). O consumidor atua como o único "gatilho" do movimento (ibidem).
} 
Como se sabe, a regra SPT sequencia as tarefas pela ordem não decrescente dos tempos de processamento, enquanto que a $L P T$ utiliza a ordem não crescente desses tempos. Para os problemas clássicos de máquina única e máquinas paralelas idênticas (com tempos de setup incluídos nos tempos de processamento), a regra $S P T$ minimiza o tempo médio de fluxo e para o ambiente com máquinas paralelas, a regra $L P T$ tende a equilibrar a carga de trabalho das máquinas. Evidentemente, para o sistema flexible flow line com tempos de setup explícitos, foi necessário adaptar os critérios de ordenação das regras clássicas.

Do segundo estágio de produção em diante, quatro regras respeitam a mesma ordenação definida para o primeiro estágio; duas regras utilizam o mesmo critério de ordenação, porém podem gerar ordenações diferentes das tarefas a partir do segundo estágio, e as outras seis utilizam a regra ERD (Earliest Release Date) para ordenação das tarefas a partir do segundo estágio. A regra de prioridade $E R D$ é equivalente à bem conhecida ordenação FIFO (First In First Out), em que as tarefas são programadas na ordem em que chegam ao estágio, ou seja, na ordem em que são concluídas no estágio anterior e, portanto, liberadas em fila para o processamento no estágio atual.

No ambiente em estudo, a aplicação da ERD foi motivada pela flexibilidade do ambiente e pela possibilidade de, num determinado estágio, antecipar o processamento das tarefas que não visitaram o anterior.

Após o estabelecimento da ordenação em cada estágio, cada tarefa é alocada sequencialmente à máquina de menor carga, que levará à menor data de término. Isto não ocorre, por exemplo, no ambiente em que o tempo de setup é dependente da sequência, pois a data de término da tarefa é afetada pela variação do tempo de setup de acordo com a tarefa anterior.

É importante observar que a regra de prioridade aplicada em um estágio $\boldsymbol{k}$ não altera no estágio $k+1$ a data de liberação das tarefas que não visitam esse estágio $k$. Pelo exemplo da seção 3.5, as tarefas 3, 5, 7, e 8 não visitam o estágio 1. Portanto, qualquer que 
seja a regra de prioridade aplicada no estágio 1, a data de liberação dessas tarefas no estágio 2 será sempre zero.

As seis primeiras regras, que utilizam o mesmo critério de ordenação em todos os estágios (porém, não necessariamente a mesma ordenação), são apresentadas a seguir. Para cada tarefa $j$ foi definido um valor utilizado na construção da sequência.

- SPT1: utiliza a ordem não decrescente da soma dos tempos de setup e de processamento no primeiro estágio $\left(s_{j 1}+p_{j 1}\right)$.

- SPT2: em cada estágio $k$, considera a ordem não decrescente da soma dos tempos de setup e de processamento no estágio seguinte $\left(s_{j(k+1)}+p_{j(k+1)}\right)$. No último estágio, considera a soma dos tempos do próprio estágio.

- SPT3: considera a ordem não decrescente da soma dos tempos de setup e de processamento em todos os estágios $\left(\sum_{k=1}^{g}\left[s_{j k}+p_{j k}\right]\right)$.

- LPT1: análoga à SPT1, utiliza a ordem não crescente da soma dos tempos de setup e de processamento no primeiro estágio $\left(s_{j 1}+p_{j 1}\right)$.

- LPT2: em cada estágio $k$, considera a ordem não crescente da soma dos tempos de setup e de processamento no estágio seguinte $\left(s_{j(k+1)}+p_{j(k+1)}\right)$. No último estágio, considera a soma dos tempos do próprio estágio.

- LPT3: considera a ordem não crescente da soma dos tempos de setup e de processamento em todos os estágios $\left(\sum_{k=1}^{g}\left[s_{j k}+p_{j k}\right]\right)$. 
Observação: Como já mencionado, embora o critério de ordenação seja o mesmo em todos os estágios, a sequência obtida pode ser diferente ao se aplicar as regras SPT2 e LPT2, por utilizarem os dados do estágio seguinte na ordenação das tarefas no estágio atual.

As seis últimas regras são análogas às apresentadas acima, diferenciando na ordenação do segundo ao último estágio, para os quais é utilizada a regra $E R D$.

- SPT1_ERD: no primeiro estágio, utiliza a ordem não decrescente da soma dos tempos de setup e de processamento no primeiro estágio $\left(s_{j 1}+p_{j 1}\right)$ e a regra $E R D$ nos estágios seguintes.

- SPT2_ERD: no primeiro estágio, considera a ordem não decrescente da soma dos tempos de setup e de processamento do segundo estágio, e aplica a regra $E R D$ nos estágios seguintes.

- SPT3_ERD: no primeiro estágio, considera a ordem não decrescente da soma dos tempos de setup e de processamento em todos os estágios $\left(\sum_{k=1}^{g}\left[s_{j k}+p_{j k}\right]\right)$, e aplica a regra $E R D$ nos estágios seguintes.

- LPT1_ERD: no primeiro estágio, utiliza a ordem não crescente da soma dos tempos de setup e de processamento no primeiro estágio $\left(s_{j 1}+p_{j 1}\right)$ e a regra $E R D$ nos estágios seguintes. 
- LPT2_ERD: no primeiro estágio, considera a ordem não crescente da soma dos tempos de setup e de processamento do segundo estágio, e aplica a regra $E R D$ nos estágios seguintes.

- LPT3_ERD: no primeiro estágio, considera a ordem não crescente da soma dos tempos de setup e de processamento em todos os estágios $\left(\sum_{k=1}^{g}\left[s_{j k}+p_{j k}\right]\right)$, e aplica a regra $E R D$ nos estágios seguintes.

Estas regras foram concebidas para ambientes com tempos de setup explícitos e independentes da sequência de tarefas. Assim, nem todas são apropriadas para o sistema flexible flow line, que incorpora características adicionais às relacionadas ao setup. Naturalmente, as regras aplicadas neste trabalho devem considerar tais características específicas de forma adequada e diferenciada, fazendo com que se constituam de vantagens em relação a outros tipos de problemas. Esta é uma das contribuições deste trabalho ao se aplicar as regras de prioridade.

Com esta premissa, deve-se analisar cuidadosamente as regras derivadas da $L P T$, que penalizam as tarefas que não visitam um estágio por terem tempos de processamento e de setup iguais a zero.

\section{$\checkmark$ Análise funcional da regra LPT1}

Pode-se perceber antecipadamente que a regra LPT1 não aproveita a vantagem das tarefas saltarem estágios, como ilustrado a seguir. De acordo com o exemplo da seção 3.5, a Tabela 4.1 apresenta a soma $\left(s_{j 1}+p_{j 1}\right)$, utilizada na ordenação pela regra LPT1. 
TABELA 4.1 - Valores para ordenação pela regra LPT1

\begin{tabular}{|c|c|c|c|c|c|c|c|c|c|}
\hline Tarefa $\boldsymbol{j}$ & $\mathbf{1}$ & $\mathbf{2}$ & $\mathbf{3}$ & $\mathbf{4}$ & $\mathbf{5}$ & $\mathbf{6}$ & $\mathbf{7}$ & $\mathbf{8}$ & $\mathbf{9}$ \\
\hline$s_{j 1}+p_{j 1}$ & 8 & 15 & 0 & 5 & 0 & 6 & 0 & 0 & 9 \\
\hline
\end{tabular}

Portanto, a sequência fornecida pela regra LPT1 é a seguinte: $2-9-1-6-4-3-5$ - 7 - 8. A soma dos tempos $\left(s_{j 1}+p_{j 1}\right)$ das tarefas $3,5,7$ e 8 , que não visitam o estágio 1 , é igual a zero e tais tarefas estão representadas na sequência dentro de retângulos $(\square)$.

Estas tarefas já estão liberadas no estágio 2 desde o início da programação, porém pela regra LPT1 elas precisam esperar até que as tarefas 2, 9, 1, 6 e 4 sejam programadas no primeiro estágio, como pode ser observado na Figura 4.1. Ou seja, as tarefas que não visitam o estágio 1 e, portanto possuem tempo de processamento e de setup nulos no problema modelado, ficam sempre em último lugar na ordenação. Neste caso, a vantagem do flexible flow line de poder antecipar as tarefas $3,5,7$ e 8 no segundo estágio seria eliminada. Isto mostra que a regra LPT1 não é apropriada para a programação no ambiente flexible flow line. Portanto, ela não será considerada na análise de desempenhos destas regras de prioridade.

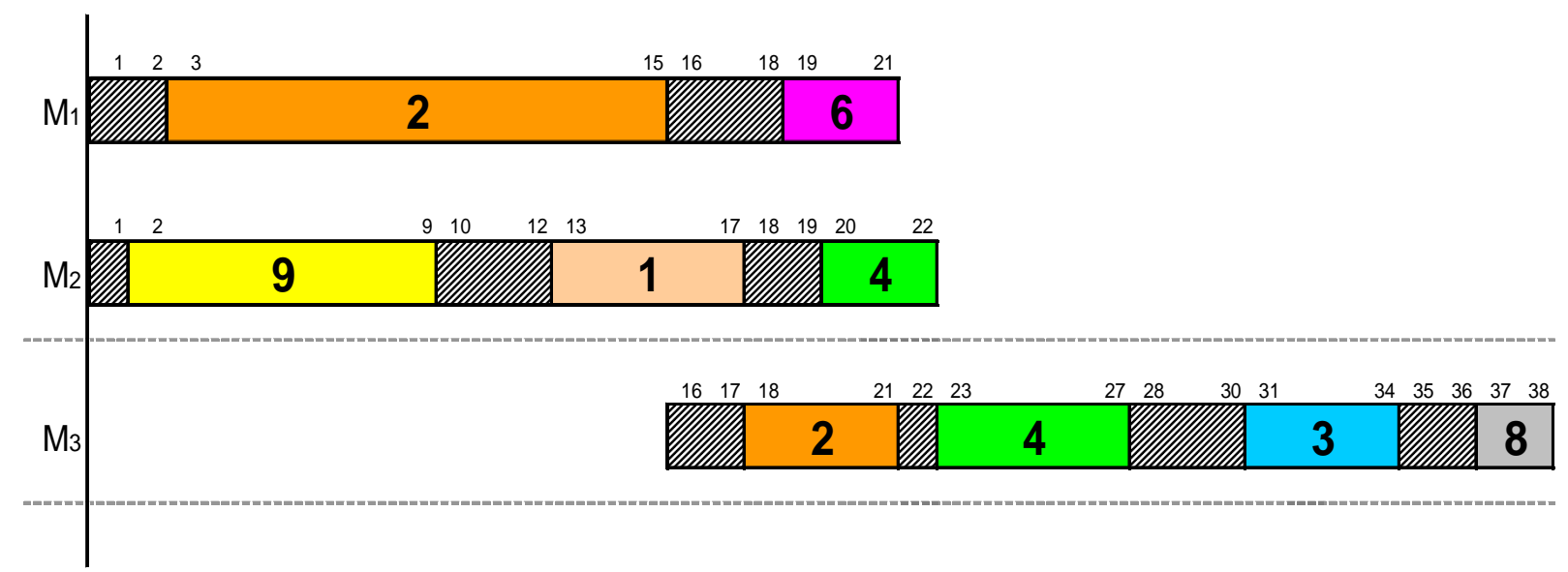

FIGURA 4.1 - Programação dos estágios 1 e 2 definida pela regra LPT1 


\section{$\checkmark$ Análise funcional da regra LPT2}

Para melhor ilustrar o comportamento da regra LPT2, será introduzido o problema exemplo 2, conforme as Tabelas 4.2 a 4.4 a seguir.

TABELA 4.2 - Dados do problema exemplo 2 (a)

\begin{tabular}{|c|c|c|c|c|}
\hline \multicolumn{5}{|c|}{ ESTÁGIO 1} \\
\hline Tarefa & 1 & 3 & 4 & 6 \\
\hline$p_{j 1}$ & 4 & 3 & 2 & 3 \\
\hline$s_{j 1}$ & 1 & 2 & 1 & 2 \\
\hline
\end{tabular}

$m_{1}=2$
TABELA 4.3 - Dados do problema exemplo 2 (b)

\begin{tabular}{|c|c|c|c|}
\hline \multicolumn{4}{|c|}{ ESTÁGIO 2} \\
\hline Tarefa & 2 & 3 & 4 \\
\hline$p_{j 2}$ & 4 & 2 & 3 \\
\hline$s_{j 2}$ & (2) & 1 & $(4)$ \\
\hline
\end{tabular}

$m_{2}=2$
TABELA 4.4 - Dados do problema exemplo 2 (c)

\begin{tabular}{|c|c|c|c|c|c|}
\hline \multicolumn{7}{|c|}{ ESTÁGIO 3 } \\
\hline Tarefa & $\mathbf{1}$ & $\mathbf{2}$ & $\mathbf{4}$ & $\mathbf{5}$ & $\mathbf{6}$ \\
\hline $\boldsymbol{p}_{j 3}$ & 3 & 4 & 6 & 5 & 3 \\
\hline $\boldsymbol{s}_{j 3}$ & $(5)$ & 1 & $(3)$ & $(7)$ & 2 \\
\hline
\end{tabular}

$m_{3}=2$

De acordo com os dados do exemplo 2 apresentado, a Tabela 4.5 apresenta a soma $\left(s_{j(k+1)}+p_{j(k+1)}\right)$ utilizada pela regra LPT2 na ordenação das tarefas em cada estágio $k$.

TABELA 4.5 - Valores para ordenação pela regra LPT2

\begin{tabular}{|c|c|c|c|c|c|c|}
\hline Tarefa $\boldsymbol{j}$ & $\mathbf{1}$ & $\mathbf{2}$ & $\mathbf{3}$ & $\mathbf{4}$ & $\mathbf{5}$ & $\mathbf{6}$ \\
\hline$k=1: s_{j 2}+p_{j 2}$ & 0 & 6 & 3 & 7 & 0 & 0 \\
\hline$k=2: s_{j 3}+p_{j 3}$ & 8 & 5 & 0 & 9 & 12 & 5 \\
\hline$k=3: s_{j 3}+p_{j 3}$ & 8 & 5 & 0 & 9 & 12 & 5 \\
\hline
\end{tabular}

A sequência fornecida pela regra LPT2 para o estágio 1 é: $4-2-3-1-5-6$. No estágio 2 a sequência fica: $5-4-1-2-6-3$. No estágio 3 , a sequência é a mesma do estágio 2, pois a ordenação também utiliza a soma $\left(s_{j 3}+p_{j 3}\right)$; explicitando as tarefas que não visitam o estágio 3, a configuração fica: $5-4-1-2-6-3$. A programação dos três estágios pode ser vista no gráfico da Figura 4.2. 


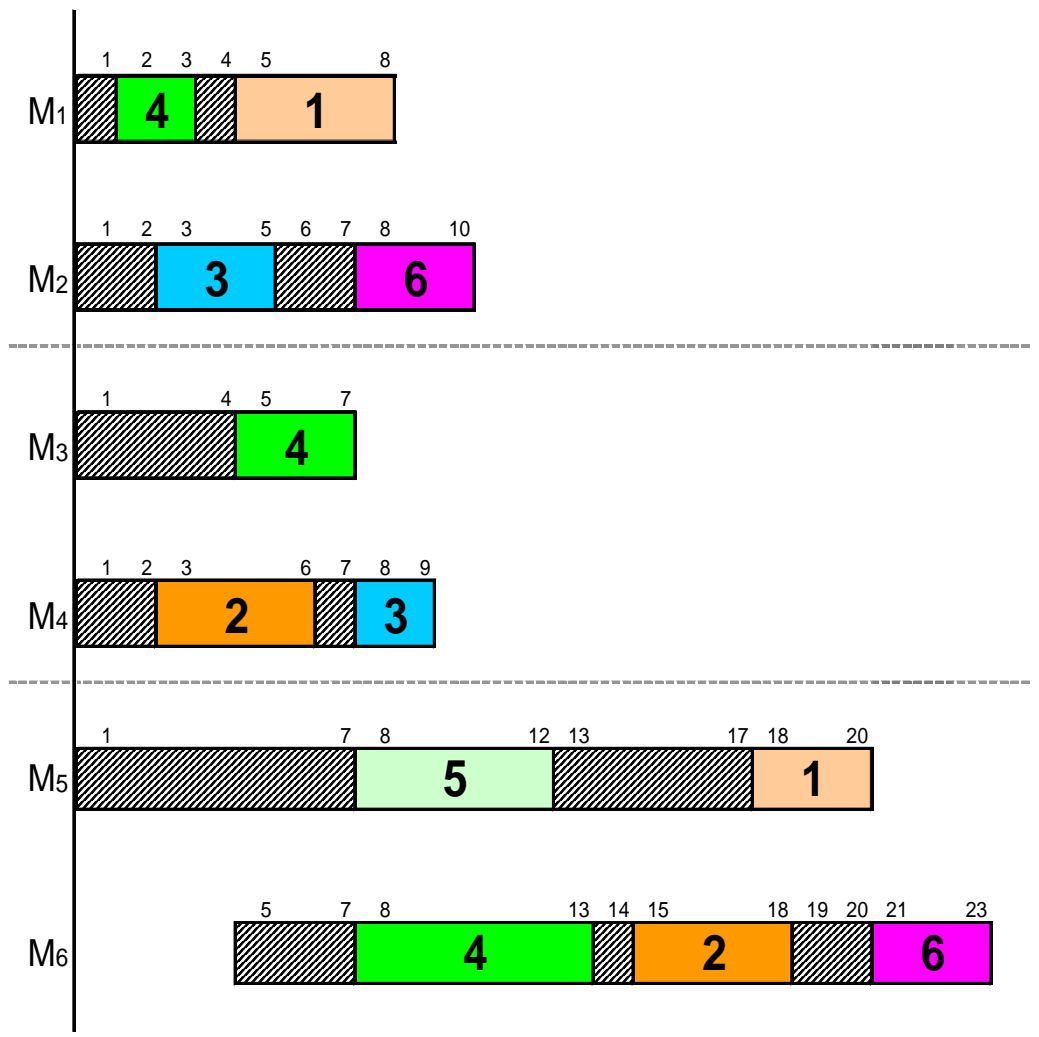

FIGURA 4.2 - Programação definida pela regra LPT2

Como pode ser visto na Figura 4.2, as tarefas do estágio 2 não precisam esperar até que todas as tarefas do estágio 1 sejam programadas, mas é suficiente que se respeite os dados do próprio estágio (datas de liberação e antecipação do setup).

Neste caso, a tarefa 4 é a primeira da sequência que visita o estágio 2. Como seu setup é antecipado, ele pode ser programado na data zero do estágio 2. Da mesma forma, a tarefa 2, que é a próxima tarefa da sequência que visita o estágio 2, pode ser programada na data zero da segunda máquina disponível no estágio $\left(M_{4}\right)$, não necessitando esperar a programação completa do estágio 1 (pois ela salta o estágio 1). Em seguida, a tarefa 3 foi programada no estágio 2 na máquina de menor carga $\left(M_{4}\right)$. No estágio 3, a situação é análoga.

Assim, como a LPT2 não penaliza na ordenação as tarefas que saltam o estágio programado nem as que saltam o estágio anterior, a regra mostra-se viável para a programação do flexible flow line. 


\section{$\checkmark$ Análise funcional da regra LPT3}

Considerando os dados do problema exemplo 2 introduzido anteriormente, a Tabela 4.6 apresenta a soma dos tempos de processamento e de setup de todos os estágios para cada $\operatorname{tarefa} j\left(\sum_{k=1}^{g}\left[s_{j k}+p_{j k}\right]\right)$, utilizada na ordenação inicial.

TABELA 4.6 - Valores para ordenação pela regra LPT3

\begin{tabular}{|c|c|c|c|c|c|c|}
\hline Tarefa $\boldsymbol{j}$ & $\mathbf{1}$ & $\mathbf{2}$ & $\mathbf{3}$ & $\mathbf{4}$ & $\mathbf{5}$ & $\mathbf{6}$ \\
\hline$\sum_{k=1}^{g}\left[s_{j k}+p_{j k}\right]$ & 13 & 11 & 8 & 19 & 12 & 10 \\
\hline
\end{tabular}

Pela regra LPT3 a mesma sequência é utilizada nos três estágios. Explicitando as tarefas que não visitam cada estágio, a configuração no estágio 1 é a seguinte: $4-1-5-2-6-$ 3; no estágio 2: 4-1]-5-2-6-3; e no estágio 3: 4-1 - 5-2-6-3. A programação dos estágios pode ser vista na Figura 4.3. 


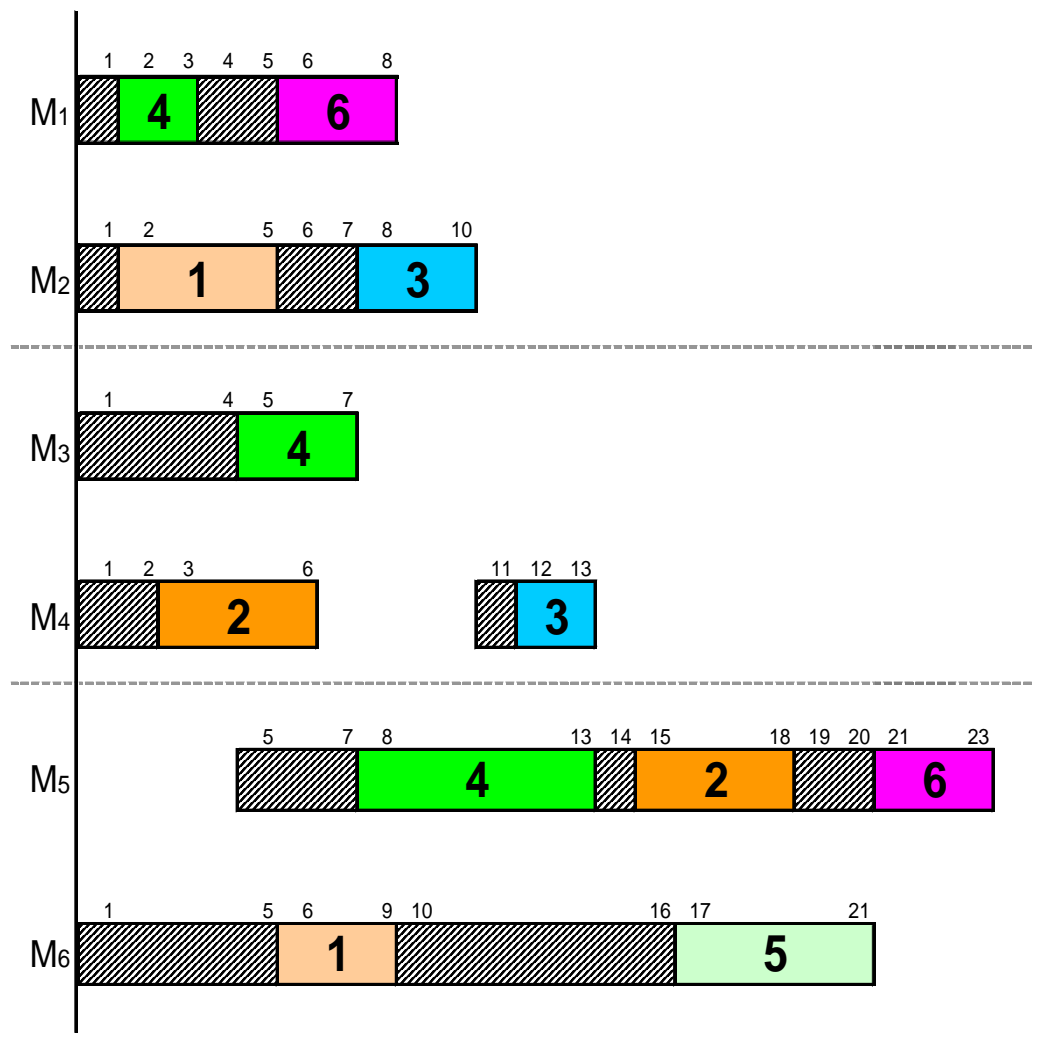

FIGURA 4.3 - Programação definida pela regra LPT3

Pela regra LPT3 também as tarefas de um estágio não precisam esperar até que todas as tarefas do estágio anterior sejam programadas, mas é suficiente que se respeite suas datas de liberação e a característica de antecipação ou não do setup.

Da mesma forma que a LPT2, a LPT3 também não penaliza as tarefas que saltam estágios, mostrando a sua viabilidade na programação do flexible flow line.

\section{$\checkmark$ Análise funcional da regra LPT1_ERD}

Embora a regra LPT1 tenha se mostrado inviável para a programação do flexible flow line, é importante analisar o comportamento da regra LPT1_ERD. Considerando o problema exemplo da seção 3.5, a Tabela 4.7 apresenta os valores para a ordenação em cada estágio, ou seja, a soma dos tempos de processamento e de setup no primeiro estágio e as datas de libera- 
ção do segundo estágio em diante, correspondentes às datas de término do primeiro ao penúltimo estágio. As células sombreadas ( $\square$ ) na tabela indicam as tarefas que saltam o estágio.

TABELA 4.7 - Valores para ordenação do primeiro estágio pela regra LPT1_ERD

\begin{tabular}{|c|c|c|c|c|c|c|c|c|c|}
\hline Tarefa $\boldsymbol{j}$ & $\mathbf{1}$ & $\mathbf{2}$ & $\mathbf{3}$ & $\mathbf{4}$ & $\mathbf{5}$ & $\mathbf{6}$ & $\mathbf{7}$ & $\mathbf{8}$ & $\mathbf{9}$ \\
\hline$k=1: s_{j 1}+p_{j 1}$ & 8 & 15 & 0 & 5 & 0 & 6 & 0 & 0 & 9 \\
\hline$k=2: r_{j 2}=C_{j 1}$ & 17 & 15 & 0 & 22 & 0 & 21 & 0 & 0 & 9 \\
\hline$k=3: r_{j 3}=C_{j 2}$ & 17 & 21 & 7 & 27 & 0 & 21 & 0 & 11 & 9 \\
\hline
\end{tabular}

A sequência fornecida pela regra LPT1_ERD para o primeiro estágio é a seguinte: $2-9-1-6-4-3-5-7-8$. Do segundo estágio em diante, a LPT1_ERD considera a ordenação pela regra $E R D$. Assim, no estágio 2 a sequência é: $3-5-7-8-9-2-1]-6-4$.

Conforme ilustrado na Figura 4.4, a tarefa 3, que salta o estágio 1 e visita o estágio 2, pode ser programada na data zero, ou seja, não precisa esperar até que todas as tarefas do estágio 1 sejam processadas, como acontecia na ordenação pela regra LPT1. Como o estágio 2 possui apenas uma máquina, a tarefa 8 , a próxima da sequência que visita o estágio e que também salta o estágio 1, é programada imediatamente após a tarefa 3. As tarefas seguintes que visitam o estágio 2 (tarefas 2 e 4) são programadas em sequência, respeitando as suas datas de liberação (término no estágio 1).

No terceiro estágio, a programação segue a mesma ideia do segundo: o sequenciamento é feito pela regra $E R D$ e a alocação à máquina de menor carga, respeitando a sua data de liberação.

É importante ressaltar que a data de liberação de uma tarefa que não visita um estágio é igual à sua data de término no último estágio visitado, não necessariamente o estágio imediatamente anterior. Consequentemente, como tal tarefa tem tempos de pro- 
cessamento e de setup nulos no estágio não visitado, sua data de término no estágio é igual à data de liberação $\left(r_{j k}=C_{j k}\right.$, para $\left.j \notin V_{k}\right)$.

Como isso ocorre recursivamente nos estágios, pode-se escrever sem perda de generalidade que $r_{j k}=\mathrm{C}_{j(k-1)}$, onde $r_{j 1}=0$, com $j \in J$ e $k \in G \backslash\{1\}$, pois se a tarefa $j$ não visitar o estágio $k-1$, a data $\mathrm{C}_{j(k-1)}$ já equivalerá à data de término do último estágio visitado, conforme a análise de cada caso a seguir: se a tarefa $j$ visita ambos os estágios $k-1$ e $k$, a expressão respeita a definição do problema e das variáveis. Se a tarefa $j$ visita o estágio $k-1$ e não visita $k$, a expressão é válida porque a data de liberação em $k\left(r_{j k}\right)$ não é afetada, ou seja, $r_{j k}=\mathrm{C}_{j k} \Leftrightarrow r_{j k}=$

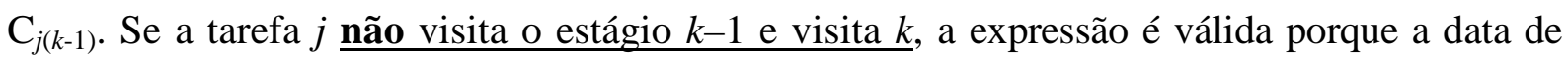
término em $k-1\left(\mathrm{C}_{j(k-1)}\right)$ não é afetada, ou seja, $C_{j(k-1)}=r_{j(k-1)} \Leftrightarrow C_{j(k-1)}=r_{j k}$. E assim se a tarefa $j$ $\underline{\text { não visita nem } k-1 \text { nem } k}$, a expressão continua válida, pois $r_{j(k-1)}=\mathrm{C}_{j(k-1)} \Leftrightarrow r_{j k}=\mathrm{C}_{j k} \Leftrightarrow r_{j k}=$ $\mathrm{C}_{j(k-1)}$.

Exemplificando, as datas de liberação das tarefas 1, 6 e 9 no estágio 3 corresponderiam às datas de término no estágio 2 , porém, como elas não visitam o estágio 2 , são consideradas então as datas de término do estágio $1\left(r_{j 3}=C_{j 2}=C_{j 1}\right.$, para $\left.j \notin V_{2}\right)$, conforme pode ser visto na Tabela 4.4. Assim, como também é apresentado na Figura 4.4, a sequência para o estágio 3 é: $5-7-3-9-8-1-2-6-4$. 


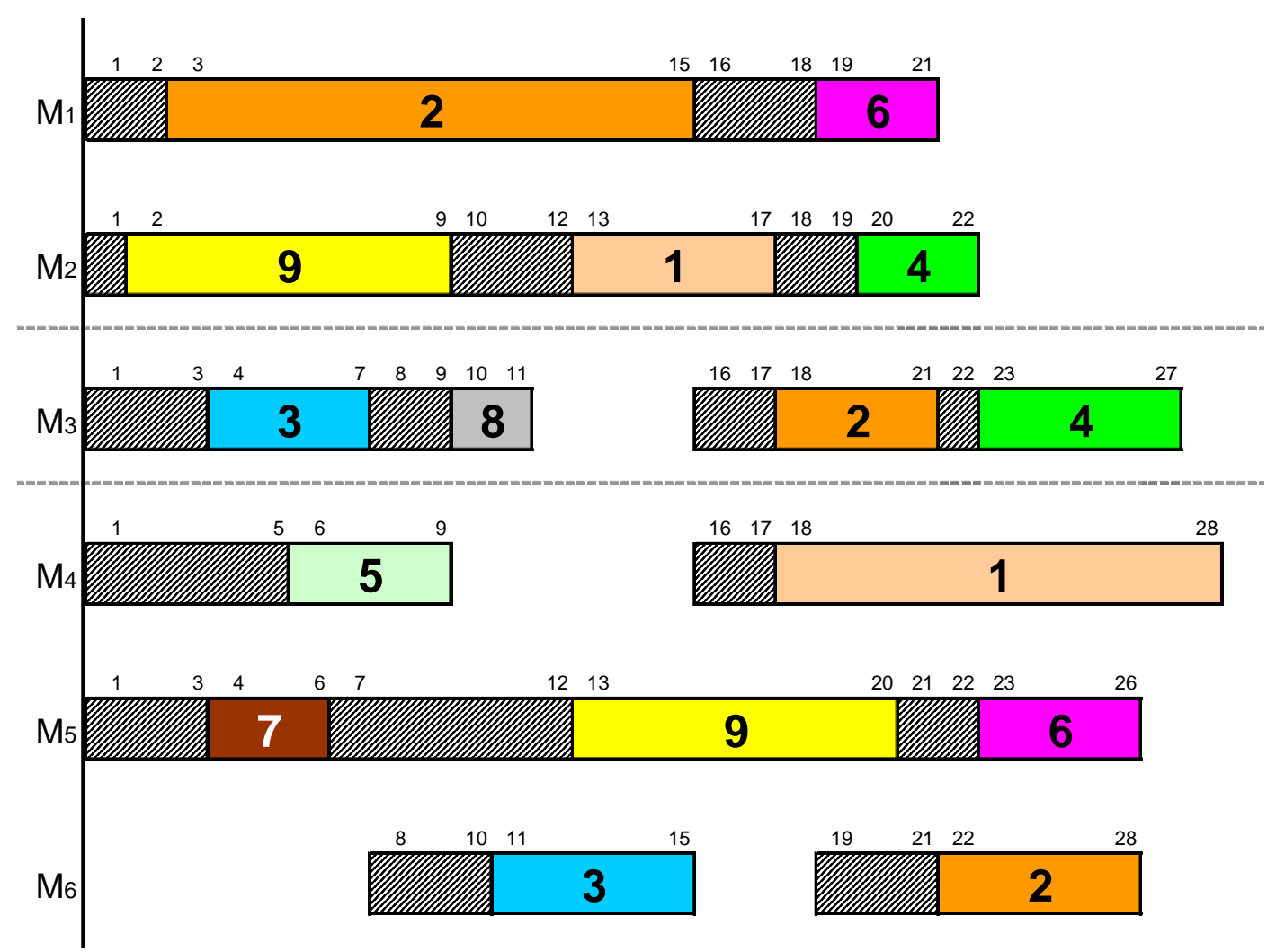

FIGURA 4.4 - Programação definida pela regra LPT1_ERD

Como pode ser visto, a LPT1_ERD não incorpora os efeitos impróprios ao flexible flow line da regra LPT1, mostrando-se aplicável ao ambiente tratado.

Chega-se a uma conclusão análoga para as demais regras derivadas da $L P T$ e que utilizam a $E R D$, ou seja, a LPT2_ERD e a LPT3_ERD que, portanto, também são viáveis para o flexible flow line.

\section{$\checkmark$ Análise funcional da regra ERD}

Nota-se que independentemente da ordenação inicial utilizada no estágio 1, a aplicação da regra $E R D$ nos estágios subsequentes consiste em uma vantagem considerável em relação à medida de desempenho do problema, por conferir maior flexibilidade na programação dos estágios intermediários. Portanto, a regra $E R D$ do segundo estágio em diante mostra-se bastante adequada a este ambiente de produção, uma vez que viabiliza a antecipação 
das tarefas que saltam estágios. Por este motivo, todas as regras que utilizam a ordenação $E R D$ foram consideradas na análise dos resultados.

A seguir é apresentado o algoritmo para a programação das tarefas utilizando as regras de prioridade descritas nesta seção.

\section{Algoritmo para as regras de prioridade para setup independente}

PASSO 1. (ORDENAÇÃO INICIAL) No estágio $k=1$, sequencie as tarefas pela regra de prioridade escolhida no conjunto: $\{$ SPT1, SPT2, LPT2, SPT3, LPT3, SPT1_ERD, LPT1_ERD, SPT2_ERD, LPT2_ERD, SPT3_ERD, LPT3_ERD\}.

PASSO 2. (ALOCAÇÃo INICIAL) Aloque sequencialmente as tarefas no estágio $k=1$ na máquina de menor carga. Faça $k=2$.

PASSO 3. (ATUALIZAÇÃo) Atualize as datas de liberação do estágio $k$ como as datas de término do estágio $k-1$.

PASSO 4. (ORDENAÇÃO DOS ESTÁGIOS $k \geq 2$ )

$\underline{\text { PASSO } 4 a}$. Se a regra de prioridade escolhida estiver entre $\{$ SPT1, SPT3, LPT3 \}, considere a mesma sequência de tarefas do estágio $k=1$.

$\underline{\text { PASSO } 4 b}$. Se a regra de prioridade escolhida for $\{$ SPT2 $\}$ :

- se não for o último estágio $(2 \geq k>g)$, sequencie as tarefas pela ordem não decrescente da soma $\left(s_{j(k+1)}+p_{j(k+1)}\right)$;

- se for o último estágio $(k=g)$, sequencie as tarefas pela ordem não decrescente da soma $\left(s_{j g}+p_{j g}\right)$.

$\underline{P A S S O} 4 c$. Se a regra de prioridade escolhida for $\{$ LPT2 $\}$ : 
- se não for o último estágio $(2 \geq k>g)$, sequencie as tarefas pela ordem não crescente da soma $\left(s_{j(k+1)}+p_{j(k+1)}\right)$;

- se for o último estágio $(k=g)$, sequencie as tarefas pela ordem não crescente da soma $\left(s_{j g}+p_{j g}\right)$.

$\underline{\text { PASSO } 4 d}$. Se a regra de prioridade escolhida estiver entre $\{$ SPT1_ERD, LPT1_ERD, SPT2_ERD, LPT2_ERD, SPT3_ERD, LPT3_ERD\}, sequencie as tarefas pela regra $E R D$.

PASSO 5. (ALOCAÇÃO DOS ESTÁGIOS $k \geq 2$ ) Aloque sequencialmente as tarefas no estágio $k$ na máquina de menor carga, respeitando as datas de liberação das tarefas e desconsiderando a carga das máquinas do estágio anterior. Se for o último estágio $(k=g)$, PARE; senão, faça $k=k+1$ e vá para o PASSO 3.

As onze regras de prioridade para setup independente a serem analisadas experimentalmente estão resumidas na Tabela 4.8 .

TABELA 4.8 - Resumo das regras de prioridade para setup independente

\begin{tabular}{|c|c|c|}
\hline Regra & Valor para ordenação inicial & $\begin{array}{l}\text { Ordenação nos } \\
\text { estágios } 2 \text { a g }\end{array}$ \\
\hline SPT1 & setup + processamento (estágio 1 ) & $\begin{array}{c}\text { mesma ordenação } \\
\text { do estágio } 1\end{array}$ \\
\hline SPT2 & \multirow{2}{*}{ setup + processamento (estágio 2 ) } & \multirow{2}{*}{ variável } \\
\hline LPT2 & & \\
\hline SPT3 & \multirow{2}{*}{ setup + processamento (todos os estágios) } & \multirow{2}{*}{$\begin{array}{l}\text { mesma ordenação } \\
\text { do estágio } 1\end{array}$} \\
\hline LPT3 & & \\
\hline SPT1_ERD & \multirow{2}{*}{ setup + processamento (estágio 1 ) } & \multirow{6}{*}{ ERD } \\
\hline LPT1_ERD & & \\
\hline SPT2_ERD & \multirow{2}{*}{ setup + processamento (estágio 2) } & \\
\hline LPT2_ERD & & \\
\hline SPT3_ERD & \multirow{2}{*}{ setup + processamento (todos os estágios) } & \\
\hline LPT3_ERD & & \\
\hline
\end{tabular}




\subsection{Regras propostas para setup dependente}

Para o problema de programação com setup dependente da sequência, foram definidas treze regras de sequenciamento para as tarefas nos diversos estágios de produção. Tais propostas, assim como para setup independente da sequência de execução das tarefas, baseiam-se nas bem conhecidas regras $S P T$ e $L P T$, bem como em adaptações de ideias e de heurísticas apresentadas por Gupta e Tunc (1994), Li (1997), Kurz e Askin (2004), Jungwattanakit et al. (2008), Urlings, Ruiz e Şerifoğlu (2008) e Ruiz, Şerifoğlu e Urlings (2008).

Além disso, as regras propostas já incorporam alguns resultados experimentais preliminares que foram obtidos para as regras com setup independente. Por exemplo, aqui não será aplicada a mesma ordenação em todos os estágios, mas a ordenação ERD do segundo estágio em diante. Assim, todas as regras são viáveis para a programação do flexible flow line.

Segundo Jungwattanakit et al. (2008), que propôs algoritmos para flexible flow line com setup dependente e máquinas paralelas não relacionadas, a ordenação $E R D$ minimiza a variação nos tempos de espera das tarefas em uma máquina.

A política de alocação empregada foi a ECT (Earliest Completion Time), em que a tarefa é programada na máquina que completa o seu processamento mais cedo. Além da diferença na carga das máquinas, a variabilidade na data de término das tarefas em um estágio acontece pela característica do setup ser dependente da sequência. No ambiente em que o setup é independente da sequência, por exemplo, a tarefa terminará o processamento mais cedo na máquina de menor carga.

Das treze regras de prioridade definidas, seis baseiam-se na regra $S P T$, outras seis na $L P T$ e a última é uma regra de ordenação aleatória no primeiro estágio, utilizada como parâmetro de comparação. As regras baseadas na $S P T$ e na $L P T$ diferenciam-se apenas pelo valor 
considerado para a ordenação, mantendo evidentemente a sequência não decrescente e a não crescente, respectivamente.

Os valores considerados para cada tarefa $j$ nas regras de prioridade são apresentados a seguir:

- SPT1 e LPT1: média dos tempos de setup das tarefas $i$ para a tarefa $j$ no primeiro estágio somada ao tempo de processamento de $j\left(\frac{\sum_{i \in V_{1} \cup\{0\}, i \neq j} s_{i j 1}}{v_{1}}+p_{j 1}\right)$. Estas regras focalizam a carga de trabalho inicial (primeiro estágio).

Observação: os tempos de setup das tarefas $i$ para $j$, desconsiderando $i \neq j$ e considerando o setup da tarefa 0 para a tarefa $j$, totalizam $v_{1}$ valores para o cálculo da média.

- SPT2 e LPT2: média dos tempos de setup das tarefas $i$ para a tarefa $j$ no segundo estágio somada ao tempo de processamento também do segundo estágio $\left(\frac{\sum_{i \in V_{2} \cup\{0\}, i \neq j} s_{i j 2}}{v_{2}}+p_{j 2}\right)$.

- SPT3 e LPT3: soma de todos os estágios da média dos tempos de setup das tarefas $i$ para a tarefa $j$ e dos tempos de processamento de $j$ $\left(\sum_{k \in G}\left[\frac{\sum_{i \in V_{k} \cup\{0\}, i \neq j} s_{i j k}}{v_{k}}+p_{j k}\right]\right)$. Estas regras consideram a carga total de trabalho. 
- SPT4 e LPT4: menor tempo de setup das tarefas $i$, que visitam o primeiro estágio, para a tarefa $j$, somado ao tempo de processamento de $j$ no primeiro estágio $\left(\min _{i \in V_{1} \cup\{0\}, i \neq j} s_{i j 1}+p_{j 1}\right)$. São regras otimistas, considerando que a carga de trabalho do primeiro estágio será a menor possível.

- SPT5 e LPT5: soma de todos os estágios do menor tempo de setup das tarefas $i$ para a tarefa $j$, que visitam o estágio, e dos tempos de processamento de $j$ $\left(\sum_{k \in G}\left[\min _{i \in V_{k} \cup\{0\}, i \neq j} s_{i j k}+p_{j k}\right]\right)$. São regras extremamente otimistas, considerando que a carga total de trabalho será a menor possível.

- SPT6 e LPT6: menor tempo de setup para a tarefa $j$ no segundo estágio, caso tal setup não seja antecipado, somado ao tempo de processamento também no segundo estágio; se tal setup for antecipado, considera-se apenas o tempo de processamento de $j\left(\left(1-A_{i j 2}\right) \min _{i \in V_{2} \cup\{0\}, i \neq j} s_{i j 2}+p_{j 2}\right)$. Estas regras diferenciam-se por considerarem uma característica do ambiente estudado (presença do setup antecipado). Salienta-se que neste problema os setups do primeiro estágio são todos não antecipados. Portanto, para considerar a presença de setup antecipado numa regra, é preciso utilizar os tempos do estágio subsequente ao primeiro.

- RAND: ordenação aleatória no primeiro estágio, considerada para efeito de comparação com as regras estruturadas. 


\section{Algoritmo para as regras de prioridade com setup dependente}

$\underline{\underline{\text { PASSO 1. }}}$. (ORDENAÇÃO INICIAL) No estágio $k=1$, sequencie as tarefas pela regra de prioridade escolhida no conjunto: \{SPT1, LPT1, SPT2, LPT2, SPT3, LPT3, SPT4, LPT4, SPT5, LPT5, SPT6, LPT6, RAND\}.

$\underline{\underline{P A S S O} 2 .}$ (ALOCAÇÃO INICIAL) Aloque sequencialmente as tarefas no estágio $k=1$ na máquina que completa o processamento mais cedo $(E C T)$. Faça $k=2$.

$\underline{\underline{P A S S O} 3}$. (ATUALIZAÇÃO) Atualize as datas de liberação do estágio $k$ como as datas de término do estágio $k-1$.

PASSO 4. (ORDENAÇÃO DOS ESTÁGIOS $k \geq 2$ ) Sequencie as tarefas pela regra ERD.

$\underline{\underline{P A S S O} 5}$. (ALOCAÇÃO DOS ESTÁGIOS $k \geq 2$ ) Aloque sequencialmente as tarefas no estágio $k$ na máquina que completa o processamento mais cedo $(E C T)$, respeitando as datas de liberação das tarefas e desconsiderando a carga das máquinas do estágio anterior. Se for o último estágio $(k=g)$, PARE; senão, faça $k=k+1$ e vá para o PASSO 3.

As treze regras de prioridade para setup dependente estão resumidas na Tabela 4.9.

TABELA 4.9 - Resumo das regras de prioridade para setup dependente

\begin{tabular}{|c|c|c|}
\hline Regra & Valor para ordenação inicial & $\begin{array}{l}\text { Ordenação nos } \\
\text { estágios } 2 \text { a g }\end{array}$ \\
\hline SPT1 e LPT1 & setup médio + processamento (estágio 1) & \multirow{7}{*}{ ERD } \\
\hline SPT2 e LPT2 & setup médio + processamento (estágio 2 ) & \\
\hline SPT3 e LPT3 & $\begin{array}{c}\text { setup médio }+ \text { processamento (todos } \\
\text { os estágios) }\end{array}$ & \\
\hline SPT4 e LPT4 & menor setup + processamento (estágio 1 ) & \\
\hline SPT5 e LPT5 & $\begin{array}{c}\text { menor setup }+ \text { processamento (todos } \\
\text { os estágios) }\end{array}$ & \\
\hline SPT6 e LPT6 & $\begin{array}{c}\text { menor setup (se não antecipado) + } \\
\text { processamento (estágio } 2 \text { ) }\end{array}$ & \\
\hline RAND & ALEATÓRIA & \\
\hline
\end{tabular}




\title{
5 HEURÍSTICAS PROPOSTAS
}

\author{
"Um raciocínio lógico leva você de A a B. Imaginação \\ o leva a qualquer lugar que você quiser."
}

Albert Einstein

\subsection{Importância dos métodos heurísticos}

Segundo Pearl (1984, p.3), heurísticas são critérios, métodos ou princípios para decidir qual, dentre muitas alternativas de ação, aparenta ser a melhor para atingir um determinado objetivo. Como afirma Colin (2007, p.371), elas têm basicamente dois objetivos: serem simples e diferenciarem boas e más ações para alcançar bons resultados.

Com o aumento da complexidade dos problemas de programação da produção, é muito comum se utilizar métodos de solução heurística. Principalmente para problemas classificados como "difíceis", cuja busca da solução ótima seja inviável computacionalmente, procuram-se desenvolver procedimentos "inteligentes" que forneçam soluções tão boas quanto possíveis.

Um grande número de problemas práticos encontrados no mundo real é do tipo $N P$ hard. Eis a importância do estudo e desenvolvimento de heurísticas eficazes e eficientes.

Como afirmou Moursli (1999, p.56), o problema de minimização do makespan em flow shop híbrido mesmo sem setup relevante (ou com setup incluído no tempo de processamento da tarefa) é classificado como NP-hard. Por este motivo, um dos principais objetivos 
desta pesquisa foi desenvolver um conjunto de heurísticas que permitam encontrar a melhor solução possível para o problema tratado.

Existem diferentes formas de se criar uma heurística, utilizando diferentes critérios para estabelecer a programação dos estágios de produção e diversas regras de sequenciamento e alocação para as tarefas nos estágios. Com base no estudo das características do ambiente estudado e em algoritmos reportados na literatura, foram elaborados quinze métodos de solução heurística para os dois problemas analisados.

Nas próximas seções, serão descritos os algoritmos heurísticos para ambos os problemas tratados neste trabalho - com setup independente (Problema I) e dependente (ProbleMA II).

\subsection{Heurísticas propostas para setup independente}

Para o problema de programação com setup independente da sequência, foram propostos seis métodos heurísticos, que serão apresentados a seguir. Com exceção da heurística Hi4, todas seguem a classificação de métodos de decomposição por estágio apresentada por Quadt e Kuhn (2007a). Cada subdivisão do problema é composta por um único estágio, ou seja, um subproblema de máquina única ou de máquinas paralelas. Assim há uma evidente redução da complexidade em relação ao problema original.

Cada estágio é composto por um subconjunto de tarefas que o visitam $\left(V_{k} \subseteq J\right)$ e é programado individual e consecutivamente. A interdependência entre os estágios está no fato da data de término das tarefas de um estágio equivaler à data de liberação das mesmas no estágio seguinte $\left(C_{j k}=r_{j(k+1)}\right)$. Assim, do primeiro ao penúltimo estágio, a medida de desempenho sugerida em algumas heurísticas é a de minimização da soma das datas de térmi- 
no das tarefas do estágio, que corresponde ao esforço para antecipar as datas de liberação das tarefas no estágio seguinte ( $\min \Sigma C_{j k} \Leftrightarrow \min \Sigma r_{j(k+1)}$ ), visando minimizar o makespan do problema original.

Por outro lado, a heurística Hi4 é classificada como método de decomposição por tarefa, pois a cada iteração uma tarefa é selecionada e associada a uma máquina em cada um dos estágios, ou seja, o sequenciamento e a alocação são feitos simultaneamente.

\section{- Heurística Hi1}

A ideia intrínseca à heurística Hil é priorizar a cada estágio as tarefas que terminam sua execução mais cedo para assim terem a menor data de liberação possível no estágio seguinte, conforme descrito anteriormente. No primeiro estágio, como todas as tarefas já estão liberadas $\left(r_{j 1}=0, \forall j\right)$ e não há setup antecipado $\left(A_{j 1}=0, \forall j\right)$, tal situação ocorre alocando-se na máquina de menor carga as tarefas sequenciadas pela regra $S P T$ considerando a soma $s_{j 1}+p_{j 1}$. Esta regra poderia ser denotada por SPST (Shortest Processing + Setup Time).

Com o setup independente da sequência e considerando-o somado ao tempo de processamento, o primeiro estágio equivale ao problema de máquinas paralelas com minimização do tempo médio de fluxo ( $P \| \bar{F}$ com $r_{j}=0, \forall j$ ). O algoritmo de solução ótima para este problema, que consta em Baker (1974, p.119), é bem conhecido e será apresentado a seguir. 


\section{Algoritmo de solução ótima para o problema $P \| \bar{F} \operatorname{com} r_{j}=0, \forall j$}

$\underline{\underline{P A S S O} 1 .}$. Ordene as tarefas pela regra SPT.

$\underline{\underline{P A S S O}}$. Aloque uma tarefa de cada vez à máquina de menor carga.

Nos estágios posteriores ao primeiro, como as datas de liberação das tarefas são diferentes de zero, considerar apenas a máquina de menor carga não garante uma boa programação. Portanto, dentre as tarefas que visitam o estágio e que ainda não foram programadas nele, o algoritmo verifica todas as possibilidades de alocação tarefa-máquina e escolhe a que leve à menor data de término. Tal procedimento constitui uma forma mais abrangente de utilizar a regra ECT (Earliest Completion Time).

\section{Algoritmo Hi1}

$\underline{\underline{P A S S O} 1}$. No estágio $k=1$, sequencie as tarefas pela ordem não decrescente da soma $\left(s_{j 1}+p_{j 1}\right)$ e aloque uma tarefa de cada vez à máquina de menor carga. Faça $k=2$.

$\underline{\underline{P A S S O} 2}$. Atualize as datas de liberação do estágio $k$ como as datas de término do estágio $k-1$.

$\underline{\underline{P A S S O} 3}$. Analise todas as possibilidades de alocação tarefa-máquina e escolha a opção com a menor data de término.

$\underline{\underline{P A S S O}}$. Repita o PASSO 3 até que todas as tarefas que visitam o estágio $k$ estejam programadas.

$\underline{\underline{P A S S O} 5}$. Se for o último estágio $(k=g)$, PARE; senão, faça $k=k+1$ e vá para o PASSO 2. 


\section{- $\underline{\text { Heurística Hi2 }}$}

A heurística Hi2 consiste numa modificação da Hil, alterando apenas a programação do último estágio, em que é aplicada uma adaptação do método de inserção denominado $M u l$ tiple Insertion, apresentado por Kurz e Askin (2001b). Tal método de inserção é transcrito a seguir.

\section{Algoritmo Multiple Insertion (MI)}

$\underline{\underline{P A S S O} \text { 1. }}$. Crie os tempos de processamento modificados: $p_{i k}^{\prime}=p_{i k}+\min _{j \in V_{k}, i \neq j} s_{i j k}$.

$\underline{\underline{P A S S O} 2}$. Sequencie as tarefas pela ordem não crescente dos tempos $p_{i k}^{\prime}$.

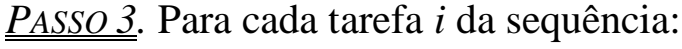

(3a) Insira a tarefa $i$ em toda posição possível em cada máquina

(3b) Utilizando os tempos de setup e os tempos de processamento originais, calcule o makespan parcial para cada inserção da tarefa $i$

(3c) Aloque a tarefa $i$ na posição e na máquina com o menor makespan parcial.

O makespan parcial consiste na duração total da programação de um subconjunto de tarefas já alocadas até um estágio genérico $k$, com $1 \leq k \leq g$. Ou seja, é a diferença entre a maior data de término das tarefas já programadas e a menor data de liberação no primeiro estágio (que é adotada igual a zero).

Como os autores aplicaram esse algoritmo ao problema com setup dependente da sequência, um comentário mais detalhado em comparação com o presente trabalho será apresentado na seção 5.3. 
Para o problema com setup independente, foram utilizados como "tempos de processamento modificados" a soma dos tempos de processamento e de setup do último estágio $\left(s_{j g}+p_{j g}\right)$, ou seja, do estágio em que o algoritmo $M I$ é aplicado.

\section{Algoritmo Hi2}

$\underline{\underline{P A S S O} 1}$. No estágio $k=1$, sequencie as tarefas pela ordem não decrescente da soma $\left(s_{j 1}+p_{j 1}\right)$ e aloque uma tarefa de cada vez à máquina de menor carga. Faça $k=2$.

$\underline{\underline{P A S S O} 2}$. Atualize as datas de liberação do estágio $k$ como as datas de término do estágio $k-1$.

$\underline{\underline{P A S S O} 3}$. Analise todas as possibilidades de alocação tarefa-máquina e escolha a opção com a menor data de término.

$\underline{\underline{P A S S O} 4}$. Repita o PASSO 3 até que todas as tarefas que visitam o estágio $k$ estejam programadas.

$\underline{\underline{P A S S O} 5}$. Se $k<g$, faça $k=k+1$ e vá para o PASSO 2; senão $(k=g)$, vá para o PASSO 6.

$\underline{\underline{P A S S O} 6}$. Sequencie as tarefas pela ordem não crescente da soma $\left(s_{j g}+p_{j g}\right)$ e para cada tarefa $j$ da sequência:

(6a) Insira a tarefa $j$ em toda posição possível em cada máquina do estágio $g$

(6b) Considerando as datas de liberação e os tempos de setup e de processamento, calcule o makespan parcial para cada inserção da tarefa $j$

(6c) Aloque a tarefa $j$ na posição e na máquina com o menor makespan parcial. 


\section{- Heurística Hi3}

A heurística Hi3 aplica o método de inserção $M I$ em todos os estágios, evidentemente com as devidas adaptações. A primeira adequação é a mesma efetuada na heurística Hi2 em relação aos tempos de processamento modificados; aqui também será considerada a soma dos tempos de processamento e de setup $\left(s_{j k}+p_{j k}\right)$ de cada estágio $k$ programado.

Uma outra importante adaptação é o fato de se considerar a soma das datas de término do estágio como medida de desempenho dos estágios anteriores ao último $(k<g)$. Como já salientado, esta função objetivo envida esforços no sentido de liberar o quanto antes as tarefas no estágio seguinte.

O último estágio tem implícita a vantagem de se manter a função objetivo original do problema, ou seja, a duração total da programação (makespan).

\section{Algoritmo Hi3}

PASSO 1. (INICIALIZAÇÃO) Faça $k=1$.

$\underline{\underline{P A S S O} 2}$. No estágio $k$, sequencie as tarefas pela ordem não crescente da soma $\left(s_{j k}+p_{j k}\right)$ e para cada tarefa $j$ da sequência:

(1a) Insira a tarefa $j$ em toda posição possível em cada máquina do estágio $k$

(1b) Considerando as datas de liberação e os tempos de setup e de processamento, calcule o soma das datas de término para cada inserção da tarefa $j$

(1c) Aloque a tarefa $j$ na posição e na máquina com a menor soma das datas de término. 
$\underline{\underline{P A S S O} 3}$. Faça $k=k+1$. Atualize as datas de liberação do estágio $k$ como as datas de término do estágio $k-1$.

$\underline{\underline{P A S S O} 4}$. Se $k<g$, vá para o PASSO 2; senão $(k=g)$, vá para o PASSO 5.

$\underline{\underline{P A S S O} 5}$. Sequencie as tarefas pela ordem não crescente da soma $\left(s_{j g}+p_{j g}\right)$ e para cada tarefa $j$ da sequência:

(4a) Insira a tarefa $j$ em toda posição possível em cada máquina do estágio $g$

(4b) Considerando as datas de liberação e os tempos de setup e de processamento, calcule o makespan parcial para cada inserção da tarefa $j$

(4c) Aloque a tarefa $j$ na posição e na máquina com o menor makespan parcial.

\section{- Heurística Hi4}

A heurística Hi4 possui um diferencial em relação às demais: a sua definição como método de decomposição por tarefa, segundo a classificação de Quadt e Kuhn (2007a), e por este motivo, o seu procedimento será ilustrado logo adiante.

Cada tarefa selecionada é alocada em todos os estágios antes da seleção da próxima tarefa, diferentemente da programação de todas as tarefas em um estágio de cada vez. Ou seja, a programação é feita por tarefa e não por estágio.

Os valores utilizados no sequenciamento das tarefas são as somas de todos os estágios dos tempos de processamento e de setup quando não antecipados $\left(\sum_{k=1}^{g}\left[\left(1-A_{j k}\right) s_{j k}+p_{j k}\right]\right)$.

Considerando os dados do problema exemplo da seção 3.5, a Tabela 5.1 apresenta os valores de ordenação utilizados pela heurística Hi4. 
TABELA 5.1 - Valores de ordenação para programação pela heurística Hi4

\begin{tabular}{|c|c|c|c|c|c|c|c|c|c|}
\hline Tarefa $\boldsymbol{j}$ & $\mathbf{1}$ & $\mathbf{2}$ & $\mathbf{3}$ & $\mathbf{4}$ & $\mathbf{5}$ & $\mathbf{6}$ & $\mathbf{7}$ & $\mathbf{8}$ & $\mathbf{9}$ \\
\hline$\sum_{k=1}^{g}\left[\left(1-A_{j k}\right)_{j k}+p_{j k}\right]$ & 19 & 26 & 12 & 10 & 9 & 10 & 7 & 4 & 17 \\
\hline
\end{tabular}

Pela ordem não crescente destes valores, a sequência de tarefas fica: $2-1-9-3-4-$ 6-5 - 7 - 8. A tarefa 2 será então programada em cada um dos três estágios, tal como aparece na Figura 5.1.

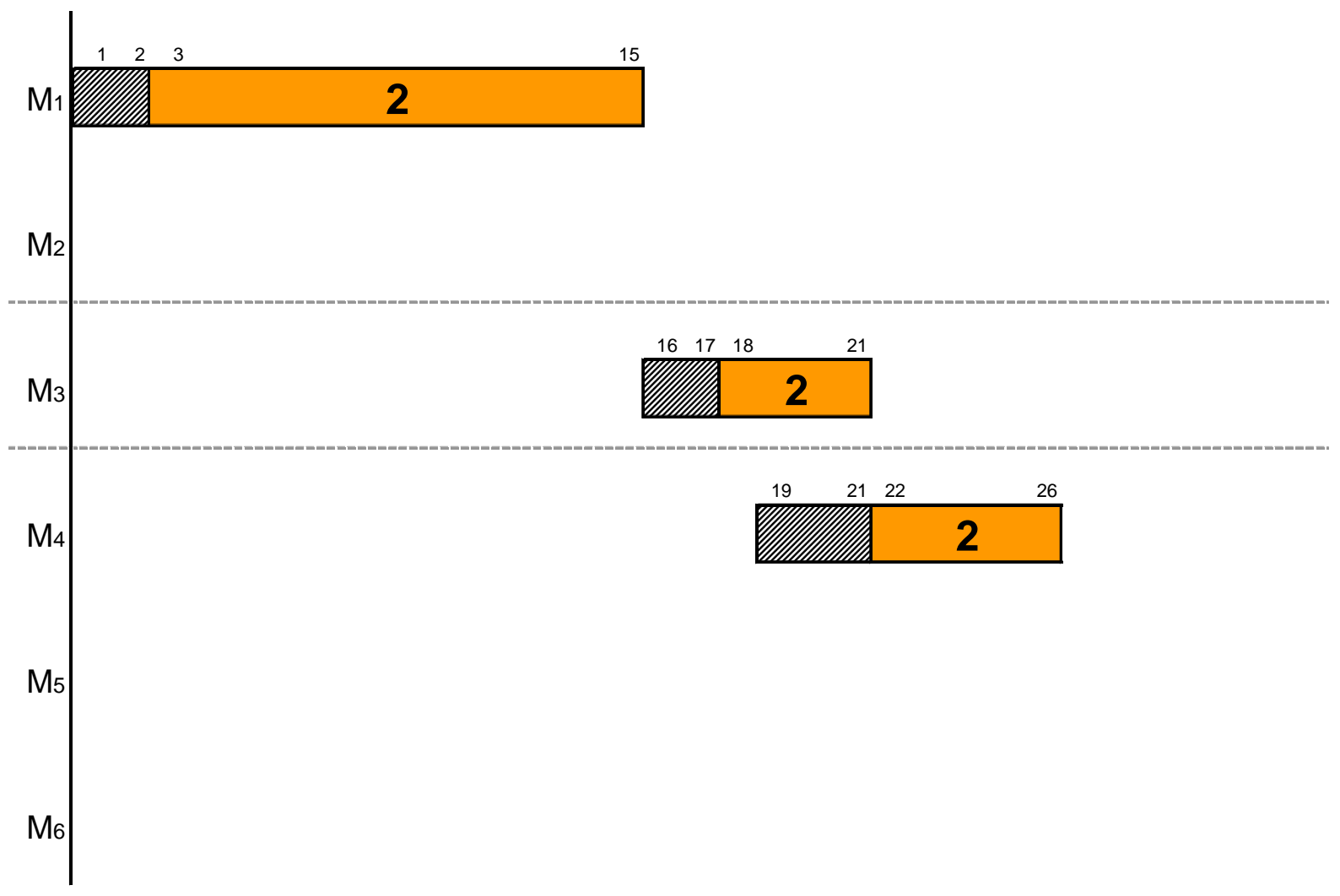

FIGURA 5.1 - Programação da primeira tarefa pela heurística Hi4

A segunda tarefa da sequência é a 1, que visita os estágios 1 e 3 e portanto será alocada em ambos, na data mais cedo possível, conforme a Figura 5.2. E em seguida, a tarefa 9 também será programada nos estágios que visita (1 e 3). 


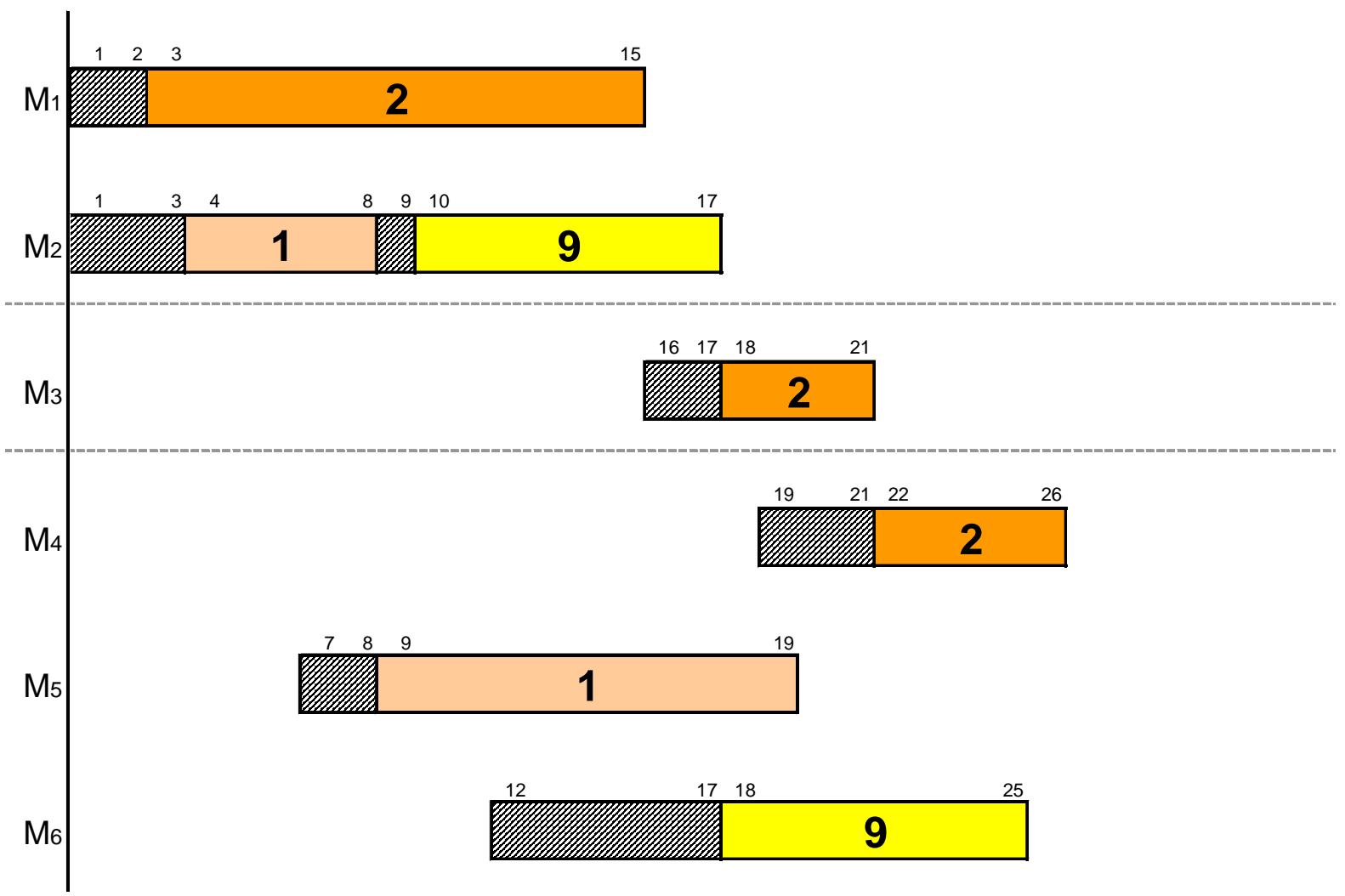

FIGURA 5.2 - Programação da segunda e da terceira tarefas pela heurística Hi4

Assim, sequencial e sucessivamente as tarefas serão programadas nos estágios em que visitam, sem precisar programar primeiro todas as tarefas que visitam o estágio 1 e só então todas as tarefas que visitam o estágio 2. A tarefa que está sendo programada é inserida em todas as posições possíveis do estágio e alocada naquela com o menor valor do makespan parcial.

A programação completa pela heurística Hi4 é mostrada na Figura 5.3. 


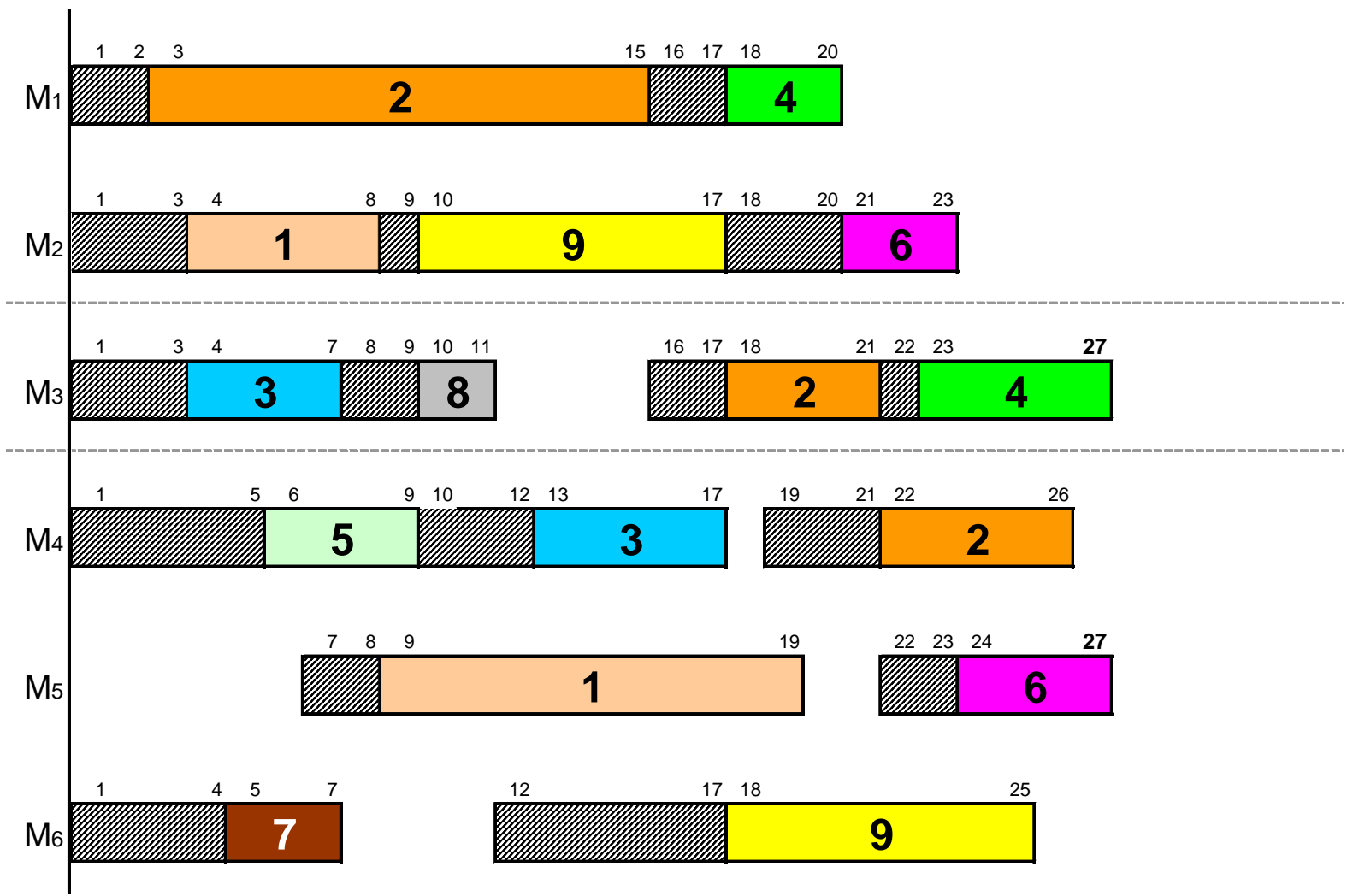

FIGURA 5.3 - Programação pela heurística Hi4

\section{Algoritmo Hi4}

$\underline{\underline{P A S S O} 1}$. Sequencie as tarefas pela ordem não crescente do valor $\sum_{k=1}^{g}\left[\left(1-A_{j k}\right) s_{j k}+p_{j k}\right]$ e aloque a primeira tarefa da sequência em cada um dos estágios iniciando na data mais cedo possível. Faça $k=1$.

$\underline{\underline{P A S S O}}$. Insira a próxima tarefa da sequência em toda posição possível em cada máquina do estágio $k$.

$\underline{\underline{P A S S O} 3}$. Considerando as datas de liberação e os tempos de setup e de processamento, para cada inserção da tarefa, calcule o makespan parcial. Caso haja mais de uma inserção com o mesmo valor do makespan parcial, o desempate será fei- 
to pela menor soma das datas de término do estágio. Guarde a posição e a máquina com o menor valor encontrado.

$\underline{\underline{P A S S O} 4}$. Aloque a tarefa na posição e na máquina do estágio $k$ com o menor valor encontrado.

$\underline{\underline{P A S S O} 5}$. Se $k<g$, faça $k=k+1$ e insira a mesma tarefa em toda posição possível em cada máquina do novo estágio $k$ e vá para o PASSO 3; senão $(k=g)$, vá para o PASso 6.

$\underline{\underline{P A S S O}}$. Se todas as tarefas já estiverem programadas, PARE; senão, faça $k=1$ e vá para o PASSO 2.

\section{- Heurística Hi5}

Analogamente à heurística Hi1, que considera o primeiro estágio do ambiente tratado como um problema de máquinas paralelas com minimização do tempo médio de fluxo ( $P \| \bar{F}$ com $r_{j}=0, \forall j$ ), existe também um conhecido algoritmo para minimização do tempo médio de fluxo dado que o makespan seja ótimo ( $P \| \bar{F}$ com $C_{\text {max }}^{*}$ e $r_{j}=0, \forall j$ ). O algoritmo heurístico para este problema consta em Morton e Pentico (1993, p.252) e será apresentado a seguir.

Algoritmo de solução heurística para o problema $P \| \bar{F} \operatorname{com} C_{\max }^{*}$ e $r_{j}=0, \forall j$

$\underline{\underline{P A S S O} 1 .}$. Ordene as tarefas pela regra LPT.

$\underline{\underline{P A S S O} 2}$. Aloque uma tarefa de cada vez à máquina de menor carga.

$\underline{\underline{P A S S O} 3}$. Reordene as tarefas de cada máquina segundo a regra SPT. 
A heurística Hi5 utiliza esta mesma ideia considerando para a ordenação a soma $s_{j k}+p_{j k}$ em cada estágio programado. Nos estágios $k>=2$, as datas de liberação são desconsideradas na alocação das tarefas visando equilibrar a carga de trabalho das máquinas do estágio, criando assim uma programação provisória. As datas de liberação são consideradas apenas na etapa de reordenação das tarefas de cada máquina, quando ocorre a programação definitiva.

\section{Algoritmo Hi5}

$\underline{\underline{P A S S O} 1}$. No estágio $k=1$, sequencie as tarefas pela ordem não crescente da soma $\left(s_{j 1}+p_{j 1}\right)$ e aloque uma tarefa de cada vez à máquina de menor carga.

$\underline{\underline{P A S S O} 2}$. Reordene as tarefas de cada máquina do estágio 1 pela ordem não decrescente da soma $\left(s_{j 1}+p_{j 1}\right)$. Faça $k=2$.

$\underline{\underline{P A S S O} 3}$. No estágio $k$, sequencie as tarefas pela ordem não crescente da soma $\left(s_{j k}+p_{j k}\right)$ e distribua uma tarefa de cada vez à máquina de menor carga do estágio $k$ desconsiderando as datas de liberação das tarefas (como se fosse $r_{j k}=0, \forall j$ ).

$\underline{\underline{P A S S O}}$. Reordene as tarefas de cada máquina do estágio $k$ pela ordem não decrescen-

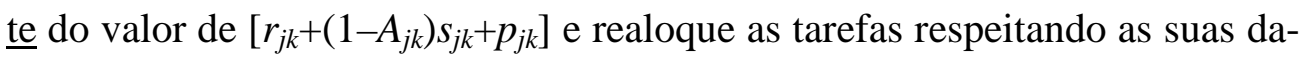
tas de liberação e a carga das máquinas.

$\underline{\underline{P A S S O} 5}$. Se for o último estágio $(k=g)$, PARE; senão, faça $k=k+1$ e vá para o PASSO 3.

\section{- $\underline{\text { Heurística Hi6 }}$}

Neste estudo foi utilizado também um método de programação aleatório que serve como base para comparar as heurísticas propostas, assim como foi feito por Moursli (1999). 
As heurísticas aleatórias são rápidas e fáceis de implementar e são denominadas "heurísticas de lista" (list heuristics). Elas procedem em duas etapas: construção de uma lista ordenada de tarefas e associação das tarefas às máquinas (MOURSLI, 1999, p.69).

Primeiramente, é gerada uma lista associando um valor aleatório a cada tarefa e, em seguida, as tarefas são sequenciadas pela ordem não decrescente desses respectivos valores. Na segunda etapa, as tarefas são alocadas sequencialmente às máquinas selecionadas por meio da geração de um número aleatório compreendido no intervalo dos índices das máquinas do estágio.

\section{Algoritmo Hi6}

PASSO 1. (INICIALIZAÇÃO) Faça $k=1$.

$\underline{\underline{P A S S O} 2}$. No estágio $k$, associe números aleatórios às tarefas que o visitam e sequencieas pela ordem não decrescente destes valores.

$\underline{\underline{P A S S O} 3}$. Aloque sequencialmente cada tarefa à máquina selecionada por meio da geração de um número aleatório compreendido no intervalo dos índices das máquinas do estágio $k$.

$\underline{\underline{P A S S O} 4}$. Repita o PASSO 3 até que todas as tarefas estejam programadas no estágio $k$.

PASSO 5. Se for o último estágio $(k=g)$, PARE; senão, faça $k=k+1$ e vá para o PASSO 2.

As seis heurísticas para o problema com setup independente definidas nesta seção estão resumidas na Tabela 5.2: 
TABELA 5.2 - Resumo dos algoritmos heurísticos para setup independente

\begin{tabular}{|c||c|c|c|}
\hline Método & $\begin{array}{c}\text { Primeiro } \\
\text { estágio }\end{array}$ & $\begin{array}{c}\text { Estágios } \\
\text { intermediários }\end{array}$ & $\begin{array}{c}\text { Último } \\
\text { estágio }\end{array}$ \\
\hline \hline $\mathrm{Hi} 1$ & SPST & $\mathrm{ECT}$ \\
\hline $\mathrm{Hi} 2$ & SPST & $\mathrm{ECT}$ & $\mathrm{MI}$ \\
\hline $\mathrm{Hi} 3$ & \multicolumn{2}{|c|}{$\mathrm{MI}_{\Sigma F}$} \\
\hline $\mathrm{Hi} 4$ & \multicolumn{3}{|c|}{$\mathrm{MI}$ (decomposição por tarefa) } \\
\hline $\mathrm{Hi} 5$ & \multicolumn{3}{|c|}{ LPST e SPST } \\
\hline $\mathrm{Hi} 6$ & \multicolumn{3}{|c|}{ ALEATÓRIA } \\
\hline
\end{tabular}

\subsection{Heurísticas propostas para setup dependente}

Nesta seção, serão descritos os métodos heurísticos construtivos para setup dependente, que seguem a classificação de métodos de decomposição por estágio apresentada por Quadt e Kuhn (2007a). O problema original é dividido em $g$ subproblemas iterativos, correspondentes aos estágios de produção e podendo conter uma única máquina ou várias máquinas paralelas idênticas.

\section{- Heurística Hd1}

Do primeiro ao penúltimo estágio $(1 \leq k<g)$, a heurística Hd1 associa uma tarefa de cada vez às máquinas do estágio em que se está programando, sem utilizar uma sequência inicial pré-determinada. $\mathrm{O}$ algoritmo verifica todas as possibilidades de alocação tarefamáquina e escolhe a que leve à menor data de término, ou seja, é utilizada a regra $E C T$.

Esta heurística utiliza a proposta citada anteriormente de se considerar a soma das datas de término do estágio como função objetivo para os estágios $k<g$, pois quanto 


\section{antes uma tarefa terminar o seu processamento em um estágio, antes estará liberada para iniciar sua atividade (setup não antecipado ou processamento) no estágio que visi- tará em seguida.}

Assim, pode-se fazer uma adaptação do algoritmo utilizado por Weng, Lu e Ren (2001) para o problema de minimização do tempo de fluxo ponderado no ambiente de máquinas paralelas não relacionadas com tempos de setup dependentes da sequência. Adequando a ideia ao problema tratado neste trabalho, a seguinte expressão foi utilizada para o cálculo da data de término das tarefas $j$ no estágio $k$ sendo programado:

$$
C_{j k}=\max \left[r_{j k}+\left(1-A_{u_{m} j k}\right) s_{u_{m} j k}, C_{u_{m} k}+s_{u_{m} j k}\right]+p_{j k}
$$

Com $j \in V_{k}, k \in G$ e onde $u_{m}$ é a última tarefa de cada máquina $m \in M_{k}$ e $j$ é uma tarefa ainda não programada que visita o estágio $k$. No início da programação, quando nenhuma tarefa foi alocada às máquinas, o índice $u_{m}$ representa a tarefa fictícia inicial $\left(u_{m}=0\right)$.

Para o primeiro estágio $(k=1)$, como todas as tarefas já estão liberadas $\left(r_{j 1}=0\right)$ e nenhum setup é antecipado $\left(A_{u_{m} j 1}=0\right)$, a expressão pode ser simplificada para:

$$
C_{j k}=C_{u_{m} 1}+s_{u_{m} j 1}+p_{j 1}
$$

Na heurística Hd1, além do esforço para antecipar as datas de liberação das tarefas nos estágios anteriores ao último $(k<g)$, no último estágio utiliza-se o algoritmo Multiple Insertion, de Kurz e Askin (2001b), para o problema de minimização do makespan em máquinas paralelas com datas de liberação e setup dependente.

Entre as quatro heurísticas avaliadas por Kurz e Askin (2001b), o algoritmo MI foi o que forneceu o melhor resultado para o problema de máquinas paralelas com setup dependen- 
te. Entretanto, a mesma ideia aplicada ao problema multiestágio (flow shop híbrido), não obteve bom desempenho entre os métodos propostos por Kurz e Askin (2004). Neste último trabalho, o melhor resultado foi alcançado pela meta-heurística random key genetic algorithm. Por este motivo, o algoritmo $M I$ foi aplicado neste trabalho no problema com setup dependente somente no último estágio.

\section{Algoritmo Hd1}

$\underline{\underline{P A S S O} 1}$. Analise todas as possibilidades de alocação tarefa-máquina e escolha a opção com a menor data de término.

$\underline{\underline{P A S S O} 2}$. Repita o PASSO 1 até que todas as tarefas estejam programadas nos estágios de 1 a $g-1$.

$\underline{\underline{P A S S O} 3}$. No último estágio $(k=g)$, aplique o Algoritmo Multiple Insertion.

\section{- Heurísticas Hd2 e Hd3}

As heurísticas Hd2 e Hd3 são adaptações da heurística Hd1 para situações específicas em que existem estágios com apenas uma máquina. Quando todos os estágios possuem máquinas paralelas, as heurísticas $\operatorname{Hd} 1, \operatorname{Hd} 2$ e $\operatorname{Hd} 3$ são idênticas.

Qualquer que seja o estágio com apenas uma única máquina, as heurísticas $\operatorname{Hd} 2$ e $\operatorname{Hd} 3$ resolvem-no como um típico Problema do Caixeiro Viajante (vide seção 2.3). Na literatura, existem diversos métodos de solução para o problema cíclico direcionado do Caixeiro Viajante e, portanto, também para o problema de programação da produção. Assim, a heurística Hd2 aplica o algoritmo FITSP (Farthest Insertion Traveling Salesman Procedure) e a heurística 
Hd3 utiliza o NITSP (Nearest Insertion Traveling Salesman Procedure), ambos descritos a seguir.

\section{Algoritmo FITSP (Farthest Insertion Traveling Salesman Procedure)}

Como descrito por Moccellin (1992, p.29-30), o algoritmo de inserção denominado FITSP escolhe arbitrariamente uma cidade $(s)$ para ser a cidade-base ou o nó inicial da rota, entre as $n$ cidades a serem visitadas. Dentre as $(n-1)$ cidades remanescentes, a próxima cidade ( $p$ ) a ser inserida na rota é determinada por meio de um critério de seleção específico. A partir de então, tem-se uma sub-rota ou um ciclo composto por dois nós ( $s$ e $p$ ). Entre os (n-2) nós remanescentes, um terceiro nó (cidade $q$ ) é selecionado e inserido no ciclo atual. As duas alternativas possíveis de inserção, $(s, \boldsymbol{q}, p, s)$ e $(s, p, \boldsymbol{q}, s)$, são examinadas, sendo escolhida a que corresponde ao menor comprimento total da sub-rota. O processo de inserção continua até que seja obtida uma rota completa.

Rosenkrantz, Stearns e Lewis (1974) comprovaram experimentalmente que o método FITSP fornece melhores resultados tanto quando comparado ao NITSP como à inserção aleatória.

O algoritmo FITSP é constituído por (n-1) iterações:

PASSO 1: Escolha arbitrariamente o nó inicial (tarefa fictícia $J_{0}$ ).

$\underline{\underline{P A S S O} 2}$ : Encontre o próximo nó da sub-rota que tenha a maior distância do nó escolhido anteriormente.

PASSO 3 (PASSO DE SELEÇÃO): Entre os nós ainda não selecionados, escolha o que tenha a maior distância de qualquer nó da sub-rota.

$\underline{\underline{P A S S O} 4}$ (PASSO DE INSERÇÃO): Examine todas as possibilidades de inserção do nó escolhido na sub-rota atual, adotando aquela que leva ao menor comprimento total. 
PASSO 5: Se todos os nós foram inseridos na rota, PARE. Caso contrário, vá para o PASSO 3.

\section{Algoritmo NITSP (Nearest Insertion Traveling Salesman Procedure)}

O algoritmo NITSP é análogo ao procedimento do FITSP, diferenciando apenas no critério de seleção do próximo nó da sub-rota (Passos 2 e 3). O algoritmo NITSP escolhe o nó que tenha a menor distância da sub-rota.

É importante salientar que tanto o algoritmo FITSP como o NITSP escolhem a subrota com o menor comprimento no critério de inserção (Passo 4).

\section{Algoritmo Hd2/Hd3}

$\underline{\underline{\text { PASSO } 1}}$. Nos estágios $k$, de 1 a $g-1$, se $k$ possuir máquinas paralelas, analise todas as possibilidades de alocação tarefa-máquina e escolha a opção com a menor data de término.

Senão, se o estágio $k$ possuir apenas uma máquina, aplique o Algoritmo FITSP (ou NITSP, na Hd3). No Passo de Seleção, considere na matriz de distâncias a soma $r_{j k}+s_{i j k}$, com $i \in V_{k} \cup\{0\}, j \in V_{k}$, e no Passo de Inserção, calcule o comprimento total considerando as datas de liberação das tarefas $\left(r_{j k}\right)$ e a antecipação ou não do setup.

$\underline{\underline{P A S S O}}$ 2. Repita o passo 1 até que todas as tarefas estejam programadas e vá para o PASSO 3.

$\underline{\underline{P A S S O} 3}$. Se o último estágio possuir máquinas paralelas, aplique o Algoritmo Multiple Insertion.

Senão, aplique o Algoritmo FITSP (ou NITSP, na Hd3), tal como no PASSO 1. 
Observação: no passo de inserção dos algoritmos FITSP e NITSP, também se consideram os valores de $r_{j k}$ e $s_{i j k}$ no cálculo do comprimento da sub-rota atual.

\section{-}

A heurística Hd4 utiliza o procedimento desenvolvido por Stinson (STINSON, 1977 apud STINSON; SMITH, 1982) tanto no sequenciamento como na alocação no flexible flow line. Stinson e Smith (1982) adaptaram o Método de Aproximação de Vogel para o sequenciamento do flow shop com setup dependente da sequência. Este método é conhecido pela sua eficácia em fornecer boas soluções iniciais para o problema de transporte.

A heurística de Stinson é utilizada para fornecer uma sequência de tarefas que minimizam o tempo total de setup. Este procedimento também já foi aplicado por Simons Jr. (1992) no flow shop tradicional, por Fuchigami (2005) na ordenação inicial para o flow shop híbrido e por Chen (2008) como uma etapa de melhoria na sua heurística para o problema de máquina única.

O procedimento proposto a partir de Stinson e Smith (1982), Simons Jr. (1992) e Chen (2008) é definido a seguir.

\section{Heurística de Stinson}

$\underline{\underline{P A S S O} 1}$. Construa uma matriz $n \times n$ dos dados de entrada do problema.

$\underline{\underline{P A S S O} 2}$. Calcule a diferença entre os dois menores elementos de cada linha e de cada coluna da matriz. O elemento $(j, j)$, onde $1 \leq j \leq n$, não é considerado. Na etapa 
em que houver apenas um elemento na linha ou coluna, considera-se a diferença igual a zero.

$\underline{\underline{P A S S O} 3}$. Identifique a linha ou a coluna com a maior diferença. Nesta, selecione o elemento $(i, j)$ com o menor valor. Desempate selecionando o elemento que possui o menor valor entre todas as linhas e/ou colunas com a maior diferença.

$\underline{\underline{P A S S O} 4}$. Elimine todos os elementos da linha $i$ e da coluna $j$ e o elemento $(j, i)$.

$\underline{\underline{P A S S O}}$. Repita os PASSOS 2 a 4 até que todas as tarefas estejam programadas.

Os dados de entrada para a construção da matriz podem ser apenas os tempos de setup ou estes tempos somados aos de processamento, ou então utilizar os dados de estágios específicos (apenas do primeiro estágio, todos os estágios etc.). A construção da matriz e os critérios de desempate utilizados durante o algoritmo influenciam no desempenho da heurística.

A programação final considerada por Simons Jr. (1992) é obtida quebrando a sequência circular (ciclo) formada pelas tarefas em cada ponto possível, implementando a programação no flow shop e selecionando a opção em que o makespan é o menor.

Fuchigami (2005) utilizou o algoritmo TOTAL de Simons Jr. (1992) apenas como regra de prioridade para o primeiro estágio, acarretando na separação dos pares de tarefas ao efetuar a alocação às máquinas. Ou seja, a sequência definida não se mantém na programação do flow shop híbrido, servindo apenas para definir a prioridade de alocação das tarefas. Naquele trabalho, também não foi considerado no algoritmo a característica de setup antecipado.

A ideia da heurística Hd4 é utilizar a sequência fornecida pela heurística de Stinson, mantendo juntas as tarefas o máximo possível na alocação. Isto pode ser feito quebrando a sequência de tarefas em " $m_{k}$ ” partes da forma mais equitativa possível, e alocando cada parte a uma máquina do estágio. 
Os métodos construtivos que programam uma tarefa de cada vez podem ser míopes, pois analisam localmente apenas a melhor opção para a tarefa sendo programada. A heurística Hd4, por utilizar matrizes com todos os tempos de setup e processamento, possibilita a análise global e a escolha de bons pares de tarefas.

O objetivo aqui é manter juntos bons pares de tarefas no primeiro estágio e considerar as características específicas do ambiente tratado. Assim, a matriz dos dados de entrada será da ordem $v_{1} \times v_{1}$ (contendo apenas as tarefas que visitam o primeiro estágio) e cada elemento $e_{i j}$ será composto pela soma dos tempos de processamento e de setup não antecipados de todos os estágios $\left(e_{i j}=\sum_{k \in G}\left[p_{j k}+\left(1-A_{i j k}\right) s_{i j k}\right]\right.$, para $\left.i, j \in V_{1}\right)$.

\section{Critério para formação de $m_{k}$ partes equitativas}

Tendo sido definida a sequência completa de tarefas que visitam o primeiro estágio, divide-se o tempo total de fluxo pela quantidade de máquinas do estágio $\left(m_{1}\right)$ e denomina-se esta quantidade de "fração $f$ ".

Todas as tarefas cujas datas de término (ou tempo de fluxo) são inferiores a $f$, serão alocadas na mesma sequência à primeira máquina do estágio. A próxima tarefa da sequência, chamada de "tarefa-limite" será alocada na primeira ou na segunda máquina, dependendo do critério descrito a seguir.

Estabelecendo a fração $f$ como um marco na sequência completa, se a maior parte da carga da tarefa-limite (tempo de setup mais tempo de processamento) ficar à esquerda de $f$, tal tarefa será alocada à primeira máquina, caso contrário, na segunda. Ou seja, se a diferença entre $f$ e o início do setup da tarefa-limite for maior do que a diferença entre o fim da tarefalimite e $f$, então a tarefa-limite será associada à primeira máquina, caso contrário, na segunda máquina. 
Considerando agora na segunda máquina a tarefa fictícia 0 antecedendo a primeira tarefa não programada, calcula-se o novo valor dos tempos de fluxos das tarefas. Da mesma forma, divide-se novamente o tempo total de fluxo pela quantidade de máquinas ainda não programadas, obtendo-se uma nova fração $f$. Verificam-se as tarefas cujas datas de término são inferiores a $f$, alocando-as sequencialmente à primeira máquina ainda não programada e utiliza-se o mesmo critério acima para definir a qual máquina será associada a nova tarefalimite.

Este procedimento é repetido até que as $m_{1}$ partes da sequência original de tarefas sejam alocadas às $m_{1}$ máquinas do primeiro estágio.

\section{Algoritmo Hd4}

$\underline{\underline{P A S S O} 1}$. No primeiro estágio, aplique a heurística de Stinson, considerando a matriz formada pelos elementos $\sum_{k=1}^{g}\left[\left(1-A_{i j k}\right) s_{j k}+p_{j k}\right], \operatorname{com} i, j \in V_{1}$.

$\underline{\underline{P A S S O} 2}$. Quebre a sequência circular obtida em cada ponto possível e selecione a sequência com o menor tempo total de fluxo (considerando a tarefa fictícia inicial e os dados do primeiro estágio) como se fosse um problema de máquina única.

$\underline{\underline{P A S S O ~ 3}}$. Quebre a sequência obtida em $m_{1}$ partes da forma mais equitativa possível e aloque cada parte a uma máquina do primeiro estágio e vá para o estágio 2.

$\underline{\underline{P A S S O}}$. Atualize as datas de liberação como as datas de término do estágio anterior.

$\underline{\underline{P A S S O}}$. Analise todas as possibilidades de alocação tarefa-máquina e escolha a opção com a menor data de término.

PASSO 6. Repita o PASSO 5 até que todas as tarefas do estágio estejam programadas. 
$\underline{\underline{P A S S O} 7}$. Vá para o próximo estágio e repita os PASSOS 4 a 6 até que todos os estágios estejam programados.

\section{- Heurísticas Hd5 e Hd6}

As heurísticas Hd5 e Hd6 efetuam a alocação das tarefas às máquinas a partir de um sequenciamento inicial de tarefas. Para isto, foram utilizadas respectivamente as regras de prioridade para setup dependente LPT3 e LPT5, que obtiveram os melhores desempenhos entre as treze regras descritas no capítulo anterior. Conforme já definido, a LPT3 é a ordem não crescente da soma dos tempos de processamento e da média dos tempos de setup em todos os estágios $\left(\sum_{k \in G}\left[\frac{\sum_{i \in V_{k} \cup\{0\}, i \neq j} s_{i j k}}{v_{k}}+p_{j k}\right]\right)$ e a LPT5 é a ordem não crescente da soma dos tempos de processamento e do menor tempo de setup de cada estágio $\left(\sum_{k \in G}\left[\min _{i \in V_{k} \cup\{0\}, i \neq j} s_{i j k}+p_{j k}\right]\right)$.

Urlings, Ruiz e Şerifoğlu (2008) propuseram e utilizaram nove regras de alocação como esquemas de representação de solução na implementação de algoritmos genéticos. As ideias de algumas dessas regras já foram utilizadas nas heurísticas definidas neste trabalho, como o caso da regra ECT. Outras não são aplicáveis neste estudo pelas diferenças nas características dos ambientes e dos métodos de solução.

As heurísticas Hd5 e Hd6 empregam a regra de alocação Next Job Same Machine $(N J S M)$. Esta regra assume que a tarefa $q$ é associada à mesma máquina que a tarefa $j$ e aloca a tarefa $j$ à máquina em que $q$ termina antes. Assim, é escolhida a máquina que otimiza 
$\min _{m \in M_{k}}\left[C_{i k}+s_{i j k}+s_{j q k}\right]$, uma vez que $p_{j k}$ e $p_{q k}$ são constantes. Salienta-se que apenas a tarefa $j$ é efetivamente alocada.

Urlings, Ruiz e Şerifoğlu (2008) afirmaram que esta regra é útil especialmente se os tempos de setup são relativamente grandes e equivale à regra ECT quando a tarefa $j$ é a última a ser alocada no estágio.

\section{Algoritmo Hd5/Hd6}

$\underline{\underline{P A S S O} 1}$. No primeiro estágio $(k=1)$, sequencie as tarefas pela regra LPT3 (ou LPT5, na Hd6). Vá ao PASso 3.

$\underline{\underline{P A S S O} 2}$. Nos estágios $k$, com $2 \leq k \leq g$, sequencie as tarefas pela regra $E R D$.

$\underline{\underline{P A S S O} 3}$. Associe sequencialmente cada tarefa de acordo com a regra NJSM, ou seja, considerando que as tarefas consecutivas $j$ e $q\left(\operatorname{com} j, q \in V_{k}\right)$ sejam alocadas na mesma máquina, aloque somente a tarefa $j$ à máquina que minimiza $C_{q k}$.

$\underline{\underline{P A S S O}}$. Repita os PASSOS 2 e 3 até que todos os estágios estejam programados.

\section{- Heurística Hd7}

Da mesma forma que para o problema com setup independente, foi também utilizado um método de programação aleatório como base de comparação com as demais heurísticas.

A heurística Hd7 é diferente da regra de prioridade RAND (da seção 4.4) para o problema com setup dependente, pois efetua tanto o sequenciamento como a alocação de forma aleatória. A regra RAND utiliza apenas o sequenciamento inicial aleatório. 
A denominação "heurística Hd7" serve apenas para diferenciar a classe de problemas resolvidos, pois o algoritmo é idêntico ao da heurística Hi6, da seção 5.2 (sendo omitido nesta seção).

As sete heurísticas para o problema com setup dependente definidas nesta seção estão resumidas na Tabela 5.3:

TABELA 5.3 - Resumo dos algoritmos heurísticos para setup dependente

\begin{tabular}{|c||c|c|c|}
\hline Método & $\begin{array}{c}\text { Primeiro } \\
\text { estágio }\end{array}$ & $\begin{array}{c}\text { Estágios } \\
\text { intermediários }\end{array}$ & $\begin{array}{c}\text { Último } \\
\text { estágio }\end{array}$ \\
\hline \hline Hd1 & \multicolumn{2}{|c|}{ ECT } & MI \\
\hline Hd2 & \multicolumn{2}{|c|}{ ECT ou FITSP } & MI ou NITSP \\
\hline Hd3 & \multicolumn{2}{|c|}{ ECT ou NITSP } \\
\hline Hd4 & Stinson & ECT \\
\hline$H d 5$ & LPT3+NJSM & ERD+NJSM \\
\hline Hd6 & LPT5+NJSM & ERD+NJSM \\
\hline Hd7 & \multicolumn{3}{|c|}{ ALEATÓRIA } \\
\hline
\end{tabular}




\section{ANÁLISE dOS RESULTADOS}

"No ato de enfrentar e ultrapassar as infelicidades da vida reside a nobreza e a coragem de um homem." Napoleão Bonaparte

\subsection{Experimentação computacional}

Foram delineados como parâmetros da experimentação computacional o número de tarefas $(n)$, número de estágios de produção $(g)$, níveis de flexibilidade $(f)$, intervalos de tempos de setup $(s)$, probabilidade do setup ser antecipado $(a)$ e probabilidade da tarefa saltar um estágio $(l)$.

Os valores desses parâmetros foram definidos para os PROBLEMAS I (setup independente) e II (setup dependente) com base em trabalhos reportados na literatura, como Kurz e Askin (2004), Logendran, Carson e Hanson (2005), Ruiz, Şerifoğlu e Urlings (2008) e Naderi, Ruiz e Zandieh (in press), e constam nas Tabelas 6.1 e 6.2 .

O três níveis de flexibilidade determinados para o número de máquinas por estágio são: baixo, em que 1/3 dos estágios possuem máquinas paralelas; médio, com 2/3 dos estágios; e alto, em que todos os estágios possuem máquinas paralelas (LOGENDRAN; CARSON; HANSON, 2005). 
TABELA 6.1 - Parâmetros e valores da experimentação computacional do problema com setup independente

\begin{tabular}{|l|c|c|l|}
\hline PARÂMETRO & $\begin{array}{c}\text { SÍM- } \\
\text { BOLO }\end{array}$ & $\begin{array}{c}\text { NÚMERO } \\
\text { DE NÍVEIS }\end{array}$ & VALORES \\
\hline \hline Número de tarefas & $n$ & 3 & $10,30,100$ \\
\hline Número de estágios & $g$ & 3 & $3,5,7$ \\
\hline Flexibilidade & $f$ & 3 & Baixa, Média, Alta \\
\hline Distribuição dos tempos de setup & $s$ & 2 & $U[25,74], U[75,125]$ \\
\hline Probabilidade do setup ser antecipado & $a$ & 2 & $U[0,50] \%, U[50,100] \%$ \\
\hline $\begin{array}{l}\text { Probabilidade de uma tarefa saltar um } \\
\text { estágio }\end{array}$ & $l$ & 2 & $0 \%, 50 \%$ \\
\hline
\end{tabular}

TABELA 6.2 - Parâmetros e valores da experimentação computacional do problema com setup dependente

\begin{tabular}{|l|c|c|l|}
\hline PARÂMETRO & $\begin{array}{c}\text { SÍM- } \\
\text { BOLO }\end{array}$ & $\begin{array}{c}\text { NÚMERO } \\
\text { DE NÍVEIS }\end{array}$ & VALORES \\
\hline \hline Número de tarefas & $n$ & 5 & $10,30,50,80,100$ \\
\hline Número de estágios & $g$ & 3 & $3,5,7$ \\
\hline Flexibilidade & $f$ & 3 & Baixa, Média, Alta \\
\hline Distribuição dos tempos de setup & $s$ & 2 & $U[25,74], U[75,125]$ \\
\hline Probabilidade do setup ser antecipado & $a$ & 2 & $U[0,50] \%, U[50,100] \%$ \\
\hline $\begin{array}{l}\text { Probabilidade de uma tarefa saltar um } \\
\text { estágio }\end{array}$ & $l$ & 2 & $10 \%, 50 \%$ \\
\hline
\end{tabular}

Para o cálculo do número de estágios com máquinas paralelas, foi utilizado neste trabalho o arredondamento. Por exemplo, para o nível médio de flexibilidade em um sistema com 5 estágios, o número de estágios com máquinas paralelas é $(2 / 3) * 5=3,33$. Assim, arredondando, tem-se 3 estágios com máquinas paralelas e 2 estágios com uma máquina. Para definir quais estágios terão as máquinas paralelas, foram utilizados valores inteiros uniformemente distribuídos. Em tais estágios, o número de máquinas paralelas é de 2 a 5.

Foi considerado um intervalo fixo para os tempos de processamento, com valores inteiros uniformemente distribuídos entre 1 e 99. Para cada classe de problemas, foram gerados aleatoriamente 100 problemas-teste visando reduzir o erro amostral. 
Desta forma, o número de classes para o PRoblema I é $3(n) * 3(g) * 3(f) * 2(s) * 2$ (a) * $2(l)=216$. Sendo 100 problemas-teste por classe, a quantidade total de problemas é 21.600. E o número de classes para o PRoblema II é $5(n) * 3(g) * 3(f) * 2(s) * 2(a) * 2(l)$ $=360$, perfazendo um total de 36.000 problemas .

De acordo com esses parâmetros, todos os problemas foram gerados aleatoriamente e resolvidos por meio de um software construído especificamente para esta finalidade. Este software gera os arquivos de entrada com os dados dos problemas e produz a saída de arquivos comparativos com o makespan e o tempo de computação de cada método.

Foi utilizado o sistema operacional Windows e a linguagem de programação Delphi. As configurações da máquina são as seguintes: processador AMD Turion com $1.8 \mathrm{GHz}$ de frequência e 512 MB de memória RAM.

\subsection{Método de análise}

Os resultados obtidos na experimentação computacional foram analisados por meio da porcentagem de sucesso, desvio relativo médio, desvio-padrão do desvio relativo e tempo médio de computação dos métodos desenvolvidos.

A porcentagem de sucesso é calculada para cada classe de problemas-teste, dividindo o número de vezes que o método forneceu a melhor solução (menor makespan), empatando ou não, pelo número de problemas da classe.

O desvio relativo é o percentual da variação correspondente à melhor solução obtida pelos métodos. Se o desvio relativo da solução de um método é igual a zero para um determinado problema, significa que tal método forneceu o menor makespan, ou seja, o algoritmo 
apresentou a melhor programação. Entretanto, mais de um método pode fornecer a melhor programação.

Desta forma, o melhor algoritmo é aquele que apresenta o menor valor de desvio relativo médio $\bar{R}$ (a média aritmética dos desvios relativos) para uma determinada classe de problemas.

O desvio relativo $\left(R_{h}\right)$ de um método $h$ para um determinado problema é assim calculado:

$$
R_{h}=\frac{C_{\max }^{h}-C_{\text {max }}^{b}}{C_{\text {max }}^{b}}
$$

onde $C_{\max }^{h}$ é o makespan fornecido pelo método $h$ e $C_{\max }^{b}$ é o melhor makespan fornecido pelo grupo de métodos analisado.

O desvio-padrão de uma amostra mede o grau de dispersão dos elementos em torno da média. Neste trabalho, o desvio-padrão do desvio relativo é o valor da variação dos desvios relativos de uma classe de problemas em torno do desvio relativo médio. Quanto menor for o valor do desvio-padrão, melhor é o método de solução quando comparado a outro, principalmente no caso em que ambos apresentarem desvios relativos médios com diferença não significativa. Além disso, quanto menor o desvio-padrão, mais estável é o desempenho do método.

O desvio-padrão do desvio relativo $\left(S_{h}\right)$ de um método $h$ é calculado da seguinte forma:

$$
S_{h}=\sqrt{\frac{\sum_{i=1}^{L}\left(R_{h}^{i}-\bar{R}\right)^{2}}{L-1}}
$$


onde $L$ é o número de problemas da classe, $R_{h}^{i}$ é o desvio relativo da solução do problema $i$ fornecida pelo método $h$ e $\bar{R}$ é o desvio relativo médio do método $h$ para a classe de problemas.

O tempo médio de computação de um método é calculado pela soma dos tempos de computação de cada problema dividida pelo número total de problemas resolvidos (média aritmética dos tempos de computação). Na experimentação computacional, o tempo médio de computação foi medido em milissegundos (ms).

\subsubsection{Proposição da medida estatística AMV}

Uma nova estatística denominada Amplitude Média de Variação (AMV) foi criada para consubstanciar os resultados focalizando na variabilidade que um determinado parâmetro exerce sobre a solução. A AMV indica a alteração da porcentagem de sucesso dos métodos em relação aos níveis de cada parâmetro dos problemas.

O valor da AMV é calculado por meio do módulo da diferença entre os resultados (em porcentagem de sucesso) para cada valor do parâmetro considerado e cada porte do problema. Por exemplo, tem-se uma matriz do desempenho em porcentagem de sucesso para cada método de solução e cada porte do problema para o intervalo de setup de [25-74] e outra matriz análoga para o intervalo de [75-125]. A AMV para o intervalo de setup é calculado por meio da média da diferença em módulo de cada elemento dessas duas matrizes.

Para desenvolver algebricamente a expressão para o cálculo da AMV, é preciso calcular primeiro o número de combinações dos níveis dos parâmetros. Para o intervalo de setup, que tem apenas dois níveis (os dois intervalos: [25-74] e [75-125]), a AMV é a média da diferença em módulo do resultado deles. Já para a flexibilidade, que tem três níveis (baixa, média 
e alta), é preciso calcular a diferença entre cada par de níveis para saber a variação de um nível para outro e depois calcular a média de todos os valores encontrados.

Como foi dito, para 2 níveis tem-se 1 combinação. Para $\boldsymbol{x}$ níveis (com $\boldsymbol{x}>1$ ) tomados dois a dois, tem-se o seguinte número de combinações: $C_{x, 2}=\frac{x !}{2 !(x-2) !}$. Para um grupo de métodos de solução e para um determinado parâmetro, o seguinte termo é calculado para cada combinação de níveis $\boldsymbol{A}$ e $\boldsymbol{B}$ :

$\frac{\sum_{\text {métodos } h} \sum_{\text {níveis n }} \sum_{\text {niveis } k}\left|S_{h n k A}-S_{h n k B}\right|}{(\text { númerodemétodosh } h)(\text { númerodeníveis } n)(\text { númerodeníveis } k)}$

sendo $S_{h n k A}$ o resultado (em \% de sucesso) do método $\boldsymbol{h}$ para $\boldsymbol{n}$ tarefas, $\boldsymbol{k}$ estágios e nível $\boldsymbol{A}$ do parâmetro e $S_{h n k B}$ análogo para o nível $\boldsymbol{B}$. O valor da AMV é a média aritmética dos termos calculados para cada combinação.

Os resultados dos procedimentos implementados, apresentados nas próximas seções, foram analisados por problema (setup independente e dependente) e pelo tipo do método de solução (regras de prioridade e heurísticas). As tabelas com os resultados a partir dos quais foram elaborados os gráficos de dispersão que constam neste capítulo encontram-se no Apêndice $\mathrm{D}$.

\subsection{Resultados do problema com setup independente}

Nesta seção será apresentada a análise dos resultados do Problema I, com tempos de setup independentes da sequência, separada pelo tipo do método de solução. 


\subsubsection{Regras de prioridade}

Na primeira fase da experimentação computacional, foram implementadas e analisadas as onze regras de prioridade para setup independente, descritas na seção 4.3 e reproduzidas na Tabela 6.3 a seguir.

TABELA 6.3 - Regras de prioridade para setup independente

\begin{tabular}{|c|c|c|}
\hline Regra & Valor para ordenação inicial & $\begin{array}{l}\text { Ordenação nos } \\
\text { estágios } 2 \text { a g }\end{array}$ \\
\hline SPT1 & setup + processamento (estágio 1 ) & $\begin{array}{c}\text { mesma ordenação } \\
\text { do estágio } 1\end{array}$ \\
\hline SPT2 & \multirow{2}{*}{ setup + processamento (estágio 2) } & \multirow{2}{*}{ variável } \\
\hline LPT2 & & \\
\hline SPT3 & \multirow{2}{*}{ setup + processamento (todos os estágios) } & \multirow{2}{*}{$\begin{array}{l}\text { mesma ordenação } \\
\text { do estágio } 1\end{array}$} \\
\hline LPT3 & & \\
\hline SPT1_ERD & \multirow{2}{*}{ setup + processamento (estágio 1 ) } & \multirow{6}{*}{ ERD } \\
\hline LPT1_ERD & & \\
\hline SPT2_ERD & \multirow{2}{*}{ setup + processamento (estágio 2 ) } & \\
\hline LPT2_ERD & & \\
\hline SPT3_ERD & \multirow{2}{*}{ setup + processamento (todos os estágios) } & \\
\hline LPT3_ERD & & \\
\hline
\end{tabular}

O gráfico da Figura 6.1 mostra a comparação do desempenho das regras de prioridade na análise global dos 21.600 problemas resolvidos.

Na totalidade dos problemas resolvidos, a regra LPT3_ERD obteve desempenho superior aos demais, atingindo $45,7 \%$ de sucesso, conforme pode ser observado na Figura 6.1. A regra SPT1_ERD ficou em segundo lugar com 32,3\% de sucesso.

Em seguida vieram as regras SPT2_ERD (24,5\% de sucesso), LPT2_ERD (19,9\%), SPT1 (18,5\%), LPT1_ERD (15,2\%), SPT3_ERD (13,6\%), LPT3 (11,1\%) e SPT3 (6,4\%). Os piores desempenhos foram apresentados pelas regras SPT2 (0,4\% de sucesso) e LPT2 (4,3\%). 


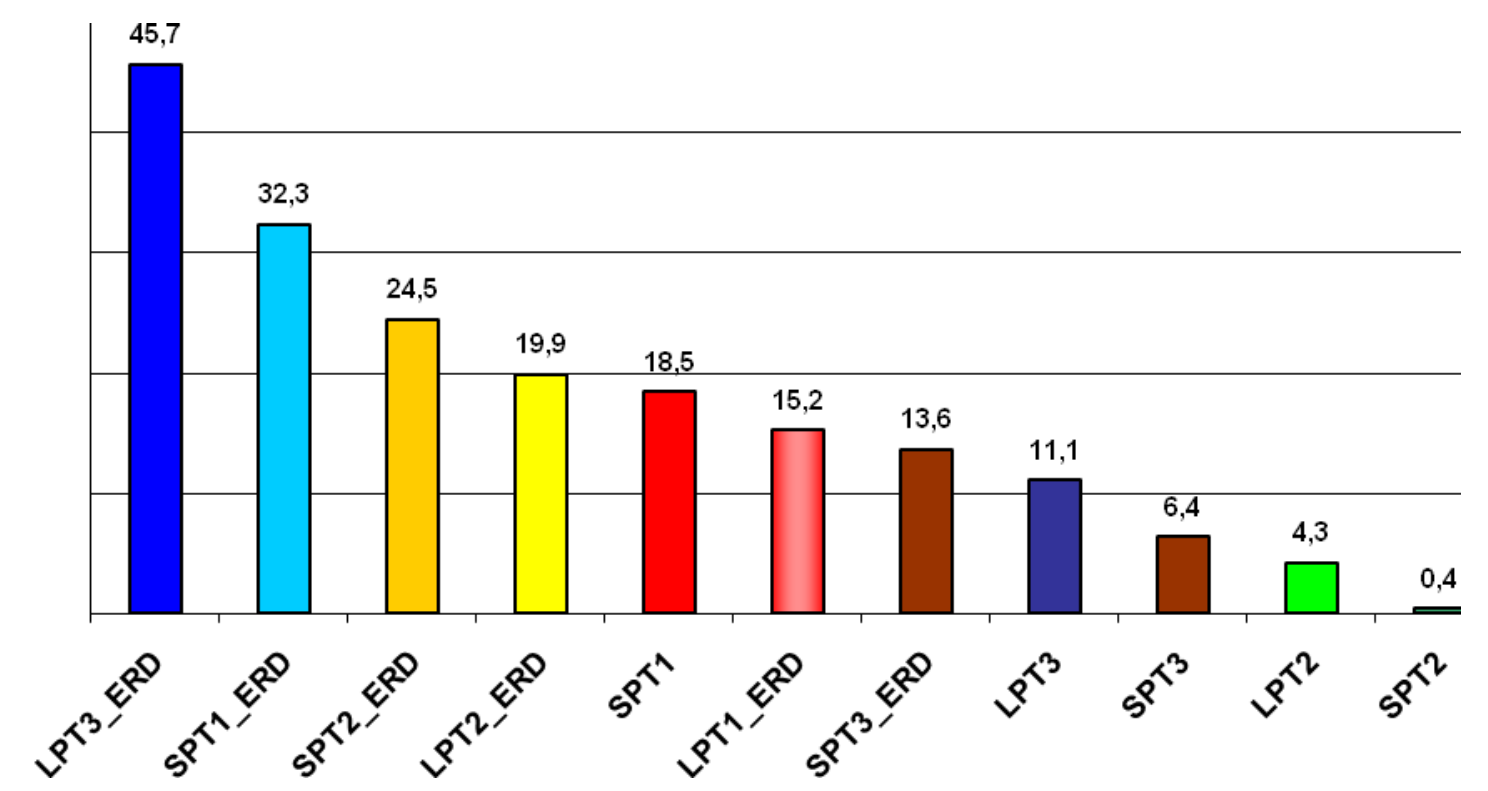

FIGURA 6.1 - Comparação de desempenho das regras de prioridade para setup independente (em \% de sucesso)

Comparando os pares de regras análogas (a regra simples e a que utiliza a $E R D$ ), em todos os casos o desempenho da aplicação da ERD predomina. Pode-se verificar claramente que do segundo estágio em diante é mais viável aplicar a regra $E R D$ do que manter a mesma ordenação em todos os estágios.

O bom desempenho da regra LPT3_ERD mostra a vantagem de se considerar a ordem não crescente da soma dos tempos de todos os estágios. Além disso, a diferença de desempenho das regras LPT3_ERD e SPT3_ERD (de 32,1\%) e a diferença entre as regras LPT3 e SPT3 (de 4,7\%) indicam que quando se utilizam os dados de todos os estágios, a ordem não crescente proporciona melhores resultados.

Por outro lado, quando se utilizam dados somente do primeiro estágio, como no caso das regras SPT1_ERD e LPT1_ERD, parece melhor utilizar a ordem não decrescente. A diferença de desempenho entre elas respectivamente foi de $17,1 \%$.

Quando se consideram os dados do segundo estágio, a ordenação crescente ou decrescente não afeta significativamente o desempenho. Os resultados das regras SPT2_ERD e 
LPT2_ERD ficaram muito próximos: 19,9\% e 18,5\% de sucesso, respectivamente. As regras LPT2 $(4,3 \%)$ e SPT2 $(0,4 \%)$, que consideram em cada estágio os dados do estágio seguinte, também obtiveram desempenhos relativamente próximos.

É interessante enfatizar que, dentre as regras puras, que não consideram a ordenação $E R D$, a SPT2 e a LPT2 são mais flexíveis do que as demais. Enquanto as regras SPT1, SPT3 e LPT3 mantêm a mesma ordenação em todos os estágios, as regras SPT2 e LPT2 mantêm o mesmo critério de ordenação em todos os estágios. Isto significa que a sequência de tarefas considerada em cada estágio é diferente, pois na ordenação de cada estágio são utilizados os dados do estágio seguinte.

O gráfico da Figura 6.2 apresenta a comparação de desempenho das onze regras de prioridade para cada opção do número de tarefas e de estágios.

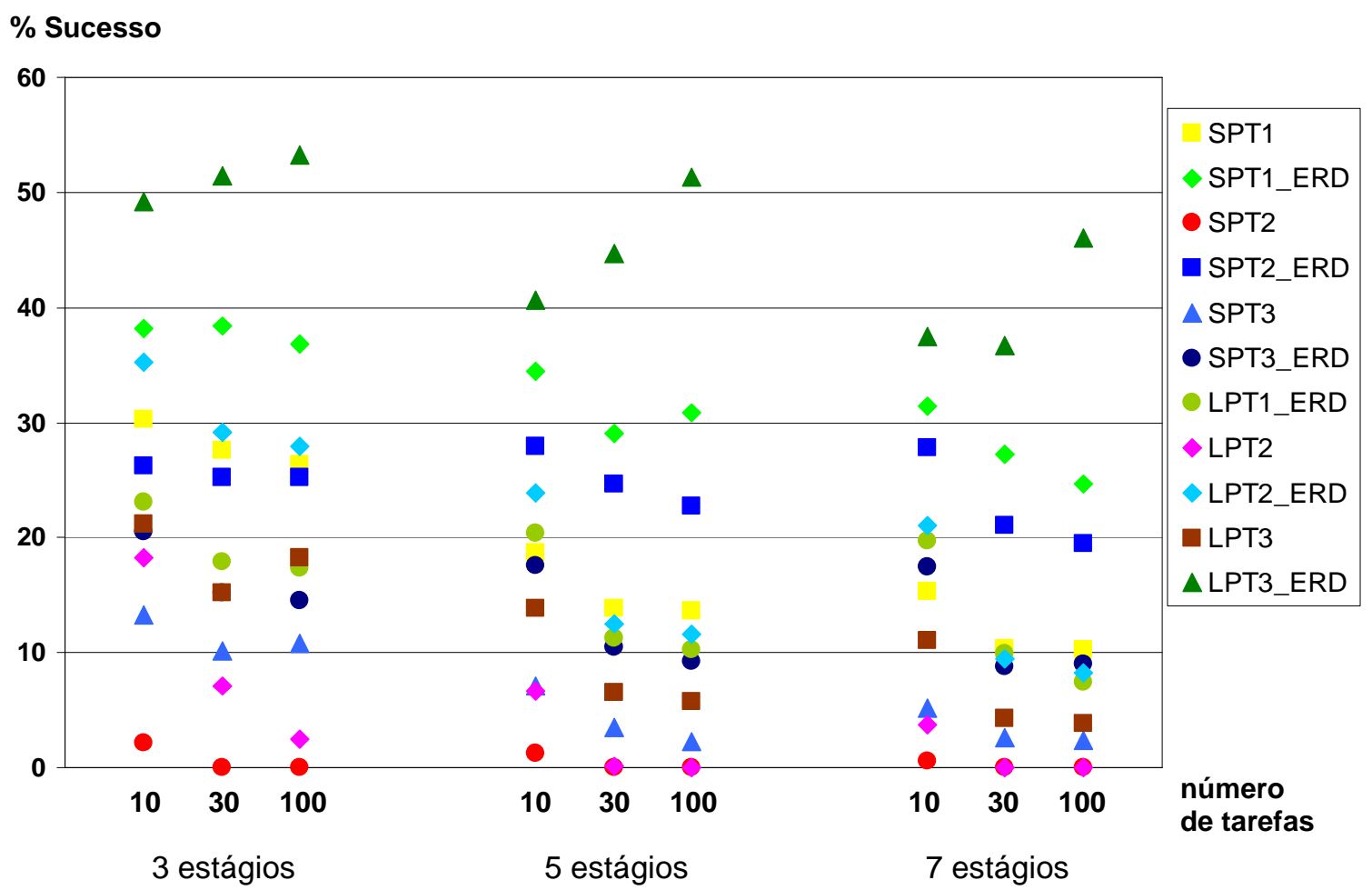

FIGURA 6.2 - Desempenho das regras para setup independente por porte do problema (em \% de sucesso) 
Como pode ser observado na Figura 6.2, a regra LPT3_ERD, que ficou em primeiro lugar, melhora seu desempenho com o aumento do número de tarefas, demonstrando ser eficaz principalmente para problemas de grande porte. Em geral, todas as outras regras pioram o desempenho com o aumento do tamanho do problema.

Em relação ao número de estágios, houve certa instabilidade no desempenho das regras, comprovada também pelos valores do desvio relativo médio e do desvio-padrão do desvio relativo. Além disso, a AMV para o número de estágios foi de 6,0, indicando uma variação mediana em relação a este parâmetro.

O número de tarefas tem uma variação razoável confirmada inclusive pelo valor da AMV de 4,2, porém influenciando menos do que o número de estágios.

A Tabela 6.4 apresenta de forma ilustrada as quatro melhores regras para setup independente para cada opção de porte do problema, com seu respectivo desempenho em porcentagem de sucesso.

TABELA 6.4 - Melhores regras para setup independente por porte do problema e suas porcentagens de sucesso

\begin{tabular}{|c|c|c|c|c|c|}
\hline$g$ & $n$ & $1^{\circ}$ lugar & $2^{\circ}$ lugar & $3^{\circ}$ lugar & $4^{\circ}$ lugar \\
\hline \multirow[t]{3}{*}{3} & 10 & $\begin{array}{c}\text { LPT3_ERD } \\
(49,2 \%)\end{array}$ & $\begin{array}{c}\text { SPT1_ERD } \\
(38,2 \%)\end{array}$ & $\begin{array}{c}\text { LPT2_ERD } \\
(35,3 \%)\end{array}$ & $\begin{array}{l}\text { SPT1 } \\
(30,3 \%)\end{array}$ \\
\hline & 30 & $\begin{array}{c}\text { LPT3_ERD } \\
(51,5 \%)\end{array}$ & $\begin{array}{c}\text { SPT1_ERD } \\
(38,4 \%)\end{array}$ & $\begin{array}{c}\text { LPT2_ERD } \\
(29,1 \%)\end{array}$ & $\begin{array}{l}\text { SPT1 } \\
(27,6 \%)\end{array}$ \\
\hline & 100 & $\begin{array}{c}\text { LPT3_ERD } \\
(53,3 \%)\end{array}$ & $\begin{array}{c}\text { SPT1_ERD } \\
(36,8 \%)\end{array}$ & $\begin{array}{c}\text { LPT2_ERD } \\
(28,0 \%)\end{array}$ & $\begin{array}{l}\text { SPT1 } \\
(26,3 \%)\end{array}$ \\
\hline \multirow[t]{3}{*}{5} & 10 & $\begin{array}{c}\text { LPT3_ERD } \\
(40,7 \%)\end{array}$ & $\begin{array}{c}\text { SPT1_ERD } \\
(34,5 \%)\end{array}$ & $\begin{array}{c}\text { SPT2_ERD } \\
(27,9 \%)\end{array}$ & $\begin{array}{c}\text { LPT2_ERD } \\
(23,8 \%)\end{array}$ \\
\hline & 30 & $\begin{array}{c}\text { LPT3 ERD } \\
(44,7 \%)\end{array}$ & $\begin{array}{c}\text { SPT1_ERD } \\
(29,1 \%)\end{array}$ & $\begin{array}{c}\text { SPT2_ERD } \\
(24,6 \%)\end{array}$ & $\begin{array}{l}\text { SPT1 } \\
(13,9 \%)\end{array}$ \\
\hline & 100 & $\begin{array}{c}\begin{array}{c}\text { LPT3_ERD } \\
(51,4 \%)\end{array} \\
\end{array}$ & $\begin{array}{c}\text { SPT1_ERD } \\
(30,8 \%)\end{array}$ & $\begin{array}{c}\text { SPT2_ERD } \\
(22,8 \%)\end{array}$ & $\begin{array}{l}\text { SPT1 } \\
(13,6 \%) \\
\end{array}$ \\
\hline \multirow[t]{3}{*}{7} & 10 & $\begin{array}{c}\text { LPT3_ERD } \\
(37,5 \%)\end{array}$ & $\begin{array}{c}\text { SPT1_ERD } \\
(31,4 \%)\end{array}$ & $\begin{array}{c}\text { SPT2 ERD } \\
(27,8 \%)\end{array}$ & $\begin{array}{c}\text { LPT2_ERD } \\
(21,1 \%)\end{array}$ \\
\hline & 30 & $\begin{array}{c}\text { LPT3_ERD } \\
\begin{array}{c}(36,7 \%) \\
\text { E ER }\end{array}\end{array}$ & $\begin{array}{c}\text { SPT1_ERD } \\
(27,3 \%)\end{array}$ & $\underset{(21,0 \%)}{\text { SPT2_ERD }}$ & $\begin{array}{c}\text { SPT1 } \\
(10,3 \%)\end{array}$ \\
\hline & 100 & $\begin{array}{c}\text { LPT3_ERD } \\
(46,0 \%)\end{array}$ & $\begin{array}{c}\text { SPT1_ERD } \\
(24,7 \%)\end{array}$ & $\begin{array}{c}\text { SPT2 ERD } \\
(19,5 \%)\end{array}$ & $\begin{array}{l}\text { SPT1 } \\
(10,3 \%)\end{array}$ \\
\hline
\end{tabular}

Como pode ser observado na Tabela 6.4, não apenas na análise global, mas no exame mais detalhado, por tamanho do problema, as regras LPT3_ERD e SPT1_ERD obtiveram os 
melhores desempenhos em todas as opções do número de tarefas e de estágios, com diferença de $13,3 \%$ em média entre elas.

Nesta análise, o terceiro melhor desempenho é mantido pela regra SPT2_ERD para problemas com 5 e 7 estágios; a regra LPT2_ERD forneceu melhores resultados que a SPT2_ERD em problemas com 3 estágios. E o quarto lugar, ocupado pela regra LPT2_ERD na análise global, foi ocupado pela regra SPT1 na maioria dos casos; o desempenho da regra LPT2_ERD foi melhor que o da SPT1 apenas para problemas com 10 tarefas e com 5 e 7 estágios.

Os diferentes níveis de flexibilidade, ou seja, a variação na quantidade de máquinas por estágio gera variabilidade no desempenho da regra. Como pode ser observado no gráfico da Figura 6.3, o comportamento das curvas de desempenho é diferente para as três opções de flexibilidade, porém sem um padrão específico, resultando em uma AMV considerável de 6,4.

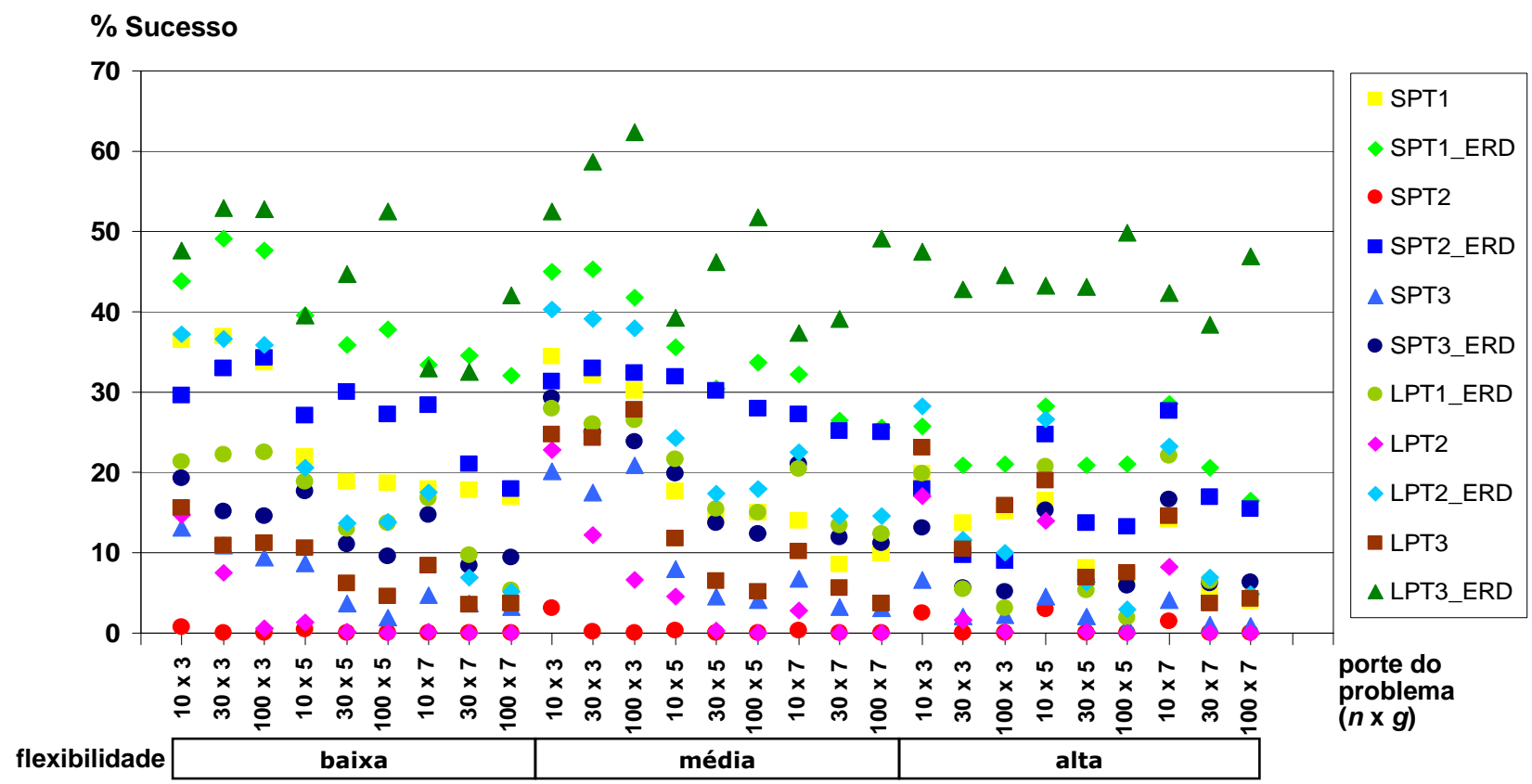

FIGURA 6.3 - Desempenho das regras para setup independente por flexibilidade e porte do problema (em $\%$ de sucesso) 
Os três parâmetros com AMV relevante associados (flexibilidade, número de tarefas e de estágios) produziram grande instabilidade como pode ser visto na variação do porte do problema para cada nível de flexibilidade.

Pode-se perceber que com a flexibilidade alta, a regra LPT3_ERD tem menos instabilidade e os outros métodos possuem desempenho inferior nos demais níveis de flexibilidade.

Os resultados ilustrados nos gráficos das Figuras 6.4 e 6.5 indicam que os intervalos de tempos de setup considerados e as probabilidades do setup ser antecipado não devem afetar de forma significativa o desempenho das regras.

Com estes parâmetros, os resultados ficaram próximos para ambas as opções de valores, o que foi confirmado pelos valores da AMV: 1,1 para os intervalos de setup e 1,0 para as probabilidades de antecipação. Estes foram os parâmetros que menos influenciaram no desempenho das regras. Isto pode indicar que neste ambiente uma maior probabilidade do setup ser antecipado não necessariamente melhoraria o resultado da regra.

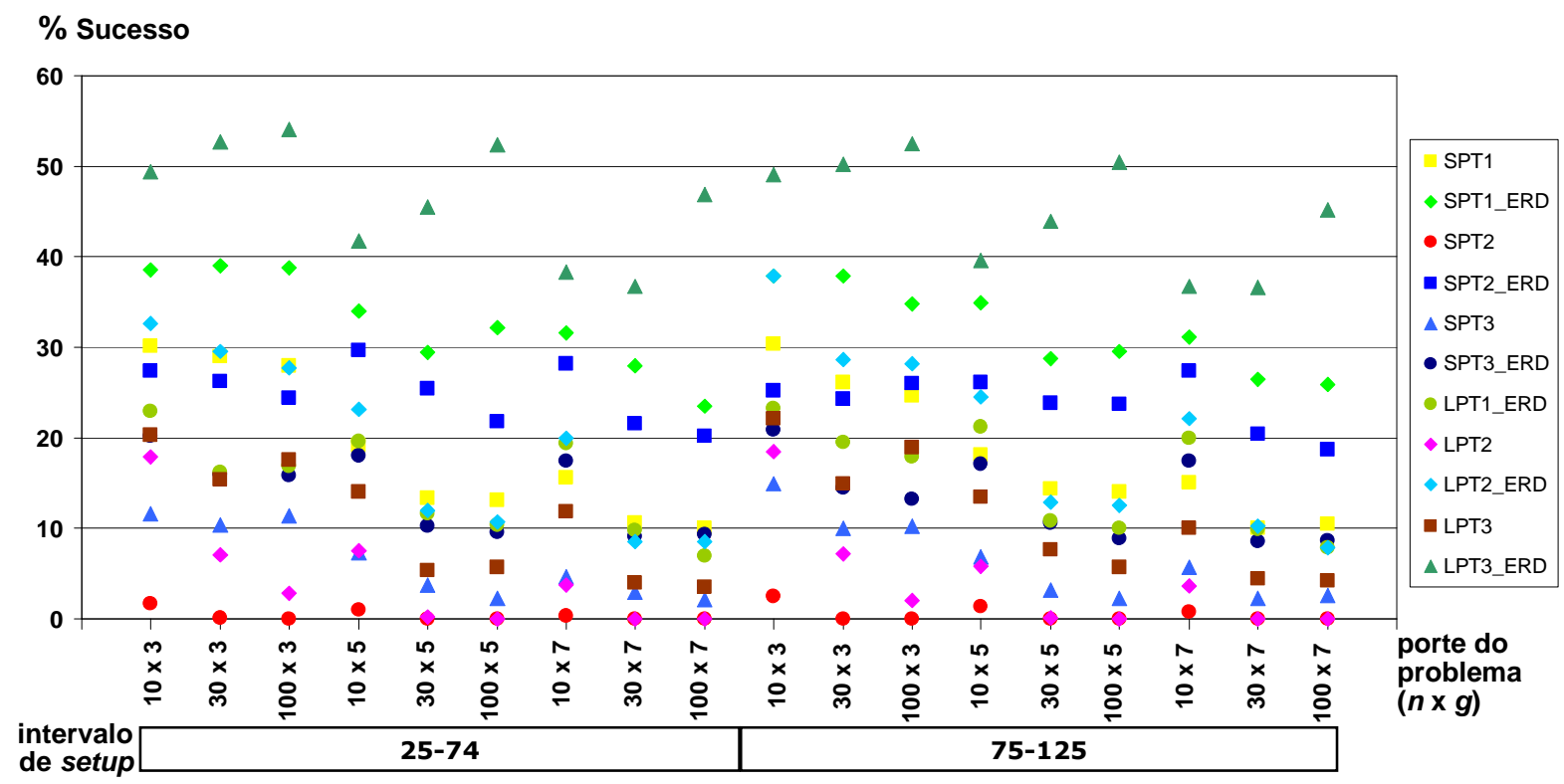

FIGURA 6.4 - Desempenho das regras para setup independente por intervalo de setup e porte do problema (em \% de sucesso) 


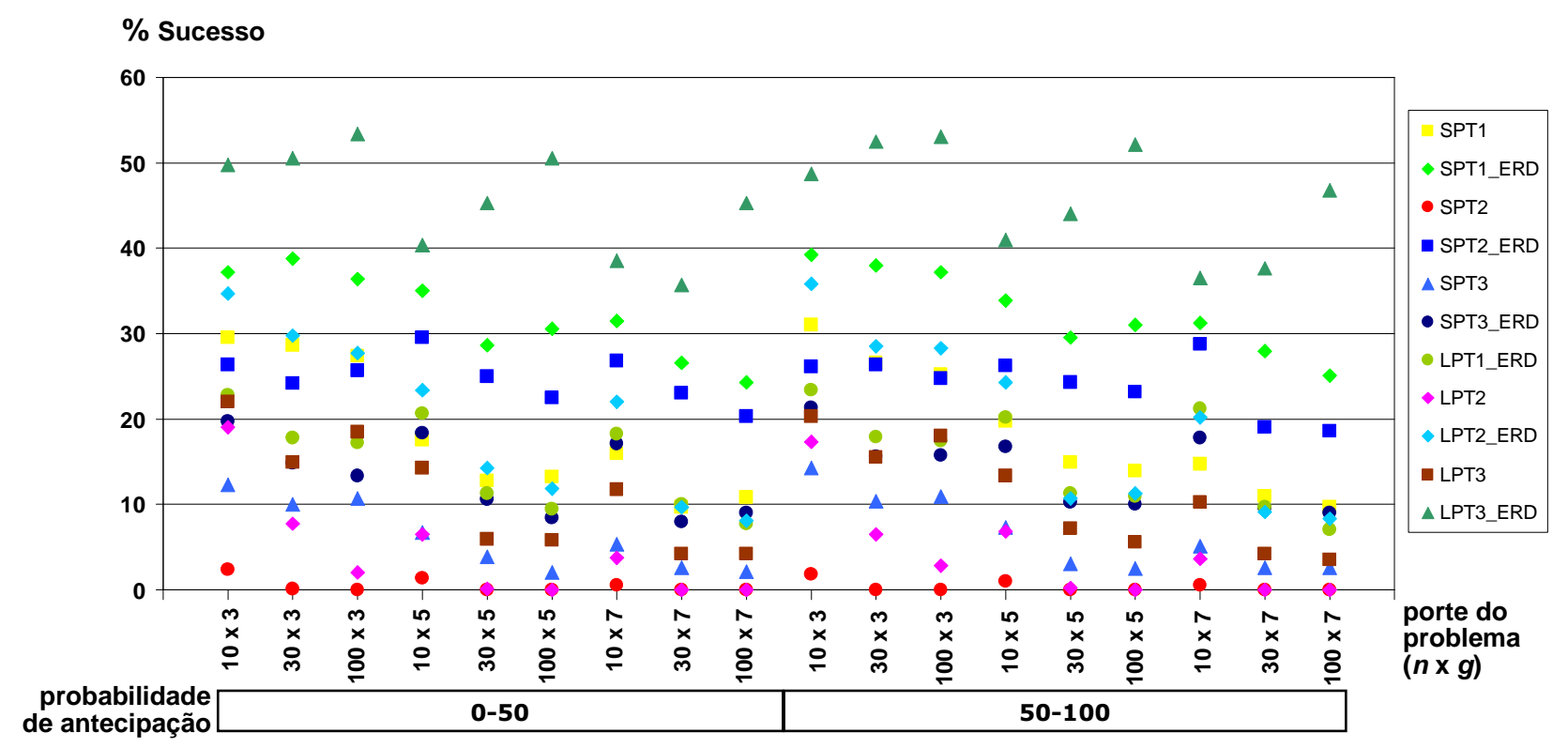

FIGURA 6.5 - Desempenho das regras para setup independente por probabilidade de antecipação do setup e porte do problema (em \% de sucesso)

Como pode ser visto na Figura 6.6, a probabilidade da tarefa saltar estágio teve uma grande relevância no resultado das regras.

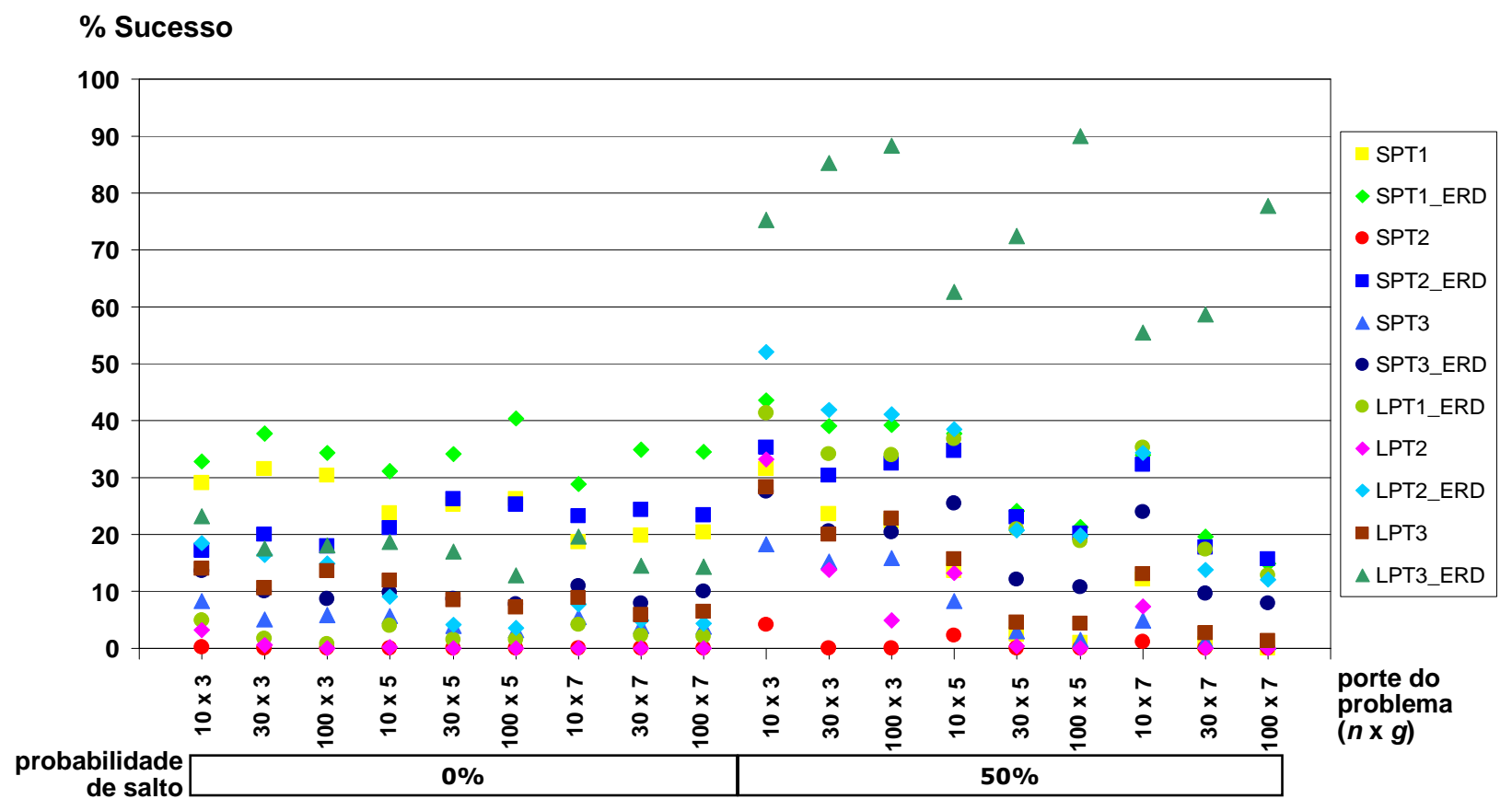

FIGURA 6.6 - Desempenho das regras para setup independente por probabilidade de salto e porte do problema (em $\%$ de sucesso) 
A análise separada para cada uma das opções de probabilidade de salto revelaram resultados diferentes da análise global. Com 50\% de probabilidade de salto, a regra LPT3_ERD ainda é a que obteve melhor desempenho e, além disso, com uma porcentagem de sucesso ainda maior: 74\% em média (na análise global foi de 45,7\%). A segunda melhor regra passou a ser a LPT2_ERD, com média de 30,5\% de sucesso. E a regra SPT1_ERD ficou em terceiro lugar, obtendo em média 30,4\% de sucesso.

Com $0 \%$ de probabilidade de salto, os resultados foram ainda mais distantes da análise global. Raramente ultrapassando os $40 \%$ de sucesso, as regras obtiveram desempenho inferior em relação à opção de 50\% de salto, com exceção das regras SPT1 e SPT1_ERD. Com a opção de 0\%, a regra SPT1_ERD passou a obter o melhor desempenho entre os onze, com média de $34,3 \%$ de sucesso. Em seguida, a regra SPT1 atingiu a média de 25\% de sucesso. E em terceiro lugar ficou a regra SPT2, com média de 22,1\%. A amplitude na diferença de desempenho é menor do que a opção de $50 \%$ de probabilidade de salto.

A regra LPT3_ERD, que obteve o melhor resultado na análise global (com 45,7\%), teve seu desempenho aproximado na faixa de $55 \%$ a $90 \%$ de sucesso na opção de $50 \%$ de probabilidade de salto. Porém, para a opção de $0 \%$ de probabilidade de salto, seu desempenho caiu para o quarto lugar, com média de $17 \%$ de sucesso e resultados sempre na faixa aproximada de $13 \%$ a $23 \%$ de sucesso.

Com uma AMV de 15,0, a probabilidade de salto foi o parâmetro que mais influenciou no desempenho das regras de prioridade, como pode ser observado na Tabela 6.5.

TABELA 6.5 - Valores da AMV para os parâmetros das regras com setup independente

\begin{tabular}{|c|c|c|c|c|c|}
\hline $\boldsymbol{n}$ & $\boldsymbol{g}$ & $\boldsymbol{f}$ & $\boldsymbol{s}$ & $\boldsymbol{a}$ & $\boldsymbol{l}$ \\
\hline \hline 4,2 & 6,0 & 6,4 & 1,1 & 1,0 & 15,0 \\
\hline
\end{tabular}


Este estudo demonstra que tanto a configuração do ambiente de produção, representada pelo número de estágios e a flexibilidade, como a característica das tarefas, especialmente a probabilidade de saltar estágios, influenciam significativamente no resultado das regras propostas.

A Figura 6.7 mostra a comparação dos desvios relativos médios das regras.

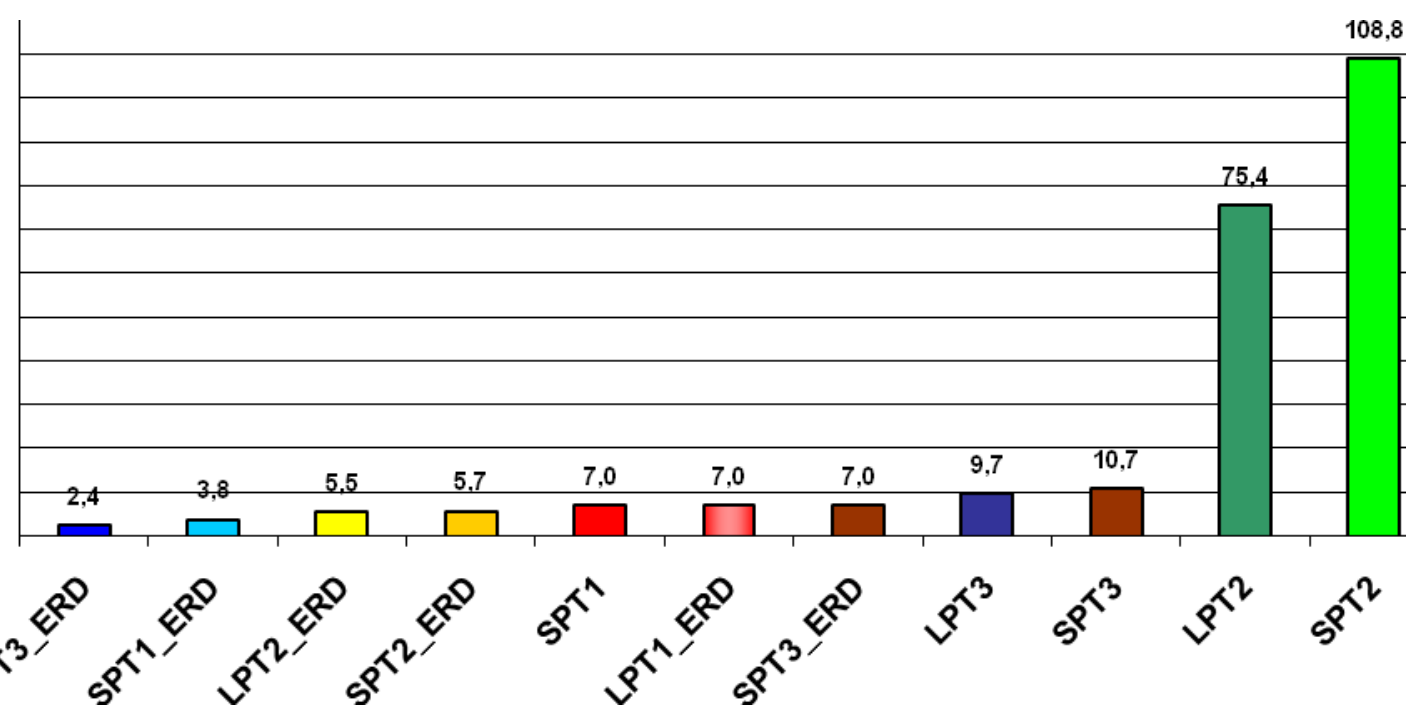

FIGURA 6.7 - Comparação do desvio relativo médio (em \%) das regras para setup independente

Os valores dos desvios relativos médios confirmaram a análise feita para a porcentagem de sucesso das regras, tendo praticamente a mesma ordem de desempenho (a única inversão, com diferença desprezível, foi entre a LPT2_ERD e a SPT2_ERD). Ou seja, as regras com maior porcentagem de sucesso tiveram os menores desvios relativos médios e as com menor porcentagem de sucesso, os maiores desvios.

A Figura 6.8 mostra o comportamento dos desvios relativos das regras em função do porte do problema. 


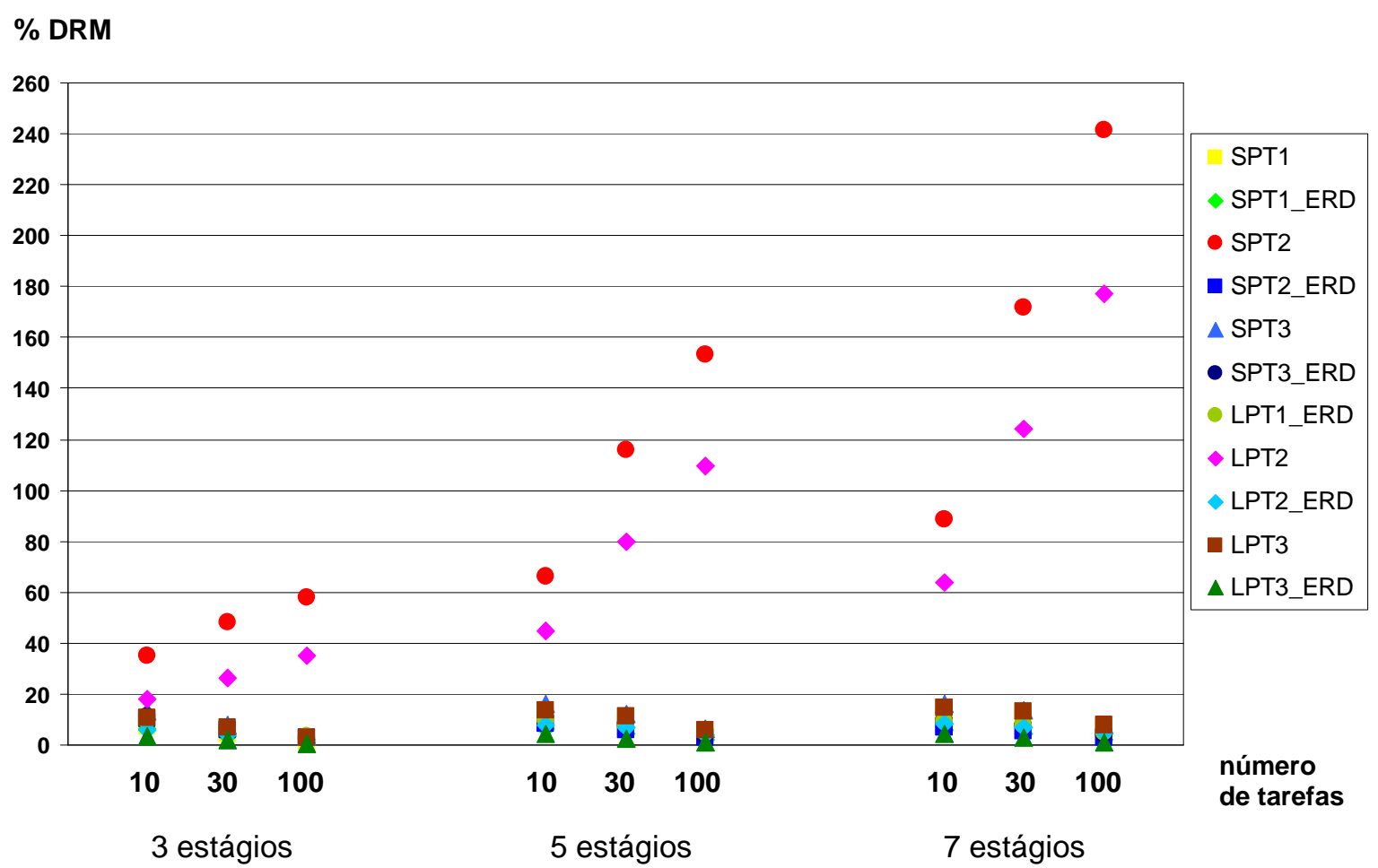

FIGURA 6.8 - Desvio relativo médio (em \%) das regras para setup independente por porte do problema

As regras SPT2 e LPT2 apresentaram os mais altos valores dos desvios relativos e grande instabilidade. Isto indica que utilizar os dados do estágio seguinte na ordenação (tanto crescente como decrescente) causa maior variação no resultado na regra em relação à melhor solução.

Com exceção destas duas regras, todas as outras reduzem os valores dos desvios relativos e desvio-padrão com o aumento do número de tarefas nas três opções do número de estágios e níveis de flexibilidade.

A Figura 6.9 apresenta a comparação do desvio-padrão do desvio relativo das regras. 


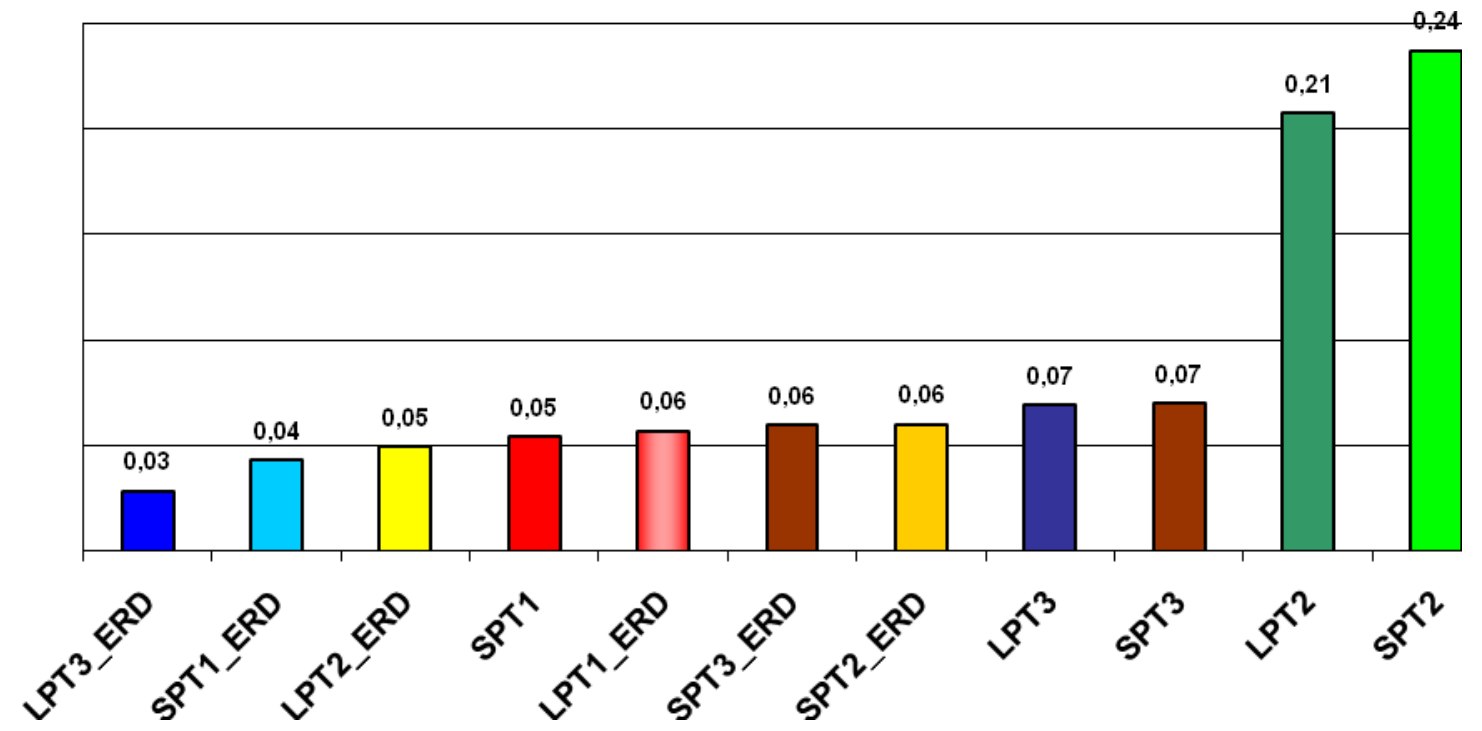

FIGURA 6.9 - Comparação do desvio-padrão do desvio relativo das regras para setup independente

Tal como aconteceu com a porcentagem de sucesso e o desvio relativo médio, as regras com os melhores valores de desvio-padrão foram a LPT3_ERD e a SPT1_ERD, e as piores foram a SPT2 e LPT2. As regras LPT2_ERD, SPT1, LPT1_ERD, SPT3_ERD e SPT2_ERD não mantiveram a mesma ordem de desempenho em relação à porcentagem de sucesso e o desvio relativo, porém tiveram valores de desvio-padrão muito próximos (aproximadamente 0,06$)$.

As curvas do desvio-padrão do desvio relativo confirmam a análise feita para os desvios relativos médios, como pode ser observado na Figura 6.10: 


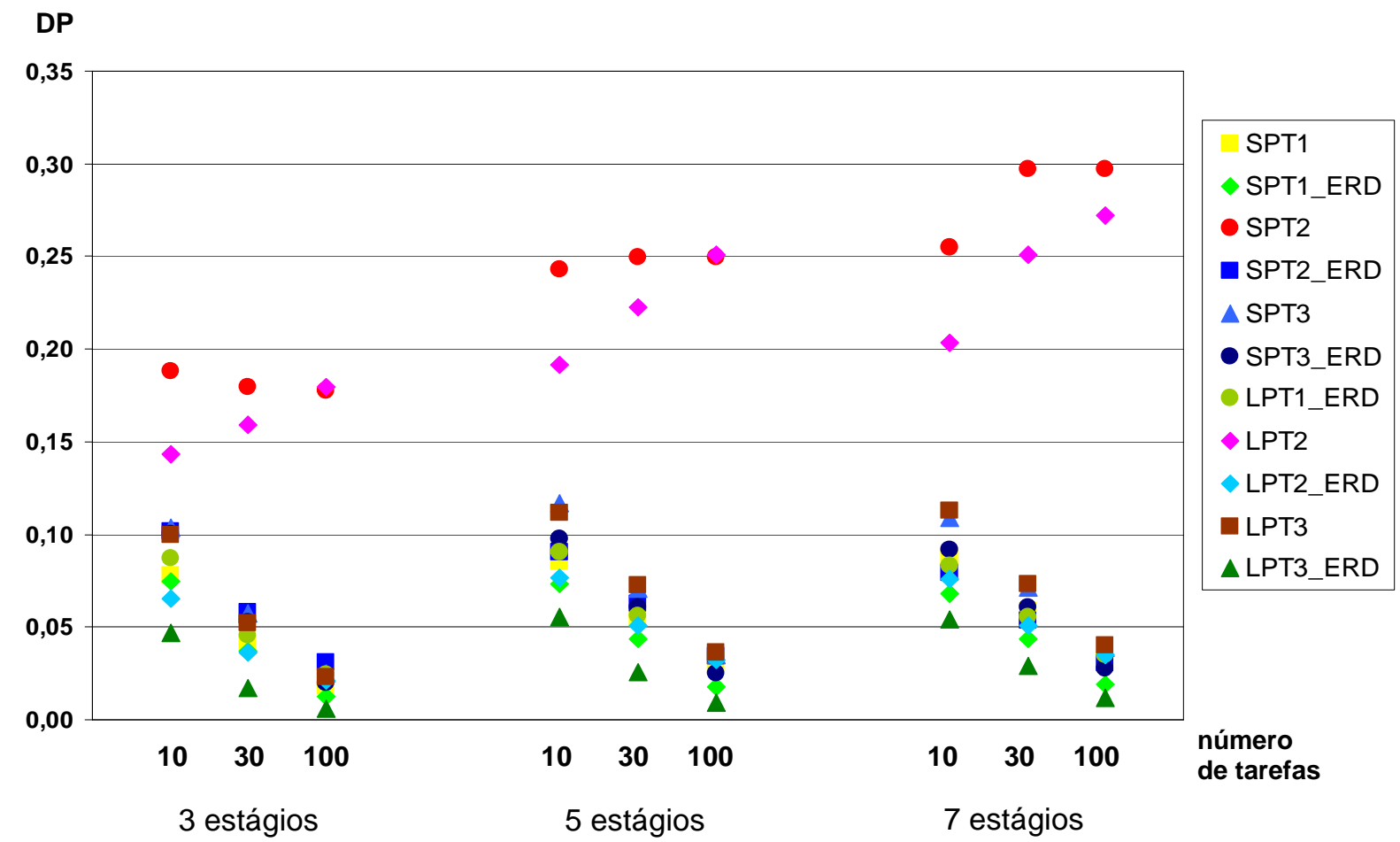

FIGURA 6.10 - Desvio-padrão do desvio relativo das regras para setup independente por porte do problema

Portanto, parece plausível aplicar as regras de prioridade propostas como método de solução do problema tratado. Este procedimento fornece até a melhor das soluções com um custo de CPU desprezível (o tempo de computação foi no máximo 16 ms). Por exemplo, os resultados de LPT3_ERD e SPT1_ERD, as duas melhores regras, atingem juntas quase $80 \%$ de sucesso.

\subsubsection{Heurísticas}

Na segunda fase da experimentação computacional do problema com tempos de setup independente da sequência, foram implementadas e analisadas as seis heurísticas apresentadas na seção 5.2. Para efeito de comparação, foram incluídas nesta análise as duas regras de prio- 
ridade que obtiveram os melhores resultados, descritos na subseção 6.3.1, perfazendo um total de oito métodos de solução, listados na Tabela 6.6 a seguir.

TABELA 6.6 - Algoritmos heurísticos e melhores regras de prioridade para setup independente

\begin{tabular}{|c|c|c|c|}
\hline Método & $\begin{array}{c}\text { Primeiro } \\
\text { estágio }\end{array}$ & $\begin{array}{c}\text { Estágios } \\
\text { intermediários } \\
\end{array}$ & $\begin{array}{l}\text { Último } \\
\text { estágio }\end{array}$ \\
\hline $\mathrm{Hi} 1$ & SPST & \multicolumn{2}{|c|}{ ECT } \\
\hline $\mathrm{Hi} 2$ & SPST & ECT & MI \\
\hline $\mathrm{Hi3}$ & \multicolumn{2}{|c|}{$\mathrm{MI}_{\Sigma F}$} & MI \\
\hline $\mathrm{Hi} 4$ & \multicolumn{3}{|c|}{ MI (decomposição por tarefa) } \\
\hline $\mathrm{Hi5}$ & \multicolumn{3}{|c|}{ LPST e SPST } \\
\hline $\mathrm{Hi6}$ & \multicolumn{3}{|c|}{ ALEATÓRIA } \\
\hline LPT3_ERD & LPST & \multicolumn{2}{|c|}{ ERD } \\
\hline SPT1_ERD & SPST & \multicolumn{2}{|c|}{ ERD } \\
\hline
\end{tabular}

A regra LPT3_ERD foi considerada pelo seu destacado desempenho (primeiro lugar entre as regras de prioridade) e a SPT1_ERD (que ficou em segundo lugar entre as regras) foi incluída pela semelhança com as heurísticas que também utilizam a regra SPT. O desempenho destas duas regras foi considerado para comparar a sua colocação em relação às heurísticas e não o seu comportamento com os diferentes parâmetros do problema, pois esta análise já foi feita na seção anterior.

Como já salientado na seção 4.2, os métodos de solução denominados neste trabalho como "regras de prioridade" são também métodos heurísticos construtivos, pois incluem em sua definição a política de alocação adotada nos estágios.

O gráfico da Figura 6.11 mostra a comparação de desempenho dos métodos de solução na análise global dos problemas resolvidos. 


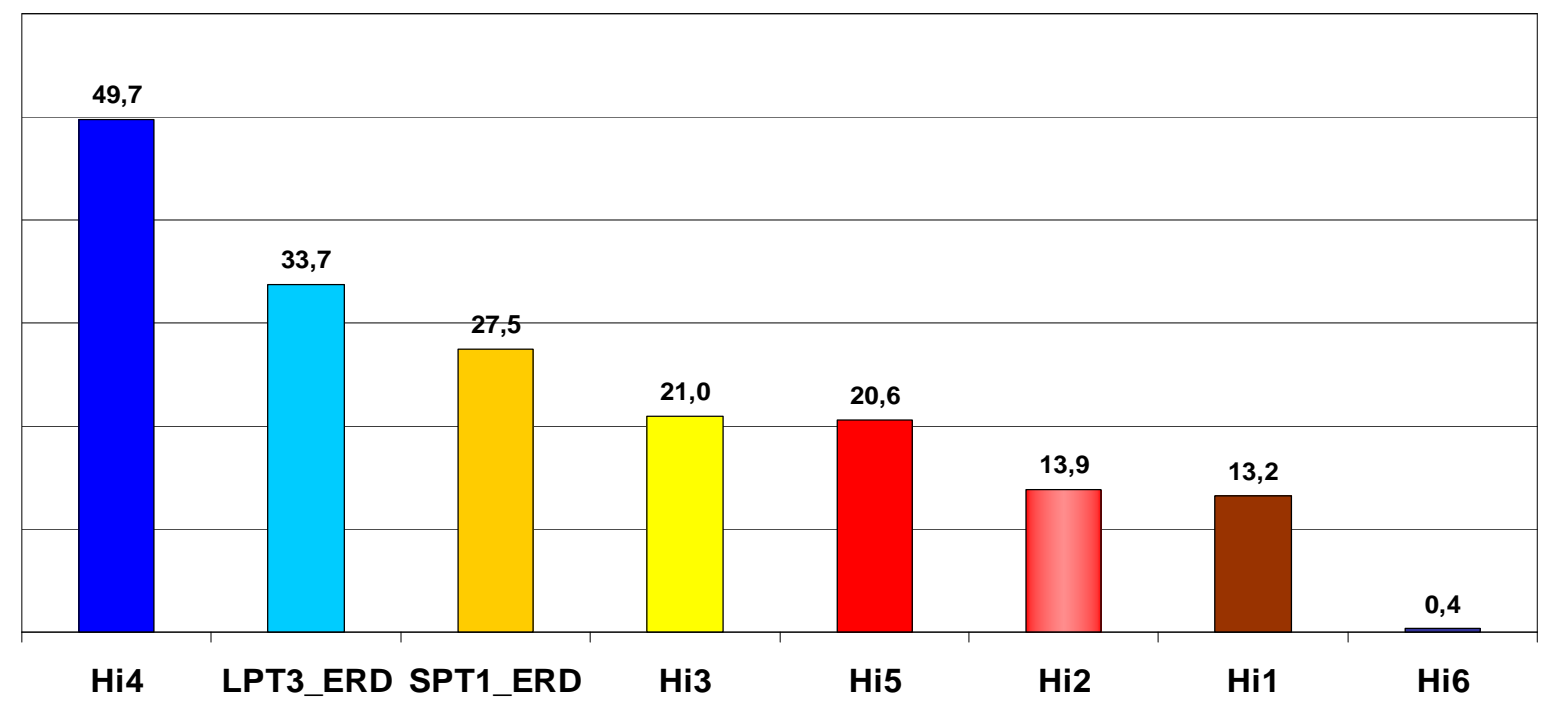

FIGURA 6.11 - Comparação de desempenho das heurísticas para setup independente (em \% de sucesso)

Dentre os 21.600 problemas, a heurística Hi4 ficou em primeiro lugar com 49,7\% de sucesso. Em seguida, os melhores desempenhos foram obtidos pelas duas regras de prioridade: LPT3_ERD, com 33,7\% de sucesso, e SPT1_ERD, com 27,5\%. Isto mostra a vantagem de se utilizar os procedimentos mais simples, como as regras de prioridade, na programação do flexible flow line, quando comparados à maioria das heurísticas.

Entre as heurísticas propostas, a Hi4 é a única classificada como método de decomposição por tarefa, ou seja, a programação é feita por tarefa e não por estágio como as demais. Além disso, ela utiliza na ordenação inicial a soma dos tempos de processamento e de setup não antecipados de todos os estágios, priorizando as tarefas com maior carga de trabalho e em seguida as tarefas menores, mais fáceis de "encaixar" na programação.

Embora tanto a heurística Hi4 como a regra LPT3_ERD utilizem a ordem não crescente com tempos de todos os estágios, elas diferem levemente, pois a LPT3_ERD soma inclusive os tempos de setup antecipados (o que não ocorre na Hi4). Além disso, as políticas de alocação de ambas são completamente distintas. 
Em quarto e quinto lugares ficaram as heurísticas $\mathrm{Hi3}$ e Hi5, com resultados bastante próximos: respectivamente, $21 \%$ e $20,6 \%$ de sucesso. Os procedimentos de programação de ambas são bastante diferentes. A heurística Hi3 utiliza o método de inserção em todos os estágios, enquanto a Hi5 considera ordenações $L P T$ e $S P T$ e a alocação à máquina de menor carga.

As heurísticas Hi1 e Hi2 também obtiveram resultados muito próximos, com 13,2\% e 13,9\% de sucesso. Ambas utilizam a regra $S P T$ na ordenação inicial, tal como a regra SPT1_ERD. Porém, esta última, que atingiu 27,5\% de sucesso em relação às heurísticas, indica que a alocação $E R D$ é mais vantajosa do que a escolha do par tarefa-máquina com menor data de término $(\boldsymbol{E C T})$, utilizada pela Hi1 e Hi2.

A heurística Hi2 foi criada como tentativa de melhoria da Hi1, tendo como única diferença a programação do último estágio, em que aplica o método de inserção. Contudo, o resultado melhorou em apenas $0,7 \%$ em média.

Em último lugar, a heurística aleatória Hi6 demonstrou a sua inferioridade, com apenas $0,4 \%$ de sucesso.

Para a visualização dos resultados com um nível de detalhamento maior, a Figura 6.12 apresenta o gráfico da comparação de desempenho das oito heurísticas para cada opção de porte do problema. 


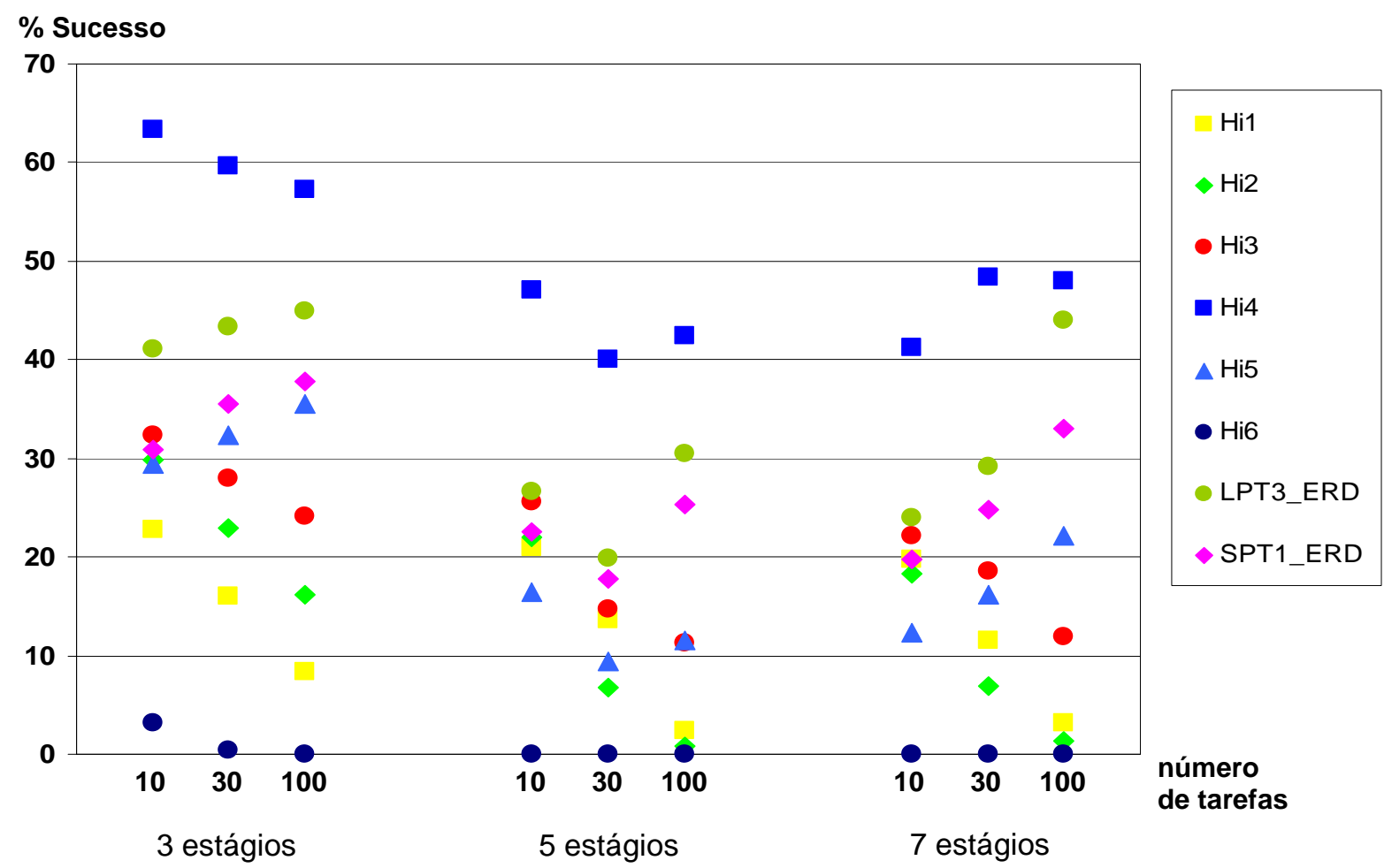

FIGURA 6.12 - Desempenho das heurísticas para setup independente por porte do problema (em \% de sucesso)

Mesmo na análise detalhada por porte do problema, a Figura 6.12 mostra claramente o desempenho superior da heurística Hi4 em relação às demais. A regra LPT3_ERD também ficou em segundo lugar em todas as opções de número de estágios e de tarefas.

Em relação aos parâmetros do porte do problema, o número de estágios teve a AMV de 8,7 e influenciou mais do que o número de tarefas, que teve a AMV de 6,7.

Para problemas com 3 estágios, as heurísticas Hi1, Hi2, Hi3, Hi4 e Hi6 reduzem o desempenho com o aumento do número de tarefas. Por outro lado, a heurística Hi5 e as duas regras de prioridade melhoram o desempenho com o aumento do número de tarefas.

Com 5 estágios, as heurísticas sempre apresentaram desempenho inferior em problemas com 30 tarefas em relação aos problemas com 10 e 100 tarefas. 
Em problemas com 7 estágios, a heurística Hi4 passa a melhorar o desempenho com o aumento do número de tarefas. Isto pode indicar que a Hi4 tem desempenho superior em problemas de pequeno e grande porte e reduzido em problemas de médio porte.

Em todos os casos, o resultado da heurística Hi6 ficou sempre próximo de zero, exceto em problemas com 10 tarefas e 3 estágios, em que obteve 3\% de sucesso.

A Tabela 6.7 apresenta de forma ilustrada as quatro melhores heurísticas para setup independente para cada opção de porte do problema, com seu respectivo desempenho em porcentagem de sucesso.

TABELA 6.7 - Melhores heurísticas para setup independente por porte do problema e suas porcentagens de sucesso

\begin{tabular}{|c|c|c|c|c|c|}
\hline$g$ & $n$ & 10 lugar & 20 lugar & $3^{\circ}$ lugar & $4^{\circ}$ lugar \\
\hline \multirow[t]{3}{*}{3} & 10 & $\underset{(63,3 \%)}{\mathrm{Hi} 4}$ & $\begin{array}{c}\text { LPT3_ERD } \\
(41,0 \%) \\
\end{array}$ & $\begin{array}{c}\mathrm{Hi3} \\
(32,3 \%)\end{array}$ & $\begin{array}{c}\text { SPT1_ERD } \\
(30,9 \%)\end{array}$ \\
\hline & 30 & $\begin{array}{c}\mathrm{Hi} 4 \\
(59,7, \%)\end{array}$ & $\begin{array}{c}\text { LPT3_ERD } \\
(43,3 \%)\end{array}$ & $\begin{array}{c}\text { SPT1_ERD } \\
(35,5 \%)\end{array}$ & $\begin{array}{c}\mathrm{Hi5} \\
(32,4 \%) \\
\end{array}$ \\
\hline & 100 & $\begin{array}{c}\mathrm{Hi} 4 \\
(57,3, \%) \\
\end{array}$ & $\begin{array}{c}\text { LPT3_ERD } \\
(44,9 \%) \\
\end{array}$ & $\begin{array}{c}\text { SPT1_ERD } \\
(37,8 \%)\end{array}$ & $\begin{array}{c}\mathrm{Hi5} \\
(35,5 \%) \\
\end{array}$ \\
\hline \multirow[t]{3}{*}{5} & 10 & $\begin{array}{c}\mathrm{Hi} 4 \\
(47,0 \%)\end{array}$ & $\begin{array}{c}\begin{array}{c}\text { LPT3_ERD } \\
(26,7 \%)\end{array} \\
\end{array}$ & $\begin{array}{c}\mathrm{Hi3} \\
(25,6 \%) \\
\end{array}$ & $\begin{array}{c}\text { SPT1_ERD } \\
(22,5 \%)\end{array}$ \\
\hline & 30 & $\begin{array}{c}\mathrm{Hi} 4 \\
(40,0 \%)\end{array}$ & $\begin{array}{c}\text { LPT3_ERD } \\
(19,9 \%)\end{array}$ & $\begin{array}{c}\text { SPT1_ERD } \\
(17,8 \%)\end{array}$ & $\underset{(14,7 \%)}{\mathrm{Hi} 3}$ \\
\hline & 100 & $\begin{array}{c}\mathrm{Hi} 4 \\
(42,5 \%) \\
\end{array}$ & $\begin{array}{c}\text { LPT3_ERD } \\
(30,5 \%) \\
\end{array}$ & $\begin{array}{c}\text { SPT1_ERD } \\
(25,3 \%) \\
\end{array}$ & $\begin{array}{c}\mathrm{Hi5} \\
(11,5 \%) \\
\end{array}$ \\
\hline \multirow[t]{3}{*}{7} & 10 & $\begin{array}{c}\mathrm{Hi} 4 \\
(41,2 \%)\end{array}$ & $\begin{array}{c}\text { LPT3_ERD } \\
(24,0 \%)\end{array}$ & $\begin{array}{c}\mathrm{Hi3} \\
(22,2 \%) \\
\end{array}$ & $\begin{array}{c}\mathrm{Hi1} \\
(19,8 \%)\end{array}$ \\
\hline & 30 & $\begin{array}{c}\mathrm{Hi} 4 \\
(48,4, \%)\end{array}$ & $\begin{array}{c}\text { LPT3_ERD } \\
(29,2 \%)\end{array}$ & $\begin{array}{c}\text { SPT1_ERD } \\
(24,8 \%)\end{array}$ & $\begin{array}{c}\mathrm{Hi3} \\
(18,6 \%)\end{array}$ \\
\hline & 100 & $\begin{array}{c}\mathrm{Hi} 4 \\
(48,0 \%)\end{array}$ & $\begin{array}{c}\text { LPT3_ERD } \\
(44,0 \%)\end{array}$ & $\begin{array}{c}\text { SPT1_ERD } \\
(33,0 \%)\end{array}$ & $\begin{array}{c}\mathrm{Hi} 5 \\
(22,2 \%)\end{array}$ \\
\hline
\end{tabular}

Os dados da Tabela 6.7 confirmam que não apenas na análise global mas também por porte do problema, em todos os casos, a heurística Hi4 ficou em primeiro lugar e a regra LPT3_ERF obteve o segundo melhor desempenho.

O terceiro lugar é disputado pela heurística Hi3 e pela regra SPT1_ERD; a Hi3 é melhor em problemas com 10 tarefas e a SPT1_ERD com 30 e 100 tarefas. O quarto lugar foi ocupado alternadamente pela Hi5 (principalmente em problemas de grande porte), pela 
SPT1_ERD (predominantemente em problemas de pequeno porte), pela Hi3 (em problemas de médio porte) e pela Hi1 (em problemas com 10 tarefas e 7 estágios).

Num nível ainda maior de detalhamento, o gráfico da Figura 6.13 apresenta os resultados dos métodos separando por nível de flexibilidade, além do porte do problema.

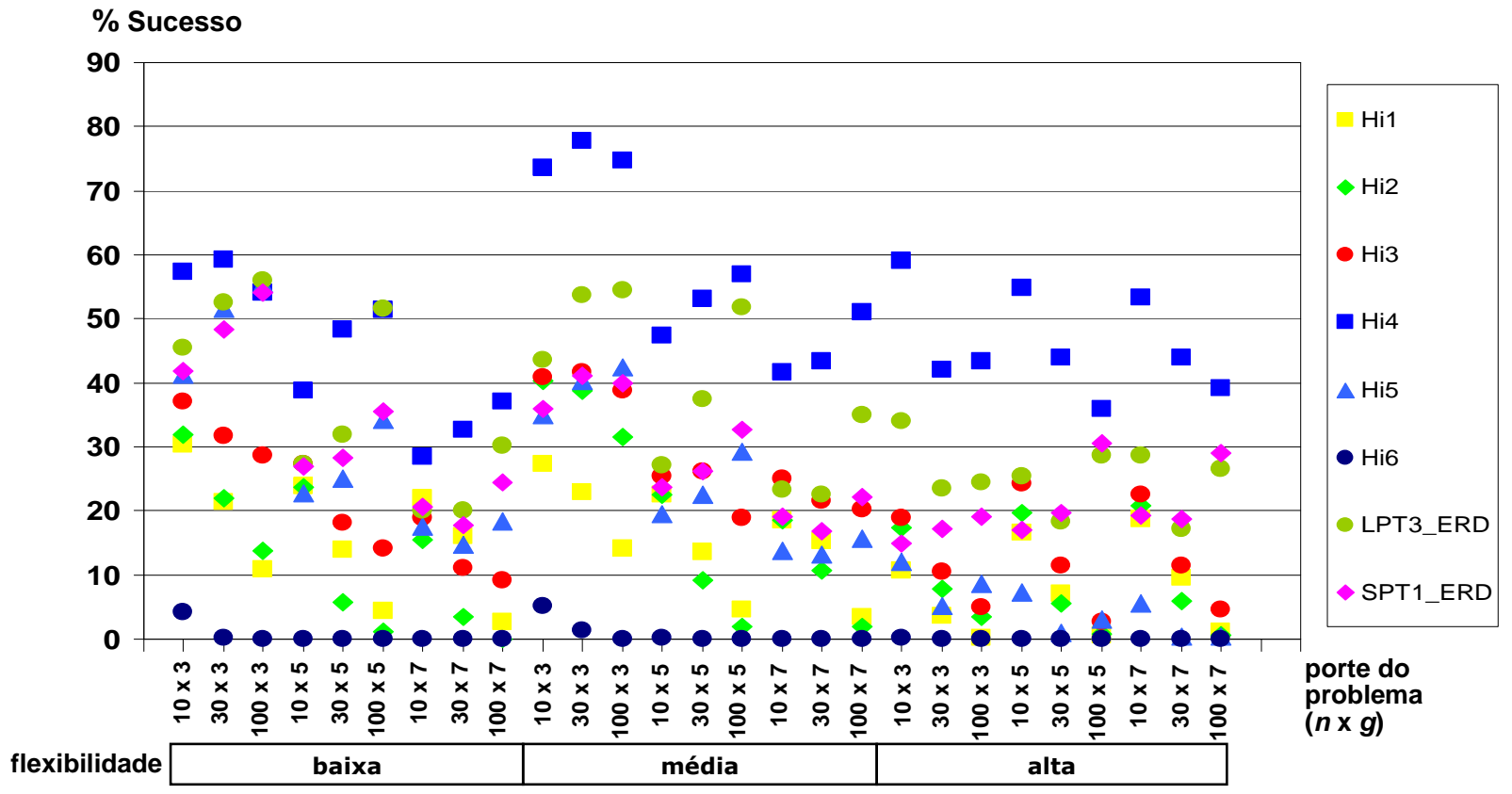

FIGURA 6.13 - Desempenho das heurísticas para setup independente por flexibilidade e porte do problema (em $\%$ de sucesso)

O nível de flexibilidade teve a AMV de 9,5, influenciando portanto ainda mais do que os parâmetros de número de tarefas e de estágios. Isto pode indicar que o layout teria mais influência do que o porte do problema.

Pelo gráfico da Figura 6.13 pode-se observar que o comportamento da curva de desempenho dos métodos é diferente para cada um dos níveis de flexibilidade, porém sem um padrão específico. 
Embora haja um claro predomínio do melhor desempenho da heurística Hi4, existem duas opções, ambas com a flexibilidade baixa, em que a regra LPT3_ERD obteve melhor desempenho, ainda que seja com uma diferença muito pequena. Em problemas com 100 tarefas e 3 estágios, a LPT3_ERD atingiu 56\% de sucesso contra 54\% da Hi4 (a regra SPT1_ERD empatou com a Hi4); e com 100 tarefas e 5 estágios, a LPT3_ERD obteve 52\% de sucesso enquanto a Hi4 atingiu $51 \%$.

Os resultados apresentados nas Figuras 6.14 e 6.15 indicam que os intervalos de setup e as probabilidades do setup ser antecipado não devem afetar de forma significativa o desempenho dos métodos. A AMV dos intervalos de setup foi de 2,0 e das probabilidades de antecipação foi ainda menor, de 1,1. Isto significa que estes dois parâmetros foram os que menos influenciaram nos resultados do problema.

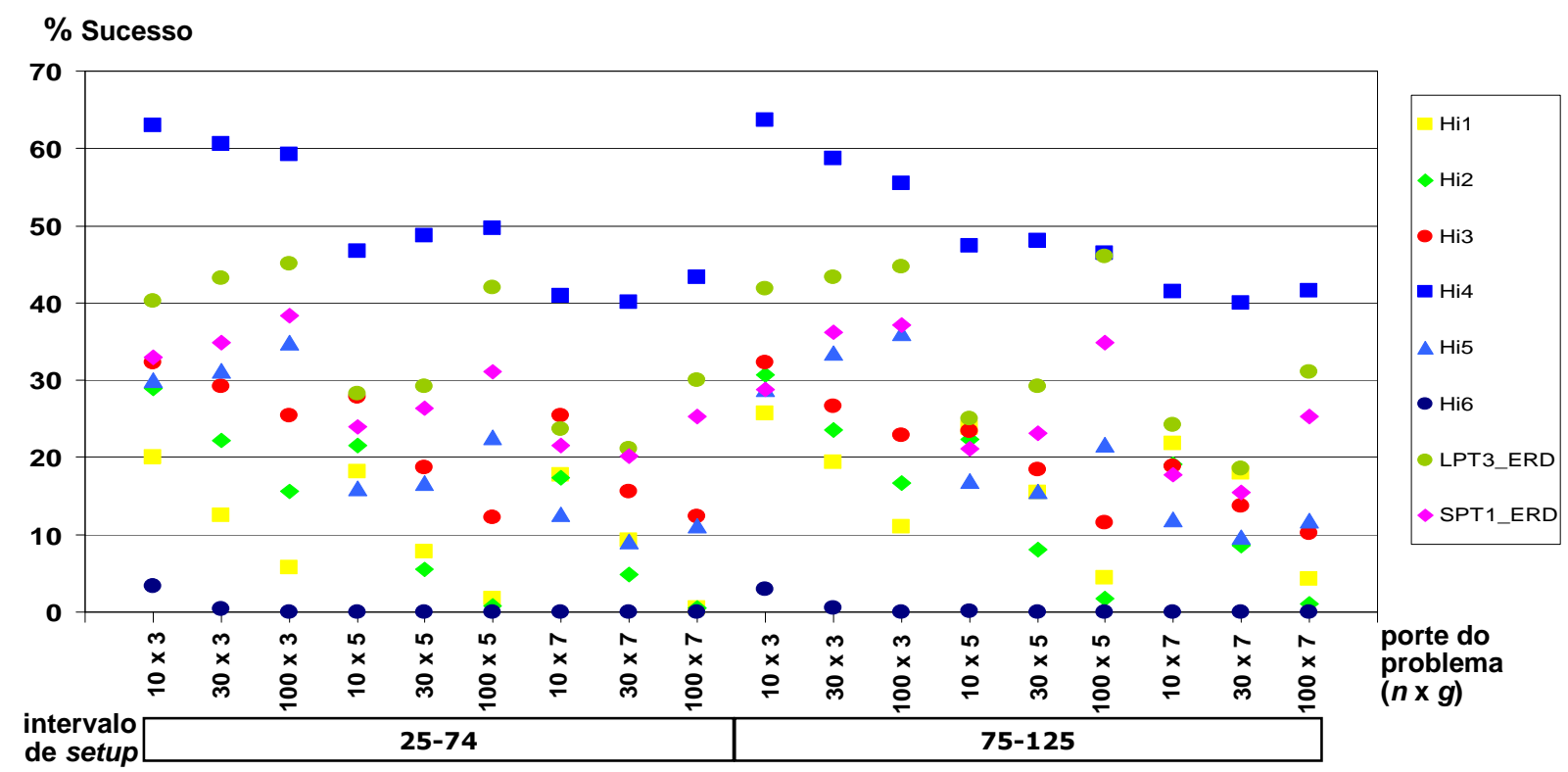

FIGURA 6.14 - Desempenho das heurísticas para setup independente por intervalo de setup e porte do problema (em \% de sucesso) 


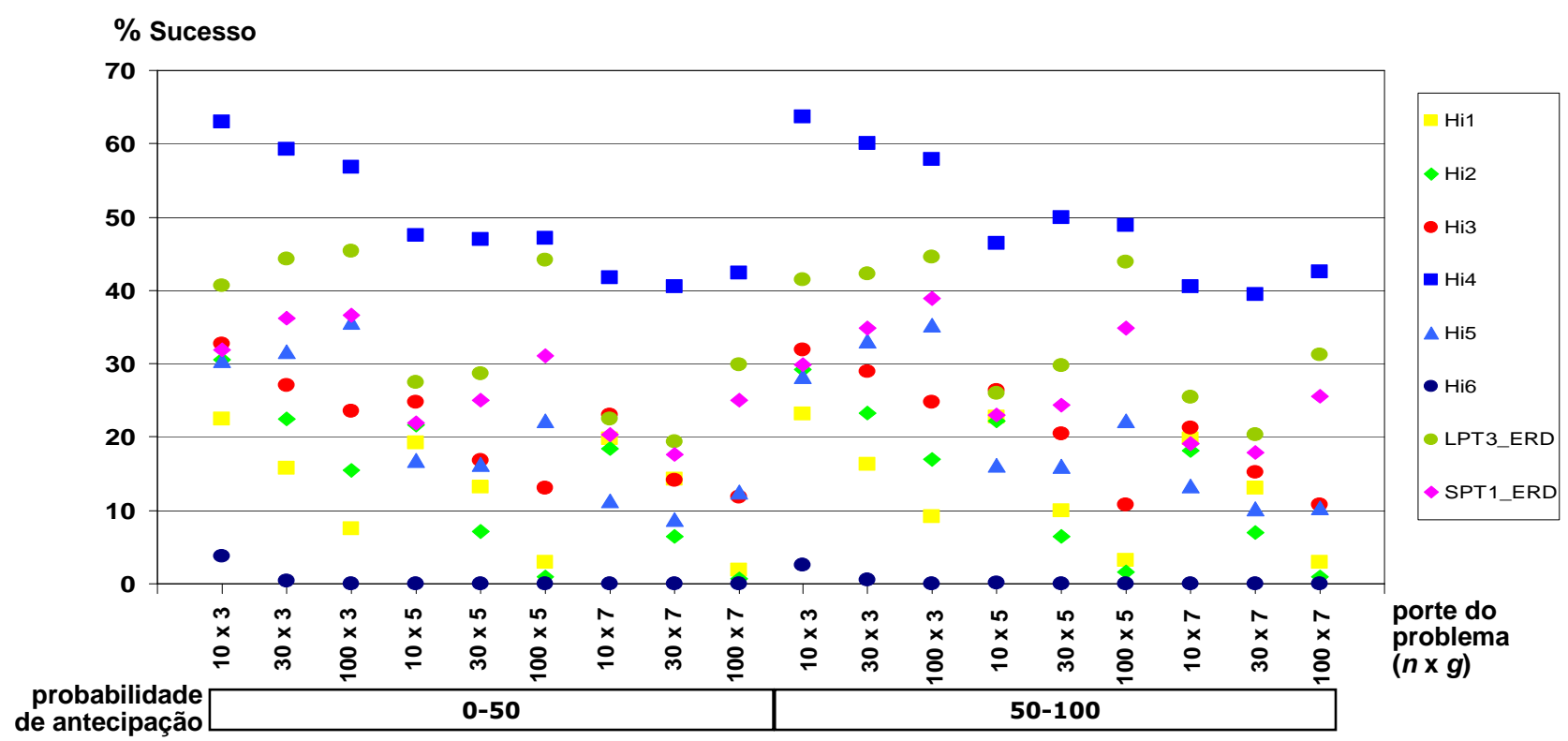

FIGURA 6.15 - Desempenho das heurísticas para setup independente por probabilidade de antecipação do setup e porte do problema (em \% de sucesso)

O gráfico da Figura 6.16 apresenta os resultados para as duas opções do parâmetro probabilidade das tarefas saltarem estágios.

\section{$\%$ Sucesso}

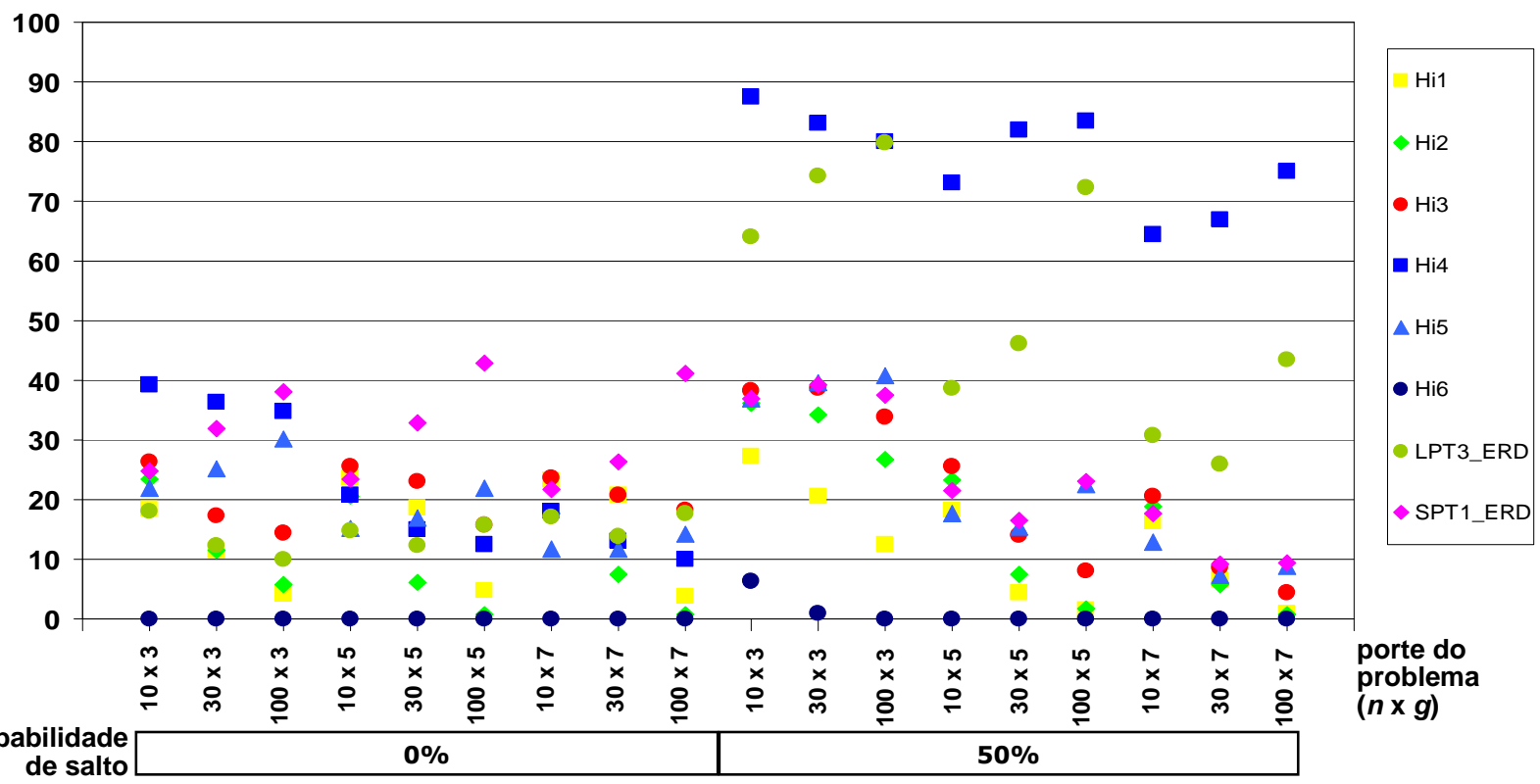

FIGURA 6.16 - Desempenho das heurísticas para setup independente por probabilidade de salto e porte do problema (em \% de sucesso) 
A probabilidade de salto foi o parâmetro que mais influenciou os resultados dos métodos, tendo a AMV de 17,4. A comparação dos valores da AMV para todos os parâmetros pode ser vista na Tabela 6.8 a seguir.

TABELA 6.8 - Valores da AMV para os parâmetros das heurísticas com setup independente

\begin{tabular}{|c|c|c|c|c|c|}
\hline $\boldsymbol{n}$ & $\boldsymbol{g}$ & $\boldsymbol{f}$ & $\boldsymbol{s}$ & $\boldsymbol{a}$ & $\boldsymbol{l}$ \\
\hline \hline 6,7 & 8,7 & 9,5 & 2,0 & 1,1 & 17,4 \\
\hline
\end{tabular}

Para cada opção de probabilidade de salto, os resultados de cada método foram substancialmente diferentes, principalmente para as duas melhores heurísticas Hi4 e LPT3_ERD. Para probabilidade de $0 \%$ de salto, ou seja, quando as tarefas não saltam nenhum estágio, o resultado da $\mathrm{Hi} 4$ ficou na faixa de $10 \%$ a $39 \%$ de sucesso, enquanto que com $50 \%$ de probabilidade de salto, o desempenho aumentou expressivamente para a faixa de $64 \%$ a $88 \%$. Com 0\% probabilidade de salto, a LPT3_ERD teve desempenho de $10 \%$ a $18 \%$ de sucesso e com $50 \%$ de probabilidade subiu para $26 \%$ a $80 \%$.

A Figura 6.17 apresenta a comparação dos desvios relativos médios dos métodos analisados nesta seção. 


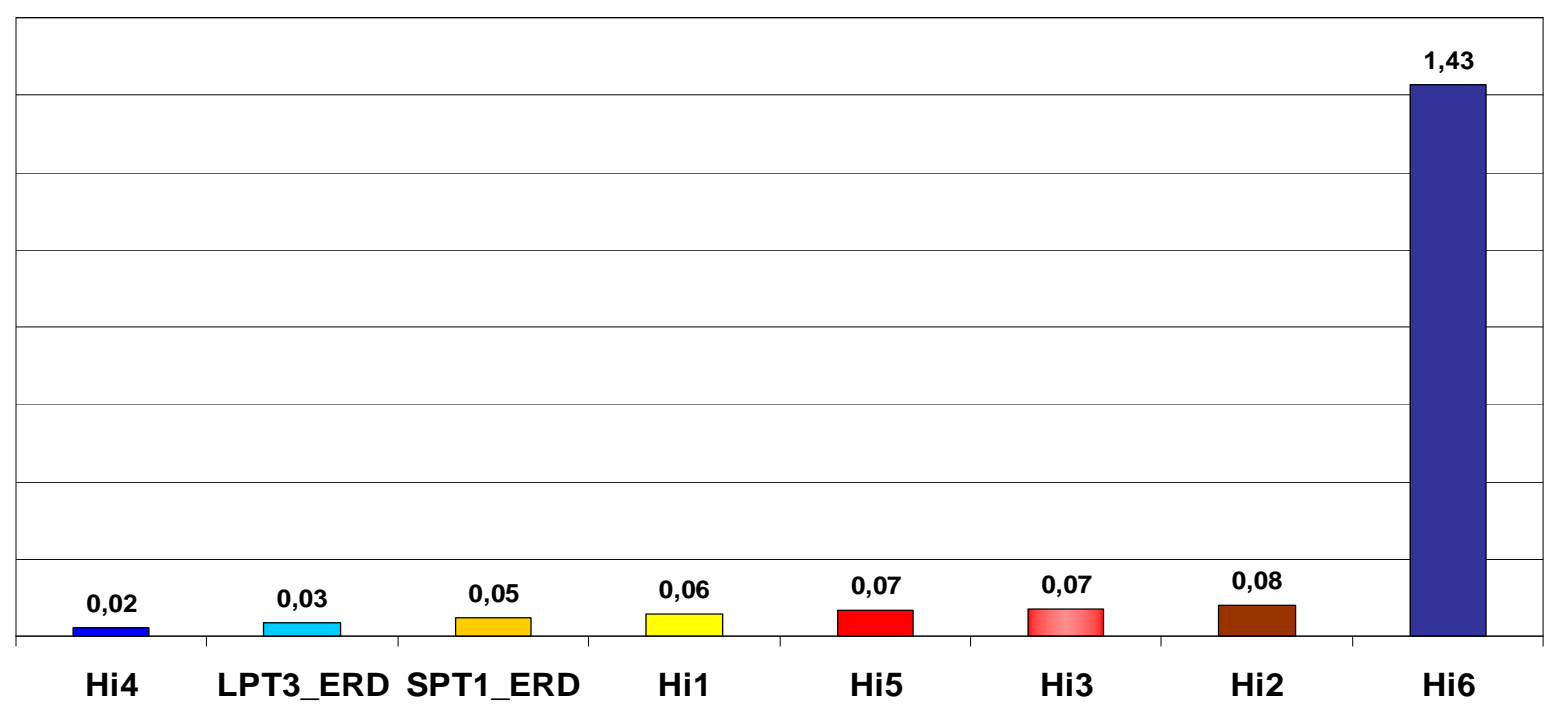

FIGURA 6.17 - Comparação do desvio relativo médio (em \%) das heurísticas para setup independente

Os valores dos desvios relativos confirmaram as conclusões da análise feita para a porcentagem de sucesso: o melhor método obteve o menor desvio relativo (a Hi4 com 0,02) e o pior método teve o maior desvio relativo (a Hi6 com 1,43).

O desvio relativo das regras foi bem pequeno: LPT3_ERD com 0,03 e SPT1_ERD com 0,05. O resultado das outras heurísticas foi o seguinte: Hil com 0,06; Hi3 e Hi5 com 0,07; e Hi2 com 0,08.

A Figura 6.18 detalha o comportamento dos desvios relativos das regras para cada número de tarefas e de estágios. 


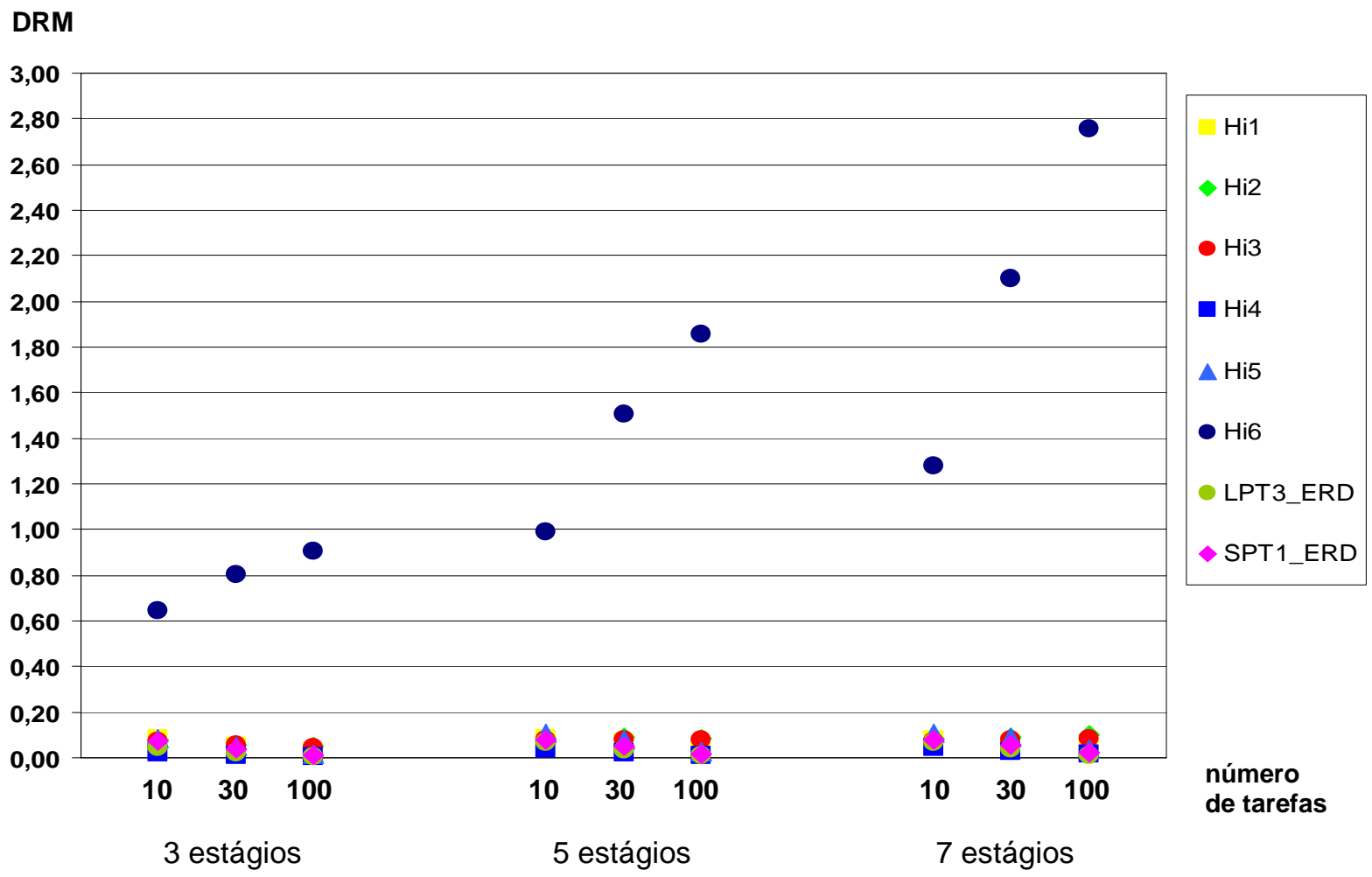

FIGURA 6.18 - Desvio relativo médio (em \%) das heurísticas para setup independente por porte do problema

A heurística Hi6 teve grande variação dos desvios relativos com o aumento do porte do problema, o que já era esperado por se tratar de um procedimento aleatório. Os outros métodos tiveram desvios relativos médios em torno de 0,01 .

O gráfico da Figura 6.19 mostra a comparação do desvio-padrão do desvio relativo dos métodos. 


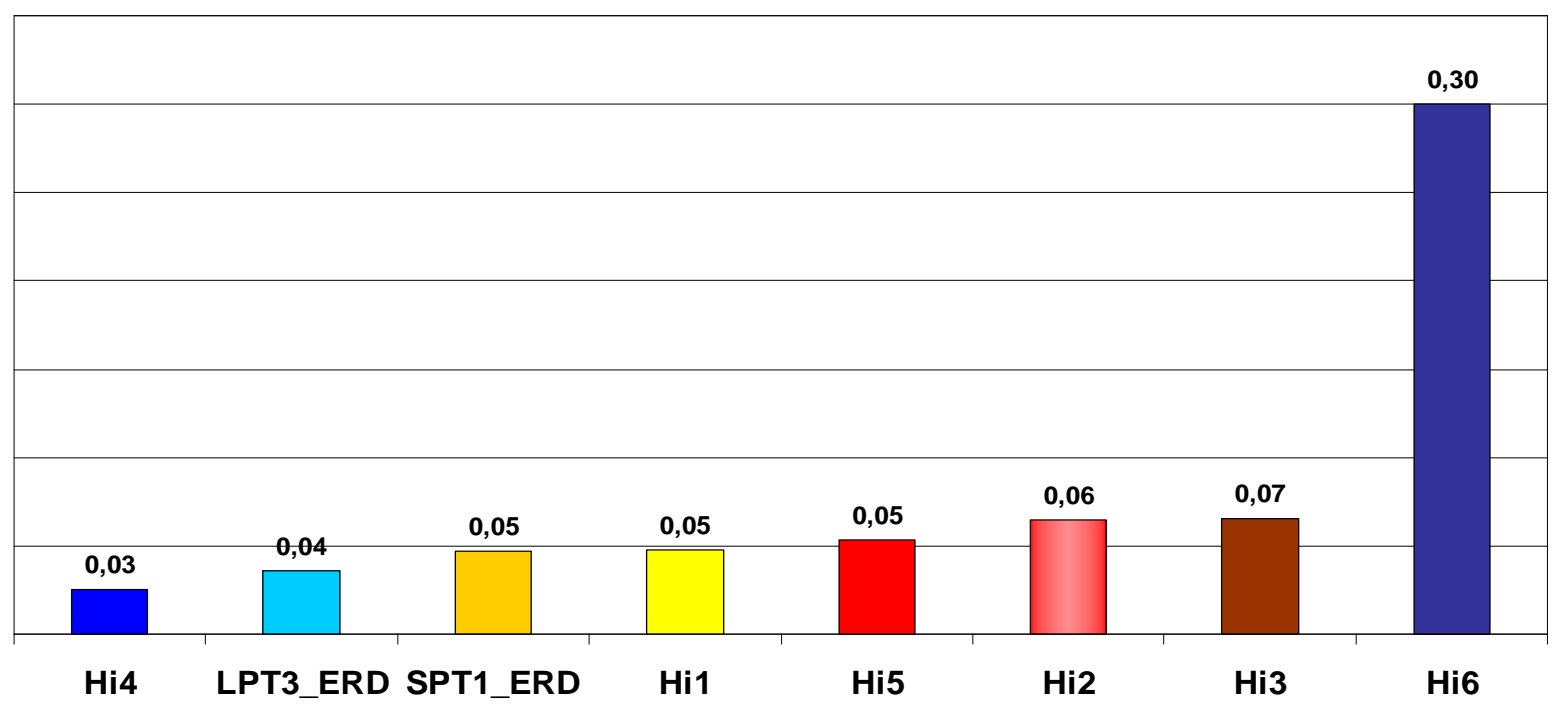

FIGURA 6.19 - Comparação do desvio-padrão do desvio relativo das heurísticas para setup independente

Com exceção da heurística aleatória Hi6, as médias dos valores do desvio-padrão dos métodos ficaram entre 0,03 (para Hi4) e 0,07 (para Hi3), uma amplitude pouco significativa, indicando que houve pequena variação do desvio relativo médio dos métodos. O desviopadrão da pior heurística foi de 0,30 .

O detalhamento dos valores de desvio-padrão do desvio relativo por porte do problema é apresentado na Figura 6.20. 


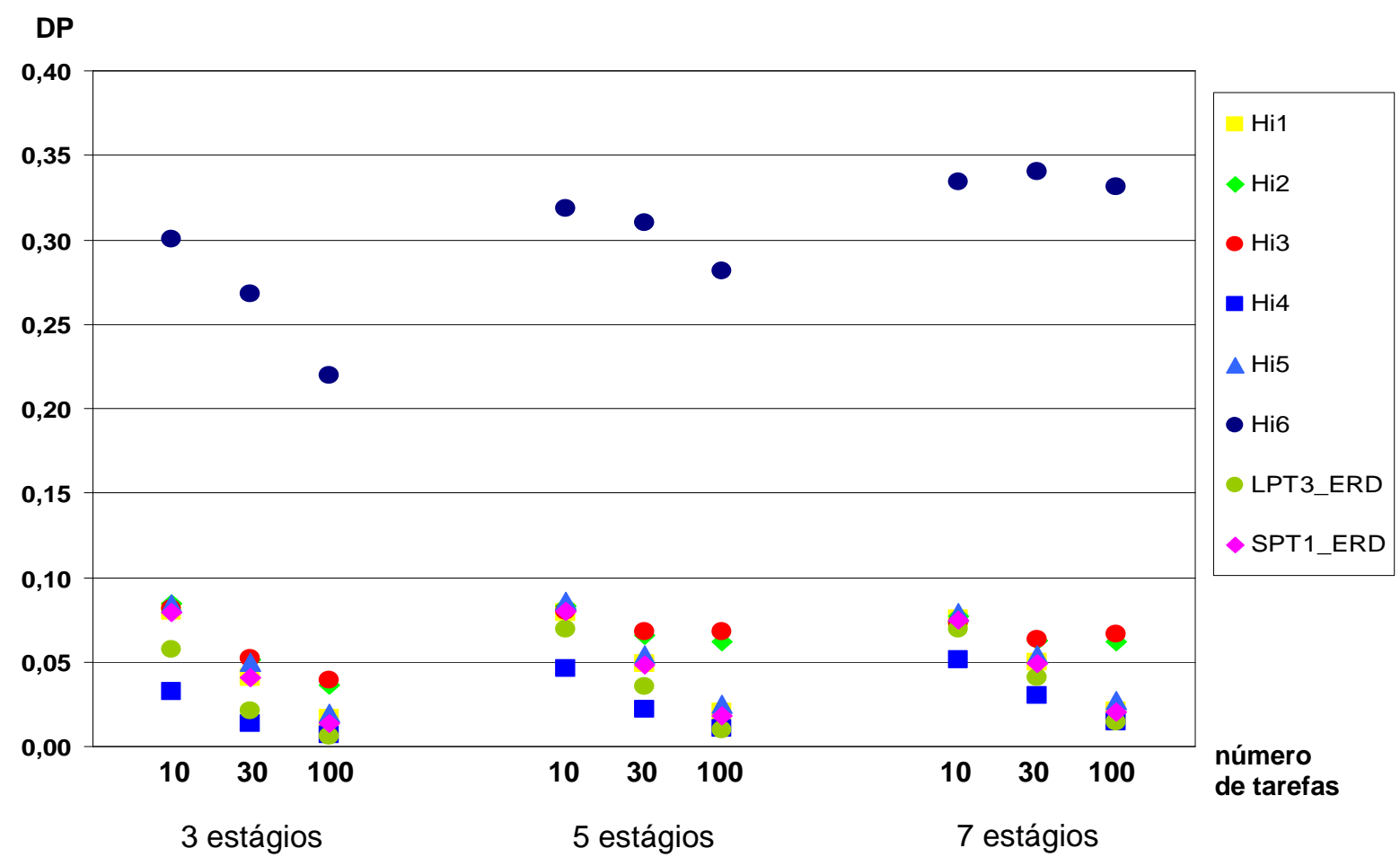

FIGURA 6.20 - Desvio-padrão do desvio relativo das heurísticas para setup independente por porte do problema

Para cada opção de número de tarefas e de estágios, os valores médios do desviopadrão da heurística aleatória Hi6 ficaram entre 0,22 e 0,34, mostrando a sua maior variabilidade, enquanto todos os dos outros métodos atingiram no máximo 0,09.

Diferentemente do tempo de computação das regras de prioridade, que foi de no máximo $16 \mathrm{~ms}$, o processamento das heurísticas consumiu mais tempo de CPU, conforme era previsto pela sua maior complexidade. Por este motivo, foram apresentados na Figura 6.21 os tempos médios de computação (em ms) de cada método analisado nesta seção. 


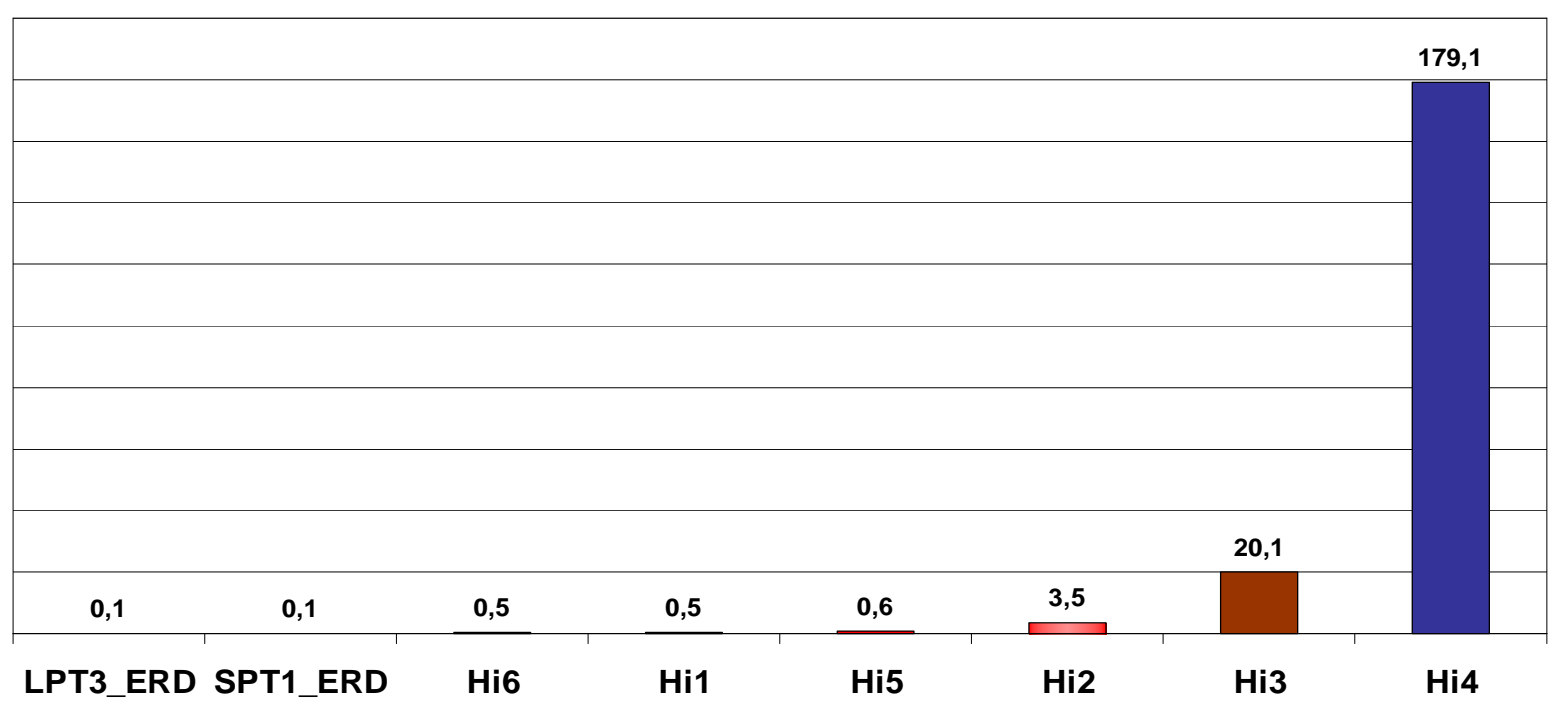

FIGURA 6.21 - Comparação do tempo médio de computação das heurísticas para setup independente (em ms)

Como pode ser observado, o processamento das regras de prioridade teve a menor duração, com média de 0,1 ms. Dentre as heurísticas, a Hi1, a Hi6 e a Hi6 foram as que tiveram menor tempo de CPU, em torno de $0,5 \mathrm{~ms}$.

O maior tempo de computação das heurísticas Hi2 (3,5 ms) e Hi3 (20,1 ms), embora ainda com valores que não comprometem o seu desempenho, pode ser explicado pela aplicação do método de inserção (apenas no último estágio na Hi2 e em todos os estágios na Hi3), cujo procedimento exige maior esforço computacional.

Já a heurística Hi4, que faz a programação por tarefa e aplica o método de inserção em todos os estágios, teve o tempo médio de CPU de 179,1 ms ou aproximadamente 0,2 segundos, o que indica que deve-se ter cautela na sua utilização dependendo do porte do problema. Esta média foi elevada especialmente por causa dos problemas com 100 tarefas, cujo tempo médio de CPU foi de 521,2 ms. Assim, por ter obtido os expressivos resultados de quase 50\% de sucesso, sua eficácia (na melhor solução) justifica a sua pequena perda de eficiência computacional nos problemas com 100 tarefas em relação a outros métodos. 
Além da abrangente comparação dos resultados dos métodos considerados nesta fase da pesquisa, esta análise permitiu confirmar as conclusões apresentadas na seção anterior em relação ao ambiente flexible flow line e às características das tarefas. Tanto o layout, principalmente no tocante à quantidade de estágios com máquinas paralelas (flexibilidade), como as características das tarefas, basicamente em relação à probabilidade de saltar estágios, influenciam significativamente no resultado dos métodos de solução propostos.

\subsection{Resultados do problema com setup dependente}

\subsubsection{Regras de prioridade}

O maior grau de complexidade do problema com setup dependente em relação ao ambiente com setup independente refletiu-se tanto na concepção das regras de prioridade como também na sua implementação. Nesta fase da experimentação computacional, foram implementadas e analisadas as treze regras de prioridade para setup dependente, definidas na seção 4.4 e reproduzidas na Tabela 6.9 a seguir.

TABELA 6.9 - Regras de prioridade para setup dependente

\begin{tabular}{|c|c|c|}
\hline Regra & Valor para ordenação inicial & $\begin{array}{l}\text { Ordenação nos } \\
\text { estágios } 2 \text { a g }\end{array}$ \\
\hline SPT1 e LPT1 & setup médio + processamento (estágio 1) & \multirow{7}{*}{ ERD } \\
\hline SPT2 e LPT2 & setup médio + processamento (estágio 2 ) & \\
\hline SPT3 e LPT3 & $\begin{array}{c}\text { setup médio + processamento (todos } \\
\text { os estágios) }\end{array}$ & \\
\hline SPT4 e LPT4 & menor setup + processamento (estágio 1 ) & \\
\hline SPT5 e LPT5 & $\begin{array}{c}\text { menor setup }+ \text { processamento (todos } \\
\text { os estágios) }\end{array}$ & \\
\hline SPT6 e LPT6 & $\begin{array}{c}\text { menor setup (se não antecipado) + } \\
\text { processamento (estágio 2) }\end{array}$ & \\
\hline RAND & ALEATÓRIA & \\
\hline
\end{tabular}


A análise global dos 36.000 problemas resolvidos mostrou que as duas melhores regras de prioridade, com uma diferença de desempenho ínfima entre elas, foram a LPT3, que obteve $25,3 \%$ de sucesso, e a LPT5, com $25,2 \%$ de sucesso, como pode ser visto na Figura 6.22. Este resultado positivo da ordenação não crescente indica que é mais vantajoso priorizar as tarefas com maiores cargas de trabalho no problema com setup dependente.

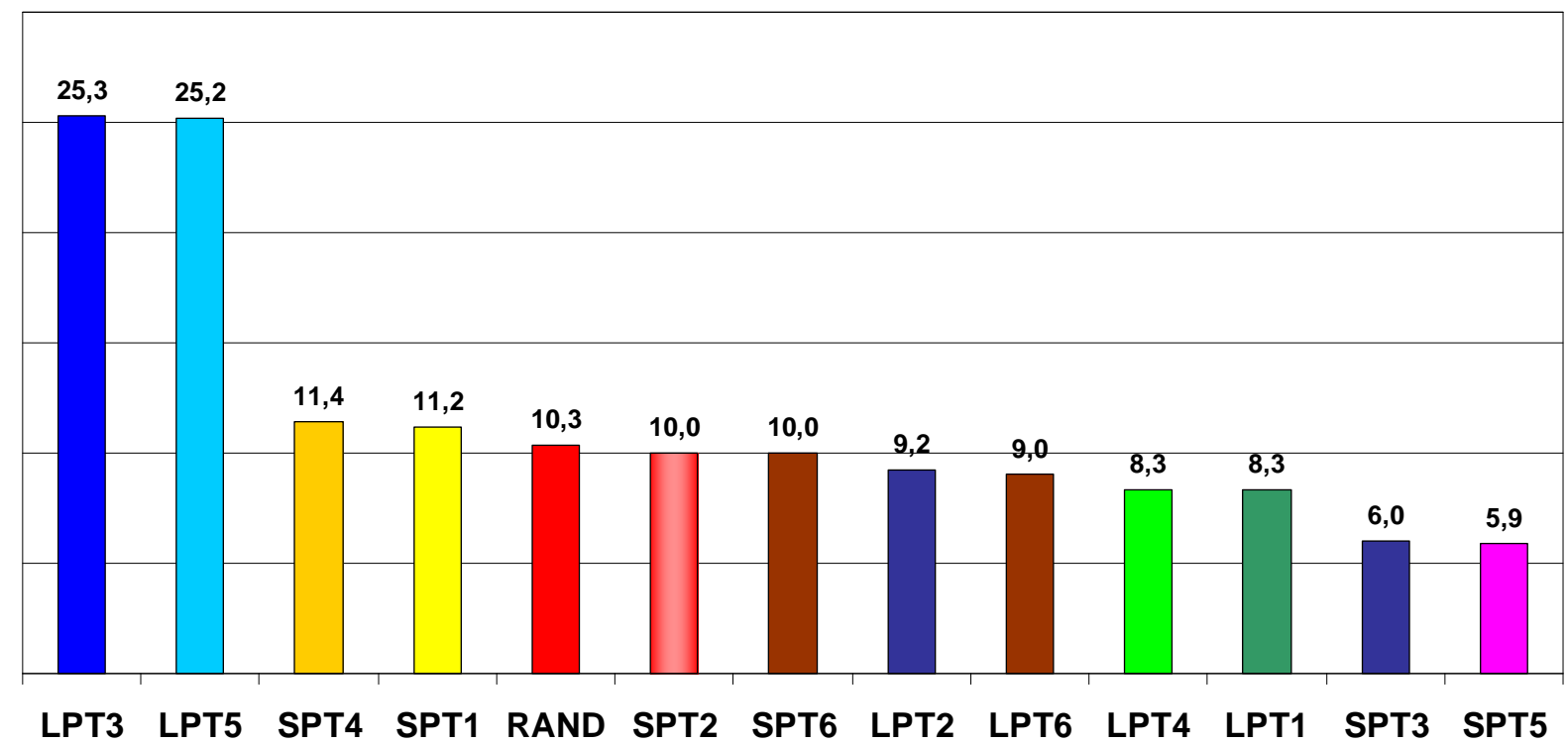

FIGURA 6.22 - Comparação de desempenho das regras de prioridade para setup dependente (em \% de sucesso)

O bom desempenho das regras LPT3 e LPT5 mostra que quando se consideram na ordenação os dados de todos os estágios, é mais eficaz sequenciar pela regra LPT. No caso de se utilizar apenas os dados do primeiro estágio, a regra SPT demonstra melhor desempenho, como no caso da SPT4 e da SPT1, que ficaram em terceiro e quarto lugares, respectivamente, com $11,4 \%$ e $11,2 \%$ de sucesso.

As quatro melhores regras juntas, LPT3, LPT5, SPT4 e SPT1, obtiveram 73,1\% de sucesso (empatando ou não). Todas as outras regras obtiveram desempenho inferior à regra RAND, que ficou em quinto lugar, com $10,3 \%$ de sucesso. 
As piores regras foram a SPT5, que obteve 5,9\% de sucesso, e a SPT3, com 6,0\% de sucesso, correspondendo à ordenação oposta das duas melhores regras. Analogamente, a terceira e quarta piores regras foram a LPT4 e LPT1, cada uma com 8,3\% de sucesso, também correspondendo ao oposto da ordenação da terceira e da quarta melhores regras.

Esta correlação entre a melhor e a pior regra não necessariamente acontece sempre. Portanto, no problema tratado, tanto os dados considerados nos valores de ordenação como a sequência desses valores influenciam de forma significativa na duração total da programação, a ponto do melhor método passar a ser o pior quando se inverte a ordenação.

As regras LPT3 e LPT5 utilizam valores de ordenação diferentes e tiveram resultados muito próximos na maioria dos problemas resolvidos, requerendo uma análise mais detalhada.

Em relação aos valores de ordenação, a diferença entre elas é que a LPT3 utiliza a média dos tempos de setup de cada estágio e a LPT5 considera o menor tempo de setup de cada estágio. Os tempos de setup foram uniformemente distribuídos em dois intervalos distintos: $U[25,74]$ e $U[75,125]$. Portanto, probabilisticamente a média e o menor valor dificilmente coincidem.

Ainda assim, em $18 \%$ dos problemas, ambas as regras forneceram o mesmo valor do makespan. E em 99,9\% dos problemas, a diferença em módulo entre o valor do makespan dessas duas regras foi de no máximo $15 \%$. E nos problemas restantes, a maior diferença em módulo do makespan foi de $43 \%$.

Isto significa que, considerando dados de todos os estágios e ordenação decrescente, a diferença entre a média dos tempos de setup e o menor tempo de setup de cada estágio não é suficiente para afetar de forma relevante a solução de uma regra de prioridade. 
A Figura 6.23 apresenta o desempenho das treze regras de prioridade detalhado por porte do problema.

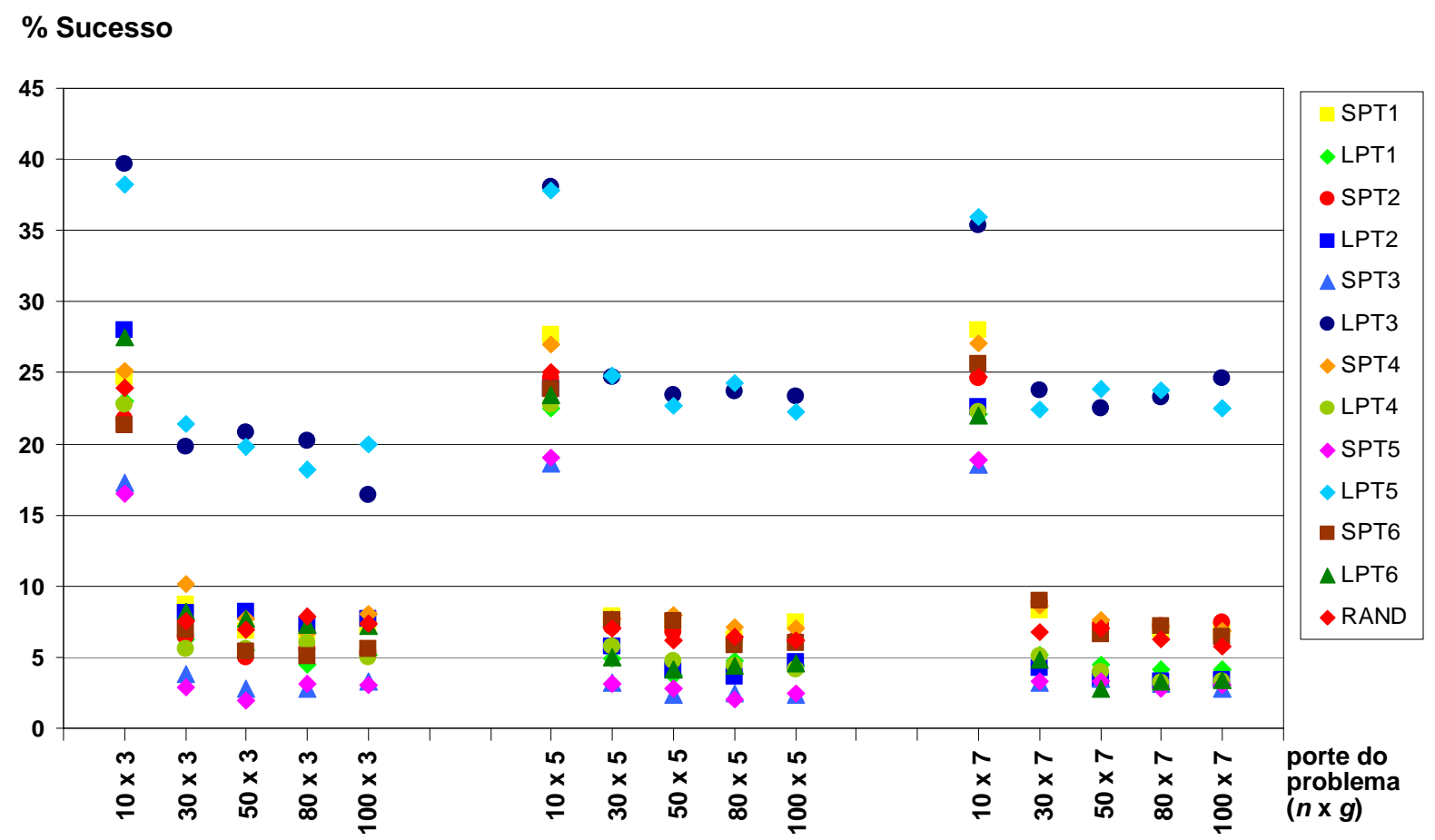

FIGURA 6.23 - Desempenho das regras de prioridade para setup dependente (em \% de sucesso)

Em relação ao porte do problema, com o aumento do número de estágios, houve certa estabilidade no desempenho das regras, podendo indicar que este parâmetro não afeta de forma relevante o resultado. O pequeno valor de 1,5 da AMV para o número de estágios reafirma esta inferência.

Já a curva de desempenho das regras para o número de tarefas forma um "degrau” da opção de 10 tarefas para as demais. Em problemas com 10 tarefas, todas as regras tiveram desempenho muito superior do que outras opções, chegando a uma diferença de 22 pontos percentuais (atingida pela regra LPT3 comparando com problemas com 100 tarefas e 3 estágios). Isto comprova o suposto bom desempenho das regras para problemas de pequeno porte. 
Esta diferença fez com que o valor da AMV para o número de tarefas fosse de 7,4, indicando a influência deste parâmetro no problema com setup dependente. Entretanto, como pode ser constatado no gráfico da Figura 6.23, esta variação dos resultados para as opções do número de tarefas ocorre apenas em relação aos problemas com 10 tarefas. Para problemas de médio e grande porte, de 30 a 100 tarefas, nas três opções do número de estágios, o desempenho das regras é estável. A título de confirmação, excluindo-se a opção de 10 tarefas, que estatisticamente constitui um ponto fora da curva, o valor da AMV para o número de tarefas passa a ser de 0,8 , ou seja, a variação de desempenho em relação ao número de tarefas para problemas com 30 a 100 tarefas é irrelevante.

A Tabela 6.10 apresenta de forma ilustrada as quatro melhores regras para setup dependente para cada opção de número de tarefas e de estágios, com seu respectivo desempenho.

TABELA 6.10 - Melhores regras para setup dependente por porte do problema e suas porcentagens de sucesso

\begin{tabular}{|c|c|c|c|c|c|}
\hline $\boldsymbol{g}$ & $n$ & 10 lugar & 20 lugar & 30 lugar & 40 Iugar \\
\hline \multirow[t]{5}{*}{3} & 10 & $\begin{array}{c}\text { LPT3 } \\
(39,7 \%)\end{array}$ & $\begin{array}{c}\text { LPT5 } \\
(38,3 \%)\end{array}$ & $\begin{array}{l}\text { LPT2 } \\
(28,0 \%)\end{array}$ & $\begin{array}{l}\text { LPT6 } \\
(27,5 \%)\end{array}$ \\
\hline & 30 & $\begin{array}{l}\text { LPT5 } \\
(21,4 \%)\end{array}$ & $\begin{array}{l}\text { LPT3 } \\
(19,8 \%)\end{array}$ & $\begin{array}{l}\text { SPT4 } \\
(10,1 \%)\end{array}$ & $\begin{array}{l}\text { SPT1 } \\
(8,7 \%)\end{array}$ \\
\hline & 50 & $\begin{array}{l}\text { LPT3 } \\
(20,8 \%)\end{array}$ & $\begin{array}{l}\text { LPT5 } \\
(19,8 \%) \\
\end{array}$ & $\begin{array}{l}\text { LPT2 } \\
(8,2 \%)\end{array}$ & $\begin{array}{l}\text { LPT6 } \\
(7,7 \%)\end{array}$ \\
\hline & 80 & $\begin{array}{l}\text { LPT3 } \\
(20,2 \%)\end{array}$ & $\begin{array}{l}\text { LPT5 } \\
(18,2 \%)\end{array}$ & $\begin{array}{l}\text { RAND } \\
(7,8 \%)\end{array}$ & $\begin{array}{l}\text { LPT2 } \\
(7,3 \%)\end{array}$ \\
\hline & 100 & $\begin{array}{l}\text { LPT5 } \\
(20,0 \%) \\
\end{array}$ & $\begin{array}{l}\text { LPT3 } \\
(16,4 \%) \\
\end{array}$ & $\begin{array}{l}\text { SPT4 } \\
(8,0 \%) \\
\end{array}$ & $\begin{array}{l}\text { LPT2 } \\
(7,7 \%) \\
\end{array}$ \\
\hline \multirow[t]{5}{*}{5} & 10 & $\begin{array}{l}\text { LPT3 } \\
(38,1 \%)\end{array}$ & $\begin{array}{l}\text { LPT5 } \\
(37,8 \%)\end{array}$ & $\begin{array}{l}\text { SPT1 } \\
(27,6 \%)\end{array}$ & $\begin{array}{l}\text { SPT4 } \\
(27,0 \%)\end{array}$ \\
\hline & 30 & $\begin{array}{l}\text { LPT5 } \\
(24,8 \%)\end{array}$ & $\begin{array}{l}\text { LPT3 } \\
(24,7 \%)\end{array}$ & $\begin{array}{l}\text { SPT1 } \\
(7,9 \%)\end{array}$ & $\begin{array}{l}\text { SPT4 } \\
(7,7 \%)\end{array}$ \\
\hline & 50 & $\begin{array}{l}\text { LPT3 } \\
(23,5 \%)\end{array}$ & $\begin{array}{l}\text { LPT5 } \\
(22,7 \%)\end{array}$ & $\begin{array}{l}\text { SPT4 } \\
(7,9 \%)\end{array}$ & $\begin{array}{l}\text { SPT6 } \\
(7,5 \%)\end{array}$ \\
\hline & 80 & $\begin{array}{l}\text { LPT5 } \\
(24,3 \%)\end{array}$ & $\begin{array}{l}\text { LPT3 } \\
(23,7 \%)\end{array}$ & $\begin{array}{l}\text { SPT4 } \\
(7,1 \%)\end{array}$ & $\begin{array}{l}\text { RAND } \\
(6,5 \%)\end{array}$ \\
\hline & 100 & $\begin{array}{l}\text { LPT3 } \\
(23,3 \%)\end{array}$ & $\begin{array}{l}\text { LPT5 } \\
(22,2 \%) \\
\end{array}$ & $\begin{array}{l}\text { SPT1 } \\
(7,5 \%)\end{array}$ & $\begin{array}{l}\text { SPT4 } \\
(7,0 \%) \\
\end{array}$ \\
\hline \multirow[t]{5}{*}{7} & 10 & $\begin{array}{l}\text { LPT5 } \\
(35,9 \%)\end{array}$ & $\begin{array}{l}\text { LPT3 } \\
(35,3 \%)\end{array}$ & $\begin{array}{l}\text { SPT1 } \\
(28,0 \%) \\
\end{array}$ & $\begin{array}{l}\text { SPT4 } \\
(27,1 \%)\end{array}$ \\
\hline & 30 & $\begin{array}{l}\text { LPT3 } \\
(23,8 \%)\end{array}$ & $\begin{array}{l}\text { LPT5 } \\
(22,4 \%)\end{array}$ & $\begin{array}{l}\text { SPT6 } \\
(9,0 \%)\end{array}$ & $\begin{array}{l}\text { SPT2 } \\
(8,9 \%)\end{array}$ \\
\hline & 50 & $\begin{array}{l}\text { LPT5 } \\
(23,8 \%)\end{array}$ & $\begin{array}{l}\text { LPT3 } \\
(22,5 \%)\end{array}$ & $\begin{array}{l}\text { SPT4 } \\
(7,6 \%)\end{array}$ & $\begin{array}{l}\text { SPT2 } \\
(7,3 \%)\end{array}$ \\
\hline & 80 & $\begin{array}{l}\text { LPT5 } \\
(23,8 \%)\end{array}$ & $\begin{array}{l}\text { LPT3 } \\
(23,3 \%)\end{array}$ & $\begin{array}{l}\text { SPT6 } \\
(7,2 \%)\end{array}$ & $\begin{array}{l}\text { SPT2 } \\
(7,2 \%)\end{array}$ \\
\hline & 100 & $\begin{array}{l}\text { LPT3 } \\
(24,6 \%)\end{array}$ & $\begin{array}{l}\text { LPT5 } \\
(22,5 \%)\end{array}$ & $\begin{array}{l}\text { SPT2 } \\
(7,5 \%)\end{array}$ & $\begin{array}{l}\text { SPT1 } \\
(6,9 \%)\end{array}$ \\
\hline
\end{tabular}


Como pode ser visto na Tabela 6.10, o primeiro e o segundo lugares foram disputados equiparadamente pelas regras LPT3 e LPT5. Já o terceiro e o quarto lugares foram bastante alternados entre as regras SPT4, SPT1, LPT2, SPT2, SPT6, LPT6 e RAND.

A Figura 6.24 mostra a comparação do desempenho das regras para cada opção de flexibilidade e porte do problema.

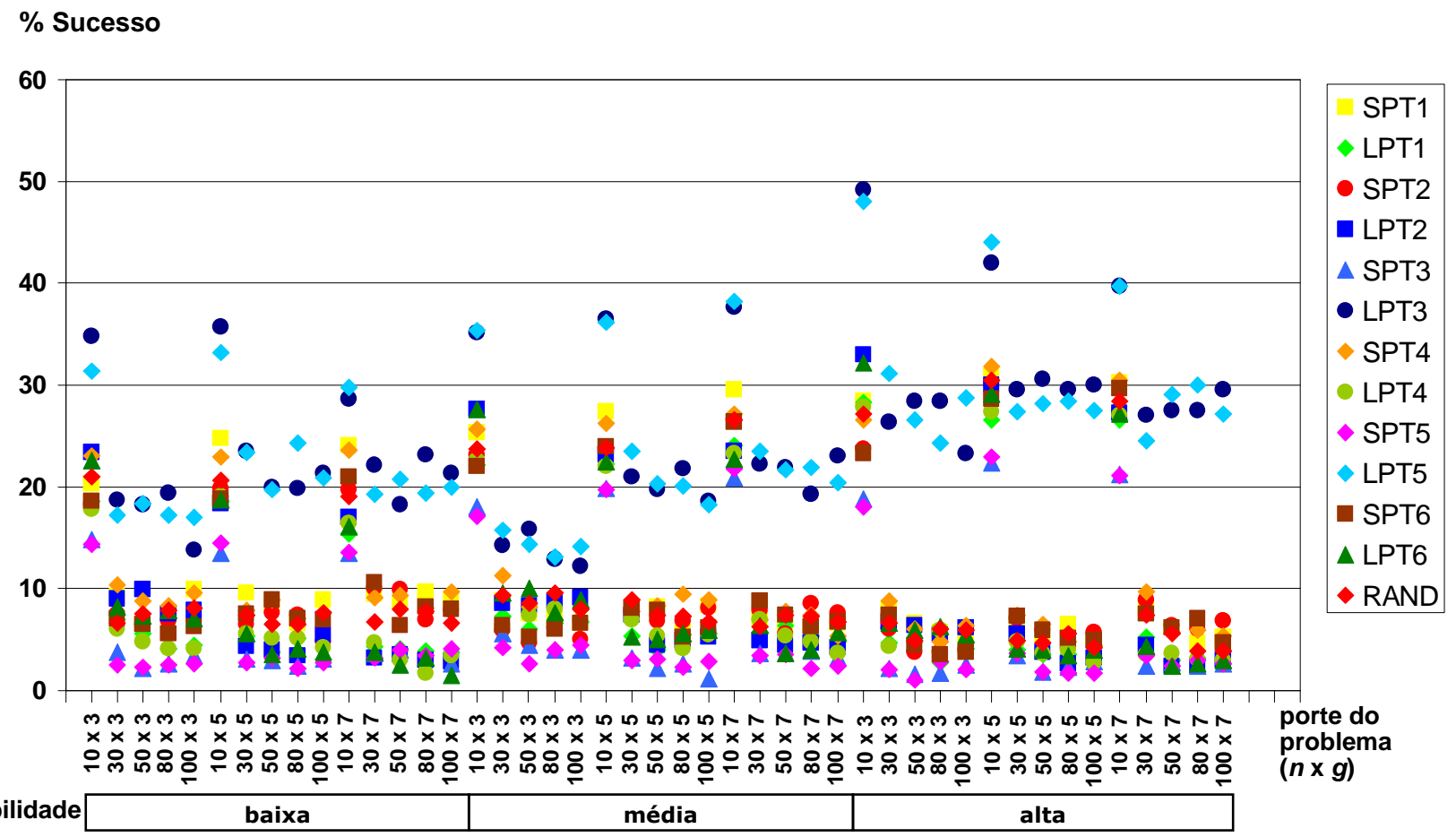

FIGURA 6.24 - Desempenho das regras para setup dependente por flexibilidade e porte do problema (em \% de sucesso)

Pode-se perceber que ambientes com flexibilidade alta têm uma leve melhoria no desempenho das regras em relação aos outros níveis, principalmente em problemas com 10 tarefas. Esta diferença é ainda mais perceptível com as duas melhores regras. Isto indica que quanto mais estágios contendo máquinas paralelas, melhor é o desempenho das regras, sobretudo da LPT3 e da LPT5. 
Pelo detalhamento da Figura 6.24, revela-se também que as regras LPT3 e LPT5 atingem o seu melhor desempenho em problemas com 10 tarefas, 3 estágios e flexibilidade alta, com respectivamente $49 \%$ e $48 \%$ de sucesso. Porém, ainda com 10 tarefas e flexibilidade alta, o desempenho dessas duas regras cai sensivelmente com o aumento do número de estágios, chegando ambas a $40 \%$ de sucesso para 7 estágios. Em outras configurações do porte do problema e flexibilidade alta, essas duas regras mantêm o desempenho na faixa em torno dos $30 \%$ de sucesso.

As demais regras mantiveram uma razoável estabilidade nos três níveis de flexibilidade. A diferença de desempenho de todas as regras em relação aos problemas com 10 tarefas continua perceptível neste nível de detalhamento por flexibilidade. O valor da AMV da flexibilidade foi de 3,0 .

A Figura 6.25 apresenta o desempenho das regras detalhado por intervalo de setup e porte do problema.

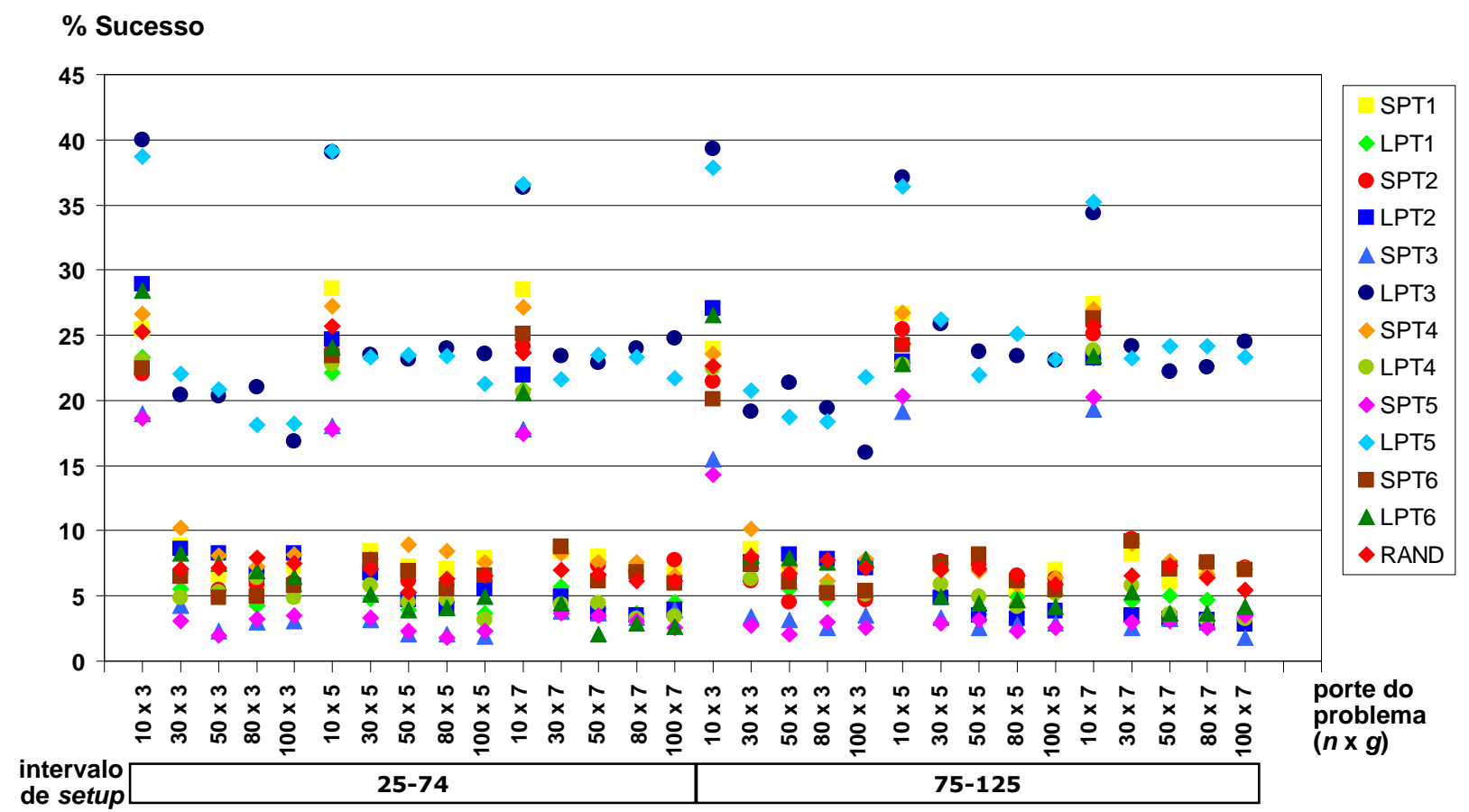

FIGURA 6.25 - Desempenho das regras para setup dependente por intervalo de setup e porte do problema (em \% de sucesso) 
Em relação aos dois intervalos de tempos de setup considerados, não houve diferenças significativas no desempenho de cada regra, podendo indicar que este parâmetro não influencia de forma relevante no desempenho das regras. Observou-se apenas que para o intervalo $[25,74]$, a regra LPT3 superou levemente a LPT5: 25,5\% de sucesso da primeira contra 25\% da segunda. E para o intervalo $[75,125]$ aconteceu o inverso: a LPT5 obteve $25,4 \%$ de sucesso enquanto a LPT3 atingiu $25,1 \%$.

O valor da AMV dos intervalos de setup foi de 1,0, confirmando a pequena variabilidade dos resultados das regras em relação às duas opções consideradas neste parâmetro.

O gráfico da Figura 6.26 ilustra o desempenho das regras para as probabilidades de antecipação dos tempos de setup por porte do problema.

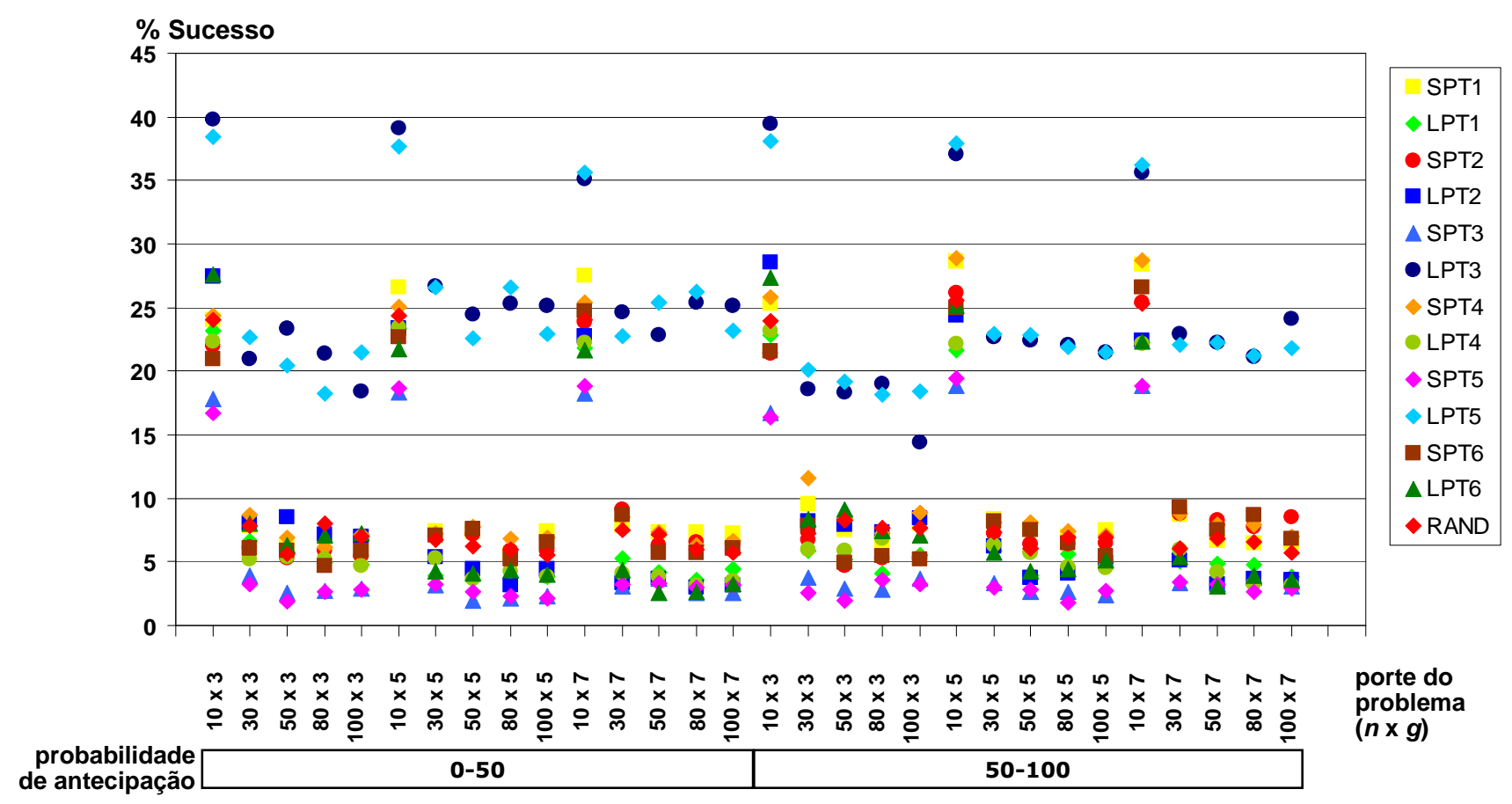

FIGURA 6.26 - Desempenho das regras para setup dependente por probabilidade de antecipação do setup e porte do problema (em \% de sucesso)

Como pode ser visto na Figura 6.26, não existem grandes variações no desempenho das regras ao passar do intervalo de [0-50]\% para o de [50-100]\%. Esta informação é confir- 
mada pelo reduzido valor de 1,1 da AMV para os intervalos de probabilidade de antecipação do setup.

Com o intervalo de $[0,50] \%$, a diferença de desempenho entre a LPT3 e a LPT5 foi maior do que no intervalo de $[50,100] \%$. No primeiro intervalo, a LPT3 teve em média 0,48 ponto percentual acima da LPT5 e no segundo, ao contrário, a LPT5 teve em média 0,21 ponto percentual acima da LPT3. Ou seja, em ambientes com menor probabilidade de antecipação do setup, a regra LPT3 é levemente superior à LPT5 e quando há maior probabilidade de antecipação, as duas regras obtêm resultados próximos.

As regras SPT6 e LPT6, que consideram a característica de antecipação do setup no valor da ordenação, não obtiveram resultados expressivos, podendo indicar que considerar a antecipação na ordenação inicial não influencia no desempenho da programação do problema com setup dependente.

A variação de desempenho em relação à probabilidade das tarefas saltarem estágios pode ser vista na Figura 6.27.

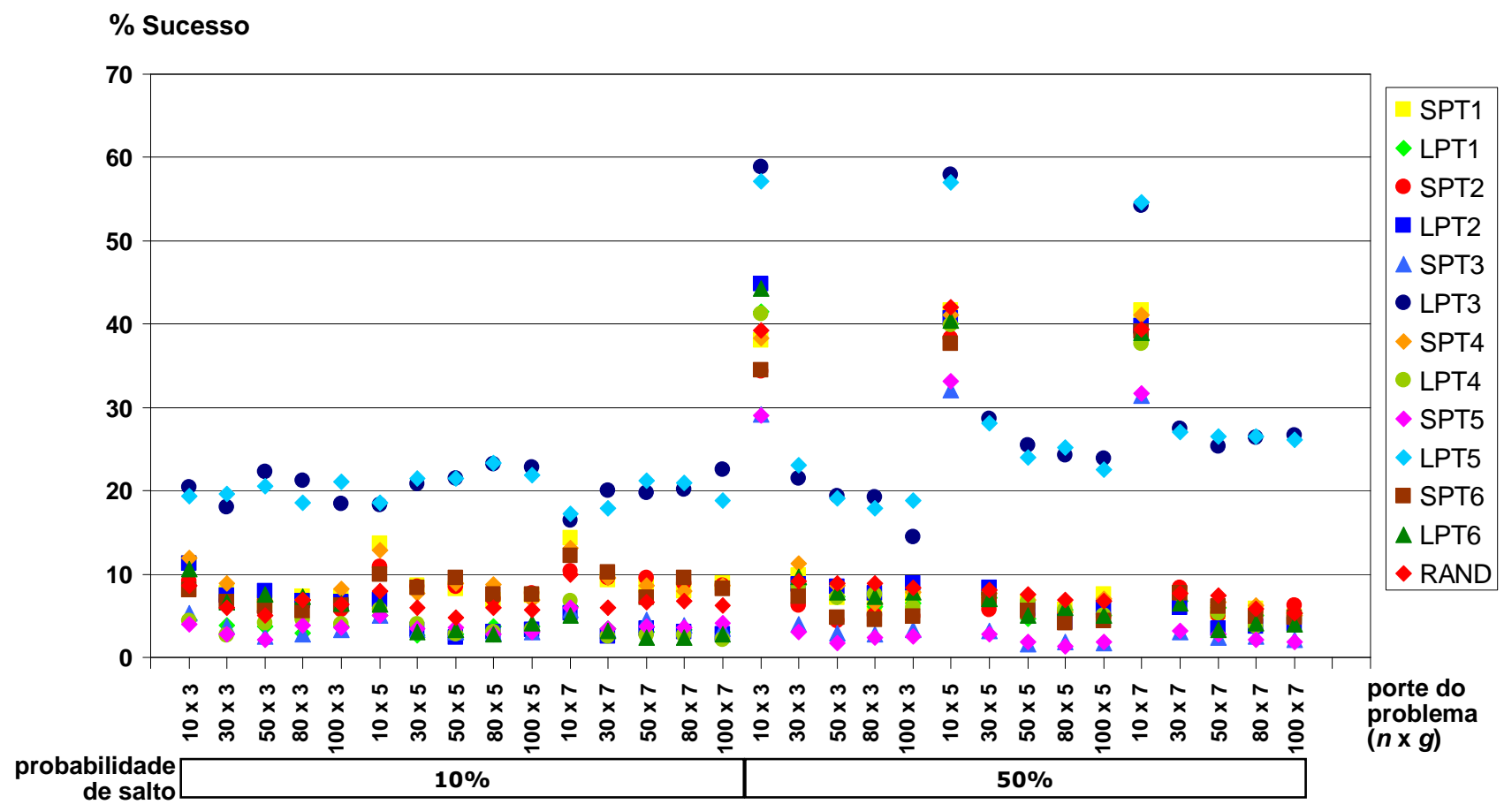

FIGURA 6.27 - Desempenho das regras para setup dependente por probabilidade de salto e porte do problema (em \% de sucesso) 
A probabilidade de salto foi a característica que mais influenciou no resultado das regras, principalmente no desempenho da LPT3 e da LPT5. Com todas as regras, especialmente em problemas com 10 tarefas, nas três opções de estágios, também houve uma considerável variação em relação a outras configurações de porte do problema, como mostra a Figura 6.27. O valor da AMV para a probabilidade de salto foi de 8,0 .

Esta grande variação no desempenho das regras em relação a este parâmetro mostra a importância do estudo da possibilidade das tarefas saltarem estágios, uma situação presente em muitos tipos de indústrias.

Quando a probabilidade de salto foi de $10 \%$, houve certa estabilidade no desempenho das regras: para a LPT3 e a LPT5 em torno de $20 \%$ de sucesso e para as outras, na faixa até $10 \%$ de sucesso. Com 50\% de probabilidade de salto, o desempenho da LPT3 e da LPT5 ficou perto dos $60 \%$ de sucesso para problemas com 10 tarefas e na faixa de $20 \%$ a $30 \%$ para problemas de 30 a 100 tarefas. Os outros métodos também demonstraram melhor desempenho com a opção de $50 \%$ de probabilidade de salto e problemas com 10 tarefas, ficando na faixa de $30 \%$ a $45 \%$.

Analisando separadamente cada opção do número de estágios, com $10 \%$ da probabilidade de salto, as regras LPT3 e LPT5 obtiveram uma leve melhora com o aumento do número de tarefas. Já para 50\% de probabilidade de salto, houve uma leve redução. Com exceção dos problemas com 10 tarefas, todos os outros métodos mantiveram certa estabilidade no desempenho.

O fato das regras LPT3 e LPT5 apresentarem desempenho superior principalmente nas opções de problemas com 10 tarefas, com alta flexibilidade (todos os estágios com máquinas paralelas) e com $50 \%$ da probabilidade de salto (a maior entre as proba- 
bilidades analisadas), mostra ainda mais a vantagem da utilização destas duas regras em ambientes flexíveis, como é o caso do flexible flow line.

A Tabela 6.11 apresenta o resumo da comparação dos valores da AMV para todos os parâmetros considerados na solução do problema com setup dependente.

TABELA 6.11 - Valores da AMV para os parâmetros das regras de prioridade com setup dependente

\begin{tabular}{|c|c|c|c|c|c|}
\hline $\boldsymbol{n}$ & $\boldsymbol{g}$ & $\boldsymbol{f}$ & $\boldsymbol{s}$ & $\boldsymbol{a}$ & $\boldsymbol{l}$ \\
\hline \hline $7,4^{*}$ & 1,5 & 3,0 & 1,0 & 1,1 & 8,0 \\
\hline
\end{tabular}

*excluindo-se a opção de $n=10$, o valor passa a ser de 0,8 .

Neste problema, o parâmetro que mais influenciou foi a probabilidade de salto com AMV de 8,0. Embora a AMV do número de tarefas tenha sido de 7,4, como já salientado anteriormente nesta seção, excluindo-se a opção de 10 tarefas por se tratar de um caso estatístico de ponto fora da curva, a AMV para o número de tarefas passa a ser de 0,8 . Ou seja, o número de tarefas tem uma pequena variação para a maioria dos casos.

A Figura 6.28 apresenta a comparação dos desvios relativos médios das regras.

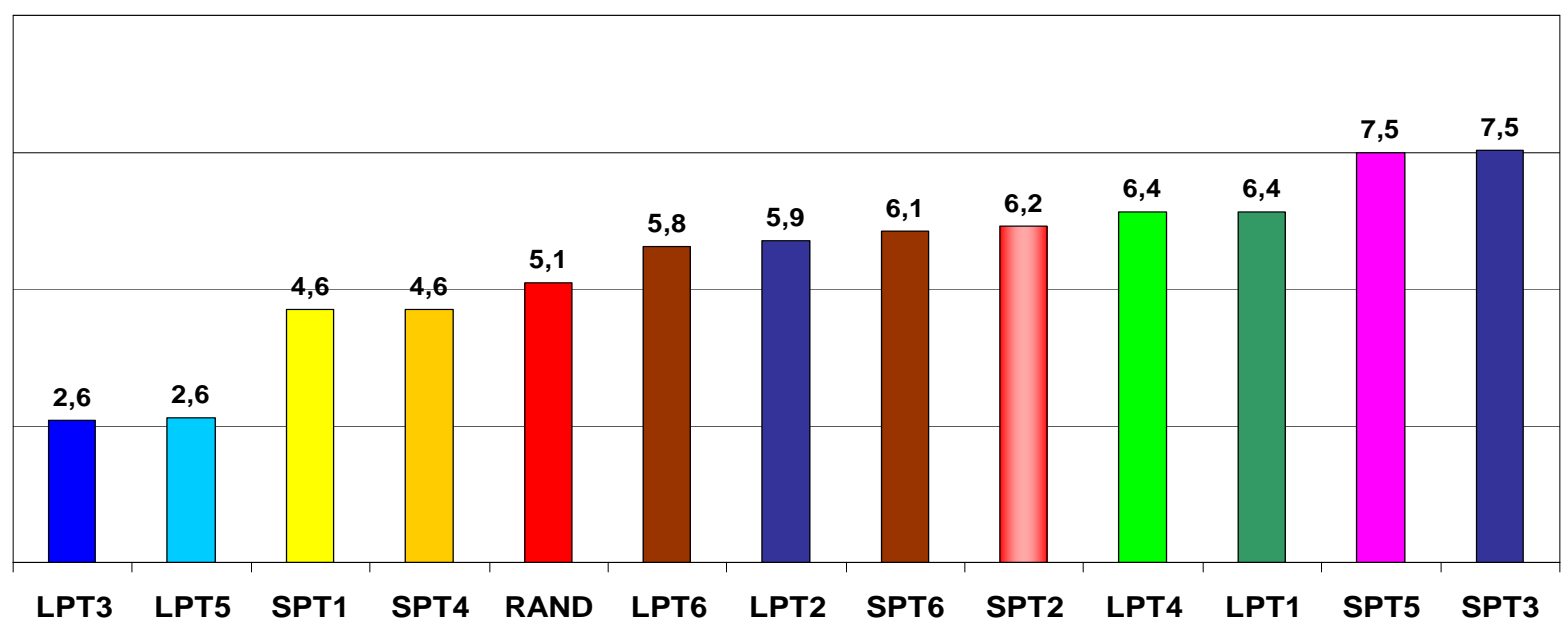

FIGURA 6.28 - Comparação do desvio relativo médio (em \%) das regras para setup dependente 
Os menores valores dos desvios relativos foram apresentados pelas duas melhores regras, sendo praticamente iguais (com diferenças de no máximo 0,01\%). Da mesma forma, os maiores valores dos desvios relativos ocorreram com as duas piores regras (SPT5 e SPT3), também com praticamente o mesmo valor.

Para uma análise mais detalhada, a Figura 6.29 mostra a curva dos valores dos desvios relativos de cada regra por porte do problema.

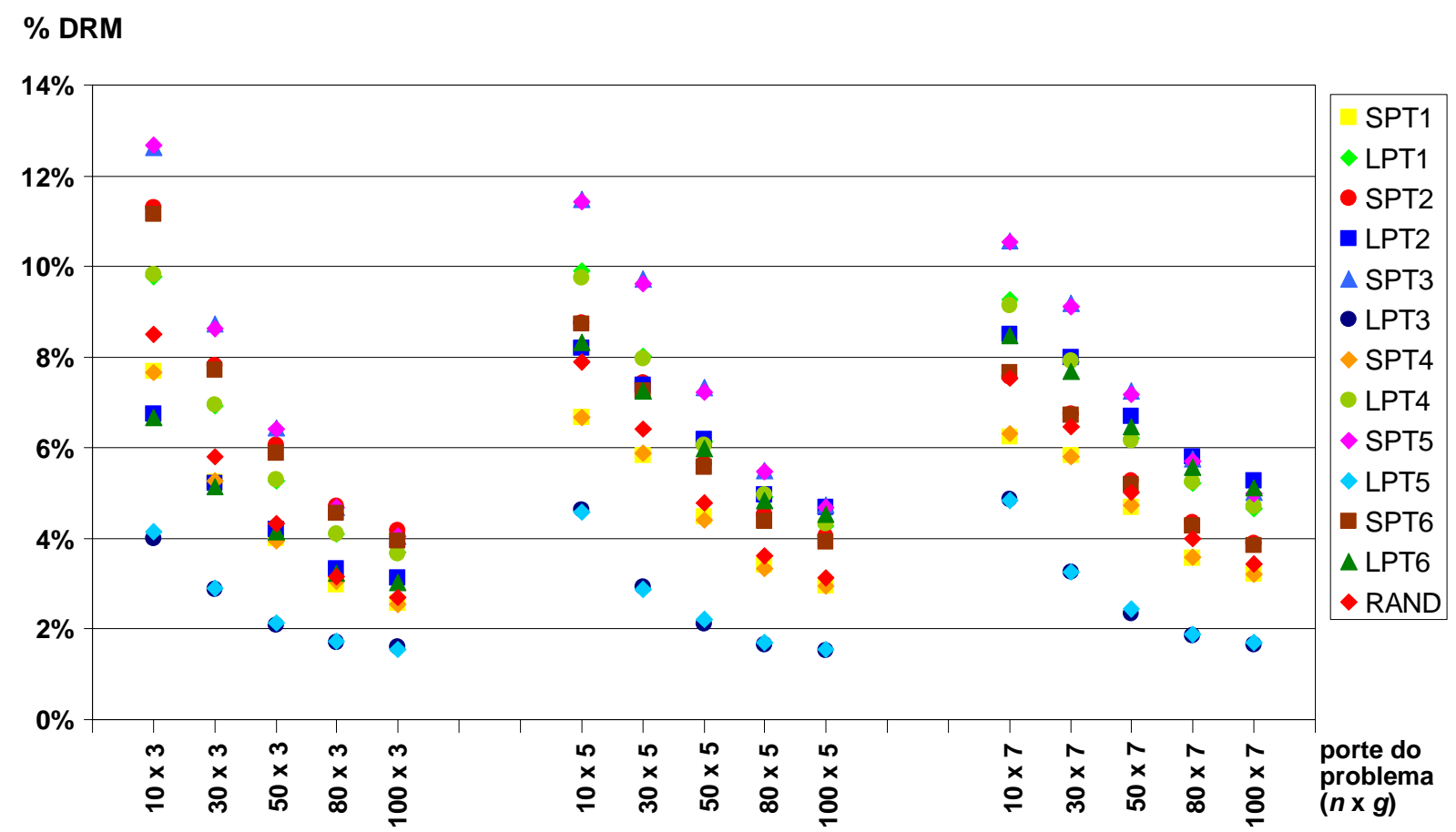

FIGURA 6.29 - Desvio relativo médio (em \%) das regras para setup dependente por porte do problema

Nas três configurações do número de estágios, com o aumento do número de tarefas, os valores dos desvios relativos de cada regra reduzem-se consideravelmente. Por outro lado, para cada opção do número de tarefas, com o aumento do número de estágios, os valores dos desvios relativos permanecem constantes. Isto confirma a análise feita anteriormente para a porcentagem de sucesso, indicando que a carga de trabalho afeta mais a variabilidade do 
resultado dos métodos do que o layout do sistema em relação ao número de estágios de produção.

Especificamente para problemas com 10 tarefas, com o aumento do número de estágios, a amplitude do intervalo entre o método com o maior (SPT5) e o método com o menor desvio relativo (LPT3) diminui. A diferença de 0,09 em problemas com 3 estágios passa para 0,06 com 7 estágios.

Dentre todas as regras e em cada uma das opções de número de estágios, os maiores valores dos desvios relativos ocorrem em problemas com 10 tarefas, indicando que as regras de prioridade fornecem soluções de menor qualidade em problemas de pequeno porte. Em todas as outras configurações de porte do problema, os desvios relativos mantiveram-se estáveis na faixa de $2 \%$ a $14 \%$.

Assim, associando aos resultados da porcentagem de sucesso, para problemas com 10 tarefas os métodos sempre forneceram resultados muito superiores às demais opções, porém com maior variabilidade da solução.

A Figura 6.30 mostra a comparação do desvio-padrão do desvio relativo das regras para setup dependente.

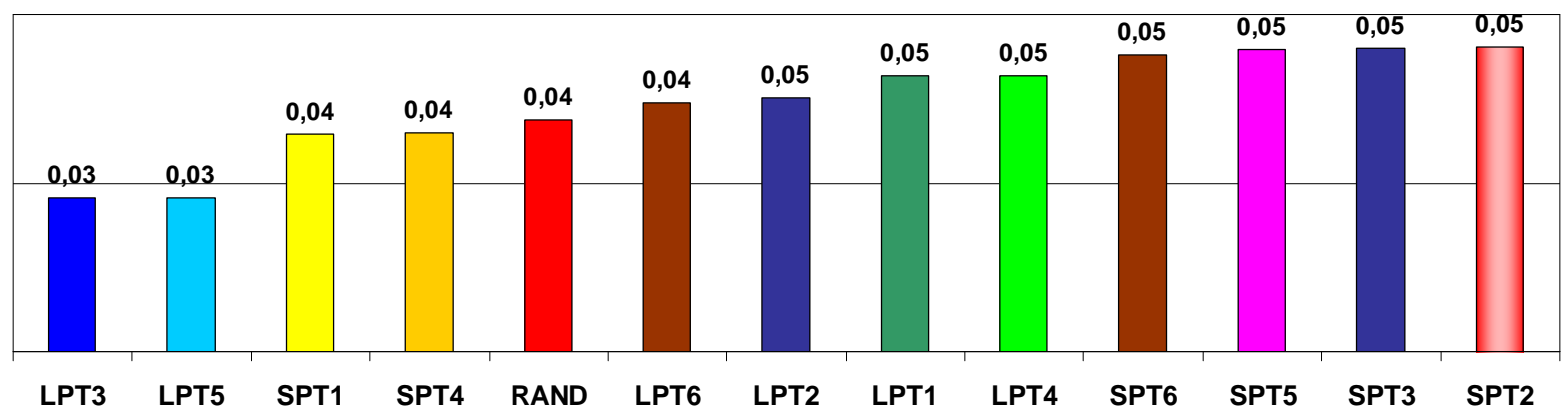

FIGURA 6.30 - Comparação do desvio-padrão do desvio relativo das regras para setup dependente 
Confirmando os resultados verificados anteriormente, as duas melhores regras também tiveram os menores valores de desvio-padrão e as duas piores regras ficaram entre as que tiveram os mais altos valores de desvio-padrão.

Pela análise global, nota-se também que os valores médios do desvio-padrão de todas as regras foram consideravelmente baixos e com uma amplitude irrelevante: na faixa de 0,03 a 0,05. Isto comprova que as regras de prioridade são bastantes estáveis mesmo para a programação em complexos ambientes de produção.

A Figura 6.31 apresenta os valores do desvio-padrão do desvio relativo das regras para cada opção de porte do problema.

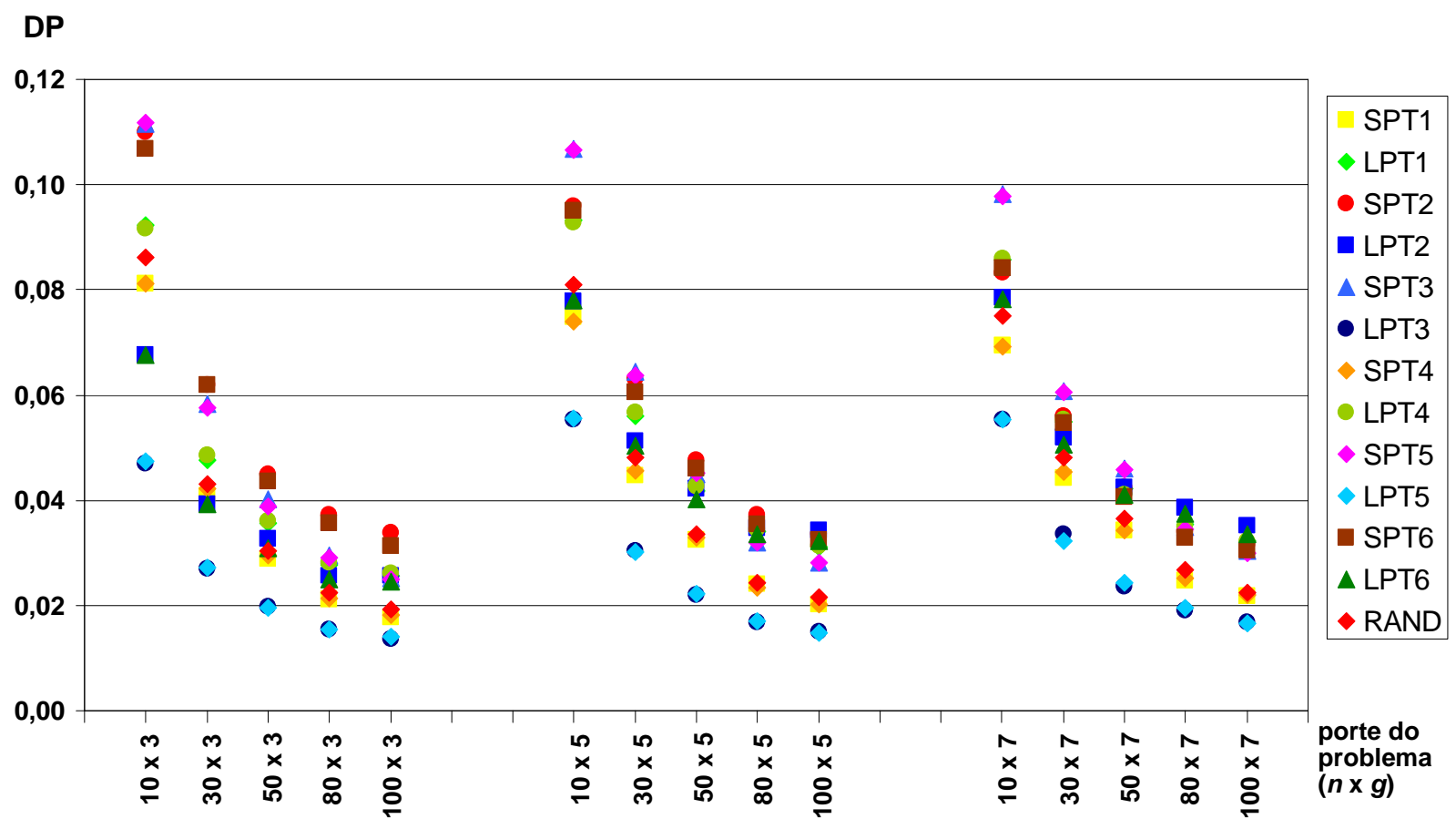

FIGURA 6.31 - Desvio-padrão do desvio relativo das regras para setup dependente por porte do problema

As curvas do desvio-padrão do desvio relativo das regras têm o mesmo comportamento que as dos desvios relativos: para cada opção do número de estágios, os valores dos desvios se reduzem consideravelmente com o aumento do número de tarefas. Ou seja, quanto menor é o problema (em termos de tarefas), menor é a qualidade da solução dos métodos. 
Mais uma vez, assim como as regras de prioridade implementadas para o problema com setup independente, o custo de CPU foi desprezível, pois a média dos tempos de computação foi de 0,27 ms e o maior tempo gasto na solução de um problema foi de 16 ms.

\subsubsection{Heurísticas}

Na última fase da experimentação computacional, foram implementados os sete algoritmos heurísticos descritos no capítulo 5. Na análise dos resultados das heurísticas, foram consideradas também as duas regras de prioridade para setup dependente que obtiveram os melhores resultados dentre as treze apresentadas na seção 4.4 - LPT3 e LPT5, totalizando nove métodos de solução heurística, reproduzidos na Tabela 6.12 a seguir.

TABELA 6.12 - Algoritmos heurísticos e melhores regras de prioridade para setup dependente

\begin{tabular}{|c||c|c|c|}
\hline Método & $\begin{array}{c}\text { Primeiro } \\
\text { estágio }\end{array}$ & $\begin{array}{c}\text { Estágios } \\
\text { intermediários }\end{array}$ & $\begin{array}{c}\text { Último } \\
\text { estágio }\end{array}$ \\
\hline \hline Hd1 & \multicolumn{2}{|c|}{ ECT } & MI \\
\hline Hd2 & \multicolumn{2}{|c|}{ ECT ou FITSP } & MI ou NITSP \\
\hline Hd3 & \multicolumn{2}{|c|}{ ECT ou NITSP } \\
\hline Hd4 & Stinson & ECT \\
\hline Hd5 & LPT3+NJSM & ERD+NJSM \\
\hline Hd6 & LPT5+NJSM & ERD+NJSM \\
\hline Hd7 & \multicolumn{2}{|c|}{ ALEATÓRIA } \\
\hline LPT3 & LPT3+ECT & ERD+ECT \\
\hline LPT5 & LPT5+ECT & \multicolumn{2}{c|}{ ERD+ECT } \\
\hline
\end{tabular}

O gráfico da Figura 3.32 apresenta a comparação do desempenho médio dos métodos de solução analisados nesta seção. 


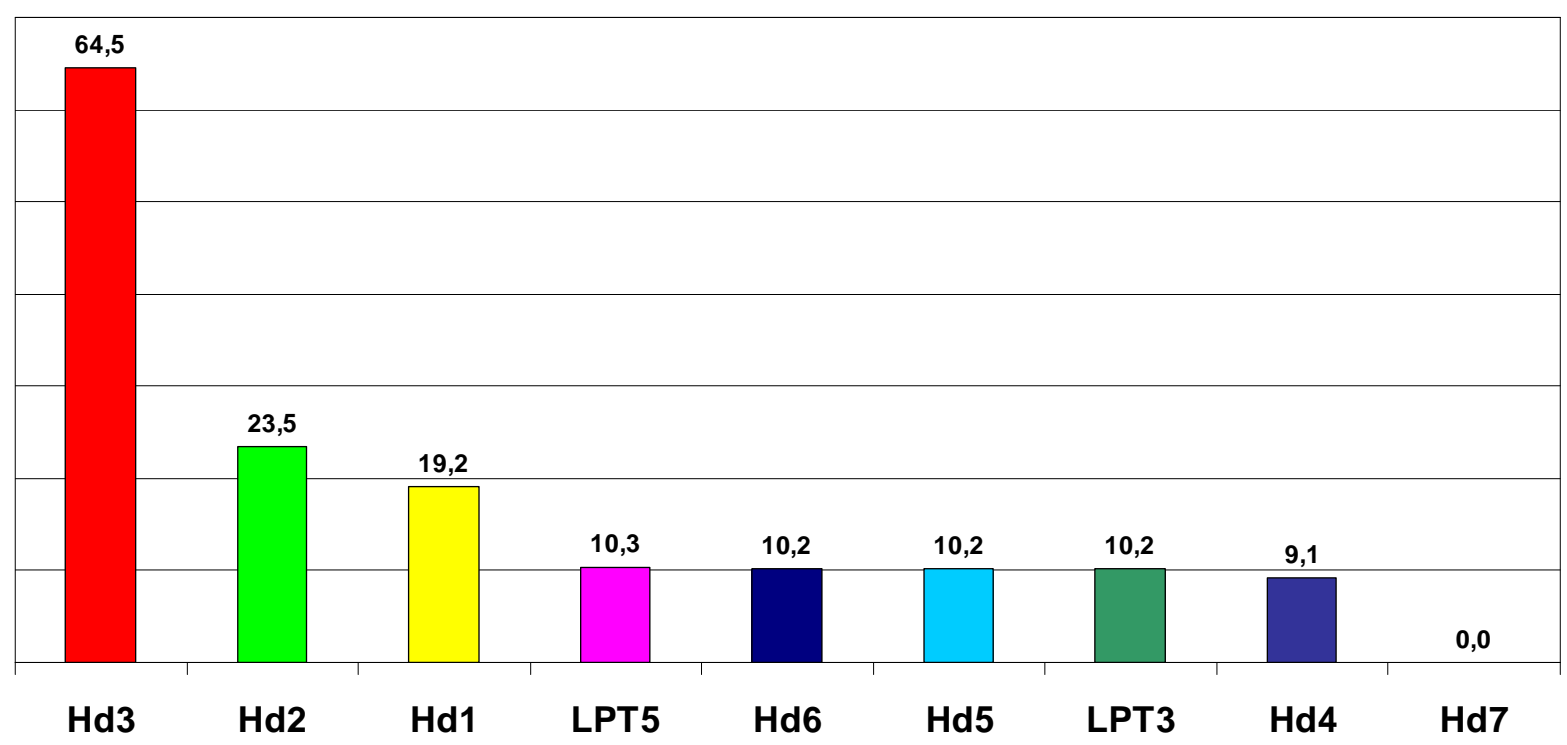

FIGURA 6.32 - Comparação de desempenho das heurísticas para setup dependente (em \% de sucesso)

Como pode ser observado na Figura 6.32, na análise global dos 36.000 problemas resolvidos, a melhor heurística foi a $\mathrm{Hd} 3$, com $64,5 \%$ de sucesso. Em segundo lugar ficou a heurística Hd2, obtendo 23,5\% de sucesso. E em terceiro, a heurística Hd1 atingiu 19,2\% de sucesso. Juntas e desconsiderando-se os empates, as heurísticas Hd1, Hd2 e Hd3 obtiveram $\mathbf{7 5 , 6 \%}$ de sucesso. Este resultado mostra a eficácia da aplicação conjunta da alocação ECT e do algoritmo Multiple Insertion no problema com setup dependente.

As heurísticas Hd2 e Hd3 constituem-se de adaptações da heurística Hd1 para casos específicos em que há estágios com uma única máquina. A superioridade de ambas demonstrou a eficácia dos algoritmos NITSP e FITSP no ambiente flexible flow line e a importância de se tratar de forma particular os estágios com máquina única, pois na prática geralmente constituem gargalos de produção (apenas não serão gargalos em casos muito particulares, quando por exemplo apenas uma tarefa visitar este estágio e possuir um pequeno tempo de processamento). 
Nos problemas em que há estágios com máquina única, os resultados da heurística Hd3 (que aplica o NITSP) foram 45,3\% melhores do que os da heurística Hd1. Para a mesma situação, o desempenho da heurística Hd2 (que utiliza o FITSP) foi superior ao da $\mathrm{Hd} 1$ em apenas $4,3 \%$.

Os seguintes métodos tiveram resultados muito próximos: LPT5, com 10,3\% de sucesso, Hd6, Hd5 e LPT3, com 10,2\%, e Hd4, com 9,1\%. Conforme poderia se esperar, devido a sua aleatoriedade, a pior heurística foi a $\mathrm{Hd} 7$, com desempenho muito próximo de zero, de $0,0194 \%$ de sucesso.

Com procedimentos mais complexos do que as regras de prioridade, por exemplo, esperava-se que a heurística Hd4 obtivesse melhores resultados, principalmente com a flexibilidade baixa, em que há maior incidência de problemas com uma máquina no primeiro estágio. Quando há apenas uma única máquina no primeiro estágio, a heurística Hd4 mantém a sequência original obtida pela Heurística de Stinson, constituindo a própria programação do estágio, uma vez que não é necessário fazer alocação de tarefas a diferentes máquinas. Quando há mais de uma máquina no primeiro estágio, ela quebra a sequência obtida.

Nos problemas com a flexibilidade baixa (em que apenas 1/3 dos estágios têm máquinas paralelas), a Hd4 subiu para o terceiro lugar, conforme pode ser visto na Tabela 6.13, enquanto na análise global ela ficou em penúltimo lugar $\left(8^{\circ}\right)$, com $9,1 \%$ de sucesso, perdendo apenas para a heurística aleatória $\mathrm{Hd} 7$.

TABELA 6.13 - Colocação das heurísticas por desempenho (em \% de sucesso) para os níveis de flexibilidade

\begin{tabular}{|c|c|c|c|c|c|c|c|c|c|}
\hline \multirow{2}{*}{ Flexibilidade } & \multicolumn{9}{|c|}{ Colocação } \\
\hline & 10 & 20 & 30 & 40 & $5^{\circ}$ & 60 & 70 & $8^{\circ}$ & 90 \\
\hline Baixa & $\begin{array}{c}\mathrm{Hd3} \\
(75,6 \%)\end{array}$ & $\begin{array}{l}\mathrm{Hd} 2 \\
(8,8 \%)\end{array}$ & $\begin{array}{l}\text { Hd4 } \\
(7,7 \%)\end{array}$ & $\begin{array}{l}\mathrm{Hd1} \\
(5,0 \%)\end{array}$ & $\underset{(2,8 \%)}{\mathrm{Hi} 5}$ & $\begin{array}{l}\text { LPT3 } \\
(2,8 \%)\end{array}$ & $\begin{array}{l}\mathrm{Hd} 6 \\
(2,6 \%)\end{array}$ & $\begin{array}{l}\text { LPT5 } \\
(2,6 \%)\end{array}$ & $\begin{array}{l}\mathrm{Hd} 7 \\
(0,0 \%)\end{array}$ \\
\hline Média & $\underset{(71,7 \%)}{\operatorname{Hd} 3}$ & $\underset{(15,3 \%)}{\mathrm{Hd} 2}$ & $\begin{array}{l}\mathrm{Hd} 1 \\
(6,3 \%)\end{array}$ & $\begin{array}{l}\text { Hd4 } \\
(6,0 \%)\end{array}$ & $\begin{array}{l}\text { Hd6 } \\
(2,7 \%)\end{array}$ & $\begin{array}{l}\text { LPT3 } \\
(2,7 \%)\end{array}$ & $\begin{array}{l}\text { LPT5 } \\
(2,7 \%)\end{array}$ & $\begin{array}{l}\text { Hd5 } \\
(2,6 \%)\end{array}$ & $\begin{array}{c}\mathrm{Hd7} \\
(0,0 \%)\end{array}$ \\
\hline Alta & $\begin{array}{c}\mathrm{Hd3} \\
(46,2 \%)\end{array}$ & $\begin{array}{c}\mathrm{Hd} 2 \\
(46,2 \%)\end{array}$ & $\begin{array}{c}\mathrm{Hd} 1 \\
(46,2 \%)\end{array}$ & $\begin{array}{l}\text { LPT5 } \\
(25,6 \%)\end{array}$ & $\begin{array}{c}\text { Hd6 } \\
(25,4 \%)\end{array}$ & $\begin{array}{c}\mathrm{Hd5} \\
(25,1 \%)\end{array}$ & $\begin{array}{l}\text { LPT3 } \\
(25,1 \%)\end{array}$ & $\begin{array}{c}\text { Hd4 } \\
(13,8 \%)\end{array}$ & $\begin{array}{l}\mathrm{Hd7} \\
(0,0 \%)\end{array}$ \\
\hline
\end{tabular}


Neste caso, a Hd4 superou até a heurística Hd1, demonstrando a eficácia do Algoritmo de Stinson quando há predominância de estágios com uma máquina.

Com a flexibilidade média, a heurística Hd4 ficou em quarto lugar, com $6 \%$ de sucesso, e na flexibilidade alta, ficou em penúltimo, com 13,8\% de sucesso. Portanto, foram os resultados da flexibilidade alta que reduziram a média do desempenho global da heurística Hd4.

Dos 12.000 problemas gerados com flexibilidade baixa, verificou-se que 7.947 possuem uma única máquina no primeiro estágio, correspondendo a $66,2 \%$. Isto sugere que a força da heurística Hd4 está mesmo na ordenação e não na política de alocação utilizada, já que nas outras opções de flexibilidade, quando há predomínio de máquinas paralelas nos estágios, o desempenho deste método foi menos significativo.

A Figura 6.33 apresenta a porcentagem de sucesso das heurísticas por porte do problema.

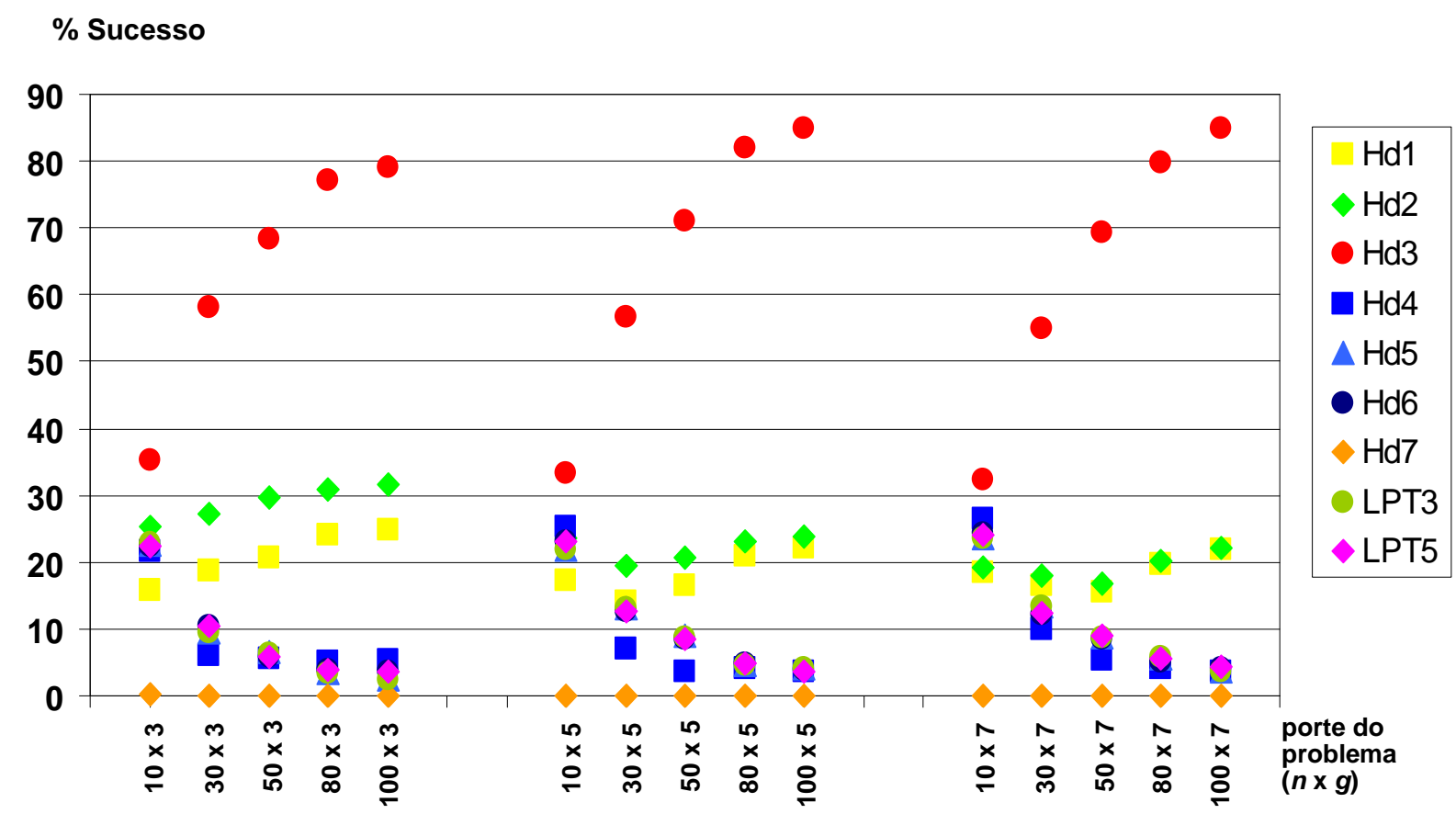

FIGURA 6.33 - Desempenho dos algoritmos heurísticos por porte do problema (em \% de sucesso) 
Como pode ser visto na Figura 6.33, com o aumento do número de tarefas, as heurísticas Hd1, Hd2 e Hd3 melhoram o seu desempenho, enquanto que os métodos Hd4, Hd5, Hd6, LPT3 e LPT5 têm uma visível piora. A heurística Hd7 tem desempenho constante e próximo de zero. A AMV para o número de tarefas é de 3,3.

A melhoria de Hd1 e Hd2 é suave e deve-se à melhoria na flexibilidade alta, como poderá ser observado mais adiante na análise detalhada. Já o aumento de desempenho da heurística Hd3 é substancial, variando de $32 \%$ de sucesso em problemas com 10 tarefas até $85 \%$ em problemas com 100 tarefas. Este resultado demonstra a grande eficácia da heurística Hd3 para problemas de grande porte.

Com o aumento do número de estágios, os métodos apresentaram certa variação no desempenho, levando a uma AMV de 10,4. Embora esta variação não seja tão perceptível pelo gráfico da Figura 6.33, as porcentagens de sucesso indicam que o número de estágios foi um dos parâmetros que mais influenciaram. Calculando separadamente em cada opção de flexibilidade, a AMV para o número de estágios foi de 7,9 para a flexibilidade alta, 7,4 para a média e 15,8 para a alta. Assim, o número de estágios tem uma grande relevância para os resultados do problema, especialmente quando há máquinas paralelas em todos eles.

Foi constatada uma peculiaridade das heurísticas $\mathrm{Hd} 1$ e $\mathrm{Hd} 2$ : seus resultados tornamse mais próximos com o aumento do número de estágios. Para problemas com 3 estágios, a diferença de desempenho entre $\mathrm{Hd} 1$ e $\mathrm{Hd} 2$ ficou em torno de 8\%; em problemas com 5 estágios, a diferença foi de $4 \%$ em média; e para 7 estágios, cerca de $1 \%$.

Ainda em relação ao porte do problema, os métodos Hd4, Hd5, Hd6, LPT3 e LPT5 apresentaram resultados muito próximos, com diferença de no máximo $6 \%$.

Sem considerar a heurística Hd7, em problemas com 10 tarefas, o intervalo da diferença de desempenho entre o melhor e o pior método ficou em torno de $17 \%$, enquanto que em 
problemas com 100 tarefas, esse intervalo foi de $80 \%$ em média. Isto demonstra que a variação da solução dos métodos é suave em problemas de pequeno porte e agressiva em problemas de grande porte.

Como as heurísticas Hd2 e Hd3 aplicam-se somente a problemas que contêm estágios com uma máquina, foi necessário fazer a análise comparativa de forma mais detalhada separando por opção de flexibilidade, tal como apresentado na Figura 6.34 a seguir.

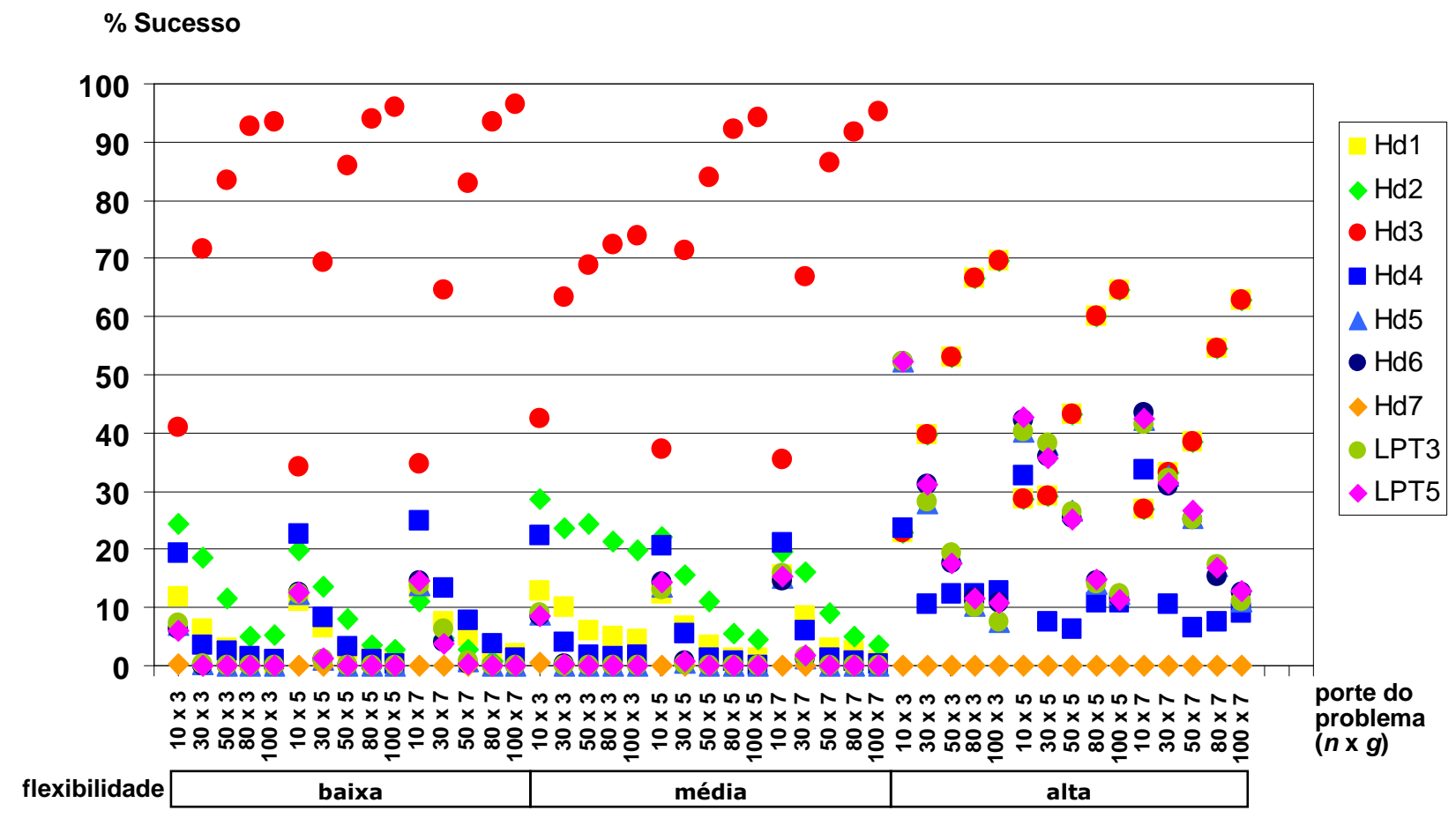

FIGURA 6.34 - Desempenho das heurísticas para setup dependente por flexibilidade e porte do problema (em \% de sucesso)

Evidentemente, para a flexibilidade alta, os resultados de $\mathrm{Hd} 1, \mathrm{Hd} 2$ e $\mathrm{Hd} 3$ foram exatamente os mesmos, pois neste caso não há estágios com uma única máquina e assim estas três heurísticas são equivalentes.

A única heurística que tem desempenho ascendente na flexibilidade alta é a Hd3. Todas as outras pioram o desempenho com o aumento do porte do problema, nas três opções de flexibilidade. 
Enquanto a AMV para o número de tarefas foi de 3,3 como já foi citado, calculando-se para cada opção de flexibilidade, o valor passa a ser de 2,2 para a flexibilidade baixa, 2,9 para a média e 4,7 para a alta. Ou seja, o parâmetro do número de tarefas influencia basicamente em problemas com flexibilidade alta.

A AMV para a flexibilidade foi de 15,5 , como pode ser visto na Tabela 6.14 , indicando que é o parâmetro que mais influenciou no desempenho das heurísticas. Como já salientado, boa parte desta variação nos resultados em relação às diferentes opções de flexibilidade deveu-se à especificidade das heurísticas Hd2 e Hd3.

TABELA 6.14 - Valores da AMV para os parâmetros das heurísticas com setup dependente

\begin{tabular}{|c||c|c|c|c|c|c|}
\hline Flexibilidade & $\boldsymbol{n}$ & $\boldsymbol{g}$ & $\boldsymbol{f}$ & $\boldsymbol{s}$ & $\boldsymbol{a}$ & $\boldsymbol{l}$ \\
\hline \hline Baixa & 2,2 & 7,9 & & 1,7 & 1,8 & 2,8 \\
\hline Média & 2,9 & 7,4 & \multirow{2}{*}{15,5} & 1,5 & 1,2 & 3,3 \\
\cline { 6 - 7 } \cline { 5 - 7 } Alta & 4,7 & 15,8 & & 5,5 & 2,8 & 5,9 \\
\hline \hline AMV global & $\mathbf{3 , 3}$ & $\mathbf{1 0 , 4}$ & $\mathbf{1 5 , 5}$ & $\mathbf{2 , 9}$ & $\mathbf{1 , 9}$ & $\mathbf{4 , 0}$ \\
\hline
\end{tabular}

De forma geral, com as flexibilidades baixa e média, a curva de desempenho dos métodos apresentou comportamento relativamente similar, sugerindo que o número de estágios com máquina única não afete significativamente o desempenho de um método. A heurística Hd3 teve resultados na faixa de 35 a $97 \%$ de sucesso, enquanto que o desempenho dos demais métodos ficou na faixa de até $29 \%$, com predominância de valores até $10 \%$ de sucesso.

$\mathrm{Na}$ flexibilidade alta, o desempenho da $\mathrm{Hd} 3$ caiu e o das outras heurísticas melhorou em relação aos outros níveis de flexibilidade. A heurística Hd3 não ultrapassou os $70 \%$ de sucesso e os outros métodos passaram a ocupar a faixa até os $52 \%$ de sucesso.

Também com a flexibilidade alta os resultados apresentaram maior instabilidade, que é ainda mais perceptível na análise de cada parâmetro individualmente. Como pode ser visto na 
Tabela 6.14, os valores da AMV dos parâmetros para a flexibilidade alta são todos mais elevados.

A Tabela 6.15 apresenta de forma ilustrada os três melhores métodos para cada opção de flexibilidade e porte do problema, com suas respectivas porcentagens de sucesso.

TABELA 6.15 - Melhores heurísticas para setup dependente por flexibilidade e porte do problema e suas porcentagens de sucesso

\begin{tabular}{|c|c|c|c|c|c|c|c|c|c|c|}
\hline \multirow{2}{*}{$\boldsymbol{g}$} & \multirow{2}{*}{$n$} & \multicolumn{3}{|c|}{ Flexibilidade baixa } & \multicolumn{3}{|c|}{ Flexibilidade média } & \multicolumn{3}{|c|}{ Flexibilidade alta } \\
\hline & & 10 & $2^{0}$ & 30 & 10 & 20 & 30 & 10 & 20 & $3^{0}$ \\
\hline \multirow[t]{5}{*}{3} & 10 & $\begin{array}{c}\mathrm{Hd} 3 \\
(40,9 \%)\end{array}$ & $\begin{array}{c}\mathrm{Hd} 2 \\
(24,3 \%)\end{array}$ & $\begin{array}{c}\mathrm{Hd4} \\
(19,3 \%)\end{array}$ & $\begin{array}{c}\mathrm{Hd} 3 \\
(42,4 \%)\end{array}$ & $\begin{array}{c}\mathrm{Hd} 2 \\
(28,8 \%)\end{array}$ & $\begin{array}{c}\mathrm{Hd} 4 \\
(22,3 \%)\end{array}$ & $\begin{array}{c}\text { Hd6/LPT5 } \\
(52,4 \%)\end{array}$ & $\begin{array}{c}\text { Hd5/LPT3 } \\
(52,3 \%)\end{array}$ & $\begin{array}{c}\mathrm{Hd} 4 \\
(23,5 \%)\end{array}$ \\
\hline & 30 & $\begin{array}{c}\mathrm{Hd} 3 \\
(71,5 \%)\end{array}$ & $\begin{array}{c}\mathrm{Hd} 2 \\
(18,6 \%)\end{array}$ & $\begin{array}{c}\mathrm{Hd} 2 \\
(6,4 \%)\end{array}$ & $\begin{array}{c}\mathrm{Hd3} \\
(63,3 \%)\end{array}$ & $\begin{array}{c}\mathrm{Hd} 2 \\
(23,6 \%)\end{array}$ & $\begin{array}{c}\text { Hd1 } \\
(10,1 \%)\end{array}$ & $\begin{array}{l}\text { Hd3* } \\
(39,8 \%)\end{array}$ & $\begin{array}{c}\text { Hd6/LPT5 } \\
(31,3 \%)\end{array}$ & $\begin{array}{c}\text { LPT3 } \\
(28,3 \%)\end{array}$ \\
\hline & 50 & $\begin{array}{c}\mathrm{Hd} 3 \\
(83,4 \%) \\
\end{array}$ & $\begin{array}{c}\mathrm{Hd} 2 \\
(11,5 \%)\end{array}$ & $\begin{array}{l}\mathrm{Hd} 2 \\
(3,1 \%)\end{array}$ & $\begin{array}{c}\mathrm{Hd3} \\
(68,8 \%) \\
\end{array}$ & $\begin{array}{c}\mathrm{Hd} 2 \\
(24,3 \%)\end{array}$ & $\begin{array}{l}\text { Hd1 } \\
(6,1 \%)\end{array}$ & $\begin{array}{c}\text { Hd3* } \\
(53,0 \%) \\
\end{array}$ & $\begin{array}{c}\text { Hd5 } \\
(19,4 \%)\end{array}$ & $\begin{array}{c}\text { LPT3 } \\
(19,3 \%)\end{array}$ \\
\hline & 80 & $\begin{array}{c}\text { Hd3 } \\
(92,6 \%) \\
\end{array}$ & $\begin{array}{c}\mathrm{Hd2} \\
(5,0 \%)\end{array}$ & $\begin{array}{l}\mathrm{Hd} 4 \\
(1,6 \%)\end{array}$ & $\begin{array}{c}\mathrm{Hd3} \\
(72,4 \%)\end{array}$ & $\begin{array}{c}\mathrm{Hd} 2 \\
(21,3 \%)\end{array}$ & $\begin{array}{c}\mathrm{Hd1} \\
(5,1 \%)\end{array}$ & $\begin{array}{c}\mathrm{Hd3} * \\
(66,5 \%) \\
\end{array}$ & $\begin{array}{c}\mathrm{Hd} 4 \\
(12,4 \%)\end{array}$ & $\begin{array}{c}\text { Hd6/LPT5 } \\
(11,5 \%)\end{array}$ \\
\hline & 100 & $\begin{array}{c}\mathrm{Hd} 3 \\
(93,5 \%) \\
\end{array}$ & $\begin{array}{c}\mathrm{Hd} 2 \\
(5,3 \%) \\
\end{array}$ & $\begin{array}{c}\mathrm{Hd} 4 \\
(1,1 \%) \\
\end{array}$ & $\begin{array}{c}\mathrm{Hd3} \\
(73,9 \%) \\
\end{array}$ & $\begin{array}{c}\text { Hd2 } \\
(19,9 \%) \\
\end{array}$ & $\begin{array}{c}\text { Hd1 } \\
(4,5 \%) \\
\end{array}$ & $\begin{array}{l}\text { Hd3* } \\
(69,6 \%) \\
\end{array}$ & $\begin{array}{c}\mathrm{Hd} 4 \\
(12,8 \%) \\
\end{array}$ & $\begin{array}{c}\text { Hd6/LPT5 } \\
(10,9 \%)\end{array}$ \\
\hline \multirow[t]{5}{*}{5} & 10 & $\begin{array}{c}\mathrm{Hd} 3 \\
(34,1 \%)\end{array}$ & $\begin{array}{c}\mathrm{Hd} 4 \\
(22,5 \%)\end{array}$ & $\begin{array}{c}\mathrm{Hd} 2 \\
(19,9 \%)\end{array}$ & $\begin{array}{c}\mathrm{Hd} 3 \\
(37,3 \%)\end{array}$ & $\begin{array}{c}\text { Hd2 } \\
(22,1 \%)\end{array}$ & $\begin{array}{c}\mathrm{Hd} 4 \\
(20,6 \%)\end{array}$ & $\begin{array}{c}\text { LPT5 } \\
(42,6 \%) \\
\end{array}$ & $\begin{array}{c}\text { Hd6 } \\
(42,3 \%)\end{array}$ & $\begin{array}{c}\mathrm{Hd} 5 / \mathrm{LPT3} \\
(40,1 \%)\end{array}$ \\
\hline & 30 & $\begin{array}{c}\mathrm{Hd} 3 \\
(69,3 \%)\end{array}$ & $\begin{array}{c}\mathrm{Hd} 2 \\
(13,5 \%)\end{array}$ & $\begin{array}{c}\mathrm{Hd} 4 \\
(8,4 \%)\end{array}$ & $\begin{array}{c}\mathrm{Hd3} \\
(71,3 \%)\end{array}$ & $\begin{array}{c}\text { Hd2 } \\
(15,5 \%)\end{array}$ & $\begin{array}{c}\mathrm{Hd1} \\
(6,8 \%)\end{array}$ & $\begin{array}{c}\text { LPT3 } \\
(38,3 \%)\end{array}$ & $\begin{array}{c}\text { Hd5 } \\
(37,9 \%)\end{array}$ & $\begin{array}{c}\mathrm{Hd} 6 \\
(36,0 \%)\end{array}$ \\
\hline & 50 & $\begin{array}{c}\mathrm{Hd3} \\
(85,9 \%) \\
\end{array}$ & $\begin{array}{c}\mathrm{Hd} 2 \\
(8,0 \%)\end{array}$ & $\begin{array}{l}\mathrm{Hd} 4 \\
(3,4 \%)\end{array}$ & $\begin{array}{c}\mathrm{Hd} 3 \\
(84,0 \%) \\
\end{array}$ & $\begin{array}{c}\mathrm{Hd} 2 \\
(11,0 \%)\end{array}$ & $\begin{array}{l}\text { Hd1 } \\
(3,6 \%)\end{array}$ & $\begin{array}{c}\mathrm{Hd} 3 * \\
(43,3 \%)\end{array}$ & $\begin{array}{c}\text { Hd5 } \\
(26,6 \%)\end{array}$ & $\begin{array}{c}\text { LPT3 } \\
(26,5 \%)\end{array}$ \\
\hline & 80 & $\begin{array}{c}\mathrm{Hd3} \\
(94,0 \%) \\
\end{array}$ & $\begin{array}{l}\mathrm{Hd} 2 \\
(3,6 \%)\end{array}$ & $\begin{array}{c}\mathrm{Hd} 1 \\
(1,4 \%)\end{array}$ & $\begin{array}{c}\mathrm{Hd3} \\
(92,1 \%) \\
\end{array}$ & $\begin{array}{c}\text { Hd2 } \\
(5,6 \%)\end{array}$ & $\begin{array}{c}\text { Hd1 } \\
(1,4 \%)\end{array}$ & $\begin{array}{c}\mathrm{Hd} 3 * \\
(60,0 \%) \\
\end{array}$ & $\begin{array}{c}\text { LPT5 } \\
(14,8 \%) \\
\end{array}$ & $\begin{array}{c}\mathrm{Hd6} \\
(14,5 \%)\end{array}$ \\
\hline & 100 & $\begin{array}{c}\mathrm{Hd3} \\
(96,0 \%) \\
\end{array}$ & $\begin{array}{c}\mathrm{Hd} 2 \\
(2,8 \%) \\
\end{array}$ & $\begin{array}{c}\text { Hd1 } \\
(1,0 \%) \\
\end{array}$ & $\begin{array}{c}\mathrm{Hd} 3 \\
(94,3 \%) \\
\end{array}$ & $\begin{array}{l}\mathrm{Hd} 2 \\
(4,5 \%) \\
\end{array}$ & $\begin{array}{c}\text { Hd1 } \\
(1,3 \%) \\
\end{array}$ & $\begin{array}{c}\mathrm{Hd} 3 * \\
(64,5 \%) \\
\end{array}$ & $\begin{array}{c}\mathrm{Hd} 5 / \mathrm{LPT3} \\
(12,4 \%)\end{array}$ & $\begin{array}{c}\text { Hd6 } \\
(11,5 \%) \\
\end{array}$ \\
\hline \multirow[t]{5}{*}{7} & 10 & $\begin{array}{c}\mathrm{Hd3} \\
(34,8 \%)\end{array}$ & $\begin{array}{c}\mathrm{Hd} 4 \\
(24,9 \%)\end{array}$ & $\begin{array}{c}\text { Hd6/LPT5 } \\
(14,5 \%)\end{array}$ & $\begin{array}{c}\text { Hd3 } \\
(35,5 \%)\end{array}$ & $\begin{array}{c}\mathrm{Hd} 4 \\
(21,0 \%)\end{array}$ & $\begin{array}{c}\text { Hd2 } \\
(19,6 \%)\end{array}$ & $\begin{array}{c}\mathrm{Hd6} \\
(43,5 \%)\end{array}$ & $\begin{array}{c}\text { LPT5 } \\
(42,5 \%) \\
\end{array}$ & $\begin{array}{c}\text { Hd5 } \\
(42,1 \%)\end{array}$ \\
\hline & 30 & $\begin{array}{c}\mathrm{Hd3} \\
(64,5 \%)\end{array}$ & $\underset{(13,3 \%)}{\mathrm{Hd} 4}$ & $\begin{array}{c}\mathrm{Hd} 1 \\
(7,6 \%)\end{array}$ & $\begin{array}{c}\mathrm{Hd3} \\
(66,9 \%) \\
\end{array}$ & $\begin{array}{c}\text { Hd2 } \\
(16,1 \%)\end{array}$ & $\begin{array}{c}\mathrm{Hd} 1 \\
(8,6 \%)\end{array}$ & $\begin{array}{c}\text { Hd3* } \\
(33,3 \%)\end{array}$ & $\begin{array}{c}\text { Hd5 } \\
(32,6 \%)\end{array}$ & $\begin{array}{c}\text { LPT5 } \\
(31,5 \%) \\
\end{array}$ \\
\hline & 50 & $\begin{array}{c}\mathrm{Hd3} \\
(83,0 \%)\end{array}$ & $\begin{array}{c}\mathrm{Hd} 4 \\
(7,8 \%)\end{array}$ & $\begin{array}{l}\mathrm{Hd1} \\
(5,0 \%)\end{array}$ & $\begin{array}{c}\mathrm{Hd} 3 \\
(86,5 \%)\end{array}$ & $\begin{array}{c}\mathrm{Hd} 2 \\
(9,0 \%)\end{array}$ & $\begin{array}{l}\text { Hd1 } \\
(3,1 \%)\end{array}$ & $\begin{array}{c}\mathrm{Hd} 3 * \\
(38,4 \%)\end{array}$ & $\begin{array}{l}\text { LPT5 } \\
(26,8 \%)\end{array}$ & $\begin{array}{c}\text { Hd5 } \\
(25,5 \%)\end{array}$ \\
\hline & 80 & $\begin{array}{c}\mathrm{Hd3} \\
(93,4 \%) \\
\end{array}$ & $\begin{array}{l}\mathrm{Hd} 4 \\
(3,9 \%)\end{array}$ & $\begin{array}{l}\text { Hd1 } \\
(1,9 \%)\end{array}$ & $\begin{array}{c}\text { Hd3 } \\
(91,8 \%) \\
\end{array}$ & $\begin{array}{l}\mathrm{Hd} 2 \\
(5,1 \%)\end{array}$ & $\begin{array}{l}\text { Hd1 } \\
(2,6 \%)\end{array}$ & $\begin{array}{c}\text { Hd3* } \\
(54,4 \%)\end{array}$ & $\begin{array}{c}\text { LPT3 } \\
(17,3 \%)\end{array}$ & $\begin{array}{c}\text { Hd5 } \\
(17,0 \%)\end{array}$ \\
\hline & 100 & $\begin{array}{c}\mathrm{Hd} 3 \\
(96,5 \%)\end{array}$ & $\begin{array}{l}\mathrm{Hd} 1 \\
(2,1 \%)\end{array}$ & $\begin{array}{c}\mathrm{Hd} 4 \\
(1,3 \%)\end{array}$ & $\begin{array}{c}\mathrm{Hd3} \\
(95,3 \%) \\
\end{array}$ & $\begin{array}{l}\mathrm{Hd} 2 \\
(3,6 \%)\end{array}$ & $\begin{array}{l}\text { Hd1 } \\
(0,9 \%)\end{array}$ & $\begin{array}{c}\text { Hd3* } \\
(62,9 \%)\end{array}$ & $\begin{array}{c}\text { LPT5 } \\
(12,9 \%) \\
\end{array}$ & $\begin{array}{c}\mathrm{Hd6} \\
(12,5 \%)\end{array}$ \\
\hline
\end{tabular}

*As heurísticas Hd1, Hd2 e Hd3 são equivalentes para a flexibilidade alta e, portanto, obtiveram o mesmo resultado. Nesta tabela, por convenção, optou-se por apresentar apenas "Hd3".

Como pode ser visto na Tabela 6.15, não apenas de forma global, mas analisando-se também mais detalhadamente por opção de flexibilidade e porte do problema, ainda há predominância de desempenho da heurística Hd3. Porém, uma informação que não aparece na 
tabela é que particularmente em problemas com 10 tarefas e flexibilidade alta, a heurística Hd3 obteve o segundo pior resultado, com média de $26,1 \%$ de sucesso nas três opções de estágio, depois apenas da heurística aleatória $\mathrm{Hd} 7$, com 0,04\% de sucesso.

A partir da segunda colocação, os métodos não mantêm a mesma ordem de superioridade.

Como já averiguado na análise das regras para setup dependente na seção anterior, os resultados da LPT3 e da LPT5 ficaram muito próximos, sendo coincidentes na maioria dos casos.

Os gráficos das análises para os parâmetros de intervalo de setup, probabilidade de antecipação e de salto também são apresentados para cada opção de flexibilidade. É importante enfatizar que neste caso o foco da comparação foi o parâmetro analisado e não mais a flexibilidade, que já foi explorada. Ou seja, os resultados foram confrontados entre as duas metades de cada gráfico e não comparando os três gráficos das flexibilidades entre si.

As Figuras 6.35, 6.36 e 6.37 apresentam os desempenhos dos métodos por intervalo de setup e porte do problema, respectivamente para as flexibilidades baixa, média e alta.

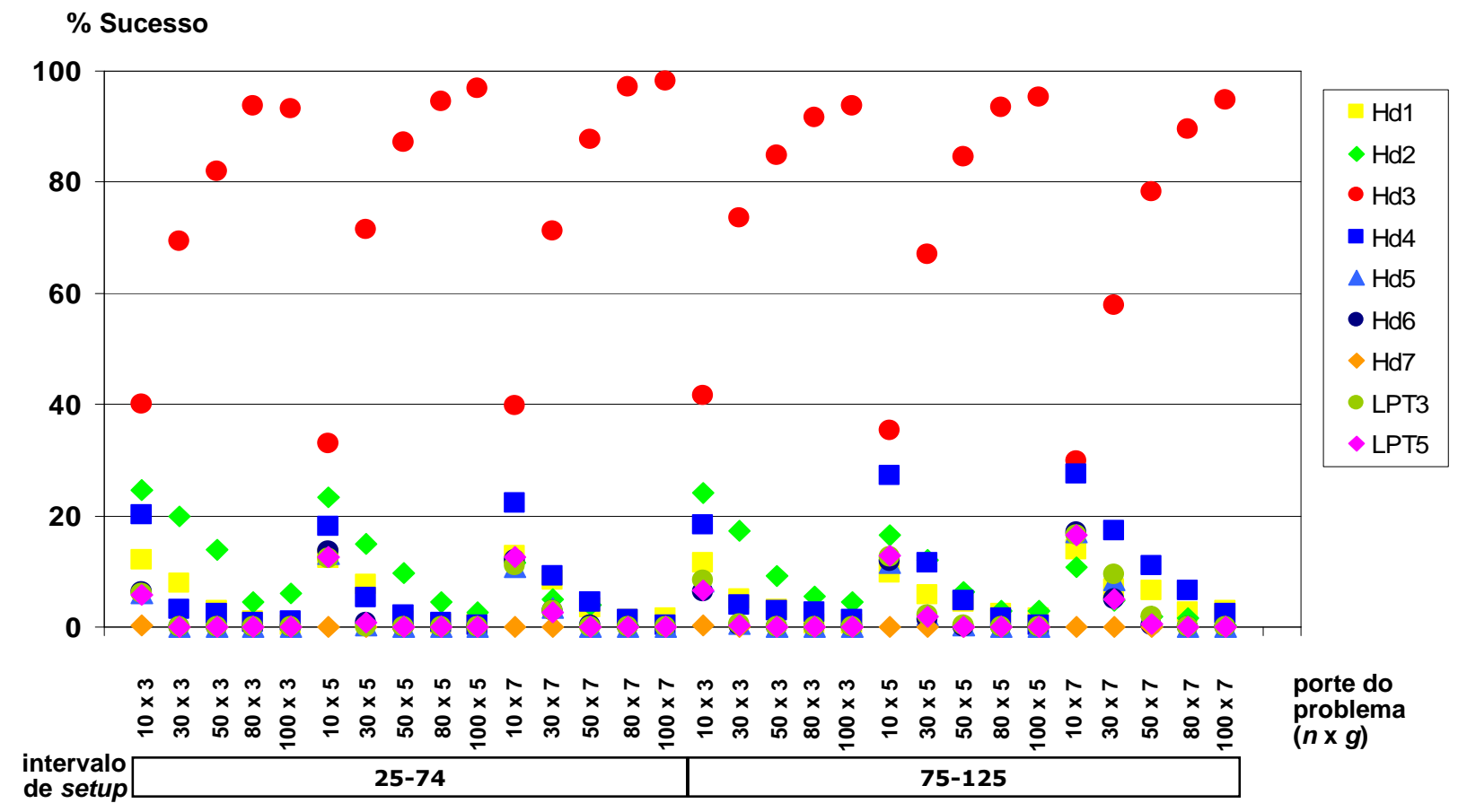

FIGURA 6.35 - Desempenho das heurísticas para setup dependente por intervalo de setup e porte do problema para flexibilidade baixa (em \% de sucesso) 


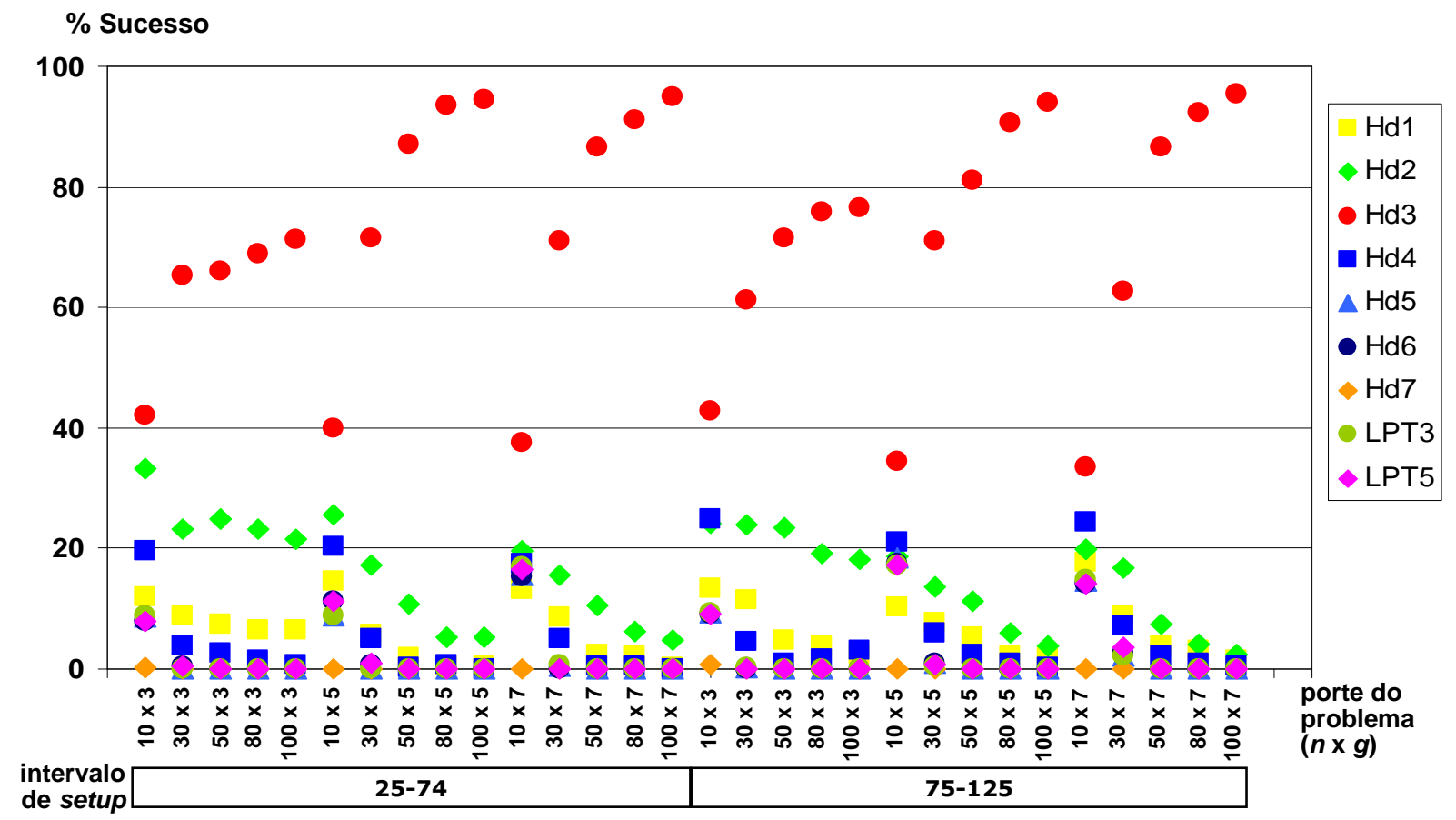

FIGURA 6.36 - Desempenho das heurísticas para setup dependente por intervalo de setup e porte do problema para flexibilidade média (em \% de sucesso)

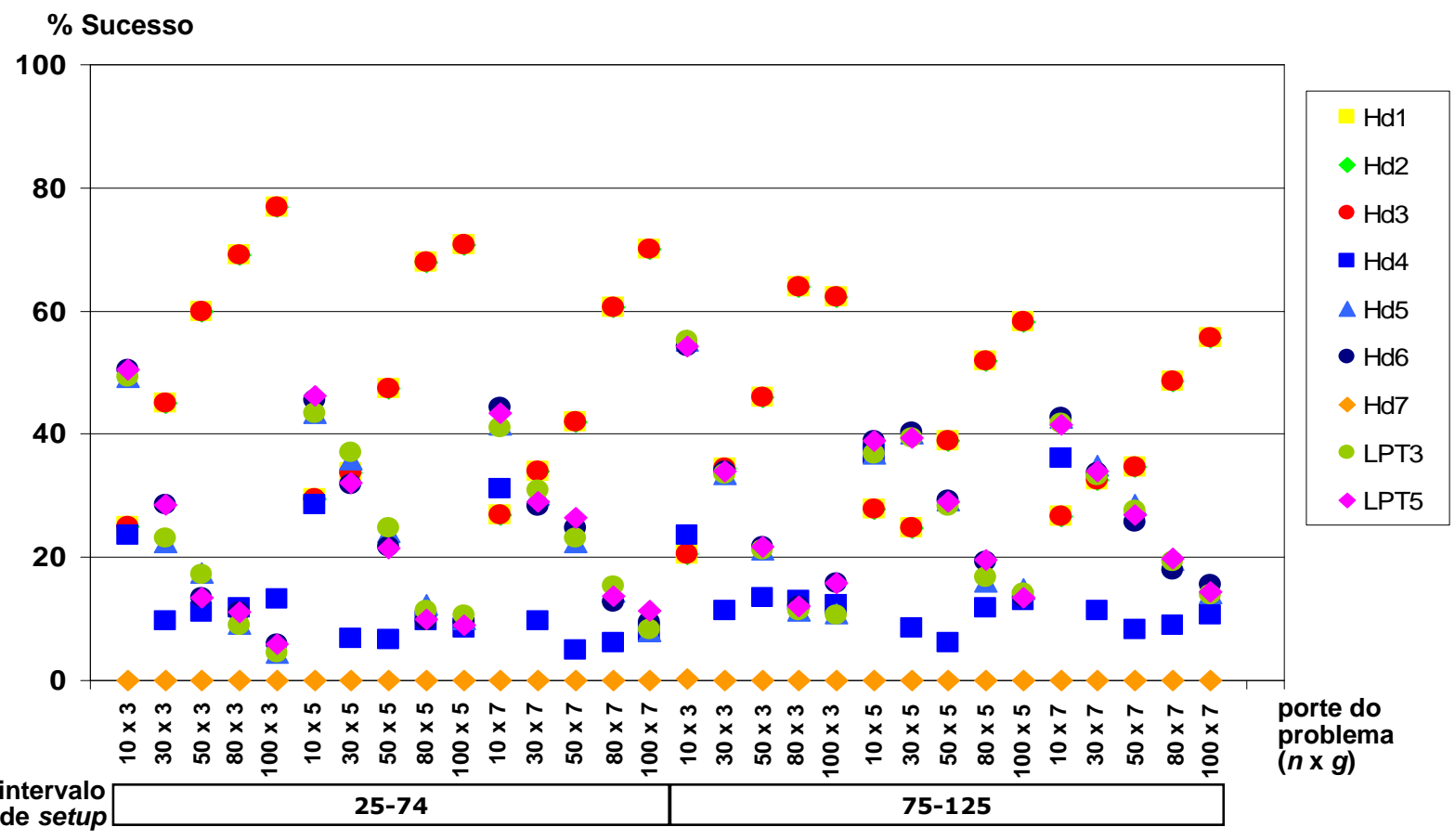

FIGURA 6.37 - Desempenho das heurísticas para setup dependente por intervalo de setup e porte do problema para flexibilidade alta (em \% de sucesso) 
Em relação aos dois intervalos dos tempos de setup considerados, não foram percebidas diferenças significativas no desempenho de cada método. Observou-se apenas que, para a flexibilidade alta, o desempenho da heurística $\mathrm{Hd} 3$ foi levemente menor quando o intervalo de setup é [75-125], ficando na faixa de $21 \%$ a $64 \%$ de sucesso, enquanto que com o setup entre [25-74] o desempenho ficou entre $25 \%$ e $77 \%$ de sucesso.

O valor da AMV para os intervalos de setup foi de 2,9, sendo 1,7 para a flexibilidade baixa, 1,5 para a média e 5,5 para a alta. Como nos outros parâmetros, a flexibilidade alta foi a que mais apresentou variação.

Em ambos os intervalos de tempos de setup, o desempenho da heurística Hd3 é reduzido levemente com o aumento do número de estágios, o que não foi verificado nos resultados desta heurística com os outros parâmetros.

As Figuras 6.38, 6.39 e 6.40 mostram a comparação de desempenho das heurísticas por opção de probabilidade de antecipação do setup e porte do problema, respectivamente para as flexibilidades baixa, média e alta.

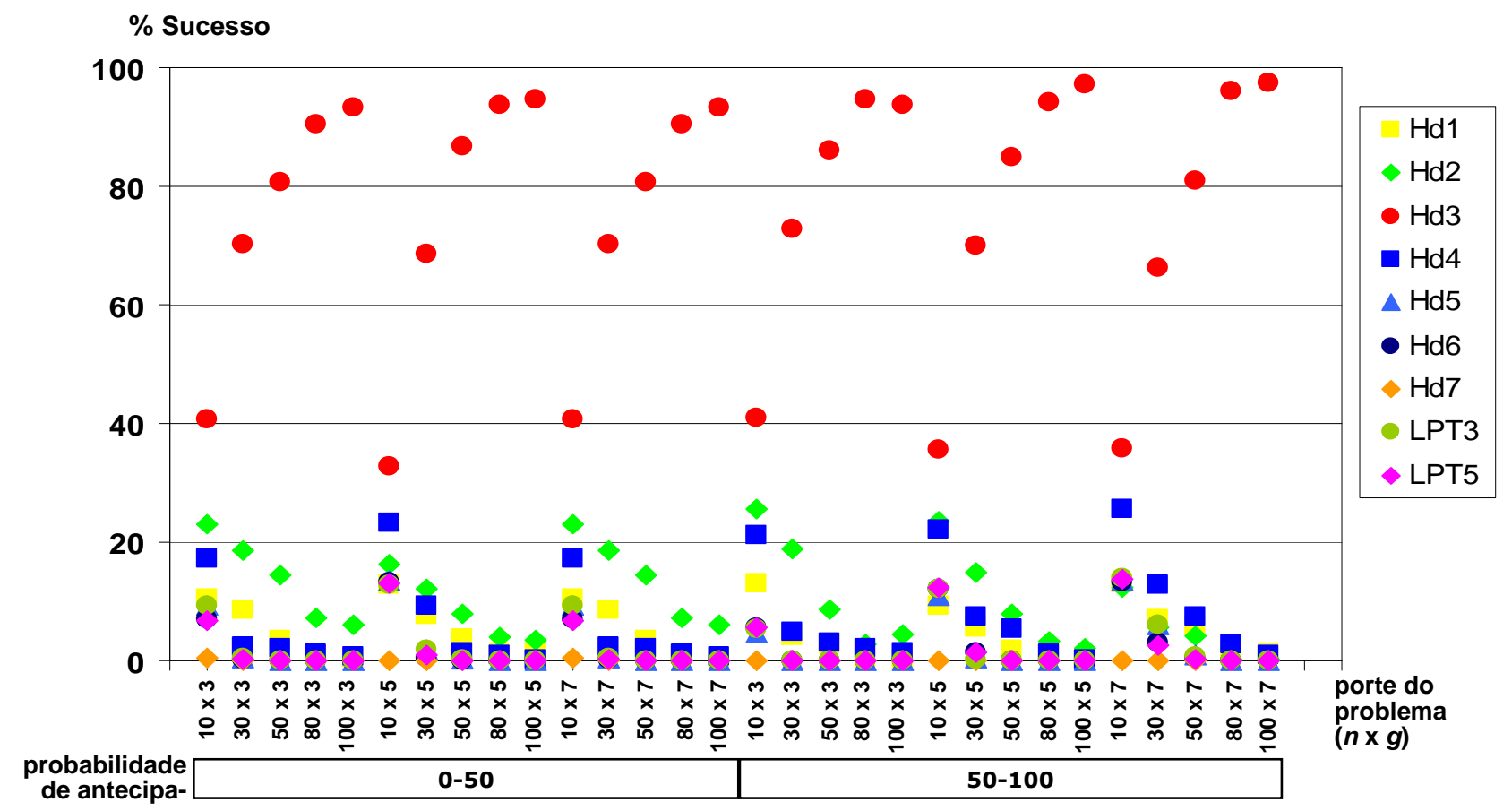

FIGURA 6.38 - Desempenho das heurísticas para setup dependente por probabilidade de antecipação do setup e porte do problema para flexibilidade baixa (em \% de sucesso) 
$\%$ Sucesso

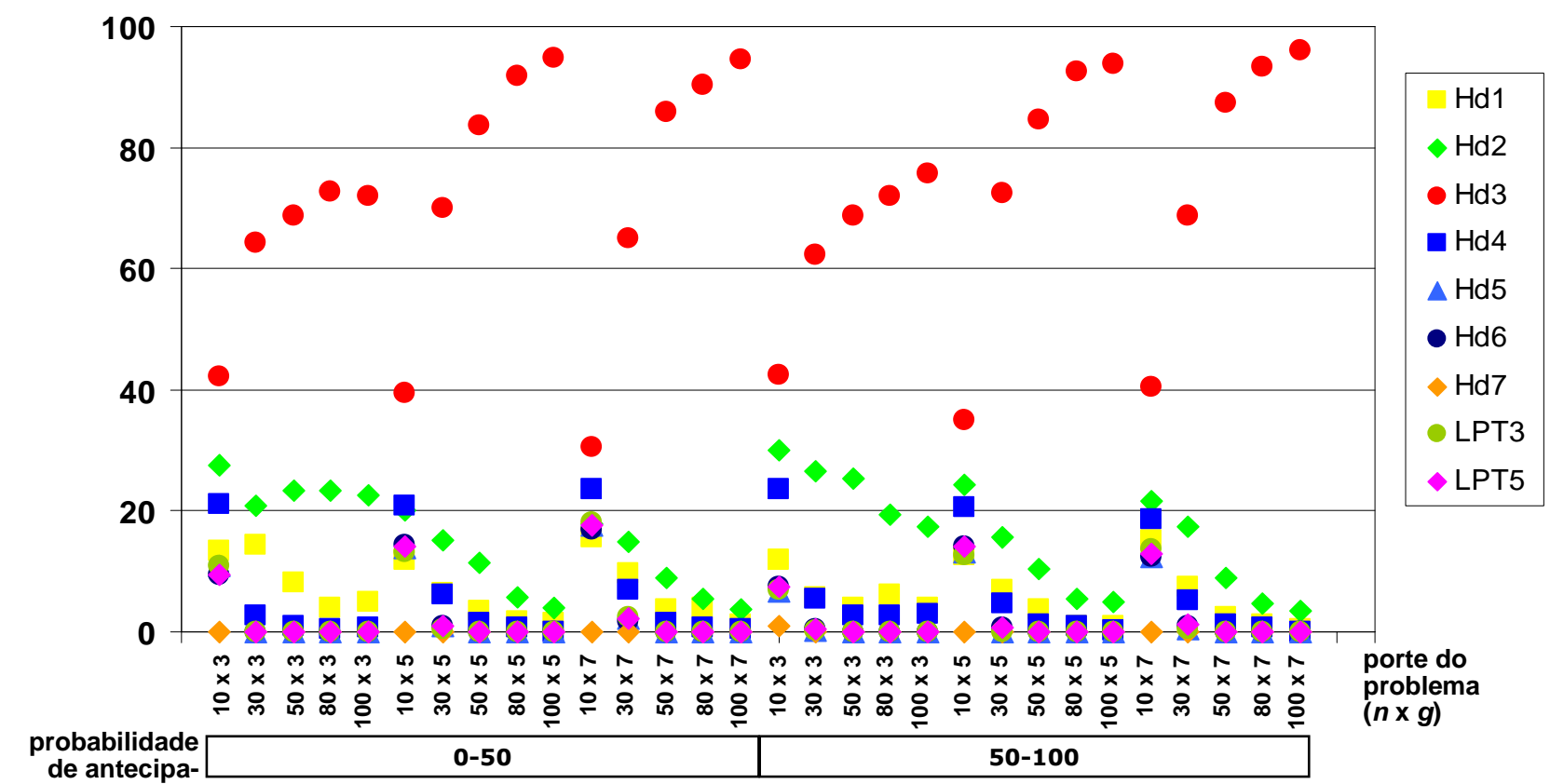

FIGURA 6.39 - Desempenho das heurísticas para setup dependente por probabilidade de antecipação do setup e porte do problema para flexibilidade média (em \% de sucesso)

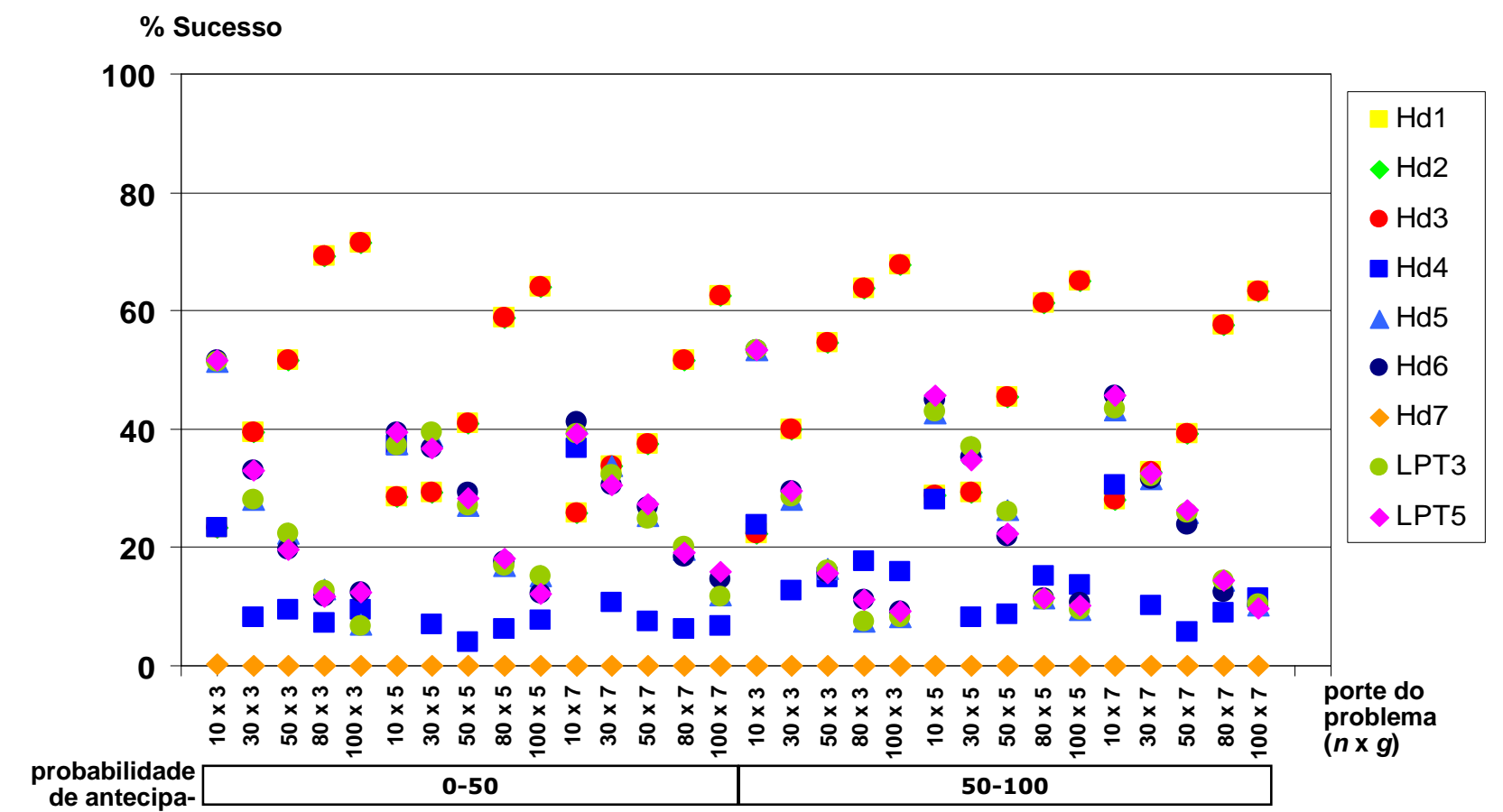

FIGURA 6.40 - Desempenho das heurísticas para setup dependente por probabilidade de antecipação do setup e porte do problema para flexibilidade alta (em \% de sucesso) 
Não houve variações significativas nos dois intervalos de porcentagem de antecipação do setup $([0,50] \%$ e $[50,100] \%)$, indicando que a quantidade de setups antecipados não afeta a qualidade da solução das heurísticas.

O valor de 1,9 da AMV confirma a estabilidade do resultado em relação aos intervalos de antecipação, representando o parâmetro que menos influenciou no desempenho das heurísticas.

Os gráficos das Figuras 6.41, 6.42 e 6.43 apresentam o desempenho dos métodos heurísticos por opção de probabilidade de salto e porte do problema, respectivamente para as flexibilidades baixa, média e alta.

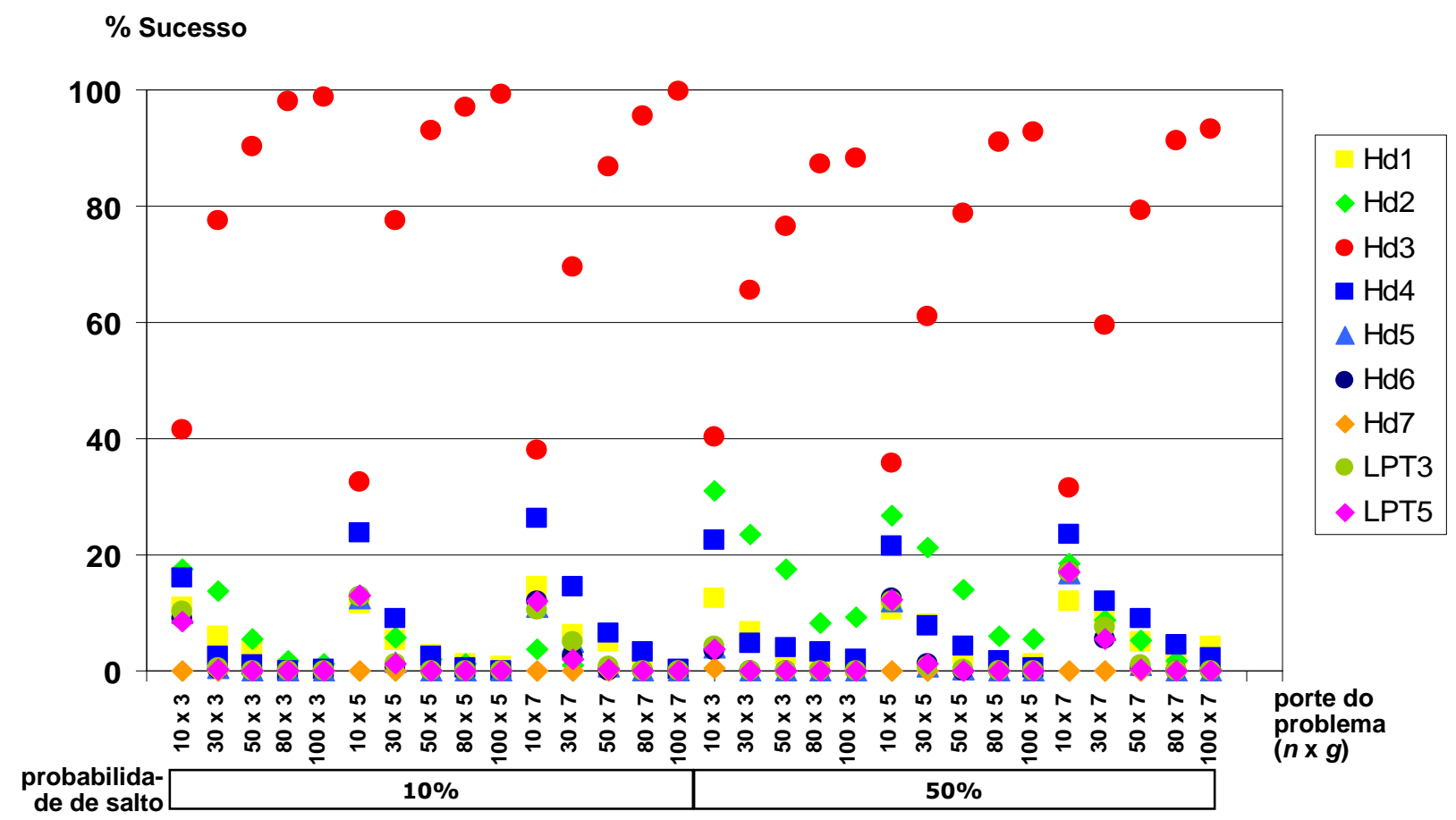

FIGURA 6.41 - Desempenho das heurísticas para setup dependente por probabilidade de salto e porte do problema para flexibilidade baixa (em \% de sucesso) 


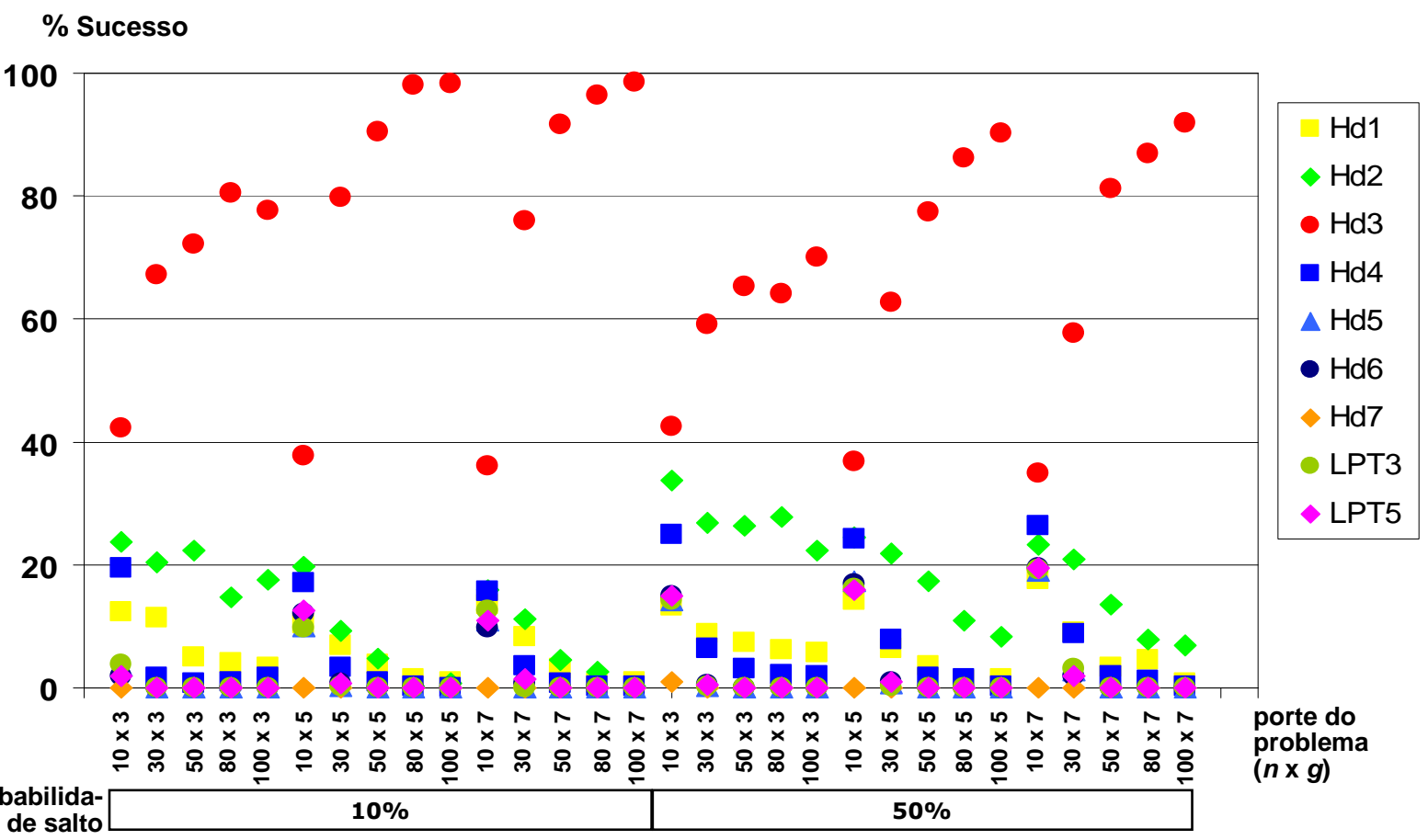

FIGURA 6.42 - Desempenho das heurísticas para setup dependente por probabilidade de salto e porte do problema para flexibilidade média (em \% de sucesso)

\section{$\%$ Sucesso}

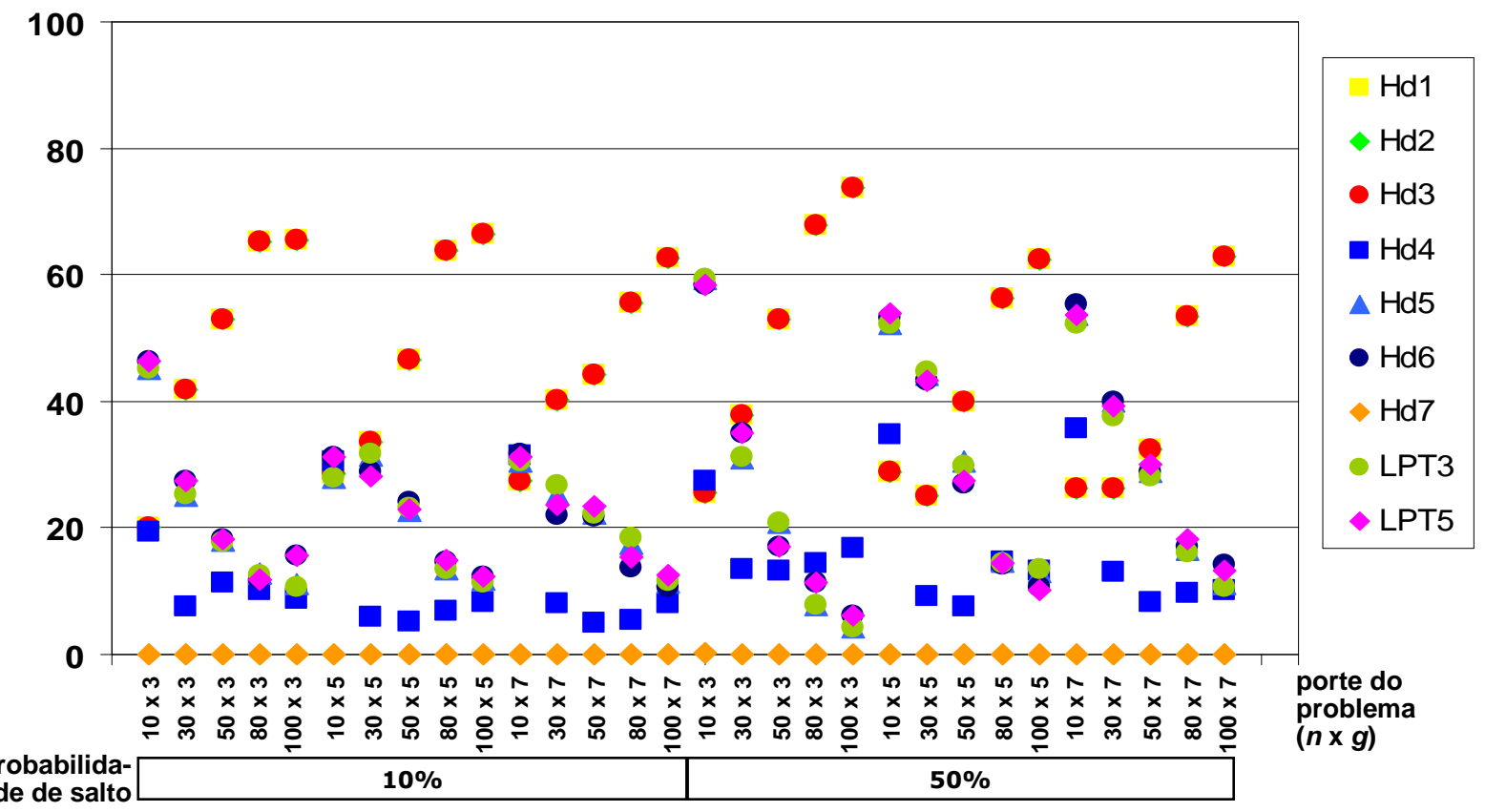

FIGURA 6.43 - Desempenho das heurísticas para setup dependente por probabilidade de salto e porte do problema para flexibilidade alta (em \% de sucesso) 
$\mathrm{Na}$ análise das opções de probabilidade das tarefas saltarem estágios, as variações mais perceptíveis ocorreram com as heurísticas $\mathrm{Hd} 2$ e $\mathrm{Hd} 3$, especialmente para os níveis de flexibilidade baixa e média.

Com as flexibilidades baixa e média, a heurística $\mathrm{Hd} 2$ obteve desempenho médio de $8 \%$ de sucesso para a opção de $10 \%$ de probabilidade de salto e passou para $16 \%$ de sucesso em média para 50\% de salto. Já a heurística Hd3, também nas opções de flexibilidade baixa e média, teve desempenho médio de $78 \%$ de sucesso para a opção de $10 \%$ de probabilidade de salto, reduzindo para $69 \%$ de sucesso com $50 \%$ de salto.

Com a flexibilidade alta, as maiores variações ocorreram com as heurísticas Hd6, Hd7, LPT3 e LPT5, ou seja, com os métodos que utilizam ordenação inicial. As maiores diferenças em relação às duas opções de probabilidade de salto ocorreram em problemas com 10 tarefas com 5 e 7 estágios, tendo desempenho em torno de $23 \%$ maior com a opção de $50 \%$ de salto. As regras de prioridade inicial tornam a programação menos flexível e portanto mais suscetível à variação de desempenho em função das características do ambiente de produção.

Estas variações verificadas proporcionaram uma AMV de 4,0 sendo 2,8 para a flexibilidade baixa, 3,3 para a média e 5,9 para a alta. Estes valores sugerem uma influência mediana para o parâmetro de probabilidade de salto.

A Figura 6.44 a seguir apresenta a análise global dos desvios relativos médios de cada método. 


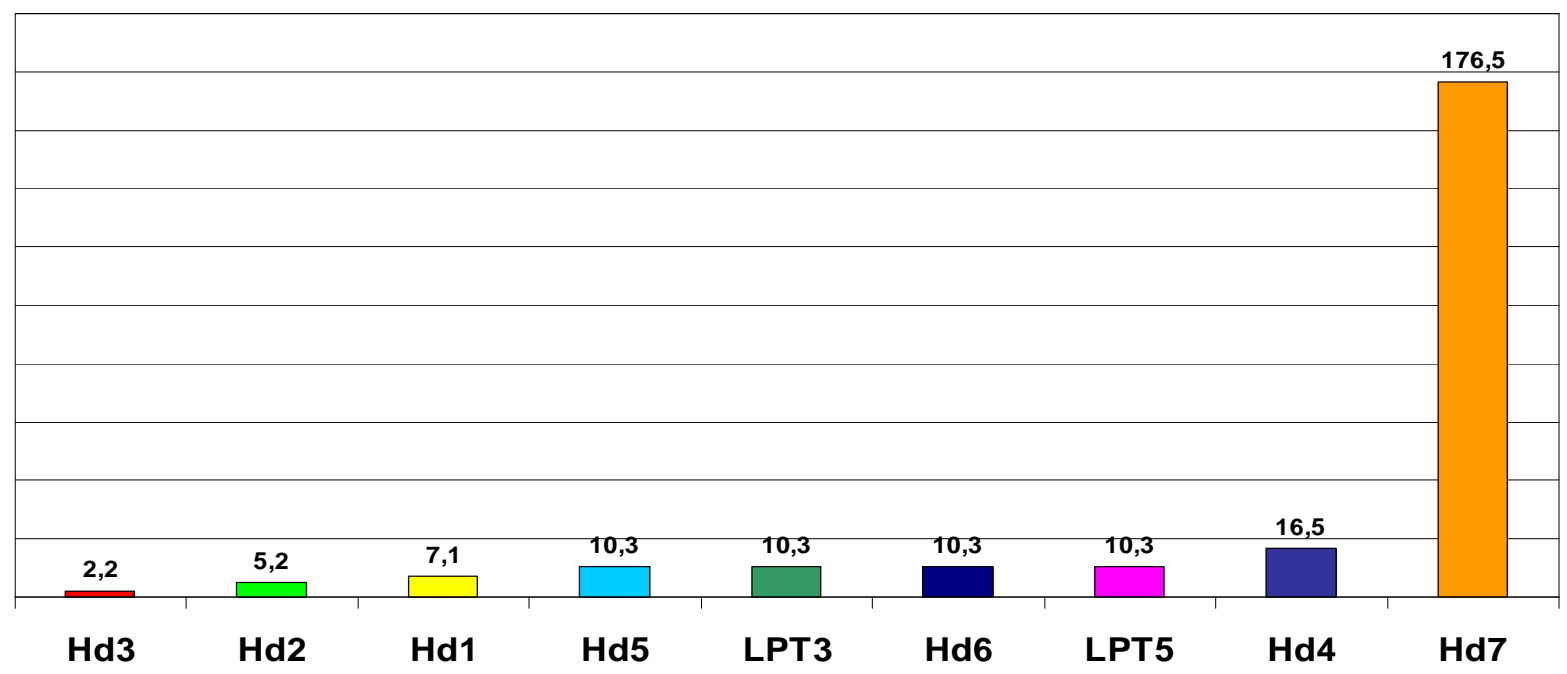

FIGURA 6.44 - Comparação do desvio relativo médio (em \%) das heurísticas para setup dependente

Os desvios relativos do método Hd3 reafirmam a sua superioridade. Além de ter os menores valores entre os métodos, tendem a se reduzir ainda mais com o aumento do porte do problema, chegando a praticamente zero, como pode ser visto na Figura 6.45.

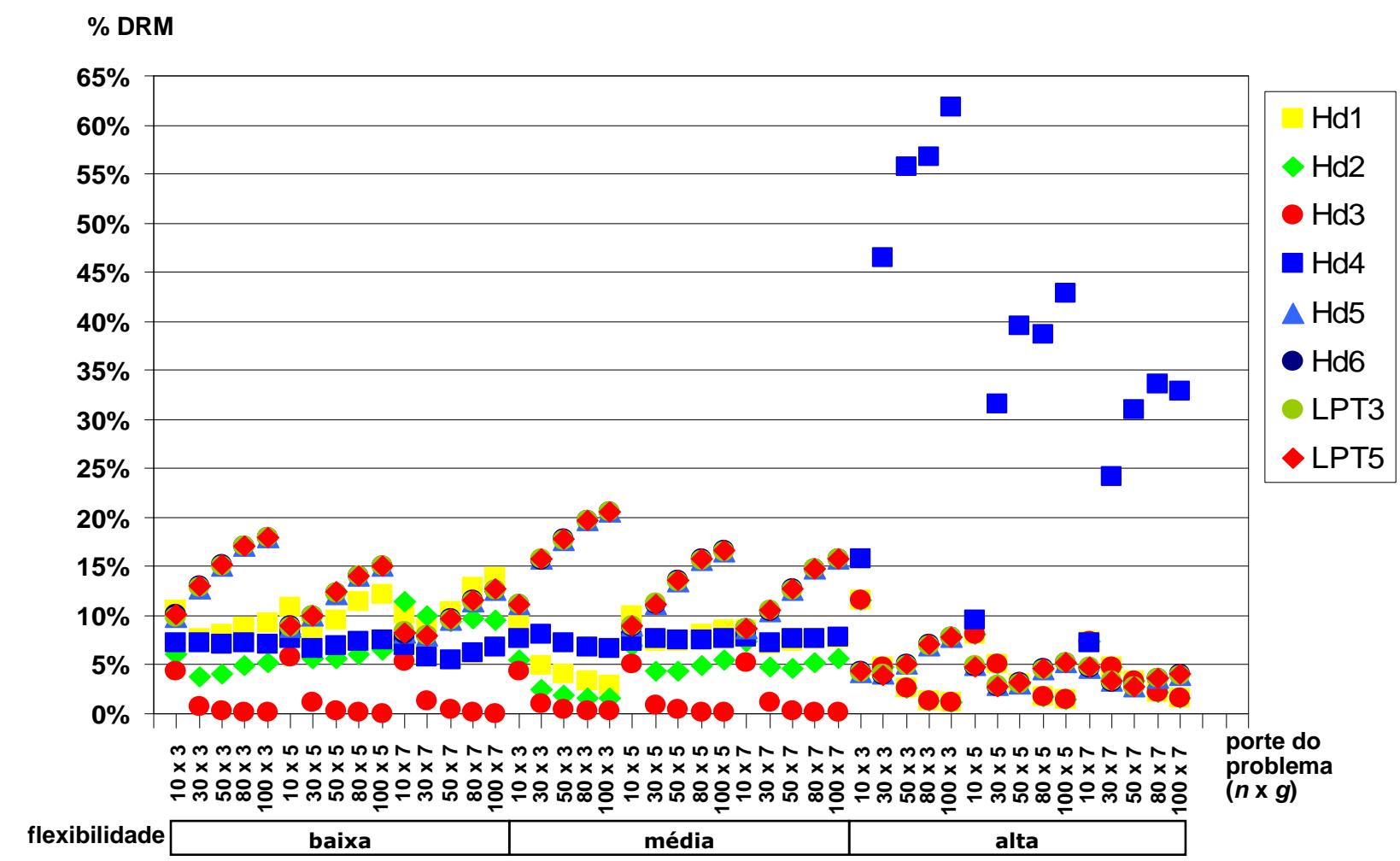

FIGURA 6.45 - Desvio relativo médio (em \%) das heurísticas para setup dependente por flexibilidade e porte do problema 
Em geral, todos os outros métodos aumentam os valores dos desvios relativos com o aumento do porte do problema, principalmente Hd5, Hd6, LPT3 e LPT5. Entretanto, em muitos casos, as heurísticas $\mathrm{Hd} 1, \mathrm{Hd} 2$ e $\mathrm{Hd} 4$ apresentam desvios relativos maiores em problemas com 10 tarefas, os menores valores em problemas com 30 tarefas e em seguida valores ascendentes com o aumento do porte do problema.

Na flexibilidade alta, os métodos Hd5, Hd6, LPT3 e LPT5 tiveram em média os mesmos valores de desvio relativo $(4,5 \%)$. A heurística Hd4 teve um grande aumento em relação às outras opções de flexibilidade, ficando na faixa de $24 \%$ a $62 \%$, com média de $35,2 \%$.

A heurística Hd7 confirmou a inferioridade do seu desempenho e a sua instabilidade no valor da solução, tendo em média 176,5\% de desvio relativo. Com valores tão elevados, para melhor visualização da comparação, a heurística Hd7 não foi considerada no gráfico da Figura 6.45 .

Os valores médios do desvio-padrão dos desvios relativos são mostrados nas Figuras 6.46 e 6.47.

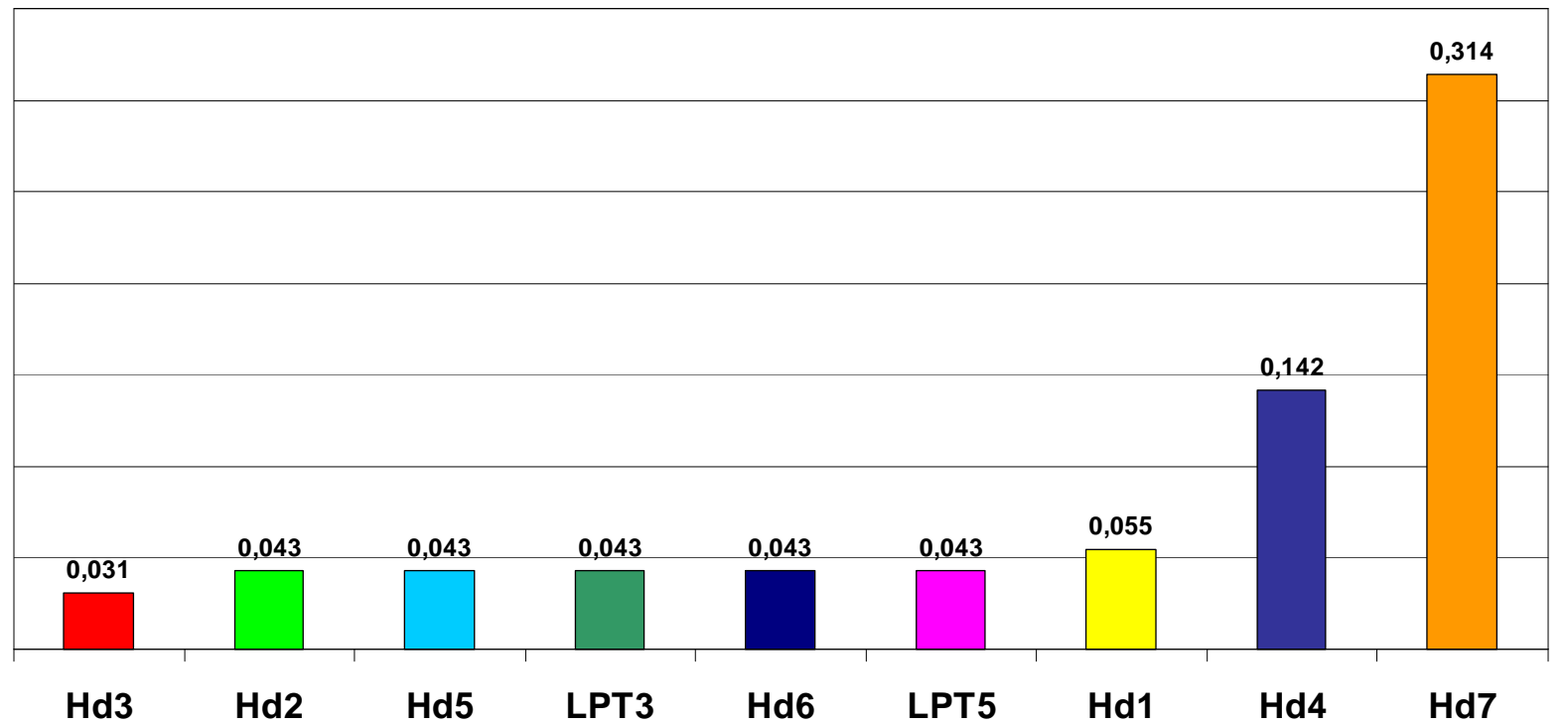

FIGURA 6.46 - Comparação do desvio-padrão dos desvios relativos das heurísticos para setup dependente 
Mais uma vez, a heurística Hd3 ficou em primeiro lugar. Em seguida, os métodos Hd2, Hd5, LPT3, Hd6 e LPT5 apresentaram o mesmo valor de desvio-padrão (0,043). Já o desvio-padrão da heurística Hd1 foi de 0,055 em média, o da heurística Hd4 foi 0,142 e o da Hd7 foi 0,314 .

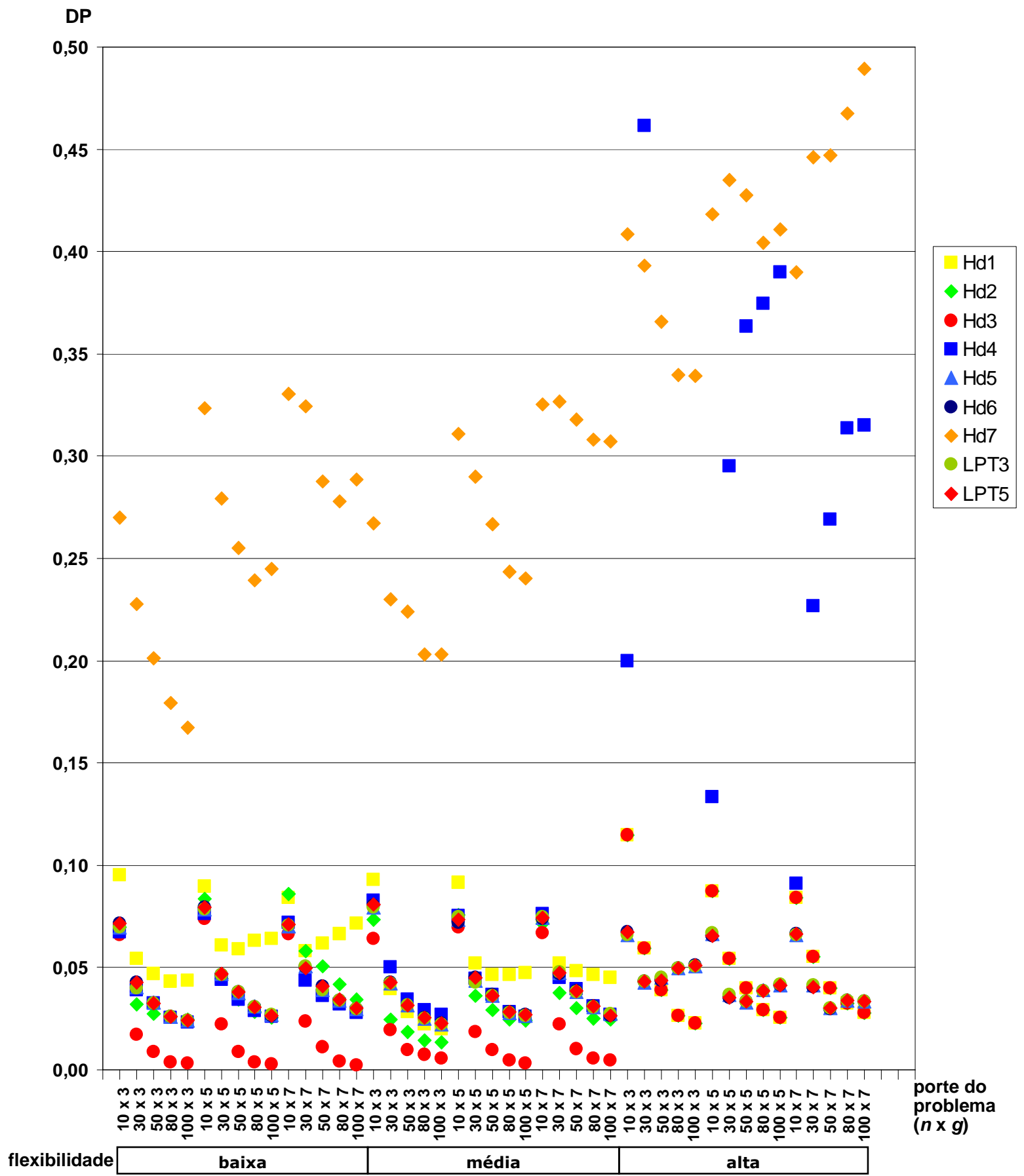

FIGURA 6.47 - Desvio-padrão dos desvios relativos das heurísticas para setup dependente por flexibilidade e porte do problema 
Como pode ser visto no gráfico da Figura 6.47, em geral os valores do desvio-padrão dos desvios relativos dos métodos ficaram na faixa até no máximo 0,10 , exceto os da heurística Hd7, que apresentaram grande instabilidade e valores ascendentes com o aumento do porte do problema e da flexibilidade. Além disso, observa-se também que a heurística Hd4 teve também grande instabilidade com a flexibilidade alta.

Para efeito de comparação, a Figura 6.48 apresenta os tempos médios de computação (em ms) dos métodos analisados nesta seção.

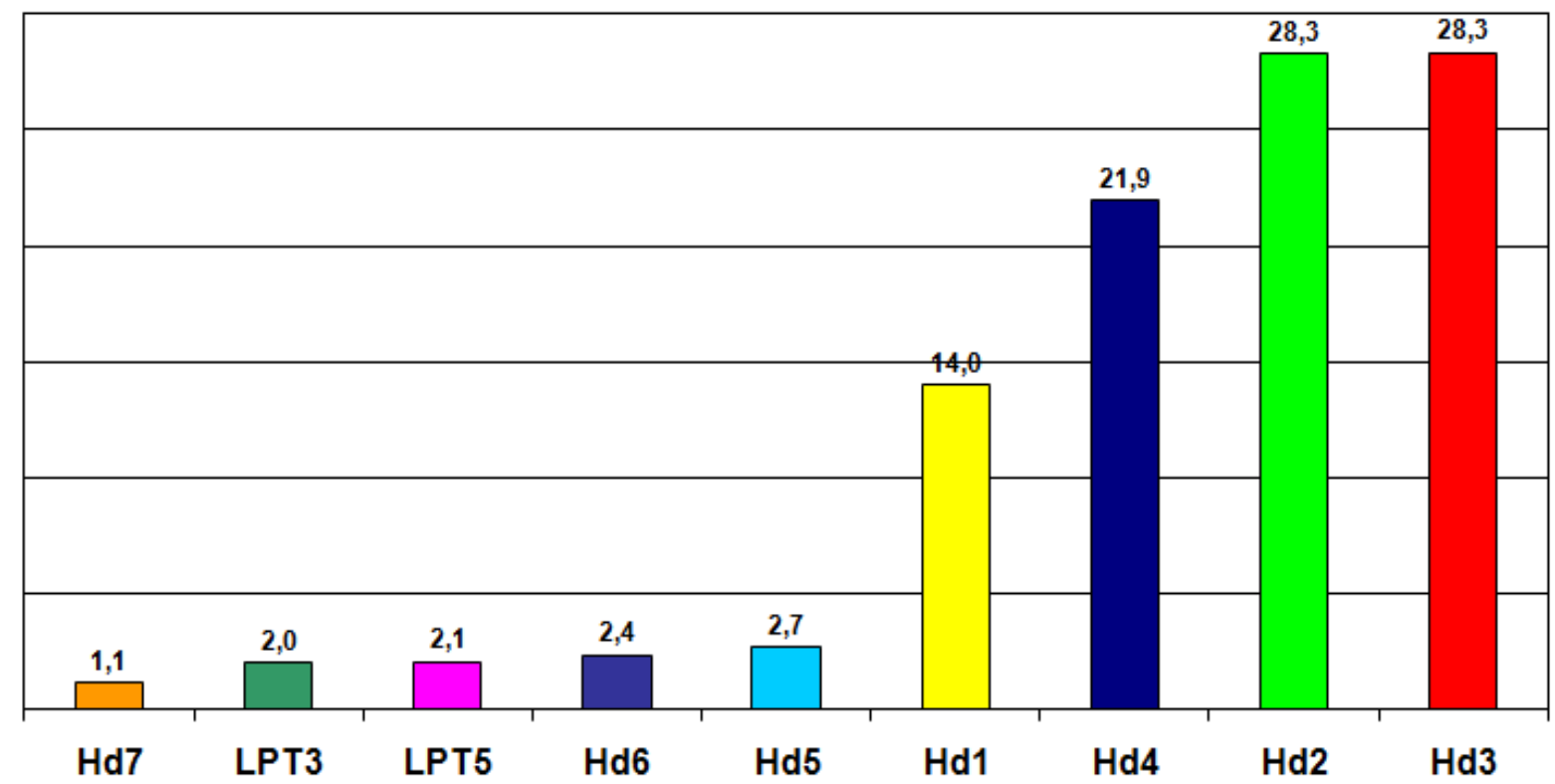

FIGURA 6.48 - Comparação do tempo médio de computação das heurísticas para setup dependente (em ms)

Como se poderia presumir, as heurísticas mais elaboradas, que empregam procedimentos com maior número de operações (Hd1, Hd2, Hd3 e $\mathrm{Hd} 4)$, consumiram mais tempo de CPU do que as demais.

Mesmo com procedimentos mais complexos do que as regras de prioridade, como as heurísticas, novamente o custo de CPU não foi relevante, uma vez que a média dos tempos de computação foi de 3,2 ms. O maior tempo gasto na solução de um problema foi de $110 \mathrm{~ms}$. 


\section{CONCLUSÕES}

"Veni vidi vici" (Vim, vi e venci)

Júlio César

Este trabalho resulta de uma extensa pesquisa realizada sobre os ambientes industriais bastante complexos e realistas denominados flexible flow line com tempos de setup. A estrutura do sistema de produção objeto de estudo foi analisada da forma mais ampla possível, considerando os vários tipos de tempos de setup: dependente e independente da sequência de execução das tarefas e a possibilidade de haver simultaneamente no problema setup antecipado e não antecipado. A dependência do setup exigiu o desdobramento do estudo em dois problemas, ou seja, com setup independente (PROBLEMA I) e setup dependente (PROBLEMA II).

Além disso, foram incorporadas características de ambientes produtivos reais, visando proporcionar contribuições tanto teóricas como práticas. Várias configurações de layout e características flexíveis das tarefas, como a possibilidade de saltar estágios, foram analisadas.

Algumas contribuições teóricas preliminares puderam ser verificadas logo na primeira parte da pesquisa, no levantamento bibliográfico, na classificação e convergência das definições dos trabalhos publicados e no estudo das características estruturais do problema.

Foi realizada uma extensa revisão bibliográfica das pesquisas com tempos de setup e dos ambientes relacionados ao problema tratado neste estudo, elucidando os trabalhos pioneiros e as publicações dos últimos dez anos: máquina única (em alusão aos estágios com má- 
quina única), máquinas paralelas (como base aos métodos de decomposição por estágio) e sistemas de máquinas em série (tanto flow shop como flow line). Registrando a evolução do ambiente de produção estudado, foram reportados os sistemas híbridos, tanto com setup explícito como incluso no tempo de processamento das tarefas.

Ainda como parte da contribuição teórica deste trabalho, foram organizadas as diversas definições divergentes constantes nos trabalhos publicados na literatura. Foi elaborada uma relação da denominação dos ambientes reportados com suas respectivas características para então apresentar a definição proposta.

Algumas características estruturais peculiares aos problemas tratados puderam ser verificadas, como o fato de não haver a antecipação de setup no primeiro estágio de produção e a probabilidade das tarefas saltarem estágios resultar na possibilidade do makespan ser definido por qualquer estágio e não apenas pelo último estágio.

Ao todo nesta pesquisa foram propostos 37 novos métodos de solução heurística, aplicando procedimentos já publicados e novas ideias. Para a elaboração das regras de prioridade, foram consideradas as características específicas dos problemas estudados e diversas combinações de valores para construir a ordenação das tarefas. Em relação à soma dos tempos de processamento e de setup, foram utilizados os tempos de todos os estágios, apenas do primeiro estágio ou então somente do estágio seguinte; em relação ao setup, foi considerada a média dos tempos de setup de um estágio ou de todos os estágios, o menor setup do estágio ou de cada estágio, ou ainda o menor setup não antecipado; em relação à ordenação, foram avaliadas as ordens não crescente e não decrescente, a mesma sequência em todos os estágio ou variando em cada estágio, e ainda uma outra ordenação $(E R D)$ do segundo estágio em diante.

Para o desenvolvimento das heurísticas construtivas, também foram combinados diversos procedimentos. Em alguns métodos, utilizou-se a mudança da medida de desempenho 
para o tempo médio de fluxo nos estágios anteriores ao último como um esforço para antecipar as datas de liberação das tarefas. Procedimentos bastante flexíveis que analisam várias possibilidades de alocação também foram considerados, tais como adaptações do método de inserção $M I$ e a verificação do melhor par tarefa-máquina. Também foram criadas heurísticas que tratam de forma específica os estágios com máquina única, os estágios gargalos. Além disso, foi incluída uma adaptação da heurística de Stinson para o flexible flow line.

Assim, foram apresentadas 24 regras de prioridade, sendo 11 para setup independente e 13 para setup dependente, e foram desenvolvidas 13 heurísticas, em que 6 são para setup independente e outras 7 para setup dependente.

O primeiro grupo de métodos de solução, composto por regras de prioridade para setup independente, comprovou o suposto bom desempenho da política de alocação $E R D$ (ordem em que as tarefas são liberadas para execução em um determinado estágio, em função das respectivas datas de término no estágio anterior), quando comparado ao das regras que mantêm a mesma ordenação ou o mesmo critério de ordenação em todos os estágios.

Entre as regras para setup independente, a LPT3_ERD (ordem não crescente da soma dos tempos de todos os estágios) apresentou o melhor desempenho, principalmente em problemas de grande porte. Considerando apenas os tempos do primeiro estágio, os melhores resultados foram obtidos pela regra SPT1_ERD (ordem não decrescente dos tempos do primeiro estágio). Os dados do segundo estágio não afetaram significativamente o desempenho das regras.

No grupo das regras de prioridade para setup dependente, a LPT3 e a LPT5 obtiveram o melhor desempenho com resultados muito próximos. Ambas consideram a ordem não crescente da soma dos tempos de todos os estágios, sendo que a primeira utiliza os tempos médios de setup e a segunda o menor tempo de setup de cada estágio. Novamente, considerando apenas os tempos do primeiro estágio, os melhores resultados foram atingidos por re- 
gras derivadas da ordem não decrescente: SPT4 e SPT1. A primeira utiliza o menor tempo de setup e a segunda o setup médio do primeiro estágio. Mais uma vez, os dados do segundo estágio mostraram que não afetam de forma relevante os resultados das regras.

Desta forma, pode-se concluir que o grande destaque das regras de prioridade foi o desempenho superior das regras com as seguintes características em comum: ordenação não crescente (LPT), utilização de dados de todos os estágios (tempos de processamento e de setup) e política de alocação ERD do segundo estágio em diante. Assim, regras com estas particularidades são mais vantajosas no ambiente flexible flow line qualquer que seja o tipo de setup, independente ou dependente da sequência de execução das tarefas, como também antecipado ou não antecipado. Os diferentes resultados das regras de prioridade demonstram também que a programação do primeiro estágio de produção exerce grande influência no valor do makespan.

No grupo das heurísticas para setup independente, o melhor desempenho foi atingido pela heurística Hi4, a única classificada como método de decomposição por tarefa. Ela utiliza a ordenação não crescente da soma dos tempos de processamento e de setup não antecipado de todos os estágios e faz a alocação pelo método de inserção $M I$. Novamente, há o predomínio do desempenho de um método que aplica uma derivação da LPT.

As heurísticas mostraram ainda que o desempenho da alocação ERD também é superior à política $E C T$ (escolha do par tarefa-máquina com menor data de término) para o problema com setup independente. Em comparação com este mesmo grupo de métodos de solução, as regras LPT3_ERD e SPT1_ERD ficaram em segundo e terceiro lugares, respectivamente.

O resultado das heurísticas para setup dependente comprovou a importância do tratamento particular aos estágios com máquina única, por se tratarem de gargalos de produção, como é o caso das heurísticas $\mathrm{Hd} 3$ e $\mathrm{Hd} 2$, que obtiveram os melhores desempenhos (juntas atingiram $88 \%$ de sucesso). Além disso, os resultados indicam a eficácia da aplicação conjun- 
ta da regra $E C T$ e do método de inserção $M I$ no último estágio para o problema com setup dependente, como a heurística Hd3, que obteve de longe o melhor desempenho deste grupo de métodos de solução (64,5\% de sucesso), principalmente em problemas de grande porte. Já no ambiente com setup independente, a aplicação do método de inserção $M I$ no último estágio (como Hi2 e Hi3) não produziu resultados expressivos.

As heurísticas aleatórias, tanto para o problema com setup dependente como independente, obtiveram sempre o pior resultado. Já a regra de prioridade aleatória, aplicada no problema com setup dependente, atingiu desempenho mediano, tendo apenas quatro regras melhores e oito regras piores do que ela. Como a programação por meio de regras é mais rígida do que aplicando heurísticas, é mais difícil estabelecer valores e prioridades que por si sós conduzam aos melhores resultados. Isto confirma a importância de procedimentos mais elaborados como as heurísticas.

As análises feitas para o desvio relativo médio e o desvio-padrão do desvio relativo confirmaram as conclusões da porcentagem de sucesso. Em geral, as regras apresentaram valores mais elevados (tanto do desvio relativo médio como do desvio-padrão do desvio relativo) do que as heurísticas. Isto mostra que a qualidade da solução das regras é menor do que das heurísticas e, além disso, o seu desempenho é menos estável. Evidentemente, as heurísticas aleatórias obtiveram os maiores valores do desvio relativo médio e do desvio-padrão do desvio relativo.

Em geral, quanto maior o porte do problema, maiores os desvios relativos médios, porém o inverso ocorre com as regras para setup dependente. Isto indica que tais regras fornecem soluções de melhor qualidade para problemas de grande porte e, além disso, são bastante estáveis de acordo com os valores do desvio-padrão do desvio relativo.

O tempo médio de computação foi desprezível, sendo de no máximo 16 ms para as regras e $110 \mathrm{~ms}$ para as heurísticas nos problemas com setup dependente. O maior tempo o- 
correu com a melhor heurística para setup independente, a Hi4, consumindo 179,1 ms em média, por aplicar o método de inserção $M I$ em todos os estágios na programação por tarefa. Entretanto, esta alta duração ocorreu apenas em problemas com 100 tarefas e a eficácia de cerca de $50 \%$ de sucesso compensa esta pequena perda de eficiência computacional.

Também como contribuição deste trabalho, foi proposta a nova medida estatística para os parâmetros dos problemas: a AMV - Amplitude Média de Variação.

Os valores da AMV mostraram que a probabilidade de salto e a flexibilidade foram os parâmetros que mais influenciaram no desempenho dos métodos. O porte do problema afetou de forma mediana e os parâmetros relacionados ao setup (intervalo e probabilidade de antecipação) exerceram pouca influência nos resultados.

A probabilidade de salto é a característica que diferencia o ambiente flexible flow line de outros sistemas do tipo flow shop. A sua forte influência na maioria dos casos analisados enfatiza ainda mais a importância do presente estudo.

O fato da AMV indicar maior variabilidade no resultado dos métodos para os diferentes níveis de flexibilidade do que para as opções do número de tarefas e de estágios sugere que no ambiente tratado o layout teria mais influência na solução do que o porte do problema.

Mesmo que os parâmetros relacionados ao setup (intervalo e probabilidade de antecipação) não tenham apresentado valores relevantes para a $\mathrm{AMV}$, não significa que na prática não sejam compensadores os esforços para se reduzir o tempo de setup ou antecipá-lo. Isto porque a AMV mede a variação da porcentagem de sucesso de um nível ao outro e não a variação do makespan.

Os resultados experimentais apresentados confirmam as hipóteses iniciais que características peculiares, tanto do ambiente de produção como das tarefas, devem ser incorporados nos métodos de solução para que obtenham bom desempenho. Tais especificidades incluem as características usuais como porte do problema e tempos de setup e as mais realísticas como o 
número flexível de estágios com máquinas paralelas e a possibilidade das tarefas saltarem estágios.

Esta pesquisa cumpriu com os seus objetivos propostos: as características estruturais dos ambientes foram amplamente exploradas; foram definidas e implementadas novas regras de prioridade para cada problema; e foram construídos e comparados algoritmos heurísticos inéditos para a solução do problema, testados experimentalmente com vários níveis de parâmetros.

Como sugestões para o desenvolvimento de futuros trabalhos, poderiam ser exploradas novas propriedades para outras heurísticas, enfatizando as características de destaque como estágios gargalos e métodos de programação por tarefa. Diferentes medidas de desempenho também poderiam ser consideradas, como tempo médio de fluxo (flow time), atraso máximo e lateness médio, ou então a utilização de duas destas medidas (problema bicritério). Para isto, outras variáveis e restrições devem ser consideradas, como por exemplo datas de entrega (due dates) e estoque intermediário limitado. Além disso, podem ser criadas meta-heurísticas para solução do problema tratado. E também poderia ser realizado um trabalho prático, como um estudo de caso em uma empresa que tenha as características do problema considerado. 


\section{REFERÊNCIAS}

ADLER, L.; FRAIMAN, N.; KOBACKER, E.; PINEDO, M.; PLOTNICOFF, J.C.; WU, T.P. BPSS: a scheduling support system for the packaging industry. Operations Research, v.41, n.4, p.641-648. 1993.

AGNETIS, A.; PACIFICI, A.; ROSSI, F.; LUCERTINI, M.; NICOLETTI, S.; NICOLO, F.; ORIOLO, G.; PACCIARELLI, D.; PESARO, E. Scheduling of flexible flow lines in an automobile assembly plant. European Journal of Operational Research, v.97, p.348-362. 1997.

ALDOWAISAN, T. A new heuristic and dominance relations for no-wait flowshop with setups. Computer and Operations Research, v.28, p.563-584. 2001.

ALFIERI, A.; NICOSIA, G. Minimum cost multi-product flow lines. Annals of Operations Research, Dordrecht, v.150, n.1, p.31-46. 2007.

ALLAHVERDI, A. Minimizing mean flowtime in a two-machine flowshop with sequenceindependent setup times. Computers and Operations Research, v.27, p.111-127. 2000.

ALLAHVERDI, A.; GUPTA, J.N.D.; ALDOWAISAN, T. A review of scheduling research involving setup considerations. Omega - The International Journal of Management Science, Oxford, v.27, p.219-239. 1999.

ALLAHVERDI, A.; NG, C.T.; CHENG, T.C.E.; KOVALYOV, M.Y. A survey of scheduling problems with setup times or costs. European Journal of Operational Research, v.187, p.985-1032. 2008.

ALLAHVERDI, A.; SOROUSH, H.M. The significance of reducing setup times/setup costs. European Journal of Operational Research, v.187, p.978-984. 2008.

ALLAOUI, H., ARTIBA, A. Integrating simulation and optimization to schedule a hybrid flow shop with maintenance constraints. Computers and Industrial Engineering, v.47, p.431-450. 2004.

ANDRÉS, C.; ALBARRACÍN, J.M.; TORMO, G.; VICENS, E.; GARCÍA-SABATER, J.P. Group technology in a hybrid flowshop environment: A case study. European Journal of Operational Research, v.167, p.272-281. 2005.

AZIZOGLU, M.; CAKMAK, E.; KONDAKCI, S. A flexible flowshop problem with total flow time minimization. European Journal of Operational Research, v.132, n.3, p.528-538. 2001. 
BAKER, K.R. Introduction to sequencing and scheduling. New York: John Wiley \& Sons, 1974. $305 \mathrm{p}$.

BIANCO, L.; RICCIARDELLI, S.; RINALDI, G.; SASSANO, A. Scheduling tasks with sequencedependent processing times. Naval Research Logistics, v.35, p.177-184. 1988.

BILGE, U.; KIRAÇ, F.; KURTULAN, M.; PEKGUN, P. A tabu search algorithm for parallel machine total tardiness problem. Computers and Operations Research, v.31, p.397-414. 2004.

BOTTA-GENOULAZ, V. Hybrid flow shop scheduling with precedence constraints and time lags to minimize maximum lateness. International Journal of Production Economics, Amsterdam, v.64, n.1-3, p.101-111, mar. 2000.

BRAH, S.A.; LOO, L.L. Heuristic for scheduling in a flow shop with multiple processors. European Journal of Operational Research, v.113, p.113-122. 1999.

BRAH, S.A.; HUNSUCKER, J.L. Branch and bound algorithm for the flow shop with multiple processors. European Journal of Operational Research, v.5, n.1, p.88-99. 1991.

BURBIDGE, J.L. The introduction of group technology. London: Heinemann, 1975.

CAMPBELL, H.G.; DUDEK, R.A.; SMITH, M.L. A heuristic algorithm for the $n$ job $m$ machine sequencing problem. Management Science, Rhode Island, v.16, p.B630-637. 1970.

CARLIER, J.; NÉRON, E. An exact method for solving the multi-processor flow-shop. RAIRO Operations Research, v.34, p.1-25. 2000.

CHANG, P.-C.; HSIEH, J.-C.; WANG, Y.-W. Genetic algorithms applied in BOPP film scheduling problems: minimizing total absolute deviation and setup times. Applied Soft Computing, v.3, p.139148. 2003.

CHEN, W.-J. Sequencing heuristic for scheduling jobs with dependent setups in a manufacturing system. International Journal of Advanced Manufacturing Technology, v.38, p176-184. 2008.

CHENG, T.C.E.; GUPTA, J.N.D.; WANG, G. A review of flowshop scheduling research with setup times. Production and Operations Management, v.9, n.3, p.262-282. 2000.

CHENG, T.C.E.; SIN, C.C.S. A state-of-the-art review of parallel-machine scheduling research. European Journal of Operational Research, Amsterdam, v.47, n.3, p.271-292, aug. 1990. 
CHOOBINEH, F.F.; MOHEBBI, E.; KHOO, H. A multi-objective tabu search for a single-machine scheduling problem with sequence-dependent setup times. European Journal of Operational Research, v.175, p.318-337. 2006.

CHUDZIK, K.; JANIAK, A. Single machine scheduling with job ready and setup times - genetic approach. Fourth International Symposium on Methods and Models in Automations and Robotics. Międzyzdroje, Poland. Aug, p.1071-1075. 1997.

COLIN, E.C. Pesquisa Operacional: 170 aplicações em Estratégia, Finanças, Logística, Produção, Marketing e Vendas. Rio de Janeiro: LTC, 2007. 501p.

CONWAY, R.W.; MAXWELL, W.L.; MILLER, L.W. Theory of scheduling. Reading: AddisonWesley, 1967. 294 p.

DING, F.Y.; KITTICHARTPHAYAK, D. Heuristics for scheduling flexible flow lines. Computers and Industrial Engineering, v.26, p.27-34. 1994.

ERDMANN, R.H. Administração da produção: planejamento, programação e controle. Florianópolis: Papa Livro, 2000.

EREN, T.; GUNER, E. A bicriteria scheduling with sequence-dependent setup times. Applied Mathematics and Computation, v.179, p.378-385. 2006.

FLOOD, M.M. (1956). The Traveling-Salesman Problem. Operations Research, Linthicum, v.4, n.1, p.61-75, feb.

FOWLER, J.W.; HORNG, N.G.; COCHRAN, J.K. A hybridized genetic algorithm to solve parallel machine scheduling problems with sequence dependent setups. International Journal of Industrial Engineering - Theory Applications and Practice, v.10, n.3, p.232-243. 2003.

FRAMINAN, J.M.; GUPTA, J.N.D.; LEISTEN, R. A review and classification of heuristics for permutation flow-shop scheduling with makespan objective. Journal of the Operational Research Society, v.55, p.1243-1255. 2004.

FUCHIGAMI, H.Y. Métodos heurísticos construtivos para o problema de programação da produção em sistemas flow shop híbridos com tempos de preparação das máquinas assimétricos e dependentes da sequência. 2005. 135p. Dissertação (Mestrado em Engenharia de Produção) - Escola de Engenharia de São Carlos, Universidade de São Paulo, São Carlos. 2005.

FUCHIGAMI, H.Y.; MOCCELLIN, J.V. Estudo da influência da relação entre os tempos de processamento e de setup em sistemas flow shop híbridos. In: ENCONTRO NACIONAL DE ENGENHARIA DE PRODUÇÃO, 25., 2005, Porto Alegre. Anais... Rio de Janeiro: Associação Brasileira de Engenharia de Produção. 2005. 1 CD-ROM. 
. Métodos heurísticos construtivos para programação da produção em sistemas flow shop híbridos com tempos de preparação das máquinas assimétricos e dependentes da sequência. In: SIMPÓSIO BRASILEIRO DE PESQUISA OPERACIONAL, 37., 2005, Gramado. Anais... Rio de Janeiro: Sociedade Brasileira de Pesquisa Operacional. 2005. 1 CD-ROM.

. Estudo da influência da programação do primeiro estágio em sistemas flow shop híbridos com tempos de setup independentes da sequência de processamento das tarefas. In: SIMPÓSIO BRASILEIRO DE PESQUISA OPERACIONAL, 38., 2006, Goiânia. Anais... Rio de Janeiro: Sociedade Brasileira de Pesquisa Operacional. 2006. 1 CD-ROM.

Análise de desempenho de regras de prioridade para programação em flow shop com múltiplas máquinas e tempos de setup independentes da sequência. In: ENCONTRO NACIONAL DE ENGENHARIA DE PRODUÇÃO, 27., 2007, Foz do Iguaçu. Anais... Rio de Janeiro: Associação Brasileira de Engenharia de Produção. 2007. 1 CD-ROM.

FUCHIGAMI, H.Y.; MOCCELLIN, J.V.; RUIZ, R. Análise comparativa do desempenho de regras de prioridade em sistemas flexible flow line com múltiplas máquinas e tempos de setup independentes da sequência. In: SIMPÓSIO BRASILEIRO DE PESQUISA OPERACIONAL, 39., 2007, Fortaleza. Anais... Rio de Janeiro: Sociedade Brasileira de Pesquisa Operacional. 2007. 1 CD-ROM.

GAITHER, N.; FRAZIER, G. Administração da produção e operações. São Paulo: Pioneira Thomson Learning, 2004. $8^{\mathrm{a}}$ ed.

GAJPAL, Y.; RAJENDRAN, C.; ZIEGLER, H. An ant colony algorithm for scheduling in flowshops with sequence-dependent setup times of job. International Journal of Advanced Manufacturing Technology, v.30, n.5-6, p.416-424. 2006.

GAREY, M.R.; JOHNSON, D.S.; SETHI, R. The complexity of flowshop and jobshop scheduling. Mathematics of Operations Research, v.1, n.2, p.117-129. 1976.

GAVETT, J.W. Three heuristic rules for sequencing jobs to a single production facility. Management Science, Linthicum, v.11, n.8, p.B166-B176. 1965.

GENDREAU, M.; LAPORTE, G.; GUIMARÃES, E.M. A divide and merge heuristic for the multiprocessor scheduling problem with sequence dependent setup times. European Journal of Operational Research, v.133, p.183-189. 2001.

GUINET, A.G.P.; SOLOMON, M.M. Scheduling hybrid flowshops to minimize maximum tardiness or maximum completion time. International Journal of Production Research, London, v.34, n.6, p.1643-1654. 1996.

GUPTA, A.K.; SIVAKUMAR, A.I. Single machine scheduling with multiple objectives in semiconductor manufacturing. The International Journal of Advanced Manufacturing Technology, v.26, n.9-10, p.950-958, jul. 2005. 
GUPTA, J.N.D.; KRUGER, K.; LAUFF, V.; WERNER, F.; SOTSKOV, Y.N. Heuristics for hybrid flow shops with controllable processing times and assignable due dates. Computers and Operations Research, v.29, n.10, p.1417-1439. 2002.

GUPTA, J.N.D.; STAFFORD JR., E.F. Flowshop scheduling research after five decades. European Journal of Operational Research, v.169, p.699-711. 2006.

GUPTA, J.N.D., TUNC, E.A. Scheduling a two-stage hybrid flowshop with separable setup and removal times. European Journal of Operational Research, v.77, p.415-428. 1994.

GUPTA, S.R.; SMITH, J.S. Algorithms for single machine total tardiness scheduling with sequence dependent setups. European Journal of Operational Research, v.175, p.722-739. 2006.

HALL, L.A.; SHMOYS, D.B. Jackson's rule for single-machine scheduling: making a good heuristic better. Mathematics of Operations Research, v.17, n.1, p.22-35. 1992.

HALL, N.G.; LIU, Z.; POTTS, C.N. Rescheduling for multiple new orders. Journal of Computing, v.19, n.4, p.633-645. 2007.

HARDING, H.A. Administração da produção. São Paulo: Atlas, 1981.

HAX, A.C.; CANDEA, D. Production and inventory management. New Jersey: Prentice-Hall, 1984.

HÄYRINEN, T.; JOHNSSON, M.; JOHTELA, T.; SMED, J.; NEVALAINEN, O. Scheduling algorithm for computer-aided line balancing in printed circuit board assembly. Production Planning and Control, v.11, n.5, p.497-510. 2000.

REZA HEJAZI, S.; SAGHAFIAN, S. Flowshop-scheduling problems with makespan criterion: a review. International Journal of Production Research, v.43, n.14, p.2895-2929, jul. 2005.

HILLIER, F.S.; LIEBERMAN, G.J. Introduction to operations research. New York: McGraw-Hill, 2005. 1061 p. $8^{\text {th }}$ ed.

HIRAISHI, K.; LEVNER, E.; VLACH, M. Scheduling of parallel identical machines to maximize the weighted number of just-in-time jobs. Computer and Operations Research, v.29, p.841-848. 2002.

HUANG, W.; LI, S. A two-stage hybrid flowshop with uniform machines and setup times. Mathematical and Computer Modeling, Oxford, v.27, n.2, p.27-45, jan. 1998. 
HURINK, J.; KNUST, S. List scheduling in a parallel machine environment with precedence constraints and setup times. Operations Research Letters, Amsterdam, v.29, n.5, p.231-239, dec. 2001.

IGNALL, E.; SCHRAGE, L. Application of the branch and bound technique to some flow-shop scheduling problems. Operations Research, Linthicum, v.13, n.3, p.400-412. 1965.

JAYAMOHAN, M.S.; RAJENDRAN, C. New dispatching rules for shop scheduling: a step forward. International Journal of Production Research, London, v.38, n.3, p.563-586. 2000.

JENABI, M.; FATEMI GHOMI, S.M.T.; TORABI, S.A.; KARIMI, B. Two hybrid meta-heuristics for the finite horizon ELSP in flexible flow lines with unrelated parallel machines. Applied Mathematics and Computation, v.186, p.230-245. 2007.

JOHNSON, L.A.; MONTGOMERY, D.C. Operations research in production planning: scheduling and inventory control. New York: Wiley, 1974.

JOHNSON, S.M. Optimal two- and three-stage production schedules with setup times included. Naval Research Logistics Quarterly, Hoboken, v.1, p.61-68. 1954.

JUNGWATTANAKIT, J.; REODECHA, M.; CHAOVALITWONGSE, P.; WERNER, F. Algorithms for flexible flow shop problems with unrelated parallel machines, setup times, and dual criteria. International Journal of Advanced Manufacturing Technology, v.37, p.354-370. 2008.

KIM, D.-W.; KIM, K.-H.; JANG, W.; CHEN, F.F. Unrelated parallel machine scheduling with setup times using simulated annealing. Robotics and Computer Integrated Manufacturing, Oxford, v.18, n.3-4, p.223-231, jun.-aug. 2002.

KIM, D.-W.; NA, D.-G.; CHEN, F.F. Unrelated parallel machine scheduling with setup times and a total weighted tardiness objective. Robotics and Computer Integrated Manufacturing, Oxford, v.19, p.173-181. 2003.

KIM, S.S.; SHIN, H.J. Scheduling jobs on parallel machines: a restricted tabu search approach. International Journal of Advanced Manufacturing Technology, v.22, p.278-287. 2003.

KIS, T.; PESCH, E. A review of exact solution methods for the non-preemptive multiprocessor flowshop problem. European Journal of Operational Research, v.164, p.592-608. 2005.

KOCHHAR, S.; MORRIS, R.J. Heuristic methods for flexible flow line scheduling. Journal of Manufacturing Systems, v.6, n.4, p.299-314. 1987.

KOULAMAS, C.; KYPARISIS, G.J. Scheduling uniform parallel machines to minimize maximum lateness. Operations Research Letters, Amsterdam, v.26, n.4, p.175-179, mai. 2000. 
KUO, W.-H., YANG, D.-L. Single machine scheduling with past-sequence-dependent setup times and learning effects. Information Processing Letters, v.102, p.22-26. 2007.

KURZ, M.E. Scheduling flexible flow line with sequence dependent setup times. 2001. 266p. Tese (Doutorado) - Departamento de Sistemas e Engenharia Industrial, Universidade do Arizona, Tucson, 2001.

KURZ, M.E.; ASKIN, R.G. An adaptable problem-space-based search method for flexible flow line scheduling. IIE Transactions, v.33, p.691-693. 2001.

Heuristic scheduling of parallel machines with sequence-dependent set-up times. International Journal of Production Research, v.39, n.16, p.3747-3769. 2001.

Comparing scheduling rules for flexible flow lines. International Journal of Production Economics, v.85, p.371-388. 2003.

. Scheduling flexible flow lines with sequence-dependent setup times. International Journal of Operational Research, v.159, p.66-82. 2004.

KRAVCHENKO, S.A.; WERNER, F. A heuristic algorithm for minimizing mean flow time with unit setups. Information Processing Letters, Amsterdam, v.79, n.6, p.291-296, sep. 2001.

LANCIA, G. Scheduling jobs with release dates and tails on two unrelated parallel machines to minimize the makespan. European Journal of Operational Research, Amsterdam, v.120, n.2, p.277288 , jan. 2000.

LAWLER, E.L.; LENSTRA, J.K.; RINNOY KAN, A.H.G.; SHMOYS, D.B. (1985). The Traveling Salesman Problem. Wiley-Interscience series in discrete mathematics and optimization. John Wiley \& Sons, New York.

LEE, C.-Y.; VAIRAKTARAKIS, G.L. Minimizing makespan in hybrid flowshops. Operations Research Letters, Amsterdam, v.16, n.3, p.149-158, oct. 1994.

LEE, I.; SIKORA, R.; SHAW, M.J. A genetic algorithm-based approach to flexible flow-line scheduling with variable lot sizes. IEEE Transactions on Systems, Man and Cybernetics - Part B: Cybernetics, v.27, n.1, p.36-54. 1997.

LEON, V.J., RAMAMOORTHY, B. An adaptable problem-space-based search method for flexible flow line scheduling. IIE Transactions, v.29, p.115-125. 1997.

LI, S. A hybrid two-stage flowshop with part family, batch production, and major and minor set-ups. European Journal of Operational Research, v.102, p.142-156. 1997. 
LIAEE, M.M.; EMMONS, H. Scheduling families of jobs with setup times. International Journal of Production Economics, Amsterdam, v.51, n.3, p.165-176. 1997.

LIAO, C.-J.; JUAN, H.-C. An ant colony optimization for single-machine tardiness scheduling with sequence-dependent setups. Computers and Operations Research, v.34, p.1899-1909. 2007.

LIESTEN, R.; KOLBE, M. A note on scheduling jobs with missing operations in permutation flow shops. International Journal of Production Research, London, v.36, n.9, p.2627-2630. 1998.

LIN, B.M.T.; CHENG, T.C.E. Two-machine flowshop batching and scheduling. Annals of Operations Research, v.133, p.149-161. 2005.

LIN, H.T.; LIAO, C.J. A case study in a two-stage hybrid flow shop with setup time and dedicated machines. International Journal of Production Economics, Amsterdam, v.86, n.2, p.133-143, nov. 2003.

LINN, R.; ZHANG, W. Hybrid flow shop scheduling: a survey. Computers \& Industrial Engineering, Oxford, v.37, n.1-2, p.57-61, oct. 1999.

LIU, C.-Y.; CHANG, S.-C. Scheduling flexible flow shops with sequence-dependent setup effects. IEEE Transactions on Robotics and Automation, v.16, n.4, p.408-419. 2000.

LIU, Z.; CHENG, T.C.E. Scheduling with job release dates, delivery times and preemption penalties. Information Processing Letters, v.82, p.107-111. 2002.

LIU, Z.; CHENG, T.C.E. Minimizing total completion time subject to job release dates and preemption penalties. Journal of Scheduling, v.7, p.313-327. 2004.

LOGENDRAN, R.; CARSON, S.; HANSON, E. Group scheduling in flexible flow shops. International Journal of Production Economics, v.96, p.143-155. 2005.

LOGENDRAN, R.; deSZOEKE, P.; BARNARD, F. Sequence-dependent group scheduling problems in flexible flow shops. International Journal of Production Economics, v.102, p.66-86. 2006.

LOW, C. Simulated annealing heuristic for flow shop scheduling problems with unrelated parallel machines. Computers and Operations Research, v.32, p.2013-2025. 2005.

LU, L.F.; YUAN, J.J. The single machine batching problem with identical family setup times to minimize maximum lateness is strongly NP-hard. European Journal of Operational Research, v.177, p.1302-1309. 2007. 
LUO, X.; CHU, F. A branch and bound algorithm of the single machine scheduling with sequence dependent setup times for minimizing total tardiness. Applied Mathematics and Computation, v.183, p.575-588. 2006.

LUO, X.; CHU, C. A branch-and-bound algorithm of the single machine schedule with sequencedependent setup times for minimizing maximum tardiness. European Journal of Operational Research, v.180, p.68-81. 2007.

MACCARTHY, B.L.; LIU, J.Y. Addressing a gap in scheduling research - a review of optimization and heuristic methods in production scheduling. International Journal of Production Research, London, v.31, n.1, p.59-79, jan. 1993.

MAZDEH, M.M.; SARHADI, M.; HINDI, K.S. A branch-and-bound algorithm for single-machine scheduling with batch delivery and job release times. Computers and Operations Research, v.35, p.1099-1111. 2008.

MENDES, A.S.; MULLER, F.M.; FRANÇA, P.M.; MOSCATO, P. Comparing meta-heuristic approaches for parallel machine scheduling problems. Production Planning and Control, v.13, n.2, p.143-154. 2002.

MOCCELLIN, J.V. Contribuição à programação de operações em sistemas de produção intermitente flow-shop. 1992. 126p. Tese (Livre Docência) - Escola de Engenharia de São Carlos, Universidade de São Paulo, São Carlos. 1992.

MOCCELLIN, J.V. A new heuristic method for the permutation flow-shop scheduling problem. Journal of the Operational Research Society, Oxford, v.46, n.7, p.883-886, jul. 1995.

MOCCELLIN, J.V.; NAGANO, M.S. Flow shop com máquinas paralelas genéricas. In: SIMPÓSIO BRASILEIRO DE PESQUISA OPERACIONAL, 35., 2003, Natal. Anais... Rio de Janeiro: Sociedade Brasileira de Pesquisa Operacional. 2003. 1 CD-ROM.

Flow shop híbrido com estágios gargalos. In: SIMPÓSIO BRASILEIRO DE PESQUISA OPERACIONAL, 35., 2003, Natal. Anais... Rio de Janeiro: Sociedade Brasileira de Pesquisa Operacional. 2003. 1 CD-ROM.

. Uma propriedade estrutural do problema de programação da produção flow shop permutacional com tempos de setup. Pesquisa Operacional, v.27, n.3, p.487-515, 2007. Set-dez.

MOKOTOFF, E. Parallel machine scheduling problems: a survey. Asia-Pacific Journal of Operational Research, v.18, n.1, p.193-242, nov. 2001.

MORTON, T.E.; PENTICO, D.W. Heuristic scheduling systems. New York: John Wiley \& Sons, 1993. $695 \mathrm{p}$. 
MOSCATO, P. Memetic algorithms: a short introduction. In: CORNE, D.; GLOVER, F.; DORIGO, M. (Eds.), New Ideas in Optimization., McGraw-Hill, Maidenhead, p.219-234. 1999.

MOURSLI, O. Scheduling the hybrid flowshop: branch and bound algorithms. 1999. 198 p. Tese (Doutorado) - Faculte des Sciences Economiques, Sociales et Politiques, Universite Catholique de Louvain, Louvain (Bélgica), 1999.

MOURSLI, O.; POCHET, Y. A branch-and-bound algorithm for the hybrid flowshop. International Journal of Production Economics, Amsterdam, v.64, n.1-3, p.113-125, mar. 2000.

NADERI, B.; RUIZ, R.; ZANDIEH, M. Algorithms for a realistic variant of flowshop scheduling. Computers \& Operations Research, in press.

NAGANO, M.S.; MOCCELLIN, J.V. A high quality solution constructive heuristic for flow shop sequencing. Journal of the Operational Research Society, Oxford, v.53, n.12, p.1374-1379, dec. 2002.

NAWAZ, M.; ENSCORE JR., E.E.; HAM, I. A heuristic algorithm for the $m$-machine $n$-job flow-shop sequencing problem. OMEGA - The International Journal of Management Science, v.11, n.1, p.91-95. 1983.

NÉRON, E.; BAPTISTE, P.; GUPTA, J.N.D. Solving hybrid flow shop problem using energetic reasoning and global operations. Omega - The International Journal of Management Science, v.29, n.6, p.501-511. 2001.

OĞUZ, C.; ERCAN, M.F.; CHENG, T.C.E.; FUNG, Y.F. Heuristic algorithms for multiprocessor task scheduling in a two-stage hybrid flow-shop. European Journal of Operational Research, Amsterdam, v.149, n.2, p.390-403, sep. 2003.

OĞUZ, C.; ZINDER, Y.; DO, V.H.; JANIAK, A. LICHTENSTEIN, M. Hybrid flow-shop scheduling problems with multiprocessor task systems. European Journal of Operational Research, Amsterdam, v.152, n.1, p.115-131, jan. 2004.

OSMAN, I.H.; POTTS, C.N. Simulated annealing for permutation flow-shop scheduling. Omega The International Journal of Management Science, Oxford,v.17, n.6, p.551-557. 1989.

PARK, Y.; KIM, S.; LEE, Y.-H. Scheduling jobs on parallel machines applying neural network and heuristic rules. Computers and Industrial Engineering, v.38, p.189-202. 2000.

PEARL, J. (1984). Heuristics: intelligent search strategies for computer problem solving. Reading, Massachusetts, Addison-Wesley. 
PINEDO, M. Scheduling: theory, algorithms, and systems. New Jersey, Prentice-Hall, 1995. 378 p.

PORTMANN, M.-C.; VIGNIER, A.; DARDILHAC, D.; DEZALAY, D. Branch and bound crossed with GA to solve hybrid flowshops. European Journal of Operational Research, v.107, n.2, p.389400. 1998.

POTTS, C.N. An adaptive branching rule for the permutation flow-shop problem. European Journal of Operational Research, Amsterdam, v.5, n.1, p.19-25, jul. 1980.

Analysis of a heuristic for one machine sequencing with release dates and delivery times. Operations Research, v.28, n.6, p.1436-1441. 1980.

PRABHAHARAN, G.; KHAN, B.S.H.; RAKESH, L. Implementation of grasp in flow shop scheduling. The International Journal of Advanced Manufacturing Technology, v.30, n.11-12, p.11261131. 2006.

PRANZO, M. Batch scheduling in a two-machine flow shop with limited buffer and sequence independent setup times and removal times. European Journal of Operational Research, v.153, p.581592. 2004.

PUGAZHENDHI, S.; THIAGARAJAN, S.; RAJENDRAN, C.; ANANTHARAMAN, N. Performance enhancement by using non-permutation schedules in flowline-based manufacturing systems. Computers and Industrial Engineering, v.44, p.133-157. 2003.

. Generating non-permutation schedules in flowline-based manufacturing systems with sequence-dependent setup times of jobs: a heuristic approach. International Journal of Advanced Manufacturing Technology, v.23, p.64-78. 2004.

Relative performance evaluation of permutation and non-permutation schedules in flowlinebased manufacturing systems with flowtime objective. International Journal of Advanced Technology, v.23, p.820-830. 2004.

QUADT, D.; KUHN, H. A conceptual framework for lot-sizing and scheduling of flexible flow lines. International Journal of Production Research, v.43, n.11, p.2291-2308. 2005.

. A taxonomy of flexible flow line scheduling procedures. European Journal of Operational Research, v.178, p.686-698. 2007.

Batch scheduling of jobs with identical process times on flexible flow lines. International Journal of Production Economics, v.105, p.385-401. 2007. 
RADHAKRISHNAN, S.; VENTURA, J.A. Simulated annealing for parallel machine scheduling with earliness-tardiness penalties and sequence-dependent set-up times. International Journal of Production Research, v.38, n.10, p.2233-2252. 2000.

RAJENDRAN, C.; CHAUDHURI, D. A multi-stage parallel processor flowshop problem with minimum flowtime. European Journal of Operational Research, v.57, n.1, p.111-122. 1992.

Scheduling in n-job, m-stage flow shop with parallel processors to minimize makespan. International Journal of Production Economics, v.27, p.137-143. 1992.

RAJENDRAN, C.; HOLTHAUS, O. A comparative study of dispatching rules in dynamic flowshops and jobshops. European Journal of Operational Research, v.116, p.156-170. 1999.

RAJENDRAN, C.; ZIEGLER, H. A performance analysis of dispatching rules and a heuristic in static flowshops with missing operations of jobs. European Journal of Operational Research, v.131, p.622-634. 2001.

. Scheduling to minimize the sum of weighted flowtime and weighted tardiness of jobs in a flowshop with sequence-dependent setup times. European Journal of Operational Research, Amsterdam, v.149, n.3, p.513-522, sep. 2003.

REDDY, V.; NARENDRAN, T.T. Heuristics for scheduling sequence-dependent set-up jobs in flow line cells. International Journal of Production Research, Oxon, v.41, n.1, p.193-206. 2003.

REEVES, C.R. A genetic algorithm for flowshop sequencing. Computers \& Operations Research, Oxford, v.22, n.1, p.5-13, jan. 1995.

REINELT, G. (1994). The Traveling Salesman: Computational Solutions for TSP Applications. Lecture Notes in Computer Science, Springer-Verlag, Berlin Heidelberg, v.840.

RIANE, F. Scheduling hybrid flowshops: algorithms and applications. 1998. Ph.D Thesis - Facultés Universitaires Catholicques de Mons. 1998.

RIANE, F.; ARTIBA, A.; ELMAGHRABY, S.E. A hybrid three-stage flowshop problem: efficient heuristics to minimize makespan. European Journal of Operational Research, Amsterdam, v.109, p.321-329, sep. 1998.

RIANE, F.; ARTIBA, A.; ELMAGHRABY, S.E. Sequencing a hybrid two-stage flowshop with dedicated machines. International Journal of Production Research, v.40, n.17, p.4353-4380. 2002.

RIANE, F.; ARTIBA, A.; IASSINOVSKI, S. An integrated production planning and scheduling system for hybrid flowshop organizations. International Journal of Production Economics, v.74, p.3348. 2001. 
ROBINSON, A. Modern approaches to manufacturing improvement: The Shingo System. Portland: Productivity Press, 1990.

ROSENKRANTZ, D.J.; STEARNS, R.E.; LEWIS, P.M. (1974). Approximate algorithms for the traveling salesperson problem. Switching and Automata Theory, IEEE Conference Record of $15^{\text {th }}$ Annual Symposium on, p.33-42, oct.

ROSENKRANTZ, D.J.; YU, L.; RAVI, S.S. Efficient construction of minimum makespan schedules for tasks with a fixed number of distinct execution times. Algorithmica, v.30, p.83-100. 2001.

RUIZ, R. Técnicas metaheurísticas para la programación flexible de la producción. 2003. 521 p. Tese (Doutorado em Ciência da Computação) - Departamento de Estatística e Pesquisa Operacional Aplicadas e Qualidade, Universidade Politécnica de Valência, Valência, 2003.

RUIZ, R.; MAROTO, C. A comprehensive review and evaluation of permutation flowshop heuristics. European Journal of Operational Research, v.165, p.479-494. 2005.

. A genetic algorithm for hybrid flowshops with sequence dependent setup times and machine eligibility. European Journal of Operational Research, v.169, p.781-800. 2006.

RUIZ, R.; MAROTO, C.; ALCARAZ, J. Solving the flowshop scheduling problem with sequence dependent setup times using advanced metaheuristics. European Journal of Operational Research, v.165, p.34-54. 2005.

. Two new robust genetic algorithm for the flowshop scheduling problem. Omega - The International Journal of Management Science, v.34, p.461-476. 2006.

RUIZ, R.; ŞERIFOĞLU, F.S.; URLINGS, T. Modeling realistic hybrid flexible flowshop scheduling problems. Computers \& Operations Research, v.35, p.1151-1175. 2008.

SALVADOR, M.S. A solution to a special case of flow shop scheduling problems. In: ELMAGHRABY, S.E. (Ed.), Symposium on the Theory of Scheduling and its Applications, Springer, Berlin, p.83-91. 1973.

SAWIK, T. A scheduling algorithm for flexible flow lines with limited intermediate buffers. Applied Stochastic Models and Data Analysis, v.9, p.127-138. 1993.

Scheduling flexible flow lines with no in-process buffers. International Journal of Production Research, v.33, n.5, p.1357-1367. 1995. 
SCHALLER, J. Scheduling on a single machine with family setups to minimize total tardiness. International Journal of Production Economics, v.105, p.329-344. 2007.

SELEN, W.J.; HOTT, D.D. A mixed-integer goal programming formulation of the standard flow-shop scheduling problem. Journal of the Operational Research Society, Oxford, v.37, n.12, p.1121-1128. 1986.

SETHANAN, K. Scheduling flexible flowshops with sequence dependent setup times. 2001. $181 \mathrm{p}$. Tese (Doutorado em Ciências de Decisão e Sistemas de Produção) - College of Engineering and Mineral Resources, West Virginia University, Morgantown, 2001.

SHINGO, S. Sistemas de produção com estoque zero: o sistema Shingo para melhorias contínuas. Porto Alegre, Bookman, 1996.

. Sistema de troca rápida de ferramenta: uma revolução nos sistemas produtivos. Porto Alegre: Bookman, 2000. 327 p.

SIMONS JR., J.V. Heuristics in flow shop scheduling with sequence dependent setup times. OMEGA - International Journal of Management Science, v.20, n.2, p.215-225. 1992.

SLACK, N. et al. Administração da produção. São Paulo: Atlas, 1999. $1^{\text {a }}$ ed.

SOEWANDI, H.; ELMAGHRABY, S.E. Sequencing on two-stage hybrid flowshops with uniform machines to minimize makespan. IIE Transactions, v.35, p.467-477. 2003.

STINSON, J.P.; SMITH, A.W. A heuristic programming procedure for sequencing the static flowshop. International Journal of Production Research, v.6, n.6, p.753-764. 1982.

SU, L.-H.; CHEN, C.-J. Minimizing total tardiness on a single machine with unequal release dates. European Journal of Operational Research, v.186, p.496-503. 2008.

ŞERIFOĞLU, F.S.; ULUSOY, G. Multiprocessor task scheduling in multistage hybrid flow-shops: A genetic algorithm approach. Journal of the Operational Research Society, v.55, p.504-512. 2004.

TANG, L.X.; ZHANG, Y.Y. Heuristic combined artificial neural networks to schedule hybrid flow shop with sequence dependent setup times. Lecture Notes in Computer Science, v.3496, p.788-793. 2005.

TUBINO, D.F. Manual de planejamento e controle da produção. São Paulo: Atlas, 2006. $2^{\mathrm{a}}$ ed.

URLINGS, T.; RUIZ, R.; ŞERIFOĞLU, F.S. Genetic algorithms for complex hybrid flexible flow line problems. International Journal of Metaheuristics, in press, 2008. 
VAKHANIA, N. Single-machine scheduling with release times and tails. Annals of Operations Research, v.129, p.253-271. 2004.

VAIRAKTARAKIS, G. Flexible Hybrid Flowshops. In: LEUNG, J.Y-T. Handbook of Scheduling: algorithms, models, and performance analysis. San Diego: Chapman \& Hall/CRC Press, 2004. p.5.15.33 .

VAN HOP, N.; NAGARUR, N.N. The scheduling problem of PCBs for multiple non-identical parallel machines. European Journal of Operational Research, v.158, p.577-594. 2004.

VIGNIER, A.; BILLAUT, J.C.; PROUST, C. Les problèmes d'ordonnancement de type flow-shop hybride: état de l'art. RAIRO - Recherche Opérationnelle, Paris, v.33, n.2, p.117-183. 1999.

WANG, H. Flexible flow shop scheduling: optimum, heuristic and artificial intelligence solutions. Expert Systems, v.22, n.2, p.78-85, may. 2005.

WENG, M.X.; LU, J.; REN, H. Unrelated parallel machine scheduling with setup consideration and a total weighted completion time objective. International Journal of Production Economics, Amsterdam, v.70, n.3, p.215-226, apr. 2001.

WIDMER, M.; HERTZ, A. A new heuristic method for the flow shop sequencing problem. European Journal of Operational Research, Amsterdam, v.41, p.186-193, jul. 1989.

WILSON, A.D.; KING, R.E.; HODGSON, T.J. Scheduling non-similar groups on a flow line: multiple group setups. Robotics and Computer-Integrated Manufacturing, v.20, p.505-515. 2004.

WILSON, J.M. Alternative formulations of a flow shop scheduling problem. Journal of the Operational Research Society, Oxford, v.40, n.4, p.395-399, apr. 1989.

WITTROCK, R.J. An adaptable scheduling algorithm for flexible flow lines. Operations Research, v.36, n.4, p.445-453. 1988.

YANG, D.L.; CHERN, M.S. Two-machine flowshop group scheduling problem. Computers \& Operations Research, Oxford, v.27, p.975-985. 2000.

YIP, Y.; CHENG, C.-Y.; LOW, C. Sequencing of an M machine flow shop with setup, processing and removal times separated. International Journal of Advanced Manufacturing Technology, v.30, p.286-292. 2006.

YUAN, J.J.; LIU, Z.H.; NG, C.T.; CHENG, T.C.E. Single machine batch scheduling problem with family setup times and release dates to minimize makespan. Journal of Scheduling, v.9, p.499-513. 2006. 
ZANDIEH, M.; FATEMI GHOMI, S.M.T.; MOATTAR HUSSEINI, S.M. An immune algorithm approach to hybrid flow shops scheduling with sequence-dependent setup times. Applied Mathematics and Computation, v.180, p.111-127. 2006.

ZHU, X.; WILHELM, W.E. Scheduling and lot sizing with sequence-dependent setup: a literature review. IIE Transactions, v.38, p.987-1007. 2006.

ZHU, Z.; HEADY, R.B. Minimizing the sum of the earliness/tardiness in multi-machine scheduling: a mixed integer programming approach. Computers and Industrial Engineering, v.38, p.297-305. 2000 . 


\section{APÊNDICE A}

\section{TRABALHOS PUBLICADOS}

A seguir são apresentados os trabalhos já publicados pelo autor desta pesquisa:

FUCHIGAMI, H.Y. Métodos heurísticos construtivos para o problema de programação da produção em sistemas flow shop híbridos com tempos de preparação das máquinas assimétricos e dependentes da sequência. 2005. 135p. Dissertação (Mestrado em Engenharia de Produção) - Escola de Engenharia de São Carlos, Universidade de São Paulo, São Carlos. 2005.

FUCHIGAMI, H.Y.; MOCCELLIN, J.V. Heuristic for hybrid flow shop scheduling with asymmetric sequence dependent setup times. In: INFORMS ANNUAL MEETING, 2005, San Francisco/USA. Anais... San Francisco: INFORMS. 2005.

FUCHIGAMI, H.Y.; MOCCELLIN, J.V. Estudo da influência da relação entre os tempos de processamento e de setup em sistemas flow shop híbridos. In: ENCONTRO NACIONAL DE ENGENHARIA DE PRODUÇÃO, 25., 2005, Porto Alegre. Anais... Rio de Janeiro: Associação Brasileira de Engenharia de Produção. 2005. 1 CD-ROM.

FUCHIGAMI, H.Y.; MOCCELLIN, J.V. Métodos heurísticos construtivos para programação da produção em sistemas flow shop híbridos com tempos de preparação das máquinas assimétricos e dependentes da sequência. In: SIMPÓSIO BRASILEIRO DE PESQUISA OPERACIONAL, 37., 2005, Gramado. Anais... Rio de Janeiro: Sociedade Brasileira de Pesquisa Operacional. 2005. 1 CD-ROM.

FUCHIGAMI, H.Y.; MOCCELLIN, J.V. Estudo da influência da programação do primeiro estágio em sistemas flow shop híbridos com tempos de setup independentes da sequência de processamento das tarefas. In: SIMPÓSIO BRASILEIRO DE PESQUISA OPERACIONAL, 38., 2006, Goiânia. Anais... Rio de Janeiro: Sociedade Brasileira de Pesquisa Operacional. 2006. 1 CD-ROM. 
FUCHIGAMI, H.Y.; MOCCELLIN, J.V. Análise de desempenho de regras de prioridade para programação em flow shop com múltiplas máquinas e tempos de setup independentes da sequência. In: ENCONTRO NACIONAL DE ENGENHARIA DE PRODUÇÃO, 27., 2007, Foz do Iguaçu. Anais... Rio de Janeiro: Associação Brasileira de Engenharia de Produção. 2007. 1 CD-ROM.

FUCHIGAMI, H.Y.; MOCCELLIN, J.V.; RUIZ, R. Análise comparativa do desempenho de regras de prioridade em sistemas flexible flow line com múltiplas máquinas e tempos de setup independentes da sequência. In: SIMPÓSIO BRASILEIRO DE PESQUISA OPERACIONAL, 39., 2007, Fortaleza. Anais... Rio de Janeiro: Sociedade Brasileira de Pesquisa Operacional. 2007. 1 CD-ROM.

FUCHIGAMI, H.Y.; MOCCELLIN, J.V. Regras de prioridade para programação em sistemas flexible flow line com tempos de setup dependentes da sequência. In: SIMPÓSIO DE ENGENHARIA DE PRODUÇÃO, 16., 2009, Bauru. Anais... Bauru: Faculdade de Engenharia de Bauru, Universidade Estadual Paulista. 2009. 1 CD-ROM. 


\section{APÊNDICE B}

\section{Estudos em ProgramaÇÃo de OPERAÇões em Máquinas}

Desde o início da década de 1990, os estudos referentes à área de Programação de Operações em Máquinas na Escola de Engenharia de São Carlos (EESC) da USP resultaram em uma tese de livre docência, uma de doutorado e onze dissertações de mestrado, apresentados a seguir em ordem cronológica:

MOCCELLIN, J.V. Contribuição à programação de operações em sistemas de produção intermitente flow-shop. 1992. 126 p. Tese (Livre Docência) - Escola de Engenharia de São Carlos, Universidade de São Paulo, São Carlos. 1992.

NAGANO, M.S. Novos procedimentos de busca tabu para o problema de programação de operações flow-shop permutacional. 1995. 118 p. Dissertação (Mestrado em Engenharia de Produção) - Escola de Engenharia de São Carlos, Universidade de São Paulo, São Carlos. 1995.

MOTA, W.L. Análise comparativa de algoritmos genéticos para o problema de programação de operações flow shop permutacional. 1996. 128 p. Dissertação (Mestrado em Engenharia de Produção) - Escola de Engenharia de São Carlos, Universidade de São Paulo, São Carlos. 1996.

NAGANO, M.S. Um novo método heurístico construtivo de alto desempenho para a programação de operações flow-shop permutacional. 1999. 71 p. Tese (Doutorado em Engenharia de Produção) - Escola de Engenharia de São Carlos, Universidade de São Paulo, São Carlos. 1999.

BUZZO, W.R. Proposição de um método metaheurístico híbrido Algoritmo GenéticoSimulated Annealing para o problema de programação de operações flow shop permutacional. 1999. 96 p. Dissertação (Mestrado em Engenharia de Produção) - Escola de Engenharia de São Carlos, Universidade de São Paulo, São Carlos. 1999. 
SOUZA, A.B.D. Desenvolvimento de um método metaheurístico híbrido Algoritmo Genético-Busca Tabu para o problema de programação de operações flow-shop permutacional. 2000. 82 p. Dissertação (Mestrado em Engenharia de Produção) - Escola de Engenharia de São Carlos, Universidade de São Paulo, São Carlos. 2000.

BARROS, A.D. Algoritmo metaheurístico para busca do gargalo flutuante em flow shop permutacional com tempos de setup assimétricos e dependentes da seqüência. 2002. 112 p. Dissertação (Mestrado em Engenharia de Produção) - Escola de Engenharia de São Carlos, Universidade de São Paulo, São Carlos. 2002.

SILVA, P.P. Métodos heurísticos construtivos para o problema de programação de operações flow shop híbrido com estágio de produção dominante. 2005. 185 p. Dissertação (Mestrado em Engenharia de Produção) - Escola de Engenharia de São Carlos, Universidade de São Paulo, São Carlos. 2005.

FUCHIGAMI, H.Y. Métodos heurísticos construtivos para o problema de programação da produção em sistemas flow shop híbridos com tempos de preparação das máquinas assimétricos e dependentes da sequência. 2005. 135 p. Dissertação (Mestrado em Engenharia de Produção) - Escola de Engenharia de São Carlos, Universidade de São Paulo, São Carlos. 2005.

BRANCO, F.J.C. Avaliação de métodos heurísticos para o problema no-wait flowshop com o critério de minimização da duração total da programação. 2006. 457 p. Dissertação (Mestrado em Engenharia de Produção) - Escola de Engenharia de São Carlos, Universidade de São Paulo, São Carlos. 2006.

SCARDOELLI, L.Y. Novos métodos heurísticos para a programação no-wait flow shop com critério de minimização do tempo total de fluxo. 2006. 159 p. Dissertação (Mestrado em Engenharia de Produção) - Escola de Engenharia de São Carlos, Universidade de São Paulo, São Carlos. 2006.

MORAIS, M.F. Métodos heurísticos construtivos para redução do estoque em processo em ambientes da produção flow shop híbridos com tempos de setup dependentes da sequiência. 2008. 299 p. Dissertação (Mestrado em Engenharia de Produção) - Escola de Engenharia de São Carlos, Universidade de São Paulo, São Carlos. 2008. 
BOYKO, T.J.P. Métodos heurísticos para a programação em flow shop permutacional com tempos de setup separados dos tempos de processamento e independentes da seqüência de tarefas. 2008. 220 p. Dissertação (Mestrado em Engenharia de Produção) - Escola de Engenharia de São Carlos, Universidade de São Paulo, São Carlos. 2008. 


\section{APÊNDICE C}

\section{FORMATO DOS ARQUIVOS DE DADOS}

As Figuras D.1 e D.2 ilustram respectivamente exemplos de arquivos de dados do problema com setup independente e dependente.

Primeira linha: número de tarefas (10), de máquinas

(6) e de estágios (3)
Segunda linha: quantidade de máquinas por estágio (3 máquinas no primeiro estágio, 1 no segundo e 2 no terceiro)
Matriz $(\boldsymbol{j}, \boldsymbol{k})$ de antecipação dos setups ( $\boldsymbol{j}$ tarefas e $\boldsymbol{k}$ estágios): "0" se setup não antecipado e "1" se setup antecipado

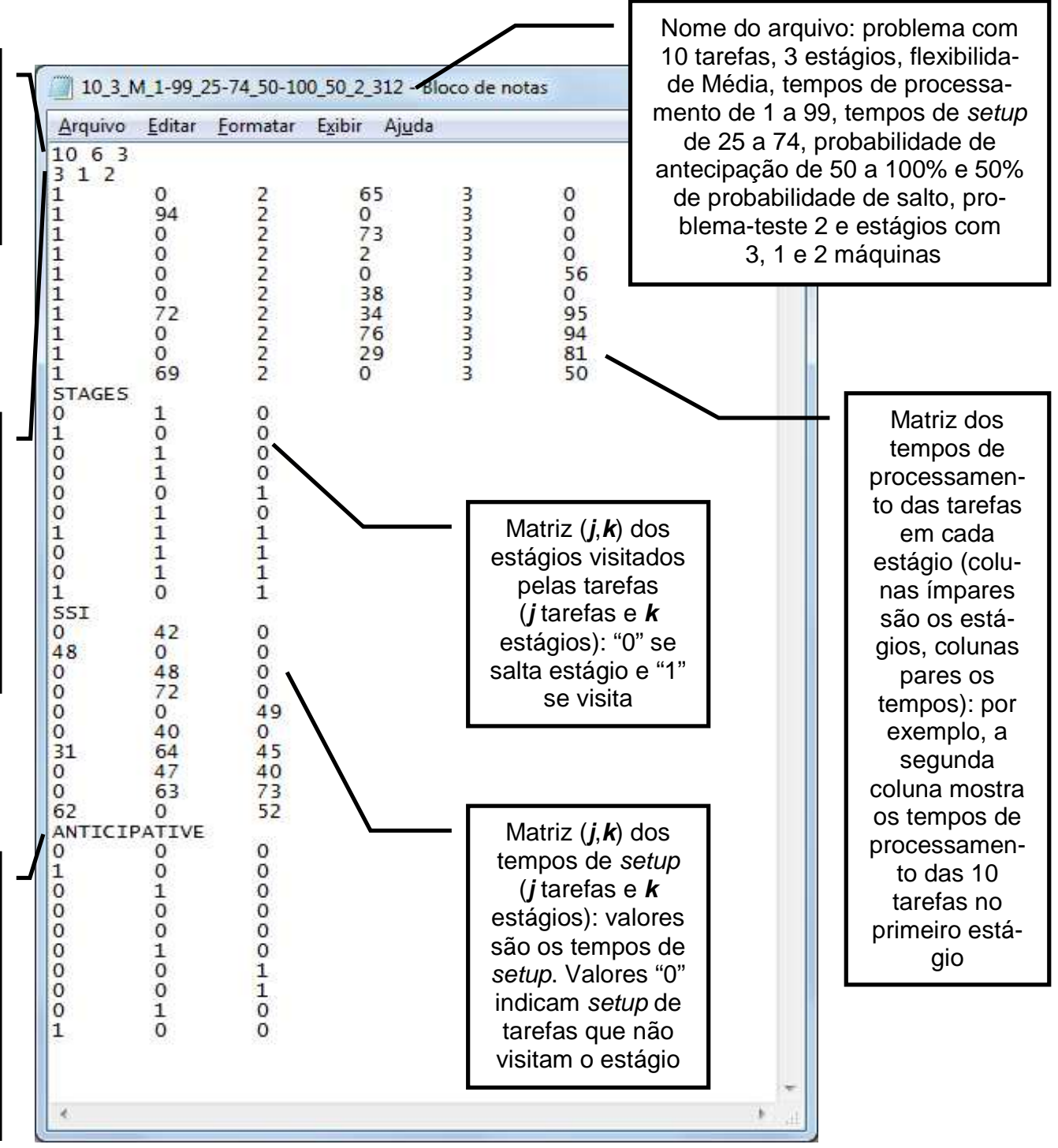

FIGURA D.1 - Exemplo de arquivo de dados do problema com setup independente 


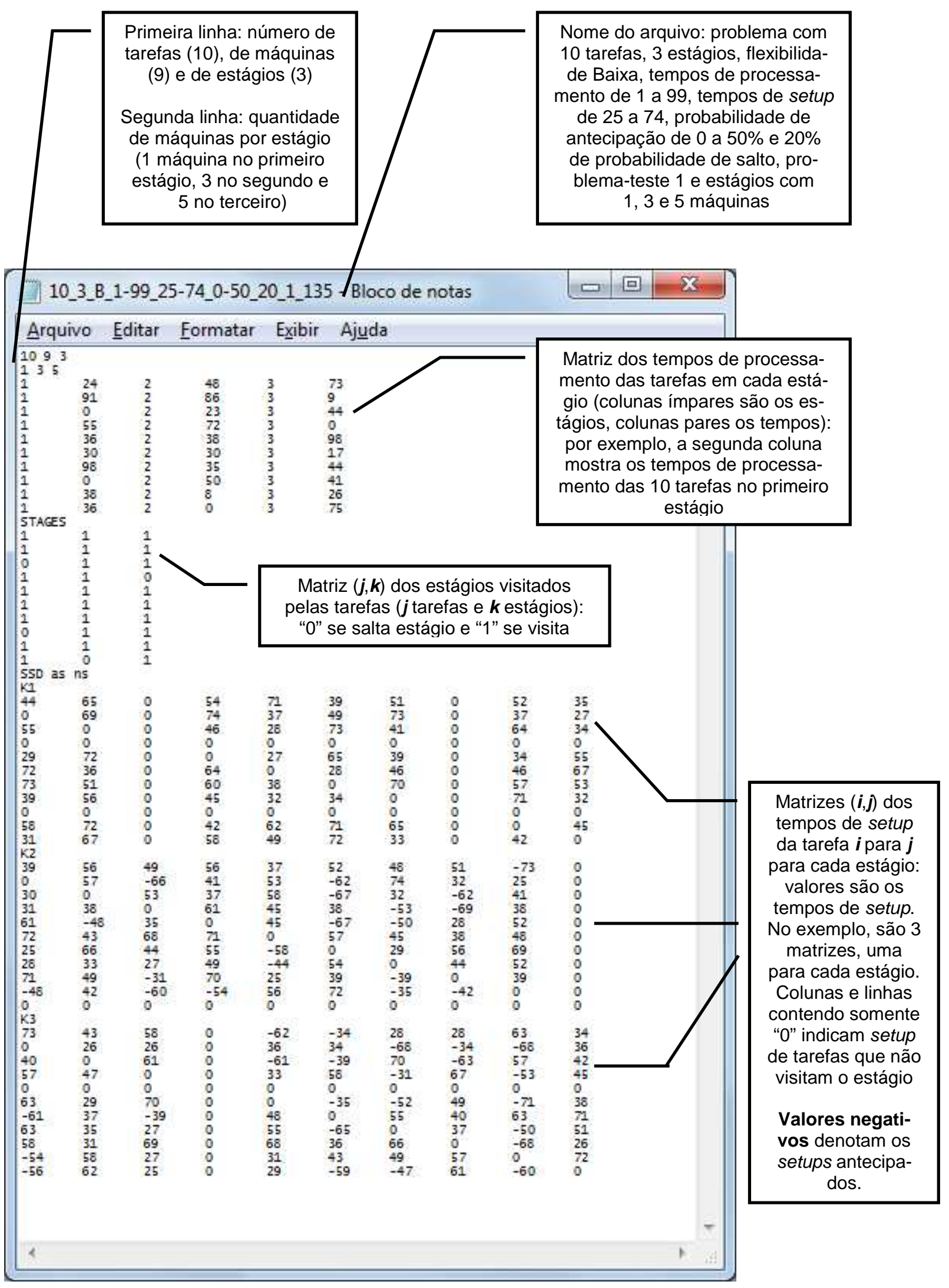

FIGURA D.2 - Exemplo de arquivo de dados do problema com setup dependente 


\section{APÊNDICE D}

\section{RESULTADOS DOS PROBLEMAS-TESTE DA EXPERIMENTAÇÃO}

As tabelas a seguir apresentam os resultados a partir dos quais foram elaborados os gráficos de dispersão que constam no Capítulo 6.

Para melhor formatação das tabelas, as regras de prioridade para cada problema foram representadas respectivamente com a seguinte notação:

\begin{tabular}{|c|c|c|c|}
\hline $\begin{array}{l}\text { Regra para setup } \\
\text { independente: }\end{array}$ & Notação: & $\begin{array}{l}\text { Regra para setup } \\
\text { dependente: }\end{array}$ & Notação: \\
\hline SPT1 & Ri1 & SPT1 & $\mathrm{Rd} 1$ \\
\hline SPT2 & Ri2 & LPT1 & $\mathrm{Rd} 2$ \\
\hline LPT2 & $\mathrm{Ri3}$ & SPT2 & $\mathrm{Rd} 3$ \\
\hline SPT3 & $\mathrm{Ri} 4$ & LPT2 & $\mathrm{Rd} 4$ \\
\hline LPT3 & Ri5 & SPT3 & $\mathrm{Rd} 5$ \\
\hline SPT1_ERD & Ri6 & LPT3 & Rd6 \\
\hline LPT1_ERD & Ri7 & SPT4 & $\mathrm{Rd} 7$ \\
\hline SPT2_ERD & Ri8 & LPT4 & $\operatorname{Rd} 8$ \\
\hline LPT2_ERD & Ri9 & SPT5 & $\mathrm{Rd} 9$ \\
\hline SPT3_ERD & Ri10 & LPT5 & $\operatorname{Rd} 10$ \\
\hline \multirow[t]{3}{*}{ LPT3_ERD } & Ri11 & SPT6 & $\operatorname{Rd} 11$ \\
\hline & & LPT6 & $\operatorname{Rd} 12$ \\
\hline & & RAND & $\operatorname{Rd} 13$ \\
\hline
\end{tabular}


TABELA D. 1 - Resultados das regras para setup independente por porte do problema (em \% de sucesso)

\begin{tabular}{ccccccccccccc}
\hline $\boldsymbol{g}$ & $\boldsymbol{n}$ & $\mathbf{R i 1}$ & $\mathbf{R i 2}$ & $\mathbf{R i 3}$ & $\mathbf{R i 4}$ & $\mathbf{R i 5}$ & $\mathbf{R i 6}$ & $\mathbf{R i 7}$ & $\mathbf{R i 8}$ & $\mathbf{R i 9}$ & $\mathbf{R i 1 0}$ & $\mathbf{R i 1 1}$ \\
\hline $\mathbf{3}$ & $\mathbf{1 0}$ & 30 & 38 & 2 & 26 & 13 & 21 & 23 & 18 & 35 & 21 & 49 \\
$\mathbf{3}$ & $\mathbf{3 0}$ & 28 & 38 & 0 & 25 & 10 & 15 & 18 & 7 & 29 & 15 & 51 \\
$\mathbf{3}$ & $\mathbf{1 0 0}$ & 26 & 37 & 0 & 25 & 11 & 15 & 17 & 2 & 28 & 18 & 53 \\
$\mathbf{5}$ & $\mathbf{1 0}$ & 19 & 34 & 1 & 28 & 7 & 18 & 20 & 7 & 24 & 14 & 41 \\
$\mathbf{5}$ & $\mathbf{3 0}$ & 14 & 29 & 0 & 25 & 4 & 10 & 11 & 0 & 12 & 7 & 45 \\
$\mathbf{5}$ & $\mathbf{1 0 0}$ & 14 & 31 & 0 & 23 & 2 & 9 & 10 & 0 & 12 & 6 & 51 \\
$\mathbf{7}$ & $\mathbf{1 0}$ & 15 & 31 & 1 & 28 & 5 & 17 & 20 & 4 & 21 & 11 & 38 \\
$\mathbf{7}$ & $\mathbf{3 0}$ & 10 & 27 & 0 & 21 & 3 & 9 & 10 & 0 & 9 & 4 & 37 \\
$\mathbf{7}$ & $\mathbf{1 0 0}$ & 10 & 25 & 0 & 19 & 2 & 9 & 7 & 0 & 8 & 4 & 46 \\
\hline
\end{tabular}

TABELA D. 2 - Resultados das regras para setup independente por flexibilidade e porte do problema (em \% de sucesso)

\begin{tabular}{cccccccccccccc}
\hline $\boldsymbol{f}$ & $\mathbf{g}$ & $\boldsymbol{n}$ & $\mathbf{R i 1}$ & $\mathbf{R i 2}$ & $\mathbf{R i 3}$ & $\mathbf{R i 4}$ & $\mathbf{R i 5}$ & $\mathbf{R i 6}$ & $\mathbf{R i 7}$ & $\mathbf{R i \mathbf { 8 }}$ & $\mathbf{R i 9}$ & $\mathbf{R i 1 0}$ & $\mathbf{R i 1 1}$ \\
\hline $\mathbf{B}$ & $\mathbf{3}$ & $\mathbf{1 0}$ & 37 & 44 & 1 & 30 & 13 & 19 & 21 & 15 & 37 & 16 & 48 \\
$\mathbf{B}$ & $\mathbf{3}$ & $\mathbf{3 0}$ & 37 & 49 & 0 & 33 & 11 & 15 & 22 & 8 & 37 & 11 & 53 \\
$\mathbf{B}$ & $\mathbf{3}$ & $\mathbf{1 0 0}$ & 34 & 48 & 0 & 34 & 9 & 15 & 23 & 1 & 36 & 11 & 53 \\
$\mathbf{B}$ & $\mathbf{5}$ & $\mathbf{1 0}$ & 22 & 40 & 0 & 27 & 9 & 18 & 19 & 1 & 21 & 11 & 40 \\
$\mathbf{B}$ & $\mathbf{5}$ & $\mathbf{3 0}$ & 19 & 36 & 0 & 30 & 4 & 11 & 13 & 0 & 14 & 6 & 45 \\
$\mathbf{B}$ & $\mathbf{5}$ & $\mathbf{1 0 0}$ & 19 & 38 & 0 & 27 & 2 & 10 & 14 & 0 & 14 & 5 & 53 \\
$\mathbf{B}$ & $\mathbf{7}$ & $\mathbf{1 0}$ & 18 & 33 & 0 & 28 & 5 & 15 & 17 & 0 & 18 & 8 & 33 \\
$\mathbf{B}$ & $\mathbf{7}$ & $\mathbf{3 0}$ & 18 & 35 & 0 & 21 & 4 & 8 & 10 & 0 & 7 & 4 & 33 \\
$\mathbf{B}$ & $\mathbf{7}$ & $\mathbf{1 0 0}$ & 17 & 32 & 0 & 18 & 3 & 9 & 5 & 0 & 5 & 4 & 42 \\
$\mathbf{M}$ & $\mathbf{3}$ & $\mathbf{1 0}$ & 34 & 45 & 3 & 31 & 20 & 29 & 28 & 23 & 40 & 25 & 53 \\
$\mathbf{M}$ & $\mathbf{3}$ & $\mathbf{3 0}$ & 32 & 45 & 0 & 33 & 18 & 25 & 26 & 12 & 39 & 24 & 59 \\
$\mathbf{M}$ & $\mathbf{3}$ & $\mathbf{1 0 0}$ & 30 & 42 & 0 & 32 & 21 & 24 & 27 & 7 & 38 & 28 & 62 \\
$\mathbf{M}$ & $\mathbf{5}$ & $\mathbf{1 0}$ & 18 & 36 & 0 & 32 & 8 & 20 & 22 & 5 & 24 & 12 & 39 \\
$\mathbf{M}$ & $\mathbf{5}$ & $\mathbf{3 0}$ & 15 & 31 & 0 & 30 & 5 & 14 & 16 & 0 & 17 & 7 & 46 \\
$\mathbf{M}$ & $\mathbf{5}$ & $\mathbf{1 0 0}$ & 15 & 34 & 0 & 28 & 4 & 12 & 15 & 0 & 18 & 5 & 52 \\
$\mathbf{M}$ & $\mathbf{7}$ & $\mathbf{1 0}$ & 14 & 32 & 0 & 27 & 7 & 21 & 20 & 3 & 23 & 10 & 37 \\
$\mathbf{M}$ & $\mathbf{7}$ & $\mathbf{3 0}$ & 9 & 27 & 0 & 25 & 3 & 12 & 13 & 0 & 15 & 6 & 39 \\
$\mathbf{M}$ & $\mathbf{7}$ & $\mathbf{1 0 0}$ & 10 & 26 & 0 & 25 & 3 & 11 & 12 & 0 & 15 & 4 & 49 \\
$\mathbf{A}$ & $\mathbf{3}$ & $\mathbf{1 0}$ & 20 & 26 & 3 & 18 & 7 & 13 & 20 & 17 & 28 & 23 & 48 \\
$\mathbf{A}$ & $\mathbf{3}$ & $\mathbf{3 0}$ & 14 & 21 & 0 & 10 & 2 & 6 & 5 & 2 & 12 & 11 & 43 \\
$\mathbf{A}$ & $\mathbf{3}$ & $\mathbf{1 0 0}$ & 15 & 21 & 0 & 9 & 2 & 5 & 3 & 0 & 10 & 16 & 45 \\
$\mathbf{A}$ & $\mathbf{5}$ & $\mathbf{1 0}$ & 17 & 28 & 3 & 25 & 5 & 15 & 21 & 14 & 27 & 19 & 43 \\
$\mathbf{A}$ & $\mathbf{5}$ & $\mathbf{3 0}$ & 8 & 21 & 0 & 14 & 2 & 7 & 5 & 0 & 6 & 7 & 43 \\
$\mathbf{A}$ & $\mathbf{5}$ & $\mathbf{1 0 0}$ & 7 & 21 & 0 & 13 & 1 & 6 & 2 & 0 & 3 & 8 & 50 \\
$\mathbf{A}$ & $\mathbf{7}$ & $\mathbf{1 0}$ & 14 & 29 & 2 & 28 & 4 & 17 & 22 & 8 & 23 & 15 & 42 \\
$\mathbf{A}$ & $\mathbf{7}$ & $\mathbf{3 0}$ & 5 & 21 & 0 & 17 & 1 & 6 & 7 & 0 & 7 & 4 & 38 \\
$\mathbf{A}$ & $\mathbf{7}$ & $\mathbf{1 0 0}$ & 4 & 17 & 0 & 16 & 1 & 6 & 5 & 0 & 5 & 4 & 47 \\
\hline
\end{tabular}


TABELA D.3 - Resultados das regras para setup independente por intervalo de setup e porte do problema (em \% de sucesso)

\begin{tabular}{cccccccccccccc}
\hline $\boldsymbol{s}$ & $\boldsymbol{g}$ & $\boldsymbol{n}$ & $\mathbf{R i 1}$ & $\mathbf{R i 2}$ & $\mathbf{R i 3}$ & $\mathbf{R i 4}$ & $\mathbf{R i 5}$ & $\mathbf{R i 6}$ & $\mathbf{R i \mathbf { 7 }}$ & $\mathbf{R i 8}$ & Ri9 & Ri10 & Ri11 \\
\hline $\mathbf{2 5 - 7 4}$ & $\mathbf{3}$ & $\mathbf{1 0}$ & 30 & 39 & 2 & 27 & 12 & 20 & 23 & 18 & 33 & 20 & 49 \\
$\mathbf{2 5 - 7 4}$ & $\mathbf{3}$ & $\mathbf{3 0}$ & 29 & 39 & 0 & 26 & 10 & 16 & 16 & 7 & 30 & 15 & 53 \\
$\mathbf{2 5 - 7 4}$ & $\mathbf{3}$ & $\mathbf{1 0 0}$ & 28 & 39 & 0 & 24 & 11 & 16 & 17 & 3 & 28 & 18 & 54 \\
$\mathbf{2 5 - 7 4}$ & $\mathbf{5}$ & $\mathbf{1 0}$ & 19 & 34 & 1 & 30 & 7 & 18 & 20 & 8 & 23 & 14 & 42 \\
$\mathbf{2 5 - 7 4}$ & $\mathbf{5}$ & $\mathbf{3 0}$ & 13 & 29 & 0 & 25 & 4 & 10 & 12 & 0 & 12 & 5 & 46 \\
$\mathbf{2 5 - 7 4}$ & $\mathbf{5}$ & $\mathbf{1 0 0}$ & 13 & 32 & 0 & 22 & 2 & 10 & 10 & 0 & 11 & 6 & 52 \\
$\mathbf{2 5 - 7 4}$ & $\mathbf{7}$ & $\mathbf{1 0}$ & 16 & 32 & 0 & 28 & 5 & 18 & 19 & 4 & 20 & 12 & 38 \\
$\mathbf{2 5 - 7 4}$ & $\mathbf{7}$ & $\mathbf{3 0}$ & 11 & 28 & 0 & 22 & 3 & 9 & 10 & 0 & 9 & 4 & 37 \\
$\mathbf{2 5 - 7 4}$ & $\mathbf{7}$ & $\mathbf{1 0 0}$ & 10 & 24 & 0 & 20 & 2 & 9 & 7 & 0 & 9 & 4 & 47 \\
$\mathbf{7 5 - 1 2 5}$ & $\mathbf{3}$ & $\mathbf{1 0}$ & 30 & 38 & 3 & 25 & 15 & 21 & 23 & 19 & 38 & 22 & 49 \\
$\mathbf{7 5 - 1 2 5}$ & $\mathbf{3}$ & $\mathbf{3 0}$ & 26 & 38 & 0 & 24 & 10 & 15 & 20 & 7 & 29 & 15 & 50 \\
$\mathbf{7 5 - 1 2 5}$ & $\mathbf{3}$ & $\mathbf{1 0 0}$ & 25 & 35 & 0 & 26 & 10 & 13 & 18 & 2 & 28 & 19 & 52 \\
$\mathbf{7 5 - 1 2 5}$ & $\mathbf{5}$ & $\mathbf{1 0}$ & 18 & 35 & 1 & 26 & 7 & 17 & 21 & 6 & 25 & 14 & 40 \\
$\mathbf{7 5 - 1 2 5}$ & $\mathbf{5}$ & $\mathbf{3 0}$ & 14 & 29 & 0 & 24 & 3 & 11 & 11 & 0 & 13 & 8 & 44 \\
$\mathbf{7 5 - 1 2 5}$ & $\mathbf{5}$ & $\mathbf{1 0 0}$ & 14 & 30 & 0 & 24 & 2 & 9 & 10 & 0 & 13 & 6 & 50 \\
$\mathbf{7 5 - 1 2 5}$ & $\mathbf{7}$ & $\mathbf{1 0}$ & 15 & 31 & 1 & 27 & 6 & 17 & 20 & 4 & 22 & 10 & 37 \\
$\mathbf{7 5 - 1 2 5}$ & $\mathbf{7}$ & $\mathbf{3 0}$ & 10 & 27 & 0 & 20 & 2 & 9 & 10 & 0 & 10 & 5 & 37 \\
$\mathbf{7 5 - 1 2 5}$ & $\mathbf{7}$ & $\mathbf{1 0 0}$ & 11 & 26 & 0 & 19 & 3 & 9 & 8 & 0 & 8 & 4 & 45 \\
\hline
\end{tabular}

TABELA D.4 - Resultados das regras para setup independente por probabilidade de antecipação do setup e porte do problema (em \% de sucesso)

\begin{tabular}{cccccccccccccc}
\hline $\boldsymbol{a}$ & $\boldsymbol{g}$ & $\boldsymbol{n}$ & $\mathbf{R i 1}$ & $\mathbf{R i 2}$ & $\mathbf{R i 3}$ & $\mathbf{R i 4}$ & $\mathbf{R i 5}$ & $\mathbf{R i 6}$ & $\mathbf{R i 7}$ & $\mathbf{R i 8}$ & $\mathbf{R i 9}$ & Ri10 & Ri11 \\
\hline $\mathbf{0 - 5 0}$ & $\mathbf{3}$ & $\mathbf{1 0}$ & 30 & 37 & 2 & 26 & 12 & 20 & 23 & 19 & 35 & 22 & 50 \\
$\mathbf{0 - 5 0}$ & $\mathbf{3}$ & $\mathbf{3 0}$ & 29 & 39 & 0 & 24 & 10 & 15 & 18 & 8 & 30 & 15 & 51 \\
$\mathbf{0 - 5 0}$ & $\mathbf{3}$ & $\mathbf{1 0 0}$ & 27 & 36 & 0 & 26 & 11 & 13 & 17 & 2 & 28 & 19 & 53 \\
$\mathbf{0 - 5 0}$ & $\mathbf{5}$ & $\mathbf{1 0}$ & 18 & 35 & 1 & 30 & 7 & 18 & 21 & 7 & 23 & 14 & 40 \\
$\mathbf{0 - 5 0}$ & $\mathbf{5}$ & $\mathbf{3 0}$ & 13 & 29 & 0 & 25 & 4 & 11 & 11 & 0 & 14 & 6 & 45 \\
$\mathbf{0 - 5 0}$ & $\mathbf{5}$ & $\mathbf{1 0 0}$ & 13 & 31 & 0 & 22 & 2 & 8 & 10 & 0 & 12 & 6 & 51 \\
$\mathbf{0 - 5 0}$ & $\mathbf{7}$ & $\mathbf{1 0}$ & 16 & 32 & 1 & 27 & 5 & 17 & 18 & 4 & 22 & 12 & 39 \\
$\mathbf{0 - 5 0}$ & $\mathbf{7}$ & $\mathbf{3 0}$ & 10 & 27 & 0 & 23 & 3 & 8 & 10 & 0 & 10 & 4 & 36 \\
$\mathbf{0 - 5 0}$ & $\mathbf{7}$ & $\mathbf{1 0 0}$ & 11 & 24 & 0 & 20 & 2 & 9 & 8 & 0 & 8 & 4 & 45 \\
$\mathbf{5 0 - 1 0 0}$ & $\mathbf{3}$ & $\mathbf{1 0}$ & 31 & 39 & 2 & 26 & 14 & 21 & 23 & 17 & 36 & 20 & 49 \\
$\mathbf{5 0 - 1 0 0}$ & $\mathbf{3}$ & $\mathbf{3 0}$ & 27 & 38 & 0 & 26 & 10 & 16 & 18 & 7 & 29 & 16 & $\mathbf{5 2}$ \\
$\mathbf{5 0 - 1 0 0}$ & $\mathbf{3}$ & $\mathbf{1 0 0}$ & 25 & 37 & 0 & 25 & 11 & 16 & 18 & 3 & 28 & 18 & 53 \\
$\mathbf{5 0 - 1 0 0}$ & $\mathbf{5}$ & $\mathbf{1 0}$ & 20 & 34 & 1 & 26 & 7 & 17 & 20 & 7 & 24 & 13 & 41 \\
$\mathbf{5 0 - 1 0 0}$ & $\mathbf{5}$ & $\mathbf{3 0}$ & 15 & 30 & 0 & 24 & 3 & 10 & 11 & 0 & 11 & 7 & 44 \\
$\mathbf{5 0 - 1 0 0}$ & $\mathbf{5}$ & $\mathbf{1 0 0}$ & 14 & 31 & 0 & 23 & 3 & 10 & 11 & 0 & 11 & 6 & $\mathbf{5 2}$ \\
$\mathbf{5 0 - 1 0 0}$ & $\mathbf{7}$ & $\mathbf{1 0}$ & 15 & 31 & 1 & 29 & 5 & 18 & 21 & 4 & 20 & 10 & 37 \\
$\mathbf{5 0 - 1 0 0}$ & $\mathbf{7}$ & $\mathbf{3 0}$ & 11 & 28 & 0 & 19 & 3 & 10 & 10 & 0 & 9 & 4 & 38 \\
$\mathbf{5 0 - 1 0 0}$ & $\mathbf{7}$ & $\mathbf{1 0 0}$ & 10 & 25 & 0 & 19 & 3 & 9 & 7 & 0 & 8 & 4 & 47 \\
\hline
\end{tabular}


TABELA D.5 - Resultados das regras para setup independente por probabilidade de salto e porte do problema (em \% de sucesso)

\begin{tabular}{cccccccccccccc}
\hline $\boldsymbol{l}$ & $\boldsymbol{g}$ & $\boldsymbol{n}$ & $\mathbf{R i 1}$ & $\mathbf{R i 2}$ & $\mathbf{R i 3}$ & $\mathbf{R i 4}$ & $\mathbf{R i 5}$ & $\mathbf{R i 6}$ & $\mathbf{R i 7}$ & $\mathbf{R i 8}$ & $\mathbf{R i 9}$ & Ri10 & Ri11 \\
\hline $\mathbf{0}$ & $\mathbf{3}$ & $\mathbf{1 0}$ & 29 & 33 & 0 & 17 & 8 & 14 & 5 & 3 & 18 & 14 & 23 \\
$\mathbf{0}$ & $\mathbf{3}$ & $\mathbf{3 0}$ & 32 & 38 & 0 & 20 & 5 & 10 & 2 & 1 & 16 & 11 & 18 \\
$\mathbf{0}$ & $\mathbf{3}$ & $\mathbf{1 0 0}$ & 30 & 34 & 0 & 18 & 6 & 9 & 1 & 0 & 15 & 14 & 18 \\
$\mathbf{0}$ & $\mathbf{5}$ & $\mathbf{1 0}$ & 24 & 31 & 0 & 21 & 6 & 10 & 4 & 0 & 9 & 12 & 19 \\
$\mathbf{0}$ & $\mathbf{5}$ & $\mathbf{3 0}$ & 25 & 34 & 0 & 26 & 4 & 9 & 2 & 0 & 4 & 9 & 17 \\
$\mathbf{0}$ & $\mathbf{5}$ & $\mathbf{1 0 0}$ & 26 & 40 & 0 & 25 & 3 & 8 & 2 & 0 & 4 & 7 & 13 \\
$\mathbf{0}$ & $\mathbf{7}$ & $\mathbf{1 0}$ & 19 & 29 & 0 & 23 & 6 & 11 & 4 & 0 & 8 & 9 & 20 \\
$\mathbf{0}$ & $\mathbf{7}$ & $\mathbf{3 0}$ & 20 & 35 & 0 & 24 & 4 & 8 & 2 & 0 & 5 & 6 & 15 \\
$\mathbf{0}$ & $\mathbf{7}$ & $\mathbf{1 0 0}$ & 20 & 35 & 0 & 23 & 4 & 10 & 2 & 0 & 4 & 6 & 14 \\
$\mathbf{5 0}$ & $\mathbf{3}$ & $\mathbf{1 0}$ & 31 & 44 & 4 & 35 & 18 & 28 & 41 & 33 & 52 & 28 & 75 \\
$\mathbf{5 0}$ & $\mathbf{3}$ & $\mathbf{3 0}$ & 24 & 39 & 0 & 30 & 15 & 21 & 34 & 14 & 42 & 20 & 85 \\
$\mathbf{5 0}$ & $\mathbf{3}$ & $\mathbf{1 0 0}$ & 22 & 39 & 0 & 33 & 16 & 20 & 34 & 5 & 41 & 23 & 88 \\
$\mathbf{5 0}$ & $\mathbf{5}$ & $\mathbf{1 0}$ & 14 & 38 & 2 & 35 & 8 & 25 & 37 & 13 & 39 & 16 & 63 \\
$\mathbf{5 0}$ & $\mathbf{5}$ & $\mathbf{3 0}$ & 3 & 24 & 0 & 23 & 3 & 12 & 21 & 0 & 21 & 5 & 72 \\
$\mathbf{5 0}$ & $\mathbf{5}$ & $\mathbf{1 0 0}$ & 1 & 21 & 0 & 20 & 1 & 11 & 19 & 0 & 20 & 4 & 90 \\
$\mathbf{5 0}$ & $\mathbf{7}$ & $\mathbf{1 0}$ & 12 & 34 & 1 & 32 & 5 & 24 & 35 & 7 & 34 & 13 & 55 \\
$\mathbf{5 0}$ & $\mathbf{7}$ & $\mathbf{3 0}$ & 1 & 20 & 0 & 18 & 1 & 10 & 17 & 0 & 14 & 3 & 59 \\
$\mathbf{5 0}$ & $\mathbf{7}$ & $\mathbf{1 0 0}$ & 0 & 15 & 0 & 16 & 1 & 8 & 13 & 0 & 12 & 1 & 78 \\
\hline
\end{tabular}

TABELA D.6 - Desvio relativo médio (em \%) das regras para setup independente por porte do problema

\begin{tabular}{ccccccccccccc}
\hline $\boldsymbol{g}$ & $\boldsymbol{n}$ & $\mathbf{R i 1}$ & $\mathbf{R i 2}$ & $\mathbf{R i 3}$ & $\mathbf{R i 4}$ & $\mathbf{R i 5}$ & $\mathbf{R i 6}$ & $\mathbf{R i 7}$ & $\mathbf{R i 8}$ & $\mathbf{R i 9}$ & $\mathbf{R i 1 0}$ & Ri11 \\
\hline $\mathbf{3}$ & $\mathbf{1 0}$ & 7,4 & 6,2 & 35,3 & 10,1 & 13,1 & 11,0 & 9,5 & 17,9 & 5,7 & 10,8 & 3,6 \\
$\mathbf{3}$ & $\mathbf{3 0}$ & 4,3 & 3,2 & 48,3 & 6,0 & 7,9 & 6,5 & 6,3 & 26,4 & 3,8 & 6,8 & 1,7 \\
$\mathbf{3}$ & $\mathbf{1 0 0}$ & 1,7 & 1,1 & 58,1 & 2,8 & 3,2 & 2,5 & 3,3 & 34,9 & 2,0 & 2,8 & 0,7 \\
$\mathbf{5}$ & $\mathbf{1 0}$ & 9,9 & 6,1 & 66,2 & 8,1 & 16,1 & 10,6 & 9,9 & 44,8 & 8,0 & 13,7 & 4,4 \\
$\mathbf{5}$ & $\mathbf{3 0}$ & 8,1 & 4,2 & 115,8 & 6,0 & 12,1 & 7,8 & 7,7 & 79,9 & 6,7 & 11,4 & 2,3 \\
$\mathbf{5}$ & $\mathbf{1 0 0}$ & 4,2 & 1,7 & 153,5 & 3,0 & 6,2 & 3,6 & 4,6 & 109,5 & 4,1 & 5,8 & 1,0 \\
$\mathbf{7}$ & $\mathbf{1 0}$ & 11,1 & 5,8 & 88,6 & 7,0 & 16,1 & 9,7 & 9,2 & 64,0 & 8,1 & 14,7 & 4,6 \\
$\mathbf{7}$ & $\mathbf{3 0}$ & 10,1 & 4,2 & 172,0 & 5,4 & 13,9 & 7,7 & 7,6 & 124,0 & 6,9 & 13,3 & 2,7 \\
$\mathbf{7}$ & $\mathbf{1 0 0}$ & 6,1 & 2,1 & 241,5 & 3,0 & 8,0 & 3,9 & 4,8 & 177,4 & 4,6 & 7,8 & 1,1 \\
\hline
\end{tabular}

TABELA D.7 - Desvio-padrão do desvio relativo das regras para setup independente por porte do problema

\begin{tabular}{ccccccccccccc}
\hline $\boldsymbol{g}$ & $\boldsymbol{n}$ & $\mathbf{R i 1}$ & $\mathbf{R i 2}$ & $\mathbf{R i 3}$ & $\mathbf{R i 4}$ & $\mathbf{R i 5}$ & $\mathbf{R i 6}$ & $\mathbf{R i 7}$ & $\mathbf{R i 8}$ & $\mathbf{R i 9}$ & $\mathbf{R i 1 0}$ & $\mathbf{R i 1 1}$ \\
\hline $\mathbf{3}$ & $\mathbf{1 0}$ & 0,08 & 0,07 & 0,19 & 0,10 & 0,10 & 0,10 & 0,09 & 0,14 & 0,07 & 0,10 & 0,05 \\
$\mathbf{3}$ & $\mathbf{3 0}$ & 0,04 & 0,04 & 0,18 & 0,06 & 0,06 & 0,05 & 0,05 & 0,16 & 0,04 & 0,05 & 0,02 \\
$\mathbf{3}$ & $\mathbf{1 0 0}$ & 0,02 & 0,01 & 0,18 & 0,03 & 0,02 & 0,02 & 0,02 & 0,18 & 0,02 & 0,02 & 0,01 \\
$\mathbf{5}$ & $\mathbf{1 0}$ & 0,09 & 0,07 & 0,24 & 0,09 & 0,12 & 0,10 & 0,09 & 0,19 & 0,08 & 0,11 & 0,06 \\
$\mathbf{5}$ & $\mathbf{3 0}$ & 0,05 & 0,04 & 0,25 & 0,06 & 0,07 & 0,06 & 0,06 & 0,22 & 0,05 & 0,07 & 0,03 \\
$\mathbf{5}$ & $\mathbf{1 0 0}$ & 0,03 & 0,02 & 0,25 & 0,03 & 0,04 & 0,03 & 0,04 & 0,25 & 0,03 & 0,04 & 0,01 \\
$\mathbf{7}$ & $\mathbf{1 0}$ & 0,09 & 0,07 & 0,25 & 0,08 & 0,11 & 0,09 & 0,08 & 0,20 & 0,08 & 0,11 & 0,05 \\
$\mathbf{7}$ & $\mathbf{3 0}$ & 0,06 & 0,04 & 0,30 & 0,05 & 0,07 & 0,06 & 0,06 & 0,25 & 0,05 & 0,07 & 0,03 \\
$\mathbf{7}$ & $\mathbf{1 0 0}$ & 0,03 & 0,02 & 0,30 & 0,03 & 0,04 & 0,03 & 0,03 & 0,27 & 0,04 & 0,04 & 0,01 \\
\hline
\end{tabular}


TABELA D.8 - Resultado das regras para setup independente por parâmetro (em \% de sucesso)

\begin{tabular}{|c|c|c|c|c|c|c|c|c|c|c|c|c|c|c|c|c|}
\hline$n$ & $g$ & $f$ & $s$ & $a$ & $l$ & Ri1 & $\mathbf{R i 2}$ & Ri3 & Ri4 & Ri5 & Ri6 & Ri7 & Ri8 & Ri9 & Ri10 & Ri11 \\
\hline 10 & 3 & A & $25-74$ & $0-50$ & 0 & 26 & 24 & 0 & 11 & 1 & 4 & 7 & 0 & 12 & 16 & 31 \\
\hline 10 & 3 & A & $25-74$ & $0-50$ & 50 & 20 & 33 & 6 & 30 & 5 & 24 & 44 & 40 & 41 & 32 & 72 \\
\hline 10 & 3 & A & $25-74$ & $50-100$ & 0 & 15 & 20 & 0 & 7 & 5 & 10 & 1 & 2 & 16 & 16 & 31 \\
\hline 10 & 3 & A & $25-74$ & $50-100$ & 50 & 22 & 28 & 4 & 27 & 11 & 20 & 33 & 32 & 38 & 33 & 64 \\
\hline 10 & 3 & A & $75-125$ & $0-50$ & 0 & 14 & 23 & 0 & 15 & 3 & 6 & 6 & 1 & 15 & 15 & 30 \\
\hline 10 & 3 & A & $75-125$ & $0-50$ & 50 & 18 & 25 & 8 & 23 & 14 & 17 & 29 & 35 & 35 & 36 & 64 \\
\hline 10 & 3 & A & $75-125$ & $50-100$ & 0 & 23 & 25 & 0 & 10 & 4 & 8 & 4 & 1 & 21 & 10 & 22 \\
\hline 10 & 3 & A & $75-125$ & $50-100$ & 50 & 21 & 28 & 2 & 20 & 10 & 16 & 35 & 26 & 48 & 27 & 66 \\
\hline 10 & 3 & B & $25-74$ & $0-50$ & 0 & 41 & 41 & 0 & 23 & 3 & 8 & 2 & 3 & 18 & 10 & 13 \\
\hline 10 & 3 & B & $25-74$ & $0-50$ & 50 & 32 & 45 & 2 & 35 & 13 & 24 & 37 & 24 & 51 & 16 & 79 \\
\hline 10 & 3 & B & $25-74$ & $50-100$ & 0 & 41 & 41 & 0 & 26 & 8 & 8 & 2 & 1 & 14 & 9 & 16 \\
\hline 10 & 3 & B & $25-74$ & $50-100$ & 50 & 32 & 45 & 2 & 37 & 21 & 27 & 38 & 32 & 54 & 17 & 75 \\
\hline 10 & 3 & B & $75-125$ & $0-50$ & 0 & 33 & 34 & 0 & 18 & 15 & 14 & 1 & 1 & 22 & 10 & 16 \\
\hline 10 & 3 & B & $75-125$ & $0-50$ & 50 & 36 & 47 & 1 & 38 & 17 & 28 & 43 & 27 & 59 & 28 & 84 \\
\hline 10 & 3 & B & $75-125$ & $50-100$ & 0 & 41 & 44 & 0 & 18 & 7 & 11 & 4 & 0 & 16 & 9 & 13 \\
\hline 10 & 3 & B & $75-125$ & $50-100$ & 50 & 36 & 54 & 1 & 41 & 21 & 34 & 44 & 30 & 64 & 26 & 85 \\
\hline 10 & 3 & M & $25-74$ & $0-50$ & 0 & 26 & 35 & 0 & 21 & 9 & 22 & 5 & 8 & 24 & 17 & 29 \\
\hline 10 & 3 & M & $25-74$ & $0-50$ & 50 & 41 & 57 & 4 & 45 & 26 & 37 & 52 & 36 & 51 & 28 & 74 \\
\hline 10 & 3 & M & $25-74$ & $50-100$ & 0 & 27 & 37 & 1 & 23 & 9 & 21 & 9 & 7 & 17 & 25 & 33 \\
\hline 10 & 3 & M & $25-74$ & $50-100$ & 50 & 39 & 56 & 2 & 43 & 28 & 37 & 45 & 30 & 56 & 24 & 76 \\
\hline 10 & 3 & M & $75-125$ & $0-50$ & 0 & 30 & 31 & 1 & 20 & 18 & 24 & 5 & 9 & 27 & 18 & 24 \\
\hline 10 & 3 & M & $75-125$ & $0-50$ & 50 & 37 & 51 & 7 & 37 & 24 & 29 & 43 & 45 & 61 & 38 & 81 \\
\hline 10 & 3 & M & $75-125$ & $50-100$ & 0 & 32 & 38 & 0 & 15 & 17 & 27 & 13 & 6 & 19 & 13 & 20 \\
\hline 10 & 3 & M & $75-125$ & $50-100$ & 50 & 43 & 55 & 10 & 47 & 30 & 37 & 52 & 41 & 67 & 35 & 83 \\
\hline 30 & 3 & A & $25-74$ & $0-50$ & 0 & 29 & 37 & 0 & 12 & 1 & 8 & 1 & 0 & 9 & 10 & 25 \\
\hline 30 & 3 & A & $25-74$ & $0-50$ & 50 & 3 & 7 & 0 & 6 & 1 & 5 & 5 & 5 & 11 & 13 & 67 \\
\hline 30 & 3 & A & $25-74$ & $50-100$ & 0 & 23 & 32 & 0 & 15 & 0 & 8 & 0 & 0 & 16 & 11 & 22 \\
\hline 30 & 3 & A & $25-74$ & $50-100$ & 50 & 1 & 5 & 0 & 5 & 0 & 3 & 6 & 2 & 9 & 13 & 72 \\
\hline 30 & 3 & A & $75-125$ & $0-50$ & 0 & 28 & 34 & 0 & 11 & 7 & 6 & 2 & 0 & 13 & 9 & 18 \\
\hline 30 & 3 & A & $75-125$ & $0-50$ & 50 & 5 & 13 & 0 & 4 & 3 & 5 & 14 & 4 & 13 & 10 & 59 \\
\hline 30 & 3 & A & $75-125$ & $50-100$ & 0 & 18 & 28 & 0 & 13 & 4 & 6 & 2 & 0 & 14 & 8 & 27 \\
\hline 30 & 3 & A & $75-125$ & $50-100$ & 50 & 3 & 11 & 0 & 12 & 1 & 4 & 13 & 2 & 8 & 10 & 52 \\
\hline 30 & 3 & B & $25-74$ & $0-50$ & 0 & 44 & 49 & 0 & 28 & 4 & 6 & 0 & 1 & 16 & 3 & 6 \\
\hline 30 & 3 & B & $25-74$ & $0-50$ & 50 & 37 & 56 & 0 & 37 & 14 & 20 & 40 & 13 & 55 & 18 & 95 \\
\hline 30 & 3 & B & $25-74$ & $50-100$ & 0 & 42 & 44 & 0 & 34 & 6 & 5 & 1 & 0 & 15 & 8 & 11 \\
\hline 30 & 3 & B & $25-74$ & $50-100$ & 50 & 28 & 51 & 0 & 41 & 22 & 31 & 46 & 11 & 57 & 10 & 98 \\
\hline 30 & 3 & B & $75-125$ & $0-50$ & 0 & 41 & 44 & 0 & 23 & 4 & 5 & 0 & 1 & 23 & 5 & 7 \\
\hline 30 & 3 & B & $75-125$ & $0-50$ & 50 & 28 & 51 & 0 & 44 & 21 & 27 & 50 & 19 & 59 & 15 & 96 \\
\hline 30 & 3 & B & $75-125$ & $50-100$ & 0 & 46 & 48 & 0 & 25 & 2 & 5 & 0 & 0 & 13 & 8 & 11 \\
\hline 30 & 3 & B & $75-125$ & $50-100$ & 50 & 29 & 50 & 0 & 32 & 14 & 22 & 41 & 15 & 55 & 20 & 100 \\
\hline 30 & 3 & M & $25-74$ & $0-50$ & 0 & 37 & 39 & 0 & 23 & 9 & 14 & 2 & 2 & 19 & 13 & 21 \\
\hline 30 & 3 & M & $25-74$ & $0-50$ & 50 & 38 & 56 & 1 & 44 & 31 & 37 & 50 & 28 & 67 & 31 & 94 \\
\hline 30 & 3 & M & $25-74$ & $50-100$ & 0 & 26 & 34 & 0 & 20 & 10 & 21 & 2 & 1 & 23 & 20 & 26 \\
\hline 30 & 3 & M & $25-74$ & $50-100$ & 50 & 40 & 58 & 0 & 50 & 26 & 34 & 42 & 22 & 58 & 35 & 96 \\
\hline 30 & 3 & M & $75-125$ & $0-50$ & 0 & 21 & 31 & 0 & 17 & 4 & 20 & 5 & 1 & 17 & 16 & 21 \\
\hline 30 & 3 & M & $75-125$ & $0-50$ & 50 & 32 & 49 & 0 & 41 & 21 & 25 & 45 & 19 & 55 & 36 & 97 \\
\hline 30 & 3 & M & $75-125$ & $50-100$ & 0 & 24 & 33 & 0 & 20 & 10 & 16 & 5 & 0 & 18 & 15 & 16 \\
\hline 30 & 3 & M & $75-125$ & $50-100$ & 50 & 39 & 62 & 0 & 49 & 29 & 33 & 57 & 25 & 56 & 28 & 98 \\
\hline 100 & 3 & A & $25-74$ & $0-50$ & 0 & 33 & 32 & 0 & 10 & 2 & 7 & 0 & 0 & 13 & 15 & 25 \\
\hline 100 & 3 & A & $25-74$ & $0-50$ & 50 & 7 & 14 & 0 & 3 & 3 & 3 & 6 & 1 & 8 & 11 & 66 \\
\hline 100 & 3 & A & $25-74$ & $50-100$ & 0 & 19 & 29 & 0 & 7 & 4 & 8 & 0 & 0 & 10 & 17 & 29 \\
\hline 100 & 3 & A & $25-74$ & $50-100$ & 50 & 4 & 17 & 0 & 5 & 1 & 2 & 4 & 0 & 5 & 19 & 71 \\
\hline 100 & 3 & A & $75-125$ & $0-50$ & 0 & 25 & 28 & 0 & 15 & 3 & 7 & 0 & 0 & 12 & 17 & 23 \\
\hline 100 & 3 & A & $75-125$ & $0-50$ & 50 & 3 & 9 & 0 & 8 & 1 & 3 & 8 & 0 & 13 & 18 & 59 \\
\hline 100 & 3 & A & $75-125$ & $50-100$ & 0 & 27 & 30 & 0 & 17 & 3 & 7 & 0 & 0 & 12 & 11 & 16 \\
\hline 100 & 3 & A & $75-125$ & $50-100$ & 50 & 3 & 9 & 0 & 7 & 1 & 4 & 7 & 0 & 7 & 19 & 68 \\
\hline 100 & 3 & B & $25-74$ & $0-50$ & 0 & 44 & 46 & 0 & 28 & 4 & 2 & 1 & 0 & 16 & 4 & 5 \\
\hline 100 & 3 & B & $25-74$ & $0-50$ & 50 & 29 & 52 & 0 & 45 & 17 & 25 & 45 & 1 & 51 & 11 & 99 \\
\hline 100 & 3 & B & $25-74$ & $50-100$ & 0 & 45 & 46 & 0 & 23 & 5 & 7 & 0 & 0 & 15 & 4 & 5 \\
\hline
\end{tabular}




\begin{tabular}{|c|c|c|c|c|c|c|c|c|c|c|c|c|c|c|c|c|}
\hline 100 & 3 & $\bar{B}$ & $25-74$ & $50-100$ & 50 & 30 & 58 & 0 & 43 & 12 & 34 & 44 & 1 & 60 & 18 & 99 \\
\hline 100 & 3 & B & $75-125$ & $0-50$ & 0 & 35 & 37 & 0 & 29 & 3 & 2 & 0 & 0 & 20 & 9 & 8 \\
\hline 100 & 3 & B & $75-125$ & $0-50$ & 50 & 25 & 49 & 0 & 43 & 13 & 21 & 39 & 1 & 53 & 23 & 100 \\
\hline 100 & 3 & B & $75-125$ & $50-100$ & 0 & 42 & 46 & 0 & 26 & 4 & 4 & 1 & 0 & 16 & 4 & 6 \\
\hline 100 & 3 & B & $75-125$ & $50-100$ & 50 & 20 & 47 & 0 & 37 & 17 & 22 & 50 & 2 & 56 & 16 & 100 \\
\hline 100 & 3 & M & $25-74$ & $0-50$ & 0 & 28 & 30 & 0 & 13 & 10 & 11 & 0 & 0 & 17 & 25 & 31 \\
\hline 100 & 3 & M & $25-74$ & $0-50$ & 50 & 39 & 55 & 0 & 47 & 30 & 33 & 50 & 11 & 59 & 38 & 98 \\
\hline 100 & 3 & $\mathbf{M}$ & $25-74$ & $50-100$ & 0 & 26 & 32 & 0 & 18 & 12 & 21 & 1 & 0 & 15 & 16 & 21 \\
\hline 100 & 3 & M & $25-74$ & $50-100$ & 50 & 32 & 54 & 0 & 51 & 37 & 37 & 51 & 20 & 64 & 33 & 100 \\
\hline 100 & 3 & M & $75-125$ & $0-50$ & 0 & 23 & 28 & 0 & 14 & 12 & 14 & 3 & 0 & 12 & 21 & 27 \\
\hline 100 & 3 & $\mathbf{M}$ & $75-125$ & $0-50$ & 50 & 38 & 57 & 0 & 53 & 30 & 32 & 55 & 11 & 58 & 30 & 100 \\
\hline 100 & 3 & $\mathbf{M}$ & $75-125$ & $50-100$ & 0 & 18 & 27 & 0 & 15 & 8 & 14 & 3 & 0 & 20 & 21 & 22 \\
\hline 100 & 3 & $\mathbf{M}$ & $75-125$ & $50-100$ & 50 & 37 & 51 & 0 & 48 & 28 & 29 & 49 & 11 & 59 & 38 & 100 \\
\hline 10 & 5 & A & $25-74$ & $0-50$ & 0 & 13 & 23 & 0 & 19 & 2 & 5 & 0 & 0 & 11 & 17 & 26 \\
\hline 10 & 5 & A & $25-74$ & $0-50$ & 50 & 20 & 34 & 6 & 33 & 8 & 24 & 40 & 31 & 41 & 28 & 59 \\
\hline 10 & 5 & A & $25-74$ & $50-100$ & 0 & 16 & 20 & 0 & 20 & 1 & 5 & 2 & 1 & 15 & 9 & 23 \\
\hline 10 & 5 & A & $25-74$ & $50-100$ & 50 & 23 & 35 & 3 & 32 & 4 & 27 & 43 & 28 & 42 & 32 & 68 \\
\hline 10 & 5 & A & $75-125$ & $0-50$ & 0 & 10 & 24 & 0 & 13 & 1 & 10 & 1 & 0 & 11 & 9 & 25 \\
\hline 10 & 5 & A & $75-125$ & $0-50$ & 50 & 20 & 33 & 8 & 35 & 9 & 27 & 43 & 21 & 40 & 24 & 62 \\
\hline 10 & 5 & A & $75-125$ & $50-100$ & 0 & 10 & 21 & 1 & 21 & 2 & 7 & 6 & 1 & 9 & 17 & 23 \\
\hline 10 & 5 & A & $75-125$ & $50-100$ & 50 & 20 & 36 & 6 & 25 & 9 & 17 & 31 & 30 & 44 & 16 & 60 \\
\hline 10 & 5 & B & $25-74$ & $0-50$ & 0 & 38 & 42 & 0 & 29 & 9 & 6 & 4 & 0 & 3 & 8 & 9 \\
\hline 10 & 5 & B & $25-74$ & $0-50$ & 50 & 10 & 40 & 0 & 32 & 9 & 26 & 28 & 2 & 34 & 7 & 62 \\
\hline 10 & 5 & B & $25-74$ & $50-100$ & 0 & 31 & 37 & 0 & 20 & 12 & 13 & 3 & 0 & 4 & 12 & 14 \\
\hline 10 & 5 & B & $25-74$ & $50-100$ & 50 & 9 & 39 & 2 & 37 & 10 & 25 & 34 & 3 & 39 & 7 & 74 \\
\hline 10 & 5 & B & $75-125$ & $0-50$ & 0 & 41 & 48 & 0 & 19 & 7 & 9 & 2 & 0 & 7 & 14 & 18 \\
\hline 10 & 5 & B & $75-125$ & $0-50$ & 50 & 7 & 39 & 1 & 38 & 8 & 28 & 41 & 3 & 37 & 13 & 63 \\
\hline 10 & 5 & B & $75-125$ & $50-100$ & 0 & 34 & 37 & 0 & 11 & 8 & 13 & 7 & 0 & 8 & 14 & 16 \\
\hline 10 & 5 & B & $75-125$ & $50-100$ & 50 & 5 & 34 & 0 & 30 & 6 & 21 & 32 & 3 & 33 & 10 & 60 \\
\hline 10 & 5 & $\mathbf{M}$ & $25-74$ & $0-50$ & 0 & 13 & 27 & 0 & 27 & 3 & 11 & 6 & 0 & 8 & 15 & 22 \\
\hline 10 & 5 & M & $25-74$ & $0-50$ & 50 & 9 & 39 & 0 & 40 & 7 & 33 & 39 & 14 & 36 & 12 & 64 \\
\hline 10 & 5 & $\mathbf{M}$ & $25-74$ & $50-100$ & 0 & 36 & 34 & 0 & 31 & 9 & 17 & 3 & 0 & 9 & 8 & 12 \\
\hline 10 & 5 & $\mathbf{M}$ & $25-74$ & $50-100$ & 50 & 12 & 38 & 1 & 36 & 13 & 24 & 34 & 11 & 36 & 14 & 68 \\
\hline 10 & 5 & $\mathbf{M}$ & $75-125$ & $0-50$ & 0 & 14 & 26 & 0 & 31 & 11 & 15 & 4 & 0 & 13 & 10 & 17 \\
\hline 10 & 5 & $\mathbf{M}$ & $75-125$ & $0-50$ & 50 & 16 & 45 & 1 & 38 & 7 & 27 & 40 & 7 & 40 & 14 & 57 \\
\hline 10 & 5 & $\mathbf{M}$ & $75-125$ & $50-100$ & 0 & 29 & 35 & 0 & 12 & 4 & 6 & 10 & 0 & 11 & 10 & 20 \\
\hline 10 & 5 & $\mathbf{M}$ & $75-125$ & $50-100$ & 50 & 12 & 41 & 0 & 40 & 10 & 26 & 37 & 5 & 41 & 11 & 54 \\
\hline 30 & 5 & A & $25-74$ & $0-50$ & 0 & 11 & 27 & 0 & 21 & 1 & 11 & 0 & 0 & 3 & 9 & 31 \\
\hline 30 & 5 & A & $25-74$ & $0-50$ & 50 & 0 & 8 & 0 & 8 & 1 & 2 & 11 & 0 & 9 & 6 & 67 \\
\hline 30 & 5 & A & $25-74$ & $50-100$ & 0 & 16 & 33 & 0 & 19 & 4 & 10 & 0 & 0 & 3 & 5 & 25 \\
\hline 30 & 5 & A & $25-74$ & $50-100$ & 50 & 1 & 15 & 0 & 11 & 0 & 1 & 14 & 0 & 5 & 2 & 58 \\
\hline 30 & 5 & A & $75-125$ & $0-50$ & 0 & 15 & 27 & 0 & 14 & 6 & 10 & 0 & 0 & 7 & 6 & 25 \\
\hline 30 & 5 & A & $75-125$ & $0-50$ & 50 & 2 & 16 & 0 & 10 & 0 & 2 & 10 & 0 & 12 & 7 & 58 \\
\hline 30 & 5 & A & $75-125$ & $50-100$ & 0 & 17 & 28 & 0 & 17 & 3 & 11 & 1 & 0 & 4 & 17 & 18 \\
\hline 30 & 5 & A & $75-125$ & $50-100$ & 50 & 3 & 13 & 0 & 10 & 2 & 5 & 6 & 1 & 8 & 3 & 63 \\
\hline 30 & 5 & B & $25-74$ & $0-50$ & 0 & 35 & 50 & 0 & 27 & 6 & 7 & 1 & 0 & 4 & 7 & 15 \\
\hline 30 & 5 & B & $25-74$ & $0-50$ & 50 & 3 & 32 & 0 & 31 & 3 & 14 & 23 & 1 & 27 & 2 & 78 \\
\hline 30 & 5 & B & $25-74$ & $50-100$ & 0 & 37 & 42 & 0 & 33 & 6 & 5 & 0 & 0 & 1 & 10 & 11 \\
\hline 30 & 5 & B & $25-74$ & $50-100$ & 50 & 3 & 28 & 0 & 29 & 3 & 15 & 28 & 0 & 20 & 3 & 72 \\
\hline 30 & 5 & B & $75-125$ & $0-50$ & 0 & 37 & 38 & 0 & 32 & 4 & 5 & 2 & 0 & 4 & 8 & 10 \\
\hline 30 & 5 & B & $75-125$ & $0-50$ & 50 & 1 & 29 & 0 & 31 & 3 & 15 & 22 & 0 & 23 & 5 & 78 \\
\hline 30 & 5 & B & $75-125$ & $50-100$ & 0 & 32 & 35 & 0 & 28 & 3 & 8 & 4 & 0 & 1 & 12 & 17 \\
\hline 30 & 5 & B & $75-125$ & $50-100$ & 50 & 3 & 33 & 0 & 29 & 2 & 19 & 24 & 0 & 29 & 3 & 77 \\
\hline 30 & 5 & $\mathbf{M}$ & $25-74$ & $0-50$ & 0 & 16 & 25 & 0 & 42 & 3 & 8 & 2 & 0 & 7 & 7 & 16 \\
\hline 30 & 5 & $\mathbf{M}$ & $25-74$ & $0-50$ & 50 & 3 & 30 & 0 & 30 & 9 & 23 & 32 & 0 & 35 & 4 & 79 \\
\hline 30 & 5 & M & $25-74$ & $50-100$ & 0 & 33 & 35 & 0 & 27 & 5 & 11 & 0 & 0 & 3 & 5 & 12 \\
\hline 30 & 5 & $\mathbf{M}$ & $25-74$ & $50-100$ & 50 & 2 & 28 & 0 & 27 & 4 & 16 & 29 & 2 & 27 & 5 & 82 \\
\hline 30 & 5 & M & $75-125$ & $0-50$ & 0 & 27 & 35 & 0 & 25 & 4 & 14 & 5 & 0 & 6 & 5 & 10 \\
\hline 30 & 5 & M & $75-125$ & $0-50$ & 50 & 3 & 26 & 0 & 29 & 7 & 16 & 27 & 0 & 34 & 5 & 77 \\
\hline 30 & 5 & M & $75-125$ & $50-100$ & 0 & 27 & 34 & 0 & 29 & 2 & 4 & 3 & 0 & 6 & 11 & 14 \\
\hline 30 & 5 & $\mathbf{M}$ & $75-125$ & $50-100$ & 50 & 6 & 31 & 0 & 32 & 3 & 18 & 26 & 0 & 21 & 10 & 80 \\
\hline 100 & 5 & A & $25-74$ & $0-50$ & 0 & 12 & 39 & 0 & 14 & 1 & 7 & 0 & 0 & 0 & 11 & 31 \\
\hline
\end{tabular}




\begin{tabular}{|c|c|c|c|c|c|c|c|c|c|c|c|c|c|c|c|c|}
\hline 100 & 5 & A & $25-74$ & $0-50$ & 50 & 0 & 7 & 0 & 10 & 1 & 4 & 5 & 0 & 2 & 5 & 72 \\
\hline 100 & 5 & A & $25-74$ & $50-100$ & 0 & 16 & 39 & 0 & 19 & 2 & 10 & 1 & 0 & 1 & 7 & 20 \\
\hline 100 & 5 & A & $25-74$ & $50-100$ & 50 & 0 & 3 & 0 & 2 & 0 & 4 & 2 & 0 & 4 & 7 & 87 \\
\hline 100 & 5 & A & $75-125$ & $0-50$ & 0 & 8 & 34 & 0 & 29 & 0 & 11 & 0 & 0 & 4 & 7 & 16 \\
\hline 100 & 5 & A & $75-125$ & $0-50$ & 50 & 0 & 5 & 0 & 5 & 1 & 3 & 5 & 0 & 7 & 6 & 74 \\
\hline 100 & 5 & A & $75-125$ & $50-100$ & 0 & 21 & 37 & 0 & 21 & 2 & 6 & 0 & 0 & 3 & 7 & 15 \\
\hline 100 & 5 & A & $75-125$ & $50-100$ & 50 & 0 & 4 & 0 & 6 & 0 & 2 & 2 & 0 & 3 & 10 & 84 \\
\hline 100 & 5 & B & $25-74$ & $0-50$ & 0 & 34 & 46 & 0 & 28 & 2 & 5 & 1 & 0 & 1 & 8 & 11 \\
\hline 100 & 5 & B & $25-74$ & $0-50$ & 50 & 2 & 33 & 0 & 28 & 1 & 16 & 29 & 0 & 27 & 3 & 94 \\
\hline 100 & 5 & B & $25-74$ & $50-100$ & 0 & 39 & 50 & 0 & 21 & 3 & 3 & 1 & 0 & 1 & 11 & 17 \\
\hline 100 & 5 & B & $25-74$ & $50-100$ & 50 & 2 & 28 & 0 & 28 & 0 & 13 & 28 & 0 & 23 & 1 & 91 \\
\hline 100 & 5 & B & $75-125$ & $0-50$ & 0 & 35 & 38 & 0 & 36 & 4 & 4 & 2 & 0 & 4 & 6 & 6 \\
\hline 100 & 5 & B & $75-125$ & $0-50$ & 50 & 1 & 27 & 0 & 22 & 0 & 9 & 17 & 0 & 24 & 1 & 95 \\
\hline 100 & 5 & B & $75-125$ & $50-100$ & 0 & 36 & 49 & 0 & 29 & 3 & 7 & 1 & 0 & 3 & 6 & 8 \\
\hline 100 & 5 & B & $75-125$ & $50-100$ & 50 & 0 & 31 & 0 & 26 & 2 & 19 & 31 & 0 & 28 & 0 & 98 \\
\hline 100 & 5 & M & $25-74$ & $0-50$ & 0 & 24 & 42 & 0 & 22 & 6 & 8 & 1 & 0 & 9 & 7 & 8 \\
\hline 100 & 5 & M & $25-74$ & $0-50$ & 50 & 2 & 29 & 0 & 30 & 4 & 15 & 27 & 0 & 29 & 2 & 94 \\
\hline 100 & 5 & M & $25-74$ & $50-100$ & 0 & 26 & 39 & 0 & 29 & 4 & 13 & 1 & 0 & 2 & 4 & 8 \\
\hline 100 & 5 & M & $25-74$ & $50-100$ & 50 & 0 & 31 & 0 & 31 & 4 & 17 & 29 & 0 & 30 & 2 & 95 \\
\hline 100 & 5 & $\mathbf{M}$ & $75-125$ & $0-50$ & 0 & 38 & 41 & 0 & 22 & 4 & 8 & 4 & 0 & 10 & 8 & 8 \\
\hline 100 & 5 & $\mathbf{M}$ & $75-125$ & $0-50$ & 50 & 3 & 26 & 0 & 23 & 1 & 11 & 23 & 0 & 26 & 6 & 98 \\
\hline 100 & 5 & $\mathbf{M}$ & $75-125$ & $50-100$ & 0 & 25 & 30 & 0 & 34 & 7 & 10 & 6 & 0 & 4 & 3 & 5 \\
\hline 100 & 5 & $\mathbf{M}$ & $75-125$ & $50-100$ & 50 & 2 & 32 & 0 & 32 & 3 & 17 & 29 & 0 & 34 & 9 & 98 \\
\hline 10 & 7 & A & $25-74$ & $0-50$ & 0 & 13 & 27 & 0 & 22 & 2 & 6 & 4 & 0 & 6 & 3 & 27 \\
\hline 10 & 7 & A & $25-74$ & $0-50$ & 50 & 17 & 33 & 1 & 28 & 1 & 21 & 33 & 17 & 38 & 25 & 64 \\
\hline 10 & 7 & A & $25-74$ & $50-100$ & 0 & 11 & 25 & 0 & 27 & 1 & 11 & 2 & 0 & 2 & 7 & 23 \\
\hline 10 & 7 & A & $25-74$ & $50-100$ & 50 & 17 & 30 & 2 & 34 & 7 & 28 & 50 & 17 & 41 & 29 & 64 \\
\hline 10 & 7 & A & $75-125$ & $0-50$ & 0 & 9 & 24 & 0 & 24 & 2 & 9 & 1 & 0 & 11 & 11 & 23 \\
\hline 10 & 7 & A & $75-125$ & $0-50$ & 50 & 19 & 34 & 5 & 32 & 8 & 25 & 37 & 19 & 41 & 23 & 61 \\
\hline 10 & 7 & A & $75-125$ & $50-100$ & 0 & 7 & 24 & 0 & 23 & 4 & 12 & 5 & 0 & 10 & 1 & 20 \\
\hline 10 & 7 & A & $75-125$ & $50-100$ & 50 & 20 & 31 & 4 & 31 & 8 & 21 & 44 & 13 & 37 & 17 & 57 \\
\hline 10 & 7 & B & $25-74$ & $0-50$ & 0 & 27 & 32 & 0 & 28 & 8 & 10 & 3 & 0 & 8 & 14 & 17 \\
\hline 10 & 7 & B & $25-74$ & $0-50$ & 50 & 4 & 40 & 0 & 34 & 2 & 22 & 29 & 0 & 29 & 8 & 45 \\
\hline 10 & 7 & B & $25-74$ & $50-100$ & 0 & 31 & 36 & 0 & 30 & 7 & 8 & 3 & 0 & 3 & 7 & 13 \\
\hline 10 & 7 & B & $25-74$ & $50-100$ & 50 & 4 & 30 & 0 & 32 & 5 & 25 & 36 & 1 & 33 & 6 & 50 \\
\hline 10 & 7 & B & $75-125$ & $0-50$ & 0 & 36 & 32 & 0 & 20 & 5 & 10 & 6 & 0 & 9 & 13 & 14 \\
\hline 10 & 7 & B & $75-125$ & $0-50$ & 50 & 6 & 24 & 0 & 29 & 1 & 14 & 25 & 0 & 29 & 3 & 60 \\
\hline 10 & 7 & B & $75-125$ & $50-100$ & 0 & 29 & 38 & 0 & 23 & 7 & 9 & 2 & 0 & 6 & 12 & 18 \\
\hline 10 & 7 & B & $75-125$ & $50-100$ & 50 & 6 & 35 & 0 & 31 & 3 & 20 & 30 & 0 & 23 & 4 & 46 \\
\hline 10 & 7 & M & $25-74$ & $0-50$ & 0 & 18 & 30 & 0 & 18 & 12 & 16 & 6 & 0 & 6 & 9 & 19 \\
\hline 10 & 7 & M & $25-74$ & $0-50$ & 50 & 18 & 36 & 1 & 30 & 3 & 26 & 29 & 4 & 32 & 12 & 52 \\
\hline 10 & 7 & M & $25-74$ & $50-100$ & 0 & 17 & 27 & 0 & 18 & 4 & 10 & 5 & 0 & 10 & 15 & 29 \\
\hline 10 & 7 & M & $25-74$ & $50-100$ & 50 & 10 & 33 & 0 & 37 & 4 & 27 & 33 & 6 & 32 & 8 & 57 \\
\hline 10 & 7 & M & $75-125$ & $0-50$ & 0 & 10 & 24 & 0 & 21 & 8 & 15 & 4 & 0 & 15 & 8 & 23 \\
\hline 10 & 7 & M & $75-125$ & $0-50$ & 50 & 14 & 42 & 0 & 35 & 12 & 31 & 42 & 5 & 40 & 12 & 58 \\
\hline 10 & 7 & $\mathbf{M}$ & $75-125$ & $50-100$ & 0 & 16 & 27 & 0 & 24 & 6 & 15 & 9 & 0 & 7 & 7 & 10 \\
\hline 10 & 7 & $\mathbf{M}$ & $75-125$ & $50-100$ & 50 & 9 & 39 & 1 & 35 & 5 & 28 & 35 & 7 & 38 & 10 & 51 \\
\hline 30 & 7 & A & $25-74$ & $0-50$ & 0 & 12 & 36 & 0 & 23 & 1 & 7 & 0 & 0 & 4 & 5 & 18 \\
\hline 30 & 7 & A & $25-74$ & $0-50$ & 50 & 0 & 15 & 0 & 12 & 0 & 3 & 9 & 0 & 8 & 4 & 52 \\
\hline 30 & 7 & A & $25-74$ & $50-100$ & 0 & 9 & 32 & 0 & 26 & 2 & 7 & 0 & 0 & 2 & 4 & 25 \\
\hline 30 & 7 & A & $25-74$ & $50-100$ & 50 & 0 & 9 & 0 & 7 & 0 & 8 & 13 & 0 & 7 & 3 & 57 \\
\hline 30 & 7 & A & $75-125$ & $0-50$ & 0 & 7 & 27 & 0 & 24 & 1 & 6 & 7 & 0 & 8 & 5 & 18 \\
\hline 30 & 7 & A & $75-125$ & $0-50$ & 50 & 0 & 11 & 0 & 12 & 1 & 3 & 6 & 0 & 9 & 1 & 59 \\
\hline 30 & 7 & A & $75-125$ & $50-100$ & 0 & 10 & 25 & 0 & 24 & 3 & 11 & 1 & 0 & 5 & 5 & 22 \\
\hline 30 & 7 & A & $75-125$ & $50-100$ & 50 & 0 & 10 & 0 & 7 & 0 & 4 & 16 & 0 & 12 & 2 & 56 \\
\hline 30 & 7 & B & $25-74$ & $0-50$ & 0 & 32 & 39 & 0 & 31 & 7 & 7 & 1 & 0 & 2 & 4 & 9 \\
\hline 30 & 7 & B & $25-74$ & $0-50$ & 50 & 1 & 24 & 0 & 20 & 1 & 8 & 19 & 0 & 13 & 0 & 56 \\
\hline 30 & 7 & B & $25-74$ & $50-100$ & 0 & 39 & 55 & 0 & 19 & 7 & 7 & 1 & 0 & 0 & 5 & 7 \\
\hline 30 & 7 & B & $25-74$ & $50-100$ & 50 & 0 & 20 & 0 & 19 & 1 & 10 & 20 & 0 & 8 & 1 & 63 \\
\hline 30 & 7 & B & $75-125$ & $0-50$ & 0 & 31 & 39 & 0 & 22 & 7 & 8 & 1 & 0 & 4 & 9 & 12 \\
\hline 30 & 7 & B & $75-125$ & $0-50$ & 50 & 0 & 26 & 0 & 24 & 0 & 10 & 21 & 0 & 13 & 1 & 54 \\
\hline 30 & 7 & B & $75-125$ & $50-100$ & 0 & 38 & 48 & 0 & 12 & 6 & 9 & 2 & 0 & 1 & 7 & 10 \\
\hline
\end{tabular}




\begin{tabular}{|c|c|c|c|c|c|c|c|c|c|c|c|c|c|c|c|c|}
\hline 30 & 7 & B & $75-125$ & $50-100$ & 50 & 1 & 26 & 0 & 21 & 0 & 8 & 13 & 0 & 14 & 1 & 49 \\
\hline 30 & 7 & M & $25-74$ & $0-50$ & 0 & 15 & 29 & 0 & 28 & 3 & 7 & 4 & 0 & 9 & 7 & 16 \\
\hline 30 & 7 & $\mathbf{M}$ & $25-74$ & $0-50$ & 50 & 2 & 26 & 0 & 22 & 3 & 16 & 26 & 0 & 18 & 5 & 66 \\
\hline 30 & 7 & M & $25-74$ & $50-100$ & 0 & 15 & 31 & 0 & 32 & 5 & 10 & 3 & 0 & 9 & 3 & 7 \\
\hline 30 & 7 & $\mathbf{M}$ & $25-74$ & $50-100$ & 50 & 2 & 20 & 0 & 20 & 5 & 19 & 22 & 0 & 23 & 7 & 65 \\
\hline 30 & 7 & M & $75-125$ & $0-50$ & 0 & 15 & 23 & 0 & 28 & 4 & 7 & 3 & 0 & 9 & 6 & 14 \\
\hline 30 & 7 & $\mathbf{M}$ & $75-125$ & $0-50$ & 50 & 1 & 24 & 0 & 30 & 3 & 14 & 23 & 0 & 20 & 4 & 54 \\
\hline 30 & 7 & M & $75-125$ & $50-100$ & 0 & 15 & 34 & 0 & 22 & 2 & 9 & 5 & 0 & 7 & 11 & 17 \\
\hline 30 & 7 & M & $75-125$ & $50-100$ & 50 & 3 & 25 & 0 & 19 & 1 & 13 & 21 & 0 & 21 & 2 & 74 \\
\hline 100 & 7 & A & $25-74$ & $0-50$ & 0 & 10 & 23 & 0 & 26 & 0 & 11 & 2 & 0 & 3 & 8 & 19 \\
\hline 100 & 7 & A & $25-74$ & $0-50$ & 50 & 0 & 3 & 0 & 6 & 0 & 2 & 8 & 0 & 5 & 2 & 78 \\
\hline 100 & 7 & A & $25-74$ & $50-100$ & 0 & 7 & 24 & 0 & 23 & 2 & 11 & 2 & 0 & 5 & 2 & 29 \\
\hline 100 & 7 & A & $25-74$ & $50-100$ & 50 & 0 & 9 & 0 & 5 & 0 & 3 & 6 & 0 & 6 & 2 & 72 \\
\hline 100 & 7 & A & $75-125$ & $0-50$ & 0 & 7 & 36 & 0 & 21 & 0 & 9 & 4 & 0 & 5 & 10 & 18 \\
\hline 100 & 7 & A & $75-125$ & $0-50$ & 50 & 0 & 7 & 0 & 6 & 0 & 3 & 6 & 0 & 6 & 2 & 73 \\
\hline 100 & 7 & A & $75-125$ & $50-100$ & 0 & 8 & 23 & 0 & 29 & 5 & 9 & 3 & 0 & 6 & 5 & 13 \\
\hline 100 & 7 & A & $75-125$ & $50-100$ & 50 & 0 & 7 & 0 & 8 & 0 & 3 & 6 & 0 & 3 & 3 & 73 \\
\hline 100 & 7 & B & $25-74$ & $0-50$ & 0 & 36 & 40 & 0 & 18 & 4 & 9 & 0 & 0 & 2 & 5 & 14 \\
\hline 100 & 7 & B & $25-74$ & $0-50$ & 50 & 0 & 18 & 0 & 21 & 1 & 10 & 6 & 0 & 9 & 0 & 72 \\
\hline 100 & 7 & B & $25-74$ & $50-100$ & 0 & 27 & 45 & 0 & 16 & 7 & 9 & 3 & 0 & 4 & 8 & 13 \\
\hline 100 & 7 & B & $25-74$ & $50-100$ & 50 & 0 & 15 & 0 & 16 & 0 & 8 & 8 & 0 & 10 & 0 & 74 \\
\hline 100 & 7 & B & $75-125$ & $0-50$ & 0 & 31 & 49 & 0 & 19 & 8 & 12 & 0 & 0 & 2 & 8 & 7 \\
\hline 100 & 7 & B & $75-125$ & $0-50$ & 50 & 0 & 18 & 0 & 17 & 0 & 5 & 14 & 0 & 6 & 0 & 71 \\
\hline 100 & 7 & B & $75-125$ & $50-100$ & 0 & 41 & 52 & 0 & 17 & 6 & 8 & 0 & 0 & 2 & 8 & 13 \\
\hline 100 & 7 & B & $75-125$ & $50-100$ & 50 & 0 & 19 & 0 & 19 & 0 & 14 & 11 & 0 & 6 & 0 & 72 \\
\hline 100 & 7 & M & $25-74$ & $0-50$ & 0 & 20 & 30 & 0 & 33 & 3 & 12 & 2 & 0 & 6 & 6 & 7 \\
\hline 100 & 7 & M & $25-74$ & $0-50$ & 50 & 0 & 21 & 0 & 29 & 5 & 13 & 25 & 0 & 24 & 3 & 88 \\
\hline 100 & 7 & M & $25-74$ & $50-100$ & 0 & 20 & 30 & 0 & 29 & 2 & 10 & 4 & 0 & 5 & 5 & 11 \\
\hline 100 & 7 & M & $25-74$ & $50-100$ & 50 & 0 & 24 & 0 & 20 & 2 & 14 & 18 & 0 & 23 & 1 & 85 \\
\hline 100 & 7 & M & $75-125$ & $0-50$ & 0 & 26 & 31 & 0 & 25 & 3 & 11 & 3 & 0 & 4 & 4 & 11 \\
\hline 100 & 7 & M & $75-125$ & $0-50$ & 50 & 0 & 16 & 0 & 23 & 2 & 11 & 23 & 0 & 25 & 2 & 85 \\
\hline 100 & 7 & M & $75-125$ & $50-100$ & 0 & 12 & 32 & 0 & 24 & 5 & 10 & 2 & 0 & 7 & 7 & 16 \\
\hline 100 & 7 & M & $75-125$ & $50-100$ & 50 & 1 & 21 & 0 & 17 & 3 & 9 & 22 & 0 & 23 & 1 & 90 \\
\hline
\end{tabular}

TABELA D.9 - Desvio relativo médio (em \%) das regras para setup independente

\begin{tabular}{|c|c|c|c|c|c|c|c|c|c|c|c|c|c|c|c|c|}
\hline$n$ & $g$ & $f$ & $S$ & $a$ & $l$ & Ri1 & Ri2 & Ri3 & Ri4 & Ri5 & Ri6 & Ri7 & Ri8 & Ri9 & Ri10 & Ri11 \\
\hline 10 & 3 & A & $25-74$ & $0-50$ & 0 & 5,7 & 5,9 & 34,4 & 11,2 & 12,1 & 10,8 & 12,8 & $\overline{18,6}$ & 7,7 & 7,9 & 4,8 \\
\hline 10 & 3 & A & $25-74$ & $0-50$ & 50 & 15,3 & 12,8 & 31,1 & 16,6 & 23,6 & 19,0 & 10,6 & 9,5 & 7,0 & 13,9 & 2,3 \\
\hline 10 & 3 & A & $25-74$ & $50-100$ & 0 & 6,7 & 6,2 & 33,2 & 11,3 & 12,5 & 10,5 & 13,0 & 17,8 & 7,3 & 8,2 & 4,5 \\
\hline 10 & 3 & A & $25-74$ & $50-100$ & 50 & 16,0 & 14,1 & 36,3 & 18,1 & 24,3 & 20,9 & 13,1 & 10,9 & 8,0 & 13,9 & 2,8 \\
\hline 10 & 3 & A & $75-125$ & $0-50$ & 0 & 8,3 & 7,9 & 29,1 & 11,0 & 11,4 & 10,5 & 12,0 & 18,6 & 6,5 & 8,0 & 5,2 \\
\hline 10 & 3 & A & $75-125$ & $0-50$ & 50 & 13,3 & 12,5 & 36,3 & 17,5 & 23,8 & 21,2 & 11,7 & 9,3 & 7,3 & 14,8 & 3,5 \\
\hline 10 & 3 & A & $75-125$ & $50-100$ & 0 & 5,8 & 5,6 & 33,5 & 9,7 & 11,1 & 9,8 & 11,1 & 21,4 & 6,3 & 8,2 & 5,7 \\
\hline 10 & 3 & A & $75-125$ & $50-100$ & 50 & 12,7 & 11,5 & 32,3 & 17,0 & 22,7 & 19,9 & 11,1 & 12,3 & 7,0 & 15,2 & 3,4 \\
\hline 10 & 3 & B & $25-74$ & $0-50$ & 0 & 3,0 & 2,9 & 49,4 & 7,8 & 8,2 & 7,5 & 12,6 & 35,2 & 6,5 & 6,8 & 5,8 \\
\hline 10 & 3 & B & $25-74$ & $0-50$ & 50 & 8,8 & 6,3 & 47,0 & 10,6 & 16,6 & 12,6 & 7,7 & 18,9 & 4,8 & 16,1 & 1,4 \\
\hline 10 & 3 & B & $25-74$ & $50-100$ & 0 & 3,2 & 3,2 & 47,6 & 7,2 & 7,2 & 7,0 & 13,0 & 36,3 & 7,8 & 8,8 & 7,2 \\
\hline 10 & 3 & B & $25-74$ & $50-100$ & 50 & 7,9 & 5,4 & 51,0 & 10,4 & 15,4 & 11,8 & 7,6 & 14,9 & 4,6 & 18,4 & 1,3 \\
\hline 10 & 3 & B & $75-125$ & $0-50$ & 0 & 2,8 & 2,7 & 45,2 & 6,3 & 5,9 & 5,8 & 9,7 & 36,7 & 5,5 & 6,1 & 5,0 \\
\hline 10 & 3 & B & $75-125$ & $0-50$ & 50 & 8,5 & 6,0 & 45,4 & 10,2 & 15,8 & 12,0 & 6,9 & 17,4 & 3,4 & 13,5 & 0,7 \\
\hline 10 & 3 & B & $75-125$ & $50-100$ & 0 & 2,2 & 2,1 & 47,8 & 5,2 & 5,6 & 5,2 & 8,7 & 37,2 & 6,3 & 6,1 & 5,3 \\
\hline 10 & 3 & B & $75-125$ & $50-100$ & 50 & 7,4 & 4,6 & 41,0 & 8,2 & 13,6 & 9,3 & 6,1 & 14,0 & 3,5 & 13,2 & 1,2 \\
\hline 10 & 3 & M & $25-74$ & $0-50$ & 0 & 4,6 & 3,8 & 25,3 & 6,0 & 7,5 & 5,8 & 8,3 & 16,0 & 5,3 & 7,4 & 4,8 \\
\hline 10 & 3 & M & $25-74$ & $0-50$ & 50 & 7,8 & 5,5 & 31,1 & 10,0 & 14,7 & 11,7 & 6,6 & 10,5 & 5,3 & 15,1 & 2,2 \\
\hline 10 & 3 & M & $25-74$ & $50-100$ & 0 & 4,4 & 3,6 & 24,3 & 6,3 & 7,5 & 6,7 & 8,2 & 14,5 & 5,3 & 5,9 & 3,8 \\
\hline 10 & 3 & M & $25-74$ & $50-100$ & 50 & 7,5 & 5,5 & 32,1 & 12,2 & 15,4 & 12,4 & 9,1 & 11,7 & 4,1 & 14,5 & 1,9 \\
\hline 10 & 3 & M & $75-125$ & $0-50$ & 0 & 4,6 & 4,3 & 19,7 & 5,8 & 6,3 & 5,4 & 7,0 & 14,0 & 5,1 & 6,1 & 4,5 \\
\hline 10 & 3 & M & $75-125$ & $0-50$ & 50 & 7,4 & 5,3 & 26,2 & 8,8 & 14,7 & 11,5 & 7,1 & 9,0 & 4,3 & 11,9 & 1,6 \\
\hline
\end{tabular}




\begin{tabular}{|c|c|c|c|c|c|c|c|c|c|c|c|c|c|c|c|c|}
\hline 10 & 3 & $\bar{M}$ & $75-125$ & $50-100$ & 0 & 4,3 & 3,5 & 20,8 & 5,6 & 6,8 & 5,6 & 7,5 & 16,2 & 4,9 & 8,0 & 4,9 \\
\hline 10 & 3 & M & $75-125$ & $50-100$ & 50 & 8,8 & 6,7 & 26,3 & 9,0 & 12,9 & 11,0 & 5,7 & 8,9 & 2,8 & 10,6 & 1,4 \\
\hline 30 & 3 & A & $25-74$ & $0-50$ & 0 & 2,4 & 2,0 & 49,1 & 6,7 & 6,9 & 5,9 & 11,3 & 34,9 & 6,4 & 5,7 & 3,7 \\
\hline 30 & 3 & A & $25-74$ & $0-50$ & 50 & 12,4 & 10,8 & 61,2 & 15,2 & 20,4 & 17,3 & 10,7 & 15,8 & 6,6 & 15,1 & 1,0 \\
\hline 30 & 3 & A & $25-74$ & $50-100$ & 0 & 3,0 & 2,4 & 49,7 & 7,1 & 6,7 & 5,5 & 10,3 & 37,3 & 6,0 & 5,2 & 3,9 \\
\hline 30 & 3 & A & $25-74$ & $50-100$ & 50 & 13,8 & 11,6 & 64,1 & 16,0 & 22,3 & 18,1 & 10,7 & 16,8 & 7,0 & 15,8 & 0,6 \\
\hline 30 & 3 & A & $75-125$ & $0-50$ & 0 & 2,0 & 1,7 & 43,9 & 5,4 & 5,5 & 4,4 & 7,6 & 34,2 & 4,4 & 4,1 & 3,1 \\
\hline 30 & 3 & A & $75-125$ & $0-50$ & 50 & 10,9 & 8,7 & 57,3 & 13,1 & 18,0 & 15,8 & 9,0 & 16,6 & 6,1 & 14,7 & 1,3 \\
\hline 30 & 3 & A & $75-125$ & $50-100$ & 0 & 3,0 & 2,6 & 45,0 & 5,3 & 6,1 & 5,2 & 7,9 & 33,8 & 4,5 & 4,5 & 3,1 \\
\hline 30 & 3 & A & $75-125$ & $50-100$ & 50 & 12,6 & 8,6 & 58,3 & 10,2 & 16,4 & 14,0 & 9,1 & 19,6 & 7,1 & 15,8 & 1,6 \\
\hline 30 & 3 & B & $25-74$ & $0-50$ & 0 & 1,4 & 1,3 & 63,3 & 5,9 & 4,4 & 4,3 & 11,1 & 53,7 & 5,7 & 4,5 & 4,0 \\
\hline 30 & 3 & B & $25-74$ & $0-50$ & 50 & 3,8 & 1,9 & 68,9 & 4,9 & 10,2 & 5,9 & 3,2 & 24,1 & 1,9 & 8,9 & 0,2 \\
\hline 30 & 3 & B & $25-74$ & $50-100$ & 0 & 1,6 & 1,6 & 59,2 & 4,7 & 4,0 & 3,8 & 10,0 & 49,7 & 6,0 & 4,1 & 3,4 \\
\hline 30 & 3 & B & $25-74$ & $50-100$ & 50 & 4,1 & 2,2 & 67,1 & 4,7 & 8,5 & 5,6 & 3,4 & 24,2 & 1,8 & 9,4 & 0,0 \\
\hline 30 & 3 & B & $75-125$ & $0-50$ & 0 & 1,2 & 1,2 & 58,8 & 4,8 & 3,8 & 3,6 & 8,0 & 52,5 & 4,2 & 3,5 & 3,2 \\
\hline 30 & 3 & B & $75-125$ & $0-50$ & 50 & 4,0 & 1,8 & 64,5 & 3,8 & 7,7 & 5,3 & 2,7 & 24,9 & 1,6 & 9,2 & 0,1 \\
\hline 30 & 3 & B & $75-125$ & $50-100$ & 0 & 1,4 & 1,4 & 59,9 & 4,2 & 3,7 & 3,5 & 7,1 & 53,2 & 4,7 & 3,0 & 2,8 \\
\hline 30 & 3 & B & $75-125$ & $50-100$ & 50 & 4,8 & 2,3 & 63,1 & 4,4 & 8,3 & 5,1 & 2,8 & 24,1 & 1,7 & 8,1 & 0,0 \\
\hline 30 & 3 & M & $25-74$ & $0-50$ & 0 & 1,3 & 1,2 & 26,8 & 2,7 & 3,1 & 2,8 & 4,1 & 20,6 & 2,1 & 2,9 & 2,0 \\
\hline 30 & 3 & M & $25-74$ & $0-50$ & 50 & 3,5 & 2,4 & 32,4 & 5,1 & 6,2 & 5,7 & 2,7 & 8,3 & 1,4 & 6,3 & 0,2 \\
\hline 30 & 3 & M & $25-74$ & $50-100$ & 0 & 1,9 & 1,4 & 24,8 & 2,5 & 2,9 & 2,4 & 3,7 & 17,6 & 2,0 & 2,8 & 2,3 \\
\hline 30 & 3 & $\mathbf{M}$ & $25-74$ & $50-100$ & 50 & 3,3 & 2,6 & 32,2 & 4,5 & 6,5 & 6,0 & 3,5 & 10,1 & 2,2 & 5,4 & 0,1 \\
\hline 30 & 3 & M & $75-125$ & $0-50$ & 0 & 2,0 & 1,6 & 23,5 & 2,1 & 2,7 & 2,2 & 3,3 & 20,6 & 2,2 & 2,9 & 2,1 \\
\hline 30 & 3 & $\mathbf{M}$ & $75-125$ & $0-50$ & 50 & 3,3 & 2,5 & 30,2 & 4,1 & 6,3 & 5,7 & 2,7 & 8,6 & 1,9 & 4,2 & 0,1 \\
\hline 30 & 3 & M & $75-125$ & $50-100$ & 0 & 2,0 & 1,6 & 26,1 & 2,1 & 2,9 & 2,5 & 3,2 & 22,4 & 2,0 & 2,7 & 2,2 \\
\hline 30 & 3 & $\mathbf{M}$ & $75-125$ & $50-100$ & 50 & 3,0 & 1,7 & 30,3 & 3,8 & 5,4 & 4,7 & 2,4 & 9,0 & 1,9 & 5,1 & 0,0 \\
\hline 100 & 3 & A & $25-74$ & $0-50$ & 0 & 1,0 & 0,9 & 58,1 & 4,9 & 2,9 & 2,5 & 6,9 & 48,5 & 3,7 & 2,0 & 1,4 \\
\hline 100 & 3 & A & $25-74$ & $0-50$ & 50 & 5,0 & 3,4 & 79,0 & 5,5 & 8,1 & 6,4 & 3,5 & 26,8 & 2,9 & 6,8 & 0,2 \\
\hline 100 & 3 & A & $25-74$ & $50-100$ & 0 & 1,1 & 1,0 & 61,7 & 4,6 & 2,8 & 2,5 & 7,3 & 51,5 & 3,9 & 1,9 & 1,5 \\
\hline 100 & 3 & A & $25-74$ & $50-100$ & 50 & 5,0 & 3,2 & 80,8 & 5,6 & 8,4 & 6,4 & 4,0 & 28,2 & 3,0 & 6,6 & 0,2 \\
\hline 100 & 3 & A & $75-125$ & $0-50$ & 0 & 0,9 & 0,8 & 56,4 & 2,8 & 2,2 & 2,0 & 4,3 & 50,2 & 2,7 & 1,6 & 1,4 \\
\hline 100 & 3 & A & $75-125$ & $0-50$ & 50 & 4,0 & 2,8 & 76,2 & 4,2 & 6,3 & 5,1 & 3,2 & 27,5 & 1,9 & 5,3 & 0,3 \\
\hline 100 & 3 & A & $75-125$ & $50-100$ & 0 & 1,0 & 0,9 & 55,8 & 2,5 & 2,1 & 1,9 & 4,5 & 49,7 & 2,7 & 1,9 & 1,5 \\
\hline 100 & 3 & A & $75-125$ & $50-100$ & 50 & 4,2 & 2,8 & 76,8 & 4,9 & 7,0 & 5,6 & 2,9 & 23,9 & 2,5 & 5,1 & 0,2 \\
\hline 100 & 3 & B & $25-74$ & $0-50$ & 0 & 0,7 & 0,7 & 71,0 & 4,2 & 1,9 & 1,9 & 9,4 & 64,6 & 4,7 & 2,0 & 1,9 \\
\hline 100 & 3 & B & $25-74$ & $0-50$ & 50 & 2,3 & 0,7 & 79,8 & 2,8 & 5,2 & 2,6 & 1,2 & 31,3 & 0,8 & 5,1 & 0,0 \\
\hline 100 & 3 & B & $25-74$ & $50-100$ & 0 & 0,7 & 0,7 & 71,1 & 5,0 & 2,0 & 2,0 & 9,5 & 62,7 & 4,9 & 2,1 & 2,0 \\
\hline 100 & 3 & B & $25-74$ & $50-100$ & 50 & 2,5 & 0,6 & 80,8 & 2,5 & 5,1 & 2,4 & 1,3 & 35,5 & 0,6 & 5,4 & 0,0 \\
\hline 100 & 3 & B & $75-125$ & $0-50$ & 0 & 0,5 & 0,5 & 67,8 & 3,4 & 1,6 & 1,6 & 6,1 & 63,0 & 3,5 & 1,4 & 1,3 \\
\hline 100 & 3 & B & $75-125$ & $0-50$ & 50 & 1,9 & 0,7 & 80,0 & 2,2 & 4,7 & 2,3 & 1,0 & 34,9 & 0,5 & 4,2 & 0,0 \\
\hline 100 & 3 & B & $75-125$ & $50-100$ & 0 & 0,5 & 0,5 & 64,4 & 2,8 & 1,4 & 1,3 & 6,2 & 60,5 & 3,9 & 1,7 & 1,6 \\
\hline 100 & 3 & B & $75-125$ & $50-100$ & 50 & 2,2 & 0,8 & 80,7 & 2,1 & 4,5 & 2,4 & 0,9 & 34,6 & 0,6 & 3,9 & 0,0 \\
\hline 100 & 3 & M & $25-74$ & $0-50$ & 0 & 0,5 & 0,4 & 26,6 & 0,9 & 1,0 & 0,9 & 1,3 & 23,8 & 0,7 & 0,8 & 0,6 \\
\hline 100 & 3 & $\mathbf{M}$ & $25-74$ & $0-50$ & 50 & 0,9 & 0,6 & 37,6 & 1,3 & 2,1 & 2,0 & 1,0 & 11,2 & 0,6 & 1,7 & 0,0 \\
\hline 100 & 3 & $\mathbf{M}$ & $25-74$ & $50-100$ & 0 & 0,5 & 0,4 & 29,8 & 0,9 & 0,9 & 0,8 & 1,5 & 25,9 & 0,8 & 1,1 & 0,8 \\
\hline 100 & 3 & $\mathbf{M}$ & $25-74$ & $50-100$ & 50 & 1,1 & 0,7 & 35,4 & 1,3 & 1,9 & 1,8 & 0,9 & 9,4 & 0,5 & 2,0 & 0,0 \\
\hline 100 & 3 & $\mathbf{M}$ & $75-125$ & $0-50$ & 0 & 0,5 & 0,4 & 27,4 & 0,7 & 0,8 & 0,7 & 0,9 & 25,2 & 0,6 & 0,7 & 0,5 \\
\hline 100 & 3 & $\mathbf{M}$ & $75-125$ & $0-50$ & 50 & 0,9 & 0,6 & 35,6 & 1,0 & 1,7 & 1,6 & 0,7 & 12,7 & 0,5 & 1,6 & 0,0 \\
\hline 100 & 3 & M & $75-125$ & $50-100$ & 0 & 0,6 & 0,5 & 27,8 & 0,7 & 0,9 & 0,8 & 1,1 & 25,1 & 0,6 & 0,8 & 0,6 \\
\hline 100 & 3 & M & $75-125$ & $50-100$ & 50 & 0,9 & 0,7 & 34,0 & 1,2 & 1,8 & 1,8 & 0,8 & 11,1 & 0,4 & 1,6 & 0,0 \\
\hline 10 & 5 & A & $25-74$ & $0-50$ & 0 & 6,9 & 5,4 & 55,3 & 9,1 & 13,3 & 11,4 & 13,0 & 38,8 & 8,7 & 9,0 & 5,0 \\
\hline 10 & 5 & A & $25-74$ & $0-50$ & 50 & 13,8 & 9,3 & 38,5 & 11,4 & 22,9 & 14,6 & 8,8 & 13,3 & 7,2 & 13,7 & 3,5 \\
\hline 10 & 5 & A & $25-74$ & $50-100$ & 0 & 6,7 & 5,6 & 52,9 & 7,8 & 12,8 & 10,0 & 12,4 & 38,7 & 8,1 & 8,7 & 5,1 \\
\hline 10 & 5 & A & $25-74$ & $50-100$ & 50 & 14,3 & 10,3 & 36,9 & 11,7 & 23,0 & 14,6 & 9,0 & 12,7 & 7,9 & 13,2 & 3,9 \\
\hline 10 & 5 & A & $75-125$ & $0-50$ & 0 & 7,8 & 5,6 & 53,2 & 6,4 & 11,4 & 8,6 & 11,5 & 43,8 & 9,8 & 10,0 & 5,8 \\
\hline 10 & 5 & A & $75-125$ & $0-50$ & 50 & 13,3 & 10,3 & 34,7 & 11,5 & 23,2 & 15,9 & 8,2 & 15,8 & 8,1 & 14,4 & 3,0 \\
\hline 10 & 5 & A & $75-125$ & $50-100$ & 0 & 7,6 & 6,2 & 51,0 & 7,9 & 11,2 & 9,4 & 11,4 & 41,3 & 9,6 & 9,3 & 6,1 \\
\hline 10 & 5 & A & $75-125$ & $50-100$ & 50 & 12,4 & 9,9 & 35,9 & 14,3 & 21,7 & 17,6 & 11,9 & 12,3 & 6,3 & 16,3 & 3,4 \\
\hline 10 & 5 & B & $25-74$ & $0-50$ & 0 & 3,8 & 3,3 & 99,8 & 4,8 & 8,0 & 7,2 & 11,2 & 88,3 & 9,9 & 8,5 & 7,1 \\
\hline 10 & 5 & B & $25-74$ & $0-50$ & 50 & 14,3 & 6,3 & 79,3 & 9,4 & 23,2 & 12,9 & 11,3 & 39,3 & 7,8 & 25,2 & 2,7 \\
\hline 10 & 5 & B & $25-74$ & $50-100$ & 0 & 3,7 & 3,3 & 94,1 & 4,9 & 7,5 & 6,6 & 11,0 & 81,0 & 9,1 & 7,4 & 6,1 \\
\hline 10 & 5 & B & $25-74$ & $50-100$ & 50 & 17,1 & 7,7 & 72,8 & 9,5 & 24,3 & 12,9 & 8,8 & 39,6 & 8,8 & 21,8 & 1,9 \\
\hline
\end{tabular}




\begin{tabular}{|c|c|c|c|c|c|c|c|c|c|c|c|c|c|c|c|c|}
\hline 10 & 5 & $\bar{B}$ & $75-125$ & $0-50$ & 0 & 2,9 & 2,4 & 97,0 & 5,8 & 7,2 & 6,7 & $\overline{10,2}$ & 87,9 & 8,0 & 6,8 & $\overline{5,5}$ \\
\hline 10 & 5 & B & $75-125$ & $0-50$ & 50 & 13,8 & 7,1 & 76,7 & 8,4 & 24,9 & 11,8 & 7,4 & 38,3 & 6,8 & 22,1 & 2,2 \\
\hline 10 & 5 & B & $75-125$ & $50-100$ & 0 & 3,7 & 3,3 & 98,2 & 5,9 & 7,1 & 6,6 & 9,0 & 88,4 & 6,4 & 5,8 & 5,0 \\
\hline 10 & 5 & B & $75-125$ & $50-100$ & 50 & 16,0 & 6,8 & 81,4 & 9,2 & 24,0 & 12,5 & 8,3 & 40,5 & 7,3 & 20,4 & 2,4 \\
\hline 10 & 5 & M & $25-74$ & $0-50$ & 0 & 5,0 & 3,8 & 71,8 & 5,5 & 9,7 & 7,7 & 10,1 & 57,4 & 8,8 & 9,0 & 6,1 \\
\hline 10 & 5 & $\mathbf{M}$ & $25-74$ & $0-50$ & 50 & 15,8 & 8,0 & 67,4 & 9,0 & 25,6 & 12,4 & 9,9 & 25,9 & 8,5 & 23,3 & 3,8 \\
\hline 10 & 5 & M & $25-74$ & $50-100$ & 0 & 4,0 & 3,1 & 72,7 & 4,5 & 7,7 & 6,5 & 11,7 & 59,7 & 9,7 & 9,6 & 7,0 \\
\hline 10 & 5 & M & $25-74$ & $50-100$ & 50 & 16,1 & 8,2 & 59,9 & 9,3 & 21,8 & 14,1 & 9,1 & 27,7 & 7,3 & 19,7 & 2,3 \\
\hline 10 & 5 & M & $75-125$ & $0-50$ & 0 & 5,2 & 4,0 & 74,2 & 4,1 & 7,2 & 5,8 & 8,7 & 64,3 & 7,4 & 8,1 & 5,5 \\
\hline 10 & 5 & $\mathbf{M}$ & $75-125$ & $0-50$ & 50 & 12,4 & 5,9 & 58,5 & 8,2 & 20,5 & 10,2 & 7,1 & 27,7 & 6,0 & 18,9 & 3,1 \\
\hline 10 & 5 & $\mathbf{M}$ & $75-125$ & $50-100$ & 0 & 4,2 & 3,6 & 74,2 & 6,0 & 8,0 & 7,1 & 9,1 & 64,3 & 6,8 & 7,1 & 5,3 \\
\hline 10 & 5 & M & $75-125$ & $50-100$ & 50 & 15,6 & 7,7 & 53,0 & 8,8 & 19,8 & 11,7 & 9,2 & 27,7 & 6,6 & 21,1 & 3,8 \\
\hline 30 & 5 & A & $25-74$ & $0-50$ & 0 & 3,7 & 2,6 & 107,8 & 4,3 & 7,3 & 5,7 & 9,9 & 91,7 & 7,7 & 6,0 & 3,3 \\
\hline 30 & 5 & A & $25-74$ & $0-50$ & 50 & 16,8 & 10,8 & 109,9 & 13,6 & 26,7 & 17,6 & 12,0 & 44,5 & 10,3 & 23,9 & 1,4 \\
\hline 30 & 5 & A & $25-74$ & $50-100$ & 0 & 4,3 & 3,0 & 104,7 & 4,8 & 7,2 & 5,5 & 9,7 & 88,7 & 7,7 & 7,1 & 4,4 \\
\hline 30 & 5 & A & $25-74$ & $50-100$ & 50 & 17,7 & 10,6 & 108,8 & 14,3 & 26,2 & 17,5 & 12,2 & 42,5 & 10,0 & 23,1 & 1,9 \\
\hline 30 & 5 & A & $75-125$ & $0-50$ & 0 & 3,7 & 2,9 & 105,6 & 4,5 & 6,4 & 5,0 & 7,8 & 95,0 & 5,5 & 5,3 & 3,3 \\
\hline 30 & 5 & A & $75-125$ & $0-50$ & 50 & 15,7 & 9,2 & 101,6 & 11,9 & 22,5 & 16,6 & 10,3 & 40,2 & 9,9 & 20,0 & 1,9 \\
\hline 30 & 5 & A & $75-125$ & $50-100$ & 0 & 3,3 & 2,6 & 104,0 & 4,1 & 5,9 & 5,0 & 7,3 & 93,5 & 6,3 & 5,2 & 3,8 \\
\hline 30 & 5 & A & $75-125$ & $50-100$ & 50 & 17,4 & 10,5 & 103,1 & 13,7 & 24,3 & 17,4 & 11,1 & 42,6 & 10,3 & 20,2 & 1,2 \\
\hline 30 & 5 & B & $25-74$ & $0-50$ & 0 & 2,0 & 1,5 & 143,0 & 4,5 & 4,5 & 4,2 & 10,2 & 134,3 & 8,6 & 4,4 & 3,9 \\
\hline 30 & 5 & B & $25-74$ & $0-50$ & 50 & 12,6 & 4,1 & 130,3 & 5,2 & 17,3 & 7,8 & 5,0 & 61,3 & 4,5 & 18,4 & 0,7 \\
\hline 30 & 5 & B & $25-74$ & $50-100$ & 0 & 2,3 & 2,1 & 142,3 & 3,4 & 4,8 & 4,5 & 9,8 & 129,2 & 9,2 & 4,8 & 4,1 \\
\hline 30 & 5 & B & $25-74$ & $50-100$ & 50 & 13,5 & 4,7 & 138,0 & 6,5 & 18,0 & 9,0 & 6,2 & 63,8 & 5,9 & 17,9 & 0,9 \\
\hline 30 & 5 & B & $75-125$ & $0-50$ & 0 & 1,8 & 1,6 & 143,9 & 2,9 & 3,9 & 3,6 & 6,9 & 137,4 & 6,3 & 3,8 & 3,4 \\
\hline 30 & 5 & B & $75-125$ & $0-50$ & 50 & 13,1 & 3,7 & 134,5 & 4,8 & 16,2 & 7,3 & 4,6 & 64,1 & 4,4 & 15,7 & 0,7 \\
\hline 30 & 5 & B & $75-125$ & $50-100$ & 0 & 1,7 & 1,6 & 144,0 & 3,2 & 4,1 & 3,7 & 7,2 & 136,0 & 6,4 & 3,8 & 3,3 \\
\hline 30 & 5 & B & $75-125$ & $50-100$ & 50 & 13,2 & 3,4 & 139,4 & 5,6 & 18,9 & 8,3 & 4,7 & 69,1 & 4,9 & 18,0 & 0,5 \\
\hline 30 & 5 & $\mathbf{M}$ & $25-74$ & $0-50$ & 0 & 3,3 & 2,8 & 104,2 & 3,6 & 5,0 & 4,3 & 7,8 & 96,1 & 6,8 & 5,1 & 3,7 \\
\hline 30 & 5 & $\mathbf{M}$ & $25-74$ & $0-50$ & 50 & 11,4 & 4,5 & 98,5 & 5,3 & 14,2 & 7,7 & 5,4 & 44,8 & 3,9 & 14,9 & 0,6 \\
\hline 30 & 5 & M & $25-74$ & $50-100$ & 0 & 2,2 & 2,0 & 107,8 & 4,0 & 4,9 & 4,4 & 9,3 & 97,3 & 7,1 & 5,0 & 4,2 \\
\hline 30 & 5 & $\mathbf{M}$ & $25-74$ & $50-100$ & 50 & 9,5 & 4,1 & 101,3 & 6,3 & 15,7 & 8,6 & 5,2 & 45,5 & 4,5 & 15,1 & 0,5 \\
\hline 30 & 5 & $\mathbf{M}$ & $75-125$ & $0-50$ & 0 & 2,4 & 1,9 & 107,0 & 2,8 & 4,0 & 3,6 & 6,3 & 102,4 & 5,3 & 4,4 & 3,3 \\
\hline 30 & 5 & $\mathbf{M}$ & $75-125$ & $0-50$ & 50 & 9,2 & 3,9 & 98,7 & 5,8 & 13,9 & 7,7 & 4,8 & 49,7 & 3,9 & 14,3 & 0,7 \\
\hline 30 & 5 & $\mathbf{M}$ & $75-125$ & $50-100$ & 0 & 2,2 & 1,6 & 108,4 & 3,0 & 4,2 & 3,8 & 6,7 & 103,5 & 5,2 & 3,8 & 3,0 \\
\hline 30 & 5 & $\mathbf{M}$ & $75-125$ & $50-100$ & 50 & 11,6 & 5,0 & 92,6 & 6,3 & 14,6 & 8,5 & 5,0 & 45,0 & 5,2 & 13,0 & 0,6 \\
\hline 100 & 5 & A & $25-74$ & $0-50$ & 0 & 1,4 & 0,9 & 147,6 & 3,2 & 3,4 & 2,7 & 6,8 & 138,0 & 5,2 & 2,4 & 1,8 \\
\hline 100 & 5 & A & $25-74$ & $0-50$ & 50 & 10,4 & 4,9 & 163,8 & 6,2 & 13,1 & 8,1 & 5,8 & 67,4 & 4,8 & 11,4 & 0,3 \\
\hline 100 & 5 & A & $25-74$ & $50-100$ & 0 & 1,4 & 0,9 & 148,8 & 3,0 & 3,1 & 2,5 & 6,5 & 138,4 & 5,5 & 2,6 & 1,8 \\
\hline 100 & 5 & A & $25-74$ & $50-100$ & 50 & 9,5 & 4,9 & 161,1 & 6,2 & 12,7 & 8,2 & 5,1 & 65,0 & 5,3 & 10,6 & 0,1 \\
\hline 100 & 5 & A & $75-125$ & $0-50$ & 0 & 1,4 & 1,1 & 145,3 & 1,6 & 2,5 & 2,1 & 4,0 & 140,7 & 4,1 & 2,2 & 1,6 \\
\hline 100 & 5 & A & $75-125$ & $0-50$ & 50 & 8,3 & 4,3 & 163,2 & 5,7 & 11,9 & 7,7 & 4,7 & 70,1 & 4,1 & 11,0 & 0,2 \\
\hline 100 & 5 & A & $75-125$ & $50-100$ & 0 & 1,1 & 0,7 & 145,8 & 1,9 & 2,6 & 2,3 & 4,5 & 139,9 & 3,6 & 2,0 & 1,5 \\
\hline 100 & 5 & A & $75-125$ & $50-100$ & 50 & 9,0 & 4,4 & 167,5 & 5,1 & 12,6 & 7,9 & 5,1 & 70,9 & 4,1 & 10,7 & 0,3 \\
\hline 100 & 5 & B & $25-74$ & $0-50$ & 0 & 1,2 & 1,1 & 178,0 & 4,4 & 2,6 & 2,5 & 9,0 & 169,9 & 8,5 & 2,8 & 2,6 \\
\hline 100 & 5 & B & $25-74$ & $0-50$ & 50 & 7,4 & 1,3 & 174,2 & 3,0 & 10,6 & 3,7 & 2,5 & 86,8 & 2,4 & 10,7 & 0,1 \\
\hline 100 & 5 & B & $25-74$ & $50-100$ & 0 & 1,1 & 1,0 & 175,9 & 4,5 & 2,7 & 2,6 & 9,1 & 166,6 & 8,2 & 2,5 & 2,4 \\
\hline 100 & 5 & B & $25-74$ & $50-100$ & 50 & 8,2 & 1,7 & 176,0 & 2,4 & 10,7 & 3,8 & 2,4 & 90,1 & 2,3 & 10,4 & 0,1 \\
\hline 100 & 5 & B & $75-125$ & $0-50$ & 0 & 1,0 & 1,0 & 172,8 & 2,3 & 1,8 & 1,8 & 5,7 & 167,5 & 6,4 & 2,2 & 2,1 \\
\hline 100 & 5 & B & $75-125$ & $0-50$ & 50 & 7,4 & 1,6 & 175,0 & 2,6 & 10,1 & 3,8 & 2,4 & 92,0 & 2,1 & 10,7 & 0,1 \\
\hline 100 & 5 & B & $75-125$ & $50-100$ & 0 & 0,9 & 0,8 & 173,8 & 2,4 & 1,8 & 1,7 & 5,6 & 169,3 & 5,7 & 2,0 & 1,8 \\
\hline 100 & 5 & B & $75-125$ & $50-100$ & 50 & 7,2 & 1,5 & 173,1 & 2,3 & 9,0 & 3,4 & 2,2 & 93,2 & 2,2 & 9,1 & 0,0 \\
\hline 100 & 5 & M & $25-74$ & $0-50$ & 0 & 1,1 & 0,9 & 127,4 & 2,6 & 2,2 & 2,0 & 7,3 & 121,4 & 4,5 & 2,4 & 2,1 \\
\hline 100 & 5 & M & $25-74$ & $0-50$ & 50 & 5,8 & 1,8 & 134,4 & 2,2 & 7,8 & 3,8 & 2,1 & 65,3 & 2,0 & 7,8 & 0,0 \\
\hline 100 & 5 & $\mathbf{M}$ & $25-74$ & $50-100$ & 0 & 1,2 & 1,0 & 126,2 & 1,6 & 1,9 & 1,7 & 6,0 & 119,6 & 5,2 & 2,3 & 2,0 \\
\hline 100 & 5 & M & $25-74$ & $50-100$ & 50 & 5,6 & 1,7 & 131,6 & 2,2 & 7,6 & 3,4 & 2,3 & 65,3 & 1,8 & 8,2 & 0,0 \\
\hline 100 & 5 & M & $75-125$ & $0-50$ & 0 & 0,7 & 0,7 & 132,7 & 1,9 & 1,7 & 1,5 & 4,6 & 130,3 & 3,4 & 1,7 & 1,5 \\
\hline 100 & 5 & $\mathbf{M}$ & $75-125$ & $0-50$ & 50 & 5,1 & 1,6 & 134,0 & 2,3 & 7,7 & 3,6 & 2,0 & 68,5 & 1,5 & 6,4 & 0,0 \\
\hline 100 & 5 & $M$ & $75-125$ & $50-100$ & 0 & 1,0 & 0,9 & 128,5 & 1,3 & 1,4 & 1,3 & 4,1 & 125,6 & 4,0 & 1,7 & 1,5 \\
\hline 100 & 5 & M & $75-125$ & $50-100$ & 50 & 3,9 & 1,4 & 128,4 & 2,2 & 7,9 & 3,3 & 1,8 & 65,8 & 1,3 & 6,4 & 0,0 \\
\hline 10 & 7 & A & $25-74$ & $0-50$ & 0 & 7,7 & 5,2 & 69,2 & 6,0 & 12,2 & 9,5 & 12,3 & 55,3 & 10,2 & 10,8 & 5,9 \\
\hline 10 & 7 & A & $25-74$ & $0-50$ & 50 & 13,5 & 9,3 & 37,6 & 10,7 & 22,1 & 13,7 & 9,4 & 17,0 & 7,7 & 13,0 & 3,0 \\
\hline
\end{tabular}




\begin{tabular}{|c|c|c|c|c|c|c|c|c|c|c|c|c|c|c|c|c|}
\hline 10 & 7 & $\bar{A}$ & $25-74$ & $50-100$ & 0 & 6,7 & 4,7 & 70,9 & 5,6 & 12,0 & 8,4 & 11,7 & 57,1 & 9,7 & 9,9 & 5,5 \\
\hline 10 & 7 & A & $25-74$ & $50-100$ & 50 & 12,7 & 8,2 & 38,0 & 9,1 & 21,6 & 11,3 & 7,4 & 17,9 & 7,2 & 13,8 & 3,5 \\
\hline 10 & 7 & A & $75-125$ & $0-50$ & 0 & 6,9 & 4,8 & 68,4 & 6,0 & 10,7 & 9,1 & 9,4 & 57,8 & 8,5 & 7,7 & 5,5 \\
\hline 10 & 7 & A & $75-125$ & $0-50$ & 50 & 14,1 & 9,0 & 41,2 & 10,4 & 21,1 & 13,7 & 8,4 & 17,7 & 7,4 & 15,8 & 2,8 \\
\hline 10 & 7 & A & $75-125$ & $50-100$ & 0 & 6,9 & 3,9 & 68,9 & 5,8 & 10,4 & 6,8 & 9,8 & 61,8 & 8,0 & 9,5 & 5,2 \\
\hline 10 & 7 & A & $75-125$ & $50-100$ & 50 & 11,8 & 7,2 & 39,8 & 8,7 & 19,3 & 12,8 & 7,4 & 18,7 & 6,8 & 14,1 & 3,9 \\
\hline 10 & 7 & B & $25-74$ & $0-50$ & 0 & 3,6 & 3,0 & 150,4 & 4,1 & 7,3 & 6,6 & 10,9 & 133,4 & 9,2 & 7,1 & 6,2 \\
\hline 10 & 7 & B & $25-74$ & $0-50$ & 50 & 21,0 & 6,4 & 118,6 & 8,0 & 27,8 & 11,7 & 9,5 & 58,1 & 8,2 & 26,8 & 3,8 \\
\hline 10 & 7 & B & $25-74$ & $50-100$ & 0 & 3,6 & 3,3 & 155,8 & 4,3 & 7,9 & 7,4 & 11,1 & 141,1 & 10,2 & 7,7 & 6,3 \\
\hline 10 & 7 & B & $25-74$ & $50-100$ & 50 & 21,7 & 7,0 & 116,0 & 7,0 & 23,9 & 10,6 & 8,0 & 60,7 & 7,8 & 27,7 & 3,0 \\
\hline 10 & 7 & B & $75-125$ & $0-50$ & 0 & 3,1 & 3,0 & 159,8 & 3,8 & 6,2 & 5,5 & 8,8 & 148,3 & 7,9 & 5,4 & 5,2 \\
\hline 10 & 7 & B & $75-125$ & $0-50$ & 50 & 20,6 & 8,5 & 126,1 & 9,1 & 26,9 & 12,8 & 7,5 & 60,5 & 8,1 & 26,9 & 2,5 \\
\hline 10 & 7 & B & $75-125$ & $50-100$ & 0 & 3,2 & 2,7 & 159,6 & 3,3 & 5,9 & 5,2 & 8,3 & 145,1 & 7,6 & 5,9 & 5,1 \\
\hline 10 & 7 & B & $75-125$ & $50-100$ & 50 & 18,2 & 5,2 & 125,1 & 7,2 & 24,4 & 11,1 & 8,4 & 65,6 & 7,7 & 29,4 & 3,1 \\
\hline 10 & 7 & M & $25-74$ & $0-50$ & 0 & 5,5 & 4,1 & 88,4 & 7,7 & 10,1 & 8,5 & 11,9 & 74,7 & 8,6 & 9,5 & 6,7 \\
\hline 10 & 7 & M & $25-74$ & $0-50$ & 50 & 15,2 & 7,0 & 57,6 & 10,1 & 24,2 & 13,6 & 10,3 & 28,9 & 7,8 & 20,0 & 3,9 \\
\hline 10 & 7 & M & $25-74$ & $50-100$ & 0 & 5,9 & 4,5 & 84,1 & 6,7 & 10,2 & 8,4 & 10,9 & 70,6 & 8,6 & 8,9 & 5,5 \\
\hline 10 & 7 & M & $25-74$ & $50-100$ & 50 & 18,6 & 7,7 & 67,3 & 7,8 & 25,5 & 10,8 & 7,5 & 34,7 & 7,4 & 24,6 & 3,5 \\
\hline 10 & 7 & M & $75-125$ & $0-50$ & 0 & 6,9 & 4,7 & 84,6 & 5,2 & 8,3 & 6,2 & 8,9 & 76,3 & 7,9 & 8,8 & 5,4 \\
\hline 10 & 7 & $\mathbf{M}$ & $75-125$ & $0-50$ & 50 & 15,7 & 7,0 & 57,5 & 7,7 & 19,1 & 11,0 & 7,0 & 28,3 & 7,1 & 19,2 & 3,7 \\
\hline 10 & 7 & M & $75-125$ & $50-100$ & 0 & 6,3 & 4,2 & 84,3 & 5,3 & 9,4 & 7,1 & 8,5 & 73,5 & 7,5 & 8,9 & 6,5 \\
\hline 10 & 7 & $\mathbf{M}$ & $75-125$ & $50-100$ & 50 & 17,7 & 8,1 & 58,2 & 9,4 & 20,3 & 11,6 & 7,8 & 32,6 & 7,4 & 21,2 & 3,9 \\
\hline 30 & 7 & A & $25-74$ & $0-50$ & 0 & 4,3 & 2,4 & 154,6 & 4,6 & 8,0 & 6,3 & 10,2 & 137,7 & 8,0 & 7,3 & 4,6 \\
\hline 30 & 7 & A & $25-74$ & $0-50$ & 50 & 20,5 & 9,0 & 141,6 & 10,9 & 27,2 & 15,4 & 10,2 & 64,2 & 9,7 & 25,4 & 2,4 \\
\hline 30 & 7 & A & $25-74$ & $50-100$ & 0 & 4,2 & 2,9 & 154,2 & 4,3 & 8,1 & 6,3 & 9,6 & 137,4 & 8,1 & 6,0 & 3,6 \\
\hline 30 & 7 & A & $25-74$ & $50-100$ & 50 & 18,7 & 10,1 & 137,5 & 11,4 & 26,0 & 14,7 & 9,7 & 58,9 & 8,5 & 23,6 & 1,8 \\
\hline 30 & 7 & A & $75-125$ & $0-50$ & 0 & 4,0 & 2,8 & 155,4 & 3,8 & 6,6 & 5,0 & 6,4 & 143,1 & 6,2 & 5,7 & 3,6 \\
\hline 30 & 7 & A & $75-125$ & $0-50$ & 50 & 17,3 & 8,6 & 137,5 & 10,2 & 25,3 & 14,3 & 10,1 & 63,1 & 8,3 & 22,9 & 1,8 \\
\hline 30 & 7 & A & $75-125$ & $50-100$ & 0 & 3,8 & 2,2 & 155,3 & 3,8 & 6,5 & 4,8 & 7,5 & 143,4 & 6,1 & 6,0 & 3,7 \\
\hline 30 & 7 & A & $75-125$ & $50-100$ & 50 & 19,5 & 8,9 & 137,8 & 10,8 & 26,1 & 14,8 & 9,1 & 59,9 & 8,3 & 21,6 & 2,1 \\
\hline 30 & 7 & B & $25-74$ & $0-50$ & 0 & 2,3 & 2,0 & 245,3 & 3,7 & 5,2 & 4,6 & 10,0 & 229,5 & 9,4 & 4,8 & 4,2 \\
\hline 30 & 7 & B & $25-74$ & $0-50$ & 50 & 17,9 & 4,2 & 225,2 & 5,4 & 24,5 & 8,9 & 6,4 & 111,3 & 7,1 & 25,3 & 1,6 \\
\hline 30 & 7 & B & $25-74$ & $50-100$ & 0 & 1,8 & 1,5 & 245,0 & 3,6 & 5,1 & 4,9 & 10,2 & 230,8 & 9,1 & 5,1 & 4,6 \\
\hline 30 & 7 & B & $25-74$ & $50-100$ & 50 & 20,3 & 5,0 & 222,6 & 5,5 & 23,9 & 8,7 & 6,8 & 111,5 & 7,5 & 24,5 & 1,6 \\
\hline 30 & 7 & B & $75-125$ & $0-50$ & 0 & 1,7 & 1,5 & 250,6 & 2,7 & 3,8 & 3,3 & 6,4 & 240,5 & 6,3 & 3,5 & 3,1 \\
\hline 30 & 7 & B & $75-125$ & $0-50$ & 50 & 17,6 & 4,0 & 225,3 & 4,3 & 20,2 & 7,2 & 5,0 & 112,9 & 5,6 & 22,3 & 2,0 \\
\hline 30 & 7 & B & $75-125$ & $50-100$ & 0 & 1,3 & 1,1 & 247,6 & 2,8 & 3,7 & 3,3 & 6,9 & 237,4 & 6,3 & 3,7 & 3,3 \\
\hline 30 & 7 & B & $75-125$ & $50-100$ & 50 & 18,2 & 5,0 & 228,4 & 5,6 & 24,0 & 8,7 & 6,5 & 118,7 & 6,5 & 21,8 & 2,3 \\
\hline 30 & 7 & M & $25-74$ & $0-50$ & 0 & 3,5 & 2,3 & 140,3 & 3,2 & 5,4 & 4,7 & 7,9 & 129,7 & 6,7 & 5,1 & 3,7 \\
\hline 30 & 7 & $\mathbf{M}$ & $25-74$ & $0-50$ & 50 & 14,6 & 5,3 & 128,6 & 6,7 & 18,3 & 9,7 & 6,3 & 60,1 & 5,6 & 17,6 & 1,4 \\
\hline 30 & 7 & $\mathbf{M}$ & $25-74$ & $50-100$ & 0 & 3,1 & 2,1 & 140,0 & 2,9 & 4,6 & 3,5 & 8,1 & 130,7 & 6,5 & 6,3 & 4,6 \\
\hline 30 & 7 & $\mathbf{M}$ & $25-74$ & $50-100$ & 50 & 14,1 & 5,4 & 127,3 & 5,6 & 18,0 & 9,1 & 5,7 & 64,6 & 5,7 & 17,8 & 1,0 \\
\hline 30 & 7 & M & $75-125$ & $0-50$ & 0 & 3,0 & 2,3 & 140,5 & 2,3 & 4,6 & 3,7 & 5,7 & 133,0 & 4,7 & 4,3 & 2,7 \\
\hline 30 & 7 & $\mathbf{M}$ & $75-125$ & $0-50$ & 50 & 13,9 & 4,9 & 123,4 & 5,4 & 15,8 & 9,0 & 6,1 & 61,8 & 4,9 & 17,5 & 1,4 \\
\hline 30 & 7 & M & $75-125$ & $50-100$ & 0 & 2,7 & 2,1 & 140,3 & 2,5 & 4,5 & 3,9 & 5,7 & 131,9 & 5,1 & 4,3 & 3,0 \\
\hline 30 & 7 & $\mathbf{M}$ & $75-125$ & $50-100$ & 50 & 13,0 & 5,8 & 124,2 & 6,3 & 17,0 & 9,7 & 6,1 & 65,0 & 5,5 & 16,1 & 0,5 \\
\hline 100 & 7 & A & $25-74$ & $0-50$ & 0 & 2,2 & 1,5 & 229,7 & 2,0 & 3,6 & 2,8 & 5,8 & 218,6 & 5,6 & 2,9 & 2,0 \\
\hline 100 & 7 & A & $25-74$ & $0-50$ & 50 & 13,4 & 5,5 & 233,8 & 6,6 & 16,0 & 9,0 & 5,5 & 105,7 & 5,2 & 14,4 & 0,2 \\
\hline 100 & 7 & A & $25-74$ & $50-100$ & 0 & 2,0 & 1,6 & 224,1 & 2,4 & 3,8 & 3,1 & 6,6 & 215,9 & 5,3 & 2,9 & 1,8 \\
\hline 100 & 7 & A & $25-74$ & $50-100$ & 50 & 13,3 & 4,9 & 241,5 & 5,9 & 16,5 & 8,3 & 5,4 & 110,4 & 5,4 & 14,8 & 0,5 \\
\hline 100 & 7 & A & $75-125$ & $0-50$ & 0 & 1,6 & 1,1 & 226,7 & 1,9 & 3,1 & 2,5 & 4,9 & 220,1 & 3,3 & 2,3 & 1,8 \\
\hline 100 & 7 & A & $75-125$ & $0-50$ & 50 & 11,4 & 4,8 & 239,8 & 5,6 & 14,3 & 8,1 & 5,0 & 107,6 & 5,4 & 13,3 & 0,4 \\
\hline 100 & 7 & A & $75-125$ & $50-100$ & 0 & 1,6 & 1,0 & 231,2 & 1,4 & 2,9 & 2,1 & 3,9 & 223,3 & 3,5 & 2,5 & 1,8 \\
\hline 100 & 7 & A & $75-125$ & $50-100$ & 50 & 11,0 & 4,4 & 238,2 & 5,4 & 14,0 & 7,5 & 4,8 & 107,1 & 5,3 & 14,2 & 0,4 \\
\hline 100 & 7 & B & $25-74$ & $0-50$ & 0 & 0,9 & 0,8 & 317,1 & 4,2 & 2,6 & 2,5 & 9,1 & 308,2 & 9,4 & 2,7 & 2,5 \\
\hline 100 & 7 & B & $25-74$ & $0-50$ & 50 & 13,1 & 2,3 & 313,9 & 3,6 & 16,6 & 5,1 & 3,8 & 165,9 & 4,5 & 17,7 & 0,4 \\
\hline 100 & 7 & B & $25-74$ & $50-100$ & 0 & 0,9 & 0,7 & 313,8 & 3,8 & 2,7 & 2,6 & 9,8 & 304,5 & 7,4 & 2,5 & 2,4 \\
\hline 100 & 7 & B & $25-74$ & $50-100$ & 50 & 14,6 & 2,2 & 310,2 & 2,9 & 17,2 & 5,0 & 3,7 & 162,3 & 4,6 & 17,7 & 0,4 \\
\hline 100 & 7 & B & $75-125$ & $0-50$ & 0 & 0,6 & 0,5 & 319,1 & 2,6 & 1,9 & 1,8 & 7,3 & 312,8 & 5,6 & 1,8 & 1,8 \\
\hline 100 & 7 & B & $75-125$ & $0-50$ & 50 & 13,5 & 2,5 & 314,5 & 3,1 & 16,2 & 5,0 & 3,1 & 166,5 & 4,3 & 16,3 & 0,6 \\
\hline 100 & 7 & B & $75-125$ & $50-100$ & 0 & 0,7 & 0,6 & 321,7 & 3,0 & 1,9 & 1,8 & 6,7 & 314,6 & 6,2 & 1,9 & 1,8 \\
\hline 100 & 7 & B & $75-125$ & $50-100$ & 50 & 12,9 & 2,3 & 311,9 & 3,1 & 15,3 & 4,7 & 3,4 & 165,5 & 4,3 & 15,6 & 0,6 \\
\hline
\end{tabular}




\begin{tabular}{|c|c|c|c|c|c|c|c|c|c|c|c|c|c|c|c|c|}
\hline 100 & 7 & $\bar{M}$ & $25-74$ & $0-50$ & 0 & 1,6 & 1,3 & 179,7 & 1,4 & 2,4 & 2,1 & 4,9 & 174,1 & 5,5 & 2,2 & 2,0 \\
\hline 100 & 7 & M & $25-74$ & $0-50$ & 50 & 7,6 & 2,1 & 174,4 & 2,2 & 9,2 & 4,0 & 2,2 & 87,3 & 2,3 & 9,1 & 0,1 \\
\hline 100 & 7 & M & $25-74$ & $50-100$ & 0 & 1,4 & 1,1 & 176,4 & 1,6 & 2,2 & 1,9 & 5,7 & 171,3 & 5,1 & 2,3 & 2,0 \\
\hline 100 & 7 & M & $25-74$ & $50-100$ & 50 & 7,5 & 2,3 & 171,1 & 2,6 & 8,9 & 4,1 & 2,8 & 84,4 & 2,4 & 8,8 & 0,1 \\
\hline 100 & 7 & M & $75-125$ & $0-50$ & 0 & 1,1 & 0,8 & 181,5 & 1,2 & 1,8 & 1,5 & 3,8 & 178,9 & 3,9 & 1,8 & 1,5 \\
\hline 100 & 7 & M & $75-125$ & $0-50$ & 50 & 6,8 & 2,1 & 174,8 & 2,2 & 8,2 & 3,5 & 1,8 & 91,1 & 2,2 & 8,1 & 0,1 \\
\hline 100 & 7 & M & $75-125$ & $50-100$ & 0 & 1,1 & 0,8 & 177,0 & 1,5 & 1,7 & 1,4 & 3,7 & 171,9 & 2,5 & 1,9 & 1,4 \\
\hline 100 & 7 & M & $75-125$ & $50-100$ & 50 & 6,6 & 2,1 & 174,9 & 2,6 & 8,4 & 4,1 & 2,6 & 89,3 & 2,1 & 8,4 & 0,1 \\
\hline
\end{tabular}

TABELA D.10 - Desvio-padrão do relativo das regras para setup independente

\begin{tabular}{|c|c|c|c|c|c|c|c|c|c|c|c|c|c|c|c|c|}
\hline$n$ & $g$ & $f$ & $S$ & $a$ & $l$ & Ri1 & Ri2 & Ri3 & Ri4 & Ri5 & Ri6 & Ri7 & Ri8 & Ri9 & Ri10 & Ri11 \\
\hline 10 & 3 & A & $25-74$ & $0-50$ & 0 & 0,07 & 0,07 & 0,12 & 0,09 & 0,08 & 0,08 & 0,09 & 0,10 & 0,06 & 0,07 & 0,05 \\
\hline 10 & 3 & A & $25-74$ & $0-50$ & 50 & 0,13 & 0,13 & 0,19 & 0,16 & 0,14 & 0,16 & 0,15 & 0,11 & 0,09 & 0,14 & 0,05 \\
\hline 10 & 3 & A & $25-74$ & $50-100$ & 0 & 0,06 & 0,06 & 0,12 & 0,08 & 0,08 & 0,08 & 0,07 & 0,11 & 0,06 & 0,07 & 0,05 \\
\hline 10 & 3 & A & $25-74$ & $50-100$ & 50 & 0,15 & 0,15 & 0,21 & 0,18 & 0,17 & 0,18 & 0,16 & 0,12 & 0,11 & 0,14 & 0,06 \\
\hline 10 & 3 & A & $75-125$ & $0-50$ & 0 & 0,07 & 0,08 & 0,11 & 0,09 & 0,08 & 0,08 & 0,07 & 0,12 & 0,06 & 0,07 & 0,06 \\
\hline 10 & 3 & A & $75-125$ & $0-50$ & 50 & 0,12 & 0,13 & 0,22 & 0,17 & 0,18 & 0,18 & 0,13 & 0,11 & 0,09 & 0,16 & 0,07 \\
\hline 10 & 3 & A & $75-125$ & $50-100$ & 0 & 0,06 & 0,06 & 0,13 & 0,08 & 0,07 & 0,07 & 0,07 & 0,12 & 0,06 & 0,07 & 0,06 \\
\hline 10 & 3 & A & $75-125$ & $50-100$ & 50 & 0,12 & 0,12 & 0,19 & 0,15 & 0,16 & 0,17 & 0,13 & 0,13 & 0,11 & 0,14 & 0,07 \\
\hline 10 & 3 & B & $25-74$ & $0-50$ & 0 & 0,04 & 0,04 & 0,20 & 0,07 & 0,05 & 0,05 & 0,07 & 0,21 & 0,06 & 0,06 & 0,05 \\
\hline 10 & 3 & B & $25-74$ & $0-50$ & 50 & 0,09 & 0,09 & 0,27 & 0,11 & 0,13 & 0,12 & 0,10 & 0,20 & 0,07 & 0,13 & 0,04 \\
\hline 10 & 3 & B & $25-74$ & $50-100$ & 0 & 0,04 & 0,04 & 0,20 & 0,07 & 0,05 & 0,05 & 0,07 & 0,22 & 0,07 & 0,06 & 0,06 \\
\hline 10 & 3 & B & $25-74$ & $50-100$ & 50 & 0,09 & 0,07 & 0,29 & 0,11 & 0,13 & 0,12 & 0,09 & 0,19 & 0,07 & 0,16 & 0,03 \\
\hline 10 & 3 & B & $75-125$ & $0-50$ & 0 & 0,03 & 0,03 & 0,22 & 0,06 & 0,05 & 0,05 & 0,05 & 0,22 & 0,05 & 0,04 & 0,04 \\
\hline 10 & 3 & B & $75-125$ & $0-50$ & 50 & 0,09 & 0,08 & 0,24 & 0,11 & 0,14 & 0,11 & 0,09 & 0,18 & 0,06 & 0,13 & 0,02 \\
\hline 10 & 3 & B & $75-125$ & $50-100$ & 0 & 0,03 & 0,03 & 0,21 & 0,04 & 0,04 & 0,04 & 0,05 & 0,20 & 0,05 & 0,04 & 0,04 \\
\hline 10 & 3 & B & $75-125$ & $50-100$ & 50 & 0,09 & 0,07 & 0,27 & 0,10 & 0,13 & 0,10 & 0,08 & 0,18 & 0,06 & 0,12 & 0,04 \\
\hline 10 & 3 & M & $25-74$ & $0-50$ & 0 & 0,04 & 0,04 & 0,13 & 0,06 & 0,06 & 0,05 & 0,04 & 0,12 & 0,05 & 0,06 & 0,04 \\
\hline 10 & 3 & M & $25-74$ & $0-50$ & 50 & 0,10 & 0,09 & 0,19 & 0,13 & 0,14 & 0,13 & 0,10 & 0,13 & 0,07 & 0,15 & 0,05 \\
\hline 10 & 3 & M & $25-74$ & $50-100$ & 0 & 0,05 & 0,05 & 0,13 & 0,07 & 0,06 & 0,07 & 0,06 & 0,10 & 0,04 & 0,06 & 0,04 \\
\hline 10 & 3 & M & $25-74$ & $50-100$ & 50 & 0,10 & 0,09 & 0,21 & 0,16 & 0,16 & 0,15 & 0,13 & 0,12 & 0,06 & 0,14 & 0,04 \\
\hline 10 & 3 & M & $75-125$ & $0-50$ & 0 & 0,05 & 0,05 & 0,11 & 0,05 & 0,06 & 0,05 & 0,05 & 0,11 & 0,05 & 0,06 & 0,04 \\
\hline 10 & 3 & M & $75-125$ & $0-50$ & 50 & 0,09 & 0,08 & 0,21 & 0,12 & 0,14 & 0,13 & 0,11 & 0,11 & 0,07 & 0,13 & 0,05 \\
\hline 10 & 3 & M & $75-125$ & $50-100$ & 0 & 0,05 & 0,04 & 0,11 & 0,05 & 0,06 & 0,06 & 0,06 & 0,11 & 0,04 & 0,06 & 0,04 \\
\hline 10 & 3 & M & $75-125$ & $50-100$ & 50 & 0,11 & 0,10 & 0,22 & 0,12 & 0,13 & 0,13 & 0,09 & 0,11 & 0,06 & 0,12 & 0,04 \\
\hline 30 & 3 & A & $25-74$ & $0-50$ & 0 & 0,03 & 0,03 & 0,14 & 0,05 & 0,04 & 0,05 & 0,04 & 0,14 & 0,05 & 0,04 & 0,03 \\
\hline 30 & 3 & A & $25-74$ & $0-50$ & 50 & 0,09 & 0,09 & 0,20 & 0,13 & 0,13 & 0,13 & 0,09 & 0,13 & 0,06 & 0,11 & 0,03 \\
\hline 30 & 3 & A & $25-74$ & $50-100$ & 0 & 0,03 & 0,03 & 0,14 & 0,06 & 0,04 & 0,04 & 0,05 & 0,16 & 0,05 & 0,04 & 0,03 \\
\hline 30 & 3 & A & $25-74$ & $50-100$ & 50 & 0,10 & 0,11 & 0,24 & 0,13 & 0,15 & 0,14 & 0,10 & 0,11 & 0,06 & 0,11 & 0,02 \\
\hline 30 & 3 & A & $75-125$ & $0-50$ & 0 & 0,02 & 0,02 & 0,12 & 0,04 & 0,04 & 0,03 & 0,04 & 0,13 & 0,03 & 0,03 & 0,03 \\
\hline 30 & 3 & A & $75-125$ & $0-50$ & 50 & 0,10 & 0,10 & 0,22 & 0,12 & 0,13 & 0,13 & 0,09 & 0,12 & 0,06 & 0,10 & 0,02 \\
\hline 30 & 3 & A & $75-125$ & $50-100$ & 0 & 0,03 & 0,03 & 0,12 & 0,05 & 0,03 & 0,03 & 0,04 & 0,13 & 0,03 & 0,03 & 0,03 \\
\hline 30 & 3 & A & $75-125$ & $50-100$ & 50 & 0,09 & 0,09 & 0,23 & 0,10 & 0,11 & 0,12 & 0,09 & 0,14 & 0,06 & 0,11 & 0,03 \\
\hline 30 & 3 & B & $25-74$ & $0-50$ & 0 & 0,02 & 0,02 & 0,22 & 0,06 & 0,03 & 0,03 & 0,05 & 0,25 & 0,05 & 0,03 & 0,02 \\
\hline 30 & 3 & B & $25-74$ & $0-50$ & 50 & 0,05 & 0,03 & 0,20 & 0,05 & 0,09 & 0,05 & 0,04 & 0,20 & 0,03 & 0,08 & 0,01 \\
\hline 30 & 3 & B & $25-74$ & $50-100$ & 0 & 0,02 & 0,02 & 0,24 & 0,06 & 0,03 & 0,03 & 0,05 & 0,28 & 0,06 & 0,03 & 0,03 \\
\hline 30 & 3 & B & $25-74$ & $50-100$ & 50 & 0,04 & 0,03 & 0,18 & 0,06 & 0,07 & 0,05 & 0,05 & 0,22 & 0,03 & 0,08 & 0,00 \\
\hline 30 & 3 & B & $75-125$ & $0-50$ & 0 & 0,02 & 0,02 & 0,24 & 0,04 & 0,02 & 0,02 & 0,03 & 0,25 & 0,04 & 0,02 & 0,02 \\
\hline 30 & 3 & B & $75-125$ & $0-50$ & 50 & 0,05 & 0,02 & 0,21 & 0,05 & 0,07 & 0,05 & 0,04 & 0,24 & 0,03 & 0,07 & 0,01 \\
\hline 30 & 3 & B & $75-125$ & $50-100$ & 0 & 0,02 & 0,02 & 0,23 & 0,04 & 0,02 & 0,02 & 0,04 & 0,27 & 0,04 & 0,02 & 0,02 \\
\hline 30 & 3 & B & $75-125$ & $50-100$ & 50 & 0,06 & 0,03 & 0,19 & 0,05 & 0,06 & 0,04 & 0,03 & 0,23 & 0,02 & 0,07 & 0,00 \\
\hline 30 & 3 & M & $25-74$ & $0-50$ & 0 & 0,02 & 0,02 & 0,12 & 0,02 & 0,02 & 0,02 & 0,02 & 0,12 & 0,02 & 0,02 & 0,02 \\
\hline 30 & 3 & M & $25-74$ & $0-50$ & 50 & 0,04 & 0,03 & 0,18 & 0,06 & 0,06 & 0,06 & 0,04 & 0,10 & 0,03 & 0,06 & 0,01 \\
\hline 30 & 3 & M & $25-74$ & $50-100$ & 0 & 0,02 & 0,02 & 0,11 & 0,02 & 0,02 & 0,02 & 0,02 & 0,10 & 0,02 & 0,03 & 0,02 \\
\hline 30 & 3 & M & $25-74$ & $50-100$ & 50 & 0,04 & 0,04 & 0,18 & 0,06 & 0,07 & 0,06 & 0,04 & 0,10 & 0,03 & 0,06 & 0,00 \\
\hline 30 & 3 & M & $75-125$ & $0-50$ & 0 & 0,02 & 0,02 & 0,11 & 0,02 & 0,02 & 0,02 & 0,02 & 0,10 & 0,02 & 0,02 & 0,02 \\
\hline 30 & 3 & M & $75-125$ & $0-50$ & 50 & 0,04 & 0,04 & 0,17 & 0,06 & 0,05 & 0,05 & 0,03 & 0,10 & 0,03 & 0,05 & 0,01 \\
\hline 30 & 3 & M & $75-125$ & $50-100$ & 0 & 0,02 & 0,02 & 0,11 & 0,02 & 0,02 & 0,02 & 0,02 & 0,12 & 0,02 & 0,02 & 0,02 \\
\hline
\end{tabular}




\begin{tabular}{|c|c|c|c|c|c|c|c|c|c|c|c|c|c|c|c|c|}
\hline 30 & 3 & $\bar{M}$ & $75-125$ & $50-100$ & 50 & 0,04 & 0,03 & 0,20 & 0,05 & 0,06 & 0,05 & 0,03 & 0,09 & 0,03 & 0,05 & 0,00 \\
\hline 100 & 3 & A & $25-74$ & $0-50$ & 0 & 0,01 & 0,01 & 0,16 & 0,05 & 0,02 & 0,02 & 0,05 & 0,16 & 0,04 & 0,02 & 0,01 \\
\hline 100 & 3 & A & $25-74$ & $0-50$ & 50 & 0,04 & 0,04 & 0,25 & 0,05 & 0,06 & 0,05 & 0,03 & 0,16 & 0,03 & 0,05 & 0,00 \\
\hline 100 & 3 & A & $25-74$ & $50-100$ & 0 & 0,01 & 0,01 & 0,16 & 0,04 & 0,02 & 0,02 & 0,04 & 0,15 & 0,04 & 0,02 & 0,02 \\
\hline 100 & 3 & A & $25-74$ & $50-100$ & 50 & 0,04 & 0,03 & 0,23 & 0,05 & 0,05 & 0,05 & 0,03 & 0,19 & 0,03 & 0,05 & 0,00 \\
\hline 100 & 3 & A & $75-125$ & $0-50$ & 0 & 0,01 & 0,01 & 0,16 & 0,03 & 0,01 & 0,01 & 0,03 & 0,15 & 0,03 & 0,01 & 0,01 \\
\hline 100 & 3 & A & $75-125$ & $0-50$ & 50 & 0,03 & 0,03 & 0,23 & 0,04 & 0,05 & 0,04 & 0,03 & 0,17 & 0,02 & 0,04 & 0,00 \\
\hline 100 & 3 & A & $75-125$ & $50-100$ & 0 & 0,01 & 0,01 & 0,15 & 0,03 & 0,02 & 0,02 & 0,03 & 0,16 & 0,03 & 0,01 & 0,01 \\
\hline 100 & 3 & A & $75-125$ & $50-100$ & 50 & 0,04 & 0,03 & 0,24 & 0,05 & 0,06 & 0,05 & 0,03 & 0,14 & 0,02 & 0,04 & 0,00 \\
\hline 100 & 3 & B & $25-74$ & $0-50$ & 0 & 0,01 & 0,01 & 0,24 & 0,05 & 0,01 & 0,01 & 0,05 & 0,28 & 0,05 & 0,01 & 0,02 \\
\hline 100 & 3 & B & $25-74$ & $0-50$ & 50 & 0,03 & 0,01 & 0,14 & 0,04 & 0,05 & 0,02 & 0,02 & 0,23 & 0,01 & 0,04 & 0,00 \\
\hline 100 & 3 & B & $25-74$ & $50-100$ & 0 & 0,01 & 0,01 & 0,26 & 0,06 & 0,01 & 0,01 & 0,05 & 0,30 & 0,06 & 0,01 & 0,01 \\
\hline 100 & 3 & B & $25-74$ & $50-100$ & 50 & 0,03 & 0,01 & 0,15 & 0,03 & 0,04 & 0,02 & 0,02 & 0,26 & 0,01 & 0,05 & 0,00 \\
\hline 100 & 3 & B & $75-125$ & $0-50$ & 0 & 0,01 & 0,01 & 0,26 & 0,04 & 0,01 & 0,01 & 0,04 & 0,29 & 0,04 & 0,01 & 0,01 \\
\hline 100 & 3 & B & $75-125$ & $0-50$ & 50 & 0,03 & 0,01 & 0,16 & 0,03 & 0,04 & 0,02 & 0,01 & 0,24 & 0,01 & 0,04 & 0,00 \\
\hline 100 & 3 & B & $75-125$ & $50-100$ & 0 & 0,01 & 0,01 & 0,28 & 0,04 & 0,01 & 0,01 & 0,04 & 0,32 & 0,04 & 0,01 & 0,01 \\
\hline 100 & 3 & B & $75-125$ & $50-100$ & 50 & 0,03 & 0,01 & 0,15 & 0,02 & 0,05 & 0,02 & 0,01 & 0,24 & 0,01 & 0,04 & 0,00 \\
\hline 100 & 3 & M & $25-74$ & $0-50$ & 0 & 0,00 & 0,00 & 0,10 & 0,01 & 0,01 & 0,01 & 0,00 & 0,11 & 0,01 & 0,01 & 0,01 \\
\hline 100 & 3 & M & $25-74$ & $0-50$ & 50 & 0,01 & 0,01 & 0,17 & 0,02 & 0,02 & 0,02 & 0,01 & 0,12 & 0,01 & 0,02 & 0,00 \\
\hline 100 & 3 & M & $25-74$ & $50-100$ & 0 & 0,01 & 0,00 & 0,11 & 0,01 & 0,01 & 0,01 & 0,01 & 0,11 & 0,01 & 0,01 & 0,01 \\
\hline 100 & 3 & $\mathbf{M}$ & $25-74$ & $50-100$ & 50 & 0,01 & 0,01 & 0,14 & 0,02 & 0,02 & 0,02 & 0,01 & 0,10 & 0,01 & 0,02 & 0,00 \\
\hline 100 & 3 & $\mathbf{M}$ & $75-125$ & $0-50$ & 0 & 0,00 & 0,00 & 0,11 & 0,01 & 0,01 & 0,01 & 0,01 & 0,12 & 0,00 & 0,01 & 0,01 \\
\hline 100 & 3 & M & $75-125$ & $0-50$ & 50 & 0,01 & 0,01 & 0,18 & 0,01 & 0,02 & 0,02 & 0,01 & 0,13 & 0,01 & 0,01 & 0,00 \\
\hline 100 & 3 & M & $75-125$ & $50-100$ & 0 & 0,01 & 0,01 & 0,10 & 0,01 & 0,01 & 0,01 & 0,01 & 0,11 & 0,01 & 0,01 & 0,01 \\
\hline 100 & 3 & $\mathbf{M}$ & $75-125$ & $50-100$ & 50 & 0,01 & 0,01 & 0,14 & 0,01 & 0,02 & 0,02 & 0,01 & 0,10 & 0,01 & 0,02 & 0,00 \\
\hline 10 & 5 & A & $25-74$ & $0-50$ & 0 & 0,06 & 0,06 & 0,17 & 0,09 & 0,08 & 0,08 & 0,08 & 0,16 & 0,07 & 0,08 & 0,05 \\
\hline 10 & 5 & A & $25-74$ & $0-50$ & 50 & 0,12 & 0,11 & 0,25 & 0,14 & 0,16 & 0,14 & 0,12 & 0,13 & 0,09 & 0,13 & 0,07 \\
\hline 10 & 5 & A & $25-74$ & $50-100$ & 0 & 0,06 & 0,06 & 0,16 & 0,07 & 0,08 & 0,07 & 0,08 & 0,15 & 0,06 & 0,07 & 0,05 \\
\hline 10 & 5 & A & $25-74$ & $50-100$ & 50 & 0,14 & 0,12 & 0,26 & 0,13 & 0,15 & 0,14 & 0,12 & 0,13 & 0,10 & 0,15 & 0,09 \\
\hline 10 & 5 & A & $75-125$ & $0-50$ & 0 & 0,06 & 0,06 & 0,16 & 0,05 & 0,07 & 0,06 & 0,07 & 0,13 & 0,07 & 0,07 & 0,05 \\
\hline 10 & 5 & A & $75-125$ & $0-50$ & 50 & 0,12 & 0,12 & 0,24 & 0,13 & 0,16 & 0,15 & 0,10 & 0,14 & 0,10 & 0,14 & 0,06 \\
\hline 10 & 5 & A & $75-125$ & $50-100$ & 0 & 0,07 & 0,06 & 0,14 & 0,07 & 0,08 & 0,08 & 0,07 & 0,15 & 0,06 & 0,08 & 0,06 \\
\hline 10 & 5 & A & $75-125$ & $50-100$ & 50 & 0,12 & 0,12 & 0,22 & 0,16 & 0,16 & 0,15 & 0,15 & 0,13 & 0,08 & 0,15 & 0,06 \\
\hline 10 & 5 & B & $25-74$ & $0-50$ & 0 & 0,04 & 0,04 & 0,22 & 0,05 & 0,05 & 0,05 & 0,07 & 0,25 & 0,07 & 0,07 & 0,06 \\
\hline 10 & 5 & B & $25-74$ & $0-50$ & 50 & 0,12 & 0,09 & 0,34 & 0,12 & 0,16 & 0,13 & 0,12 & 0,23 & 0,09 & 0,18 & 0,05 \\
\hline 10 & 5 & B & $25-74$ & $50-100$ & 0 & 0,04 & 0,04 & 0,24 & 0,05 & 0,06 & 0,05 & 0,07 & 0,24 & 0,06 & 0,05 & 0,05 \\
\hline 10 & 5 & B & $25-74$ & $50-100$ & 50 & 0,13 & 0,10 & 0,38 & 0,11 & 0,19 & 0,13 & 0,10 & 0,24 & 0,11 & 0,17 & 0,05 \\
\hline 10 & 5 & B & $75-125$ & $0-50$ & 0 & 0,04 & 0,03 & 0,20 & 0,05 & 0,06 & 0,06 & 0,06 & 0,24 & 0,06 & 0,05 & 0,05 \\
\hline 10 & 5 & B & $75-125$ & $0-50$ & 50 & 0,11 & 0,09 & 0,35 & 0,11 & 0,20 & 0,13 & 0,10 & 0,22 & 0,08 & 0,17 & 0,04 \\
\hline 10 & 5 & B & $75-125$ & $50-100$ & 0 & 0,04 & 0,04 & 0,23 & 0,05 & 0,05 & 0,05 & 0,06 & 0,22 & 0,05 & 0,05 & 0,04 \\
\hline 10 & 5 & B & $75-125$ & $50-100$ & 50 & 0,12 & 0,08 & 0,35 & 0,11 & 0,18 & 0,12 & 0,09 & 0,24 & 0,09 & 0,17 & 0,04 \\
\hline 10 & 5 & M & $25-74$ & $0-50$ & 0 & 0,05 & 0,04 & 0,19 & 0,06 & 0,06 & 0,06 & 0,07 & 0,17 & 0,06 & 0,07 & 0,06 \\
\hline 10 & 5 & $\mathbf{M}$ & $25-74$ & $0-50$ & 50 & 0,11 & 0,09 & 0,33 & 0,12 & 0,19 & 0,14 & 0,13 & 0,21 & 0,09 & 0,17 & 0,08 \\
\hline 10 & 5 & $\mathbf{M}$ & $25-74$ & $50-100$ & 0 & 0,05 & 0,04 & 0,18 & 0,05 & 0,06 & 0,06 & 0,07 & 0,18 & 0,07 & 0,07 & 0,06 \\
\hline 10 & 5 & M & $25-74$ & $50-100$ & 50 & 0,14 & 0,11 & 0,32 & 0,12 & 0,18 & 0,14 & 0,11 & 0,23 & 0,09 & 0,15 & 0,05 \\
\hline 10 & 5 & M & $75-125$ & $0-50$ & 0 & 0,05 & 0,04 & 0,17 & 0,05 & 0,05 & 0,05 & 0,06 & 0,21 & 0,06 & 0,06 & 0,05 \\
\hline 10 & 5 & $\mathbf{M}$ & $75-125$ & $0-50$ & 50 & 0,11 & 0,09 & 0,26 & 0,11 & 0,17 & 0,12 & 0,10 & 0,19 & 0,08 & 0,16 & 0,06 \\
\hline 10 & 5 & M & $75-125$ & $50-100$ & 0 & 0,04 & 0,04 & 0,18 & 0,05 & 0,05 & 0,05 & 0,06 & 0,21 & 0,05 & 0,06 & 0,05 \\
\hline 10 & 5 & M & $75-125$ & $50-100$ & 50 & 0,12 & 0,10 & 0,29 & 0,12 & 0,15 & 0,12 & 0,11 & 0,19 & 0,08 & 0,17 & 0,06 \\
\hline 30 & 5 & A & $25-74$ & $0-50$ & 0 & 0,03 & 0,03 & 0,18 & 0,05 & 0,04 & 0,05 & 0,05 & 0,18 & 0,04 & 0,04 & 0,03 \\
\hline 30 & 5 & A & $25-74$ & $0-50$ & 50 & 0,09 & 0,10 & 0,32 & 0,12 & 0,15 & 0,13 & 0,11 & 0,18 & 0,09 & 0,14 & 0,03 \\
\hline 30 & 5 & A & $25-74$ & $50-100$ & 0 & 0,04 & 0,04 & 0,19 & 0,05 & 0,05 & 0,05 & 0,04 & 0,17 & 0,04 & 0,05 & 0,04 \\
\hline 30 & 5 & A & $25-74$ & $50-100$ & 50 & 0,09 & 0,10 & 0,33 & 0,14 & 0,13 & 0,13 & 0,11 & 0,19 & 0,08 & 0,14 & 0,03 \\
\hline 30 & 5 & A & $75-125$ & $0-50$ & 0 & 0,03 & 0,03 & 0,19 & 0,04 & 0,04 & 0,04 & 0,03 & 0,19 & 0,04 & 0,04 & 0,03 \\
\hline 30 & 5 & A & $75-125$ & $0-50$ & 50 & 0,08 & 0,09 & 0,29 & 0,12 & 0,11 & 0,11 & 0,08 & 0,18 & 0,08 & 0,12 & 0,04 \\
\hline 30 & 5 & A & $75-125$ & $50-100$ & 0 & 0,03 & 0,03 & 0,20 & 0,04 & 0,04 & 0,04 & 0,04 & 0,21 & 0,04 & 0,04 & 0,04 \\
\hline 30 & 5 & A & $75-125$ & $50-100$ & 50 & 0,10 & 0,10 & 0,30 & 0,12 & 0,13 & 0,13 & 0,10 & 0,18 & 0,09 & 0,12 & 0,02 \\
\hline 30 & 5 & B & $25-74$ & $0-50$ & 0 & 0,02 & 0,02 & 0,22 & 0,05 & 0,03 & 0,03 & 0,05 & 0,27 & 0,05 & 0,04 & 0,04 \\
\hline 30 & 5 & B & $25-74$ & $0-50$ & 50 & 0,09 & 0,05 & 0,29 & 0,07 & 0,10 & 0,07 & 0,05 & 0,26 & 0,05 & 0,11 & 0,02 \\
\hline 30 & 5 & B & $25-74$ & $50-100$ & 0 & 0,03 & 0,03 & 0,27 & 0,04 & 0,03 & 0,03 & 0,05 & 0,26 & 0,05 & 0,03 & 0,03 \\
\hline 30 & 5 & B & $25-74$ & $50-100$ & 50 & 0,08 & 0,05 & 0,26 & 0,07 & 0,09 & 0,08 & 0,07 & 0,24 & 0,05 & 0,11 & 0,02 \\
\hline 30 & 5 & B & $75-125$ & $0-50$ & 0 & 0,02 & 0,02 & 0,26 & 0,03 & 0,02 & 0,02 & 0,04 & 0,26 & 0,04 & 0,03 & 0,03 \\
\hline
\end{tabular}




\begin{tabular}{|c|c|c|c|c|c|c|c|c|c|c|c|c|c|c|c|c|}
\hline 30 & 5 & B & $75-125$ & $0-50$ & 50 & 0,08 & 0,04 & 0,27 & 0,06 & 0,09 & 0,06 & 0,05 & 0,27 & 0,04 & 0,10 & 0,02 \\
\hline 30 & 5 & B & $75-125$ & $50-100$ & 0 & 0,02 & 0,02 & 0,26 & 0,03 & 0,03 & 0,02 & 0,04 & 0,25 & 0,03 & 0,03 & 0,03 \\
\hline 30 & 5 & B & $75-125$ & $50-100$ & 50 & 0,08 & 0,04 & 0,28 & 0,06 & 0,10 & 0,06 & 0,04 & 0,23 & 0,05 & 0,11 & 0,01 \\
\hline 30 & 5 & M & $25-74$ & $0-50$ & 0 & 0,03 & 0,03 & 0,21 & 0,04 & 0,03 & 0,03 & 0,05 & 0,24 & 0,05 & 0,03 & 0,03 \\
\hline 30 & 5 & M & $25-74$ & $0-50$ & 50 & 0,08 & 0,05 & 0,28 & 0,07 & 0,11 & 0,08 & 0,06 & 0,24 & 0,05 & 0,09 & 0,01 \\
\hline 30 & 5 & M & $25-74$ & $50-100$ & 0 & 0,03 & 0,02 & 0,19 & 0,05 & 0,03 & 0,03 & 0,05 & 0,20 & 0,05 & 0,03 & 0,03 \\
\hline 30 & 5 & M & $25-74$ & $50-100$ & 50 & 0,06 & 0,04 & 0,25 & 0,06 & 0,11 & 0,07 & 0,06 & 0,24 & 0,05 & 0,11 & 0,02 \\
\hline 30 & 5 & M & $75-125$ & $0-50$ & 0 & 0,02 & 0,02 & 0,22 & 0,04 & 0,03 & 0,03 & 0,04 & 0,24 & 0,04 & 0,03 & 0,02 \\
\hline 30 & 5 & M & $75-125$ & $0-50$ & 50 & 0,07 & 0,04 & 0,25 & 0,07 & 0,10 & 0,07 & 0,05 & 0,22 & 0,04 & 0,09 & 0,02 \\
\hline 30 & 5 & M & $75-125$ & $50-100$ & 0 & 0,02 & 0,02 & 0,20 & 0,04 & 0,03 & 0,03 & 0,04 & 0,20 & 0,04 & 0,03 & 0,02 \\
\hline 30 & 5 & M & $75-125$ & $50-100$ & 50 & 0,09 & 0,05 & 0,28 & 0,07 & 0,08 & 0,07 & 0,05 & 0,23 & 0,05 & 0,10 & 0,02 \\
\hline 100 & 5 & A & $25-74$ & $0-50$ & 0 & 0,01 & 0,01 & 0,28 & 0,04 & 0,02 & 0,02 & 0,05 & 0,28 & 0,04 & 0,02 & 0,02 \\
\hline 100 & 5 & A & $25-74$ & $0-50$ & 50 & 0,05 & 0,04 & 0,32 & 0,06 & 0,07 & 0,06 & 0,05 & 0,22 & 0,03 & 0,07 & 0,01 \\
\hline 100 & 5 & A & $25-74$ & $50-100$ & 0 & 0,01 & 0,01 & 0,26 & 0,04 & 0,02 & 0,02 & 0,04 & 0,25 & 0,04 & 0,02 & 0,02 \\
\hline 100 & 5 & A & $25-74$ & $50-100$ & 50 & 0,06 & 0,04 & 0,31 & 0,06 & 0,06 & 0,06 & 0,05 & 0,22 & 0,04 & 0,07 & 0,00 \\
\hline 100 & 5 & A & $75-125$ & $0-50$ & 0 & 0,01 & 0,01 & 0,27 & 0,02 & 0,01 & 0,02 & 0,03 & 0,27 & 0,03 & 0,01 & 0,01 \\
\hline 100 & 5 & A & $75-125$ & $0-50$ & 50 & 0,05 & 0,04 & 0,32 & 0,05 & 0,07 & 0,05 & 0,04 & 0,21 & 0,03 & 0,07 & 0,01 \\
\hline 100 & 5 & A & $75-125$ & $50-100$ & 0 & 0,01 & 0,01 & 0,30 & 0,02 & 0,02 & 0,02 & 0,03 & 0,30 & 0,03 & 0,01 & 0,01 \\
\hline 100 & 5 & A & $75-125$ & $50-100$ & 50 & 0,04 & 0,03 & 0,33 & 0,04 & 0,06 & 0,05 & 0,04 & 0,23 & 0,03 & 0,07 & 0,01 \\
\hline 100 & 5 & B & $25-74$ & $0-50$ & 0 & 0,02 & 0,02 & 0,23 & 0,05 & 0,02 & 0,02 & 0,05 & 0,27 & 0,05 & 0,02 & 0,02 \\
\hline 100 & 5 & B & $25-74$ & $0-50$ & 50 & 0,06 & 0,02 & 0,22 & 0,04 & 0,05 & 0,03 & 0,03 & 0,24 & 0,03 & 0,06 & 0,00 \\
\hline 100 & 5 & B & $25-74$ & $50-100$ & 0 & 0,02 & 0,02 & 0,24 & 0,05 & 0,02 & 0,01 & 0,05 & 0,30 & 0,05 & 0,02 & 0,02 \\
\hline 100 & 5 & B & $25-74$ & $50-100$ & 50 & 0,05 & 0,02 & 0,19 & 0,03 & 0,06 & 0,03 & 0,02 & 0,21 & 0,02 & 0,05 & 0,01 \\
\hline 100 & 5 & B & $75-125$ & $0-50$ & 0 & 0,01 & 0,01 & 0,28 & 0,03 & 0,01 & 0,01 & 0,04 & 0,32 & 0,04 & 0,01 & 0,01 \\
\hline 100 & 5 & B & $75-125$ & $0-50$ & 50 & 0,06 & 0,02 & 0,19 & 0,03 & 0,05 & 0,02 & 0,02 & 0,22 & 0,02 & 0,06 & 0,00 \\
\hline 100 & 5 & B & $75-125$ & $50-100$ & 0 & 0,01 & 0,01 & 0,27 & 0,03 & 0,01 & 0,01 & 0,03 & 0,30 & 0,03 & 0,01 & 0,01 \\
\hline 100 & 5 & B & $75-125$ & $50-100$ & 50 & 0,05 & 0,02 & 0,22 & 0,03 & 0,05 & 0,02 & 0,02 & 0,26 & 0,03 & 0,05 & 0,00 \\
\hline 100 & 5 & M & $25-74$ & $0-50$ & 0 & 0,01 & 0,01 & 0,24 & 0,04 & 0,02 & 0,02 & 0,06 & 0,29 & 0,05 & 0,02 & 0,02 \\
\hline 100 & 5 & M & $25-74$ & $0-50$ & 50 & 0,04 & 0,02 & 0,20 & 0,02 & 0,05 & 0,03 & 0,02 & 0,22 & 0,02 & 0,05 & 0,00 \\
\hline 100 & 5 & M & $25-74$ & $50-100$ & 0 & 0,01 & 0,01 & 0,23 & 0,03 & 0,01 & 0,01 & 0,05 & 0,26 & 0,05 & 0,01 & 0,01 \\
\hline 100 & 5 & M & $25-74$ & $50-100$ & 50 & 0,05 & 0,02 & 0,20 & 0,03 & 0,05 & 0,03 & 0,02 & 0,24 & 0,02 & 0,05 & 0,00 \\
\hline 100 & 5 & M & $75-125$ & $0-50$ & 0 & 0,01 & 0,01 & 0,23 & 0,03 & 0,01 & 0,01 & 0,04 & 0,24 & 0,04 & 0,01 & 0,01 \\
\hline 100 & 5 & M & $75-125$ & $0-50$ & 50 & 0,05 & 0,02 & 0,22 & 0,02 & 0,06 & 0,02 & 0,02 & 0,23 & 0,01 & 0,04 & 0,00 \\
\hline 100 & 5 & M & $75-125$ & $50-100$ & 0 & 0,01 & 0,01 & 0,23 & 0,02 & 0,01 & 0,01 & 0,04 & 0,24 & 0,04 & 0,01 & 0,01 \\
\hline 100 & 5 & M & $75-125$ & $50-100$ & 50 & 0,03 & 0,02 & 0,19 & 0,02 & 0,06 & 0,03 & 0,02 & 0,23 & 0,01 & 0,04 & 0,00 \\
\hline 10 & 7 & A & $25-74$ & $0-50$ & 0 & 0,07 & 0,06 & 0,18 & 0,06 & 0,07 & 0,07 & 0,08 & 0,18 & 0,07 & 0,08 & 0,07 \\
\hline 10 & 7 & A & $25-74$ & $0-50$ & 50 & 0,11 & 0,11 & 0,23 & 0,11 & 0,15 & 0,13 & 0,11 & 0,14 & 0,10 & 0,12 & 0,06 \\
\hline 10 & 7 & A & $25-74$ & $50-100$ & 0 & 0,05 & 0,05 & 0,18 & 0,06 & 0,06 & 0,06 & 0,07 & 0,16 & 0,07 & 0,07 & 0,06 \\
\hline 10 & 7 & A & $25-74$ & $50-100$ & 50 & 0,10 & 0,08 & 0,24 & 0,10 & 0,15 & 0,12 & 0,11 & 0,14 & 0,09 & 0,13 & 0,06 \\
\hline 10 & 7 & A & $75-125$ & $0-50$ & 0 & 0,06 & 0,06 & 0,18 & 0,07 & 0,07 & 0,08 & 0,07 & 0,19 & 0,06 & 0,06 & 0,05 \\
\hline 10 & 7 & A & $75-125$ & $0-50$ & 50 & 0,11 & 0,10 & 0,25 & 0,13 & 0,14 & 0,14 & 0,11 & 0,15 & 0,10 & 0,14 & 0,05 \\
\hline 10 & 7 & A & $75-125$ & $50-100$ & 0 & 0,05 & 0,04 & 0,20 & 0,06 & 0,06 & 0,06 & 0,07 & 0,18 & 0,05 & 0,06 & 0,04 \\
\hline 10 & 7 & A & $75-125$ & $50-100$ & 50 & 0,10 & 0,07 & 0,22 & 0,09 & 0,14 & 0,12 & 0,10 & 0,13 & 0,08 & 0,13 & 0,06 \\
\hline 10 & 7 & B & $25-74$ & $0-50$ & 0 & 0,04 & 0,04 & 0,26 & 0,05 & 0,05 & 0,05 & 0,06 & 0,23 & 0,06 & 0,06 & 0,06 \\
\hline 10 & 7 & B & $25-74$ & $0-50$ & 50 & 0,13 & 0,08 & 0,42 & 0,09 & 0,18 & 0,13 & 0,11 & 0,26 & 0,10 & 0,20 & 0,05 \\
\hline 10 & 7 & B & $25-74$ & $50-100$ & 0 & 0,04 & 0,04 & 0,21 & 0,05 & 0,05 & 0,05 & 0,06 & 0,23 & 0,06 & 0,05 & 0,05 \\
\hline 10 & 7 & B & $25-74$ & $50-100$ & 50 & 0,14 & 0,10 & 0,37 & 0,09 & 0,16 & 0,12 & 0,10 & 0,27 & 0,09 & 0,19 & 0,05 \\
\hline 10 & 7 & B & $75-125$ & $0-50$ & 0 & 0,04 & 0,04 & 0,27 & 0,03 & 0,05 & 0,04 & 0,05 & 0,27 & 0,06 & 0,05 & 0,04 \\
\hline 10 & 7 & B & $75-125$ & $0-50$ & 50 & 0,13 & 0,09 & 0,38 & 0,10 & 0,16 & 0,11 & 0,08 & 0,27 & 0,09 & 0,16 & 0,04 \\
\hline 10 & 7 & B & $75-125$ & $50-100$ & 0 & 0,03 & 0,04 & 0,23 & 0,03 & 0,05 & 0,04 & 0,05 & 0,25 & 0,06 & 0,05 & 0,04 \\
\hline 10 & 7 & B & $75-125$ & $50-100$ & 50 & 0,13 & 0,06 & 0,38 & 0,10 & 0,16 & 0,12 & 0,09 & 0,27 & 0,08 & 0,20 & 0,04 \\
\hline 10 & 7 & M & $25-74$ & $0-50$ & 0 & 0,05 & 0,04 & 0,21 & 0,07 & 0,07 & 0,07 & 0,08 & 0,20 & 0,07 & 0,07 & 0,07 \\
\hline 10 & 7 & M & $25-74$ & $0-50$ & 50 & 0,13 & 0,10 & 0,28 & 0,13 & 0,16 & 0,14 & 0,12 & 0,18 & 0,10 & 0,19 & 0,07 \\
\hline 10 & 7 & M & $25-74$ & $50-100$ & 0 & 0,05 & 0,04 & 0,19 & 0,06 & 0,07 & 0,06 & 0,06 & 0,19 & 0,06 & 0,08 & 0,06 \\
\hline 10 & 7 & M & $25-74$ & $50-100$ & 50 & 0,16 & 0,10 & 0,29 & 0,10 & 0,19 & 0,13 & 0,10 & 0,21 & 0,09 & 0,19 & 0,06 \\
\hline 10 & 7 & M & $75-125$ & $0-50$ & 0 & 0,06 & 0,05 & 0,21 & 0,05 & 0,06 & 0,05 & 0,05 & 0,19 & 0,06 & 0,06 & 0,05 \\
\hline 10 & 7 & M & $75-125$ & $0-50$ & 50 & 0,14 & 0,10 & 0,26 & 0,09 & 0,15 & 0,13 & 0,09 & 0,19 & 0,10 & 0,14 & 0,06 \\
\hline 10 & 7 & M & $75-125$ & $50-100$ & 0 & 0,06 & 0,05 & 0,19 & 0,05 & 0,06 & 0,06 & 0,05 & 0,21 & 0,06 & 0,06 & 0,05 \\
\hline 10 & 7 & M & $75-125$ & $50-100$ & 50 & 0,13 & 0,11 & 0,28 & 0,11 & 0,15 & 0,13 & 0,10 & 0,20 & 0,10 & 0,15 & 0,06 \\
\hline 30 & 7 & A & $25-74$ & $0-50$ & 0 & 0,03 & 0,03 & 0,26 & 0,04 & 0,04 & 0,05 & 0,05 & 0,25 & 0,04 & 0,04 & 0,04 \\
\hline 30 & 7 & A & $25-74$ & $0-50$ & 50 & 0,10 & 0,10 & 0,37 & 0,11 & 0,14 & 0,13 & 0,08 & 0,20 & 0,08 & 0,12 & 0,04 \\
\hline 30 & 7 & A & $25-74$ & $50-100$ & 0 & 0,03 & 0,03 & 0,24 & 0,04 & 0,05 & 0,04 & 0,04 & 0,25 & 0,04 & 0,04 & 0,03 \\
\hline
\end{tabular}




\begin{tabular}{|c|c|c|c|c|c|c|c|c|c|c|c|c|c|c|c|c|}
\hline 30 & 7 & A & $25-74$ & $50-100$ & 50 & 0,09 & 0,09 & 0,35 & 0,11 & 0,13 & 0,13 & 0,10 & 0,19 & 0,08 & 0,11 & 0,03 \\
\hline 30 & 7 & A & $75-125$ & $0-50$ & 0 & 0,03 & 0,03 & 0,25 & 0,04 & 0,03 & 0,04 & 0,04 & 0,25 & 0,04 & 0,04 & 0,03 \\
\hline 30 & 7 & A & $75-125$ & $0-50$ & 50 & 0,08 & 0,08 & 0,36 & 0,11 & 0,13 & 0,12 & 0,09 & 0,22 & 0,07 & 0,12 & 0,03 \\
\hline 30 & 7 & A & $75-125$ & $50-100$ & 0 & 0,03 & 0,03 & 0,28 & 0,04 & 0,04 & 0,04 & 0,04 & 0,27 & 0,04 & 0,04 & 0,04 \\
\hline 30 & 7 & A & $75-125$ & $50-100$ & 50 & 0,10 & 0,09 & 0,41 & 0,11 & 0,11 & 0,11 & 0,08 & 0,24 & 0,07 & 0,12 & 0,04 \\
\hline 30 & 7 & B & $25-74$ & $0-50$ & 0 & 0,03 & 0,03 & 0,22 & 0,04 & 0,03 & 0,03 & 0,04 & 0,26 & 0,04 & 0,03 & 0,03 \\
\hline 30 & 7 & B & $25-74$ & $0-50$ & 50 & 0,08 & 0,04 & 0,34 & 0,05 & 0,11 & 0,07 & 0,06 & 0,28 & 0,07 & 0,13 & 0,03 \\
\hline 30 & 7 & B & $25-74$ & $50-100$ & 0 & 0,02 & 0,02 & 0,28 & 0,03 & 0,03 & 0,03 & 0,05 & 0,29 & 0,04 & 0,03 & 0,03 \\
\hline 30 & 7 & B & $25-74$ & $50-100$ & 50 & 0,12 & 0,05 & 0,39 & 0,06 & 0,11 & 0,07 & 0,06 & 0,28 & 0,06 & 0,13 & 0,03 \\
\hline 30 & 7 & B & $75-125$ & $0-50$ & 0 & 0,02 & 0,02 & 0,28 & 0,02 & 0,03 & 0,03 & 0,03 & 0,33 & 0,04 & 0,02 & 0,03 \\
\hline 30 & 7 & B & $75-125$ & $0-50$ & 50 & 0,08 & 0,04 & 0,34 & 0,05 & 0,09 & 0,06 & 0,05 & 0,26 & 0,05 & 0,11 & 0,03 \\
\hline 30 & 7 & B & $75-125$ & $50-100$ & 0 & 0,02 & 0,02 & 0,28 & 0,02 & 0,02 & 0,03 & 0,03 & 0,29 & 0,03 & 0,02 & 0,02 \\
\hline 30 & 7 & B & $75-125$ & $50-100$ & 50 & 0,10 & 0,05 & 0,33 & 0,06 & 0,10 & 0,07 & 0,06 & 0,27 & 0,06 & 0,10 & 0,03 \\
\hline 30 & 7 & M & $25-74$ & $0-50$ & 0 & 0,03 & 0,02 & 0,19 & 0,03 & 0,03 & 0,03 & 0,05 & 0,18 & 0,05 & 0,04 & 0,03 \\
\hline 30 & 7 & M & $25-74$ & $0-50$ & 50 & 0,10 & 0,06 & 0,32 & 0,06 & 0,10 & 0,08 & 0,07 & 0,25 & 0,05 & 0,11 & 0,03 \\
\hline 30 & 7 & M & $25-74$ & $50-100$ & 0 & 0,03 & 0,02 & 0,21 & 0,03 & 0,03 & 0,03 & 0,04 & 0,24 & 0,05 & 0,04 & 0,03 \\
\hline 30 & 7 & M & $25-74$ & $50-100$ & 50 & 0,09 & 0,05 & 0,37 & 0,05 & 0,10 & 0,07 & 0,06 & 0,28 & 0,05 & 0,11 & 0,02 \\
\hline 30 & 7 & M & $75-125$ & $0-50$ & 0 & 0,02 & 0,02 & 0,20 & 0,03 & 0,03 & 0,03 & 0,04 & 0,22 & 0,03 & 0,03 & 0,03 \\
\hline 30 & 7 & M & $75-125$ & $0-50$ & 50 & 0,09 & 0,05 & 0,32 & 0,06 & 0,09 & 0,07 & 0,06 & 0,23 & 0,04 & 0,10 & 0,02 \\
\hline 30 & 7 & M & $75-125$ & $50-100$ & 0 & 0,02 & 0,02 & 0,24 & 0,03 & 0,03 & 0,03 & 0,04 & 0,24 & 0,04 & 0,03 & 0,02 \\
\hline 30 & 7 & M & $75-125$ & $50-100$ & 50 & 0,07 & 0,05 & 0,31 & 0,06 & 0,10 & 0,08 & 0,06 & 0,25 & 0,06 & 0,09 & 0,01 \\
\hline 100 & 7 & A & $25-74$ & $0-50$ & 0 & 0,02 & 0,01 & 0,38 & 0,02 & 0,02 & 0,02 & 0,04 & 0,37 & 0,05 & 0,02 & 0,02 \\
\hline 100 & 7 & A & $25-74$ & $0-50$ & 50 & 0,06 & 0,04 & 0,40 & 0,06 & 0,08 & 0,06 & 0,04 & 0,25 & 0,04 & 0,07 & 0,01 \\
\hline 100 & 7 & A & $25-74$ & $50-100$ & 0 & 0,02 & 0,02 & 0,33 & 0,03 & 0,02 & 0,02 & 0,04 & 0,31 & 0,04 & 0,02 & 0,02 \\
\hline 100 & 7 & A & $25-74$ & $50-100$ & 50 & 0,06 & 0,04 & 0,37 & 0,05 & 0,08 & 0,06 & 0,04 & 0,25 & 0,04 & 0,07 & 0,01 \\
\hline 100 & 7 & A & $75-125$ & $0-50$ & 0 & 0,01 & 0,01 & 0,40 & 0,02 & 0,02 & 0,02 & 0,03 & 0,40 & 0,03 & 0,02 & 0,02 \\
\hline 100 & 7 & A & $75-125$ & $0-50$ & 50 & 0,05 & 0,04 & 0,40 & 0,05 & 0,07 & 0,05 & 0,04 & 0,27 & 0,04 & 0,07 & 0,01 \\
\hline 100 & 7 & A & $75-125$ & $50-100$ & 0 & 0,01 & 0,01 & 0,36 & 0,02 & 0,02 & 0,02 & 0,03 & 0,36 & 0,03 & 0,02 & 0,01 \\
\hline 100 & 7 & A & $75-125$ & $50-100$ & 50 & 0,05 & 0,04 & 0,41 & 0,05 & 0,07 & 0,06 & 0,04 & 0,27 & 0,04 & 0,07 & 0,01 \\
\hline 100 & 7 & B & $25-74$ & $0-50$ & 0 & 0,01 & 0,01 & 0,26 & 0,03 & 0,02 & 0,02 & 0,05 & 0,30 & 0,04 & 0,02 & 0,02 \\
\hline 100 & 7 & B & $25-74$ & $0-50$ & 50 & 0,06 & 0,02 & 0,25 & 0,04 & 0,06 & 0,03 & 0,03 & 0,27 & 0,04 & 0,06 & 0,01 \\
\hline 100 & 7 & B & $25-74$ & $50-100$ & 0 & 0,01 & 0,01 & 0,25 & 0,03 & 0,02 & 0,02 & 0,05 & 0,29 & 0,05 & 0,02 & 0,02 \\
\hline 100 & 7 & B & $25-74$ & $50-100$ & 50 & 0,06 & 0,02 & 0,27 & 0,03 & 0,06 & 0,03 & 0,03 & 0,20 & 0,04 & 0,07 & 0,01 \\
\hline 100 & 7 & B & $75-125$ & $0-50$ & 0 & 0,01 & 0,01 & 0,28 & 0,02 & 0,01 & 0,01 & 0,03 & 0,32 & 0,03 & 0,01 & 0,01 \\
\hline 100 & 7 & B & $75-125$ & $0-50$ & 50 & 0,06 & 0,02 & 0,26 & 0,03 & 0,06 & 0,03 & 0,03 & 0,25 & 0,03 & 0,06 & 0,01 \\
\hline 100 & 7 & B & $75-125$ & $50-100$ & 0 & 0,01 & 0,01 & 0,32 & 0,03 & 0,01 & 0,01 & 0,03 & 0,32 & 0,03 & 0,01 & 0,01 \\
\hline 100 & 7 & B & $75-125$ & $50-100$ & 50 & 0,05 & 0,02 & 0,28 & 0,03 & 0,06 & 0,03 & 0,03 & 0,25 & 0,04 & 0,06 & 0,01 \\
\hline 100 & 7 & M & $25-74$ & $0-50$ & 0 & 0,01 & 0,01 & 0,25 & 0,02 & 0,02 & 0,02 & 0,05 & 0,25 & 0,05 & 0,02 & 0,02 \\
\hline 100 & 7 & M & $25-74$ & $0-50$ & 50 & 0,05 & 0,02 & 0,23 & 0,03 & 0,06 & 0,03 & 0,03 & 0,21 & 0,02 & 0,06 & 0,00 \\
\hline 100 & 7 & M & $25-74$ & $50-100$ & 0 & 0,01 & 0,01 & 0,23 & 0,02 & 0,01 & 0,01 & 0,05 & 0,25 & 0,05 & 0,02 & 0,01 \\
\hline 100 & 7 & M & $25-74$ & $50-100$ & 50 & 0,04 & 0,02 & 0,28 & 0,03 & 0,06 & 0,03 & 0,03 & 0,23 & 0,02 & 0,06 & 0,00 \\
\hline 100 & 7 & M & $75-125$ & $0-50$ & 0 & 0,01 & 0,01 & 0,21 & 0,01 & 0,01 & 0,01 & 0,03 & 0,21 & 0,03 & 0,01 & 0,01 \\
\hline 100 & 7 & M & $75-125$ & $0-50$ & 50 & 0,04 & 0,02 & 0,25 & 0,02 & 0,05 & 0,03 & 0,02 & 0,25 & 0,02 & 0,05 & 0,00 \\
\hline 100 & 7 & M & $75-125$ & $50-100$ & 0 & 0,01 & 0,01 & 0,23 & 0,02 & 0,01 & 0,01 & 0,03 & 0,22 & 0,03 & 0,01 & 0,01 \\
\hline 100 & 7 & M & $75-125$ & $50-100$ & 50 & 0,04 & 0,02 & 0,26 & 0,03 & 0,05 & 0,03 & 0,02 & 0,22 & 0,02 & 0,05 & 0,00 \\
\hline
\end{tabular}

TABELA D.11 - Resultados das heurísticas para setup independente por porte do problema (em \% de sucesso)

\begin{tabular}{cccccccccc}
\hline $\boldsymbol{g}$ & $\boldsymbol{n}$ & $\mathbf{H i 1}$ & $\mathbf{H i 2}$ & $\mathbf{H i 3}$ & $\mathbf{H i 4}$ & Hi5 & Hi6 & Ri11 & Ri6 \\
\hline $\mathbf{3}$ & $\mathbf{1 0}$ & 23 & 30 & 32 & 63 & 29 & 3 & 41 & 31 \\
$\mathbf{3}$ & $\mathbf{3 0}$ & 16 & 23 & 28 & 60 & 32 & 0 & 43 & 36 \\
$\mathbf{3}$ & $\mathbf{1 0 0}$ & 8 & 16 & 24 & 57 & 36 & 0 & 45 & 38 \\
$\mathbf{5}$ & $\mathbf{1 0}$ & 21 & 22 & 26 & 47 & 17 & 0 & 27 & 23 \\
$\mathbf{5}$ & $\mathbf{3 0}$ & 14 & 7 & 15 & 40 & 9 & 0 & 20 & 18 \\
$\mathbf{5}$ & $\mathbf{1 0 0}$ & 2 & 1 & 11 & 42 & 12 & 0 & 31 & 25 \\
$\mathbf{7}$ & $\mathbf{1 0}$ & 20 & 18 & 22 & 41 & 12 & 0 & 24 & 20 \\
$\mathbf{7}$ & $\mathbf{3 0}$ & 12 & 7 & 19 & 48 & 16 & 0 & 29 & 25 \\
$\mathbf{7}$ & $\mathbf{1 0 0}$ & 3 & 1 & 12 & 48 & 22 & 0 & 44 & 33 \\
\hline
\end{tabular}


TABELA D.12 - Resultados das heurísticas para setup independente por flexibilidade e porte do problema (em \% de sucesso)

\begin{tabular}{ccccccccccc}
\hline $\boldsymbol{f}$ & $\boldsymbol{g}$ & $\boldsymbol{n}$ & $\mathbf{H i 1}$ & $\mathbf{H i 2}$ & $\mathbf{H i 3}$ & $\mathbf{H i 4}$ & $\mathbf{H i 5}$ & Hi6 & $\mathbf{R i 1 1}$ & $\mathbf{R i 6}$ \\
\hline $\mathbf{B}$ & $\mathbf{3}$ & $\mathbf{1 0}$ & 30 & 32 & 37 & 57 & 41 & 4 & 46 & 42 \\
$\mathbf{B}$ & $\mathbf{3}$ & $\mathbf{3 0}$ & 21 & 22 & 32 & 59 & 52 & 0 & 53 & 48 \\
$\mathbf{B}$ & $\mathbf{3}$ & $\mathbf{1 0 0}$ & 11 & 14 & 29 & 54 & 55 & 0 & 56 & 54 \\
$\mathbf{B}$ & $\mathbf{5}$ & $\mathbf{1 0}$ & 24 & 24 & 27 & 39 & 23 & 0 & 27 & 27 \\
$\mathbf{B}$ & $\mathbf{5}$ & $\mathbf{3 0}$ & 14 & 6 & 18 & 48 & 25 & 0 & 32 & 28 \\
$\mathbf{B}$ & $\mathbf{5}$ & $\mathbf{1 0 0}$ & 4 & 1 & 14 & 51 & 34 & 0 & 52 & 36 \\
$\mathbf{B}$ & $\mathbf{7}$ & $\mathbf{1 0}$ & 22 & 16 & 19 & 29 & 18 & 0 & 20 & 21 \\
$\mathbf{B}$ & $\mathbf{7}$ & $\mathbf{3 0}$ & 16 & 4 & 11 & 33 & 15 & 0 & 20 & 18 \\
$\mathbf{B}$ & $\mathbf{7}$ & $\mathbf{1 0 0}$ & 3 & 0 & 9 & 37 & 18 & 0 & 30 & 25 \\
$\mathbf{M}$ & $\mathbf{3}$ & $\mathbf{1 0}$ & 27 & 40 & 41 & 74 & 35 & 5 & 44 & 36 \\
$\mathbf{M}$ & $\mathbf{3}$ & $\mathbf{3 0}$ & 23 & 39 & 42 & 78 & 40 & 1 & 54 & 41 \\
$\mathbf{M}$ & $\mathbf{3}$ & $\mathbf{1 0 0}$ & 14 & 32 & 39 & 75 & 43 & 0 & 54 & 40 \\
$\mathbf{M}$ & $\mathbf{5}$ & $\mathbf{1 0}$ & 23 & 23 & 25 & 47 & 20 & 0 & 27 & 24 \\
$\mathbf{M}$ & $\mathbf{5}$ & $\mathbf{3 0}$ & 14 & 9 & 26 & 53 & 23 & 0 & 37 & 26 \\
$\mathbf{M}$ & $\mathbf{5}$ & $\mathbf{1 0 0}$ & 5 & 2 & 19 & 57 & 29 & 0 & 52 & 33 \\
$\mathbf{M}$ & $\mathbf{7}$ & $\mathbf{1 0}$ & 19 & 19 & 25 & 42 & 14 & 0 & 23 & 19 \\
$\mathbf{M}$ & $\mathbf{7}$ & $\mathbf{3 0}$ & 15 & 11 & 22 & 43 & 13 & 0 & 23 & 17 \\
$\mathbf{M}$ & $\mathbf{7}$ & $\mathbf{1 0 0}$ & 3 & 2 & 20 & 51 & 16 & 0 & 35 & 22 \\
$\mathbf{A}$ & $\mathbf{3}$ & $\mathbf{1 0}$ & 11 & 17 & 19 & 59 & 12 & 0 & 34 & 15 \\
$\mathbf{A}$ & $\mathbf{3}$ & $\mathbf{3 0}$ & 4 & 8 & 11 & 42 & 5 & 0 & 24 & 17 \\
$\mathbf{A}$ & $\mathbf{3}$ & $\mathbf{1 0 0}$ & 0 & 3 & 5 & 43 & 9 & 0 & 24 & 19 \\
$\mathbf{A}$ & $\mathbf{5}$ & $\mathbf{1 0}$ & 17 & 20 & 24 & 55 & 7 & 0 & 26 & 17 \\
$\mathbf{A}$ & $\mathbf{5}$ & $\mathbf{3 0}$ & 7 & 6 & 12 & 44 & 1 & 0 & 18 & 20 \\
$\mathbf{A}$ & $\mathbf{5}$ & $\mathbf{1 0 0}$ & 1 & 1 & 3 & 36 & 3 & 0 & 29 & 31 \\
$\mathbf{A}$ & $\mathbf{7}$ & $\mathbf{1 0}$ & 19 & 21 & 23 & 53 & 6 & 0 & 29 & 19 \\
$\mathbf{A}$ & $\mathbf{7}$ & $\mathbf{3 0}$ & 10 & 6 & 11 & 44 & 0 & 0 & 17 & 19 \\
$\mathbf{A}$ & $\mathbf{7}$ & $\mathbf{1 0 0}$ & 1 & 1 & 5 & 39 & 0 & 0 & 27 & 29 \\
\hline & & & & & & & & & &
\end{tabular}

TABELA D.13 - Resultados das heurísticas para setup independente por intervalo de setup e porte do problema (em \% de sucesso)

\begin{tabular}{ccccccccccc}
\hline $\boldsymbol{s}$ & $\boldsymbol{g}$ & $\boldsymbol{n}$ & $\mathbf{H i 1}$ & $\mathbf{H i 2}$ & $\mathbf{H i 3}$ & $\mathbf{H i 4}$ & Hi5 & Hi6 & Ri11 & Ri6 \\
\hline $\mathbf{2 5 - 7 4}$ & $\mathbf{3}$ & $\mathbf{1 0}$ & 20 & 29 & 32 & 63 & 30 & 3 & 40 & 33 \\
$\mathbf{2 5 - 7 4}$ & $\mathbf{3}$ & $\mathbf{3 0}$ & 13 & 22 & 29 & 61 & 31 & 0 & 43 & 35 \\
$\mathbf{2 5 - 7 4}$ & $\mathbf{3}$ & $\mathbf{1 0 0}$ & 6 & 16 & 25 & 59 & 35 & 0 & 45 & 38 \\
$\mathbf{2 5 - 7 4}$ & $\mathbf{5}$ & $\mathbf{1 0}$ & 18 & 22 & 28 & 47 & 16 & 0 & 28 & 24 \\
$\mathbf{2 5 - 7 4}$ & $\mathbf{5}$ & $\mathbf{3 0}$ & 8 & 6 & 19 & 49 & 17 & 0 & 29 & 26 \\
$\mathbf{2 5 - 7 4}$ & $\mathbf{5}$ & $\mathbf{1 0 0}$ & 2 & 1 & 12 & 50 & 23 & 0 & 42 & 31 \\
$\mathbf{2 5 - 7 4}$ & $\mathbf{7}$ & $\mathbf{1 0}$ & 18 & 17 & 26 & 41 & 13 & 0 & 24 & 22 \\
$\mathbf{2 5 - 7 4}$ & $\mathbf{7}$ & $\mathbf{3 0}$ & $\mathbf{9}$ & 5 & 16 & 40 & 9 & 0 & 21 & 20 \\
$\mathbf{2 5 - 7 4}$ & $\mathbf{7}$ & $\mathbf{1 0 0}$ & 1 & 1 & 12 & 43 & 11 & 0 & 30 & 25 \\
$\mathbf{7 5 - 1 2 5}$ & $\mathbf{3}$ & $\mathbf{1 0}$ & 26 & 31 & 32 & 64 & 29 & 3 & 42 & 29 \\
$\mathbf{7 5 - 1 2 5}$ & $\mathbf{3}$ & $\mathbf{3 0}$ & 19 & 24 & 27 & 59 & 34 & 1 & 43 & 36 \\
$\mathbf{7 5 - 1 2 5}$ & $\mathbf{3}$ & $\mathbf{1 0 0}$ & 11 & 17 & 23 & $\mathbf{5 6}$ & 36 & 0 & 45 & 37 \\
$\mathbf{7 5 - 1 2 5}$ & $\mathbf{5}$ & $\mathbf{1 0}$ & 24 & 22 & 23 & 47 & 17 & 0 & 25 & 21 \\
$\mathbf{7 5 - 1 2 5}$ & $\mathbf{5}$ & $\mathbf{3 0}$ & 15 & 8 & 19 & 48 & 16 & 0 & 29 & 23 \\
$\mathbf{7 5 - 1 2 5}$ & $\mathbf{5}$ & $\mathbf{1 0 0}$ & 5 & 2 & 12 & 46 & 22 & 0 & 46 & 35 \\
$\mathbf{7 5 - 1 2 5}$ & $\mathbf{7}$ & $\mathbf{1 0}$ & 22 & 19 & 19 & 41 & 12 & 0 & 24 & 18 \\
$\mathbf{7 5 - 1 2 5}$ & $\mathbf{7}$ & $\mathbf{3 0}$ & 18 & $\mathbf{9}$ & 14 & 40 & 10 & 0 & 19 & 15 \\
$\mathbf{7 5 - 1 2 5}$ & $\mathbf{7}$ & $\mathbf{1 0 0}$ & 4 & 1 & 10 & 42 & 12 & 0 & 31 & 25 \\
\hline & & & & & & & & & &
\end{tabular}


TABELA D.14 - Resultados das heurísticas para setup independente por probabilidade de antecipação do setup e porte do problema (em \% de sucesso)

\begin{tabular}{ccccccccccc}
\hline $\boldsymbol{s}$ & $\boldsymbol{g}$ & $\boldsymbol{n}$ & $\mathbf{H i 1}$ & $\mathbf{H i 2}$ & $\mathbf{H i 3}$ & $\mathbf{H i 4}$ & $\mathbf{H i 5}$ & $\mathbf{H i 6}$ & $\mathbf{R i 1 1}$ & $\mathbf{R i 6}$ \\
\hline $\mathbf{0 - 5 0}$ & $\mathbf{3}$ & $\mathbf{1 0}$ & 23 & 31 & 33 & 63 & 30 & 4 & 41 & 32 \\
$\mathbf{0 - 5 0}$ & $\mathbf{3}$ & $\mathbf{3 0}$ & 16 & 22 & 27 & 59 & 32 & 0 & 44 & 36 \\
$\mathbf{0 - 5 0}$ & $\mathbf{3}$ & $\mathbf{1 0 0}$ & 8 & 16 & 24 & 57 & 36 & 0 & 45 & 37 \\
$\mathbf{0 - 5 0}$ & $\mathbf{5}$ & $\mathbf{1 0}$ & 19 & 22 & 25 & 48 & 17 & 0 & 27 & 22 \\
$\mathbf{0 - 5 0}$ & $\mathbf{5}$ & $\mathbf{3 0}$ & 13 & 7 & 17 & 47 & 16 & 0 & 29 & 25 \\
$\mathbf{0 - 5 0}$ & $\mathbf{5}$ & $\mathbf{1 0 0}$ & 3 & 1 & 13 & 47 & 22 & 0 & 44 & 31 \\
$\mathbf{0 - 5 0}$ & $\mathbf{7}$ & $\mathbf{1 0}$ & 20 & 18 & 23 & 42 & 11 & 0 & 23 & 20 \\
$\mathbf{0 - 5 0}$ & $\mathbf{7}$ & $\mathbf{3 0}$ & 14 & 6 & 14 & 41 & 9 & 0 & 19 & 18 \\
$\mathbf{0 - 5 0}$ & $\mathbf{7}$ & $\mathbf{1 0 0}$ & 2 & 1 & 12 & 42 & 13 & 0 & 30 & 25 \\
$\mathbf{5 0 - 1 0 0}$ & $\mathbf{3}$ & $\mathbf{1 0}$ & 23 & 29 & 32 & 64 & 28 & 3 & 41 & 30 \\
$\mathbf{5 0 - 1 0 0}$ & $\mathbf{3}$ & $\mathbf{3 0}$ & 16 & 23 & 29 & 60 & 33 & 1 & 42 & 35 \\
$\mathbf{5 0 - 1 0 0}$ & $\mathbf{3}$ & $\mathbf{1 0 0}$ & 9 & 17 & 25 & 58 & 35 & 0 & 45 & 39 \\
$\mathbf{5 0 - 1 0 0}$ & $\mathbf{5}$ & $\mathbf{1 0}$ & 23 & 22 & 26 & 46 & 16 & 0 & 26 & 23 \\
$\mathbf{5 0 - 1 0 0}$ & $\mathbf{5}$ & $\mathbf{3 0}$ & 10 & 7 & 20 & 50 & 16 & 0 & 30 & 24 \\
$\mathbf{5 0 - 1 0 0}$ & $\mathbf{5}$ & $\mathbf{1 0 0}$ & 3 & 2 & 11 & 49 & 22 & 0 & 44 & 35 \\
$\mathbf{5 0 - 1 0 0}$ & $\mathbf{7}$ & $\mathbf{1 0}$ & 20 & 18 & 21 & 41 & 13 & 0 & 25 & 19 \\
$\mathbf{5 0 - 1 0 0}$ & $\mathbf{7}$ & $\mathbf{3 0}$ & 13 & 7 & 15 & 40 & 10 & 0 & 20 & 18 \\
$\mathbf{5 0 - 1 0 0}$ & $\mathbf{7}$ & $\mathbf{1 0 0}$ & 3 & 1 & 11 & 43 & 10 & 0 & 31 & 26 \\
\hline
\end{tabular}

TABELA D.15 - Resultados das heurísticas para setup independente por probabilidade de salto e porte do problema (em \% de sucesso)

\begin{tabular}{ccccccccccc}
\hline $\boldsymbol{l}$ & $\boldsymbol{g}$ & $\boldsymbol{n}$ & $\mathbf{H i 1}$ & $\mathbf{H i 2}$ & $\mathbf{H i 3}$ & $\mathbf{H i 4}$ & $\mathbf{H i 5}$ & Hi6 & Ri11 & Ri6 \\
\hline $\mathbf{0}$ & $\mathbf{3}$ & $\mathbf{1 0}$ & 18 & 23 & 26 & 39 & 22 & 0 & 18 & 25 \\
$\mathbf{0}$ & $\mathbf{3}$ & $\mathbf{3 0}$ & 12 & 12 & 17 & 36 & 25 & 0 & 12 & 32 \\
$\mathbf{0}$ & $\mathbf{3}$ & $\mathbf{1 0 0}$ & 4 & 6 & 14 & 35 & 30 & 0 & 10 & 38 \\
$\mathbf{0}$ & $\mathbf{5}$ & $\mathbf{1 0}$ & 24 & 21 & 26 & 21 & 15 & 0 & 15 & 23 \\
$\mathbf{0}$ & $\mathbf{5}$ & $\mathbf{3 0}$ & 19 & 6 & 23 & 15 & 17 & 0 & 12 & 33 \\
$\mathbf{0}$ & $\mathbf{5}$ & $\mathbf{1 0 0}$ & 5 & 1 & 16 & 13 & 22 & 0 & 16 & 43 \\
$\mathbf{0}$ & $\mathbf{7}$ & $\mathbf{1 0}$ & 23 & 18 & 24 & 18 & 12 & 0 & 17 & 22 \\
$\mathbf{0}$ & $\mathbf{7}$ & $\mathbf{3 0}$ & 21 & 8 & 21 & 13 & 12 & 0 & 14 & 26 \\
$\mathbf{0}$ & $\mathbf{7}$ & $\mathbf{1 0 0}$ & 4 & 1 & 18 & 10 & 14 & 0 & 18 & 41 \\
$\mathbf{5 0}$ & $\mathbf{3}$ & $\mathbf{1 0}$ & 27 & 36 & 38 & 88 & 37 & 6 & 64 & 37 \\
$\mathbf{5 0}$ & $\mathbf{3}$ & $\mathbf{3 0}$ & 21 & 34 & 39 & 83 & 40 & 1 & 74 & 39 \\
$\mathbf{5 0}$ & $\mathbf{3}$ & $\mathbf{1 0 0}$ & 13 & 27 & 34 & 80 & 41 & 0 & 80 & 37 \\
$\mathbf{5 0}$ & $\mathbf{5}$ & $\mathbf{1 0}$ & 18 & 23 & 26 & 73 & 18 & 0 & 39 & 22 \\
$\mathbf{5 0}$ & $\mathbf{5}$ & $\mathbf{3 0}$ & 4 & 8 & 14 & 82 & 15 & 0 & 46 & 17 \\
$\mathbf{5 0}$ & $\mathbf{5}$ & $\mathbf{1 0 0}$ & 2 & 2 & 8 & 84 & 22 & 0 & 72 & 23 \\
$\mathbf{5 0}$ & $\mathbf{7}$ & $\mathbf{1 0}$ & 16 & 19 & 21 & 64 & 13 & 0 & 31 & 18 \\
$\mathbf{5 0}$ & $\mathbf{7}$ & $\mathbf{3 0}$ & $\mathbf{7}$ & 6 & 9 & 67 & 7 & 0 & 26 & 9 \\
$\mathbf{5 0}$ & $\mathbf{7}$ & $\mathbf{1 0 0}$ & 1 & 1 & 4 & 75 & 9 & 0 & 43 & 9 \\
\hline
\end{tabular}


TABela D.16 - Desvio relativo médio (em \%) das heurísticas para setup independente por porte do problema

\begin{tabular}{cccccccccc}
\hline $\boldsymbol{g}$ & $\boldsymbol{n}$ & $\mathbf{H i 1}$ & $\mathbf{H i 2}$ & $\mathbf{H i 3}$ & $\mathbf{H i 4}$ & $\mathbf{H i 5}$ & $\mathbf{H i 6}$ & $\mathbf{R i 1 1}$ & $\mathbf{R i 6}$ \\
\hline $\mathbf{3}$ & $\mathbf{1 0}$ & 8,2 & 7,8 & 7,3 & 2,2 & 8,7 & 64,3 & 4,6 & 7,5 \\
$\mathbf{3}$ & $\mathbf{3 0}$ & 5,0 & 5,9 & 5,5 & 1,2 & 5,3 & 80,2 & 2,1 & 3,8 \\
$\mathbf{3}$ & $\mathbf{1 0 0}$ & 2,7 & 4,9 & 4,7 & 0,6 & 1,8 & 90,5 & 0,7 & 1,2 \\
$\mathbf{5}$ & $\mathbf{1 0}$ & 8,3 & 8,5 & 7,7 & 3,7 & 10,5 & 99,2 & 6,6 & 8,2 \\
$\mathbf{5}$ & $\mathbf{3 0}$ & 6,5 & 9,1 & 7,9 & 2,2 & 7,8 & 150,4 & 3,4 & 5,3 \\
$\mathbf{5}$ & $\mathbf{1 0 0}$ & 3,8 & 8,8 & 7,8 & 1,3 & 3,0 & 185,6 & 1,0 & 1,8 \\
$\mathbf{7}$ & $\mathbf{1 0}$ & 8,1 & 8,4 & 7,3 & 4,4 & 10,8 & 127,8 & 6,9 & 8,1 \\
$\mathbf{7}$ & $\mathbf{3 0}$ & 6,4 & 9,1 & $\mathbf{7 , 9}$ & 3,0 & 8,9 & 209,9 & 4,2 & 5,8 \\
$\mathbf{7}$ & $\mathbf{1 0 0}$ & 4,3 & 10,1 & 8,7 & 1,8 & 4,0 & 275,5 & 1,4 & 2,3 \\
\hline
\end{tabular}

TABELA D.17 - Desvio-padrão do desvio relativo das heurísticas para setup independente por porte do problema

\begin{tabular}{cccccccccc}
\hline $\boldsymbol{g}$ & $\boldsymbol{n}$ & $\mathbf{H i 1}$ & $\mathbf{H i 2}$ & $\mathbf{H i 3}$ & $\mathbf{H i 4}$ & $\mathbf{H i 5}$ & Hi6 & Ri11 & Ri6 \\
\hline $\mathbf{3}$ & $\mathbf{1 0}$ & 0,08 & 0,08 & 0,08 & 0,03 & 0,08 & 0,30 & 0,06 & 0,08 \\
$\mathbf{3}$ & $\mathbf{3 0}$ & 0,04 & 0,05 & 0,05 & 0,01 & 0,05 & 0,27 & 0,02 & 0,04 \\
$\mathbf{3}$ & $\mathbf{1 0 0}$ & 0,02 & 0,04 & 0,04 & 0,01 & 0,02 & 0,22 & 0,01 & 0,01 \\
$\mathbf{5}$ & $\mathbf{1 0}$ & 0,08 & 0,08 & 0,08 & 0,05 & 0,09 & 0,32 & 0,07 & 0,08 \\
$\mathbf{5}$ & $\mathbf{3 0}$ & 0,05 & 0,07 & 0,07 & 0,02 & 0,05 & 0,31 & 0,04 & 0,05 \\
$\mathbf{5}$ & $\mathbf{1 0 0}$ & 0,02 & 0,06 & 0,07 & 0,01 & 0,03 & 0,28 & 0,01 & 0,02 \\
$\mathbf{7}$ & $\mathbf{1 0}$ & 0,08 & 0,08 & 0,07 & 0,05 & 0,08 & 0,33 & 0,07 & 0,07 \\
$\mathbf{7}$ & $\mathbf{3 0}$ & 0,05 & 0,06 & 0,06 & 0,03 & 0,05 & 0,34 & 0,04 & 0,05 \\
$\mathbf{7}$ & $\mathbf{1 0 0}$ & 0,02 & 0,06 & 0,07 & 0,01 & 0,03 & 0,33 & 0,01 & 0,02 \\
\hline
\end{tabular}

TABELA D.18 - Resultado das heurísticas para setup independente por parâmetro (em \% de sucesso)

\begin{tabular}{|c|c|c|c|c|c|c|c|c|c|c|c|c|c|}
\hline$n$ & $g$ & $f$ & $S$ & $a$ & $l$ & Hi1 & $\mathrm{Hi2}$ & $\mathrm{Hi3}$ & $\mathrm{Hi4}$ & Hi5 & Hi6 & Ri11 & Ri6 \\
\hline 10 & 3 & B & $25-74$ & $0-50$ & 0 & 18 & 19 & 28 & 18 & 46 & 0 & 13 & 50 \\
\hline 10 & 3 & B & $25-74$ & $0-50$ & 50 & 30 & 39 & 40 & 92 & 39 & 13 & 74 & 41 \\
\hline 10 & 3 & B & $25-74$ & $50-100$ & 0 & 26 & 22 & 33 & 21 & 39 & 0 & 12 & 45 \\
\hline 10 & 3 & B & $25-74$ & $50-100$ & 50 & 27 & 38 & 46 & 97 & 42 & 3 & 75 & 41 \\
\hline 10 & 3 & B & $75-125$ & $0-50$ & 0 & 34 & 21 & 28 & 18 & 43 & 0 & 16 & 38 \\
\hline 10 & 3 & B & $75-125$ & $0-50$ & 50 & 36 & 45 & 50 & 99 & 43 & 10 & 75 & 42 \\
\hline 10 & 3 & B & $75-125$ & $50-100$ & 0 & 33 & 25 & 29 & 17 & 32 & 0 & 17 & 27 \\
\hline 10 & 3 & B & $75-125$ & $50-100$ & 50 & 39 & 46 & 43 & 97 & 46 & 7 & 82 & 51 \\
\hline 10 & 3 & M & $25-74$ & $0-50$ & 0 & 11 & 36 & 33 & 52 & 26 & 0 & 19 & 30 \\
\hline 10 & 3 & M & $25-74$ & $0-50$ & 50 & 39 & 50 & 49 & 89 & 52 & 13 & 68 & 53 \\
\hline 10 & 3 & M & $25-74$ & $50-100$ & 0 & 23 & 37 & 42 & 57 & 24 & 0 & 19 & 28 \\
\hline 10 & 3 & M & $25-74$ & $50-100$ & 50 & 32 & 45 & 47 & 88 & 45 & 10 & 69 & 47 \\
\hline 10 & 3 & M & $75-125$ & $0-50$ & 0 & 22 & 28 & 30 & 58 & 19 & 0 & 18 & 20 \\
\hline 10 & 3 & M & $75-125$ & $0-50$ & 50 & 39 & 52 & 51 & 91 & 50 & 8 & 68 & 49 \\
\hline 10 & 3 & M & $75-125$ & $50-100$ & 0 & 17 & 27 & 26 & 62 & 18 & 0 & 18 & 10 \\
\hline 10 & 3 & M & $75-125$ & $50-100$ & 50 & 36 & 47 & 49 & 91 & 45 & 10 & 70 & 50 \\
\hline 10 & 3 & A & $25-74$ & $0-50$ & 0 & 7 & 14 & 16 & 42 & 4 & 0 & 20 & 14 \\
\hline 10 & 3 & A & $25-74$ & $0-50$ & 50 & 9 & 18 & 22 & 82 & 20 & 1 & 51 & 16 \\
\hline 10 & 3 & A & $25-74$ & $50-100$ & 0 & 9 & 18 & 16 & 41 & 3 & 0 & 19 & 14 \\
\hline 10 & 3 & A & $25-74$ & $50-100$ & 50 & 9 & 12 & 16 & 77 & 20 & 0 & 44 & 16 \\
\hline 10 & 3 & A & $75-125$ & $0-50$ & 0 & 8 & 22 & 23 & 39 & 4 & 0 & 20 & 12 \\
\hline 10 & 3 & A & $75-125$ & $0-50$ & 50 & 17 & 22 & 22 & 76 & 19 & 0 & 46 & 18 \\
\hline 10 & 3 & A & $75-125$ & $50-100$ & 0 & 13 & 12 & 12 & 45 & 4 & 0 & 25 & 9 \\
\hline
\end{tabular}




\begin{tabular}{|c|c|c|c|c|c|c|c|c|c|c|c|c|c|}
\hline 10 & 3 & A & $75-125$ & $50-100$ & 50 & 14 & 21 & 24 & 71 & 22 & 1 & 47 & 20 \\
\hline 10 & 5 & B & $25-74$ & $0-50$ & 0 & 22 & 27 & 28 & 9 & 17 & 0 & 16 & 32 \\
\hline 10 & 5 & B & $25-74$ & $0-50$ & 50 & 17 & 30 & 39 & 67 & 26 & 0 & 49 & 32 \\
\hline 10 & 5 & B & $25-74$ & $50-100$ & 0 & 24 & 19 & 26 & 11 & 34 & 0 & 10 & 32 \\
\hline 10 & 5 & B & $25-74$ & $50-100$ & 50 & 20 & 28 & 28 & 64 & 17 & 0 & 42 & 20 \\
\hline 10 & 5 & B & $75-125$ & $0-50$ & 0 & 29 & 19 & 25 & 18 & 24 & 0 & 11 & 21 \\
\hline 10 & 5 & B & $75-125$ & $0-50$ & 50 & 22 & 27 & 24 & 64 & 18 & 0 & 38 & 19 \\
\hline 10 & 5 & B & $75-125$ & $50-100$ & 0 & 35 & 15 & 21 & 9 & 25 & 0 & 14 & 33 \\
\hline 10 & 5 & B & $75-125$ & $50-100$ & 50 & 22 & 24 & 27 & 69 & 21 & 0 & 39 & 26 \\
\hline 10 & 5 & M & $25-74$ & $0-50$ & 0 & 20 & 19 & 22 & 21 & 17 & 0 & 18 & 24 \\
\hline 10 & 5 & M & $25-74$ & $0-50$ & 50 & 17 & 21 & 25 & 79 & 22 & 0 & 42 & 23 \\
\hline 10 & 5 & M & $25-74$ & $50-100$ & 0 & 27 & 26 & 34 & 18 & 20 & 0 & 16 & 24 \\
\hline 10 & 5 & M & $25-74$ & $50-100$ & 50 & 12 & 17 & 23 & 72 & 13 & 0 & 39 & 22 \\
\hline 10 & 5 & M & $75-125$ & $0-50$ & 0 & 25 & 19 & 22 & 25 & 24 & 0 & 9 & 25 \\
\hline 10 & 5 & M & $75-125$ & $0-50$ & 50 & 19 & 26 & 22 & 72 & 24 & 0 & 40 & 22 \\
\hline 10 & 5 & M & $75-125$ & $50-100$ & 0 & 35 & 24 & 26 & 17 & 15 & 0 & 14 & 29 \\
\hline 10 & 5 & $\mathbf{M}$ & $75-125$ & $50-100$ & 50 & 25 & 28 & 29 & 75 & 21 & 1 & 39 & 20 \\
\hline 10 & 5 & A & $25-74$ & $0-50$ & 0 & 14 & 19 & 27 & 25 & 3 & 0 & 21 & 20 \\
\hline 10 & 5 & A & $25-74$ & $0-50$ & 50 & 13 & 16 & 22 & 84 & 14 & 0 & 34 & 16 \\
\hline 10 & 5 & A & $25-74$ & $50-100$ & 0 & 14 & 14 & 33 & 30 & 0 & 0 & 15 & 21 \\
\hline 10 & 5 & A & $25-74$ & $50-100$ & 50 & 18 & 23 & 27 & 80 & 10 & 0 & 37 & 21 \\
\hline 10 & 5 & A & $75-125$ & $0-50$ & 0 & 17 & 18 & 21 & 36 & 2 & 0 & 17 & 9 \\
\hline 10 & 5 & A & $75-125$ & $0-50$ & 50 & 16 & 19 & 21 & 71 & 11 & 0 & 34 & 21 \\
\hline 10 & 5 & A & $75-125$ & $50-100$ & 0 & 23 & 28 & 22 & 31 & 2 & 0 & 16 & 11 \\
\hline 10 & 5 & A & $75-125$ & $50-100$ & 50 & 18 & 21 & 21 & 81 & 16 & 0 & 30 & 17 \\
\hline 10 & 7 & B & $25-74$ & $0-50$ & 0 & 25 & 16 & 27 & 6 & 22 & 0 & 15 & 29 \\
\hline 10 & 7 & B & $25-74$ & $0-50$ & 50 & 11 & 12 & 18 & 48 & 14 & 0 & 22 & 12 \\
\hline 10 & 7 & B & $25-74$ & $50-100$ & 0 & 20 & 8 & 24 & 7 & 22 & 0 & 18 & 31 \\
\hline 10 & 7 & B & $25-74$ & $50-100$ & 50 & 12 & 18 & 15 & 52 & 13 & 0 & 31 & 14 \\
\hline 10 & 7 & B & $75-125$ & $0-50$ & 0 & 37 & 17 & 14 & 8 & 19 & 0 & 13 & 27 \\
\hline 10 & 7 & B & $75-125$ & $0-50$ & 50 & 21 & 23 & 19 & 47 & 9 & 0 & 23 & 10 \\
\hline 10 & 7 & B & $75-125$ & $50-100$ & 0 & 36 & 16 & 18 & 12 & 25 & 0 & 14 & 27 \\
\hline 10 & 7 & B & $75-125$ & $50-100$ & 50 & 14 & 14 & 17 & 48 & 16 & 0 & 24 & 15 \\
\hline 10 & 7 & M & $25-74$ & $0-50$ & 0 & 25 & 19 & 27 & 20 & 14 & 0 & 14 & 22 \\
\hline 10 & 7 & M & $25-74$ & $0-50$ & 50 & 8 & 14 & 32 & 67 & 11 & 0 & 29 & 23 \\
\hline 10 & 7 & M & $25-74$ & $50-100$ & 0 & 22 & 21 & 35 & 22 & 14 & 0 & 10 & 17 \\
\hline 10 & 7 & M & $25-74$ & $50-100$ & 50 & 15 & 20 & 21 & 58 & 20 & 0 & 34 & 21 \\
\hline 10 & 7 & M & $75-125$ & $0-50$ & 0 & 23 & 20 & 25 & 19 & 10 & 0 & 20 & 23 \\
\hline 10 & 7 & $\mathbf{M}$ & $75-125$ & $0-50$ & 50 & 20 & 23 & 23 & 70 & 17 & 0 & 25 & 18 \\
\hline 10 & 7 & M & $75-125$ & $50-100$ & 0 & 26 & 21 & 22 & 17 & 13 & 0 & 20 & 15 \\
\hline 10 & 7 & M & $75-125$ & $50-100$ & 50 & 10 & 11 & 15 & 60 & 11 & 0 & 34 & 14 \\
\hline 10 & 7 & A & $25-74$ & $0-50$ & 0 & 10 & 13 & 28 & 28 & 0 & 0 & 19 & 20 \\
\hline 10 & 7 & A & $25-74$ & $0-50$ & 50 & 25 & 26 & 27 & 81 & 8 & 0 & 35 & 26 \\
\hline 10 & 7 & A & $25-74$ & $50-100$ & 0 & 19 & 18 & 27 & 16 & 2 & 0 & 25 & 19 \\
\hline 10 & 7 & A & $25-74$ & $50-100$ & 50 & 21 & 24 & 25 & 86 & 12 & 0 & 33 & 25 \\
\hline 10 & 7 & A & $75-125$ & $0-50$ & 0 & 18 & 20 & 21 & 30 & 0 & 0 & 17 & 19 \\
\hline 10 & 7 & A & $75-125$ & $0-50$ & 50 & 15 & 18 & 15 & 77 & 11 & 0 & 38 & 15 \\
\hline 10 & 7 & A & $75-125$ & $50-100$ & 0 & 18 & 23 & 16 & 31 & 0 & 0 & 20 & 12 \\
\hline 10 & 7 & A & $75-125$ & $50-100$ & 50 & 24 & 24 & 21 & 78 & 12 & 0 & 42 & 19 \\
\hline 30 & 3 & B & $25-74$ & $0-50$ & 0 & 19 & 6 & 17 & 24 & 48 & 0 & 14 & 40 \\
\hline 30 & 3 & B & $25-74$ & $0-50$ & 50 & 23 & 47 & 50 & 100 & 55 & 0 & 94 & 53 \\
\hline 30 & 3 & B & $25-74$ & $50-100$ & 0 & 13 & 2 & 22 & 13 & 51 & 0 & 8 & 54 \\
\hline 30 & 3 & B & $25-74$ & $50-100$ & 50 & 17 & 40 & 48 & 100 & 52 & 0 & 95 & 53 \\
\hline 30 & 3 & B & $75-125$ & $0-50$ & 0 & 17 & 0 & 10 & 21 & 52 & 0 & 9 & 43 \\
\hline 30 & 3 & B & $75-125$ & $0-50$ & 50 & 25 & 37 & 43 & 100 & 51 & 0 & 99 & 51 \\
\hline 30 & 3 & B & $75-125$ & $50-100$ & 0 & 29 & 4 & 12 & 16 & 46 & 0 & 6 & 33 \\
\hline 30 & 3 & B & $75-125$ & $50-100$ & 50 & 28 & 40 & 52 & 100 & 58 & 1 & 96 & 60 \\
\hline 30 & 3 & M & $25-74$ & $0-50$ & 0 & 7 & 19 & 23 & 56 & 13 & 0 & 14 & 21 \\
\hline 30 & 3 & $\mathbf{M}$ & $25-74$ & $0-50$ & 50 & 33 & 48 & 56 & 100 & 52 & 3 & 94 & 56 \\
\hline 30 & 3 & M & $25-74$ & $50-100$ & 0 & 5 & 27 & 35 & 52 & 27 & 0 & 16 & 28 \\
\hline 30 & 3 & M & $25-74$ & $50-100$ & 50 & 30 & 51 & 57 & 99 & 56 & 2 & 92 & 55 \\
\hline 30 & 3 & M & $75-125$ & $0-50$ & 0 & 12 & 27 & 21 & 58 & 32 & 0 & 15 & 29 \\
\hline
\end{tabular}




\begin{tabular}{|c|c|c|c|c|c|c|c|c|c|c|c|c|c|}
\hline 30 & 3 & $M$ & $75-125$ & $0-50$ & 50 & 37 & 51 & 55 & 99 & 59 & 2 & 98 & 56 \\
\hline 30 & 3 & M & $75-125$ & $50-100$ & 0 & 10 & 22 & 20 & 58 & 22 & 0 & 6 & 17 \\
\hline 30 & 3 & M & $75-125$ & $50-100$ & 50 & 50 & 65 & 66 & 100 & 62 & 3 & 95 & 66 \\
\hline 30 & 3 & A & $25-74$ & $0-50$ & 0 & 1 & 6 & 13 & 31 & 2 & 0 & 17 & 34 \\
\hline 30 & 3 & A & $25-74$ & $0-50$ & 50 & 0 & 8 & 13 & 51 & 7 & 0 & 27 & 4 \\
\hline 30 & 3 & A & $25-74$ & $50-100$ & 0 & 3 & 7 & 9 & 47 & 5 & 0 & 19 & 15 \\
\hline 30 & 3 & A & $25-74$ & $50-100$ & 50 & 0 & 6 & 8 & 54 & 7 & 0 & 29 & 6 \\
\hline 30 & 3 & A & $75-125$ & $0-50$ & 0 & 13 & 9 & 14 & 27 & 2 & 0 & 14 & 38 \\
\hline 30 & 3 & A & $75-125$ & $0-50$ & 50 & 2 & 11 & 9 & 44 & 6 & 0 & 36 & 9 \\
\hline 30 & 3 & A & $75-125$ & $50-100$ & 0 & 9 & 10 & 11 & 33 & 2 & 0 & 10 & 31 \\
\hline 30 & 3 & A & $75-125$ & $50-100$ & 50 & 1 & 6 & 7 & 49 & 10 & 0 & 36 & 1 \\
\hline 30 & 5 & B & $25-74$ & $0-50$ & 0 & 20 & 5 & 23 & 7 & 29 & 0 & 9 & 45 \\
\hline 30 & 5 & B & $25-74$ & $0-50$ & 50 & 5 & 5 & 11 & 85 & 21 & 0 & 49 & 17 \\
\hline 30 & 5 & B & $25-74$ & $50-100$ & 0 & 16 & 1 & 20 & 14 & 26 & 0 & 8 & 35 \\
\hline 30 & 5 & B & $25-74$ & $50-100$ & 50 & 2 & 9 & 16 & 89 & 26 & 0 & 58 & 22 \\
\hline 30 & 5 & B & $75-125$ & $0-50$ & 0 & 35 & 9 & 22 & 5 & 33 & 0 & 7 & 34 \\
\hline 30 & 5 & B & $75-125$ & $0-50$ & 50 & 6 & 8 & 10 & 85 & 16 & 0 & 52 & 18 \\
\hline 30 & 5 & B & $75-125$ & $50-100$ & 0 & 25 & 4 & 25 & 11 & 25 & 0 & 12 & 28 \\
\hline 30 & 5 & B & $75-125$ & $50-100$ & 50 & 3 & 5 & 18 & 90 & 25 & 0 & 61 & 27 \\
\hline 30 & 5 & $\mathbf{M}$ & $25-74$ & $0-50$ & 0 & 14 & 3 & 29 & 21 & 27 & 0 & 11 & 30 \\
\hline 30 & 5 & M & $25-74$ & $0-50$ & 50 & 6 & 13 & 24 & 89 & 22 & 0 & 64 & 20 \\
\hline 30 & 5 & $\mathbf{M}$ & $25-74$ & $50-100$ & 0 & 12 & 4 & 39 & 12 & 21 & 0 & 11 & 32 \\
\hline 30 & 5 & M & $25-74$ & $50-100$ & 50 & 1 & 11 & 25 & 92 & 24 & 0 & 63 & 25 \\
\hline 30 & 5 & $\mathbf{M}$ & $75-125$ & $0-50$ & 0 & 30 & 10 & 19 & 16 & 19 & 0 & 11 & 24 \\
\hline 30 & 5 & M & $75-125$ & $0-50$ & 50 & 12 & 12 & 22 & 89 & 24 & 0 & 67 & 25 \\
\hline 30 & 5 & M & $75-125$ & $50-100$ & 0 & 26 & 9 & 29 & 15 & 20 & 0 & 11 & 27 \\
\hline 30 & 5 & M & $75-125$ & $50-100$ & 50 & 8 & 11 & 23 & 91 & 23 & 0 & 61 & 27 \\
\hline 30 & 5 & A & $25-74$ & $0-50$ & 0 & 8 & 4 & 12 & 18 & 2 & 0 & 15 & 47 \\
\hline 30 & 5 & A & $25-74$ & $0-50$ & 50 & 2 & 5 & 5 & 61 & 1 & 0 & 22 & 8 \\
\hline 30 & 5 & A & $25-74$ & $50-100$ & 0 & 7 & 5 & 17 & 25 & 0 & 0 & 20 & 33 \\
\hline 30 & 5 & A & $25-74$ & $50-100$ & 50 & 0 & 2 & 4 & 72 & 1 & 0 & 21 & 2 \\
\hline 30 & 5 & A & $75-125$ & $0-50$ & 0 & 16 & 7 & 21 & 15 & 1 & 0 & 18 & 30 \\
\hline 30 & 5 & A & $75-125$ & $0-50$ & 50 & 5 & 5 & 4 & 72 & 0 & 0 & 19 & 3 \\
\hline 30 & 5 & A & $75-125$ & $50-100$ & 0 & 16 & 13 & 22 & 21 & 1 & 0 & 14 & 30 \\
\hline 30 & 5 & A & $75-125$ & $50-100$ & 50 & 3 & 4 & 7 & 67 & 1 & 0 & 17 & 5 \\
\hline 30 & 7 & B & $25-74$ & $0-50$ & 0 & 19 & 4 & 20 & 3 & 20 & 0 & 12 & 27 \\
\hline 30 & 7 & B & $25-74$ & $0-50$ & 50 & 5 & 1 & 9 & 65 & 9 & 0 & 31 & 13 \\
\hline 30 & 7 & B & $25-74$ & $50-100$ & 0 & 20 & 1 & 15 & 3 & 21 & 0 & 12 & 32 \\
\hline 30 & 7 & B & $25-74$ & $50-100$ & 50 & 5 & 4 & 4 & 60 & 7 & 0 & 28 & 5 \\
\hline 30 & 7 & B & $75-125$ & $0-50$ & 0 & 33 & 3 & 10 & 2 & 22 & 0 & 14 & 26 \\
\hline 30 & 7 & B & $75-125$ & $0-50$ & 50 & 10 & 2 & 4 & 65 & 4 & 0 & 23 & 8 \\
\hline 30 & 7 & B & $75-125$ & $50-100$ & 0 & 24 & 5 & 18 & 3 & 24 & 0 & 13 & 23 \\
\hline 30 & 7 & B & $75-125$ & $50-100$ & 50 & 13 & 8 & 9 & 61 & 11 & 0 & 27 & 8 \\
\hline 30 & 7 & M & $25-74$ & $0-50$ & 0 & 18 & 7 & 30 & 17 & 12 & 0 & 10 & 24 \\
\hline 30 & 7 & $\mathbf{M}$ & $25-74$ & $0-50$ & 50 & 2 & 5 & 20 & 73 & 10 & 0 & 35 & 9 \\
\hline 30 & 7 & $\mathbf{M}$ & $25-74$ & $50-100$ & 0 & 16 & 9 & 30 & 14 & 17 & 0 & 16 & 25 \\
\hline 30 & 7 & M & $25-74$ & $50-100$ & 50 & 5 & 11 & 14 & 73 & 13 & 0 & 34 & 17 \\
\hline 30 & 7 & M & $75-125$ & $0-50$ & 0 & 30 & 17 & 28 & 19 & 11 & 0 & 6 & 14 \\
\hline 30 & 7 & $\mathbf{M}$ & $75-125$ & $0-50$ & 50 & 10 & 12 & 14 & 68 & 16 & 0 & 30 & 10 \\
\hline 30 & 7 & M & $75-125$ & $50-100$ & 0 & 30 & 14 & 28 & 18 & 13 & 0 & 11 & 21 \\
\hline 30 & 7 & M & $75-125$ & $50-100$ & 50 & 12 & 10 & 9 & 65 & 14 & 0 & 38 & 15 \\
\hline 30 & 7 & A & $25-74$ & $0-50$ & 0 & 6 & 3 & 13 & 23 & 0 & 0 & 20 & 42 \\
\hline 30 & 7 & A & $25-74$ & $0-50$ & 50 & 5 & 5 & 5 & 64 & 0 & 0 & 20 & 9 \\
\hline 30 & 7 & A & $25-74$ & $50-100$ & 0 & 8 & 6 & 22 & 14 & 0 & 0 & 20 & 35 \\
\hline 30 & 7 & A & $25-74$ & $50-100$ & 50 & 3 & 2 & 6 & 73 & 1 & 0 & 16 & 4 \\
\hline 30 & 7 & A & $75-125$ & $0-50$ & 0 & 30 & 14 & 14 & 20 & 0 & 0 & 14 & 23 \\
\hline 30 & 7 & A & $75-125$ & $0-50$ & 50 & 4 & 4 & 3 & 68 & 1 & 0 & 18 & 7 \\
\hline 30 & 7 & A & $75-125$ & $50-100$ & 0 & 16 & 8 & 22 & 21 & 0 & 0 & 18 & 24 \\
\hline 30 & 7 & A & $75-125$ & $50-100$ & 50 & 4 & 6 & 6 & 69 & 1 & 0 & 11 & 6 \\
\hline 100 & 3 & B & $25-74$ & $0-50$ & 0 & 6 & 3 & 25 & 9 & 57 & 0 & 11 & 53 \\
\hline 100 & 3 & B & $25-74$ & $0-50$ & 50 & 8 & 28 & 40 & 100 & 57 & 0 & 100 & 57 \\
\hline 100 & 3 & B & $25-74$ & $50-100$ & 0 & 5 & 1 & 28 & 8 & 54 & 0 & 11 & 61 \\
\hline
\end{tabular}




\begin{tabular}{|c|c|c|c|c|c|c|c|c|c|c|c|c|c|}
\hline 100 & 3 & B & $25-74$ & $50-100$ & 50 & 12 & 27 & 38 & 100 & 57 & 0 & 100 & 59 \\
\hline 100 & 3 & B & $75-125$ & $0-50$ & 0 & 8 & 1 & 14 & 10 & 65 & 0 & 10 & 54 \\
\hline 100 & 3 & B & $75-125$ & $0-50$ & 50 & 21 & 21 & 28 & 99 & 45 & 0 & 100 & 43 \\
\hline 100 & 3 & B & $75-125$ & $50-100$ & 0 & 11 & 3 & 18 & 6 & 57 & 0 & 16 & 51 \\
\hline 100 & 3 & B & $75-125$ & $50-100$ & 50 & 16 & 26 & 38 & 100 & 51 & 0 & 100 & 55 \\
\hline 100 & 3 & M & $25-74$ & $0-50$ & 0 & 1 & 12 & 21 & 49 & 23 & 0 & 13 & 24 \\
\hline 100 & 3 & $\mathbf{M}$ & $25-74$ & $0-50$ & 50 & 15 & 47 & 60 & 100 & 60 & 0 & 99 & 57 \\
\hline 100 & 3 & M & $25-74$ & $50-100$ & 0 & 0 & 9 & 18 & 62 & 22 & 0 & 9 & 20 \\
\hline 100 & 3 & $\mathbf{M}$ & $25-74$ & $50-100$ & 50 & 22 & 47 & 54 & 100 & 55 & 0 & 99 & 55 \\
\hline 100 & 3 & M & $75-125$ & $0-50$ & 0 & 8 & 13 & 17 & 41 & 32 & 0 & 10 & 19 \\
\hline 100 & 3 & $\mathbf{M}$ & $75-125$ & $0-50$ & 50 & 24 & 50 & 58 & 100 & 57 & 0 & 100 & 55 \\
\hline 100 & 3 & M & $75-125$ & $50-100$ & 0 & 10 & 22 & 23 & 45 & 32 & 0 & 5 & 29 \\
\hline 100 & 3 & $\mathbf{M}$ & $75-125$ & $50-100$ & 50 & 33 & 52 & 60 & 100 & 59 & 0 & 100 & 61 \\
\hline 100 & 3 & A & $25-74$ & $0-50$ & 0 & 0 & 2 & 2 & 46 & 4 & 0 & 15 & 33 \\
\hline 100 & 3 & A & $25-74$ & $0-50$ & 50 & 0 & 4 & 9 & 45 & 10 & 0 & 39 & 3 \\
\hline 100 & 3 & A & $25-74$ & $50-100$ & 0 & 0 & 0 & 0 & 50 & 9 & 0 & 6 & 36 \\
\hline 100 & 3 & A & $25-74$ & $50-100$ & 50 & 0 & 8 & 10 & 41 & 11 & 0 & 39 & 2 \\
\hline 100 & 3 & A & $75-125$ & $0-50$ & 0 & 0 & 1 & 1 & 45 & 6 & 0 & 7 & 40 \\
\hline 100 & 3 & A & $75-125$ & $0-50$ & 50 & 0 & 4 & 7 & 37 & 12 & 0 & 40 & 1 \\
\hline 100 & 3 & A & $75-125$ & $50-100$ & 0 & 1 & 2 & 5 & 46 & 2 & 0 & 8 & 37 \\
\hline 100 & 3 & A & $75-125$ & $50-100$ & 50 & 0 & 6 & 5 & 37 & 15 & 0 & 41 & 1 \\
\hline 100 & 5 & B & $25-74$ & $0-50$ & 0 & 2 & 0 & 27 & 6 & 32 & 0 & 9 & 37 \\
\hline 100 & 5 & B & $25-74$ & $0-50$ & 50 & 3 & 0 & 9 & 98 & 35 & 0 & 85 & 31 \\
\hline 100 & 5 & B & $25-74$ & $50-100$ & 0 & 6 & 1 & 17 & 7 & 39 & 0 & 11 & 39 \\
\hline 100 & 5 & B & $25-74$ & $50-100$ & 50 & 1 & 2 & 8 & 99 & 31 & 0 & 79 & 30 \\
\hline 100 & 5 & B & $75-125$ & $0-50$ & 0 & 9 & 0 & 18 & 3 & 33 & 0 & 20 & 33 \\
\hline 100 & 5 & B & $75-125$ & $0-50$ & 50 & 4 & 1 & 10 & 96 & 37 & 0 & 97 & 35 \\
\hline 100 & 5 & B & $75-125$ & $50-100$ & 0 & 6 & 1 & 15 & 4 & 34 & 0 & 17 & 45 \\
\hline 100 & 5 & B & $75-125$ & $50-100$ & 50 & 4 & 4 & 9 & 98 & 33 & 0 & 95 & 35 \\
\hline 100 & 5 & M & $25-74$ & $0-50$ & 0 & 5 & 1 & 25 & 12 & 32 & 0 & 13 & 34 \\
\hline 100 & 5 & $\mathbf{M}$ & $25-74$ & $0-50$ & 50 & 0 & 1 & 12 & 100 & 22 & 0 & 85 & 22 \\
\hline 100 & 5 & M & $25-74$ & $50-100$ & 0 & 4 & 1 & 27 & 16 & 32 & 0 & 18 & 34 \\
\hline 100 & 5 & $\mathbf{M}$ & $25-74$ & $50-100$ & 50 & 0 & 2 & 14 & 100 & 34 & 0 & 92 & 35 \\
\hline 100 & 5 & M & $75-125$ & $0-50$ & 0 & 6 & 1 & 25 & 15 & 28 & 0 & 10 & 34 \\
\hline 100 & 5 & M & $75-125$ & $0-50$ & 50 & 4 & 3 & 14 & 96 & 30 & 0 & 94 & 35 \\
\hline 100 & 5 & $\mathbf{M}$ & $75-125$ & $50-100$ & 0 & 15 & 3 & 22 & 18 & 28 & 0 & 5 & 35 \\
\hline 100 & 5 & $\mathbf{M}$ & $75-125$ & $50-100$ & 50 & 2 & 4 & 13 & 98 & 28 & 0 & 97 & 32 \\
\hline 100 & 5 & A & $25-74$ & $0-50$ & 0 & 0 & 0 & 1 & 26 & 2 & 0 & 23 & 48 \\
\hline 100 & 5 & A & $25-74$ & $0-50$ & 50 & 0 & 2 & 5 & 49 & 10 & 0 & 37 & 3 \\
\hline 100 & 5 & A & $25-74$ & $50-100$ & 0 & 0 & 0 & 1 & 21 & 1 & 0 & 25 & 52 \\
\hline 100 & 5 & A & $25-74$ & $50-100$ & 50 & 0 & 0 & 1 & 62 & 2 & 0 & 27 & 8 \\
\hline 100 & 5 & A & $75-125$ & $0-50$ & 0 & 3 & 2 & 9 & 9 & 1 & 0 & 23 & 57 \\
\hline 100 & 5 & A & $75-125$ & $0-50$ & 50 & 0 & 1 & 1 & 56 & 4 & 0 & 34 & 4 \\
\hline 100 & 5 & A & $75-125$ & $50-100$ & 0 & 1 & 0 & 3 & 14 & 1 & 0 & 16 & 66 \\
\hline 100 & 5 & A & $75-125$ & $50-100$ & 50 & 0 & 1 & 0 & 50 & 3 & 0 & 45 & 7 \\
\hline 100 & 7 & B & $25-74$ & $0-50$ & 0 & 1 & 0 & 21 & 0 & 26 & 0 & 15 & 38 \\
\hline 100 & 7 & B & $25-74$ & $0-50$ & 50 & 0 & 0 & 1 & 74 & 11 & 0 & 39 & 9 \\
\hline 100 & 7 & B & $25-74$ & $50-100$ & 0 & 0 & 0 & 18 & 1 & 19 & 0 & 21 & 43 \\
\hline 100 & 7 & B & $25-74$ & $50-100$ & 50 & 1 & 0 & 1 & 77 & 6 & 0 & 38 & 6 \\
\hline 100 & 7 & B & $75-125$ & $0-50$ & 0 & 5 & 0 & 14 & 0 & 34 & 0 & 15 & 38 \\
\hline 100 & 7 & B & $75-125$ & $0-50$ & 50 & 1 & 0 & 5 & 69 & 11 & 0 & 53 & 10 \\
\hline 100 & 7 & B & $75-125$ & $50-100$ & 0 & 11 & 0 & 11 & 0 & 28 & 0 & 15 & 40 \\
\hline 100 & 7 & B & $75-125$ & $50-100$ & 50 & 3 & 0 & 3 & 76 & 12 & 0 & 45 & 12 \\
\hline 100 & 7 & M & $25-74$ & $0-50$ & 0 & 2 & 0 & 32 & 16 & 16 & 0 & 16 & 31 \\
\hline 100 & 7 & $\mathbf{M}$ & $25-74$ & $0-50$ & 50 & 0 & 4 & 18 & 89 & 23 & 0 & 52 & 17 \\
\hline 100 & 7 & M & $25-74$ & $50-100$ & 0 & 2 & 0 & 39 & 13 & 20 & 0 & 12 & 28 \\
\hline 100 & 7 & $\mathbf{M}$ & $25-74$ & $50-100$ & 50 & 1 & 1 & 9 & 91 & 12 & 0 & 51 & 12 \\
\hline 100 & 7 & $\mathbf{M}$ & $75-125$ & $0-50$ & 0 & 6 & 2 & 26 & 15 & 17 & 0 & 16 & 27 \\
\hline 100 & 7 & M & $75-125$ & $0-50$ & 50 & 3 & 2 & 6 & 85 & 13 & 0 & 52 & 11 \\
\hline 100 & 7 & M & $75-125$ & $50-100$ & 0 & 11 & 6 & 28 & 15 & 10 & 0 & 9 & 37 \\
\hline 100 & 7 & $\mathbf{M}$ & $75-125$ & $50-100$ & 50 & 2 & 0 & 4 & 84 & 15 & 0 & 71 & 15 \\
\hline 100 & 7 & A & $25-74$ & $0-50$ & 0 & 0 & 0 & 3 & 15 & 0 & 0 & 23 & 59 \\
\hline
\end{tabular}




\begin{tabular}{cccccccccccccc}
\hline $\mathbf{1 0 0}$ & $\mathbf{7}$ & A & $\mathbf{2 5 - 7 4}$ & $\mathbf{0 - 5 0}$ & $\mathbf{5 0}$ & 0 & 0 & 2 & 67 & 0 & 0 & 32 & 1 \\
$\mathbf{1 0 0}$ & $\mathbf{7}$ & A & $\mathbf{2 5 - 7 4}$ & $\mathbf{5 0 - 1 0 0}$ & $\mathbf{0}$ & 0 & 0 & 5 & 18 & 0 & 0 & 26 & 54 \\
$\mathbf{1 0 0}$ & $\mathbf{7}$ & A & $\mathbf{2 5 - 7 4}$ & $\mathbf{5 0 - 1 0 0}$ & $\mathbf{5 0}$ & 0 & 1 & 0 & 59 & 1 & 0 & 35 & 6 \\
$\mathbf{1 0 0}$ & $\mathbf{7}$ & A & $\mathbf{7 5 - 1 2 5}$ & $\mathbf{0 - 5 0}$ & $\mathbf{0}$ & 4 & 0 & 12 & 13 & 0 & 0 & 20 & 52 \\
$\mathbf{1 0 0}$ & $\mathbf{7}$ & A & $\mathbf{7 5 - 1 2 5}$ & $\mathbf{0 - 5 0}$ & $\mathbf{5 0}$ & 0 & 0 & 2 & 66 & 0 & 0 & 26 & 7 \\
$\mathbf{1 0 0}$ & $\mathbf{7}$ & A & $\mathbf{7 5 - 1 2 5}$ & $\mathbf{5 0 - 1 0 0}$ & $\mathbf{0}$ & 5 & 2 & 11 & 13 & 0 & 0 & 24 & 48 \\
$\mathbf{1 0 0}$ & $\mathbf{7}$ & A & $\mathbf{7 5 - 1 2 5}$ & $\mathbf{5 0 - 1 0 0}$ & $\mathbf{5 0}$ & 0 & 1 & 1 & 63 & 2 & 0 & 27 & 6 \\
\hline
\end{tabular}

TABEla D.19 - Desvio relativo médio (em \%) das heurísticas para setup independente

\begin{tabular}{|c|c|c|c|c|c|c|c|c|c|c|c|c|c|}
\hline$n$ & $g$ & $f$ & $\boldsymbol{s}$ & $a$ & $l$ & Hi1 & $\mathrm{Hi2}$ & $\mathrm{Hi3}$ & $\mathrm{Hi} 4$ & Hi5 & Hi6 & Ri11 & Ri6 \\
\hline 10 & 3 & B & $25-74$ & $0-50$ & 0 & 4,3 & 5,2 & 4,0 & 5,9 & 2,4 & 73,9 & 6,8 & 2,3 \\
\hline 10 & 3 & B & $25-74$ & $0-50$ & 50 & 8,5 & 7,7 & 7,4 & 0,5 & 7,6 & 45,0 & 1,9 & 7,2 \\
\hline 10 & 3 & B & $25-74$ & $50-100$ & 0 & 3,9 & 5,1 & 3,9 & 5,5 & 2,8 & 72,9 & 6,4 & 2,7 \\
\hline 10 & 3 & B & $25-74$ & $50-100$ & 50 & 8,3 & 7,9 & 6,8 & 0,2 & 7,5 & 50,7 & 2,6 & 7,9 \\
\hline 10 & 3 & B & $75-125$ & $0-50$ & 0 & 2,9 & 5,4 & 4,9 & 5,3 & 2,2 & 75,6 & 5,4 & 2,5 \\
\hline 10 & 3 & B & $75-125$ & $0-50$ & 50 & 5,2 & 5,2 & 5,4 & 0,0 & 6,3 & 38,8 & 2,1 & 6,3 \\
\hline 10 & 3 & B & $75-125$ & $50-100$ & 0 & 2,9 & 4,7 & 4,9 & 4,6 & 2,3 & 76,8 & 5,3 & 3,7 \\
\hline 10 & 3 & B & $75-125$ & $50-100$ & 50 & 6,6 & 6,3 & 6,4 & 0,2 & 6,3 & 45,6 & 1,6 & 5,6 \\
\hline 10 & 3 & M & $25-74$ & $0-50$ & 0 & 5,5 & 4,5 & 4,1 & 1,9 & 5,0 & 45,9 & 4,6 & 4,6 \\
\hline 10 & 3 & M & $25-74$ & $0-50$ & 50 & 8,1 & 7,3 & 7,4 & 0,7 & 7,1 & 43,2 & 2,9 & 6,6 \\
\hline 10 & 3 & M & $25-74$ & $50-100$ & 0 & 4,7 & 4,3 & 3,5 & 1,5 & 4,8 & 46,2 & 5,6 & 4,6 \\
\hline 10 & 3 & M & $25-74$ & $50-100$ & 50 & 9,3 & 8,2 & 7,8 & 0,5 & 8,9 & 49,2 & 3,3 & 7,9 \\
\hline 10 & 3 & M & $75-125$ & $0-50$ & 0 & 4,2 & 4,1 & 4,0 & 2,1 & 4,8 & 47,8 & 5,6 & 5,5 \\
\hline 10 & 3 & M & $75-125$ & $0-50$ & 50 & 8,0 & 7,3 & 7,3 & 0,5 & 7,1 & 42,8 & 2,6 & 7,4 \\
\hline 10 & 3 & $\mathbf{M}$ & $75-125$ & $50-100$ & 0 & 6,3 & 6,0 & 5,7 & 1,7 & 6,1 & 50,4 & 5,1 & 6,9 \\
\hline 10 & 3 & M & $75-125$ & $50-100$ & 50 & 7,0 & 6,6 & 6,7 & 0,5 & 7,3 & 38,1 & 3,6 & 7,0 \\
\hline 10 & 3 & A & $25-74$ & $0-50$ & 0 & 10,6 & 8,8 & 7,2 & 3,1 & 14,9 & 95,1 & 6,4 & 8,0 \\
\hline 10 & 3 & A & $25-74$ & $0-50$ & 50 & 18,5 & 17,3 & 15,9 & 0,8 & 17,2 & 81,9 & 4,1 & 15,9 \\
\hline 10 & 3 & A & $25-74$ & $50-100$ & 0 & 9,9 & 8,1 & 6,8 & 3,6 & 14,3 & 96,0 & 6,4 & 7,8 \\
\hline 10 & 3 & A & $25-74$ & $50-100$ & 50 & 16,3 & 14,7 & 13,5 & 1,5 & 17,8 & 82,8 & 5,7 & 13,7 \\
\hline 10 & 3 & A & $75-125$ & $0-50$ & 0 & 7,6 & 6,7 & 6,7 & 3,7 & 12,1 & 93,0 & 5,8 & 8,3 \\
\hline 10 & 3 & A & $75-125$ & $0-50$ & 50 & 14,5 & 13,4 & 12,5 & 1,7 & 14,1 & 76,3 & 5,5 & 13,1 \\
\hline 10 & 3 & A & $75-125$ & $50-100$ & 0 & 9,1 & 8,6 & 7,7 & 3,7 & 15,4 & 97,2 & 6,2 & 8,8 \\
\hline 10 & 3 & A & $75-125$ & $50-100$ & 50 & 15,1 & 14,1 & 13,8 & 2,0 & 14,3 & 78,8 & 5,4 & 14,7 \\
\hline 10 & 5 & B & $25-74$ & $0-50$ & 0 & 4,1 & 4,8 & 3,9 & 7,3 & 3,9 & 122,2 & 7,0 & 3,3 \\
\hline 10 & 5 & B & $25-74$ & $0-50$ & 50 & 9,6 & 9,0 & 8,1 & 2,3 & 10,4 & 83,6 & 4,9 & 9,6 \\
\hline 10 & 5 & B & $25-74$ & $50-100$ & 0 & 4,5 & 5,8 & 4,2 & 6,6 & 3,2 & 123,2 & 6,8 & 3,7 \\
\hline 10 & 5 & B & $25-74$ & 50-100 & 50 & 11,5 & 11,0 & 10,0 & 2,4 & 11,7 & 82,2 & 6,4 & 11,8 \\
\hline 10 & 5 & B & $75-125$ & $0-50$ & 0 & 2,4 & 4,6 & 4,1 & 5,4 & 2,9 & 128,4 & 6,3 & 3,3 \\
\hline 10 & 5 & B & $75-125$ & $0-50$ & 50 & 9,3 & 9,8 & 9,9 & 2,0 & 9,8 & 82,5 & 6,3 & 9,9 \\
\hline 10 & 5 & B & $75-125$ & $50-100$ & 0 & 2,7 & 5,9 & 5,4 & 6,4 & 3,5 & 125,3 & 6,5 & 3,5 \\
\hline 10 & 5 & B & $75-125$ & 50-100 & 50 & 10,8 & 10,7 & 9,6 & 2,0 & 11,6 & 77,4 & 5,8 & 10,7 \\
\hline 10 & 5 & M & $25-74$ & $0-50$ & 0 & 4,9 & 5,0 & 4,0 & 5,2 & 4,7 & 102,5 & 6,0 & 4,3 \\
\hline 10 & 5 & M & $25-74$ & $0-50$ & 50 & 12,8 & 12,2 & 12,0 & 1,6 & 12,3 & 68,3 & 6,8 & 12,5 \\
\hline 10 & 5 & M & $25-74$ & $50-100$ & 0 & 4,8 & 5,1 & 3,6 & 6,4 & 5,0 & 102,5 & 7,0 & 4,9 \\
\hline 10 & 5 & M & $25-74$ & $50-100$ & 50 & 12,4 & 12,3 & 11,1 & 1,7 & 12,3 & 74,1 & 6,8 & 11,7 \\
\hline 10 & 5 & M & $75-125$ & $0-50$ & 0 & 3,6 & 5,6 & 5,0 & 5,4 & 4,6 & 101,2 & 5,8 & 4,6 \\
\hline 10 & 5 & M & $75-125$ & $0-50$ & 50 & 10,9 & 10,7 & 10,9 & 1,4 & 10,4 & 73,0 & 5,5 & 10,1 \\
\hline 10 & 5 & M & $75-125$ & $50-100$ & 0 & 3,2 & 4,8 & 4,2 & 6,2 & 4,3 & 100,1 & 6,0 & 4,3 \\
\hline 10 & 5 & M & $75-125$ & 50-100 & 50 & 10,2 & 10,1 & 10,1 & 1,4 & 11,3 & 69,9 & 6,2 & 11,9 \\
\hline 10 & 5 & A & $25-74$ & $0-50$ & 0 & 7,0 & 6,6 & 5,4 & 4,8 & 14,4 & 121,3 & 5,8 & 6,1 \\
\hline 10 & 5 & A & $25-74$ & $0-50$ & 50 & 15,6 & 14,6 & 13,2 & 1,4 & 19,9 & 88,4 & 7,9 & 14,2 \\
\hline 10 & 5 & A & $25-74$ & $50-100$ & 0 & 7,2 & 6,8 & 5,0 & 5,0 & 16,5 & 128,0 & 6,7 & 6,1 \\
\hline 10 & 5 & A & $25-74$ & $50-100$ & 50 & 13,5 & 12,2 & 11,0 & 1,3 & 15,9 & 90,5 & 6,5 & 12,0 \\
\hline 10 & 5 & A & $75-125$ & $0-50$ & 0 & 6,0 & 5,9 & 5,1 & 5,6 & 15,2 & 127,9 & 6,9 & 6,9 \\
\hline 10 & 5 & A & $75-125$ & $0-50$ & 50 & 13,4 & 12,8 & 12,5 & 2,1 & 15,5 & 94,4 & 9,0 & 12,8 \\
\hline 10 & 5 & A & $75-125$ & $50-100$ & 0 & 6,3 & 5,8 & 5,8 & 4,7 & 16,7 & 124,1 & 8,1 & 6,8 \\
\hline 10 & 5 & A & $75-125$ & $50-100$ & 50 & 12,8 & 12,4 & 11,6 & 1,1 & 15,6 & 88,7 & 6,4 & 11,3 \\
\hline
\end{tabular}




\begin{tabular}{|c|c|c|c|c|c|c|c|c|c|c|c|c|c|}
\hline 10 & 7 & B & $25-74$ & $0-50$ & 0 & 3,8 & 5,1 & 3,3 & 7,7 & 3,5 & 183,9 & 6,8 & 3,0 \\
\hline 10 & 7 & B & $25-74$ & $0-50$ & 50 & 10,9 & 10,8 & 9,2 & 3,8 & 10,9 & 117,1 & 8,1 & 10,8 \\
\hline 10 & 7 & B & $25-74$ & $50-100$ & 0 & 4,0 & 5,6 & 4,0 & 8,1 & 3,4 & 183,4 & 7,0 & 3,0 \\
\hline 10 & 7 & B & $25-74$ & $50-100$ & 50 & 12,2 & 12,3 & 11,8 & 4,5 & 12,2 & 117,6 & 7,5 & 12,7 \\
\hline 10 & 7 & B & $75-125$ & $0-50$ & 0 & 1,9 & 4,7 & 4,8 & 7,4 & 2,7 & 188,4 & 5,6 & 2,9 \\
\hline 10 & 7 & B & $75-125$ & $0-50$ & 50 & 8,1 & 8,0 & 8,3 & 3,5 & 10,1 & 107,5 & 9,4 & 10,9 \\
\hline 10 & 7 & B & $75-125$ & $50-100$ & 0 & 2,2 & 4,6 & 4,9 & 6,9 & 2,8 & 190,4 & 5,3 & 3,1 \\
\hline 10 & 7 & B & $75-125$ & $50-100$ & 50 & 10,8 & 10,8 & 9,6 & 4,0 & 10,3 & 116,2 & 8,2 & 10,8 \\
\hline 10 & 7 & M & $25-74$ & $0-50$ & 0 & 4,6 & 5,0 & 4,4 & 6,2 & 6,4 & 126,5 & 6,7 & 5,5 \\
\hline 10 & 7 & M & $25-74$ & $0-50$ & 50 & 12,8 & 12,1 & 9,0 & 3,5 & 13,7 & 94,1 & 8,6 & 11,1 \\
\hline 10 & 7 & M & $25-74$ & $50-100$ & 0 & 4,9 & 5,4 & 3,5 & 6,0 & 6,6 & 123,0 & 7,0 & 5,4 \\
\hline 10 & 7 & M & $25-74$ & $50-100$ & 50 & 12,3 & 11,7 & 10,2 & 3,1 & 11,0 & 91,7 & 6,4 & 10,2 \\
\hline 10 & 7 & M & $75-125$ & $0-50$ & 0 & 3,6 & 4,6 & 3,9 & 4,9 & 5,3 & 129,5 & 5,4 & 4,2 \\
\hline 10 & 7 & M & $75-125$ & $0-50$ & 50 & 10,5 & 10,5 & 9,5 & 1,8 & 10,4 & 89,8 & 8,1 & 10,8 \\
\hline 10 & 7 & M & $75-125$ & $50-100$ & 0 & 3,8 & 4,3 & 4,2 & 5,7 & 5,3 & 129,0 & 6,3 & 5,5 \\
\hline 10 & 7 & M & $75-125$ & $50-100$ & 50 & 12,6 & 12,6 & 12,0 & 2,7 & 14,0 & 94,6 & 6,7 & 11,9 \\
\hline 10 & 7 & A & $25-74$ & $0-50$ & 0 & 7,0 & 6,8 & 4,8 & 5,0 & 15,9 & 143,3 & 5,7 & 6,1 \\
\hline 10 & 7 & A & $25-74$ & $0-50$ & 50 & 11,7 & 11,3 & 9,7 & 1,1 & 15,9 & 97,0 & 6,9 & 10,6 \\
\hline 10 & 7 & A & $25-74$ & $50-100$ & 0 & 6,3 & 6,0 & 4,0 & 5,2 & 15,5 & 142,3 & 5,4 & 5,0 \\
\hline 10 & 7 & A & $25-74$ & $50-100$ & 50 & 12,1 & 11,9 & 10,3 & 1,0 & 14,5 & 95,0 & 7,5 & 11,1 \\
\hline 10 & 7 & A & $75-125$ & $0-50$ & 0 & 5,4 & 5,3 & 5,1 & 4,5 & 16,4 & 149,2 & 6,1 & 6,3 \\
\hline 10 & 7 & A & $75-125$ & $0-50$ & 50 & 12,4 & 12,0 & 12,1 & 1,6 & 17,0 & 105,0 & 8,0 & 13,6 \\
\hline 10 & 7 & A & $75-125$ & $50-100$ & 0 & 6,2 & 6,1 & 5,4 & 5,1 & 16,4 & 152,5 & 7,0 & 6,8 \\
\hline 10 & 7 & A & $75-125$ & $50-100$ & 50 & 13,2 & 13,2 & 12,1 & 1,5 & 18,1 & 100,2 & 6,5 & 13,6 \\
\hline 30 & 3 & B & $25-74$ & $0-50$ & 0 & 2,7 & 8,9 & 8,2 & 2,8 & 1,0 & 96,4 & 3,2 & 1,2 \\
\hline 30 & 3 & B & $25-74$ & $0-50$ & 50 & 3,4 & 3,0 & 2,7 & 0,0 & 2,5 & 62,7 & 0,1 & 2,7 \\
\hline 30 & 3 & B & $25-74$ & $50-100$ & 0 & 2,8 & 9,4 & 8,6 & 4,0 & 0,8 & 95,0 & 4,1 & 1,0 \\
\hline 30 & 3 & B & $25-74$ & $50-100$ & 50 & 3,5 & 3,3 & 3,1 & 0,0 & 2,4 & 71,3 & 0,1 & 2,4 \\
\hline 30 & 3 & B & $75-125$ & $0-50$ & 0 & 2,2 & 10,5 & 10,6 & 2,5 & 0,9 & 96,5 & 3,3 & 1,1 \\
\hline 30 & 3 & B & $75-125$ & $0-50$ & 50 & 2,7 & 2,9 & 3,0 & 0,0 & 2,3 & 67,0 & 0,0 & 2,2 \\
\hline 30 & 3 & B & $75-125$ & $50-100$ & 0 & 1,4 & 11,4 & 11,5 & 2,9 & 0,8 & 98,7 & 3,2 & 1,3 \\
\hline 30 & 3 & B & $75-125$ & $50-100$ & 50 & 2,1 & 2,2 & 1,9 & 0,0 & 1,8 & 66,6 & 0,2 & 1,7 \\
\hline 30 & 3 & M & $25-74$ & $0-50$ & 0 & 2,5 & 2,1 & 1,7 & 0,6 & 2,0 & 54,7 & 2,1 & 1,9 \\
\hline 30 & 3 & M & $25-74$ & $0-50$ & 50 & 3,2 & 3,0 & 2,6 & 0,0 & 2,8 & 36,0 & 0,1 & 2,6 \\
\hline 30 & 3 & M & $25-74$ & $50-100$ & 0 & 2,4 & 1,9 & 1,4 & 0,8 & 1,6 & 54,0 & 2,6 & 1,7 \\
\hline 30 & 3 & M & $25-74$ & $50-100$ & 50 & 2,8 & 2,5 & 2,1 & 0,0 & 2,1 & 35,4 & 0,3 & 2,2 \\
\hline 30 & 3 & M & $75-125$ & $0-50$ & 0 & 1,8 & 1,8 & 1,7 & 0,8 & 1,7 & 53,3 & 2,3 & 1,7 \\
\hline 30 & 3 & M & $75-125$ & $0-50$ & 50 & 2,4 & 2,2 & 2,1 & 0,0 & 2,2 & 42,6 & 0,1 & 2,3 \\
\hline 30 & 3 & M & $75-125$ & $50-100$ & 0 & 2,0 & 2,0 & 2,0 & 0,8 & 2,0 & 56,9 & 2,4 & 2,0 \\
\hline 30 & 3 & M & $75-125$ & $50-100$ & 50 & 1,9 & 1,7 & 1,8 & 0,0 & 1,8 & 35,3 & 0,2 & 1,8 \\
\hline 30 & 3 & A & $25-74$ & $0-50$ & 0 & 7,6 & 6,1 & 4,6 & 2,6 & 11,0 & 119,4 & 3,9 & 3,0 \\
\hline 30 & 3 & A & $25-74$ & $0-50$ & 50 & 15,0 & 12,9 & 13,3 & 1,1 & 16,9 & 110,3 & 3,2 & 13,7 \\
\hline 30 & 3 & A & $25-74$ & $50-100$ & 0 & 6,8 & 6,2 & 5,3 & 1,5 & 10,5 & 119,2 & 3,9 & 4,1 \\
\hline 30 & 3 & A & $25-74$ & $50-100$ & 50 & 15,6 & 13,7 & 12,2 & 1,2 & 15,7 & 109,8 & 2,8 & 12,5 \\
\hline 30 & 3 & A & $75-125$ & $0-50$ & 0 & 4,3 & 5,3 & 4,3 & 2,6 & 9,4 & 118,5 & 3,9 & 2,6 \\
\hline 30 & 3 & A & $75-125$ & $0-50$ & 50 & 11,8 & 10,5 & 10,5 & 1,2 & 13,0 & 111,4 & 2,5 & 10,6 \\
\hline 30 & 3 & A & $75-125$ & $50-100$ & 0 & 4,4 & 4,9 & 4,8 & 2,9 & 8,9 & 113,7 & 3,9 & 3,2 \\
\hline 30 & 3 & A & $75-125$ & $50-100$ & 50 & 13,6 & 12,6 & 11,6 & 0,9 & 13,2 & 101,0 & 2,8 & 12,1 \\
\hline 30 & 5 & B & $25-74$ & $0-50$ & 0 & 3,0 & 10,5 & 9,0 & 4,6 & 1,4 & 176,3 & 4,1 & 1,2 \\
\hline 30 & 5 & B & $25-74$ & $0-50$ & 50 & 6,7 & 7,7 & 6,8 & 0,3 & 4,9 & 128,5 & 2,0 & 5,1 \\
\hline 30 & 5 & B & $25-74$ & $50-100$ & 0 & 3,5 & 11,9 & 10,3 & 4,2 & 2,0 & 179,6 & 4,2 & 1,7 \\
\hline 30 & 5 & B & $25-74$ & $50-100$ & 50 & 6,1 & 7,2 & 6,5 & 0,2 & 5,6 & 129,8 & 2,2 & 5,5 \\
\hline 30 & 5 & B & $75-125$ & $0-50$ & 0 & 1,5 & 11,6 & 10,9 & 4,3 & 1,2 & 182,7 & 3,8 & 1,2 \\
\hline 30 & 5 & B & $75-125$ & $0-50$ & 50 & 6,1 & 7,8 & 7,6 & 0,3 & 5,7 & 131,0 & 2,4 & 5,3 \\
\hline 30 & 5 & B & $75-125$ & $50-100$ & 0 & 1,8 & 9,9 & 8,7 & 3,5 & 1,5 & 181,6 & 3,3 & 1,6 \\
\hline 30 & 5 & B & $75-125$ & $50-100$ & 50 & 5,3 & 6,2 & 6,2 & 0,2 & 5,2 & 128,0 & 1,9 & 4,9 \\
\hline 30 & 5 & M & $25-74$ & $0-50$ & 0 & 3,1 & 6,9 & 5,6 & 2,7 & 2,0 & 137,8 & 3,5 & 2,1 \\
\hline 30 & 5 & M & $25-74$ & $0-50$ & 50 & 7,1 & 7,0 & 5,5 & 0,2 & 5,8 & 105,9 & 1,5 & 5,3 \\
\hline 30 & 5 & M & $25-74$ & $50-100$ & 0 & 3,5 & 7,3 & 5,4 & 3,6 & 2,4 & 136,4 & 3,8 & 2,0 \\
\hline 30 & 5 & M & $25-74$ & $50-100$ & 50 & 6,6 & 6,9 & 6,1 & 0,2 & 5,3 & 108,2 & 1,5 & 5,1 \\
\hline 30 & 5 & M & $75-125$ & $0-50$ & 0 & 1,9 & 7,8 & 6,9 & 2,9 & 2,4 & 142,1 & 3,3 & 2,2 \\
\hline 30 & 5 & $\mathbf{M}$ & $75-125$ & $0-50$ & 50 & 5,6 & 6,4 & 5,8 & 0,2 & 5,2 & 101,9 & 1,1 & 4,8 \\
\hline
\end{tabular}




\begin{tabular}{|c|c|c|c|c|c|c|c|c|c|c|c|c|c|}
\hline 30 & 5 & M & $75-125$ & $50-100$ & 0 & 1,9 & 7,6 & 6,1 & 3,1 & 2,0 & 138,9 & 3,3 & 2,3 \\
\hline 30 & 5 & M & $75-125$ & $50-100$ & 50 & 5,2 & 5,8 & 5,7 & 0,1 & 4,9 & 103,5 & 1,2 & 4,7 \\
\hline 30 & 5 & A & $25-74$ & $0-50$ & 0 & 6,8 & 7,6 & 4,6 & 3,8 & 11,3 & 179,3 & 3,6 & 2,6 \\
\hline 30 & 5 & A & $25-74$ & $0-50$ & 50 & 19,2 & 18,4 & 16,4 & 1,2 & 20,9 & 162,3 & 5,9 & 15,7 \\
\hline 30 & 5 & A & $25-74$ & $50-100$ & 0 & 6,7 & 7,0 & 4,5 & 4,1 & 13,5 & 186,3 & 4,0 & 3,1 \\
\hline 30 & 5 & A & $25-74$ & $50-100$ & 50 & 18,8 & 18,0 & 15,8 & 0,8 & 21,5 & 169,7 & 5,7 & 15,4 \\
\hline 30 & 5 & A & $75-125$ & $0-50$ & 0 & 4,0 & 5,6 & 4,0 & 6,0 & 13,2 & 187,3 & 4,3 & 2,8 \\
\hline 30 & 5 & A & $75-125$ & $0-50$ & 50 & 14,6 & 14,6 & 13,6 & 0,7 & 19,2 & 157,1 & 5,2 & 14,4 \\
\hline 30 & 5 & A & $75-125$ & $50-100$ & 0 & 3,7 & 4,7 & 4,0 & 4,8 & 11,4 & 187,1 & 4,6 & 3,2 \\
\hline 30 & 5 & A & $75-125$ & $50-100$ & 50 & 13,9 & 13,7 & 13,4 & 1,1 & 18,6 & 169,3 & 6,1 & 14,3 \\
\hline 30 & 7 & B & $25-74$ & $0-50$ & 0 & 2,9 & 10,9 & 8,4 & 5,8 & 2,0 & 282,7 & 4,1 & 1,7 \\
\hline 30 & 7 & B & $25-74$ & $0-50$ & 50 & 9,1 & 11,0 & 10,1 & 1,6 & 8,1 & 212,8 & 4,3 & 8,1 \\
\hline 30 & 7 & B & $25-74$ & $50-100$ & 0 & 2,3 & 11,5 & 10,1 & 5,8 & 1,8 & 282,5 & 4,4 & 1,6 \\
\hline 30 & 7 & B & $25-74$ & $50-100$ & 50 & 7,4 & 8,7 & 9,1 & 1,4 & 8,4 & 213,4 & 3,6 & 8,4 \\
\hline 30 & 7 & B & $75-125$ & $0-50$ & 0 & 1,3 & 12,6 & 11,8 & 5,4 & 1,2 & 289,3 & 3,2 & 1,5 \\
\hline 30 & 7 & B & $75-125$ & $0-50$ & 50 & 6,9 & 9,3 & 9,1 & 1,3 & 7,2 & 214,8 & 4,7 & 6,6 \\
\hline 30 & 7 & B & $75-125$ & $50-100$ & 0 & 1,7 & 11,1 & 10,1 & 5,4 & 1,3 & 289,7 & 3,3 & 1,5 \\
\hline 30 & 7 & B & $75-125$ & $50-100$ & 50 & 6,3 & 9,0 & 8,9 & 1,8 & 6,6 & 222,8 & 3,7 & 6,7 \\
\hline 30 & 7 & M & $25-74$ & $0-50$ & 0 & 3,7 & 5,9 & 3,9 & 3,3 & 3,2 & 179,8 & 3,7 & 2,3 \\
\hline 30 & 7 & M & $25-74$ & $0-50$ & 50 & 7,8 & 8,1 & 5,8 & 1,0 & 7,0 & 134,9 & 2,9 & 7,3 \\
\hline 30 & 7 & M & $25-74$ & $50-100$ & 0 & 3,4 & 5,7 & 4,0 & 3,6 & 2,9 & 177,7 & 4,0 & 2,6 \\
\hline 30 & 7 & M & $25-74$ & $50-100$ & 50 & 8,8 & 9,2 & 7,7 & 0,8 & 8,3 & 141,0 & 3,0 & 7,4 \\
\hline 30 & 7 & M & $75-125$ & $0-50$ & 0 & 2,1 & 5,2 & 4,1 & 3,7 & 2,8 & 184,2 & 4,1 & 2,5 \\
\hline 30 & 7 & M & $75-125$ & $0-50$ & 50 & 5,9 & 6,3 & 6,5 & 0,9 & 6,6 & 133,1 & 2,6 & 6,1 \\
\hline 30 & 7 & M & $75-125$ & $50-100$ & 0 & 2,0 & 6,3 & 5,8 & 3,4 & 2,8 & 183,8 & 3,6 & 2,4 \\
\hline 30 & 7 & M & $75-125$ & $50-100$ & 50 & 6,1 & 6,6 & 7,0 & 0,9 & 6,9 & 140,3 & 2,8 & 6,5 \\
\hline 30 & 7 & A & $25-74$ & $0-50$ & 0 & 6,1 & 6,8 & 4,2 & 5,5 & 14,0 & 232,5 & 4,2 & 2,6 \\
\hline 30 & 7 & A & $25-74$ & $0-50$ & 50 & 16,1 & 15,8 & 12,9 & 1,1 & 20,3 & 193,1 & 5,9 & 12,8 \\
\hline 30 & 7 & A & $25-74$ & $50-100$ & 0 & 5,3 & 5,8 & 4,2 & 5,8 & 14,5 & 237,2 & 4,4 & 3,3 \\
\hline 30 & 7 & A & $25-74$ & $50-100$ & 50 & 16,3 & 16,2 & 13,3 & 1,1 & 20,6 & 210,3 & 7,1 & 13,6 \\
\hline 30 & 7 & A & $75-125$ & $0-50$ & 0 & 3,3 & 4,8 & 4,1 & 5,3 & 13,8 & 240,3 & 3,9 & 3,4 \\
\hline 30 & 7 & A & $75-125$ & $0-50$ & 50 & 12,9 & 13,3 & 13,5 & 1,4 & 20,2 & 199,4 & 7,0 & 13,8 \\
\hline 30 & 7 & A & $75-125$ & $50-100$ & 0 & 4,1 & 5,3 & 4,3 & 5,1 & 14,8 & 238,6 & 3,9 & 3,6 \\
\hline 30 & 7 & A & $75-125$ & $50-100$ & 50 & 12,2 & 12,3 & 11,6 & 1,1 & 19,3 & 204,3 & 6,4 & 12,0 \\
\hline 100 & 3 & B & $25-74$ & $0-50$ & 0 & 3,7 & 13,6 & 12,2 & 1,7 & 0,3 & 111,5 & 1,7 & 0,4 \\
\hline 100 & 3 & B & $25-74$ & $0-50$ & 50 & 1,8 & 2,4 & 2,4 & 0,0 & 0,6 & 89,7 & 0,0 & 0,6 \\
\hline 100 & 3 & B & $25-74$ & $50-100$ & 0 & 3,8 & 14,5 & 12,9 & 2,0 & 0,3 & 109,8 & 1,8 & 0,4 \\
\hline 100 & 3 & B & $25-74$ & $50-100$ & 50 & 1,6 & 2,5 & 2,5 & 0,0 & 0,6 & 89,6 & 0,0 & 0,6 \\
\hline 100 & 3 & B & $75-125$ & $0-50$ & 0 & 1,9 & 16,2 & 15,8 & 1,3 & 0,3 & 112,5 & 1,4 & 0,3 \\
\hline 100 & 3 & B & $75-125$ & $0-50$ & 50 & 0,9 & 2,5 & 2,6 & 0,0 & 0,7 & 87,9 & 0,0 & 0,8 \\
\hline 100 & 3 & B & $75-125$ & $50-100$ & 0 & 1,8 & 15,5 & 15,2 & 1,4 & 0,3 & 112,7 & 1,3 & 0,3 \\
\hline 100 & 3 & B & $75-125$ & $50-100$ & 50 & 1,0 & 2,4 & 2,3 & 0,0 & 0,7 & 87,4 & 0,0 & 0,6 \\
\hline 100 & 3 & M & $25-74$ & $0-50$ & 0 & 1,3 & 1,1 & 0,7 & 0,3 & 0,5 & 54,9 & 0,8 & 0,5 \\
\hline 100 & 3 & M & $25-74$ & $0-50$ & 50 & 0,9 & 0,7 & 0,7 & 0,0 & 0,7 & 46,4 & 0,0 & 0,7 \\
\hline 100 & 3 & M & $25-74$ & $50-100$ & 0 & 1,4 & 1,2 & 0,9 & 0,3 & 0,7 & 55,7 & 0,8 & 0,7 \\
\hline 100 & 3 & M & $25-74$ & $50-100$ & 50 & 1,3 & 1,0 & 0,9 & 0,0 & 1,0 & 49,8 & 0,0 & 0,9 \\
\hline 100 & 3 & M & $75-125$ & $0-50$ & 0 & 0,8 & 1,0 & 1,1 & 0,4 & 0,5 & 56,9 & 0,8 & 0,7 \\
\hline 100 & 3 & M & $75-125$ & $0-50$ & 50 & 0,7 & 0,6 & 0,6 & 0,0 & 0,6 & 47,3 & 0,0 & 0,6 \\
\hline 100 & 3 & M & $75-125$ & $50-100$ & 0 & 0,7 & 0,8 & 0,8 & 0,4 & 0,5 & 55,7 & 0,8 & 0,5 \\
\hline 100 & 3 & M & $75-125$ & $50-100$ & 50 & 0,7 & 0,7 & 0,5 & 0,0 & 0,6 & 42,8 & 0,0 & 0,5 \\
\hline 100 & 3 & A & $25-74$ & $0-50$ & 0 & 5,5 & 6,6 & 6,3 & 1,2 & 4,6 & 129,1 & 1,7 & 1,4 \\
\hline 100 & 3 & A & $25-74$ & $0-50$ & 50 & 6,5 & 5,1 & 5,4 & 0,3 & 4,1 & 117,1 & 0,3 & 4,0 \\
\hline 100 & 3 & A & $25-74$ & $50-100$ & 0 & 5,6 & 6,1 & 5,6 & 1,0 & 4,2 & 124,8 & 1,6 & 1,3 \\
\hline 100 & 3 & A & $25-74$ & $50-100$ & 50 & 6,7 & 5,6 & 5,8 & 0,3 & 5,0 & 116,2 & 0,4 & 4,3 \\
\hline 100 & 3 & A & $75-125$ & $0-50$ & 0 & 3,1 & 5,2 & 4,9 & 1,2 & 4,2 & 123,1 & 1,6 & 1,3 \\
\hline 100 & 3 & A & $75-125$ & $0-50$ & 50 & 4,6 & 3,9 & 4,2 & 0,5 & 3,8 & 110,3 & 0,4 & 3,4 \\
\hline 100 & 3 & A & $75-125$ & $50-100$ & 0 & 3,2 & 5,3 & 5,0 & 1,6 & 4,8 & 125,2 & 1,7 & 1,3 \\
\hline 100 & 3 & A & $75-125$ & $50-100$ & 50 & 4,9 & 4,3 & 4,4 & 0,4 & 4,2 & 115,6 & 0,5 & 3,8 \\
\hline 100 & 5 & B & $25-74$ & $0-50$ & 0 & 4,0 & 14,7 & 12,3 & 2,9 & 0,7 & 217,5 & 2,3 & 0,7 \\
\hline 100 & 5 & B & $25-74$ & $0-50$ & 50 & 3,1 & 6,4 & 6,0 & 0,0 & 1,5 & 179,2 & 0,2 & 1,5 \\
\hline 100 & 5 & B & $25-74$ & $50-100$ & 0 & 3,9 & 17,0 & 14,4 & 2,7 & 0,6 & 216,9 & 2,1 & 0,6 \\
\hline 100 & 5 & B & $25-74$ & $50-100$ & 50 & 3,5 & 7,9 & 7,0 & 0,1 & 1,7 & 181,2 & 0,2 & 1,8 \\
\hline
\end{tabular}




\begin{tabular}{|c|c|c|c|c|c|c|c|c|c|c|c|c|c|}
\hline 100 & 5 & B & $75-125$ & $0-50$ & 0 & 1,7 & 16,5 & 15,5 & 2,3 & 0,6 & 218,9 & 1,6 & $\overline{0,6}$ \\
\hline 100 & 5 & B & $75-125$ & $0-50$ & 50 & 2,2 & 7,1 & 7,1 & 0,1 & 1,5 & 178,1 & 0,0 & 1,5 \\
\hline 100 & 5 & B & $75-125$ & $50-100$ & 0 & 1,9 & 17,4 & 16,5 & 2,3 & 0,5 & 218,0 & 1,5 & 0,5 \\
\hline 100 & 5 & B & $75-125$ & $50-100$ & 50 & 2,1 & 6,5 & 6,5 & 0,0 & 1,5 & 181,4 & 0,1 & 1,4 \\
\hline 100 & 5 & M & $25-74$ & $0-50$ & 0 & 3,6 & 10,2 & 8,2 & 1,7 & 0,9 & 161,1 & 1,6 & 1,0 \\
\hline 100 & 5 & M & $25-74$ & $0-50$ & 50 & 3,1 & 4,6 & 3,7 & 0,0 & 1,9 & 140,3 & 0,2 & 1,9 \\
\hline 100 & 5 & M & $25-74$ & $50-100$ & 0 & 3,7 & 9,9 & 7,8 & 1,7 & 0,9 & 166,4 & 1,6 & 0,9 \\
\hline 100 & 5 & M & $25-74$ & $50-100$ & 50 & 2,8 & 4,1 & 3,5 & 0,0 & 1,4 & 134,7 & 0,1 & 1,4 \\
\hline 100 & 5 & M & $75-125$ & $0-50$ & 0 & 1,8 & 9,8 & 9,0 & 1,4 & 0,7 & 164,1 & 1,3 & 0,8 \\
\hline 100 & 5 & M & $75-125$ & $0-50$ & 50 & 1,9 & 4,7 & 4,5 & 0,0 & 1,5 & 137,3 & 0,0 & 1,3 \\
\hline 100 & 5 & M & $75-125$ & $50-100$ & 0 & 1,5 & 11,2 & 10,7 & 1,4 & 0,8 & 166,1 & 1,4 & 0,7 \\
\hline 100 & 5 & M & $75-125$ & $50-100$ & 50 & 2,2 & 5,1 & 4,7 & 0,0 & 1,7 & 136,2 & 0,0 & 1,6 \\
\hline 100 & 5 & A & $25-74$ & $0-50$ & 0 & 5,5 & 7,1 & 5,3 & 2,5 & 6,4 & 212,7 & 1,5 & 1,1 \\
\hline 100 & 5 & A & $25-74$ & $0-50$ & 50 & 8,5 & 7,7 & 7,1 & 0,3 & 6,2 & 196,7 & 0,7 & 5,1 \\
\hline 100 & 5 & A & $25-74$ & $50-100$ & 0 & 5,6 & 7,7 & 6,1 & 2,9 & 6,0 & 217,0 & 1,5 & 0,9 \\
\hline 100 & 5 & A & $25-74$ & $50-100$ & 50 & 9,2 & 9,1 & 8,7 & 0,3 & 8,0 & 196,2 & 0,7 & 6,2 \\
\hline 100 & 5 & A & $75-125$ & $0-50$ & 0 & 2,8 & 5,8 & 4,9 & 3,6 & 6,4 & 221,3 & 1,5 & 0,6 \\
\hline 100 & 5 & A & $75-125$ & $0-50$ & 50 & 5,8 & 6,4 & 6,3 & 0,3 & 6,4 & 191,7 & 0,6 & 4,8 \\
\hline 100 & 5 & A & $75-125$ & $50-100$ & 0 & 2,8 & 6,3 & 5,8 & 3,8 & 6,4 & 223,4 & 1,6 & 0,7 \\
\hline 100 & 5 & A & $75-125$ & $50-100$ & 50 & 6,8 & 7,1 & 6,7 & 0,3 & 6,9 & 198,9 & 0,8 & 4,9 \\
\hline 100 & 7 & B & $25-74$ & $0-50$ & 0 & 3,8 & 19,4 & 16,4 & 4,4 & 0,8 & 364,9 & 2,5 & 0,6 \\
\hline 100 & 7 & B & $25-74$ & $0-50$ & 50 & 5,0 & 14,2 & 13,1 & 0,6 & 3,4 & 311,9 & 1,9 & 3,4 \\
\hline 100 & 7 & B & $25-74$ & $50-100$ & 0 & 4,0 & 19,3 & 16,5 & 4,3 & 0,9 & 362,4 & 2,3 & 0,8 \\
\hline 100 & 7 & B & $25-74$ & $50-100$ & 50 & 5,1 & 11,2 & 10,1 & 0,4 & 3,2 & 304,9 & 1,1 & 3,1 \\
\hline 100 & 7 & B & $75-125$ & $0-50$ & 0 & 1,6 & 19,2 & 17,9 & 4,0 & 0,5 & 369,6 & 1,7 & 0,5 \\
\hline 100 & 7 & B & $75-125$ & $0-50$ & 50 & 3,6 & 11,8 & 11,6 & 0,6 & 3,1 & 308,9 & 1,0 & 3,0 \\
\hline 100 & 7 & B & $75-125$ & $50-100$ & 0 & 1,6 & 19,0 & 17,7 & 3,8 & 0,5 & 372,8 & 1,7 & 0,5 \\
\hline 100 & 7 & B & $75-125$ & $50-100$ & 50 & 3,0 & 12,3 & 12,2 & 0,5 & 2,7 & 303,7 & 1,4 & 2,7 \\
\hline 100 & 7 & M & $25-74$ & $0-50$ & 0 & 3,9 & 7,4 & 4,5 & 1,9 & 1,3 & 212,7 & 2,0 & 1,0 \\
\hline 100 & 7 & M & $25-74$ & $0-50$ & 50 & 3,6 & 5,1 & 3,7 & 0,0 & 2,5 & 189,0 & 0,7 & 2,4 \\
\hline 100 & 7 & M & $25-74$ & $50-100$ & 0 & 4,1 & 8,2 & 5,5 & 1,9 & 1,4 & 216,2 & 1,8 & 1,1 \\
\hline 100 & 7 & M & $25-74$ & $50-100$ & 50 & 4,1 & 5,3 & 3,8 & 0,1 & 2,4 & 183,3 & 0,5 & 2,4 \\
\hline 100 & 7 & M & $75-125$ & $0-50$ & 0 & 1,7 & 8,5 & 7,8 & 1,3 & 0,9 & 218,7 & 1,3 & 0,8 \\
\hline 100 & 7 & M & $75-125$ & $0-50$ & 50 & 2,7 & 4,8 & 4,6 & 0,1 & 2,5 & 179,5 & 0,5 & 2,5 \\
\hline 100 & 7 & M & $75-125$ & $50-100$ & 0 & 1,8 & 7,6 & 6,7 & 1,5 & 1,1 & 218,4 & 1,4 & 0,8 \\
\hline 100 & 7 & M & $75-125$ & $50-100$ & 50 & 2,7 & 4,5 & 4,2 & 0,1 & 2,5 & 181,3 & 0,3 & 2,4 \\
\hline 100 & 7 & A & $25-74$ & $0-50$ & 0 & 5,8 & 8,0 & 5,7 & 4,0 & 7,8 & 298,7 & 1,9 & 0,9 \\
\hline 100 & 7 & A & $25-74$ & $0-50$ & 50 & 9,9 & 9,8 & 8,7 & 0,3 & 9,4 & 270,6 & 1,2 & 6,6 \\
\hline 100 & 7 & A & $25-74$ & $50-100$ & 0 & 5,7 & 8,5 & 5,7 & 3,6 & 7,3 & 303,9 & 1,4 & 0,9 \\
\hline 100 & 7 & A & $25-74$ & $50-100$ & 50 & 9,9 & 10,4 & 8,7 & 0,5 & 9,6 & 274,8 & 1,1 & 6,2 \\
\hline 100 & 7 & A & $75-125$ & $0-50$ & 0 & 3,0 & 6,6 & 5,3 & 3,8 & 7,6 & 307,8 & 1,5 & 0,9 \\
\hline 100 & 7 & A & $75-125$ & $0-50$ & 50 & 6,7 & 8,1 & 7,8 & 0,4 & 9,3 & 272,0 & 1,4 & 5,6 \\
\hline 100 & 7 & A & $75-125$ & $50-100$ & 0 & 2,7 & 5,5 & 4,4 & 4,2 & 7,8 & 309,8 & 1,4 & 0,8 \\
\hline 100 & 7 & A & $75-125$ & $50-100$ & 50 & 7,0 & 8,1 & 7,1 & 0,4 & 8,1 & 275,4 & 1,2 & 5,1 \\
\hline
\end{tabular}

TABELA D.20 - Desvio-padrão do relativo das heurísticas para setup independente

\begin{tabular}{|c|c|c|c|c|c|c|c|c|c|c|c|c|c|}
\hline$n$ & $g$ & $f$ & $s$ & $a$ & $l$ & Hi1 & $\mathrm{Hi} 2$ & $\mathrm{Hi3}$ & $\mathrm{Hi4}$ & Hi5 & $\mathrm{Hi6}$ & Ri11 & Ri6 \\
\hline 10 & 3 & B & $25-74$ & $0-50$ & 0 & 0,04 & 0,05 & $\overline{0,04}$ & 0,05 & 0,03 & 0,17 & 0,05 & 0,03 \\
\hline 10 & 3 & B & $25-74$ & $0-50$ & 50 & 0,10 & 0,10 & 0,09 & 0,02 & 0,10 & 0,35 & 0,05 & 0,09 \\
\hline 10 & 3 & B & $25-74$ & $50-100$ & 0 & 0,04 & 0,05 & 0,05 & 0,05 & 0,04 & 0,19 & 0,05 & 0,04 \\
\hline 10 & 3 & B & $25-74$ & $50-100$ & 50 & 0,09 & 0,09 & 0,09 & 0,02 & 0,09 & 0,31 & 0,06 & 0,09 \\
\hline 10 & 3 & B & $75-125$ & $0-50$ & 0 & 0,03 & 0,05 & 0,05 & 0,05 & 0,03 & 0,20 & 0,05 & 0,03 \\
\hline 10 & 3 & B & $75-125$ & $0-50$ & 50 & 0,07 & 0,08 & 0,07 & 0,00 & 0,08 & 0,28 & 0,05 & 0,08 \\
\hline 10 & 3 & B & $75-125$ & $50-100$ & 0 & 0,03 & 0,05 & 0,05 & 0,04 & 0,03 & 0,20 & 0,05 & 0,03 \\
\hline 10 & 3 & B & $75-125$ & $50-100$ & 50 & 0,08 & 0,08 & 0,08 & 0,01 & 0,09 & 0,33 & 0,04 & 0,08 \\
\hline 10 & 3 & M & $25-74$ & $0-50$ & 0 & 0,05 & 0,05 & 0,05 & 0,03 & 0,05 & 0,20 & 0,04 & 0,05 \\
\hline 10 & 3 & M & $25-74$ & $0-50$ & 50 & 0,11 & 0,11 & 0,11 & 0,02 & 0,11 & 0,39 & 0,06 & 0,11 \\
\hline 10 & 3 & M & $25-74$ & $50-100$ & 0 & 0,05 & 0,05 & 0,05 & 0,02 & 0,05 & 0,18 & 0,05 & 0,05 \\
\hline
\end{tabular}




\begin{tabular}{|c|c|c|c|c|c|c|c|c|c|c|c|c|c|}
\hline 10 & 3 & $\bar{M}$ & $25-74$ & $50-100$ & 50 & 0,11 & 0,11 & 0,11 & 0,02 & 0,12 & 0,39 & 0,07 & 0,10 \\
\hline 10 & 3 & $\mathbf{M}$ & $75-125$ & $0-50$ & 0 & 0,04 & 0,04 & 0,04 & 0,03 & 0,04 & 0,19 & 0,05 & 0,05 \\
\hline 10 & 3 & $\mathbf{M}$ & $75-125$ & $0-50$ & 50 & 0,10 & 0,11 & 0,10 & 0,02 & 0,10 & 0,33 & 0,05 & 0,10 \\
\hline 10 & 3 & M & $75-125$ & $50-100$ & 0 & 0,06 & 0,06 & 0,06 & 0,03 & 0,06 & 0,14 & 0,04 & 0,06 \\
\hline 10 & 3 & M & $75-125$ & $50-100$ & 50 & 0,09 & 0,09 & 0,09 & 0,02 & 0,10 & 0,37 & 0,07 & 0,10 \\
\hline 10 & 3 & A & $25-74$ & $0-50$ & 0 & 0,08 & 0,09 & 0,08 & 0,04 & 0,10 & 0,39 & 0,06 & 0,08 \\
\hline 10 & 3 & A & $25-74$ & $0-50$ & 50 & 0,14 & 0,15 & 0,15 & 0,02 & 0,14 & 0,42 & 0,06 & 0,14 \\
\hline 10 & 3 & A & $25-74$ & $50-100$ & 0 & 0,08 & 0,08 & 0,07 & 0,04 & 0,09 & 0,34 & 0,06 & 0,07 \\
\hline 10 & 3 & A & $25-74$ & $50-100$ & 50 & 0,12 & 0,13 & 0,13 & 0,04 & 0,15 & 0,40 & 0,08 & 0,12 \\
\hline 10 & 3 & A & $75-125$ & $0-50$ & 0 & 0,07 & 0,07 & 0,07 & 0,05 & 0,08 & 0,33 & 0,06 & 0,07 \\
\hline 10 & 3 & A & $75-125$ & $0-50$ & 50 & 0,12 & 0,13 & 0,12 & 0,04 & 0,14 & 0,41 & 0,09 & 0,12 \\
\hline 10 & 3 & A & $75-125$ & $50-100$ & 0 & 0,08 & 0,08 & 0,07 & 0,05 & 0,09 & 0,32 & 0,06 & 0,07 \\
\hline 10 & 3 & A & $75-125$ & $50-100$ & 50 & 0,13 & 0,14 & 0,14 & 0,05 & 0,14 & 0,39 & 0,08 & 0,14 \\
\hline 10 & 5 & B & $25-74$ & $0-50$ & 0 & 0,04 & 0,05 & 0,04 & 0,05 & 0,03 & 0,22 & 0,06 & 0,04 \\
\hline 10 & 5 & B & $25-74$ & $0-50$ & 50 & 0,09 & 0,09 & 0,10 & 0,04 & 0,11 & 0,30 & 0,08 & 0,11 \\
\hline 10 & 5 & B & $25-74$ & $50-100$ & 0 & 0,05 & 0,05 & 0,04 & 0,05 & 0,04 & 0,24 & 0,06 & 0,04 \\
\hline 10 & 5 & B & $25-74$ & $50-100$ & 50 & 0,11 & 0,11 & 0,10 & 0,05 & 0,11 & 0,32 & 0,09 & 0,12 \\
\hline 10 & 5 & B & $75-125$ & $0-50$ & 0 & 0,03 & 0,04 & 0,04 & 0,04 & 0,03 & 0,23 & 0,05 & 0,03 \\
\hline 10 & 5 & B & $75-125$ & $0-50$ & 50 & 0,11 & 0,11 & 0,10 & 0,04 & 0,10 & 0,37 & 0,08 & 0,10 \\
\hline 10 & 5 & B & $75-125$ & $50-100$ & 0 & 0,04 & 0,05 & 0,05 & 0,04 & 0,04 & 0,20 & 0,05 & 0,04 \\
\hline 10 & 5 & B & $75-125$ & $50-100$ & 50 & 0,11 & 0,11 & 0,10 & 0,05 & 0,11 & 0,37 & 0,08 & 0,11 \\
\hline 10 & 5 & $\mathbf{M}$ & $25-74$ & $0-50$ & 0 & 0,05 & 0,05 & 0,04 & 0,05 & 0,04 & 0,23 & 0,06 & 0,04 \\
\hline 10 & 5 & $\mathbf{M}$ & $25-74$ & $0-50$ & 50 & 0,13 & 0,13 & 0,12 & 0,06 & 0,12 & 0,37 & 0,08 & 0,12 \\
\hline 10 & 5 & $\mathbf{M}$ & $25-74$ & $50-100$ & 0 & 0,05 & 0,05 & 0,04 & 0,05 & 0,05 & 0,24 & 0,06 & 0,05 \\
\hline 10 & 5 & M & $25-74$ & $50-100$ & 50 & 0,11 & 0,11 & 0,11 & 0,04 & 0,11 & 0,35 & 0,09 & 0,12 \\
\hline 10 & 5 & M & $75-125$ & $0-50$ & 0 & 0,04 & 0,05 & 0,05 & 0,05 & 0,05 & 0,22 & 0,05 & 0,05 \\
\hline 10 & 5 & $\mathbf{M}$ & $75-125$ & $0-50$ & 50 & 0,10 & 0,10 & 0,10 & 0,04 & 0,10 & 0,37 & 0,07 & 0,09 \\
\hline 10 & 5 & $\mathbf{M}$ & $75-125$ & $50-100$ & 0 & 0,04 & 0,05 & 0,04 & 0,05 & 0,04 & 0,22 & 0,05 & 0,05 \\
\hline 10 & 5 & M & $75-125$ & $50-100$ & 50 & 0,11 & 0,11 & 0,11 & 0,04 & 0,12 & 0,39 & 0,08 & 0,11 \\
\hline 10 & 5 & A & $25-74$ & $0-50$ & 0 & 0,06 & 0,06 & 0,06 & 0,05 & 0,07 & 0,32 & 0,06 & 0,06 \\
\hline 10 & 5 & A & $25-74$ & $0-50$ & 50 & 0,14 & 0,14 & 0,14 & 0,04 & 0,15 & 0,36 & 0,09 & 0,12 \\
\hline 10 & 5 & A & $25-74$ & $50-100$ & 0 & 0,07 & 0,07 & 0,06 & 0,05 & 0,10 & 0,34 & 0,05 & 0,07 \\
\hline 10 & 5 & A & $25-74$ & $50-100$ & 50 & 0,13 & 0,13 & 0,12 & 0,03 & 0,13 & 0,46 & 0,09 & 0,12 \\
\hline 10 & 5 & A & $75-125$ & $0-50$ & 0 & 0,06 & 0,06 & 0,06 & 0,06 & 0,08 & 0,27 & 0,06 & 0,07 \\
\hline 10 & 5 & A & $75-125$ & $0-50$ & 50 & 0,12 & 0,12 & 0,11 & 0,06 & 0,13 & 0,46 & 0,10 & 0,10 \\
\hline 10 & 5 & A & $75-125$ & $50-100$ & 0 & 0,07 & 0,07 & 0,06 & 0,05 & 0,09 & 0,35 & 0,06 & 0,06 \\
\hline 10 & 5 & A & $75-125$ & $50-100$ & 50 & 0,10 & 0,10 & 0,10 & 0,03 & 0,11 & 0,45 & 0,07 & 0,10 \\
\hline 10 & 7 & B & $25-74$ & $0-50$ & 0 & 0,04 & 0,05 & 0,04 & 0,05 & 0,03 & 0,24 & 0,06 & 0,03 \\
\hline 10 & 7 & B & $25-74$ & $0-50$ & 50 & 0,09 & 0,09 & 0,09 & 0,06 & 0,09 & 0,36 & 0,07 & 0,09 \\
\hline 10 & 7 & B & $25-74$ & $50-100$ & 0 & 0,04 & 0,04 & 0,04 & 0,06 & 0,04 & 0,26 & 0,06 & 0,04 \\
\hline 10 & 7 & B & $25-74$ & $50-100$ & 50 & 0,11 & 0,11 & 0,10 & 0,07 & 0,11 & 0,39 & 0,09 & 0,11 \\
\hline 10 & 7 & B & $75-125$ & $0-50$ & 0 & 0,02 & 0,04 & 0,04 & 0,05 & 0,03 & 0,24 & 0,05 & 0,03 \\
\hline 10 & 7 & B & $75-125$ & $0-50$ & 50 & 0,08 & 0,08 & 0,08 & 0,05 & 0,09 & 0,39 & 0,10 & 0,10 \\
\hline 10 & 7 & B & $75-125$ & $50-100$ & 0 & 0,03 & 0,04 & 0,04 & 0,05 & 0,03 & 0,25 & 0,04 & 0,03 \\
\hline 10 & 7 & B & $75-125$ & $50-100$ & 50 & 0,08 & 0,08 & 0,08 & 0,05 & 0,09 & 0,41 & 0,07 & 0,09 \\
\hline 10 & 7 & M & $25-74$ & $0-50$ & 0 & 0,05 & 0,05 & 0,05 & 0,06 & 0,06 & 0,25 & 0,06 & 0,05 \\
\hline 10 & 7 & M & $25-74$ & $0-50$ & 50 & 0,10 & 0,10 & 0,10 & 0,07 & 0,11 & 0,38 & 0,10 & 0,11 \\
\hline 10 & 7 & M & $25-74$ & $50-100$ & 0 & 0,05 & 0,05 & 0,04 & 0,05 & 0,06 & 0,25 & 0,05 & 0,05 \\
\hline 10 & 7 & $\mathbf{M}$ & $25-74$ & $50-100$ & 50 & 0,12 & 0,12 & 0,12 & 0,07 & 0,11 & 0,40 & 0,08 & 0,11 \\
\hline 10 & 7 & M & $75-125$ & $0-50$ & 0 & 0,04 & 0,05 & 0,04 & 0,04 & 0,05 & 0,24 & 0,05 & 0,04 \\
\hline 10 & 7 & M & $75-125$ & $0-50$ & 50 & 0,10 & 0,10 & 0,09 & 0,04 & 0,09 & 0,33 & 0,08 & 0,09 \\
\hline 10 & 7 & $\mathbf{M}$ & $75-125$ & $50-100$ & 0 & 0,04 & 0,04 & 0,04 & 0,05 & 0,04 & 0,24 & 0,05 & 0,05 \\
\hline 10 & 7 & M & $75-125$ & $50-100$ & 50 & 0,11 & 0,11 & 0,12 & 0,05 & 0,12 & 0,40 & 0,08 & 0,10 \\
\hline 10 & 7 & A & $25-74$ & $0-50$ & 0 & 0,06 & 0,06 & 0,06 & 0,06 & 0,07 & 0,33 & 0,05 & 0,06 \\
\hline 10 & 7 & A & $25-74$ & $0-50$ & 50 & 0,12 & 0,12 & 0,11 & 0,03 & 0,11 & 0,39 & 0,09 & 0,11 \\
\hline 10 & 7 & A & $25-74$ & $50-100$ & 0 & 0,06 & 0,06 & 0,05 & 0,05 & 0,07 & 0,29 & 0,05 & 0,05 \\
\hline 10 & 7 & A & $25-74$ & $50-100$ & 50 & 0,12 & 0,12 & 0,11 & 0,03 & 0,11 & 0,41 & 0,09 & 0,11 \\
\hline 10 & 7 & A & $75-125$ & $0-50$ & 0 & 0,06 & 0,06 & 0,05 & 0,05 & 0,07 & 0,32 & 0,06 & 0,06 \\
\hline 10 & 7 & A & $75-125$ & $0-50$ & 50 & 0,11 & 0,11 & 0,09 & 0,04 & 0,12 & 0,45 & 0,09 & 0,10 \\
\hline 10 & 7 & A & $75-125$ & $50-100$ & 0 & 0,06 & 0,06 & 0,06 & 0,06 & 0,07 & 0,34 & 0,07 & 0,06 \\
\hline 10 & 7 & A & $75-125$ & $50-100$ & 50 & 0,12 & 0,12 & 0,11 & 0,05 & 0,13 & 0,45 & 0,08 & 0,12 \\
\hline 30 & 3 & B & $25-74$ & $0-50$ & 0 & 0,03 & 0,06 & 0,06 & 0,03 & 0,01 & 0,15 & 0,02 & 0,02 \\
\hline
\end{tabular}




\begin{tabular}{|c|c|c|c|c|c|c|c|c|c|c|c|c|c|}
\hline 30 & 3 & B & $25-74$ & $0-50$ & 50 & $\overline{0,04}$ & 0,04 & 0,04 & 0,00 & 0,04 & 0,27 & $\overline{0,00}$ & 0,04 \\
\hline 30 & 3 & B & $25-74$ & $50-100$ & 0 & 0,02 & 0,06 & 0,07 & 0,03 & 0,01 & 0,14 & 0,03 & 0,02 \\
\hline 30 & 3 & B & $25-74$ & $50-100$ & 50 & 0,03 & 0,04 & 0,04 & 0,00 & 0,03 & 0,30 & 0,01 & 0,03 \\
\hline 30 & 3 & B & $75-125$ & $0-50$ & 0 & 0,02 & 0,07 & 0,08 & 0,02 & 0,01 & 0,14 & 0,02 & 0,01 \\
\hline 30 & 3 & B & $75-125$ & $0-50$ & 50 & 0,03 & 0,03 & 0,04 & 0,00 & 0,03 & 0,27 & 0,00 & 0,03 \\
\hline 30 & 3 & B & $75-125$ & $50-100$ & 0 & 0,01 & 0,07 & 0,07 & 0,02 & 0,01 & 0,16 & 0,02 & 0,01 \\
\hline 30 & 3 & B & $75-125$ & $50-100$ & 50 & 0,02 & 0,03 & 0,03 & 0,00 & 0,03 & 0,25 & 0,01 & 0,03 \\
\hline 30 & 3 & M & $25-74$ & $0-50$ & 0 & 0,02 & 0,02 & 0,02 & 0,01 & 0,02 & 0,17 & 0,02 & 0,02 \\
\hline 30 & 3 & M & $25-74$ & $0-50$ & 50 & 0,04 & 0,04 & 0,04 & 0,00 & 0,04 & 0,23 & 0,01 & 0,04 \\
\hline 30 & 3 & M & $25-74$ & $50-100$ & 0 & 0,02 & 0,02 & 0,02 & 0,01 & 0,02 & 0,17 & 0,02 & 0,02 \\
\hline 30 & 3 & M & $25-74$ & $50-100$ & 50 & 0,03 & 0,03 & 0,03 & 0,00 & 0,03 & 0,21 & 0,01 & 0,03 \\
\hline 30 & 3 & M & $75-125$ & $0-50$ & 0 & 0,02 & 0,02 & 0,02 & 0,01 & 0,02 & 0,18 & 0,02 & 0,02 \\
\hline 30 & 3 & $\mathbf{M}$ & $75-125$ & $0-50$ & 50 & 0,03 & 0,03 & 0,03 & 0,00 & 0,03 & 0,25 & 0,00 & 0,03 \\
\hline 30 & 3 & M & $75-125$ & $50-100$ & 0 & 0,02 & 0,02 & 0,02 & 0,01 & 0,02 & 0,17 & 0,02 & 0,02 \\
\hline 30 & 3 & M & $75-125$ & $50-100$ & 50 & 0,03 & 0,03 & 0,03 & 0,00 & 0,03 & 0,23 & 0,01 & 0,03 \\
\hline 30 & 3 & A & $25-74$ & $0-50$ & 0 & 0,04 & 0,04 & 0,04 & 0,03 & 0,08 & 0,30 & 0,03 & 0,04 \\
\hline 30 & 3 & A & $25-74$ & $0-50$ & 50 & 0,10 & 0,11 & 0,12 & 0,02 & 0,15 & 0,46 & 0,04 & 0,10 \\
\hline 30 & 3 & A & $25-74$ & $50-100$ & 0 & 0,04 & 0,04 & 0,04 & 0,02 & 0,08 & 0,33 & 0,03 & 0,04 \\
\hline 30 & 3 & A & $25-74$ & $50-100$ & 50 & 0,11 & 0,12 & 0,12 & 0,02 & 0,12 & 0,45 & 0,04 & 0,12 \\
\hline 30 & 3 & A & $75-125$ & $0-50$ & 0 & 0,04 & 0,04 & 0,04 & 0,03 & 0,07 & 0,28 & 0,03 & 0,04 \\
\hline 30 & 3 & A & $75-125$ & $0-50$ & 50 & 0,11 & 0,11 & 0,11 & 0,02 & 0,15 & 0,54 & 0,03 & 0,11 \\
\hline 30 & 3 & A & $75-125$ & $50-100$ & 0 & 0,03 & 0,04 & 0,04 & 0,03 & 0,06 & 0,30 & 0,03 & 0,04 \\
\hline 30 & 3 & A & $75-125$ & $50-100$ & 50 & 0,10 & 0,11 & 0,11 & 0,01 & 0,12 & 0,48 & 0,04 & 0,11 \\
\hline 30 & 5 & B & $25-74$ & $0-50$ & 0 & 0,03 & 0,06 & 0,07 & 0,03 & 0,02 & 0,20 & 0,03 & 0,02 \\
\hline 30 & 5 & B & $25-74$ & $0-50$ & 50 & 0,05 & 0,05 & 0,05 & 0,01 & 0,05 & 0,37 & 0,03 & 0,05 \\
\hline 30 & 5 & B & $25-74$ & $50-100$ & 0 & 0,03 & 0,06 & 0,07 & 0,03 & 0,02 & 0,18 & 0,03 & 0,02 \\
\hline 30 & 5 & B & $25-74$ & $50-100$ & 50 & 0,04 & 0,06 & 0,05 & 0,01 & 0,05 & 0,36 & 0,04 & 0,05 \\
\hline 30 & 5 & B & $75-125$ & $0-50$ & 0 & 0,02 & 0,08 & 0,09 & 0,03 & 0,01 & 0,18 & 0,03 & 0,02 \\
\hline 30 & 5 & B & $75-125$ & $0-50$ & 50 & 0,05 & 0,06 & 0,06 & 0,01 & 0,05 & 0,36 & 0,04 & 0,05 \\
\hline 30 & 5 & B & $75-125$ & $50-100$ & 0 & 0,02 & 0,07 & 0,08 & 0,03 & 0,02 & 0,21 & 0,02 & 0,02 \\
\hline 30 & 5 & B & $75-125$ & $50-100$ & 50 & 0,04 & 0,05 & 0,05 & 0,01 & 0,05 & 0,30 & 0,04 & 0,05 \\
\hline 30 & 5 & M & $25-74$ & $0-50$ & 0 & 0,03 & 0,05 & 0,06 & 0,03 & 0,02 & 0,20 & 0,02 & 0,03 \\
\hline 30 & 5 & $\mathbf{M}$ & $25-74$ & $0-50$ & 50 & 0,06 & 0,06 & 0,06 & 0,01 & 0,06 & 0,31 & 0,03 & 0,05 \\
\hline 30 & 5 & M & $25-74$ & $50-100$ & 0 & 0,03 & 0,05 & 0,06 & 0,03 & 0,02 & 0,21 & 0,03 & 0,02 \\
\hline 30 & 5 & $\mathbf{M}$ & $25-74$ & $50-100$ & 50 & 0,05 & 0,05 & 0,06 & 0,01 & 0,05 & 0,31 & 0,03 & 0,05 \\
\hline 30 & 5 & M & $75-125$ & $0-50$ & 0 & 0,02 & 0,07 & 0,07 & 0,03 & 0,02 & 0,20 & 0,02 & 0,02 \\
\hline 30 & 5 & M & $75-125$ & $0-50$ & 50 & 0,05 & 0,05 & 0,05 & 0,01 & 0,05 & 0,32 & 0,02 & 0,05 \\
\hline 30 & 5 & M & $75-125$ & $50-100$ & 0 & 0,02 & 0,07 & 0,07 & 0,02 & 0,02 & 0,19 & 0,02 & 0,02 \\
\hline 30 & 5 & $\mathbf{M}$ & $75-125$ & $50-100$ & 50 & 0,05 & 0,05 & 0,06 & 0,00 & 0,05 & 0,28 & 0,02 & 0,05 \\
\hline 30 & 5 & A & $25-74$ & $0-50$ & 0 & 0,05 & 0,04 & 0,04 & 0,03 & 0,06 & 0,34 & 0,03 & 0,04 \\
\hline 30 & 5 & A & $25-74$ & $0-50$ & 50 & 0,12 & 0,13 & 0,12 & 0,02 & 0,12 & 0,48 & 0,06 & 0,12 \\
\hline 30 & 5 & A & $25-74$ & $50-100$ & 0 & 0,04 & 0,04 & 0,04 & 0,04 & 0,07 & 0,33 & 0,03 & 0,04 \\
\hline 30 & 5 & A & $25-74$ & $50-100$ & 50 & 0,10 & 0,11 & 0,12 & 0,02 & 0,11 & 0,43 & 0,07 & 0,10 \\
\hline 30 & 5 & A & $75-125$ & $0-50$ & 0 & 0,04 & 0,04 & 0,04 & 0,04 & 0,06 & 0,31 & 0,03 & 0,03 \\
\hline 30 & 5 & A & $75-125$ & $0-50$ & 50 & 0,11 & 0,11 & 0,11 & 0,02 & 0,11 & 0,52 & 0,06 & 0,11 \\
\hline 30 & 5 & A & $75-125$ & $50-100$ & 0 & 0,04 & 0,04 & 0,04 & 0,04 & 0,06 & 0,35 & 0,04 & 0,04 \\
\hline 30 & 5 & A & $75-125$ & $50-100$ & 50 & 0,11 & 0,11 & 0,11 & 0,03 & 0,12 & 0,51 & 0,07 & 0,11 \\
\hline 30 & 7 & B & $25-74$ & $0-50$ & 0 & 0,03 & 0,06 & 0,06 & 0,03 & 0,02 & 0,22 & 0,03 & 0,02 \\
\hline 30 & 7 & B & $25-74$ & $0-50$ & 50 & 0,06 & 0,07 & 0,07 & 0,03 & 0,07 & 0,43 & 0,06 & 0,07 \\
\hline 30 & 7 & B & $25-74$ & $50-100$ & 0 & 0,02 & 0,06 & 0,06 & 0,04 & 0,02 & 0,21 & 0,03 & 0,02 \\
\hline 30 & 7 & B & $25-74$ & $50-100$ & 50 & 0,05 & 0,06 & 0,06 & 0,03 & 0,06 & 0,43 & 0,04 & 0,06 \\
\hline 30 & 7 & B & $75-125$ & $0-50$ & 0 & 0,01 & 0,07 & 0,07 & 0,03 & 0,01 & 0,18 & 0,02 & 0,02 \\
\hline 30 & 7 & B & $75-125$ & $0-50$ & 50 & 0,06 & 0,06 & 0,06 & 0,02 & 0,06 & 0,40 & 0,05 & 0,05 \\
\hline 30 & 7 & B & $75-125$ & $50-100$ & 0 & 0,02 & 0,07 & 0,07 & 0,03 & 0,01 & 0,20 & 0,02 & 0,02 \\
\hline 30 & 7 & B & $75-125$ & $50-100$ & 50 & 0,06 & 0,07 & 0,07 & 0,03 & 0,05 & 0,37 & 0,05 & 0,05 \\
\hline 30 & 7 & M & $25-74$ & $0-50$ & 0 & 0,03 & 0,05 & 0,05 & 0,03 & 0,03 & 0,25 & 0,03 & 0,02 \\
\hline 30 & 7 & $\mathbf{M}$ & $25-74$ & $0-50$ & 50 & 0,04 & 0,05 & 0,05 & 0,02 & 0,05 & 0,35 & 0,03 & 0,05 \\
\hline 30 & 7 & M & $25-74$ & $50-100$ & 0 & 0,03 & 0,05 & 0,05 & 0,03 & 0,03 & 0,25 & 0,03 & 0,03 \\
\hline 30 & 7 & $\mathbf{M}$ & $25-74$ & $50-100$ & 50 & 0,07 & 0,07 & 0,07 & 0,02 & 0,08 & 0,37 & 0,04 & 0,07 \\
\hline 30 & 7 & M & $75-125$ & $0-50$ & 0 & 0,02 & 0,05 & 0,06 & 0,03 & 0,02 & 0,22 & 0,03 & 0,02 \\
\hline 30 & 7 & M & $75-125$ & $0-50$ & 50 & 0,05 & 0,05 & 0,05 & 0,02 & 0,05 & 0,36 & 0,03 & 0,05 \\
\hline 30 & 7 & M & $75-125$ & $50-100$ & 0 & 0,03 & 0,06 & 0,07 & 0,03 & 0,02 & 0,22 & 0,03 & 0,02 \\
\hline
\end{tabular}




\begin{tabular}{|c|c|c|c|c|c|c|c|c|c|c|c|c|c|}
\hline 30 & 7 & $\bar{M}$ & $75-125$ & $50-100$ & 50 & 0,06 & 0,06 & 0,05 & 0,02 & 0,06 & 0,38 & 0,04 & 0,06 \\
\hline 30 & 7 & A & $25-74$ & $0-50$ & 0 & 0,04 & 0,04 & 0,03 & 0,05 & 0,06 & 0,35 & 0,04 & 0,04 \\
\hline 30 & 7 & A & $25-74$ & $0-50$ & 50 & 0,10 & 0,11 & 0,10 & 0,02 & 0,12 & 0,50 & 0,06 & 0,10 \\
\hline 30 & 7 & A & $25-74$ & $50-100$ & 0 & 0,04 & 0,04 & 0,04 & 0,04 & 0,06 & 0,31 & 0,04 & 0,04 \\
\hline 30 & 7 & A & $25-74$ & $50-100$ & 50 & 0,10 & 0,10 & 0,10 & 0,03 & 0,11 & 0,45 & 0,07 & 0,10 \\
\hline 30 & 7 & A & $75-125$ & $0-50$ & 0 & 0,04 & 0,04 & 0,04 & 0,04 & 0,04 & 0,39 & 0,03 & 0,04 \\
\hline 30 & 7 & A & $75-125$ & $0-50$ & 50 & 0,10 & 0,10 & 0,10 & 0,03 & 0,11 & 0,48 & 0,08 & 0,11 \\
\hline 30 & 7 & A & $75-125$ & $50-100$ & 0 & 0,04 & 0,04 & 0,04 & 0,04 & 0,06 & 0,32 & 0,03 & 0,04 \\
\hline 30 & 7 & A & $75-125$ & $50-100$ & 50 & 0,09 & 0,09 & 0,09 & 0,02 & 0,10 & 0,54 & 0,06 & 0,09 \\
\hline 100 & 3 & B & $25-74$ & $0-50$ & 0 & 0,02 & 0,07 & 0,09 & 0,01 & 0,01 & 0,12 & 0,01 & 0,01 \\
\hline 100 & 3 & B & $25-74$ & $0-50$ & 50 & 0,01 & 0,03 & 0,03 & 0,00 & 0,01 & 0,18 & 0,00 & 0,01 \\
\hline 100 & 3 & B & $25-74$ & $50-100$ & 0 & 0,02 & 0,07 & 0,09 & 0,01 & 0,01 & 0,10 & 0,01 & 0,01 \\
\hline 100 & 3 & B & $25-74$ & $50-100$ & 50 & 0,01 & 0,03 & 0,03 & 0,00 & 0,01 & 0,15 & 0,00 & 0,01 \\
\hline 100 & 3 & B & $75-125$ & $0-50$ & 0 & 0,01 & 0,09 & 0,10 & 0,01 & 0,01 & 0,13 & 0,01 & 0,01 \\
\hline 100 & 3 & B & $75-125$ & $0-50$ & 50 & 0,01 & 0,03 & 0,03 & 0,00 & 0,01 & 0,19 & 0,00 & 0,01 \\
\hline 100 & 3 & B & $75-125$ & $50-100$ & 0 & 0,01 & 0,10 & 0,11 & 0,01 & 0,01 & 0,13 & 0,01 & 0,01 \\
\hline 100 & 3 & B & $75-125$ & $50-100$ & 50 & 0,01 & 0,03 & 0,03 & 0,00 & 0,01 & 0,20 & 0,00 & 0,01 \\
\hline 100 & 3 & $\mathbf{M}$ & $25-74$ & $0-50$ & 0 & 0,01 & 0,01 & 0,01 & 0,00 & 0,01 & 0,15 & 0,01 & 0,01 \\
\hline 100 & 3 & $\mathbf{M}$ & $25-74$ & $0-50$ & 50 & 0,01 & 0,01 & 0,01 & 0,00 & 0,01 & 0,16 & 0,00 & 0,01 \\
\hline 100 & 3 & M & $25-74$ & $50-100$ & 0 & 0,01 & 0,01 & 0,01 & 0,00 & 0,01 & 0,16 & 0,01 & 0,01 \\
\hline 100 & 3 & $\mathbf{M}$ & $25-74$ & $50-100$ & 50 & 0,01 & 0,01 & 0,01 & 0,00 & 0,01 & 0,19 & 0,00 & 0,01 \\
\hline 100 & 3 & M & $75-125$ & $0-50$ & 0 & 0,01 & 0,01 & 0,01 & 0,01 & 0,01 & 0,17 & 0,01 & 0,01 \\
\hline 100 & 3 & $\mathbf{M}$ & $75-125$ & $0-50$ & 50 & 0,01 & 0,01 & 0,01 & 0,00 & 0,01 & 0,17 & 0,00 & 0,01 \\
\hline 100 & 3 & $\mathbf{M}$ & $75-125$ & $50-100$ & 0 & 0,01 & 0,01 & 0,01 & 0,00 & 0,01 & 0,16 & 0,01 & 0,01 \\
\hline 100 & 3 & $\mathbf{M}$ & $75-125$ & $50-100$ & 50 & 0,01 & 0,01 & 0,01 & 0,00 & 0,01 & 0,17 & 0,00 & 0,01 \\
\hline 100 & 3 & A & $25-74$ & $0-50$ & 0 & 0,02 & 0,04 & 0,05 & 0,02 & 0,04 & 0,30 & 0,01 & 0,02 \\
\hline 100 & 3 & A & $25-74$ & $0-50$ & 50 & 0,04 & 0,05 & 0,04 & 0,00 & 0,04 & 0,38 & 0,00 & 0,04 \\
\hline 100 & 3 & A & $25-74$ & $50-100$ & 0 & 0,03 & 0,04 & 0,04 & 0,02 & 0,04 & 0,32 & 0,01 & 0,02 \\
\hline 100 & 3 & A & $25-74$ & $50-100$ & 50 & 0,04 & 0,05 & 0,05 & 0,00 & 0,06 & 0,36 & 0,01 & 0,04 \\
\hline 100 & 3 & A & $75-125$ & $0-50$ & 0 & 0,02 & 0,04 & 0,04 & 0,02 & 0,04 & 0,31 & 0,01 & 0,02 \\
\hline 100 & 3 & A & $75-125$ & $0-50$ & 50 & 0,03 & 0,04 & 0,04 & 0,01 & 0,04 & 0,37 & 0,00 & 0,03 \\
\hline 100 & 3 & A & $75-125$ & $50-100$ & 0 & 0,02 & 0,04 & 0,04 & 0,02 & 0,04 & 0,32 & 0,01 & 0,02 \\
\hline 100 & 3 & A & $75-125$ & $50-100$ & 50 & 0,03 & 0,04 & 0,04 & 0,01 & 0,05 & 0,37 & 0,01 & 0,03 \\
\hline 100 & 5 & B & $25-74$ & $0-50$ & 0 & 0,02 & 0,09 & 0,11 & 0,02 & 0,01 & 0,18 & 0,02 & 0,01 \\
\hline 100 & 5 & B & $25-74$ & $0-50$ & 50 & 0,02 & 0,05 & 0,06 & 0,00 & 0,02 & 0,26 & 0,01 & 0,02 \\
\hline 100 & 5 & B & $25-74$ & $50-100$ & 0 & 0,02 & 0,09 & 0,11 & 0,02 & 0,01 & 0,15 & 0,02 & 0,01 \\
\hline 100 & 5 & B & $25-74$ & $50-100$ & 50 & 0,02 & 0,06 & 0,06 & 0,01 & 0,02 & 0,24 & 0,01 & 0,02 \\
\hline 100 & 5 & B & $75-125$ & $0-50$ & 0 & 0,01 & 0,11 & 0,12 & 0,01 & 0,01 & 0,16 & 0,01 & 0,01 \\
\hline 100 & 5 & B & $75-125$ & $0-50$ & 50 & 0,01 & 0,06 & 0,06 & 0,00 & 0,02 & 0,22 & 0,00 & 0,02 \\
\hline 100 & 5 & B & $75-125$ & $50-100$ & 0 & 0,01 & 0,11 & 0,11 & 0,01 & 0,01 & 0,15 & 0,01 & 0,01 \\
\hline 100 & 5 & B & $75-125$ & $50-100$ & 50 & 0,01 & 0,05 & 0,06 & 0,00 & 0,01 & 0,23 & 0,00 & 0,01 \\
\hline 100 & 5 & M & $25-74$ & $0-50$ & 0 & 0,02 & 0,07 & 0,09 & 0,01 & 0,01 & 0,21 & 0,01 & 0,01 \\
\hline 100 & 5 & M & $25-74$ & $0-50$ & 50 & 0,02 & 0,03 & 0,04 & 0,00 & 0,02 & 0,25 & 0,00 & 0,02 \\
\hline 100 & 5 & $\mathbf{M}$ & $25-74$ & $50-100$ & 0 & 0,02 & 0,08 & 0,10 & 0,02 & 0,01 & 0,19 & 0,02 & 0,01 \\
\hline 100 & 5 & $\mathbf{M}$ & $25-74$ & $50-100$ & 50 & 0,02 & 0,03 & 0,04 & 0,00 & 0,01 & 0,22 & 0,00 & 0,01 \\
\hline 100 & 5 & $\mathbf{M}$ & $75-125$ & $0-50$ & 0 & 0,01 & 0,10 & 0,11 & 0,01 & 0,01 & 0,19 & 0,01 & 0,01 \\
\hline 100 & 5 & M & $75-125$ & $0-50$ & 50 & 0,01 & 0,04 & 0,04 & 0,00 & 0,01 & 0,26 & 0,00 & 0,01 \\
\hline 100 & 5 & M & $75-125$ & $50-100$ & 0 & 0,01 & 0,10 & 0,11 & 0,01 & 0,01 & 0,20 & 0,01 & 0,01 \\
\hline 100 & 5 & $\mathbf{M}$ & $75-125$ & $50-100$ & 50 & 0,01 & 0,04 & 0,05 & 0,00 & 0,02 & 0,23 & 0,00 & 0,02 \\
\hline 100 & 5 & A & $25-74$ & $0-50$ & 0 & 0,02 & 0,04 & 0,04 & 0,03 & 0,05 & 0,41 & 0,01 & 0,02 \\
\hline 100 & 5 & A & $25-74$ & $0-50$ & 50 & 0,04 & 0,05 & 0,05 & 0,00 & 0,06 & 0,47 & 0,01 & 0,05 \\
\hline 100 & 5 & A & $25-74$ & $50-100$ & 0 & 0,02 & 0,04 & 0,05 & 0,03 & 0,04 & 0,41 & 0,01 & 0,02 \\
\hline 100 & 5 & A & $25-74$ & $50-100$ & 50 & 0,05 & 0,05 & 0,05 & 0,00 & 0,06 & 0,46 & 0,01 & 0,05 \\
\hline 100 & 5 & A & $75-125$ & $0-50$ & 0 & 0,02 & 0,05 & 0,05 & 0,03 & 0,06 & 0,41 & 0,01 & 0,01 \\
\hline 100 & 5 & A & $75-125$ & $0-50$ & 50 & 0,03 & 0,04 & 0,03 & 0,01 & 0,05 & 0,41 & 0,01 & 0,03 \\
\hline 100 & 5 & A & $75-125$ & $50-100$ & 0 & 0,02 & 0,05 & 0,05 & 0,03 & 0,04 & 0,40 & 0,01 & 0,01 \\
\hline 100 & 5 & A & $75-125$ & $50-100$ & 50 & 0,04 & 0,04 & 0,04 & 0,01 & 0,05 & 0,45 & 0,01 & 0,04 \\
\hline 100 & 7 & B & $25-74$ & $0-50$ & 0 & 0,02 & 0,09 & 0,10 & 0,02 & 0,01 & 0,18 & 0,02 & 0,01 \\
\hline 100 & 7 & B & $25-74$ & $0-50$ & 50 & 0,02 & 0,07 & 0,07 & 0,01 & 0,02 & 0,27 & 0,02 & 0,03 \\
\hline 100 & 7 & B & $25-74$ & $50-100$ & 0 & 0,02 & 0,09 & 0,10 & 0,02 & 0,01 & 0,18 & 0,02 & 0,01 \\
\hline 100 & 7 & B & $25-74$ & $50-100$ & 50 & 0,02 & 0,06 & 0,07 & 0,01 & 0,02 & 0,33 & 0,02 & 0,02 \\
\hline 100 & 7 & B & $75-125$ & $0-50$ & 0 & 0,01 & 0,10 & 0,11 & 0,01 & 0,01 & 0,18 & 0,01 & 0,01 \\
\hline
\end{tabular}




\begin{tabular}{|c|c|c|c|c|c|c|c|c|c|c|c|c|c|}
\hline 100 & 7 & B & $75-125$ & $0-50$ & 50 & 0,02 & 0,07 & 0,07 & 0,01 & 0,02 & 0,33 & 0,02 & 0,02 \\
\hline 100 & 7 & B & $75-125$ & $50-100$ & 0 & 0,01 & 0,10 & 0,10 & 0,01 & 0,01 & 0,19 & 0,01 & 0,01 \\
\hline 100 & 7 & B & $75-125$ & $50-100$ & 50 & 0,02 & 0,07 & 0,08 & 0,01 & 0,02 & 0,31 & 0,02 & 0,02 \\
\hline 100 & 7 & M & $25-74$ & $0-50$ & 0 & 0,02 & 0,07 & 0,08 & 0,02 & 0,01 & 0,23 & 0,02 & 0,01 \\
\hline 100 & 7 & M & $25-74$ & $0-50$ & 50 & 0,02 & 0,03 & 0,03 & 0,00 & 0,02 & 0,35 & 0,01 & 0,02 \\
\hline 100 & 7 & M & $25-74$ & $50-100$ & 0 & 0,02 & 0,07 & 0,08 & 0,02 & 0,01 & 0,24 & 0,01 & 0,01 \\
\hline 100 & 7 & M & $25-74$ & $50-100$ & 50 & 0,02 & 0,03 & 0,03 & 0,00 & 0,02 & 0,31 & 0,01 & 0,02 \\
\hline 100 & 7 & M & $75-125$ & $0-50$ & 0 & 0,01 & 0,09 & 0,10 & 0,01 & 0,01 & 0,22 & 0,01 & 0,01 \\
\hline 100 & 7 & M & $75-125$ & $0-50$ & 50 & 0,02 & 0,04 & 0,04 & 0,00 & 0,02 & 0,30 & 0,01 & 0,02 \\
\hline 100 & 7 & M & $75-125$ & $50-100$ & 0 & 0,01 & 0,09 & 0,10 & 0,01 & 0,01 & 0,23 & 0,01 & 0,01 \\
\hline 100 & 7 & M & $75-125$ & $50-100$ & 50 & 0,02 & 0,04 & 0,04 & 0,00 & 0,02 & 0,31 & 0,01 & 0,02 \\
\hline 100 & 7 & A & $25-74$ & $0-50$ & 0 & 0,02 & 0,04 & 0,04 & 0,03 & 0,04 & 0,46 & 0,02 & 0,02 \\
\hline 100 & 7 & A & $25-74$ & $0-50$ & 50 & 0,04 & 0,05 & 0,05 & 0,01 & 0,06 & 0,48 & 0,02 & 0,05 \\
\hline 100 & 7 & A & $25-74$ & $50-100$ & 0 & 0,02 & 0,05 & 0,05 & 0,03 & 0,04 & 0,43 & 0,02 & 0,01 \\
\hline 100 & 7 & A & $25-74$ & $50-100$ & 50 & 0,04 & 0,05 & 0,05 & 0,01 & 0,06 & 0,48 & 0,02 & 0,05 \\
\hline 100 & 7 & A & $75-125$ & $0-50$ & 0 & 0,01 & 0,05 & 0,05 & 0,03 & 0,04 & 0,49 & 0,01 & 0,01 \\
\hline 100 & 7 & A & $75-125$ & $0-50$ & 50 & 0,04 & 0,04 & 0,04 & 0,01 & 0,06 & 0,49 & 0,02 & 0,04 \\
\hline 100 & 7 & A & $75-125$ & $50-100$ & 0 & 0,01 & 0,05 & 0,05 & 0,03 & 0,04 & 0,45 & 0,01 & 0,01 \\
\hline 100 & 7 & A & $75-125$ & $50-100$ & 50 & 0,04 & 0,04 & 0,04 & 0,01 & 0,06 & 0,52 & 0,01 & 0,04 \\
\hline
\end{tabular}

TABELA D.21 - Resultados das regras para setu dependente por porte do problema (em \% de sucesso)

\begin{tabular}{ccccccccccccccc}
\hline $\boldsymbol{g}$ & $\boldsymbol{n}$ & $\mathbf{R d 1}$ & $\mathbf{R d 2}$ & $\mathbf{R d 3}$ & $\mathbf{R d 4}$ & $\mathbf{R d 5}$ & $\mathbf{R d 6}$ & $\mathbf{R d 7}$ & $\mathbf{R d 8}$ & $\mathbf{R d 9}$ & $\mathbf{R d 1 0}$ & $\mathbf{R d 1 1}$ & $\mathbf{R d 1 2}$ & Rd13 \\
\hline $\mathbf{3}$ & $\mathbf{1 0}$ & 25 & 23 & 22 & 28 & 17 & 40 & 25 & 23 & 17 & 38 & 21 & 27 & 24 \\
$\mathbf{3}$ & $\mathbf{3 0}$ & 9 & 6 & 6 & 8 & 4 & 20 & 10 & 6 & 3 & 21 & 7 & 8 & 8 \\
$\mathbf{3}$ & $\mathbf{5 0}$ & 7 & 5 & 5 & 8 & 3 & 21 & 8 & 6 & 2 & 20 & 5 & 8 & 7 \\
$\mathbf{3}$ & $\mathbf{8 0}$ & 7 & 5 & 6 & 7 & 3 & 20 & 7 & 6 & 3 & 18 & 5 & 7 & 8 \\
$\mathbf{3}$ & $\mathbf{1 0 0}$ & 7 & 5 & 5 & 8 & 3 & 16 & 8 & 5 & 3 & 20 & 6 & 7 & 7 \\
$\mathbf{5}$ & $\mathbf{1 0}$ & 28 & 23 & 25 & 24 & 19 & 38 & 27 & 23 & 19 & 38 & 24 & 23 & 25 \\
$\mathbf{5}$ & $\mathbf{3 0}$ & 8 & 5 & 7 & 6 & 3 & 25 & 8 & 6 & 3 & 25 & 8 & 5 & 7 \\
$\mathbf{5}$ & $\mathbf{5 0}$ & 7 & 4 & 7 & 4 & 2 & 23 & 8 & 5 & 3 & 23 & 8 & 4 & 6 \\
$\mathbf{5}$ & $\mathbf{8 0}$ & 6 & 5 & 6 & 4 & 2 & 24 & 7 & 4 & 2 & 24 & 6 & 4 & 6 \\
$\mathbf{5}$ & $\mathbf{1 0 0}$ & 7 & 4 & 6 & 5 & 2 & 23 & 7 & 4 & 2 & 22 & 6 & 5 & 6 \\
$\mathbf{7}$ & $\mathbf{1 0}$ & 28 & 22 & 25 & 23 & 19 & 35 & 27 & 22 & 19 & 36 & 26 & 22 & 25 \\
$\mathbf{7}$ & $\mathbf{3 0}$ & 8 & 5 & 9 & 4 & 3 & 24 & 9 & 5 & 3 & 22 & 9 & 5 & 7 \\
$\mathbf{7}$ & $\mathbf{5 0}$ & 7 & 5 & 7 & 3 & 3 & 23 & 8 & 4 & 3 & 24 & 7 & 3 & 7 \\
$\mathbf{7}$ & $\mathbf{8 0}$ & 7 & 4 & 7 & 3 & 3 & 23 & 7 & 3 & 3 & 24 & 7 & 3 & 6 \\
$\mathbf{7}$ & $\mathbf{1 0 0}$ & 7 & 4 & 7 & 3 & 3 & 25 & 7 & 3 & 3 & 23 & 6 & 3 & 6 \\
\hline
\end{tabular}


TABELA D.22 - Resultados das regras para setup dependente por flexibilidade e porte do problema (em \% de sucesso)

\begin{tabular}{|c|c|c|c|c|c|c|c|c|c|c|c|c|c|c|c|}
\hline$f$ & $g$ & $n$ & Rd1 & Rd2 & Rd3 & Rd4 & Rd5 & Rd6 & Rd7 & Rd8 & Rd9 & Rd10 & Rd11 & Rd12 & Rd13 \\
\hline B & 3 & 10 & 20 & 19 & 18 & 23 & 15 & 35 & 23 & 18 & 14 & 31 & 19 & 23 & 21 \\
\hline B & 3 & 30 & 9 & 7 & 8 & 9 & 4 & 19 & 10 & 6 & 3 & 17 & 7 & 8 & 7 \\
\hline B & 3 & 50 & 7 & 6 & 7 & 10 & 2 & 18 & 9 & 5 & 2 & 18 & 7 & 7 & 8 \\
\hline B & 3 & 80 & 8 & 4 & 7 & 8 & 3 & 19 & 8 & 4 & 3 & 17 & 6 & 8 & 8 \\
\hline B & 3 & 100 & 10 & 5 & 7 & 8 & 3 & 14 & 10 & 4 & 3 & 17 & 6 & 7 & 8 \\
\hline B & 5 & 10 & 25 & 19 & 20 & 18 & 14 & 36 & 23 & 19 & 15 & 33 & 19 & 19 & 21 \\
\hline B & 5 & 30 & 10 & 5 & 7 & 4 & 3 & 24 & 8 & 6 & 3 & 23 & 8 & 6 & 7 \\
\hline B & 5 & 50 & 9 & 4 & 8 & 4 & 3 & 20 & 9 & 5 & 3 & 20 & 9 & 4 & 7 \\
\hline B & 5 & 80 & 7 & 5 & 7 & 3 & 2 & 20 & 7 & 5 & 2 & 24 & 7 & 4 & 7 \\
\hline B & 5 & 100 & 9 & 3 & 5 & 6 & 3 & 21 & 8 & 4 & 3 & 21 & 7 & 4 & 8 \\
\hline B & 7 & 10 & 24 & 15 & 20 & 17 & 14 & 29 & 24 & 16 & 14 & 30 & 21 & 16 & 19 \\
\hline B & 7 & 30 & 10 & 4 & 10 & 3 & 4 & 22 & 9 & 5 & 3 & 19 & 11 & 4 & 7 \\
\hline B & 7 & 50 & 9 & 4 & 10 & 4 & 4 & 18 & 9 & 3 & 4 & 21 & 6 & 3 & 8 \\
\hline B & 7 & 80 & 10 & 4 & 7 & 3 & 3 & 23 & 8 & 2 & 3 & 19 & 8 & 3 & 8 \\
\hline B & 7 & 100 & 9 & 4 & 8 & 3 & 3 & 21 & 10 & 3 & 4 & 20 & 8 & 2 & 7 \\
\hline M & 3 & 10 & 25 & 22 & 23 & 28 & 18 & 35 & 26 & 23 & 17 & 35 & 22 & 28 & 24 \\
\hline M & 3 & 30 & 9 & 7 & 6 & 9 & 6 & 14 & 11 & 6 & 4 & 16 & 6 & 10 & 9 \\
\hline M & 3 & 50 & 8 & 6 & 5 & 8 & 5 & 16 & 8 & 7 & 3 & 14 & 5 & 10 & 9 \\
\hline M & 3 & 80 & 7 & 7 & 6 & 9 & 4 & 13 & 7 & 8 & 4 & 13 & 6 & 8 & 10 \\
\hline M & 3 & 100 & 7 & 7 & 5 & 9 & 4 & 12 & 8 & 7 & 5 & 14 & 7 & 9 & 8 \\
\hline M & 5 & 10 & 27 & 22 & 24 & 23 & 20 & 37 & 26 & 22 & 20 & 36 & 24 & 23 & 24 \\
\hline M & 5 & 30 & 8 & 5 & 8 & 7 & 3 & 21 & 8 & 7 & 3 & 24 & 8 & 5 & 9 \\
\hline M & 5 & 50 & 8 & 4 & 7 & 5 & 2 & 20 & 8 & 5 & 3 & 20 & 8 & 5 & 7 \\
\hline M & 5 & 80 & 6 & 6 & 7 & 5 & 3 & 22 & 10 & 4 & 2 & 20 & 5 & 6 & 7 \\
\hline M & 5 & 100 & 8 & 6 & 8 & 5 & 1 & 19 & 9 & 6 & 3 & 18 & 6 & 6 & 7 \\
\hline M & 7 & 10 & 30 & 24 & 27 & 24 & 21 & 38 & 27 & 23 & 22 & 38 & 26 & 23 & 27 \\
\hline M & 7 & 30 & 7 & 6 & 8 & 5 & 4 & 22 & 7 & 7 & 3 & 24 & 9 & 6 & 6 \\
\hline M & 7 & 50 & 6 & 6 & 6 & 5 & 4 & 22 & 8 & 5 & 4 & 22 & 7 & 4 & 7 \\
\hline M & 7 & 80 & 6 & 5 & 9 & 5 & 4 & 19 & 7 & 5 & 2 & 22 & 6 & 4 & 7 \\
\hline M & 7 & 100 & 7 & 5 & 8 & 4 & 3 & 23 & 5 & 4 & 2 & 20 & 7 & 6 & 7 \\
\hline A & 3 & 10 & 28 & 28 & 24 & 33 & 19 & 49 & 27 & 28 & 18 & 48 & 23 & 32 & 27 \\
\hline A & 3 & 30 & 8 & 5 & 6 & 7 & 2 & 26 & 9 & 4 & 2 & 31 & 7 & 7 & 7 \\
\hline A & 3 & 50 & 7 & 5 & 4 & 6 & 2 & 28 & 6 & 5 & 1 & 27 & 5 & 6 & 5 \\
\hline A & 3 & 80 & 6 & 3 & 4 & 6 & 2 & 28 & 5 & 6 & 3 & 24 & 4 & 6 & 6 \\
\hline A & 3 & 100 & 5 & 4 & 4 & 6 & 3 & 23 & 6 & 4 & 2 & 29 & 4 & 6 & 6 \\
\hline A & 5 & 10 & 31 & 27 & 30 & 30 & 22 & 42 & 32 & 27 & 23 & 44 & 29 & 29 & 31 \\
\hline A & 5 & 30 & 7 & 4 & 7 & 6 & 3 & 30 & 7 & 5 & 4 & 27 & 7 & 4 & 5 \\
\hline A & 5 & 50 & 6 & 4 & 6 & 4 & 2 & 31 & 7 & 4 & 2 & 28 & 6 & 4 & 5 \\
\hline A & 5 & 80 & 7 & 4 & 4 & 3 & 2 & 30 & 5 & 4 & 2 & 28 & 5 & 3 & 6 \\
\hline A & 5 & 100 & 5 & 4 & 6 & 3 & 3 & 30 & 5 & 3 & 2 & 28 & 5 & 4 & 4 \\
\hline A & 7 & 10 & 30 & 27 & 28 & 27 & 21 & 40 & 31 & 27 & 21 & 40 & 30 & 27 & 28 \\
\hline A & 7 & 30 & 8 & 5 & 9 & 5 & 2 & 27 & 10 & 4 & 3 & 25 & 8 & 4 & 7 \\
\hline A & 7 & 50 & 6 & 3 & 6 & 2 & 3 & 28 & 6 & 4 & 2 & 29 & 6 & 2 & 6 \\
\hline A & 7 & 80 & 5 & 3 & 6 & 2 & 2 & 28 & 6 & 3 & 3 & 30 & 7 & 3 & 4 \\
\hline A & 7 & 100 & 5 & 4 & 7 & 3 & 3 & 30 & 5 & 3 & 3 & 27 & 5 & 3 & 4 \\
\hline
\end{tabular}


TABELA D.23 - Resultados das regras para setup dependente por intervalo de setup e porte do problema (em \% de sucesso)

\begin{tabular}{|c|c|c|c|c|c|c|c|c|c|c|c|c|c|c|c|}
\hline$s$ & $g$ & $n$ & Rd1 & Rd2 & Rd3 & Rd4 & Rd5 & Rd6 & Rd7 & Rd8 & Rd9 & Rd10 & Rd11 & $\begin{array}{l}\text { Rd12 } \\
\end{array}$ & Rd13 \\
\hline $25-74$ & 3 & 10 & 25 & 23 & 22 & 29 & 19 & 40 & 27 & 23 & 19 & 39 & 23 & 28 & 25 \\
\hline $25-74$ & 3 & 30 & 9 & 6 & 7 & 9 & 4 & 20 & 10 & 5 & 3 & 22 & 7 & 8 & 7 \\
\hline $25-74$ & 3 & 50 & 7 & 5 & 5 & 8 & 2 & 20 & 8 & 5 & 2 & 21 & 5 & 8 & 7 \\
\hline $25-74$ & 3 & 80 & 6 & 4 & 6 & 7 & 3 & 21 & 7 & 6 & 3 & 18 & 5 & 7 & 8 \\
\hline $25-74$ & 3 & 100 & 7 & 5 & 6 & 8 & 3 & 17 & 8 & 5 & 4 & 18 & 6 & 7 & 8 \\
\hline $25-74$ & 5 & 10 & 29 & 22 & 24 & 25 & 18 & 39 & 27 & 23 & 18 & 39 & 23 & 24 & 26 \\
\hline $25-74$ & 5 & 30 & 8 & 5 & 7 & 7 & 3 & 24 & 8 & 6 & 3 & 23 & 8 & 5 & 7 \\
\hline $25-74$ & 5 & 50 & 7 & 4 & 6 & 5 & 2 & 23 & 9 & 5 & 2 & 24 & 7 & 4 & 5 \\
\hline $25-74$ & 5 & 80 & 7 & 5 & 6 & 4 & 2 & 24 & 8 & 5 & 2 & 23 & 6 & 4 & 6 \\
\hline $25-74$ & 5 & 100 & 8 & 4 & 6 & 6 & 2 & 24 & 8 & 3 & 2 & 21 & 7 & 5 & 7 \\
\hline $25-74$ & 7 & 10 & 29 & 21 & 24 & 22 & 18 & 36 & 27 & 21 & 17 & 37 & 25 & 21 & 24 \\
\hline $25-74$ & 7 & 30 & 8 & 6 & 9 & 5 & 4 & 23 & 8 & 4 & 4 & 22 & 9 & 4 & 7 \\
\hline $25-74$ & 7 & 50 & 8 & 4 & 7 & 4 & 4 & 23 & 8 & 4 & 4 & 24 & 6 & 2 & 7 \\
\hline $25-74$ & 7 & 80 & 7 & 4 & 7 & 4 & 3 & 24 & 8 & 3 & 3 & 23 & 7 & 3 & 6 \\
\hline $25-74$ & 7 & 100 & 7 & 5 & 8 & 4 & 4 & 25 & 7 & 3 & 3 & 22 & 6 & 3 & 6 \\
\hline $75-125$ & 3 & 10 & 24 & 23 & 21 & 27 & 16 & 39 & 24 & 22 & 14 & 38 & 20 & 27 & 23 \\
\hline $75-125$ & 3 & 30 & 9 & 7 & 6 & 8 & 3 & 19 & 10 & 6 & 3 & 21 & 7 & 8 & 8 \\
\hline $75-125$ & 3 & 50 & 7 & 6 & 5 & 8 & 3 & 21 & 7 & 6 & 2 & 19 & 6 & 8 & 7 \\
\hline $75-125$ & 3 & 80 & 8 & 5 & 5 & 8 & 3 & 19 & 6 & 6 & 3 & 18 & 5 & 8 & 8 \\
\hline $75-125$ & 3 & 100 & 7 & 5 & 5 & 7 & 4 & 16 & 8 & 5 & 3 & 22 & 5 & 8 & 7 \\
\hline $75-125$ & 5 & 10 & 27 & 23 & 25 & 23 & 19 & 37 & 27 & 23 & 20 & 36 & 24 & 23 & 24 \\
\hline $75-125$ & 5 & 30 & 7 & 5 & 8 & 5 & 3 & 26 & 8 & 6 & 3 & 26 & 8 & 5 & 7 \\
\hline $75-125$ & 5 & 50 & 8 & 4 & 7 & 4 & 3 & 24 & 7 & 5 & 3 & 22 & 8 & 4 & 7 \\
\hline $75-125$ & 5 & 80 & 6 & 5 & 7 & 3 & 3 & 23 & 6 & 4 & 2 & 25 & 6 & 5 & 7 \\
\hline $75-125$ & 5 & 100 & 7 & 5 & 6 & 4 & 3 & 23 & 6 & 5 & 3 & 23 & 5 & 4 & 6 \\
\hline $75-125$ & 7 & 10 & 27 & 23 & 25 & 23 & 19 & 34 & 27 & 24 & 20 & 35 & 26 & 23 & 26 \\
\hline $75-125$ & 7 & 30 & 8 & 5 & 9 & 4 & 3 & 24 & 9 & 6 & 3 & 23 & 9 & 5 & 7 \\
\hline $75-125$ & 7 & 50 & 6 & 5 & 7 & 3 & 3 & 22 & 8 & 4 & 3 & 24 & 7 & 4 & 7 \\
\hline $75-125$ & 7 & 80 & 7 & 5 & 7 & 3 & 3 & 23 & 7 & 3 & 3 & 24 & 8 & 4 & 6 \\
\hline $75-125$ & 7 & 100 & 7 & 4 & 7 & 3 & 2 & 25 & 7 & 3 & 4 & 23 & 7 & 4 & 5 \\
\hline
\end{tabular}


TABELA D.24 - Resultados das regras para setup dependente por probabilidade de antecipação do setup e porte do problema (em \% de sucesso)

\begin{tabular}{|c|c|c|c|c|c|c|c|c|c|c|c|c|c|c|c|}
\hline$a$ & $g$ & $n$ & Rd1 & Rd2 & Rd3 & Rd4 & Rd5 & Rd6 & Rd7 & Rd8 & Rd9 & Rd10 & Rd11 & Rd12 & Rd13 \\
\hline $0-50$ & 3 & 10 & 24 & 23 & 22 & 27 & 18 & 40 & 24 & 22 & 17 & 38 & 21 & 28 & 24 \\
\hline $0-50$ & 3 & 30 & 8 & 7 & 6 & 8 & 4 & 21 & 9 & 5 & 3 & 23 & 6 & 8 & 8 \\
\hline $0-50$ & 3 & 50 & 6 & 6 & 5 & 9 & 3 & 23 & 7 & 5 & 2 & 20 & 6 & 6 & 6 \\
\hline $0-50$ & 3 & 80 & 7 & 5 & 6 & 7 & 3 & 21 & 6 & 5 & 3 & 18 & 5 & 7 & 8 \\
\hline $0-50$ & 3 & 100 & 6 & 5 & 5 & 7 & 3 & 18 & 7 & 5 & 3 & 22 & 6 & 7 & 7 \\
\hline $0-50$ & 5 & 10 & 27 & 23 & 23 & 23 & 18 & 39 & 25 & 23 & 19 & 38 & 23 & 22 & 24 \\
\hline $0-50$ & 5 & 30 & 7 & 4 & 7 & 5 & 3 & 27 & 7 & 5 & 3 & 27 & 7 & 4 & 7 \\
\hline $0-50$ & 5 & 50 & 7 & 4 & 7 & 4 & 2 & 25 & 8 & 4 & 3 & 23 & 8 & 4 & 6 \\
\hline $0-50$ & 5 & 80 & 6 & 4 & 6 & 3 & 2 & 25 & 7 & 4 & 2 & 27 & 5 & 4 & 6 \\
\hline $0-50$ & 5 & 100 & 7 & 4 & 6 & 4 & 2 & 25 & 7 & 4 & 2 & 23 & 7 & 4 & 6 \\
\hline $0-50$ & 7 & 10 & 28 & 22 & 24 & 23 & 18 & 35 & 25 & 22 & 19 & 36 & 25 & 22 & 24 \\
\hline $0-50$ & 7 & 30 & 8 & 5 & 9 & 3 & 3 & 25 & 9 & 4 & 3 & 23 & 9 & 4 & 8 \\
\hline $0-50$ & 7 & 50 & 7 & 4 & 6 & 4 & 4 & 23 & 7 & 4 & 3 & 25 & 6 & 3 & 7 \\
\hline $0-50$ & 7 & 80 & 7 & 4 & 7 & 3 & 3 & 25 & 6 & 3 & 3 & 26 & 6 & 3 & 6 \\
\hline $0-50$ & 7 & 100 & 7 & 4 & 6 & 3 & 3 & 25 & 7 & 4 & 3 & 23 & 6 & 3 & 6 \\
\hline 50-100 & 3 & 10 & 25 & 23 & 21 & 29 & 17 & 40 & 26 & 23 & 16 & 38 & 22 & 27 & 24 \\
\hline $50-100$ & 3 & 30 & 10 & 6 & 7 & 8 & 4 & 19 & 12 & 6 & 3 & 20 & 8 & 8 & 7 \\
\hline 50-100 & 3 & 50 & 8 & 5 & 5 & 8 & 3 & 18 & 8 & 6 & 2 & 19 & 5 & 9 & 8 \\
\hline 50-100 & 3 & 80 & 7 & 4 & 5 & 7 & 3 & 19 & 7 & 7 & 4 & 18 & 5 & 7 & 8 \\
\hline 50-100 & 3 & 100 & 8 & 6 & 5 & 8 & 4 & 14 & 9 & 5 & 3 & 18 & 5 & 7 & 8 \\
\hline $50-100$ & 5 & 10 & 29 & 22 & 26 & 24 & 19 & 37 & 29 & 22 & 19 & 38 & 25 & 25 & 26 \\
\hline 50-100 & 5 & 30 & 8 & 6 & 7 & 6 & 3 & 23 & 8 & 6 & 3 & 23 & 8 & 6 & 7 \\
\hline $50-100$ & 5 & 50 & 8 & 4 & 6 & 4 & 3 & 22 & 8 & 6 & 3 & 23 & 8 & 4 & 6 \\
\hline 50-100 & 5 & 80 & 7 & 6 & 6 & 4 & 3 & 22 & 7 & 5 & 2 & 22 & 7 & 4 & 7 \\
\hline 50-100 & 5 & 100 & 8 & 5 & 7 & 5 & 2 & 22 & 7 & 5 & 3 & 22 & 5 & 5 & 7 \\
\hline 50-100 & 7 & 10 & 28 & 22 & 25 & 22 & 19 & 36 & 29 & 22 & 19 & 36 & 27 & 22 & 25 \\
\hline 50-100 & 7 & 30 & 9 & 5 & 9 & 5 & 3 & 23 & 9 & 6 & 3 & 22 & 9 & 5 & 6 \\
\hline 50-100 & 7 & 50 & 7 & 5 & 8 & 3 & 3 & 22 & 8 & 4 & 3 & 22 & 8 & 3 & 7 \\
\hline $50-100$ & 7 & 80 & 7 & 5 & 8 & 4 & 4 & 21 & 8 & 3 & 3 & 21 & 9 & 4 & 7 \\
\hline 50-100 & 7 & 100 & 7 & 4 & 9 & 4 & 3 & 24 & 7 & 3 & 3 & 22 & 7 & 4 & 6 \\
\hline
\end{tabular}


TABELA D.25 - Resultados das regras para setup dependente por probabilidade de salto e porte do problema (em \% de sucesso)

\begin{tabular}{|c|c|c|c|c|c|c|c|c|c|c|c|c|c|c|c|}
\hline$S$ & $g$ & $n$ & Rd1 & Rd2 & Rd3 & Rd4 & Rd5 & Rd6 & Rd7 & Rd8 & Rd9 & Rd10 & Rd11 & Rd12 & Rd13 \\
\hline 10 & 3 & 10 & 11 & 5 & 9 & 11 & 5 & 20 & 12 & 4 & 4 & 19 & 8 & 11 & 9 \\
\hline 10 & 3 & 30 & 8 & 4 & 7 & 7 & 4 & 18 & 9 & 3 & 3 & 20 & 7 & 7 & 6 \\
\hline 10 & 3 & 50 & 7 & 4 & 6 & 8 & 3 & 22 & 7 & 4 & 2 & 21 & 6 & 8 & 5 \\
\hline 10 & 3 & 80 & 7 & 3 & 6 & 7 & 3 & 21 & 7 & 5 & 4 & 19 & 6 & 7 & 7 \\
\hline 10 & 3 & 100 & 7 & 4 & 6 & 7 & 3 & 18 & 8 & 4 & 4 & 21 & 6 & 7 & 6 \\
\hline 10 & 5 & 10 & 14 & 5 & 11 & 7 & 5 & 18 & 13 & 6 & 5 & 19 & 10 & 6 & 8 \\
\hline 10 & 5 & 30 & 9 & 3 & 9 & 3 & 3 & 21 & 8 & 4 & 4 & 21 & 8 & 3 & 6 \\
\hline 10 & 5 & 50 & 8 & 3 & 9 & 2 & 3 & 21 & 9 & 3 & 4 & 21 & 10 & 3 & 5 \\
\hline 10 & 5 & 80 & 7 & 4 & 7 & 3 & 3 & 23 & 9 & 3 & 3 & 23 & 8 & 3 & 6 \\
\hline 10 & 5 & 100 & 7 & 4 & 8 & 3 & 3 & 23 & 7 & 3 & 3 & 22 & 8 & 4 & 6 \\
\hline 10 & 7 & 10 & 14 & 6 & 10 & 5 & 6 & 16 & 13 & 7 & 6 & 17 & 12 & 5 & 10 \\
\hline 10 & 7 & 30 & 9 & 4 & 10 & 3 & 3 & 20 & 10 & 3 & 4 & 18 & 10 & 3 & 6 \\
\hline 10 & 7 & 50 & 9 & 3 & 10 & 3 & 5 & 20 & 9 & 3 & 4 & 21 & 7 & 2 & 7 \\
\hline 10 & 7 & 80 & 8 & 3 & 9 & 3 & 4 & 20 & 8 & 3 & 4 & 21 & 10 & 2 & 7 \\
\hline 10 & 7 & 100 & 9 & 3 & 9 & 3 & 4 & 23 & 9 & 2 & 4 & 19 & 8 & 3 & 6 \\
\hline 50 & 3 & 10 & 38 & 42 & 34 & 45 & 29 & 59 & 38 & 41 & 29 & 57 & 35 & 44 & 39 \\
\hline 50 & 3 & 30 & 10 & 9 & 6 & 9 & 4 & 22 & 11 & 9 & 3 & 23 & 7 & 10 & 9 \\
\hline 50 & 3 & 50 & 7 & 7 & 4 & 9 & 3 & 19 & 9 & 7 & 2 & 19 & 5 & 8 & 9 \\
\hline 50 & 3 & 80 & 6 & 6 & 5 & 8 & 3 & 19 & 7 & 8 & 2 & 18 & 5 & 7 & 9 \\
\hline 50 & 3 & 100 & 7 & 7 & 5 & 9 & 3 & 14 & 8 & 6 & 3 & 19 & 5 & 8 & 8 \\
\hline 50 & 5 & 10 & 42 & 40 & 38 & 41 & 32 & 58 & 41 & 40 & 33 & 57 & 38 & 41 & 42 \\
\hline 50 & 5 & 30 & 7 & 7 & 6 & 8 & 3 & 29 & 8 & 8 & 3 & 28 & 7 & 7 & 8 \\
\hline 50 & 5 & 50 & 7 & 5 & 5 & 6 & 2 & 26 & 7 & 7 & 2 & 24 & 6 & 5 & 8 \\
\hline 50 & 5 & 80 & 6 & 6 & 5 & 4 & 2 & 24 & 6 & 6 & 1 & 25 & 4 & 6 & 7 \\
\hline 50 & 5 & 100 & 8 & 5 & 5 & 6 & 2 & 24 & 7 & 5 & 2 & 23 & 4 & 5 & 7 \\
\hline 50 & 7 & 10 & 42 & 38 & 39 & 40 & 31 & 54 & 41 & 38 & 32 & 55 & 39 & 39 & 39 \\
\hline 50 & 7 & 30 & 7 & 7 & 8 & 6 & 3 & 28 & 8 & 8 & 3 & 27 & 8 & 7 & 8 \\
\hline 50 & 7 & 50 & 5 & 6 & 5 & 4 & 2 & 25 & 7 & 5 & 3 & 27 & 6 & 3 & 7 \\
\hline 50 & 7 & 80 & 6 & 5 & 6 & 4 & 3 & 26 & 6 & 4 & 2 & 27 & 5 & 4 & 6 \\
\hline 50 & 7 & 100 & 5 & 5 & 6 & 4 & 2 & 27 & 5 & 5 & 2 & 26 & 5 & 4 & 5 \\
\hline
\end{tabular}

TABELA D.26 - Desvio relativo médio (em \%) das regras para setup dependente por porte do problema

\begin{tabular}{ccccccccccccccc}
\hline $\mathbf{g}$ & $\boldsymbol{n}$ & $\mathbf{R d 1}$ & $\mathbf{R d 2}$ & $\mathbf{R d 3}$ & $\mathbf{R d 4}$ & $\mathbf{R d 5}$ & $\mathbf{R d 6}$ & $\mathbf{R d 7}$ & $\mathbf{R d 8}$ & $\mathbf{R d 9}$ & $\mathbf{R d 1 0}$ & $\mathbf{R d 1 1}$ & $\mathbf{R d 1 2}$ & $\mathbf{R d 1 3}$ \\
\hline $\mathbf{3}$ & $\mathbf{1 0}$ & $\mathbf{7 , 7}$ & $\mathbf{9 , 8}$ & 11,3 & 6,7 & 12,6 & 4,0 & 7,7 & 9,8 & 12,7 & 4,1 & 11,2 & 6,7 & 8,5 \\
$\mathbf{3}$ & $\mathbf{3 0}$ & 5,2 & 6,9 & 7,8 & 5,2 & 8,7 & 2,9 & 5,3 & 6,9 & 8,6 & 2,9 & 7,7 & 5,1 & 5,8 \\
$\mathbf{3}$ & $\mathbf{5 0}$ & 4,0 & 5,3 & 6,1 & 4,2 & 6,4 & 2,1 & 4,0 & 5,3 & 6,4 & 2,1 & 5,9 & 4,1 & 4,3 \\
$\mathbf{3}$ & $\mathbf{8 0}$ & 3,0 & 4,1 & 4,7 & 3,3 & 4,7 & 1,7 & 3,1 & 4,1 & 4,7 & 1,7 & 4,6 & 3,2 & 3,1 \\
$\mathbf{3}$ & $\mathbf{1 0 0}$ & 2,6 & 3,7 & 4,2 & 3,1 & 4,0 & 1,6 & 2,5 & 3,7 & 4,0 & 1,6 & 4,0 & 3,0 & 2,7 \\
$\mathbf{5}$ & $\mathbf{1 0}$ & 6,7 & 9,9 & 8,8 & 8,2 & 11,5 & 4,6 & 6,7 & 9,8 & 11,4 & 4,6 & 8,7 & 8,3 & 7,9 \\
$\mathbf{5}$ & $\mathbf{3 0}$ & 5,8 & 8,0 & 7,4 & 7,4 & $\mathbf{9 , 7}$ & 2,9 & 5,9 & 8,0 & 9,6 & 2,9 & 7,2 & 7,3 & 6,4 \\
$\mathbf{5}$ & $\mathbf{5 0}$ & 4,5 & 6,1 & 5,7 & 6,2 & 7,3 & 2,1 & 4,4 & 6,1 & 7,2 & 2,2 & 5,6 & 6,0 & 4,8 \\
$\mathbf{5}$ & $\mathbf{8 0}$ & 3,4 & 4,9 & 4,5 & 5,0 & 5,5 & 1,6 & 3,3 & 5,0 & 5,5 & 1,7 & 4,4 & 4,8 & 3,6 \\
$\mathbf{5}$ & $\mathbf{1 0 0}$ & 2,9 & 4,3 & 4,0 & 4,7 & 4,7 & 1,5 & 3,0 & 4,3 & 4,7 & 1,6 & 3,9 & 4,5 & 3,1 \\
$\mathbf{7}$ & $\mathbf{1 0}$ & 6,2 & $\mathbf{9} 3$ & 7,6 & 8,5 & 10,6 & 4,9 & 6,3 & 9,1 & 10,5 & 4,8 & 7,7 & 8,5 & 7,5 \\
$\mathbf{7}$ & $\mathbf{3 0}$ & 5,8 & $\mathbf{7 , 9}$ & 6,7 & 8,0 & $\mathbf{9 , 2}$ & 3,3 & 5,8 & 7,9 & 9,1 & 3,3 & 6,7 & 7,7 & 6,5 \\
$\mathbf{7}$ & $\mathbf{5 0}$ & 4,7 & 6,2 & 5,3 & 6,7 & 7,3 & 2,3 & 4,7 & 6,2 & 7,2 & 2,4 & 5,2 & 6,5 & 5,0 \\
$\mathbf{7}$ & $\mathbf{8 0}$ & 3,6 & 5,2 & 4,4 & 5,8 & 5,8 & 1,9 & 3,6 & 5,2 & 5,7 & 1,9 & 4,3 & 5,6 & 4,0 \\
$\mathbf{7}$ & $\mathbf{1 0 0}$ & 3,2 & 4,7 & 3,9 & 5,3 & 5,0 & 1,6 & 3,2 & 4,7 & 5,0 & 1,7 & 3,9 & 5,1 & 3,4 \\
\hline
\end{tabular}


TABELA D.27 - Desvio-padrão do desvio relativo das regras para setup dependente por porte do problema

\begin{tabular}{ccccccccccccccc}
\hline $\mathbf{g}$ & $\boldsymbol{n}$ & $\mathbf{R d 1}$ & $\mathbf{R d 2}$ & $\mathbf{R d 3}$ & $\mathbf{R d 4}$ & $\mathbf{R d 5}$ & $\mathbf{R d 6}$ & $\mathbf{R d 7}$ & $\mathbf{R d 8}$ & $\mathbf{R d 9}$ & $\mathbf{R d 1 0}$ & $\mathbf{R d 1 1}$ & $\mathbf{R d 1 2}$ & $\mathbf{R d 1 3}$ \\
\hline $\mathbf{3}$ & $\mathbf{1 0}$ & 0,08 & 0,09 & 0,11 & 0,07 & 0,11 & 0,05 & 0,08 & 0,09 & 0,11 & 0,05 & 0,11 & 0,07 & 0,09 \\
$\mathbf{3}$ & $\mathbf{3 0}$ & 0,04 & 0,05 & 0,06 & 0,04 & 0,06 & 0,03 & 0,04 & 0,05 & 0,06 & 0,03 & 0,06 & 0,04 & 0,04 \\
$\mathbf{3}$ & $\mathbf{5 0}$ & 0,03 & 0,04 & 0,04 & 0,03 & 0,04 & 0,02 & 0,03 & 0,04 & 0,04 & 0,02 & 0,04 & 0,03 & 0,03 \\
$\mathbf{3}$ & $\mathbf{8 0}$ & 0,02 & 0,03 & 0,04 & 0,03 & 0,03 & 0,02 & 0,02 & 0,03 & 0,03 & 0,02 & 0,04 & 0,02 & 0,02 \\
$\mathbf{3}$ & $\mathbf{1 0 0}$ & 0,02 & 0,03 & 0,03 & 0,03 & 0,03 & 0,01 & 0,02 & 0,03 & 0,02 & 0,01 & 0,03 & 0,02 & 0,02 \\
$\mathbf{5}$ & $\mathbf{1 0}$ & 0,07 & 0,09 & 0,10 & 0,08 & 0,11 & 0,06 & 0,07 & 0,09 & 0,11 & 0,06 & 0,09 & 0,08 & 0,08 \\
$\mathbf{5}$ & $\mathbf{3 0}$ & 0,04 & 0,06 & 0,06 & 0,05 & 0,06 & 0,03 & 0,05 & 0,06 & 0,06 & 0,03 & 0,06 & 0,05 & 0,05 \\
$\mathbf{5}$ & $\mathbf{5 0}$ & 0,03 & 0,04 & 0,05 & 0,04 & 0,04 & 0,02 & 0,03 & 0,04 & 0,05 & 0,02 & 0,05 & 0,04 & 0,03 \\
$\mathbf{5}$ & $\mathbf{8 0}$ & 0,02 & 0,03 & 0,04 & 0,03 & 0,03 & 0,02 & 0,02 & 0,03 & 0,03 & 0,02 & 0,04 & 0,03 & 0,02 \\
$\mathbf{5}$ & $\mathbf{1 0 0}$ & 0,02 & 0,03 & 0,03 & 0,03 & 0,03 & 0,01 & 0,02 & 0,03 & 0,03 & 0,01 & 0,03 & 0,03 & 0,02 \\
$\mathbf{7}$ & $\mathbf{1 0}$ & 0,07 & 0,09 & 0,08 & 0,08 & 0,10 & 0,06 & 0,07 & 0,09 & 0,10 & 0,06 & 0,08 & 0,08 & 0,08 \\
$\mathbf{7}$ & $\mathbf{3 0}$ & 0,04 & 0,05 & 0,06 & 0,05 & 0,06 & 0,03 & 0,05 & 0,06 & 0,06 & 0,03 & 0,05 & 0,05 & 0,05 \\
$\mathbf{7}$ & $\mathbf{5 0}$ & 0,03 & 0,04 & 0,04 & 0,04 & 0,05 & 0,02 & 0,03 & 0,04 & 0,05 & 0,02 & 0,04 & 0,04 & 0,04 \\
$\mathbf{7}$ & $\mathbf{8 0}$ & 0,02 & 0,04 & 0,03 & 0,04 & 0,03 & 0,02 & 0,03 & 0,04 & 0,03 & 0,02 & 0,03 & 0,04 & 0,03 \\
$\mathbf{7}$ & $\mathbf{1 0 0}$ & 0,02 & 0,03 & 0,03 & 0,04 & 0,03 & 0,02 & 0,02 & 0,03 & 0,03 & 0,02 & 0,03 & 0,03 & 0,02 \\
\hline
\end{tabular}

TABELA D.28 - Resultado das regras para setup dependente por parâmetro (em \% de sucesso)

\begin{tabular}{|c|c|c|c|c|c|c|c|c|c|c|c|c|c|c|c|c|c|c|}
\hline$n$ & $g$ & $f$ & $s$ & $a$ & $l$ & Rd1 & Rd2 & Rd3 & Rd4 & Rd5 & Rd6 & Rd7 & Rd8 & Rd9 & Rd10 & Rd11 & Rd12 & Rd13 \\
\hline 10 & 3 & B & $25-74$ & $0-50$ & 10 & 8 & 5 & 5 & 8 & 9 & 18 & 16 & 7 & 5 & 16 & 11 & 6 & 7 \\
\hline 10 & 3 & B & $25-74$ & $0-50$ & 50 & 28 & 34 & 30 & 34 & 30 & 53 & 34 & 32 & 32 & 50 & 31 & 33 & 35 \\
\hline 10 & 3 & B & $25-74$ & $50-100$ & 10 & 6 & 3 & 8 & 14 & 2 & 19 & 9 & 1 & 4 & 19 & 13 & 10 & 10 \\
\hline 10 & 3 & B & $25-74$ & 50-100 & 50 & 28 & 32 & 23 & 33 & 20 & 48 & 29 & 34 & 20 & 41 & 24 & 32 & 32 \\
\hline 10 & 3 & B & $75-125$ & $0-50$ & 10 & 11 & 2 & 13 & 8 & 3 & 22 & 10 & 2 & 4 & 20 & 5 & 13 & 6 \\
\hline 10 & 3 & B & $75-125$ & $0-50$ & 50 & 33 & 32 & 26 & 38 & 22 & 46 & 32 & 28 & 20 & 42 & 26 & 41 & 33 \\
\hline 10 & 3 & B & $75-125$ & $50-100$ & 10 & 12 & 4 & 8 & 12 & 6 & 20 & 21 & 4 & 4 & 12 & 5 & 7 & 10 \\
\hline 10 & 3 & B & $75-125$ & $50-100$ & 50 & 36 & 37 & 33 & 40 & 27 & 52 & 33 & 34 & 26 & 51 & 34 & 39 & 35 \\
\hline 10 & 3 & M & $25-74$ & $0-50$ & 10 & 7 & 4 & 16 & 12 & 5 & 11 & 10 & 4 & 6 & 17 & 9 & 11 & 12 \\
\hline 10 & 3 & M & $25-74$ & $0-50$ & 50 & 40 & 37 & 34 & 44 & 31 & 52 & 43 & 37 & 31 & 52 & 33 & 43 & 42 \\
\hline 10 & 3 & M & $25-74$ & $50-100$ & 10 & 11 & 4 & 12 & 8 & 9 & 17 & 11 & 4 & 6 & 19 & 10 & 15 & 4 \\
\hline 10 & 3 & M & $25-74$ & $50-100$ & 50 & 45 & 39 & 39 & 47 & 32 & 57 & 45 & 42 & 35 & 53 & 40 & 43 & 43 \\
\hline 10 & 3 & M & $75-125$ & $0-50$ & 10 & 11 & 8 & 5 & 13 & 6 & 24 & 9 & 6 & 1 & 16 & 7 & 10 & 9 \\
\hline 10 & 3 & M & $75-125$ & $0-50$ & 50 & 39 & 41 & 35 & 44 & 30 & 51 & 37 & 42 & 29 & 50 & 34 & 45 & 35 \\
\hline 10 & 3 & M & $75-125$ & $50-100$ & 10 & 11 & 7 & 6 & 13 & 1 & 13 & 11 & 9 & 2 & 18 & 7 & 15 & 9 \\
\hline 10 & 3 & $\mathbf{M}$ & $75-125$ & $50-100$ & 50 & 39 & 37 & 38 & 40 & 30 & 56 & 39 & 37 & 27 & 58 & 36 & 39 & 36 \\
\hline 10 & 3 & A & $25-74$ & $0-50$ & 10 & 16 & 6 & 5 & 9 & 6 & 30 & 11 & 4 & 3 & 27 & 7 & 12 & 7 \\
\hline 10 & 3 & A & $25-74$ & $0-50$ & 50 & 46 & 56 & 48 & 58 & 39 & 75 & 45 & 53 & 39 & 74 & 47 & 58 & 50 \\
\hline 10 & 3 & A & $25-74$ & $50-100$ & 10 & 19 & 1 & 6 & 13 & 6 & 24 & 16 & 1 & 5 & 22 & 5 & 12 & 10 \\
\hline 10 & 3 & A & $25-74$ & 50-100 & 50 & 51 & 59 & 38 & 67 & 39 & 76 & 50 & 58 & 38 & 74 & 40 & 66 & 51 \\
\hline 10 & 3 & A & $75-125$ & $0-50$ & 10 & 12 & 6 & 10 & 12 & 6 & 24 & 9 & 6 & 2 & 23 & 6 & 10 & 7 \\
\hline 10 & 3 & A & $75-125$ & $0-50$ & 50 & 37 & 47 & 37 & 49 & 27 & 72 & 36 & 47 & 28 & 74 & 36 & 49 & 45 \\
\hline 10 & 3 & A & $75-125$ & $50-100$ & 10 & 11 & 4 & 15 & 13 & 5 & 23 & 10 & 4 & 6 & 24 & 12 & 6 & 13 \\
\hline 10 & 3 & A & $75-125$ & $50-100$ & 50 & 35 & 47 & 31 & 43 & 23 & 69 & 36 & 50 & 23 & 66 & 33 & 44 & 34 \\
\hline 10 & 5 & B & $25-74$ & $0-50$ & 10 & 19 & 4 & 6 & 7 & 3 & 17 & 8 & 8 & 4 & 18 & 7 & 7 & 11 \\
\hline 10 & 5 & B & $25-74$ & $0-50$ & 50 & 30 & 25 & 26 & 24 & 19 & 49 & 30 & 26 & 19 & 40 & 25 & 18 & 23 \\
\hline 10 & 5 & B & $25-74$ & $50-100$ & 10 & 18 & 6 & 14 & 7 & 3 & 15 & 13 & 6 & 3 & 16 & 8 & 6 & 8 \\
\hline 10 & 5 & B & $25-74$ & $50-100$ & 50 & 36 & 33 & 31 & 37 & 24 & 55 & 39 & 37 & 25 & 56 & 32 & 40 & 40 \\
\hline 10 & 5 & B & $75-125$ & $0-50$ & 10 & 16 & 6 & 11 & 5 & 1 & 24 & 14 & 4 & 4 & 19 & 6 & 5 & 8 \\
\hline 10 & 5 & B & $75-125$ & $0-50$ & 50 & 31 & 42 & 28 & 30 & 27 & 52 & 31 & 36 & 29 & 49 & 27 & 31 & 34 \\
\hline 10 & 5 & B & $75-125$ & $50-100$ & 10 & 9 & 6 & 9 & 4 & 4 & 23 & 11 & 8 & 3 & 18 & 13 & 8 & 6 \\
\hline 10 & 5 & B & $75-125$ & $50-100$ & 50 & 39 & 27 & 34 & 33 & 27 & 51 & 37 & 27 & 29 & 50 & 33 & 35 & 35 \\
\hline 10 & 5 & M & $25-74$ & $0-50$ & 10 & 11 & 5 & 11 & 8 & 8 & 19 & 10 & 7 & 6 & 15 & 13 & 8 & 4 \\
\hline 10 & 5 & $\mathbf{M}$ & $25-74$ & $0-50$ & 50 & 43 & 51 & 36 & 47 & 35 & 62 & 46 & 45 & 34 & 61 & 36 & 46 & 44 \\
\hline 10 & 5 & $\mathbf{M}$ & $25-74$ & $50-100$ & 10 & 20 & 5 & 5 & 3 & 7 & 22 & 19 & 5 & 5 & 18 & 5 & 7 & 10 \\
\hline 10 & 5 & $\mathbf{M}$ & $25-74$ & $50-100$ & 50 & 46 & 34 & 43 & 41 & 32 & 50 & 43 & 36 & 35 & 53 & 46 & 42 & 41 \\
\hline
\end{tabular}




\begin{tabular}{|c|c|c|c|c|c|c|c|c|c|c|c|c|c|c|c|c|c|c|}
\hline 10 & 5 & $M$ & $75-125$ & $0-50$ & 10 & 13 & 8 & 12 & 8 & 10 & 18 & 7 & 8 & 8 & 20 & 13 & 4 & 5 \\
\hline 10 & 5 & M & $75-125$ & $0-50$ & 50 & 38 & 38 & 37 & 37 & 32 & 58 & 33 & 40 & 33 & 53 & 37 & 34 & 47 \\
\hline 10 & 5 & M & $75-125$ & $50-100$ & 10 & 10 & 5 & 12 & 8 & 2 & 17 & 14 & 4 & 2 & 22 & 13 & 3 & 5 \\
\hline 10 & 5 & M & $75-125$ & $50-100$ & 50 & 38 & 32 & 35 & 33 & 33 & 46 & 38 & 31 & 35 & 47 & 29 & 36 & 35 \\
\hline 10 & 5 & A & $25-74$ & $0-50$ & 10 & 10 & 3 & 10 & 9 & 5 & 24 & 15 & 2 & 4 & 27 & 11 & 7 & 10 \\
\hline 10 & 5 & A & $25-74$ & $0-50$ & 50 & 46 & 49 & 42 & 48 & 39 & 70 & 47 & 51 & 39 & 72 & 41 & 45 & 54 \\
\hline 10 & 5 & A & $25-74$ & $50-100$ & 10 & 13 & 3 & 15 & 10 & 6 & 13 & 10 & 4 & 3 & 17 & 11 & 7 & 15 \\
\hline 10 & 5 & A & $25-74$ & $50-100$ & 50 & 51 & 47 & 46 & 55 & 35 & 73 & 47 & 47 & 36 & 77 & 46 & 56 & 48 \\
\hline 10 & 5 & A & $75-125$ & $0-50$ & 10 & 14 & 4 & 12 & 9 & 5 & 14 & 16 & 6 & 7 & 19 & 11 & 8 & 5 \\
\hline 10 & 5 & A & $75-125$ & $0-50$ & 50 & 48 & 45 & 45 & 48 & 36 & 62 & 44 & 48 & 37 & 59 & 45 & 48 & 48 \\
\hline 10 & 5 & A & $75-125$ & $50-100$ & 10 & 11 & 5 & 14 & 5 & 7 & 13 & 18 & 6 & 11 & 14 & 9 & 7 & 9 \\
\hline 10 & 5 & A & $75-125$ & $50-100$ & 50 & 53 & 57 & 56 & 56 & 46 & 67 & 58 & 55 & 46 & 67 & 55 & 55 & 55 \\
\hline 10 & 7 & B & $25-74$ & $0-50$ & 10 & 17 & 1 & 13 & 8 & 5 & 15 & 13 & 1 & 3 & 18 & 13 & 3 & 7 \\
\hline 10 & 7 & B & $25-74$ & $0-50$ & 50 & 33 & 25 & 31 & 31 & 21 & 43 & 28 & 29 & 23 & 47 & 30 & 28 & 28 \\
\hline 10 & 7 & B & $25-74$ & $50-100$ & 10 & 19 & 5 & 9 & 1 & 8 & 17 & 16 & 7 & 4 & 17 & 10 & 1 & 9 \\
\hline 10 & 7 & B & $25-74$ & $50-100$ & 50 & 33 & 22 & 30 & 31 & 22 & 41 & 35 & 21 & 21 & 41 & 34 & 31 & 28 \\
\hline 10 & 7 & B & $75-125$ & $0-50$ & 10 & 15 & 6 & 7 & 6 & 4 & 14 & 17 & 7 & 6 & 16 & 8 & 5 & 13 \\
\hline 10 & 7 & B & $75-125$ & $0-50$ & 50 & 32 & 30 & 29 & 26 & 21 & 43 & 33 & 29 & 22 & 41 & 26 & 26 & 31 \\
\hline 10 & 7 & B & $75-125$ & $50-100$ & 10 & 14 & 6 & 10 & 3 & 3 & 7 & 18 & 8 & 6 & 11 & 18 & 4 & 10 \\
\hline 10 & 7 & B & $75-125$ & $50-100$ & 50 & 30 & 28 & 29 & 30 & 24 & 49 & 29 & 29 & 24 & 47 & 29 & 31 & 26 \\
\hline 10 & 7 & M & $25-74$ & $0-50$ & 10 & 12 & 7 & 6 & 6 & 5 & 29 & 11 & 5 & 5 & 22 & 10 & 5 & 7 \\
\hline 10 & 7 & $\mathbf{M}$ & $25-74$ & $0-50$ & 50 & 50 & 40 & 43 & 41 & 39 & 62 & 48 & 38 & 40 & 66 & 40 & 41 & 44 \\
\hline 10 & 7 & M & $25-74$ & $50-100$ & 10 & 14 & 9 & 15 & 8 & 8 & 12 & 13 & 5 & 8 & 13 & 16 & 5 & 7 \\
\hline 10 & 7 & $\mathbf{M}$ & $25-74$ & $50-100$ & 50 & 44 & 37 & 36 & 34 & 33 & 58 & 43 & 38 & 35 & 55 & 38 & 34 & 46 \\
\hline 10 & 7 & M & $75-125$ & $0-50$ & 10 & 13 & 8 & 11 & 7 & 8 & 14 & 5 & 7 & 9 & 19 & 6 & 4 & 12 \\
\hline 10 & 7 & $\mathbf{M}$ & $75-125$ & $0-50$ & 50 & 41 & 37 & 39 & 38 & 28 & 45 & 37 & 37 & 30 & 47 & 38 & 39 & 32 \\
\hline 10 & 7 & M & $75-125$ & $50-100$ & 10 & 10 & 5 & 14 & 3 & 6 & 19 & 8 & 8 & 7 & 24 & 13 & 5 & 7 \\
\hline 10 & 7 & M & $75-125$ & $50-100$ & 50 & 52 & 50 & 49 & 51 & 40 & 62 & 52 & 48 & 40 & 60 & 50 & 49 & 58 \\
\hline 10 & 7 & A & $25-74$ & $0-50$ & 10 & 16 & 4 & 9 & 4 & 5 & 18 & 11 & 7 & 6 & 17 & 14 & 6 & 11 \\
\hline 10 & 7 & A & $25-74$ & $0-50$ & 50 & 44 & 48 & 47 & 49 & 34 & 62 & 45 & 50 & 34 & 62 & 48 & 47 & 48 \\
\hline 10 & 7 & A & $25-74$ & $50-100$ & 10 & 19 & 9 & 13 & 4 & 4 & 16 & 22 & 8 & 2 & 14 & 11 & 2 & 14 \\
\hline 10 & 7 & A & $25-74$ & $50-100$ & 50 & 41 & 43 & 38 & 46 & 29 & 63 & 41 & 38 & 28 & 67 & 37 & 44 & 35 \\
\hline 10 & 7 & A & $75-125$ & $0-50$ & 10 & 10 & 9 & 5 & 7 & 9 & 17 & 9 & 11 & 9 & 14 & 17 & 9 & 10 \\
\hline 10 & 7 & A & $75-125$ & $0-50$ & 50 & 47 & 47 & 46 & 50 & 40 & 59 & 48 & 46 & 39 & 58 & 47 & 47 & 45 \\
\hline 10 & 7 & A & $75-125$ & $50-100$ & 10 & 13 & 4 & 12 & 7 & 3 & 19 & 14 & 7 & 6 & 22 & 11 & 11 & 12 \\
\hline 10 & 7 & A & $75-125$ & $50-100$ & 50 & 52 & 49 & 50 & 51 & 46 & 64 & 54 & 49 & 45 & 64 & 52 & 51 & 52 \\
\hline 30 & 3 & B & $25-74$ & $0-50$ & 10 & 11 & 2 & 12 & 9 & 1 & 23 & 12 & 1 & 2 & 12 & 2 & 9 & 4 \\
\hline 30 & 3 & B & $25-74$ & $0-50$ & 50 & 8 & 9 & 6 & 10 & 7 & 20 & 13 & 7 & 6 & 19 & 9 & 6 & 7 \\
\hline 30 & 3 & B & $25-74$ & $50-100$ & 10 & 7 & 2 & 4 & 11 & 4 & 15 & 11 & 3 & 0 & 18 & 10 & 9 & 7 \\
\hline 30 & 3 & B & $25-74$ & $50-100$ & 50 & 14 & 6 & 10 & 11 & 5 & 19 & 8 & 9 & 4 & 21 & 6 & 8 & 7 \\
\hline 30 & 3 & B & $75-125$ & $0-50$ & 10 & 8 & 2 & 5 & 6 & 5 & 20 & 9 & 4 & 2 & 21 & 6 & 5 & 7 \\
\hline 30 & 3 & B & $75-125$ & $0-50$ & 50 & 11 & 13 & 8 & 14 & 2 & 15 & 10 & 12 & 1 & 18 & 10 & 12 & 6 \\
\hline 30 & 3 & B & $75-125$ & $50-100$ & 10 & 9 & 5 & 8 & 6 & 5 & 23 & 7 & 1 & 2 & 17 & 6 & 7 & 4 \\
\hline 30 & 3 & B & $75-125$ & $50-100$ & 50 & 6 & 17 & 7 & 5 & 1 & 15 & 13 & 11 & 3 & 12 & 8 & 10 & 11 \\
\hline 30 & 3 & $\mathbf{M}$ & $25-74$ & $0-50$ & 10 & 6 & 6 & 2 & 12 & 8 & 14 & 7 & 2 & 5 & 16 & 5 & 12 & 5 \\
\hline 30 & 3 & M & $25-74$ & $0-50$ & 50 & 15 & 4 & 5 & 8 & 5 & 17 & 15 & 4 & 4 & 18 & 2 & 8 & 13 \\
\hline 30 & 3 & M & $25-74$ & $50-100$ & 10 & 2 & 9 & 8 & 9 & 2 & 16 & 9 & 6 & 4 & 13 & 9 & 6 & 7 \\
\hline 30 & 3 & M & $25-74$ & $50-100$ & 50 & 10 & 9 & 8 & 9 & 8 & 15 & 13 & 8 & 2 & 18 & 7 & 13 & 9 \\
\hline 30 & 3 & M & $75-125$ & $0-50$ & 10 & 6 & 10 & 7 & 7 & 6 & 13 & 7 & 4 & 3 & 14 & 5 & 7 & 11 \\
\hline 30 & 3 & $\mathbf{M}$ & $75-125$ & $0-50$ & 50 & 7 & 10 & 7 & 5 & 7 & 16 & 9 & 12 & 7 & 18 & 9 & 11 & 13 \\
\hline 30 & 3 & M & $75-125$ & $50-100$ & 10 & 9 & 4 & 7 & 8 & 5 & 9 & 6 & 4 & 5 & 17 & 11 & 9 & 7 \\
\hline 30 & 3 & $\mathbf{M}$ & $75-125$ & $50-100$ & 50 & 15 & 6 & 3 & 10 & 4 & 14 & 24 & 11 & 4 & 12 & 3 & 11 & 10 \\
\hline 30 & 3 & A & $25-74$ & $0-50$ & 10 & 4 & 3 & 5 & 3 & 0 & 24 & 6 & 1 & 3 & 35 & 7 & 4 & 6 \\
\hline 30 & 3 & A & $25-74$ & $0-50$ & 50 & 5 & 8 & 6 & 8 & 4 & 32 & 5 & 7 & 3 & 36 & 8 & 8 & 8 \\
\hline 30 & 3 & A & $25-74$ & $50-100$ & 10 & 12 & 0 & 9 & 3 & 5 & 15 & 14 & 3 & 4 & 21 & 6 & 6 & 5 \\
\hline 30 & 3 & A & $25-74$ & $50-100$ & 50 & 12 & 8 & 6 & 10 & 2 & 35 & 9 & 7 & 0 & 37 & 7 & 10 & 7 \\
\hline 30 & 3 & A & $75-125$ & $0-50$ & 10 & 8 & 3 & 9 & 8 & 1 & 22 & 4 & 1 & 2 & 30 & 4 & 4 & 5 \\
\hline 30 & 3 & A & $75-125$ & $0-50$ & 50 & 5 & 10 & 2 & 6 & 1 & 36 & 7 & 7 & 1 & 35 & 6 & 10 & 9 \\
\hline 30 & 3 & A & $75-125$ & $50-100$ & 10 & 10 & 0 & 5 & 7 & 2 & 23 & 15 & 2 & 1 & 22 & 8 & 2 & 4 \\
\hline 30 & 3 & A & $75-125$ & $50-100$ & 50 & 9 & 5 & 6 & 9 & 2 & 24 & 10 & 7 & 2 & 33 & 13 & 9 & 9 \\
\hline 30 & 5 & B & $25-74$ & $0-50$ & 10 & 13 & 4 & 6 & 2 & 3 & 15 & 9 & 6 & 4 & 15 & 13 & 4 & 7 \\
\hline 30 & 5 & B & $25-74$ & $0-50$ & 50 & 5 & 9 & 4 & 7 & 2 & 29 & 4 & 10 & 3 & 29 & 4 & 6 & 8 \\
\hline
\end{tabular}




\begin{tabular}{|c|c|c|c|c|c|c|c|c|c|c|c|c|c|c|c|c|c|c|}
\hline 30 & 5 & B & $25-74$ & $50-100$ & 10 & 16 & 3 & 9 & 1 & 5 & 17 & 7 & 1 & 4 & 20 & 10 & 2 & 5 \\
\hline 30 & 5 & B & $25-74$ & $50-100$ & 50 & 7 & 5 & 5 & 9 & 3 & 18 & 8 & 9 & 1 & 25 & 6 & 10 & 13 \\
\hline 30 & 5 & B & $75-125$ & $0-50$ & 10 & 13 & 2 & 15 & 2 & 5 & 21 & 11 & 2 & 1 & 14 & 7 & 0 & 8 \\
\hline 30 & 5 & B & $75-125$ & $0-50$ & 50 & 6 & 4 & 1 & 5 & 1 & 41 & 7 & 6 & 3 & 37 & 5 & 9 & 5 \\
\hline 30 & 5 & B & $75-125$ & $50-100$ & 10 & 11 & 4 & 7 & 3 & 4 & 19 & 6 & 3 & 6 & 20 & 7 & 5 & 7 \\
\hline 30 & 5 & B & $75-125$ & $50-100$ & 50 & 6 & 12 & 5 & 6 & 2 & 28 & 11 & 8 & 0 & 27 & 8 & 9 & 6 \\
\hline 30 & 5 & M & $25-74$ & $0-50$ & 10 & 2 & 2 & 9 & 6 & 6 & 23 & 10 & 1 & 4 & 24 & 6 & 2 & 6 \\
\hline 30 & 5 & M & $25-74$ & $0-50$ & 50 & 8 & 4 & 4 & 14 & 3 & 23 & 10 & 7 & 4 & 24 & 5 & 10 & 8 \\
\hline 30 & 5 & M & $25-74$ & $50-100$ & 10 & 11 & 3 & 5 & 6 & 2 & 14 & 7 & 6 & 3 & 21 & 13 & 3 & 7 \\
\hline 30 & 5 & M & $25-74$ & $50-100$ & 50 & 6 & 12 & 9 & 13 & 1 & 24 & 8 & 11 & 1 & 15 & 11 & 11 & 11 \\
\hline 30 & 5 & M & $75-125$ & $0-50$ & 10 & 9 & 4 & 12 & 2 & 1 & 20 & 3 & 5 & 4 & 23 & 8 & 4 & 7 \\
\hline 30 & 5 & M & $75-125$ & $0-50$ & 50 & 7 & 5 & 5 & 6 & 7 & 28 & 5 & 7 & 3 & 32 & 8 & 3 & 9 \\
\hline 30 & 5 & M & $75-125$ & $50-100$ & 10 & 5 & 3 & 7 & 5 & 1 & 16 & 9 & 11 & 2 & 23 & 4 & 4 & 11 \\
\hline 30 & 5 & M & $75-125$ & $50-100$ & 50 & 12 & 10 & 11 & 7 & 5 & 20 & 10 & 8 & 3 & 26 & 10 & 5 & 12 \\
\hline 30 & 5 & A & $25-74$ & $0-50$ & 10 & 8 & 3 & 7 & 3 & 3 & 23 & 9 & 3 & 4 & 20 & 8 & 1 & 8 \\
\hline 30 & 5 & A & $25-74$ & $0-50$ & 50 & 9 & 5 & 6 & 7 & 2 & 33 & 9 & 7 & 4 & 35 & 6 & 3 & 7 \\
\hline 30 & 5 & A & $25-74$ & $50-100$ & 10 & 8 & 0 & 9 & 3 & 3 & 29 & 8 & 4 & 5 & 22 & 5 & 3 & 3 \\
\hline 30 & 5 & A & $25-74$ & $50-100$ & 50 & 8 & 7 & 6 & 10 & 5 & 34 & 5 & 4 & 3 & 30 & 6 & 6 & 2 \\
\hline 30 & 5 & A & $75-125$ & $0-50$ & 10 & 6 & 2 & 7 & 1 & 3 & 28 & 7 & 1 & 3 & 29 & 7 & 4 & 3 \\
\hline 30 & 5 & A & $75-125$ & $0-50$ & 50 & 3 & 3 & 8 & 9 & 2 & 36 & 3 & 8 & 2 & 37 & 8 & 5 & 5 \\
\hline 30 & 5 & A & $75-125$ & $50-100$ & 10 & 2 & 2 & 9 & 5 & 4 & 24 & 6 & 5 & 2 & 26 & 13 & 4 & 0 \\
\hline 30 & 5 & A & $75-125$ & $50-100$ & 50 & 8 & 10 & 5 & 7 & 5 & 29 & 12 & 6 & 6 & 20 & 5 & 7 & 11 \\
\hline 30 & 7 & B & $25-74$ & $0-50$ & 10 & 15 & 3 & 13 & 0 & 5 & 19 & 10 & 0 & 2 & 12 & 10 & 2 & 9 \\
\hline 30 & 7 & B & $25-74$ & $0-50$ & 50 & 8 & 5 & 7 & 6 & 3 & 21 & 6 & 6 & 4 & 29 & 10 & 6 & 4 \\
\hline 30 & 7 & B & $25-74$ & $50-100$ & 10 & 12 & 4 & 12 & 5 & 5 & 17 & 10 & 2 & 4 & 16 & 10 & 0 & 3 \\
\hline 30 & 7 & B & $25-74$ & $50-100$ & 50 & 6 & 7 & 12 & 7 & 5 & 30 & 8 & 2 & 3 & 17 & 10 & 6 & 9 \\
\hline 30 & 7 & B & $75-125$ & $0-50$ & 10 & 7 & 5 & 9 & 0 & 4 & 23 & 5 & 3 & 3 & 15 & 11 & 3 & 13 \\
\hline 30 & 7 & B & $75-125$ & $0-50$ & 50 & 5 & 4 & 11 & 3 & 5 & 25 & 10 & 6 & 3 & 28 & 9 & 6 & 4 \\
\hline 30 & 7 & B & $75-125$ & $50-100$ & 10 & 14 & 2 & 7 & 2 & 2 & 19 & 12 & 6 & 6 & 15 & 13 & 1 & 3 \\
\hline 30 & 7 & B & $75-125$ & $50-100$ & 50 & 9 & 5 & 9 & 3 & 0 & 23 & 12 & 12 & 1 & 22 & 12 & 6 & 9 \\
\hline 30 & 7 & M & $25-74$ & $0-50$ & 10 & 5 & 5 & 6 & 3 & 2 & 21 & 7 & 3 & 5 & 16 & 18 & 5 & 4 \\
\hline 30 & 7 & $\mathbf{M}$ & $25-74$ & $0-50$ & 50 & 4 & 10 & 9 & 4 & 4 & 29 & 6 & 9 & 4 & 28 & 4 & 6 & 7 \\
\hline 30 & 7 & M & $25-74$ & $50-100$ & 10 & 4 & 3 & 8 & 10 & 3 & 17 & 7 & 4 & 4 & 19 & 9 & 3 & 9 \\
\hline 30 & 7 & M & $25-74$ & $50-100$ & 50 & 10 & 8 & 7 & 11 & 6 & 18 & 10 & 10 & 2 & 29 & 5 & 10 & 4 \\
\hline 30 & 7 & M & $75-125$ & $0-50$ & 10 & 11 & 4 & 10 & 0 & 4 & 17 & 8 & 3 & 4 & 23 & 8 & 4 & 4 \\
\hline 30 & 7 & $\mathbf{M}$ & $75-125$ & $0-50$ & 50 & 6 & 6 & 9 & 5 & 3 & 27 & 8 & 7 & 3 & 27 & 11 & 8 & 7 \\
\hline 30 & 7 & M & $75-125$ & $50-100$ & 10 & 14 & 3 & 5 & 1 & 5 & 18 & 5 & 7 & 3 & 18 & 8 & 7 & 7 \\
\hline 30 & 7 & M & $75-125$ & $50-100$ & 50 & 3 & 7 & 9 & 5 & 2 & 31 & 5 & 13 & 2 & 28 & 7 & 8 & 8 \\
\hline 30 & 7 & A & $25-74$ & $0-50$ & 10 & 11 & 3 & 8 & 1 & 3 & 22 & 12 & 0 & 3 & 24 & 9 & 3 & 4 \\
\hline 30 & 7 & A & $25-74$ & $0-50$ & 50 & 11 & 7 & 6 & 5 & 1 & 36 & 6 & 5 & 4 & 23 & 4 & 3 & 17 \\
\hline 30 & 7 & A & $25-74$ & $50-100$ & 10 & 6 & 3 & 7 & 2 & 5 & 27 & 14 & 2 & 4 & 19 & 7 & 3 & 3 \\
\hline 30 & 7 & A & $25-74$ & $50-100$ & 50 & 8 & 10 & 7 & 5 & 4 & 24 & 3 & 9 & 5 & 27 & 9 & 6 & 11 \\
\hline 30 & 7 & A & $75-125$ & $0-50$ & 10 & 5 & 5 & 15 & 5 & 1 & 22 & 16 & 0 & 0 & 19 & 6 & 1 & 6 \\
\hline 30 & 7 & A & $75-125$ & $0-50$ & 50 & 6 & 6 & 6 & 8 & 2 & 34 & 8 & 7 & 4 & 29 & 4 & 5 & 11 \\
\hline 30 & 7 & A & $75-125$ & $50-100$ & 10 & 7 & 2 & 14 & 1 & 1 & 19 & 8 & 1 & 4 & 18 & 14 & 6 & 6 \\
\hline 30 & 7 & A & $75-125$ & $50-100$ & 50 & 11 & 6 & 8 & 9 & 2 & 32 & 11 & 4 & 3 & 37 & 7 & 8 & 1 \\
\hline 50 & 3 & B & $25-74$ & $0-50$ & 10 & 9 & 5 & 6 & 8 & 1 & 21 & 8 & 4 & 3 & 20 & 6 & 6 & 3 \\
\hline 50 & 3 & B & $25-74$ & $0-50$ & 50 & 5 & 8 & 10 & 14 & 2 & 21 & 5 & 8 & 3 & 18 & 5 & 6 & 6 \\
\hline 50 & 3 & B & $25-74$ & $50-100$ & 10 & 9 & 0 & 11 & 6 & 2 & 16 & 11 & 3 & 2 & 14 & 9 & 10 & 8 \\
\hline 50 & 3 & B & $25-74$ & $50-100$ & 50 & 5 & 7 & 5 & 12 & 3 & 13 & 12 & 6 & 2 & 17 & 4 & 8 & 11 \\
\hline 50 & 3 & B & $75-125$ & $0-50$ & 10 & 2 & 6 & 6 & 12 & 2 & 18 & 7 & 1 & 2 & 24 & 12 & 2 & 6 \\
\hline 50 & 3 & B & $75-125$ & $0-50$ & 50 & 8 & 7 & 8 & 10 & 4 & 18 & 7 & 3 & 2 & 19 & 8 & 7 & 8 \\
\hline 50 & 3 & B & $75-125$ & $50-100$ & 10 & 6 & 2 & 3 & 7 & 2 & 25 & 8 & 3 & 3 & 18 & 6 & 10 & 8 \\
\hline 50 & 3 & B & $75-125$ & $50-100$ & 50 & 8 & 10 & 3 & 10 & 1 & 14 & 12 & 10 & 1 & 17 & 2 & 9 & 10 \\
\hline 50 & 3 & M & $25-74$ & $0-50$ & 10 & 9 & 4 & 9 & 11 & 2 & 20 & 6 & 6 & 2 & 11 & 4 & 9 & 7 \\
\hline 50 & 3 & $\mathbf{M}$ & $25-74$ & $0-50$ & 50 & 6 & 8 & 3 & 8 & 4 & 17 & 7 & 8 & 3 & 18 & 3 & 8 & 13 \\
\hline 50 & 3 & M & $25-74$ & $50-100$ & 10 & 8 & 5 & 7 & 7 & 6 & 12 & 10 & 4 & 2 & 20 & 4 & 10 & 6 \\
\hline 50 & 3 & M & $25-74$ & $50-100$ & 50 & 9 & 7 & 1 & 10 & 2 & 8 & 12 & 9 & 2 & 17 & 4 & 13 & 11 \\
\hline 50 & 3 & M & $75-125$ & $0-50$ & 10 & 3 & 4 & 3 & 5 & 4 & 23 & 8 & 6 & 4 & 18 & 9 & 11 & 2 \\
\hline 50 & 3 & M & $75-125$ & $0-50$ & 50 & 12 & 8 & 8 & 9 & 6 & 12 & 10 & 10 & 1 & 5 & 11 & 6 & 6 \\
\hline 50 & 3 & M & $75-125$ & $50-100$ & 10 & 6 & 5 & 4 & 10 & 8 & 20 & 4 & 7 & 3 & 12 & 3 & 11 & 7 \\
\hline 50 & 3 & $\mathbf{M}$ & $75-125$ & $50-100$ & 50 & 7 & 7 & 2 & 7 & 4 & 15 & 9 & 9 & 4 & 14 & 4 & 12 & 16 \\
\hline
\end{tabular}




\begin{tabular}{|c|c|c|c|c|c|c|c|c|c|c|c|c|c|c|c|c|c|c|}
\hline 50 & 3 & $\bar{A}$ & $25-74$ & $0-50$ & 10 & 5 & 2 & 2 & 6 & 0 & 37 & 7 & 2 & 2 & 25 & 2 & 5 & 6 \\
\hline 50 & 3 & A & $25-74$ & $0-50$ & 50 & 3 & 9 & 2 & 7 & 2 & 25 & 8 & 6 & 0 & 30 & 5 & 5 & 6 \\
\hline 50 & 3 & A & $25-74$ & $50-100$ & 10 & 6 & 4 & 4 & 6 & 1 & 25 & 7 & 4 & 1 & 27 & 8 & 5 & 4 \\
\hline 50 & 3 & A & $25-74$ & $50-100$ & 50 & 5 & 6 & 5 & 4 & 3 & 29 & 4 & 3 & 1 & 33 & 4 & 5 & 5 \\
\hline 50 & 3 & A & $75-125$ & $0-50$ & 10 & 5 & 2 & 4 & 5 & 1 & 34 & 1 & 2 & 1 & 34 & 4 & 6 & 1 \\
\hline 50 & 3 & A & $75-125$ & $0-50$ & 50 & 8 & 6 & 2 & 7 & 3 & 34 & 9 & 8 & 0 & 23 & 2 & 5 & 4 \\
\hline 50 & 3 & A & $75-125$ & $50-100$ & 10 & 11 & 5 & 7 & 12 & 2 & 16 & 4 & 7 & 1 & 23 & 6 & 6 & 2 \\
\hline 50 & 3 & A & $75-125$ & $50-100$ & 50 & 10 & 4 & 4 & 4 & 1 & 27 & 8 & 6 & 2 & 18 & 5 & 10 & 11 \\
\hline 50 & 5 & B & $25-74$ & $0-50$ & 10 & 13 & 3 & 8 & 2 & 5 & 12 & 13 & 5 & 5 & 15 & 13 & 2 & 4 \\
\hline 50 & 5 & B & $25-74$ & $0-50$ & 50 & 9 & 2 & 7 & 7 & 2 & 25 & 6 & 2 & 1 & 23 & 6 & 4 & 7 \\
\hline 50 & 5 & B & $25-74$ & $50-100$ & 10 & 13 & 5 & 4 & 3 & 3 & 20 & 10 & 4 & 2 & 17 & 11 & 1 & 7 \\
\hline 50 & 5 & B & $25-74$ & $50-100$ & 50 & 4 & 6 & 6 & 5 & 2 & 21 & 7 & 8 & 1 & 21 & 8 & 7 & 8 \\
\hline 50 & 5 & B & $75-125$ & $0-50$ & 10 & 4 & 3 & 12 & 1 & 5 & 21 & 13 & 1 & 6 & 17 & 9 & 4 & 4 \\
\hline 50 & 5 & B & $75-125$ & $0-50$ & 50 & 6 & 2 & 4 & 8 & 1 & 29 & 7 & 8 & 1 & 25 & 7 & 3 & 8 \\
\hline 50 & 5 & B & $75-125$ & $50-100$ & 10 & 12 & 2 & 9 & 2 & 5 & 17 & 8 & 4 & 8 & 18 & 10 & 0 & 7 \\
\hline 50 & 5 & B & $75-125$ & $50-100$ & 50 & 7 & 7 & 11 & 4 & 1 & 15 & 7 & 9 & 2 & 22 & 7 & 7 & 7 \\
\hline 50 & 5 & M & $25-74$ & $0-50$ & 10 & 10 & 2 & 14 & 7 & 0 & 11 & 15 & 2 & 6 & 20 & 8 & 3 & 2 \\
\hline 50 & 5 & $\mathbf{M}$ & $25-74$ & $0-50$ & 50 & 5 & 9 & 4 & 7 & 3 & 22 & 3 & 6 & 0 & 28 & 6 & 6 & 7 \\
\hline 50 & 5 & $\mathbf{M}$ & $25-74$ & $50-100$ & 10 & 11 & 2 & 7 & 3 & 2 & 17 & 10 & 3 & 4 & 27 & 7 & 4 & 4 \\
\hline 50 & 5 & M & $25-74$ & $50-100$ & 50 & 7 & 3 & 5 & 6 & 3 & 21 & 11 & 10 & 4 & 17 & 6 & 4 & 8 \\
\hline 50 & 5 & M & $75-125$ & $0-50$ & 10 & 6 & 4 & 9 & 1 & 2 & 26 & 5 & 3 & 4 & 17 & 15 & 2 & 8 \\
\hline 50 & 5 & $\mathbf{M}$ & $75-125$ & $0-50$ & 50 & 11 & 1 & 4 & 5 & 1 & 26 & 7 & 2 & 3 & 21 & 7 & 4 & 13 \\
\hline 50 & 5 & M & $75-125$ & $50-100$ & 10 & 9 & 5 & 7 & 2 & 3 & 16 & 10 & 4 & 2 & 15 & 8 & 12 & 7 \\
\hline 50 & 5 & M & $75-125$ & $50-100$ & 50 & 7 & 6 & 5 & 5 & 3 & 19 & 6 & 13 & 2 & 17 & 6 & 5 & 10 \\
\hline 50 & 5 & A & $25-74$ & $0-50$ & 10 & 6 & 1 & 8 & 1 & 1 & 37 & 5 & 2 & 1 & 22 & 8 & 4 & 4 \\
\hline 50 & 5 & A & $25-74$ & $0-50$ & 50 & 3 & 6 & 4 & 7 & 0 & 27 & 7 & 5 & 0 & 31 & 0 & 8 & 8 \\
\hline 50 & 5 & A & $25-74$ & $50-100$ & 10 & 2 & 1 & 5 & 2 & 2 & 29 & 8 & 2 & 2 & 38 & 7 & 1 & 1 \\
\hline 50 & 5 & A & $25-74$ & $50-100$ & 50 & 4 & 7 & 2 & 6 & 2 & 36 & 12 & 5 & 2 & 23 & 3 & 3 & 3 \\
\hline 50 & 5 & A & $75-125$ & $0-50$ & 10 & 6 & 4 & 8 & 2 & 3 & 27 & 8 & 2 & 1 & 22 & 9 & 4 & 5 \\
\hline 50 & 5 & A & $75-125$ & $0-50$ & 50 & 9 & 6 & 4 & 5 & 1 & 31 & 4 & 6 & 4 & 30 & 3 & 5 & 5 \\
\hline 50 & 5 & A & $75-125$ & $50-100$ & 10 & 7 & 2 & 11 & 2 & 6 & 24 & 2 & 2 & 2 & 29 & 9 & 3 & 4 \\
\hline 50 & 5 & A & $75-125$ & $50-100$ & 50 & 7 & 1 & 5 & 5 & 0 & 34 & 6 & 5 & 3 & 30 & 8 & 4 & 7 \\
\hline 50 & 7 & B & $25-74$ & $0-50$ & 10 & 9 & 2 & 10 & 1 & 10 & 12 & 14 & 2 & 5 & 20 & 4 & 2 & 10 \\
\hline 50 & 7 & B & $25-74$ & $0-50$ & 50 & 6 & 5 & 9 & 6 & 1 & 29 & 9 & 6 & 2 & 18 & 4 & 0 & 9 \\
\hline 50 & 7 & B & $25-74$ & $50-100$ & 10 & 13 & 0 & 14 & 6 & 3 & 14 & 13 & 3 & 4 & 15 & 6 & 1 & 8 \\
\hline 50 & 7 & B & $25-74$ & $50-100$ & 50 & 5 & 7 & 7 & 1 & 4 & 17 & 6 & 3 & 3 & 28 & 8 & 6 & 7 \\
\hline 50 & 7 & B & $75-125$ & $0-50$ & 10 & 11 & 2 & 10 & 4 & 6 & 14 & 12 & 0 & 7 & 15 & 11 & 1 & 7 \\
\hline 50 & 7 & B & $75-125$ & $0-50$ & 50 & 8 & 6 & 4 & 4 & 2 & 19 & 6 & 2 & 3 & 31 & 5 & 5 & 8 \\
\hline 50 & 7 & B & $75-125$ & $50-100$ & 10 & 10 & 5 & 17 & 2 & 3 & 13 & 9 & 2 & 7 & 19 & 6 & 2 & 7 \\
\hline 50 & 7 & B & $75-125$ & $50-100$ & 50 & 7 & 6 & 8 & 4 & 3 & 28 & 6 & 6 & 1 & 20 & 7 & 3 & 8 \\
\hline 50 & 7 & $\mathbf{M}$ & $25-74$ & $0-50$ & 10 & 11 & 2 & 8 & 6 & 5 & 22 & 9 & 5 & 3 & 24 & 2 & 1 & 4 \\
\hline 50 & 7 & M & $25-74$ & $0-50$ & 50 & 7 & 10 & 2 & 6 & 3 & 21 & 4 & 8 & 4 & 19 & 9 & 4 & 9 \\
\hline 50 & 7 & M & $25-74$ & $50-100$ & 10 & 11 & 6 & 8 & 2 & 5 & 27 & 6 & 5 & 4 & 18 & 6 & 0 & 6 \\
\hline 50 & 7 & M & $25-74$ & $50-100$ & 50 & 7 & 6 & 7 & 4 & 2 & 23 & 12 & 5 & 6 & 20 & 11 & 1 & 6 \\
\hline 50 & 7 & $\mathbf{M}$ & $75-125$ & $0-50$ & 10 & 6 & 6 & 7 & 3 & 1 & 17 & 2 & 3 & 4 & 25 & 10 & 5 & 12 \\
\hline 50 & 7 & M & $75-125$ & $0-50$ & 50 & 5 & 9 & 2 & 4 & 5 & 20 & 10 & 5 & 2 & 30 & 3 & 5 & 7 \\
\hline 50 & 7 & M & $75-125$ & $50-100$ & 10 & 2 & 5 & 5 & 6 & 4 & 19 & 13 & 3 & 2 & 17 & 10 & 7 & 7 \\
\hline 50 & 7 & M & $75-125$ & $50-100$ & 50 & 1 & 7 & 6 & 5 & 4 & 26 & 6 & 9 & 3 & 20 & 8 & 6 & 8 \\
\hline 50 & 7 & A & $25-74$ & $0-50$ & 10 & 9 & 2 & 7 & 5 & 3 & 24 & 6 & 0 & 3 & 31 & 7 & 1 & 3 \\
\hline 50 & 7 & A & $25-74$ & $0-50$ & 50 & 5 & 3 & 4 & 2 & 1 & 31 & 3 & 4 & 2 & 37 & 5 & 2 & 8 \\
\hline 50 & 7 & A & $25-74$ & $50-100$ & 10 & 10 & 2 & 8 & 3 & 5 & 25 & 4 & 5 & 3 & 21 & 7 & 3 & 4 \\
\hline 50 & 7 & A & $25-74$ & $50-100$ & 50 & 3 & 3 & 4 & 2 & 2 & 30 & 5 & 7 & 3 & 31 & 5 & 3 & 6 \\
\hline 50 & 7 & A & $75-125$ & $0-50$ & 10 & 4 & 2 & 8 & 1 & 6 & 32 & 8 & 4 & 1 & 21 & 5 & 3 & 5 \\
\hline 50 & 7 & A & $75-125$ & $0-50$ & 50 & 7 & 1 & 5 & 2 & 1 & 33 & 5 & 7 & 4 & 34 & 4 & 2 & 4 \\
\hline 50 & 7 & A & $75-125$ & $50-100$ & 10 & 7 & 2 & 12 & 2 & 3 & 18 & 7 & 0 & 2 & 28 & 12 & 2 & 6 \\
\hline 50 & 7 & A & $75-125$ & $50-100$ & 50 & 4 & 9 & 3 & 2 & 1 & 27 & 8 & 2 & 1 & 30 & 4 & 3 & 9 \\
\hline 80 & 3 & B & $25-74$ & $0-50$ & 10 & 7 & 3 & 8 & 3 & 2 & 19 & 9 & 3 & 4 & 21 & 7 & 5 & 10 \\
\hline 80 & 3 & B & $25-74$ & $0-50$ & 50 & 7 & 8 & 4 & 3 & 5 & 19 & 10 & 4 & 1 & 20 & 1 & 8 & 13 \\
\hline 80 & 3 & B & $25-74$ & $50-100$ & 10 & 9 & 0 & 9 & 7 & 4 & 22 & 11 & 2 & 5 & 12 & 5 & 10 & 5 \\
\hline 80 & 3 & B & $25-74$ & $50-100$ & 50 & 4 & 7 & 7 & 9 & 2 & 20 & 7 & 7 & 2 & 16 & 5 & 9 & 7 \\
\hline 80 & 3 & B & $75-125$ & $0-50$ & 10 & 5 & 0 & 4 & 9 & 2 & 27 & 8 & 2 & 3 & 18 & 11 & 7 & 6 \\
\hline 80 & 3 & B & $75-125$ & $0-50$ & 50 & 10 & 7 & 8 & 13 & 0 & 16 & 2 & 6 & 0 & 18 & 4 & 8 & 9 \\
\hline
\end{tabular}




\begin{tabular}{|c|c|c|c|c|c|c|c|c|c|c|c|c|c|c|c|c|c|c|}
\hline 80 & 3 & B & $75-125$ & $50-100$ & 10 & 10 & 2 & 10 & 7 & 2 & 15 & 13 & 3 & 2 & 19 & 6 & 7 & 5 \\
\hline 80 & 3 & B & $75-125$ & $50-100$ & 50 & 8 & 6 & 5 & 9 & 4 & 17 & 7 & 6 & 3 & 14 & 6 & 9 & 8 \\
\hline 80 & 3 & M & $25-74$ & $0-50$ & 10 & 7 & 6 & 8 & 12 & 4 & 17 & 6 & 7 & 2 & 11 & 3 & 7 & 10 \\
\hline 80 & 3 & M & $25-74$ & $0-50$ & 50 & 6 & 7 & 7 & 6 & 5 & 12 & 9 & 9 & 1 & 12 & 9 & 9 & 9 \\
\hline 80 & 3 & M & $25-74$ & $50-100$ & 10 & 7 & 5 & 7 & 6 & 6 & 15 & 3 & 5 & 10 & 14 & 6 & 6 & 10 \\
\hline 80 & 3 & M & $25-74$ & $50-100$ & 50 & 2 & 9 & 5 & 8 & 2 & 12 & 12 & 12 & 3 & 14 & 7 & 5 & 13 \\
\hline 80 & 3 & M & $75-125$ & $0-50$ & 10 & 9 & 5 & 6 & 8 & 4 & 9 & 9 & 4 & 7 & 19 & 3 & 9 & 8 \\
\hline 80 & 3 & M & $75-125$ & $0-50$ & 50 & 10 & 8 & 6 & 12 & 5 & 8 & 5 & 9 & 2 & 12 & 5 & 8 & 10 \\
\hline 80 & 3 & M & $75-125$ & $50-100$ & 10 & 8 & 7 & 7 & 8 & 3 & 14 & 6 & 8 & 3 & 14 & 5 & 11 & 6 \\
\hline 80 & 3 & M & $75-125$ & $50-100$ & 50 & 8 & 6 & 3 & 10 & 3 & 16 & 6 & 10 & 4 & 9 & 10 & 6 & 11 \\
\hline 80 & 3 & A & $25-74$ & $0-50$ & 10 & 10 & 0 & 4 & 4 & 2 & 38 & 6 & 2 & 0 & 18 & 5 & 5 & 6 \\
\hline 80 & 3 & A & $25-74$ & $0-50$ & 50 & 3 & 4 & 5 & 7 & 1 & 37 & 3 & 6 & 4 & 21 & 4 & 7 & 1 \\
\hline 80 & 3 & A & $25-74$ & $50-100$ & 10 & 4 & 1 & 3 & 7 & 2 & 26 & 4 & 10 & 4 & 25 & 5 & 6 & 4 \\
\hline 80 & 3 & A & $25-74$ & $50-100$ & 50 & 6 & 1 & 3 & 8 & 1 & 15 & 7 & 10 & 3 & 33 & 2 & 6 & 7 \\
\hline 80 & 3 & A & $75-125$ & $0-50$ & 10 & 4 & 6 & 6 & 6 & 1 & 22 & 2 & 3 & 4 & 28 & 4 & 7 & 7 \\
\hline 80 & 3 & A & $75-125$ & $0-50$ & 50 & 5 & 5 & 5 & 3 & 2 & 33 & 5 & 7 & 4 & 21 & 0 & 5 & 7 \\
\hline 80 & 3 & A & $75-125$ & $50-100$ & 10 & 7 & 0 & 2 & 4 & 2 & 30 & 6 & 5 & 2 & 24 & 7 & 7 & 5 \\
\hline 80 & 3 & A & $75-125$ & $50-100$ & 50 & 7 & 5 & 2 & 5 & 3 & 26 & 5 & 4 & 2 & 24 & 1 & 7 & 11 \\
\hline 80 & 5 & B & $25-74$ & $0-50$ & 10 & 5 & 2 & 8 & 4 & 3 & 14 & 14 & 4 & 4 & 24 & 10 & 2 & 7 \\
\hline 80 & 5 & B & $25-74$ & $0-50$ & 50 & 8 & 4 & 5 & 4 & 3 & 23 & 5 & 5 & 2 & 29 & 0 & 5 & 8 \\
\hline 80 & 5 & B & $25-74$ & $50-100$ & 10 & 8 & 5 & 8 & 2 & 1 & 22 & 12 & 2 & 1 & 19 & 10 & 2 & 8 \\
\hline 80 & 5 & B & $25-74$ & $50-100$ & 50 & 9 & 9 & 5 & 4 & 1 & 21 & 3 & 7 & 3 & 24 & 5 & 6 & 5 \\
\hline 80 & 5 & B & $75-125$ & $0-50$ & 10 & 4 & 1 & 8 & 2 & 2 & 25 & 7 & 4 & 4 & 21 & 12 & 2 & 8 \\
\hline 80 & 5 & B & $75-125$ & $0-50$ & 50 & 4 & 8 & 7 & 4 & 1 & 21 & 5 & 8 & 0 & 25 & 5 & 8 & 6 \\
\hline 80 & 5 & B & $75-125$ & $50-100$ & 10 & 8 & 4 & 8 & 2 & 4 & 24 & 4 & 4 & 1 & 23 & 9 & 4 & 6 \\
\hline 80 & 5 & B & $75-125$ & $50-100$ & 50 & 7 & 8 & 10 & 5 & 4 & 9 & 7 & 7 & 2 & 29 & 6 & 4 & 4 \\
\hline 80 & 5 & M & $25-74$ & $0-50$ & 10 & 8 & 3 & 11 & 2 & 3 & 19 & 13 & 7 & 2 & 21 & 6 & 4 & 2 \\
\hline 80 & 5 & $\mathbf{M}$ & $25-74$ & $0-50$ & 50 & 2 & 6 & 5 & 9 & 1 & 25 & 10 & 4 & 2 & 21 & 0 & 7 & 9 \\
\hline 80 & 5 & $\mathbf{M}$ & $25-74$ & $50-100$ & 10 & 6 & 6 & 5 & 6 & 2 & 18 & 13 & 1 & 2 & 20 & 9 & 5 & 7 \\
\hline 80 & 5 & $\mathbf{M}$ & $25-74$ & $50-100$ & 50 & 11 & 3 & 5 & 7 & 3 & 21 & 8 & 5 & 1 & 19 & 3 & 8 & 9 \\
\hline 80 & 5 & $\mathbf{M}$ & $75-125$ & $0-50$ & 10 & 6 & 2 & 9 & 2 & 4 & 25 & 7 & 1 & 6 & 22 & 5 & 5 & 7 \\
\hline 80 & 5 & $\mathbf{M}$ & $75-125$ & $0-50$ & 50 & 3 & 10 & 5 & 5 & 0 & 29 & 6 & 5 & 1 & 23 & 5 & 5 & 8 \\
\hline 80 & 5 & $\mathbf{M}$ & $75-125$ & $50-100$ & 10 & 8 & 7 & 8 & 5 & 5 & 22 & 10 & 3 & 4 & 17 & 9 & 1 & 2 \\
\hline 80 & 5 & $\mathbf{M}$ & $75-125$ & $50-100$ & 50 & 2 & 7 & 7 & 3 & 3 & 15 & 9 & 7 & 0 & 18 & 5 & 10 & 14 \\
\hline 80 & 5 & A & $25-74$ & $0-50$ & 10 & 9 & 6 & 3 & 1 & 2 & 35 & 6 & 3 & 2 & 24 & 5 & 2 & 4 \\
\hline 80 & 5 & A & $25-74$ & $0-50$ & 50 & 4 & 2 & 4 & 2 & 3 & 34 & 2 & 5 & 0 & 34 & 7 & 3 & 1 \\
\hline 80 & 5 & A & $25-74$ & $50-100$ & 10 & 8 & 4 & 6 & 3 & 2 & 20 & 10 & 6 & 1 & 24 & 6 & 2 & 9 \\
\hline 80 & 5 & A & $25-74$ & $50-100$ & 50 & 7 & 4 & 4 & 4 & 0 & 36 & 5 & 7 & 1 & 22 & 5 & 3 & 7 \\
\hline 80 & 5 & A & $75-125$ & $0-50$ & 10 & 9 & 0 & 3 & 2 & 3 & 25 & 4 & 0 & 4 & 40 & 3 & 3 & 5 \\
\hline 80 & 5 & A & $75-125$ & $0-50$ & 50 & 5 & 1 & 3 & 1 & 1 & 29 & 3 & 5 & 1 & 35 & 4 & 6 & 7 \\
\hline 80 & 5 & A & $75-125$ & $50-100$ & 10 & 3 & 5 & 7 & 5 & 4 & 29 & 5 & 2 & 2 & 25 & 6 & 1 & 7 \\
\hline 80 & 5 & A & $75-125$ & $50-100$ & 50 & 7 & 6 & 4 & 3 & 3 & 28 & 3 & 4 & 3 & 23 & 5 & 7 & 5 \\
\hline 80 & 7 & B & $25-74$ & $0-50$ & 10 & 13 & 5 & 10 & 2 & 4 & 21 & 10 & 2 & 7 & 10 & 5 & 3 & 8 \\
\hline 80 & 7 & B & $25-74$ & $0-50$ & 50 & 9 & 2 & 6 & 7 & 2 & 21 & 7 & 2 & 3 & 29 & 4 & 4 & 6 \\
\hline 80 & 7 & B & $25-74$ & $50-100$ & 10 & 15 & 1 & 7 & 2 & 5 & 18 & 11 & 1 & 5 & 15 & 6 & 2 & 12 \\
\hline 80 & 7 & B & $25-74$ & $50-100$ & 50 & 5 & 8 & 5 & 5 & 3 & 29 & 6 & 1 & 2 & 25 & 8 & 3 & 4 \\
\hline 80 & 7 & B & $75-125$ & $0-50$ & 10 & 10 & 1 & 8 & 2 & 4 & 15 & 11 & 0 & 4 & 21 & 14 & 1 & 10 \\
\hline 80 & 7 & B & $75-125$ & $0-50$ & 50 & 9 & 5 & 5 & 0 & 1 & 37 & 5 & 3 & 1 & 22 & 6 & 2 & 7 \\
\hline 80 & 7 & B & $75-125$ & $50-100$ & 10 & 15 & 1 & 13 & 1 & 3 & 20 & 6 & 1 & 4 & 13 & 16 & 1 & 8 \\
\hline 80 & 7 & B & $75-125$ & $50-100$ & 50 & 2 & 8 & 2 & 5 & 4 & 24 & 9 & 4 & 1 & 20 & 7 & 10 & 7 \\
\hline 80 & 7 & M & $25-74$ & $0-50$ & 10 & 3 & 7 & 9 & 7 & 4 & 18 & 9 & 3 & 1 & 26 & 4 & 1 & 8 \\
\hline 80 & 7 & M & $25-74$ & $0-50$ & 50 & 6 & 7 & 10 & 3 & 2 & 26 & 5 & 7 & 1 & 22 & 5 & 7 & 3 \\
\hline 80 & 7 & M & $25-74$ & $50-100$ & 10 & 6 & 2 & 12 & 6 & 10 & 15 & 9 & 6 & 3 & 11 & 10 & 3 & 11 \\
\hline 80 & 7 & $\mathbf{M}$ & $25-74$ & $50-100$ & 50 & 5 & 1 & 4 & 4 & 4 & 22 & 10 & 6 & 3 & 22 & 7 & 5 & 7 \\
\hline 80 & 7 & M & $75-125$ & $0-50$ & 10 & 8 & 3 & 5 & 5 & 4 & 25 & 4 & 3 & 6 & 22 & 7 & 1 & 7 \\
\hline 80 & 7 & M & $75-125$ & $0-50$ & 50 & 8 & 7 & 8 & 2 & 4 & 17 & 6 & 5 & 2 & 29 & 2 & 5 & 8 \\
\hline 80 & 7 & M & $75-125$ & $50-100$ & 10 & 7 & 8 & 13 & 2 & 0 & 17 & 9 & 3 & 0 & 23 & 12 & 4 & 2 \\
\hline 80 & 7 & M & $75-125$ & $50-100$ & 50 & 8 & 8 & 7 & 8 & 3 & 14 & 7 & 5 & 1 & 20 & 3 & 6 & 12 \\
\hline 80 & 7 & A & $25-74$ & $0-50$ & 10 & 5 & 2 & 3 & 1 & 1 & 29 & 8 & 4 & 5 & 29 & 9 & 2 & 3 \\
\hline 80 & 7 & A & $25-74$ & $0-50$ & 50 & 8 & 3 & 2 & 0 & 1 & 35 & 4 & 4 & 0 & 34 & 4 & 2 & 5 \\
\hline 80 & 7 & A & $25-74$ & $50-100$ & 10 & 6 & 4 & 11 & 1 & 2 & 19 & 6 & 2 & 4 & 23 & 16 & 3 & 5 \\
\hline 80 & 7 & A & $25-74$ & $50-100$ & 50 & 3 & 2 & 4 & 4 & 2 & 35 & 6 & 1 & 3 & 34 & 4 & 0 & 2 \\
\hline
\end{tabular}




\begin{tabular}{|c|c|c|c|c|c|c|c|c|c|c|c|c|c|c|c|c|c|c|}
\hline 80 & 7 & $\bar{A}$ & $75-125$ & $0-50$ & 10 & 5 & 0 & 5 & 4 & 2 & 30 & 6 & 2 & 3 & 33 & 5 & 2 & 3 \\
\hline 80 & 7 & A & $75-125$ & $0-50$ & 50 & 4 & 1 & 8 & 3 & 2 & 31 & 1 & 3 & 3 & 38 & 4 & 2 & 4 \\
\hline 80 & 7 & A & $75-125$ & $50-100$ & 10 & 3 & 5 & 10 & 3 & 7 & 15 & 7 & 5 & 1 & 26 & 10 & 6 & 4 \\
\hline 80 & 7 & A & $75-125$ & $50-100$ & 50 & 3 & 9 & 5 & 3 & 2 & 26 & 9 & 4 & 5 & 23 & 5 & 4 & 5 \\
\hline 100 & 3 & B & $25-74$ & $0-50$ & 10 & 13 & 1 & 10 & 7 & 0 & 15 & 14 & 4 & 2 & 15 & 9 & 6 & 6 \\
\hline 100 & 3 & B & $25-74$ & $0-50$ & 50 & 7 & 8 & 7 & 9 & 1 & 12 & 8 & 9 & 0 & 15 & 4 & 8 & 14 \\
\hline 100 & 3 & B & $25-74$ & $50-100$ & 10 & 11 & 2 & 5 & 6 & 7 & 19 & 9 & 3 & 7 & 9 & 10 & 6 & 7 \\
\hline 100 & 3 & B & $25-74$ & $50-100$ & 50 & 8 & 8 & 7 & 10 & 4 & 9 & 9 & 5 & 2 & 18 & 5 & 5 & 10 \\
\hline 100 & 3 & B & $75-125$ & $0-50$ & 10 & 11 & 3 & 6 & 5 & 2 & 20 & 8 & 2 & 2 & 27 & 6 & 4 & 5 \\
\hline 100 & 3 & B & $75-125$ & $0-50$ & 50 & 5 & 4 & 7 & 8 & 3 & 15 & 4 & 3 & 3 & 22 & 4 & 16 & 8 \\
\hline 100 & 3 & B & $75-125$ & $50-100$ & 10 & 13 & 2 & 8 & 7 & 5 & 10 & 14 & 3 & 2 & 20 & 5 & 6 & 5 \\
\hline 100 & 3 & B & $75-125$ & $50-100$ & 50 & 11 & 8 & 6 & 11 & 5 & 10 & 11 & 4 & 3 & 10 & 7 & 6 & 10 \\
\hline 100 & 3 & M & $25-74$ & $0-50$ & 10 & 6 & 11 & 7 & 9 & 2 & 16 & 4 & 1 & 8 & 14 & 7 & 12 & 5 \\
\hline 100 & 3 & $\mathbf{M}$ & $25-74$ & $0-50$ & 50 & 6 & 5 & 6 & 8 & 4 & 13 & 7 & 9 & 4 & 14 & 10 & 6 & 9 \\
\hline 100 & 3 & M & $25-74$ & $50-100$ & 10 & 5 & 4 & 8 & 9 & 5 & 8 & 13 & 8 & 4 & 13 & 3 & 10 & 10 \\
\hline 100 & 3 & $\mathbf{M}$ & $25-74$ & $50-100$ & 50 & 8 & 7 & 6 & 10 & 4 & 10 & 9 & 6 & 6 & 13 & 7 & 8 & 7 \\
\hline 100 & 3 & M & $75-125$ & $0-50$ & 10 & 4 & 6 & 3 & 7 & 6 & 14 & 5 & 8 & 6 & 18 & 6 & 10 & 7 \\
\hline 100 & 3 & $\mathbf{M}$ & $75-125$ & $0-50$ & 50 & 9 & 6 & 3 & 9 & 5 & 11 & 12 & 7 & 4 & 14 & 6 & 4 & 10 \\
\hline 100 & 3 & M & $75-125$ & $50-100$ & 10 & 5 & 8 & 3 & 10 & 2 & 16 & 4 & 6 & 2 & 17 & 10 & 11 & 6 \\
\hline 100 & 3 & $\mathbf{M}$ & $75-125$ & $50-100$ & 50 & 10 & 7 & 4 & 11 & 4 & 10 & 10 & 10 & 2 & 10 & 4 & 10 & 10 \\
\hline 100 & 3 & A & $25-74$ & $0-50$ & 10 & 4 & 3 & 3 & 4 & 4 & 34 & 6 & 4 & 2 & 23 & 4 & 3 & 7 \\
\hline 100 & 3 & A & $25-74$ & $0-50$ & 50 & 6 & 2 & 5 & 12 & 1 & 27 & 6 & 3 & 1 & 27 & 4 & 4 & 4 \\
\hline 100 & 3 & A & $25-74$ & $50-100$ & 10 & 7 & 2 & 8 & 8 & 1 & 20 & 5 & 3 & 3 & 33 & 6 & 0 & 5 \\
\hline 100 & 3 & A & $25-74$ & $50-100$ & 50 & 6 & 11 & 0 & 7 & 4 & 19 & 8 & 3 & 3 & 24 & 0 & 10 & 6 \\
\hline 100 & 3 & A & $75-125$ & $0-50$ & 10 & 2 & 1 & 2 & 3 & 4 & 26 & 6 & 1 & 2 & 36 & 6 & 7 & 5 \\
\hline 100 & 3 & A & $75-125$ & $0-50$ & 50 & 4 & 7 & 6 & 3 & 3 & 18 & 6 & 5 & 0 & 33 & 5 & 7 & 4 \\
\hline 100 & 3 & A & $75-125$ & $50-100$ & 10 & 5 & 2 & 6 & 4 & 2 & 23 & 10 & 5 & 3 & 28 & 2 & 3 & 8 \\
\hline 100 & 3 & A & $75-125$ & $50-100$ & 50 & 7 & 5 & 2 & 8 & 1 & 19 & 4 & 7 & 2 & 26 & 3 & 10 & 8 \\
\hline 100 & 5 & B & $25-74$ & $0-50$ & 10 & 8 & 4 & 7 & 6 & 1 & 19 & 7 & 2 & 4 & 16 & 15 & 5 & 6 \\
\hline 100 & 5 & B & $25-74$ & $0-50$ & 50 & 10 & 1 & 2 & 9 & 1 & 27 & 7 & 3 & 1 & 18 & 5 & 7 & 10 \\
\hline 100 & 5 & B & $25-74$ & $50-100$ & 10 & 14 & 1 & 4 & 5 & 2 & 23 & 12 & 4 & 4 & 16 & 4 & 3 & 8 \\
\hline 100 & 5 & B & $25-74$ & $50-100$ & 50 & 6 & 2 & 5 & 9 & 6 & 12 & 8 & 7 & 4 & 25 & 10 & 4 & 3 \\
\hline 100 & 5 & B & $75-125$ & $0-50$ & 10 & 8 & 3 & 7 & 1 & 8 & 20 & 5 & 3 & 2 & 30 & 8 & 1 & 5 \\
\hline 100 & 5 & B & $75-125$ & $0-50$ & 50 & 11 & 2 & 2 & 7 & 1 & 29 & 12 & 3 & 1 & 21 & 2 & 4 & 6 \\
\hline 100 & 5 & B & $75-125$ & $50-100$ & 10 & 10 & 4 & 9 & 1 & 5 & 22 & 5 & 2 & 2 & 21 & 4 & 4 & 11 \\
\hline 100 & 5 & B & $75-125$ & $50-100$ & 50 & 4 & 8 & 2 & 6 & 1 & 19 & 5 & 10 & 4 & 20 & 8 & 2 & 12 \\
\hline 100 & 5 & $\mathbf{M}$ & $25-74$ & $0-50$ & 10 & 4 & 6 & 8 & 4 & 1 & 22 & 7 & 4 & 4 & 19 & 12 & 7 & 3 \\
\hline 100 & 5 & M & $25-74$ & $0-50$ & 50 & 11 & 6 & 4 & 6 & 0 & 22 & 13 & 2 & 1 & 18 & 3 & 6 & 9 \\
\hline 100 & 5 & M & $25-74$ & $50-100$ & 10 & 8 & 4 & 11 & 4 & 1 & 27 & 10 & 2 & 3 & 11 & 7 & 5 & 7 \\
\hline 100 & 5 & $\mathbf{M}$ & $25-74$ & $50-100$ & 50 & 12 & 6 & 7 & 8 & 0 & 10 & 13 & 6 & 3 & 19 & 2 & 8 & 9 \\
\hline 100 & 5 & $\mathbf{M}$ & $75-125$ & $0-50$ & 10 & 4 & 4 & 10 & 1 & 4 & 19 & 6 & 8 & 2 & 21 & 9 & 6 & 7 \\
\hline 100 & 5 & M & $75-125$ & $0-50$ & 50 & 7 & 8 & 9 & 7 & 1 & 14 & 6 & 8 & 4 & 24 & 6 & 2 & 6 \\
\hline 100 & 5 & M & $75-125$ & $50-100$ & 10 & 10 & 3 & 13 & 5 & 0 & 18 & 10 & 6 & 4 & 14 & 6 & 6 & 5 \\
\hline 100 & 5 & M & $75-125$ & $50-100$ & 50 & 11 & 8 & 3 & 7 & 2 & 17 & 6 & 8 & 2 & 20 & 4 & 7 & 8 \\
\hline 100 & 5 & A & $25-74$ & $0-50$ & 10 & 7 & 2 & 6 & 4 & 4 & 27 & 3 & 0 & 1 & 30 & 6 & 3 & 7 \\
\hline 100 & 5 & A & $25-74$ & $0-50$ & 50 & 6 & 6 & 6 & 3 & 2 & 38 & 3 & 4 & 1 & 21 & 4 & 3 & 5 \\
\hline 100 & 5 & A & $25-74$ & $50-100$ & 10 & 6 & 3 & 9 & 3 & 3 & 24 & 4 & 1 & 2 & 32 & 7 & 2 & 5 \\
\hline 100 & 5 & A & $25-74$ & $50-100$ & 50 & 3 & 3 & 4 & 5 & 1 & 32 & 4 & 3 & 0 & 30 & 4 & 6 & 7 \\
\hline 100 & 5 & A & $75-125$ & $0-50$ & 10 & 9 & 1 & 4 & 2 & 2 & 28 & 9 & 6 & 4 & 27 & 7 & 1 & 1 \\
\hline 100 & 5 & A & $75-125$ & $0-50$ & 50 & 4 & 3 & 6 & 3 & 3 & 37 & 5 & 3 & 1 & 30 & 2 & 3 & 1 \\
\hline 100 & 5 & A & $75-125$ & $50-100$ & 10 & 1 & 9 & 4 & 4 & 6 & 24 & 5 & 2 & 4 & 26 & 6 & 6 & 3 \\
\hline 100 & 5 & A & $75-125$ & $50-100$ & 50 & 5 & 8 & 7 & 2 & 2 & 30 & 3 & 3 & 1 & 24 & 3 & 8 & 5 \\
\hline 100 & 7 & B & $25-74$ & $0-50$ & 10 & 18 & 3 & 11 & 2 & 4 & 16 & 12 & 2 & 4 & 15 & 6 & 0 & 7 \\
\hline 100 & 7 & B & $25-74$ & $0-50$ & 50 & 9 & 6 & 6 & 4 & 1 & 24 & 8 & 7 & 0 & 21 & 7 & 2 & 5 \\
\hline 100 & 7 & B & $25-74$ & $50-100$ & 10 & 13 & 2 & 6 & 3 & 3 & 21 & 18 & 2 & 6 & 12 & 5 & 1 & 8 \\
\hline 100 & 7 & B & $25-74$ & $50-100$ & 50 & 2 & 6 & 7 & 5 & 3 & 25 & 4 & 2 & 4 & 25 & 9 & 2 & 7 \\
\hline 100 & 7 & B & $75-125$ & $0-50$ & 10 & 7 & 2 & 6 & 3 & 4 & 20 & 9 & 1 & 5 & 19 & 16 & 1 & 8 \\
\hline 100 & 7 & B & $75-125$ & $0-50$ & 50 & 5 & 3 & 9 & 3 & 0 & 26 & 9 & 5 & 2 & 26 & 3 & 3 & 7 \\
\hline 100 & 7 & B & $75-125$ & $50-100$ & 10 & 12 & 2 & 10 & 3 & 5 & 16 & 12 & 3 & 11 & 10 & 12 & 0 & 4 \\
\hline 100 & 7 & B & $75-125$ & $50-100$ & 50 & 4 & 6 & 8 & 0 & 1 & 23 & 6 & 5 & 1 & 32 & 6 & 3 & 7 \\
\hline 100 & 7 & M & $25-74$ & $0-50$ & 10 & 6 & 4 & 11 & 3 & 5 & 22 & 5 & 5 & 3 & 17 & 9 & 3 & 7 \\
\hline 100 & 7 & $\mathbf{M}$ & $25-74$ & $0-50$ & 50 & 6 & 7 & 6 & 4 & 3 & 28 & 0 & 8 & 1 & 18 & 5 & 7 & 8 \\
\hline
\end{tabular}




\begin{tabular}{lllllllllllllllllll}
\hline $\mathbf{1 0 0}$ & $\mathbf{7}$ & $\mathbf{M}$ & $\mathbf{2 5 - 7 4}$ & $\mathbf{5 0 - 1 0 0}$ & $\mathbf{1 0}$ & 5 & 3 & 16 & 5 & 6 & 24 & 6 & 0 & 1 & 18 & 8 & 3 & 5 \\
$\mathbf{1 0 0}$ & $\mathbf{7}$ & $\mathbf{M}$ & $\mathbf{2 5 - 7 4}$ & $\mathbf{5 0 - 1 0 0}$ & $\mathbf{5 0}$ & 7 & 6 & 3 & 5 & 6 & 19 & 4 & 6 & 5 & 25 & 4 & 4 & 7 \\
$\mathbf{1 0 0}$ & $\mathbf{7}$ & $\mathbf{M}$ & $\mathbf{7 5 - 1 2 5}$ & $\mathbf{0 - 5 0}$ & $\mathbf{1 0}$ & 8 & 2 & 3 & 4 & 2 & 31 & 6 & 0 & 3 & 22 & 8 & 4 & 7 \\
$\mathbf{1 0 0}$ & $\mathbf{7}$ & $\mathbf{M}$ & $\mathbf{7 5 - 1 2 5}$ & $\mathbf{0 - 5 0}$ & $\mathbf{5 0}$ & $\mathbf{7}$ & 6 & 3 & 2 & 2 & 25 & 8 & 3 & 4 & 24 & 6 & 8 & 2 \\
$\mathbf{1 0 0}$ & $\mathbf{7}$ & $\mathbf{M}$ & $\mathbf{7 5 - 1 2 5}$ & $\mathbf{5 0 - 1 0 0}$ & $\mathbf{1 0}$ & 8 & 3 & 10 & 4 & 0 & 15 & 10 & 3 & 1 & 18 & 12 & 9 & 8 \\
$\mathbf{1 0 0}$ & $\mathbf{7}$ & $\mathbf{M}$ & $\mathbf{7 5 - 1 2 5}$ & $\mathbf{5 0 - 1 0 0}$ & $\mathbf{5 0}$ & 6 & 7 & 9 & 7 & 2 & 20 & 4 & 4 & 1 & 21 & 2 & 8 & 10 \\
$\mathbf{1 0 0}$ & $\mathbf{7}$ & $\mathbf{A}$ & $\mathbf{2 5 - 7 4}$ & $\mathbf{0 - 5 0}$ & $\mathbf{1 0}$ & 3 & 4 & 9 & 3 & 5 & 29 & 6 & 2 & 4 & 21 & 3 & 5 & 6 \\
$\mathbf{1 0 0}$ & $\mathbf{7}$ & $\mathbf{A}$ & $\mathbf{2 5 - 7 4}$ & $\mathbf{0 - 5 0}$ & $\mathbf{5 0}$ & 1 & 9 & 1 & 6 & 3 & 28 & 5 & 3 & 0 & 37 & 4 & 1 & 4 \\
$\mathbf{1 0 0}$ & $\mathbf{7}$ & $\mathbf{A}$ & $\mathbf{2 5 - 7 4}$ & $\mathbf{5 0 - 1 0 0}$ & $\mathbf{1 0}$ & 7 & 3 & 6 & 3 & 4 & 28 & 9 & 1 & 2 & 25 & 6 & 1 & 5 \\
$\mathbf{1 0 0}$ & $\mathbf{7}$ & $\mathbf{A}$ & $\mathbf{2 5 - 7 4}$ & $\mathbf{5 0 - 1 0 0}$ & $\mathbf{5 0}$ & 4 & 1 & 11 & 4 & 4 & 33 & 2 & 3 & 1 & 26 & 5 & 3 & 4 \\
$\mathbf{1 0 0}$ & $\mathbf{7}$ & $\mathbf{A}$ & $\mathbf{7 5 - 1 2 5}$ & $\mathbf{0 - 5 0}$ & $\mathbf{1 0}$ & 11 & 4 & 8 & 0 & 2 & 25 & 6 & 2 & 9 & 25 & 1 & 3 & 6 \\
$\mathbf{1 0 0}$ & $\mathbf{7}$ & $\mathbf{A}$ & $\mathbf{7 5 - 1 2 5}$ & $\mathbf{0 - 5 0}$ & $\mathbf{5 0}$ & 6 & 3 & 4 & 4 & 0 & 28 & 6 & 4 & 3 & 33 & 5 & 2 & 2 \\
$\mathbf{1 0 0}$ & $\mathbf{7}$ & $\mathbf{A}$ & $\mathbf{7 5 - 1 2 5}$ & $\mathbf{5 0 - 1 0 0}$ & $\mathbf{1 0}$ & 8 & 4 & 8 & 0 & 2 & 24 & 5 & 5 & 1 & 24 & 12 & 4 & 4 \\
$\mathbf{1 0 0}$ & $\mathbf{7}$ & $\mathbf{A}$ & $\mathbf{7 5 - 1 2 5}$ & $\mathbf{5 0 - 1 0 0}$ & $\mathbf{5 0}$ & 2 & 3 & 8 & 4 & 1 & 41 & 4 & 4 & 1 & 26 & 1 & 5 & 0 \\
\hline
\end{tabular}

TABEla D.29 - Desvio relativo médio (em \%) das regras para setup dependente

\begin{tabular}{|c|c|c|c|c|c|c|c|c|c|c|c|c|c|c|c|c|c|c|}
\hline$n$ & $g$ & $f$ & $s$ & $a$ & $l$ & Rd1 & Rd2 & Rd3 & Rd4 & Rd5 & Rd6 & Rd7 & Rd8 & Rd9 & Rd10 & Rd11 & Rd12 & Rd13 \\
\hline 10 & 3 & B & $25-74$ & $0-50$ & 10 & 6,9 & $\overline{12,7}$ & 12,8 & 8,2 & 11,7 & $\overline{5,4}$ & $\overline{6,4}$ & 13,2 & 11,7 & 6,3 & 12,0 & 8,0 & 9,1 \\
\hline 10 & 3 & B & 25-74 & $0-50$ & 50 & 7,9 & 9,6 & 11,2 & 6,4 & 3,5 & 2,5 & 6,5 & 9,6 & 3,6 & 2,7 & 1,1 & 6,2 & 8,8 \\
\hline 10 & 3 & B & $25-74$ & $50-100$ & 10 & 8,0 & 13,7 & 12,0 & 8,4 & 3,1 & 5,7 & 7,1 & 13,4 & 12,4 & ,8 & 1,9 & 8,4 & 8,5 \\
\hline 10 & 3 & B & $25-74$ & $50-100$ & 50 & 8,2 & 9,5 & 13,9 & 5,9 & 15,0 & 2,7 & 8,4 & 8,6 & 14,5 & 3,3 & 12,9 & 6,0 & 7,6 \\
\hline 10 & 3 & B & $75-125$ & $0-50$ & 10 & 6,6 & 9,6 & 9,4 & 6,8 & 10,1 & 4,6 & 6,8 & 10,0 & 10,2 & 4,7 & 9,0 & 6,2 & 8,3 \\
\hline 10 & 3 & B & $75-125$ & $0-50$ & 50 & 5,5 & 7,0 & 9,4 & 4,0 & 11,1 & 2,9 & 5,8 & 7,7 & 11,3 & 3,1 & 9,8 & 4,0 & 6,4 \\
\hline 10 & 3 & B & $75-125$ & $50-100$ & 10 & 5,2 & 9,6 & 8,5 & 6,4 & 9,8 & 4,6 & 5,1 & 10,3 & 9,5 & 5,1 & 8,6 & 7,3 & 6,1 \\
\hline 10 & 3 & B & $75-125$ & 50-100 & 50 & 5,2 & 5,0 & 8,7 & 3,7 & 9,8 & 2,1 & 5,2 & 5,0 & 9,7 & 2,2 & 8,0 & 3,7 & 5,8 \\
\hline 10 & 3 & M & $25-74$ & $0-50$ & 10 & 8,5 & 11,4 & 10,1 & 8,5 & 11,4 & 7,6 & 8,1 & 11,6 & 11,7 & 6,8 & 10,2 & 8,0 & 9,9 \\
\hline 10 & 3 & M & $25-74$ & $0-50$ & 50 & 8,4 & 10,6 & 14,1 & 5,8 & 14,5 & 3,7 & 7,9 & 11,0 & 14,3 & 3,8 & 14,7 & 5,5 & 7,6 \\
\hline 10 & 3 & M & $25-74$ & $50-100$ & 10 & 7,5 & 10,1 & 9,4 & 7,6 & 10,3 & 7,0 & 7,6 & 9,9 & 10,9 & 6,6 & 9,9 & 7,6 & 9,6 \\
\hline 10 & 3 & M & $25-74$ & $50-100$ & 50 & 6,1 & 8,7 & 9,9 & 4,8 & 11,5 & 2,8 & 6,5 & 7,6 & 10,9 & 3,2 & 9,8 & 5,0 & 6,1 \\
\hline 10 & 3 & M & $75-125$ & $0-50$ & 10 & 8,1 & 8,9 & 10,2 & 7,9 & 9,7 & 5,0 & 8,4 & 9,2 & 10,0 & 5,8 & 9,8 & 7,5 & 8,7 \\
\hline 10 & 3 & M & $75-125$ & $0-50$ & 50 & 6,1 & 7,3 & 9,8 & 4,1 & 11,2 & 1,7 & 5,8 & 7,4 & 11,4 & 1,8 & 9,5 & 4,1 & 6,8 \\
\hline 10 & 3 & M & $75-125$ & $50-100$ & 10 & 6,1 & 7,6 & 8,4 & 5,7 & 8,8 & 4,3 & 6,4 & 8,1 & 8,9 & 4,1 & 7,4 & 5,2 & 6,8 \\
\hline 10 & 3 & M & $75-125$ & $50-100$ & 50 & 5,0 & 5,5 & 7,8 & 4,1 & 7,4 & 2,1 & 4,6 & 5,3 & 8,0 & 1,9 & 7,1 & 3,9 & 5,4 \\
\hline 10 & 3 & A & $25-74$ & $0-50$ & 10 & 10,4 & 15,8 & 16,3 & 10,8 & 18,2 & 5,4 & 10,5 & 15,8 & 18,5 & 5,7 & 15,9 & 10,4 & 12,6 \\
\hline 10 & 3 & A & $25-74$ & $0-50$ & 50 & 8,4 & 8,0 & 12,2 & 4,6 & 13,8 & 1,9 & 8,7 & 8,3 & 14,2 & 2,0 & 12,0 & 4,5 & 9,0 \\
\hline 10 & 3 & A & $25-74$ & $50-100$ & 10 & 10,9 & 17,5 & 16,2 & 10,9 & 17,5 & 6,2 & 10,6 & 17,1 & 18,1 & 6,0 & 16,1 & 11,1 & 11,7 \\
\hline 10 & 3 & A & $25-74$ & $50-100$ & 50 & 8,1 & 6,1 & 13,2 & 4,6 & 14,6 & 1,9 & 8,2 & 6,5 & 14,4 & 1,9 & 12,6 & 4,2 & 8,6 \\
\hline 10 & 3 & A & $75-125$ & $0-50$ & 10 & 8,4 & 12,2 & 12,0 & 10,6 & 13,7 & 5,4 & 9,0 & 12,2 & 14,0 & 6,0 & 12,7 & 9,7 & 11,0 \\
\hline 10 & 3 & A & $75-125$ & $0-50$ & 50 & 9,5 & 9,7 & 14,4 & 6,0 & 18,0 & 1,8 & 10,8 & 9,8 & 18,3 & 1,7 & 15,3 & 5,9 & 10,4 \\
\hline 10 & 3 & A & $75-125$ & $50-100$ & 10 & 9,0 & 11,1 & 9,7 & 8,7 & 13,4 & 6,1 & 9,3 & 11,3 & 13,1 & 6,2 & 9,8 & 10,3 & 9,6 \\
\hline 10 & 3 & A & $75-125$ & $50-100$ & 50 & 10,6 & 7,6 & 11,8 & 7,5 & 15,1 & 2,5 & 10,2 & 6,6 & 14,9 & 2,5 & 11,8 & 7,4 & 9,9 \\
\hline 10 & 5 & B & $25-74$ & $0-50$ & 10 & 6,3 & 12,6 & 10,3 & 10,4 & 12,6 & 6,4 & 6,4 & 12,6 & 12,2 & 6,0 & 9,6 & 10,7 & 8,4 \\
\hline 10 & 5 & B & $25-74$ & $0-50$ & 50 & 8,3 & 13,4 & 10,8 & 8,7 & 16,8 & 3,6 & 8,7 & 12,4 & 16,3 & 4,3 & 11,1 & 9,3 & 12,2 \\
\hline 10 & 5 & B & $25-74$ & $50-100$ & 10 & 6,7 & 12,8 & 8,7 & 11,7 & 10,8 & 6,7 & 7,0 & 12,3 & 11,5 & 7,0 & 8,9 & 11,2 & 9,0 \\
\hline 10 & 5 & B & $25-74$ & $50-100$ & 50 & 6,3 & 9,9 & 10,0 & 6,6 & 12,2 & 2,8 & 7,1 & 9,6 & 12,6 & 2,4 & 9,9 & 6,6 & 7,2 \\
\hline 10 & 5 & B & $75-125$ & $0-50$ & 10 & 5,9 & 9,9 & 7,1 & 9,2 & 9,8 & 5,7 & 5,6 & 10,4 & 9,5 & 5,9 & 7,5 & 9,3 & 8,1 \\
\hline 10 & 5 & B & $75-125$ & $0-50$ & 50 & 6,7 & 8,5 & 10,7 & 6,7 & 13,2 & 3,2 & 7,3 & 8,7 & 13,0 & 3,5 & 10,8 & 6,8 & 7,6 \\
\hline 10 & 5 & B & $75-125$ & $50-100$ & 10 & 6,6 & 9,9 & 7,7 & 8,7 & 10,3 & 5,0 & 6,6 & 10,1 & 10,4 & 5,2 & 7,3 & 9,2 & 8,2 \\
\hline 10 & 5 & B & $75-125$ & 50-100 & 50 & 4,8 & 7,7 & 7,0 & 6,2 & 8,7 & 3,2 & 4,9 & 7,5 & 8,7 & 3,2 & 6,3 & 6,0 & 6,2 \\
\hline 10 & 5 & M & $25-74$ & $0-50$ & 10 & 7,6 & 11,2 & 8,5 & 10,1 & 10,5 & 6,9 & 7,2 & 10,9 & 11,2 & 6,6 & 8,4 & 10,5 & 9,0 \\
\hline 10 & 5 & M & $25-74$ & $0-50$ & 50 & 6,2 & 6,9 & 9,5 & 6,1 & 12,1 & 2,6 & 5,8 & 8,1 & 12,5 & 3,2 & 9,3 & 6,2 & 7,8 \\
\hline 10 & 5 & M & $25-74$ & $50-100$ & 10 & 7,4 & 13,4 & 10,9 & 11,3 & 12,9 & 6,7 & 7,5 & 13,3 & 12,8 & 6,8 & 10,7 & 11,5 & 9,5 \\
\hline 10 & 5 & M & $25-74$ & $50-100$ & 50 & 5,4 & 10,3 & 8,9 & 5,4 & 10,9 & 3,9 & 6,1 & 9,5 & 10,5 & 3,7 & 8,8 & 5,7 & 7,2 \\
\hline 10 & 5 & M & $75-125$ & $0-50$ & 10 & 6,3 & 9,6 & 7,9 & 8,7 & 9,2 & 5,5 & 6,2 & 9,2 & 9,6 & 5,1 & 6,9 & 8,7 & 9,0 \\
\hline 10 & 5 & M & $75-125$ & $0-50$ & 50 & 7,4 & 8,3 & 8,6 & 7,6 & 12,1 & 2,7 & 7,1 & 8,0 & 11,9 & 2,9 & 8,1 & 8,0 & 7,4 \\
\hline 10 & 5 & M & $75-125$ & $50-100$ & 10 & 6,1 & 9,3 & 7,6 & 8,2 & 10,2 & 5,0 & 6,1 & 9,2 & 10,2 & 4,7 & 6,6 & 8,5 & 8,1 \\
\hline 10 & 5 & M & $75-125$ & $50-100$ & 50 & 5,7 & 7,9 & 7,3 & 6,6 & 9,7 & 3,3 & 5,5 & 8,0 & 9,7 & 3,3 & 7,6 & 5,8 & 5,6 \\
\hline 10 & 5 & A & $25-74$ & $0-50$ & 10 & 8,0 & 12,5 & 9,6 & 10,8 & 12,9 & 6,8 & 7,3 & 11,6 & 13,0 & 5,8 & 9,7 & 12,1 & 9,1 \\
\hline
\end{tabular}




\begin{tabular}{|c|c|c|c|c|c|c|c|c|c|c|c|c|c|c|c|c|c|c|}
\hline 10 & 5 & $\bar{A}$ & $25-74$ & $0-50$ & 50 & 7,4 & 7,5 & 11,1 & 5,7 & 13,5 & 2,0 & 7,4 & 8,1 & 12,7 & 2,1 & 11,5 & 6,1 & 6,8 \\
\hline 10 & 5 & A & $25-74$ & $50-100$ & 10 & 7,5 & 13,2 & 7,9 & 11,1 & 12,0 & 7,2 & 7,2 & 13,0 & 12,0 & 6,9 & 8,7 & 10,2 & 8,5 \\
\hline 10 & 5 & A & $25-74$ & $50-100$ & 50 & 6,8 & 8,6 & 9,0 & 5,0 & 12,5 & 2,6 & 7,0 & 9,0 & 12,6 & 1,8 & 9,0 & 5,3 & 5,9 \\
\hline 10 & 5 & A & $75-125$ & $0-50$ & 10 & 6,5 & 10,1 & 9,2 & 9,9 & 11,9 & 6,5 & 6,8 & 9,5 & 11,8 & 6,1 & 9,1 & 10,3 & 8,9 \\
\hline 10 & 5 & A & $75-125$ & $0-50$ & 50 & 6,1 & 8,6 & 8,5 & 5,8 & 10,8 & 3,2 & 6,5 & 8,3 & 10,6 & 3,6 & 8,3 & 5,8 & 6,5 \\
\hline 10 & 5 & A & $75-125$ & $50-100$ & 10 & 8,2 & 10,8 & 7,7 & 11,8 & 11,5 & 7,2 & 7,9 & 10,3 & 11,1 & 7,5 & 9,1 & 11,1 & 8,5 \\
\hline 10 & 5 & A & $75-125$ & $50-100$ & 50 & 5,5 & 4,6 & 5,7 & 4,5 & 8,1 & 2,3 & 5,1 & 4,6 & 7,9 & 2,3 & 6,3 & 4,7 & 4,4 \\
\hline 10 & 7 & B & $25-74$ & $0-50$ & 10 & 6,2 & 11,5 & 5,9 & 9,9 & 8,8 & 6,8 & 6,2 & 10,9 & 9,4 & 6,8 & 6,2 & 10,3 & 8,5 \\
\hline 10 & 7 & B & $25-74$ & $0-50$ & 50 & 8,5 & 9,4 & 9,2 & 9,3 & 14,7 & 4,4 & 8,3 & 9,3 & 14,7 & 4,3 & 9,9 & 9,0 & 9,5 \\
\hline 10 & 7 & B & $25-74$ & $50-100$ & 10 & 5,5 & 11,8 & 7,6 & 11,6 & 10,4 & 6,4 & 6,2 & 12,1 & 10,7 & 6,3 & 8,1 & 12,8 & 9,3 \\
\hline 10 & 7 & B & $25-74$ & $50-100$ & 50 & 6,3 & 11,5 & 9,0 & 8,6 & 12,6 & 3,8 & 5,8 & 11,2 & 12,5 & 4,2 & 8,2 & 8,9 & 7,9 \\
\hline 10 & 7 & B & $75-125$ & $0-50$ & 10 & 5,2 & 8,9 & 6,5 & 8,5 & 8,3 & 5,9 & 5,2 & 8,9 & 8,1 & 5,8 & 6,0 & 9,4 & 6,5 \\
\hline 10 & 7 & B & $75-125$ & $0-50$ & 50 & 6,7 & 8,1 & 8,7 & 8,1 & 11,1 & 3,9 & 6,2 & 8,1 & 11,2 & 4,0 & 9,1 & 7,7 & 7,3 \\
\hline 10 & 7 & B & $75-125$ & $50-100$ & 10 & 5,6 & 10,8 & 6,5 & 9,8 & 9,2 & 7,8 & 5,3 & 10,1 & 9,0 & 6,8 & 7,2 & 9,7 & 7,6 \\
\hline 10 & 7 & B & $75-125$ & $50-100$ & 50 & 7,0 & 8,9 & 8,4 & 8,5 & 11,9 & 3,2 & 7,2 & 8,1 & 11,8 & 3,3 & 8,7 & 8,0 & 8,3 \\
\hline 10 & 7 & M & $25-74$ & $0-50$ & 10 & 7,8 & 13,1 & 9,7 & 10,6 & 12,3 & 4,9 & 8,1 & 13,1 & 11,5 & 5,7 & 9,3 & 10,8 & 9,4 \\
\hline 10 & 7 & M & $25-74$ & $0-50$ & 50 & 4,8 & 7,4 & 7,2 & 6,8 & 9,4 & 2,4 & 5,1 & 7,7 & 9,4 & 2,2 & 7,5 & 6,5 & 6,4 \\
\hline 10 & 7 & M & $25-74$ & $50-100$ & 10 & 7,1 & 11,0 & 7,9 & 9,5 & 11,1 & 7,2 & 7,4 & 11,0 & 10,8 & 7,1 & 8,2 & 9,4 & 8,5 \\
\hline 10 & 7 & M & $25-74$ & $50-100$ & 50 & 6,1 & 9,8 & 8,9 & 7,6 & 11,8 & 3,5 & 6,1 & 10,2 & 11,9 & 4,0 & 9,3 & 7,6 & 6,3 \\
\hline 10 & 7 & M & $75-125$ & $0-50$ & 10 & 7,5 & 10,0 & 7,7 & 9,6 & 10,8 & 5,6 & 7,8 & 9,3 & 11,1 & 5,6 & 8,5 & 9,2 & 8,5 \\
\hline 10 & 7 & M & $75-125$ & $0-50$ & 50 & 5,9 & 8,4 & 8,1 & 8,1 & 10,8 & 4,0 & 7,0 & 7,4 & 10,8 & 3,8 & 8,1 & 7,7 & 7,8 \\
\hline 10 & 7 & M & $75-125$ & $50-100$ & 10 & 6,5 & 8,6 & 6,6 & 10,1 & 10,0 & 6,5 & 7,0 & 8,5 & 9,7 & 5,9 & 6,6 & 9,3 & 8,1 \\
\hline 10 & 7 & M & $75-125$ & $50-100$ & 50 & 3,9 & 5,4 & 5,8 & 4,2 & 7,7 & 2,3 & 3,8 & 4,9 & 7,7 & 2,2 & 5,4 & 4,5 & 4,2 \\
\hline 10 & 7 & A & $25-74$ & $0-50$ & 10 & 6,4 & 9,8 & 7,4 & 10,2 & 11,0 & 7,0 & 6,2 & 9,7 & 10,5 & 7,2 & 7,4 & 9,7 & 8,1 \\
\hline 10 & 7 & A & $25-74$ & $0-50$ & 50 & 5,2 & 5,6 & 7,1 & 5,7 & 9,1 & 1,8 & 5,1 & 6,1 & 9,0 & 1,8 & 6,9 & 5,5 & 5,6 \\
\hline 10 & 7 & A & $25-74$ & $50-100$ & 10 & 6,6 & 12,2 & 7,2 & 12,0 & 11,6 & 7,3 & 7,2 & 12,1 & 11,7 & 7,2 & 8,7 & 11,9 & 8,3 \\
\hline 10 & 7 & A & $25-74$ & $50-100$ & 50 & 6,4 & 6,6 & 6,6 & 6,3 & 9,7 & 3,3 & 5,8 & 7,4 & 10,2 & 2,7 & 6,7 & 6,6 & 7,5 \\
\hline 10 & 7 & A & $75-125$ & $0-50$ & 10 & 7,0 & 9,9 & 8,1 & 9,2 & 10,2 & 6,8 & 6,6 & 9,3 & 10,0 & 6,9 & 7,1 & 9,4 & 7,5 \\
\hline 10 & 7 & A & $75-125$ & $0-50$ & 50 & 4,5 & 5,5 & 5,6 & 4,9 & 8,8 & 2,7 & 4,5 & 5,7 & 8,9 & 2,7 & 5,9 & 4,8 & 4,2 \\
\hline 10 & 7 & A & $75-125$ & $50-100$ & 10 & 8,0 & 11,3 & 8,7 & 10,1 & 12,6 & 6,1 & 8,2 & 11,2 & 12,6 & 6,5 & 8,7 & 8,8 & 9,1 \\
\hline 10 & 7 & A & $75-125$ & $50-100$ & 50 & 5,0 & 6,7 & 7,3 & 5,1 & 9,5 & 3,1 & 4,8 & 7,0 & 9,5 & 2,9 & 6,5 & 5,7 & 6,1 \\
\hline 30 & 3 & B & $25-74$ & $0-50$ & 10 & 4,2 & 10,8 & 8,7 & 6,8 & 9,0 & 3,0 & 4,2 & 10,7 & 8,0 & 3,9 & 8,8 & 6,4 & 6,7 \\
\hline 30 & 3 & B & $25-74$ & $0-50$ & 50 & 4,7 & 6,2 & 6,8 & 4,5 & 8,2 & 2,8 & 4,5 & 5,9 & 8,1 & 3,1 & 6,7 & 4,8 & 5,8 \\
\hline 30 & 3 & B & $25-74$ & 50-100 & 10 & 4,3 & 10,0 & 8,9 & 6,2 & 8,2 & 3,7 & 4,5 & 10,5 & 8,5 & 3,6 & 8,4 & 6,2 & 6,1 \\
\hline 30 & 3 & B & $25-74$ & $50-100$ & 50 & 4,7 & 5,5 & 6,0 & 4,1 & 7,5 & 2,8 & 4,6 & 5,6 & 7,1 & 2,9 & 6,5 & 4,4 & 5,2 \\
\hline 30 & 3 & B & $75-125$ & $0-50$ & 10 & 4,1 & 7,6 & 6,7 & 4,9 & 6,5 & 2,5 & 3,9 & 7,4 & 6,3 & 2,4 & 6,2 & 4,4 & 4,4 \\
\hline 30 & 3 & B & $75-125$ & $0-50$ & 50 & 4,2 & 4,3 & 6,4 & 3,1 & 8,1 & 1,8 & 4,3 & 4,4 & 8,1 & 2,0 & 6,5 & 3,3 & 4,5 \\
\hline 30 & 3 & B & $75-125$ & $50-100$ & 10 & 3,1 & 6,8 & 6,6 & 4,2 & 5,5 & 2,1 & 3,3 & 6,7 & 5,5 & 2,2 & 6,0 & 3,8 & 4,1 \\
\hline 30 & 3 & B & $75-125$ & $50-100$ & 50 & 3,4 & 3,5 & 5,4 & 2,9 & 7,0 & 2,1 & 3,2 & 3,6 & 6,8 & 2,1 & 5,3 & 2,8 & 3,7 \\
\hline 30 & 3 & M & $25-74$ & $0-50$ & 10 & 5,1 & 5,8 & 5,6 & 4,7 & 6,6 & 3,5 & 5,2 & 5,7 & 6,1 & 3,5 & 5,6 & 4,6 & 5,2 \\
\hline 30 & 3 & M & $25-74$ & $0-50$ & 50 & 5,6 & 6,5 & 7,6 & 5,1 & 9,0 & 3,2 & 5,6 & 6,5 & 9,4 & 3,6 & 7,9 & 5,4 & 5,6 \\
\hline 30 & 3 & M & $25-74$ & $50-100$ & 10 & 4,9 & 5,7 & 5,2 & 4,5 & 6,6 & 3,8 & 4,7 & 5,5 & 6,2 & 3,3 & 5,5 & 4,7 & 5,2 \\
\hline 30 & 3 & M & $25-74$ & $50-100$ & 50 & 5,3 & 5,3 & 6,5 & 4,5 & 7,4 & 3,8 & 5,2 & 5,1 & 7,4 & 3,6 & 6,4 & 4,6 & 5,1 \\
\hline 30 & 3 & M & $75-125$ & $0-50$ & 10 & 3,5 & 3,8 & 4,5 & 3,1 & 4,5 & 2,6 & 3,4 & 4,1 & 4,5 & 2,6 & 4,3 & 2,9 & 3,7 \\
\hline 30 & 3 & M & $75-125$ & $0-50$ & 50 & 3,6 & 4,4 & 5,9 & 3,7 & 6,6 & 2,5 & 3,9 & 4,0 & 6,9 & 2,4 & 6,1 & 3,3 & 3,8 \\
\hline 30 & 3 & M & $75-125$ & $50-100$ & 10 & 3,0 & 3,9 & 3,5 & 3,2 & 4,2 & 2,6 & 3,3 & 4,0 & 4,1 & 2,5 & 3,4 & 3,2 & 3,5 \\
\hline 30 & 3 & M & $75-125$ & $50-100$ & 50 & 3,6 & 3,9 & 5,0 & 3,0 & 5,8 & 2,6 & 3,4 & 4,0 & 5,8 & 2,6 & 4,8 & 2,9 & 3,4 \\
\hline 30 & 3 & A & $25-74$ & $0-50$ & 10 & 7,4 & 11,0 & 12,3 & 8,6 & 12,2 & 3,5 & 7,4 & 11,6 & 10,9 & 3,4 & 12,0 & 7,7 & 8,8 \\
\hline 30 & 3 & A & $25-74$ & $0-50$ & 50 & 10,9 & 10,8 & 14,2 & 8,0 & 17,8 & 3,2 & 10,9 & 11,3 & 17,5 & 2,8 & 14,9 & 7,6 & 10,5 \\
\hline 30 & 3 & A & $25-74$ & $50-100$ & 10 & 5,6 & 10,5 & 8,9 & 8,2 & 9,4 & 4,3 & 5,7 & 10,3 & 9,8 & 4,3 & 9,1 & 8,4 & 7,2 \\
\hline 30 & 3 & A & $25-74$ & $50-100$ & 50 & 8,9 & 9,6 & 14,4 & 7,5 & 16,0 & 2,6 & 9,8 & 9,7 & 15,7 & 2,7 & 14,0 & 7,1 & 9,3 \\
\hline 30 & 3 & A & $75-125$ & $0-50$ & 10 & 5,7 & 8,4 & 8,9 & 6,4 & 9,9 & 2,4 & 5,7 & 8,6 & 9,6 & 2,3 & 8,5 & 6,1 & 6,5 \\
\hline 30 & 3 & A & $75-125$ & $0-50$ & 50 & 8,8 & 8,5 & 13,3 & 6,6 & 15,7 & 2,1 & 8,7 & 9,2 & 15,6 & 2,2 & 13,6 & 6,8 & 8,9 \\
\hline 30 & 3 & A & $75-125$ & $50-100$ & 10 & 4,5 & 7,1 & 7,1 & 5,9 & 7,4 & 2,7 & 4,6 & 6,6 & 7,7 & 2,8 & 6,5 & 5,9 & 5,5 \\
\hline 30 & 3 & A & $75-125$ & $50-100$ & 50 & 6,5 & 5,8 & 9,0 & 5,7 & 10,6 & 3,3 & 6,2 & 5,7 & 10,9 & 2,7 & 7,7 & 5,8 & 6,3 \\
\hline 30 & 5 & B & $25-74$ & $0-50$ & 10 & 5,0 & 8,9 & 5,7 & 9,4 & 7,1 & 4,0 & 4,9 & 8,7 & 7,2 & 4,0 & 5,7 & 9,2 & 5,9 \\
\hline 30 & 5 & B & $25-74$ & $0-50$ & 50 & 6,5 & 7,8 & 8,2 & 6,9 & 11,7 & 2,6 & 6,4 & 7,4 & 11,3 & 2,6 & 8,0 & 6,9 & 7,3 \\
\hline 30 & 5 & B & $25-74$ & $50-100$ & 10 & 4,4 & 8,8 & 6,1 & 9,0 & 7,4 & 3,5 & 4,8 & 9,0 & 7,8 & 3,6 & 5,8 & 9,4 & 5,4 \\
\hline 30 & 5 & B & $25-74$ & $50-100$ & 50 & 6,0 & 7,6 & 8,4 & 6,8 & 10,6 & 2,8 & 6,4 & 7,7 & 10,7 & 2,9 & 8,3 & 6,7 & 6,4 \\
\hline 30 & 5 & B & $75-125$ & $0-50$ & 10 & 4,0 & 7,4 & 5,1 & 8,0 & 6,5 & 3,0 & 4,3 & 7,2 & 6,8 & 3,1 & 4,8 & 7,3 & 5,1 \\
\hline 30 & 5 & B & $75-125$ & $0-50$ & 50 & 5,7 & 5,5 & 7,2 & 5,5 & 9,4 & 1,6 & 5,6 & 5,7 & 9,2 & 1,6 & 6,8 & 5,2 & 5,6 \\
\hline 30 & 5 & B & $75-125$ & $50-100$ & 10 & 3,7 & 7,4 & 4,8 & 6,6 & 6,0 & 3,2 & 3,6 & 7,0 & 5,9 & 3,0 & 4,7 & 6,0 & 4,8 \\
\hline
\end{tabular}




\begin{tabular}{|c|c|c|c|c|c|c|c|c|c|c|c|c|c|c|c|c|c|c|}
\hline 30 & 5 & B & $75-125$ & $50-100$ & 50 & 4,2 & 4,8 & 5,9 & 5,0 & $\overline{7,2}$ & 2,3 & 4,2 & 5,0 & 7,4 & 2,2 & 5,4 & 5,1 & 5,4 \\
\hline 30 & 5 & M & $25-74$ & $0-50$ & 10 & 5,6 & 9,2 & 6,6 & 6,8 & 8,3 & 2,7 & 5,7 & 9,2 & 7,8 & 3,1 & 7,2 & 7,0 & 6,3 \\
\hline 30 & 5 & M & $25-74$ & $0-50$ & 50 & 6,2 & 8,4 & 8,7 & 6,1 & 10,9 & 2,9 & 6,0 & 7,6 & 10,3 & 2,7 & 8,6 & 6,5 & 6,5 \\
\hline 30 & 5 & M & $25-74$ & $50-100$ & 10 & 4,9 & 8,5 & 6,6 & 6,8 & 8,2 & 3,4 & 4,9 & 8,1 & 7,7 & 3,1 & 6,1 & 6,9 & 5,9 \\
\hline 30 & 5 & M & $25-74$ & $50-100$ & 50 & 5,6 & 5,7 & 6,1 & 5,5 & 9,6 & 2,8 & 5,1 & 5,9 & 9,3 & 2,9 & 5,9 & 5,6 & 5,3 \\
\hline 30 & 5 & M & $75-125$ & $0-50$ & 10 & 4,4 & 6,3 & 4,7 & 5,2 & 6,8 & 2,5 & 4,6 & 6,0 & 7,0 & 2,4 & 4,2 & 5,1 & 4,6 \\
\hline 30 & 5 & M & $75-125$ & $0-50$ & 50 & 5,8 & 6,6 & 7,7 & 6,1 & 10,7 & 2,1 & 6,4 & 6,2 & 10,7 & 1,9 & 7,7 & 6,3 & 6,2 \\
\hline 30 & 5 & M & $75-125$ & $50-100$ & 10 & 4,2 & 5,8 & 4,4 & 5,6 & 6,1 & 2,6 & 4,1 & 5,4 & 5,7 & 2,4 & 4,2 & 5,1 & 4,1 \\
\hline 30 & 5 & M & $75-125$ & 50-100 & 50 & 3,7 & 4,4 & 4,5 & 4,1 & 6,3 & 2,3 & 4,0 & 4,3 & 6,2 & 2,2 & 4,1 & 4,1 & 3,7 \\
\hline 30 & 5 & A & $25-74$ & $0-50$ & 10 & 6,3 & 10,8 & 8,3 & 9,7 & 10,2 & 3,7 & 6,5 & 11,3 & 9,7 & 4,1 & 8,8 & 10,1 & 7,3 \\
\hline 30 & 5 & A & $25-74$ & $0-50$ & 50 & 9,2 & 12,3 & 12,8 & 11,6 & 17,3 & 3,3 & 9,6 & 13,1 & 17,4 & 3,3 & 13,3 & 11,7 & 10,7 \\
\hline 30 & 5 & A & $25-74$ & $50-100$ & 10 & 6,3 & 10,4 & 8,7 & 9,7 & 10,6 & 3,9 & 6,5 & 10,8 & 10,4 & 3,6 & 8,1 & 9,2 & 7,4 \\
\hline 30 & 5 & A & $25-74$ & $50-100$ & 50 & 9,7 & 11,5 & 13,4 & 9,8 & 16,8 & 3,2 & 9,9 & 11,7 & 16,6 & 3,2 & 12,4 & 9,6 & 10,2 \\
\hline 30 & 5 & A & $75-125$ & $0-50$ & 10 & 5,7 & 9,0 & 7,2 & 7,9 & 9,3 & 2,9 & 5,6 & 9,0 & 9,6 & 2,6 & 7,2 & 7,4 & 6,7 \\
\hline 30 & 5 & A & $75-125$ & $0-50$ & 50 & 9,6 & 11,3 & 12,3 & 9,9 & 17,2 & 2,7 & 9,7 & 10,7 & 17,1 & 2,7 & 12,8 & 9,5 & 10,2 \\
\hline 30 & 5 & A & $75-125$ & $50-100$ & 10 & 5,8 & 6,7 & 6,1 & 6,7 & 8,0 & 3,3 & 5,4 & 7,0 & 8,4 & 2,9 & 5,2 & 6,3 & 6,0 \\
\hline 30 & 5 & A & $75-125$ & $50-100$ & 50 & 7,6 & 7,2 & 8,9 & 8,2 & 11,3 & 3,0 & 7,1 & 7,6 & 10,8 & 3,0 & 8,6 & 8,0 & 7,2 \\
\hline 30 & 7 & B & $25-74$ & $0-50$ & 10 & 3,9 & 9,1 & 4,9 & 10,5 & 6,8 & 4,0 & 3,8 & 9,2 & 6,6 & 4,2 & 5,0 & 10,4 & 5,3 \\
\hline 30 & 7 & B & $25-74$ & $0-50$ & 50 & 7,1 & 8,9 & 8,3 & 8,9 & 11,8 & 3,3 & 6,9 & 8,7 & 11,4 & 2,9 & 7,8 & 8,8 & 7,5 \\
\hline 30 & 7 & B & $25-74$ & $50-100$ & 10 & 4,7 & 9,4 & 6,0 & 10,9 & 6,5 & 3,9 & 4,8 & 9,9 & 7,1 & 3,9 & 6,1 & 9,8 & 5,9 \\
\hline 30 & 7 & B & $25-74$ & $50-100$ & 50 & 6,2 & 7,7 & 7,1 & 8,6 & 10,3 & 3,1 & 6,1 & 7,8 & 10,4 & 3,4 & 7,6 & 7,8 & 6,7 \\
\hline 30 & 7 & B & $75-125$ & $0-50$ & 10 & 4,0 & 7,5 & 4,8 & 7,8 & 5,9 & 3,0 & 3,8 & 7,5 & 5,9 & 3,3 & 4,6 & 6,9 & 4,4 \\
\hline 30 & 7 & B & $75-125$ & $0-50$ & 50 & 6,0 & 7,3 & 6,7 & 7,3 & 10,3 & 2,8 & 6,0 & 6,9 & 10,6 & 3,0 & 7,1 & 6,8 & 7,2 \\
\hline 30 & 7 & B & $75-125$ & $50-100$ & 10 & 3,7 & 7,5 & 4,6 & 8,3 & 6,1 & 3,6 & 3,9 & 7,4 & 5,8 & 3,4 & 4,3 & 7,3 & 5,0 \\
\hline 30 & 7 & B & $75-125$ & $50-100$ & 50 & 4,9 & 6,0 & 5,7 & 7,5 & 7,7 & 2,7 & 5,0 & 6,1 & 7,8 & 2,7 & 5,6 & 7,0 & 5,7 \\
\hline 30 & 7 & M & $25-74$ & $0-50$ & 10 & 4,8 & 8,1 & 5,8 & 7,4 & 7,8 & 3,2 & 5,0 & 8,0 & 7,6 & 3,4 & 5,5 & 7,1 & 6,0 \\
\hline 30 & 7 & M & $25-74$ & $0-50$ & 50 & 6,9 & 7,4 & 7,6 & 7,2 & 10,3 & 2,9 & 7,0 & 7,5 & 10,5 & 2,8 & 7,8 & 7,1 & 7,0 \\
\hline 30 & 7 & M & $25-74$ & $50-100$ & 10 & 5,6 & 7,2 & 5,7 & 6,5 & 7,2 & 3,8 & 5,4 & 7,0 & 6,5 & 3,9 & 5,8 & 6,9 & 5,6 \\
\hline 30 & 7 & M & $25-74$ & $50-100$ & 50 & 5,6 & 6,4 & 6,2 & 6,3 & 9,0 & 3,2 & 5,0 & 6,2 & 9,3 & 2,7 & 6,0 & 6,3 & 6,2 \\
\hline 30 & 7 & M & $75-125$ & $0-50$ & 10 & 3,7 & 6,8 & 5,0 & 5,7 & 6,3 & 2,5 & 3,8 & 7,1 & 6,4 & 2,6 & 4,6 & 5,6 & 5,0 \\
\hline 30 & 7 & M & $75-125$ & $0-50$ & 50 & 5,9 & 6,6 & 6,4 & 5,6 & 9,3 & 2,4 & 6,0 & 6,6 & 9,4 & 2,5 & 6,9 & 5,8 & 6,0 \\
\hline 30 & 7 & M & $75-125$ & $50-100$ & 10 & 3,9 & 5,6 & 4,2 & 5,1 & 5,6 & 3,1 & 3,9 & 5,5 & 5,7 & 2,8 & 4,1 & 4,8 & 4,4 \\
\hline 30 & 7 & M & $75-125$ & $50-100$ & 50 & 5,5 & 5,4 & 5,9 & 5,3 & 8,5 & 1,8 & 5,3 & 5,5 & 8,4 & 1,9 & 6,1 & 5,0 & 5,0 \\
\hline 30 & 7 & A & $25-74$ & $0-50$ & 10 & 6,2 & 10,1 & 7,1 & 9,9 & 10,0 & 4,3 & 6,3 & 10,2 & 9,5 & 4,1 & 6,6 & 9,5 & 8,1 \\
\hline 30 & 7 & A & $25-74$ & $0-50$ & 50 & 10,6 & 10,5 & 12,1 & 10,7 & 16,6 & 3,3 & 9,9 & 10,2 & 16,3 & 3,7 & 12,2 & 10,8 & 9,8 \\
\hline 30 & 7 & A & $25-74$ & $50-100$ & 10 & 5,8 & 10,4 & 7,9 & 9,6 & 10,1 & 4,2 & 5,8 & 10,5 & 10,1 & 4,0 & 7,6 & 8,9 & 7,8 \\
\hline 30 & 7 & A & $25-74$ & $50-100$ & 50 & 9,6 & 9,5 & 10,0 & 10,4 & 13,5 & 4,1 & 9,5 & 9,2 & 13,0 & 3,7 & 9,8 & 10,6 & 8,6 \\
\hline 30 & 7 & A & $75-125$ & $0-50$ & 10 & 4,9 & 7,6 & 5,6 & 7,4 & 8,5 & 3,3 & 4,5 & 8,2 & 8,0 & 3,6 & 5,5 & 7,6 & 6,0 \\
\hline 30 & 7 & A & $75-125$ & $0-50$ & 50 & 8,4 & 9,3 & 10,8 & 8,7 & 13,4 & 2,9 & 8,7 & 9,1 & 13,3 & 3,0 & 10,5 & 8,9 & 8,4 \\
\hline 30 & 7 & A & $75-125$ & $50-100$ & 10 & 5,5 & 7,3 & 5,1 & 7,5 & 7,7 & 3,6 & 5,6 & 7,4 & 7,7 & 3,7 & 4,9 & 6,6 & 5,7 \\
\hline 30 & 7 & A & $75-125$ & $50-100$ & 50 & 6,7 & 8,0 & 8,4 & 8,4 & 11,1 & 3,1 & 7,3 & 8,4 & 11,5 & 2,8 & 9,0 & 8,4 & 7,9 \\
\hline 50 & 3 & B & $25-74$ & $0-50$ & 10 & 3,5 & 8,6 & 6,8 & 5,3 & 5,7 & 2,2 & 3,4 & 8,7 & 5,4 & 2,4 & 7,0 & 5,4 & 4,7 \\
\hline 50 & 3 & B & $25-74$ & $0-50$ & 50 & 3,8 & 4,4 & 5,2 & 3,5 & 6,5 & 1,9 & 3,8 & 4,5 & 6,5 & 2,2 & 5,4 & 3,6 & 4,1 \\
\hline 50 & 3 & B & $25-74$ & $50-100$ & 10 & 3,4 & 9,0 & 6,4 & 5,2 & 5,6 & 2,6 & 3,0 & 9,0 & 5,5 & 2,7 & 6,3 & 4,8 & 3,9 \\
\hline 50 & 3 & B & $25-74$ & $50-100$ & 50 & 3,8 & 4,0 & 5,9 & 3,6 & 6,2 & 2,5 & 3,4 & 3,8 & 6,1 & 2,4 & 5,1 & 3,6 & 3,9 \\
\hline 50 & 3 & B & $75-125$ & $0-50$ & 10 & 3,3 & 5,7 & 5,3 & 4,2 & 5,0 & 1,9 & 3,1 & 5,7 & 4,9 & 1,8 & 4,7 & 3,9 & 3,7 \\
\hline 50 & 3 & B & $75-125$ & $0-50$ & 50 & 2,9 & 3,0 & 3,9 & 2,7 & 5,0 & 1,4 & 2,9 & 3,2 & 5,2 & 1,3 & 3,9 & 2,4 & 3,1 \\
\hline 50 & 3 & B & $75-125$ & $50-100$ & 10 & 2,5 & 5,5 & 5,0 & 3,3 & 4,5 & 1,5 & 2,6 & 5,5 & 4,4 & 1,7 & 4,5 & 3,0 & 2,8 \\
\hline 50 & 3 & B & $75-125$ & $50-100$ & 50 & 2,5 & 2,6 & 4,4 & 2,6 & 4,6 & 1,6 & 2,4 & 2,9 & 4,3 & 1,8 & 4,2 & 2,6 & 2,5 \\
\hline 50 & 3 & M & $25-74$ & $0-50$ & 10 & 3,6 & 4,0 & 4,0 & 3,4 & 4,7 & 2,6 & 3,9 & 4,2 & 4,6 & 3,1 & 4,0 & 3,6 & 3,8 \\
\hline 50 & 3 & M & $25-74$ & $0-50$ & 50 & 4,5 & 4,6 & 5,9 & 3,9 & 6,5 & 2,6 & 4,5 & 4,8 & 6,7 & 2,8 & 5,4 & 4,1 & 3,9 \\
\hline 50 & 3 & M & $25-74$ & $50-100$ & 10 & 3,7 & 4,0 & 4,2 & 3,7 & 4,3 & 2,8 & 3,7 & 4,2 & 4,8 & 2,5 & 4,4 & 3,4 & 4,1 \\
\hline 50 & 3 & M & $25-74$ & $50-100$ & 50 & 3,5 & 4,1 & 4,8 & 3,4 & 5,4 & 2,8 & 3,8 & 4,2 & 5,6 & 3,0 & 4,7 & 3,4 & 4,0 \\
\hline 50 & 3 & M & $75-125$ & $0-50$ & 10 & 2,9 & 2,9 & 3,0 & 2,5 & 3,6 & 1,5 & 2,4 & 2,9 & 3,8 & 1,5 & 2,7 & 2,2 & 3,0 \\
\hline 50 & 3 & M & $75-125$ & $0-50$ & 50 & 2,7 & 2,9 & 3,6 & 2,5 & 4,2 & 1,8 & 2,7 & 2,9 & 4,6 & 2,0 & 3,5 & 2,6 & 3,0 \\
\hline 50 & 3 & M & $75-125$ & $50-100$ & 10 & 2,4 & 2,8 & 2,9 & 2,1 & 3,0 & 1,6 & 2,9 & 2,8 & 2,9 & 1,7 & 3,0 & 2,1 & 2,4 \\
\hline 50 & 3 & M & $75-125$ & $50-100$ & 50 & 2,7 & 2,8 & 3,4 & 2,3 & 3,9 & 1,8 & 2,6 & 2,5 & 3,9 & 1,9 & 3,1 & 2,2 & 2,6 \\
\hline 50 & 3 & A & $25-74$ & $0-50$ & 10 & 5,7 & 9,0 & 10,0 & 7,4 & 9,1 & 1,9 & 5,1 & 9,0 & 9,1 & 2,0 & 10,0 & 7,4 & 6,4 \\
\hline 50 & 3 & A & $25-74$ & $0-50$ & 50 & 7,9 & 8,5 & 11,9 & 6,8 & 13,8 & 2,7 & 7,9 & 8,9 & 12,9 & 2,4 & 11,8 & 6,9 & 8,1 \\
\hline 50 & 3 & A & $25-74$ & $50-100$ & 10 & 4,6 & 7,6 & 7,9 & 6,6 & 7,8 & 2,5 & 4,6 & 7,6 & 7,6 & 2,6 & 7,5 & 6,9 & 6,1 \\
\hline 50 & 3 & A & $25-74$ & $50-100$ & 50 & 6,6 & 6,7 & 10,4 & 6,0 & 11,3 & 2,2 & 6,9 & 7,1 & 11,2 & 2,3 & 10,3 & 5,8 & 6,7 \\
\hline 50 & 3 & A & $75-125$ & $0-50$ & 10 & 5,1 & 7,0 & 7,3 & 5,4 & 7,8 & 1,6 & 5,1 & 6,5 & 7,7 & 1,6 & 7,5 & 5,1 & 5,7 \\
\hline
\end{tabular}




\begin{tabular}{|c|c|c|c|c|c|c|c|c|c|c|c|c|c|c|c|c|c|c|}
\hline 50 & 3 & $\bar{A}$ & $75-125$ & $0-50$ & 50 & 5,7 & 6,2 & $\overline{9,6}$ & $\overline{4,9}$ & $\overline{10,9}$ & $\overline{1,6}$ & 5,5 & 6,2 & 10,8 & $\overline{1,9}$ & 9,8 & 5,1 & 6,8 \\
\hline 50 & 3 & A & $75-125$ & $50-100$ & 10 & 3,5 & 5,7 & 5,7 & 5,1 & 6,0 & 2,0 & 3,4 & 5,5 & 6,0 & 2,0 & 5,5 & 4,9 & 4,0 \\
\hline 50 & 3 & A & $75-125$ & $50-100$ & 50 & 4,8 & 4,7 & 7,9 & 4,4 & 9,0 & 2,1 & 5,3 & 4,2 & 9,4 & 2,1 & 6,9 & 4,2 & 4,9 \\
\hline 50 & 5 & B & $25-74$ & $0-50$ & 10 & 3,7 & 7,7 & 4,9 & 8,5 & 5,2 & 3,4 & 3,4 & 7,6 & 5,1 & 3,3 & 4,6 & 8,5 & 4,4 \\
\hline 50 & 5 & B & $25-74$ & $0-50$ & 50 & 5,1 & 6,4 & 6,6 & 5,6 & 8,9 & 1,9 & 5,0 & 6,3 & 9,0 & 2,4 & 6,6 & 5,5 & 5,1 \\
\hline 50 & 5 & B & $25-74$ & $50-100$ & 10 & 3,3 & 8,4 & 5,5 & 8,8 & 6,0 & 2,6 & 3,2 & 8,6 & 6,0 & 2,8 & 5,5 & 8,5 & 4,7 \\
\hline 50 & 5 & B & $25-74$ & $50-100$ & 50 & 4,5 & 5,2 & 5,2 & 5,4 & 8,0 & 2,1 & 4,7 & 4,8 & 7,4 & 2,1 & 5,0 & 5,2 & 4,5 \\
\hline 50 & 5 & B & $75-125$ & $0-50$ & 10 & 3,2 & 6,2 & 4,5 & 7,7 & 4,9 & 2,1 & 3,2 & 5,9 & 4,9 & 2,3 & 4,0 & 6,6 & 3,4 \\
\hline 50 & 5 & B & $75-125$ & $0-50$ & 50 & 4,2 & 4,7 & 4,8 & 5,0 & 7,4 & 1,4 & 4,1 & 4,8 & 7,8 & 1,8 & 4,8 & 4,8 & 4,1 \\
\hline 50 & 5 & B & $75-125$ & $50-100$ & 10 & 2,7 & 5,9 & 4,0 & 6,9 & 4,6 & 2,1 & 2,7 & 5,7 & 4,6 & 2,3 & 3,8 & 6,2 & 3,7 \\
\hline 50 & 5 & B & $75-125$ & $50-100$ & 50 & 3,2 & 3,8 & 4,1 & 4,1 & 5,9 & 1,8 & 3,3 & 4,0 & 5,9 & 1,6 & 4,1 & 3,9 & 3,7 \\
\hline 50 & 5 & M & $25-74$ & $0-50$ & 10 & 3,7 & 6,4 & 4,6 & 5,8 & 5,7 & 2,8 & 3,5 & 6,3 & 5,4 & 2,7 & 4,9 & 6,0 & 4,1 \\
\hline 50 & 5 & M & $25-74$ & $0-50$ & 50 & 5,4 & 5,5 & 6,4 & 4,7 & 8,2 & 2,4 & 5,1 & 5,5 & 8,6 & 2,5 & 5,9 & 4,8 & 4,5 \\
\hline 50 & 5 & M & $25-74$ & $50-100$ & 10 & 3,6 & 7,4 & 5,1 & 5,9 & 5,9 & 2,5 & 3,8 & 7,1 & 6,0 & 2,6 & 5,2 & 6,1 & 4,3 \\
\hline 50 & 5 & M & $25-74$ & $50-100$ & 50 & 4,1 & 5,0 & 5,3 & 4,7 & 6,7 & 2,3 & 3,9 & 5,0 & 6,1 & 2,6 & 5,4 & 4,8 & 4,5 \\
\hline 50 & 5 & M & $75-125$ & $0-50$ & 10 & 3,2 & 4,5 & 3,0 & 4,7 & 4,6 & 1,8 & 3,0 & 4,6 & 4,5 & 1,9 & 3,0 & 4,4 & 3,0 \\
\hline 50 & 5 & M & $75-125$ & $0-50$ & 50 & 3,6 & 5,2 & 4,9 & 4,0 & 7,3 & 1,6 & 3,8 & 4,9 & 7,3 & 1,7 & 4,8 & 4,1 & 4,2 \\
\hline 50 & 5 & M & $75-125$ & $50-100$ & 10 & 2,7 & 4,2 & 3,8 & 3,9 & 4,2 & 1,9 & 2,6 & 4,1 & 4,4 & 1,9 & 3,2 & 3,2 & 3,2 \\
\hline 50 & 5 & M & $75-125$ & $50-100$ & 50 & 3,2 & 3,4 & 4,1 & 3,1 & 5,4 & 1,7 & 3,5 & 3,4 & 5,4 & 1,6 & 3,9 & 2,9 & 3,1 \\
\hline 50 & 5 & A & $25-74$ & $0-50$ & 10 & 5,4 & 9,2 & 6,7 & 8,8 & 8,9 & 2,2 & 5,3 & 9,1 & 8,5 & 2,8 & 6,6 & 8,3 & 6,7 \\
\hline 50 & 5 & A & 25-74 & $0-50$ & 50 & 9,0 & 9,6 & 11,6 & 9,6 & 15,1 & 2,2 & 8,8 & 9,5 & 14,9 & 2,4 & 11,2 & 9,3 & 8,0 \\
\hline 50 & 5 & A & $25-74$ & $50-100$ & 10 & 5,7 & 8,3 & 7,2 & 8,4 & 9,2 & 2,1 & 5,5 & 8,2 & 8,8 & 2,0 & 7,3 & 8,3 & 5,9 \\
\hline 50 & 5 & A & $25-74$ & $50-100$ & 50 & 7,1 & 7,5 & 9,0 & 7,8 & 11,6 & 2,3 & 6,9 & 7,1 & 11,1 & 2,6 & 9,3 & 8,0 & 7,6 \\
\hline 50 & 5 & A & $75-125$ & $0-50$ & 10 & 4,1 & 5,9 & 4,8 & 6,4 & 6,6 & 2,2 & 4,1 & 5,8 & 6,5 & 2,0 & 4,5 & 5,7 & 4,6 \\
\hline 50 & 5 & A & $75-125$ & $0-50$ & 50 & 6,8 & 6,5 & 8,2 & 7,4 & 11,0 & 1,8 & 6,7 & 6,7 & 10,7 & 1,9 & 8,7 & 7,2 & 7,4 \\
\hline 50 & 5 & A & $75-125$ & $50-100$ & 10 & 3,9 & 5,1 & 4,4 & 6,0 & 5,9 & 1,9 & 3,9 & 5,2 & 5,8 & 2,0 & 4,4 & 5,4 & 4,5 \\
\hline 50 & 5 & A & $75-125$ & $50-100$ & 50 & 5,9 & 5,1 & 6,9 & 5,4 & 9,1 & 1,6 & 5,8 & 5,3 & 9,1 & 1,8 & 6,9 & 5,8 & 5,6 \\
\hline 50 & 7 & B & $25-74$ & $0-50$ & 10 & 3,6 & 8,2 & 5,3 & 10,6 & 5,5 & 2,8 & 3,4 & 8,0 & 5,4 & 3,1 & 5,6 & 10,4 & 4,2 \\
\hline 50 & 7 & B & $25-74$ & $0-50$ & 50 & 5,2 & 6,8 & 5,4 & 7,8 & 8,7 & 2,7 & 5,0 & 6,5 & 8,3 & 3,1 & 5,5 & 7,6 & 5,4 \\
\hline 50 & 7 & B & $25-74$ & $50-100$ & 10 & 3,5 & 8,5 & 4,5 & 9,3 & 5,6 & 3,2 & 3,7 & 8,4 & 5,4 & 3,3 & 4,6 & 9,1 & 4,6 \\
\hline 50 & 7 & B & $25-74$ & $50-100$ & 50 & 4,7 & 5,7 & 5,8 & 6,5 & 7,5 & 2,8 & 4,9 & 5,7 & 7,9 & 2,7 & 5,6 & 6,6 & 5,8 \\
\hline 50 & 7 & B & $75-125$ & $0-50$ & 10 & 3,0 & 5,8 & 4,0 & 7,1 & 4,1 & 2,3 & 2,9 & 5,9 & 4,0 & 2,6 & 3,5 & 6,1 & 3,7 \\
\hline 50 & 7 & B & $75-125$ & $0-50$ & 50 & 4,4 & 4,9 & 4,6 & 6,1 & 6,9 & 2,1 & 4,3 & 4,8 & 7,0 & 2,3 & 4,4 & 5,6 & 4,4 \\
\hline 50 & 7 & B & $75-125$ & $50-100$ & 10 & 2,8 & 5,7 & 3,1 & 8,2 & 4,3 & 2,8 & 2,9 & 6,0 & 4,3 & 2,6 & 3,4 & 7,3 & 3,8 \\
\hline 50 & 7 & B & $75-125$ & $50-100$ & 50 & 4,1 & 5,1 & 4,2 & 6,1 & 6,4 & 1,9 & 4,3 & 5,0 & 6,6 & 2,1 & 4,0 & 5,7 & 4,4 \\
\hline 50 & 7 & M & $25-74$ & $0-50$ & 10 & 4,1 & 6,3 & 5,0 & 5,9 & 6,4 & 2,4 & 4,4 & 6,1 & 6,2 & 2,6 & 4,6 & 6,0 & 4,7 \\
\hline 50 & 7 & M & $25-74$ & $0-50$ & 50 & 5,4 & 6,1 & 6,2 & 5,6 & 8,5 & 2,9 & 5,8 & 6,1 & 8,4 & 3,1 & 5,9 & 5,7 & 5,7 \\
\hline 50 & 7 & M & $25-74$ & $50-100$ & 10 & 3,7 & 6,8 & 4,4 & 5,7 & 5,9 & 2,2 & 4,1 & 6,5 & 5,8 & 2,7 & 4,7 & 6,0 & 4,8 \\
\hline 50 & 7 & M & $25-74$ & $50-100$ & 50 & 4,5 & 5,2 & 5,3 & 5,2 & 7,2 & 2,7 & 4,8 & 4,8 & 7,1 & 2,8 & 5,2 & 5,5 & 4,8 \\
\hline 50 & 7 & M & $75-125$ & $0-50$ & 10 & 3,3 & 4,9 & 3,7 & 4,6 & 5,0 & 2,0 & 3,5 & 5,2 & 5,0 & 2,0 & 3,3 & 4,3 & 3,5 \\
\hline 50 & 7 & M & $75-125$ & $0-50$ & 50 & 4,4 & 4,2 & 5,2 & 4,8 & 7,4 & 1,7 & 4,4 & 4,4 & 7,2 & 1,6 & 5,4 & 4,5 & 4,3 \\
\hline 50 & 7 & M & $75-125$ & $50-100$ & 10 & 3,3 & 4,7 & 3,5 & 3,8 & 4,5 & 2,2 & 2,7 & 4,5 & 4,5 & 2,2 & 3,2 & 3,6 & 3,4 \\
\hline 50 & 7 & M & $75-125$ & $50-100$ & 50 & 3,9 & 3,4 & 3,6 & 3,3 & 5,3 & 1,5 & 3,7 & 3,3 & 5,1 & 1,6 & 3,4 & 3,3 & 3,4 \\
\hline 50 & 7 & A & $25-74$ & $0-50$ & 10 & 5,0 & 6,8 & 4,9 & 7,2 & 7,6 & 2,5 & 5,1 & 6,7 & 7,4 & 2,4 & 5,1 & 7,5 & 5,0 \\
\hline 50 & 7 & A & $25-74$ & $0-50$ & 50 & 9,2 & 9,3 & 9,5 & 9,7 & 13,1 & 2,4 & 8,8 & 9,0 & 13,1 & 2,1 & 9,1 & 9,3 & 8,5 \\
\hline 50 & 7 & A & $25-74$ & $50-100$ & 10 & 4,3 & 7,9 & 6,3 & 7,9 & 7,7 & 2,8 & 4,9 & 7,6 & 7,8 & 2,8 & 5,7 & 7,5 & 5,4 \\
\hline 50 & 7 & A & $25-74$ & $50-100$ & 50 & 8,4 & 8,4 & 9,1 & 8,5 & 12,5 & 2,4 & 8,4 & 8,8 & 12,7 & 2,5 & 9,1 & 8,7 & 8,1 \\
\hline 50 & 7 & A & $75-125$ & $0-50$ & 10 & 4,3 & 6,0 & 4,4 & 7,0 & 6,7 & 1,9 & 4,1 & 5,7 & 6,3 & 2,1 & 4,6 & 6,2 & 5,0 \\
\hline 50 & 7 & A & $75-125$ & $0-50$ & 50 & 7,3 & 7,7 & 8,4 & 7,6 & 12,2 & 1,9 & 7,6 & 8,2 & 11,9 & 2,0 & 8,5 & 7,6 & 7,7 \\
\hline 50 & 7 & A & $75-125$ & $50-100$ & 10 & 4,5 & 5,3 & 4,1 & 6,0 & 5,9 & 2,1 & 4,4 & 5,3 & 6,0 & 2,1 & 4,1 & 5,2 & 4,2 \\
\hline 50 & 7 & A & $75-125$ & $50-100$ & 50 & 5,5 & 5,2 & 5,7 & 6,1 & 9,2 & 2,0 & 5,5 & 5,2 & 8,9 & 2,1 & 5,6 & 5,6 & 5,7 \\
\hline 80 & 3 & B & $25-74$ & $0-50$ & 10 & 2,6 & 7,1 & 5,3 & 4,8 & 4,1 & 2,1 & 2,5 & 7,3 & 3,8 & 1,8 & 5,1 & 4,5 & 2,8 \\
\hline 80 & 3 & B & $25-74$ & $0-50$ & 50 & 3,2 & 3,3 & 5,4 & 2,7 & 5,5 & 2,0 & 3,0 & 3,4 & 5,4 & 1,9 & 5,4 & 2,8 & 2,8 \\
\hline 80 & 3 & B & $25-74$ & $50-100$ & 10 & 3,0 & 7,9 & 6,1 & 4,7 & 4,0 & 2,0 & 2,8 & 7,5 & 3,9 & 2,3 & 6,2 & 4,1 & 3,4 \\
\hline 80 & 3 & B & $25-74$ & $50-100$ & 50 & 2,8 & 3,5 & 4,3 & 2,6 & 4,3 & 1,9 & 2,7 & 3,3 & 4,2 & 2,0 & 4,2 & 2,5 & 3,0 \\
\hline 80 & 3 & B & $75-125$ & $0-50$ & 10 & 1,9 & 5,2 & 4,4 & 3,7 & 3,5 & 1,5 & 2,0 & 5,0 & 3,5 & 1,6 & 4,1 & 3,4 & 2,5 \\
\hline 80 & 3 & B & $75-125$ & $0-50$ & 50 & 2,6 & 2,6 & 3,9 & 1,9 & 4,3 & 1,4 & 2,5 & 2,8 & 4,5 & 1,3 & 3,9 & 1,9 & 2,5 \\
\hline 80 & 3 & B & $75-125$ & $50-100$ & 10 & 1,7 & 4,6 & 4,0 & 3,1 & 3,3 & 1,4 & 1,8 & 4,4 & 3,3 & 1,5 & 3,5 & 3,0 & 2,0 \\
\hline 80 & 3 & B & $75-125$ & $50-100$ & 50 & 2,2 & 2,5 & 3,6 & 2,1 & 3,6 & 1,6 & 2,3 & 2,4 & 3,6 & 1,6 & 3,3 & 2,0 & 2,2 \\
\hline 80 & 3 & M & $25-74$ & $0-50$ & 10 & 2,7 & 3,4 & 3,1 & 2,9 & 3,4 & 2,0 & 2,9 & 3,1 & 3,6 & 2,2 & 3,3 & 2,9 & 2,8 \\
\hline 80 & 3 & M & $25-74$ & $0-50$ & 50 & 3,1 & 3,3 & 3,8 & 2,6 & 4,4 & 2,5 & 3,0 & 3,1 & 4,5 & 2,4 & 3,8 & 2,8 & 3,4 \\
\hline 80 & 3 & M & $25-74$ & $50-100$ & 10 & 2,8 & 2,9 & 3,1 & 2,8 & 3,4 & 2,4 & 3,2 & 3,3 & 3,4 & 2,2 & 2,8 & 2,6 & 3,0 \\
\hline
\end{tabular}




\begin{tabular}{|c|c|c|c|c|c|c|c|c|c|c|c|c|c|c|c|c|c|c|}
\hline 80 & 3 & M & $25-74$ & $50-100$ & 50 & 3,1 & 3,2 & 3,6 & 3,2 & 4,1 & 2,1 & 2,9 & 3,0 & 4,3 & 2,2 & 3,7 & 2,9 & 2,9 \\
\hline 80 & 3 & M & $75-125$ & $0-50$ & 10 & 2,0 & 2,1 & 2,3 & 2,0 & 2,5 & 1,7 & 2,2 & 2,3 & 2,4 & 1,4 & 2,4 & 1,9 & 1,9 \\
\hline 80 & 3 & M & $75-125$ & $0-50$ & 50 & 2,2 & 2,2 & 2,9 & 1,8 & 3,5 & 1,7 & 2,4 & 2,3 & 3,4 & 1,6 & 3,0 & 1,8 & 2,2 \\
\hline 80 & 3 & M & $75-125$ & $50-100$ & 10 & 2,0 & 2,3 & 2,1 & 2,0 & 2,4 & 1,4 & 1,9 & 2,1 & 2,4 & 1,6 & 2,2 & 1,8 & 2,0 \\
\hline 80 & 3 & M & $75-125$ & $50-100$ & 50 & 2,0 & 1,9 & 2,5 & 1,8 & 3,0 & 1,5 & 2,0 & 2,1 & 2,8 & 1,5 & 2,5 & 2,1 & 1,9 \\
\hline 80 & 3 & A & $25-74$ & $0-50$ & 10 & 3,8 & 7,4 & 7,7 & 5,9 & 6,1 & 1,3 & 4,1 & 7,2 & 5,9 & 1,6 & 7,3 & 5,9 & 4,6 \\
\hline 80 & 3 & A & $25-74$ & $0-50$ & 50 & 5,6 & 5,2 & 8,7 & 4,5 & 9,7 & 1,6 & 6,0 & 5,3 & 9,7 & 1,9 & 8,8 & 4,7 & 6,0 \\
\hline 80 & 3 & A & $25-74$ & $50-100$ & 10 & 3,8 & 6,8 & 7,0 & 5,6 & 5,8 & 2,0 & 4,0 & 6,5 & 5,9 & 2,0 & 6,5 & 5,7 & 4,3 \\
\hline 80 & 3 & A & $25-74$ & $50-100$ & 50 & 4,7 & 5,0 & 7,1 & 3,8 & 8,3 & 1,9 & 4,8 & 4,8 & 8,4 & 1,8 & 6,7 & 3,7 & 4,7 \\
\hline 80 & 3 & A & $75-125$ & $0-50$ & 10 & 3,5 & 4,7 & 5,5 & 4,7 & 5,2 & 1,6 & 3,6 & 5,0 & 5,3 & 1,4 & 5,1 & 4,2 & 3,9 \\
\hline 80 & 3 & A & $75-125$ & $0-50$ & 50 & 4,3 & 4,7 & 7,1 & 4,2 & 7,9 & 1,1 & 4,6 & 4,3 & 8,1 & 1,2 & 6,8 & 4,0 & 4,2 \\
\hline 80 & 3 & A & $75-125$ & $50-100$ & 10 & 2,6 & 3,8 & 4,3 & 3,7 & 4,3 & 1,2 & 2,8 & 3,8 & 4,5 & 1,2 & 3,7 & 3,4 & 3,0 \\
\hline 80 & 3 & A & $75-125$ & 50-100 & 50 & 3,5 & 3,2 & 4,9 & 3,0 & 5,8 & 1,4 & 3,7 & 3,9 & 5,8 & 1,3 & 5,1 & 3,0 & 3,4 \\
\hline 80 & 5 & B & $25-74$ & $0-50$ & 10 & 3,1 & 6,8 & 5,0 & 8,4 & 4,3 & 2,3 & 3,0 & 7,0 & 4,2 & 2,4 & 4,8 & 8,4 & 3,3 \\
\hline 80 & 5 & B & $25-74$ & $0-50$ & 50 & 3,9 & 4,7 & 4,9 & 4,3 & 6,4 & 1,6 & 3,9 & 4,6 & 6,3 & 1,8 & 4,7 & 4,1 & 3,6 \\
\hline 80 & 5 & B & $25-74$ & $50-100$ & 10 & 2,9 & 7,4 & 4,7 & 8,3 & 4,6 & 2,1 & 2,7 & 7,6 & 4,4 & 2,3 & 4,3 & 8,1 & 3,3 \\
\hline 80 & 5 & B & $25-74$ & $50-100$ & 50 & 3,4 & 3,9 & 4,5 & 4,5 & 5,8 & 2,0 & 3,7 & 4,0 & 5,6 & 1,9 & 4,4 & 4,4 & 3,8 \\
\hline 80 & 5 & B & $75-125$ & $0-50$ & 10 & 2,5 & 6,0 & 4,1 & 6,3 & 4,3 & 1,5 & 2,6 & 6,0 & 4,1 & 1,7 & 3,6 & 5,2 & 3,1 \\
\hline 80 & 5 & B & $75-125$ & $0-50$ & 50 & 3,0 & 3,3 & 4,1 & 3,8 & 5,8 & 1,1 & 3,1 & 3,5 & 5,9 & 1,1 & 4,2 & 3,5 & 3,4 \\
\hline 80 & 5 & B & $75-125$ & $50-100$ & 10 & 2,4 & 5,1 & 4,2 & 6,3 & 3,5 & 1,5 & 2,3 & 5,1 & 3,6 & 1,7 & 3,5 & 6,0 & 2,9 \\
\hline 80 & 5 & B & $75-125$ & $50-100$ & 50 & 2,5 & 2,5 & 2,9 & 2,8 & 4,2 & 1,4 & 2,5 & 2,6 & 4,1 & 1,1 & 2,9 & 2,9 & 2,4 \\
\hline 80 & 5 & M & $25-74$ & $0-50$ & 10 & 2,9 & 5,6 & 3,4 & 5,7 & 4,2 & 2,2 & 2,7 & 5,5 & 4,5 & 2,2 & 3,5 & 5,5 & 3,4 \\
\hline 80 & 5 & M & $25-74$ & $0-50$ & 50 & 4,0 & 4,7 & 4,6 & 4,2 & 6,3 & 2,1 & 3,5 & 5,0 & 6,2 & 2,1 & 4,6 & 4,0 & 3,8 \\
\hline 80 & 5 & M & $25-74$ & $50-100$ & 10 & 2,8 & 6,2 & 4,2 & 5,2 & 4,6 & 2,1 & 2,4 & 6,4 & 4,5 & 2,1 & 4,5 & 5,4 & 3,0 \\
\hline 80 & 5 & M & $25-74$ & 50-100 & 50 & 3,1 & 3,9 & 4,3 & 3,2 & 5,5 & 1,8 & 3,3 & 3,7 & 5,4 & 2,0 & 4,3 & 3,0 & 3,1 \\
\hline 80 & 5 & M & $75-125$ & $0-50$ & 10 & 2,5 & 4,0 & 3,1 & 4,1 & 3,2 & 1,2 & 2,5 & 3,9 & 3,4 & 1,4 & 2,8 & 3,8 & 2,4 \\
\hline 80 & 5 & M & $75-125$ & $0-50$ & 50 & 2,9 & 3,0 & 3,4 & 3,0 & 4,9 & 1,2 & 2,8 & 2,9 & 5,0 & 1,3 & 3,4 & 2,7 & 2,9 \\
\hline 80 & 5 & M & $75-125$ & $50-100$ & 10 & 2,0 & 3,9 & 3,0 & 3,2 & 3,3 & 1,5 & 1,9 & 3,9 & 3,4 & 1,5 & 2,7 & 3,0 & 2,3 \\
\hline 80 & 5 & M & $75-125$ & 50-100 & 50 & 2,5 & 2,6 & 2,6 & 2,5 & 3,9 & 1,3 & 2,4 & 2,9 & 4,0 & 1,4 & 2,7 & 2,2 & 2,3 \\
\hline 80 & 5 & A & $25-74$ & $0-50$ & 10 & 4,0 & 6,4 & 5,5 & 6,9 & 5,9 & 1,8 & 3,9 & 6,7 & 5,9 & 2,1 & 5,7 & 7,0 & 4,3 \\
\hline 80 & 5 & A & $25-74$ & $0-50$ & 50 & 6,5 & 7,4 & 7,8 & 6,7 & 10,8 & 1,8 & 6,6 & 7,0 & 10,6 & 1,8 & 7,4 & 6,9 & 7,1 \\
\hline 80 & 5 & A & $25-74$ & $50-100$ & 10 & 4,1 & 6,5 & 5,6 & 6,3 & 6,0 & 1,9 & 3,8 & 6,6 & 6,0 & 1,8 & 5,4 & 6,2 & 4,1 \\
\hline 80 & 5 & A & $25-74$ & $50-100$ & 50 & 5,2 & 5,3 & 6,8 & 5,2 & 8,7 & 1,7 & 5,3 & 4,9 & 8,2 & 2,1 & 6,4 & 6,1 & 5,4 \\
\hline 80 & 5 & A & $75-125$ & $0-50$ & 10 & 3,2 & 5,5 & 4,8 & 4,9 & 5,3 & 1,3 & 3,1 & 5,4 & 5,7 & 1,1 & 4,6 & 4,4 & 3,8 \\
\hline 80 & 5 & A & $75-125$ & $0-50$ & 50 & 5,5 & 5,5 & 6,7 & 5,3 & 9,3 & 1,3 & 5,3 & 5,5 & 9,4 & 1,4 & 6,5 & 4,7 & 5,8 \\
\hline 80 & 5 & A & $75-125$ & $50-100$ & 10 & 3,1 & 4,0 & 3,4 & 4,7 & 4,9 & 1,4 & 3,2 & 4,1 & 4,7 & 1,4 & 3,2 & 4,5 & 3,1 \\
\hline 80 & 5 & A & $75-125$ & 50-100 & 50 & 3,8 & 3,8 & 5,4 & 3,7 & 6,2 & 1,3 & 3,6 & 3,9 & 6,3 & 1,4 & 4,8 & 3,8 & 3,8 \\
\hline 80 & 7 & B & $25-74$ & $0-50$ & 10 & 2,8 & 7,2 & 4,0 & 10,1 & 4,2 & 2,4 & 2,8 & 7,1 & 4,0 & 2,9 & 4,0 & 9,9 & 3,7 \\
\hline 80 & 7 & B & $25-74$ & $0-50$ & 50 & 3,8 & 5,6 & 4,9 & 5,8 & 7,1 & 1,9 & 3,7 & 5,8 & 6,9 & 2,0 & 4,8 & 5,7 & 4,6 \\
\hline 80 & 7 & B & $25-74$ & $50-100$ & 10 & 2,4 & 7,7 & 5,3 & 9,4 & 4,2 & 2,5 & 2,5 & 7,9 & 4,5 & 2,5 & 4,9 & 9,4 & 3,6 \\
\hline 80 & 7 & B & $25-74$ & $50-100$ & 50 & 4,0 & 5,2 & 5,4 & 6,1 & 6,7 & 2,0 & 4,4 & 5,3 & 6,5 & 2,0 & 5,4 & 5,8 & 4,4 \\
\hline 80 & 7 & B & $75-125$ & $0-50$ & 10 & 2,2 & 4,9 & 2,9 & 6,8 & 3,2 & 1,9 & 2,2 & 5,0 & 3,4 & 1,9 & 2,5 & 6,0 & 2,4 \\
\hline 80 & 7 & B & $75-125$ & $0-50$ & 50 & 3,4 & 4,5 & 4,3 & 5,2 & 6,4 & 1,4 & 3,5 & 4,2 & 6,3 & 1,5 & 4,1 & 5,0 & 3,6 \\
\hline 80 & 7 & B & $75-125$ & $50-100$ & 10 & 2,1 & 4,9 & 3,2 & 7,6 & 3,4 & 1,8 & 2,4 & 4,8 & 3,1 & 2,0 & 2,8 & 6,8 & 3,1 \\
\hline 80 & 7 & B & $75-125$ & $50-100$ & 50 & 3,2 & 3,7 & 3,7 & 4,7 & 5,4 & 1,7 & 3,0 & 3,8 & 5,6 & 1,9 & 3,7 & 4,6 & 3,4 \\
\hline 80 & 7 & M & $25-74$ & $0-50$ & 10 & 2,6 & 4,9 & 3,4 & 4,7 & 4,2 & 1,8 & 2,8 & 4,9 & 4,2 & 1,7 & 3,6 & 4,5 & 3,1 \\
\hline 80 & 7 & M & $25-74$ & $0-50$ & 50 & 4,0 & 4,3 & 4,4 & 4,2 & 6,2 & 1,8 & 3,9 & 4,3 & 6,0 & 2,0 & 4,5 & 4,1 & 4,1 \\
\hline 80 & 7 & M & $25-74$ & $50-100$ & 10 & 3,1 & 5,3 & 3,5 & 5,1 & 4,1 & 2,1 & 3,2 & 5,2 & 4,4 & 2,3 & 3,5 & 5,4 & 3,0 \\
\hline 80 & 7 & M & $25-74$ & $50-100$ & 50 & 3,8 & 4,8 & 4,6 & 4,2 & 5,9 & 1,8 & 3,8 & 4,5 & 5,9 & 2,1 & 4,4 & 3,9 & 4,1 \\
\hline 80 & 7 & M & $75-125$ & $0-50$ & 10 & 2,4 & 3,6 & 2,8 & 3,3 & 3,6 & 1,3 & 2,3 & 3,7 & 3,4 & 1,5 & 2,6 & 3,2 & 2,7 \\
\hline 80 & 7 & $\mathbf{M}$ & $75-125$ & $0-50$ & 50 & 3,0 & 3,5 & 3,3 & 3,1 & 5,3 & 1,5 & 3,0 & 3,5 & 5,2 & 1,2 & 3,4 & 2,9 & 3,3 \\
\hline 80 & 7 & M & $75-125$ & $50-100$ & 10 & 2,3 & 3,5 & 2,6 & 3,2 & 3,5 & 1,6 & 2,2 & 3,5 & 3,5 & 1,4 & 2,6 & 2,8 & 2,5 \\
\hline 80 & 7 & M & $75-125$ & $50-100$ & 50 & 2,7 & 2,9 & 2,8 & 2,9 & 4,2 & 1,6 & 2,7 & 3,0 & 4,2 & 1,7 & 2,8 & 2,8 & 2,7 \\
\hline 80 & 7 & A & $25-74$ & $0-50$ & 10 & 4,3 & 6,7 & 5,0 & 7,5 & 6,6 & 2,2 & 4,3 & 6,9 & 6,3 & 2,0 & 5,2 & 7,2 & 5,0 \\
\hline 80 & 7 & A & $25-74$ & $0-50$ & 50 & 7,3 & 8,2 & 8,8 & 8,5 & 12,0 & 1,9 & 7,1 & 8,3 & 12,3 & 1,6 & 8,7 & 8,4 & 7,8 \\
\hline 80 & 7 & A & $25-74$ & $50-100$ & 10 & 3,4 & 5,9 & 4,0 & 7,5 & 5,5 & 2,4 & 3,6 & 5,9 & 5,6 & 2,2 & 3,6 & 7,4 & 4,5 \\
\hline 80 & 7 & A & $25-74$ & $50-100$ & 50 & 6,1 & 7,8 & 7,2 & 6,2 & 10,3 & 2,0 & 6,0 & 7,6 & 9,8 & 2,1 & 7,2 & 6,3 & 6,5 \\
\hline 80 & 7 & A & $75-125$ & $0-50$ & 10 & 3,5 & 5,6 & 4,3 & 5,4 & 5,8 & 1,5 & 3,6 & 5,7 & 5,7 & 1,4 & 4,2 & 5,1 & 4,1 \\
\hline 80 & 7 & A & $75-125$ & $0-50$ & 50 & 6,2 & 6,3 & 6,3 & 6,5 & 9,8 & 1,6 & 6,1 & 6,6 & 9,5 & 1,5 & 6,5 & 6,3 & 6,4 \\
\hline 80 & 7 & A & $75-125$ & $50-100$ & 10 & 3,0 & 4,0 & 3,2 & 5,8 & 4,2 & 2,0 & 3,0 & 4,1 & 4,2 & 1,8 & 3,2 & 5,1 & 3,1 \\
\hline 80 & 7 & A & $75-125$ & $50-100$ & 50 & 4,1 & 4,1 & 4,8 & 4,9 & 6,1 & 2,0 & 4,2 & 4,2 & 6,4 & 2,3 & 4,7 & 4,9 & 4,1 \\
\hline 100 & 3 & B & $25-74$ & $0-50$ & 10 & 2,0 & 7,6 & 6,0 & 4,2 & 3,6 & 1,7 & 2,0 & 7,2 & 3,6 & 1,8 & 6,1 & 4,2 & 2,8 \\
\hline
\end{tabular}




\begin{tabular}{|c|c|c|c|c|c|c|c|c|c|c|c|c|c|c|c|c|c|c|}
\hline 100 & 3 & B & $25-74$ & $0-50$ & 50 & 2,4 & 3,1 & 4,2 & 2,6 & 4,7 & 2,1 & 2,4 & 2,9 & $\overline{4,7}$ & 2,0 & $\overline{3,7}$ & 2,5 & $\overline{2,4}$ \\
\hline 100 & 3 & B & $25-74$ & $50-100$ & 10 & 2,3 & 6,5 & 4,7 & 4,9 & 3,4 & 1,6 & 2,2 & 6,4 & 3,3 & 1,9 & 4,5 & 4,5 & 2,5 \\
\hline 100 & 3 & B & $25-74$ & $50-100$ & 50 & 2,6 & 3,0 & 4,1 & 2,6 & 4,2 & 2,0 & 2,5 & 3,0 & 4,1 & 2,0 & 4,1 & 2,8 & 2,7 \\
\hline 100 & 3 & B & $75-125$ & $0-50$ & 10 & 1,6 & 4,3 & 3,8 & 3,2 & 3,0 & 1,2 & 1,6 & 4,2 & 3,0 & 1,2 & 3,2 & 3,1 & 2,1 \\
\hline 100 & 3 & B & $75-125$ & $0-50$ & 50 & 1,9 & 2,5 & 2,9 & 1,7 & 3,3 & 1,2 & 1,9 & 2,5 & 3,3 & 1,2 & 2,9 & 1,6 & 2,0 \\
\hline 100 & 3 & B & $75-125$ & $50-100$ & 10 & 1,6 & 4,1 & 3,9 & 3,2 & 3,0 & 1,4 & 1,6 & 4,1 & 3,0 & 1,3 & 3,4 & 2,7 & 2,0 \\
\hline 100 & 3 & B & $75-125$ & $50-100$ & 50 & 1,5 & 1,8 & 2,6 & 1,7 & 3,3 & 1,3 & 1,7 & 1,9 & 3,2 & 1,2 & 2,5 & 1,7 & 1,6 \\
\hline 100 & 3 & M & $25-74$ & $0-50$ & 10 & 2,4 & 2,5 & 2,7 & 2,2 & 3,1 & 2,1 & 2,7 & 2,9 & 3,0 & 1,9 & 2,8 & 2,3 & 2,7 \\
\hline 100 & 3 & M & $25-74$ & $0-50$ & 50 & 2,7 & 2,9 & 3,3 & 2,6 & 3,8 & 2,2 & 2,7 & 2,7 & 3,7 & 2,3 & 3,2 & 2,6 & 2,9 \\
\hline 100 & 3 & M & $25-74$ & $50-100$ & 10 & 2,7 & 3,0 & 3,0 & 2,3 & 3,0 & 2,2 & 2,6 & 2,8 & 3,0 & 1,9 & 2,8 & 2,4 & 2,6 \\
\hline 100 & 3 & M & $25-74$ & $50-100$ & 50 & 2,7 & 2,6 & 2,9 & 2,4 & 3,4 & 2,1 & 2,3 & 2,7 & 3,5 & 2,2 & 3,1 & 2,5 & 2,8 \\
\hline 100 & 3 & M & $75-125$ & $0-50$ & 10 & 1,8 & 1,8 & 2,2 & 1,7 & 2,0 & 1,5 & 1,8 & 1,8 & 2,0 & 1,5 & 2,1 & 1,5 & 2,0 \\
\hline 100 & 3 & M & $75-125$ & $0-50$ & 50 & 1,9 & 2,0 & 2,4 & 1,7 & 2,9 & 1,3 & 1,8 & 2,0 & 2,9 & 1,5 & 2,2 & 1,8 & 1,9 \\
\hline 100 & 3 & M & $75-125$ & $50-100$ & 10 & 1,8 & 1,8 & 1,7 & 1,5 & 2,0 & 1,3 & 1,6 & 1,7 & 2,1 & 1,2 & 1,7 & 1,4 & 1,9 \\
\hline 100 & 3 & M & $75-125$ & $50-100$ & 50 & 1,7 & 1,9 & 2,1 & 1,5 & 2,4 & 1,5 & 1,7 & 1,7 & 2,5 & 1,6 & 2,1 & 1,5 & 1,7 \\
\hline 100 & 3 & A & $25-74$ & $0-50$ & 10 & 3,3 & 6,4 & 6,4 & 5,3 & 5,1 & 1,6 & 3,6 & 6,1 & 4,9 & 1,5 & 6,1 & 5,4 & 3,5 \\
\hline 100 & 3 & A & $25-74$ & $0-50$ & 50 & 4,7 & 4,9 & 7,4 & 4,1 & 7,7 & 1,6 & 4,4 & 5,0 & 7,6 & 1,5 & 7,1 & 4,3 & 4,3 \\
\hline 100 & 3 & A & $25-74$ & $50-100$ & 10 & 3,7 & 6,4 & 6,9 & 6,3 & 5,2 & 1,7 & 3,6 & 6,7 & 5,4 & 1,4 & 6,9 & 6,3 & 3,5 \\
\hline 100 & 3 & A & $25-74$ & $50-100$ & 50 & 4,0 & 4,0 & 6,3 & 3,3 & 7,1 & 1,7 & 4,0 & 4,3 & 6,8 & 1,7 & 6,2 & 3,1 & 4,4 \\
\hline 100 & 3 & A & $75-125$ & $0-50$ & 10 & 3,0 & 4,7 & 5,3 & 4,9 & 4,7 & 1,2 & 3,0 & 4,7 & 4,7 & 1,1 & 4,8 & 4,4 & 3,1 \\
\hline 100 & 3 & A & $75-125$ & $0-50$ & 50 & 4,2 & 4,1 & 6,1 & 3,7 & 7,2 & 1,3 & 4,2 & 3,9 & 7,5 & 1,0 & 5,7 & 3,6 & 4,1 \\
\hline 100 & 3 & A & $75-125$ & $50-100$ & 10 & 2,3 & 3,6 & 4,5 & 4,6 & 3,9 & 1,3 & 2,2 & 3,6 & 3,8 & 1,4 & 3,8 & 4,1 & 2,6 \\
\hline 100 & 3 & A & $75-125$ & $50-100$ & 50 & 2,9 & 2,8 & 4,3 & 2,7 & 5,3 & 1,2 & 3,0 & 2,9 & 5,2 & 1,2 & 4,2 & 2,3 & 2,9 \\
\hline 100 & 5 & B & $25-74$ & $0-50$ & 10 & 2,6 & 6,4 & 5,4 & 8,8 & 4,2 & 1,9 & 2,3 & 6,7 & 4,2 & 2,0 & 4,9 & 8,7 & 3,1 \\
\hline 100 & 5 & B & $25-74$ & $0-50$ & 50 & 3,1 & 3,7 & 4,5 & 3,7 & 5,7 & 1,5 & 3,5 & 3,9 & 5,3 & 1,8 & 4,5 & 3,7 & 3,3 \\
\hline 100 & 5 & B & $25-74$ & $50-100$ & 10 & 2,3 & 6,8 & 4,9 & 8,4 & 3,7 & 1,8 & 2,3 & 6,9 & 3,5 & 2,0 & 4,7 & 8,2 & 3,0 \\
\hline 100 & 5 & B & $25-74$ & $50-100$ & 50 & 2,9 & 3,3 & 3,7 & 3,3 & 4,7 & 1,7 & 2,8 & 3,2 & 4,5 & 1,8 & 3,5 & 3,4 & 2,9 \\
\hline 100 & 5 & B & $75-125$ & $0-50$ & 10 & 2,0 & 4,6 & 3,4 & 6,1 & 3,2 & 1,5 & 2,0 & 4,7 & 3,3 & 1,4 & 3,1 & 5,4 & 2,6 \\
\hline 100 & 5 & B & $75-125$ & $0-50$ & 50 & 2,1 & 3,4 & 3,7 & 3,3 & 4,7 & 1,0 & 2,0 & 3,2 & 4,8 & 1,1 & 3,3 & 3,1 & 2,7 \\
\hline 100 & 5 & B & $75-125$ & $50-100$ & 10 & 1,9 & 4,4 & 3,6 & 6,2 & 3,0 & 1,6 & 1,8 & 4,5 & 2,8 & 1,4 & 3,1 & 5,8 & 2,0 \\
\hline 100 & 5 & B & $75-125$ & $50-100$ & 50 & 2,4 & 2,5 & 3,2 & 2,5 & 3,8 & 1,3 & 2,3 & 2,2 & 3,8 & 1,3 & 2,8 & 2,6 & 2,1 \\
\hline 100 & 5 & M & $25-74$ & $0-50$ & 10 & 2,8 & 5,0 & 3,8 & 5,0 & 3,9 & 1,8 & 2,6 & 5,1 & 3,7 & 1,9 & 3,7 & 4,5 & 3,1 \\
\hline 100 & 5 & M & $25-74$ & $0-50$ & 50 & 3,1 & 3,9 & 4,0 & 3,1 & 5,2 & 1,5 & 3,1 & 4,1 & 5,5 & 1,8 & 4,4 & 3,0 & 3,5 \\
\hline 100 & 5 & M & $25-74$ & $50-100$ & 10 & 2,5 & 5,2 & 3,3 & 4,8 & 3,8 & 1,8 & 2,8 & 5,4 & 3,9 & 2,2 & 3,1 & 4,9 & 2,8 \\
\hline 100 & 5 & M & $25-74$ & $50-100$ & 50 & 2,6 & 3,2 & 3,5 & 3,2 & 4,5 & 1,8 & 2,7 & 3,4 & 4,5 & 1,9 & 3,5 & 3,2 & 3,1 \\
\hline 100 & 5 & M & $75-125$ & $0-50$ & 10 & 2,1 & 3,6 & 2,5 & 3,7 & 2,8 & 1,6 & 2,0 & 3,6 & 2,8 & 1,5 & 2,4 & 3,6 & 2,1 \\
\hline 100 & 5 & M & $75-125$ & $0-50$ & 50 & 2,5 & 2,6 & 2,8 & 2,5 & 4,2 & 1,3 & 2,4 & 2,6 & 4,0 & 1,1 & 2,9 & 2,5 & 2,5 \\
\hline 100 & 5 & M & $75-125$ & $50-100$ & 10 & 1,9 & 3,4 & 2,3 & 3,6 & 3,0 & 1,4 & 1,9 & 3,3 & 2,7 & 1,5 & 2,4 & 3,0 & 2,0 \\
\hline 100 & 5 & M & $75-125$ & $50-100$ & 50 & 1,9 & 2,1 & 2,4 & 1,9 & 3,3 & 1,2 & 2,0 & 2,2 & 3,2 & 1,3 & 2,5 & 2,2 & 1,8 \\
\hline 100 & 5 & A & $25-74$ & $0-50$ & 10 & 3,9 & 5,6 & 4,7 & 6,0 & 5,4 & 1,6 & 4,0 & 5,5 & 5,3 & 1,8 & 4,5 & 6,0 & 3,9 \\
\hline 100 & 5 & A & 25-74 & $0-50$ & 50 & 5,9 & 6,5 & 7,6 & 5,9 & 9,1 & 1,7 & 6,0 & 6,6 & 9,1 & 1,9 & 7,5 & 6,2 & 6,2 \\
\hline 100 & 5 & A & $25-74$ & $50-100$ & 10 & 3,4 & 5,6 & 4,8 & 6,8 & 5,2 & 2,0 & 3,6 & 5,8 & 5,4 & 1,7 & 4,5 & 6,9 & 3,7 \\
\hline 100 & 5 & A & $25-74$ & $50-100$ & 50 & 5,0 & 5,1 & 6,5 & 5,3 & 8,4 & 1,4 & 5,0 & 5,3 & 8,6 & 1,4 & 6,5 & 5,4 & 4,7 \\
\hline 100 & 5 & A & $75-125$ & $0-50$ & 10 & 2,6 & 4,1 & 3,2 & 4,7 & 3,9 & 1,4 & 2,8 & 4,1 & 3,9 & 1,2 & 3,4 & 4,7 & 3,1 \\
\hline 100 & 5 & A & $75-125$ & $0-50$ & 50 & 5,0 & 4,7 & 5,6 & 5,4 & 8,2 & 1,0 & 5,0 & 4,9 & 8,0 & 1,0 & 5,7 & 5,1 & 4,9 \\
\hline 100 & 5 & A & $75-125$ & $50-100$ & 10 & 2,4 & 3,5 & 2,9 & 4,0 & 3,7 & 1,2 & 2,3 & 3,4 & 3,6 & 1,2 & 2,9 & 3,7 & 2,4 \\
\hline 100 & 5 & A & $75-125$ & $50-100$ & 50 & 3,6 & 3,2 & 4,4 & 3,7 & 6,0 & 1,1 & 3,6 & 3,5 & 5,9 & 1,2 & 4,2 & 3,3 & 3,6 \\
\hline 100 & 7 & B & $25-74$ & $0-50$ & 10 & 2,1 & 7,2 & 4,3 & 9,8 & 3,7 & 2,0 & 2,5 & 7,1 & 3,7 & 2,3 & 4,5 & 9,6 & 3,1 \\
\hline 100 & 7 & B & $25-74$ & $0-50$ & 50 & 3,6 & 4,7 & 4,8 & 5,7 & 6,6 & 1,8 & 3,5 & 4,9 & 6,4 & 1,8 & 4,8 & 5,7 & 3,8 \\
\hline 100 & 7 & B & $25-74$ & $50-100$ & 10 & 2,4 & 7,5 & 5,3 & 10,3 & 3,7 & 2,4 & 2,2 & 7,5 & 3,7 & 2,4 & 4,7 & 10,0 & 3,0 \\
\hline 100 & 7 & B & $25-74$ & $50-100$ & 50 & 3,5 & 4,0 & 3,6 & 4,7 & 5,2 & 1,7 & 3,2 & 4,0 & 5,0 & 1,6 & 3,3 & 4,6 & 3,1 \\
\hline 100 & 7 & B & $75-125$ & $0-50$ & 10 & 2,3 & 4,5 & 3,1 & 7,4 & 3,0 & 1,5 & 2,4 & 4,6 & 2,9 & 1,8 & 2,5 & 6,2 & 2,6 \\
\hline 100 & 7 & B & $75-125$ & $0-50$ & 50 & 3,5 & 4,1 & 3,9 & 5,2 & 5,6 & 1,6 & 3,2 & 4,0 & 5,8 & 1,5 & 4,2 & 5,1 & 3,6 \\
\hline 100 & 7 & B & $75-125$ & $50-100$ & 10 & 2,0 & 4,7 & 2,8 & 8,1 & 2,9 & 2,1 & 2,0 & 4,8 & 2,9 & 2,2 & 2,5 & 7,1 & 2,9 \\
\hline 100 & 7 & B & $75-125$ & $50-100$ & 50 & 3,2 & 3,2 & 3,5 & 4,8 & 5,1 & 1,5 & 3,0 & 3,5 & 5,1 & 1,3 & 3,5 & 4,7 & 3,0 \\
\hline 100 & 7 & M & $25-74$ & $0-50$ & 10 & 2,8 & 5,0 & 3,0 & 4,7 & 3,9 & 1,8 & 3,0 & 4,8 & 4,1 & 2,0 & 3,1 & 4,5 & 2,8 \\
\hline 100 & 7 & M & 25-74 & $0-50$ & 50 & 3,6 & 3,8 & 4,0 & 3,4 & 5,6 & 1,6 & 3,5 & 3,7 & 5,5 & 1,9 & 4,0 & 3,6 & 3,6 \\
\hline 100 & 7 & M & $25-74$ & $50-100$ & 10 & 2,5 & 5,2 & 2,8 & 4,5 & 3,7 & 2,1 & 2,5 & 5,5 & 4,0 & 1,7 & 3,2 & 4,4 & 3,0 \\
\hline 100 & 7 & M & $25-74$ & $50-100$ & 50 & 3,3 & 3,4 & 3,9 & 3,3 & 5,2 & 1,9 & 3,7 & 3,9 & 4,9 & 1,9 & 3,9 & 3,3 & 3,2 \\
\hline 100 & 7 & M & $75-125$ & $0-50$ & 10 & 2,2 & 3,8 & 2,7 & 3,1 & 3,4 & 1,1 & 2,1 & 3,7 & 3,4 & 1,2 & 2,6 & 2,9 & 2,3 \\
\hline 100 & 7 & M & $75-125$ & $0-50$ & 50 & 2,9 & 3,2 & 3,2 & 2,8 & 4,4 & 1,2 & 3,0 & 3,4 & 4,4 & 1,2 & 3,3 & 2,6 & 3,0 \\
\hline 100 & 7 & M & $75-125$ & $50-100$ & 10 & 2,0 & 3,1 & 2,2 & 3,1 & 2,8 & 1,4 & 1,9 & 3,2 & 3,0 & 1,3 & 2,0 & 2,7 & 2,0 \\
\hline
\end{tabular}




\begin{tabular}{|c|c|c|c|c|c|c|c|c|c|c|c|c|c|c|c|c|c|c|}
\hline 100 & 7 & $\bar{M}$ & $75-125$ & $50-100$ & 50 & 2,2 & 2,5 & 2,7 & 2,2 & 3,9 & 1,3 & 2,3 & 2,4 & 3,8 & 1,3 & 2,6 & 2,4 & 2,4 \\
\hline 100 & 7 & A & $25-74$ & $0-50$ & 10 & 3,6 & 5,8 & 4,1 & 6,4 & 5,3 & 1,9 & 3,6 & 5,9 & 5,2 & 1,9 & 4,4 & 6,4 & 3,9 \\
\hline 100 & 7 & A & $25-74$ & $0-50$ & 50 & 6,1 & 6,8 & 7,5 & 5,8 & 9,4 & 1,8 & 6,4 & 7,1 & 9,5 & 1,9 & 7,2 & 6,2 & 6,3 \\
\hline 100 & 7 & A & $25-74$ & $50-100$ & 10 & 3,6 & 5,7 & 4,1 & 6,5 & 5,2 & 1,9 & 3,3 & 6,0 & 5,0 & 1,8 & 4,1 & 6,4 & 3,7 \\
\hline 100 & 7 & A & $25-74$ & 50-100 & 50 & 5,3 & 5,8 & 5,4 & 5,9 & 8,2 & 1,8 & 5,1 & 5,3 & 8,2 & 2,2 & 6,1 & 6,1 & 5,6 \\
\hline 100 & 7 & A & $75-125$ & $0-50$ & 10 & 2,7 & 4,2 & 3,3 & 5,1 & 3,8 & 1,3 & 2,8 & 4,1 & 3,9 & 1,6 & 3,3 & 4,7 & 3,3 \\
\hline 100 & 7 & A & $75-125$ & $0-50$ & 50 & 5,1 & 5,7 & 5,9 & 5,0 & 8,9 & 1,2 & 5,3 & 5,6 & 8,7 & 1,3 & 5,8 & 5,4 & 5,1 \\
\hline 100 & 7 & A & $75-125$ & 50-100 & 10 & 2,7 & 3,8 & 2,8 & 4,9 & 4,3 & 1,5 & 2,7 & 3,7 & 4,1 & 1,6 & 2,6 & 4,2 & 2,8 \\
\hline 100 & 7 & A & $75-125$ & $50-100$ & 50 & 4,0 & 4,2 & 4,4 & 3,9 & 6,2 & 1,0 & 3,9 & 4,1 & 6,5 & 1,0 & 4,2 & 4,0 & 4,2 \\
\hline
\end{tabular}

TABELA D.30 - Desvio-padrão do relativo das regras para setup dependente

\begin{tabular}{|c|c|c|c|c|c|c|c|c|c|c|c|c|c|c|c|c|c|c|}
\hline$n$ & $g$ & $f$ & $s$ & $a$ & $l$ & Rd1 & Rd2 & Rd3 & Rd4 & Rd5 & Rd6 & Rd7 & Rd8 & Rd9 & Rd10 & Rd11 & Rd12 & Rd13 \\
\hline 10 & 3 & B & $25-74$ & $0-50$ & 10 & 0,05 & 0,09 & 0,11 & 0,06 & 0,09 & 0,05 & 0,06 & 0,10 & 0,09 & 0,06 & 0,10 & 0,06 & 0,07 \\
\hline 10 & 3 & B & $25-74$ & $0-50$ & 50 & 0,09 & 0,13 & 0,13 & 0,07 & 0,16 & 0,04 & 0,08 & 0,13 & 0,16 & 0,04 & 0,13 & 0,07 & 0,12 \\
\hline 10 & 3 & B & $25-74$ & $50-100$ & 10 & 0,06 & 0,09 & 0,09 & 0,06 & 0,08 & 0,05 & 0,06 & 0,09 & 0,08 & 0,05 & 0,09 & 0,06 & 0,06 \\
\hline 10 & 3 & B & $25-74$ & $50-100$ & 50 & 0,09 & 0,11 & 0,14 & 0,07 & 0,14 & 0,04 & 0,09 & 0,10 & 0,13 & 0,05 & 0,12 & 0,07 & 0,09 \\
\hline 10 & 3 & B & $75-125$ & $0-50$ & 10 & 0,05 & 0,06 & 0,07 & 0,05 & 0,07 & 0,05 & 0,05 & 0,06 & 0,07 & 0,04 & 0,07 & 0,06 & 0,06 \\
\hline 10 & 3 & B & 75-125 & $0-50$ & 50 & 0,07 & 0,09 & 0,11 & 0,05 & 0,11 & 0,04 & 0,08 & 0,09 & 0,12 & 0,04 & 0,11 & 0,06 & 0,08 \\
\hline 10 & 3 & B & $75-125$ & $50-100$ & 10 & 0,05 & 0,06 & 0,07 & 0,05 & 0,06 & 0,04 & 0,05 & 0,06 & 0,06 & 0,04 & 0,07 & 0,06 & 0,05 \\
\hline 10 & 3 & B & $75-125$ & $50-100$ & 50 & 0,07 & 0,07 & 0,11 & 0,05 & 0,11 & 0,03 & 0,06 & 0,07 & 0,11 & 0,03 & 0,10 & 0,05 & 0,07 \\
\hline 10 & 3 & M & $25-74$ & $0-50$ & 10 & 0,06 & 0,08 & 0,09 & 0,06 & 0,09 & 0,06 & 0,06 & 0,08 & 0,08 & 0,05 & 0,09 & 0,05 & 0,07 \\
\hline 10 & 3 & M & $25-74$ & $0-50$ & 50 & 0,11 & 0,13 & 0,16 & 0,09 & 0,15 & 0,06 & 0,11 & 0,14 & 0,16 & 0,06 & 0,16 & 0,09 & 0,10 \\
\hline 10 & 3 & M & $25-74$ & $50-100$ & 10 & 0,06 & 0,07 & 0,07 & 0,05 & 0,07 & 0,06 & 0,06 & 0,07 & 0,07 & 0,06 & 0,08 & 0,06 & 0,05 \\
\hline 10 & 3 & M & $25-74$ & $50-100$ & 50 & 0,09 & 0,11 & 0,12 & 0,07 & 0,12 & 0,04 & 0,09 & 0,11 & 0,12 & 0,05 & 0,12 & 0,07 & 0,09 \\
\hline 10 & 3 & M & $75-125$ & $0-50$ & 10 & 0,07 & 0,06 & 0,08 & 0,06 & 0,07 & 0,05 & 0,06 & 0,07 & 0,07 & 0,05 & 0,08 & 0,05 & 0,07 \\
\hline 10 & 3 & M & $75-125$ & $0-50$ & 50 & 0,09 & 0,10 & 0,13 & 0,06 & 0,13 & 0,03 & 0,08 & 0,10 & 0,14 & 0,03 & 0,12 & 0,06 & 0,10 \\
\hline 10 & 3 & M & $75-125$ & $50-100$ & 10 & 0,04 & 0,05 & 0,06 & 0,05 & 0,06 & 0,04 & 0,05 & 0,06 & 0,06 & 0,04 & 0,06 & 0,05 & 0,05 \\
\hline 10 & 3 & M & $75-125$ & $50-100$ & 50 & 0,08 & 0,07 & 0,10 & 0,06 & 0,09 & 0,03 & 0,07 & 0,07 & 0,10 & 0,03 & 0,10 & 0,05 & 0,07 \\
\hline 10 & 3 & A & $25-74$ & $0-50$ & 10 & 0,09 & 0,11 & 0,12 & 0,08 & 0,14 & 0,06 & 0,08 & 0,10 & 0,13 & 0,06 & 0,12 & 0,07 & 0,10 \\
\hline 10 & 3 & A & $25-74$ & $0-50$ & 50 & 0,12 & 0,12 & 0,16 & 0,07 & 0,16 & 0,04 & 0,13 & 0,13 & 0,17 & 0,04 & 0,15 & 0,07 & 0,13 \\
\hline 10 & 3 & A & $25-74$ & $50-100$ & 10 & 0,10 & 0,10 & 0,11 & 0,08 & 0,12 & 0,05 & 0,10 & 0,10 & 0,12 & 0,05 & 0,11 & 0,08 & 0,10 \\
\hline 10 & 3 & A & $25-74$ & $50-100$ & 50 & 0,11 & 0,10 & 0,15 & 0,08 & 0,16 & 0,05 & 0,11 & 0,11 & 0,17 & 0,04 & 0,14 & 0,08 & 0,13 \\
\hline 10 & 3 & A & $75-125$ & $0-50$ & 10 & 0,07 & 0,08 & 0,09 & 0,08 & 0,10 & 0,06 & 0,08 & 0,08 & 0,10 & 0,06 & 0,09 & 0,07 & 0,08 \\
\hline 10 & 3 & A & $75-125$ & $0-50$ & 50 & 0,12 & 0,14 & 0,16 & 0,09 & 0,17 & 0,04 & 0,14 & 0,14 & 0,18 & 0,04 & 0,16 & 0,09 & 0,14 \\
\hline 10 & 3 & A & $75-125$ & $50-100$ & 10 & 0,08 & 0,07 & 0,08 & 0,07 & 0,09 & 0,06 & 0,08 & 0,07 & 0,09 & 0,06 & 0,08 & 0,07 & 0,08 \\
\hline 10 & 3 & A & $75-125$ & $50-100$ & 50 & 0,13 & 0,10 & 0,13 & 0,10 & 0,13 & 0,05 & 0,13 & 0,09 & 0,13 & 0,05 & 0,13 & 0,10 & 0,12 \\
\hline 10 & 5 & B & $25-74$ & $0-50$ & 10 & 0,06 & 0,08 & 0,09 & 0,07 & 0,09 & 0,06 & 0,06 & 0,08 & 0,09 & 0,06 & 0,08 & 0,07 & 0,07 \\
\hline 10 & 5 & B & $25-74$ & $0-50$ & 50 & 0,10 & 0,14 & 0,13 & 0,09 & 0,16 & 0,06 & 0,10 & 0,13 & 0,16 & 0,06 & 0,13 & 0,09 & 0,13 \\
\hline 10 & 5 & B & 25-74 & $50-100$ & 10 & 0,06 & 0,09 & 0,08 & 0,08 & 0,08 & 0,06 & 0,06 & 0,08 & 0,08 & 0,06 & 0,07 & 0,08 & 0,08 \\
\hline 10 & 5 & B & $25-74$ & $50-100$ & 50 & 0,08 & 0,11 & 0,12 & 0,08 & 0,11 & 0,05 & 0,09 & 0,11 & 0,12 & 0,05 & 0,12 & 0,08 & 0,09 \\
\hline 10 & 5 & B & $75-125$ & $0-50$ & 10 & 0,05 & 0,08 & 0,06 & 0,06 & 0,07 & 0,05 & 0,05 & 0,08 & 0,08 & 0,05 & 0,06 & 0,06 & 0,06 \\
\hline 10 & 5 & B & $75-125$ & $0-50$ & 50 & 0,08 & 0,11 & 0,13 & 0,08 & 0,15 & 0,05 & 0,09 & 0,11 & 0,15 & 0,05 & 0,13 & 0,08 & 0,09 \\
\hline 10 & 5 & B & $75-125$ & $50-100$ & 10 & 0,05 & 0,07 & 0,06 & 0,06 & 0,07 & 0,05 & 0,05 & 0,07 & 0,07 & 0,05 & 0,06 & 0,07 & 0,06 \\
\hline 10 & 5 & B & $75-125$ & $50-100$ & 50 & 0,06 & 0,09 & 0,09 & 0,09 & 0,09 & 0,05 & 0,06 & 0,09 & 0,10 & 0,05 & 0,08 & 0,08 & 0,08 \\
\hline 10 & 5 & M & $25-74$ & $0-50$ & 10 & 0,06 & 0,08 & 0,07 & 0,07 & 0,08 & 0,07 & 0,06 & 0,08 & 0,08 & 0,06 & 0,07 & 0,07 & 0,06 \\
\hline 10 & 5 & M & $25-74$ & $0-50$ & 50 & 0,10 & 0,11 & 0,14 & 0,09 & 0,15 & 0,06 & 0,09 & 0,12 & 0,15 & 0,07 & 0,13 & 0,09 & 0,11 \\
\hline 10 & 5 & M & $25-74$ & $50-100$ & 10 & 0,07 & 0,09 & 0,07 & 0,08 & 0,08 & 0,07 & 0,07 & 0,09 & 0,07 & 0,06 & 0,07 & 0,08 & 0,07 \\
\hline 10 & 5 & M & $25-74$ & $50-100$ & 50 & 0,08 & 0,12 & 0,13 & 0,07 & 0,14 & 0,06 & 0,09 & 0,12 & 0,14 & 0,06 & 0,13 & 0,08 & 0,10 \\
\hline 10 & 5 & M & $75-125$ & $0-50$ & 10 & 0,06 & 0,07 & 0,06 & 0,07 & 0,07 & 0,05 & 0,06 & 0,06 & 0,07 & 0,05 & 0,06 & 0,06 & 0,07 \\
\hline 10 & 5 & M & $75-125$ & $0-50$ & 50 & 0,11 & 0,11 & 0,11 & 0,10 & 0,14 & 0,05 & 0,10 & 0,11 & 0,14 & 0,05 & 0,12 & 0,10 & 0,11 \\
\hline 10 & 5 & M & $75-125$ & $50-100$ & 10 & 0,05 & 0,06 & 0,06 & 0,06 & 0,07 & 0,05 & 0,05 & 0,06 & 0,06 & 0,05 & 0,06 & 0,06 & 0,06 \\
\hline 10 & 5 & M & $75-125$ & $50-100$ & 50 & 0,08 & 0,09 & 0,10 & 0,08 & 0,11 & 0,04 & 0,08 & 0,09 & 0,12 & 0,05 & 0,10 & 0,08 & 0,08 \\
\hline 10 & 5 & A & $25-74$ & $0-50$ & 10 & 0,07 & 0,08 & 0,08 & 0,08 & 0,08 & 0,07 & 0,06 & 0,08 & 0,09 & 0,06 & 0,08 & 0,08 & 0,07 \\
\hline 10 & 5 & A & $25-74$ & $0-50$ & 50 & 0,11 & 0,11 & 0,15 & 0,09 & 0,16 & 0,04 & 0,11 & 0,13 & 0,16 & 0,05 & 0,16 & 0,09 & 0,11 \\
\hline 10 & 5 & A & $25-74$ & $50-100$ & 10 & 0,07 & 0,08 & 0,08 & 0,08 & 0,10 & 0,07 & 0,06 & 0,08 & 0,09 & 0,07 & 0,08 & 0,07 & 0,07 \\
\hline 10 & 5 & A & $25-74$ & $50-100$ & 50 & 0,09 & 0,12 & 0,12 & 0,08 & 0,15 & 0,06 & 0,09 & 0,12 & 0,15 & 0,04 & 0,13 & 0,08 & 0,09 \\
\hline 10 & 5 & A & $75-125$ & $0-50$ & 10 & 0,06 & 0,07 & 0,07 & 0,07 & 0,08 & 0,05 & 0,06 & 0,06 & 0,08 & 0,05 & 0,08 & 0,07 & 0,07 \\
\hline 10 & 5 & A & $75-125$ & $0-50$ & 50 & 0,09 & 0,13 & 0,12 & 0,10 & 0,14 & 0,06 & 0,08 & 0,12 & 0,14 & 0,06 & 0,12 & 0,09 & 0,10 \\
\hline
\end{tabular}




\begin{tabular}{|c|c|c|c|c|c|c|c|c|c|c|c|c|c|c|c|c|c|c|}
\hline 10 & 5 & A & $75-125$ & $50-100$ & 10 & 0,07 & 0,06 & 0,07 & 0,07 & 0,08 & 0,06 & 0,07 & 0,07 & 0,08 & 0,07 & 0,07 & 0,07 & 0,07 \\
\hline 10 & 5 & A & $75-125$ & 50-100 & 50 & 0,09 & 0,08 & 0,10 & 0,08 & 0,11 & 0,05 & 0,09 & 0,08 & 0,11 & 0,05 & 0,11 & 0,08 & 0,07 \\
\hline 10 & 7 & B & $25-74$ & $0-50$ & 10 & 0,05 & 0,07 & 0,06 & 0,07 & 0,07 & 0,06 & 0,05 & 0,07 & 0,07 & 0,06 & 0,06 & 0,06 & 0,06 \\
\hline 10 & 7 & B & $25-74$ & $0-50$ & 50 & 0,10 & 0,10 & 0,11 & 0,10 & 0,15 & 0,06 & 0,10 & 0,10 & 0,14 & 0,06 & 0,12 & 0,09 & 0,11 \\
\hline 10 & 7 & B & $25-74$ & $50-100$ & 10 & 0,05 & 0,08 & 0,06 & 0,07 & 0,08 & 0,06 & 0,05 & 0,08 & 0,07 & 0,05 & 0,07 & 0,08 & 0,07 \\
\hline 10 & 7 & B & $25-74$ & $50-100$ & 50 & 0,08 & 0,12 & 0,11 & 0,10 & 0,12 & 0,05 & 0,08 & 0,11 & 0,12 & 0,06 & 0,11 & 0,10 & 0,09 \\
\hline 10 & 7 & B & $75-125$ & $0-50$ & 10 & 0,05 & 0,07 & 0,05 & 0,06 & 0,07 & 0,06 & 0,05 & 0,07 & 0,06 & 0,06 & 0,05 & 0,07 & 0,05 \\
\hline 10 & 7 & B & $75-125$ & $0-50$ & 50 & 0,08 & 0,09 & 0,11 & 0,09 & 0,12 & 0,06 & 0,07 & 0,09 & 0,12 & 0,06 & 0,11 & 0,09 & 0,09 \\
\hline 10 & 7 & B & $75-125$ & $50-100$ & 10 & 0,05 & 0,07 & 0,05 & 0,05 & 0,06 & 0,06 & 0,05 & 0,07 & 0,06 & 0,06 & 0,06 & 0,06 & 0,06 \\
\hline 10 & 7 & B & $75-125$ & $50-100$ & 50 & 0,09 & 0,10 & 0,10 & 0,10 & 0,12 & 0,05 & 0,09 & 0,10 & 0,12 & 0,05 & 0,11 & 0,09 & 0,10 \\
\hline 10 & 7 & M & $25-74$ & $0-50$ & 10 & 0,07 & 0,09 & 0,07 & 0,07 & 0,08 & 0,05 & 0,06 & 0,09 & 0,09 & 0,05 & 0,07 & 0,07 & 0,07 \\
\hline 10 & 7 & M & $25-74$ & $0-50$ & 50 & 0,08 & 0,10 & 0,11 & 0,10 & 0,14 & 0,04 & 0,08 & 0,11 & 0,14 & 0,04 & 0,11 & 0,10 & 0,09 \\
\hline 10 & 7 & M & $25-74$ & $50-100$ & 10 & 0,06 & 0,09 & 0,07 & 0,06 & 0,08 & 0,06 & 0,06 & 0,08 & 0,08 & 0,06 & 0,07 & 0,07 & 0,06 \\
\hline 10 & 7 & M & $25-74$ & $50-100$ & 50 & 0,08 & 0,13 & 0,12 & 0,09 & 0,13 & 0,07 & 0,08 & 0,13 & 0,13 & 0,07 & 0,12 & 0,09 & 0,09 \\
\hline 10 & 7 & M & $75-125$ & $0-50$ & 10 & 0,06 & 0,08 & 0,06 & 0,07 & 0,08 & 0,05 & 0,06 & 0,08 & 0,08 & 0,05 & 0,06 & 0,06 & 0,06 \\
\hline 10 & 7 & M & $75-125$ & $0-50$ & 50 & 0,08 & 0,11 & 0,13 & 0,10 & 0,13 & 0,05 & 0,10 & 0,09 & 0,13 & 0,05 & 0,13 & 0,10 & 0,09 \\
\hline 10 & 7 & M & $75-125$ & $50-100$ & 10 & 0,05 & 0,06 & 0,06 & 0,07 & 0,07 & 0,06 & 0,05 & 0,06 & 0,07 & 0,06 & 0,05 & 0,06 & 0,06 \\
\hline 10 & 7 & M & $75-125$ & $50-100$ & 50 & 0,07 & 0,08 & 0,09 & 0,06 & 0,10 & 0,04 & 0,06 & 0,07 & 0,10 & 0,04 & 0,09 & 0,06 & 0,08 \\
\hline 10 & 7 & A & $25-74$ & $0-50$ & 10 & 0,06 & 0,07 & 0,07 & 0,07 & 0,08 & 0,06 & 0,06 & 0,07 & 0,08 & 0,06 & 0,06 & 0,06 & 0,07 \\
\hline 10 & 7 & A & $25-74$ & $0-50$ & 50 & 0,09 & 0,08 & 0,10 & 0,09 & 0,11 & 0,04 & 0,08 & 0,09 & 0,11 & 0,04 & 0,10 & 0,08 & 0,08 \\
\hline 10 & 7 & A & $25-74$ & $50-100$ & 10 & 0,06 & 0,08 & 0,07 & 0,08 & 0,08 & 0,06 & 0,07 & 0,09 & 0,08 & 0,06 & 0,08 & 0,08 & 0,07 \\
\hline 10 & 7 & A & $25-74$ & $50-100$ & 50 & 0,09 & 0,08 & 0,08 & 0,09 & 0,10 & 0,06 & 0,08 & 0,09 & 0,10 & 0,05 & 0,08 & 0,09 & 0,08 \\
\hline 10 & 7 & A & $75-125$ & $0-50$ & 10 & 0,06 & 0,07 & 0,06 & 0,06 & 0,08 & 0,06 & 0,05 & 0,07 & 0,07 & 0,07 & 0,06 & 0,07 & 0,06 \\
\hline 10 & 7 & A & $75-125$ & $0-50$ & 50 & 0,08 & 0,08 & 0,09 & 0,08 & 0,11 & 0,05 & 0,08 & 0,08 & 0,11 & 0,05 & 0,09 & 0,08 & 0,06 \\
\hline 10 & 7 & A & $75-125$ & $50-100$ & 10 & 0,07 & 0,08 & 0,07 & 0,08 & 0,08 & 0,07 & 0,07 & 0,08 & 0,08 & 0,07 & 0,07 & 0,06 & 0,07 \\
\hline 10 & 7 & A & $75-125$ & $50-100$ & 50 & 0,07 & 0,10 & 0,11 & 0,08 & 0,12 & 0,05 & 0,08 & 0,10 & 0,12 & 0,05 & 0,09 & 0,09 & 0,09 \\
\hline 30 & 3 & B & $25-74$ & $0-50$ & 10 & 0,03 & 0,06 & 0,07 & 0,05 & 0,05 & 0,03 & 0,03 & 0,06 & 0,05 & 0,03 & 0,07 & 0,05 & 0,04 \\
\hline 30 & 3 & B & $25-74$ & $0-50$ & 50 & 0,03 & 0,06 & 0,06 & 0,04 & 0,06 & 0,02 & 0,03 & 0,05 & 0,06 & 0,03 & 0,06 & 0,03 & 0,05 \\
\hline 30 & 3 & B & $25-74$ & $50-100$ & 10 & 0,03 & 0,06 & 0,07 & 0,05 & 0,05 & 0,03 & 0,03 & 0,06 & 0,05 & 0,03 & 0,07 & 0,05 & 0,04 \\
\hline 30 & 3 & B & $25-74$ & $50-100$ & 50 & 0,04 & 0,05 & 0,06 & 0,03 & 0,05 & 0,03 & 0,03 & 0,05 & 0,05 & 0,03 & 0,06 & 0,03 & 0,04 \\
\hline 30 & 3 & B & $75-125$ & $0-50$ & 10 & 0,03 & 0,04 & 0,05 & 0,03 & 0,04 & 0,02 & 0,03 & 0,04 & 0,03 & 0,02 & 0,04 & 0,03 & 0,03 \\
\hline 30 & 3 & B & $75-125$ & $0-50$ & 50 & 0,04 & 0,04 & 0,06 & 0,03 & 0,06 & 0,02 & 0,04 & 0,04 & 0,06 & 0,02 & 0,06 & 0,03 & 0,04 \\
\hline 30 & 3 & B & $75-125$ & $50-100$ & 10 & 0,02 & 0,04 & 0,05 & 0,03 & 0,03 & 0,02 & 0,02 & 0,04 & 0,03 & 0,02 & 0,04 & 0,03 & 0,03 \\
\hline 30 & 3 & B & $75-125$ & $50-100$ & 50 & 0,03 & 0,04 & 0,05 & 0,02 & 0,05 & 0,02 & 0,03 & 0,04 & 0,05 & 0,02 & 0,05 & 0,02 & 0,03 \\
\hline 30 & 3 & M & $25-74$ & $0-50$ & 10 & 0,03 & 0,03 & 0,03 & 0,04 & 0,04 & 0,03 & 0,03 & 0,03 & 0,04 & 0,03 & 0,03 & 0,03 & 0,03 \\
\hline 30 & 3 & M & $25-74$ & $0-50$ & 50 & 0,05 & 0,05 & 0,06 & 0,04 & 0,07 & 0,03 & 0,05 & 0,06 & 0,07 & 0,03 & 0,07 & 0,04 & 0,05 \\
\hline 30 & 3 & M & $25-74$ & $50-100$ & 10 & 0,03 & 0,04 & 0,04 & 0,03 & 0,03 & 0,03 & 0,03 & 0,03 & 0,03 & 0,03 & 0,04 & 0,03 & 0,03 \\
\hline 30 & 3 & M & $25-74$ & $50-100$ & 50 & 0,04 & 0,04 & 0,07 & 0,04 & 0,07 & 0,03 & 0,04 & 0,04 & 0,05 & 0,03 & 0,07 & 0,04 & 0,04 \\
\hline 30 & 3 & M & $75-125$ & $0-50$ & 10 & 0,03 & 0,03 & 0,03 & 0,02 & 0,03 & 0,02 & 0,02 & 0,03 & 0,03 & 0,02 & 0,03 & 0,02 & 0,03 \\
\hline 30 & 3 & M & $75-125$ & $0-50$ & 50 & 0,03 & 0,04 & 0,05 & 0,03 & 0,05 & 0,02 & 0,04 & 0,03 & 0,05 & 0,02 & 0,06 & 0,03 & 0,04 \\
\hline 30 & 3 & M & $75-125$ & $50-100$ & 10 & 0,02 & 0,02 & 0,03 & 0,02 & 0,03 & 0,02 & 0,02 & 0,02 & 0,02 & 0,02 & 0,02 & 0,02 & 0,02 \\
\hline 30 & 3 & M & $75-125$ & $50-100$ & 50 & 0,03 & 0,03 & 0,04 & 0,02 & 0,05 & 0,02 & 0,03 & 0,04 & 0,05 & 0,02 & 0,04 & 0,03 & 0,03 \\
\hline 30 & 3 & A & $25-74$ & $0-50$ & 10 & 0,05 & 0,06 & 0,09 & 0,05 & 0,07 & 0,04 & 0,05 & 0,06 & 0,07 & 0,04 & 0,08 & 0,05 & 0,06 \\
\hline 30 & 3 & A & $25-74$ & $0-50$ & 50 & 0,09 & 0,07 & 0,10 & 0,06 & 0,12 & 0,04 & 0,09 & 0,08 & 0,13 & 0,03 & 0,11 & 0,06 & 0,08 \\
\hline 30 & 3 & A & $25-74$ & $50-100$ & 10 & 0,04 & 0,06 & 0,07 & 0,05 & 0,07 & 0,04 & 0,04 & 0,07 & 0,07 & 0,05 & 0,06 & 0,05 & 0,05 \\
\hline 30 & 3 & A & $25-74$ & $50-100$ & 50 & 0,08 & 0,07 & 0,11 & 0,06 & 0,11 & 0,03 & 0,08 & 0,07 & 0,10 & 0,03 & 0,11 & 0,06 & 0,08 \\
\hline 30 & 3 & A & $75-125$ & $0-50$ & 10 & 0,04 & 0,05 & 0,07 & 0,04 & 0,06 & 0,02 & 0,05 & 0,05 & 0,06 & 0,02 & 0,06 & 0,04 & 0,05 \\
\hline 30 & 3 & A & $75-125$ & $0-50$ & 50 & 0,07 & 0,07 & 0,11 & 0,06 & 0,10 & 0,02 & 0,08 & 0,07 & 0,10 & 0,02 & 0,11 & 0,06 & 0,07 \\
\hline 30 & 3 & A & $75-125$ & $50-100$ & 10 & 0,04 & 0,04 & 0,06 & 0,04 & 0,05 & 0,03 & 0,04 & 0,04 & 0,05 & 0,03 & 0,05 & 0,04 & 0,04 \\
\hline 30 & 3 & A & $75-125$ & $50-100$ & 50 & 0,05 & 0,04 & 0,08 & 0,05 & 0,07 & 0,03 & 0,06 & 0,05 & 0,08 & 0,03 & 0,07 & 0,05 & 0,05 \\
\hline 30 & 5 & B & $25-74$ & $0-50$ & 10 & 0,04 & 0,05 & 0,04 & 0,05 & 0,04 & 0,04 & 0,04 & 0,05 & 0,05 & 0,04 & 0,05 & 0,05 & 0,04 \\
\hline 30 & 5 & B & $25-74$ & $0-50$ & 50 & 0,05 & 0,06 & 0,07 & 0,05 & 0,08 & 0,03 & 0,05 & 0,06 & 0,08 & 0,03 & 0,07 & 0,05 & 0,06 \\
\hline 30 & 5 & B & $25-74$ & $50-100$ & 10 & 0,04 & 0,06 & 0,05 & 0,05 & 0,04 & 0,03 & 0,04 & 0,06 & 0,05 & 0,03 & 0,05 & 0,05 & 0,04 \\
\hline 30 & 5 & B & $25-74$ & $50-100$ & 50 & 0,05 & 0,06 & 0,08 & 0,06 & 0,08 & 0,03 & 0,05 & 0,06 & 0,07 & 0,03 & 0,07 & 0,05 & 0,06 \\
\hline 30 & 5 & B & $75-125$ & $0-50$ & 10 & 0,03 & 0,04 & 0,04 & 0,05 & 0,04 & 0,03 & 0,03 & 0,04 & 0,04 & 0,03 & 0,03 & 0,04 & 0,03 \\
\hline 30 & 5 & B & $75-125$ & $0-50$ & 50 & 0,05 & 0,04 & 0,06 & 0,05 & 0,06 & 0,02 & 0,04 & 0,04 & 0,06 & 0,02 & 0,05 & 0,04 & 0,04 \\
\hline 30 & 5 & B & $75-125$ & $50-100$ & 10 & 0,03 & 0,04 & 0,04 & 0,04 & 0,04 & 0,03 & 0,03 & 0,04 & 0,04 & 0,03 & 0,03 & 0,04 & 0,03 \\
\hline 30 & 5 & B & $75-125$ & $50-100$ & 50 & 0,03 & 0,04 & 0,05 & 0,04 & 0,05 & 0,03 & 0,04 & 0,04 & 0,05 & 0,03 & 0,04 & 0,04 & 0,04 \\
\hline 30 & 5 & M & $25-74$ & $0-50$ & 10 & 0,04 & 0,06 & 0,06 & 0,05 & 0,05 & 0,03 & 0,04 & 0,05 & 0,05 & 0,03 & 0,06 & 0,05 & 0,04 \\
\hline 30 & 5 & M & $25-74$ & $0-50$ & 50 & 0,05 & 0,06 & 0,07 & 0,06 & 0,08 & 0,03 & 0,05 & 0,06 & 0,07 & 0,03 & 0,07 & 0,06 & 0,06 \\
\hline 30 & 5 & M & $25-74$ & $50-100$ & 10 & 0,04 & 0,05 & 0,06 & 0,04 & 0,05 & 0,03 & 0,03 & 0,06 & 0,05 & 0,04 & 0,06 & 0,05 & 0,04 \\
\hline 30 & 5 & M & 25-74 & $50-100$ & 50 & 0,05 & 0,05 & 0,07 & 0,05 & 0,06 & 0,03 & 0,05 & 0,05 & 0,06 & 0,03 & 0,06 & 0,05 & 0,05 \\
\hline
\end{tabular}




\begin{tabular}{|c|c|c|c|c|c|c|c|c|c|c|c|c|c|c|c|c|c|c|}
\hline 30 & 5 & $\bar{M}$ & $75-125$ & $0-50$ & 10 & 0,03 & 0,04 & 0,04 & 0,04 & 0,04 & 0,02 & 0,03 & 0,04 & 0,04 & 0,02 & 0,03 & 0,03 & $\overline{0,03}$ \\
\hline 30 & 5 & M & $75-125$ & $0-50$ & 50 & 0,04 & 0,05 & 0,06 & 0,05 & 0,07 & 0,03 & 0,05 & 0,05 & 0,07 & 0,02 & 0,06 & 0,05 & 0,06 \\
\hline 30 & 5 & M & $75-125$ & $50-100$ & 10 & 0,03 & 0,04 & 0,04 & 0,03 & 0,03 & 0,02 & 0,03 & 0,04 & 0,03 & 0,02 & 0,03 & 0,03 & 0,03 \\
\hline 30 & 5 & M & $75-125$ & $50-100$ & 50 & 0,03 & 0,04 & 0,04 & 0,04 & 0,05 & 0,02 & 0,04 & 0,03 & 0,05 & 0,02 & 0,04 & 0,04 & 0,03 \\
\hline 30 & 5 & A & $25-74$ & $0-50$ & 10 & 0,05 & 0,07 & 0,07 & 0,05 & 0,07 & 0,04 & 0,05 & 0,06 & 0,06 & 0,04 & 0,07 & 0,05 & 0,05 \\
\hline 30 & 5 & A & $25-74$ & $0-50$ & 50 & 0,08 & 0,10 & 0,12 & 0,09 & 0,13 & 0,04 & 0,08 & 0,11 & 0,13 & 0,04 & 0,12 & 0,09 & 0,08 \\
\hline 30 & 5 & A & $25-74$ & $50-100$ & 10 & 0,05 & 0,06 & 0,08 & 0,05 & 0,07 & 0,04 & 0,05 & 0,06 & 0,07 & 0,04 & 0,07 & 0,05 & 0,04 \\
\hline 30 & 5 & A & $25-74$ & $50-100$ & 50 & 0,08 & 0,09 & 0,10 & 0,07 & 0,12 & 0,03 & 0,08 & 0,09 & 0,12 & 0,04 & 0,11 & 0,07 & 0,07 \\
\hline 30 & 5 & A & $75-125$ & $0-50$ & 10 & 0,04 & 0,05 & 0,05 & 0,05 & 0,05 & 0,03 & 0,04 & 0,05 & 0,06 & 0,03 & 0,05 & 0,04 & 0,05 \\
\hline 30 & 5 & A & $75-125$ & $0-50$ & 50 & 0,06 & 0,08 & 0,10 & 0,07 & 0,11 & 0,03 & 0,07 & 0,08 & 0,10 & 0,03 & 0,11 & 0,06 & 0,08 \\
\hline 30 & 5 & A & $75-125$ & $50-100$ & 10 & 0,03 & 0,05 & 0,05 & 0,04 & 0,05 & 0,04 & 0,03 & 0,05 & 0,05 & 0,03 & 0,04 & 0,04 & 0,04 \\
\hline 30 & 5 & A & $75-125$ & $50-100$ & 50 & 0,06 & 0,06 & 0,07 & 0,06 & 0,08 & 0,03 & 0,07 & 0,06 & 0,08 & 0,03 & 0,07 & 0,06 & 0,06 \\
\hline 30 & 7 & B & $25-74$ & $0-50$ & 10 & 0,03 & 0,05 & 0,04 & 0,05 & 0,04 & 0,04 & 0,03 & 0,05 & 0,04 & 0,04 & 0,04 & 0,05 & 0,04 \\
\hline 30 & 7 & B & $25-74$ & $0-50$ & 50 & 0,05 & 0,07 & 0,07 & 0,07 & 0,08 & 0,03 & 0,05 & 0,07 & 0,08 & 0,03 & 0,07 & 0,07 & 0,06 \\
\hline 30 & 7 & B & $25-74$ & $50-100$ & 10 & 0,04 & 0,06 & 0,05 & 0,06 & 0,05 & 0,04 & 0,04 & 0,05 & 0,04 & 0,04 & 0,05 & 0,05 & 0,04 \\
\hline 30 & 7 & B & $25-74$ & $50-100$ & 50 & 0,05 & 0,06 & 0,06 & 0,07 & 0,06 & 0,03 & 0,04 & 0,05 & 0,07 & 0,03 & 0,06 & 0,06 & 0,05 \\
\hline 30 & 7 & B & $75-125$ & $0-50$ & 10 & 0,03 & 0,04 & 0,04 & 0,04 & 0,04 & 0,03 & 0,03 & 0,04 & 0,04 & 0,03 & 0,04 & 0,04 & 0,03 \\
\hline 30 & 7 & B & $75-125$ & $0-50$ & 50 & 0,05 & 0,06 & 0,06 & 0,06 & 0,08 & 0,03 & 0,05 & 0,05 & 0,08 & 0,03 & 0,06 & 0,05 & 0,05 \\
\hline 30 & 7 & B & $75-125$ & $50-100$ & 10 & 0,03 & 0,04 & 0,03 & 0,04 & 0,03 & 0,03 & 0,03 & 0,04 & 0,04 & 0,03 & 0,03 & 0,04 & 0,03 \\
\hline 30 & 7 & B & $75-125$ & $50-100$ & 50 & 0,04 & 0,05 & 0,05 & 0,05 & 0,05 & 0,03 & 0,04 & 0,05 & 0,05 & 0,03 & 0,05 & 0,05 & 0,04 \\
\hline 30 & 7 & M & $25-74$ & $0-50$ & 10 & 0,03 & 0,06 & 0,05 & 0,05 & 0,05 & 0,03 & 0,04 & 0,05 & 0,05 & 0,03 & 0,05 & 0,05 & 0,04 \\
\hline 30 & 7 & M & $25-74$ & $0-50$ & 50 & 0,05 & 0,07 & 0,07 & 0,05 & 0,08 & 0,03 & 0,06 & 0,07 & 0,08 & 0,03 & 0,06 & 0,05 & 0,06 \\
\hline 30 & 7 & M & $25-74$ & $50-100$ & 10 & 0,03 & 0,05 & 0,04 & 0,04 & 0,04 & 0,04 & 0,03 & 0,05 & 0,04 & 0,03 & 0,04 & 0,04 & 0,04 \\
\hline 30 & 7 & M & $25-74$ & $50-100$ & 50 & 0,04 & 0,05 & 0,05 & 0,05 & 0,07 & 0,03 & 0,04 & 0,05 & 0,07 & 0,03 & 0,05 & 0,05 & 0,04 \\
\hline 30 & 7 & M & $75-125$ & $0-50$ & 10 & 0,03 & 0,05 & 0,04 & 0,03 & 0,04 & 0,03 & 0,03 & 0,04 & 0,04 & 0,03 & 0,04 & 0,03 & 0,03 \\
\hline 30 & 7 & M & $75-125$ & $0-50$ & 50 & 0,04 & 0,05 & 0,06 & 0,04 & 0,07 & 0,03 & 0,05 & 0,05 & 0,07 & 0,03 & 0,06 & 0,05 & 0,05 \\
\hline 30 & 7 & M & $75-125$ & $50-100$ & 10 & 0,03 & 0,04 & 0,03 & 0,03 & 0,04 & 0,03 & 0,03 & 0,04 & 0,04 & 0,02 & 0,03 & 0,03 & 0,03 \\
\hline 30 & 7 & M & $75-125$ & $50-100$ & 50 & 0,03 & 0,05 & 0,05 & 0,04 & 0,05 & 0,02 & 0,04 & 0,05 & 0,05 & 0,02 & 0,04 & 0,04 & 0,04 \\
\hline 30 & 7 & A & $25-74$ & $0-50$ & 10 & 0,05 & 0,05 & 0,05 & 0,05 & 0,07 & 0,04 & 0,05 & 0,05 & 0,06 & 0,04 & 0,06 & 0,05 & 0,05 \\
\hline 30 & 7 & A & 25-74 & $0-50$ & 50 & 0,09 & 0,08 & 0,10 & 0,08 & 0,11 & 0,04 & 0,08 & 0,08 & 0,11 & 0,04 & 0,09 & 0,08 & 0,09 \\
\hline 30 & 7 & A & $25-74$ & $50-100$ & 10 & 0,04 & 0,06 & 0,05 & 0,06 & 0,06 & 0,04 & 0,05 & 0,05 & 0,06 & 0,04 & 0,05 & 0,05 & 0,05 \\
\hline 30 & 7 & A & $25-74$ & $50-100$ & 50 & 0,08 & 0,07 & 0,10 & 0,07 & 0,11 & 0,04 & 0,08 & 0,08 & 0,10 & 0,04 & 0,10 & 0,07 & 0,09 \\
\hline 30 & 7 & A & $75-125$ & $0-50$ & 10 & 0,04 & 0,05 & 0,05 & 0,05 & 0,05 & 0,03 & 0,04 & 0,05 & 0,05 & 0,03 & 0,05 & 0,04 & 0,04 \\
\hline 30 & 7 & A & $75-125$ & $0-50$ & 50 & 0,07 & 0,08 & 0,09 & 0,07 & 0,10 & 0,04 & 0,07 & 0,09 & 0,10 & 0,03 & 0,09 & 0,07 & 0,07 \\
\hline 30 & 7 & A & $75-125$ & $50-100$ & 10 & 0,04 & 0,04 & 0,05 & 0,05 & 0,05 & 0,03 & 0,04 & 0,05 & 0,05 & 0,03 & 0,04 & 0,04 & 0,04 \\
\hline 30 & 7 & A & $75-125$ & $50-100$ & 50 & 0,05 & 0,05 & 0,07 & 0,06 & 0,07 & 0,04 & 0,06 & 0,06 & 0,08 & 0,04 & 0,07 & 0,06 & 0,05 \\
\hline 50 & 3 & B & $25-74$ & $0-50$ & 10 & 0,02 & 0,05 & 0,06 & 0,05 & 0,03 & 0,02 & 0,03 & 0,05 & 0,03 & 0,02 & 0,06 & 0,04 & 0,03 \\
\hline 50 & 3 & B & $25-74$ & $0-50$ & 50 & 0,03 & 0,04 & 0,04 & 0,03 & 0,04 & 0,02 & 0,03 & 0,03 & 0,04 & 0,02 & 0,04 & 0,03 & 0,03 \\
\hline 50 & 3 & B & $25-74$ & $50-100$ & 10 & 0,02 & 0,05 & 0,06 & 0,05 & 0,03 & 0,02 & 0,02 & 0,05 & 0,03 & 0,02 & 0,06 & 0,04 & 0,03 \\
\hline 50 & 3 & B & $25-74$ & $50-100$ & 50 & 0,03 & 0,03 & 0,04 & 0,03 & 0,04 & 0,02 & 0,02 & 0,03 & 0,04 & 0,02 & 0,04 & 0,03 & 0,03 \\
\hline 50 & 3 & B & $75-125$ & $0-50$ & 10 & 0,02 & 0,04 & 0,04 & 0,03 & 0,03 & 0,02 & 0,02 & 0,04 & 0,03 & 0,02 & 0,04 & 0,03 & 0,02 \\
\hline 50 & 3 & B & $75-125$ & $0-50$ & 50 & 0,02 & 0,02 & 0,04 & 0,02 & 0,04 & 0,01 & 0,02 & 0,02 & 0,04 & 0,01 & 0,04 & 0,02 & 0,02 \\
\hline 50 & 3 & B & $75-125$ & $50-100$ & 10 & 0,02 & 0,04 & 0,04 & 0,03 & 0,03 & 0,02 & 0,02 & 0,04 & 0,03 & 0,01 & 0,03 & 0,03 & 0,02 \\
\hline 50 & 3 & B & $75-125$ & $50-100$ & 50 & 0,02 & 0,02 & 0,04 & 0,02 & 0,03 & 0,01 & 0,02 & 0,02 & 0,03 & 0,01 & 0,03 & 0,02 & 0,02 \\
\hline 50 & 3 & M & $25-74$ & $0-50$ & 10 & 0,03 & 0,03 & 0,03 & 0,02 & 0,03 & 0,02 & 0,03 & 0,03 & 0,03 & 0,02 & 0,03 & 0,02 & 0,02 \\
\hline 50 & 3 & M & $25-74$ & $0-50$ & 50 & 0,03 & 0,04 & 0,04 & 0,03 & 0,04 & 0,02 & 0,03 & 0,04 & 0,04 & 0,03 & 0,04 & 0,03 & 0,03 \\
\hline 50 & 3 & M & 25-74 & $50-100$ & 10 & 0,02 & 0,02 & 0,03 & 0,02 & 0,03 & 0,02 & 0,03 & 0,03 & 0,03 & 0,02 & 0,03 & 0,02 & 0,02 \\
\hline 50 & 3 & M & $25-74$ & $50-100$ & 50 & 0,03 & 0,03 & 0,03 & 0,02 & 0,04 & 0,02 & 0,03 & 0,03 & 0,03 & 0,02 & 0,03 & 0,02 & 0,03 \\
\hline 50 & 3 & M & $75-125$ & $0-50$ & 10 & 0,02 & 0,02 & 0,02 & 0,01 & 0,02 & 0,01 & 0,02 & 0,02 & 0,02 & 0,01 & 0,02 & 0,02 & 0,02 \\
\hline 50 & 3 & M & $75-125$ & $0-50$ & 50 & 0,02 & 0,02 & 0,03 & 0,02 & 0,03 & 0,01 & 0,02 & 0,03 & 0,03 & 0,01 & 0,03 & 0,02 & 0,02 \\
\hline 50 & 3 & M & $75-125$ & $50-100$ & 10 & 0,02 & 0,02 & 0,02 & 0,02 & 0,02 & 0,01 & 0,02 & 0,02 & 0,02 & 0,01 & 0,02 & 0,02 & 0,02 \\
\hline 50 & 3 & M & $75-125$ & $50-100$ & 50 & 0,02 & 0,02 & 0,02 & 0,02 & 0,02 & 0,01 & 0,02 & 0,02 & 0,03 & 0,01 & 0,02 & 0,02 & 0,02 \\
\hline 50 & 3 & A & $25-74$ & $0-50$ & 10 & 0,04 & 0,05 & 0,06 & 0,06 & 0,05 & 0,02 & 0,04 & 0,05 & 0,05 & 0,02 & 0,06 & 0,05 & 0,04 \\
\hline 50 & 3 & A & $25-74$ & $0-50$ & 50 & 0,06 & 0,06 & 0,07 & 0,05 & 0,09 & 0,03 & 0,06 & 0,07 & 0,08 & 0,03 & 0,08 & 0,05 & 0,06 \\
\hline 50 & 3 & A & $25-74$ & $50-100$ & 10 & 0,03 & 0,04 & 0,06 & 0,05 & 0,04 & 0,03 & 0,03 & 0,05 & 0,04 & 0,03 & 0,06 & 0,06 & 0,04 \\
\hline 50 & 3 & A & $25-74$ & $50-100$ & 50 & 0,05 & 0,05 & 0,08 & 0,05 & 0,07 & 0,02 & 0,05 & 0,06 & 0,07 & 0,03 & 0,07 & 0,04 & 0,05 \\
\hline 50 & 3 & A & $75-125$ & $0-50$ & 10 & 0,03 & 0,04 & 0,05 & 0,04 & 0,04 & 0,02 & 0,03 & 0,04 & 0,04 & 0,02 & 0,05 & 0,03 & 0,04 \\
\hline 50 & 3 & A & $75-125$ & $0-50$ & 50 & 0,05 & 0,05 & 0,08 & 0,04 & 0,08 & 0,02 & 0,05 & 0,05 & 0,08 & 0,02 & 0,09 & 0,04 & 0,06 \\
\hline 50 & 3 & A & $75-125$ & $50-100$ & 10 & 0,03 & 0,04 & 0,04 & 0,04 & 0,04 & 0,02 & 0,02 & 0,04 & 0,04 & 0,02 & 0,04 & 0,04 & 0,03 \\
\hline 50 & 3 & A & $75-125$ & $50-100$ & 50 & 0,04 & 0,04 & 0,06 & 0,03 & 0,05 & 0,02 & 0,04 & 0,03 & 0,06 & 0,02 & 0,05 & 0,03 & 0,03 \\
\hline 50 & 5 & B & $25-74$ & $0-50$ & 10 & 0,03 & 0,05 & 0,04 & 0,05 & 0,03 & 0,03 & 0,03 & 0,05 & 0,03 & 0,03 & 0,05 & 0,05 & 0,03 \\
\hline 50 & 5 & B & $25-74$ & $0-50$ & 50 & 0,04 & 0,04 & 0,05 & 0,04 & 0,05 & 0,02 & 0,04 & 0,04 & 0,05 & 0,02 & 0,05 & 0,04 & 0,04 \\
\hline
\end{tabular}




\begin{tabular}{|c|c|c|c|c|c|c|c|c|c|c|c|c|c|c|c|c|c|c|}
\hline$\overline{50}$ & 5 & B & $25-74$ & $50-100$ & 10 & 0,03 & 0,05 & 0,04 & 0,05 & 0,04 & 0,02 & 0,03 & 0,05 & 0,04 & 0,03 & 0,05 & 0,05 & $\overline{0,03}$ \\
\hline 50 & 5 & B & $25-74$ & $50-100$ & 50 & 0,03 & 0,04 & 0,04 & 0,04 & 0,05 & 0,02 & 0,03 & 0,04 & 0,05 & 0,02 & 0,04 & 0,04 & 0,03 \\
\hline 50 & 5 & B & $75-125$ & $0-50$ & 10 & 0,02 & 0,04 & 0,04 & 0,04 & 0,03 & 0,02 & 0,02 & 0,04 & 0,03 & 0,02 & 0,03 & 0,04 & 0,02 \\
\hline 50 & 5 & B & $75-125$ & $0-50$ & 50 & 0,03 & 0,03 & 0,04 & 0,04 & 0,05 & 0,02 & 0,03 & 0,03 & 0,05 & 0,02 & 0,04 & 0,04 & 0,03 \\
\hline 50 & 5 & B & $75-125$ & $50-100$ & 10 & 0,02 & 0,04 & 0,04 & 0,05 & 0,03 & 0,02 & 0,02 & 0,04 & 0,03 & 0,02 & 0,03 & 0,04 & 0,02 \\
\hline 50 & 5 & B & $75-125$ & $50-100$ & 50 & 0,02 & 0,03 & 0,04 & 0,03 & 0,03 & 0,02 & 0,02 & 0,03 & 0,03 & 0,02 & 0,03 & 0,03 & 0,03 \\
\hline 50 & 5 & M & $25-74$ & $0-50$ & 10 & 0,03 & 0,05 & 0,04 & 0,05 & 0,03 & 0,02 & 0,03 & 0,04 & 0,03 & 0,02 & 0,04 & 0,04 & 0,03 \\
\hline 50 & 5 & M & $25-74$ & $0-50$ & 50 & 0,03 & 0,05 & 0,05 & 0,03 & 0,05 & 0,03 & 0,04 & 0,05 & 0,05 & 0,02 & 0,04 & 0,04 & 0,03 \\
\hline 50 & 5 & M & $25-74$ & $50-100$ & 10 & 0,02 & 0,05 & 0,05 & 0,04 & 0,03 & 0,03 & 0,02 & 0,05 & 0,03 & 0,03 & 0,05 & 0,04 & 0,03 \\
\hline 50 & 5 & M & $25-74$ & $50-100$ & 50 & 0,03 & 0,03 & 0,04 & 0,03 & 0,04 & 0,03 & 0,03 & 0,04 & 0,04 & 0,03 & 0,04 & 0,03 & 0,03 \\
\hline 50 & 5 & M & $75-125$ & $0-50$ & 10 & 0,02 & 0,03 & 0,03 & 0,03 & 0,03 & 0,02 & 0,02 & 0,03 & 0,03 & 0,02 & 0,03 & 0,03 & 0,02 \\
\hline 50 & 5 & M & $75-125$ & $0-50$ & 50 & 0,03 & 0,04 & 0,04 & 0,03 & 0,05 & 0,02 & 0,03 & 0,04 & 0,05 & 0,02 & 0,04 & 0,03 & 0,03 \\
\hline 50 & 5 & M & $75-125$ & $50-100$ & 10 & 0,02 & 0,03 & 0,03 & 0,03 & 0,02 & 0,02 & 0,02 & 0,03 & 0,03 & 0,02 & 0,02 & 0,03 & 0,02 \\
\hline 50 & 5 & M & $75-125$ & $50-100$ & 50 & 0,03 & 0,03 & 0,03 & 0,02 & 0,03 & 0,01 & 0,03 & 0,03 & 0,03 & 0,01 & 0,03 & 0,02 & 0,03 \\
\hline 50 & 5 & A & $25-74$ & $0-50$ & 10 & 0,04 & 0,06 & 0,06 & 0,05 & 0,05 & 0,03 & 0,04 & 0,06 & 0,04 & 0,03 & 0,06 & 0,05 & 0,04 \\
\hline 50 & 5 & A & $25-74$ & $0-50$ & 50 & 0,07 & 0,07 & 0,09 & 0,07 & 0,09 & 0,02 & 0,07 & 0,07 & 0,09 & 0,03 & 0,09 & 0,07 & 0,06 \\
\hline 50 & 5 & A & $25-74$ & $50-100$ & 10 & 0,04 & 0,05 & 0,06 & 0,05 & 0,05 & 0,03 & 0,04 & 0,05 & 0,05 & 0,03 & 0,05 & 0,05 & 0,04 \\
\hline 50 & 5 & A & $25-74$ & $50-100$ & 50 & 0,06 & 0,06 & 0,08 & 0,06 & 0,07 & 0,03 & 0,06 & 0,06 & 0,08 & 0,02 & 0,08 & 0,05 & 0,06 \\
\hline 50 & 5 & A & $75-125$ & $0-50$ & 10 & 0,03 & 0,04 & 0,04 & 0,04 & 0,04 & 0,02 & 0,03 & 0,04 & 0,03 & 0,02 & 0,04 & 0,04 & 0,04 \\
\hline 50 & 5 & A & $75-125$ & $0-50$ & 50 & 0,05 & 0,05 & 0,07 & 0,05 & 0,08 & 0,02 & 0,05 & 0,05 & 0,08 & 0,02 & 0,07 & 0,05 & 0,06 \\
\hline 50 & 5 & A & $75-125$ & 50-100 & 10 & 0,02 & 0,03 & 0,04 & 0,04 & 0,03 & 0,02 & 0,02 & 0,03 & 0,04 & 0,02 & 0,03 & 0,03 & 0,03 \\
\hline 50 & 5 & A & $75-125$ & $50-100$ & 50 & 0,05 & 0,03 & 0,06 & 0,04 & 0,06 & 0,02 & 0,04 & 0,04 & 0,06 & 0,02 & 0,07 & 0,05 & 0,04 \\
\hline 50 & 7 & B & $25-74$ & $0-50$ & 10 & 0,03 & 0,05 & 0,04 & 0,05 & 0,04 & 0,02 & 0,02 & 0,05 & 0,03 & 0,03 & 0,04 & 0,05 & 0,03 \\
\hline 50 & 7 & B & $25-74$ & $0-50$ & 50 & 0,04 & 0,04 & 0,04 & 0,05 & 0,06 & 0,03 & 0,04 & 0,05 & 0,05 & 0,03 & 0,04 & 0,05 & 0,04 \\
\hline 50 & 7 & B & $25-74$ & $50-100$ & 10 & 0,03 & 0,05 & 0,04 & 0,05 & 0,03 & 0,03 & 0,03 & 0,05 & 0,03 & 0,03 & 0,04 & 0,06 & 0,03 \\
\hline 50 & 7 & B & $25-74$ & $50-100$ & 50 & 0,04 & 0,04 & 0,05 & 0,04 & 0,05 & 0,03 & 0,03 & 0,04 & 0,05 & 0,03 & 0,05 & 0,05 & 0,04 \\
\hline 50 & 7 & B & $75-125$ & $0-50$ & 10 & 0,02 & 0,04 & 0,03 & 0,04 & 0,03 & 0,02 & 0,02 & 0,04 & 0,03 & 0,02 & 0,03 & 0,03 & 0,03 \\
\hline 50 & 7 & B & $75-125$ & $0-50$ & 50 & 0,03 & 0,03 & 0,03 & 0,04 & 0,05 & 0,02 & 0,03 & 0,03 & 0,05 & 0,03 & 0,04 & 0,04 & 0,03 \\
\hline 50 & 7 & B & $75-125$ & $50-100$ & 10 & 0,02 & 0,03 & 0,03 & 0,04 & 0,03 & 0,02 & 0,02 & 0,03 & 0,03 & 0,02 & 0,03 & 0,04 & 0,02 \\
\hline 50 & 7 & B & $75-125$ & $50-100$ & 50 & 0,03 & 0,03 & 0,04 & 0,05 & 0,04 & 0,02 & 0,03 & 0,04 & 0,04 & 0,02 & 0,04 & 0,04 & 0,03 \\
\hline 50 & 7 & M & $25-74$ & $0-50$ & 10 & 0,03 & 0,04 & 0,04 & 0,04 & 0,04 & 0,02 & 0,03 & 0,05 & 0,04 & 0,03 & 0,04 & 0,04 & 0,03 \\
\hline 50 & 7 & M & $25-74$ & $0-50$ & 50 & 0,05 & 0,05 & 0,05 & 0,04 & 0,05 & 0,03 & 0,05 & 0,04 & 0,06 & 0,03 & 0,05 & 0,04 & 0,05 \\
\hline 50 & 7 & M & $25-74$ & $50-100$ & 10 & 0,03 & 0,05 & 0,03 & 0,04 & 0,03 & 0,02 & 0,03 & 0,04 & 0,04 & 0,02 & 0,03 & 0,04 & 0,03 \\
\hline 50 & 7 & M & $25-74$ & $50-100$ & 50 & 0,03 & 0,04 & 0,04 & 0,03 & 0,05 & 0,02 & 0,04 & 0,03 & 0,05 & 0,03 & 0,04 & 0,03 & 0,03 \\
\hline 50 & 7 & M & $75-125$ & $0-50$ & 10 & 0,02 & 0,03 & 0,03 & 0,03 & 0,03 & 0,02 & 0,02 & 0,03 & 0,03 & 0,02 & 0,03 & 0,03 & 0,03 \\
\hline 50 & 7 & M & $75-125$ & $0-50$ & 50 & 0,03 & 0,03 & 0,04 & 0,04 & 0,05 & 0,02 & 0,03 & 0,03 & 0,05 & 0,02 & 0,04 & 0,03 & 0,03 \\
\hline 50 & 7 & M & $75-125$ & $50-100$ & 10 & 0,02 & 0,03 & 0,03 & 0,03 & 0,03 & 0,02 & 0,02 & 0,03 & 0,03 & 0,02 & 0,02 & 0,02 & 0,02 \\
\hline 50 & 7 & M & $75-125$ & $50-100$ & 50 & 0,02 & 0,03 & 0,03 & 0,02 & 0,03 & 0,02 & 0,03 & 0,03 & 0,03 & 0,02 & 0,03 & 0,02 & 0,03 \\
\hline 50 & 7 & A & $25-74$ & $0-50$ & 10 & 0,04 & 0,04 & 0,04 & 0,05 & 0,05 & 0,03 & 0,04 & 0,04 & 0,04 & 0,03 & 0,04 & 0,04 & 0,04 \\
\hline 50 & 7 & A & $25-74$ & $0-50$ & 50 & 0,07 & 0,08 & 0,09 & 0,07 & 0,09 & 0,03 & 0,07 & 0,07 & 0,09 & 0,03 & 0,08 & 0,06 & 0,06 \\
\hline 50 & 7 & A & $25-74$ & $50-100$ & 10 & 0,03 & 0,05 & 0,05 & 0,05 & 0,05 & 0,03 & 0,03 & 0,05 & 0,04 & 0,03 & 0,05 & 0,05 & 0,04 \\
\hline 50 & 7 & A & $25-74$ & $50-100$ & 50 & 0,06 & 0,06 & 0,07 & 0,05 & 0,08 & 0,03 & 0,06 & 0,05 & 0,08 & 0,03 & 0,07 & 0,05 & 0,07 \\
\hline 50 & 7 & A & $75-125$ & $0-50$ & 10 & 0,03 & 0,04 & 0,04 & 0,04 & 0,04 & 0,02 & 0,03 & 0,04 & 0,04 & 0,02 & 0,04 & 0,04 & 0,03 \\
\hline 50 & 7 & A & $75-125$ & $0-50$ & 50 & 0,06 & 0,06 & 0,07 & 0,05 & 0,08 & 0,02 & 0,06 & 0,06 & 0,08 & 0,02 & 0,07 & 0,05 & 0,07 \\
\hline 50 & 7 & A & $75-125$ & $50-100$ & 10 & 0,03 & 0,03 & 0,03 & 0,04 & 0,03 & 0,02 & 0,03 & 0,03 & 0,03 & 0,02 & 0,03 & 0,03 & 0,02 \\
\hline 50 & 7 & A & $75-125$ & $50-100$ & 50 & 0,04 & 0,04 & 0,04 & 0,04 & 0,05 & 0,02 & 0,04 & 0,03 & 0,06 & 0,02 & 0,04 & 0,04 & 0,04 \\
\hline 80 & 3 & B & $25-74$ & $0-50$ & 10 & 0,02 & 0,05 & 0,05 & 0,04 & 0,03 & 0,02 & 0,02 & 0,05 & 0,02 & 0,02 & 0,05 & 0,04 & 0,02 \\
\hline 80 & 3 & B & $25-74$ & $0-50$ & 50 & 0,02 & 0,03 & 0,04 & 0,02 & 0,03 & 0,02 & 0,02 & 0,02 & 0,03 & 0,02 & 0,04 & 0,02 & 0,02 \\
\hline 80 & 3 & B & $25-74$ & $50-100$ & 10 & 0,02 & 0,04 & 0,05 & 0,04 & 0,02 & 0,02 & 0,02 & 0,04 & 0,02 & 0,02 & 0,05 & 0,04 & 0,02 \\
\hline 80 & 3 & B & $25-74$ & $50-100$ & 50 & 0,02 & 0,03 & 0,03 & 0,02 & 0,03 & 0,02 & 0,02 & 0,03 & 0,03 & 0,02 & 0,03 & 0,02 & 0,02 \\
\hline 80 & 3 & B & $75-125$ & $0-50$ & 10 & 0,01 & 0,03 & 0,04 & 0,03 & 0,02 & 0,02 & 0,01 & 0,03 & 0,02 & 0,01 & 0,03 & 0,03 & 0,02 \\
\hline 80 & 3 & B & $75-125$ & $0-50$ & 50 & 0,02 & 0,02 & 0,03 & 0,01 & 0,03 & 0,01 & 0,02 & 0,02 & 0,03 & 0,01 & 0,03 & 0,01 & 0,02 \\
\hline 80 & 3 & B & $75-125$ & $50-100$ & 10 & 0,01 & 0,03 & 0,03 & 0,03 & 0,02 & 0,01 & 0,01 & 0,03 & 0,02 & 0,01 & 0,03 & 0,03 & 0,01 \\
\hline 80 & 3 & B & $75-125$ & $50-100$ & 50 & 0,02 & 0,02 & 0,03 & 0,01 & 0,03 & 0,01 & 0,02 & 0,02 & 0,03 & 0,01 & 0,03 & 0,01 & 0,02 \\
\hline 80 & 3 & M & $25-74$ & $0-50$ & 10 & 0,02 & 0,02 & 0,02 & 0,02 & 0,02 & 0,02 & 0,02 & 0,02 & 0,02 & 0,02 & 0,02 & 0,02 & 0,02 \\
\hline 80 & 3 & M & $25-74$ & $0-50$ & 50 & 0,02 & 0,02 & 0,03 & 0,02 & 0,03 & 0,02 & 0,02 & 0,02 & 0,03 & 0,02 & 0,03 & 0,02 & 0,03 \\
\hline 80 & 3 & M & $25-74$ & $50-100$ & 10 & 0,02 & 0,02 & 0,02 & 0,02 & 0,02 & 0,02 & 0,02 & 0,02 & 0,02 & 0,02 & 0,02 & 0,02 & 0,02 \\
\hline 80 & 3 & M & $25-74$ & $50-100$ & 50 & 0,02 & 0,02 & 0,03 & 0,02 & 0,03 & 0,02 & 0,02 & 0,02 & 0,03 & 0,02 & 0,03 & 0,02 & 0,02 \\
\hline 80 & 3 & M & $75-125$ & $0-50$ & 10 & 0,01 & 0,01 & 0,01 & 0,01 & 0,01 & 0,01 & 0,01 & 0,01 & 0,01 & 0,01 & 0,01 & 0,01 & 0,01 \\
\hline 80 & 3 & M & $75-125$ & $0-50$ & 50 & 0,02 & 0,02 & 0,02 & 0,01 & 0,02 & 0,01 & 0,01 & 0,02 & 0,02 & 0,01 & 0,02 & 0,01 & 0,02 \\
\hline 80 & 3 & M & $75-125$ & $50-100$ & 10 & 0,01 & 0,01 & 0,01 & 0,01 & 0,01 & 0,01 & 0,01 & 0,01 & 0,01 & 0,01 & 0,01 & 0,01 & 0,01 \\
\hline 80 & 3 & M & $75-125$ & $50-100$ & 50 & 0,02 & 0,01 & 0,02 & 0,01 & 0,02 & 0,01 & 0,01 & 0,01 & 0,02 & 0,01 & 0,02 & 0,01 & 0,02 \\
\hline
\end{tabular}




\begin{tabular}{|c|c|c|c|c|c|c|c|c|c|c|c|c|c|c|c|c|c|c|}
\hline 80 & 3 & $\bar{A}$ & $25-74$ & $0-50$ & 10 & 0,03 & 0,05 & 0,05 & 0,05 & 0,04 & 0,02 & 0,03 & 0,05 & 0,04 & 0,01 & 0,06 & 0,04 & $\overline{0,03}$ \\
\hline 80 & 3 & A & $25-74$ & $0-50$ & 50 & 0,04 & 0,04 & 0,07 & 0,03 & 0,06 & 0,02 & 0,04 & 0,04 & 0,06 & 0,02 & 0,07 & 0,04 & 0,04 \\
\hline 80 & 3 & A & $25-74$ & $50-100$ & 10 & 0,02 & 0,05 & 0,05 & 0,05 & 0,04 & 0,02 & 0,03 & 0,05 & 0,04 & 0,02 & 0,05 & 0,05 & 0,03 \\
\hline 80 & 3 & A & $25-74$ & $50-100$ & 50 & 0,03 & 0,04 & 0,06 & 0,02 & 0,06 & 0,02 & 0,04 & 0,04 & 0,05 & 0,02 & 0,05 & 0,03 & 0,04 \\
\hline 80 & 3 & A & $75-125$ & $0-50$ & 10 & 0,02 & 0,04 & 0,05 & 0,04 & 0,03 & 0,02 & 0,02 & 0,04 & 0,03 & 0,02 & 0,04 & 0,03 & 0,03 \\
\hline 80 & 3 & A & $75-125$ & $0-50$ & 50 & 0,03 & 0,04 & 0,06 & 0,03 & 0,06 & 0,01 & 0,04 & 0,04 & 0,06 & 0,01 & 0,06 & 0,03 & 0,03 \\
\hline 80 & 3 & A & $75-125$ & $50-100$ & 10 & 0,02 & 0,03 & 0,03 & 0,03 & 0,02 & 0,01 & 0,02 & 0,03 & 0,02 & 0,01 & 0,03 & 0,03 & 0,02 \\
\hline 80 & 3 & A & $75-125$ & $50-100$ & 50 & 0,03 & 0,02 & 0,04 & 0,02 & 0,04 & 0,01 & 0,03 & 0,02 & 0,04 & 0,01 & 0,04 & 0,02 & 0,03 \\
\hline 80 & 5 & B & $25-74$ & $0-50$ & 10 & 0,02 & 0,04 & 0,05 & 0,06 & 0,03 & 0,02 & 0,02 & 0,04 & 0,03 & 0,02 & 0,04 & 0,06 & 0,02 \\
\hline 80 & 5 & B & $25-74$ & $0-50$ & 50 & 0,03 & 0,03 & 0,04 & 0,03 & 0,03 & 0,02 & 0,03 & 0,03 & 0,03 & 0,02 & 0,03 & 0,03 & 0,03 \\
\hline 80 & 5 & B & $25-74$ & $50-100$ & 10 & 0,03 & 0,05 & 0,04 & 0,05 & 0,03 & 0,02 & 0,02 & 0,05 & 0,02 & 0,02 & 0,04 & 0,05 & 0,02 \\
\hline 80 & 5 & B & $25-74$ & $50-100$ & 50 & 0,02 & 0,04 & 0,04 & 0,03 & 0,03 & 0,02 & 0,03 & 0,04 & 0,03 & 0,02 & 0,04 & 0,03 & 0,03 \\
\hline 80 & 5 & B & $75-125$ & $0-50$ & 10 & 0,01 & 0,03 & 0,03 & 0,04 & 0,02 & 0,02 & 0,02 & 0,03 & 0,02 & 0,02 & 0,03 & 0,03 & 0,02 \\
\hline 80 & 5 & B & $75-125$ & $0-50$ & 50 & 0,02 & 0,02 & 0,03 & 0,03 & 0,03 & 0,01 & 0,02 & 0,03 & 0,03 & 0,01 & 0,03 & 0,03 & 0,02 \\
\hline 80 & 5 & B & $75-125$ & $50-100$ & 10 & 0,02 & 0,04 & 0,03 & 0,05 & 0,02 & 0,02 & 0,02 & 0,03 & 0,02 & 0,02 & 0,03 & 0,04 & 0,02 \\
\hline 80 & 5 & B & $75-125$ & $50-100$ & 50 & 0,02 & 0,02 & 0,03 & 0,02 & 0,03 & 0,01 & 0,02 & 0,02 & 0,03 & 0,01 & 0,03 & 0,02 & 0,02 \\
\hline 80 & 5 & M & $25-74$ & $0-50$ & 10 & 0,02 & 0,05 & 0,03 & 0,04 & 0,03 & 0,02 & 0,02 & 0,04 & 0,03 & 0,02 & 0,03 & 0,04 & 0,02 \\
\hline 80 & 5 & M & $25-74$ & $0-50$ & 50 & 0,02 & 0,03 & 0,03 & 0,03 & 0,04 & 0,02 & 0,02 & 0,04 & 0,03 & 0,02 & 0,03 & 0,03 & 0,03 \\
\hline 80 & 5 & M & $25-74$ & $50-100$ & 10 & 0,02 & 0,04 & 0,04 & 0,04 & 0,02 & 0,02 & 0,02 & 0,04 & 0,02 & 0,02 & 0,04 & 0,04 & 0,02 \\
\hline 80 & 5 & M & $25-74$ & $50-100$ & 50 & 0,03 & 0,03 & 0,03 & 0,02 & 0,03 & 0,02 & 0,02 & 0,02 & 0,03 & 0,02 & 0,03 & 0,02 & 0,03 \\
\hline 80 & 5 & M & $75-125$ & $0-50$ & 10 & 0,02 & 0,03 & 0,02 & 0,03 & 0,02 & 0,01 & 0,02 & 0,03 & 0,02 & 0,01 & 0,02 & 0,03 & 0,01 \\
\hline 80 & 5 & M & $75-125$ & $0-50$ & 50 & 0,02 & 0,02 & 0,03 & 0,02 & 0,03 & 0,01 & 0,02 & 0,02 & 0,03 & 0,01 & 0,03 & 0,02 & 0,02 \\
\hline 80 & 5 & M & $75-125$ & $50-100$ & 10 & 0,01 & 0,03 & 0,03 & 0,02 & 0,02 & 0,02 & 0,01 & 0,03 & 0,02 & 0,01 & 0,02 & 0,02 & 0,02 \\
\hline 80 & 5 & M & $75-125$ & $50-100$ & 50 & 0,02 & 0,02 & 0,02 & 0,01 & 0,02 & 0,01 & 0,02 & 0,02 & 0,02 & 0,01 & 0,02 & 0,01 & 0,02 \\
\hline 80 & 5 & A & $25-74$ & $0-50$ & 10 & 0,03 & 0,05 & 0,04 & 0,05 & 0,03 & 0,02 & 0,02 & 0,05 & 0,03 & 0,02 & 0,04 & 0,05 & 0,03 \\
\hline 80 & 5 & A & $25-74$ & $0-50$ & 50 & 0,05 & 0,05 & 0,05 & 0,04 & 0,06 & 0,02 & 0,05 & 0,05 & 0,06 & 0,02 & 0,05 & 0,04 & 0,04 \\
\hline 80 & 5 & A & $25-74$ & $50-100$ & 10 & 0,03 & 0,05 & 0,05 & 0,05 & 0,04 & 0,02 & 0,03 & 0,05 & 0,04 & 0,02 & 0,05 & 0,05 & 0,03 \\
\hline 80 & 5 & A & 25-74 & $50-100$ & 50 & 0,04 & 0,04 & 0,06 & 0,04 & 0,05 & 0,02 & 0,04 & 0,04 & 0,05 & 0,02 & 0,05 & 0,04 & 0,03 \\
\hline 80 & 5 & A & $75-125$ & $0-50$ & 10 & 0,02 & 0,03 & 0,04 & 0,03 & 0,03 & 0,01 & 0,02 & 0,03 & 0,03 & 0,01 & 0,03 & 0,03 & 0,02 \\
\hline 80 & 5 & A & $75-125$ & $0-50$ & 50 & 0,04 & 0,04 & 0,05 & 0,03 & 0,06 & 0,02 & 0,04 & 0,04 & 0,06 & 0,02 & 0,05 & 0,04 & 0,04 \\
\hline 80 & 5 & A & $75-125$ & $50-100$ & 10 & 0,02 & 0,03 & 0,03 & 0,03 & 0,03 & 0,01 & 0,02 & 0,03 & 0,03 & 0,01 & 0,02 & 0,03 & 0,02 \\
\hline 80 & 5 & A & $75-125$ & $50-100$ & 50 & 0,03 & 0,03 & 0,05 & 0,03 & 0,04 & 0,01 & 0,03 & 0,03 & 0,05 & 0,01 & 0,04 & 0,03 & 0,03 \\
\hline 80 & 7 & B & $25-74$ & $0-50$ & 10 & 0,02 & 0,04 & 0,03 & 0,05 & 0,03 & 0,02 & 0,02 & 0,04 & 0,02 & 0,02 & 0,03 & 0,05 & 0,03 \\
\hline 80 & 7 & B & $25-74$ & $0-50$ & 50 & 0,03 & 0,03 & 0,04 & 0,04 & 0,04 & 0,02 & 0,02 & 0,03 & 0,04 & 0,02 & 0,03 & 0,04 & 0,03 \\
\hline 80 & 7 & B & $25-74$ & $50-100$ & 10 & 0,02 & 0,05 & 0,04 & 0,05 & 0,03 & 0,02 & 0,02 & 0,05 & 0,03 & 0,02 & 0,03 & 0,05 & 0,02 \\
\hline 80 & 7 & B & $25-74$ & $50-100$ & 50 & 0,03 & 0,04 & 0,04 & 0,04 & 0,04 & 0,02 & 0,03 & 0,03 & 0,04 & 0,02 & 0,04 & 0,04 & 0,03 \\
\hline 80 & 7 & B & $75-125$ & $0-50$ & 10 & 0,02 & 0,03 & 0,02 & 0,04 & 0,02 & 0,02 & 0,02 & 0,03 & 0,02 & 0,02 & 0,02 & 0,03 & 0,02 \\
\hline 80 & 7 & B & $75-125$ & $0-50$ & 50 & 0,02 & 0,03 & 0,04 & 0,04 & 0,04 & 0,02 & 0,02 & 0,03 & 0,04 & 0,02 & 0,03 & 0,04 & 0,03 \\
\hline 80 & 7 & B & $75-125$ & $50-100$ & 10 & 0,02 & 0,03 & 0,03 & 0,04 & 0,02 & 0,02 & 0,02 & 0,03 & 0,02 & 0,02 & 0,03 & 0,04 & 0,02 \\
\hline 80 & 7 & B & $75-125$ & $50-100$ & 50 & 0,02 & 0,02 & 0,03 & 0,03 & 0,03 & 0,02 & 0,02 & 0,03 & 0,03 & 0,02 & 0,03 & 0,04 & 0,02 \\
\hline 80 & 7 & M & $25-74$ & $0-50$ & 10 & 0,02 & 0,04 & 0,03 & 0,04 & 0,02 & 0,02 & 0,02 & 0,04 & 0,02 & 0,02 & 0,03 & 0,03 & 0,02 \\
\hline 80 & 7 & M & $25-74$ & $0-50$ & 50 & 0,02 & 0,03 & 0,03 & 0,03 & 0,04 & 0,02 & 0,03 & 0,03 & 0,03 & 0,02 & 0,04 & 0,03 & 0,03 \\
\hline 80 & 7 & M & $25-74$ & $50-100$ & 10 & 0,02 & 0,04 & 0,03 & 0,05 & 0,03 & 0,02 & 0,02 & 0,04 & 0,02 & 0,02 & 0,03 & 0,04 & 0,02 \\
\hline 80 & 7 & M & $25-74$ & $50-100$ & 50 & 0,03 & 0,03 & 0,03 & 0,02 & 0,03 & 0,02 & 0,03 & 0,03 & 0,03 & 0,02 & 0,03 & 0,02 & 0,03 \\
\hline 80 & 7 & M & $75-125$ & $0-50$ & 10 & 0,02 & 0,03 & 0,02 & 0,03 & 0,02 & 0,01 & 0,02 & 0,03 & 0,02 & 0,01 & 0,02 & 0,02 & 0,02 \\
\hline 80 & 7 & M & $75-125$ & $0-50$ & 50 & 0,02 & 0,03 & 0,02 & 0,02 & 0,04 & 0,01 & 0,02 & 0,03 & 0,04 & 0,01 & 0,03 & 0,02 & 0,02 \\
\hline 80 & 7 & M & $75-125$ & $50-100$ & 10 & 0,02 & 0,03 & 0,03 & 0,02 & 0,02 & 0,01 & 0,01 & 0,02 & 0,02 & 0,01 & 0,02 & 0,02 & 0,02 \\
\hline 80 & 7 & M & $75-125$ & $50-100$ & 50 & 0,02 & 0,02 & 0,02 & 0,02 & 0,03 & 0,01 & 0,02 & 0,02 & 0,03 & 0,02 & 0,02 & 0,02 & 0,02 \\
\hline 80 & 7 & A & $25-74$ & $0-50$ & 10 & 0,03 & 0,04 & 0,04 & 0,05 & 0,04 & 0,02 & 0,03 & 0,05 & 0,04 & 0,02 & 0,04 & 0,04 & 0,03 \\
\hline 80 & 7 & A & $25-74$ & $0-50$ & 50 & 0,05 & 0,06 & 0,06 & 0,06 & 0,08 & 0,02 & 0,05 & 0,06 & 0,08 & 0,02 & 0,06 & 0,06 & 0,06 \\
\hline 80 & 7 & A & $25-74$ & $50-100$ & 10 & 0,02 & 0,04 & 0,04 & 0,05 & 0,03 & 0,02 & 0,02 & 0,04 & 0,03 & 0,02 & 0,04 & 0,05 & 0,03 \\
\hline 80 & 7 & A & $25-74$ & $50-100$ & 50 & 0,04 & 0,05 & 0,05 & 0,04 & 0,06 & 0,02 & 0,04 & 0,05 & 0,06 & 0,02 & 0,05 & 0,04 & 0,04 \\
\hline 80 & 7 & A & $75-125$ & $0-50$ & 10 & 0,02 & 0,03 & 0,03 & 0,04 & 0,03 & 0,02 & 0,02 & 0,04 & 0,03 & 0,02 & 0,03 & 0,03 & 0,02 \\
\hline 80 & 7 & A & $75-125$ & $0-50$ & 50 & 0,04 & 0,05 & 0,05 & 0,04 & 0,06 & 0,02 & 0,04 & 0,05 & 0,06 & 0,02 & 0,05 & 0,04 & 0,04 \\
\hline 80 & 7 & A & $75-125$ & $50-100$ & 10 & 0,02 & 0,03 & 0,03 & 0,04 & 0,03 & 0,02 & 0,02 & 0,03 & 0,02 & 0,02 & 0,02 & 0,04 & 0,02 \\
\hline 80 & 7 & A & $75-125$ & $50-100$ & 50 & 0,03 & 0,03 & 0,04 & 0,03 & 0,04 & 0,02 & 0,03 & 0,03 & 0,04 & 0,03 & 0,04 & 0,04 & 0,03 \\
\hline 100 & 3 & B & $25-74$ & $0-50$ & 10 & 0,02 & 0,04 & 0,05 & 0,04 & 0,02 & 0,02 & 0,02 & 0,04 & 0,02 & 0,02 & 0,05 & 0,04 & 0,02 \\
\hline 100 & 3 & B & $25-74$ & $0-50$ & 50 & 0,02 & 0,02 & 0,03 & 0,02 & 0,03 & 0,02 & 0,02 & 0,02 & 0,03 & 0,02 & 0,03 & 0,02 & 0,02 \\
\hline 100 & 3 & B & $25-74$ & $50-100$ & 10 & 0,02 & 0,04 & 0,05 & 0,04 & 0,02 & 0,01 & 0,02 & 0,04 & 0,02 & 0,01 & 0,05 & 0,04 & 0,02 \\
\hline 100 & 3 & B & $25-74$ & $50-100$ & 50 & 0,02 & 0,03 & 0,03 & 0,02 & 0,03 & 0,01 & 0,02 & 0,02 & 0,03 & 0,02 & 0,04 & 0,02 & 0,02 \\
\hline 100 & 3 & B & $75-125$ & $0-50$ & 10 & 0,01 & 0,03 & 0,04 & 0,03 & 0,02 & 0,01 & 0,01 & 0,03 & 0,02 & 0,01 & 0,03 & 0,03 & 0,01 \\
\hline 100 & 3 & B & $75-125$ & $0-50$ & 50 & 0,01 & 0,02 & 0,03 & 0,01 & 0,02 & 0,01 & 0,01 & 0,02 & 0,02 & 0,01 & 0,02 & 0,01 & 0,02 \\
\hline
\end{tabular}




\begin{tabular}{|c|c|c|c|c|c|c|c|c|c|c|c|c|c|c|c|c|c|c|}
\hline 100 & 3 & B & $75-125$ & $50-100$ & 10 & 0,01 & 0,03 & 0,04 & 0,03 & 0,02 & 0,01 & 0,01 & 0,03 & 0,02 & 0,01 & 0,03 & 0,02 & $\overline{0,01}$ \\
\hline 100 & 3 & B & $75-125$ & 50-100 & 50 & 0,01 & 0,01 & 0,02 & 0,01 & 0,02 & 0,01 & 0,01 & 0,01 & 0,02 & 0,01 & 0,02 & 0,01 & 0,01 \\
\hline 100 & 3 & M & $25-74$ & $0-50$ & 10 & 0,01 & 0,02 & 0,02 & 0,02 & 0,02 & 0,02 & 0,02 & 0,02 & 0,02 & 0,02 & 0,02 & 0,02 & 0,02 \\
\hline 100 & 3 & M & $25-74$ & $0-50$ & 50 & 0,02 & 0,02 & 0,02 & 0,02 & 0,02 & 0,02 & 0,02 & 0,02 & 0,02 & 0,02 & 0,02 & 0,02 & 0,02 \\
\hline 100 & 3 & M & $25-74$ & $50-100$ & 10 & 0,02 & 0,02 & 0,02 & 0,02 & 0,02 & 0,01 & 0,02 & 0,02 & 0,02 & 0,02 & 0,02 & 0,02 & 0,02 \\
\hline 100 & 3 & M & $25-74$ & $50-100$ & 50 & 0,02 & 0,02 & 0,02 & 0,02 & 0,02 & 0,02 & 0,02 & 0,02 & 0,02 & 0,02 & 0,02 & 0,02 & 0,02 \\
\hline 100 & 3 & M & $75-125$ & $0-50$ & 10 & 0,01 & 0,01 & 0,01 & 0,01 & 0,01 & 0,01 & 0,01 & 0,01 & 0,01 & 0,01 & 0,01 & 0,01 & 0,01 \\
\hline 100 & 3 & M & $75-125$ & $0-50$ & 50 & 0,01 & 0,01 & 0,01 & 0,01 & 0,02 & 0,01 & 0,01 & 0,01 & 0,02 & 0,01 & 0,02 & 0,01 & 0,01 \\
\hline 100 & 3 & M & $75-125$ & $50-100$ & 10 & 0,01 & 0,01 & 0,01 & 0,01 & 0,01 & 0,01 & 0,01 & 0,01 & 0,01 & 0,01 & 0,01 & 0,01 & 0,01 \\
\hline 100 & 3 & M & $75-125$ & $50-100$ & 50 & 0,01 & 0,01 & 0,01 & 0,01 & 0,02 & 0,01 & 0,01 & 0,01 & 0,01 & 0,01 & 0,01 & 0,01 & 0,01 \\
\hline 100 & 3 & A & $25-74$ & $0-50$ & 10 & 0,02 & 0,05 & 0,05 & 0,05 & 0,03 & 0,02 & 0,02 & 0,05 & 0,03 & 0,02 & 0,05 & 0,05 & 0,02 \\
\hline 100 & 3 & A & $25-74$ & $0-50$ & 50 & 0,03 & 0,03 & 0,05 & 0,03 & 0,04 & 0,02 & 0,03 & 0,04 & 0,04 & 0,02 & 0,05 & 0,03 & 0,03 \\
\hline 100 & 3 & A & $25-74$ & $50-100$ & 10 & 0,02 & 0,05 & 0,06 & 0,06 & 0,03 & 0,02 & 0,02 & 0,05 & 0,03 & 0,01 & 0,05 & 0,05 & 0,03 \\
\hline 100 & 3 & A & $25-74$ & $50-100$ & 50 & 0,03 & 0,03 & 0,05 & 0,03 & 0,04 & 0,02 & 0,03 & 0,03 & 0,05 & 0,02 & 0,05 & 0,03 & 0,03 \\
\hline 100 & 3 & A & $75-125$ & $0-50$ & 10 & 0,02 & 0,03 & 0,04 & 0,04 & 0,03 & 0,01 & 0,02 & 0,03 & 0,03 & 0,01 & 0,04 & 0,04 & 0,02 \\
\hline 100 & 3 & A & $75-125$ & $0-50$ & 50 & 0,03 & 0,03 & 0,06 & 0,03 & 0,05 & 0,01 & 0,03 & 0,03 & 0,05 & 0,01 & 0,05 & 0,03 & 0,03 \\
\hline 100 & 3 & A & $75-125$ & $50-100$ & 10 & 0,02 & 0,02 & 0,04 & 0,05 & 0,02 & 0,01 & 0,01 & 0,03 & 0,02 & 0,02 & 0,03 & 0,04 & 0,02 \\
\hline 100 & 3 & A & $75-125$ & $50-100$ & 50 & 0,02 & 0,02 & 0,03 & 0,02 & 0,03 & 0,01 & 0,02 & 0,02 & 0,03 & 0,01 & 0,03 & 0,02 & 0,02 \\
\hline 100 & 5 & B & $25-74$ & $0-50$ & 10 & 0,02 & 0,04 & 0,05 & 0,06 & 0,02 & 0,02 & 0,02 & 0,05 & 0,02 & 0,02 & 0,05 & 0,06 & 0,02 \\
\hline 100 & 5 & B & $25-74$ & $0-50$ & 50 & 0,02 & 0,03 & 0,03 & 0,03 & 0,03 & 0,02 & 0,02 & 0,03 & 0,03 & 0,01 & 0,03 & 0,03 & 0,02 \\
\hline 100 & 5 & B & $25-74$ & $50-100$ & 10 & 0,02 & 0,05 & 0,04 & 0,06 & 0,02 & 0,02 & 0,02 & 0,05 & 0,02 & 0,02 & 0,04 & 0,06 & 0,02 \\
\hline 100 & 5 & B & $25-74$ & $50-100$ & 50 & 0,02 & 0,02 & 0,03 & 0,02 & 0,03 & 0,01 & 0,02 & 0,03 & 0,03 & 0,01 & 0,03 & 0,02 & 0,02 \\
\hline 100 & 5 & B & $75-125$ & $0-50$ & 10 & 0,02 & 0,03 & 0,03 & 0,04 & 0,02 & 0,01 & 0,01 & 0,03 & 0,02 & 0,02 & 0,03 & 0,04 & 0,02 \\
\hline 100 & 5 & B & $75-125$ & $0-50$ & 50 & 0,02 & 0,02 & 0,03 & 0,03 & 0,03 & 0,01 & 0,02 & 0,02 & 0,03 & 0,01 & 0,03 & 0,02 & 0,02 \\
\hline 100 & 5 & B & $75-125$ & $50-100$ & 10 & 0,02 & 0,03 & 0,03 & 0,04 & 0,02 & 0,02 & 0,01 & 0,03 & 0,02 & 0,01 & 0,02 & 0,04 & 0,02 \\
\hline 100 & 5 & B & $75-125$ & $50-100$ & 50 & 0,02 & 0,02 & 0,03 & 0,02 & 0,02 & 0,01 & 0,01 & 0,02 & 0,02 & 0,01 & 0,02 & 0,02 & 0,02 \\
\hline 100 & 5 & M & $25-74$ & $0-50$ & 10 & 0,02 & 0,04 & 0,04 & 0,04 & 0,02 & 0,02 & 0,02 & 0,04 & 0,02 & 0,02 & 0,04 & 0,04 & 0,02 \\
\hline 100 & 5 & M & $25-74$ & $0-50$ & 50 & 0,02 & 0,03 & 0,03 & 0,02 & 0,03 & 0,02 & 0,02 & 0,03 & 0,03 & 0,02 & 0,04 & 0,02 & 0,02 \\
\hline 100 & 5 & M & $25-74$ & $50-100$ & 10 & 0,02 & 0,04 & 0,03 & 0,04 & 0,02 & 0,02 & 0,02 & 0,04 & 0,02 & 0,02 & 0,03 & 0,04 & 0,02 \\
\hline 100 & 5 & M & $25-74$ & $50-100$ & 50 & 0,02 & 0,02 & 0,02 & 0,02 & 0,02 & 0,02 & 0,02 & 0,02 & 0,02 & 0,02 & 0,02 & 0,02 & 0,02 \\
\hline 100 & 5 & M & $75-125$ & $0-50$ & 10 & 0,01 & 0,03 & 0,03 & 0,03 & 0,02 & 0,02 & 0,01 & 0,03 & 0,02 & 0,02 & 0,02 & 0,03 & 0,01 \\
\hline 100 & 5 & M & $75-125$ & $0-50$ & 50 & 0,02 & 0,02 & 0,02 & 0,02 & 0,03 & 0,01 & 0,02 & 0,02 & 0,03 & 0,01 & 0,02 & 0,02 & 0,02 \\
\hline 100 & 5 & M & $75-125$ & $50-100$ & 10 & 0,01 & 0,03 & 0,02 & 0,03 & 0,02 & 0,01 & 0,01 & 0,03 & 0,02 & 0,01 & 0,02 & 0,02 & 0,01 \\
\hline 100 & 5 & M & $75-125$ & $50-100$ & 50 & 0,01 & 0,02 & 0,02 & 0,01 & 0,02 & 0,01 & 0,02 & 0,02 & 0,02 & 0,01 & 0,02 & 0,02 & 0,01 \\
\hline 100 & 5 & A & $25-74$ & $0-50$ & 10 & 0,02 & 0,04 & 0,04 & 0,05 & 0,03 & 0,02 & 0,02 & 0,04 & 0,03 & 0,02 & 0,04 & 0,04 & 0,03 \\
\hline 100 & 5 & A & $25-74$ & $0-50$ & 50 & 0,04 & 0,05 & 0,07 & 0,04 & 0,07 & 0,02 & 0,04 & 0,05 & 0,06 & 0,02 & 0,06 & 0,04 & 0,04 \\
\hline 100 & 5 & A & $25-74$ & $50-100$ & 10 & 0,02 & 0,04 & 0,04 & 0,05 & 0,03 & 0,02 & 0,02 & 0,04 & 0,03 & 0,02 & 0,04 & 0,05 & 0,03 \\
\hline 100 & 5 & A & $25-74$ & $50-100$ & 50 & 0,03 & 0,04 & 0,04 & 0,04 & 0,05 & 0,02 & 0,04 & 0,04 & 0,05 & 0,02 & 0,05 & 0,04 & 0,03 \\
\hline 100 & 5 & A & $75-125$ & $0-50$ & 10 & 0,02 & 0,03 & 0,03 & 0,04 & 0,03 & 0,01 & 0,02 & 0,03 & 0,03 & 0,01 & 0,03 & 0,03 & 0,02 \\
\hline 100 & 5 & A & $75-125$ & $0-50$ & 50 & 0,03 & 0,04 & 0,04 & 0,04 & 0,05 & 0,01 & 0,03 & 0,03 & 0,05 & 0,01 & 0,05 & 0,03 & 0,03 \\
\hline 100 & 5 & A & $75-125$ & $50-100$ & 10 & 0,01 & 0,03 & 0,02 & 0,04 & 0,02 & 0,01 & 0,01 & 0,03 & 0,02 & 0,01 & 0,02 & 0,03 & 0,02 \\
\hline 100 & 5 & A & $75-125$ & 50-100 & 50 & 0,03 & 0,02 & 0,04 & 0,02 & 0,04 & 0,01 & 0,02 & 0,03 & 0,04 & 0,01 & 0,03 & 0,02 & 0,03 \\
\hline 100 & 7 & B & $25-74$ & $0-50$ & 10 & 0,02 & 0,04 & 0,04 & 0,05 & 0,02 & 0,02 & 0,02 & 0,04 & 0,02 & 0,02 & 0,04 & 0,05 & 0,02 \\
\hline 100 & 7 & B & $25-74$ & $0-50$ & 50 & 0,03 & 0,04 & 0,04 & 0,04 & 0,04 & 0,02 & 0,03 & 0,04 & 0,03 & 0,02 & 0,04 & 0,03 & 0,03 \\
\hline 100 & 7 & B & $25-74$ & $50-100$ & 10 & 0,02 & 0,04 & 0,04 & 0,06 & 0,02 & 0,02 & 0,02 & 0,04 & 0,02 & 0,02 & 0,03 & 0,05 & 0,02 \\
\hline 100 & 7 & B & $25-74$ & $50-100$ & 50 & 0,02 & 0,03 & 0,03 & 0,03 & 0,03 & 0,02 & 0,02 & 0,03 & 0,03 & 0,02 & 0,03 & 0,03 & 0,02 \\
\hline 100 & 7 & B & $75-125$ & $0-50$ & 10 & 0,02 & 0,03 & 0,02 & 0,04 & 0,02 & 0,02 & 0,02 & 0,03 & 0,02 & 0,02 & 0,02 & 0,04 & 0,02 \\
\hline 100 & 7 & B & $75-125$ & $0-50$ & 50 & 0,02 & 0,03 & 0,03 & 0,04 & 0,03 & 0,02 & 0,02 & 0,03 & 0,04 & 0,02 & 0,03 & 0,04 & 0,03 \\
\hline 100 & 7 & B & $75-125$ & $50-100$ & 10 & 0,02 & 0,03 & 0,03 & 0,04 & 0,02 & 0,02 & 0,02 & 0,03 & 0,02 & 0,02 & 0,02 & 0,03 & 0,02 \\
\hline 100 & 7 & B & $75-125$ & $50-100$ & 50 & 0,02 & 0,02 & 0,03 & 0,03 & 0,03 & 0,02 & 0,02 & 0,02 & 0,03 & 0,01 & 0,03 & 0,03 & 0,02 \\
\hline 100 & 7 & M & $25-74$ & $0-50$ & 10 & 0,02 & 0,04 & 0,02 & 0,04 & 0,02 & 0,02 & 0,02 & 0,04 & 0,02 & 0,02 & 0,02 & 0,03 & 0,02 \\
\hline 100 & 7 & M & $25-74$ & $0-50$ & 50 & 0,02 & 0,03 & 0,03 & 0,02 & 0,03 & 0,02 & 0,02 & 0,03 & 0,03 & 0,02 & 0,03 & 0,02 & 0,02 \\
\hline 100 & 7 & M & $25-74$ & $50-100$ & 10 & 0,02 & 0,04 & 0,03 & 0,03 & 0,02 & 0,02 & 0,02 & 0,04 & 0,02 & 0,01 & 0,03 & 0,03 & 0,02 \\
\hline 100 & 7 & M & $25-74$ & $50-100$ & 50 & 0,02 & 0,02 & 0,03 & 0,02 & 0,03 & 0,02 & 0,02 & 0,03 & 0,03 & 0,02 & 0,03 & 0,02 & 0,02 \\
\hline 100 & 7 & M & $75-125$ & $0-50$ & 10 & 0,01 & 0,03 & 0,02 & 0,02 & 0,02 & 0,01 & 0,01 & 0,03 & 0,02 & 0,01 & 0,02 & 0,02 & 0,01 \\
\hline 100 & 7 & M & $75-125$ & $0-50$ & 50 & 0,02 & 0,02 & 0,02 & 0,02 & 0,03 & 0,01 & 0,02 & 0,02 & 0,02 & 0,01 & 0,02 & 0,02 & 0,02 \\
\hline 100 & 7 & M & $75-125$ & $50-100$ & 10 & 0,01 & 0,02 & 0,02 & 0,02 & 0,02 & 0,01 & 0,01 & 0,02 & 0,02 & 0,01 & 0,02 & 0,02 & 0,01 \\
\hline 100 & 7 & M & $75-125$ & $50-100$ & 50 & 0,02 & 0,02 & 0,02 & 0,02 & 0,02 & 0,01 & 0,02 & 0,02 & 0,02 & 0,01 & 0,02 & 0,02 & 0,02 \\
\hline 100 & 7 & A & $25-74$ & $0-50$ & 10 & 0,02 & 0,04 & 0,03 & 0,05 & 0,03 & 0,02 & 0,02 & 0,04 & 0,03 & 0,02 & 0,03 & 0,05 & 0,03 \\
\hline 100 & 7 & A & $25-74$ & $0-50$ & 50 & 0,04 & 0,05 & 0,06 & 0,04 & 0,07 & 0,02 & 0,04 & 0,05 & 0,07 & 0,02 & 0,06 & 0,04 & 0,04 \\
\hline 100 & 7 & A & $25-74$ & $50-100$ & 10 & 0,02 & 0,04 & 0,03 & 0,05 & 0,03 & 0,02 & 0,02 & 0,04 & 0,03 & 0,02 & 0,03 & 0,05 & 0,02 \\
\hline 100 & 7 & A & $25-74$ & $50-100$ & 50 & 0,03 & 0,04 & 0,04 & 0,04 & 0,05 & 0,02 & 0,03 & 0,04 & 0,05 & 0,02 & 0,05 & 0,04 & 0,04 \\
\hline
\end{tabular}




\begin{tabular}{lllllllllllllllllll}
\hline $\mathbf{1 0 0}$ & $\mathbf{7}$ & $\mathbf{A}$ & $\mathbf{7 5 - 1 2 5}$ & $\mathbf{0 - 5 0}$ & $\mathbf{1 0}$ & $\mathbf{0 , 0 2}$ & $\mathbf{0 , 0 3}$ & $\mathbf{0 , 0 3}$ & $\mathbf{0 , 0 4}$ & $\mathbf{0 , 0 3}$ & $\mathbf{0 , 0 2}$ & $\mathbf{0 , 0 2}$ & $\mathbf{0 , 0 3}$ & $\mathbf{0 , 0 3}$ & 0,02 & 0,02 & 0,03 & 0,02 \\
$\mathbf{1 0 0}$ & $\mathbf{7}$ & $\mathbf{A}$ & $\mathbf{7 5 - 1 2 5}$ & $\mathbf{0 - 5 0}$ & $\mathbf{5 0}$ & $\mathbf{0 , 0 4}$ & $\mathbf{0 , 0 4}$ & $\mathbf{0 , 0 5}$ & $\mathbf{0 , 0 3}$ & $\mathbf{0 , 0 6}$ & $\mathbf{0 , 0 1}$ & $\mathbf{0 , 0 4}$ & $\mathbf{0 , 0 4}$ & $\mathbf{0 , 0 6}$ & 0,01 & 0,05 & 0,04 & 0,03 \\
$\mathbf{1 0 0}$ & $\mathbf{7}$ & $\mathbf{A}$ & $\mathbf{7 5 - 1 2 5}$ & $\mathbf{5 0 - 1 0 0}$ & $\mathbf{1 0}$ & $\mathbf{0 , 0 2}$ & $\mathbf{0 , 0 3}$ & $\mathbf{0 , 0 2}$ & $\mathbf{0 , 0 4}$ & $\mathbf{0 , 0 2}$ & $\mathbf{0 , 0 2}$ & $\mathbf{0 , 0 2}$ & $\mathbf{0 , 0 3}$ & $\mathbf{0 , 0 2}$ & $\mathbf{0 , 0 2}$ & 0,02 & 0,03 & 0,02 \\
$\mathbf{1 0 0}$ & $\mathbf{7}$ & $\mathbf{A}$ & $\mathbf{7 5 - 1 2 5}$ & $\mathbf{5 0 - 1 0 0}$ & $\mathbf{5 0}$ & $\mathbf{0 , 0 3}$ & $\mathbf{0 , 0 3}$ & $\mathbf{0 , 0 3}$ & $\mathbf{0 , 0 3}$ & $\mathbf{0 , 0 4}$ & $\mathbf{0 , 0 1}$ & $\mathbf{0 , 0 3}$ & $\mathbf{0 , 0 3}$ & $\mathbf{0 , 0 4}$ & $\mathbf{0 , 0 1}$ & 0,03 & 0,03 & 0,03 \\
\hline
\end{tabular}

TABELA D.31 - Resultados das heurísticas para setup dependente por porte do problema (em $\%$ de sucesso)

\begin{tabular}{ccccccccccc}
\hline $\boldsymbol{g}$ & $\boldsymbol{n}$ & Hd1 & Hd2 & Hd3 & Hd4 & Hd5 & Hd6 & Hd7 & Rd6 & Rd10 \\
\hline $\mathbf{3}$ & $\mathbf{1 0}$ & 16 & 25 & 35 & 22 & 23 & 22 & 0 & 23 & 22 \\
$\mathbf{3}$ & $\mathbf{3 0}$ & 19 & 27 & 58 & 6 & 9 & 11 & 0 & 10 & 11 \\
$\mathbf{3}$ & $\mathbf{5 0}$ & 21 & 30 & 68 & 6 & 6 & 6 & 0 & 6 & 6 \\
$\mathbf{3}$ & $\mathbf{8 0}$ & 24 & 31 & 77 & 5 & 3 & 4 & 0 & 3 & 4 \\
$\mathbf{3}$ & $\mathbf{1 0 0}$ & 25 & 32 & 79 & 5 & 3 & 4 & 0 & 3 & 4 \\
$\mathbf{5}$ & $\mathbf{1 0}$ & 17 & 24 & 33 & 25 & 22 & 23 & 0 & 22 & 23 \\
$\mathbf{5}$ & $\mathbf{3 0}$ & 14 & 19 & 57 & 7 & 13 & 13 & 0 & 13 & 13 \\
$\mathbf{5}$ & $\mathbf{5 0}$ & 17 & 21 & 71 & 4 & 9 & 9 & 0 & 9 & 8 \\
$\mathbf{5}$ & $\mathbf{8 0}$ & 21 & 23 & 82 & 4 & 5 & 5 & 0 & 5 & 5 \\
$\mathbf{5}$ & $\mathbf{1 0 0}$ & 22 & 24 & 85 & 4 & 4 & 4 & 0 & 4 & 4 \\
$\mathbf{7}$ & $\mathbf{1 0}$ & 19 & 19 & 32 & 27 & 24 & 24 & 0 & 24 & 24 \\
$\mathbf{7}$ & $\mathbf{3 0}$ & 17 & 18 & 55 & 10 & 13 & 12 & 0 & 13 & 12 \\
$\mathbf{7}$ & $\mathbf{5 0}$ & 16 & 17 & 69 & 5 & 9 & 9 & 0 & 9 & 9 \\
$\mathbf{7}$ & $\mathbf{8 0}$ & 20 & 20 & 80 & 4 & 6 & 5 & 0 & 6 & 6 \\
$\mathbf{7}$ & $\mathbf{1 0 0}$ & 22 & 22 & 85 & 4 & 4 & 4 & 0 & 4 & 4 \\
\hline
\end{tabular}

TABELA D.32 - Resultados das heurísticas para setup dependente por flexibilidade e porte do problema (em \% de sucesso)

\begin{tabular}{|c|c|c|c|c|c|c|c|c|c|c|c|}
\hline$f$ & $g$ & $n$ & Hd1 & Hd2 & $\mathrm{Hd} 3$ & $\mathrm{Hd} 4$ & Hd5 & Hd6 & Hd7 & Rd6 & Rd10 \\
\hline B & 3 & 10 & 12 & 24 & 41 & 19 & 7 & 6 & 0 & 7 & 6 \\
\hline B & 3 & 30 & 6 & 19 & 72 & 4 & 0 & 0 & 0 & 0 & 0 \\
\hline B & 3 & 50 & 3 & 12 & 83 & 3 & 0 & 0 & 0 & 0 & 0 \\
\hline B & 3 & 80 & 1 & 5 & 93 & 2 & 0 & 0 & 0 & 0 & 0 \\
\hline B & 3 & 100 & 0 & 5 & 94 & 1 & 0 & 0 & 0 & 0 & 0 \\
\hline B & 5 & 10 & 11 & 20 & 34 & 23 & 12 & 13 & 0 & 12 & 13 \\
\hline B & 5 & 30 & 7 & 14 & 69 & 8 & 1 & 1 & 0 & 1 & 1 \\
\hline B & 5 & 50 & 3 & 8 & 86 & 3 & 0 & 0 & 0 & 0 & 0 \\
\hline B & 5 & 80 & 1 & 4 & 94 & 1 & 0 & 0 & 0 & 0 & 0 \\
\hline B & 5 & 100 & 1 & 3 & 96 & 0 & 0 & 0 & 0 & 0 & 0 \\
\hline B & 7 & 10 & 13 & 11 & 35 & 25 & 14 & 15 & 0 & 14 & 15 \\
\hline B & 7 & 30 & 8 & 5 & 65 & 13 & 6 & 4 & 0 & 6 & 4 \\
\hline B & 7 & 50 & 5 & 3 & 83 & 8 & 1 & 0 & 0 & 1 & 0 \\
\hline B & 7 & 80 & 2 & 1 & 93 & 4 & 0 & 0 & 0 & 0 & 0 \\
\hline B & 7 & 100 & 2 & 0 & 97 & 1 & 0 & 0 & 0 & 0 & 0 \\
\hline M & 3 & 10 & 13 & 29 & 42 & 22 & 9 & 9 & 1 & 9 & 9 \\
\hline M & 3 & 30 & 10 & 24 & 63 & 4 & 0 & 0 & 0 & 0 & 0 \\
\hline M & 3 & 50 & 6 & 24 & 69 & 2 & 0 & 0 & 0 & 0 & 0 \\
\hline M & 3 & 80 & 5 & 21 & 72 & 2 & 0 & 0 & 0 & 0 & 0 \\
\hline M & 3 & 100 & 5 & 20 & 74 & 2 & 0 & 0 & 0 & 0 & 0 \\
\hline M & 5 & 10 & 12 & 22 & 37 & 21 & 14 & 14 & 0 & 13 & 14 \\
\hline M & 5 & 30 & 7 & 16 & 71 & 6 & 1 & 1 & 0 & 0 & 1 \\
\hline M & 5 & 50 & 4 & 11 & 84 & 1 & 0 & 0 & 0 & 0 & 0 \\
\hline M & 5 & 80 & 1 & 6 & 92 & 1 & 0 & 0 & 0 & 0 & 0 \\
\hline M & 5 & 100 & 1 & 5 & 94 & 0 & 0 & 0 & 0 & 0 & 0 \\
\hline M & 7 & 10 & 16 & 20 & 36 & 21 & 15 & 15 & 0 & 16 & 15 \\
\hline M & 7 & 30 & 9 & 16 & 67 & 6 & 1 & 1 & 0 & 2 & 2 \\
\hline M & 7 & 50 & 3 & 9 & 87 & 1 & 0 & 0 & 0 & 0 & 0 \\
\hline
\end{tabular}




\begin{tabular}{lccccccccccc}
\hline $\mathbf{M}$ & $\mathbf{7}$ & $\mathbf{8 0}$ & 3 & 5 & 92 & 1 & 0 & 0 & 0 & 0 & 0 \\
$\mathbf{M}$ & $\mathbf{7}$ & $\mathbf{1 0 0}$ & 1 & 4 & 95 & 0 & 0 & 0 & 0 & 0 & 0 \\
$\mathbf{A}$ & $\mathbf{3}$ & $\mathbf{1 0}$ & 23 & 23 & 23 & 24 & 52 & 52 & 0 & 52 & 52 \\
$\mathbf{A}$ & $\mathbf{3}$ & $\mathbf{3 0}$ & 40 & 40 & 40 & 11 & 28 & 31 & 0 & 28 & 31 \\
$\mathbf{A}$ & $\mathbf{3}$ & $\mathbf{5 0}$ & 53 & 53 & 53 & 12 & 19 & 18 & 0 & 19 & 18 \\
$\mathbf{A}$ & $\mathbf{3}$ & $\mathbf{8 0}$ & 67 & 67 & 67 & 12 & 10 & 12 & 0 & 10 & 12 \\
$\mathbf{A}$ & $\mathbf{3}$ & $\mathbf{1 0 0}$ & 70 & 70 & 70 & 13 & 8 & 11 & 0 & 8 & 11 \\
$\mathbf{A}$ & $\mathbf{5}$ & $\mathbf{1 0}$ & 29 & 29 & 29 & 33 & 40 & 42 & 0 & 40 & 43 \\
$\mathbf{A}$ & $\mathbf{5}$ & $\mathbf{3 0}$ & 29 & 29 & 29 & 8 & 38 & 36 & 0 & 38 & 36 \\
$\mathbf{A}$ & $\mathbf{5}$ & $\mathbf{5 0}$ & 43 & 43 & 43 & 6 & 27 & 26 & 0 & 27 & 25 \\
$\mathbf{A}$ & $\mathbf{5}$ & $\mathbf{8 0}$ & 60 & 60 & 60 & 11 & 14 & 15 & 0 & 14 & 15 \\
$\mathbf{A}$ & $\mathbf{5}$ & $\mathbf{1 0 0}$ & 65 & 65 & 65 & 11 & 12 & 12 & 0 & 12 & 11 \\
$\mathbf{A}$ & $\mathbf{7}$ & $\mathbf{1 0}$ & 27 & 27 & 27 & 34 & 42 & 44 & 0 & 41 & 43 \\
$\mathbf{A}$ & $\mathbf{7}$ & $\mathbf{3 0}$ & 33 & 33 & 33 & 11 & 33 & 31 & 0 & 32 & 32 \\
$\mathbf{A}$ & $\mathbf{7}$ & $\mathbf{5 0}$ & 38 & 38 & 38 & 7 & 26 & 25 & 0 & 25 & 27 \\
$\mathbf{A}$ & $\mathbf{7}$ & $\mathbf{8 0}$ & 55 & 55 & 55 & 8 & 17 & 15 & 0 & 17 & 17 \\
$\mathbf{A}$ & $\mathbf{7}$ & $\mathbf{1 0 0}$ & 63 & 63 & 63 & 9 & 11 & 13 & 0 & 11 & 13 \\
\hline
\end{tabular}

TABELA D.33 - Resultados das heurísticas para setup dependente por intervalo de setup e porte do problema para flexibilidade baixa (em \% de sucesso)

\begin{tabular}{cccccccccccc}
\hline $\boldsymbol{s}$ & $\boldsymbol{g}$ & $\boldsymbol{n}$ & $\mathbf{H d 1}$ & $\mathbf{H d 2}$ & $\mathbf{H d 3}$ & Hd4 & Hd5 & Hd6 & Hd7 & Rd6 & Rd10 \\
\hline $\mathbf{2 5 - 7 4}$ & $\mathbf{3}$ & $\mathbf{1 0}$ & 12 & 25 & 40 & 20 & 6 & 6 & 0 & 6 & 6 \\
$\mathbf{2 5 - 7 4}$ & $\mathbf{3}$ & $\mathbf{3 0}$ & 8 & 20 & 70 & 3 & 0 & 0 & 0 & 0 & 0 \\
$\mathbf{2 5 - 7 4}$ & $\mathbf{3}$ & $\mathbf{5 0}$ & 3 & 14 & 82 & 2 & 0 & 0 & 0 & 0 & 0 \\
$\mathbf{2 5 - 7 4}$ & $\mathbf{3}$ & $\mathbf{8 0}$ & 1 & 5 & 94 & 1 & 0 & 0 & 0 & 0 & 0 \\
$\mathbf{2 5 - 7 4}$ & $\mathbf{3}$ & $\mathbf{1 0 0}$ & 0 & 6 & 93 & 1 & 0 & 0 & 0 & 0 & 0 \\
$\mathbf{2 5 - 7 4}$ & $\mathbf{5}$ & $\mathbf{1 0}$ & 12 & 23 & 33 & 18 & 13 & 14 & 0 & 12 & 13 \\
$\mathbf{2 5 - 7 4}$ & $\mathbf{5}$ & $\mathbf{3 0}$ & 8 & 15 & 72 & 5 & 0 & 1 & 0 & 0 & 1 \\
$\mathbf{2 5 - 7 4}$ & $\mathbf{5}$ & $\mathbf{5 0}$ & 1 & 10 & 87 & 2 & 0 & 0 & 0 & 0 & 0 \\
$\mathbf{2 5 - 7 4}$ & $\mathbf{5}$ & $\mathbf{8 0}$ & 1 & 5 & 95 & 1 & 0 & 0 & 0 & 0 & 0 \\
$\mathbf{2 5 - 7 4}$ & $\mathbf{5}$ & $\mathbf{1 0 0}$ & 1 & 3 & 97 & 0 & 0 & 0 & 0 & 0 & 0 \\
$\mathbf{2 5 - 7 4}$ & $\mathbf{7}$ & $\mathbf{1 0}$ & 13 & 12 & 40 & 22 & 11 & 12 & 0 & 11 & 13 \\
$\mathbf{2 5 - 7 4}$ & $\mathbf{7}$ & $\mathbf{3 0}$ & 9 & 5 & 71 & 9 & 4 & 3 & 0 & 3 & 3 \\
$\mathbf{2 5 - 7 4}$ & $\mathbf{7}$ & $\mathbf{5 0}$ & 4 & 4 & 88 & 5 & 0 & 0 & 0 & 0 & 0 \\
$\mathbf{2 5 - 7 4}$ & $\mathbf{7}$ & $\mathbf{8 0}$ & 1 & 0 & 97 & 1 & 0 & 0 & 0 & 0 & 0 \\
$\mathbf{2 5 - 7 4}$ & $\mathbf{7}$ & $\mathbf{1 0 0}$ & 2 & 0 & 98 & 0 & 0 & 0 & 0 & 0 & 0 \\
$\mathbf{7 5 - 1 2 5}$ & $\mathbf{3}$ & $\mathbf{1 0}$ & 12 & 24 & 42 & 18 & 8 & 6 & 0 & 9 & 7 \\
$\mathbf{7 5 - 1 2 5}$ & $\mathbf{3}$ & $\mathbf{3 0}$ & 5 & 17 & 74 & 4 & 1 & 0 & 0 & 1 & 0 \\
$\mathbf{7 5 - 1 2 5}$ & $\mathbf{3}$ & $\mathbf{5 0}$ & 3 & 9 & 85 & 3 & 0 & 0 & 0 & 0 & 0 \\
$\mathbf{7 5 - 1 2 5}$ & $\mathbf{3}$ & $\mathbf{8 0}$ & 1 & 6 & 92 & 3 & 0 & 0 & 0 & 0 & 0 \\
$\mathbf{7 5 - 1 2 5}$ & $\mathbf{3}$ & $\mathbf{1 0 0}$ & 1 & 5 & 94 & 1 & 0 & 0 & 0 & 0 & 0 \\
$\mathbf{7 5 - 1 2 5}$ & $\mathbf{5}$ & $\mathbf{1 0}$ & 10 & 17 & 35 & 27 & 12 & 12 & 0 & 13 & 13 \\
$\mathbf{7 5 - 1 2 5}$ & $\mathbf{5}$ & $\mathbf{3 0}$ & 6 & 12 & 67 & 12 & 2 & 1 & 0 & 2 & 2 \\
$\mathbf{7 5 - 1 2 5}$ & $\mathbf{5}$ & $\mathbf{5 0}$ & 5 & 6 & 85 & 5 & 0 & 0 & 0 & 0 & 0 \\
$\mathbf{7 5 - 1 2 5}$ & $\mathbf{5}$ & $\mathbf{8 0}$ & 2 & 3 & 94 & 2 & 0 & 0 & 0 & 0 & 0 \\
$\mathbf{7 5 - 1 2 5}$ & $\mathbf{5}$ & $\mathbf{1 0 0}$ & 2 & 3 & 95 & 0 & 0 & 0 & 0 & 0 & 0 \\
$\mathbf{7 5 - 1 2 5}$ & $\mathbf{7}$ & $\mathbf{1 0}$ & 14 & 11 & 30 & 28 & 17 & 17 & 0 & 17 & 17 \\
$\mathbf{7 5 - 1 2 5}$ & $\mathbf{7}$ & $\mathbf{3 0}$ & 7 & 5 & 58 & 17 & 9 & 5 & 0 & 10 & 5 \\
$\mathbf{7 5 - 1 2 5}$ & $\mathbf{7}$ & $\mathbf{5 0}$ & 7 & 2 & 78 & 11 & 2 & 0 & 0 & 2 & 1 \\
$\mathbf{7 5 - 1 2 5}$ & $\mathbf{7}$ & $\mathbf{8 0}$ & 3 & 2 & 90 & 7 & 0 & 0 & 0 & 0 & 0 \\
$\mathbf{7 5 - 1 2 5}$ & $\mathbf{7}$ & $\mathbf{1 0 0}$ & 3 & 0 & 95 & 2 & 0 & 0 & 0 & 0 & 0 \\
\hline & & & & & & & & & & &
\end{tabular}


TABELA D.34 - Resultados das heurísticas para setup dependente por intervalo de setup e porte do problema para flexibilidade média (em \% de sucesso)

\begin{tabular}{cccccccccccc}
\hline $\boldsymbol{s}$ & $\boldsymbol{g}$ & $\boldsymbol{n}$ & $\mathbf{H d 1}$ & $\mathbf{H d 2}$ & $\mathbf{H d} \mathbf{3}$ & $\mathbf{H d 4}$ & Hd5 & Hd6 & Hd7 & Rd6 & Rd10 \\
\hline $\mathbf{2 5 - 7 4}$ & $\mathbf{3}$ & $\mathbf{1 0}$ & 12 & 33 & 42 & 20 & 9 & 8 & 0 & 9 & 8 \\
$\mathbf{2 5 - 7 4}$ & $\mathbf{3}$ & $\mathbf{3 0}$ & 9 & 23 & 65 & 4 & 0 & 1 & 0 & 0 & 1 \\
$\mathbf{2 5 - 7 4}$ & $\mathbf{3}$ & $\mathbf{5 0}$ & 8 & 25 & 66 & 3 & 0 & 0 & 0 & 0 & 0 \\
$\mathbf{2 5 - 7 4}$ & $\mathbf{3}$ & $\mathbf{8 0}$ & 7 & 23 & 69 & 2 & 0 & 0 & 0 & 0 & 0 \\
$\mathbf{2 5 - 7 4}$ & $\mathbf{3}$ & $\mathbf{1 0 0}$ & 7 & 22 & 71 & 1 & 0 & 0 & 0 & 0 & 0 \\
$\mathbf{2 5 - 7 4}$ & $\mathbf{5}$ & $\mathbf{1 0}$ & 15 & 26 & 40 & 20 & 9 & 11 & 0 & 9 & 11 \\
$\mathbf{2 5 - 7 4}$ & $\mathbf{5}$ & $\mathbf{3 0}$ & 6 & 17 & 72 & 5 & 0 & 1 & 0 & 0 & 1 \\
$\mathbf{2 5 - 7 4}$ & $\mathbf{5}$ & $\mathbf{5 0}$ & 2 & 11 & 87 & 0 & 0 & 0 & 0 & 0 & 0 \\
$\mathbf{2 5 - 7 4}$ & $\mathbf{5}$ & $\mathbf{8 0}$ & 1 & 5 & 94 & 1 & 0 & 0 & 0 & 0 & 0 \\
$\mathbf{2 5 - 7 4}$ & $\mathbf{5}$ & $\mathbf{1 0 0}$ & 1 & 5 & 95 & 0 & 0 & 0 & 0 & 0 & 0 \\
$\mathbf{2 5 - 7 4}$ & $\mathbf{7}$ & $\mathbf{1 0}$ & 13 & 20 & 38 & 18 & 16 & 15 & 0 & 17 & 17 \\
$\mathbf{2 5 - 7 4}$ & $\mathbf{7}$ & $\mathbf{3 0}$ & 9 & 16 & 71 & 5 & 1 & 0 & 0 & 1 & 0 \\
$\mathbf{2 5 - 7 4}$ & $\mathbf{7}$ & $\mathbf{5 0}$ & 3 & 11 & 87 & 1 & 0 & 0 & 0 & 0 & 0 \\
$\mathbf{2 5 - 7 4}$ & $\mathbf{7}$ & $\mathbf{8 0}$ & 2 & 6 & 91 & 1 & 0 & 0 & 0 & 0 & 0 \\
$\mathbf{2 5 - 7 4}$ & $\mathbf{7}$ & $\mathbf{1 0 0}$ & 0 & 5 & 95 & 0 & 0 & 0 & 0 & 0 & 0 \\
$\mathbf{7 5 - 1 2 5}$ & $\mathbf{3}$ & $\mathbf{1 0}$ & 14 & 24 & 43 & 25 & 9 & 9 & 1 & 9 & 9 \\
$\mathbf{7 5 - 1 2 5}$ & $\mathbf{3}$ & $\mathbf{3 0}$ & 12 & 24 & 61 & 5 & 0 & 0 & 0 & 0 & 0 \\
$\mathbf{7 5 - 1 2 5}$ & $\mathbf{3}$ & $\mathbf{5 0}$ & 5 & 24 & 72 & 1 & 0 & 0 & 0 & 0 & 0 \\
$\mathbf{7 5 - 1 2 5}$ & $\mathbf{3}$ & $\mathbf{8 0}$ & 4 & 19 & 76 & 2 & 0 & 0 & 0 & 0 & 0 \\
$\mathbf{7 5 - 1 2 5}$ & $\mathbf{3}$ & $\mathbf{1 0 0}$ & 3 & 18 & 77 & 3 & 0 & 0 & 0 & 0 & 0 \\
$\mathbf{7 5 - 1 2 5}$ & $\mathbf{5}$ & $\mathbf{1 0}$ & 10 & 19 & 35 & 21 & 19 & 18 & 0 & 17 & 17 \\
$\mathbf{7 5 - 1 2 5}$ & $\mathbf{5}$ & $\mathbf{3 0}$ & 8 & 14 & 71 & 6 & 1 & 1 & 0 & 1 & 1 \\
$\mathbf{7 5 - 1 2 5}$ & $\mathbf{5}$ & $\mathbf{5 0}$ & 5 & 11 & 81 & 3 & 0 & 0 & 0 & 0 & 0 \\
$\mathbf{7 5 - 1 2 5}$ & $\mathbf{5}$ & $\mathbf{8 0}$ & 2 & 6 & 91 & 1 & 0 & 0 & 0 & 0 & 0 \\
$\mathbf{7 5 - 1 2 5}$ & $\mathbf{5}$ & $\mathbf{1 0 0}$ & 2 & 4 & 94 & 0 & 0 & 0 & 0 & 0 & 0 \\
$\mathbf{7 5 - 1 2 5}$ & $\mathbf{7}$ & $\mathbf{1 0}$ & 18 & 20 & 34 & 25 & 15 & 14 & 0 & 15 & 14 \\
$\mathbf{7 5 - 1 2 5}$ & $\mathbf{7}$ & $\mathbf{3 0}$ & 9 & 17 & 63 & 7 & 2 & 3 & 0 & 2 & 4 \\
$\mathbf{7 5 - 1 2 5}$ & $\mathbf{7}$ & $\mathbf{5 0}$ & 4 & 8 & 87 & 2 & 0 & 0 & 0 & 0 & 0 \\
$\mathbf{7 5 - 1 2 5}$ & $\mathbf{7}$ & $\mathbf{8 0}$ & 3 & 4 & 92 & 1 & 0 & 0 & 0 & 0 & 0 \\
$\mathbf{7 5 - 1 2 5}$ & $\mathbf{7}$ & $\mathbf{1 0 0}$ & 2 & 3 & 96 & 1 & 0 & 0 & 0 & 0 & 0 \\
\hline & & & & & & & & & & & \\
\hline
\end{tabular}


TABELA D.35 - Resultados das heurísticas para setup dependente por intervalo de setup e porte do problema para flexibilidade alta (em \% de sucesso)

\begin{tabular}{cccccccccccc}
\hline $\boldsymbol{s}$ & $\boldsymbol{g}$ & $\boldsymbol{n}$ & $\mathbf{H d 1}$ & $\mathbf{H d 2}$ & $\mathbf{H d 3}$ & $\mathbf{H d 4}$ & $\mathbf{H d 5}$ & Hd6 & Hd7 & Rd6 & Rd10 \\
\hline $\mathbf{2 5 - 7 4}$ & $\mathbf{3}$ & $\mathbf{1 0}$ & 25 & 25 & 25 & 24 & 49 & 51 & 0 & 49 & 51 \\
$\mathbf{2 5 - 7 4}$ & $\mathbf{3}$ & $\mathbf{3 0}$ & 45 & 45 & 45 & 10 & 23 & 29 & 0 & 23 & 29 \\
$\mathbf{2 5 - 7 4}$ & $\mathbf{3}$ & $\mathbf{5 0}$ & 60 & 60 & 60 & 11 & 18 & 14 & 0 & 17 & 14 \\
$\mathbf{2 5 - 7 4}$ & $\mathbf{3}$ & $\mathbf{8 0}$ & 69 & 69 & 69 & 12 & 9 & 11 & 0 & 9 & 11 \\
$\mathbf{2 5 - 7 4}$ & $\mathbf{3}$ & $\mathbf{1 0 0}$ & 77 & 77 & 77 & 13 & 5 & 6 & 0 & 5 & 6 \\
$\mathbf{2 5 - 7 4}$ & $\mathbf{5}$ & $\mathbf{1 0}$ & 30 & 30 & 30 & 29 & 44 & 46 & 0 & 44 & 46 \\
$\mathbf{2 5 - 7 4}$ & $\mathbf{5}$ & $\mathbf{3 0}$ & 34 & 34 & 34 & 7 & 36 & 32 & 0 & 37 & 32 \\
$\mathbf{2 5 - 7 4}$ & $\mathbf{5}$ & $\mathbf{5 0}$ & 48 & 48 & 48 & 7 & 24 & 22 & 0 & 25 & 22 \\
$\mathbf{2 5 - 7 4}$ & $\mathbf{5}$ & $\mathbf{8 0}$ & 68 & 68 & 68 & 10 & 12 & 10 & 0 & 11 & 10 \\
$\mathbf{2 5 - 7 4}$ & $\mathbf{5}$ & $\mathbf{1 0 0}$ & 71 & 71 & 71 & 9 & 10 & 10 & 0 & 11 & 9 \\
$\mathbf{2 5 - 7 4}$ & $\mathbf{7}$ & $\mathbf{1 0}$ & 27 & 27 & 27 & 31 & 42 & 44 & 0 & 41 & 44 \\
$\mathbf{2 5 - 7 4}$ & $\mathbf{7}$ & $\mathbf{3 0}$ & 34 & 34 & 34 & 10 & 30 & 28 & 0 & 31 & 29 \\
$\mathbf{2 5 - 7 4}$ & $\mathbf{7}$ & $\mathbf{5 0}$ & 42 & 42 & 42 & 5 & 23 & 25 & 0 & 23 & 27 \\
$\mathbf{2 5 - 7 4}$ & $\mathbf{7}$ & $\mathbf{8 0}$ & 61 & 61 & 61 & 6 & 15 & 13 & 0 & 15 & 14 \\
$\mathbf{2 5 - 7 4}$ & $\mathbf{7}$ & $\mathbf{1 0 0}$ & 70 & 70 & 70 & 8 & 8 & 10 & 0 & 8 & 11 \\
$\mathbf{7 5 - 1 2 5}$ & $\mathbf{3}$ & $\mathbf{1 0}$ & 21 & 21 & 21 & 24 & 55 & 54 & 0 & 55 & 54 \\
$\mathbf{7 5 - 1 2 5}$ & $\mathbf{3}$ & $\mathbf{3 0}$ & 35 & 35 & 35 & 11 & 34 & 34 & 0 & 34 & 34 \\
$\mathbf{7 5 - 1 2 5}$ & $\mathbf{3}$ & $\mathbf{5 0}$ & 46 & 46 & 46 & 14 & 21 & 22 & 0 & 21 & 22 \\
$\mathbf{7 5 - 1 2 5}$ & $\mathbf{3}$ & $\mathbf{8 0}$ & 64 & 64 & 64 & 13 & 11 & 12 & 0 & 11 & 12 \\
$\mathbf{7 5 - 1 2 5}$ & $\mathbf{3}$ & $\mathbf{1 0 0}$ & 62 & 62 & 62 & 12 & 11 & 16 & 0 & 11 & 16 \\
$\mathbf{7 5 - 1 2 5}$ & $\mathbf{5}$ & $\mathbf{1 0}$ & 28 & 28 & 28 & 37 & 37 & 39 & 0 & 37 & 39 \\
$\mathbf{7 5 - 1 2 5}$ & $\mathbf{5}$ & $\mathbf{3 0}$ & 25 & 25 & 25 & 9 & 40 & 40 & 0 & 40 & 40 \\
$\mathbf{7 5 - 1 2 5}$ & $\mathbf{5}$ & $\mathbf{5 0}$ & 39 & 39 & 39 & 6 & 29 & 29 & 0 & 28 & 29 \\
$\mathbf{7 5 - 1 2 5}$ & $\mathbf{5}$ & $\mathbf{8 0}$ & 52 & 52 & 52 & 12 & 16 & 19 & 0 & 17 & 20 \\
$\mathbf{7 5 - 1 2 5}$ & $\mathbf{5}$ & $\mathbf{1 0 0}$ & 58 & 58 & 58 & 13 & 15 & 14 & 0 & 14 & 14 \\
$\mathbf{7 5 - 1 2 5}$ & $\mathbf{7}$ & $\mathbf{1 0}$ & 27 & 27 & 27 & 36 & 43 & 43 & 0 & 42 & 42 \\
$\mathbf{7 5 - 1 2 5}$ & $\mathbf{7}$ & $\mathbf{3 0}$ & 33 & 33 & 33 & 11 & 35 & 34 & 0 & 33 & 34 \\
$\mathbf{7 5 - 1 2 5}$ & $\mathbf{7}$ & $\mathbf{5 0}$ & 35 & 35 & 35 & 8 & 29 & 26 & 0 & 28 & 27 \\
$\mathbf{7 5 - 1 2 5}$ & $\mathbf{7}$ & $\mathbf{8 0}$ & 49 & 49 & 49 & 9 & 20 & 18 & 0 & 19 & 20 \\
$\mathbf{7 5 - 1 2 5}$ & $\mathbf{7}$ & $\mathbf{1 0 0}$ & 56 & 56 & 56 & 11 & 14 & 16 & 0 & 14 & 15 \\
\hline & & & & & & & & & & & \\
\hline
\end{tabular}


TABELA D.36 - Resultados das heurísticas para setup dependente por probabilidade de antecipação do setup e porte do problema para flexibilidade baixa (em \% de sucesso)

\begin{tabular}{|c|c|c|c|c|c|c|c|c|c|c|c|}
\hline$a$ & $g$ & $n$ & Hd1 & Hd2 & Hd3 & Hd4 & Hd5 & Hd6 & Hd7 & Rd6 & Rd10 \\
\hline $0-50$ & 3 & 10 & 11 & 23 & 41 & 17 & 9 & 7 & 1 & 9 & 7 \\
\hline $0-50$ & 3 & 30 & 9 & 19 & 70 & 2 & 1 & 0 & 0 & 1 & 0 \\
\hline $0-50$ & 3 & 50 & 4 & 15 & 81 & 2 & 0 & 0 & 0 & 0 & 0 \\
\hline $0-50$ & 3 & 80 & 1 & 7 & 91 & 1 & 0 & 0 & 0 & 0 & 0 \\
\hline $0-50$ & 3 & 100 & 1 & 6 & 93 & 1 & 0 & 0 & 0 & 0 & 0 \\
\hline $0-50$ & 5 & 10 & 13 & 16 & 33 & 23 & 14 & 13 & 0 & 13 & 13 \\
\hline $0-50$ & 5 & 30 & 8 & 12 & 69 & 9 & 2 & 1 & 0 & 2 & 1 \\
\hline $0-50$ & 5 & 50 & 4 & 8 & 87 & 2 & 0 & 0 & 0 & 0 & 0 \\
\hline $0-50$ & 5 & 80 & 1 & 4 & 94 & 1 & 0 & 0 & 0 & 0 & 0 \\
\hline $0-50$ & 5 & 100 & 2 & 4 & 95 & 0 & 0 & 0 & 0 & 0 & 0 \\
\hline $0-50$ & 7 & 10 & 11 & 23 & 41 & 17 & 9 & 7 & 1 & 9 & 7 \\
\hline $0-50$ & 7 & 30 & 9 & 19 & 70 & 2 & 1 & 0 & 0 & 1 & 0 \\
\hline $0-50$ & 7 & 50 & 4 & 15 & 81 & 2 & 0 & 0 & 0 & 0 & 0 \\
\hline $0-50$ & 7 & 80 & 1 & 7 & 91 & 1 & 0 & 0 & 0 & 0 & 0 \\
\hline $0-50$ & 7 & 100 & 1 & 6 & 93 & 1 & 0 & 0 & 0 & 0 & 0 \\
\hline $50-100$ & 3 & 10 & 13 & 26 & 41 & 21 & 5 & 6 & 0 & 5 & 6 \\
\hline $50-100$ & 3 & 30 & 4 & 19 & 73 & 5 & 0 & 0 & 0 & 0 & 0 \\
\hline $50-100$ & 3 & 50 & 3 & 9 & 86 & 3 & 0 & 0 & 0 & 0 & 0 \\
\hline $50-100$ & 3 & 80 & 1 & 3 & 95 & 2 & 0 & 0 & 0 & 0 & 0 \\
\hline $50-100$ & 3 & 100 & 0 & 5 & 94 & 2 & 0 & 0 & 0 & 0 & 0 \\
\hline $50-100$ & 5 & 10 & 9 & 24 & 36 & 22 & 11 & 12 & 0 & 12 & 12 \\
\hline $50-100$ & 5 & 30 & 6 & 15 & 70 & 8 & 1 & 2 & 0 & 0 & 2 \\
\hline $50-100$ & 5 & 50 & 2 & 8 & 85 & 5 & 0 & 0 & 0 & 0 & 0 \\
\hline $50-100$ & 5 & 80 & 2 & 3 & 94 & 1 & 0 & 0 & 0 & 0 & 0 \\
\hline $50-100$ & 5 & 100 & 1 & 2 & 97 & 0 & 0 & 0 & 0 & 0 & 0 \\
\hline $50-100$ & 7 & 10 & 13 & 12 & 36 & 26 & 14 & 13 & 0 & 14 & 14 \\
\hline $50-100$ & 7 & 30 & 7 & 6 & 66 & 13 & 6 & 3 & 0 & 6 & 3 \\
\hline $50-100$ & 7 & 50 & 6 & 4 & 81 & 8 & 1 & 1 & 0 & 1 & 0 \\
\hline $50-100$ & 7 & 80 & 1 & 0 & 96 & 3 & 0 & 0 & 0 & 0 & 0 \\
\hline $50-100$ & 7 & 100 & 1 & 0 & 98 & 1 & 0 & 0 & 0 & 0 & 0 \\
\hline
\end{tabular}


TABELA D.37 - Resultados das heurísticas para setup dependente por probabilidade de antecipação do setup e porte do problema para flexibilidade média (em \% de sucesso)

\begin{tabular}{|c|c|c|c|c|c|c|c|c|c|c|c|}
\hline$a$ & $g$ & $n$ & Hd1 & Hd2 & Hd3 & Hd4 & Hd5 & Hd6 & Hd7 & Rd6 & Rd10 \\
\hline $0-50$ & 3 & 10 & 14 & 28 & 42 & 21 & 11 & 10 & 0 & 11 & 10 \\
\hline $0-50$ & 3 & 30 & 15 & 21 & 64 & 3 & 0 & 0 & 0 & 0 & 0 \\
\hline $0-50$ & 3 & 50 & 8 & 23 & 69 & 1 & 0 & 0 & 0 & 0 & 0 \\
\hline $0-50$ & 3 & 80 & 4 & 23 & 73 & 1 & 0 & 0 & 0 & 0 & 0 \\
\hline $0-50$ & 3 & 100 & 5 & 23 & 72 & 1 & 0 & 0 & 0 & 0 & 0 \\
\hline $0-50$ & 5 & 10 & 12 & 20 & 40 & 21 & 14 & 15 & 0 & 13 & 14 \\
\hline $0-50$ & 5 & 30 & 7 & 15 & 70 & 6 & 1 & 1 & 0 & 1 & 1 \\
\hline $0-50$ & 5 & 50 & 4 & 12 & 84 & 2 & 0 & 0 & 0 & 0 & 0 \\
\hline $0-50$ & 5 & 80 & 2 & 6 & 92 & 1 & 0 & 0 & 0 & 0 & 0 \\
\hline $0-50$ & 5 & 100 & 2 & 4 & 95 & 0 & 0 & 0 & 0 & 0 & 0 \\
\hline $0-50$ & 7 & 10 & 16 & 18 & 31 & 24 & 18 & 17 & 0 & 18 & 18 \\
\hline $0-50$ & 7 & 30 & 10 & 15 & 65 & 7 & 2 & 2 & 0 & 3 & 2 \\
\hline $0-50$ & 7 & 50 & 4 & 9 & 86 & 2 & 0 & 0 & 0 & 0 & 0 \\
\hline $0-50$ & 7 & 80 & 4 & 6 & 90 & 1 & 0 & 0 & 0 & 0 & 0 \\
\hline $0-50$ & 7 & 100 & 1 & 4 & 95 & 1 & 0 & 0 & 0 & 0 & 0 \\
\hline $50-100$ & 3 & 10 & 12 & 30 & 43 & 24 & 7 & 8 & 1 & 7 & 8 \\
\hline $50-100$ & 3 & 30 & 6 & 27 & 62 & 6 & 0 & 1 & 0 & 0 & 1 \\
\hline $50-100$ & 3 & 50 & 4 & 25 & 69 & 3 & 0 & 0 & 0 & 0 & 0 \\
\hline $50-100$ & 3 & 80 & 6 & 19 & 72 & 3 & 0 & 0 & 0 & 0 & 0 \\
\hline $50-100$ & 3 & 100 & 4 & 17 & 76 & 3 & 0 & 0 & 0 & 0 & 0 \\
\hline $50-100$ & 5 & 10 & 13 & 24 & 35 & 21 & 13 & 14 & 0 & 13 & 14 \\
\hline $50-100$ & 5 & 30 & 7 & 16 & 73 & 5 & 0 & 1 & 0 & 0 & 1 \\
\hline $50-100$ & 5 & 50 & 4 & 11 & 85 & 1 & 0 & 0 & 0 & 0 & 0 \\
\hline $50-100$ & 5 & 80 & 1 & 6 & 93 & 1 & 0 & 0 & 0 & 0 & 0 \\
\hline $50-100$ & 5 & 100 & 1 & 5 & 94 & 0 & 0 & 0 & 0 & 0 & 0 \\
\hline $50-100$ & 7 & 10 & 15 & 22 & 41 & 19 & 13 & 13 & 0 & 14 & 13 \\
\hline $50-100$ & 7 & 30 & 8 & 17 & 69 & 5 & 1 & 1 & 0 & 1 & 1 \\
\hline $50-100$ & 7 & 50 & 3 & 9 & 87 & 1 & 0 & 0 & 0 & 0 & 0 \\
\hline $50-100$ & 7 & 80 & 1 & 5 & 93 & 1 & 0 & 0 & 0 & 0 & 0 \\
\hline $50-100$ & 7 & 100 & 1 & 4 & 96 & 0 & 0 & 0 & 0 & 0 & 0 \\
\hline
\end{tabular}


TABELA D.38 - Resultados das heurísticas para setup dependente por probabilidade de antecipação do setup e porte do problema para flexibilidade alta (em \% de sucesso)

\begin{tabular}{cccccccccccc}
\hline $\boldsymbol{a}$ & $\boldsymbol{g}$ & $\boldsymbol{n}$ & $\mathbf{H d} \mathbf{1}$ & $\mathbf{H d} \mathbf{2}$ & $\mathbf{H d} \mathbf{3}$ & $\mathbf{H d} \mathbf{4}$ & $\mathbf{H d 5}$ & Hd6 & Hd7 & Rd6 & Rd10 \\
\hline $\mathbf{0 - 5 0}$ & $\mathbf{3}$ & $\mathbf{1 0}$ & 23 & 23 & 23 & 23 & 51 & 52 & 0 & 51 & 52 \\
$\mathbf{0 - 5 0}$ & $\mathbf{3}$ & $\mathbf{3 0}$ & 40 & 40 & 40 & 8 & 28 & 33 & 0 & 28 & 33 \\
$\mathbf{0 - 5 0}$ & $\mathbf{3}$ & $\mathbf{5 0}$ & 52 & 52 & 52 & 10 & 22 & 20 & 0 & 22 & 20 \\
$\mathbf{0 - 5 0}$ & $\mathbf{3}$ & $\mathbf{8 0}$ & 69 & 69 & 69 & 7 & 13 & 12 & 0 & 13 & 12 \\
$\mathbf{0 - 5 0}$ & $\mathbf{3}$ & $\mathbf{1 0 0}$ & 72 & 72 & 72 & 10 & 7 & 13 & 0 & 7 & 13 \\
$\mathbf{0 - 5 0}$ & $\mathbf{5}$ & $\mathbf{1 0}$ & 29 & 29 & 29 & 37 & 38 & 40 & 0 & 37 & 40 \\
$\mathbf{0 - 5 0}$ & $\mathbf{5}$ & $\mathbf{3 0}$ & 29 & 29 & 29 & 7 & 39 & 37 & 0 & 40 & 37 \\
$\mathbf{0 - 5 0}$ & $\mathbf{5}$ & $\mathbf{5 0}$ & 41 & 41 & 41 & 4 & 27 & 29 & 0 & 27 & 28 \\
$\mathbf{0 - 5 0}$ & $\mathbf{5}$ & $\mathbf{8 0}$ & 59 & 59 & 59 & 6 & 17 & 18 & 0 & 17 & 18 \\
$\mathbf{0 - 5 0}$ & $\mathbf{5}$ & $\mathbf{1 0 0}$ & 64 & 64 & 64 & 8 & 15 & 12 & 0 & 15 & 12 \\
$\mathbf{0 - 5 0}$ & $\mathbf{7}$ & $\mathbf{1 0}$ & 26 & 26 & 26 & 37 & 41 & 41 & 0 & 39 & 39 \\
$\mathbf{0 - 5 0}$ & $\mathbf{7}$ & $\mathbf{3 0}$ & 34 & 34 & 34 & 11 & 34 & 31 & 0 & 32 & 31 \\
$\mathbf{0 - 5 0}$ & $\mathbf{7}$ & $\mathbf{5 0}$ & 38 & 38 & 38 & 8 & 25 & 27 & 0 & 25 & 27 \\
$\mathbf{0 - 5 0}$ & $\mathbf{7}$ & $\mathbf{8 0}$ & 52 & 52 & 52 & 6 & 20 & 18 & 0 & 20 & 19 \\
$\mathbf{0 - 5 0}$ & $\mathbf{7}$ & $\mathbf{1 0 0}$ & 63 & 63 & 63 & 7 & 12 & 15 & 0 & 12 & 16 \\
$\mathbf{5 0 - 1 0 0}$ & $\mathbf{3}$ & $\mathbf{1 0}$ & 22 & 22 & 22 & 24 & 53 & 53 & 0 & 53 & 53 \\
$\mathbf{5 0 - 1 0 0}$ & $\mathbf{3}$ & $\mathbf{3 0}$ & 40 & 40 & 40 & 13 & 28 & 30 & 0 & 29 & 30 \\
$\mathbf{5 0 - 1 0 0}$ & $\mathbf{3}$ & $\mathbf{5 0}$ & 55 & 55 & 55 & 15 & 17 & 16 & 0 & 16 & 16 \\
$\mathbf{5 0 - 1 0 0}$ & $\mathbf{3}$ & $\mathbf{8 0}$ & 64 & 64 & 64 & 18 & 8 & 11 & 0 & 8 & 11 \\
$\mathbf{5 0 - 1 0 0}$ & $\mathbf{3}$ & $\mathbf{1 0 0}$ & 68 & 68 & 68 & 16 & 8 & 9 & 0 & 8 & 9 \\
$\mathbf{5 0 - 1 0 0}$ & $\mathbf{5}$ & $\mathbf{1 0}$ & 29 & 29 & 29 & 28 & 43 & 45 & 0 & 43 & 46 \\
$\mathbf{5 0 - 1 0 0}$ & $\mathbf{5}$ & $\mathbf{3 0}$ & 29 & 29 & 29 & 8 & 37 & 35 & 0 & 37 & 35 \\
$\mathbf{5 0 - 1 0 0}$ & $\mathbf{5}$ & $\mathbf{5 0}$ & 46 & 46 & 46 & 9 & 26 & 22 & 0 & 26 & 22 \\
$\mathbf{5 0 - 1 0 0}$ & $\mathbf{5}$ & $\mathbf{8 0}$ & 61 & 61 & 61 & 15 & 12 & 12 & 0 & 11 & 12 \\
$\mathbf{5 0 - 1 0 0}$ & $\mathbf{5}$ & $\mathbf{1 0 0}$ & 65 & 65 & 65 & 14 & 10 & 11 & 0 & 10 & 10 \\
$\mathbf{5 0 - 1 0 0}$ & $\mathbf{7}$ & $\mathbf{1 0}$ & 28 & 28 & 28 & 31 & 43 & 46 & 0 & 44 & 46 \\
$\mathbf{5 0 - 1 0 0}$ & $\mathbf{7}$ & $\mathbf{3 0}$ & 33 & 33 & 33 & 10 & 32 & 32 & 0 & 32 & 33 \\
$\mathbf{5 0 - 1 0 0}$ & $\mathbf{7}$ & $\mathbf{5 0}$ & 39 & 39 & 39 & 6 & 26 & 24 & 0 & 26 & 26 \\
$\mathbf{5 0 - 1 0 0}$ & $\mathbf{7}$ & $\mathbf{8 0}$ & $\mathbf{5 8}$ & $\mathbf{5 8}$ & 58 & 9 & 15 & 13 & 0 & 15 & 15 \\
$\mathbf{5 0 - 1 0 0}$ & $\mathbf{7}$ & $\mathbf{1 0 0}$ & 63 & 63 & 63 & 12 & 10 & 10 & 0 & 11 & 10 \\
\hline & & & & & & & & & & &
\end{tabular}


TABELA D.39 - Resultados das heurísticas para setup dependente por probabilidade de salto e porte do problema para flexibilidade baixa (em \% de sucesso)

\begin{tabular}{cccccccccccc}
\hline $\boldsymbol{l}$ & $\boldsymbol{g}$ & $\boldsymbol{n}$ & $\mathbf{H d 1}$ & $\mathbf{H d 2}$ & $\mathbf{H d 3}$ & $\mathbf{H d 4}$ & $\mathbf{H d 5}$ & $\mathbf{H d 6}$ & Hd7 & Rd6 & Rd10 \\
\hline $\mathbf{1 0}$ & $\mathbf{3}$ & $\mathbf{1 0}$ & 11 & 18 & 42 & 16 & 10 & 9 & 0 & 10 & 9 \\
$\mathbf{1 0}$ & $\mathbf{3}$ & $\mathbf{3 0}$ & 6 & 14 & 78 & 3 & 1 & 0 & 0 & 1 & 0 \\
$\mathbf{1 0}$ & $\mathbf{3}$ & $\mathbf{5 0}$ & 4 & 6 & 90 & 1 & 0 & 0 & 0 & 0 & 0 \\
$\mathbf{1 0}$ & $\mathbf{3}$ & $\mathbf{8 0}$ & 0 & 2 & 98 & 0 & 0 & 0 & 0 & 0 & 0 \\
$\mathbf{1 0}$ & $\mathbf{3}$ & $\mathbf{1 0 0}$ & 0 & 1 & 99 & 0 & 0 & 0 & 0 & 0 & 0 \\
$\mathbf{1 0}$ & $\mathbf{5}$ & $\mathbf{1 0}$ & 12 & 13 & 33 & 24 & 13 & 13 & 0 & 13 & 13 \\
$\mathbf{1 0}$ & $\mathbf{5}$ & $\mathbf{3 0}$ & 5 & 6 & 78 & 9 & 2 & 1 & 0 & 1 & 1 \\
$\mathbf{1 0}$ & $\mathbf{5}$ & $\mathbf{5 0}$ & 3 & 2 & 93 & 3 & 0 & 0 & 0 & 0 & 0 \\
$\mathbf{1 0}$ & $\mathbf{5}$ & $\mathbf{8 0}$ & 1 & 1 & 97 & 1 & 0 & 0 & 0 & 0 & 0 \\
$\mathbf{1 0}$ & $\mathbf{5}$ & $\mathbf{1 0 0}$ & 1 & 0 & 99 & 0 & 0 & 0 & 0 & 0 & 0 \\
$\mathbf{1 0}$ & $\mathbf{7}$ & $\mathbf{1 0}$ & 15 & 4 & 38 & 26 & 11 & 12 & 0 & 11 & 12 \\
$\mathbf{1 0}$ & $\mathbf{7}$ & $\mathbf{3 0}$ & 6 & 1 & 70 & 15 & 5 & 3 & 0 & 5 & 2 \\
$\mathbf{1 0}$ & $\mathbf{7}$ & $\mathbf{5 0}$ & 5 & 1 & 87 & 7 & 1 & 0 & 0 & 1 & 0 \\
$\mathbf{1 0}$ & $\mathbf{7}$ & $\mathbf{8 0}$ & 1 & 0 & 96 & 3 & 0 & 0 & 0 & 0 & 0 \\
$\mathbf{1 0}$ & $\mathbf{7}$ & $\mathbf{1 0 0}$ & 0 & 0 & 100 & 0 & 0 & 0 & 0 & 0 & 0 \\
$\mathbf{5 0}$ & $\mathbf{3}$ & $\mathbf{1 0}$ & 13 & 31 & 40 & 23 & 4 & 4 & 1 & 4 & 4 \\
$\mathbf{5 0}$ & $\mathbf{3}$ & $\mathbf{3 0}$ & 7 & 24 & 66 & 5 & 0 & 0 & 0 & 0 & 0 \\
$\mathbf{5 0}$ & $\mathbf{3}$ & $\mathbf{5 0}$ & 3 & 18 & 77 & 4 & 0 & 0 & 0 & 0 & 0 \\
$\mathbf{5 0}$ & $\mathbf{3}$ & $\mathbf{8 0}$ & 1 & 8 & 87 & 3 & 0 & 0 & 0 & 0 & 0 \\
$\mathbf{5 0}$ & $\mathbf{3}$ & $\mathbf{1 0 0}$ & 1 & 9 & 88 & 2 & 0 & 0 & 0 & 0 & 0 \\
$\mathbf{5 0}$ & $\mathbf{5}$ & $\mathbf{1 0}$ & 11 & 27 & 36 & 22 & 12 & 13 & 0 & 12 & 12 \\
$\mathbf{5 0}$ & $\mathbf{5}$ & $\mathbf{3 0}$ & 8 & 21 & 61 & 8 & 1 & 1 & 0 & 1 & 1 \\
$\mathbf{5 0}$ & $\mathbf{5}$ & $\mathbf{5 0}$ & 3 & 14 & 79 & 4 & 0 & 0 & 0 & 0 & 0 \\
$\mathbf{5 0}$ & $\mathbf{5}$ & $\mathbf{8 0}$ & 2 & 6 & 91 & 2 & 0 & 0 & 0 & 0 & 0 \\
$\mathbf{5 0}$ & $\mathbf{5}$ & $\mathbf{1 0 0}$ & 1 & 6 & 93 & 1 & 0 & 0 & 0 & 0 & 0 \\
$\mathbf{5 0}$ & $\mathbf{7}$ & $\mathbf{1 0}$ & 12 & 19 & 32 & 24 & 17 & 17 & 0 & 17 & 17 \\
$\mathbf{5 0}$ & $\mathbf{7}$ & $\mathbf{3 0}$ & 9 & 9 & 60 & 12 & 7 & 6 & 0 & 8 & 6 \\
$\mathbf{5 0}$ & $\mathbf{7}$ & $\mathbf{5 0}$ & $\mathbf{5}$ & $\mathbf{5}$ & $\mathbf{7 9}$ & 9 & 1 & 1 & 0 & 1 & 0 \\
$\mathbf{5 0}$ & $\mathbf{7}$ & $\mathbf{8 0}$ & 3 & 2 & 91 & 5 & 0 & 0 & 0 & 0 & 0 \\
$\mathbf{5 0}$ & $\mathbf{7}$ & $\mathbf{1 0 0}$ & 4 & 0 & 93 & 2 & 0 & 0 & 0 & 0 & 0 \\
\hline & & & & & & & & & & & \\
\hline
\end{tabular}


TABELA D.40 - Resultados das heurísticas para setup dependente por probabilidade de salto e porte do problema para flexibilidade média (em \% de sucesso)

\begin{tabular}{cccccccccccc}
\hline $\boldsymbol{l}$ & $\boldsymbol{g}$ & $\boldsymbol{n}$ & Hd1 & Hd2 & Hd3 & Hd4 & Hd5 & Hd6 & Hd7 & Rd6 & Rd10 \\
\hline $\mathbf{1 0}$ & $\mathbf{3}$ & $\mathbf{1 0}$ & 12 & 24 & 42 & 20 & 4 & 2 & 0 & 4 & 2 \\
$\mathbf{1 0}$ & $\mathbf{3}$ & $\mathbf{3 0}$ & 12 & 21 & 67 & 2 & 0 & 0 & 0 & 0 & 0 \\
$\mathbf{1 0}$ & $\mathbf{3}$ & $\mathbf{5 0}$ & 5 & 22 & 72 & 1 & 0 & 0 & 0 & 0 & 0 \\
$\mathbf{1 0}$ & $\mathbf{3}$ & $\mathbf{8 0}$ & 4 & 15 & 81 & 1 & 0 & 0 & 0 & 0 & 0 \\
$\mathbf{1 0}$ & $\mathbf{3}$ & $\mathbf{1 0 0}$ & 3 & 18 & 78 & 2 & 0 & 0 & 0 & 0 & 0 \\
$\mathbf{1 0}$ & $\mathbf{5}$ & $\mathbf{1 0}$ & 11 & 20 & 38 & 17 & 10 & 12 & 0 & 10 & 13 \\
$\mathbf{1 0}$ & $\mathbf{5}$ & $\mathbf{3 0}$ & 7 & 9 & 80 & 3 & 0 & 1 & 0 & 0 & 1 \\
$\mathbf{1 0}$ & $\mathbf{5}$ & $\mathbf{5 0}$ & 4 & 5 & 91 & 1 & 0 & 0 & 0 & 0 & 0 \\
$\mathbf{1 0}$ & $\mathbf{5}$ & $\mathbf{8 0}$ & 2 & 0 & 98 & 0 & 0 & 0 & 0 & 0 & 0 \\
$\mathbf{1 0}$ & $\mathbf{5}$ & $\mathbf{1 0 0}$ & 1 & 1 & 98 & 0 & 0 & 0 & 0 & 0 & 0 \\
$\mathbf{1 0}$ & $\mathbf{7}$ & $\mathbf{1 0}$ & 14 & 16 & 36 & 16 & 11 & 10 & 0 & 13 & 11 \\
$\mathbf{1 0}$ & $\mathbf{7}$ & $\mathbf{3 0}$ & 8 & 11 & 76 & 4 & 0 & 1 & 0 & 0 & 2 \\
$\mathbf{1 0}$ & $\mathbf{7}$ & $\mathbf{5 0}$ & 3 & 5 & 92 & 1 & 0 & 0 & 0 & 0 & 0 \\
$\mathbf{1 0}$ & $\mathbf{7}$ & $\mathbf{8 0}$ & 1 & 3 & 97 & 0 & 0 & 0 & 0 & 0 & 0 \\
$\mathbf{1 0}$ & $\mathbf{7}$ & $\mathbf{1 0 0}$ & 1 & 0 & 99 & 0 & 0 & 0 & 0 & 0 & 0 \\
$\mathbf{5 0}$ & $\mathbf{3}$ & $\mathbf{1 0}$ & 13 & 34 & 43 & 25 & 14 & 15 & 1 & 14 & 15 \\
$\mathbf{5 0}$ & $\mathbf{3}$ & $\mathbf{3 0}$ & 9 & 27 & 59 & 7 & 0 & 1 & 0 & 0 & 1 \\
$\mathbf{5 0}$ & $\mathbf{3}$ & $\mathbf{5 0}$ & 7 & 26 & 65 & 3 & 0 & 0 & 0 & 0 & 0 \\
$\mathbf{5 0}$ & $\mathbf{3}$ & $\mathbf{8 0}$ & 6 & 28 & 64 & 2 & 0 & 0 & 0 & 0 & 0 \\
$\mathbf{5 0}$ & $\mathbf{3}$ & $\mathbf{1 0 0}$ & 6 & 22 & 70 & 2 & 0 & 0 & 0 & 0 & 0 \\
$\mathbf{5 0}$ & $\mathbf{5}$ & $\mathbf{1 0}$ & 14 & 25 & 37 & 24 & 17 & 17 & 0 & 16 & 16 \\
$\mathbf{5 0}$ & $\mathbf{5}$ & $\mathbf{3 0}$ & 7 & 22 & 63 & 8 & 1 & 1 & 0 & 0 & 1 \\
$\mathbf{5 0}$ & $\mathbf{5}$ & $\mathbf{5 0}$ & 4 & 17 & 78 & 2 & 0 & 0 & 0 & 0 & 0 \\
$\mathbf{5 0}$ & $\mathbf{5}$ & $\mathbf{8 0}$ & 1 & 11 & 86 & 2 & 0 & 0 & 0 & 0 & 0 \\
$\mathbf{5 0}$ & $\mathbf{5}$ & $\mathbf{1 0 0}$ & 2 & 8 & 90 & 0 & 0 & 0 & 0 & 0 & 0 \\
$\mathbf{5 0}$ & $\mathbf{7}$ & $\mathbf{1 0}$ & 18 & 23 & 35 & 26 & 19 & 20 & 0 & 19 & 20 \\
$\mathbf{5 0}$ & $\mathbf{7}$ & $\mathbf{3 0}$ & 9 & 21 & 58 & 9 & 3 & 2 & 0 & 3 & 2 \\
$\mathbf{5 0}$ & $\mathbf{7}$ & $\mathbf{5 0}$ & 3 & 14 & 81 & 2 & 0 & 0 & 0 & 0 & 0 \\
$\mathbf{5 0}$ & $\mathbf{7}$ & $\mathbf{8 0}$ & 5 & 8 & 87 & 1 & 0 & 0 & 0 & 0 & 0 \\
$\mathbf{5 0}$ & $\mathbf{7}$ & $\mathbf{1 0 0}$ & 1 & 7 & 92 & 0 & 0 & 0 & 0 & 0 & 0 \\
\hline & & & & & & & & & & &
\end{tabular}


TABELA D.41 - Resultados das heurísticas para setup dependente por probabilidade de salto e porte do problema para flexibilidade alta (em \% de sucesso)

\begin{tabular}{cccccccccccc}
\hline $\boldsymbol{l}$ & $\boldsymbol{g}$ & $\boldsymbol{n}$ & $\mathbf{H d 1}$ & $\mathbf{H d 2}$ & $\mathbf{H d 3}$ & $\mathbf{H d 4}$ & $\mathbf{H d 5}$ & $\mathbf{H d 6}$ & $\mathbf{H d 7}$ & $\mathbf{R d 6}$ & $\mathbf{R d 1 0}$ \\
\hline $\mathbf{1 0}$ & $\mathbf{3}$ & $\mathbf{1 0}$ & 20 & 20 & 20 & 20 & 45 & 46 & 0 & 45 & 46 \\
$\mathbf{1 0}$ & $\mathbf{3}$ & $\mathbf{3 0}$ & 42 & 42 & 42 & 8 & 25 & 28 & 0 & 25 & $\mathbf{2 8}$ \\
$\mathbf{1 0}$ & $\mathbf{3}$ & $\mathbf{5 0}$ & 53 & 53 & 53 & 11 & 18 & 18 & 0 & 18 & 18 \\
$\mathbf{1 0}$ & $\mathbf{3}$ & $\mathbf{8 0}$ & 65 & 65 & 65 & 10 & 13 & 12 & 0 & 13 & 12 \\
$\mathbf{1 0}$ & $\mathbf{3}$ & $\mathbf{1 0 0}$ & 66 & 66 & 66 & 9 & 11 & 16 & 0 & 11 & 16 \\
$\mathbf{1 0}$ & $\mathbf{5}$ & $\mathbf{1 0}$ & 29 & 29 & 29 & 31 & 28 & 31 & 0 & 28 & 31 \\
$\mathbf{1 0}$ & $\mathbf{5}$ & $\mathbf{3 0}$ & 34 & 34 & 34 & 6 & 32 & 29 & 0 & 32 & $\mathbf{2 8}$ \\
$\mathbf{1 0}$ & $\mathbf{5}$ & $\mathbf{5 0}$ & 47 & 47 & 47 & 5 & 23 & 24 & 0 & 23 & 23 \\
$\mathbf{1 0}$ & $\mathbf{5}$ & $\mathbf{8 0}$ & 64 & 64 & 64 & 7 & 14 & 15 & 0 & 14 & 15 \\
$\mathbf{1 0}$ & $\mathbf{5}$ & $\mathbf{1 0 0}$ & 67 & 67 & 67 & 8 & 12 & 12 & 0 & 11 & 12 \\
$\mathbf{1 0}$ & $\mathbf{7}$ & $\mathbf{1 0}$ & 28 & 28 & 28 & 32 & 31 & 32 & 0 & 31 & 31 \\
$\mathbf{1 0}$ & $\mathbf{7}$ & $\mathbf{3 0}$ & 40 & 40 & 40 & 8 & 25 & 22 & 0 & 27 & 24 \\
$\mathbf{1 0}$ & $\mathbf{7}$ & $\mathbf{5 0}$ & 44 & 44 & 44 & 5 & 22 & 22 & 0 & 22 & 24 \\
$\mathbf{1 0}$ & $\mathbf{7}$ & $\mathbf{8 0}$ & $\mathbf{5 6}$ & $\mathbf{5 6}$ & 56 & 6 & 18 & 14 & 0 & 19 & 15 \\
$\mathbf{1 0}$ & $\mathbf{7}$ & $\mathbf{1 0 0}$ & 63 & 63 & 63 & 8 & 11 & 11 & 0 & 12 & 13 \\
$\mathbf{5 0}$ & $\mathbf{3}$ & $\mathbf{1 0}$ & 26 & 26 & 26 & 28 & 59 & 59 & 0 & 59 & 59 \\
$\mathbf{5 0}$ & $\mathbf{3}$ & $\mathbf{3 0}$ & 38 & 38 & 38 & 14 & 31 & 35 & 0 & 31 & 35 \\
$\mathbf{5 0}$ & $\mathbf{3}$ & $\mathbf{5 0}$ & 53 & 53 & 53 & 13 & 21 & 17 & 0 & 21 & 17 \\
$\mathbf{5 0}$ & $\mathbf{3}$ & $\mathbf{8 0}$ & 68 & 68 & 68 & 15 & 8 & 11 & 0 & 8 & 11 \\
$\mathbf{5 0}$ & $\mathbf{3}$ & $\mathbf{1 0 0}$ & 74 & 74 & 74 & 17 & 4 & 6 & 0 & 4 & 6 \\
$\mathbf{5 0}$ & $\mathbf{5}$ & $\mathbf{1 0}$ & 29 & 29 & 29 & 35 & 52 & 53 & 0 & 52 & 54 \\
$\mathbf{5 0}$ & $\mathbf{5}$ & $\mathbf{3 0}$ & 25 & 25 & 25 & 9 & 44 & 43 & 0 & 45 & 43 \\
$\mathbf{5 0}$ & $\mathbf{5}$ & $\mathbf{5 0}$ & 40 & 40 & 40 & 8 & 31 & 27 & 0 & 30 & 28 \\
$\mathbf{5 0}$ & $\mathbf{5}$ & $\mathbf{8 0}$ & $\mathbf{5 6}$ & $\mathbf{5 6}$ & $\mathbf{5 6}$ & 15 & 15 & 14 & 0 & 15 & 15 \\
$\mathbf{5 0}$ & $\mathbf{5}$ & $\mathbf{1 0 0}$ & 63 & 63 & 63 & 13 & 13 & 11 & 0 & 14 & 10 \\
$\mathbf{5 0}$ & $\mathbf{7}$ & $\mathbf{1 0}$ & 26 & 26 & 26 & 36 & 54 & 55 & 0 & 52 & 54 \\
$\mathbf{5 0}$ & $\mathbf{7}$ & $\mathbf{3 0}$ & 26 & 26 & 26 & 13 & 40 & 40 & 0 & 38 & 39 \\
$\mathbf{5 0}$ & $\mathbf{7}$ & $\mathbf{5 0}$ & 33 & 33 & 33 & 8 & 29 & 29 & 0 & 28 & 30 \\
$\mathbf{5 0}$ & $\mathbf{7}$ & $\mathbf{8 0}$ & $\mathbf{5 4}$ & $\mathbf{5 4}$ & $\mathbf{5 4}$ & 10 & 17 & 17 & 0 & 16 & 18 \\
$\mathbf{5 0}$ & $\mathbf{7}$ & $\mathbf{1 0 0}$ & 63 & 63 & 63 & 10 & 11 & 14 & 0 & 11 & 13 \\
\hline & & & & & & & & & & & \\
\hline
\end{tabular}


TABEla D.42 - Desvio relativo médio (em \%) das heurísticas para setup dependente por flexibilidade e porte do problema

\begin{tabular}{|c|c|c|c|c|c|c|c|c|c|c|c|}
\hline$f$ & $g$ & $n$ & Hd1 & Hd2 & $\mathrm{Hd} 3$ & $\mathrm{Hd} 4$ & Hd5 & Hd6 & Hd7 & Rd6 & Rd10 \\
\hline B & 3 & 10 & 10,6 & 6,0 & 4,4 & 7,2 & 9,8 & 10,2 & 68,7 & 9,8 & 10,2 \\
\hline B & 3 & 30 & 7,7 & 3,7 & 0,7 & 7,2 & 12,8 & 13,0 & 101,6 & 12,8 & 13,0 \\
\hline B & 3 & 50 & 8,1 & 4,1 & 0,3 & 7,2 & 15,1 & 15,2 & 117,4 & 15,1 & 15,2 \\
\hline B & 3 & 80 & 8,8 & 5,0 & 0,1 & 7,3 & 17,1 & 17,1 & 130,6 & 17,1 & 17,1 \\
\hline B & 3 & 100 & 9,3 & 5,2 & 0,1 & 7,2 & 18,0 & 18,0 & 134,2 & 18,0 & 18,0 \\
\hline B & 5 & 10 & 10,8 & 8,1 & 5,7 & 7,7 & 8,9 & 9,0 & 111,6 & 8,9 & 9,0 \\
\hline B & 5 & 30 & 8,8 & 5,7 & 1,1 & 6,6 & 10,0 & 10,0 & 175,0 & 10,0 & 10,0 \\
\hline B & 5 & 50 & 9,5 & 5,6 & 0,3 & 7,0 & 12,2 & 12,4 & 203,0 & 12,2 & 12,4 \\
\hline B & 5 & 80 & 11,4 & 6,1 & 0,1 & 7,3 & 14,1 & 14,1 & 229,7 & 14,1 & 14,1 \\
\hline B & 5 & 100 & 12,2 & 6,5 & 0,1 & 7,5 & 15,1 & 15,1 & 238,8 & 15,1 & 15,1 \\
\hline B & 7 & 10 & 10,1 & 11,4 & 5,4 & 6,9 & 8,3 & 8,2 & 151,6 & 8,3 & 8,3 \\
\hline B & 7 & 30 & 8,6 & 9,9 & 1,2 & 5,8 & 7,9 & 8,0 & 263,5 & 7,9 & 8,0 \\
\hline B & 7 & 50 & 10,5 & 9,4 & 0,4 & 5,6 & 9,6 & 9,7 & 316,0 & 9,6 & 9,8 \\
\hline B & 7 & 80 & 12,9 & 9,7 & 0,1 & 6,3 & 11,5 & 11,6 & 361,3 & 11,5 & 11,6 \\
\hline B & 7 & 100 & 13,9 & 9,5 & 0,1 & 6,8 & 12,7 & 12,7 & 382,4 & 12,6 & 12,7 \\
\hline M & 3 & 10 & 9,2 & 5,5 & 4,4 & 7,7 & 11,2 & 11,2 & 53,7 & 11,2 & 11,2 \\
\hline M & 3 & 30 & 4,9 & 2,5 & 1,0 & 8,1 & 15,8 & 15,7 & 66,8 & 15,8 & 15,7 \\
\hline M & 3 & 50 & 4,0 & 1,9 & 0,5 & 7,3 & 17,7 & 17,8 & 74,4 & 17,7 & 17,8 \\
\hline M & 3 & 80 & 3,3 & 1,7 & 0,3 & 6,8 & 19,6 & 19,6 & 81,3 & 19,6 & 19,6 \\
\hline M & 3 & 100 & 2,9 & 1,6 & 0,2 & 6,6 & 20,5 & 20,5 & 81,8 & 20,5 & 20,5 \\
\hline M & 5 & 10 & 9,9 & 6,9 & 5,1 & 7,4 & 8,9 & 8,8 & 97,0 & 9,0 & 9,0 \\
\hline M & 5 & 30 & 7,3 & 4,4 & 0,9 & 7,6 & 11,2 & 11,1 & 144,5 & 11,2 & 11,2 \\
\hline M & 5 & 50 & 7,4 & 4,4 & 0,4 & 7,6 & 13,5 & 13,6 & 164,1 & 13,5 & 13,6 \\
\hline M & 5 & 80 & 8,1 & 5,0 & 0,1 & 7,6 & 15,7 & 15,8 & 182,9 & 15,7 & 15,8 \\
\hline M & 5 & 100 & 8,5 & 5,4 & 0,1 & 7,7 & 16,5 & 16,6 & 191,2 & 16,5 & 16,6 \\
\hline M & 7 & 10 & 8,6 & 7,4 & 5,2 & 7,8 & 8,7 & 8,7 & 117,8 & 8,7 & 8,8 \\
\hline M & 7 & 30 & 7,1 & 4,7 & 1,2 & 7,3 & 10,5 & 10,5 & 181,8 & 10,6 & 10,5 \\
\hline M & 7 & 50 & 7,3 & 4,7 & 0,3 & 7,7 & 12,6 & 12,7 & 211,3 & 12,6 & 12,7 \\
\hline M & 7 & 80 & 7,7 & 5,1 & 0,2 & 7,7 & 14,7 & 14,8 & 236,0 & 14,7 & 14,8 \\
\hline M & 7 & 100 & 7,7 & 5,6 & 0,1 & 7,9 & 15,8 & 15,8 & 247,9 & 15,8 & 15,8 \\
\hline A & 3 & 10 & 11,6 & 11,6 & 11,6 & 15,8 & 4,2 & 4,3 & 95,8 & 4,2 & 4,3 \\
\hline A & 3 & 30 & 4,7 & 4,7 & 4,7 & 46,4 & 4,0 & 3,9 & 118,6 & 4,0 & 3,9 \\
\hline A & 3 & 50 & 2,6 & 2,6 & 2,6 & 55,8 & 5,0 & 5,0 & 128,8 & 5,0 & 5,0 \\
\hline A & 3 & 80 & 1,4 & 1,4 & 1,4 & 56,8 & 7,0 & 7,0 & 136,5 & 7,0 & 7,0 \\
\hline A & 3 & 100 & 1,2 & 1,2 & 1,2 & 61,9 & 7,9 & 7,8 & 142,2 & 7,9 & 7,8 \\
\hline A & 5 & 10 & 8,2 & 8,2 & 8,2 & 9,6 & 4,9 & 4,7 & 118,2 & 4,9 & 4,7 \\
\hline A & 5 & 30 & 5,0 & 5,0 & 5,0 & 31,6 & 2,9 & 2,8 & 184,2 & 2,9 & 2,8 \\
\hline A & 5 & 50 & 3,0 & 3,0 & 3,0 & 39,6 & 3,1 & 3,2 & 205,9 & 3,1 & 3,2 \\
\hline A & 5 & 80 & 1,7 & 1,7 & 1,7 & 38,7 & 4,5 & 4,6 & 221,0 & 4,5 & 4,6 \\
\hline A & 5 & 100 & 1,4 & 1,4 & 1,4 & 42,8 & 5,3 & 5,3 & 226,9 & 5,3 & 5,3 \\
\hline A & 7 & 10 & 7,4 & 7,4 & 7,4 & 7,3 & 4,7 & 4,7 & 134,8 & 4,7 & 4,7 \\
\hline A & 7 & 30 & 4,8 & 4,8 & 4,8 & 24,1 & 3,3 & 3,3 & 230,7 & 3,3 & 3,3 \\
\hline A & 7 & 50 & 3,4 & 3,4 & 3,4 & 31,0 & 2,8 & 2,8 & 268,3 & 2,8 & 2,8 \\
\hline A & 7 & 80 & 2,1 & 2,1 & 2,1 & 33,5 & 3,7 & 3,6 & 300,8 & 3,7 & 3,6 \\
\hline A & 7 & 100 & 1,6 & 1,6 & 1,6 & 32,9 & 3,9 & 4,0 & 310,8 & 4,0 & 4,0 \\
\hline
\end{tabular}


TABELA D.43 - Desvio-padrão do desvio relativo das heurísticas para setup dependente por flexibilidade e porte do problema

\begin{tabular}{|c|c|c|c|c|c|c|c|c|c|c|c|}
\hline$f$ & $g$ & $n$ & Hd1 & Hd2 & Hd3 & $\mathrm{Hd} 4$ & Hd5 & Hd6 & Hd7 & Rd6 & Rd10 \\
\hline B & 3 & 10 & 0,10 & 0,07 & 0,07 & 0,07 & 0,07 & 0,07 & 0,27 & 0,07 & 0,07 \\
\hline B & & 30 & 0,05 & 0,03 & 0,02 & 0,04 & 0,04 & 0,04 & 0,23 & 0,04 & 0,04 \\
\hline B & & 50 & 0,05 & 0,03 & 0,01 & 0,03 & 0,03 & 0,03 & 0,20 & 0,03 & 0,03 \\
\hline B & & 80 & 0,04 & 0,03 & 0,00 & 0,03 & 0,03 & 0,03 & 0,18 & 0,03 & 0,03 \\
\hline B & & 100 & 0,04 & 0,02 & 0,00 & 0,02 & 0,02 & 0,02 & 0,17 & 0,02 & 0,02 \\
\hline B & & 10 & 0,09 & 0,08 & 0,07 & 0,08 & 0,08 & 0,08 & 0,32 & 0,08 & 0,08 \\
\hline B & & 30 & 0,06 & 0,04 & 0,02 & 0,04 & 0,05 & 0,05 & 0,28 & 0,05 & 0,05 \\
\hline B & & 50 & 0,06 & 0,03 & 0,01 & 0,03 & 0,04 & 0,04 & 0,25 & 0,04 & 0,04 \\
\hline B & & 80 & 0,06 & 0,03 & 0,00 & 0,03 & 0,03 & 0,03 & 0,24 & 0,03 & 0,03 \\
\hline B & & 100 & 0,06 & 0,03 & 0,00 & 0,03 & 0,03 & 0,03 & 0,24 & 0,03 & 0,03 \\
\hline B & & 10 & 0,08 & 0,09 & 0,07 & 0,07 & 0,07 & 0,07 & 0,33 & 0,07 & 0,07 \\
\hline B & & 30 & 0,06 & 0,06 & 0,02 & 0,04 & 0,05 & 0,05 & 0,32 & 0,05 & 0,05 \\
\hline B & & 50 & 0,06 & 0,05 & 0,01 & 0,04 & 0,04 & 0,04 & 0,29 & 0,04 & 0,04 \\
\hline B & & 80 & 0,07 & 0,04 & 0,00 & 0,03 & 0,03 & 0,03 & 0,28 & 0,03 & 0,03 \\
\hline B & & 100 & 0,07 & 0,03 & 0,00 & 0,03 & 0,03 & 0,03 & 0,29 & 0,03 & 0,03 \\
\hline M & & 10 & 0,09 & 0,07 & 0,06 & 0,08 & 0,08 & 0,08 & 0,27 & 0,08 & 0,08 \\
\hline M & & 30 & 0,04 & 0,02 & 0,02 & 0,05 & 0,04 & 0,04 & 0,23 & 0,04 & 0,04 \\
\hline M & & 50 & 0,03 & 0,02 & 0,01 & 0,03 & 0,03 & 0,03 & 0,22 & 0,03 & 0,03 \\
\hline M & & 80 & 0,02 & 0,01 & 0,01 & 0,03 & 0,03 & 0,03 & 0,20 & 0,03 & 0,03 \\
\hline M & & 100 & 0,02 & 0,01 & 0,01 & 0,03 & 0,02 & 0,02 & 0,20 & 0,02 & 0,02 \\
\hline M & & 10 & 0,09 & 0,08 & 0,07 & 0,08 & 0,07 & 0,07 & 0,31 & 0,07 & 0,07 \\
\hline M & 5 & 30 & 0,05 & 0,04 & & 0,04 & 0,04 & 0,04 & 0,29 & 0,04 & 0,05 \\
\hline M & & 50 & & 0,03 & 01 & 0,04 & 0,04 & 0,04 & 0,27 & 0,04 & 0,04 \\
\hline M & & 80 & & 0,02 & 0,00 & 0,03 & 0,03 & 0,03 & 0,24 & 0,03 & 0,03 \\
\hline M & & 100 & 0,05 & 0,02 & 0,00 & 0,03 & 0,03 & 0,03 & 0,24 & 0,03 & 0,03 \\
\hline M & 7 & 10 & 0,08 & 0,07 & 0,07 & 0,08 & 0,07 & 0,07 & 0,33 & 0,07 & 0,07 \\
\hline M & & 30 & & & & & & & & & 0,05 \\
\hline M & & 50 & & 0,03 & 0,01 & 0,04 & 0,04 & 0,04 & 0,32 & 0,04 & 0,04 \\
\hline M & & 80 & & & & 0,03 & 0,03 & 0,0 & 0,31 & 0,03 & 0,03 \\
\hline M & & 100 & & & & 0,0 & 0,0 & & 0, & 0,03 & 0,03 \\
\hline A & & 10 & & & & 0,20 & 0,07 & 0,07 & 0,41 & 0,07 & 0,07 \\
\hline A & & 30 & & & & 0,46 & 0,04 & 0,04 & 0,39 & 0,04 & 0,04 \\
\hline A & & 50 & & & & & 0,0 & 0,0 & 0,37 & 0,05 & 0,04 \\
\hline A & & 80 & 0,03 & 0, & 0 & 0,56 & 0,05 & 0,05 & 0,34 & 0,05 & 0,05 \\
\hline A & & 100 & & 0, & & 0,5 & & $0, c$ & 0,34 & 0,05 & 0,05 \\
\hline A & & 10 & & & & & & & 0,42 & 0,07 & 0,07 \\
\hline A & & 30 & 0,05 & 0,05 & & 0,30 & 0 & 0,04 & 0,43 & 0,04 & 0,04 \\
\hline A & & 50 & 0,04 & 0,04 & 0,04 & 0,36 & 0,03 & 0,03 & 0,43 & 0,03 & 0,03 \\
\hline A & & 80 & & & & 0,37 & & 0,04 & 0,40 & 0,04 & 0,04 \\
\hline A & 5 & 100 & & & & & 0,04 & 0,04 & 0,41 & 0,04 & 0,04 \\
\hline A & & 10 & 0,0 & 0,08 & 0,08 & 0,09 & 0,07 & 0,07 & 0,39 & 0,07 & 0,07 \\
\hline A & & 30 & & & & & & & & 04 & 0,04 \\
\hline A & 7 & 50 & 0,04 & 0,0 & 0, & 0,27 & 0,0 & 0,03 & 0,45 & 0,03 & 0,03 \\
\hline A & & 80 & 0,0 & 0,03 & 0,0 & 0,31 & 0,03 & 0,03 & 0,47 & 0,03 & 0,03 \\
\hline A & 7 & 100 & 0,03 & 0,03 & 0,03 & 0,31 & 0,03 & 0,03 & 0,49 & 0,03 & 0,03 \\
\hline
\end{tabular}


TABELA D.44 - Resultado das heurísticas para setup dependente por parâmetro (em \% de sucesso)

\begin{tabular}{|c|c|c|c|c|c|c|c|c|c|c|c|c|c|c|}
\hline$n$ & $g$ & $f$ & $S$ & $a$ & $l$ & Hd1 & $\mathrm{Hd} 2$ & Hd3 & $\mathrm{Hd} 4$ & Hd5 & Hd6 & Hd7 & Rd6 & Rd10 \\
\hline 10 & 3 & B & $25-74$ & $0-50$ & 10 & 12 & 15 & 42 & 15 & 13 & 8 & 0 & 13 & 7 \\
\hline 10 & 3 & B & $25-74$ & $0-50$ & 50 & 14 & 33 & 34 & 23 & 4 & 4 & 1 & 4 & 4 \\
\hline 10 & 3 & B & $25-74$ & $50-100$ & 10 & 12 & 21 & 40 & 17 & 4 & 9 & 0 & 4 & 8 \\
\hline 10 & 3 & B & $25-74$ & $50-100$ & 50 & 10 & 29 & 44 & 26 & 3 & 4 & 0 & 3 & 4 \\
\hline 10 & 3 & B & $75-125$ & $0-50$ & 10 & 8 & 14 & 44 & 15 & 13 & 12 & 0 & 13 & 12 \\
\hline 10 & 3 & B & $75-125$ & $0-50$ & 50 & 8 & 30 & 43 & 16 & 7 & 4 & 1 & 7 & 4 \\
\hline 10 & 3 & B & $75-125$ & $50-100$ & 10 & 12 & 20 & 40 & 17 & 10 & 7 & 0 & 11 & 7 \\
\hline 10 & 3 & B & $75-125$ & $50-100$ & 50 & 18 & 32 & 40 & 25 & 2 & 2 & 0 & 3 & 3 \\
\hline 10 & 3 & $\mathbf{M}$ & $25-74$ & $0-50$ & 10 & 15 & 25 & 44 & 14 & 6 & 2 & 0 & 6 & 2 \\
\hline 10 & 3 & M & $25-74$ & $0-50$ & 50 & 13 & 37 & 45 & 18 & 15 & 16 & 0 & 15 & 16 \\
\hline 10 & 3 & M & $25-74$ & $50-100$ & 10 & 6 & 30 & 43 & 20 & 0 & 1 & 0 & 1 & 1 \\
\hline 10 & 3 & M & $25-74$ & $50-100$ & 50 & 14 & 41 & 36 & 26 & 13 & 13 & 1 & 13 & 13 \\
\hline 10 & 3 & M & $75-125$ & $0-50$ & 10 & 15 & 23 & 32 & 27 & 5 & 2 & 0 & 5 & 2 \\
\hline 10 & 3 & $\mathbf{M}$ & $75-125$ & $0-50$ & 50 & 11 & 25 & 48 & 25 & 18 & 18 & 0 & 18 & 18 \\
\hline 10 & 3 & M & $75-125$ & $50-100$ & 10 & 13 & 17 & 50 & 17 & 3 & 3 & 0 & 3 & 3 \\
\hline 10 & 3 & M & $75-125$ & $50-100$ & 50 & 15 & 32 & 41 & 31 & 11 & 13 & 3 & 11 & 13 \\
\hline 10 & 3 & A & $25-74$ & $0-50$ & 10 & 27 & 27 & 27 & 14 & 42 & 43 & 0 & 42 & 43 \\
\hline 10 & 3 & A & $25-74$ & $0-50$ & 50 & 29 & 29 & 29 & 31 & 53 & 51 & 0 & 53 & 51 \\
\hline 10 & 3 & A & $25-74$ & $50-100$ & 10 & 18 & 18 & 18 & 17 & 45 & 53 & 0 & 45 & 53 \\
\hline 10 & 3 & A & $25-74$ & $50-100$ & 50 & 26 & 26 & 26 & 32 & 57 & 55 & 0 & 57 & 55 \\
\hline 10 & 3 & A & $75-125$ & $0-50$ & 10 & 17 & 17 & 17 & 22 & 47 & 47 & 0 & 47 & 47 \\
\hline 10 & 3 & A & $75-125$ & $0-50$ & 50 & 20 & 20 & 20 & 26 & 63 & 65 & 1 & 63 & 65 \\
\hline 10 & 3 & A & $75-125$ & $50-100$ & 10 & 18 & 18 & 18 & 25 & 47 & 42 & 0 & 47 & 42 \\
\hline 10 & 3 & A & $75-125$ & $50-100$ & 50 & 27 & 27 & 27 & 21 & 64 & 63 & 0 & 64 & 63 \\
\hline 10 & 5 & B & $25-74$ & $0-50$ & 10 & 17 & 14 & 26 & 22 & 13 & 13 & 0 & 11 & 12 \\
\hline 10 & 5 & B & $25-74$ & $0-50$ & 50 & 11 & 22 & 33 & 19 & 19 & 17 & 0 & 18 & 16 \\
\hline 10 & 5 & B & $25-74$ & $50-100$ & 10 & 12 & 22 & 35 & 17 & 12 & 11 & 0 & 12 & 10 \\
\hline 10 & 5 & B & $25-74$ & $50-100$ & 50 & 9 & 35 & 38 & 14 & 8 & 13 & 0 & 8 & 12 \\
\hline 10 & 5 & B & $75-125$ & $0-50$ & 10 & 12 & 7 & 34 & 28 & 11 & 13 & 0 & 11 & 14 \\
\hline 10 & 5 & B & $75-125$ & $0-50$ & 50 & 11 & 22 & 38 & 24 & 11 & 10 & 0 & 11 & 10 \\
\hline 10 & 5 & B & $75-125$ & $50-100$ & 10 & 5 & 9 & 35 & 28 & 14 & 14 & 0 & 17 & 16 \\
\hline 10 & 5 & B & $75-125$ & $50-100$ & 50 & 11 & 28 & 34 & 29 & 10 & 10 & 0 & 11 & 11 \\
\hline 10 & 5 & $\mathbf{M}$ & $25-74$ & $0-50$ & 10 & 12 & 18 & 43 & 20 & 3 & 8 & 0 & 3 & 8 \\
\hline 10 & 5 & M & $25-74$ & $0-50$ & 50 & 13 & 28 & 43 & 23 & 13 & 14 & 0 & 13 & 14 \\
\hline 10 & 5 & $\mathbf{M}$ & $25-74$ & $50-100$ & 10 & 14 & 27 & 36 & 13 & 8 & 11 & 0 & 8 & 11 \\
\hline 10 & 5 & $\mathbf{M}$ & $25-74$ & $50-100$ & 50 & 19 & 29 & 38 & 25 & 11 & 12 & 0 & 11 & 12 \\
\hline 10 & 5 & $\mathbf{M}$ & $75-125$ & $0-50$ & 10 & 11 & 16 & 38 & 13 & 16 & 14 & 0 & 15 & 15 \\
\hline 10 & 5 & $\mathbf{M}$ & $75-125$ & $0-50$ & 50 & 12 & 18 & 34 & 27 & 24 & 22 & 0 & 22 & 20 \\
\hline 10 & 5 & M & $75-125$ & $50-100$ & 10 & 5 & 18 & 34 & 22 & 13 & 15 & 0 & 13 & 16 \\
\hline 10 & 5 & $\mathbf{M}$ & $75-125$ & $50-100$ & 50 & 13 & 23 & 32 & 22 & 21 & 19 & 0 & 19 & 18 \\
\hline 10 & 5 & A & $25-74$ & $0-50$ & 10 & 30 & 30 & 30 & 29 & 30 & 31 & 0 & 30 & 31 \\
\hline 10 & 5 & A & $25-74$ & $0-50$ & 50 & 26 & 26 & 26 & 38 & 54 & 56 & 0 & 53 & 56 \\
\hline 10 & 5 & A & $25-74$ & $50-100$ & 10 & 34 & 34 & 34 & 20 & 33 & 34 & 0 & 33 & 34 \\
\hline 10 & 5 & A & $25-74$ & $50-100$ & 50 & 28 & 28 & 28 & 27 & 57 & 61 & 0 & 58 & 64 \\
\hline 10 & 5 & A & $75-125$ & $0-50$ & 10 & 25 & 25 & 25 & 39 & 21 & 29 & 0 & 21 & 29 \\
\hline 10 & 5 & A & $75-125$ & $0-50$ & 50 & 33 & 33 & 33 & 43 & 45 & 42 & 0 & 45 & 42 \\
\hline 10 & 5 & A & $75-125$ & $50-100$ & 10 & 25 & 25 & 25 & 34 & 28 & 31 & 0 & 28 & 31 \\
\hline 10 & 5 & A & $75-125$ & $50-100$ & 50 & 28 & 28 & 28 & 31 & 53 & 54 & 0 & 53 & 54 \\
\hline 10 & 7 & B & $25-74$ & $0-50$ & 10 & 15 & 3 & 41 & 24 & 10 & 12 & 0 & 8 & 11 \\
\hline 10 & 7 & B & $25-74$ & $0-50$ & 50 & 8 & 19 & 39 & 16 & 14 & 17 & 0 & 15 & 18 \\
\hline 10 & 7 & B & $25-74$ & $50-100$ & 10 & 11 & 8 & 46 & 21 & 8 & 9 & 0 & 9 & 10 \\
\hline 10 & 7 & B & $25-74$ & $50-100$ & 50 & 17 & 16 & 33 & 28 & 11 & 10 & 0 & 12 & 11 \\
\hline 10 & 7 & B & $75-125$ & $0-50$ & 10 & 18 & 1 & 26 & 32 & 13 & 15 & 0 & 12 & 15 \\
\hline 10 & 7 & B & $75-125$ & $0-50$ & 50 & 13 & 17 & 29 & 25 & 20 & 19 & 0 & 19 & 17 \\
\hline 10 & 7 & B & $75-125$ & $50-100$ & 10 & 14 & 3 & 39 & 28 & 13 & 12 & 0 & 13 & 12 \\
\hline 10 & 7 & B & $75-125$ & $50-100$ & 50 & 10 & 22 & 25 & 25 & 22 & 22 & 0 & 22 & 22 \\
\hline 10 & 7 & $\mathbf{M}$ & $25-74$ & $0-50$ & 10 & 14 & 16 & 31 & 13 & 15 & 8 & 0 & 18 & 13 \\
\hline 10 & 7 & M & $25-74$ & $0-50$ & 50 & 14 & 25 & 30 & 24 & 23 & 27 & 0 & 22 & 25 \\
\hline
\end{tabular}




\begin{tabular}{|c|c|c|c|c|c|c|c|c|c|c|c|c|c|c|}
\hline 10 & 7 & $\bar{M}$ & $25-74$ & $50-100$ & 10 & 15 & 17 & 46 & 11 & 4 & 9 & 0 & 6 & 9 \\
\hline 10 & 7 & M & $25-74$ & $50-100$ & 50 & 10 & 20 & 43 & 22 & 20 & 17 & 0 & 22 & 19 \\
\hline 10 & 7 & M & $75-125$ & $0-50$ & 10 & 13 & 15 & 28 & 26 & 12 & 11 & 0 & 12 & 11 \\
\hline 10 & 7 & M & $75-125$ & $0-50$ & 50 & 22 & 15 & 33 & 31 & 20 & 21 & 0 & 20 & 21 \\
\hline 10 & 7 & M & $75-125$ & $50-100$ & 10 & 12 & 16 & 39 & 13 & 13 & 11 & 0 & 14 & 11 \\
\hline 10 & 7 & M & $75-125$ & $50-100$ & 50 & 24 & 33 & 34 & 28 & 13 & 13 & 0 & 13 & 13 \\
\hline 10 & 7 & A & $25-74$ & $0-50$ & 10 & 25 & 25 & 25 & 37 & 26 & 31 & 0 & 26 & 30 \\
\hline 10 & 7 & A & $25-74$ & $0-50$ & 50 & 22 & 22 & 22 & 39 & 53 & 54 & 0 & 49 & 50 \\
\hline 10 & 7 & A & $25-74$ & $50-100$ & 10 & 36 & 36 & 36 & 23 & 27 & 28 & 0 & 28 & 29 \\
\hline 10 & 7 & A & $25-74$ & $50-100$ & 50 & 25 & 25 & 25 & 26 & 60 & 64 & 0 & 61 & 65 \\
\hline 10 & 7 & A & $75-125$ & $0-50$ & 10 & 25 & 25 & 25 & 40 & 30 & 25 & 0 & 29 & 24 \\
\hline 10 & 7 & A & $75-125$ & $0-50$ & 50 & 31 & 31 & 31 & 31 & 55 & 55 & 0 & 53 & 53 \\
\hline 10 & 7 & A & $75-125$ & $50-100$ & 10 & 24 & 24 & 24 & 26 & 39 & 43 & 0 & 39 & 42 \\
\hline 10 & 7 & A & $75-125$ & $50-100$ & 50 & 27 & 27 & 27 & 47 & 47 & 48 & 0 & 46 & 47 \\
\hline 30 & 3 & B & $25-74$ & $0-50$ & 10 & 9 & 18 & 74 & 0 & 0 & 0 & 0 & 0 & 0 \\
\hline 30 & 3 & B & $25-74$ & $0-50$ & 50 & 12 & 21 & 64 & 3 & 0 & 0 & 0 & 0 & 0 \\
\hline 30 & 3 & B & $25-74$ & $50-100$ & 10 & 5 & 17 & 74 & 4 & 0 & 0 & 0 & 0 & 0 \\
\hline 30 & 3 & B & $25-74$ & $50-100$ & 50 & 5 & 24 & 66 & 6 & 0 & 0 & 0 & 0 & 0 \\
\hline 30 & 3 & B & $75-125$ & $0-50$ & 10 & 5 & 8 & 83 & 1 & 2 & 1 & 0 & 2 & 1 \\
\hline 30 & 3 & B & $75-125$ & $0-50$ & 50 & 8 & 27 & 60 & 5 & 0 & 0 & 0 & 0 & 0 \\
\hline 30 & 3 & B & $75-125$ & $50-100$ & 10 & 5 & 12 & 79 & 5 & 0 & 0 & 0 & 0 & 0 \\
\hline 30 & 3 & B & $75-125$ & $50-100$ & 50 & 2 & 22 & 72 & 5 & 0 & 0 & 0 & 0 & 0 \\
\hline 30 & 3 & M & $25-74$ & $0-50$ & 10 & 14 & 17 & 73 & 0 & 0 & 0 & 0 & 0 & 0 \\
\hline 30 & 3 & M & $25-74$ & $0-50$ & 50 & 11 & 28 & 58 & 5 & 0 & 0 & 0 & 0 & 0 \\
\hline 30 & 3 & M & $25-74$ & $50-100$ & 10 & 8 & 22 & 67 & 3 & 0 & 0 & 0 & 0 & 0 \\
\hline 30 & 3 & M & $25-74$ & $50-100$ & 50 & 2 & 26 & 63 & 7 & 0 & 2 & 0 & 0 & 2 \\
\hline 30 & 3 & M & $75-125$ & $0-50$ & 10 & 16 & 16 & 68 & 0 & 0 & 0 & 0 & 0 & 0 \\
\hline 30 & 3 & M & $75-125$ & $0-50$ & 50 & 17 & 22 & 58 & 6 & 0 & 0 & 0 & 0 & 0 \\
\hline 30 & 3 & M & $75-125$ & $50-100$ & 10 & 8 & 27 & 61 & 4 & 0 & 0 & 0 & 0 & 0 \\
\hline 30 & 3 & M & $75-125$ & $50-100$ & 50 & 5 & 31 & 58 & 8 & 1 & 0 & 0 & 1 & 0 \\
\hline 30 & 3 & A & $25-74$ & $0-50$ & 10 & 46 & 46 & 46 & 6 & 19 & 31 & 0 & 19 & 31 \\
\hline 30 & 3 & A & $25-74$ & $0-50$ & 50 & 47 & 47 & 47 & 11 & 24 & 28 & 0 & 24 & 28 \\
\hline 30 & 3 & A & $25-74$ & $50-100$ & 10 & 50 & 50 & 50 & 10 & 17 & 22 & 0 & 18 & 22 \\
\hline 30 & 3 & A & $25-74$ & $50-100$ & 50 & 37 & 37 & 37 & 12 & 30 & 33 & 0 & 31 & 33 \\
\hline 30 & 3 & A & $75-125$ & $0-50$ & 10 & 37 & 37 & 37 & 2 & 29 & 34 & 0 & 29 & 34 \\
\hline 30 & 3 & A & $75-125$ & $0-50$ & 50 & 28 & 28 & 28 & 14 & 40 & 39 & 0 & 40 & 39 \\
\hline 30 & 3 & A & $75-125$ & $50-100$ & 10 & 34 & 34 & 34 & 12 & 35 & 23 & 0 & 35 & 23 \\
\hline 30 & 3 & A & $75-125$ & $50-100$ & 50 & 39 & 39 & 39 & 17 & 30 & 40 & 0 & 30 & 40 \\
\hline 30 & 5 & B & $25-74$ & $0-50$ & 10 & 4 & 6 & 83 & 8 & 0 & 0 & 0 & 0 & 0 \\
\hline 30 & 5 & B & $25-74$ & $0-50$ & 50 & 14 & 24 & 58 & 4 & 0 & 0 & 0 & 0 & 0 \\
\hline 30 & 5 & B & $25-74$ & $50-100$ & 10 & 6 & 9 & 82 & 2 & 1 & 0 & 0 & 0 & 0 \\
\hline 30 & 5 & B & $25-74$ & $50-100$ & 50 & 6 & 21 & 63 & 7 & 0 & 3 & 0 & 0 & 3 \\
\hline 30 & 5 & B & $75-125$ & $0-50$ & 10 & 8 & 1 & 70 & 14 & 4 & 1 & 0 & 4 & 3 \\
\hline 30 & 5 & B & $75-125$ & $0-50$ & 50 & 5 & 17 & 63 & 11 & 3 & 1 & 0 & 3 & 1 \\
\hline 30 & 5 & B & $75-125$ & $50-100$ & 10 & 3 & 7 & 75 & 12 & 1 & 2 & 0 & 1 & 2 \\
\hline 30 & 5 & B & $75-125$ & $50-100$ & 50 & 7 & 23 & 60 & 9 & 0 & 1 & 0 & 0 & 1 \\
\hline 30 & 5 & M & $25-74$ & $0-50$ & 10 & 3 & 11 & 83 & 2 & 0 & 1 & 0 & 0 & 1 \\
\hline 30 & 5 & M & $25-74$ & $0-50$ & 50 & 7 & 23 & 58 & 11 & 0 & 0 & 0 & 0 & 1 \\
\hline 30 & 5 & M & $25-74$ & $50-100$ & 10 & 6 & 13 & 79 & 1 & 0 & 1 & 0 & 0 & 1 \\
\hline 30 & 5 & M & $25-74$ & $50-100$ & 50 & 7 & 22 & 66 & 6 & 0 & 1 & 0 & 0 & 1 \\
\hline 30 & 5 & M & $75-125$ & $0-50$ & 10 & 9 & 5 & 80 & 5 & 1 & 0 & 0 & 1 & 0 \\
\hline 30 & 5 & M & $75-125$ & $0-50$ & 50 & 7 & 22 & 59 & 7 & 3 & 3 & 0 & 1 & 2 \\
\hline 30 & 5 & M & $75-125$ & $50-100$ & 10 & 10 & 8 & 77 & 5 & 0 & 1 & 0 & 0 & 1 \\
\hline 30 & 5 & M & $75-125$ & $50-100$ & 50 & 5 & 20 & 68 & 7 & 0 & 0 & 0 & 0 & 0 \\
\hline 30 & 5 & A & $25-74$ & $0-50$ & 10 & 45 & 45 & 45 & 7 & 28 & 17 & 0 & 30 & 18 \\
\hline 30 & 5 & A & $25-74$ & $0-50$ & 50 & 24 & 24 & 24 & 8 & 40 & 50 & 0 & 43 & 50 \\
\hline 30 & 5 & A & $25-74$ & $50-100$ & 10 & 37 & 37 & 37 & 1 & 35 & 27 & 0 & 34 & 25 \\
\hline 30 & 5 & A & $25-74$ & $50-100$ & 50 & 29 & 29 & 29 & 11 & 40 & 33 & 0 & 41 & 35 \\
\hline 30 & 5 & A & $75-125$ & $0-50$ & 10 & 21 & 21 & 21 & 10 & 34 & 36 & 0 & 34 & 36 \\
\hline 30 & 5 & A & $75-125$ & $0-50$ & 50 & 27 & 27 & 27 & 3 & 53 & 44 & 0 & 51 & 43 \\
\hline 30 & 5 & A & $75-125$ & $50-100$ & 10 & 31 & 31 & 31 & 6 & 29 & 35 & 0 & 29 & 34 \\
\hline 30 & 5 & A & $75-125$ & $50-100$ & 50 & 20 & 20 & 20 & 15 & 44 & 46 & 0 & 44 & 45 \\
\hline
\end{tabular}




\begin{tabular}{|c|c|c|c|c|c|c|c|c|c|c|c|c|c|c|}
\hline 30 & 7 & B & $25-74$ & $0-50$ & 10 & 12 & 0 & 78 & 7 & 2 & 1 & 0 & 1 & 1 \\
\hline 30 & 7 & B & $25-74$ & $0-50$ & 50 & 10 & 10 & 64 & 10 & 2 & 4 & 0 & 2 & 4 \\
\hline 30 & 7 & B & $25-74$ & $50-100$ & 10 & 3 & 3 & 75 & 13 & 1 & 3 & 0 & 2 & 2 \\
\hline 30 & 7 & B & $25-74$ & $50-100$ & 50 & 9 & 7 & 68 & 7 & 9 & 4 & 0 & 7 & 3 \\
\hline 30 & 7 & B & $75-125$ & $0-50$ & 10 & 5 & 1 & 61 & 17 & 10 & 4 & 0 & 11 & 4 \\
\hline 30 & 7 & B & $75-125$ & $0-50$ & 50 & 6 & 6 & 48 & 21 & 10 & 11 & 0 & 12 & 11 \\
\hline 30 & 7 & B & $75-125$ & $50-100$ & 10 & 5 & 0 & 64 & 21 & 7 & 2 & 0 & 6 & 1 \\
\hline 30 & 7 & B & $75-125$ & $50-100$ & 50 & 11 & 12 & 58 & 10 & 7 & 3 & 0 & 9 & 4 \\
\hline 30 & 7 & M & $25-74$ & $0-50$ & 10 & 11 & 13 & 77 & 1 & 0 & 0 & 0 & 0 & 0 \\
\hline 30 & 7 & M & $25-74$ & $0-50$ & 50 & 10 & 17 & 62 & 9 & 2 & 0 & 0 & 3 & 0 \\
\hline 30 & 7 & $\mathbf{M}$ & $25-74$ & $50-100$ & 10 & 5 & 12 & 80 & 3 & 0 & 0 & 0 & 0 & 0 \\
\hline 30 & 7 & M & $25-74$ & $50-100$ & 50 & 8 & 20 & 65 & 7 & 0 & 0 & 0 & 0 & 0 \\
\hline 30 & 7 & M & $75-125$ & $0-50$ & 10 & 7 & 13 & 71 & 5 & 0 & 2 & 0 & 0 & 4 \\
\hline 30 & 7 & M & $75-125$ & $0-50$ & 50 & 11 & 17 & 50 & 13 & 7 & 5 & 0 & 7 & 5 \\
\hline 30 & 7 & $\mathbf{M}$ & $75-125$ & $50-100$ & 10 & 10 & 7 & 76 & 5 & 0 & 1 & 0 & 0 & 2 \\
\hline 30 & 7 & $\mathbf{M}$ & $75-125$ & $50-100$ & 50 & 7 & 30 & 54 & 6 & 2 & 3 & 0 & 2 & 3 \\
\hline 30 & 7 & A & $25-74$ & $0-50$ & 10 & 49 & 49 & 49 & 7 & 19 & 19 & 0 & 19 & 21 \\
\hline 30 & 7 & A & $25-74$ & $0-50$ & 50 & 19 & 19 & 19 & 14 & 44 & 35 & 0 & 43 & 34 \\
\hline 30 & 7 & A & $25-74$ & $50-100$ & 10 & 38 & 38 & 38 & 6 & 25 & 20 & 0 & 32 & 24 \\
\hline 30 & 7 & A & $25-74$ & $50-100$ & 50 & 30 & 30 & 30 & 12 & 33 & 39 & 0 & 30 & 37 \\
\hline 30 & 7 & A & $75-125$ & $0-50$ & 10 & 34 & 34 & 34 & 12 & 29 & 25 & 0 & 29 & 26 \\
\hline 30 & 7 & A & $75-125$ & $0-50$ & 50 & 33 & 33 & 33 & 10 & 43 & 43 & 0 & 38 & 41 \\
\hline 30 & 7 & A & $75-125$ & $50-100$ & 10 & 40 & 40 & 40 & 7 & 28 & 24 & 0 & 27 & 24 \\
\hline 30 & 7 & A & $75-125$ & $50-100$ & 50 & 23 & 23 & 23 & 16 & 40 & 43 & 0 & 39 & 45 \\
\hline 50 & 3 & B & $25-74$ & $0-50$ & 10 & 3 & 9 & 88 & 1 & 0 & 0 & 0 & 0 & 0 \\
\hline 50 & 3 & B & $25-74$ & $0-50$ & 50 & 4 & 26 & 69 & 3 & 0 & 0 & 0 & 0 & 0 \\
\hline 50 & 3 & B & $25-74$ & $50-100$ & 10 & 2 & 3 & 94 & 1 & 0 & 0 & 0 & 0 & 0 \\
\hline 50 & 3 & B & $25-74$ & $50-100$ & 50 & 3 & 17 & 77 & 4 & 0 & 0 & 0 & 0 & 0 \\
\hline 50 & 3 & B & $75-125$ & $0-50$ & 10 & 5 & 7 & 87 & 1 & 0 & 0 & 0 & 0 & 0 \\
\hline 50 & 3 & B & $75-125$ & $0-50$ & 50 & 2 & 16 & 79 & 3 & 0 & 0 & 0 & 0 & 0 \\
\hline 50 & 3 & B & $75-125$ & $50-100$ & 10 & 4 & 3 & 92 & 1 & 0 & 0 & 0 & 0 & 0 \\
\hline 50 & 3 & B & $75-125$ & $50-100$ & 50 & 2 & 11 & 81 & 6 & 0 & 0 & 0 & 0 & 0 \\
\hline 50 & 3 & M & $25-74$ & $0-50$ & 10 & 9 & 24 & 67 & 0 & 0 & 0 & 0 & 0 & 0 \\
\hline 50 & 3 & $\mathbf{M}$ & $25-74$ & $0-50$ & 50 & 10 & 22 & 68 & 3 & 0 & 0 & 0 & 0 & 0 \\
\hline 50 & 3 & $\mathbf{M}$ & $25-74$ & $50-100$ & 10 & 4 & 22 & 72 & 2 & 0 & 0 & 0 & 0 & 0 \\
\hline 50 & 3 & $\mathbf{M}$ & $25-74$ & $50-100$ & 50 & 7 & 32 & 57 & 6 & 0 & 0 & 0 & 0 & 0 \\
\hline 50 & 3 & M & $75-125$ & $0-50$ & 10 & 6 & 23 & 72 & 0 & 0 & 0 & 0 & 0 & 0 \\
\hline 50 & 3 & $\mathbf{M}$ & $75-125$ & $0-50$ & 50 & 8 & 24 & 68 & 1 & 0 & 0 & 0 & 0 & 0 \\
\hline 50 & 3 & M & $75-125$ & $50-100$ & 10 & 1 & 20 & 78 & 1 & 0 & 0 & 0 & 0 & 0 \\
\hline 50 & 3 & M & $75-125$ & $50-100$ & 50 & 4 & 27 & 68 & 2 & 0 & 0 & 0 & 0 & 0 \\
\hline 50 & 3 & A & $25-74$ & $0-50$ & 10 & 59 & 59 & 59 & 6 & 22 & 13 & 0 & 22 & 13 \\
\hline 50 & 3 & A & $25-74$ & $0-50$ & 50 & 56 & 56 & 56 & 9 & 18 & 22 & 0 & 18 & 22 \\
\hline 50 & 3 & A & $25-74$ & $50-100$ & 10 & 61 & 61 & 61 & 19 & 11 & 11 & 0 & 10 & 11 \\
\hline 50 & 3 & A & $25-74$ & $50-100$ & 50 & 64 & 64 & 64 & 10 & 19 & 8 & 0 & 19 & 8 \\
\hline 50 & 3 & A & $75-125$ & $0-50$ & 10 & 45 & 45 & 45 & 7 & 25 & 23 & 0 & 25 & 23 \\
\hline 50 & 3 & A & $75-125$ & $0-50$ & 50 & 46 & 46 & 46 & 16 & 24 & 20 & 0 & 24 & 20 \\
\hline 50 & 3 & A & $75-125$ & $50-100$ & 10 & 47 & 47 & 47 & 13 & 14 & 26 & 0 & 14 & 26 \\
\hline 50 & 3 & A & $75-125$ & $50-100$ & 50 & 46 & 46 & 46 & 18 & 22 & 18 & 0 & 22 & 18 \\
\hline 50 & 5 & B & $25-74$ & $0-50$ & 10 & 1 & 6 & 93 & 0 & 0 & 0 & 0 & 0 & 0 \\
\hline 50 & 5 & B & $25-74$ & $0-50$ & 50 & 2 & 15 & 82 & 1 & 0 & 0 & 0 & 0 & 0 \\
\hline 50 & 5 & B & $25-74$ & $50-100$ & 10 & 0 & 0 & 100 & 0 & 0 & 0 & 0 & 0 & 0 \\
\hline 50 & 5 & B & $25-74$ & $50-100$ & 50 & 1 & 18 & 74 & 7 & 0 & 0 & 0 & 0 & 0 \\
\hline 50 & 5 & B & $75-125$ & $0-50$ & 10 & 5 & 1 & 94 & 1 & 0 & 0 & 0 & 0 & 0 \\
\hline 50 & 5 & B & $75-125$ & $0-50$ & 50 & 7 & 10 & 78 & 4 & 1 & 0 & 0 & 1 & 0 \\
\hline 50 & 5 & B & $75-125$ & $50-100$ & 10 & 5 & 1 & 85 & 9 & 0 & 0 & 0 & 0 & 0 \\
\hline 50 & 5 & B & $75-125$ & $50-100$ & 50 & 1 & 13 & 81 & 5 & 0 & 0 & 0 & 0 & 0 \\
\hline 50 & 5 & M & $25-74$ & $0-50$ & 10 & 1 & 6 & 93 & 0 & 0 & 0 & 0 & 0 & 0 \\
\hline 50 & 5 & $\mathbf{M}$ & $25-74$ & $0-50$ & 50 & 4 & 15 & 81 & 0 & 0 & 0 & 0 & 0 & 0 \\
\hline 50 & 5 & M & $25-74$ & $50-100$ & 10 & 0 & 4 & 95 & 1 & 0 & 0 & 0 & 0 & 0 \\
\hline 50 & 5 & M & $25-74$ & $50-100$ & 50 & 3 & 18 & 79 & 0 & 0 & 0 & 0 & 0 & 0 \\
\hline 50 & 5 & $\mathbf{M}$ & $75-125$ & $0-50$ & 10 & 5 & 6 & 88 & 1 & 0 & 0 & 0 & 0 & 0 \\
\hline 50 & 5 & $\mathbf{M}$ & $75-125$ & $0-50$ & 50 & 4 & 19 & 72 & 5 & 0 & 0 & 0 & 0 & 0 \\
\hline
\end{tabular}




\begin{tabular}{|c|c|c|c|c|c|c|c|c|c|c|c|c|c|c|}
\hline 50 & 5 & $\bar{M}$ & $75-125$ & $50-100$ & 10 & 9 & 3 & 86 & 2 & 0 & 0 & 0 & 0 & 0 \\
\hline 50 & 5 & M & $75-125$ & $50-100$ & 50 & 3 & 17 & 78 & 2 & 0 & 0 & 0 & 0 & 0 \\
\hline 50 & 5 & A & $25-74$ & $0-50$ & 10 & 50 & 50 & 50 & 5 & 26 & 18 & 0 & 27 & 15 \\
\hline 50 & 5 & A & $25-74$ & $0-50$ & 50 & 43 & 43 & 43 & 5 & 23 & 31 & 0 & 23 & 32 \\
\hline 50 & 5 & A & $25-74$ & $50-100$ & 10 & 54 & 54 & 54 & 6 & 16 & 21 & 0 & 18 & 21 \\
\hline 50 & 5 & A & $25-74$ & $50-100$ & 50 & 43 & 43 & 43 & 10 & 31 & 17 & 0 & 31 & 18 \\
\hline 50 & 5 & A & $75-125$ & $0-50$ & 10 & 42 & 42 & 42 & 3 & 22 & 31 & 0 & 23 & 31 \\
\hline 50 & 5 & A & $75-125$ & $0-50$ & 50 & 29 & 29 & 29 & 3 & 37 & 37 & 0 & 35 & 35 \\
\hline 50 & 5 & A & $75-125$ & $50-100$ & 10 & 40 & 40 & 40 & 7 & 27 & 26 & 0 & 25 & 25 \\
\hline 50 & 5 & A & $75-125$ & $50-100$ & 50 & 45 & 45 & 45 & 12 & 31 & 23 & 0 & 30 & 25 \\
\hline 50 & 7 & B & $25-74$ & $0-50$ & 10 & 2 & 0 & 96 & 2 & 0 & 0 & 0 & 0 & 0 \\
\hline 50 & 7 & B & $25-74$ & $0-50$ & 50 & 4 & 2 & 87 & 7 & 0 & 0 & 0 & 0 & 0 \\
\hline 50 & 7 & B & $25-74$ & $50-100$ & 10 & 3 & 1 & 94 & 2 & 0 & 0 & 0 & 0 & 0 \\
\hline 50 & 7 & B & $25-74$ & $50-100$ & 50 & 5 & 13 & 74 & 7 & 0 & 1 & 0 & 0 & 0 \\
\hline 50 & 7 & B & $75-125$ & $0-50$ & 10 & 3 & 0 & 84 & 10 & 1 & 0 & 0 & 2 & 1 \\
\hline 50 & 7 & B & $75-125$ & $0-50$ & 50 & 8 & 4 & 73 & 13 & 2 & 0 & 0 & 2 & 0 \\
\hline 50 & 7 & B & $75-125$ & $50-100$ & 10 & 12 & 1 & 73 & 12 & 2 & 0 & 0 & 1 & 0 \\
\hline 50 & 7 & B & $75-125$ & $50-100$ & 50 & 3 & 2 & 83 & 9 & 2 & 1 & 0 & 2 & 1 \\
\hline 50 & 7 & M & $25-74$ & $0-50$ & 10 & 1 & 7 & 92 & 0 & 0 & 0 & 0 & 0 & 0 \\
\hline 50 & 7 & M & $25-74$ & $0-50$ & 50 & 5 & 17 & 77 & 1 & 0 & 0 & 0 & 0 & 0 \\
\hline 50 & 7 & M & $25-74$ & $50-100$ & 10 & 2 & 6 & 92 & 0 & 0 & 0 & 0 & 0 & 0 \\
\hline 50 & 7 & M & $25-74$ & $50-100$ & 50 & 2 & 12 & 85 & 1 & 0 & 0 & 0 & 0 & 0 \\
\hline 50 & 7 & M & $75-125$ & $0-50$ & 10 & 3 & 1 & 94 & 2 & 0 & 0 & 0 & 0 & 0 \\
\hline 50 & 7 & M & $75-125$ & $0-50$ & 50 & 6 & 11 & 80 & 3 & 0 & 0 & 0 & 0 & 0 \\
\hline 50 & 7 & M & $75-125$ & $50-100$ & 10 & 6 & 4 & 89 & 1 & 0 & 0 & 0 & 0 & 0 \\
\hline 50 & 7 & M & $75-125$ & $50-100$ & 50 & 0 & 14 & 83 & 3 & 0 & 0 & 0 & 0 & 0 \\
\hline 50 & 7 & A & $25-74$ & $0-50$ & 10 & 55 & 55 & 55 & 3 & 14 & 22 & 0 & 15 & 23 \\
\hline 50 & 7 & A & $25-74$ & $0-50$ & 50 & 35 & 35 & 35 & 9 & 21 & 32 & 0 & 21 & 33 \\
\hline 50 & 7 & A & $25-74$ & $50-100$ & 10 & 45 & 45 & 45 & 3 & 24 & 18 & 0 & 26 & 20 \\
\hline 50 & 7 & A & $25-74$ & $50-100$ & 50 & 33 & 33 & 33 & 5 & 31 & 27 & 0 & 30 & 30 \\
\hline 50 & 7 & A & $75-125$ & $0-50$ & 10 & 33 & 33 & 33 & 9 & 30 & 23 & 0 & 28 & 22 \\
\hline 50 & 7 & A & $75-125$ & $0-50$ & 50 & 27 & 27 & 27 & 9 & 36 & 30 & 0 & 35 & 31 \\
\hline 50 & 7 & A & $75-125$ & $50-100$ & 10 & 44 & 44 & 44 & 5 & 21 & 24 & 0 & 20 & 29 \\
\hline 50 & 7 & A & $75-125$ & $50-100$ & 50 & 35 & 35 & 35 & 10 & 27 & 26 & 0 & 27 & 26 \\
\hline 80 & 3 & B & $25-74$ & $0-50$ & 10 & 1 & 2 & 97 & 0 & 0 & 0 & 0 & 0 & 0 \\
\hline 80 & 3 & B & $25-74$ & $0-50$ & 50 & 2 & 12 & 85 & 1 & 0 & 0 & 0 & 0 & 0 \\
\hline 80 & 3 & B & $25-74$ & $50-100$ & 10 & 0 & 1 & 99 & 0 & 0 & 0 & 0 & 0 & 0 \\
\hline 80 & 3 & B & $25-74$ & $50-100$ & 50 & 1 & 3 & 94 & 2 & 0 & 0 & 0 & 0 & 0 \\
\hline 80 & 3 & B & $75-125$ & $0-50$ & 10 & 0 & 4 & 96 & 0 & 0 & 0 & 0 & 0 & 0 \\
\hline 80 & 3 & B & $75-125$ & $0-50$ & 50 & 1 & 11 & 84 & 4 & 0 & 0 & 0 & 0 & 0 \\
\hline 80 & 3 & B & $75-125$ & $50-100$ & 10 & 0 & 0 & 100 & 0 & 0 & 0 & 0 & 0 & 0 \\
\hline 80 & 3 & B & $75-125$ & $50-100$ & 50 & 1 & 7 & 86 & 6 & 0 & 0 & 0 & 0 & 0 \\
\hline 80 & 3 & M & $25-74$ & $0-50$ & 10 & 4 & 14 & 82 & 0 & 0 & 0 & 0 & 0 & 0 \\
\hline 80 & 3 & M & $25-74$ & $0-50$ & 50 & 5 & 29 & 67 & 0 & 0 & 0 & 0 & 0 & 0 \\
\hline 80 & 3 & M & $25-74$ & $50-100$ & 10 & 6 & 18 & 74 & 2 & 0 & 0 & 0 & 0 & 0 \\
\hline 80 & 3 & M & $25-74$ & $50-100$ & 50 & 11 & 32 & 53 & 4 & 0 & 0 & 0 & 0 & 0 \\
\hline 80 & 3 & M & $75-125$ & $0-50$ & 10 & 4 & 17 & 79 & 0 & 0 & 0 & 0 & 0 & 0 \\
\hline 80 & 3 & M & $75-125$ & $0-50$ & 50 & 3 & 33 & 63 & 2 & 0 & 0 & 0 & 0 & 0 \\
\hline 80 & 3 & M & $75-125$ & $50-100$ & 10 & 2 & 10 & 87 & 2 & 0 & 0 & 0 & 0 & 0 \\
\hline 80 & 3 & M & $75-125$ & $50-100$ & 50 & 6 & 17 & 74 & 3 & 0 & 0 & 0 & 0 & 0 \\
\hline 80 & 3 & A & $25-74$ & $0-50$ & 10 & 78 & 78 & 78 & 3 & 13 & 6 & 0 & 12 & 6 \\
\hline 80 & 3 & A & $25-74$ & $0-50$ & 50 & 66 & 66 & 66 & 12 & 14 & 12 & 0 & 14 & 12 \\
\hline 80 & 3 & A & $25-74$ & $50-100$ & 10 & 65 & 65 & 65 & 15 & 9 & 11 & 0 & 9 & 11 \\
\hline 80 & 3 & A & $25-74$ & $50-100$ & 50 & 67 & 67 & 67 & 17 & 1 & 15 & 0 & 1 & 15 \\
\hline 80 & 3 & A & $75-125$ & $0-50$ & 10 & 61 & 61 & 61 & 1 & 16 & 22 & 0 & 16 & 22 \\
\hline 80 & 3 & A & $75-125$ & $0-50$ & 50 & 72 & 72 & 72 & 13 & 9 & 7 & 0 & 9 & 7 \\
\hline 80 & 3 & A & $75-125$ & $50-100$ & 10 & 57 & 57 & 57 & 22 & 13 & 8 & 0 & 13 & 8 \\
\hline 80 & 3 & A & $75-125$ & $50-100$ & 50 & 66 & 66 & 66 & 16 & 7 & 11 & 0 & 7 & 11 \\
\hline 80 & 5 & B & $25-74$ & $0-50$ & 10 & 0 & 1 & 99 & 0 & 0 & 0 & 0 & 0 & 0 \\
\hline 80 & 5 & B & $25-74$ & $0-50$ & 50 & 1 & 8 & 90 & 1 & 0 & 0 & 0 & 0 & 0 \\
\hline 80 & 5 & B & $25-74$ & $50-100$ & 10 & 0 & 2 & 98 & 0 & 0 & 0 & 0 & 0 & 0 \\
\hline 80 & 5 & B & $25-74$ & $50-100$ & 50 & 1 & 7 & 91 & 2 & 0 & 0 & 0 & 0 & 0 \\
\hline
\end{tabular}




\begin{tabular}{|c|c|c|c|c|c|c|c|c|c|c|c|c|c|c|}
\hline 80 & 5 & B & $75-125$ & $0-50$ & 10 & 2 & 0 & 96 & 2 & 0 & 0 & 0 & $\overline{0}$ & 0 \\
\hline 80 & 5 & B & $75-125$ & $0-50$ & 50 & 2 & 7 & 90 & 1 & 0 & 0 & 0 & 0 & 0 \\
\hline 80 & 5 & B & $75-125$ & $50-100$ & 10 & 3 & 2 & 95 & 0 & 0 & 0 & 0 & 0 & 0 \\
\hline 80 & 5 & B & $75-125$ & $50-100$ & 50 & 2 & 2 & 93 & 3 & 0 & 0 & 0 & 0 & 0 \\
\hline 80 & 5 & $\mathbf{M}$ & $25-74$ & $0-50$ & 10 & 0 & 0 & 100 & 0 & 0 & 0 & 0 & 0 & 0 \\
\hline 80 & 5 & M & $25-74$ & $0-50$ & 50 & 1 & 9 & 89 & 1 & 0 & 0 & 0 & 0 & 0 \\
\hline 80 & 5 & M & $25-74$ & $50-100$ & 10 & 1 & 1 & 98 & 0 & 0 & 0 & 0 & 0 & 0 \\
\hline 80 & 5 & M & $25-74$ & $50-100$ & 50 & 0 & 11 & 87 & 2 & 0 & 0 & 0 & 0 & 0 \\
\hline 80 & 5 & M & $75-125$ & $0-50$ & 10 & 4 & 0 & 95 & 1 & 0 & 0 & 0 & 0 & 0 \\
\hline 80 & 5 & M & $75-125$ & $0-50$ & 50 & 2 & 14 & 83 & 1 & 0 & 0 & 0 & 0 & 0 \\
\hline 80 & 5 & M & $75-125$ & $50-100$ & 10 & 1 & 0 & 99 & 0 & 0 & 0 & 0 & 0 & 0 \\
\hline 80 & 5 & M & $75-125$ & $50-100$ & 50 & 2 & 10 & 86 & 2 & 0 & 0 & 0 & 0 & 0 \\
\hline 80 & 5 & A & $25-74$ & $0-50$ & 10 & 76 & 76 & 76 & 1 & 11 & 9 & 0 & 11 & 11 \\
\hline 80 & 5 & A & $25-74$ & $0-50$ & 50 & 61 & 61 & 61 & 8 & 18 & 13 & 0 & 17 & 13 \\
\hline 80 & 5 & A & $25-74$ & $50-100$ & 10 & 70 & 70 & 70 & 10 & 13 & 10 & 0 & 12 & 8 \\
\hline 80 & 5 & A & $25-74$ & $50-100$ & 50 & 65 & 65 & 65 & 20 & 7 & 7 & 0 & 5 & 8 \\
\hline 80 & 5 & A & $75-125$ & $0-50$ & 10 & 53 & 53 & 53 & 5 & 16 & 25 & 0 & 16 & 25 \\
\hline 80 & 5 & A & $75-125$ & $0-50$ & 50 & 45 & 45 & 45 & 11 & 22 & 23 & 0 & 23 & 23 \\
\hline 80 & 5 & A & $75-125$ & $50-100$ & 10 & 56 & 56 & 56 & 11 & 14 & 15 & 0 & 15 & 16 \\
\hline 80 & 5 & A & $75-125$ & $50-100$ & 50 & 54 & 54 & 54 & 20 & 12 & 14 & 0 & 13 & 14 \\
\hline 80 & 7 & B & $25-74$ & $0-50$ & 10 & 1 & 0 & 98 & 1 & 0 & 0 & 0 & 0 & 0 \\
\hline 80 & 7 & B & $25-74$ & $0-50$ & 50 & 3 & 1 & 93 & 3 & 0 & 0 & 0 & 0 & 0 \\
\hline 80 & 7 & B & $25-74$ & $50-100$ & 10 & 0 & 0 & 99 & 1 & 0 & 0 & 0 & 0 & 0 \\
\hline 80 & 7 & B & $25-74$ & $50-100$ & 50 & 1 & 0 & 99 & 0 & 0 & 0 & 0 & 0 & 0 \\
\hline 80 & 7 & B & $75-125$ & $0-50$ & 10 & 3 & 0 & 90 & 7 & 0 & 0 & 0 & 0 & 0 \\
\hline 80 & 7 & B & $75-125$ & $0-50$ & 50 & 4 & 5 & 82 & 9 & 0 & 0 & 0 & 0 & 0 \\
\hline 80 & 7 & B & $75-125$ & $50-100$ & 10 & 1 & 0 & 95 & 4 & 0 & 0 & 0 & 0 & 0 \\
\hline 80 & 7 & B & $75-125$ & $50-100$ & 50 & 2 & 1 & 91 & 6 & 0 & 0 & 0 & 0 & 0 \\
\hline 80 & 7 & $\mathbf{M}$ & $25-74$ & $0-50$ & 10 & 0 & 4 & 96 & 0 & 0 & 0 & 0 & 0 & 0 \\
\hline 80 & 7 & M & $25-74$ & $0-50$ & 50 & 6 & 12 & 83 & 0 & 0 & 0 & 0 & 0 & 0 \\
\hline 80 & 7 & M & $25-74$ & $50-100$ & 10 & 0 & 2 & 98 & 0 & 0 & 0 & 0 & 0 & 0 \\
\hline 80 & 7 & M & $25-74$ & $50-100$ & 50 & 3 & 7 & 88 & 2 & 0 & 0 & 0 & 0 & 0 \\
\hline 80 & 7 & $\mathbf{M}$ & $75-125$ & $0-50$ & 10 & 2 & 3 & 95 & 0 & 0 & 0 & 0 & 0 & 0 \\
\hline 80 & 7 & M & $75-125$ & $0-50$ & 50 & 8 & 3 & 87 & 3 & 0 & 0 & 0 & 0 & 0 \\
\hline 80 & 7 & M & $75-125$ & $50-100$ & 10 & 1 & 1 & 97 & 1 & 0 & 0 & 0 & 0 & 0 \\
\hline 80 & 7 & M & $75-125$ & $50-100$ & 50 & 1 & 9 & 90 & 0 & 0 & 0 & 0 & 0 & 0 \\
\hline 80 & 7 & A & $25-74$ & $0-50$ & 10 & 61 & 61 & 61 & 6 & 20 & 8 & 0 & 19 & 9 \\
\hline 80 & 7 & A & $25-74$ & $0-50$ & 50 & 55 & 55 & 55 & 8 & 15 & 18 & 0 & 15 & 20 \\
\hline 80 & 7 & A & $25-74$ & $50-100$ & 10 & 66 & 66 & 66 & 2 & 8 & 12 & 0 & 14 & 13 \\
\hline 80 & 7 & A & $25-74$ & $50-100$ & 50 & 60 & 60 & 60 & 9 & 15 & 13 & 0 & 13 & 13 \\
\hline 80 & 7 & A & $75-125$ & $0-50$ & 10 & 47 & 47 & 47 & 6 & 21 & 19 & 0 & 25 & 19 \\
\hline 80 & 7 & A & $75-125$ & $0-50$ & 50 & 43 & 43 & 43 & 5 & 22 & 28 & 0 & 21 & 28 \\
\hline 80 & 7 & A & $75-125$ & $50-100$ & 10 & 48 & 48 & 48 & 8 & 21 & 16 & 0 & 16 & 20 \\
\hline 80 & 7 & A & $75-125$ & $50-100$ & 50 & 56 & 56 & 56 & 17 & 14 & 9 & 0 & 15 & 12 \\
\hline 100 & 3 & B & $25-74$ & $0-50$ & 10 & 0 & 3 & 98 & 0 & 0 & 0 & 0 & 0 & 0 \\
\hline 100 & 3 & B & $25-74$ & $0-50$ & 50 & 0 & 11 & 89 & 1 & 0 & 0 & 0 & 0 & 0 \\
\hline 100 & 3 & B & $25-74$ & $50-100$ & 10 & 0 & 0 & 100 & 0 & 0 & 0 & 0 & 0 & 0 \\
\hline 100 & 3 & B & $25-74$ & $50-100$ & 50 & 1 & 10 & 86 & 3 & 0 & 0 & 0 & 0 & 0 \\
\hline 100 & 3 & B & $75-125$ & $0-50$ & 10 & 0 & 0 & 100 & 0 & 0 & 0 & 0 & 0 & 0 \\
\hline 100 & 3 & B & $75-125$ & $0-50$ & 50 & 2 & 10 & 86 & 2 & 0 & 0 & 0 & 0 & 0 \\
\hline 100 & 3 & B & $75-125$ & $50-100$ & 10 & 0 & 2 & 97 & 1 & 0 & 0 & 0 & 0 & 0 \\
\hline 100 & 3 & B & $75-125$ & $50-100$ & 50 & 0 & 6 & 92 & 2 & 0 & 0 & 0 & 0 & 0 \\
\hline 100 & 3 & $\mathbf{M}$ & $25-74$ & $0-50$ & 10 & 5 & 24 & 71 & 0 & 0 & 0 & 0 & 0 & 0 \\
\hline 100 & 3 & M & $25-74$ & $0-50$ & 50 & 8 & 26 & 65 & 1 & 0 & 0 & 0 & 0 & 0 \\
\hline 100 & 3 & M & $25-74$ & $50-100$ & 10 & 5 & 17 & 77 & 1 & 0 & 0 & 0 & 0 & 0 \\
\hline 100 & 3 & M & $25-74$ & $50-100$ & 50 & 8 & 19 & 72 & 1 & 0 & 0 & 0 & 0 & 0 \\
\hline 100 & 3 & $\mathbf{M}$ & $75-125$ & $0-50$ & 10 & 3 & 11 & 87 & 0 & 0 & 0 & 0 & 0 & 0 \\
\hline 100 & 3 & M & $75-125$ & $0-50$ & 50 & 4 & 29 & 65 & 2 & 0 & 0 & 0 & 0 & 0 \\
\hline 100 & 3 & $\mathbf{M}$ & $75-125$ & $50-100$ & 10 & 0 & 18 & 76 & 6 & 0 & 0 & 0 & 0 & 0 \\
\hline 100 & 3 & M & $75-125$ & $50-100$ & 50 & 3 & 15 & 78 & 4 & 0 & 0 & 0 & 0 & 0 \\
\hline 100 & 3 & A & $25-74$ & $0-50$ & 10 & 85 & 85 & 85 & 3 & 3 & 9 & 0 & 3 & 9 \\
\hline 100 & 3 & A & $25-74$ & $0-50$ & 50 & 73 & 73 & 73 & 19 & 3 & 6 & 0 & 3 & 6 \\
\hline
\end{tabular}




\begin{tabular}{|c|c|c|c|c|c|c|c|c|c|c|c|c|c|c|}
\hline 100 & 3 & $\bar{A}$ & $25-74$ & $50-100$ & 10 & 77 & 77 & 77 & 8 & 9 & 8 & 0 & 9 & 8 \\
\hline 100 & 3 & A & $25-74$ & $50-100$ & 50 & 73 & 73 & 73 & 23 & 3 & 1 & 0 & 3 & 1 \\
\hline 100 & 3 & A & $75-125$ & $0-50$ & 10 & 54 & 54 & 54 & 6 & 15 & 25 & 0 & 14 & 25 \\
\hline 100 & 3 & A & $75-125$ & $0-50$ & 50 & 74 & 74 & 74 & 10 & 7 & 10 & 0 & 7 & 10 \\
\hline 100 & 3 & A & $75-125$ & $50-100$ & 10 & 46 & 46 & 46 & 18 & 17 & 20 & 0 & 17 & 20 \\
\hline 100 & 3 & A & $75-125$ & $50-100$ & 50 & 75 & 75 & 75 & 15 & 4 & 8 & 0 & 4 & 8 \\
\hline 100 & 5 & B & $25-74$ & $0-50$ & 10 & 1 & 0 & 99 & 0 & 0 & 0 & 0 & 0 & 0 \\
\hline 100 & 5 & B & $25-74$ & $0-50$ & 50 & 0 & 5 & 94 & 1 & 0 & 0 & 0 & 0 & 0 \\
\hline 100 & 5 & B & $25-74$ & $50-100$ & 10 & 0 & 0 & 100 & 0 & 0 & 0 & 0 & 0 & 0 \\
\hline 100 & 5 & B & $25-74$ & $50-100$ & 50 & 1 & 5 & 94 & 0 & 0 & 0 & 0 & 0 & 0 \\
\hline 100 & 5 & B & $75-125$ & $0-50$ & 10 & 2 & 0 & 98 & 0 & 0 & 0 & 0 & 0 & 0 \\
\hline 100 & 5 & B & $75-125$ & $0-50$ & 50 & 3 & 9 & 88 & 0 & 0 & 0 & 0 & 0 & 0 \\
\hline 100 & 5 & B & $75-125$ & $50-100$ & 10 & 0 & 0 & 100 & 0 & 0 & 0 & 0 & 0 & 0 \\
\hline 100 & 5 & B & $75-125$ & $50-100$ & 50 & 1 & 3 & 95 & 1 & 0 & 0 & 0 & 0 & 0 \\
\hline 100 & 5 & $\mathbf{M}$ & $25-74$ & $0-50$ & 10 & 0 & 0 & 100 & 0 & 0 & 0 & 0 & 0 & 0 \\
\hline 100 & 5 & M & $25-74$ & $0-50$ & 50 & 0 & 7 & 94 & 0 & 0 & 0 & 0 & 0 & 0 \\
\hline 100 & 5 & $\mathbf{M}$ & $25-74$ & $50-100$ & 10 & 1 & 3 & 96 & 0 & 0 & 0 & 0 & 0 & 0 \\
\hline 100 & 5 & M & $25-74$ & $50-100$ & 50 & 1 & 11 & 88 & 0 & 0 & 0 & 0 & 0 & 0 \\
\hline 100 & 5 & $\mathbf{M}$ & $75-125$ & $0-50$ & 10 & 1 & 0 & 99 & 0 & 0 & 0 & 0 & 0 & 0 \\
\hline 100 & 5 & M & $75-125$ & $0-50$ & 50 & 5 & 9 & 86 & 0 & 0 & 0 & 0 & 0 & 0 \\
\hline 100 & 5 & $\mathbf{M}$ & $75-125$ & $50-100$ & 10 & 2 & 0 & 98 & 0 & 0 & 0 & 0 & 0 & 0 \\
\hline 100 & 5 & M & $75-125$ & $50-100$ & 50 & 0 & 6 & 93 & 1 & 0 & 0 & 0 & 0 & 0 \\
\hline 100 & 5 & A & $25-74$ & $0-50$ & 10 & 74 & 74 & 74 & 3 & 14 & 7 & 0 & 13 & 9 \\
\hline 100 & 5 & A & $25-74$ & $0-50$ & 50 & 70 & 70 & 70 & 10 & 12 & 7 & 0 & 13 & 7 \\
\hline 100 & 5 & A & $25-74$ & $50-100$ & 10 & 73 & 73 & 73 & 6 & 5 & 15 & 0 & 6 & 11 \\
\hline 100 & 5 & A & $25-74$ & $50-100$ & 50 & 66 & 66 & 66 & 15 & 9 & 9 & 0 & 10 & 9 \\
\hline 100 & 5 & A & $75-125$ & $0-50$ & 10 & 58 & 58 & 58 & 8 & 17 & 17 & 0 & 17 & 17 \\
\hline 100 & 5 & A & $75-125$ & $0-50$ & 50 & 54 & 54 & 54 & 10 & 18 & 18 & 0 & 18 & 16 \\
\hline 100 & 5 & A & $75-125$ & $50-100$ & 10 & 61 & 61 & 61 & 16 & 11 & 10 & 0 & 9 & 12 \\
\hline 100 & 5 & A & $75-125$ & $50-100$ & 50 & 60 & 60 & 60 & 18 & 13 & 9 & 0 & 13 & 9 \\
\hline 100 & 7 & B & $25-74$ & $0-50$ & 10 & 0 & 0 & 100 & 0 & 0 & 0 & 0 & 0 & 0 \\
\hline 100 & 7 & B & $25-74$ & $0-50$ & 50 & 5 & 0 & 94 & 1 & 0 & 0 & 0 & 0 & 0 \\
\hline 100 & 7 & B & $25-74$ & $50-100$ & 10 & 0 & 0 & 100 & 0 & 0 & 0 & 0 & 0 & 0 \\
\hline 100 & 7 & B & $25-74$ & $50-100$ & 50 & 1 & 0 & 99 & 0 & 0 & 0 & 0 & 0 & 0 \\
\hline 100 & 7 & B & $75-125$ & $0-50$ & 10 & 0 & 0 & 99 & 1 & 0 & 0 & 0 & 0 & 0 \\
\hline 100 & 7 & B & $75-125$ & $0-50$ & 50 & 7 & 0 & 89 & 4 & 0 & 0 & 0 & 0 & 0 \\
\hline 100 & 7 & B & $75-125$ & $50-100$ & 10 & 0 & 0 & 100 & 0 & 0 & 0 & 0 & 0 & 0 \\
\hline 100 & 7 & B & $75-125$ & $50-100$ & 50 & 4 & 1 & 91 & 4 & 0 & 0 & 0 & 0 & 0 \\
\hline 100 & 7 & M & $25-74$ & $0-50$ & 10 & 0 & 0 & 100 & 0 & 0 & 0 & 0 & 0 & 0 \\
\hline 100 & 7 & M & $25-74$ & $0-50$ & 50 & 0 & 11 & 89 & 0 & 0 & 0 & 0 & 0 & 0 \\
\hline 100 & 7 & $\mathbf{M}$ & $25-74$ & $50-100$ & 10 & 0 & 1 & 99 & 0 & 0 & 0 & 0 & 0 & 0 \\
\hline 100 & 7 & M & $25-74$ & $50-100$ & 50 & 1 & 7 & 92 & 0 & 0 & 0 & 0 & 0 & 0 \\
\hline 100 & 7 & $\mathbf{M}$ & $75-125$ & $0-50$ & 10 & 3 & 0 & 96 & 1 & 0 & 0 & 0 & 0 & 0 \\
\hline 100 & 7 & M & $75-125$ & $0-50$ & 50 & 2 & 4 & 93 & 1 & 0 & 0 & 0 & 0 & 0 \\
\hline 100 & 7 & $\mathbf{M}$ & $75-125$ & $50-100$ & 10 & 1 & 0 & 99 & 0 & 0 & 0 & 0 & 0 & 0 \\
\hline 100 & 7 & M & $75-125$ & $50-100$ & 50 & 0 & 6 & 94 & 0 & 0 & 0 & 0 & 0 & 0 \\
\hline 100 & 7 & A & $25-74$ & $0-50$ & 10 & 69 & 69 & 69 & 5 & 9 & 8 & 0 & 11 & 13 \\
\hline 100 & 7 & A & $25-74$ & $0-50$ & 50 & 72 & 72 & 72 & 8 & 4 & 14 & 0 & 5 & 13 \\
\hline 100 & 7 & A & $25-74$ & $50-100$ & 10 & 73 & 73 & 73 & 6 & 7 & 8 & 0 & 6 & 11 \\
\hline 100 & 7 & A & $25-74$ & $50-100$ & 50 & 66 & 66 & 66 & 12 & 12 & 8 & 0 & 11 & 8 \\
\hline 100 & 7 & A & $75-125$ & $0-50$ & 10 & 60 & 60 & 60 & 8 & 15 & 13 & 0 & 13 & 14 \\
\hline 100 & 7 & A & $75-125$ & $0-50$ & 50 & 49 & 49 & 49 & 6 & 20 & 24 & 0 & 18 & 24 \\
\hline 100 & 7 & A & $75-125$ & $50-100$ & 10 & 49 & 49 & 49 & 13 & 14 & 14 & 0 & 16 & 12 \\
\hline 100 & 7 & A & $75-125$ & $50-100$ & 50 & 65 & 65 & 65 & 15 & 8 & 11 & 0 & 9 & 8 \\
\hline
\end{tabular}


TABELA D.45 - Desvio relativo médio (em \%) das heurísticas para setup dependente

\begin{tabular}{|c|c|c|c|c|c|c|c|c|c|c|c|c|c|c|}
\hline$n$ & $g$ & $f$ & $s$ & $a$ & $l$ & Hd1 & Hd2 & Hd3 & $\mathrm{Hd} 4$ & Hd5 & Hd6 & Hd7 & Rd6 & Rd10 \\
\hline 10 & 3 & B & $25-74$ & $0-50$ & 10 & 7,9 & 6,9 & 3,6 & 8,4 & 8,9 & 9,7 & 86,7 & 8,9 & 9,8 \\
\hline 10 & 3 & B & $25-74$ & $0-50$ & 50 & 14,9 & 6,5 & 7,6 & 9,2 & 13,5 & 13,7 & 60,8 & 13,5 & 13,7 \\
\hline 10 & 3 & B & $25-74$ & $50-100$ & 10 & 9,5 & 5,8 & 3,6 & 8,2 & 10,8 & 10,8 & 85,8 & 10,8 & 10,8 \\
\hline 10 & 3 & B & $25-74$ & $50-100$ & 50 & 13,7 & 6,8 & 5,2 & 8,7 & 12,6 & 13,4 & 53,2 & 12,6 & 13,4 \\
\hline 10 & 3 & B & $75-125$ & $0-50$ & 10 & 9,4 & 6,1 & 2,7 & 6,6 & 7,0 & 7,1 & 81,3 & 7,1 & 7,1 \\
\hline 10 & 3 & B & $75-125$ & $0-50$ & 50 & 12,9 & 5,1 & 4,6 & 5,7 & 8,7 & 8,9 & 48,7 & 8,7 & 8,9 \\
\hline 10 & 3 & B & $75-125$ & $50-100$ & 10 & 7,7 & 5,1 & 2,6 & 5,3 & 7,7 & 8,2 & 80,5 & 7,7 & 8,2 \\
\hline 10 & 3 & B & $75-125$ & $50-100$ & 50 & 9,1 & 5,8 & 4,9 & 5,9 & 9,4 & 9,5 & 52,6 & 9,3 & 9,4 \\
\hline 10 & 3 & $\mathbf{M}$ & $25-74$ & $0-50$ & 10 & 7,5 & 4,2 & 2,2 & 8,7 & 13,5 & 12,7 & 60,7 & 13,7 & 12,9 \\
\hline 10 & 3 & M & $25-74$ & $0-50$ & 50 & 12,6 & 7,4 & 6,2 & 11,5 & 12,4 & 12,5 & 52,7 & 12,5 & 12,6 \\
\hline 10 & 3 & M & $25-74$ & $50-100$ & 10 & 9,1 & 4,0 & 3,2 & 8,3 & 15,3 & 14,8 & 63,1 & 15,2 & 14,8 \\
\hline 10 & 3 & M & $25-74$ & $50-100$ & 50 & 11,3 & 5,4 & 6,5 & 7,5 & 12,6 & 13,2 & 48,5 & 12,6 & 13,2 \\
\hline 10 & 3 & M & $75-125$ & $0-50$ & 10 & 6,3 & 5,0 & 4,0 & 5,3 & 9,1 & 9,9 & 59,5 & 9,0 & 9,9 \\
\hline 10 & 3 & M & $75-125$ & $0-50$ & 50 & 10,5 & 7,3 & 4,9 & 8,5 & 8,1 & 8,2 & 47,1 & 8,1 & 8,2 \\
\hline 10 & 3 & M & $75-125$ & $50-100$ & 10 & 5,9 & 4,2 & 1,8 & 6,2 & 9,1 & 9,1 & 55,6 & 9,2 & 9,0 \\
\hline 10 & 3 & M & $75-125$ & $50-100$ & 50 & 10,1 & 6,9 & 6,1 & 5,6 & 9,2 & 9,0 & 42,7 & 9,3 & 9,1 \\
\hline 10 & 3 & A & $25-74$ & $0-50$ & 10 & 10,2 & 10,2 & 10,2 & 17,3 & 3,9 & 4,2 & 110,5 & 3,9 & 4,2 \\
\hline 10 & 3 & A & $25-74$ & $0-50$ & 50 & 12,7 & 12,7 & 12,7 & 14,5 & 5,2 & 5,3 & 86,0 & 5,2 & 5,3 \\
\hline 10 & 3 & A & $25-74$ & $50-100$ & 10 & 10,3 & 10,3 & 10,3 & 14,5 & 3,3 & 3,1 & 103,0 & 3,3 & 3,1 \\
\hline 10 & 3 & A & $25-74$ & $50-100$ & 50 & 13,5 & 13,5 & 13,5 & 17,2 & 6,4 & 6,4 & 87,4 & 6,4 & 6,4 \\
\hline 10 & 3 & A & $75-125$ & $0-50$ & 10 & 8,7 & 8,7 & 8,7 & 15,0 & 3,3 & 3,9 & 101,3 & 3,3 & 3,9 \\
\hline 10 & 3 & A & $75-125$ & $0-50$ & 50 & 15,2 & 15,2 & 15,2 & 17,7 & 4,2 & 4,2 & 89,6 & 4,2 & 4,2 \\
\hline 10 & 3 & A & $75-125$ & $50-100$ & 10 & 9,4 & 9,4 & 9,4 & 13,0 & 3,9 & 4,0 & 97,6 & 3,9 & 4,0 \\
\hline 10 & 3 & A & $75-125$ & $50-100$ & 50 & 12,5 & 12,5 & 12,5 & 17,2 & 3,1 & 3,1 & 91,5 & 3,1 & 3,1 \\
\hline 10 & 5 & B & $25-74$ & $0-50$ & 10 & 8,4 & 8,5 & 4,5 & 6,6 & 8,2 & 8,0 & 131,4 & 8,5 & 8,1 \\
\hline 10 & 5 & B & $25-74$ & $0-50$ & 50 & 13,7 & 8,5 & 7,6 & 10,8 & 9,7 & 10,3 & 95,3 & 9,8 & 10,4 \\
\hline 10 & 5 & B & $25-74$ & $50-100$ & 10 & 7,9 & 6,2 & 3,8 & 6,8 & 8,8 & 9,0 & 133,4 & 8,6 & 8,9 \\
\hline 10 & 5 & B & $25-74$ & $50-100$ & 50 & 13,4 & 7,7 & 8,5 & 11,4 & 11,4 & 11,0 & 88,8 & 11,6 & 11,2 \\
\hline 10 & 5 & B & $75-125$ & $0-50$ & 10 & 8,4 & 8,5 & 4,1 & 5,6 & 7,4 & 7,5 & 128,4 & 7,4 & 7,6 \\
\hline 10 & 5 & B & $75-125$ & $0-50$ & 50 & 13,1 & 10,6 & 7,4 & 9,1 & 9,5 & 9,8 & 87,8 & 9,6 & 9,9 \\
\hline 10 & 5 & B & $75-125$ & $50-100$ & 10 & 9,3 & 8,7 & 4,2 & 4,8 & 6,8 & 6,9 & 137,8 & 6,7 & 6,9 \\
\hline 10 & 5 & B & $75-125$ & $50-100$ & 50 & 12,2 & 6,1 & 5,8 & 6,1 & 9,3 & 9,3 & 89,9 & 9,0 & 9,0 \\
\hline 10 & 5 & M & $25-74$ & $0-50$ & 10 & 7,8 & 6,0 & 4,1 & 6,9 & 10,4 & 9,9 & 114,2 & 10,4 & 10,0 \\
\hline 10 & 5 & M & $25-74$ & $0-50$ & 50 & 13,7 & 9,8 & 7,5 & 8,4 & 10,0 & 10,4 & 85,7 & 10,2 & 10,8 \\
\hline 10 & 5 & M & $25-74$ & $50-100$ & 10 & 8,8 & 5,2 & 3,6 & 9,4 & 10,3 & 10,3 & 119,6 & 10,2 & 10,3 \\
\hline 10 & 5 & M & $25-74$ & $50-100$ & 50 & 12,2 & 7,0 & 5,9 & 9,8 & 12,5 & 12,3 & 75,9 & 12,4 & 12,2 \\
\hline 10 & 5 & M & $75-125$ & $0-50$ & 10 & 7,6 & 6,7 & 3,9 & 6,2 & 6,9 & 6,4 & 113,1 & 7,0 & 6,6 \\
\hline 10 & 5 & M & $75-125$ & $0-50$ & 50 & 12,4 & 8,2 & 6,7 & 7,4 & 6,5 & 6,8 & 78,0 & 7,0 & 7,2 \\
\hline 10 & 5 & M & $75-125$ & $50-100$ & 10 & 7,4 & 5,4 & 3,6 & 5,1 & 6,8 & 6,4 & 114,9 & 6,7 & 6,5 \\
\hline 10 & 5 & M & $75-125$ & $50-100$ & 50 & 9,6 & 7,0 & 5,5 & 6,3 & 8,1 & 8,0 & 74,6 & 8,2 & 8,1 \\
\hline 10 & 5 & A & $25-74$ & $0-50$ & 10 & 6,1 & 6,1 & 6,1 & 8,8 & 5,0 & 4,1 & 131,2 & 5,1 & 4,1 \\
\hline 10 & 5 & A & $25-74$ & $0-50$ & 50 & 11,8 & 11,8 & 11,8 & 11,2 & 4,2 & 4,3 & 95,8 & 4,4 & 4,5 \\
\hline 10 & 5 & A & $25-74$ & $50-100$ & 10 & 5,8 & 5,8 & 5,8 & 10,1 & 5,4 & 5,2 & 136,9 & 5,4 & 5,2 \\
\hline 10 & 5 & A & $25-74$ & $50-100$ & 50 & 9,9 & 9,9 & 9,9 & 12,1 & 4,0 & 3,4 & 101,6 & 3,9 & 3,2 \\
\hline 10 & 5 & A & $75-125$ & $0-50$ & 10 & 6,3 & 6,3 & 6,3 & 6,4 & 5,2 & 4,9 & 124,5 & 5,2 & 4,9 \\
\hline 10 & 5 & A & $75-125$ & $0-50$ & 50 & 8,1 & 8,1 & 8,1 & 9,6 & 5,5 & 5,9 & 104,4 & 5,6 & 6,0 \\
\hline 10 & 5 & A & $75-125$ & $50-100$ & 10 & 6,5 & 6,5 & 6,5 & 8,1 & 4,9 & 5,2 & 148,0 & 4,9 & 5,1 \\
\hline 10 & 5 & A & $75-125$ & $50-100$ & 50 & 10,6 & 10,6 & 10,6 & 10,4 & 5,0 & 5,0 & 103,3 & 5,0 & 5,0 \\
\hline 10 & 7 & B & $25-74$ & $0-50$ & 10 & 7,6 & 13,4 & 4,3 & 5,2 & 8,9 & 9,0 & 180,2 & 8,9 & 9,0 \\
\hline 10 & 7 & B & $25-74$ & $0-50$ & 50 & 13,8 & 10,9 & 6,0 & 9,5 & 10,4 & 10,3 & 115,4 & 10,4 & 10,4 \\
\hline 10 & 7 & B & $25-74$ & $50-100$ & 10 & 8,4 & 11,4 & 3,1 & 6,1 & 7,4 & 7,1 & 182,5 & 7,1 & 7,0 \\
\hline 10 & 7 & B & $25-74$ & $50-100$ & 50 & 12,5 & 10,9 & 7,4 & 8,4 & 9,8 & 10,2 & 118,1 & 10,1 & 10,5 \\
\hline 10 & 7 & B & $75-125$ & $0-50$ & 10 & 6,8 & 12,1 & 4,0 & 4,4 & 6,3 & 6,2 & 181,1 & 6,4 & 6,3 \\
\hline 10 & 7 & B & $75-125$ & $0-50$ & 50 & 11,7 & 10,9 & 6,6 & 8,5 & 8,2 & 8,2 & 118,2 & 8,4 & 8,4 \\
\hline 10 & 7 & B & $75-125$ & $50-100$ & 10 & 7,1 & 12,3 & 4,0 & 4,5 & 8,1 & 7,1 & 197,5 & 8,3 & 7,3 \\
\hline 10 & 7 & B & $75-125$ & $50-100$ & 50 & 13,0 & 9,0 & 7,6 & 8,6 & 7,1 & 7,2 & 119,4 & 7,1 & 7,2 \\
\hline 10 & 7 & M & $25-74$ & $0-50$ & 10 & 6,9 & 6,5 & 4,6 & 7,7 & 7,2 & 8,0 & 135,6 & 7,2 & 8,0 \\
\hline 10 & 7 & M & $25-74$ & $0-50$ & 50 & 10,3 & 7,2 & 6,4 & 9,4 & 8,6 & 8,4 & 95,1 & 8,6 & 8,3 \\
\hline 10 & 7 & M & $25-74$ & $50-100$ & 10 & 8,5 & 6,8 & 3,6 & 8,6 & 11,5 & 11,2 & 144,2 & 11,3 & 11,2 \\
\hline
\end{tabular}




\begin{tabular}{|c|c|c|c|c|c|c|c|c|c|c|c|c|c|c|}
\hline 10 & 7 & $M$ & $25-74$ & $50-100$ & 50 & 11,7 & 8,9 & 7,0 & 9,8 & 9,7 & 10,3 & 95,9 & 9,7 & $\overline{10,3}$ \\
\hline 10 & 7 & $\mathbf{M}$ & $75-125$ & $0-50$ & 10 & 6,9 & 6,7 & 3,9 & 6,1 & 7,4 & 7,3 & 134,5 & 7,4 & 7,5 \\
\hline 10 & 7 & $\mathbf{M}$ & $75-125$ & $0-50$ & 50 & 9,4 & 10,5 & 7,1 & 8,2 & 8,5 & 8,3 & 93,5 & 9,0 & 8,8 \\
\hline 10 & 7 & $\mathbf{M}$ & $75-125$ & $50-100$ & 10 & 7,1 & 5,7 & 3,1 & 6,7 & 8,0 & 7,5 & 145,1 & 8,1 & 7,4 \\
\hline 10 & 7 & $\mathbf{M}$ & $75-125$ & $50-100$ & 50 & 8,0 & 6,7 & 5,5 & 6,0 & 8,3 & 8,2 & 98,7 & 8,5 & 8,5 \\
\hline 10 & 7 & A & $25-74$ & $0-50$ & 10 & 5,9 & 5,9 & 5,9 & 5,3 & 5,1 & 5,3 & 142,3 & 5,2 & 5,3 \\
\hline 10 & 7 & A & $25-74$ & $0-50$ & 50 & 9,6 & 9,6 & 9,6 & 7,9 & 4,4 & 4,3 & 102,0 & 4,6 & 4,7 \\
\hline 10 & 7 & A & $25-74$ & $50-100$ & 10 & 4,8 & 4,8 & 4,8 & 7,8 & 5,7 & 5,8 & 168,6 & 5,7 & 5,7 \\
\hline 10 & 7 & A & $25-74$ & $50-100$ & 50 & 9,2 & 9,2 & 9,2 & 11,1 & 3,5 & 2,9 & 112,7 & 3,5 & 2,9 \\
\hline 10 & 7 & A & $75-125$ & $0-50$ & 10 & 6,1 & 6,1 & 6,1 & 4,9 & 5,7 & 5,8 & 148,6 & 5,8 & 5,8 \\
\hline 10 & 7 & A & $75-125$ & $0-50$ & 50 & 7,3 & 7,3 & 7,3 & 7,4 & 4,1 & 4,2 & 104,2 & 4,1 & 4,1 \\
\hline 10 & 7 & A & $75-125$ & $50-100$ & 10 & 6,7 & 6,7 & 6,7 & 6,5 & 4,4 & 4,9 & 178,8 & 4,5 & 4,9 \\
\hline 10 & 7 & A & $75-125$ & $50-100$ & 50 & 9,3 & 9,3 & 9,3 & 7,5 & 4,5 & 4,4 & 121,2 & 4,5 & 4,4 \\
\hline 30 & 3 & B & $25-74$ & $0-50$ & 10 & 7,6 & 4,6 & 0,5 & 9,9 & 13,6 & 14,5 & 122,0 & 13,6 & 14,6 \\
\hline 30 & 3 & B & $25-74$ & $0-50$ & 50 & 7,9 & 3,9 & 0,9 & 9,1 & 17,1 & 17,5 & 96,8 & 17,1 & 17,5 \\
\hline 30 & 3 & B & $25-74$ & $50-100$ & 10 & 7,9 & 4,2 & 0,6 & 8,4 & 14,7 & 14,6 & 119,5 & 14,8 & 14,6 \\
\hline 30 & 3 & B & $25-74$ & $50-100$ & 50 & 8,0 & 3,3 & 1,0 & 8,0 & 17,4 & 17,6 & 90,5 & 17,5 & 17,6 \\
\hline 30 & 3 & B & $75-125$ & $0-50$ & 10 & 9,0 & 4,3 & 0,3 & 6,0 & 8,2 & 8,1 & 106,9 & 8,2 & 8,2 \\
\hline 30 & 3 & B & $75-125$ & $0-50$ & 50 & 6,1 & 2,9 & 1,2 & 5,9 & 11,4 & 11,5 & 83,3 & 11,4 & 11,5 \\
\hline 30 & 3 & B & $75-125$ & $50-100$ & 10 & 8,7 & 3,6 & 0,5 & 4,9 & 8,6 & 8,7 & 110,8 & 8,6 & 8,7 \\
\hline 30 & 3 & B & $75-125$ & $50-100$ & 50 & 6,1 & 2,9 & 0,9 & 5,5 & 11,4 & 11,4 & 83,4 & 11,4 & 11,4 \\
\hline 30 & 3 & $\mathbf{M}$ & $25-74$ & $0-50$ & 10 & 5,0 & 2,8 & 0,5 & 11,1 & 19,0 & 19,0 & 77,8 & 19,0 & 19,0 \\
\hline 30 & 3 & $\mathbf{M}$ & $25-74$ & $0-50$ & 50 & 6,9 & 3,0 & 1,4 & 10,2 & 18,6 & 19,1 & 68,8 & 18,6 & 19,1 \\
\hline 30 & 3 & $\mathbf{M}$ & $25-74$ & $50-100$ & 10 & 5,9 & 2,6 & 0,6 & 8,8 & 20,3 & 19,8 & 78,3 & 20,3 & 19,8 \\
\hline 30 & 3 & $\mathbf{M}$ & $25-74$ & $50-100$ & 50 & 6,8 & 2,6 & 1,4 & 9,7 & 18,7 & 18,6 & 62,9 & 18,8 & 18,6 \\
\hline 30 & 3 & $\mathbf{M}$ & $75-125$ & $0-50$ & 10 & 2,7 & 2,7 & 0,5 & 7,5 & 11,9 & 12,0 & 68,2 & 12,0 & 12,1 \\
\hline 30 & 3 & $\mathbf{M}$ & $75-125$ & $0-50$ & 50 & 4,2 & 2,5 & 1,4 & 6,7 & 12,2 & 12,1 & 57,8 & 12,2 & 12,1 \\
\hline 30 & 3 & $\mathbf{M}$ & $75-125$ & $50-100$ & 10 & 3,0 & 2,0 & 0,6 & 5,5 & 12,9 & 12,8 & 68,1 & 13,0 & 12,8 \\
\hline 30 & 3 & $\mathbf{M}$ & $75-125$ & $50-100$ & 50 & 4,9 & 1,6 & 1,3 & 5,4 & 12,4 & 12,4 & 52,9 & 12,4 & 12,4 \\
\hline 30 & 3 & A & $25-74$ & $0-50$ & 10 & 3,4 & 3,4 & 3,4 & 53,4 & 5,0 & 4,9 & 134,2 & 5,1 & 4,9 \\
\hline 30 & 3 & A & $25-74$ & $0-50$ & 50 & 5,7 & 5,7 & 5,7 & 45,5 & 5,1 & 4,7 & 115,5 & 5,1 & 4,7 \\
\hline 30 & 3 & A & $25-74$ & $50-100$ & 10 & 2,6 & 2,6 & 2,6 & 46,9 & 5,5 & 5,5 & 129,3 & 5,4 & 5,5 \\
\hline 30 & 3 & A & $25-74$ & $50-100$ & 50 & 6,4 & 6,4 & 6,4 & 41,1 & 4,6 & 4,7 & 107,2 & 4,5 & 4,7 \\
\hline 30 & 3 & A & $75-125$ & $0-50$ & 10 & 4,2 & 4,2 & 4,2 & 55,6 & 1,9 & 1,8 & 126,0 & 1,9 & 1,8 \\
\hline 30 & 3 & A & $75-125$ & $0-50$ & 50 & 7,2 & 7,2 & 7,2 & 41,9 & 2,8 & 2,9 & 106,5 & 2,8 & 2,9 \\
\hline 30 & 3 & A & $75-125$ & $50-100$ & 10 & 3,8 & 3,8 & 3,8 & 47,7 & 3,0 & 3,0 & 127,6 & 3,0 & 3,0 \\
\hline 30 & 3 & A & $75-125$ & $50-100$ & 50 & 4,4 & 4,4 & 4,4 & 39,3 & 4,4 & 3,9 & 102,8 & 4,4 & 3,9 \\
\hline 30 & 5 & B & $25-74$ & $0-50$ & 10 & 9,9 & 7,3 & 0,5 & 7,2 & 11,4 & 11,4 & 201,8 & 11,4 & 11,4 \\
\hline 30 & 5 & B & $25-74$ & $0-50$ & 50 & 7,8 & 5,3 & 1,9 & 8,4 & 12,4 & 12,4 & 159,3 & 12,4 & 12,4 \\
\hline 30 & 5 & B & $25-74$ & $50-100$ & 10 & 9,1 & 6,5 & 0,4 & 7,6 & 11,5 & 11,6 & 203,0 & 11,5 & 11,5 \\
\hline 30 & 5 & B & $25-74$ & $50-100$ & 50 & 9,0 & 5,5 & 1,8 & 8,2 & 13,1 & 13,1 & 157,5 & 13,1 & 13,1 \\
\hline 30 & 5 & B & $75-125$ & $0-50$ & 10 & 8,9 & 6,1 & 0,9 & 4,4 & 6,8 & 6,8 & 188,4 & 6,9 & 6,9 \\
\hline 30 & 5 & B & $75-125$ & $0-50$ & 50 & 7,5 & 5,5 & 2,0 & 6,4 & 8,0 & 8,1 & 149,9 & 8,1 & 8,1 \\
\hline 30 & 5 & B & $75-125$ & $50-100$ & 10 & 10,3 & 5,9 & 0,6 & 4,7 & 7,4 & 7,3 & 198,7 & 7,5 & 7,3 \\
\hline 30 & 5 & B & $75-125$ & $50-100$ & 50 & 7,5 & 3,7 & 1,1 & 5,9 & 9,2 & 9,0 & 141,4 & 9,2 & 9,1 \\
\hline 30 & 5 & $\mathbf{M}$ & $25-74$ & $0-50$ & 10 & 7,7 & 5,2 & 0,4 & 9,4 & 12,2 & 12,6 & 165,5 & 12,3 & 12,7 \\
\hline 30 & 5 & M & $25-74$ & $0-50$ & 50 & 8,3 & 4,8 & 1,6 & 10,4 & 14,5 & 14,4 & 130,4 & 14,5 & 14,3 \\
\hline 30 & 5 & $\mathbf{M}$ & $25-74$ & $50-100$ & 10 & 6,8 & 4,4 & 0,6 & 8,4 & 12,4 & 12,1 & 166,6 & 12,4 & 12,1 \\
\hline 30 & 5 & $\mathbf{M}$ & $25-74$ & $50-100$ & 50 & 9,4 & 4,1 & 1,4 & 9,5 & 15,6 & 15,6 & 131,1 & 15,6 & 15,7 \\
\hline 30 & 5 & $\mathbf{M}$ & $75-125$ & $0-50$ & 10 & 6,9 & 4,9 & 0,5 & 5,6 & 7,9 & 7,9 & 154,3 & 8,0 & 7,9 \\
\hline 30 & 5 & M & $75-125$ & $0-50$ & 50 & 6,8 & 4,0 & 1,7 & 7,0 & 8,3 & 8,2 & 127,1 & 8,4 & 8,2 \\
\hline 30 & 5 & $\mathbf{M}$ & $75-125$ & $50-100$ & 10 & 6,4 & 4,0 & 0,5 & 4,9 & 8,5 & 8,3 & 159,4 & 8,5 & 8,3 \\
\hline 30 & 5 & $\mathbf{M}$ & $75-125$ & $50-100$ & 50 & 6,3 & 3,4 & 0,7 & 5,7 & 10,2 & 10,1 & 121,9 & 10,2 & 10,2 \\
\hline 30 & 5 & A & $25-74$ & $0-50$ & 10 & 3,4 & 3,4 & 3,4 & 34,1 & 3,8 & 4,1 & 201,5 & 3,7 & 4,2 \\
\hline 30 & 5 & A & $25-74$ & $0-50$ & 50 & 7,1 & 7,1 & 7,1 & 29,5 & 2,5 & 2,5 & 163,1 & 2,5 & 2,6 \\
\hline 30 & 5 & A & $25-74$ & $50-100$ & 10 & 3,0 & 3,0 & 3,0 & 30,0 & 3,4 & 3,1 & 202,6 & 3,5 & 3,2 \\
\hline 30 & 5 & A & $25-74$ & $50-100$ & 50 & 6,8 & 6,8 & 6,8 & 26,7 & 3,1 & 3,0 & 172,3 & 3,0 & 3,0 \\
\hline 30 & 5 & A & $75-125$ & $0-50$ & 10 & 4,1 & 4,1 & 4,1 & 33,8 & 2,5 & 2,2 & 198,8 & 2,5 & 2,2 \\
\hline 30 & 5 & A & $75-125$ & $0-50$ & 50 & 6,4 & 6,4 & 6,4 & 36,6 & 2,4 & 2,4 & 170,5 & 2,5 & 2,5 \\
\hline 30 & 5 & A & $75-125$ & $50-100$ & 10 & 3,6 & 3,6 & 3,6 & 32,5 & 2,6 & 2,2 & 201,1 & 2,7 & 2,3 \\
\hline 30 & 5 & A & $75-125$ & $50-100$ & 50 & 5,9 & 5,9 & 5,9 & 29,6 & 2,6 & 2,4 & 163,9 & 2,5 & 2,4 \\
\hline 30 & 7 & B & $25-74$ & $0-50$ & 10 & 7,5 & 11,9 & 0,6 & 5,8 & 8,7 & 8,9 & 293,7 & 8,6 & 8,9 \\
\hline
\end{tabular}




\begin{tabular}{|c|c|c|c|c|c|c|c|c|c|c|c|c|c|c|}
\hline 30 & 7 & $\bar{B}$ & $25-74$ & $0-50$ & 50 & 7,9 & 8,8 & 1,7 & 8,6 & 10,3 & 10,0 & 231,2 & 10,4 & 10,0 \\
\hline 30 & 7 & B & $25-74$ & $50-100$ & 10 & 9,7 & 10,4 & 0,6 & 6,3 & 8,4 & 8,6 & 305,9 & 8,4 & 8,4 \\
\hline 30 & 7 & B & $25-74$ & $50-100$ & 50 & 8,7 & 8,0 & 1,4 & 7,2 & 10,6 & 10,7 & 233,9 & 10,6 & 10,9 \\
\hline 30 & 7 & B & $75-125$ & $0-50$ & 10 & 10,2 & 12,6 & 1,0 & 3,6 & 5,2 & 5,5 & 294,0 & 5,2 & 5,6 \\
\hline 30 & 7 & B & $75-125$ & $0-50$ & 50 & 7,6 & 9,8 & 2,1 & 5,8 & 6,9 & 7,1 & 225,4 & 6,9 & 7,1 \\
\hline 30 & 7 & B & $75-125$ & $50-100$ & 10 & 9,9 & 9,8 & 0,9 & 3,2 & 5,5 & 5,2 & 299,5 & 5,5 & 5,3 \\
\hline 30 & 7 & B & $75-125$ & $50-100$ & 50 & 7,7 & 8,1 & 1,7 & 5,8 & 7,9 & 8,0 & 224,5 & 7,9 & 7,9 \\
\hline 30 & 7 & M & $25-74$ & $0-50$ & 10 & 6,6 & 5,0 & 0,5 & 9,1 & 12,1 & 12,3 & 200,6 & 12,1 & 12,3 \\
\hline 30 & 7 & M & $25-74$ & $0-50$ & 50 & 9,1 & 5,3 & 2,0 & 9,3 & 12,4 & 12,4 & 165,8 & 12,5 & 12,4 \\
\hline 30 & 7 & $\mathbf{M}$ & $25-74$ & $50-100$ & 10 & 6,5 & 4,2 & 0,4 & 8,1 & 12,6 & 12,7 & 207,0 & 12,6 & 12,7 \\
\hline 30 & 7 & M & $25-74$ & $50-100$ & 50 & 8,9 & 5,2 & 1,5 & 10,0 & 13,9 & 13,4 & 166,1 & 13,9 & 13,5 \\
\hline 30 & 7 & $\mathbf{M}$ & $75-125$ & $0-50$ & 10 & 5,4 & 5,1 & 0,8 & 5,3 & 7,4 & 7,6 & 201,1 & 7,4 & 7,6 \\
\hline 30 & 7 & M & $75-125$ & $0-50$ & 50 & 7,1 & 5,1 & 2,2 & 6,1 & 8,2 & 8,2 & 157,5 & 8,3 & 8,4 \\
\hline 30 & 7 & M & $75-125$ & $50-100$ & 10 & 6,8 & 4,5 & 0,6 & 4,4 & 8,4 & 8,0 & 207,0 & 8,4 & 8,0 \\
\hline 30 & 7 & M & $75-125$ & $50-100$ & 50 & 6,2 & 3,6 & 1,4 & 5,9 & 9,0 & 9,2 & 149,5 & 9,1 & 9,2 \\
\hline 30 & 7 & A & $25-74$ & $0-50$ & 10 & 2,6 & 2,6 & 2,6 & 23,8 & 4,2 & 4,1 & 251,4 & 4,3 & 4,1 \\
\hline 30 & 7 & A & $25-74$ & $0-50$ & 50 & 6,9 & 6,9 & 6,9 & 25,9 & 3,4 & 3,8 & 199,2 & 3,5 & 3,9 \\
\hline 30 & 7 & A & $25-74$ & $50-100$ & 10 & 3,7 & 3,7 & 3,7 & 22,3 & 3,2 & 2,9 & 261,6 & 3,1 & 2,9 \\
\hline 30 & 7 & A & $25-74$ & $50-100$ & 50 & 6,7 & 6,7 & 6,7 & 24,2 & 3,7 & 3,1 & 203,3 & 3,6 & 3,3 \\
\hline 30 & 7 & A & $75-125$ & $0-50$ & 10 & 3,4 & 3,4 & 3,4 & 21,2 & 3,0 & 3,3 & 249,9 & 3,0 & 3,3 \\
\hline 30 & 7 & A & $75-125$ & $0-50$ & 50 & 6,4 & 6,4 & 6,4 & 24,5 & 3,1 & 3,2 & 205,5 & 3,2 & 3,3 \\
\hline 30 & 7 & A & $75-125$ & $50-100$ & 10 & 3,3 & 3,3 & 3,3 & 25,0 & 2,8 & 2,9 & 265,0 & 2,8 & 3,0 \\
\hline 30 & 7 & A & $75-125$ & $50-100$ & 50 & 5,5 & 5,5 & 5,5 & 26,2 & 2,8 & 2,6 & 210,1 & 2,8 & 2,5 \\
\hline 50 & 3 & B & $25-74$ & $0-50$ & 10 & 9,4 & 5,0 & 0,1 & 9,6 & 16,2 & 16,3 & 136,6 & 16,2 & 16,4 \\
\hline 50 & 3 & B & $25-74$ & $0-50$ & 50 & 6,6 & 3,7 & 0,6 & 8,5 & 19,7 & 20,0 & 112,3 & 19,7 & 20,0 \\
\hline 50 & 3 & B & $25-74$ & $50-100$ & 10 & 9,6 & 5,1 & 0,1 & 9,8 & 17,9 & 18,1 & 133,8 & 17,9 & 18,1 \\
\hline 50 & 3 & B & $25-74$ & $50-100$ & 50 & 6,8 & 3,8 & 0,4 & 7,1 & 20,8 & 20,7 & 110,1 & 20,8 & 20,7 \\
\hline 50 & 3 & B & $75-125$ & $0-50$ & 10 & 11,1 & 4,4 & 0,1 & 7,0 & 10,2 & 10,2 & 123,3 & 10,2 & 10,1 \\
\hline 50 & 3 & B & $75-125$ & $0-50$ & 50 & 5,6 & 3,1 & 0,4 & 5,3 & 12,5 & 12,4 & 102,3 & 12,5 & 12,4 \\
\hline 50 & 3 & B & $75-125$ & $50-100$ & 10 & 10,4 & 4,3 & 0,2 & 5,1 & 10,3 & 10,4 & 125,8 & 10,3 & 10,4 \\
\hline 50 & 3 & B & $75-125$ & $50-100$ & 50 & 5,5 & 3,4 & 0,3 & 4,9 & 13,2 & 13,3 & 95,2 & 13,2 & 13,3 \\
\hline 50 & 3 & M & $25-74$ & $0-50$ & 10 & 4,0 & 2,3 & 0,4 & 11,2 & 21,6 & 22,1 & 89,4 & 21,6 & 22,1 \\
\hline 50 & 3 & M & $25-74$ & $0-50$ & 50 & 5,4 & 2,3 & 0,6 & 7,8 & 21,0 & 21,2 & 75,4 & 21,0 & 21,2 \\
\hline 50 & 3 & $\mathbf{M}$ & $25-74$ & $50-100$ & 10 & 4,8 & 2,0 & 0,3 & 8,1 & 22,5 & 22,2 & 86,3 & 22,5 & 22,2 \\
\hline 50 & 3 & $\mathbf{M}$ & $25-74$ & $50-100$ & 50 & 5,5 & 1,7 & 0,8 & 7,6 & 22,2 & 22,5 & 70,2 & 22,2 & 22,4 \\
\hline 50 & 3 & $\mathbf{M}$ & $75-125$ & $0-50$ & 10 & 2,9 & 1,9 & 0,3 & 8,1 & 13,5 & 13,5 & 76,3 & 13,5 & 13,5 \\
\hline 50 & 3 & $\mathbf{M}$ & $75-125$ & $0-50$ & 50 & 3,2 & 1,5 & 0,4 & 5,7 & 12,9 & 13,2 & 63,3 & 12,9 & 13,2 \\
\hline 50 & 3 & M & $75-125$ & $50-100$ & 10 & 2,9 & 2,1 & 0,2 & 5,2 & 13,9 & 14,0 & 71,1 & 13,8 & 14,0 \\
\hline 50 & 3 & M & $75-125$ & $50-100$ & 50 & 3,5 & 1,6 & 0,5 & 4,5 & 13,6 & 13,8 & 63,0 & 13,6 & 13,8 \\
\hline 50 & 3 & A & $25-74$ & $0-50$ & 10 & 2,3 & 2,3 & 2,3 & 61,0 & 5,2 & 5,2 & 142,7 & 5,1 & 5,2 \\
\hline 50 & 3 & A & $25-74$ & $0-50$ & 50 & 2,9 & 2,9 & 2,9 & 56,0 & 6,2 & 5,8 & 128,3 & 6,2 & 5,8 \\
\hline 50 & 3 & A & $25-74$ & $50-100$ & 10 & 1,5 & 1,5 & 1,5 & 46,5 & 7,6 & 7,6 & 138,7 & 7,5 & 7,6 \\
\hline 50 & 3 & A & $25-74$ & $50-100$ & 50 & 1,9 & 1,9 & 1,9 & 50,4 & 7,1 & 7,2 & 122,3 & 7,1 & 7,2 \\
\hline 50 & 3 & A & $75-125$ & $0-50$ & 10 & 3,2 & 3,2 & 3,2 & 65,8 & 2,8 & 2,8 & 134,0 & 2,8 & 2,8 \\
\hline 50 & 3 & A & $75-125$ & $0-50$ & 50 & 3,2 & 3,2 & 3,2 & 51,3 & 3,2 & 3,5 & 120,6 & 3,2 & 3,5 \\
\hline 50 & 3 & A & $75-125$ & $50-100$ & 10 & 2,7 & 2,7 & 2,7 & 60,5 & 3,7 & 3,6 & 134,1 & 3,7 & 3,6 \\
\hline 50 & 3 & A & $75-125$ & $50-100$ & 50 & 2,9 & 2,9 & 2,9 & 54,7 & 4,2 & 4,3 & 109,7 & 4,2 & 4,3 \\
\hline 50 & 5 & B & $25-74$ & $0-50$ & 10 & 12,1 & 6,9 & 0,0 & 9,2 & 14,4 & 14,3 & 227,3 & 14,5 & 14,4 \\
\hline 50 & 5 & B & $25-74$ & $0-50$ & 50 & 9,4 & 5,3 & 0,5 & 9,7 & 16,5 & 17,0 & 191,8 & 16,5 & 17,0 \\
\hline 50 & 5 & B & $25-74$ & $50-100$ & 10 & 10,8 & 6,6 & 0,0 & 8,6 & 13,6 & 13,7 & 231,0 & 13,6 & 13,7 \\
\hline 50 & 5 & B & $25-74$ & $50-100$ & 50 & 7,9 & 5,3 & 0,6 & 7,6 & 16,7 & 16,7 & 190,4 & 16,8 & 16,7 \\
\hline 50 & 5 & B & $75-125$ & $0-50$ & 10 & 10,8 & 6,6 & 0,1 & 5,5 & 8,0 & 8,3 & 214,0 & 8,0 & 8,3 \\
\hline 50 & 5 & B & $75-125$ & $0-50$ & 50 & 7,4 & 4,5 & 0,5 & 6,2 & 9,2 & 9,6 & 176,0 & 9,2 & 9,6 \\
\hline 50 & 5 & B & $75-125$ & $50-100$ & 10 & 10,7 & 5,5 & 0,2 & 4,1 & 8,4 & 8,6 & 218,4 & 8,4 & 8,6 \\
\hline 50 & 5 & B & $75-125$ & $50-100$ & 50 & 6,8 & 4,2 & 0,5 & 4,9 & 10,9 & 10,8 & 174,9 & 10,9 & 10,8 \\
\hline 50 & 5 & M & $25-74$ & $0-50$ & 10 & 8,4 & 5,3 & 0,1 & 10,0 & 15,8 & 15,6 & 185,5 & 15,9 & 15,7 \\
\hline 50 & 5 & $\mathbf{M}$ & $25-74$ & $0-50$ & 50 & 7,4 & 4,0 & 0,5 & 9,0 & 17,0 & 17,1 & 157,6 & 17,0 & 17,1 \\
\hline 50 & 5 & $\mathbf{M}$ & $25-74$ & $50-100$ & 10 & 8,5 & 5,6 & 0,0 & 9,9 & 16,0 & 16,1 & 190,8 & 16,0 & 16,1 \\
\hline 50 & 5 & $\mathbf{M}$ & $25-74$ & $50-100$ & 50 & 7,3 & 3,6 & 0,6 & 9,1 & 17,9 & 18,4 & 152,9 & 17,9 & 18,3 \\
\hline 50 & 5 & M & $75-125$ & $0-50$ & 10 & 7,8 & 4,8 & 0,1 & 5,8 & 9,3 & 9,4 & 172,8 & 9,3 & 9,4 \\
\hline 50 & 5 & M & $75-125$ & $0-50$ & 50 & 6,2 & 3,7 & 0,8 & 6,4 & 10,3 & 10,5 & 140,9 & 10,3 & 10,5 \\
\hline 50 & 5 & $\mathbf{M}$ & $75-125$ & $50-100$ & 10 & 8,0 & 4,6 & 0,2 & 5,2 & 10,0 & 10,0 & 171,4 & 10,1 & 10,1 \\
\hline
\end{tabular}




\begin{tabular}{|c|c|c|c|c|c|c|c|c|c|c|c|c|c|c|}
\hline 50 & 5 & $M$ & $75-125$ & $50-100$ & 50 & 5,8 & 3,3 & 0,6 & 5,5 & 11,5 & 11,4 & 141,0 & 11,6 & 11,4 \\
\hline 50 & 5 & A & $25-74$ & $0-50$ & 10 & 2,0 & 2,0 & 2,0 & 45,1 & 2,9 & 3,5 & 228,9 & 2,9 & 3,6 \\
\hline 50 & 5 & A & $25-74$ & $0-50$ & 50 & 3,4 & 3,4 & 3,4 & 41,6 & 3,4 & 3,5 & 195,5 & 3,4 & 3,6 \\
\hline 50 & 5 & A & $25-74$ & $50-100$ & 10 & 2,2 & 2,2 & 2,2 & 37,4 & 4,0 & 3,8 & 230,8 & 3,9 & 3,7 \\
\hline 50 & 5 & A & $25-74$ & $50-100$ & 50 & 3,6 & 3,6 & 3,6 & 33,3 & 4,2 & 4,5 & 193,0 & 4,2 & 4,5 \\
\hline 50 & 5 & A & $75-125$ & $0-50$ & 10 & 2,2 & 2,2 & 2,2 & 41,4 & 2,4 & 2,2 & 209,8 & 2,4 & 2,2 \\
\hline 50 & 5 & A & $75-125$ & $0-50$ & 50 & 5,0 & 5,0 & 5,0 & 39,7 & 2,1 & 2,2 & 188,2 & 2,2 & 2,3 \\
\hline 50 & 5 & A & $75-125$ & $50-100$ & 10 & 2,9 & 2,9 & 2,9 & 40,6 & 2,5 & 2,5 & 225,7 & 2,5 & 2,5 \\
\hline 50 & 5 & A & $75-125$ & $50-100$ & 50 & 3,0 & 3,0 & 3,0 & 37,3 & 3,0 & 3,2 & 175,7 & 3,0 & 3,1 \\
\hline 50 & 7 & B & $25-74$ & $0-50$ & 10 & 11,9 & 11,5 & 0,0 & 6,7 & 10,2 & 10,5 & 349,3 & 10,2 & 10,6 \\
\hline 50 & 7 & B & $25-74$ & $0-50$ & 50 & 9,2 & 9,0 & 0,4 & 7,0 & 12,8 & 13,3 & 290,3 & 13,0 & 13,4 \\
\hline 50 & 7 & B & $25-74$ & $50-100$ & 10 & 12,7 & 10,6 & 0,1 & 6,8 & 11,0 & 11,0 & 354,1 & 10,9 & 11,0 \\
\hline 50 & 7 & B & $25-74$ & $50-100$ & 50 & 9,6 & 8,1 & 0,6 & 7,1 & 13,0 & 12,9 & 292,4 & 13,1 & 13,0 \\
\hline 50 & 7 & B & $75-125$ & $0-50$ & 10 & 12,3 & 11,1 & 0,3 & 3,7 & 5,9 & 6,2 & 336,5 & 5,9 & 6,2 \\
\hline 50 & 7 & B & $75-125$ & $0-50$ & 50 & 7,8 & 8,5 & 1,0 & 5,0 & 8,4 & 8,5 & 279,7 & 8,3 & 8,5 \\
\hline 50 & 7 & B & $75-125$ & $50-100$ & 10 & 11,6 & 9,1 & 0,5 & 3,6 & 6,8 & 6,8 & 347,6 & 6,8 & 6,7 \\
\hline 50 & 7 & B & $75-125$ & $50-100$ & 50 & 8,8 & 7,7 & 0,5 & 4,6 & 8,6 & 8,8 & 278,0 & 8,6 & 8,8 \\
\hline 50 & 7 & $\mathbf{M}$ & $25-74$ & $0-50$ & 10 & 8,5 & 4,8 & 0,2 & 9,7 & 14,6 & 14,8 & 240,0 & 14,6 & 14,8 \\
\hline 50 & 7 & $\mathbf{M}$ & $25-74$ & $0-50$ & 50 & 6,8 & 4,1 & 0,7 & 9,2 & 16,0 & 16,1 & 190,6 & 16,1 & 16,2 \\
\hline 50 & 7 & $\mathbf{M}$ & $25-74$ & $50-100$ & 10 & 8,6 & 5,1 & 0,1 & 9,1 & 14,6 & 15,1 & 236,5 & 14,5 & 15,1 \\
\hline 50 & 7 & $\mathbf{M}$ & $25-74$ & $50-100$ & 50 & 8,8 & 4,6 & 0,4 & 9,6 & 16,9 & 17,0 & 198,4 & 17,0 & 17,1 \\
\hline 50 & 7 & $\mathbf{M}$ & $75-125$ & $0-50$ & 10 & 6,7 & 5,4 & 0,1 & 5,5 & 9,0 & 9,0 & 223,2 & 9,0 & 9,0 \\
\hline 50 & 7 & $\mathbf{M}$ & $75-125$ & $0-50$ & 50 & 6,5 & 4,5 & 0,5 & 7,6 & 9,6 & 9,6 & 196,9 & 9,7 & 9,6 \\
\hline 50 & 7 & $\mathbf{M}$ & $75-125$ & $50-100$ & 10 & 6,7 & 5,1 & 0,2 & 5,1 & 9,5 & 9,5 & 222,7 & 9,5 & 9,5 \\
\hline 50 & 7 & $\mathbf{M}$ & $75-125$ & $50-100$ & 50 & 6,1 & 4,0 & 0,4 & 5,7 & 10,4 & 10,5 & 182,0 & 10,5 & 10,5 \\
\hline 50 & 7 & A & $25-74$ & $0-50$ & 10 & 1,7 & 1,7 & 1,7 & 32,2 & 3,1 & 2,9 & 286,1 & 3,1 & 2,9 \\
\hline 50 & 7 & A & $25-74$ & $0-50$ & 50 & 4,6 & 4,6 & 4,6 & 30,9 & 3,2 & 2,9 & 247,4 & 3,3 & 2,9 \\
\hline 50 & 7 & A & $25-74$ & $50-100$ & 10 & 2,2 & 2,2 & 2,2 & 32,8 & 2,9 & 3,1 & 298,0 & 3,0 & 3,0 \\
\hline 50 & 7 & A & $25-74$ & $50-100$ & 50 & 3,5 & 3,5 & 3,5 & 24,0 & 3,6 & 3,5 & 245,7 & 3,4 & 3,5 \\
\hline 50 & 7 & A & $75-125$ & $0-50$ & 10 & 3,4 & 3,4 & 3,4 & 28,6 & 2,0 & 2,2 & 284,2 & 2,0 & 2,3 \\
\hline 50 & 7 & A & $75-125$ & $0-50$ & 50 & 5,7 & 5,7 & 5,7 & 36,1 & 2,4 & 2,6 & 249,3 & 2,5 & 2,6 \\
\hline 50 & 7 & A & $75-125$ & $50-100$ & 10 & 2,6 & 2,6 & 2,6 & 36,4 & 2,7 & 2,6 & 295,1 & 2,6 & 2,6 \\
\hline 50 & 7 & A & $75-125$ & $50-100$ & 50 & 3,4 & 3,4 & 3,4 & 27,0 & 2,6 & 2,6 & 240,3 & 2,5 & 2,6 \\
\hline 80 & 3 & B & $25-74$ & $0-50$ & 10 & 11,0 & 5,8 & 0,0 & 11,3 & 19,5 & 19,1 & 147,8 & 19,5 & 19,1 \\
\hline 80 & 3 & B & $25-74$ & $0-50$ & 50 & 6,5 & 4,3 & 0,2 & 7,4 & 22,3 & 22,1 & 128,0 & 22,3 & 22,1 \\
\hline 80 & 3 & B & $25-74$ & $50-100$ & 10 & 10,9 & 5,8 & 0,0 & 10,6 & 19,9 & 20,1 & 148,0 & 19,9 & 20,1 \\
\hline 80 & 3 & B & $25-74$ & $50-100$ & 50 & 6,5 & 5,2 & 0,1 & 7,8 & 22,7 & 22,8 & 130,7 & 22,7 & 22,8 \\
\hline 80 & 3 & B & $75-125$ & $0-50$ & 10 & 12,8 & 5,5 & 0,0 & 7,0 & 11,9 & 11,9 & 133,2 & 11,9 & 12,0 \\
\hline 80 & 3 & B & $75-125$ & $0-50$ & 50 & 5,6 & 3,8 & 0,2 & 4,5 & 13,8 & 13,8 & 113,7 & 13,8 & 13,8 \\
\hline 80 & 3 & B & $75-125$ & $50-100$ & 10 & 12,4 & 5,3 & 0,0 & 5,9 & 12,2 & 12,4 & 135,1 & 12,2 & 12,4 \\
\hline 80 & 3 & B & $75-125$ & $50-100$ & 50 & 5,0 & 3,9 & 0,2 & 3,9 & 14,2 & 14,3 & 108,5 & 14,2 & 14,3 \\
\hline 80 & 3 & $\mathbf{M}$ & $25-74$ & $0-50$ & 10 & 3,7 & 2,0 & 0,1 & 11,2 & 23,9 & 24,3 & 94,4 & 24,0 & 24,3 \\
\hline 80 & 3 & M & $25-74$ & $0-50$ & 50 & 4,4 & 1,6 & 0,4 & 7,6 & 24,2 & 24,1 & 86,3 & 24,2 & 24,1 \\
\hline 80 & 3 & $\mathbf{M}$ & $25-74$ & $50-100$ & 10 & 3,6 & 2,2 & 0,3 & 8,3 & 24,6 & 24,4 & 92,9 & 24,6 & 24,4 \\
\hline 80 & 3 & $\mathbf{M}$ & $25-74$ & $50-100$ & 50 & 4,5 & 1,3 & 0,8 & 7,3 & 24,0 & 24,2 & 83,0 & 24,0 & 24,2 \\
\hline 80 & 3 & $\mathbf{M}$ & $75-125$ & $0-50$ & 10 & 2,3 & 2,1 & 0,2 & 6,9 & 14,9 & 14,6 & 80,7 & 14,9 & 14,6 \\
\hline 80 & 3 & $\mathbf{M}$ & $75-125$ & $0-50$ & 50 & 2,7 & 0,9 & 0,5 & 4,5 & 15,1 & 15,0 & 65,4 & 15,1 & 15,0 \\
\hline 80 & 3 & $\mathbf{M}$ & $75-125$ & $50-100$ & 10 & 2,5 & 2,0 & 0,1 & 4,4 & 14,9 & 15,1 & 80,5 & 14,9 & 15,1 \\
\hline 80 & 3 & $\mathbf{M}$ & $75-125$ & $50-100$ & 50 & 2,9 & 1,1 & 0,3 & 3,8 & 15,5 & 15,5 & 67,2 & 15,5 & 15,5 \\
\hline 80 & 3 & A & $25-74$ & $0-50$ & 10 & 0,9 & 0,9 & 0,9 & 58,5 & 7,4 & 7,7 & 149,0 & 7,4 & 7,7 \\
\hline 80 & 3 & A & $25-74$ & $0-50$ & 50 & 1,3 & 1,3 & 1,3 & 54,7 & 9,0 & 9,4 & 138,9 & 9,0 & 9,4 \\
\hline 80 & 3 & A & $25-74$ & $50-100$ & 10 & 1,0 & 1,0 & 1,0 & 54,5 & 8,8 & 8,8 & 147,0 & 8,8 & 8,8 \\
\hline 80 & 3 & A & $25-74$ & $50-100$ & 50 & 1,5 & 1,5 & 1,5 & 49,4 & 9,9 & 9,8 & 139,3 & 9,9 & 9,8 \\
\hline 80 & 3 & A & $75-125$ & $0-50$ & 10 & 2,0 & 2,0 & 2,0 & 75,8 & 4,0 & 3,8 & 141,4 & 4,0 & 3,8 \\
\hline 80 & 3 & A & $75-125$ & $0-50$ & 50 & 1,0 & 1,0 & 1,0 & 61,6 & 5,1 & 5,2 & 123,8 & 5,1 & 5,2 \\
\hline 80 & 3 & A & $75-125$ & $50-100$ & 10 & 2,2 & 2,2 & 2,2 & 47,3 & 5,2 & 5,2 & 134,4 & 5,2 & 5,2 \\
\hline 80 & 3 & A & $75-125$ & $50-100$ & 50 & 1,2 & 1,2 & 1,2 & 52,5 & 6,4 & 6,4 & 118,1 & 6,4 & 6,4 \\
\hline 80 & 5 & B & $25-74$ & $0-50$ & 10 & 13,9 & 7,3 & 0,0 & 9,6 & 16,0 & 16,0 & 252,7 & 15,9 & 16,0 \\
\hline 80 & 5 & B & $25-74$ & $0-50$ & 50 & 9,6 & 5,6 & 0,2 & 9,2 & 18,4 & 18,5 & 222,8 & 18,3 & 18,5 \\
\hline 80 & 5 & B & $25-74$ & $50-100$ & 10 & 14,2 & 6,9 & 0,0 & 9,3 & 15,9 & 16,0 & 254,5 & 15,9 & 16,1 \\
\hline 80 & 5 & B & $25-74$ & $50-100$ & 50 & 9,4 & 5,7 & 0,1 & 8,6 & 18,9 & 18,9 & 225,1 & 18,9 & 18,8 \\
\hline 80 & 5 & B & $75-125$ & $0-50$ & 10 & 13,9 & 6,9 & 0,0 & 6,6 & 9,6 & 9,8 & 240,6 & 9,6 & 9,8 \\
\hline
\end{tabular}




\begin{tabular}{|c|c|c|c|c|c|c|c|c|c|c|c|c|c|c|}
\hline 80 & 5 & B & $75-125$ & $0-50$ & 50 & 8,4 & 5,2 & 0,2 & 5,5 & 11,4 & 11,4 & 204,5 & 11,5 & 11,4 \\
\hline 80 & 5 & B & $75-125$ & $50-100$ & 10 & 13,1 & 6,3 & 0,0 & 4,8 & 9,8 & 10,0 & 236,9 & 9,8 & 10,0 \\
\hline 80 & 5 & B & $75-125$ & $50-100$ & 50 & 8,5 & 4,9 & 0,1 & 4,9 & 12,5 & 12,2 & 200,4 & 12,5 & 12,2 \\
\hline 80 & 5 & M & $25-74$ & $0-50$ & 10 & 10,7 & 6,2 & 0,0 & 11,2 & 18,9 & 18,7 & 203,1 & 18,8 & 18,8 \\
\hline 80 & 5 & M & $25-74$ & $0-50$ & 50 & 7,1 & 4,6 & 0,1 & 8,7 & 19,7 & 19,7 & 177,4 & 19,7 & 19,7 \\
\hline 80 & 5 & M & $25-74$ & $50-100$ & 10 & 10,5 & 6,1 & 0,0 & 10,3 & 18,3 & 18,4 & 210,9 & 18,3 & 18,4 \\
\hline 80 & 5 & M & $25-74$ & $50-100$ & 50 & 7,8 & 4,5 & 0,3 & 8,7 & 20,7 & 21,0 & 173,7 & 20,8 & 21,0 \\
\hline 80 & 5 & M & $75-125$ & $0-50$ & 10 & 8,2 & 5,2 & 0,1 & 6,0 & 10,7 & 10,9 & 186,7 & 10,6 & 10,9 \\
\hline 80 & 5 & M & $75-125$ & $0-50$ & 50 & 5,7 & 3,8 & 0,3 & 5,5 & 12,2 & 12,5 & 158,2 & 12,3 & 12,4 \\
\hline 80 & 5 & M & $75-125$ & $50-100$ & 10 & 9,0 & 5,3 & 0,1 & 5,5 & 11,6 & 11,7 & 191,8 & 11,7 & 11,7 \\
\hline 80 & 5 & M & $75-125$ & $50-100$ & 50 & 5,9 & 4,2 & 0,2 & 4,9 & 13,4 & 13,5 & 161,7 & 13,4 & 13,5 \\
\hline 80 & 5 & A & $25-74$ & $0-50$ & 10 & 0,8 & 0,8 & 0,8 & 43,9 & 5,3 & 5,5 & 237,2 & 5,3 & 5,6 \\
\hline 80 & 5 & A & $25-74$ & $0-50$ & 50 & 1,5 & 1,5 & 1,5 & 44,2 & 4,9 & 4,8 & 216,1 & 4,8 & 4,8 \\
\hline 80 & 5 & A & $25-74$ & $50-100$ & 10 & 1,0 & 1,0 & 1,0 & 32,8 & 5,8 & 5,6 & 234,9 & 5,8 & 5,6 \\
\hline 80 & 5 & A & $25-74$ & $50-100$ & 50 & 1,5 & 1,5 & 1,5 & 28,0 & 6,6 & 7,0 & 213,6 & 6,6 & 7,0 \\
\hline 80 & 5 & A & $75-125$ & $0-50$ & 10 & 2,8 & 2,8 & 2,8 & 47,4 & 2,7 & 2,5 & 232,6 & 2,7 & 2,5 \\
\hline 80 & 5 & A & $75-125$ & $0-50$ & 50 & 2,3 & 2,3 & 2,3 & 36,9 & 3,0 & 3,0 & 200,9 & 3,0 & 3,0 \\
\hline 80 & 5 & A & $75-125$ & $50-100$ & 10 & 1,9 & 1,9 & 1,9 & 41,6 & 3,6 & 3,6 & 232,8 & 3,6 & 3,6 \\
\hline 80 & 5 & A & $75-125$ & $50-100$ & 50 & 2,0 & 2,0 & 2,0 & 34,8 & 4,5 & 4,5 & 199,8 & 4,4 & 4,6 \\
\hline 80 & 7 & B & $25-74$ & $0-50$ & 10 & 13,8 & 11,7 & 0,0 & 7,4 & 12,6 & 13,1 & 393,8 & 12,5 & 13,1 \\
\hline 80 & 7 & B & $25-74$ & $0-50$ & 50 & 11,1 & 9,6 & 0,2 & 7,9 & 14,9 & 15,1 & 350,0 & 14,9 & 15,1 \\
\hline 80 & 7 & B & $25-74$ & $50-100$ & 10 & 16,4 & 11,1 & 0,0 & 8,1 & 13,1 & 13,2 & 399,9 & 13,2 & 13,2 \\
\hline 80 & 7 & B & $25-74$ & $50-100$ & 50 & 10,4 & 9,0 & 0,0 & 8,0 & 16,4 & 16,3 & 344,8 & 16,2 & 16,3 \\
\hline 80 & 7 & B & $75-125$ & $0-50$ & 10 & 14,7 & 10,5 & 0,1 & 4,7 & 8,0 & 8,0 & 374,8 & 8,0 & 8,0 \\
\hline 80 & 7 & B & $75-125$ & $0-50$ & 50 & 9,9 & 8,0 & 0,3 & 5,0 & 8,8 & 8,9 & 322,8 & 8,8 & 8,9 \\
\hline 80 & 7 & B & $75-125$ & $50-100$ & 10 & 15,8 & 9,5 & 0,1 & 4,5 & 7,9 & 8,1 & 380,3 & 7,9 & 8,1 \\
\hline 80 & 7 & B & $75-125$ & $50-100$ & 50 & 10,6 & 8,1 & 0,2 & 4,8 & 10,3 & 10,5 & 323,6 & 10,3 & 10,5 \\
\hline 80 & 7 & M & $25-74$ & $0-50$ & 10 & 9,1 & 6,0 & 0,1 & 10,4 & 17,4 & 17,3 & 266,0 & 17,4 & 17,2 \\
\hline 80 & 7 & M & $25-74$ & $0-50$ & 50 & 8,4 & 4,5 & 0,6 & 9,9 & 19,0 & 19,2 & 223,5 & 18,9 & 19,2 \\
\hline 80 & 7 & M & $25-74$ & $50-100$ & 10 & 9,6 & 6,2 & 0,0 & 10,4 & 17,3 & 17,4 & 263,9 & 17,3 & 17,5 \\
\hline 80 & 7 & M & $25-74$ & $50-100$ & 50 & 8,1 & 4,6 & 0,2 & 8,6 & 19,2 & 19,5 & 231,3 & 19,2 & 19,5 \\
\hline 80 & 7 & M & $75-125$ & $0-50$ & 10 & 7,3 & 5,5 & 0,0 & 6,2 & 10,3 & 10,3 & 241,3 & 10,3 & 10,4 \\
\hline 80 & 7 & M & $75-125$ & $0-50$ & 50 & 6,1 & 4,5 & 0,2 & 5,8 & 11,3 & 11,1 & 206,6 & 11,4 & 11,1 \\
\hline 80 & 7 & M & $75-125$ & $50-100$ & 10 & 6,8 & 5,7 & 0,0 & 5,6 & 11,2 & 10,9 & 246,9 & 11,1 & 10,9 \\
\hline 80 & 7 & M & $75-125$ & $50-100$ & 50 & 6,3 & 4,0 & 0,1 & 5,0 & 12,3 & 12,3 & 208,6 & 12,3 & 12,3 \\
\hline 80 & 7 & A & $25-74$ & $0-50$ & 10 & 1,3 & 1,3 & 1,3 & 35,7 & 4,2 & 4,0 & 320,7 & 4,2 & 4,1 \\
\hline 80 & 7 & A & $25-74$ & $0-50$ & 50 & 2,8 & 2,8 & 2,8 & 37,3 & 4,0 & 3,7 & 286,1 & 3,9 & 3,6 \\
\hline 80 & 7 & A & $25-74$ & $50-100$ & 10 & 1,3 & 1,3 & 1,3 & 34,6 & 4,6 & 4,2 & 332,2 & 4,4 & 4,2 \\
\hline 80 & 7 & A & $25-74$ & $50-100$ & 50 & 1,8 & 1,8 & 1,8 & 25,9 & 5,1 & 5,2 & 277,3 & 5,1 & 5,2 \\
\hline 80 & 7 & A & $75-125$ & $0-50$ & 10 & 2,6 & 2,6 & 2,6 & 36,9 & 2,6 & 2,5 & 320,0 & 2,6 & 2,5 \\
\hline 80 & 7 & A & $75-125$ & $0-50$ & 50 & 2,9 & 2,9 & 2,9 & 36,2 & 2,7 & 2,6 & 275,2 & 2,8 & 2,7 \\
\hline 80 & 7 & A & $75-125$ & $50-100$ & 10 & 2,6 & 2,6 & 2,6 & 31,7 & 2,7 & 2,5 & 323,2 & 2,7 & 2,5 \\
\hline 80 & 7 & A & $75-125$ & $50-100$ & 50 & 1,6 & 1,6 & 1,6 & 30,1 & 3,7 & 4,0 & 271,5 & 3,7 & 4,0 \\
\hline 100 & 3 & B & $25-74$ & $0-50$ & 10 & 10,4 & 5,7 & 0,0 & 11,1 & 20,3 & 20,4 & 151,8 & 20,3 & 20,4 \\
\hline 100 & 3 & B & $25-74$ & $0-50$ & 50 & 6,8 & 4,9 & 0,2 & 7,7 & 23,6 & 23,5 & 131,5 & 23,6 & 23,5 \\
\hline 100 & 3 & B & $25-74$ & $50-100$ & 10 & 12,1 & 6,1 & 0,0 & 10,8 & 20,5 & 20,9 & 151,3 & 20,5 & 20,9 \\
\hline 100 & 3 & B & $25-74$ & $50-100$ & 50 & 6,9 & 4,7 & 0,2 & 6,8 & 24,0 & 24,0 & 132,0 & 24,0 & 24,0 \\
\hline 100 & 3 & B & $75-125$ & $0-50$ & 10 & 13,7 & 5,8 & 0,0 & 7,2 & 12,6 & 12,6 & 137,5 & 12,6 & 12,5 \\
\hline 100 & 3 & B & $75-125$ & $0-50$ & 50 & 5,8 & 4,3 & 0,2 & 4,2 & 14,8 & 14,7 & 118,9 & 14,8 & 14,7 \\
\hline 100 & 3 & B & $75-125$ & $50-100$ & 10 & 13,0 & 5,5 & 0,1 & 5,5 & 12,7 & 12,6 & 134,8 & 12,7 & 12,6 \\
\hline 100 & 3 & B & $75-125$ & $50-100$ & 50 & 5,6 & 4,3 & 0,1 & 3,9 & 15,4 & 15,3 & 116,0 & 15,4 & 15,3 \\
\hline 100 & 3 & M & $25-74$ & $0-50$ & 10 & 3,7 & 1,8 & 0,3 & 10,8 & 25,6 & 25,4 & 95,4 & 25,6 & 25,4 \\
\hline 100 & 3 & M & $25-74$ & $0-50$ & 50 & 3,7 & 1,2 & 0,3 & 7,7 & 25,2 & 25,3 & 80,8 & 25,2 & 25,3 \\
\hline 100 & 3 & M & $25-74$ & $50-100$ & 10 & 3,7 & 2,2 & 0,2 & 8,4 & 25,6 & 25,3 & 95,6 & 25,6 & 25,3 \\
\hline 100 & 3 & M & $25-74$ & $50-100$ & 50 & 3,3 & 1,3 & 0,2 & 6,4 & 25,2 & 25,3 & 85,9 & 25,2 & 25,3 \\
\hline 100 & 3 & M & $75-125$ & $0-50$ & 10 & 2,0 & 1,9 & 0,1 & 7,3 & 15,7 & 15,7 & 79,1 & 15,7 & 15,7 \\
\hline 100 & 3 & M & $75-125$ & $0-50$ & 50 & 2,5 & 1,1 & 0,3 & 4,4 & 15,4 & 15,6 & 70,8 & 15,4 & 15,6 \\
\hline 100 & 3 & M & $75-125$ & $50-100$ & 10 & 2,2 & 1,9 & 0,2 & 4,4 & 15,7 & 15,6 & 78,7 & 15,7 & 15,6 \\
\hline 100 & 3 & M & $75-125$ & $50-100$ & 50 & 2,3 & 1,1 & 0,2 & 3,8 & 15,8 & 16,0 & 68,2 & 15,8 & 16,0 \\
\hline 100 & 3 & A & $25-74$ & $0-50$ & 10 & 0,4 & 0,4 & 0,4 & 59,3 & 8,7 & 8,7 & 152,3 & 8,7 & 8,7 \\
\hline 100 & 3 & A & $25-74$ & $0-50$ & 50 & 0,7 & 0,7 & 0,7 & 38,7 & 10,9 & 10,8 & 142,3 & 10,9 & 10,8 \\
\hline 100 & 3 & A & $25-74$ & $50-100$ & 10 & 1,0 & 1,0 & 1,0 & 69,9 & 8,3 & 8,0 & 163,3 & 8,3 & 8,0 \\
\hline
\end{tabular}




\begin{tabular}{|c|c|c|c|c|c|c|c|c|c|c|c|c|c|c|}
\hline 100 & 3 & $\bar{A}$ & $25-74$ & $50-100$ & 50 & 0,9 & 0,9 & 0,9 & 49,6 & 12,6 & 12,6 & 142,2 & 12,6 & 12,6 \\
\hline 100 & 3 & A & $75-125$ & $0-50$ & 10 & 2,3 & 2,3 & 2,3 & 79,9 & 4,2 & 4,1 & 142,4 & 4,2 & 4,1 \\
\hline 100 & 3 & A & $75-125$ & $0-50$ & 50 & 0,8 & 0,8 & 0,8 & 71,0 & 6,5 & 6,1 & 125,9 & 6,5 & 6,1 \\
\hline 100 & 3 & A & $75-125$ & $50-100$ & 10 & 2,6 & 2,6 & 2,6 & 61,5 & 5,1 & 5,2 & 142,6 & 5,1 & 5,2 \\
\hline 100 & 3 & A & $75-125$ & $50-100$ & 50 & 0,7 & 0,7 & 0,7 & 65,1 & 6,6 & 6,6 & 126,7 & 6,6 & 6,6 \\
\hline 100 & 5 & B & $25-74$ & $0-50$ & 10 & 14,3 & 7,6 & 0,0 & 10,2 & 17,1 & 17,2 & 263,4 & 17,1 & 17,2 \\
\hline 100 & 5 & B & $25-74$ & $0-50$ & 50 & 10,2 & 6,2 & 0,1 & 8,9 & 20,3 & 20,5 & 235,1 & 20,3 & 20,5 \\
\hline 100 & 5 & B & $25-74$ & $50-100$ & 10 & 15,6 & 7,7 & 0,0 & 10,1 & 16,7 & 16,9 & 263,8 & 16,7 & 16,9 \\
\hline 100 & 5 & B & $25-74$ & $50-100$ & 50 & 9,1 & 6,4 & 0,0 & 8,7 & 20,4 & 20,5 & 230,6 & 20,4 & 20,5 \\
\hline 100 & 5 & B & $75-125$ & $0-50$ & 10 & 14,8 & 7,1 & 0,0 & 6,1 & 10,1 & 10,0 & 243,4 & 10,1 & 9,9 \\
\hline 100 & 5 & B & $75-125$ & $0-50$ & 50 & 8,8 & 5,1 & 0,1 & 5,4 & 12,2 & 12,3 & 211,3 & 12,2 & 12,3 \\
\hline 100 & 5 & B & $75-125$ & $50-100$ & 10 & 15,0 & 6,8 & 0,0 & 5,8 & 10,8 & 10,7 & 247,0 & 10,8 & 10,7 \\
\hline 100 & 5 & B & $75-125$ & $50-100$ & 50 & 9,9 & 5,5 & 0,1 & 5,2 & 13,0 & 13,0 & 215,4 & 13,0 & 13,0 \\
\hline 100 & 5 & M & $25-74$ & $0-50$ & 10 & 10,5 & 6,8 & 0,0 & 11,4 & 19,3 & 19,3 & 214,5 & 19,3 & 19,4 \\
\hline 100 & 5 & M & $25-74$ & $0-50$ & 50 & 7,2 & 5,0 & 0,1 & 9,0 & 20,7 & 21,1 & 188,4 & 20,6 & 21,1 \\
\hline 100 & 5 & M & $25-74$ & $50-100$ & 10 & 10,3 & 6,3 & 0,1 & 10,3 & 19,4 & 19,8 & 213,5 & 19,3 & 19,8 \\
\hline 100 & 5 & M & $25-74$ & $50-100$ & 50 & 7,9 & 5,1 & 0,2 & 8,1 & 21,8 & 21,8 & 187,5 & 21,8 & 21,8 \\
\hline 100 & 5 & M & $75-125$ & $0-50$ & 10 & 9,9 & 6,1 & 0,0 & 6,9 & 12,2 & 12,0 & 195,0 & 12,2 & 12,1 \\
\hline 100 & 5 & M & $75-125$ & $0-50$ & 50 & 5,9 & 4,3 & 0,2 & 5,4 & 13,4 & 13,2 & 164,4 & 13,4 & 13,2 \\
\hline 100 & 5 & M & $75-125$ & $50-100$ & 10 & 10,2 & 5,7 & 0,0 & 5,8 & 11,9 & 12,0 & 196,4 & 11,9 & 12,0 \\
\hline 100 & 5 & M & $75-125$ & $50-100$ & 50 & 6,3 & 4,3 & 0,1 & 4,6 & 13,8 & 13,8 & 169,6 & 13,7 & 13,8 \\
\hline 100 & 5 & A & $25-74$ & $0-50$ & 10 & 0,8 & 0,8 & 0,8 & 49,8 & 6,3 & 6,5 & 242,1 & 6,3 & 6,4 \\
\hline 100 & 5 & A & $25-74$ & $0-50$ & 50 & 1,1 & 1,1 & 1,1 & 40,6 & 6,1 & 6,3 & 221,9 & 6,1 & 6,4 \\
\hline 100 & 5 & A & $25-74$ & $50-100$ & 10 & 0,9 & 0,9 & 0,9 & 35,3 & 5,9 & 5,7 & 245,4 & 6,0 & 5,7 \\
\hline 100 & 5 & A & $25-74$ & $50-100$ & 50 & 1,1 & 1,1 & 1,1 & 37,2 & 7,4 & 7,3 & 224,1 & 7,3 & 7,3 \\
\hline 100 & 5 & A & $75-125$ & $0-50$ & 10 & 2,2 & 2,2 & 2,2 & 48,2 & 3,4 & 3,3 & 234,4 & 3,4 & 3,3 \\
\hline 100 & 5 & A & $75-125$ & $0-50$ & 50 & 2,0 & 2,0 & 2,0 & 51,7 & 3,0 & 3,0 & 208,3 & 3,0 & 3,0 \\
\hline 100 & 5 & A & $75-125$ & $50-100$ & 10 & 1,8 & 1,8 & 1,8 & 42,5 & 4,8 & 4,9 & 235,9 & 4,9 & 4,9 \\
\hline 100 & 5 & A & $75-125$ & $50-100$ & 50 & 1,3 & 1,3 & 1,3 & 37,3 & 5,2 & 5,3 & 203,0 & 5,2 & 5,3 \\
\hline 100 & 7 & B & $25-74$ & $0-50$ & 10 & 16,2 & 11,2 & 0,0 & 8,8 & 14,4 & 14,6 & 414,8 & 14,4 & 14,7 \\
\hline 100 & 7 & B & $25-74$ & $0-50$ & 50 & 11,1 & 9,0 & 0,1 & 8,1 & 16,7 & 16,6 & 369,1 & 16,7 & 16,6 \\
\hline 100 & 7 & B & $25-74$ & $50-100$ & 10 & 16,1 & 11,0 & 0,0 & 8,9 & 14,5 & 14,6 & 414,9 & 14,4 & 14,5 \\
\hline 100 & 7 & B & $25-74$ & $50-100$ & 50 & 13,5 & 9,5 & 0,0 & 9,0 & 18,2 & 18,1 & 371,5 & 18,2 & 18,1 \\
\hline 100 & 7 & B & $75-125$ & $0-50$ & 10 & 15,1 & 10,3 & 0,0 & 4,8 & 7,9 & 8,2 & 397,1 & 7,9 & 8,2 \\
\hline 100 & 7 & B & $75-125$ & $0-50$ & 50 & 11,2 & 8,6 & 0,2 & 5,3 & 10,1 & 10,0 & 340,0 & 10,1 & 10,0 \\
\hline 100 & 7 & B & $75-125$ & $50-100$ & 10 & 16,0 & 8,6 & 0,0 & 4,6 & 8,7 & 8,8 & 399,6 & 8,7 & 8,7 \\
\hline 100 & 7 & B & $75-125$ & $50-100$ & 50 & 11,8 & 7,9 & 0,2 & 4,4 & 10,7 & 10,6 & 351,9 & 10,8 & 10,5 \\
\hline 100 & 7 & M & $25-74$ & $0-50$ & 10 & 9,1 & 6,5 & 0,0 & 10,9 & 18,4 & 18,7 & 272,2 & 18,5 & 18,8 \\
\hline 100 & 7 & M & $25-74$ & $0-50$ & 50 & 7,7 & 4,9 & 0,2 & 9,2 & 19,5 & 19,7 & 244,1 & 19,5 & 19,9 \\
\hline 100 & 7 & M & $25-74$ & $50-100$ & 10 & 10,0 & 6,3 & 0,0 & 10,5 & 19,1 & 18,7 & 271,8 & 19,1 & 18,7 \\
\hline 100 & 7 & M & $25-74$ & $50-100$ & 50 & 7,9 & 5,2 & 0,2 & 9,0 & 20,7 & 20,6 & 244,6 & 20,7 & 20,6 \\
\hline 100 & 7 & M & $75-125$ & $0-50$ & 10 & 7,1 & 6,0 & 0,1 & 6,5 & 11,0 & 11,1 & 250,2 & 11,1 & 11,2 \\
\hline 100 & 7 & M & $75-125$ & $0-50$ & 50 & 5,8 & 4,8 & 0,2 & 5,9 & 12,4 & 12,4 & 223,1 & 12,4 & 12,4 \\
\hline 100 & 7 & M & $75-125$ & $50-100$ & 10 & 8,4 & 5,9 & 0,0 & 5,8 & 11,9 & 11,8 & 255,5 & 11,9 & 11,8 \\
\hline 100 & 7 & M & $75-125$ & $50-100$ & 50 & 5,7 & 5,2 & 0,1 & 5,2 & 13,0 & 13,1 & 222,0 & 13,1 & 13,1 \\
\hline 100 & 7 & A & $25-74$ & $0-50$ & 10 & 1,1 & 1,1 & 1,1 & 34,3 & 4,7 & 4,8 & 328,4 & 4,8 & 4,8 \\
\hline 100 & 7 & A & $25-74$ & $0-50$ & 50 & 1,2 & 1,2 & 1,2 & 37,4 & 4,8 & 5,0 & 303,8 & 4,9 & 5,0 \\
\hline 100 & 7 & A & $25-74$ & $50-100$ & 10 & 0,8 & 0,8 & 0,8 & 31,7 & 4,6 & 4,4 & 335,0 & 4,5 & 4,5 \\
\hline 100 & 7 & A & $25-74$ & $50-100$ & 50 & 1,0 & 1,0 & 1,0 & 30,2 & 4,8 & 5,1 & 294,9 & 4,8 & 5,1 \\
\hline 100 & 7 & A & $75-125$ & $0-50$ & 10 & 2,2 & 2,2 & 2,2 & 33,7 & 2,6 & 2,8 & 316,0 & 2,5 & 2,8 \\
\hline 100 & 7 & A & $75-125$ & $0-50$ & 50 & 2,0 & 2,0 & 2,0 & 39,7 & 2,9 & 3,2 & 296,0 & 3,0 & 3,2 \\
\hline 100 & 7 & A & $75-125$ & $50-100$ & 10 & 2,5 & 2,5 & 2,5 & 31,3 & 3,1 & 3,1 & 333,5 & 3,1 & 3,1 \\
\hline 100 & 7 & A & $75-125$ & $50-100$ & 50 & 1,7 & 1,7 & 1,7 & 24,8 & 4,0 & 3,9 & 279,0 & 4,0 & 4,0 \\
\hline
\end{tabular}


TABELA D.46 - Desvio-padrão do relativo das heurísticas para setup dependente

\begin{tabular}{|c|c|c|c|c|c|c|c|c|c|c|c|c|c|c|}
\hline$n$ & $g$ & $f$ & $s$ & $a$ & $l$ & Hd1 & Hd2 & Hd3 & $\mathrm{Hd} 4$ & Hd5 & Hd6 & $\mathrm{Hd} 7$ & Rd6 & Rd10 \\
\hline 10 & 3 & B & $25-74$ & $0-50$ & 10 & $\overline{0,06}$ & 0,06 & 0,05 & 0,07 & 0,07 & 0,07 & 0,23 & 0,07 & 0,07 \\
\hline 10 & 3 & B & $25-74$ & $0-50$ & 50 & 0,14 & 0,10 & 0,11 & 0,10 & 0,09 & 0,09 & 0,35 & 0,09 & 0,09 \\
\hline 10 & 3 & B & $25-74$ & $50-100$ & 10 & 0,07 & 0,05 & 0,05 & 0,06 & 0,07 & 0,08 & 0,23 & 0,07 & 0,08 \\
\hline 10 & 3 & B & $25-74$ & $50-100$ & 50 & 0,13 & 0,09 & 0,09 & 0,09 & 0,09 & 0,09 & 0,30 & 0,09 & 0,09 \\
\hline 10 & 3 & B & $75-125$ & $0-50$ & 10 & 0,07 & 0,05 & 0,04 & 0,05 & 0,06 & 0,06 & 0,24 & 0,06 & 0,06 \\
\hline 10 & 3 & B & $75-125$ & $0-50$ & 50 & 0,13 & 0,07 & 0,07 & 0,05 & 0,06 & 0,06 & 0,26 & 0,06 & 0,06 \\
\hline 10 & 3 & B & $75-125$ & $50-100$ & 10 & 0,06 & 0,05 & 0,03 & 0,04 & 0,06 & 0,06 & 0,21 & 0,06 & 0,06 \\
\hline 10 & 3 & B & $75-125$ & $50-100$ & 50 & 0,10 & 0,09 & 0,08 & 0,07 & 0,06 & 0,06 & 0,33 & 0,06 & 0,06 \\
\hline 10 & 3 & $\mathbf{M}$ & $25-74$ & $0-50$ & 10 & 0,07 & 0,05 & 0,03 & 0,08 & 0,07 & 0,07 & 0,21 & 0,07 & 0,07 \\
\hline 10 & 3 & $\mathbf{M}$ & $25-74$ & $0-50$ & 50 & 0,13 & 0,10 & 0,09 & 0,14 & 0,10 & 0,10 & 0,30 & 0,10 & 0,10 \\
\hline 10 & 3 & M & $25-74$ & $50-100$ & 10 & 0,07 & 0,05 & 0,05 & 0,07 & 0,08 & 0,08 & 0,23 & 0,08 & 0,08 \\
\hline 10 & 3 & M & $25-74$ & $50-100$ & 50 & 0,12 & 0,09 & 0,09 & 0,08 & 0,10 & 0,11 & 0,33 & 0,10 & 0,11 \\
\hline 10 & 3 & M & $75-125$ & $0-50$ & 10 & 0,06 & 0,06 & 0,05 & 0,05 & 0,07 & 0,07 & 0,26 & 0,07 & 0,07 \\
\hline 10 & 3 & M & $75-125$ & $0-50$ & 50 & 0,11 & 0,10 & 0,08 & 0,11 & 0,08 & 0,08 & 0,28 & 0,08 & 0,08 \\
\hline 10 & 3 & M & $75-125$ & $50-100$ & 10 & 0,05 & 0,05 & 0,03 & 0,05 & 0,05 & 0,05 & 0,24 & 0,05 & 0,05 \\
\hline 10 & 3 & M & $75-125$ & $50-100$ & 50 & 0,13 & 0,11 & 0,10 & 0,08 & 0,09 & 0,09 & 0,30 & 0,09 & 0,09 \\
\hline 10 & 3 & A & $25-74$ & $0-50$ & 10 & 0,10 & 0,10 & 0,10 & 0,19 & 0,06 & 0,06 & 0,41 & 0,06 & 0,06 \\
\hline 10 & 3 & A & $25-74$ & $0-50$ & 50 & 0,14 & 0,14 & 0,14 & 0,19 & 0,08 & 0,08 & 0,38 & 0,08 & 0,08 \\
\hline 10 & 3 & A & $25-74$ & $50-100$ & 10 & 0,09 & 0,09 & 0,09 & 0,17 & 0,05 & 0,05 & 0,37 & 0,05 & 0,05 \\
\hline 10 & 3 & A & $25-74$ & $50-100$ & 50 & 0,14 & 0,14 & 0,14 & 0,22 & 0,11 & 0,11 & 0,41 & 0,11 & 0,11 \\
\hline 10 & 3 & A & $75-125$ & $0-50$ & 10 & 0,08 & 0,08 & 0,08 & 0,18 & 0,05 & 0,05 & 0,39 & 0,05 & 0,05 \\
\hline 10 & 3 & A & $75-125$ & $0-50$ & 50 & 0,14 & 0,14 & 0,14 & 0,24 & 0,08 & 0,08 & 0,50 & 0,08 & 0,08 \\
\hline 10 & 3 & A & $75-125$ & $50-100$ & 10 & 0,08 & 0,08 & 0,08 & 0,17 & 0,05 & 0,05 & 0,34 & 0,05 & 0,05 \\
\hline 10 & 3 & A & $75-125$ & $50-100$ & 50 & 0,14 & 0,14 & 0,14 & 0,24 & 0,06 & 0,06 & 0,48 & 0,06 & 0,06 \\
\hline 10 & 5 & B & $25-74$ & $0-50$ & 10 & 0,07 & 0,08 & 0,05 & 0,06 & 0,07 & 0,06 & 0,24 & 0,07 & 0,06 \\
\hline 10 & 5 & B & $25-74$ & $0-50$ & 50 & 0,13 & 0,12 & 0,10 & 0,11 & 0,13 & 0,13 & 0,36 & 0,13 & 0,13 \\
\hline 10 & 5 & B & $25-74$ & $50-100$ & 10 & 0,06 & 0,06 & 0,05 & 0,06 & 0,06 & 0,06 & 0,28 & 0,06 & 0,06 \\
\hline 10 & 5 & B & $25-74$ & $50-100$ & 50 & 0,12 & 0,09 & 0,11 & 0,10 & 0,09 & 0,09 & 0,42 & 0,09 & 0,09 \\
\hline 10 & 5 & B & $75-125$ & $0-50$ & 10 & 0,07 & 0,06 & 0,05 & 0,06 & 0,06 & 0,06 & 0,27 & 0,06 & 0,06 \\
\hline 10 & 5 & B & $75-125$ & $0-50$ & 50 & 0,10 & 0,12 & 0,10 & 0,10 & 0,09 & 0,09 & 0,38 & 0,09 & 0,09 \\
\hline 10 & 5 & B & $75-125$ & $50-100$ & 10 & 0,06 & 0,07 & 0,05 & 0,05 & 0,06 & 0,06 & 0,26 & 0,06 & 0,06 \\
\hline 10 & 5 & B & $75-125$ & $50-100$ & 50 & 0,11 & 0,07 & 0,07 & 0,07 & 0,08 & 0,08 & 0,36 & 0,08 & 0,08 \\
\hline 10 & 5 & M & $25-74$ & $0-50$ & 10 & 0,06 & 0,05 & 0,05 & 0,08 & 0,07 & 0,07 & 0,23 & 0,07 & 0,07 \\
\hline 10 & 5 & M & $25-74$ & $0-50$ & 50 & 0,14 & 0,11 & 0,12 & 0,08 & 0,08 & 0,08 & 0,40 & 0,08 & 0,09 \\
\hline 10 & 5 & M & $25-74$ & $50-100$ & 10 & 0,07 & 0,05 & 0,04 & 0,07 & 0,08 & 0,07 & 0,27 & 0,08 & 0,07 \\
\hline 10 & 5 & $\mathbf{M}$ & $25-74$ & $50-100$ & 50 & 0,13 & 0,10 & 0,08 & 0,10 & 0,10 & 0,10 & 0,35 & 0,10 & 0,10 \\
\hline 10 & 5 & M & $75-125$ & $0-50$ & 10 & 0,06 & 0,07 & 0,05 & 0,05 & 0,05 & 0,05 & 0,30 & 0,05 & 0,05 \\
\hline 10 & 5 & M & $75-125$ & $0-50$ & 50 & 0,13 & 0,09 & 0,09 & 0,10 & 0,08 & 0,08 & 0,36 & 0,09 & 0,09 \\
\hline 10 & 5 & M & $75-125$ & $50-100$ & 10 & 0,05 & 0,05 & 0,04 & 0,05 & 0,05 & 0,05 & 0,27 & 0,05 & 0,05 \\
\hline 10 & 5 & M & $75-125$ & $50-100$ & 50 & 0,09 & 0,07 & 0,07 & 0,07 & 0,07 & 0,07 & 0,30 & 0,07 & 0,07 \\
\hline 10 & 5 & A & $25-74$ & $0-50$ & 10 & 0,06 & 0,06 & 0,06 & 0,10 & 0,06 & 0,05 & 0,33 & 0,06 & 0,05 \\
\hline 10 & 5 & A & $25-74$ & $0-50$ & 50 & 0,13 & 0,13 & 0,13 & 0,15 & 0,07 & 0,08 & 0,43 & 0,07 & 0,08 \\
\hline 10 & 5 & A & $25-74$ & $50-100$ & 10 & 0,07 & 0,07 & 0,07 & 0,12 & 0,06 & 0,06 & 0,39 & 0,06 & 0,06 \\
\hline 10 & 5 & A & $25-74$ & $50-100$ & 50 & 0,10 & 0,10 & 0,10 & 0,15 & 0,07 & 0,06 & 0,47 & 0,07 & 0,06 \\
\hline 10 & 5 & A & $75-125$ & $0-50$ & 10 & 0,07 & 0,07 & 0,07 & 0,11 & 0,06 & 0,06 & 0,34 & 0,06 & 0,06 \\
\hline 10 & 5 & A & $75-125$ & $0-50$ & 50 & 0,10 & 0,10 & 0,10 & 0,16 & 0,09 & 0,09 & 0,46 & 0,09 & 0,09 \\
\hline 10 & 5 & A & $75-125$ & $50-100$ & 10 & 0,06 & 0,06 & 0,06 & 0,12 & 0,05 & 0,05 & 0,42 & 0,05 & 0,05 \\
\hline 10 & 5 & A & $75-125$ & $50-100$ & 50 & 0,11 & 0,11 & 0,11 & 0,16 & 0,07 & 0,08 & 0,51 & 0,07 & 0,08 \\
\hline 10 & 7 & B & $25-74$ & $0-50$ & 10 & 0,06 & 0,08 & 0,06 & 0,05 & 0,06 & 0,07 & 0,29 & 0,07 & 0,07 \\
\hline 10 & 7 & B & $25-74$ & $0-50$ & 50 & 0,10 & 0,09 & 0,08 & 0,09 & 0,09 & 0,09 & 0,37 & 0,09 & 0,09 \\
\hline 10 & 7 & B & $25-74$ & $50-100$ & 10 & 0,06 & 0,07 & 0,04 & 0,06 & 0,06 & 0,06 & 0,29 & 0,06 & 0,06 \\
\hline 10 & 7 & B & $25-74$ & $50-100$ & 50 & 0,12 & 0,10 & 0,09 & 0,10 & 0,09 & 0,09 & 0,39 & 0,08 & 0,09 \\
\hline 10 & 7 & B & $75-125$ & $0-50$ & 10 & 0,05 & 0,08 & 0,04 & 0,05 & 0,06 & 0,06 & 0,30 & 0,06 & 0,06 \\
\hline 10 & 7 & B & $75-125$ & $0-50$ & 50 & 0,10 & 0,09 & 0,08 & 0,08 & 0,08 & 0,08 & 0,36 & 0,08 & 0,08 \\
\hline 10 & 7 & B & $75-125$ & $50-100$ & 10 & 0,06 & 0,07 & 0,05 & 0,05 & 0,06 & 0,05 & 0,27 & 0,06 & 0,06 \\
\hline 10 & 7 & B & $75-125$ & $50-100$ & 50 & 0,11 & 0,10 & 0,08 & 0,09 & 0,07 & 0,07 & 0,37 & 0,07 & 0,07 \\
\hline 10 & 7 & M & $25-74$ & $0-50$ & 10 & 0,06 & 0,06 & 0,05 & 0,07 & 0,06 & 0,06 & 0,29 & 0,06 & 0,06 \\
\hline 10 & 7 & $\mathbf{M}$ & $25-74$ & $0-50$ & 50 & 0,09 & 0,08 & 0,09 & 0,10 & 0,08 & 0,09 & 0,35 & 0,08 & 0,08 \\
\hline 10 & 7 & M & $25-74$ & $50-100$ & 10 & 0,07 & 0,06 & 0,05 & 0,06 & 0,07 & 0,08 & 0,29 & 0,07 & 0,07 \\
\hline
\end{tabular}




\begin{tabular}{|c|c|c|c|c|c|c|c|c|c|c|c|c|c|c|}
\hline 10 & 7 & $\bar{M}$ & $25-74$ & $50-100$ & 50 & 0,10 & 0,09 & 0,10 & 0,09 & 0,09 & 0,09 & $\overline{0,40}$ & 0,09 & $\overline{0,09}$ \\
\hline 10 & 7 & M & $75-125$ & $0-50$ & 10 & 0,06 & 0,06 & 0,05 & 0,06 & 0,06 & 0,06 & 0,27 & 0,06 & 0,06 \\
\hline 10 & 7 & $\mathbf{M}$ & $75-125$ & $0-50$ & 50 & 0,09 & 0,10 & 0,08 & 0,10 & 0,08 & 0,08 & 0,31 & 0,08 & 0,09 \\
\hline 10 & 7 & $\mathbf{M}$ & $75-125$ & $50-100$ & 10 & 0,06 & 0,05 & 0,04 & 0,05 & 0,07 & 0,06 & 0,31 & 0,07 & 0,06 \\
\hline 10 & 7 & $\mathbf{M}$ & $75-125$ & $50-100$ & 50 & 0,08 & 0,07 & 0,07 & 0,07 & 0,08 & 0,08 & 0,38 & 0,08 & 0,08 \\
\hline 10 & 7 & A & $25-74$ & $0-50$ & 10 & 0,06 & 0,06 & 0,06 & 0,08 & 0,05 & 0,06 & 0,31 & 0,05 & 0,06 \\
\hline 10 & 7 & A & $25-74$ & $0-50$ & 50 & 0,11 & 0,11 & 0,11 & 0,12 & 0,09 & 0,09 & 0,34 & 0,09 & 0,09 \\
\hline 10 & 7 & A & $25-74$ & $50-100$ & 10 & 0,06 & 0,06 & 0,06 & 0,07 & 0,06 & 0,06 & 0,39 & 0,06 & 0,06 \\
\hline 10 & 7 & A & $25-74$ & $50-100$ & 50 & 0,11 & 0,11 & 0,11 & 0,13 & 0,07 & 0,06 & 0,42 & 0,07 & 0,06 \\
\hline 10 & 7 & A & $75-125$ & $0-50$ & 10 & 0,07 & 0,07 & 0,07 & 0,06 & 0,06 & 0,06 & 0,36 & 0,06 & 0,06 \\
\hline 10 & 7 & A & $75-125$ & $0-50$ & 50 & 0,09 & 0,09 & 0,09 & 0,09 & 0,07 & 0,07 & 0,41 & 0,06 & 0,06 \\
\hline 10 & 7 & A & $75-125$ & $50-100$ & 10 & 0,08 & 0,08 & 0,08 & 0,07 & 0,06 & 0,07 & 0,40 & 0,06 & 0,07 \\
\hline 10 & 7 & A & $75-125$ & $50-100$ & 50 & 0,10 & 0,10 & 0,10 & 0,11 & 0,07 & 0,07 & 0,49 & 0,07 & 0,07 \\
\hline 30 & 3 & B & $25-74$ & $0-50$ & 10 & 0,05 & 0,04 & 0,01 & 0,05 & 0,05 & 0,05 & 0,19 & 0,05 & 0,05 \\
\hline 30 & 3 & B & $25-74$ & $0-50$ & 50 & 0,06 & 0,04 & 0,02 & 0,05 & 0,05 & 0,05 & 0,28 & 0,05 & 0,06 \\
\hline 30 & 3 & B & $25-74$ & $50-100$ & 10 & 0,06 & 0,03 & 0,01 & 0,04 & 0,05 & 0,05 & 0,18 & 0,05 & 0,05 \\
\hline 30 & 3 & B & $25-74$ & $50-100$ & 50 & 0,06 & 0,03 & 0,02 & 0,05 & 0,04 & 0,05 & 0,29 & 0,04 & 0,05 \\
\hline 30 & 3 & B & $75-125$ & $0-50$ & 10 & 0,06 & 0,03 & 0,01 & 0,03 & 0,04 & 0,04 & 0,15 & 0,04 & 0,04 \\
\hline 30 & 3 & B & $75-125$ & $0-50$ & 50 & 0,05 & 0,03 & 0,02 & 0,04 & 0,04 & 0,04 & 0,29 & 0,04 & 0,04 \\
\hline 30 & 3 & B & $75-125$ & $50-100$ & 10 & 0,06 & 0,03 & 0,01 & 0,03 & 0,03 & 0,03 & 0,19 & 0,03 & 0,03 \\
\hline 30 & 3 & B & $75-125$ & $50-100$ & 50 & 0,04 & 0,03 & 0,02 & 0,03 & 0,03 & 0,03 & 0,26 & 0,03 & 0,03 \\
\hline 30 & 3 & M & $25-74$ & $0-50$ & 10 & 0,04 & 0,02 & 0,01 & 0,04 & 0,04 & 0,04 & 0,22 & 0,04 & 0,04 \\
\hline 30 & 3 & $\mathbf{M}$ & $25-74$ & $0-50$ & 50 & 0,06 & 0,04 & 0,03 & 0,08 & 0,05 & 0,06 & 0,31 & 0,05 & 0,06 \\
\hline 30 & 3 & M & $25-74$ & $50-100$ & 10 & 0,04 & 0,02 & 0,01 & 0,05 & 0,05 & 0,04 & 0,17 & 0,05 & 0,05 \\
\hline 30 & 3 & $\mathbf{M}$ & $25-74$ & $50-100$ & 50 & 0,05 & 0,03 & 0,02 & 0,09 & 0,06 & 0,07 & 0,28 & 0,06 & 0,07 \\
\hline 30 & 3 & M & $75-125$ & $0-50$ & 10 & 0,03 & 0,02 & 0,01 & 0,04 & 0,03 & 0,03 & 0,16 & 0,03 & 0,03 \\
\hline 30 & 3 & $\mathbf{M}$ & $75-125$ & $0-50$ & 50 & 0,04 & 0,02 & 0,03 & 0,04 & 0,04 & 0,04 & 0,27 & 0,04 & 0,04 \\
\hline 30 & 3 & M & $75-125$ & $50-100$ & 10 & 0,02 & 0,02 & 0,01 & 0,03 & 0,03 & 0,03 & 0,18 & 0,03 & 0,03 \\
\hline 30 & 3 & $\mathbf{M}$ & $75-125$ & $50-100$ & 50 & 0,04 & 0,02 & 0,03 & 0,04 & 0,03 & 0,03 & 0,25 & 0,03 & 0,03 \\
\hline 30 & 3 & A & $25-74$ & $0-50$ & 10 & 0,05 & 0,05 & 0,05 & 0,50 & 0,05 & 0,05 & 0,38 & 0,05 & 0,05 \\
\hline 30 & 3 & A & $25-74$ & $0-50$ & 50 & 0,08 & 0,08 & 0,08 & 0,47 & 0,05 & 0,05 & 0,48 & 0,05 & 0,05 \\
\hline 30 & 3 & A & $25-74$ & $50-100$ & 10 & 0,04 & 0,04 & 0,04 & 0,45 & 0,05 & 0,06 & 0,40 & 0,05 & 0,06 \\
\hline 30 & 3 & A & $25-74$ & $50-100$ & 50 & 0,08 & 0,08 & 0,08 & 0,45 & 0,05 & 0,05 & 0,43 & 0,05 & 0,05 \\
\hline 30 & 3 & A & $75-125$ & $0-50$ & 10 & 0,05 & 0,05 & 0,05 & 0,49 & 0,02 & 0,02 & 0,31 & 0,02 & 0,02 \\
\hline 30 & 3 & A & $75-125$ & $0-50$ & 50 & 0,09 & 0,09 & 0,09 & 0,47 & 0,04 & 0,04 & 0,39 & 0,04 & 0,04 \\
\hline 30 & 3 & A & $75-125$ & $50-100$ & 10 & 0,04 & 0,04 & 0,04 & 0,45 & 0,03 & 0,03 & 0,32 & 0,03 & 0,03 \\
\hline 30 & 3 & A & $75-125$ & $50-100$ & 50 & 0,05 & 0,05 & 0,05 & 0,41 & 0,05 & 0,05 & 0,44 & 0,05 & 0,05 \\
\hline 30 & 5 & B & $25-74$ & $0-50$ & 10 & 0,06 & 0,05 & 0,01 & 0,05 & 0,05 & 0,05 & 0,22 & 0,05 & 0,05 \\
\hline 30 & 5 & B & $25-74$ & $0-50$ & 50 & 0,07 & 0,05 & 0,03 & 0,05 & 0,06 & 0,06 & 0,38 & 0,06 & 0,06 \\
\hline 30 & 5 & B & $25-74$ & $50-100$ & 10 & 0,06 & 0,05 & 0,01 & 0,04 & 0,05 & 0,05 & 0,21 & 0,05 & 0,05 \\
\hline 30 & 5 & B & $25-74$ & $50-100$ & 50 & 0,06 & 0,05 & 0,03 & 0,05 & 0,05 & 0,05 & 0,34 & 0,05 & 0,05 \\
\hline 30 & 5 & B & $75-125$ & $0-50$ & 10 & 0,06 & 0,03 & 0,02 & 0,03 & 0,04 & 0,04 & 0,20 & 0,04 & 0,04 \\
\hline 30 & 5 & B & $75-125$ & $0-50$ & 50 & 0,06 & 0,05 & 0,04 & 0,05 & 0,05 & 0,05 & 0,33 & 0,05 & 0,05 \\
\hline 30 & 5 & B & $75-125$ & $50-100$ & 10 & 0,06 & 0,04 & 0,01 & 0,04 & 0,04 & 0,04 & 0,23 & 0,04 & 0,04 \\
\hline 30 & 5 & B & $75-125$ & $50-100$ & 50 & 0,05 & 0,03 & 0,02 & 0,04 & 0,04 & 0,04 & 0,33 & 0,04 & 0,04 \\
\hline 30 & 5 & $\mathbf{M}$ & $25-74$ & $0-50$ & 10 & 0,05 & 0,04 & 0,01 & 0,05 & 0,05 & 0,05 & 0,25 & 0,05 & 0,05 \\
\hline 30 & 5 & $\mathbf{M}$ & $25-74$ & $0-50$ & 50 & 0,06 & 0,05 & 0,03 & 0,07 & 0,06 & 0,06 & 0,33 & 0,06 & 0,06 \\
\hline 30 & 5 & $\mathbf{M}$ & $25-74$ & $50-100$ & 10 & 0,05 & 0,03 & 0,01 & 0,04 & 0,05 & 0,05 & 0,24 & 0,04 & 0,05 \\
\hline 30 & 5 & $\mathbf{M}$ & $25-74$ & $50-100$ & 50 & 0,06 & 0,04 & 0,03 & 0,06 & 0,05 & 0,06 & 0,35 & 0,05 & 0,06 \\
\hline 30 & 5 & $\mathbf{M}$ & $75-125$ & $0-50$ & 10 & 0,05 & 0,03 & 0,01 & 0,04 & 0,03 & 0,03 & 0,26 & 0,03 & 0,03 \\
\hline 30 & 5 & $\mathbf{M}$ & $75-125$ & $0-50$ & 50 & 0,05 & 0,04 & 0,03 & 0,05 & 0,04 & 0,04 & 0,33 & 0,04 & 0,04 \\
\hline 30 & 5 & M & $75-125$ & $50-100$ & 10 & 0,05 & 0,03 & 0,01 & 0,03 & 0,03 & 0,04 & 0,21 & 0,03 & 0,03 \\
\hline 30 & 5 & $\mathbf{M}$ & $75-125$ & $50-100$ & 50 & 0,04 & 0,03 & 0,02 & 0,03 & 0,04 & 0,04 & 0,36 & 0,03 & 0,04 \\
\hline 30 & 5 & A & $25-74$ & $0-50$ & 10 & 0,04 & 0,04 & 0,04 & 0,30 & 0,04 & 0,04 & 0,40 & 0,04 & 0,04 \\
\hline 30 & 5 & A & $25-74$ & $0-50$ & 50 & 0,07 & 0,07 & 0,07 & 0,29 & 0,04 & 0,04 & 0,53 & 0,04 & 0,04 \\
\hline 30 & 5 & A & $25-74$ & $50-100$ & 10 & 0,04 & 0,04 & 0,04 & 0,28 & 0,04 & 0,04 & 0,32 & 0,04 & 0,04 \\
\hline 30 & 5 & A & $25-74$ & $50-100$ & 50 & 0,07 & 0,07 & 0,07 & 0,27 & 0,04 & 0,04 & 0,48 & 0,04 & 0,04 \\
\hline 30 & 5 & A & $75-125$ & $0-50$ & 10 & 0,04 & 0,04 & 0,04 & 0,30 & 0,03 & 0,03 & 0,38 & 0,03 & 0,03 \\
\hline 30 & 5 & A & $75-125$ & $0-50$ & 50 & 0,07 & 0,07 & 0,07 & 0,32 & 0,04 & 0,04 & 0,47 & 0,04 & 0,04 \\
\hline 30 & 5 & A & $75-125$ & $50-100$ & 10 & 0,04 & 0,04 & 0,04 & 0,27 & 0,03 & 0,03 & 0,41 & 0,03 & 0,02 \\
\hline 30 & 5 & A & $75-125$ & $50-100$ & 50 & 0,06 & 0,06 & 0,06 & 0,33 & 0,03 & 0,03 & 0,48 & 0,03 & 0,03 \\
\hline 30 & 7 & B & $25-74$ & $0-50$ & 10 & 0,05 & 0,05 & 0,02 & 0,04 & 0,05 & 0,05 & 0,26 & 0,05 & 0,05 \\
\hline
\end{tabular}




\begin{tabular}{|c|c|c|c|c|c|c|c|c|c|c|c|c|c|c|}
\hline 30 & 7 & $\bar{B}$ & $25-74$ & $0-50$ & 50 & 0,06 & 0,06 & 0,03 & 0,06 & 0,06 & 0,06 & 0,39 & 0,06 & 0,06 \\
\hline 30 & 7 & B & $25-74$ & $50-100$ & 10 & 0,05 & 0,05 & 0,01 & 0,04 & 0,04 & 0,05 & 0,25 & 0,04 & 0,05 \\
\hline 30 & 7 & B & $25-74$ & $50-100$ & 50 & 0,07 & 0,06 & 0,03 & 0,05 & 0,07 & 0,06 & 0,41 & 0,07 & 0,06 \\
\hline 30 & 7 & B & $75-125$ & $0-50$ & 10 & 0,06 & 0,06 & 0,02 & 0,03 & 0,04 & 0,04 & 0,23 & 0,04 & 0,04 \\
\hline 30 & 7 & B & $75-125$ & $0-50$ & 50 & 0,06 & 0,07 & 0,04 & 0,05 & 0,05 & 0,05 & 0,39 & 0,05 & 0,05 \\
\hline 30 & 7 & B & $75-125$ & $50-100$ & 10 & 0,06 & 0,05 & 0,02 & 0,03 & 0,04 & 0,03 & 0,24 & 0,04 & 0,03 \\
\hline 30 & 7 & B & $75-125$ & $50-100$ & 50 & 0,06 & 0,06 & 0,03 & 0,04 & 0,05 & 0,05 & 0,43 & 0,05 & 0,05 \\
\hline 30 & 7 & M & $25-74$ & $0-50$ & 10 & 0,05 & 0,04 & 0,01 & 0,04 & 0,05 & 0,04 & 0,26 & 0,05 & 0,04 \\
\hline 30 & 7 & M & $25-74$ & $0-50$ & 50 & 0,07 & 0,04 & 0,04 & 0,06 & 0,06 & 0,06 & 0,37 & 0,06 & 0,07 \\
\hline 30 & 7 & M & $25-74$ & $50-100$ & 10 & 0,04 & 0,03 & 0,01 & 0,04 & 0,05 & 0,05 & 0,29 & 0,05 & 0,05 \\
\hline 30 & 7 & M & $25-74$ & $50-100$ & 50 & 0,06 & 0,04 & 0,03 & 0,06 & 0,06 & 0,06 & 0,39 & 0,06 & 0,06 \\
\hline 30 & 7 & M & $75-125$ & $0-50$ & 10 & 0,04 & 0,04 & 0,02 & 0,04 & 0,04 & 0,04 & 0,27 & 0,04 & 0,04 \\
\hline 30 & 7 & M & $75-125$ & $0-50$ & 50 & 0,06 & 0,04 & 0,03 & 0,05 & 0,05 & 0,05 & 0,40 & 0,05 & 0,05 \\
\hline 30 & 7 & M & $75-125$ & $50-100$ & 10 & 0,05 & 0,03 & 0,01 & 0,03 & 0,04 & 0,03 & 0,26 & 0,03 & 0,03 \\
\hline 30 & 7 & M & $75-125$ & $50-100$ & 50 & 0,04 & 0,04 & 0,02 & 0,04 & 0,04 & 0,04 & 0,38 & 0,04 & 0,04 \\
\hline 30 & 7 & A & $25-74$ & $0-50$ & 10 & 0,04 & 0,04 & 0,04 & 0,21 & 0,04 & 0,04 & 0,40 & 0,04 & 0,04 \\
\hline 30 & 7 & A & $25-74$ & $0-50$ & 50 & 0,07 & 0,07 & 0,07 & 0,25 & 0,05 & 0,05 & 0,49 & 0,06 & 0,05 \\
\hline 30 & 7 & A & $25-74$ & $50-100$ & 10 & 0,05 & 0,05 & 0,05 & 0,19 & 0,04 & 0,03 & 0,45 & 0,04 & 0,03 \\
\hline 30 & 7 & A & $25-74$ & $50-100$ & 50 & 0,08 & 0,08 & 0,08 & 0,25 & 0,04 & 0,04 & 0,50 & 0,04 & 0,04 \\
\hline 30 & 7 & A & $75-125$ & $0-50$ & 10 & 0,04 & 0,04 & 0,04 & 0,18 & 0,04 & 0,04 & 0,34 & 0,04 & 0,04 \\
\hline 30 & 7 & A & $75-125$ & $0-50$ & 50 & 0,07 & 0,07 & 0,07 & 0,25 & 0,05 & 0,05 & 0,46 & 0,05 & 0,05 \\
\hline 30 & 7 & A & $75-125$ & $50-100$ & 10 & 0,04 & 0,04 & 0,04 & 0,21 & 0,03 & 0,04 & 0,38 & 0,03 & 0,04 \\
\hline 30 & 7 & A & $75-125$ & $50-100$ & 50 & 0,06 & 0,06 & 0,06 & 0,28 & 0,04 & 0,04 & 0,54 & 0,04 & 0,04 \\
\hline 50 & 3 & B & $25-74$ & $0-50$ & 10 & 0,05 & 0,03 & 0,00 & 0,03 & 0,03 & 0,03 & 0,15 & 0,03 & 0,03 \\
\hline 50 & 3 & B & $25-74$ & $0-50$ & 50 & 0,04 & 0,03 & 0,01 & 0,04 & 0,04 & 0,04 & 0,25 & 0,04 & 0,04 \\
\hline 50 & 3 & B & $25-74$ & $50-100$ & 10 & 0,04 & 0,02 & 0,00 & 0,04 & 0,04 & 0,04 & 0,14 & 0,04 & 0,04 \\
\hline 50 & 3 & B & $25-74$ & $50-100$ & 50 & 0,04 & 0,03 & 0,01 & 0,04 & 0,04 & 0,04 & 0,27 & 0,04 & 0,04 \\
\hline 50 & 3 & B & $75-125$ & $0-50$ & 10 & 0,07 & 0,03 & 0,01 & 0,03 & 0,03 & 0,03 & 0,14 & 0,03 & 0,03 \\
\hline 50 & 3 & B & $75-125$ & $0-50$ & 50 & 0,04 & 0,03 & 0,01 & 0,03 & 0,03 & 0,03 & 0,25 & 0,03 & 0,03 \\
\hline 50 & 3 & B & $75-125$ & $50-100$ & 10 & 0,06 & 0,02 & 0,01 & 0,03 & 0,03 & 0,03 & 0,13 & 0,03 & 0,03 \\
\hline 50 & 3 & B & $75-125$ & $50-100$ & 50 & 0,04 & 0,03 & 0,01 & 0,02 & 0,02 & 0,03 & 0,27 & 0,02 & 0,03 \\
\hline 50 & 3 & M & $25-74$ & $0-50$ & 10 & 0,03 & 0,02 & 0,01 & 0,04 & 0,03 & 0,03 & 0,21 & 0,03 & 0,03 \\
\hline 50 & 3 & M & $25-74$ & $0-50$ & 50 & 0,04 & 0,02 & 0,01 & 0,05 & 0,04 & 0,04 & 0,28 & 0,04 & 0,04 \\
\hline 50 & 3 & M & $25-74$ & $50-100$ & 10 & 0,03 & 0,02 & 0,01 & 0,04 & 0,03 & 0,04 & 0,25 & 0,03 & 0,04 \\
\hline 50 & 3 & M & $25-74$ & $50-100$ & 50 & 0,04 & 0,02 & 0,02 & 0,04 & 0,05 & 0,05 & 0,26 & 0,05 & 0,05 \\
\hline 50 & 3 & M & $75-125$ & $0-50$ & 10 & 0,02 & 0,02 & 0,01 & 0,03 & 0,02 & 0,02 & 0,18 & 0,02 & 0,02 \\
\hline 50 & 3 & M & $75-125$ & $0-50$ & 50 & 0,03 & 0,02 & 0,01 & 0,03 & 0,03 & 0,03 & 0,24 & 0,03 & 0,03 \\
\hline 50 & 3 & M & $75-125$ & $50-100$ & 10 & 0,02 & 0,02 & 0,01 & 0,03 & 0,02 & 0,02 & 0,19 & 0,02 & 0,02 \\
\hline 50 & 3 & M & $75-125$ & $50-100$ & 50 & 0,02 & 0,02 & 0,01 & 0,02 & 0,03 & 0,03 & 0,20 & 0,03 & 0,03 \\
\hline 50 & 3 & A & $25-74$ & $0-50$ & 10 & 0,04 & 0,04 & 0,04 & 0,52 & 0,05 & 0,05 & 0,33 & 0,05 & 0,05 \\
\hline 50 & 3 & A & $25-74$ & $0-50$ & 50 & 0,04 & 0,04 & 0,04 & 0,54 & 0,06 & 0,05 & 0,38 & 0,06 & 0,05 \\
\hline 50 & 3 & A & $25-74$ & $50-100$ & 10 & 0,03 & 0,03 & 0,03 & 0,52 & 0,06 & 0,06 & 0,28 & 0,06 & 0,06 \\
\hline 50 & 3 & A & $25-74$ & $50-100$ & 50 & 0,04 & 0,04 & 0,04 & 0,54 & 0,06 & 0,06 & 0,46 & 0,06 & 0,06 \\
\hline 50 & 3 & A & $75-125$ & $0-50$ & 10 & 0,04 & 0,04 & 0,04 & 0,56 & 0,03 & 0,03 & 0,32 & 0,03 & 0,03 \\
\hline 50 & 3 & A & $75-125$ & $0-50$ & 50 & 0,04 & 0,04 & 0,04 & 0,56 & 0,03 & 0,03 & 0,41 & 0,03 & 0,03 \\
\hline 50 & 3 & A & $75-125$ & $50-100$ & 10 & 0,04 & 0,04 & 0,04 & 0,59 & 0,03 & 0,04 & 0,36 & 0,03 & 0,04 \\
\hline 50 & 3 & A & $75-125$ & $50-100$ & 50 & 0,05 & 0,05 & 0,05 & 0,56 & 0,04 & 0,04 & 0,38 & 0,04 & 0,04 \\
\hline 50 & 5 & B & $25-74$ & $0-50$ & 10 & 0,06 & 0,04 & 0,00 & 0,03 & 0,04 & 0,04 & 0,19 & 0,04 & 0,04 \\
\hline 50 & 5 & B & $25-74$ & $0-50$ & 50 & 0,06 & 0,04 & 0,02 & 0,04 & 0,05 & 0,05 & 0,32 & 0,05 & 0,05 \\
\hline 50 & 5 & B & $25-74$ & $50-100$ & 10 & 0,06 & 0,03 & 0,00 & 0,03 & 0,04 & 0,04 & 0,20 & 0,04 & 0,04 \\
\hline 50 & 5 & B & $25-74$ & $50-100$ & 50 & 0,05 & 0,04 & 0,02 & 0,05 & 0,05 & 0,05 & 0,31 & 0,05 & 0,05 \\
\hline 50 & 5 & B & $75-125$ & $0-50$ & 10 & 0,08 & 0,03 & 0,00 & 0,03 & 0,03 & 0,03 & 0,19 & 0,03 & 0,03 \\
\hline 50 & 5 & B & $75-125$ & $0-50$ & 50 & 0,05 & 0,03 & 0,01 & 0,03 & 0,04 & 0,04 & 0,28 & 0,04 & 0,04 \\
\hline 50 & 5 & B & $75-125$ & $50-100$ & 10 & 0,07 & 0,03 & 0,01 & 0,02 & 0,03 & 0,03 & 0,21 & 0,03 & 0,03 \\
\hline 50 & 5 & B & $75-125$ & $50-100$ & 50 & 0,04 & 0,03 & 0,01 & 0,03 & 0,03 & 0,03 & 0,34 & 0,03 & 0,03 \\
\hline 50 & 5 & M & $25-74$ & $0-50$ & 10 & 0,04 & 0,03 & 0,00 & 0,04 & 0,04 & 0,04 & 0,26 & 0,04 & 0,04 \\
\hline 50 & 5 & M & $25-74$ & $0-50$ & 50 & 0,05 & 0,03 & 0,01 & 0,04 & 0,05 & 0,05 & 0,32 & 0,05 & 0,05 \\
\hline 50 & 5 & M & $25-74$ & $50-100$ & 10 & 0,04 & 0,03 & 0,00 & 0,04 & 0,04 & 0,04 & 0,23 & 0,04 & 0,04 \\
\hline 50 & 5 & M & $25-74$ & $50-100$ & 50 & 0,04 & 0,03 & 0,02 & 0,05 & 0,05 & 0,05 & 0,31 & 0,05 & 0,05 \\
\hline 50 & 5 & M & $75-125$ & $0-50$ & 10 & 0,06 & 0,03 & 0,00 & 0,03 & 0,03 & 0,03 & 0,21 & 0,03 & 0,03 \\
\hline 50 & 5 & M & $75-125$ & $0-50$ & 50 & 0,04 & 0,03 & 0,02 & 0,04 & 0,03 & 0,03 & 0,29 & 0,03 & 0,03 \\
\hline 50 & 5 & M & $75-125$ & $50-100$ & 10 & 0,06 & 0,02 & 0,01 & 0,03 & 0,03 & 0,03 & 0,22 & 0,03 & 0,03 \\
\hline
\end{tabular}




\begin{tabular}{|c|c|c|c|c|c|c|c|c|c|c|c|c|c|c|}
\hline 50 & 5 & $M$ & $75-125$ & $50-100$ & 50 & 0,04 & 0,03 & 0,01 & 0,03 & 0,03 & 0,03 & 0,30 & 0,03 & 0,03 \\
\hline 50 & 5 & A & $25-74$ & $0-50$ & 10 & 0,03 & 0,03 & 0,03 & 0,40 & 0,03 & 0,03 & 0,32 & 0,03 & 0,03 \\
\hline 50 & 5 & A & $25-74$ & $0-50$ & 50 & 0,04 & 0,04 & 0,04 & 0,38 & 0,04 & 0,04 & 0,47 & 0,04 & 0,04 \\
\hline 50 & 5 & A & $25-74$ & $50-100$ & 10 & 0,03 & 0,03 & 0,03 & 0,34 & 0,04 & 0,04 & 0,42 & 0,04 & 0,04 \\
\hline 50 & 5 & A & $25-74$ & $50-100$ & 50 & 0,05 & 0,05 & 0,05 & 0,35 & 0,05 & 0,04 & 0,51 & 0,05 & 0,04 \\
\hline 50 & 5 & A & $75-125$ & $0-50$ & 10 & 0,03 & 0,03 & 0,03 & 0,36 & 0,02 & 0,02 & 0,38 & 0,02 & 0,02 \\
\hline 50 & 5 & A & $75-125$ & $0-50$ & 50 & 0,05 & 0,05 & 0,05 & 0,36 & 0,03 & 0,03 & 0,46 & 0,03 & 0,03 \\
\hline 50 & 5 & A & $75-125$ & $50-100$ & 10 & 0,04 & 0,04 & 0,04 & 0,38 & 0,03 & 0,03 & 0,39 & 0,03 & 0,03 \\
\hline 50 & 5 & A & $75-125$ & $50-100$ & 50 & 0,04 & 0,04 & 0,04 & 0,34 & 0,03 & 0,03 & 0,48 & 0,03 & 0,03 \\
\hline 50 & 7 & B & $25-74$ & $0-50$ & 10 & 0,06 & 0,05 & 0,00 & 0,04 & 0,04 & 0,04 & 0,23 & 0,04 & 0,04 \\
\hline 50 & 7 & B & $25-74$ & $0-50$ & 50 & 0,06 & 0,06 & 0,01 & 0,05 & 0,05 & 0,05 & 0,34 & 0,05 & 0,05 \\
\hline 50 & 7 & B & $25-74$ & $50-100$ & 10 & 0,07 & 0,05 & 0,00 & 0,03 & 0,03 & 0,04 & 0,22 & 0,03 & 0,04 \\
\hline 50 & 7 & B & $25-74$ & $50-100$ & 50 & 0,06 & 0,06 & 0,01 & 0,05 & 0,05 & 0,05 & 0,37 & 0,05 & 0,05 \\
\hline 50 & 7 & B & $75-125$ & $0-50$ & 10 & 0,07 & 0,05 & 0,01 & 0,02 & 0,03 & 0,03 & 0,21 & 0,03 & 0,03 \\
\hline 50 & 7 & B & $75-125$ & $0-50$ & 50 & 0,05 & 0,05 & 0,02 & 0,04 & 0,04 & 0,04 & 0,36 & 0,04 & 0,04 \\
\hline 50 & 7 & B & $75-125$ & $50-100$ & 10 & 0,08 & 0,04 & 0,01 & 0,03 & 0,03 & 0,03 & 0,21 & 0,03 & 0,03 \\
\hline 50 & 7 & B & $75-125$ & $50-100$ & 50 & 0,06 & 0,05 & 0,01 & 0,03 & 0,04 & 0,04 & 0,36 & 0,04 & 0,04 \\
\hline 50 & 7 & M & $25-74$ & $0-50$ & 10 & 0,05 & 0,03 & 0,01 & 0,04 & 0,04 & 0,05 & 0,27 & 0,04 & 0,05 \\
\hline 50 & 7 & $\mathbf{M}$ & $25-74$ & $0-50$ & 50 & 0,05 & 0,04 & 0,02 & 0,06 & 0,05 & 0,05 & 0,36 & 0,05 & 0,05 \\
\hline 50 & 7 & $\mathbf{M}$ & $25-74$ & $50-100$ & 10 & 0,04 & 0,03 & 0,00 & 0,03 & 0,04 & 0,03 & 0,25 & 0,04 & 0,04 \\
\hline 50 & 7 & $\mathbf{M}$ & $25-74$ & $50-100$ & 50 & 0,05 & 0,04 & 0,01 & 0,05 & 0,05 & 0,05 & 0,39 & 0,05 & 0,05 \\
\hline 50 & 7 & M & $75-125$ & $0-50$ & 10 & 0,06 & 0,02 & 0,01 & 0,03 & 0,03 & 0,03 & 0,26 & 0,03 & 0,03 \\
\hline 50 & 7 & $\mathbf{M}$ & $75-125$ & $0-50$ & 50 & 0,05 & 0,03 & 0,01 & 0,05 & 0,04 & 0,04 & 0,37 & 0,04 & 0,04 \\
\hline 50 & 7 & $\mathbf{M}$ & $75-125$ & $50-100$ & 10 & 0,05 & 0,02 & 0,01 & 0,03 & 0,03 & 0,03 & 0,26 & 0,03 & 0,03 \\
\hline 50 & 7 & $\mathbf{M}$ & $75-125$ & $50-100$ & 50 & 0,03 & 0,03 & 0,01 & 0,03 & 0,03 & 0,03 & 0,36 & 0,03 & 0,03 \\
\hline 50 & 7 & A & $25-74$ & $0-50$ & 10 & 0,03 & 0,03 & 0,03 & 0,21 & 0,03 & 0,03 & 0,40 & 0,03 & 0,03 \\
\hline 50 & 7 & A & $25-74$ & $0-50$ & 50 & 0,05 & 0,05 & 0,05 & 0,30 & 0,03 & 0,03 & 0,47 & 0,03 & 0,03 \\
\hline 50 & 7 & A & $25-74$ & $50-100$ & 10 & 0,03 & 0,03 & 0,03 & 0,27 & 0,03 & 0,03 & 0,44 & 0,03 & 0,03 \\
\hline 50 & 7 & A & $25-74$ & $50-100$ & 50 & 0,04 & 0,04 & 0,04 & 0,27 & 0,05 & 0,04 & 0,52 & 0,04 & 0,04 \\
\hline 50 & 7 & A & $75-125$ & $0-50$ & 10 & 0,04 & 0,04 & 0,04 & 0,23 & 0,02 & 0,02 & 0,40 & 0,02 & 0,02 \\
\hline 50 & 7 & A & $75-125$ & $0-50$ & 50 & 0,05 & 0,05 & 0,05 & 0,31 & 0,03 & 0,03 & 0,47 & 0,03 & 0,03 \\
\hline 50 & 7 & A & $75-125$ & $50-100$ & 10 & 0,04 & 0,04 & 0,04 & 0,29 & 0,03 & 0,03 & 0,40 & 0,02 & 0,03 \\
\hline 50 & 7 & A & $75-125$ & $50-100$ & 50 & 0,04 & 0,04 & 0,04 & 0,27 & 0,03 & 0,03 & 0,48 & 0,03 & 0,03 \\
\hline 80 & 3 & B & $25-74$ & $0-50$ & 10 & 0,05 & 0,03 & 0,00 & 0,03 & 0,03 & 0,03 & 0,14 & 0,03 & 0,03 \\
\hline 80 & 3 & B & $25-74$ & $0-50$ & 50 & 0,03 & 0,03 & 0,01 & 0,03 & 0,03 & 0,03 & 0,23 & 0,03 & 0,03 \\
\hline 80 & 3 & B & $25-74$ & $50-100$ & 10 & 0,04 & 0,02 & 0,00 & 0,03 & 0,03 & 0,03 & 0,15 & 0,03 & 0,03 \\
\hline 80 & 3 & B & $25-74$ & $50-100$ & 50 & 0,03 & 0,03 & 0,01 & 0,03 & 0,03 & 0,03 & 0,23 & 0,03 & 0,03 \\
\hline 80 & 3 & B & $75-125$ & $0-50$ & 10 & 0,06 & 0,02 & 0,00 & 0,02 & 0,02 & 0,02 & 0,14 & 0,02 & 0,02 \\
\hline 80 & 3 & B & $75-125$ & $0-50$ & 50 & 0,04 & 0,03 & 0,01 & 0,02 & 0,02 & 0,02 & 0,18 & 0,02 & 0,02 \\
\hline 80 & 3 & B & $75-125$ & $50-100$ & 10 & 0,07 & 0,02 & 0,00 & 0,02 & 0,02 & 0,02 & 0,14 & 0,02 & 0,02 \\
\hline 80 & 3 & B & $75-125$ & $50-100$ & 50 & 0,03 & 0,02 & 0,01 & 0,02 & 0,02 & 0,02 & 0,22 & 0,02 & 0,02 \\
\hline 80 & 3 & $\mathbf{M}$ & $25-74$ & $0-50$ & 10 & 0,02 & 0,02 & 0,00 & 0,03 & 0,03 & 0,03 & 0,18 & 0,03 & 0,03 \\
\hline 80 & 3 & $\mathbf{M}$ & $25-74$ & $0-50$ & 50 & 0,03 & 0,02 & 0,01 & 0,03 & 0,04 & 0,03 & 0,26 & 0,04 & 0,03 \\
\hline 80 & 3 & $\mathbf{M}$ & $25-74$ & $50-100$ & 10 & 0,03 & 0,02 & 0,01 & 0,05 & 0,03 & 0,03 & 0,19 & 0,03 & 0,03 \\
\hline 80 & 3 & $\mathbf{M}$ & $25-74$ & $50-100$ & 50 & 0,03 & 0,01 & 0,01 & 0,05 & 0,03 & 0,04 & 0,23 & 0,03 & 0,04 \\
\hline 80 & 3 & $\mathbf{M}$ & $75-125$ & $0-50$ & 10 & 0,02 & 0,02 & 0,01 & 0,02 & 0,02 & 0,02 & 0,16 & 0,02 & 0,02 \\
\hline 80 & 3 & $\mathbf{M}$ & $75-125$ & $0-50$ & 50 & 0,02 & 0,01 & 0,01 & 0,02 & 0,02 & 0,02 & 0,19 & 0,02 & 0,02 \\
\hline 80 & 3 & $\mathbf{M}$ & $75-125$ & $50-100$ & 10 & 0,01 & 0,02 & 0,00 & 0,02 & 0,02 & 0,02 & 0,19 & 0,02 & 0,02 \\
\hline 80 & 3 & $\mathbf{M}$ & $75-125$ & $50-100$ & 50 & 0,02 & 0,01 & 0,01 & 0,02 & 0,02 & 0,02 & 0,22 & 0,02 & 0,02 \\
\hline 80 & 3 & A & $25-74$ & $0-50$ & 10 & 0,02 & 0,02 & 0,02 & 0,56 & 0,05 & 0,05 & 0,31 & 0,05 & 0,05 \\
\hline 80 & 3 & A & $25-74$ & $0-50$ & 50 & 0,02 & 0,02 & 0,02 & 0,57 & 0,06 & 0,06 & 0,36 & 0,06 & 0,06 \\
\hline 80 & 3 & A & $25-74$ & $50-100$ & 10 & 0,02 & 0,02 & 0,02 & 0,54 & 0,07 & 0,07 & 0,28 & 0,07 & 0,07 \\
\hline 80 & 3 & A & $25-74$ & $50-100$ & 50 & 0,03 & 0,03 & 0,03 & 0,57 & 0,06 & 0,06 & 0,41 & 0,06 & 0,06 \\
\hline 80 & 3 & A & $75-125$ & $0-50$ & 10 & 0,03 & 0,03 & 0,03 & 0,65 & 0,03 & 0,03 & 0,32 & 0,03 & 0,03 \\
\hline 80 & 3 & A & $75-125$ & $0-50$ & 50 & 0,02 & 0,02 & 0,02 & 0,53 & 0,04 & 0,04 & 0,36 & 0,04 & 0,04 \\
\hline 80 & 3 & A & $75-125$ & $50-100$ & 10 & 0,04 & 0,04 & 0,04 & 0,50 & 0,04 & 0,04 & 0,28 & 0,04 & 0,04 \\
\hline 80 & 3 & A & $75-125$ & $50-100$ & 50 & 0,03 & 0,03 & 0,03 & 0,53 & 0,04 & 0,04 & 0,39 & 0,04 & 0,04 \\
\hline 80 & 5 & B & $25-74$ & $0-50$ & 10 & 0,06 & 0,03 & 0,00 & 0,03 & 0,04 & 0,04 & 0,19 & 0,04 & 0,04 \\
\hline 80 & 5 & B & $25-74$ & $0-50$ & 50 & 0,05 & 0,03 & 0,01 & 0,03 & 0,04 & 0,04 & 0,31 & 0,04 & 0,04 \\
\hline 80 & 5 & B & $25-74$ & $50-100$ & 10 & 0,07 & 0,03 & 0,00 & 0,03 & 0,03 & 0,03 & 0,21 & 0,03 & 0,03 \\
\hline 80 & 5 & B & $25-74$ & $50-100$ & 50 & 0,04 & 0,03 & 0,00 & 0,04 & 0,04 & 0,04 & 0,30 & 0,04 & 0,04 \\
\hline 80 & 5 & B & $75-125$ & $0-50$ & 10 & 0,08 & 0,02 & 0,00 & 0,03 & 0,03 & 0,03 & 0,20 & 0,03 & 0,03 \\
\hline
\end{tabular}




\begin{tabular}{|c|c|c|c|c|c|c|c|c|c|c|c|c|c|c|}
\hline 80 & 5 & $\bar{B}$ & $75-125$ & $0-50$ & 50 & 0,05 & 0,03 & 0,01 & 0,03 & 0,03 & 0,03 & 0,26 & 0,03 & 0,03 \\
\hline 80 & 5 & B & $75-125$ & $50-100$ & 10 & 0,08 & 0,02 & 0,00 & 0,02 & 0,03 & 0,03 & 0,18 & 0,03 & 0,03 \\
\hline 80 & 5 & B & $75-125$ & $50-100$ & 50 & 0,06 & 0,03 & 0,00 & 0,03 & 0,02 & 0,02 & 0,27 & 0,02 & 0,02 \\
\hline 80 & 5 & M & $25-74$ & $0-50$ & 10 & 0,05 & 0,02 & 0,00 & 0,03 & 0,03 & 0,03 & 0,19 & 0,03 & 0,03 \\
\hline 80 & 5 & M & $25-74$ & $0-50$ & 50 & 0,04 & 0,03 & 0,00 & 0,04 & 0,03 & 0,04 & 0,28 & 0,03 & 0,04 \\
\hline 80 & 5 & M & $25-74$ & $50-100$ & 10 & 0,04 & 0,02 & 0,00 & 0,03 & 0,03 & 0,03 & 0,24 & 0,03 & 0,03 \\
\hline 80 & 5 & M & $25-74$ & $50-100$ & 50 & 0,03 & 0,03 & 0,01 & 0,04 & 0,04 & 0,04 & 0,28 & 0,03 & 0,04 \\
\hline 80 & 5 & M & $75-125$ & $0-50$ & 10 & 0,06 & 0,02 & 0,00 & 0,03 & 0,02 & 0,02 & 0,21 & 0,02 & 0,02 \\
\hline 80 & 5 & M & $75-125$ & $0-50$ & 50 & 0,04 & 0,03 & 0,01 & 0,03 & 0,02 & 0,03 & 0,27 & 0,03 & 0,03 \\
\hline 80 & 5 & M & $75-125$ & $50-100$ & 10 & 0,07 & 0,02 & 0,01 & 0,02 & 0,02 & 0,02 & 0,22 & 0,02 & 0,02 \\
\hline 80 & 5 & M & $75-125$ & $50-100$ & 50 & 0,04 & 0,03 & 0,01 & 0,02 & 0,02 & 0,02 & 0,26 & 0,02 & 0,02 \\
\hline 80 & 5 & A & $25-74$ & $0-50$ & 10 & 0,02 & 0,02 & 0,02 & 0,39 & 0,05 & 0,05 & 0,41 & 0,05 & 0,05 \\
\hline 80 & 5 & A & $25-74$ & $0-50$ & 50 & 0,03 & 0,03 & 0,03 & 0,40 & 0,05 & 0,04 & 0,42 & 0,05 & 0,04 \\
\hline 80 & 5 & A & $25-74$ & $50-100$ & 10 & 0,02 & 0,02 & 0,02 & 0,35 & 0,04 & 0,04 & 0,36 & 0,04 & 0,04 \\
\hline 80 & 5 & A & $25-74$ & $50-100$ & 50 & 0,03 & 0,03 & 0,03 & 0,33 & 0,05 & 0,05 & 0,46 & 0,04 & 0,05 \\
\hline 80 & 5 & A & $75-125$ & $0-50$ & 10 & 0,04 & 0,04 & 0,04 & 0,42 & 0,03 & 0,03 & 0,39 & 0,03 & 0,03 \\
\hline 80 & 5 & A & $75-125$ & $0-50$ & 50 & 0,04 & 0,04 & 0,04 & 0,34 & 0,03 & 0,03 & 0,45 & 0,03 & 0,03 \\
\hline 80 & 5 & A & $75-125$ & $50-100$ & 10 & 0,03 & 0,03 & 0,03 & 0,37 & 0,03 & 0,04 & 0,35 & 0,03 & 0,04 \\
\hline 80 & 5 & A & $75-125$ & $50-100$ & 50 & 0,03 & 0,03 & 0,03 & 0,41 & 0,04 & 0,04 & 0,40 & 0,04 & 0,04 \\
\hline 80 & 7 & B & $25-74$ & $0-50$ & 10 & 0,06 & 0,04 & 0,00 & 0,03 & 0,04 & 0,03 & 0,25 & 0,04 & 0,03 \\
\hline 80 & 7 & B & $25-74$ & $0-50$ & 50 & 0,06 & 0,05 & 0,01 & 0,04 & 0,04 & 0,04 & 0,32 & 0,04 & 0,04 \\
\hline 80 & 7 & B & $25-74$ & $50-100$ & 10 & 0,06 & 0,04 & 0,00 & 0,03 & 0,03 & 0,04 & 0,22 & 0,03 & 0,03 \\
\hline 80 & 7 & B & $25-74$ & $50-100$ & 50 & 0,06 & 0,05 & 0,00 & 0,04 & 0,04 & 0,04 & 0,37 & 0,04 & 0,04 \\
\hline 80 & 7 & B & $75-125$ & $0-50$ & 10 & 0,08 & 0,04 & 0,00 & 0,03 & 0,03 & 0,03 & 0,22 & 0,03 & 0,03 \\
\hline 80 & 7 & B & $75-125$ & $0-50$ & 50 & 0,06 & 0,05 & 0,01 & 0,04 & 0,03 & 0,04 & 0,30 & 0,04 & 0,04 \\
\hline 80 & 7 & B & $75-125$ & $50-100$ & 10 & 0,08 & 0,04 & 0,00 & 0,03 & 0,03 & 0,03 & 0,23 & 0,03 & 0,03 \\
\hline 80 & 7 & B & $75-125$ & $50-100$ & 50 & 0,06 & 0,04 & 0,01 & 0,03 & 0,03 & 0,03 & 0,32 & 0,03 & 0,03 \\
\hline 80 & 7 & M & $25-74$ & $0-50$ & 10 & 0,04 & 0,02 & 0,01 & 0,03 & 0,04 & 0,03 & 0,27 & 0,03 & 0,03 \\
\hline 80 & 7 & M & $25-74$ & $0-50$ & 50 & 0,04 & 0,03 & 0,02 & 0,04 & 0,03 & 0,04 & 0,36 & 0,03 & 0,04 \\
\hline 80 & 7 & M & $25-74$ & $50-100$ & 10 & 0,04 & 0,02 & 0,00 & 0,03 & 0,03 & 0,03 & 0,29 & 0,03 & 0,03 \\
\hline 80 & 7 & M & $25-74$ & $50-100$ & 50 & 0,05 & 0,03 & 0,01 & 0,03 & 0,04 & 0,04 & 0,38 & 0,04 & 0,04 \\
\hline 80 & 7 & M & $75-125$ & $0-50$ & 10 & 0,06 & 0,02 & 0,00 & 0,03 & 0,02 & 0,03 & 0,28 & 0,02 & 0,03 \\
\hline 80 & 7 & M & $75-125$ & $0-50$ & 50 & 0,04 & 0,03 & 0,01 & 0,03 & 0,03 & 0,03 & 0,30 & 0,03 & 0,03 \\
\hline 80 & 7 & M & $75-125$ & $50-100$ & 10 & 0,06 & 0,02 & 0,00 & 0,02 & 0,02 & 0,02 & 0,27 & 0,02 & 0,02 \\
\hline 80 & 7 & M & $75-125$ & $50-100$ & 50 & 0,04 & 0,02 & 0,00 & 0,02 & 0,02 & 0,03 & 0,32 & 0,02 & 0,03 \\
\hline 80 & 7 & A & $25-74$ & $0-50$ & 10 & 0,02 & 0,02 & 0,02 & 0,30 & 0,04 & 0,04 & 0,38 & 0,04 & 0,04 \\
\hline 80 & 7 & A & $25-74$ & $0-50$ & 50 & 0,04 & 0,04 & 0,04 & 0,37 & 0,04 & 0,04 & 0,51 & 0,03 & 0,04 \\
\hline 80 & 7 & A & $25-74$ & $50-100$ & 10 & 0,02 & 0,02 & 0,02 & 0,30 & 0,04 & 0,04 & 0,46 & 0,04 & 0,04 \\
\hline 80 & 7 & A & $25-74$ & $50-100$ & 50 & 0,03 & 0,03 & 0,03 & 0,26 & 0,04 & 0,04 & 0,51 & 0,04 & 0,04 \\
\hline 80 & 7 & A & $75-125$ & $0-50$ & 10 & 0,04 & 0,04 & 0,04 & 0,30 & 0,03 & 0,03 & 0,40 & 0,03 & 0,03 \\
\hline 80 & 7 & A & $75-125$ & $0-50$ & 50 & 0,04 & 0,04 & 0,04 & 0,36 & 0,03 & 0,03 & 0,45 & 0,03 & 0,03 \\
\hline 80 & 7 & A & $75-125$ & $50-100$ & 10 & 0,03 & 0,03 & 0,03 & 0,28 & 0,03 & 0,02 & 0,47 & 0,03 & 0,02 \\
\hline 80 & 7 & A & $75-125$ & $50-100$ & 50 & 0,03 & 0,03 & 0,03 & 0,33 & 0,03 & 0,03 & 0,56 & 0,03 & 0,03 \\
\hline 100 & 3 & B & $25-74$ & $0-50$ & 10 & 0,04 & 0,02 & 0,00 & 0,02 & 0,03 & 0,03 & 0,15 & 0,03 & 0,03 \\
\hline 100 & 3 & B & $25-74$ & $0-50$ & 50 & 0,03 & 0,04 & 0,01 & 0,03 & 0,03 & 0,03 & 0,20 & 0,03 & 0,03 \\
\hline 100 & 3 & B & $25-74$ & $50-100$ & 10 & 0,04 & 0,02 & 0,00 & 0,03 & 0,03 & 0,03 & 0,15 & 0,03 & 0,03 \\
\hline 100 & 3 & B & $25-74$ & $50-100$ & 50 & 0,04 & 0,03 & 0,00 & 0,03 & 0,03 & 0,03 & 0,20 & 0,03 & 0,03 \\
\hline 100 & 3 & B & $75-125$ & $0-50$ & 10 & 0,06 & 0,02 & 0,00 & 0,02 & 0,02 & 0,02 & 0,13 & 0,02 & 0,02 \\
\hline 100 & 3 & B & $75-125$ & $0-50$ & 50 & 0,04 & 0,03 & 0,01 & 0,02 & 0,02 & 0,02 & 0,22 & 0,02 & 0,02 \\
\hline 100 & 3 & B & $75-125$ & $50-100$ & 10 & 0,07 & 0,02 & 0,00 & 0,02 & 0,02 & 0,02 & 0,12 & 0,02 & 0,02 \\
\hline 100 & 3 & B & $75-125$ & $50-100$ & 50 & 0,03 & 0,03 & 0,00 & 0,02 & 0,02 & 0,02 & 0,18 & 0,02 & 0,02 \\
\hline 100 & 3 & M & $25-74$ & $0-50$ & 10 & 0,02 & 0,02 & 0,01 & 0,02 & 0,03 & 0,03 & 0,18 & 0,03 & 0,03 \\
\hline 100 & 3 & M & $25-74$ & $0-50$ & 50 & 0,03 & 0,01 & 0,01 & 0,03 & 0,03 & 0,03 & 0,22 & 0,03 & 0,03 \\
\hline 100 & 3 & M & $25-74$ & $50-100$ & 10 & 0,03 & 0,02 & 0,00 & 0,04 & 0,02 & 0,02 & 0,20 & 0,02 & 0,02 \\
\hline 100 & 3 & M & $25-74$ & $50-100$ & 50 & 0,03 & 0,01 & 0,01 & 0,03 & 0,03 & 0,03 & 0,27 & 0,03 & 0,03 \\
\hline 100 & 3 & M & $75-125$ & $0-50$ & 10 & 0,01 & 0,01 & 0,00 & 0,02 & 0,02 & 0,02 & 0,17 & 0,02 & 0,02 \\
\hline 100 & 3 & M & $75-125$ & $0-50$ & 50 & 0,02 & 0,01 & 0,01 & 0,02 & 0,02 & 0,02 & 0,19 & 0,02 & 0,02 \\
\hline 100 & 3 & M & $75-125$ & $50-100$ & 10 & 0,01 & 0,02 & 0,00 & 0,02 & 0,02 & 0,01 & 0,18 & 0,02 & 0,01 \\
\hline 100 & 3 & M & $75-125$ & $50-100$ & 50 & 0,02 & 0,01 & 0,00 & 0,02 & 0,02 & 0,02 & 0,20 & 0,02 & 0,02 \\
\hline 100 & 3 & A & $25-74$ & $0-50$ & 10 & 0,01 & 0,01 & 0,01 & 0,52 & 0,06 & 0,06 & 0,26 & 0,06 & 0,06 \\
\hline 100 & 3 & A & $25-74$ & $0-50$ & 50 & 0,02 & 0,02 & 0,02 & 0,48 & 0,07 & 0,06 & 0,40 & 0,07 & 0,06 \\
\hline 100 & 3 & A & $25-74$ & $50-100$ & 10 & 0,03 & 0,03 & 0,03 & 0,59 & 0,06 & 0,06 & 0,33 & 0,06 & 0,06 \\
\hline
\end{tabular}




\begin{tabular}{|c|c|c|c|c|c|c|c|c|c|c|c|c|c|c|}
\hline 100 & 3 & $\bar{A}$ & $25-74$ & $50-100$ & 50 & 0,02 & 0,02 & 0,02 & 0,56 & 0,06 & 0,06 & 0,35 & 0,06 & $\overline{0,06}$ \\
\hline 100 & 3 & A & $75-125$ & $0-50$ & 10 & 0,03 & 0,03 & 0,03 & 0,65 & 0,04 & 0,04 & 0,29 & 0,04 & 0,04 \\
\hline 100 & 3 & A & $75-125$ & $0-50$ & 50 & 0,02 & 0,02 & 0,02 & 0,64 & 0,04 & 0,04 & 0,41 & 0,04 & 0,04 \\
\hline 100 & 3 & A & $75-125$ & $50-100$ & 10 & 0,03 & 0,03 & 0,03 & 0,59 & 0,04 & 0,04 & 0,33 & 0,04 & 0,04 \\
\hline 100 & 3 & A & $75-125$ & $50-100$ & 50 & 0,01 & 0,01 & 0,01 & 0,58 & 0,04 & 0,04 & 0,34 & 0,04 & 0,04 \\
\hline 100 & 5 & B & $25-74$ & $0-50$ & 10 & 0,07 & 0,02 & 0,00 & 0,03 & 0,03 & 0,03 & 0,21 & 0,03 & 0,03 \\
\hline 100 & 5 & B & $25-74$ & $0-50$ & 50 & 0,05 & 0,03 & 0,01 & 0,03 & 0,03 & 0,03 & 0,29 & 0,03 & 0,03 \\
\hline 100 & 5 & B & $25-74$ & $50-100$ & 10 & 0,07 & 0,03 & 0,00 & 0,02 & 0,03 & 0,03 & 0,22 & 0,03 & 0,03 \\
\hline 100 & 5 & B & $25-74$ & $50-100$ & 50 & 0,05 & 0,03 & 0,00 & 0,04 & 0,03 & 0,03 & 0,33 & 0,03 & 0,03 \\
\hline 100 & 5 & B & $75-125$ & $0-50$ & 10 & 0,09 & 0,02 & 0,00 & 0,03 & 0,03 & 0,03 & 0,18 & 0,02 & 0,03 \\
\hline 100 & 5 & B & $75-125$ & $0-50$ & 50 & 0,06 & 0,03 & 0,00 & 0,02 & 0,02 & 0,02 & 0,29 & 0,02 & 0,02 \\
\hline 100 & 5 & B & $75-125$ & $50-100$ & 10 & 0,09 & 0,02 & 0,00 & 0,02 & 0,02 & 0,02 & 0,17 & 0,02 & 0,02 \\
\hline 100 & 5 & B & $75-125$ & $50-100$ & 50 & 0,05 & 0,03 & 0,01 & 0,02 & 0,02 & 0,02 & 0,28 & 0,02 & 0,02 \\
\hline 100 & 5 & $\mathbf{M}$ & $25-74$ & $0-50$ & 10 & 0,04 & 0,02 & 0,00 & 0,03 & 0,03 & 0,03 & 0,24 & 0,03 & 0,03 \\
\hline 100 & 5 & $\mathbf{M}$ & $25-74$ & $0-50$ & 50 & 0,04 & 0,03 & 0,00 & 0,03 & 0,03 & 0,03 & 0,29 & 0,03 & 0,03 \\
\hline 100 & 5 & $\mathbf{M}$ & $25-74$ & $50-100$ & 10 & 0,05 & 0,03 & 0,00 & 0,03 & 0,03 & 0,03 & 0,18 & 0,03 & 0,03 \\
\hline 100 & 5 & $\mathbf{M}$ & $25-74$ & $50-100$ & 50 & 0,03 & 0,03 & 0,01 & 0,04 & 0,03 & 0,03 & 0,26 & 0,03 & 0,03 \\
\hline 100 & 5 & $\mathbf{M}$ & $75-125$ & $0-50$ & 10 & 0,07 & 0,02 & 0,00 & 0,03 & 0,02 & 0,02 & 0,19 & 0,02 & 0,02 \\
\hline 100 & 5 & $\mathbf{M}$ & $75-125$ & $0-50$ & 50 & 0,04 & 0,03 & 0,01 & 0,02 & 0,03 & 0,03 & 0,27 & 0,02 & 0,02 \\
\hline 100 & 5 & $\mathbf{M}$ & $75-125$ & $50-100$ & 10 & 0,07 & 0,02 & 0,00 & 0,02 & 0,02 & 0,02 & 0,20 & 0,02 & 0,02 \\
\hline 100 & 5 & $\mathbf{M}$ & $75-125$ & $50-100$ & 50 & 0,04 & 0,02 & 0,00 & 0,02 & 0,02 & 0,02 & 0,29 & 0,02 & 0,02 \\
\hline 100 & 5 & A & $25-74$ & $0-50$ & 10 & 0,02 & 0,02 & 0,02 & 0,39 & 0,05 & 0,05 & 0,32 & 0,05 & 0,05 \\
\hline 100 & 5 & A & $25-74$ & $0-50$ & 50 & 0,02 & 0,02 & 0,02 & 0,39 & 0,05 & 0,05 & 0,42 & 0,05 & 0,05 \\
\hline 100 & 5 & A & $25-74$ & $50-100$ & 10 & 0,02 & 0,02 & 0,02 & 0,33 & 0,05 & 0,05 & 0,38 & 0,05 & 0,05 \\
\hline 100 & 5 & A & $25-74$ & $50-100$ & 50 & 0,02 & 0,02 & 0,02 & 0,39 & 0,05 & 0,05 & 0,44 & 0,05 & 0,05 \\
\hline 100 & 5 & A & $75-125$ & $0-50$ & 10 & 0,03 & 0,03 & 0,03 & 0,42 & 0,03 & 0,03 & 0,41 & 0,03 & 0,03 \\
\hline 100 & 5 & A & $75-125$ & $0-50$ & 50 & 0,03 & 0,03 & 0,03 & 0,43 & 0,03 & 0,03 & 0,48 & 0,03 & 0,03 \\
\hline 100 & 5 & A & $75-125$ & $50-100$ & 10 & 0,03 & 0,03 & 0,03 & 0,41 & 0,04 & 0,04 & 0,42 & 0,04 & 0,04 \\
\hline 100 & 5 & A & $75-125$ & $50-100$ & 50 & 0,02 & 0,02 & 0,02 & 0,36 & 0,04 & 0,04 & 0,43 & 0,04 & 0,04 \\
\hline 100 & 7 & B & $25-74$ & $0-50$ & 10 & 0,07 & 0,04 & 0,00 & 0,02 & 0,03 & 0,03 & 0,24 & 0,03 & 0,03 \\
\hline 100 & 7 & B & $25-74$ & $0-50$ & 50 & 0,06 & 0,04 & 0,00 & 0,04 & 0,03 & 0,03 & 0,34 & 0,03 & 0,03 \\
\hline 100 & 7 & B & $25-74$ & $50-100$ & 10 & 0,07 & 0,03 & 0,00 & 0,03 & 0,03 & 0,03 & 0,23 & 0,03 & 0,03 \\
\hline 100 & 7 & B & $25-74$ & $50-100$ & 50 & 0,06 & 0,04 & 0,00 & 0,04 & 0,03 & 0,03 & 0,37 & 0,03 & 0,03 \\
\hline 100 & 7 & B & $75-125$ & $0-50$ & 10 & 0,09 & 0,03 & 0,00 & 0,02 & 0,02 & 0,02 & 0,22 & 0,02 & 0,02 \\
\hline 100 & 7 & B & $75-125$ & $0-50$ & 50 & 0,07 & 0,04 & 0,01 & 0,03 & 0,03 & 0,03 & 0,38 & 0,03 & 0,03 \\
\hline 100 & 7 & B & $75-125$ & $50-100$ & 10 & 0,09 & 0,03 & 0,00 & 0,02 & 0,02 & 0,02 & 0,22 & 0,02 & 0,02 \\
\hline 100 & 7 & B & $75-125$ & $50-100$ & 50 & 0,07 & 0,03 & 0,01 & 0,03 & 0,03 & 0,03 & 0,31 & 0,03 & 0,03 \\
\hline 100 & 7 & M & $25-74$ & $0-50$ & 10 & 0,04 & 0,02 & 0,00 & 0,03 & 0,03 & 0,03 & 0,26 & 0,03 & 0,03 \\
\hline 100 & 7 & $\mathbf{M}$ & $25-74$ & $0-50$ & 50 & 0,04 & 0,03 & 0,01 & 0,03 & 0,03 & 0,03 & 0,39 & 0,03 & 0,03 \\
\hline 100 & 7 & M & $25-74$ & $50-100$ & 10 & 0,04 & 0,02 & 0,00 & 0,03 & 0,03 & 0,03 & 0,26 & 0,03 & 0,03 \\
\hline 100 & 7 & $\mathbf{M}$ & $25-74$ & $50-100$ & 50 & 0,04 & 0,03 & 0,01 & 0,03 & 0,03 & 0,03 & 0,41 & 0,03 & 0,03 \\
\hline 100 & 7 & $\mathbf{M}$ & $75-125$ & $0-50$ & 10 & 0,06 & 0,02 & 0,00 & 0,03 & 0,02 & 0,02 & 0,25 & 0,02 & 0,02 \\
\hline 100 & 7 & $\mathbf{M}$ & $75-125$ & $0-50$ & 50 & 0,04 & 0,03 & 0,01 & 0,03 & 0,03 & 0,02 & 0,33 & 0,03 & 0,02 \\
\hline 100 & 7 & M & $75-125$ & $50-100$ & 10 & 0,07 & 0,02 & 0,00 & 0,02 & 0,02 & 0,02 & 0,25 & 0,02 & 0,02 \\
\hline 100 & 7 & $\mathbf{M}$ & $75-125$ & $50-100$ & 50 & 0,04 & 0,03 & 0,00 & 0,02 & 0,02 & 0,02 & 0,32 & 0,02 & 0,02 \\
\hline 100 & 7 & A & $25-74$ & $0-50$ & 10 & 0,02 & 0,02 & 0,02 & 0,27 & 0,04 & 0,04 & 0,41 & 0,04 & 0,04 \\
\hline 100 & 7 & A & $25-74$ & $0-50$ & 50 & 0,03 & 0,03 & 0,03 & 0,37 & 0,03 & 0,04 & 0,51 & 0,03 & 0,04 \\
\hline 100 & 7 & A & $25-74$ & $50-100$ & 10 & 0,02 & 0,02 & 0,02 & 0,32 & 0,03 & 0,03 & 0,43 & 0,03 & 0,03 \\
\hline 100 & 7 & A & $25-74$ & $50-100$ & 50 & 0,02 & 0,02 & 0,02 & 0,36 & 0,04 & 0,04 & 0,58 & 0,04 & 0,04 \\
\hline 100 & 7 & A & $75-125$ & $0-50$ & 10 & 0,04 & 0,04 & 0,04 & 0,26 & 0,03 & 0,03 & 0,44 & 0,03 & 0,03 \\
\hline 100 & 7 & A & $75-125$ & $0-50$ & 50 & 0,03 & 0,03 & 0,03 & 0,34 & 0,03 & 0,03 & 0,57 & 0,03 & 0,03 \\
\hline 100 & 7 & A & $75-125$ & $50-100$ & 10 & 0,04 & 0,04 & 0,04 & 0,28 & 0,03 & 0,03 & 0,42 & 0,03 & 0,03 \\
\hline 100 & 7 & A & $75-125$ & $50-100$ & 50 & 0,03 & 0,03 & 0,03 & 0,32 & 0,03 & 0,03 & 0,56 & 0,03 & 0,03 \\
\hline
\end{tabular}




\section{APÊNDICE E}

\section{CódIGO-FONTE DOS PROGRAMAS COMPUTACIONAIS}

\section{- Regras para setup independente}

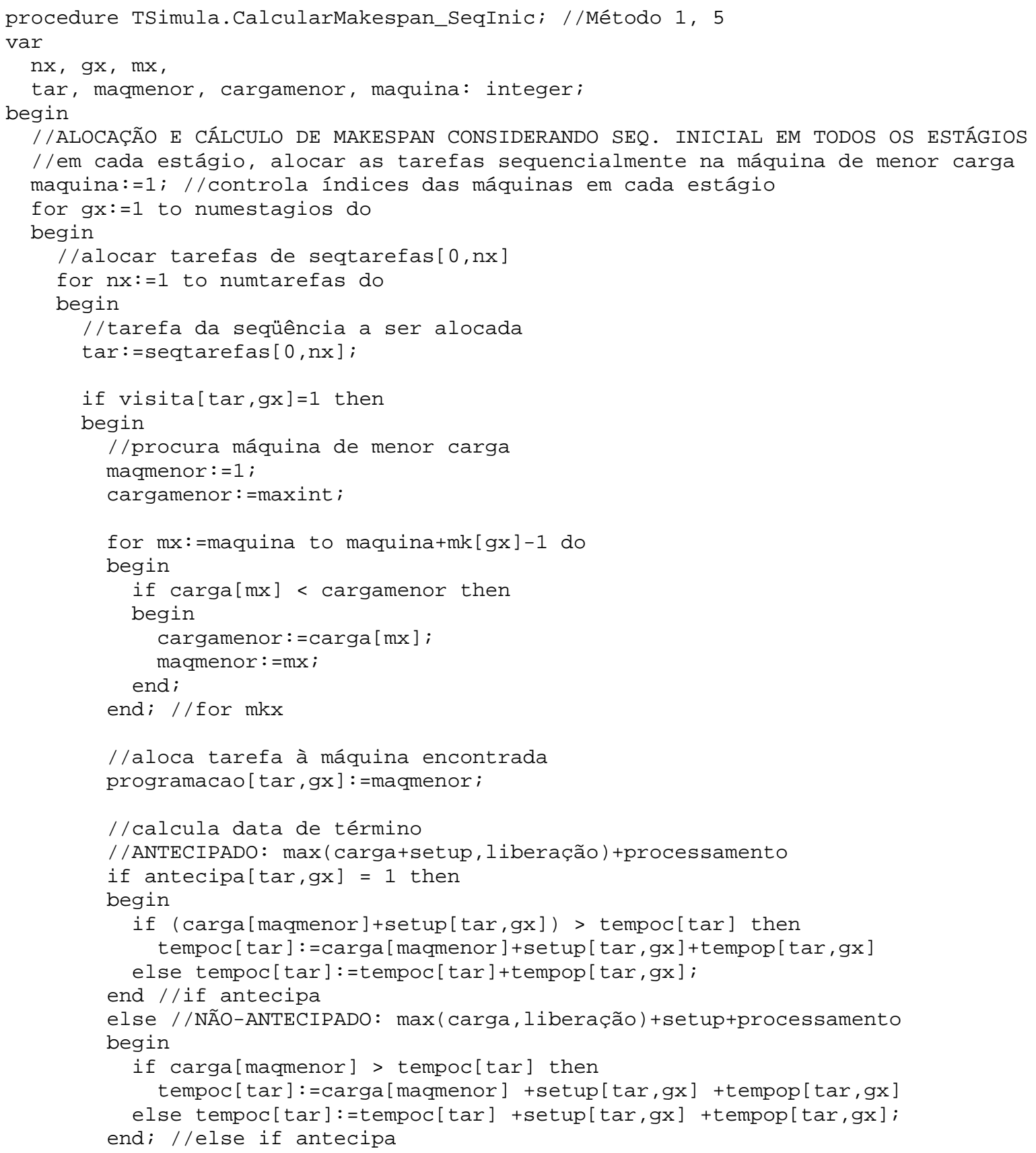




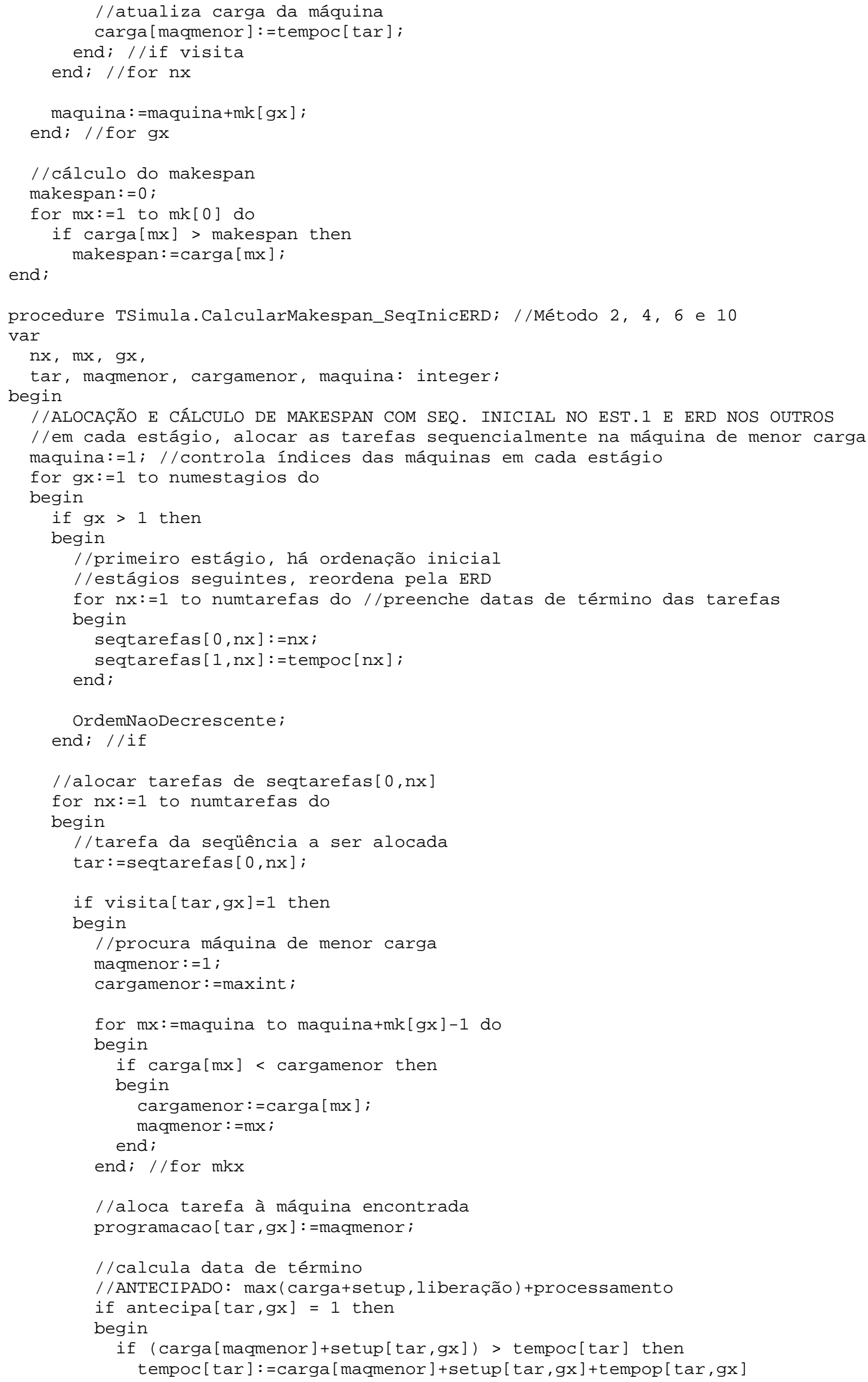




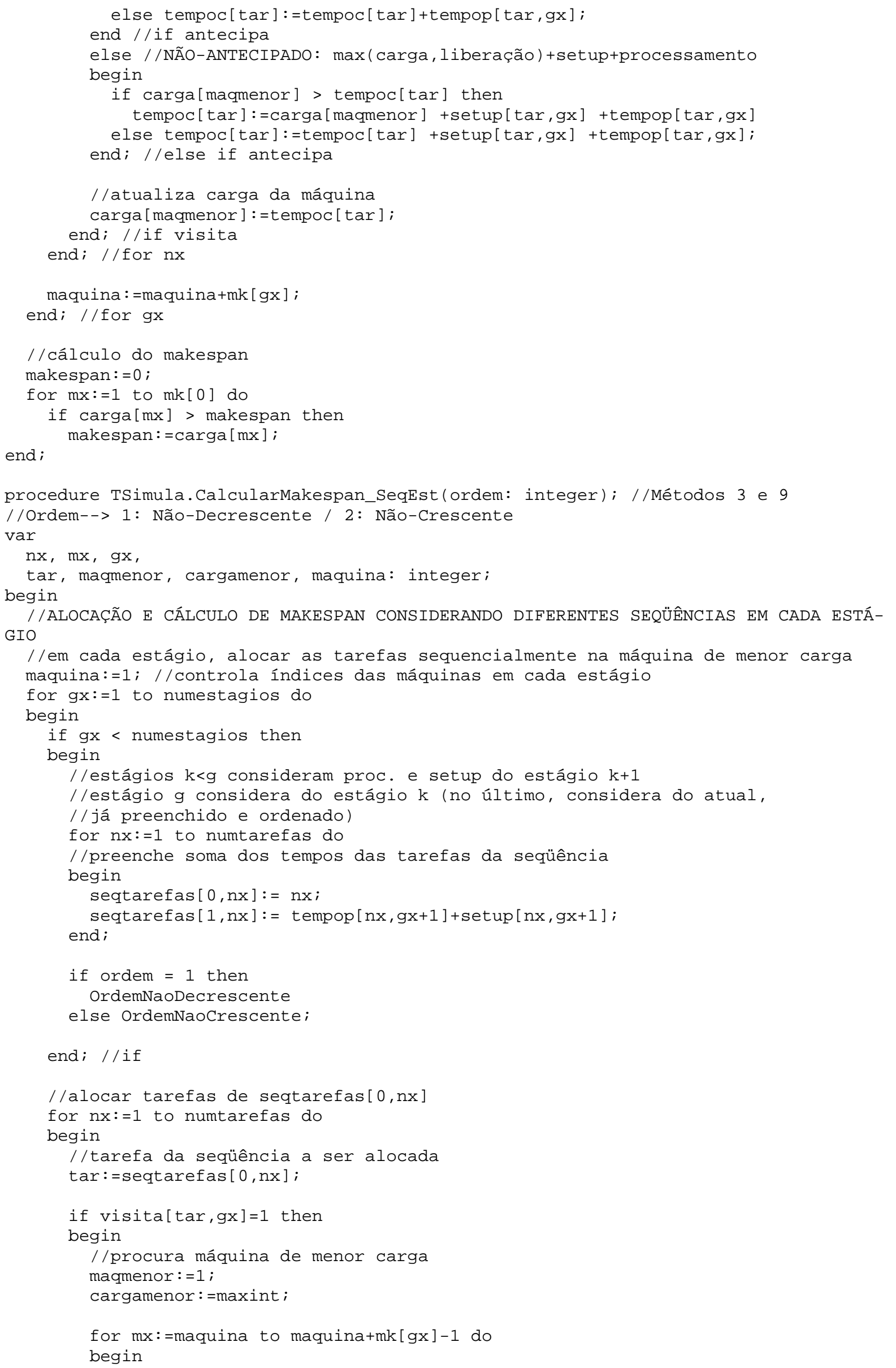




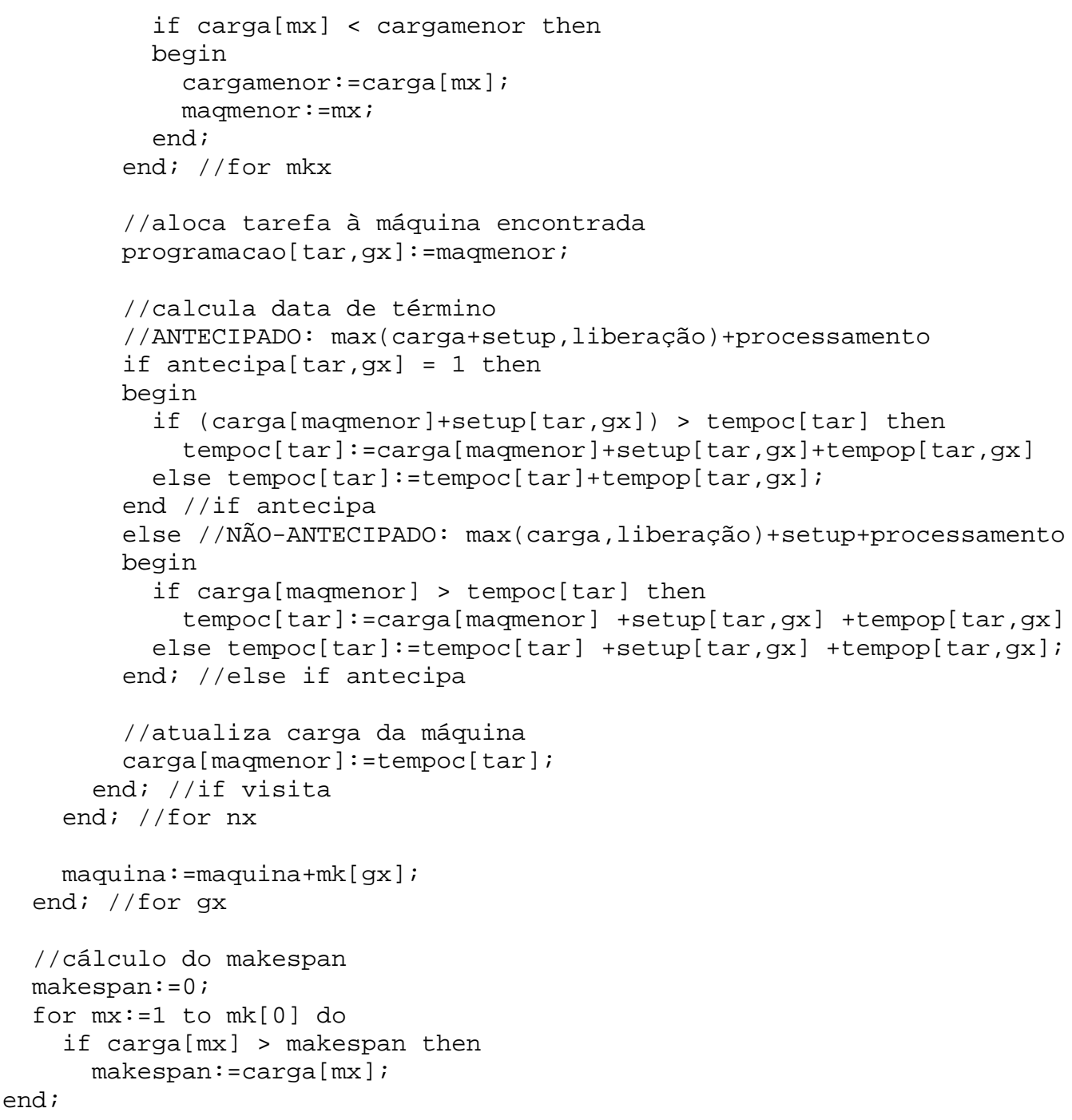

\section{- Regras para setup dependente}

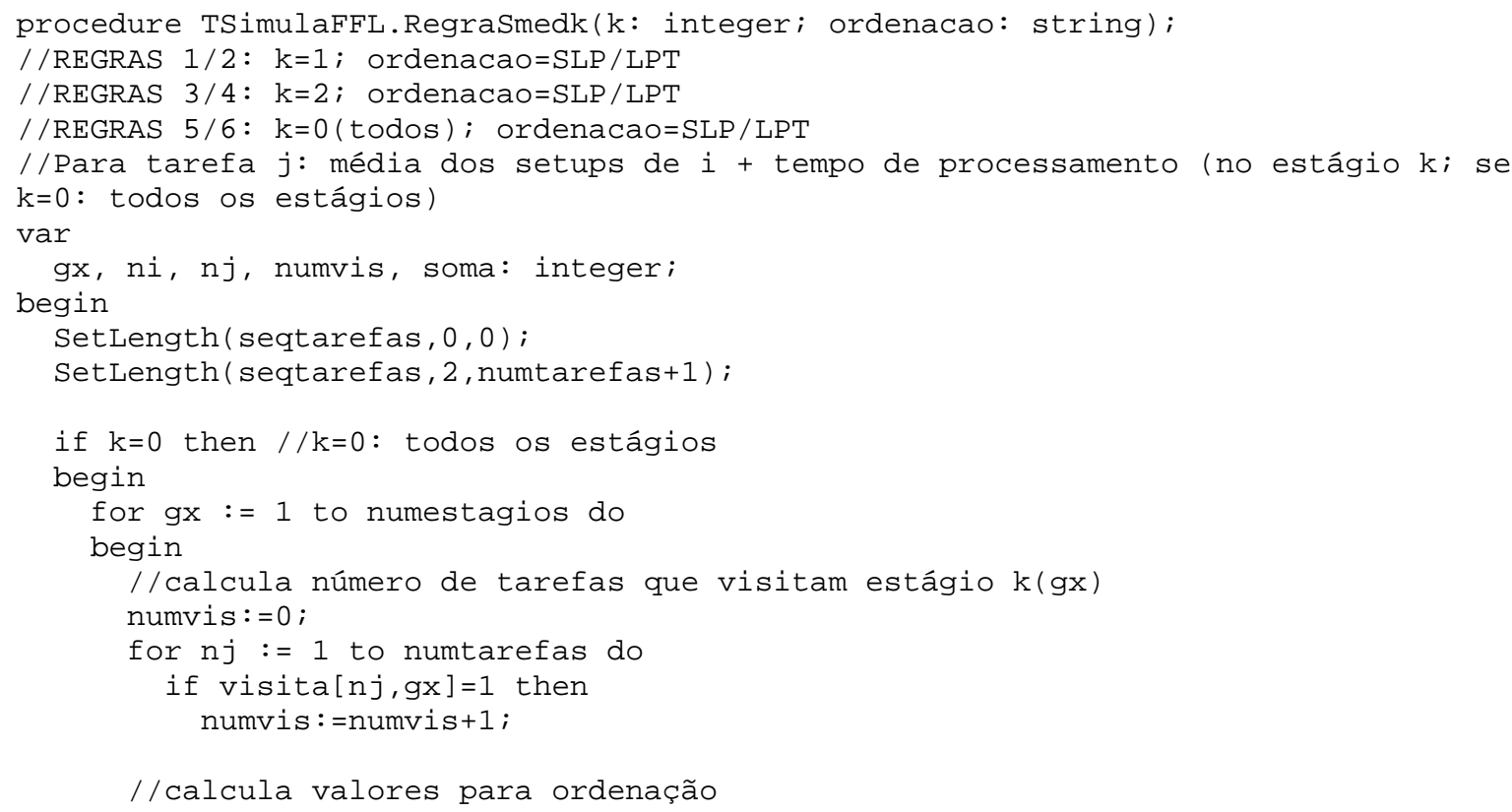




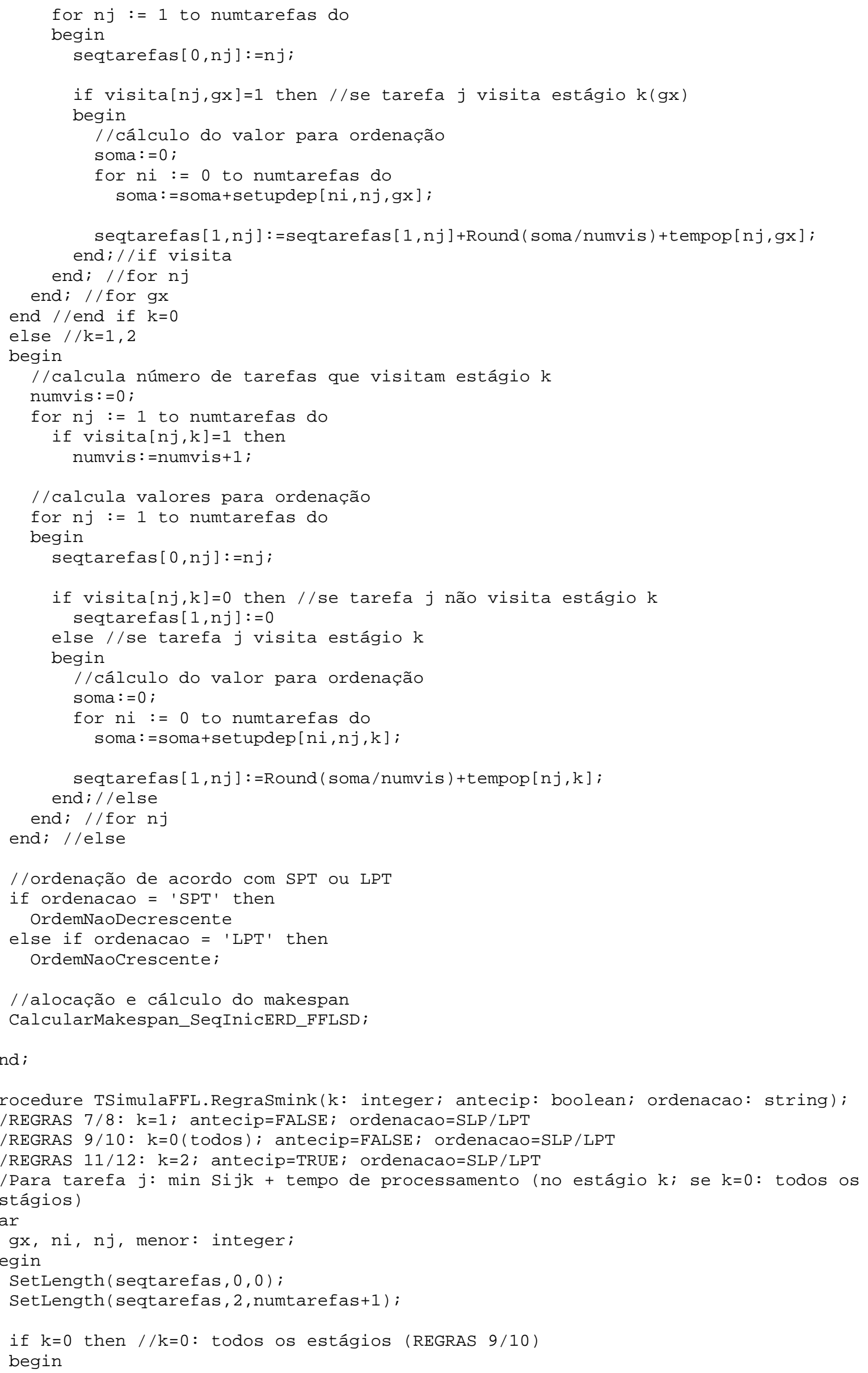




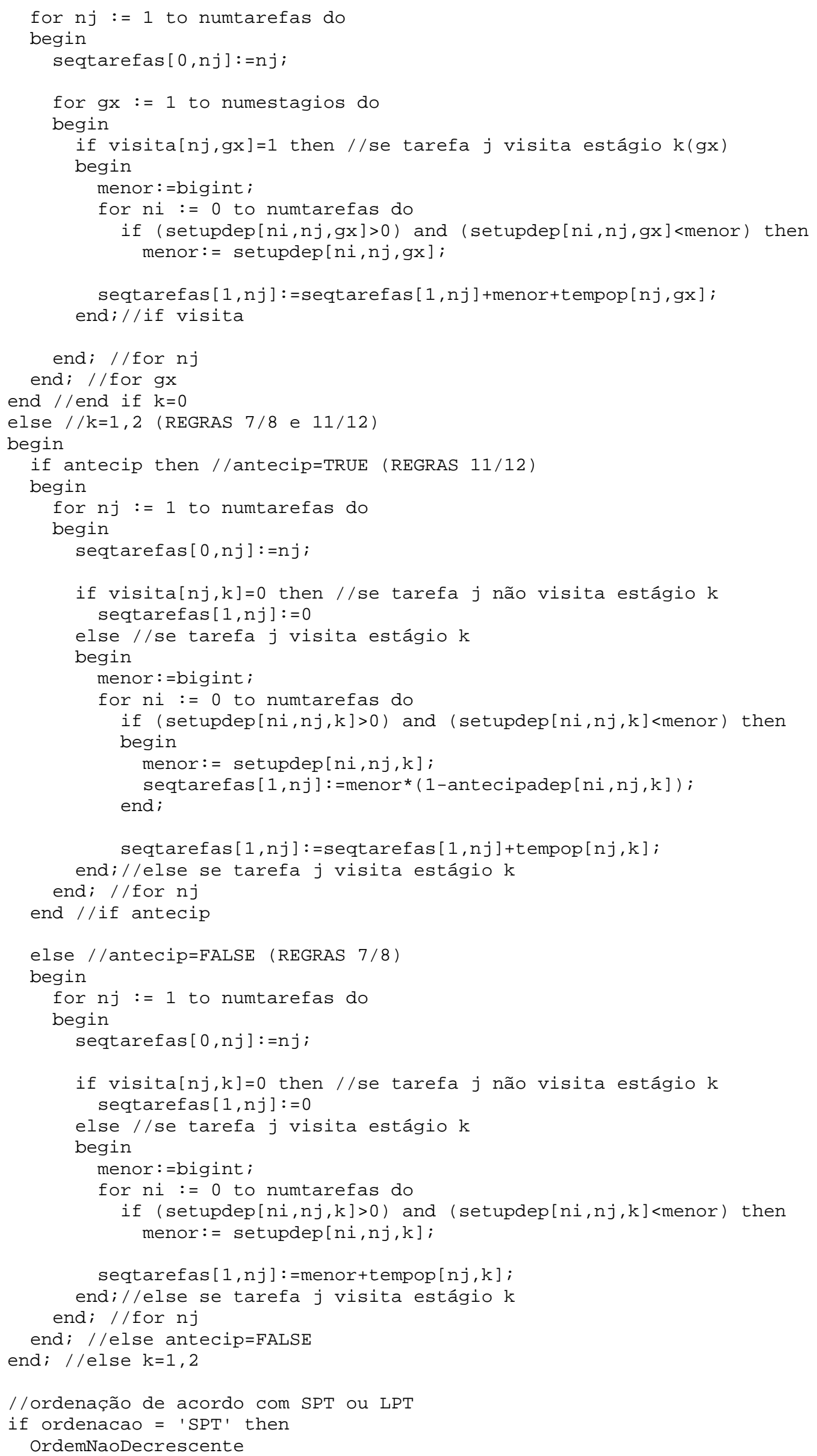




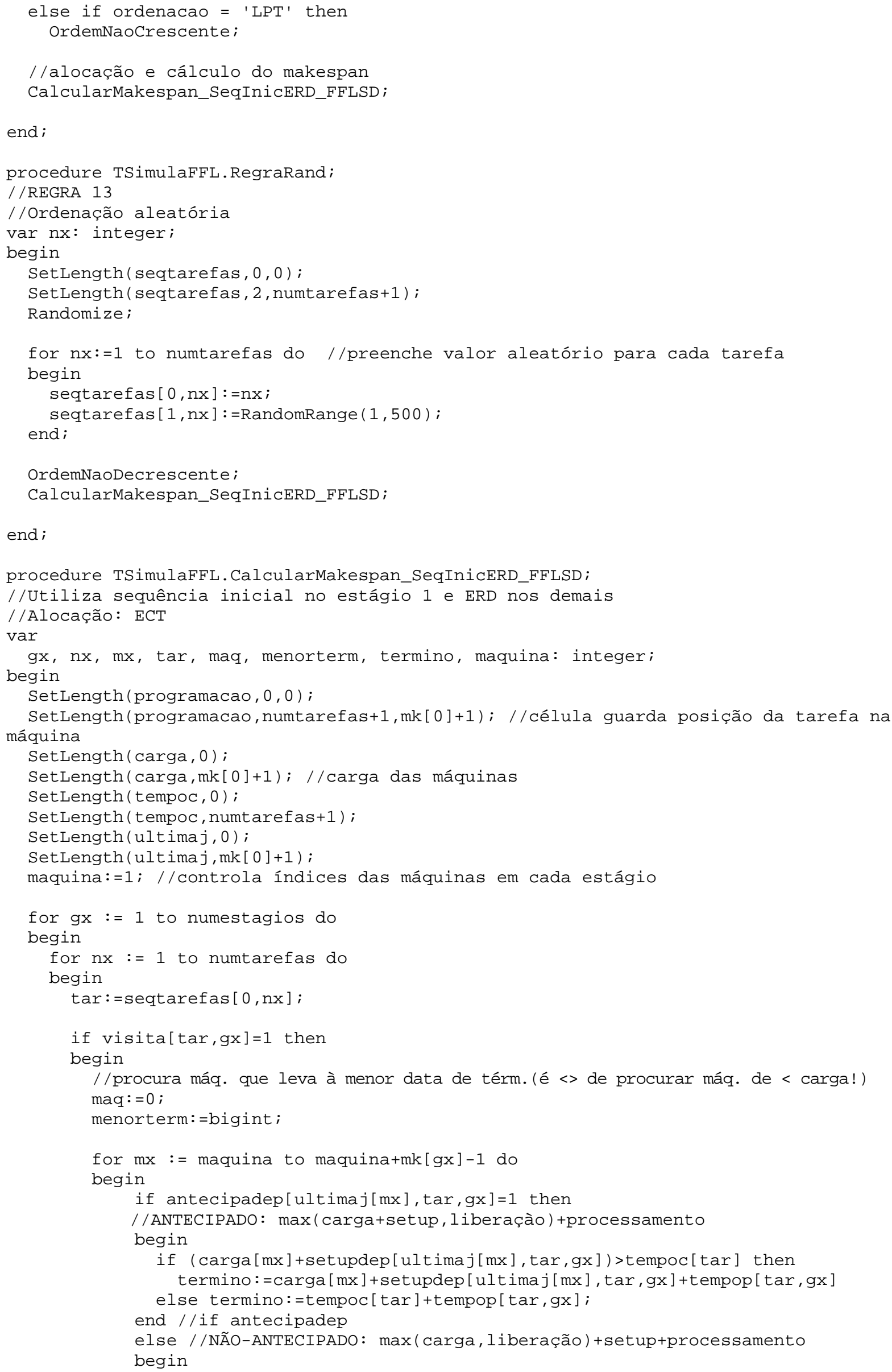




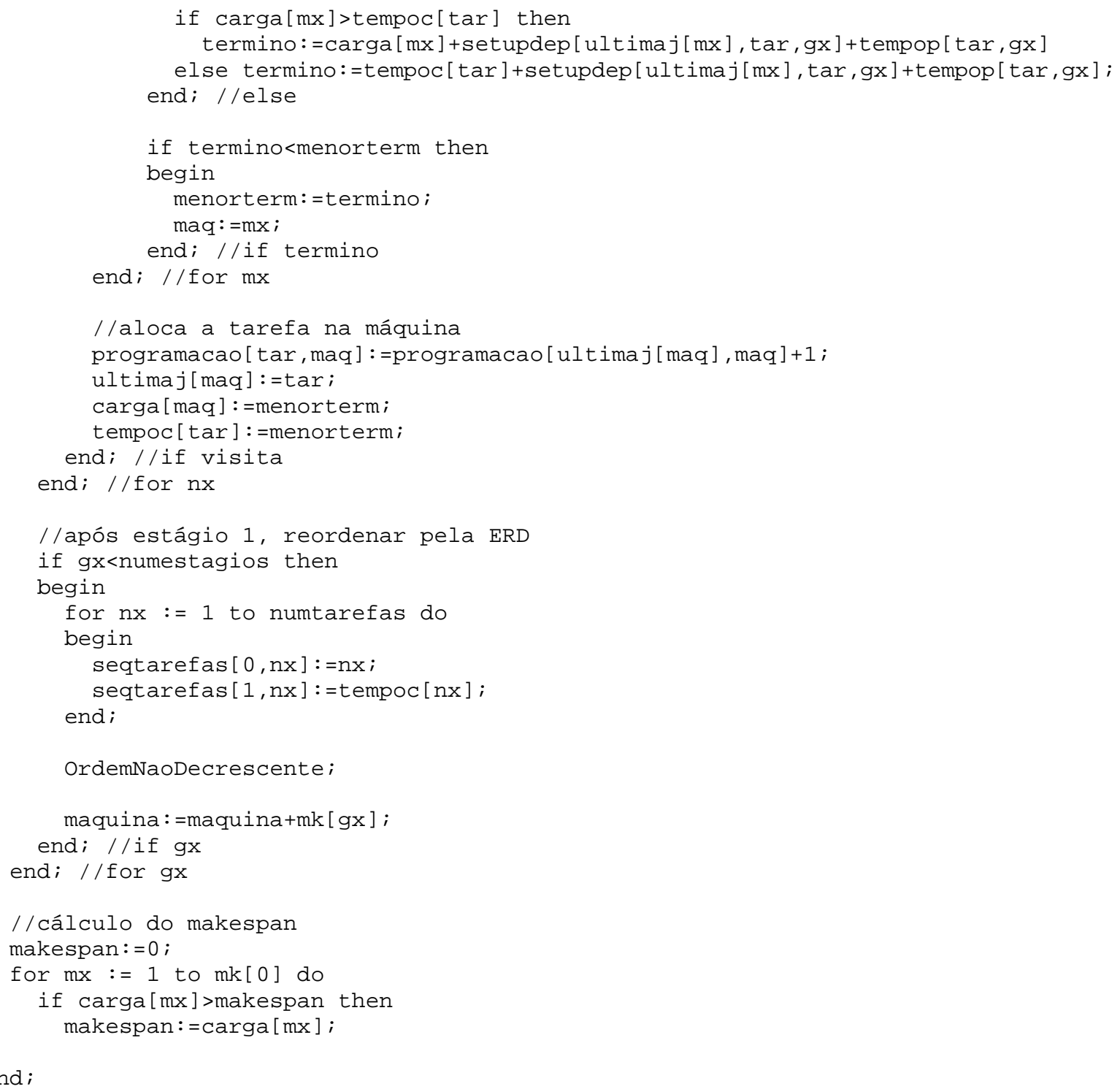

\section{- Heurísticas para setup independente}

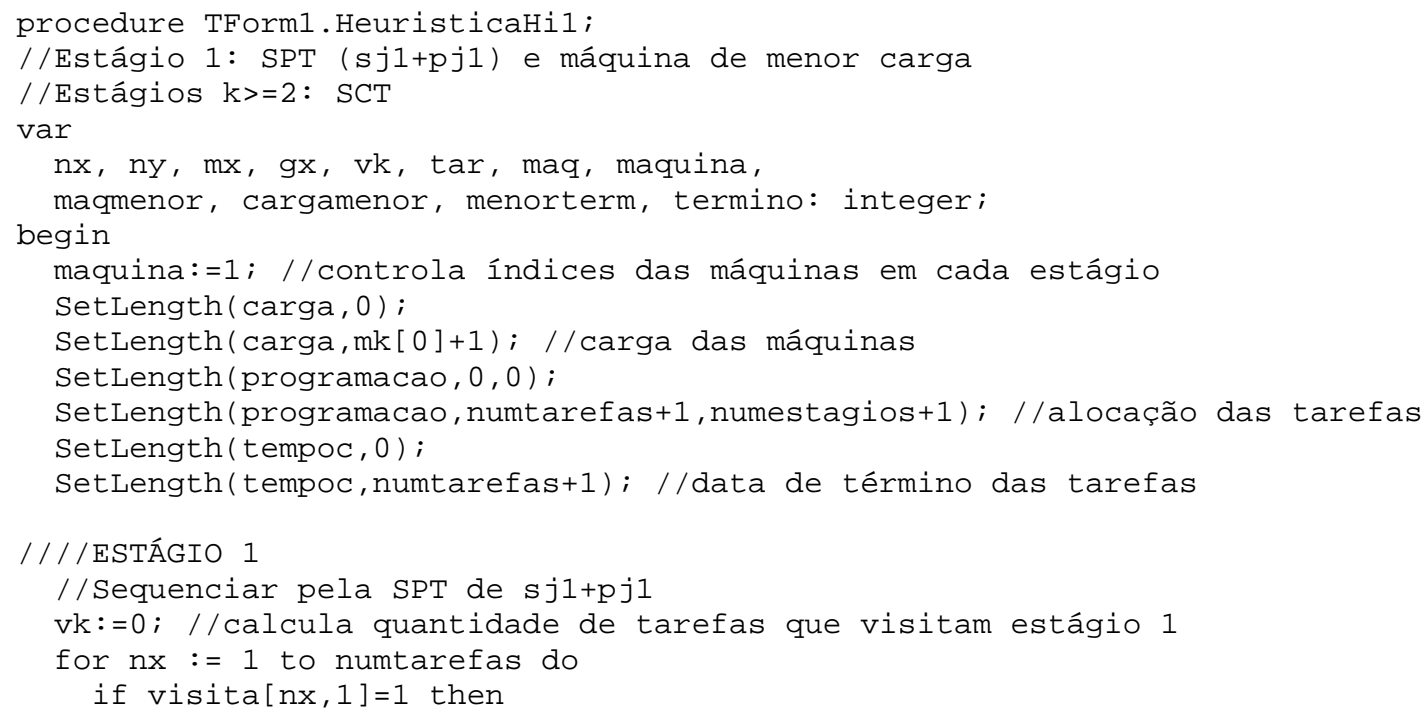


$\mathrm{vk}:=\mathrm{vk}+1$

SetLength ( seqtarefas, 0,0 );

SetLength (seqtarefas, 2, numtarefas+1);

for $\mathrm{nx}:=1$ to numtarefas do

begin

seqtarefas $[0, \mathrm{nx}]:=\mathrm{nx}$

if visita $[\mathrm{nx}, 1]<>0$ then

seqtarefas $[1, n x]:=\operatorname{setup}[n x, 1]+\operatorname{tempop}[n x, 1]$

else seqtarefas $[1, \mathrm{nx}]:=$ bigint;

end; //for $\mathrm{nx}$

OrdemNaoDecrescente;

//Alocar na máquina de menor carga

for $\mathrm{nx}:=1$ to $\mathrm{vk}$ do

begin

//tarefa a ser alocada

tar: $=$ seqtarefas $[0, \mathrm{nx}]$;

//procura máquina de menor carga

maqmenor: $=1$;

cargamenor:=maxint;

for $\mathrm{mx}:=$ maquina to maquina+mk[1]-1 do

begin

if carga $[\mathrm{mx}]<$ cargamenor then

begin

cargamenor: =carga $[\mathrm{mx}]$;

maqmenor: $=\mathrm{mx}$;

end;//if carga [mx]

end; //for $\mathrm{mx}$

//aloca tarefa à máquina encontrada

programacao[tar, 1$]:=$ maqmenor;

//calcula data de término (no estágio 1, todos os setups são NÃo antecipados)

tempoc [tar] := carga [maqmenor] +setup [tar, 1] +tempop [tar, 1];

//atualiza carga da máquina

carga [maqmenor] :=tempoc [tar] ;

end;//for $\mathrm{nx}$

maquina:=maquina $+m k[1]$

////ESTÁGIOS k $>=2$

//Analisa todas as possibilidades tarefa-máquina

for $g x:=2$ to numestagios do

begin

SetLength (alocada, 0);

SetLength (alocada, numtarefas+1);

$\mathrm{vk}:=0 ; / /$ calcula quantidade de tarefas que visitam estágio k

for $n x:=1$ to numtarefas do

if visita $[\mathrm{nx}, \mathrm{gx}]=1$ then

$\mathrm{vk}:=\mathrm{vk}+1 ;$

for ny := 1 to vk do //"vk" verificações

begin

$\operatorname{tar}:=0$

maq: $=0$;

menorterm: =bigint;

for $\mathrm{nx}:=1$ to numtarefas do //para cada verificação, vk*mk pares begin 


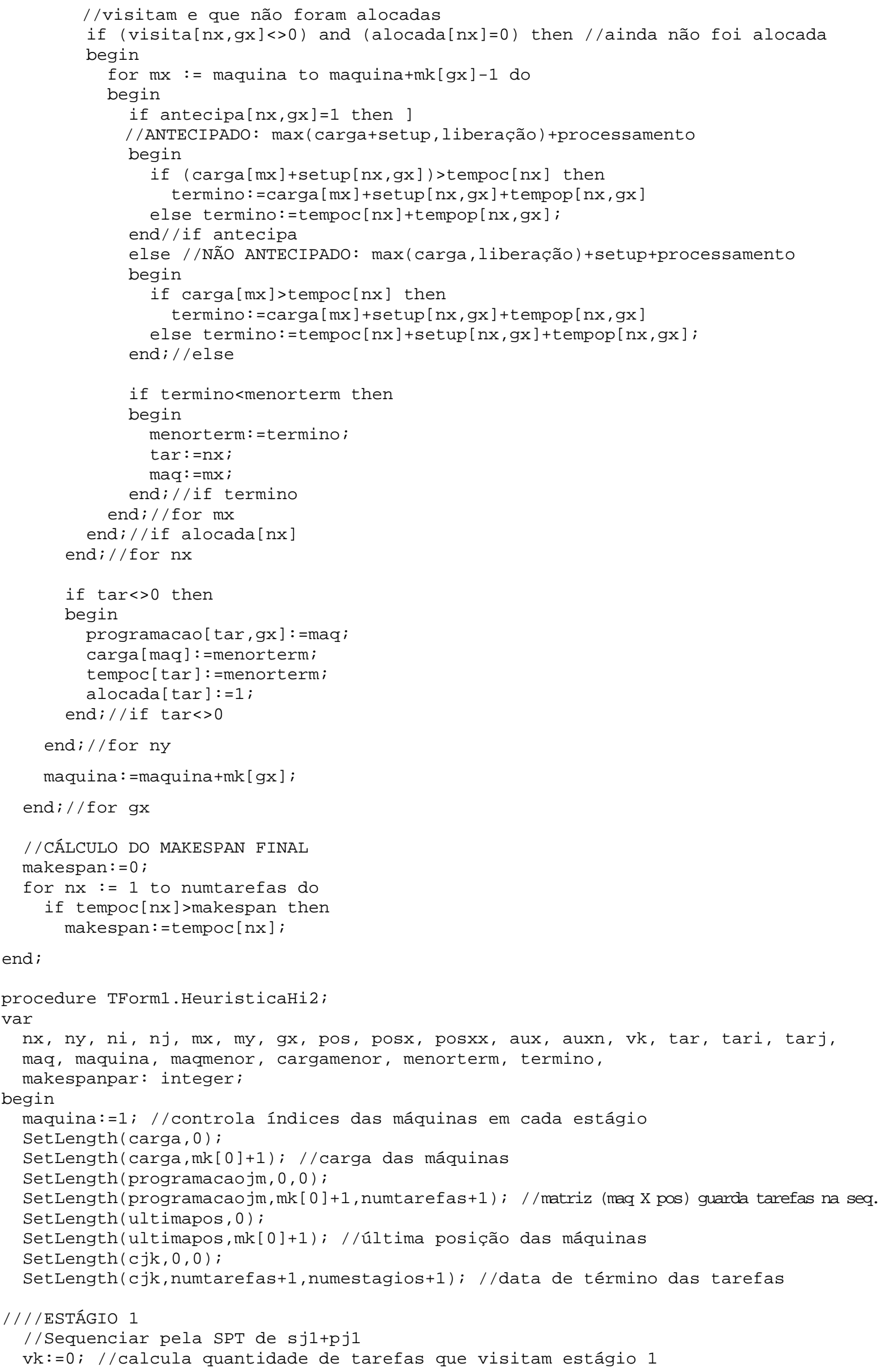




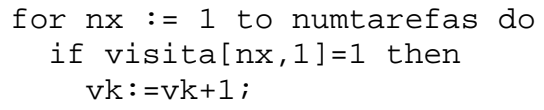




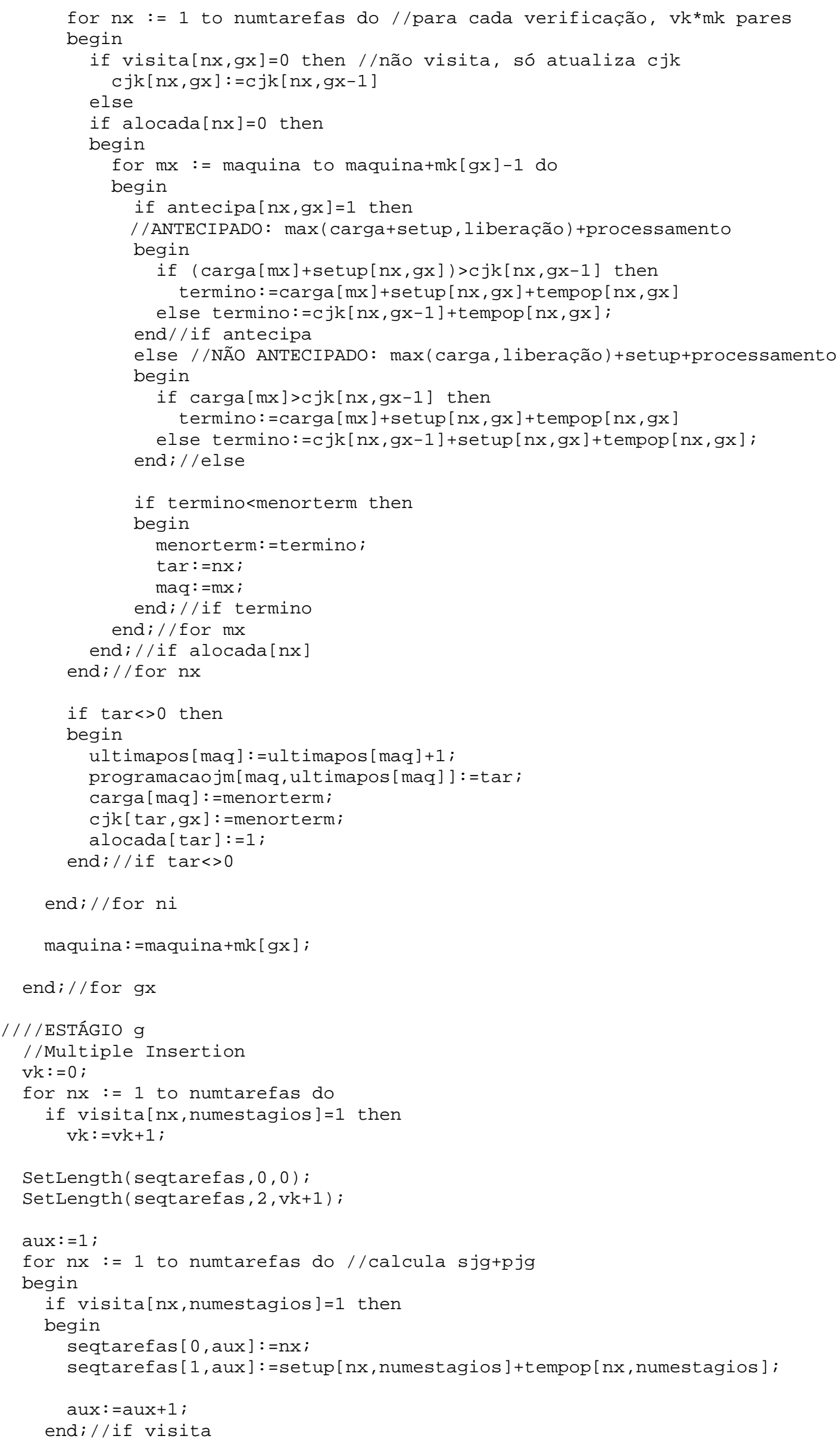




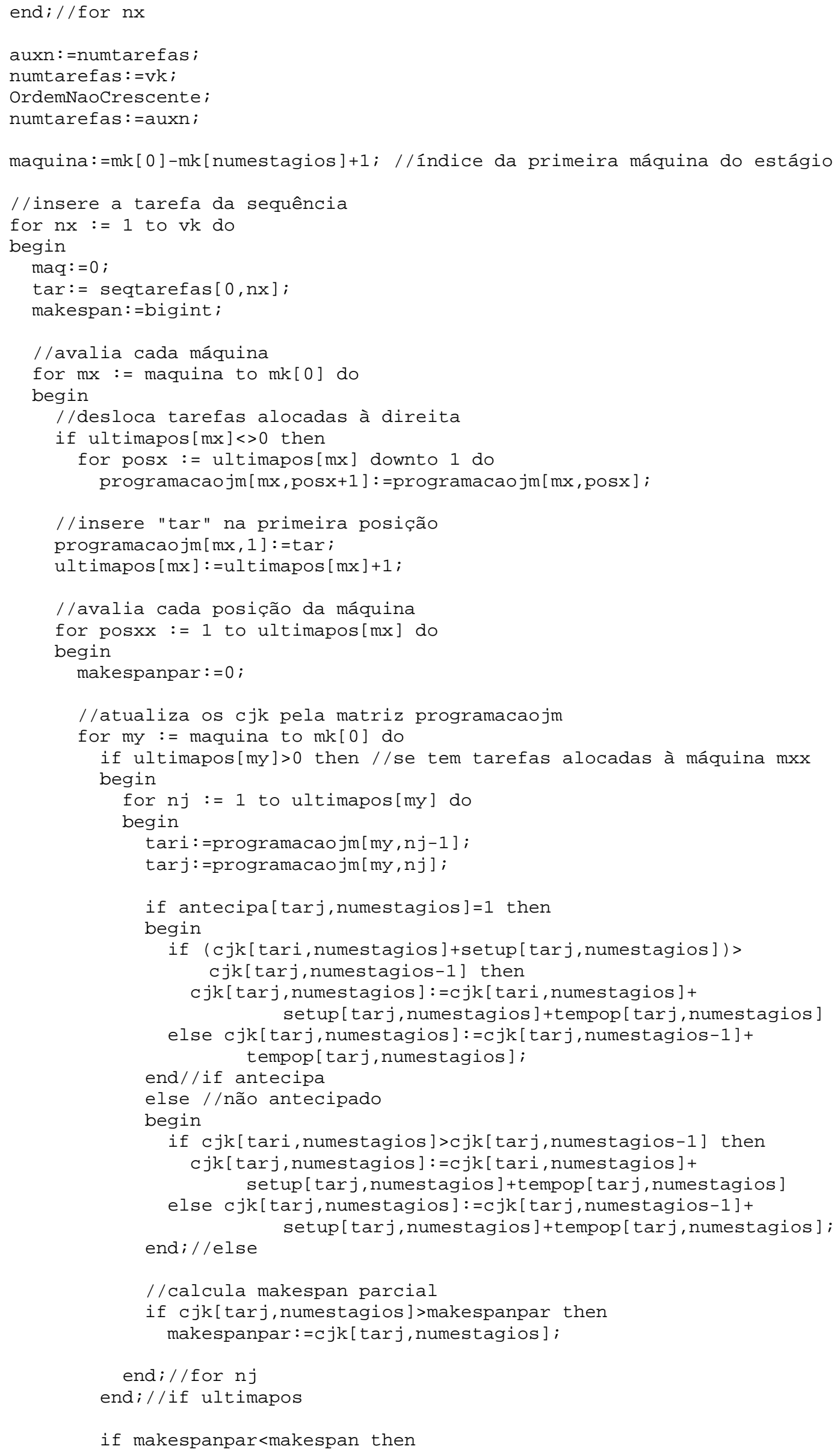




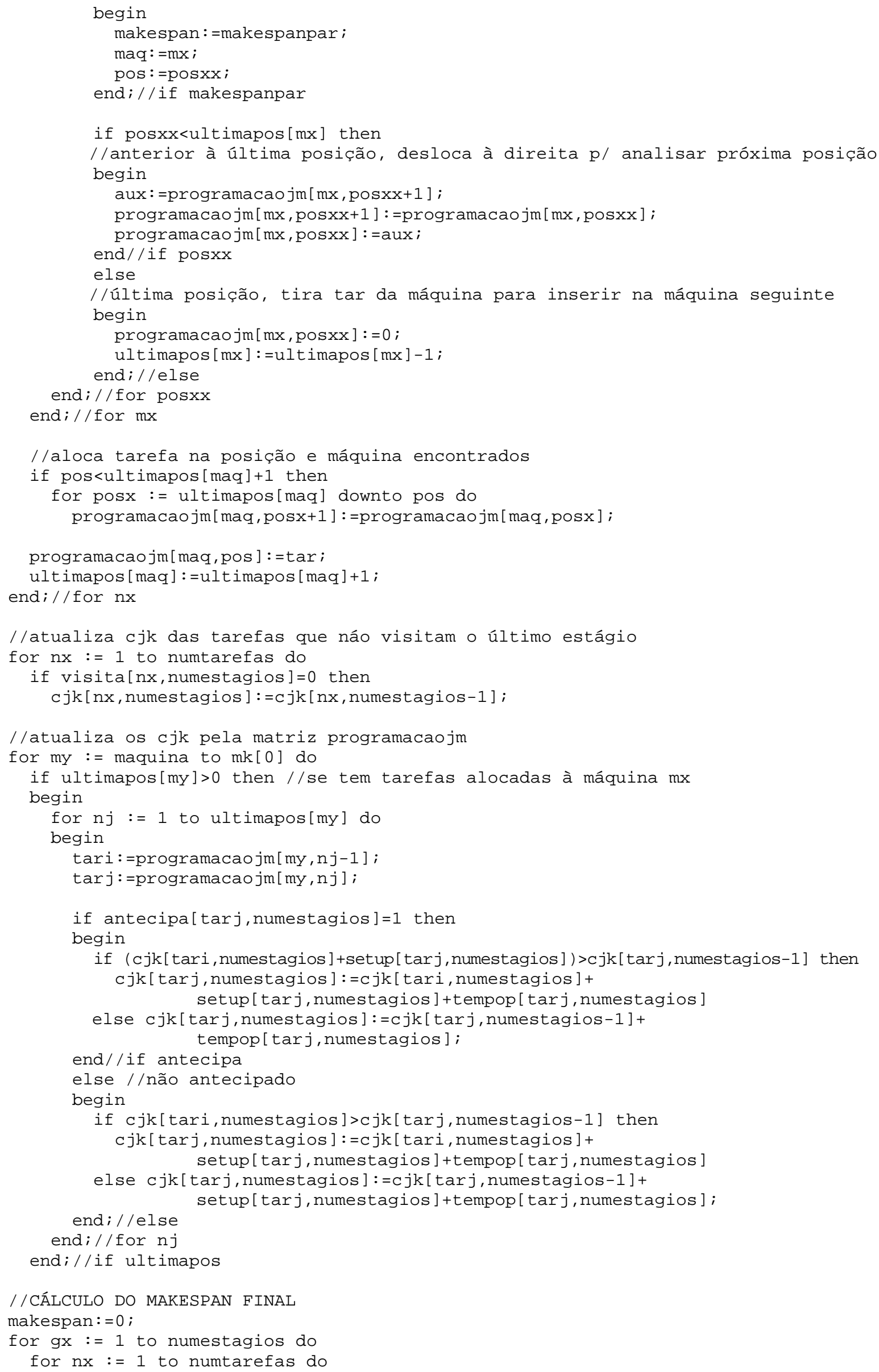


if $c j k[n x, g x]>m a k e s p a n$ then makespan: $=c j k[n x, g x]$;

end;

procedure TForm1.HeuristicaHi3;

//Multiple Insertion em todos os estágios ( $k g$ : flow time / k=g: makespan) $\operatorname{var}$

nx, ny, mx, my, gx, vk, aux, auxn, maq, tar, tari, tarj, pos, posx, posxx, nj, maquina, nalocadas, flowtime, flowtimepar, makespanpar: integer; begin

Set Length (programacaojm, 0,0);

SetLength (programacaojm, mk[0]+1, numtarefas+1); //matriz (maq X pos) guarda tarefas na seq.

SetLength (ultimapos, 0);

SetLength (ultimapos, mk[0]+1); //última posição das máquinas

SetLength $(\mathrm{cjk}, 0,0)$;

SetLength (cjk, numtarefas+1, numestagios+1); //data de término das tarefas

maquina:=1; //controla índices das máquinas em cada estágio

for $g x:=1$ to numestagios do

begin

vk: $=0$;

for $\mathrm{nx}:=1$ to numtarefas do

if visita $[n x, g x]=1$ then

$\mathrm{vk}:=\mathrm{vk}+1$;

SetLength (seqtarefas, 0,0 );

SetLength ( seqtarefas, 2, vk+1);

//calcula sjk+pjk

aux:=1;

for $n x:=1$ to numtarefas do

begin

if visita $[\mathrm{n} x, \mathrm{gx}]=1$ then

begin

seqtarefas $[0$, aux $]:=n x$

seqtarefas $[1$, aux $]:=\operatorname{setup}[\mathrm{nx}, \mathrm{gx}]+\operatorname{tempop}[\mathrm{nx}, \mathrm{gx}]$;

aux: $=a u x+1$

endi//if visita

end;//for $\mathrm{nx}$

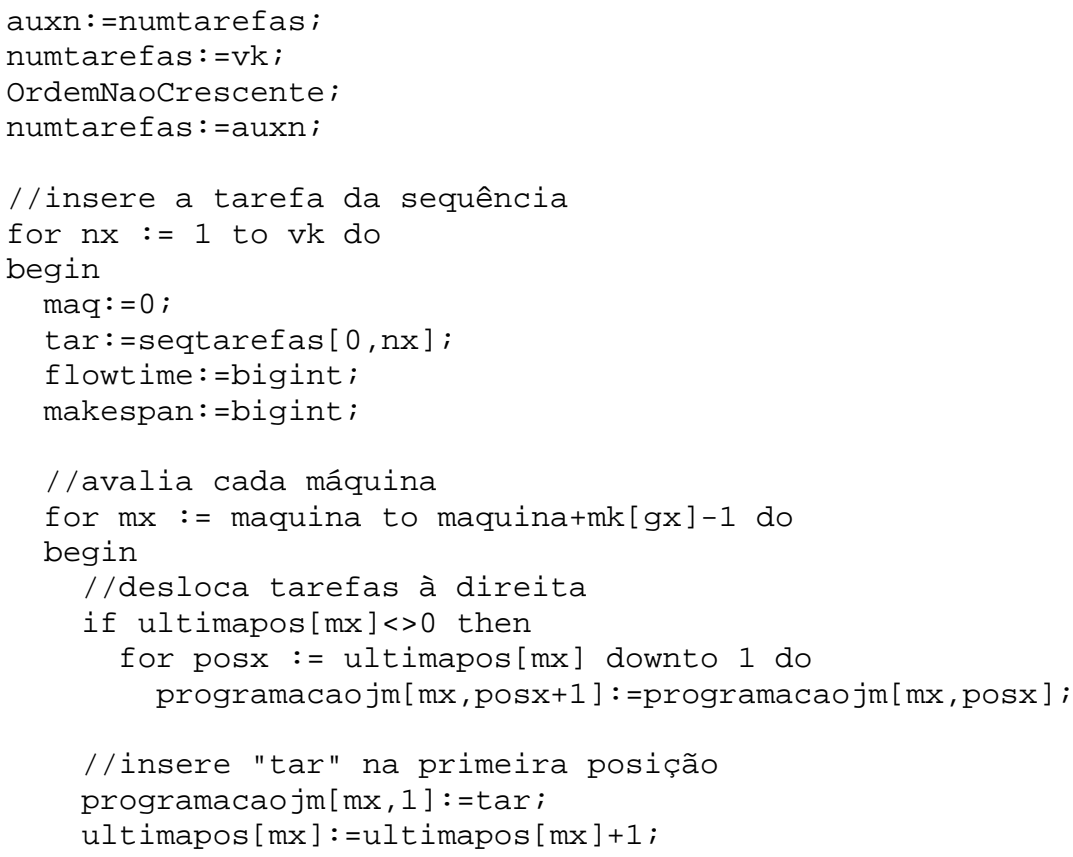




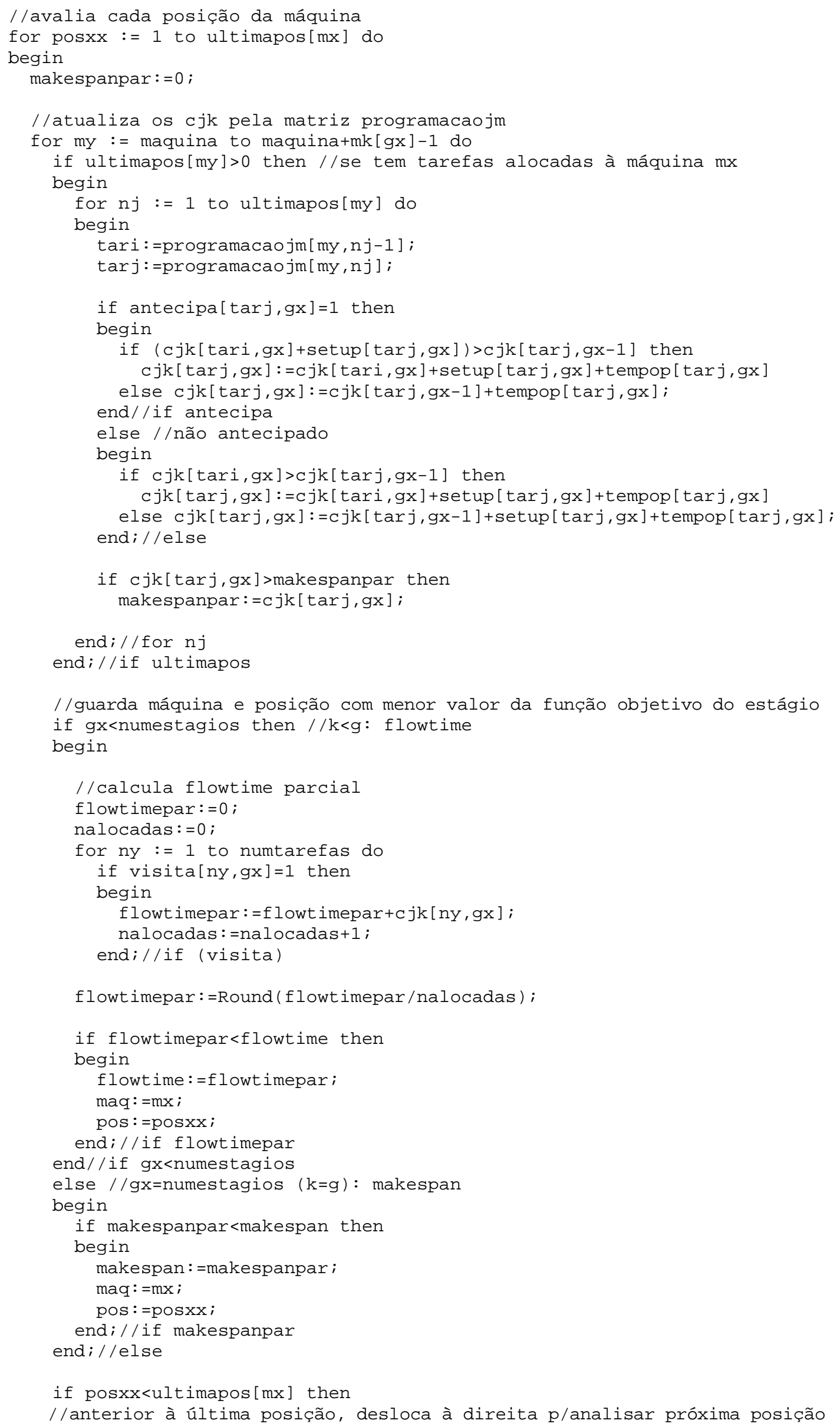




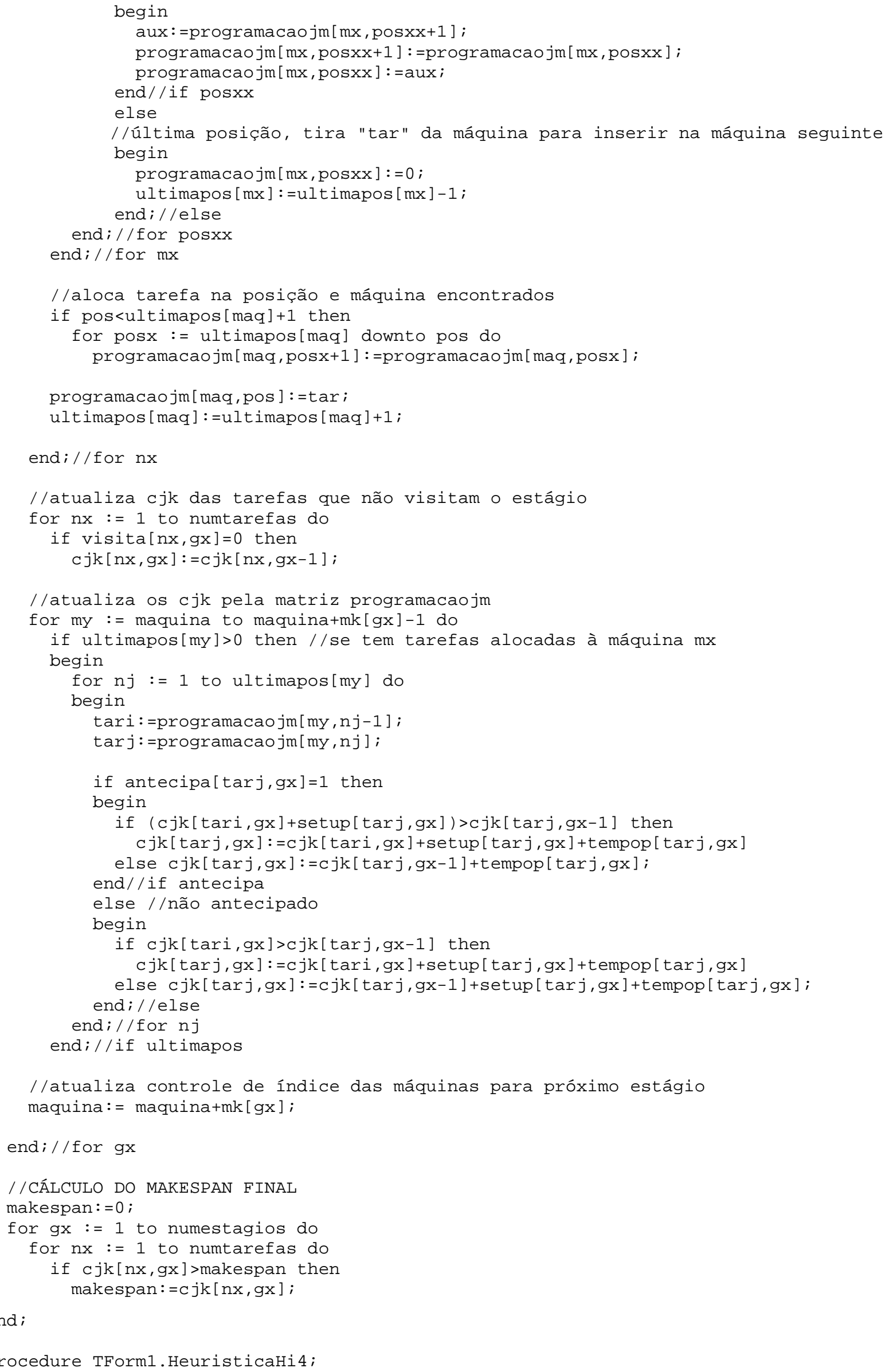




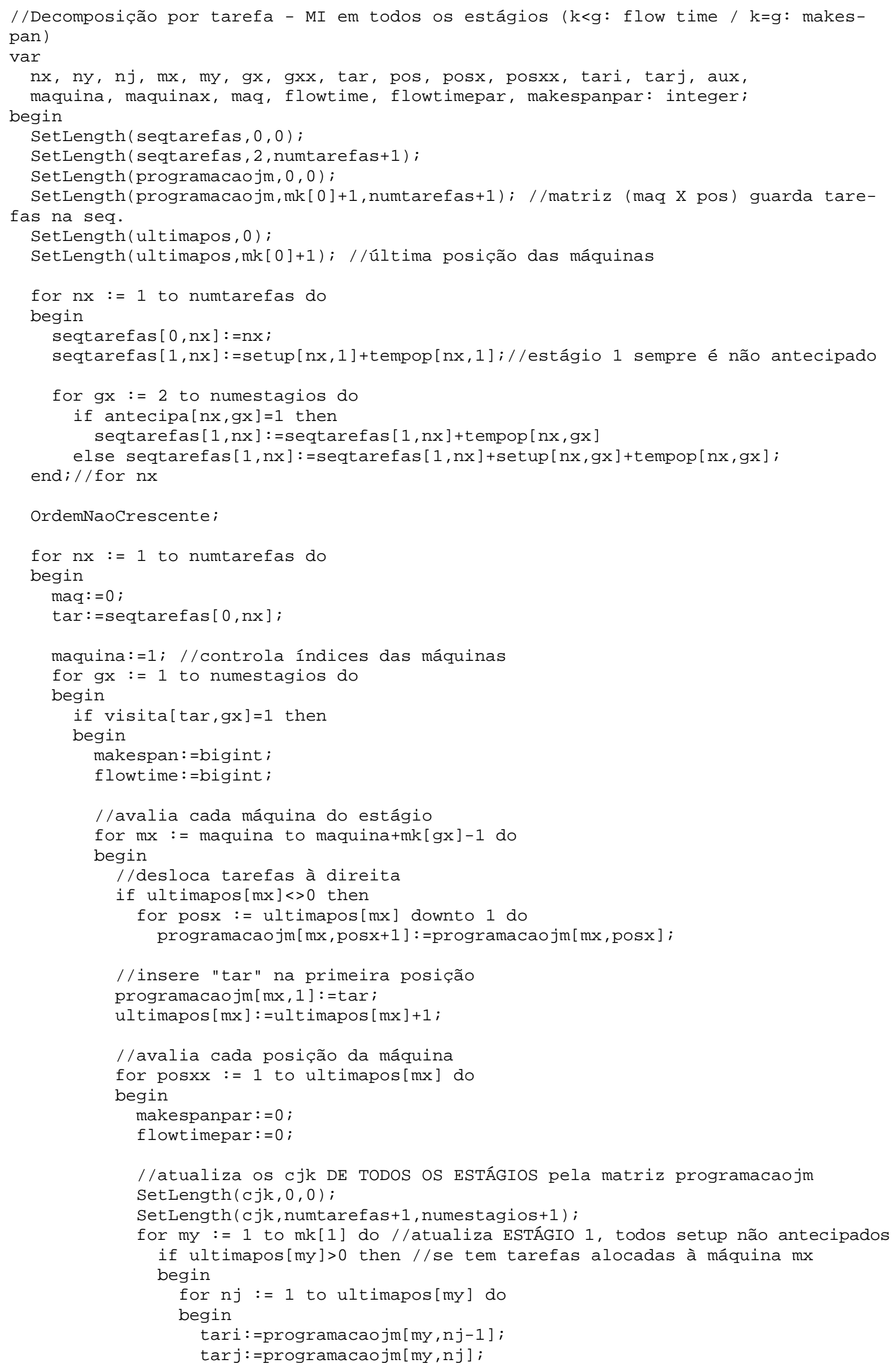




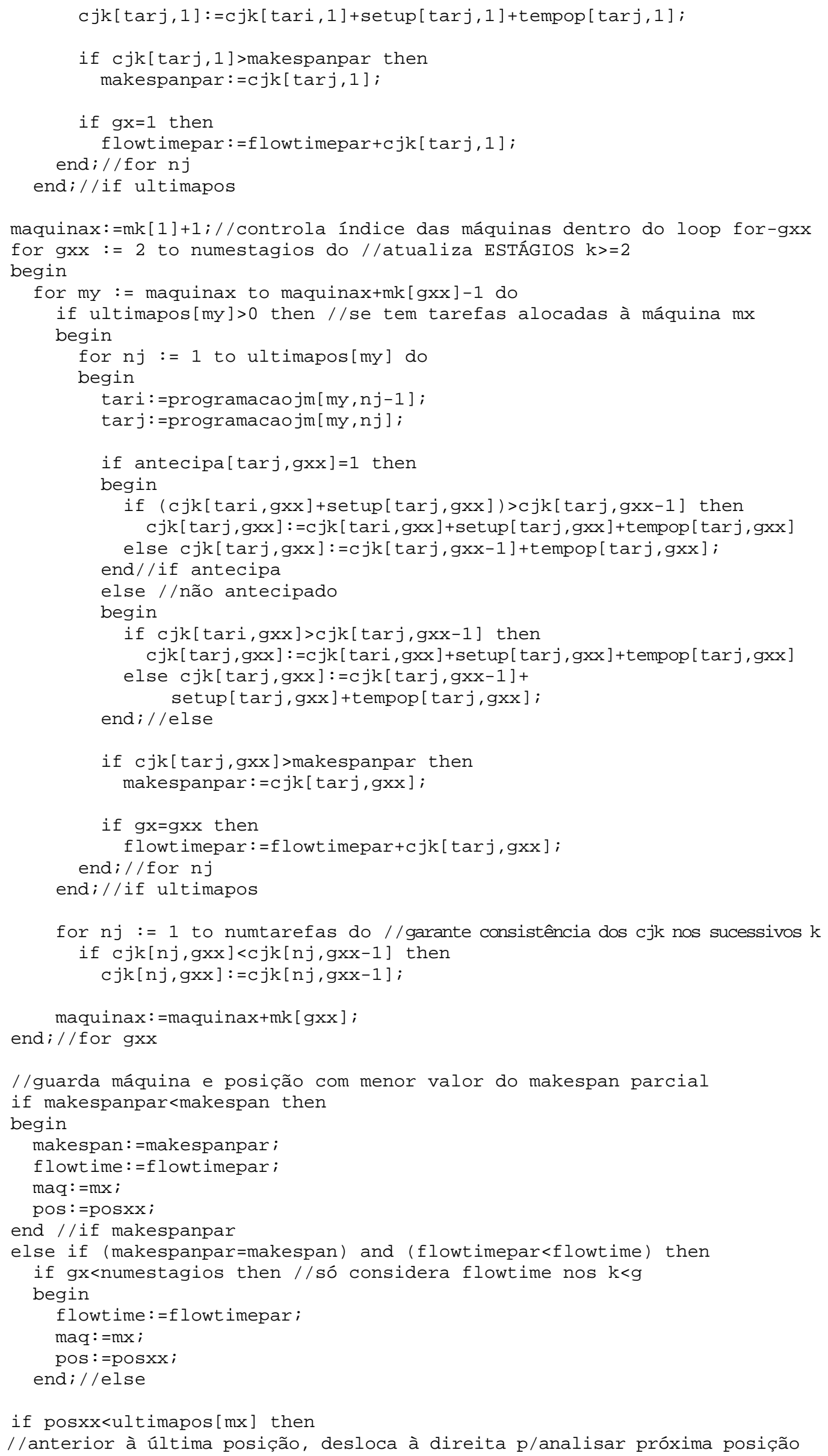




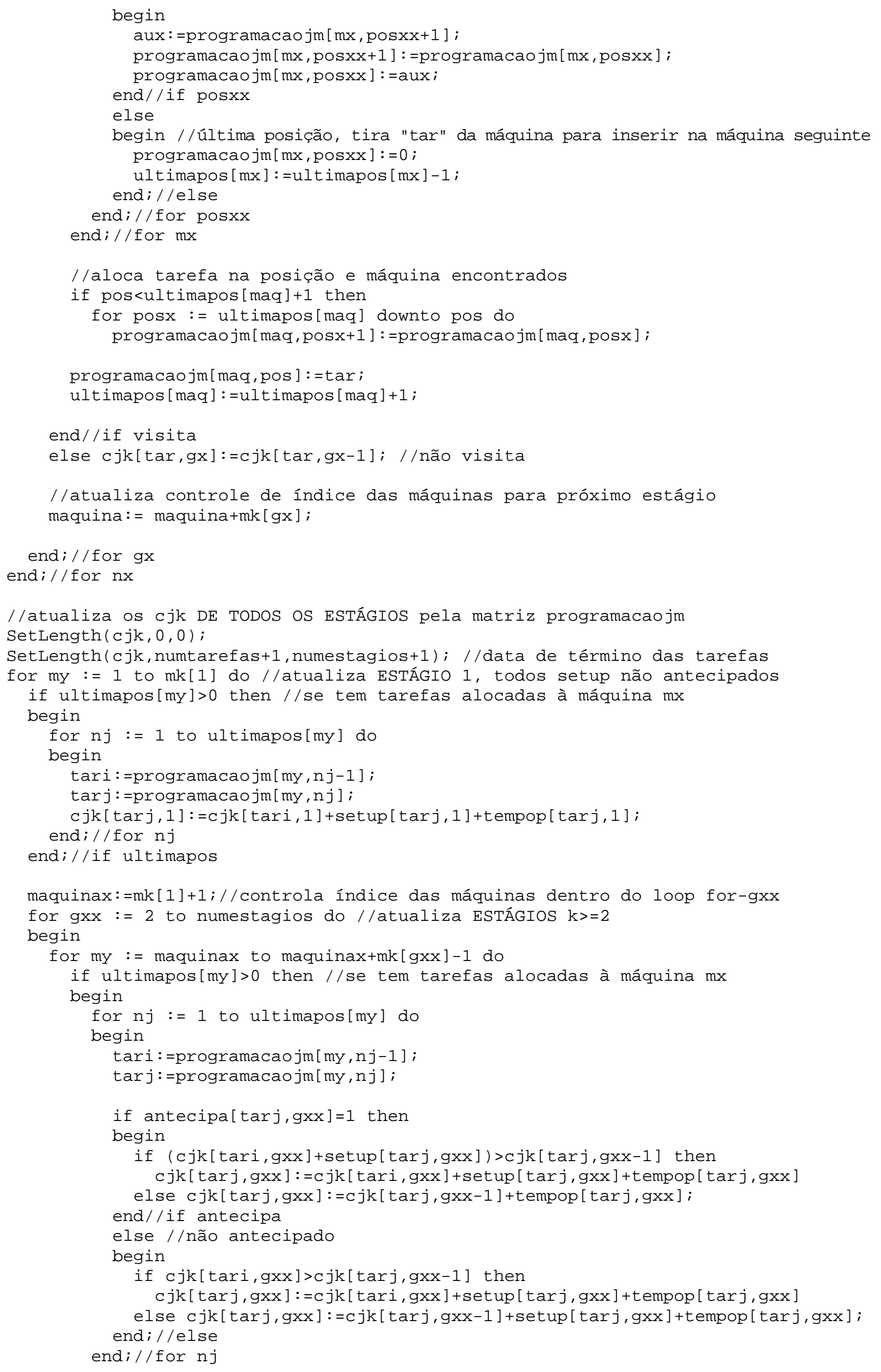




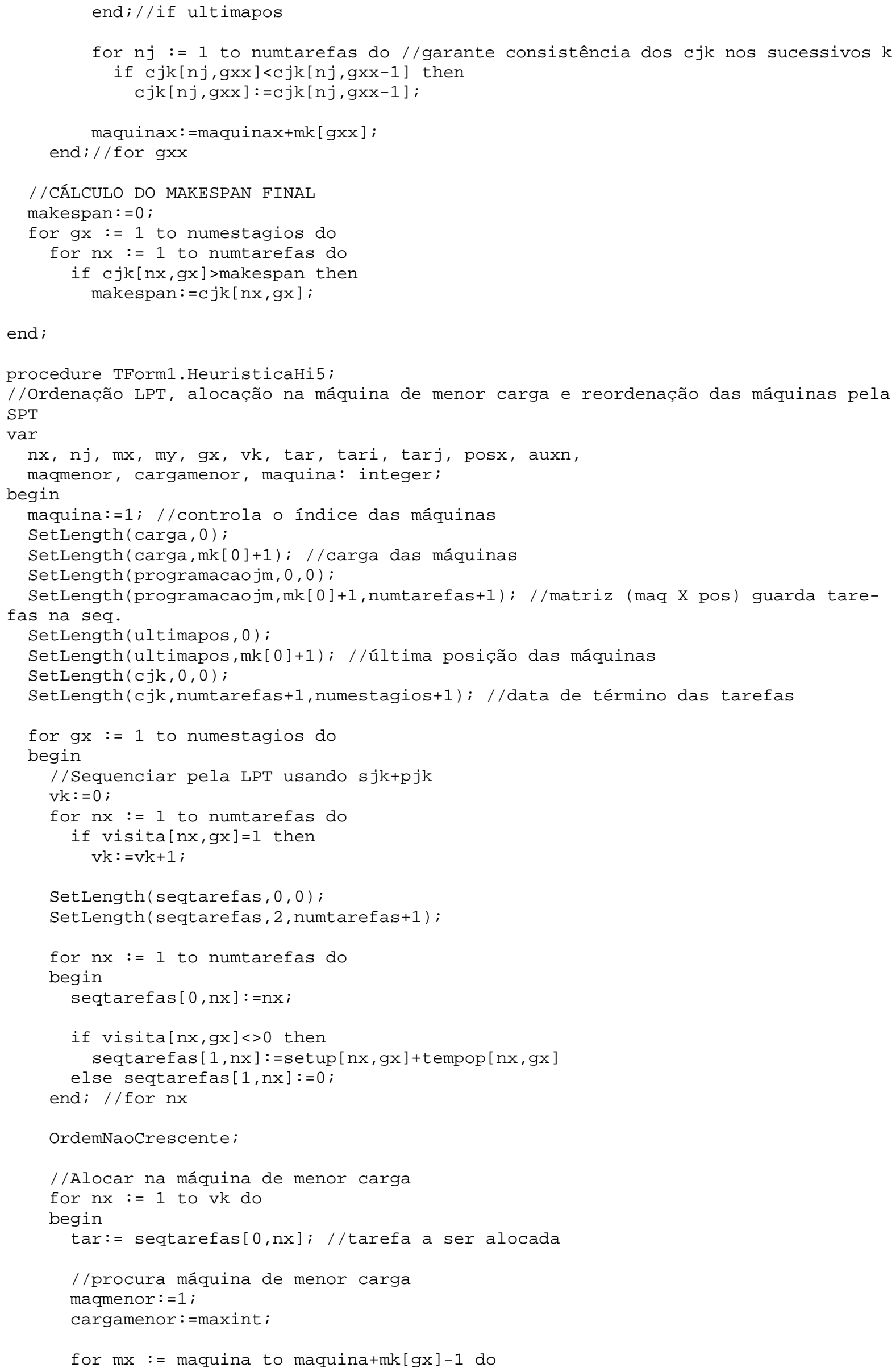




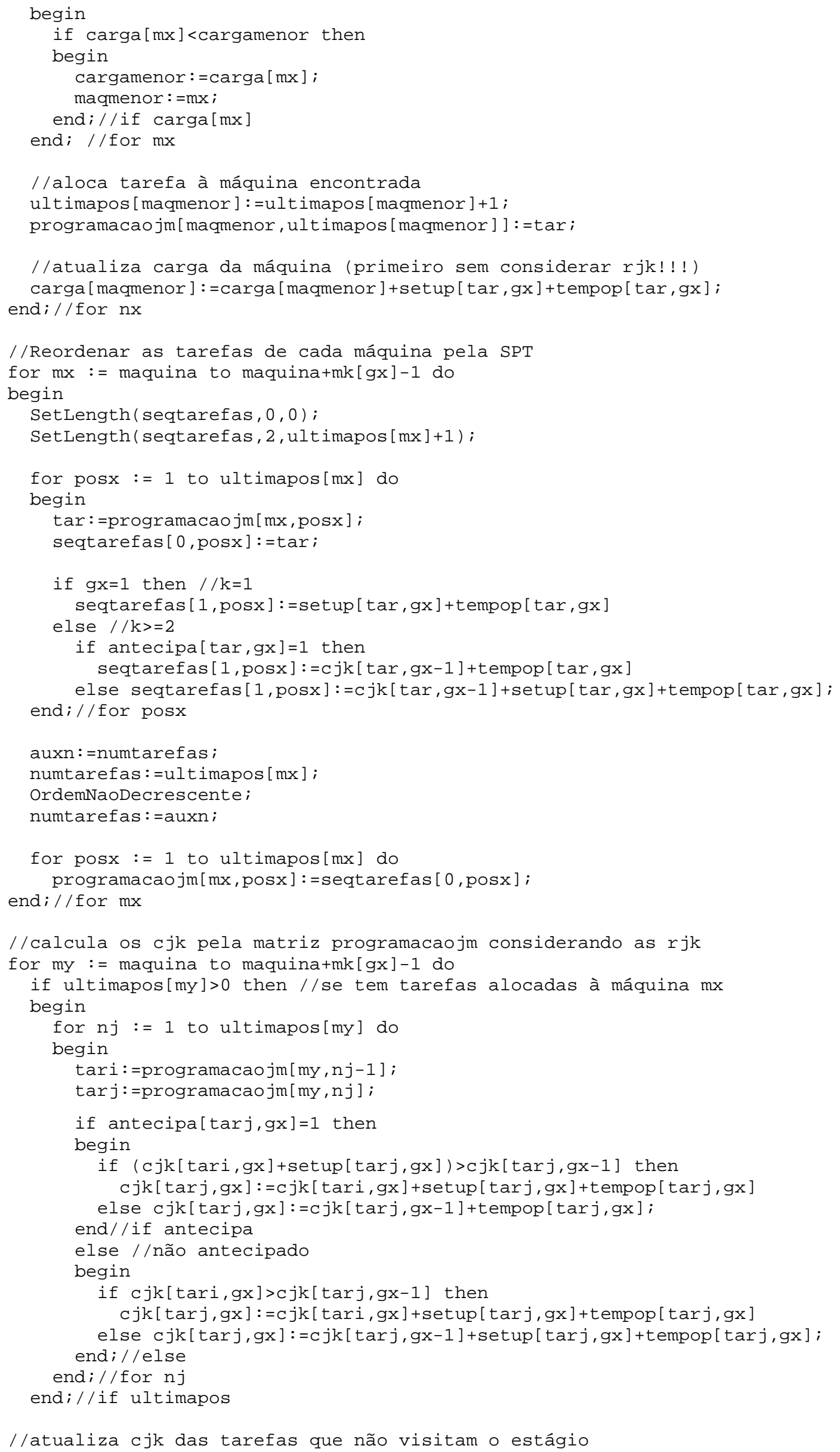




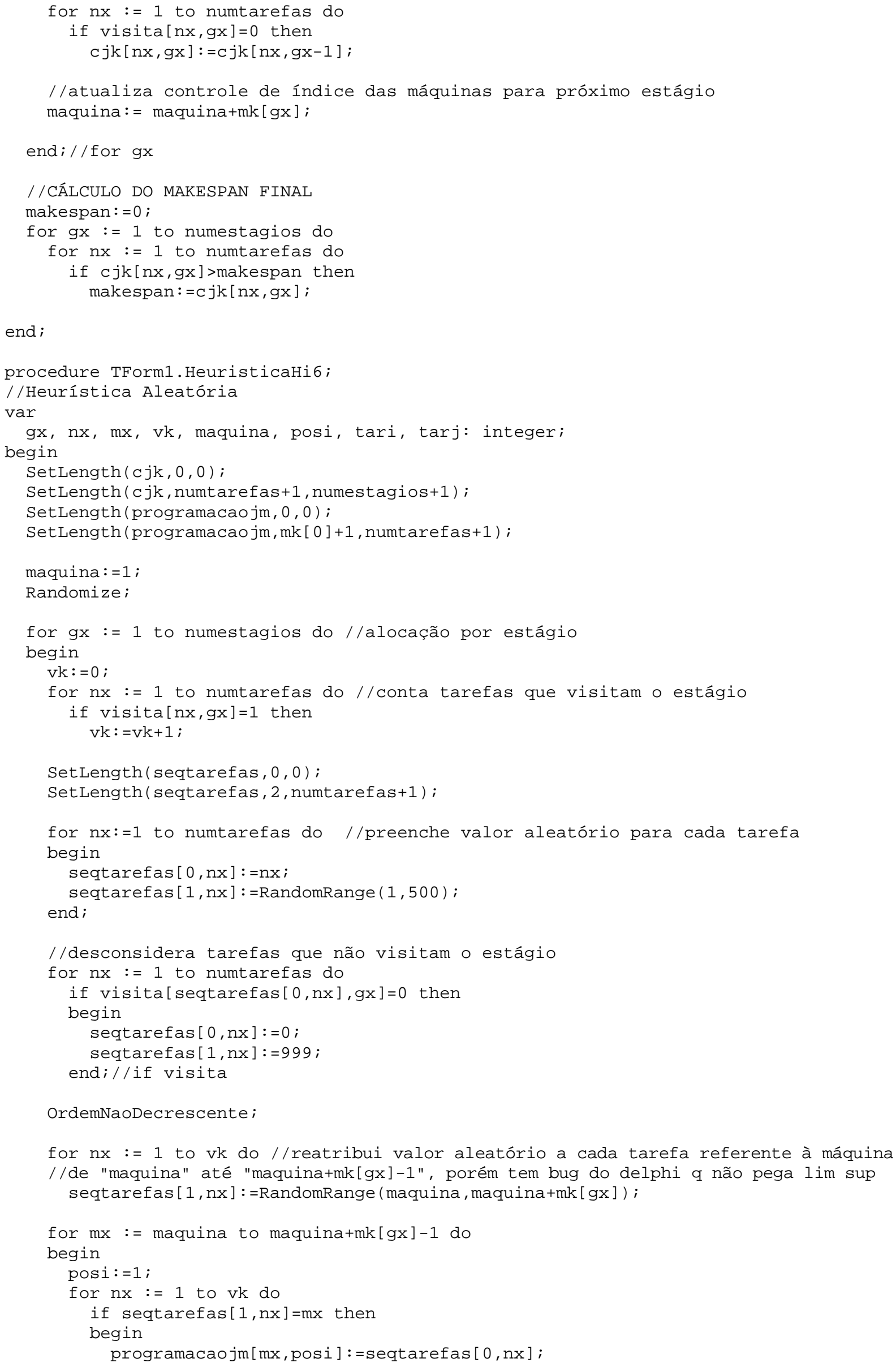




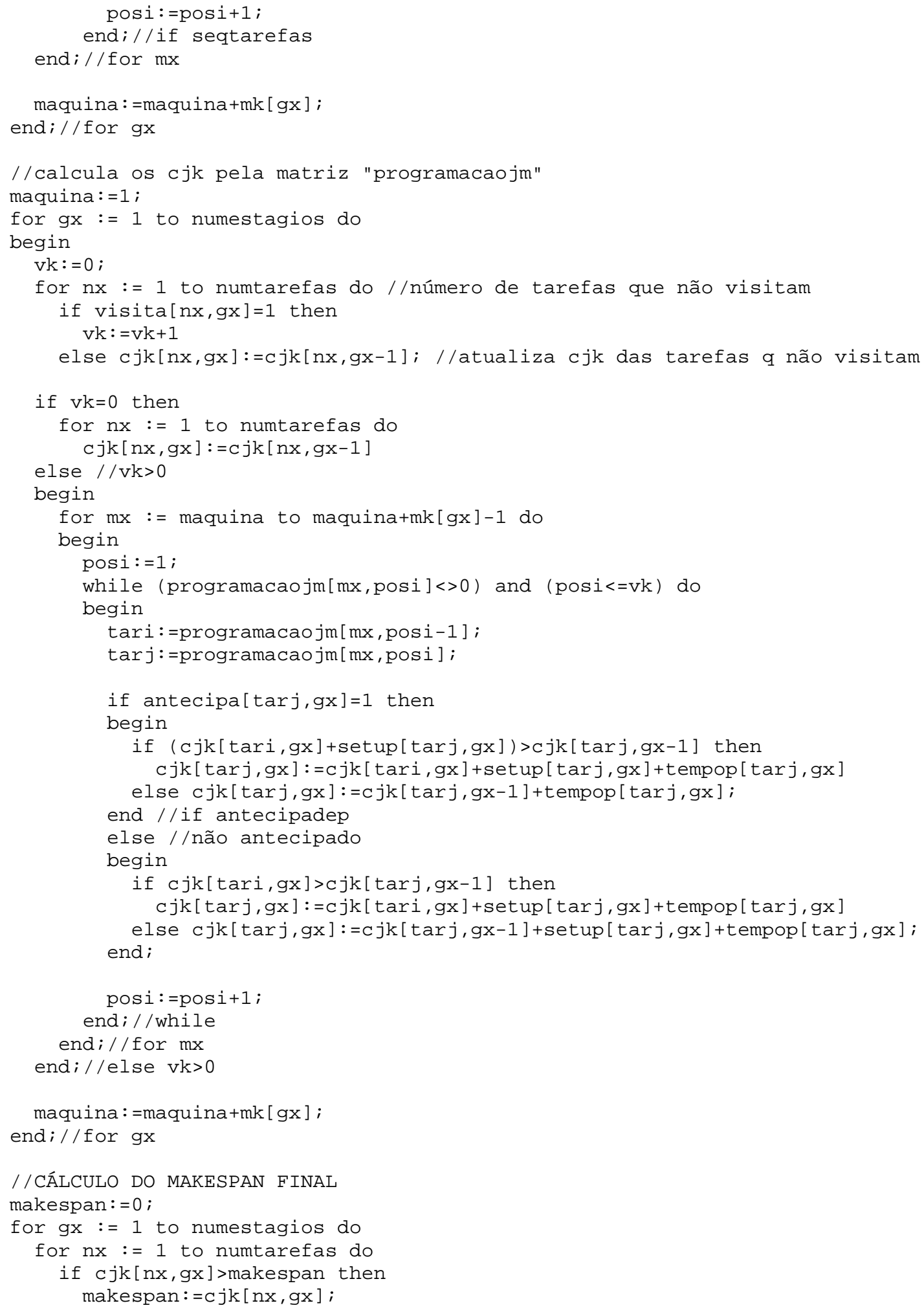

\section{- Heurísticas para setup dependente}

procedure TSimulaFFL.HeuristicaECT_MIH_TSP(modo: string); //H1: modo='normal'; H2: modo='FITSP'; H3: modo='NITSP'; var

nx, gx, kx, mx, my, ny, ni, nj, tar, tari, tarj, pos, posx, posxx, maq, maquina, 
menorterm, termino, minsetup, makespanpar, posmaq, aux, vk, auxn: integer; begin

//SetLength (programacaojm, 0,0);

programacaojm:=nil;

SetLength (programacaojm, mk[0]+1, numtarefas+1); //matriz (maq X pos) guarda tarefas na seq.

SetLength (carga, 0);

SetLength (carga, mk[0]+1); //carga das máquinas

SetLength $(c j k, 0,0)$;

SetLength (cjk, numtarefas+1, numestagios+1);

SetLength (ultimaj,0);

SetLength (ultimaj, mk [0]+1);

SetLength (ultimapos, 0) ;

SetLength (ultimapos, mk [0]+1);

maquina:=1; //controla índices das máquinas em cada estágio

maq $:=1$

pos:=bigint

//PRIMEIRO AO PENÚLTIMO ESTÁGIO

for $\mathrm{gx}:=1$ to numestagios-1 do

begin

//calcula número de tarefas que visitam estágio

$\mathrm{vk}:=0$;

for ny $:=1$ to numtarefas do

if visita $[\mathrm{ny}, \mathrm{gx}]=1$ then

$\mathrm{vk}:=\mathrm{vk}+1$

if $\mathrm{vk}=0$ then //nenhuma tarefa visita

for $\mathrm{nx}:=1$ to numtarefas do //só atualiza os cjk

$c j k[n x, g x]:=c j k[n x, g x-1]$

else //if vk>0

begin

if $\left(\operatorname{modo}={ }^{\prime}\right.$ ITSP') and $(\mathrm{mk}[\mathrm{gx}]=1)$ then //HEURÍSTICA H2

begin

FITSP_NITSP (1, gx);

//encontra índice da máquina única

$\operatorname{maq}:=0$;

for $\mathrm{kx}:=1$ to $\mathrm{gx}$ do

$\operatorname{maq}:=\operatorname{maq}+\operatorname{mk}[\mathrm{kx}]$;

for $\mathrm{nx}:=1$ to $\mathrm{vk}$ do

programacaojm $[\mathrm{maq}, \mathrm{nx}]:=$ seqtarefas $[0, \mathrm{nx}]$;

end//if modo=FITSP

else if (modo='NITSP') and (mk $[\mathrm{gx}]=1)$ then //HEURÍSTICA H3

begin

FITSP_NITSP $(-1$, gx);

//encontra índice da máquina única

maq $:=0$;

for $\mathrm{kx}:=1$ to $\mathrm{gx}$ do

maq: $=\operatorname{maq}+\operatorname{mk}[k x]$;

for $\mathrm{nx}:=1$ to $\mathrm{vk}$ do

programacaojm $[\mathrm{maq}, \mathrm{nx}]:=$ seqtarefas $[0, \mathrm{nx}]$;

end//if modo=NITSP

else //modo 'normal' e casos em que não há estágios com máq. única //ECT - HEURÍSTICA H1 begin

SetLength (alocada, 0);

Set Length (alocada, numtarefas+1);

for ny $:=1$ to $\mathrm{vk}$ do

begin

$\operatorname{tar}:=0 ;$

maq: $=0$;

menorterm:=bigint; 


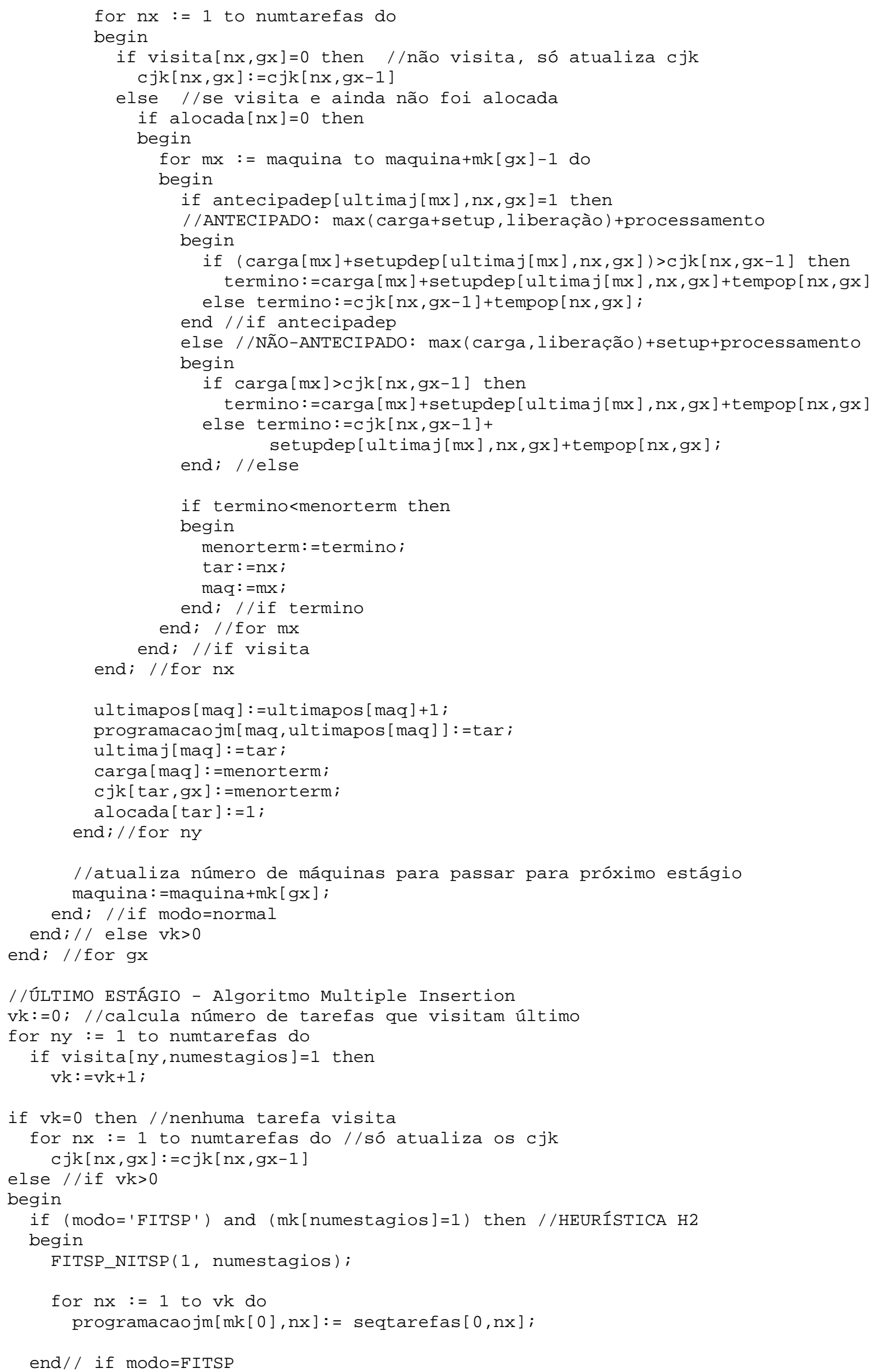




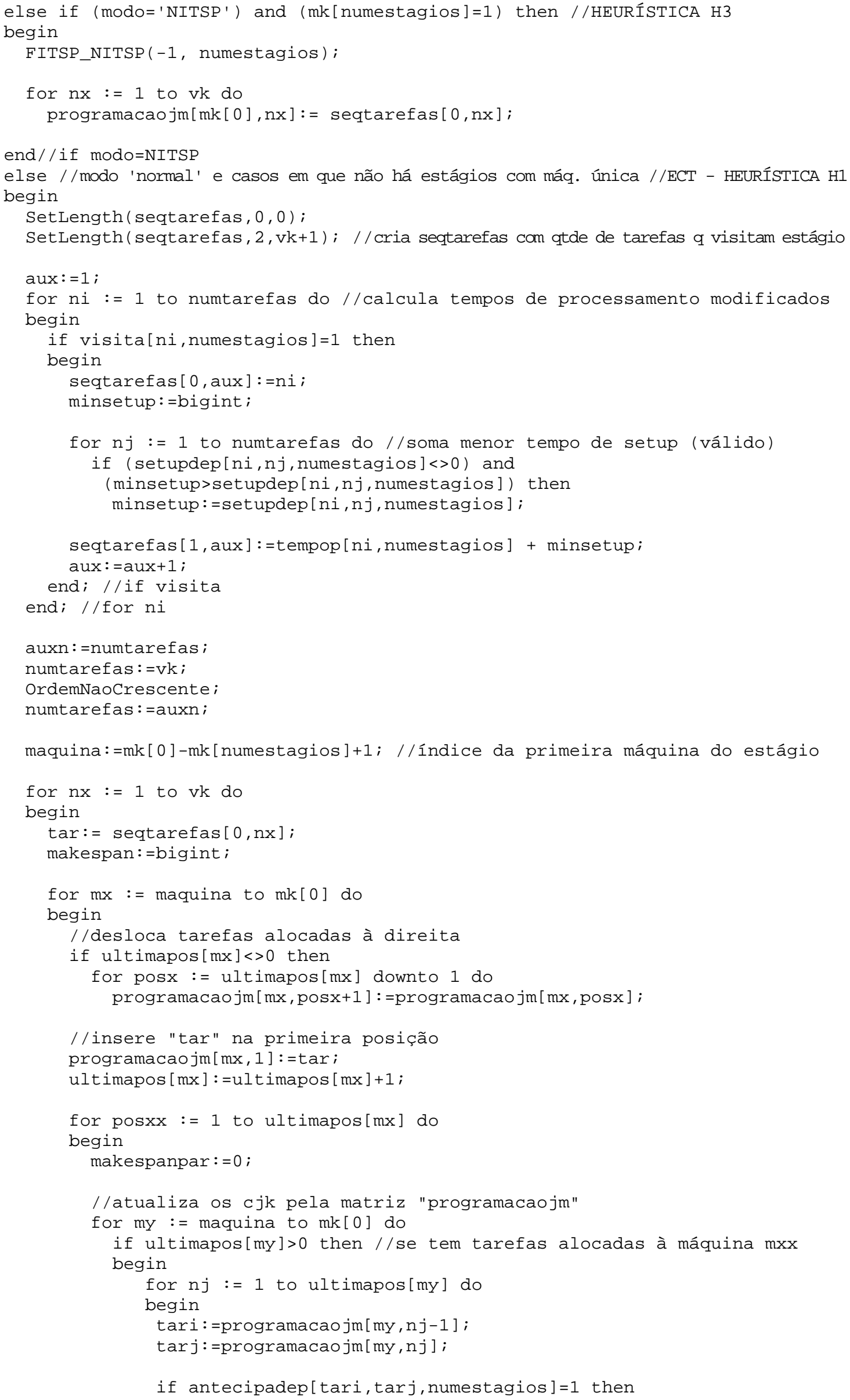




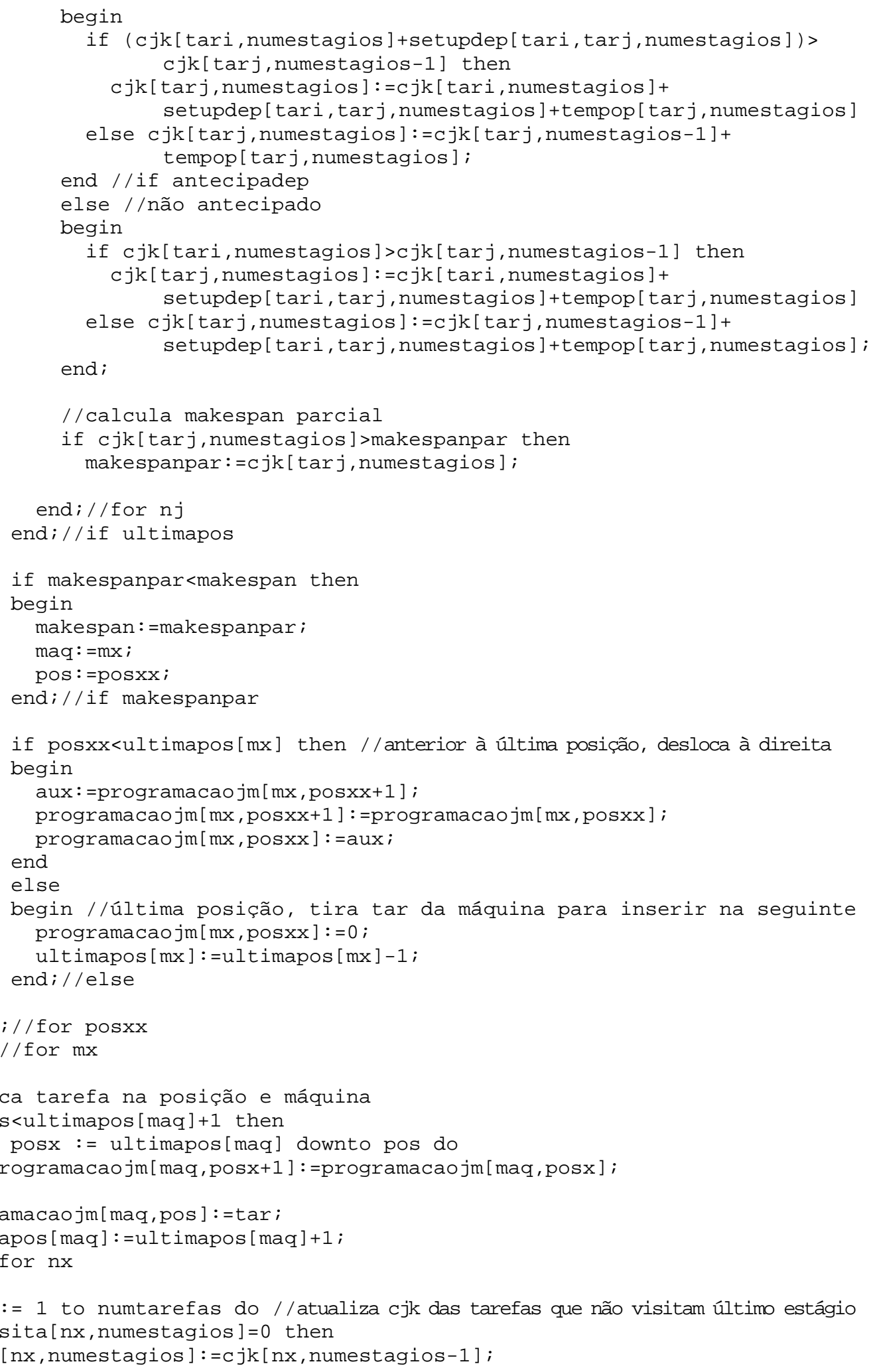

end;//if modo=normal end;//else vk $>0$

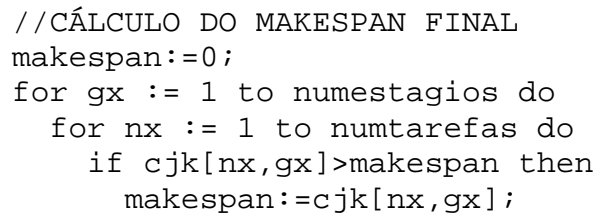




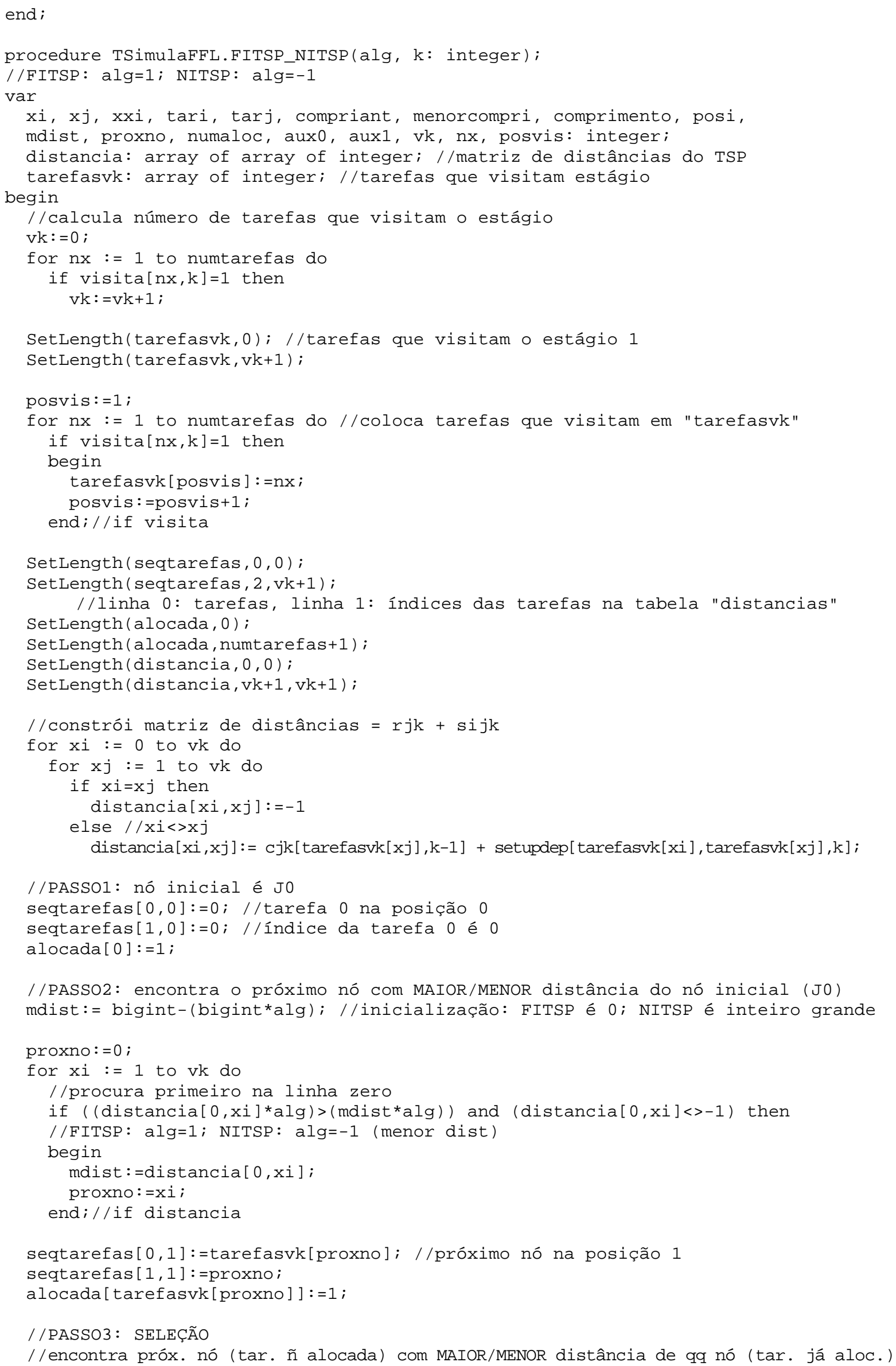




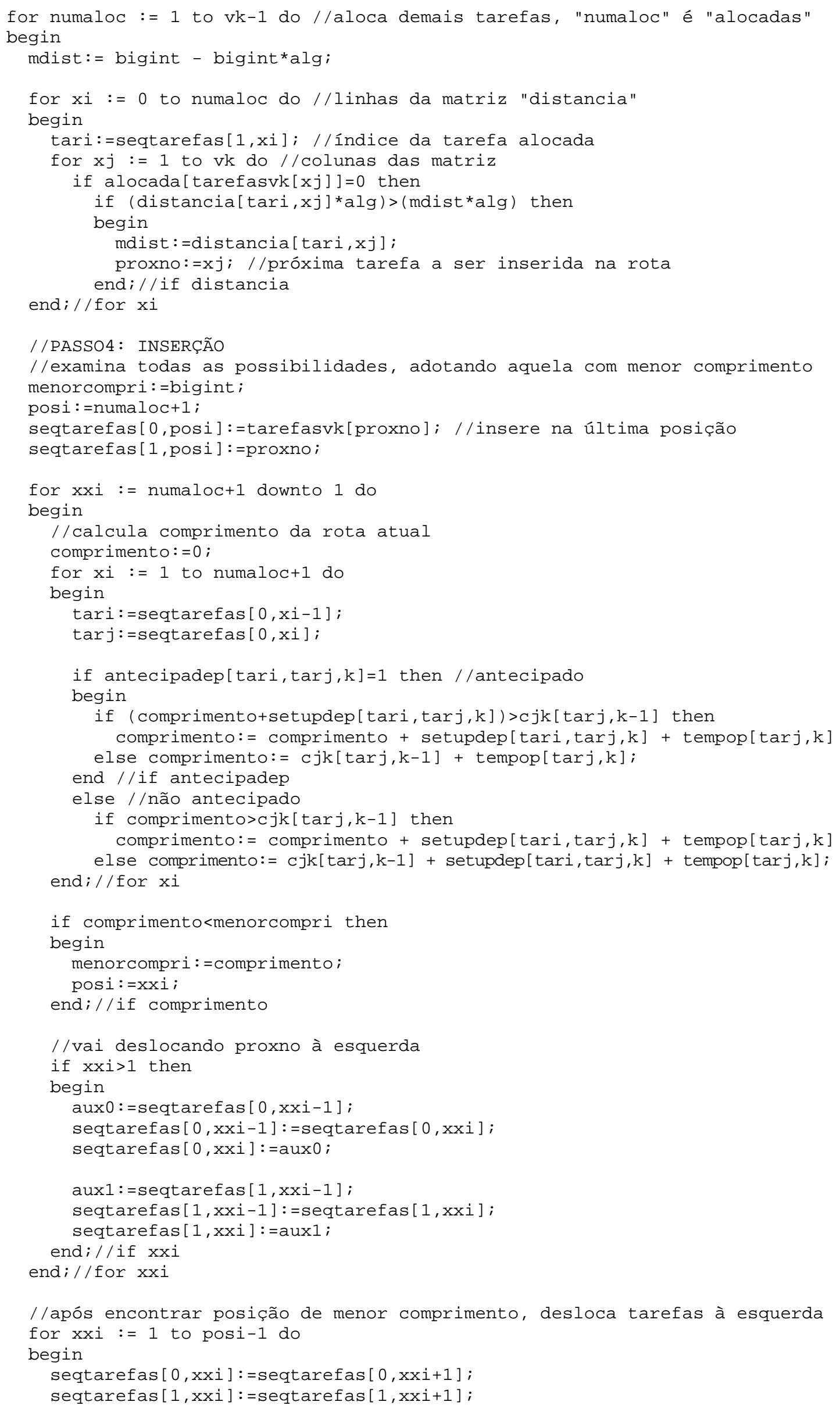


end;

seqtarefas [0,posi] :=tarefasvk [proxno];

seqtarefas [1,posi] :=proxno;

alocada [tarefasvk [proxno] ] :=1;

end;//for numaloc

//calcula os cjk

for $x i:=1$ to $\mathrm{vk}$ do

begin

tari:=seqtarefas $[0, x i-1]$;

$\operatorname{tar} j:=$ seqtarefas $[0, \mathrm{xi}]$;

if antecipadep[tari,tarj,k]=1 then //antecipado

begin

if $(\mathrm{cjk}[\operatorname{tari}, k]+\operatorname{setupdep}[\operatorname{tari}, \operatorname{tarj}, k])>c j k[\operatorname{tarj}, k-1]$ then

$\operatorname{cjk}[\operatorname{tarj}, k]:=\operatorname{cjk}[\operatorname{tar} i, k]+\operatorname{setupdep}[\operatorname{tar} i, \operatorname{tarj}, k]+$ tempop[tarj,k]

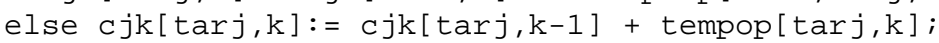

end //if antecipadep

else //não antecipado

if cjk[tari,k]>cjk[tarj,k-1] then

$c j k[\operatorname{tarj}, k]:=c j k[t a r i, k]+\operatorname{setupdep}[\operatorname{tari}, \operatorname{tarj}, k]+$ tempop [tarj,k]

else $c j k[\operatorname{tarj}, k]:=c j k[\operatorname{tarj}, k-1]+\operatorname{setupdep}[\operatorname{tari}, \operatorname{tarj,k]}+$ tempop[tarj,k]; endi//for xi

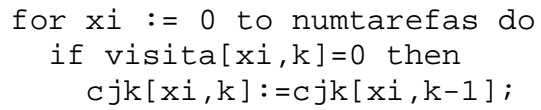

end;

procedure TSimulaFFL.HeuristicaStinson;

var

gx, mx, ni, nj, nx, ny, xtar, xx, menorl, menor2, menor, maior, col, lin, tar, ant, tari, tarj, fluxocircular, minfluxo, fluxo, posi, aux, fracao, maq, posvis, vk, menorterm, termino, maquina, primeiratarefa: integer;

sucessora: array of integer;

tarefasvk: array of integer;

matriz: array of array of integer;

achou: boolean;

begin

SetLength $(c j k, 0,0)$;

SetLength (cjk, numtarefas+1, numestagios+1);

Set Length (programacaojm, 0,0)

SetLength (programacaojm, mk [0]+1, numtarefas+1);

lin $:=0$

col: $=0$;

//calcula número de tarefas que visitam estágio 1

$\mathrm{vk}:=0$;

for $n x:=1$ to numtarefas do

if visita $[\mathrm{nx}, 1]=1$ then

$\mathrm{vk}:=\mathrm{vk}+1$

if $v k=1$ then //se só 1 tarefa visita

begin

//encontra a tarefa que visita

for $\mathrm{nx}:=1$ to numtarefas do

if visita $[\mathrm{nx}, 1]=1$ then

tar: $=\mathrm{nx}$;

//aloca na primeira máquina, primeira posição

programacaojm $[1,1]:=$ tar;

cjk $[$ tar, 1] :=setupdep $[0, \operatorname{tar}, 1]+$ tempop $[$ tar, 1];

end

else if $v k>1$ then//if $v k>1$

begin 
SetLength (tarefasvk,0); //tarefas que visitam o estágio 1 SetLength (tarefasvk, vk+1);

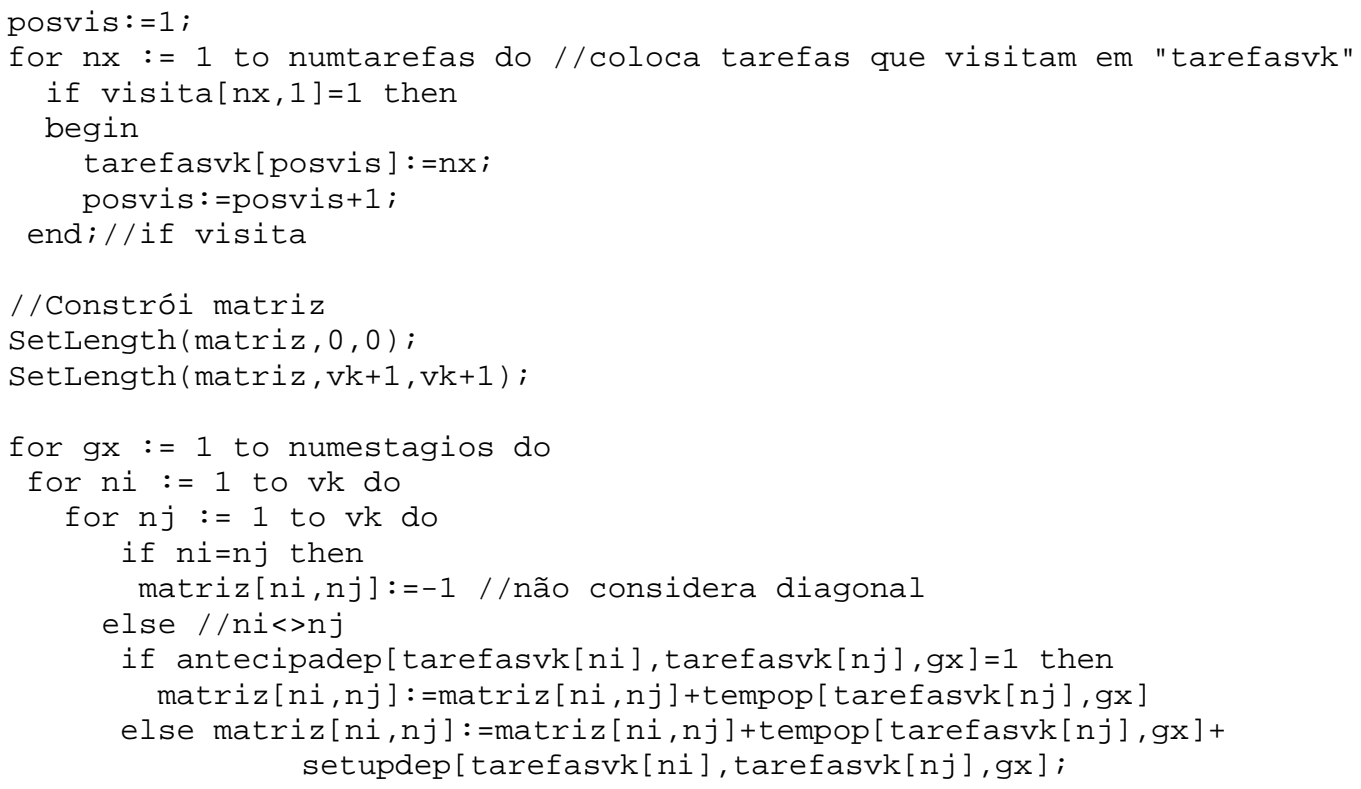

////ALGORITMO DE STINSON

SetLength (sucessora, 0); //Ex.: sucessora[3]=7 significa par "J3-J7"

SetLength (sucessora, numtarefas+1);

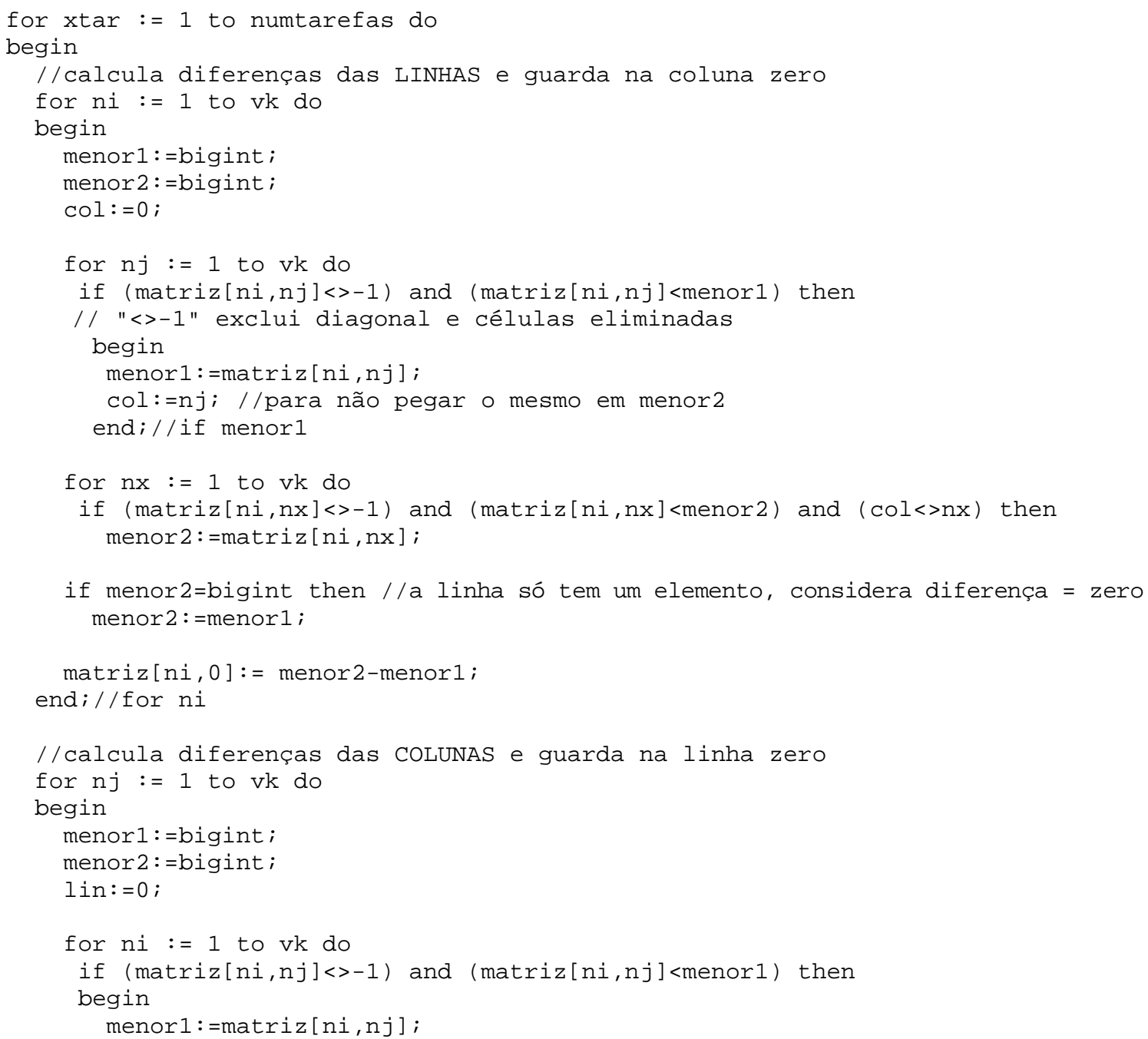




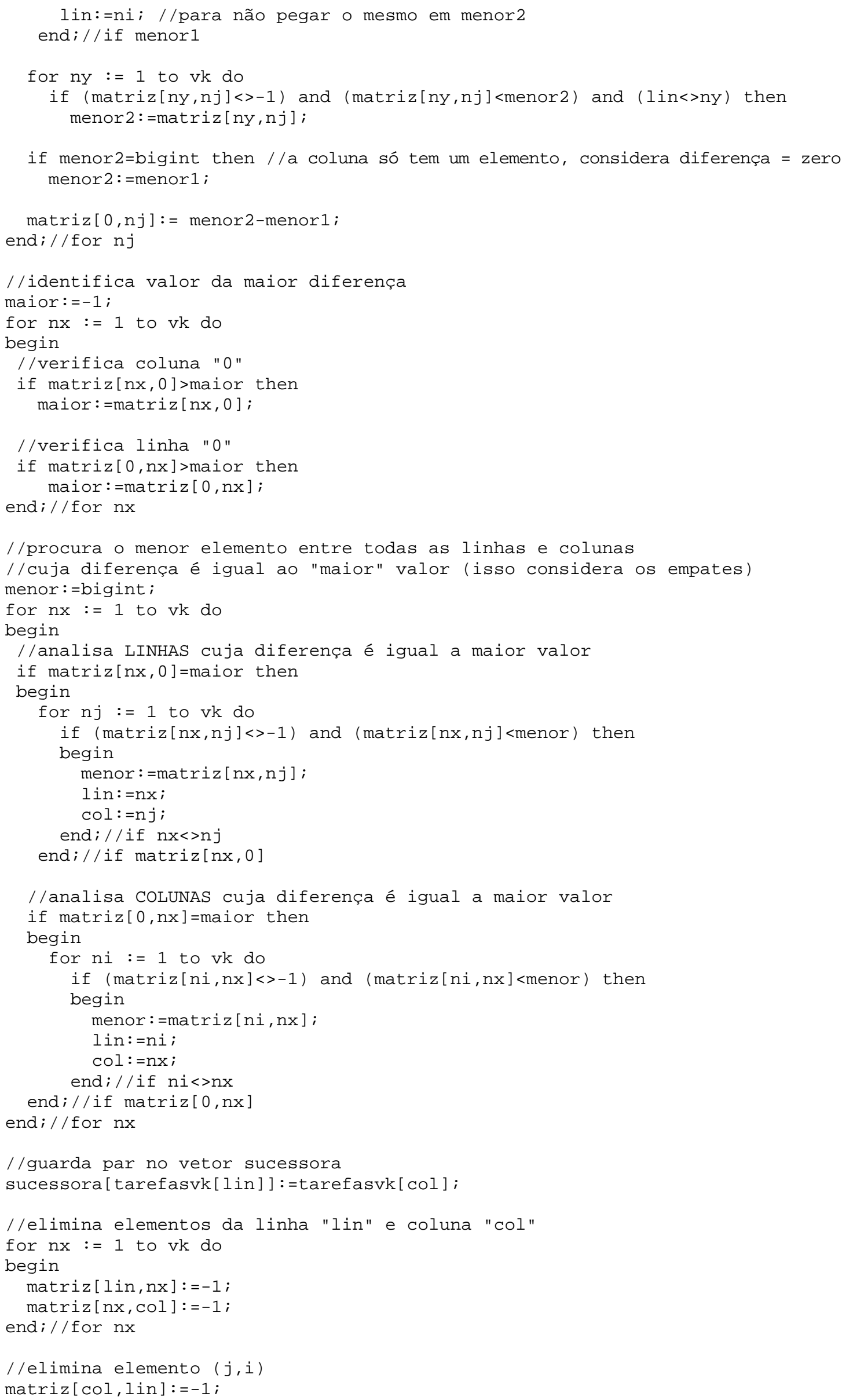


end;//for xtar

////FIM ALGORITMO STINSON

//coloca sequência obtida em seqtarefas

Set Length ( seqtarefas, 0,0 );

SetLength (seqtarefas, 2, vk+1);

$\operatorname{tar}:=1$

while sucessora[tar]=0 do //procura primeira tarefa com sucessora

tar: $=$ tarti

seqtarefas[0,vk]:=tar; //coloca na última posição

for $\mathrm{nx}:=\mathrm{vk}-1$ downto 1 do //da última posição até a primeira (q visitam) begin

ant $:=0$;

for $n j:=1$ to numtarefas do

begin

if sucessora[nj]=tar then //procura índice da tarefa "tar"

begin

ant $:=n j ;$

sucessora[nj]:=0; //já foi para seqtarefas

end;//if sucessora

endi//for $n j$

if ant=0 then //se não encontrou antecessora, escolhe aleatoriamente begin

ant $:=1$;

achou:=false;

while not achou do

begin

if (sucessora[ant] =0) and (ant<numtarefas) then

ant:=ant+1 //"ant" vai caminhando em "sucessora" até encontrar valor válido

else

begin

ant: $=$ sucessora $[$ ant $]$

achou:=true;

end;//else

end;//while

end;//if ant=0

seqtarefas $[0, \mathrm{nx}]:=a n t ;$

tar:=ant;

end;//for ni

//quebra sequência circular e seleciona aquela com menor tempo total de fluxo

fluxocircular: $=0$;

fluxo: $=0$;

for $\mathrm{nx}:=1$ to $\mathrm{vk}$ do //calcula fluxo total da sequência inicial

fluxo:=fluxo+setupdep [seqtarefas $[0, n x-1]$, seqtarefas $[0, n x], 1]+$

tempop [ seqtarefas $[0, \mathrm{nx}], 1]$;

minfluxo:=fluxo;

primeiratarefa: $=1$;

fluxocircular:=fluxo-setupdep $[0$, seqtarefas $[0,1], 1]+$ setupdep [ seqtarefas $[0, \mathrm{vk}]$, seqtarefas $[0,1], 1]$;

//fluxo total circular (sem fictícia)

for $\mathrm{nx}:=2$ to $\mathrm{vk}$ do //calcula fluxo total das outras opções de quebra da sequência begin

fluxo:=fluxocircular-setupdep [seqtarefas $[0, n x-1]$, seqtarefas $[0, n x], 1]+$ setupdep $[0$, seqtarefas $[0, \mathrm{nx}], 1]$;

if fluxo<minfluxo then

begin

minfluxo:=fluxo; 


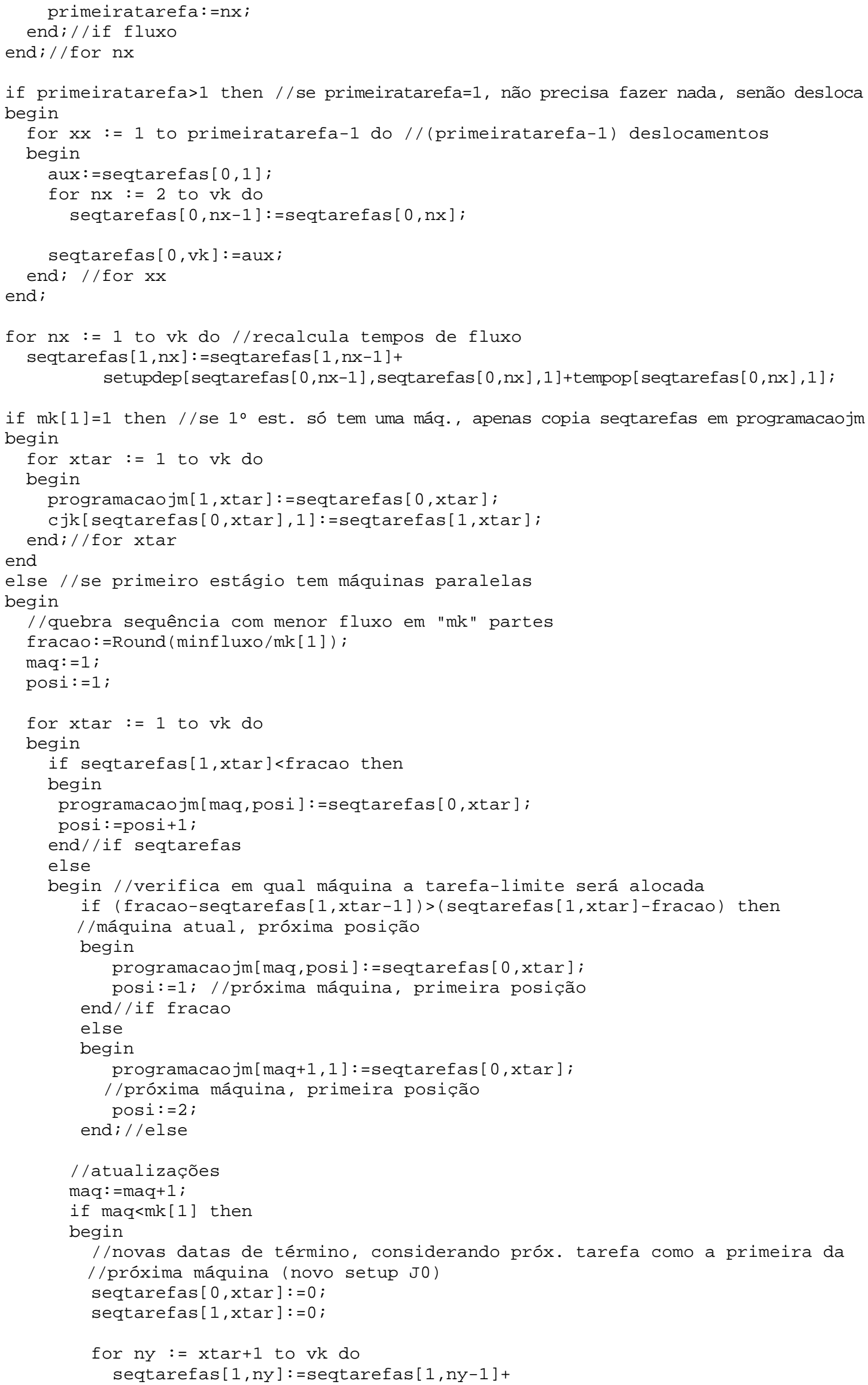




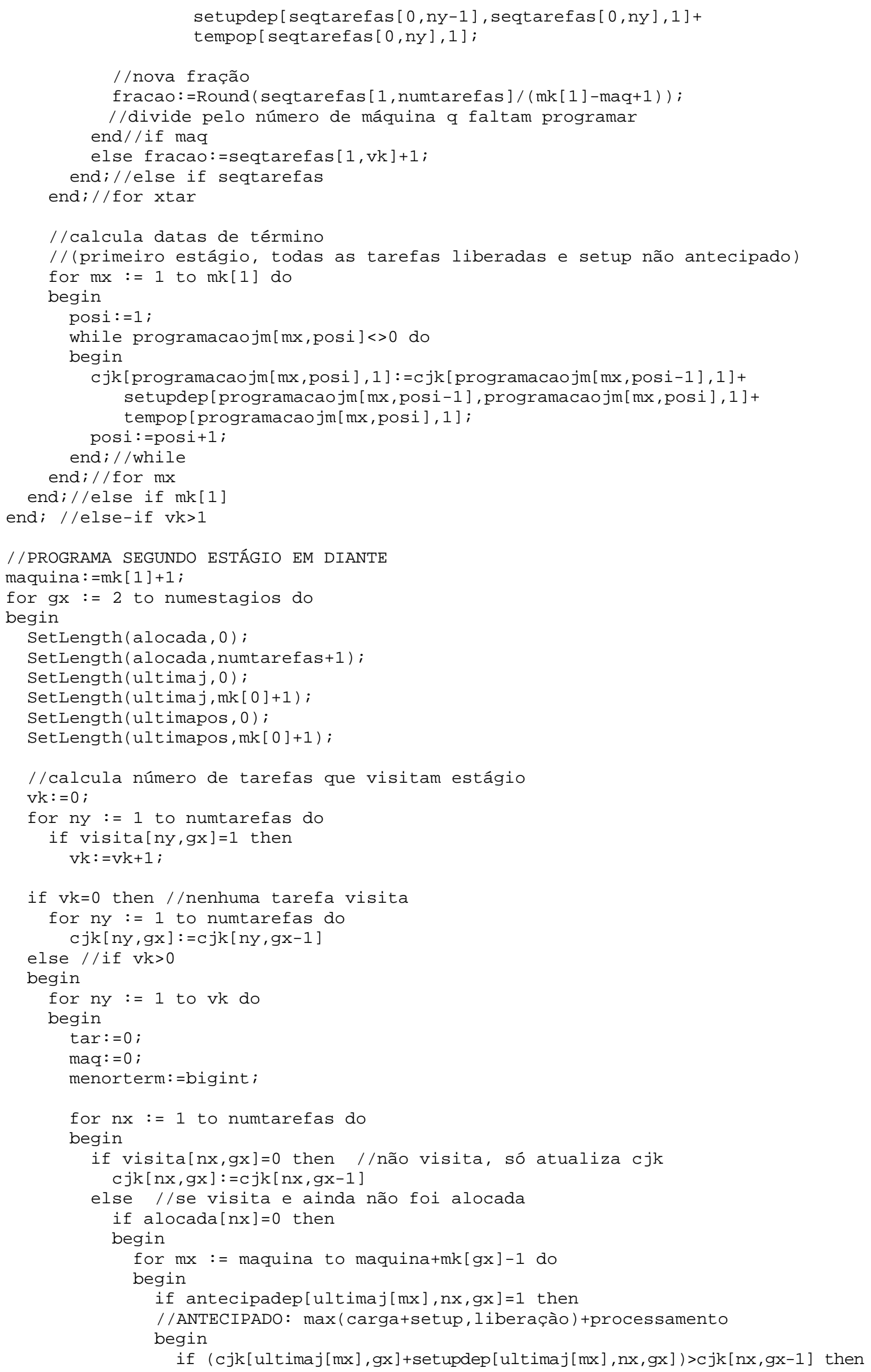




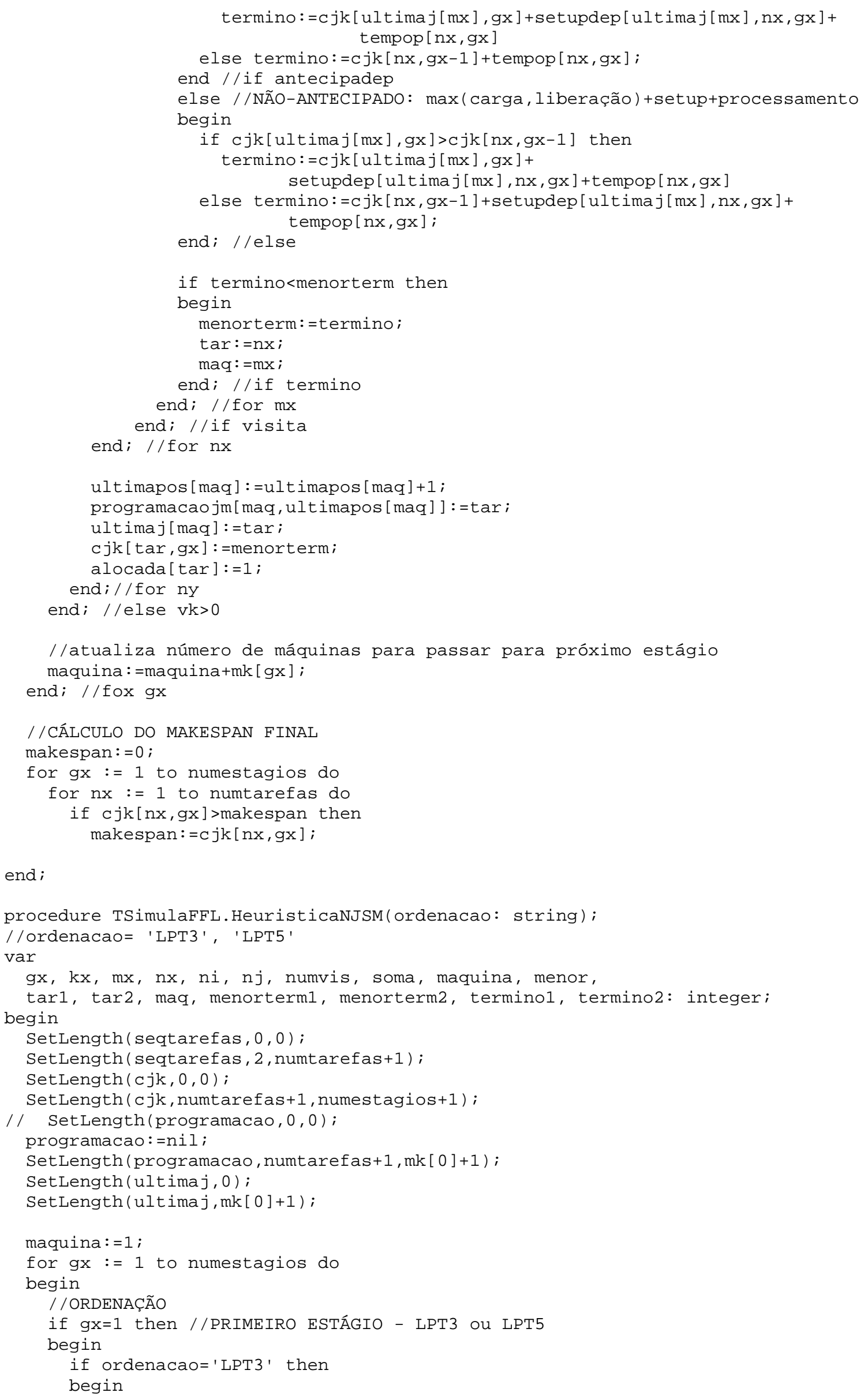




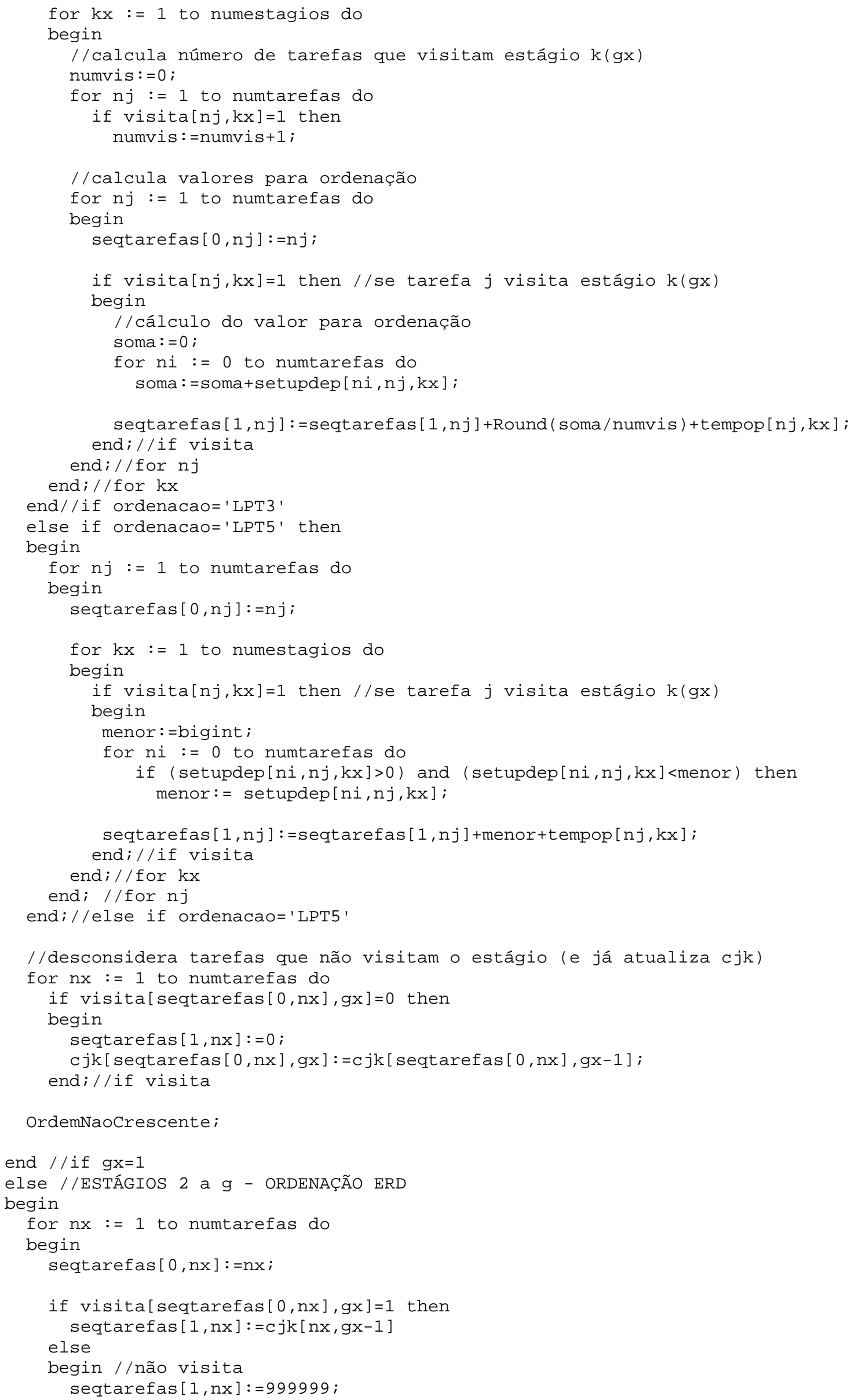




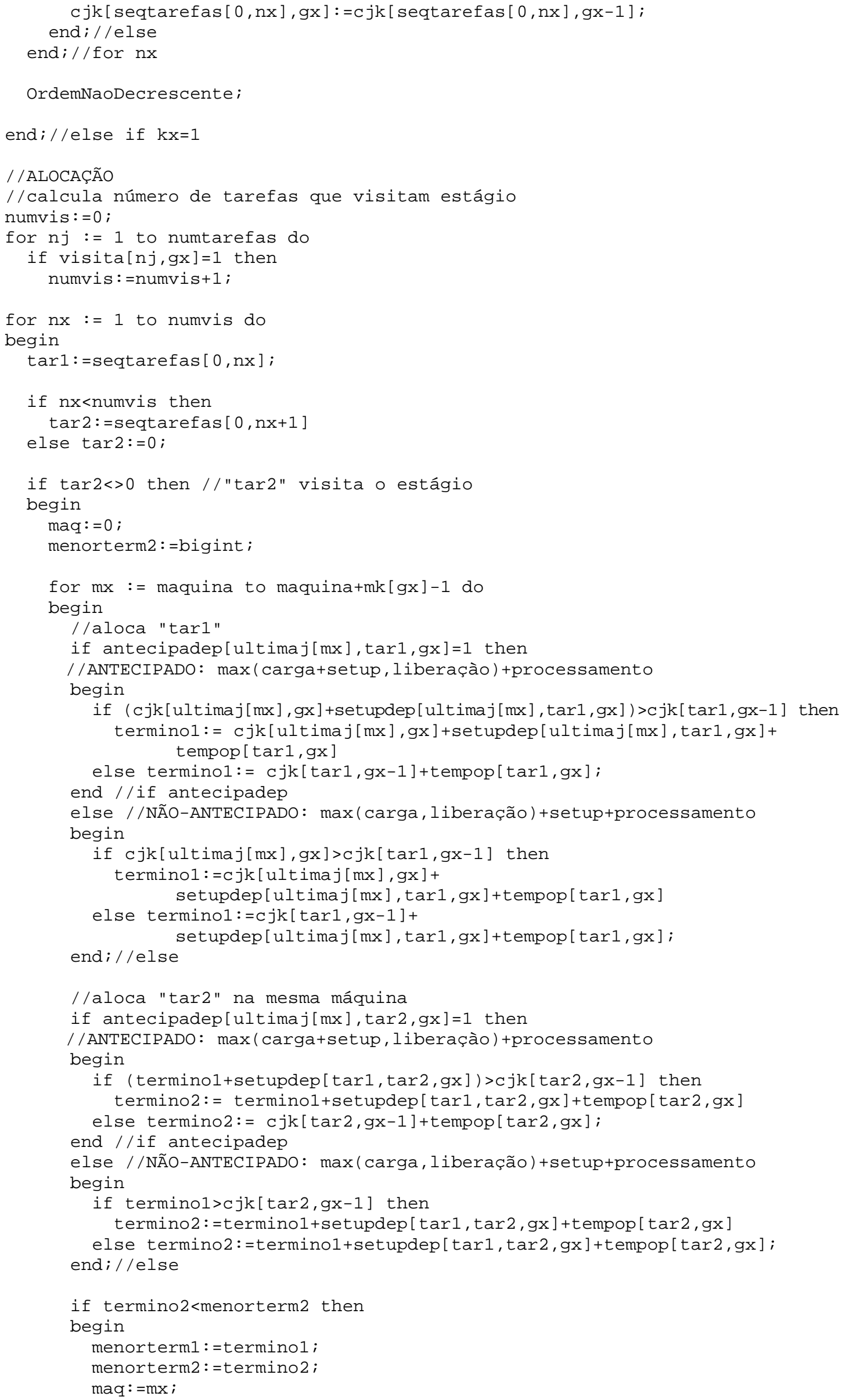


end;//if termino2

end;//for $\mathrm{mx}$

end//if visita

else //tar2=0: "tar1" é ultima tarefas da lista, testa só "tarl"

begin

maq: $=0$;

menorterm1:=bigint;

for $\mathrm{mx}:=$ maquina to maquina+mk $[\mathrm{gx}]-1$ do

begin

if antecipadep[ultimaj[mx], tar $1, \mathrm{gx}]=1$ then

//ANTECIPADO: max(carga+setup, liberaçào)+processamento

begin

if (cjk[ultimaj[mx], gx]+setupdep[ultimaj[mx], tarl,gx]) >cjk[tarl,gx-1] then terminol:= cjk[ultimaj[mx],gx]+ setupdep [ultimaj[mx], $\operatorname{tar} 1, \mathrm{gx}]+$ tempop [tar1, gx ]

else terminol:= cjk[tar1,gx-1]+tempop[tar1,gx];

end //if antecipadep

else //NÃO-ANTECIPADO: $\max ($ carga, liberação) +setup+processamento begin

if cjk[ultimaj[mx], gx]>cjk[tarl,gx-1] then

terminol:=cjk[ultimaj[mx], gx] +setupdep[ultimaj[mx], tar1,gx]+ tempop [tar $1, \mathrm{gx}]$

else terminol:=cjk[tar1, gx-1]+

end;//else setupdep [ultimaj[mx], $\operatorname{tar} 1, \mathrm{gx}]+$ tempop [tarl, gx] ;

if terminol<menorterm1 then

begin

menorterm $1:=$ terminol;

maq : $=\mathrm{mx}$;

end;//if terminol

end;//for $\mathrm{mx}$

end;//else

//aloca a "tarl" na máquina com menor término

programacao [tarl, maq] :=programacao [ultimaj [maq], maq] +1;

ultimaj [maq] :=tarl;

cjk $[\operatorname{tar} 1, g x]:=$ menorterm 1 ;

end;//for $\mathrm{nx}$

maquina:=maquina+mk $[g x]$;

//para as que não visitam

for $n j:=1$ to numtarefas do

if visita $[n j, g x]=0$ then

cjk $[n j, g x]:=c j k[n j, g x-1]$;

end;//for $g x$

//CÁLCULO DO MAKESPAN FINAL

makespan: $=0$;

for $g x:=1$ to numestagios do

for $\mathrm{nx}:=1$ to numtarefas do

if $c j k[n x, g x]>m a k e s p a n$ then

makespan: $=c j k[n x, g x]$;

end;

procedure TSimulaFFL.HeuristicaRandom;

var

gx, $\mathrm{nx}, \mathrm{nxx}, \mathrm{mx}, \mathrm{vk}$, maquina, posi, tari, tarj: integer;

begin

SetLength $(c j k, 0,0)$;

SetLength (cjk, numtarefas+1, numestagios+1);

SetLength (programacaojm, 0,0);

SetLength (programacaojm, mk [0]+1, numtarefas+1);

maquina: $=1$ 


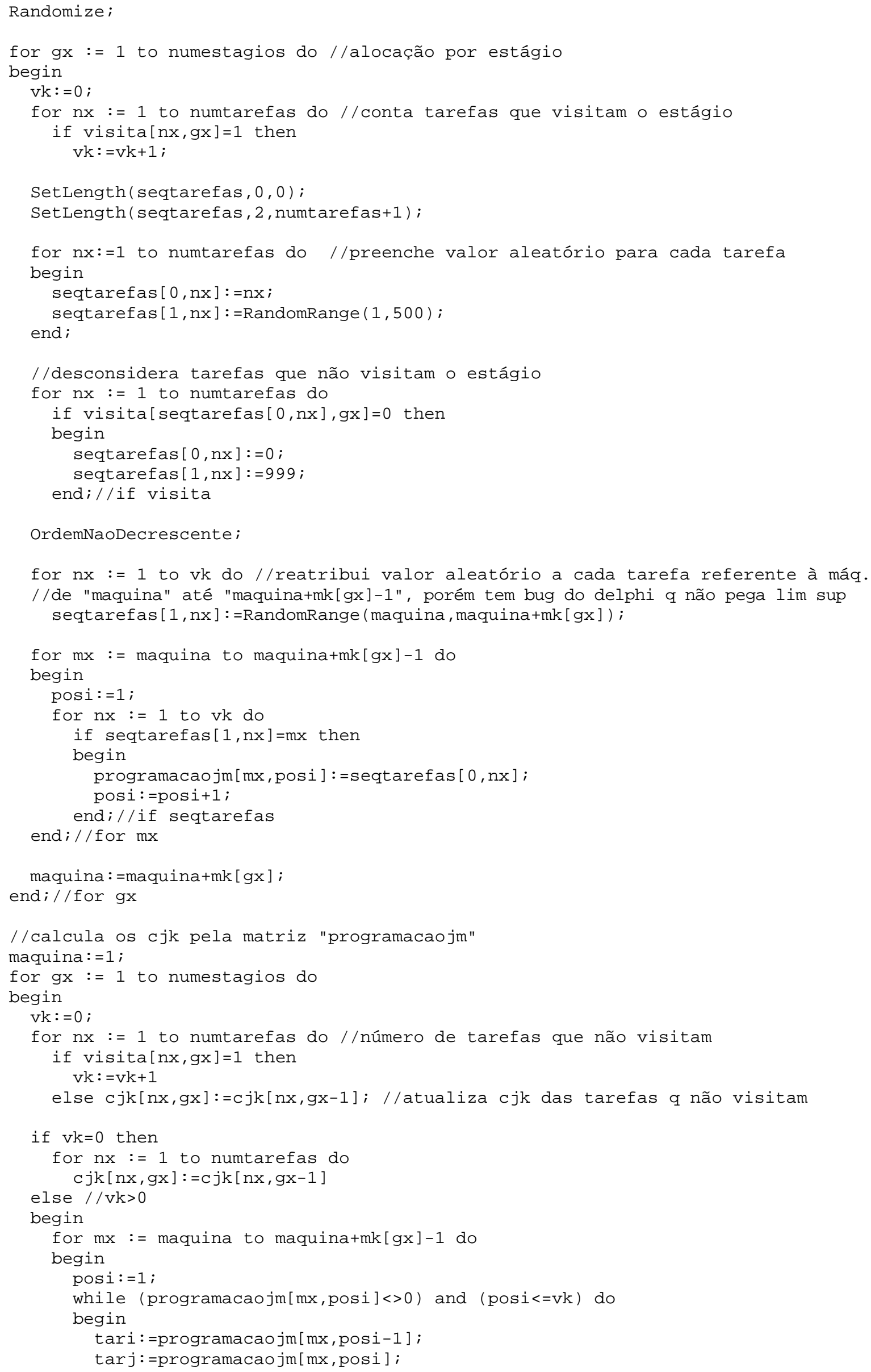


if antecipadep[tari, tarj,gx]=1 then

begin

if (cjk[tari,gx]+setupdep[tari, $\operatorname{tarj}, g x])>c j k[\operatorname{tarj}, g x-1]$ then

$c j k[\operatorname{tarj}, g x]:=c j k[\operatorname{tar} i, g x]+\operatorname{setupdep}[\operatorname{tar} i, \operatorname{tarj}, g x]+t e m p o p[\operatorname{tarj}, g x]$

else cjk[tarj,gx]:=cjk[tarj,gx-1]+tempop[tarj,gx];

end //if antecipadep

else //não antecipado

begin

if $c j k[\operatorname{tar} i, g x]>c j k[\operatorname{tar} j, g x-1]$ then

cjk [tarj, gx] :=cjk[tari, gx] +setupdep [tari, tarj,gx]+ tempop [tarj, gx]

else cjk[tarj,gx]:=cjk[tarj,gx-1]+setupdep[tari,tarj,gx]+tempop [tarj,gx] ; end;

posi: $=$ positi

end;//while

end;//for $m x$

end;//else $v k>0$

maquina:=maquinatmk $[g x]$

end;//for gx

//CÁLCULO DO MAKESPAN FINAL

makespan: $=0$;

for $g x:=1$ to numestagios do

for $n x:=1$ to numtarefas do

if $c j k[n x, g x]>m a k e s p a n$ then

end;

makespan: $=$ cjk $[n x, g x]$; 